\title{
Österreichische Zeitgeschichte - Zeitgeschichte in Österreich
}

Eine Standortbestimmung

in Zeiten des Umbruchs 


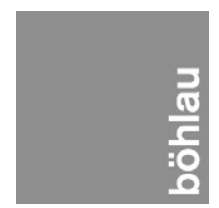

(c) 2021 Böhlau Verlag | Brill Österreich GmbH https://doi.org/10.7767/9783205209980 | CC BY-NC 4.0 


\title{
Böhlaus Zeitgeschichtliche Bibliothek
}

\author{
Begründet von Helmut Konrad
}

\section{Herausgegeben von Marcus Gräser und Dirk Rupnow}

\section{Band 41}

Die "Zeitgeschichtliche Bibliothek“ im Böhlau Verlag veröffentlicht Arbeiten zur österreichischen und internationalen Zeitgeschichte. Als "Zeitgeschichte" wird dabei die Geschichte des 20. und 21. Jahrhunderts verstanden, wobei - dem Verständnis von "Zeitgeschichte" als "Vorgeschichte der Gegenwart" folgend - problemorientiert auch frühere Jahrzehnte relevant sein können. Im Zugriff auf Methoden und Theorien herrschen Offenheit und Pluralität, wobei Arbeiten mit einer gesellschaftsgeschichtlichen und/oder internationalen Perspektive im Mittelpunkt stehen. Eingereichte Manuskripte durchlaufen ein Peer Review, entweder durch die Begutachtung in akademischen Qualifizierungsverfahren, im Rahmen des bei Forschungsförderungsorganisationen beantragten Druckkostenzuschusses oder durch von den Herausgebern veranlasste Gutachten. 
Marcus Gräser, Dirk Rupnow (Hg.)

\section{Österreichische Zeitgeschichte - Zeitgeschichte in Österreich}

Eine Standortbestimmung in Zeiten des Umbruchs 
Gedruckt mit Unterstützung durch:

Amt der Niederösterreichischen Landesregierung

Nationalfonds der Republik Österreich für Opfer des Nationalsozialismus

Stadt Wien Kultur

Zukunftsfonds der Republik Österreich

Linzer Hochschulfonds

Open Access Publikationsfonds der Johannes Kepler Universität Linz

Universität Innsbruck, Vizerektorat für Forschung und Philosophisch-Historische Fakultät

WISSENSCHAFT - FORSCHUNG

NIEDERÖSTERREICH

NATIONALFONDS

DER REPUBLIK ÖSTERREICH FÜR OPFER DES NATIONALSOZIALISMUS

\section{- Stadt W Wien kutur

Bibliografische Information der Deutschen Bibliothek:

Die Deutsche Nationalbibliothek verzeichnet diese Publikation in der

Deutschen Nationalbibliografie; detaillierte bibliografische Daten

sind im Internet über https://dnb.de abrufbar.

(C) 2021 Böhlau Verlag, Zeltgasse 1, A-1080 Wien, ein Imprint der Brill-Gruppe

(Koninklijke Brill NV, Leiden, Niederlande; Brill USA Inc., Boston MA, USA; Brill Asia Pte Ltd, Singapore; Brill Deutschland GmbH, Paderborn, Deutschland; Brill Österreich GmbH, Wien, Österreich) Koninklijke Brill NV umfasst die Imprints Brill, Brill Nijhoff, Brill Hotei, Brill Schöningh, Brill Fink, Brill mentis, Vandenhoeck \& Ruprecht, Böhlau, Verlag Antike und V\&R unipress.

Korrektorat: Anja Borkam

Umschlaggestaltung: Michael Haderer, Wien

Satz: Bettina Waringer, Wien

Vandenhoeck \& Ruprecht Verlage | www.vandenhoeck-ruprecht-verlage.com

ISBN 978-3-205-20998-0

DOI https://doi.org/10.7767/9783205209980

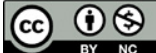

Dieses Material steht unter der Creative-Commons-Lizenz Namensnennung -

Nicht kommerziell 4.0 International. Um eine Kopie dieser Lizenz zu sehen, besuchen Sie http://creativecommons.org/licenses/by-nc/4.0/ 


\section{Inhalt}

Einleitung

Marcus Gräser und Dirk Rupnow . . . . . . . . . . . . . . . . . . . . . 9

Zeitgeschichtsforschung in Österreich seit 1945 - Ein Rückblick

Helmut Konrad . . . . . . . . . . . . . . . . . . . . . 21

EPOCHEN UND ZäSUREN

Erste Republik

Marcus Gräser . . . . . . . . . . . . . . . . . . . . . . . . . . . . . . 39

Austrofaschismus

Florian Wenninger . . . . . . . . . . . . . . . . . . . . . 67

NS-Zeit und Zweiter Weltkrieg

Georg Hoffmann . . . . . . . . . . . . . . . . . . . 108

Holocaust

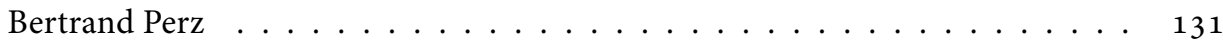

Zweite Republik

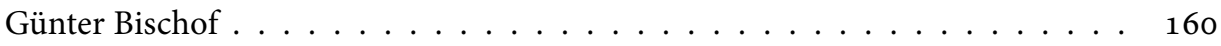

Kalter Krieg

Maximilian Graf . . . . . . . . . . . . . . . . . . . . 178

EU und Europa

Anita Ziegerhofer . . . . . . . . . . . . . . . . . . . . . . . . 197 
FELDER UND THEMEN

Geschlecht

Martina Gugglberger . . . . . . . . . . . . . . . . . . . . . . . 217

Migration

Dirk Rupnow . . . . . . . . . . . . . . . . . . . . . 236

Gedächtnis und Erinnerungskultur

Ljiljana Radonić und Heidemarie Uhl . . . . . . . . . . . . . . . . 263

Justiz und Strafverfolgung

Christian Rabl . . . . . . . . . . . . . . . . . . . . . . . . 284

Zwangsarbeit

Kerstin von Lingen . . . . . . . . . . . . . . . . . . . . 303

Postkolonialismus

Eric Burton . . . . . . . . . . . . . . . . . . 321

Transnationalismus

Claudia Kraft . . . . . . . . . . . . . . . . . . 348

Public History

Stefan Benedik und Lisbeth Matzer . . . . . . . . . . . . . . . . . . 367

Kriegsfolgenforschung

Barbara Stelzl-Marx . . . . . . . . . . . . . . . . . . 390

Film

Christina Wieder. . . . . . . . . . . . . . . . . 412

Fernsehen und Video

Renée Winter . . . . . . . . . . . . . . . . . . . . . . . . 429

Fotografie

Markus Wurzer. . . . . . . . . . . . . . . . . . . . 448 
Digital History und Digitalisierung

Eva Pfanzelter und Sarah Oberbichler

NS-Vermögensentzug, Restitution und Provenienzforschung

Birgit Kirchmayr . . . . . . . . . . . . . . . . . . . . . . . . 497

Parteien

Margit Reiter . . . . . . . . . . . . . . . . . . . . . 511

Medizin

Ina Friedmann und Christian Lechner . . . . . . . . . . . . . . . 534

Universitäten

Maria Wirth und Andreas Huber . . . . . . . . . . . . . . . . . . 554

Sport

Agnes Meisinger und Rudolf Müllner ～. . . . . . . . . . . . . . . . 576

\section{VERH ÄLTNISSE}

Zeitgeschichte und Wirtschaftsgeschichte

Ernst Langthaler . . . . . . . . . . . . . . . . . . . . . . . . 599

Zeitgeschichte und Umweltgeschichte

Robert Groß . . . . . . . . . . . . . . . . . . . . . . . 618

Zeitgeschichte und Politikwissenschaft

Anton Pelinka . . . . . . . . . . . . . . . . 638

Zeitgeschichte und Kulturwissenschaften

Regina Thumser-Wöhs . . . . . . . . . . . . . . . . . . . . 656

Zeitgeschichte und Rechtsgeschichte

Kamila Staudigl-Ciechowicz. . . . . . . . . . . . . . . . . . . 671 
Zeitgeschichte und Literaturwissenschaft

Norbert Christian Wolf . . . . . . . . . . . . . . . . . . . . . . 691

Zeitgeschichte und Jüdische Geschichte

Nikolaus Hagen . . . . . . . . . . . . . . . . 705

Zeitgeschichte und Queer Studies

Elisa Heinrich und Johann Kirchknopf . . . . . . . . . . . . . . . . . . 724

Zeitgeschichte und Politische Bildung

Thomas Hellmuth . . . . . . . . . . . . . . . . . . . 745

Zeitgeschichte und Geschichtsunterricht

Christoph Kühberger. . . . . . . . . . . . . . . . . . . . . . . 759

Zeitgeschichte und Internationale Geschichte

Elisabeth Röhrlich . . . . . . . . . . . . . . . . . . . 783

Zeitgeschichte und Museen

Monika Sommer . . . . . . . . . . . . . . . . . . . . 798

Zeitgeschichte und Archive

Stefan Eminger . . . . . . . . . . . . . . . . . . . 826

Autorinnen und Autoren. . . . . . . . . . . . . . . . . . 846 


\section{Einleitung}

Das vorliegende Buch „Österreichische Zeitgeschichte - Zeitgeschichte in Österreich" versucht, eine umfassende Standortbestimmung der Zeitgeschichtsforschung in Österreich vorzunehmen. In den Beiträgen sollen gleichermaßen Bilanz gezogen und Perspektiven eröffnet werden.

Der Band beginnt mit einem, auch autobiographisch motivierten, Beitrag von Helmut Konrad über die Entwicklung der Zeitgeschichtsforschung in Österreich in der Zweiten Republik. Im folgenden Teil wird dann chronologisch ein Überblick zu den Epochen und großen Zäsuren der österreichischen Geschichte seit dem Ende des Ersten Weltkriegs gegeben. Dem schließt sich ein umfänglicher Teil an, in dem Felder und Themen der Zeitgeschichtsforschung präsentiert werden. Klassische Themen der politischen Geschichte des Landes werden dabei ebenso aufgerufen wie neue Felder der Zeitgeschichtsforschung (etwa Public History und Digital Humanities), die vor allem von der jüngeren Generation der ZeithistorikerInnen gestaltet werden. Dem folgt als dritter und abschließender Teil ein Blick auf das Verhältnis der Zeitgeschichte zu anderen Abteilungen der Geschichtswissenschaft und zu den Nachbardisziplinen. Erst in einer solchen Abmessung der Unterschiede und Gemeinsamkeiten werden das Profil der Zeitgeschichtsforschung und ihre Notwendigkeit klar bestimmt werden können.

Keinesfalls beabsichtigt ist eine gefällige Selbstbespiegelung der Zeitgeschichtsforschung: Die Herausgeber gehen davon aus, dass sich die Zeitgeschichte in einer Umbruchsituation befindet. Auf den ersten Blick mag eine Kennzeichnung als Umbruch für HistorikerInnen trivial sein: Umbruch ist immer. Gleichwohl: Die Herausforderung durch internationale und globale Perspektiven sowie neue Themenfelder und Agenden, die Frage nach der Rolle der Wissenschaft im öffentlichen Leben, veränderte Anforderungen an Karriereprofile und das beständige Ringen um Aufmerksamkeit und finanzielle Mittel für unsere Wissenschaft sind nur einige der Aspekte, die Anlass geben, uns selbst (und unserem Publikum) Rechenschaft abzulegen und danach zu fragen, ob uns ausreichend Ideen und Stoff zur Verfügung stehen, um halbwegs frohgemut in die Zukunft schauen zu können. Hinzu kommt ein Generationenwechsel an den Universitäten und Forschungseinrichtungen. Der Band zeichnet gleichzeitig auch so etwas wie ein Gruppenporträt der Zeitgeschichtsforschung in Österreich, vor allem der mittleren und jüngeren Generation.

Als Zeitgeschichte wird dabei die Geschichte des 20. und 21. Jahrhunderts verstanden, wobei - dem von Hans Günter Hockerts eingeführten Verständnis von 
Zeitgeschichte als „Problemgeschichte der Gegenwart“ entsprechend ${ }^{1}$ - problemorientiert auch Rückblicke darüber hinaus relevant sein können. Damit folgen wir im Wesentlichen der klassischen Markierung von Hans Rothfels, 1917/1918 - mit dem Kriegseintritt der USA und der Russischen Revolution - beginne sich eine "neue universalgeschichtliche Epoche" abzuzeichnen, weniger seinem mittlerweile dazu in Spannung stehenden Diktum, Zeitgeschichte sei die „Geschichte der Mitlebenden und ihre wissenschaftliche Behandlung". ${ }^{2}$ Gemäß der Mitlebenden-Definition wird vielfach der Beginn der Zeitgeschichte in Deutschland ja bereits nach dem Ende des Zweiten Weltkriegs angesetzt. In Österreich ist unterdessen (von Oliver Rathkolb) zuletzt eher eine Ausdehnung zurück in die Mitte des 19. Jahrhunderts vorgeschlagen worden, um vor diesem Hintergrund die Konflikte des 20. Jahrhunderts zu analysieren. Klassisch hatte aber auch etwa Hanns Leo Mikoletzky die „Österreichische Zeitgeschichte“ „,om Ende der Monarchie bis zur Gegenwart“ (1962/1969) aufgespannt, während Erika Weinzierl in ihrer programmatischen Einleitung des ersten „Zeitgeschichte“-Hefts 1973 sich interessanterweise explizit auf die französische Histoire Contemporaine bezog und Themen bis zurück zur Französischen Revolution, aber auch zu Gegenwartsfragen in Aussicht stellte - mit einem Fokus auf Österreich, aber auch einem Blick über Österreich und Europa hinaus. ${ }^{3}$

Die in der Zeitgeschichtsforschung vorgenommene Rekonstruktion der unmittelbaren Vorgeschichte der Gegenwart und vor allem die forschende Auseinandersetzung mit den Ursachen und Folgen des Nationalsozialismus stellen historisches Wissen bereit, das in einer lebendigen Demokratie unverzichtbar ist. Zeitgeschichtsforschung ist immer auch Zeitdiagnose. Die Vergangenheit und ihre Deutung bilden den Kontext, in dem StaatsbürgerInnen ihre Entscheidungen treffen. Auch darum ist die Zeitgeschichte in den Augen der Öffentlichkeit heute jenes Feld der Geschichtswissenschaft, das keiner weiteren Begründung bedarf und mit einem hohen $\mathrm{Ma} ß$ an Anerkennung rechnen kann - auch wenn sich dies nicht in einer, aus der Sicht der Forschenden, ausreichenden Finanzierung durch die öffentliche Hand widerspiegelt.

Der Einbruch der Zeitgenossenschaft in die historische Forschung, die Klärung der eigenen Lebenszeit oder ihrer unmittelbaren Vorgeschichte, wiewohl seit der

1 Hans-Günther Hockerts, Zeitgeschichte in Deutschland. Begriffe, Methoden, Themenfelder, in: Historisches Jahrbuch 113 (1993), 98-127.

2 Hans Rothfels, Zeitgeschichte als Aufgabe, in: Vierteljahrshefte für Zeitgeschichte 1 (1953) 1, 1-8.

3 Hanns Leo Mikoletzky, Österreichische Zeitgeschichte: Vom Ende der Monarchie bis zum Abschluß des Staatsvertrages 1955, Wien 1962; ders., Österreichische Zeitgeschichte: Vom Ende der Monarchie bis zur Gegenwart, Wien ${ }^{3} 1969$; Erika Weinzierl, Zeitgeschichte - Programm einer Zeitschrift, in: zeitgeschichte 1 (1973) 1, 3 . 
antiken Historiographie bekannt (Thukydides), ist keineswegs schon immer eine vornehme Aufgabe im breiten Strom der Geschichtswissenschaft gewesen. Die Politikwissenschaft, die als eigenständiges Fach in der ersten Hälfte des 20. Jahrhunderts entstand, hat die Forschung zur Gegenwart und ihrer Vorgeschichte durchaus für sich reklamiert. Noch bis in die 1970er Jahre hinein haben zahlreiche Historiker (und die wenigen Historikerinnen, die es gab) ihre Reputation nicht auf der Zeitgeschichte aufgebaut, sondern sind mit Studien zum 19. Jahrhundert oder noch weiter zurückliegenden Epochen hervorgetreten. Der Begriff Zeitgeschichte - wiewohl er bereits im und nach dem Ersten Weltkrieg auftauchte - wurde im deutschsprachigen Raum erst seit 1945 in auffälliger Weise verwendet, und der Zusammenhang mit dem „Zivilisationsbruch“ durch die nationalsozialistische Herrschaft ist offenkundig.

Die Institutionalisierung der Zeitgeschichte an den Universitäten in Österreich aber erfolgte verzögert: Keineswegs löste allein schon die Erfahrung des Nationalsozialismus einen Schub in der Forschung aus, ebenso wenig war der Zerfall der berühmten These von Österreich als „erstem Opfer" des Nationalsozialismus, der sich in den Debatten um Kurt Waldheim 1986/1987 abzuzeichnen begann, ausschlaggebend. Tatsächlich setzte sich die Zeitgeschichte an österreichischen Universitäten in den späten 1960er-Jahren durch, auf halbem Weg zwischen dem Ende der nationalsozialistischen Herrschaft und der Waldheim-Debatte also, und die Ursachen dafür sind vielfältig.

Die Pionierphase der österreichischen Zeitgeschichtsforschung ist ohne die Aufbruchstimmung der 1970er-Jahre, die Reformeuphorie der Kreisky-Jahre nicht denkbar, und ohne die Generationen der PionierInnen und ihrer SchülerInnen wären die Debatte um Waldheim, der Zusammenbruch des Opfermythos und das Bekenntnis zur österreichischen Mitschuld an der nationalsozialistischen Herrschaft und am Holocaust nicht zu haben gewesen.

Die schnelle Etablierung der Zeitgeschichte als Feld der Geschichtswissenschaft aber hat ihren Preis: Was einmal, in der Pionierphase, eine provokante, manchmal auch widerständige und oppositionelle, neue Form der Wissenschaft, auch der Wissenschaftsvermittlung, gewesen war, geriet spätestens seit den 1990er-Jahren in eine fast staatstragende Rolle. Zeitgeschichtsforschung legitimiert heute die Gedächtniskultur der Zweiten Republik - wie überhaupt Zeitgeschichte und österreichisches Nation Building eng zusammenhängen. (Darin liegt im Übrigen auch eine der Ursachen für die in den letzten Jahren deutlich zu beobachtende Nervosität, mit der weite Teile der österreichischen Öffentlichkeit auf die Berufung deutscher Staatsangehöriger auf Zeitgeschichteprofessuren in Österreich reagieren.) 
In einer Demokratie ist die Legitimationsfunktion der Geschichtswissenschaft natürlich nicht notwendigerweise von Übel - denn die Rahmenbedingungen für die freie Entfaltung der Wissenschaft sind gegeben und einen öffentlichen Nutzen der Zeitgeschichtsforschung wird keine Wissenschaftlerin und kein Wissenschaftler bestreiten wollen. Immer wieder kritisiert wurde allerdings die enge Anbindung der etablierten österreichischen Zeitgeschichtsforschung an die Politik, ihre „Staatsabhängigkeit“, die vor allem Ernst Hanisch diagnostiziert hat. ${ }^{4}$ Schon 1993 hatte Gerhard Botz eine „starke politische Funktion der Zeitgeschichte“ festgestellt, die nicht zuletzt auch ihren offensichtlichen Österreichzentrismus erkläre. ${ }^{5}$ Tatsächlich muss auf dem Feld der Zeitgeschichte das Verhältnis von Politik und Wissenschaft immer wieder neu ausgehandelt werden: in den 1970er-Jahren ebenso wie im Zuge der Waldheim-Affäre oder im Rahmen der großen Historikerkommission der Republik Österreich Ende der 1990er, aber auch bei heutigen Forschungsprojekten und kommissionellen Tätigkeiten.

Die institutionelle Welt der Zeitgeschichtsforschung in Österreich ist durchaus überschaubar: Entsprechend ausgerichtete Institute bzw. Professuren mit einschlägiger Denomination gibt es an den Universitäten in Graz (seit 1984), Innsbruck (1983), Klagenfurt (1974), Linz (1968), Salzburg (1967) und Wien (1966). Einige außeruniversitäre Einrichtungen forschen und publizieren zu Fragen der Zeitgeschichte. Eine besondere Rolle spielt dabei seit seiner Gründung von ehemaligen WiderstandskämpferInnen, Verfolgten und engagierten Historikern im Jahr 1963 das Dokumentationsarchiv des österreichischen Widerstands (DÖW). Die KZ-Gedenkstätte Mauthausen/Mauthausen Memorial, die über eine eigene Forschungsstelle verfügt, wurde 2017 von einer Abteilung des Innenministeriums in eine Bundesanstalt öffentlichen Rechts überführt. Seit 1993 existiert das Ludwig Boltzmann Institut für Kriegsfolgenforschung in Graz. 2009 wurde das Wiener Wiesenthal Institut für Holocaust-Studien (VWI) gegründet. Von 1982 bis 2017 bestand das Ludwig Boltzmann Institut für Historische Sozialwissenschaft, von 2005 bis 2013 das Ludwig Boltzmann Institut für Europäische Geschichte und Öffentlichkeit, von

4 Ernst Hanisch, Die Dominanz des Staates. Österreichische Zeitgeschichte im Drehkreuz von Politik und Wissenschaft, in: Alexander Nützenadel/Wolfgang Schieder (Hg.), Zeitgeschichte als Problem. Nationale Traditionen und Perspektiven der Forschung in Europa (Geschichte und Gesellschaft, Sonderheft 20), Göttingen 2004, 54-77. Der Text erschien später online mit leicht variiertem Titel: Ernst Hanisch, Österreich - Die Dominanz des Staates. Zeitgeschichte im Drehkreuz von Politik und Wissenschaft, Docupedia-Zeitgeschichte, URL: https://docupedia.de/zg/\%C3\%96sterreich_-_ Die_Dominanz_des_Staates (abgerufen 28.12.2020).

5 Gerhard Botz, Zwölf Thesen zur Zeitgeschichte in Österreich, in: Ingrid Böhler/Rolf Steininger (Hg.), Österreichischer Zeitgeschichtetage 1993. 24. bis 27. Mai 1993 in Innsbruck, Innsbruck/ Wien 1995, 19-33. 
2011 bzw. 2013 bis 2020 an der Österreichischen Akademie der Wissenschaften ein Zentrum bzw. Institut für Neuzeit- und Zeitgeschichtsforschung, das einem Institut zur Erforschung der Habsburgermonarchie und des Balkanraumes gewichen ist. Das 2019 gegründete Ludwig Boltzmann Institute for Digital History (LBIDH) ging aus dem Ludwig Boltzmann Institut für Geschichte und Gesellschaft (1977) hervor. Auch das Institut für die Wissenschaften vom Menschen (IWM) und das Internationale Forschungszentrum Kulturwissenschaften (IFK), beide in Wien, letzteres aber mittlerweile ein Teil der Kunstuniversität Linz, spielen eine wichtige Rolle für die österreichische Zeitgeschichtsforschung.

Von großer Bedeutung sind die Archive, die anfangs durch einen restriktiven Aktenzugang die Arbeit der ZeithistorikerInnen eher behinderten, aber in den letzten zwanzig Jahren verstärkt das Feld der Zeitgeschichte in den Vordergrund ihrer Arbeit gerückt haben und infolgedessen auch Arbeitsplätze für ZeithistorikerInnen haben schaffen können: das Österreichische Staatsarchiv mit seinen Abteilungen, vor allem das 1983 errichtete Archiv der Republik, die Landesarchive und die Stadtarchive. Letztere haben eine Pionierrolle in der Bearbeitung der NS-Vergangenheit eingenommen. ${ }^{6}$ Daneben ist eine Reihe von Spezialarchiven zu nennen wie der Verein für Geschichte der ArbeiterInnenbewegung, das Bruno Kreisky-Archiv oder auch das Forschungsinstitut für politisch-historische Studien Dr. Wilfried-HaslauerBibliothek in Salzburg. Bedeutsam ist der Positionsgewinn der Zeitgeschichte auch auf dem Feld der Gedenkstätten und Museen. 2003 wurde der Lern- und Gedenkort Schloss Hartheim mit der Ausstellung „Wert des Lebens" eröffnet. Mit dem Haus der Geschichte Österreich (seit 2018 in der Wiener Hofburg am Heldenplatz) und dem Haus der Geschichte im Museum Niederösterreich (seit 2017 in St. Pölten) existieren mittlerweile zwei neue Museen, die der Geschichte des 20. und 21. Jahrhunderts sowohl in der Dauer- als auch in den Sonderausstellungen einen zentralen Platz einzuräumen. In den traditionsreichen Landesmuseen nahm die Zeitgeschichte lange Zeit, wenn überhaupt, nur eine Randstellung ein - anders als in den drei jüdischen Museen in Eisenstadt, Hohenems und Wien. In Ebensee gibt es seit 2001 ein eigenes Zeitgeschichtemuseum im Gedenken an das dortige NS-Konzentrationslager und den Widerstand in der Region, in Linz seit 2014 das „Zeitgeschichte MUSEUM“ der voestalpine AG zur Erinnerung an die NS-Zwangsarbeiterinnen und Zwangsarbeiter der Reichswerke Hermann Göring.

Eine wichtige Rolle für die zeitgeschichtliche Forschung in Österreich im neuen Jahrtausend spielen darüber hinaus der Nationalfonds der Republik Österreich für

6 Vgl. am Beispiel Linz: Fritz Mayrhofer/Walter Schuster, Nationalsozialismus in Linz, 2 Bde., Linz 2001. 
Opfer des Nationalsozialismus (gegründet 1995) und der Zukunftsfonds der Republik Österreich (gegründet 2005), vor allem durch die Finanzierung von Forschungsprojekten, Publikationen und Veranstaltungen. „erinnern.at - Nationalsozialismus und Holocaust: Gedächtnis und Gegenwart" (gegründet 2000) ist unterdessen im Bildungsministerium für Holocaust Education verantwortlich und widmet sich mit seinen dezentralen Netzwerken in den Bundesländern vor allem der Fortbildung von LehrerInnen sowie der historisch-politischen Bildung und Geschichtsvermittlung.

Um die institutionalisierte Zeitgeschichte und die etablierten ZeithistorikerInnen herum gibt es eine große Gruppe von wenig abgesicherten KollegInnen, aber auch Laien oder Journalisten, die zeithistorisch arbeiten - ebenso wie es KollegInnen in angrenzenden Gebieten der Geschichte (Österreichische Geschichte, Wirtschaftsund Sozialgeschichte, Außereuropäische Geschichte usw.) gibt, die sich selbst wohl nicht als ZeithistorikerInnen bezeichnen würden und oft auch nicht in das Feld entsprechend eingebunden sind, aber zeithistorisch relevante Themen bearbeiten.

Unterscheiden lassen sich zunächst zwei Aufbauphasen in den späten 1960erund frühen 1980er-Jahren. Der nächste große Entwicklungsschritt für die Zeitgeschichtsforschung in Österreich - und ein beachtlicher kollektiver Kraftakt - war dann wohl die Historikerkommission der Republik Österreich zur Aufarbeitung des Vermögensentzugs während der NS-Zeit sowie seither erfolgte Rückgaben bzw. Entschädigungsmaßnahmen (1998-2003). In 47 Projekten arbeiteten bis zu 160 HistorikerInnen, aber auch Juristen, die Ergebnisse wurden in 49 Bänden veröffentlicht. Parallel dazu verschob sich der Fokus der Zeitgeschichte in Österreich von der Zwischenkriegszeit auf die NS-Zeit und ihre vielfältigen und langanhaltenden Folgen. Mittlerweile ist die Zeitgeschichtsforschung ein äußerst breites und ausdifferenziertes Feld, wobei der Österreichzentrismus im Wesentlichen erhalten geblieben ist. Wenn sich Rothfels 1953 in seinem grundlegenden Aufsatz mit dem Vorwurf konfrontiert sah, dass durch die Etablierung einer Zeitgeschichte als weiterer Epoche die Einheit der Geschichtswissenschaft in Gefahr sei, so kann man sich inzwischen fragen, inwieweit es überhaupt noch eine Einheit der Zeitgeschichte in Österreich gibt - so viele verschiedene Themen und Perspektiven, Zugänge und Methoden sind präsent. Dies belegt nicht zuletzt der vorliegende Band. Die Vielfalt der österreichischen Zeitgeschichte kann sowohl als eine Stärke als auch als eine Schwäche verstanden werden.

Als Forum für die einschlägige Community hat sich der alle zwei Jahre stattfindende Österreichische Zeitgeschichtetag etabliert: Erstmals 1993 an der Universität Innsbruck vom Institut für Zeitgeschichte ausgerichtet, infolge der Bemerkung des damaligen ÖVP-Wissenschaftsministers Erhard Busek, er sei unzufrieden mit der 
heimischen Zeitgeschichtsforschung und -lehre angesichts des Lobs des FPÖ-Politikers Jörg Haider für die „ordentliche Beschäftigungspolitik“ der Nazis. 2020 fand er - als Nummer 13 - pandemiebedingt virtuell statt, organisiert abermals in Innsbruck. ${ }^{7}$ Diskutiert wird in der österreichischen Zeitgeschichtsforschung also zumindest alle zwei Jahre. Aber es gibt Defizite: Nie hat sich ein umfängliches Rezensionswesen in den zuständigen Fachzeitschriften herausgebildet. Die österreichischen Tageszeitungen können dies schwerlich kompensieren. Ein dauerndes Gespräch der österreichischen Zeitgeschichtsforschung mit sich selbst durch gegenseitiges Rezensieren der veröffentlichten Literatur findet nicht statt - in der Summe wird in den deutschen historischen Zeitschriften mehr Literatur zur österreichischen Zeitgeschichte rezensiert als in den österreichischen.

Gestritten wird wenig bis gar nicht, und das mag man als Problem sehen. Konfliktlinien entlang unterschiedlicher Einschätzungen zentraler Problemfelder der österreichischen Zeitgeschichte sind in der Wissenschaft nicht erkennbar: Der Konflikt um Begriffe wie Austrofaschismus und Ständestaat scheint entschärft und war ohnehin meist eher Ausdruck politischer Gesinnung gewesen. Eine Neuauflage von Gerhard Botz' und Gerald Sprengnagels Aufsatzsammlung „Kontroversen um Österreichs Zeitgeschichte", in der die unterschiedlichen Herausforderungen der Zeitgeschichtsforschung der Jahre seit der Waldheim-Debatte 1986/1987 zusammengefasst wurden, erschien 2008. Und seither? Der vorliegende Band kann kaum über neue Kontroversen berichten. Die Ursachen dafür sind vielfältig: Die enorme Ausdifferenzierung der Arbeitsfelder lässt viel Freiraum, führt aber auch zu einer relativen Beziehungslosigkeit bzw. zu einem freundlichen Nebeneinander. Der latente Bedeutungsverlust der politischen Geschichte hat alte politische Kontroversen - Kontroversen an der Schnittstelle von Wissenschaft und Politik - in den Hintergrund treten lassen. Die Dominanz der Forschung zum Nationalsozialismus und zum Holocaust wiederum ist - ebenso wie die dazugehörige Erinnerungskultur - in der Wissenschaft und in weiten Teilen der Öffentlichkeit längst konsensual verankert und löst keinen Streit mehr aus. Nicht ausgeschlossen werden kann aber auch, dass die prekäre Situation, in der sich viele der jüngeren (und manche der älteren) WissenschaftlerInnen befinden, die sich von Projekt zu Projekt und von Zeitvertrag

7 Ingrid Böhler/Dirk Rupnow, Während der Corona-Krise. Der 13. Österreichische Zeitgeschichtetag 2020 in Innsbruck („Nach den Jubiläen“) als 1. Virtueller Österreichischer Zeitgeschichtetag, in: zeitgeschichte 47 (2020) 4, 523-530.

8 Gerhard Botz/Gerald Sprengnagel (Hg.), Kontroversen um Österreichs Zeitgeschichte. Verdrängte Vergangenheit, Österreich-Identität, Waldheim und die Historiker (Studien zur historischen Sozialwissenschaft 13), Frankfurt a. M. ${ }^{2}$ 2008. (Die erste Auflage, herausgegeben von Gerhard Botz, war 1994 erschienen.) 
zu Zeitvertrag hangeln müssen, dazu führt, dass Fragen und Probleme, die Konflikte auslösen könnten, vermieden werden. Auftragsforschung nimmt selten Risiken in Kauf.

Angetrieben wurde die Zeitgeschichtsforschung in den letzten Jahren nicht zuletzt durch Jahrestage und Jubiläen: der beiden Weltkriege, der beiden Republiken, der Verfassung, der Formulierung der Menschenrechte, aber etwa auch der Salzburger Festspiele oder der „Gastarbeiter“-Anwerbeabkommen in den 196oer-Jahren ebenso wie der Abschaffung der Demokratie und des Endes der Ersten Republik, des „Anschlusses“, des Novemberpogroms. Das garantiert öffentliche und mediale Aufmerksamkeit für die Zeitgeschichte, widerspricht aber doch häufig der Logik der Forschung; wie es auch ein gängiges Missverständnis ist, von Historikerkommissionen, die inzwischen zur Allzweckwaffe geworden zu sein scheinen, einen Abschluss und/oder eine Entlastung zu erwarten.

Währenddessen steckt die Musealisierung der österreichischen Zeitgeschichte nach dem übervollen Erinnerungs- und Gedenkjahr 2018 in einer Krise wie selten zuvor. Hier zeigt sich, dass das Hinterherhecheln hinter den jeweils gerade allen kurzfristig bewusst werdenden Jubiläen ermüdend und sicher keine gute und vor allem keine nachhaltige Strategie ist. Eine klare Perspektive für das im November 2018 eröffnete Haus der Geschichte Österreich in der Hofburg in Wien fehlt - wie auch eine eindeutige Haltung gegenüber dem vom Verteidigungsministerium verantworteten Heeresgeschichtlichen Museum, das mit seinen skandalösen Geschichtsbildern zum Lieblingsausflugsort der internationalen Rechtsextremisten geworden ist. Doch über all das schweigt sich das aktuelle türkis-grüne Regierungsabkommen aus. Dabei könnte die alte Ruhmeshalle der k.u.k.-Armee mit ihren exzeptionellen Sammlungen angesichts einer Welt voller militärischer Konflikte, der „immerwährenden Neutralität“ und des Selbstbildes Österreichs als Vermittler und Brückenbauer zu einem Ort der Friedenspädagogik und Menschenrechtsbildung weiterentwickelt werden anstatt dort Mittelaltermärkte und sonst noch anderes zu dulden. Und auch für Braunau am Inn bräuchte es ein paar gute Ideen. Der durch die Bundespolitik eingeschlagene Weg einer „Neutralisierung“ des Hitler-Geburtshauses durch Ansiedlung einer Polizeistation und architektonische Umgestaltung inklusive des versuchten Abbaus bestehender Gedenkzeichen wird eher früher als später in einem Desaster enden. Verantwortungsvolle Geschichtspolitik sieht anders aus. Eine Löschung der Vergangenheit wird nicht ernsthaft als ein konstruktiver Beitrag zur Erinnerungskultur im 21. Jahrhundert erklärt werden können.

Schwer bestimmbar ist das Verhältnis der österreichischen Zeitgeschichte zu Deutschland: Manche Entwicklungen in Deutschland scheinen mit Zeitverzögerung in Österreich nachvollzogen zu werden, öffentliche Debatten finden aber weit- 
gehend getrennt statt. Nur wenige österreichische HistorikerInnen verirren sich in deutsche Historikerstreite und Feuilletondebatten. Während man sich bestimmte Aspekte und Abschnitte der Geschichte und der Zeitgeschichte teilt, wird sehr leicht übersehen, dass die österreichische Republikgeschichte nach 1918 mit der Habsburgermonarchie eine sehr andere Grundlage und Vorgeschichte hat und in vielfältigen anderen Bezügen steht als ihr deutsches Pendant; ebenso, wie oft ignoriert zu werden scheint, dass die österreichische Geschichte in der ersten Jahrhunderthälfte eben zwei Diktaturen und zwei miteinander konkurrierende Faschismen kennt - was sie etwas komplizierter macht als die deutsche Geschichte in diesem Zeitraum, die wohl weithin als Modellfall angesehen wird und allgemein vertrauter und präsenter ist. Damit im Zusammenhang steht auch die Angst vor dem Verlust der österreichischen Zeitgeschichte in einer stärker internationalisierten Wissenschaftslandschaft, sei es aufgrund der Personalpolitik an den heimischen Universitäten wie der Besetzung von Zeitgeschichteprofessuren mit Deutschen (wie im Fall der beiden Herausgeber) oder auch aufgrund der Dominanz neuer Forschungsperspektiven jenseits des Nationalen. Die österreichische Zeitgeschichte wird durch Europäisierung und Globalisierung provinzialisiert - darin steckt aber gleichzeitig auch das Rezept für ihre Deprovinzialisierung.

Die Zeitgeschichtsforschung in Österreich muss neues Terrain gewinnen - und der vorliegende Band will dafür werben: für die stärkere Internationalisierung der österreichischen Zeitgeschichte, für die Einbindung der nationalen (und ebenso auch der regionalen) Geschichte in eine europäische und eine globale Perspektive, schließlich für die Nutzung des Vergleichs als Methode, mit der Gemeinsamkeiten und Differenzen in größeren, transregionalen und transnationalen Zusammenhängen herausgearbeitet werden können. Ausreichend Potenzial ist vorhanden.

Letztlich geht es darum, die österreichische Zeitgeschichte zu bewahren, ohne bei einem Österreichzentrismus stehen zu bleiben und in Provinzialismus zu versinken. Impulse wie Transnationalismus, Globalgeschichte und Migration/Diversität müssen ebenso aufgenommen werden wie neue Zugänge und Themen und auf Österreich produktiv angewendet werden. Die österreichische Zeitgeschichte muss damit auch für ein Publikum jenseits des Landes interessant und relevant gemacht werden, was angesichts der internationalen Dominanz der deutschen Geschichte des 20. Jahrhunderts und des großen Interesses für die Geschichte des Habsburgerreiches (vor allem des späten), aber weniger für die Republikgeschichte nach 1918, nicht ganz einfach ist.

Zeitgeschichte muss in Österreich wie anderswo ein Hybridwesen sein: regional verankert, aber europäisch und global/international ausgerichtet; sie muss auf Deutsch (mit österreichischem Zungenschlag) und ganz selbstverständlich auch auf 
Englisch funktionieren; sie muss Grundlagenforschung ebenso können wie Auftragsforschung für Gemeinden, Städte und Bundesländer oder auch für Firmen und Interessensgemeinschaften; sie ist ein Teil der Erinnerungskultur, aber auch ihr kritisches Gegenüber; sie muss große Forschungsprojekte kompetitiv akquirieren wie auch ein breites Publikum leichtverständlich ansprechen können; sie muss eng mit den Medien kooperieren und in ihnen präsent sein, ohne sich von ihnen oder auch der Politik vereinnahmen zu lassen.

Die Beiträge unserer AutorInnen demonstrieren eindrücklich, dass die Zeitgeschichte in Österreich ein äußerst lebendiges und dynamisches Feld ist, dass auch öffentlich und medial sehr präsent ist. Wie sich zeigt, gibt es viele Zeitgeschichten in Österreich - und dementsprechend auch nicht nur eine Entstehungsgeschichte der Zeitgeschichte in Österreich. Viele Versionen und Zugänge werden in den einzelnen Texten sichtbar: etablierte und weniger etablierte. Alle unsere AutorInnen würden wohl darauf verweisen, dass in dem von ihnen vorgestellten Forschungsbereich die größten Desiderate vorhanden seien. Alle hier verhandelten Themen verdienen es offensichtlich, intensiver beforscht und ausgebaut zu werden. Im Übrigen auch die Fachgeschichte: Zeitgeschichte braucht Selbstreflexion ihrer Wurzeln und Entwicklungswege. Wie schwer dies alles ist, spiegelt nur die Kleinheit der institutionalisierten Zeitgeschichtsforschung in Österreich wider: an Personal und an Ressourcen. Hinzu kommt, dass sich nur wenige Einrichtungen und Lehrstühle außerhalb Österreichs der österreichischen Zeitgeschichte und ihren verschiedenen Aspekten widmen. Im Ausland steht im Allgemeinen die Geschichte der Habsburgermonarchie im Vordergrund - bei den HistorikerInnen wie bei den TouristInnen, die es nach Österreich zieht. Umgekehrt wird in Österreich selbst Zeitgeschichte nicht nur von akademisch ausgebildeten, professionellen ZeithistorikerInnen betrieben, sondern auch von Laien und vor allem auch von JournalistInnen - oft in Zusammenarbeit, gelegentlich aber auch in Konkurrenz zueinander.

Und das Coronavirus? Die Fertigstellung dieses Buches in den Jahren 2020/2021 ist nicht zuletzt durch die Corona-Pandemie stark verzögert worden: Aufgrund von Lockdowns hatten die beteiligten KollegInnen teilweise keinen Zugang zu ihren Unterlagen und Materialien, Bibliotheken waren nicht geöffnet, neue Methoden des "distant learning/teaching" hatten Vorrang und nahmen viel Zeit in Anspruch. Aber wird das Coronavirus die Geschichte verändern, wie dies schon kurz nach dem Ausbruch von einigen Großdenkern vorausgesagt wurde? Läutet die Corona-Pandemie das Ende der Globalisierung ein und den Beginn abgeschotteter nationaler Überwachungsstaaten, bringt sie das Ende des Kapitalismus und den Beginn einer neuen solidarischen Gesellschaft, destabilisiert sie die politische Weltordnung? HistorikerInnen sind bekanntermaßen keine Propheten, höchstens rückwärtsgewandte. Be- 
zeichnenderweise spielt etwa die Spanische Grippe in der Zeitgeschichte praktisch keine Rolle: Obwohl sie mit ihren drei Wellen 1918/1919 weltweit möglicherweise mehr Opfer forderte als der Erste und Zweite Weltkrieg zusammen und somit vermutlich den größten demographischen Einschnitt im 20. Jahrhundert darstellt, hat sie kaum Spuren im kulturellen Gedächtnis hinterlassen. Wenig bis nichts ist gesichert bekannt über die Folgen, die sie gezeitigt hat, wohl nicht zuletzt deshalb, weil sie von einem anderen, menschengemachten Großereignis überlagert wird: dem Ende des Ersten Weltkriegs und dem Zusammenbruch dreier Imperien. Mit Blick auf die Spanische Grippe darf man skeptisch sein, welche Folgen die CoronaPandemie, die in diesem Jahr unsere Aufmerksamkeit und Energie absorbiert hat, langfristig und nachhaltig haben wird. Abschätzen können wir das als HistorikerInnen heute jedenfalls noch nicht.

Das vorliegende Buch markiert auch eine persönliche Zäsur: Mit diesem Band geht die Herausgeberschaft der „Zeitgeschichtlichen Bibliothek“ im Böhlau Verlag von Helmut Konrad (Graz) an Marcus Gräser (Linz) und Dirk Rupnow (Innsbruck) über. Helmut Konrad hat diese Reihe seit 1976 herausgegeben und sie zu einer der wichtigsten zeitgeschichtlichen Publikationsreihen in Österreich werden lassen. Wir stehen in seiner Schuld - und hoffen, dass wir seinem Anspruch in Zukunft gerecht werden können.

So bleibt uns nur noch, allen BeiträgerInnen zu danken: dass sie sich mit uns auf dieses einigermaßen unberechenbare Abenteuer eines äußerst umfangreichen Sammelbandes und unsere Themenvorgaben eingelassen haben und auch nicht angesichts der Corona-Beschwernisse abgesprungen sind. Dank gebührt ebenso den institutionellen Fördergebern, allen voran unseren beiden Universitäten in Innsbruck und Linz sowie dem Böhlau Verlag und Ursula Huber für die professionelle Begleitung und nicht zuletzt ihre große Geduld. Unser Dank geht auch an Marina Blum (Innsbruck), die freundlicherweise die äußerst mühevolle Arbeit der Vereinheitlichung der Manuskripte übernommen hat, und an Julia Roßberg, Anja Borkam und Bettina Waringer vom Böhlau Verlag, die mit Umsicht die Drucklegung begleitet haben.

Marcus Gräser und Dirk Rupnow

Linz und Innsbruck, Jänner 2021 
(c) 2021 Böhlau Verlag | Brill Österreich GmbH https://doi.org/10.7767/9783205209980 | CC BY-NC 4.0 


\title{
Zeitgeschichtsforschung in Österreich seit 1945 - Ein Rückblick
}

\author{
Helmut Konrad
}

\section{Die Gründergeneration}

Es wäre eine grobe Verkürzung, von Lehre und Forschung im Fach Zeitgeschichte in Österreich erst ab der formellen Gründung einschlägiger Universitätsinstitute zu sprechen. Dies würde den Beginn auf 1966 mit der Einrichtung des Instituts für Zeitgeschichte an der Universität Wien als erste akademisch institutionalisierte Organisationseinheit im Fach festsetzen. Formal kann man zwar so argumentieren, aber schon früher konnten interessierte StudentInnen an allen österreichischen Universitäten zeitgeschichtliche Vorlesungen hören, Bücher auch zur österreichischen Geschichte des 20. Jahrhunderts lesen oder selbst Forschungsschritte in der Disziplin in einschlägigen Archiven unternehmen. Wohl war die Disziplin noch formell an den Universitäten nicht etabliert, aber Fragen und Problemstellungen zur jüngsten, meist österreichischen Geschichte waren durchaus im Lehrangebot der Universitäten vorhanden. Das ist erstaunlich, wenn man den kurzen Zeitabstand bedenkt, der diese Angebote vom Ende des Zweiten Weltkriegs trennte. Ich selbst hatte jedenfalls aktuell, also im 21. Jahrhundert, in meiner Berufslaufbahn die letzten gerade vergangenen Jahrzehnte nicht wirklich auf dem Radar, sondern begrenzte meine Lehre meist mit 1989.

Selbst institutionell greift man zu kurz, wenn man den Beginn einer österreichischen Zeitgeschichtsschreibung mit dem Jahr 1966 ansetzt. Der Verein für Geschichte der Arbeiterbewegung (VGA), bis heute im Besitz wesentlicher Quellen zur österreichischen und internationalen Zeitgeschichte und daher gerade international hoch angesehen, öffnete bereits 1959 seine Pforten und vier Jahre später begann das Dokumentationsarchiv des Österreichischen Widerstandes (DÖW) seine verdienstvolle Tätigkeit, die wiederum eigentlich unmittelbar nach dem Kriegsende mit dem „Rot-Weiß-Rot-Buch“ ihren Anfang genommen hatte. ${ }^{1}$ Seit 1964 hält die Interna-

1 Rot-Weiß-Rot-Buch. Gerechtigkeit für Österreich! Darstellungen, Dokumente und Nachweise zur Vorgeschichte und Geschichte der Okkupation Österreichs. Erster Teil (Nach amtlichen Quellen), Wien 1946. 
tionale Tagung der Historiker der Arbeiterbewegung (ITH) jährliche Konferenzen ab, sehr bald am Standort Linz. Damit wurden früh ForscherInnen nach Österreich gebracht, wie etwa Eric Hobsbawm oder Felix Kreissler, die sich mit Offenheit und kollegialer Freundschaft um die Nachwuchskräfte im Land bemühten. Der Vorwurf einer „Verdrängung“ oder zumindest der Vermeidung heikler Fragen aus der Geschichte des 20. Jahrhunderts, den meine Generation, mich eingeschlossen, in den späten 1960er-Jahren so lautstark erhob, war jedenfalls teilweise unberechtigt und widersprach der eigenen Erfahrung, die man im Studium machen konnte und durchaus auch machte. Richtig aber war, dass nicht nur in der Geschichte, sondern auch in vielen anderen akademischen Fächern, von der Volkskunde oder der Theaterwissenschaft bis hin zur Germanistik, teilweise noch Lehrpersonal am Pult stand, das nicht nur biographisch, sondern wohl auch in den Positionen bei den vorgetragenen Inhalten einer vorausgegangenen Epoche verbunden war. Es waren mehr die Biographien einzelner Lehrender, die das Konfliktpotenzial schufen, nicht das Fehlen zeithistorischer Lehrinhalte oder das Verhindern einer Beschäftigung mit kritischen zeitnahen Themenfeldern.

Meint man heute mit der „GründerInnengeneration“ der österreichischen Zeitgeschichtsschreibung vor allem das Dreigestirn Ludwig Jedlicka, Karl R. Stadler und Erika Weinzierl, so muss man doch im Auge haben, dass schon 1954 Heinrich Benedikt seinen Sammelband „Geschichte der Republik Österreich“2 herausgegeben hatte, wobei vor allem der Beitrag von Adam Wandruszka zu den politischen Lagern in Österreich ${ }^{3}$ lange diskursbestimmend, zustimmend und ablehnend, bleiben konnte. Alfons Lhotsky hatte früh so manche Tür geöffnet, aber auch Friedrich Engel-Janosi oder aber Friedrich Heer prägten Studierendengenerationen im Fach Zeitgeschichte lange vor den formellen Institutsgründungen. An der Diplomatischen Akademie lehrten früh Emigranten, wie Karl R. Stadler, Zeitgeschichte und Charles Adams Gulick, Professor an der University of California in Berkeley, veröffentlichte schon 1948 sein bahnbrechendes Werk zur österreichischen Zeitgeschichte, das noch im selben Jahr mit dem Titel „Zwischen Habsburg und Hitler“4 auch in deutscher Sprache einer breiteren Öffentlichkeit zur Verfügung stand. Es war also keine Tabula rasa, auf die die ersten einschlägigen Universitätsinstitute aufsetzten, sondern es gab durchaus ein bereits zumindest partiell gut bearbeitetes Feld.

2 Heinrich Benedikt, Geschichte der Republik Österreich, München 1954.

3 Adam Wandruszka, Österreichs politische Struktur. Die Entwicklung der politischen Parteien und Bewegungen, in: Heinrich Benedikt (Hg.), Geschichte der Republik Österreich, München 1954, 289-485.

4 Charles A. Gulick, Österreich von Habsburg zu Hitler, 5 Bde., Wien 1948. 
Dennoch: Mit Erika Weinzierl, Karl R. Stadler und Ludwig Jedlicka bekam das Fach seine akademische Anerkennung als eigenständige Disziplin. Mit- und gegeneinander prägten sie das junge Fach. Das Gegeneinander (stärker zwischen Jedlicka und Weinzierl, Stadler war dazwischen verbindend) war den unterschiedlichen Biographien und der unterschiedlichen politischen Verortung geschuldet, das Miteinander dem gemeinsamen Bemühen, das Fach zu etablieren und den außeruniversitären Institutionen, wie dem DÖW und dem VGA, zur fachlichen Anerkennung zu verhelfen.

Karl R. Stadler war der Älteste dieses Trios. 1913 in Wien geboren, verkörperte er fast idealtypisch den „Neuen Menschen“ im Roten Wien, eingebettet in einen Kreis Gleichgesinnter und überzeugt von der Überlegenheit sozialistischer Weltbilder. ${ }^{5}$ Das passive Verhalten der Sozialdemokratie in der Auseinandersetzung mit den demokratiebedrohenden politischen Kräften führte ihn nach links, für die Kommunisten galten er und seine Freunde aber bald als „Trotzkisten“. Im März 1938 verteilte er noch vor Wiener Fabriktoren Flugblätter gegen Hitler, ehe er im letzten Augenblick über Frankreich nach England fliehen konnte, wo seine Freundin schon Unterschlupf gefunden hatte. Sie war als Jüdin dort von Hilfsorganisationen aufgenommen worden, er hingegen galt bald als „enemy alien“, wurde interniert und konnte erst später seine Studien fortsetzen. An der University of Nottingham brachte er es zum Senior Lecturer und war in der Erwachsenenbildung tätig. Sein Forschungsinteresse galt aber Österreich, und sein altes Netzwerk aus den 1930er-Jahren, darunter der spätere Justizminister Christian Broda, öffneten ihm die Türen, erst zur Diplomatischen Akademie in Wien und dann, mit der Gründung der damaligen Hochschule für Sozial- und Wirtschaftswissenschaften, der heutigen Johannes Kepler Universität, nach Linz, wo er ab 1968 seine Lehrkanzel und das Institut für Neuere Geschichte und Zeitgeschichte zum dynamischen Mittelpunkt der österreichischen Zeitgeschichtsschreibung ausbauen sollte. Politisch klar positioniert (Stadler war auch der erste Direktor des sozialdemokratischen Renner-Instituts und Präsident des Österreichischen Volkshochschulverbandes) und ausgestattet mit den Zusatzmöglichkeiten, die das erste Ludwig Boltzmann Institut auf dem Gebiet der Geistes, Kultur- und Sozialwissenschaften, das Ludwig Boltzmann Institut für Geschichte der Arbeiterbewegung, vor allem auch auf dem Feld der Buchveröffentlichungen bot, eröffnete er der Generation der österreichischen „1968er “ Forschungs- und Publikationsmöglichkeiten, die damals einzigartig waren und auch international ausstrahlten. Wegen der drei Jahrzehnte, die er in der Emigration verbringen musste,

5 Siehe dazu: Helmut Konrad/Gabriella Hauch, Hundert Jahre Rotes Wien. Die Zukunft einer Geschichte, Wien 2019. 
erhielt er nach seiner Emeritierung noch Ehrenjahre an der Universität, er konnte also noch über das siebzigste Lebensjahr hinaus aktiv bleiben. 1987 verstarb Karl R. Stadler in Linz.

Drei Jahre jünger als Karl R. Stadler war Ludwig Jedlicka. Schon mit 14 Jahren war er 1930 in die Hitlerjugend eingetreten. Er wurde 1939 bei Heinrich von Srbik promoviert, war aber neben seiner wissenschaftlichen Arbeit auch politisch tätig. Seine Einstufung als „Alter Kämpfer“ - er war auch am Sturm auf das Erzbischöfliche Palais beteiligt - trug ihm die Position eines Stadtoberinspektors ein. Wegen seiner körperlichen Behinderung durch eine frühkindliche Kinderlähmung war er für den Militärdienst untauglich und er verbrachte die Kriegsjahre als Gefreiter im Heeresmuseum der Wehrmacht im Arsenal in Wien. Ab 1943 war er im Kontakt mit dem militärischen Widerstand gegen Hitler und versorgte den Widerstand und auch die Alliierten mit Informationen. Daher wurde nach 1945 sein Verfahren vor dem Volksgericht eingestellt und er konnte als unbelastet gelten. Ab 1961 unterrichtete er an der Militärakademie in Wien. Er war 1945 dem CV beigetreten und 1949 auch der ÖVP. In der 1960 gegründeten Österreichischen Gesellschaft für Zeitgeschichte, die das damals doch schmerzlich vermisste universitäre Institut für Zeitgeschichte partiell ersetzen sollte (und gleichzeitig auf die Geschichte der Zwischenkriegszeit einen alternativen Blick zur in der öffentlichen Wahrnehmung „linken“ Sichtweise erarbeiten sollte), hatte er die Funktion des Generalsekretärs inne, und als diese Gesellschaft ein Institut für Zeitgeschichte einrichtete, war Jedlicka auch dort tätig. Mit Herbert Steiner, dem Motor des DÖW, stand Jedlicka an der Wiege dieser Einrichtung im Jahr 1963, die prinzipiell überparteilich organisiert war, aber in der Mehrheit der MitarbeiterInnen eine Linkslastigkeit aufwies. Herbert Steiner war Mitglied der KPÖ und hatte die Kriegsjahre im englischen Exil verbracht. 1965 wurde Jedlicka an der Universität Wien zum außerordentlichen Universitätsprofessor ernannt und er erhielt die Leitung des 1966 gegründeten Instituts für Zeitgeschichte. 1969 wurde er gegen etlichen Widerstand gerade auch der Studierenden zum Ordinarius ernannt. Er stand dem Institut bis zu seinem Tod im Jahr 1977 vor und prägte in diesem Jahrzehnt die junge österreichische Zeitgeschichtsforschung entscheidend mit.

Erika Weinzierl, die Jüngste des Dreigestirns, wurde 1925 in Wien geboren. Vom Elternhaus her gegen den Nationalsozialismus immunisiert, fand sie nach der Matura in einer Gruppe der Katholischen Studentenseelsorge Halt, der auch Otto Maurer, Hans Tuppy, Kurt Schubert oder Kurt Skalnik angehörten, alles Persönlichkeiten des wissenschaftlichen und künstlerischen Lebens der Zweiten Republik und Gegner des Nationalsozialismus. Schon 1948 konnte sie bei Leo Santifaller promovieren und eine Stelle im Haus, Hof- und Staatsarchiv antreten. 1961 habilitierte sie bei 
Alfons Lhotsky mit einer Arbeit über die österreichischen Konkordate. 1964 wurde sie an das Institut für kirchliche Zeitgeschichte in Salzburg berufen. Die Universität Salzburg konnte ihr ab 1967 eine außerordentliche und ab 1969 eine ordentliche Professur für Österreichische Geschichte unter besonderer Berücksichtigung der Zeitgeschichte bieten. 1977 wurde von ihr das Ludwig Boltzmann Institut für Geschichte der Gesellschaftswissenschaften gegründet. 1979 wurde Erika Weinzierl in der Nachfolge von Ludwig Jedlicka Professorin für Zeitgeschichte und Leiterin des Instituts für Zeitgeschichte an der Universität Wien, eine Position, die sie bis zu ihrer Emeritierung 1995 innehatte. Gemeinsam mit Karl R. Stadler und dem damaligen Justizminister Christian Broda etablierte sie die Forschungskolloquien und die Schriftenreihe "Justiz und Zeitgeschichte ". ${ }^{6}$ Mit Herbert Steiner vom DÖW war sie lebenslang freundschaftlich verbunden. Bis zu ihrem Tod im hohen Alter von über neunzig Jahren war Erika Weinzierl eine moralische Autorität, nicht nur im Fach, sondern für die gesamte Republik Österreich.

Schaut man auf diese "Gründergeneration“ zurück, so drängt sich die Frage auf, ob hier "Schulen“ geschaffen wurden. Das ist nicht ganz einfach zu beantworten. Am ehesten spricht man von einer "Stadler-Schule“, obwohl gerade in diesem Fall wichtige Elemente fehlen. Linz bildete damals keine HistorikerInnen aus, Zeitgeschichte war nur ein Wahlfach bei den Sozial- und Wirtschaftswissenschaften. Daher durchlief niemand im Fach Geschichte oder gar Zeitgeschichte in Linz ein ganzes Studium. Die „Schüler" kamen als fertig ausgebildete Historiker (die männliche Form ist hier für die Anfänge berechtigt) aus Wien. Gerhard Botz und Hans Hautmann hatten bei Jedlicka studiert und promoviert, Helmut Konrad bei Richard G. Plaschka, dem jungen Ordinarius für Osteuropäische Geschichte, der viele Arbeiten zum Widerstand gegen den Nationalsozialismus anregte und der in Forschungsfragen und methodischen Zugängen ein Innovator war. Dennoch schweißte das Forschungsfeld Arbeitergeschichte und das Ludwig Boltzmann Institut die kleine Gruppe zu einer stilbildenden Kohorte zusammen, die allerdings ihr Wissen mangels eines Studiengangs nicht an künftige HistorikerInnen weitergeben konnte. Auch Rudolf Ardelt, Gabriella Hauch, Ingrid Bauer, Raimund Löw oder Helene Maimann darf man dazu zählen, obwohl sie nicht an der Universität Linz ihren Lehr- oder Forschungsstandort hatten. Reinhard Kannonier kam über einen spannenden und breiten Ausbildungsweg letztlich aus Salzburg und war eine tragende Säule im Linzer Kernteam, und nur Josef Weidenholzer hatte als einziges Mitglied dieses Teams in Linz studiert,

6 Erika Weinzierl/Karl. R. Stadler (Hg.), Justiz und Zeitgeschichte (Schriftenreihe des Ludwig Boltzmann-Instituts für Geschichte der Gesellschaftswissenschaften), Wien 1977. 
aber eben nicht Geschichte, sondern Soziologie. Verbunden wurde das Team durch eine politisch durch die Linke geprägte Sichtweise.

Ludwig Jedlicka hatte hingegen neben Botz und Hautmann auch Gerhard Jagschitz, Anton Staudinger, Karl Stuhlpfarrer, Wolfgang Neugebauer, Peter Huemer, Norbert Schausberger, August Maria Knoll und viele andere prägende Persönlichkeiten des Fachs ausgebildet, ohne allerdings methodisch stilbildend zu wirken. Die Themen banden sie zusammen, denn fast alle Arbeiten kreisten um die Geschichte der Ersten Republik. Die politische Bandbreite war aber, verglichen zu Linz, deutlich größer.

Erika Weinzierl hatte in ihren Salzburger und Wiener Jahren Rudolf Ardelt, Ernst Hanisch, Siegfried Mattl, Oliver Rathkolb, Gabriella Hauch, Erika Thurner, Ingrid Bauer, Winfried Garscha, Brigitte Bailer oder Brigitte Mazohl unter ihren Fittichen. Ein Weinzierl-Stil ist aber ebenfalls nicht zu erkennen, höchstens die Konzentration auf demokratisch-antifaschistische Inhalte in den Forschungsarbeiten. „Schule“ gab es also nur dort, wo eigentlich nicht mehr ausgebildet wurde und wo es die Inhalte waren, die zur Gruppenbildung führten. Vor allem aber gab es keinen verbindlichen Methodenkanon. Auch im Theorieverständnis war man nicht wirklich innovativ, sondern dem traditionellen Historismus verbunden. Insgesamt galt an allen drei Standorten, vielleicht vor allem für die jüngere Generation, der Blick nach Bielefeld als richtungsweisend.

Neben diesen drei Einrichtungen, die ganz dezidiert der österreichischen Zeitgeschichtsschreibung verpflichtet waren, gab es weitere akademische Lehrer, die Forschungen im Feld selbst durchführten und Studierende dazu anregten, sich zeitgeschichtlichen Themen zuzuwenden. Hier ist an erster Stelle Gerald Stourzh von der Universität Wien zu nennen, der eine breite weltpolitische Perspektive einbrachte und der bis heute die Zeitgeschichte in Österreich mit seinem Wissen klug begleitet. Bei ihm fanden sich vor allem jene Studierenden ein, die an internationalen Fragestellungen interessiert waren. Weiter zu nennen wäre Erich Zöllner, der Österreichhistoriker, der etwa Manfried Rauchensteiner zur Promotion führte. Bei Michael Mitterauer, der seit 1971 außerordentlicher und seit 1973 ordentlicher Professor für Sozial- und Wirtschaftsgeschichte an der Universität Wien war, arbeiteten Ernst Bruckmüller, Reinhard Sieder, Peter Feldbauer, Hannes Stekl, Hubert Christian Ehalt und Wolfgang Maderthaner - auch in manchmal kritischer Distanz zu ihrem Lehrer. Die Seminare bei Mitterauer mit den anschließenden langen Diskussionen im Kaffeehaus haben manche ForscherInnen der damals jüngeren Generation stark geprägt, weit über das Fach Wirtschafts- und Sozialgeschichte hinaus. Hier kann man ganz deutlich, zumindest deutlicher als bei den Lehrkanzeln für Zeitgeschichte, von einer „Schule“ sprechen, weil Mitterauer und seine Studierenden methodisch 
Neuland betraten, sich für sozialwissenschaftliche Theoriebildung interessierten und eigene Publikationsforen schufen.

Richard G. Plaschka machte am Institut für Osteuropäische Geschichte schon 1967 das Tor zur Zeitgeschichte weit auf und führte Helmut Konrad oder Willibald Ingo Holzer zur Promotion über Widerstandsthemen, die einen Bezug zu Osteuropa hatten. Auch Adam Wandruszka ermöglichte einschlägige Arbeiten für seine Studierenden. Selbst in Graz arbeiteten früh Grete Klingenstein oder Alfred Ableitinger vom Nominalfach Neuzeit auch oder sogar hauptsächlich im zeithistorischen Feld. Seit 1969 war dort Ferdinand Hauptmann aus Belgrad als nicht unumstrittener, da als jugoslawischer Staatsbürger gerade in der Steiermark nicht einfach in die traditionell antijugoslawische Öffentlichkeit zu integrierender Professor für Ost- und Südosteuropäische Geschichte tätig und regte etliche zeithistorische Arbeiten an. Fritz Fellner als Querdenker brachte frischen Wind nicht nur ins Fach Zeitgeschichte, sondern in die gesamte Salzburger Universitätslandschaft. Auch er war formal im Teilfach Neuzeit tätig, arbeitete aber überwiegend zur Zeitgeschichte.

Ohne dass damit hier Anspruch auf Vollständigkeit gestellt werden könnte, so ist doch klar zu konstatieren, dass schon um, ja sogar vor dem Jahr 1968 und vor dem Beginn der Ära Kreisky an Österreichs Universitäten das Fach Zeitgeschichte (oder zumindest zeitgeschichtliche Themen) im Rahmen des Gesamtfachs Geschichte nicht marginalisiert war. Im Gegenteil: Es überrascht heute, dass schon knappe zwei Jahrzehnte nach dem Ende des Zweiten Weltkriegs diese Vielfalt an Möglichkeiten zur Beschäftigung mit der jüngsten Vergangenheit auch in Österreich, dem Musterland der Verdrängung, bereits gegeben war.

\section{Die Institutionalisierung}

Die Institutionalisierung des Fachs Zeitgeschichte war in der zweiten Hälfte der 1960er-Jahre nur ein konsequenter Schritt, obwohl die Errichtung eigener Organisationseinheiten nicht unumstritten war. $\mathrm{Zu}$ eng waren die bisherigen Forschungen einerseits an das Teilfach Österreichische Geschichte gebunden und zu komplex gestaltete sich andererseits die Abgrenzung zum etablierten Bereich der Geschichte der Neuzeit. Daher weisen die ersten Institutionen einer universitären Zeitgeschichte auch unterschiedliche Konstruktionen auf, die den universitätspolitischen Rahmenbedingungen an den jeweiligen Standorten geschuldet waren.

In Wien war die Ausgangssituation klar. Die Österreichische Gesellschaft für Zeitgeschichte forcierte mit der Rückendeckung etlicher politiknaher Mitglieder die Gründung eines eigenständigen Instituts, was 1966 auch gelang. Das Institut für 
Zeitgeschichte an der Universität Wien ist somit die älteste eigenständige Organisationseinheit für Zeitgeschichte in der österreichischen Universitätslandschaft. Wegen seines durchaus von Brüchen und Wendungen gezeichneten Lebenslaufs fiel die Begrüßung des ersten Lehrstuhlinhabers ambivalent aus. Für mich ist das eine der ersten Erinnerungen an mein Studium: Karikaturen von Ludwig Jedlicka auf einer Schaukel im Wind, affichiert von konservativen Studierenden, die in ihm einen politischen Wendehals sahen.

Linz folgte 1968 mit dem Ruf von Karl R. Stadler auf eine außerordentliche Professur für Neuere Geschichte und Zeitgeschichte, die rasch in eine ordentliche Professur umgewandelt wurde. Es wurden zwei historische Institute errichtet, an einer Universität, die über keine geisteswissenschaftliche Fakultät verfügte und die kein Geschichtsstudium anbot. Gustav Otruba leitete das Institut für Sozial- und Wirtschaftsgeschichte. Zeitgeschichte erhob zumindest im Institutsnamen den Anspruch, die Neuere Geschichte mit zu vertreten, allerdings reichte die Lehr- und Forschungstätigkeit selten in die Zeit vor 1848 zurück. Dass es sich um ein eigenständiges Institut handelte, stand außer Frage, und die Personalunion zum ebenfalls 1968 gegründeten Ludwig Boltzmann Institut für Geschichte der Arbeiterbewegung machte die Besonderheit aus, da fast unbegrenzt Publikationsmöglichkeiten zur Verfügung standen. In mehreren Schriftenreihen waren sehr rasch gut hundert Bücher am Markt. Das war vor allem möglich, weil die Personalkosten durch die Anstellungen an der Universität gedeckt waren und daher die Mittel des Forschungsinstituts fast vollständig in die Publikationsvorhaben fließen konnten. Bemerkenswert ist dies vor allem auch deshalb, weil diese Konstruktion eines mit dem Universitätsinstituts personenidenten außeruniversitären Instituts noch aus der Zeit der Großen Koalition stammte, einer Koalition, die bei der Gründung der Linzer Hochschule erstaunliche Kompromisse fand, etwa auch bei der Rückholung von Persönlichkeiten, die 1938 aus Österreich vertrieben worden waren. Das war neben Karl R. Stadler vor allem der Nationalökonom Kurt W. Rothschild.

In Salzburg wurde 1969 der neu geschaffene Lehrstuhl für „Österreichische Geschichte mit besonderer Berücksichtigung der Zeitgeschichte“ mit Erika Weinzierl besetzt, die schon 1967 zur außerordentlichen Universitätsprofessorin im Fach ernannt worden war. Damit war in Salzburg die Zeitgeschichte kein eigenes Institut, sondern Teil des übergeordneten Instituts für Geschichte. Zehn Jahre lang blieb Erika Weinzierl in dieser Position, ehe sie in Wien die Nachfolge von Ludwig Jedlicka antrat und Gerhard Botz ihr in Salzburg nachfolgte (und letztendlich dann auch in Wien). Ernst Hanisch stand über die personellen Änderungen hinweg als Konstante im Fach, als einer der prägendsten Vertreter einer österreichischen Zeitgeschichtsschreibung. 
An den drei Standorten, die von der Gründergeneration geprägt wurden, sah man also drei verschiedene institutionelle Konstruktionen: das Institut für Zeitgeschichte in Wien, das Institut für Neuere Geschichte und Zeitgeschichte in Linz (in Personalunion mit dem Ludwig Boltzmann Institut) und den Lehrstuhl für Österreichische Geschichte mit besonderer Berücksichtigung der Zeitgeschichte in Salzburg. Die anderen Universitäten, also Innsbruck, Graz und Klagenfurt, die mit der Institutionalisierung der Zeitgeschichte folgten, hatten damit unterschiedliche Vorbilder.

Innsbruck startete erst am Anfang der 1980er-Jahre den Versuch, eine Professur für Zeitgeschichte zu besetzen. Das Verfahren zog sich hin, zwei Semester lang vertrat Helmut Konrad den vakanten Lehrstuhl, ehe man 1983 die Verhandlungen mit Rolf Steininger abschließen konnte. Für diesen stand außer Frage, dass die Innsbrucker Zeitgeschichte dem Wiener Modell folgen sollte. Zeitgeschichte wurde so ein eigenständiges Institut und ist das auch in der Folge bis heute geblieben. Als Arbeitsschwerpunkte bildeten sich Südtirol und die Geschichte Europas, vor allem Deutschlands, nach dem Ende des Zweiten Weltkrieges heraus, was Innsbruck zu einer Sonderstellung im Rahmen der österreichischen Institutionen für Zeitgeschichte führte.

Das Rennen um die Zeitgeschichte in Graz starte kurz nach dem in Innsbruck. Die Universität Graz hatte den Beschluss gefasst, eine „Allgemeine Zeitgeschichte mit Berücksichtigung außereuropäischer Länder und Kulturen“ auszuschreiben, wollte also auch aus der Häufung der Angebote zur auf Österreich fixierten Zeitgeschichte heraus. Mit dem 1. März 1984 trat in Graz Helmut Konrad die Professur an und er sollte fast 33 Jahre diese Position innehaben, womit er der mit Abstand am längsten an einem Standort arbeitende Ordinarius werden sollte. Ihm war die Einbindung in das große Institut für Geschichte wichtig, sodass die Grazer Zeitgeschichte eine Abteilung des Instituts für Geschichte wurde. Das war also letztlich das vierte Modell einer Verankerung des Fachs an Österreichs Universitäten. Zudem konnte Konrad eine Außenstelle des Linzer Ludwig Boltzmann Instituts nach Graz mitnehmen, was zusätzliche Arbeitsmöglichkeiten bot.

Klagenfurt, damals die junge Hochschule für Bildungswissenschaften, hatte seit 1972 Norbert Schausberger, einen ehemaligen Gymnasiallehrer für Geschichte und Geographie, im Personalstand. Ab 1975 ging Schausberger an die Errichtung einer Lehrkanzel für „Neueste Österreichische Geschichte mit besonderer Berücksichtigung der Didaktik“. 1975 habilitierte er in Klagenfurt und konnte das Vorhaben einer eigenen Lehrkanzel realisieren. Mit dem Wandel der Hochschule hin zu einer Universität ging die didaktische Schwerpunktsetzung zurück und mit Schausbergers Nachfolger Karl Stuhlpfarrer sah sich Klagenfurt stark in der von Wien vorgezeichneten Tradition. 
Somit kann man konstatieren, dass sich zwischen 1966 und 1984 Zeitgeschichte an den österreichischen Universitäten etablieren konnte. Der Vollausbau war erreicht, und die unterschiedlichen Konstruktionen und inhaltlichen Schwerpunktsetzungen waren klar erkennbar. Bei allen Differenzen und bei allen unvermeidlichen Konflikten, die sich auch aus der überschaubaren Zahl der handelnden Persönlichkeiten ergaben, bis zu einem wirklichen „österreichischen Historikerstreit“ hat es die Zunft nie gebracht. Vielmehr zeigte sich, vor allem im Zusammenhang mit den erfolgreichen Zeitgeschichtetagen, die ab 1993 veranstaltet wurden, sehr bald eine anregende Konkurrenz. ${ }^{7}$ Die Zeitgeschichtetage sollten von da an die Diskussion beleben, die Kontakte fördern und die neuen Fragestellungen und Trends auf den Prüfstand stellen. Der wechselseitige Austausch war keine Ausnahme, und dadurch, dass die Gruppe der ProfessorInnen teilweise gemeinsame Wurzeln hatte (beispielhaft sei erwähnt: Gerhard Botz und Helmut Konrad teilten in Linz in den 1970erJahren ein Büro) und nicht wenige in ihren Karrieren mit mehr als einem Standort vertraut waren, ergaben sich belastbare Beziehungen, bei denen inhaltliche Differenzen nicht zu Brüchen führen mussten.

\section{Die prägenden Forschungsfragen}

Der österreichischen Zeitgeschichtsschreibung wird bis heute eine thematische Engführung vorgeworfen. Das ist nicht ganz unrichtig, denn die Gründergeneration, einer „Koalitionsgeschichtsschreibung“ verpflichtet, hatte in erster Linie die mühsame politische Abgleichung der Positionen rund um die Erste Republik und vor allem deren dramatische Endjahre im Auge. Dazu kam die Widerstandsforschung, die großkoalitionär, wenn auch links dominiert, das Erbe des „Rot-Weiß-Rot-Buches“ zu wahren versuchte. Dieses Buch war der erste Versuch gewesen, Österreichs „Opferrolle“ unter der nationalsozialistischen Herrschaft durch Dokumente zu untermauern. Diese unterstellte Engführung hat mit den Biographien der ersten Generation der ForscherInnen zu tun, aber auch mit der Zugänglichkeit archivalischer Quellen. Die etwas Jüngeren im Fach verstanden sich oft weniger als HistorikerInnen im klassischen Sinn, sondern hatten inhaltliche und methodische Bezugspunkte zu anderen Wissenschaften, wie der Soziologie oder der Politikwissenschaft. Die meisten fühlten sich den Protestbewegungen von 1968 zumindest emotional nahe oder

7 Die Zeitgeschichtetage starteten 1993 in Innsbruck und sind bis heute wichtige Konferenzen, die abwechselnd an allen österreichischen Universitäten mit einschlägigen Instituten im zweijährigen Rhythmus stattfinden. 
waren gar durch diese geprägt. So bekam das Fach das Etikett, „links“ zu sein. In jedem Fall aber war es konsequent antifaschistisch, dem „Nie-Wieder“ verpflichtet. So war man sicher, „Geschichte als demokratischen Auftrag ${ }^{\text {“8 }}$ verstehen zu dürfen, ja zu müssen. Daraus resultierte auch das Anliegen, über die Universität hinaus in der Erwachsenenbildung tätig zu sein, öffentlich aufzutreten und sich zur Tagespolitik zu äußern. Manche sahen sich durchaus in der Tradition der aufklärerischen Bemühungen, die das „Rote Wien“ gekennzeichnet hatte.

Dennoch, daneben gab es auch noch die alte Koalitionsgeschichtsschreibung, den von den Großparteien angestrebten Versuch, die Lehren aus den letztlich dramatischen Konsequenzen der politischen Differenzen der Zwischenkriegszeit zu ziehen. "Justiz und Zeitgeschichte", angeregt von Christian Broda und als Tagungsreihe veranstaltet von Erika Weinzierl und Karl R. Stadler, war der signifikante Ausdruck dafür, dass der Händedruck vor den Gräbern der Opfer des Februar 1934, den die Politspitzen in den 1960er-Jahren symbolisch und später wohl auch in der Realpolitik vorgenommen hatten, in den 1970er-Jahren von der Geschichtswissenschaft unterfüttert und legitimiert werden sollte.

In diesem Spannungsfeld - zwischen dem aufklärerisch-kritischen Anspruch auf der einen und der Rückbindung an die politischen Anforderungen auf der anderen Seite - suchte das Fach nach seinen zentralen Themensetzungen. Da war einerseits klar, dass durch die rege Publikationstätigkeit, die das Linzer Institut auszeichnete, die Geschichte der Arbeiterbewegung quantitativ dominierte. Das war nicht nur dem Ludwig Boltzmann Institut geschuldet, sondern wohl auch den Linzer Konferenzen der ITH. Arbeiterbewegungsgeschichte, also Organisationsgeschichte, bildete durch die Sonderentwicklung der österreichischen Arbeiterbewegung fast ausschließlich die Parteiengeschichte der Sozialdemokratie ab. Wohl hielt etwa Hans Hautmann den Blick auf die Kräfte links davon offen und auch die christlichen Arbeiterorganisationen fanden in den Linzer Publikationen ihren Niederschlag, der Großteil der Arbeiten aber galt dem Austromarxismus, dessen theoretischen und konkreten Leistungen, dessen Vorläufern, dessen Konkurrenten oder aber dessen Erben.

Chronologisch ergab dies für das Fach, dass der Geschichte der Ersten Republik das Hauptaugenmerk galt, vor allem den Ereignissen von 1927 bis 1938, dem innenpolitisch so dramatischen Jahrzehnt. Das dokumentieren auch die Konferenzen und Publikationen, die von den wissenschaftlichen Fördereinrichtungen des Leopold Kunschak und des Theodor Körner Fonds initiiert wurden. Durch die liberale Zu-

8 Helmut Konrad, Geschichte als demokratischer Auftrag. Karl R. Stadler zum 7o. Geburtstag, Wien 1983.

9 Siehe Fußnote 6. 
gangspolitik zu den Quellen, die im DÖW gelebte Praxis war, stellte der Widerstand gegen den Nationalsozialismus den zweiten zeitlichen Schwerpunkt dar.

Methodisch konnte der Fachbereich Zeitgeschichte innerhalb der österreichischen Geschichtswissenschaft nicht wirklich als der Hort der Offenheit für neue Wege bezeichnet werden. Einzig Gerhard Botz unternahm mit seinen „Quant-Kursen“, später mit den „Quant-Qual-Kursen“, den Versuch, bei den Methodendiskursen wirklich mitzumischen. Es blieb aber doch die Wirtschafts- und Sozialgeschichte der Universität Wien, von wo die entscheidenden Impulse ausgingen, von denen letztlich auch die Zeitgeschichte profitieren konnte.

\section{Schlüsselwerke}

Will man die richtungsweisenden großen Werke benennen, die dem Fach Zeitgeschichte in Österreich die Konturen gaben, so muss man eingestehen, dass eine solche Auswahl von hoher Subjektivität sein muss und sicher zu Irritationen führt. Ein solcher subjektiver Rückblick auf ein gut halbes Jahrhundert Zeitgeschichtsschreibung in Österreich ist also sehr gewagt, dennoch sollte er versucht werden. Das soll in themenbezogenen Kategorien geschehen.

Unter den (wenigen) großen Würfen, mit denen Gesamtdarstellungen oder Überblicke versucht wurden, ist ohne Zweifel „Der lange Schatten des Staates. Österreichische Gesellschaftsgeschichte im 20. Jahrhundert, 1890-1990"10 von Ernst Hanisch zu nennen. Dieses Werk, das auch dazu diente, dass sich in den 1990er-Jahren mehrere HistorikerInnen der nächsten Generation daran abarbeiten konnten, unternahm den gewagten Versuch, den Anspruch einer umfassenden Gesellschaftsgeschichte nach dem Modell der Bielefelder Schule auf Österreich umzusetzen. War auch mancher Kritikpunkt, etwa aus der Sicht der Gender Studies, an diesem Werk nicht unberechtigt, so ist Hanischs Buch doch der einzige zeithistorische Versuch, die Einzeldarstellungen hinter sich zu lassen und die große Gesamtschau über das ganze Jahrhundert zu wagen. Es ist eine Gesellschaftsgeschichte in der Tradition von Hans-Ulrich Wehler und Jürgen Kocka, kann also durchaus den Anspruch erheben, solide theoretisch fundiert zu sein.

Für die am genauesten untersuchte und dennoch kontroverse Phase der Ersten Republik stellt die schon 1966 fertiggestellte Dissertation, die 1976 als Buch und 1983 erweitert in einer zweiten Auflage erschienene Arbeit von Gerhard Botz „Ge-

10 Ernst Hanisch, Der lange Schatten des Staates. Österreichische Gesellschaftsgeschichte im 20. Jahrhundert (Österreichische Geschichte 1890-1990), Wien 1994. 
walt in der Politik. Attentate, Zusammenstöße, Putschversuche, Unruhen in Österreich 1918 bis $1938^{{ }^{\prime 11}}$ das Schlüsselwerk dar. Der „Schattenmesser“ (Gerhard Botz analysierte durch Nachstellungen die Schattenlänge der damals geschossenen Fotos und stellte somit einen minutiösen Ablauf her) blieb dem Thema jahrzehntelang treu, mit immer verfeinerten Analysen, speziell zum Brand des Justizpalastes von 1927. Das Werk war stilbildend, empirisch von größter Genauigkeit und getragen von dem moralischen Anspruch, mit einer Analyse des Entstehens von Gewalt auch die pädagogische Verpflichtung einzulösen, eine zukünftige Möglichkeit von innenpolitischer Gewalt zu verhindern. Nicht zufällig kann man Gerhard Botz und Ernst Hanisch als Antipoden im Fach in der zweiten Generation begreifen, sowohl im Karriereverlauf (sie waren Konkurrenten bei der Nachfolge von Erika Weinzierl in Salzburg) als auch in der Themenwahl und Vorgangsweise beim Verfassen ihrer Arbeiten. Hanisch versuchte immer den größeren Blick, Botz sah genau auf die Details.

Zwei große Arbeiten, die gleichsam am Rande der institutionalisierten Zeitgeschichte verfasst wurden, kann man als Umrandung der Epoche von 1914 bis 1955 , also vom Ausbruch des Ersten Weltkriegs bis zum Österreichischen Staatsvertrag lesen. Manfred Rauchensteiners „Der Tod des Doppeladlers. Österreich-Ungarn und der Erste Weltkrieg“, ${ }^{12} 1993$ erschienen und 2013 überarbeitet und erweitert unter dem Titel „Der Erste Weltkrieg und das Ende der Habsburgermonarchie“ ${ }^{{ }_{13}}$ neu aufgelegt, kann als exemplarische militärhistorische Studie gelten, die den Verfasser, obwohl die Arbeit eigentlich der klassischen Militärgeschichte zugerechnet werden muss, mit in die erste Reihe der ZeithistorikerInnen stellt. Detailgenau, kenntnisreich auch auf jenen Gebieten, auf die sich die anderen Personen im Fach kaum vorwagen (etwa der Waffengattungen, der Auszeichnungen und der genauen militärischen Analyse), ist das Werk unerlässlich für alle, die sich mit der „Urkatastrophe“ des 20. Jahrhunderts aus österreichischer Perspektive beschäftigen wollen. Ebenso prägend ist die eindrucksvolle, bescheiden „Kleine Geschichte des Österreichischen Staatsvertrags ${ }^{{ }^{11}}{ }^{2}$ genannte Publikation von Gerald Stourzh, erstmals 1975 erschienen und in seither fünf Auflagen, erweitert und überarbeitet, auf dem Markt. Hier hat die Diplomatiegeschichte, die Geschichte der Internationalen Beziehungen,

11 Gerhard Botz, Gewalt in der Politik. Attentate, Zusammenstöße, Putschversuche, Unruhen in Österreich 1918 bis 1938, München 1976.

12 Manfried Rauchensteiner, Der Tod des Doppeladlers. Österreich-Ungarn und der Erste Weltkrieg, Wien 1993.

13 Manfried Rauchensteiner, Der Erste Weltkrieg und das Ende der Habsburgermonarchie 19141918, Wien 2013.

14 Gerald Stourzh, Kleine Geschichte des Österreichischen Staatsvertrages, Wien 1975. 
gezeigt, wie unerlässlich sie für ein Gesamtverständnis der österreichischen Zeitgeschichte ist.

Die nächste Generation der österreichischen ZeithistorikerInnen betrat dann sowohl von ihrer Themenwahl als auch von ihrem Theorie- und Methodenverständnis her Neuland. Obwohl dies schon über den in diesem Beitrag zu schildernden zeitlichen und inhaltlichen Rahmen hinausweist, soll noch auf Heidemarie Uhls großes Werk „Zwischen Versöhnung und Verstörung. Eine Kontroverse um Österreichs historische Identität fünfzig Jahre nach dem ,Anschluss “" ${ }_{15}$ hingewiesen werden. Diese 1988 verfasste und 1992 erschienene Studie machte zumindest zwei neue Türen auf, die seither im Mittelpunkt der Forschung stehen. Das sind auf der inhaltlichen Seite die Identitätskonstruktionen und auf der Seite der Methodologie das Feld der Erinnerungskultur. Damit hatte die zeithistorische Forschung in Österreich die Einbindung in den internationalen Diskurs im Fach wohl definitiv geschafft. Neben diesem neuen Zugang der „Generation Gedächtnis“ haben vor allem aber auch die Gender Studies, deren ProponentInnen sich exemplarisch an Ernst Hanischs großem Werk abgearbeitet hatten, neue Sichtweisen aus der nächsten Generation eingebracht. Hier hat sich ein breites Feld aufgetan. Ingrid Bauer, Gabriella Hauch oder Karin Schmidlechner seien aus der großen Gruppe der Forscherinnen genannt.

\section{Versuch einer "Familienaufstellung"}

Eine Art „Stammbaum“ der handelnden Personen im Fach Zeitgeschichte zeigt sofort eine Besonderheit. Im Gegensatz zu den meisten anderen wissenschaftlichen Disziplinen gibt es in der frühen Phase kaum Personen, die nicht aus Österreich stammen und die nicht den Großteil ihrer Arbeiten der österreichischen Geschichte des 20. Jahrhunderts gewidmet haben. Die Zeitgeschichte in Österreich war dominant „österreichische Zeitgeschichte“, ein Umstand, der bis zur Gegenwart den Hintergrund für manche Kontroverse, vor allem bei der (Nach)Besetzung von Lehrstühlen gebildet hat.

Klar zu fassen ist die erste Generation, die „Eltern“. Karl R. Stadler, Erika Weinzierl und Ludwig Jedlicka haben das Fach aufgebaut, geprägt und akademisch verankert. Sie taten das im Umfeld einer größeren Verwandtschaft, zu der Gerald Stourzh, Richard G. Plaschka, Adam Wandruszka, Michael Mitterauer, Fritz Fellner und viele mehr zählten, die das Feld mit aufbereitet hatten.

15 Heidemarie Uhl, Zwischen Versöhnung und Verstörung. Eine Kontroverse um Österreichs historische Identität fünfzig Jahre nach dem „Anschluss“, Wien 1992. 
Die zweite Generation zeigte sich rasch breit aufgestellt. Gerhard Botz, Ernst Hanisch, Manfried Rauchensteiner, Karl Stuhlpfarrer, Anton Staudinger, Gerhard Jagschitz, Helmut Konrad, Hans Hautmann, Rudolf Ardelt, Reinhard Kannonier, Rolf Steininger, Norbert Schausberger, Ingrid Bauer, Wolfgang Neugebauer, Oliver Rathkolb, Wolfgang Maderthaner, Dieter Binder, Gabriella Hauch, Michael Gehler und mit ihnen zahlreiche andere KollegInnen prägten das Fach in enger Verbindung zu Sozial- und WirtschaftshistorikerInnen, wie Ernst Bruckmüller oder Reinhard Sieder. In der Tradition von Erika Weinzierl und Karl R. Stadler scheuten sie die Öffentlichkeit nicht, waren auch in politischen Diskussionen präsent und erhoben ihre Stimme im gemeinsamen Verständnis, dass Zeitgeschichte auch eine gesellschaftspolitische Aufgabe wahrzunehmen habe. Nicht zufällig übernahmen einige aus dieser Gruppe auch hohe akademische Funktionen. ${ }^{16}$

Die nächste Generation, wobei „Generation“ nicht unbedingt eine Altersdifferenz von gut zwei Jahrzehnten meint, führte das Fach stärker in die Internationalität und zu einer theoretischen und methodischen Anbindung an den internationalen Diskurs. Mit Aleida Assmann aus Konstanz als große Anleiterin und Förderin konnte sich in Österreich die "Generation Gedächtnis“ signifikant etablieren, vor allem mit Heidemarie Uhl und Dirk Rupnow, und auch einige aus der Generation vorher schafften den Wechsel zu den neuen Fragestellungen. Die Gender Studies blühten daneben auf und sind seither ein besonders aktiver Zweig im Fach, mit den bereits genannten AkteurInnen. Durch die Berufung von ForscherInnen aus dem Ausland (Marcus Gräser oder Sybille Steinbach als Beispiele) wurde die überregionale $\mathrm{Zu}$ gangsweise verstärkt.

So blickt die Zeitgeschichte in Österreich auf eine Entwicklung zurück, die vor mehr als einem halben Jahrhundert begann und die zur heute unhinterfragten Position in der österreichischen Wissenschaftslandschaft geführt hat. Die nächsten Generationen von ForscherInnen haben darauf schon sehr erfolgreich aufgebaut und sich ihre im Wissenschaftsbetrieb anerkannte Position an den Universitäten und den außeruniversitären Forschungseinrichtungen sichern können. Mit diesem wissenschaftlichen Nachwuchs braucht man keine Sorge um die Zukunft der österreichischen Zeitgeschichte haben.

16 Reinhard Kannonier war für 19 Jahre (2000 bis 2019) Rektor der Kunstuniversität Linz, Helmut Konrad war Rektor der Universität Graz (1993 bis 1997) und Rudolf Ardelt Rektor der Universität Linz (2000 bis 2007). 
(c) 2021 Böhlau Verlag | Brill Österreich GmbH https://doi.org/10.7767/9783205209980 | CC BY-NC 4.0 


\section{EPOCHEN UND ZÄSUREN}


(c) 2021 Böhlau Verlag | Brill Österreich GmbH https://doi.org/10.7767/9783205209980 | CC BY-NC 4.0 


\section{Erste Republik}

Marcus Gräser

An Gesamtdarstellungen zur Geschichte der Ersten Republik herrscht kein Mangel. Dass dieser Abschnitt der österreichischen Geschichte ,schnell' vorbei war und durch zwei eindeutige Zäsuren - 1918 und $1938^{1}$ - markiert wird, hat in der Geschichtsschreibung das Genre der Gesamtdarstellung favorisiert. Auch das Legitimationsbedürfnis der Zweiten Republik legte die kompakte Sicht auf die Jahre zwischen dem Zerfall der Habsburgermonarchie und dem "Anschluss“ an NS-Deutschland nahe: Vor dem Hintergrund der gescheiterten Ersten Republik konnten Stabilität und Erfolge der neuen Republik ermessen werden. Zugleich stand im kompakten Überblick aber auch eine geschichtspolitische Ressource zur Verfügung, die von den Parteien für die politische Auseinandersetzung genutzt werden konnte: Denn im Unterschied zur Bundesrepublik Deutschland, wo der Trennungsstrich zur Weimarer Republik streng gezogen wurde - „Bonn darf nicht Weimar werden“" ${ }^{\text {- }}$, stand die Zweite Republik in vieler Hinsicht in bewusster Kontinuität zur Vorgängerrepublik, nicht zuletzt durch die Betonung der wiedereingesetzten Eigenstaatlichkeit mit dem Rückgriff auf die Verfassung in der Version von 1929. Das Durchnummerieren - von der Ersten zur Zweiten Republik - suggerierte zudem die Möglichkeit, den Nationalsozialismus einfach zu ,überspringen ' - mit allen Konsequenzen, die das für die österreichische Erinnerungskultur hatte (bzw.

Für Lektüre und Kritik danke ich Cornelia Sulzbacher, Ernst Langthaler und Dirk Rupnow; für Diskussionsbereitschaft und Anregungen geht mein Dank an die Kolleginnen und Kollegen aus dem Linzer Mittwochskolloquium.

1 In aller Regel wird der Begriff der Ersten Republik in der Literatur für die Jahre zwischen 1918 und 1938 genutzt, abweichend davon setzen Tálos, Dachs, Hanisch und Staudinger (Emmerich Tálos/ Herbert Dachs/Ernst Hanisch/Anton Staudinger (Hg.), Handbuch des politischen Systems Österreich. Erste Republik 1918-1933, Wien 1995) die Zäsur für 1933 an.

2 Vgl. Sebastian Ullrich, Der Weimar-Komplex. Das Scheitern der ersten deutschen Demokratie und die politische Kultur der frühen Bundesrepublik 1945-1959, Göttingen 2009; Jörn Leonhard, Prekäre Selbstversicherung. Die Weimarer Republik als Metapher und geschichtspolitisches Argument, in: Aus Politik und Zeitgeschichte 68 (2018) 18-20, 11-18. Für Österreich vgl. Oliver Rathkolb, Der lange Schatten der 8er Jahre. Kritische Geschichtsbetrachtung und Demokratiebewusstsein, in: Aus Politik und Zeitgeschichte 68 (2018) 34-35, 41-46. 
eben nicht hatte). ${ }^{3}$ Ein „Rückbruch“ (Josef Schöner) ${ }^{4}$ ereignete sich 1945, der ungeachtet der Transformationen, die sich durch die NS-Herrschaft und den Zweiten Weltkrieg in der österreichischen Gesellschaft vollzogen hatten, das politische Gefüge der Ersten Republik grosso modo wiederherstellte - ohne paramilitärische Verbände und mit einem zunächst eingeschränkten Spielraum für die Deutschnationalen und (ehemaligen) Nationalsozialisten.

\section{Tendenzen der Forschung}

Einher mit diesem „Rückbruch“ ging, trotz der Bereitschaft der beiden großen Parteien SPÖ und ÖVP zur Koalition, eine stark unterschiedliche Sicht auf die Erste Republik, in der sich die Polarisierung der politischen Landschaft in den Jahren vor 1938 widerspiegelte. Nicht von ungefähr stieß die erste große Gesamtdarstellung der Geschichte der Ersten Republik, die monumentale, über 1.800 Seiten umfassende Studie von Charles A. Gulick - „Austria: From Habsburg to Hitler“ -, die 1948 in den USA und zwei Jahre darauf in deutscher Übersetzung in Wien erschien, ${ }^{5}$ auf Widerspruch im bürgerlichen Milieu: Allzu sehr schien Gulick der Sozialdemokratie verbunden zu sein - und tatsächlich nahmen die wohlfahrtspolitischen Leistungen des „Roten Wien“ als fast einzige wirkliche Errungenschaften der Zwischenkriegszeit einen prominenten Platz in seiner Darstellung ein. Gulick war Nationalökonom und Spezialist für Arbeitsbeziehungen an der University of California, Berkeley; er hatte seit den 1930er Jahren über Österreich gearbeitet und zahlreiche Aufenthalte im Land absolviert. Was ursprünglich gut und gerne eine Studie über das zeitgenössische Österreich der 1930er Jahre hätte werden können, wurde durch die lange Arbeit am Buch dann unter der Hand zu einer Studie über eine abgeschlossene Epoche der österreichischen Geschichte. ${ }^{6}$ Eine weitere, quasi ,offiziöse' Gesamtdarstellung der Geschichte der Ersten Republik erschien dann 1954 unter der Herausgeberschaft von Heinrich Benedikt - mit der Betonung auf das „Märtyrertum“ Österreichs.7

3 Der Begriff Zweite Republik findet sich schon bei Walter Goldinger, Der geschichtliche Ablauf der Ereignisse in Österreich von 1918 bis 1945, in: Heinrich Benedikt (Hg.), Geschichte der Republik Österreich, Wien 1954, 15-288, 288.

4 Hier zit. n. Ernst Hanisch, Der lange Schatten des Staates. Österreichische Gesellschaftsgeschichte im 20. Jahrhundert (Österreichische Geschichte 1890-1990), Wien 1994, 395.

5 Charles A. Gulick, Austria: From Habsburg to Hitler, 2 Bde., Berkeley 1948.

6 Zu Gulick vgl. Florian Wenninger, Austrian Politics of History, Made in Berkeley? The Economist Charles A. Gulick as Historian of Interwar Austria, Research Paper, Berkeley 2018, URL: https:// www.marshallplan.at/news-2019/2018/3/17/new-research-papers (abgerufen 19.05.2020).

7 Benedikt (Hg.), Österreich, 14. 
Unter den Beiträgen in dieser „Geschichte der Republik Österreich“ avancierte das Kapitel von Adam Wandruszka - „Österreichs politische Struktur“ - zu einem der meistzitierten Texte zur Geschichte der Jahre zwischen 1918 und 1938, nicht zuletzt wegen der griffigen Klassifizierung der drei politischen Parteien - christlichsozial, sozialistisch, deutschnational - als "Lager“.

Verblüffenderweise blieben die strukturgeschichtlichen Anregungen, die sich in den Texten von Gulick und Wandruszka fanden - also etwa Gulicks Versuch einer integralen politischen Ökonomie der Ersten Republik und Wandruszkas Hinweise auf die Spannweite zwischen politischer Theorie (der Parteien) und rückständiger („unzeitgemäßer“) Staatsform ${ }^{8}$-, lange ohne erkennbare Wirkungen auf die österreichische Forschung zur Zeit vor 1938. Die Herausbildung einer eigenen Subdisziplin "Zeitgeschichte" hat seit den 1960er-Jahren eher die politische Ereignisgeschichte favorisiert. Schon auf der Reichenauer Tagung 1960 - die auf Einladung des Unterrichtsministers Heinrich Drimmel Universitätshistoriker und Pädagogen versammelte und „Zeitgeschichte“ für den Schulunterricht etablieren wollte - stand in den Leitvorträgen des Wiener Historikers Ludwig Jedlicka ausschließlich, und ohne begrifflichen Ehrgeiz, die Abfolge der politischen Ereignisse im Vordergrund. ${ }^{9}$ Auch an der Universität Linz, wo 1968 mit der Berufung des Emigranten Karl R. Stadler auf eine Lehrkanzel für Neuere Geschichte und Zeitgeschichte (aus der 1970 das Institut gleichen Namens hervorgehen sollte) neben Wien ein weiterer wichtiger Standort für das neue Fach Zeitgeschichte entstanden war, blieb die Politik im Mittelpunkt: Zwar orientierte man sich in Linz an modernisierenden Tendenzen der Geschichtswissenschaft, erforschte die Geschichte der Arbeiterbewegung, nutzte Theoriebildungen aus den weiteren Sozialwissenschaften und leistete Pionierarbeit in der Analyse des Nationalsozialismus ${ }^{10}$ - aber die Politik stand immer im Vordergrund. Stadler blieb dabei, im Unterschied zu seinen Assistenten Gerhard Botz und

8 Vgl. Adam Wandruszka, Österreichs politische Struktur. Die Entwicklung der Parteien und politischen Bewegungen, in: Benedikt (Hg.), Österreich, 289-486, 428.

9 Ludwig Jedlicka, Österreich 1919-1938, in: Anton Kolbabek (Hg.), Österreichische Zeitgeschichte im Geschichtsunterricht. Bericht über die Expertentagung von 14.XII. bis 16.XII.1960 in Reichenau, Wien 1961, 36-59.

10 Vgl. Gerhard Botz, Zeitgeschichte zwischen Politik, Biografie und Methodik. Autobiografische Anmerkungen, in: ders., Zeitgeschichte zwischen Politik, Biografie und Methodik, Köln 2016, 23-101; Helmut Konrad, Von Linz aus. Die Formierung der österreichischen Zeitgeschichte, in: Heinrich Berger/Melanie Dejnega/Regina Fritz/Alexander Prenninger (Hg.), Politische Gewalt und Machtausübung im 20. Jahrhundert. Festschrift für Gerhard Botz, Wien 2011, 47-57. Die Literatur der politischen Emigranten, die nicht nach Österreich zurückkehrten, wurde kaum beachtet - Franz Borkenaus glänzende Studie „Austria and After“, die 1938 in London erschien, hätte eine Rezeption verdient gehabt. 
Helmut Konrad, noch ganz einer traditionellen politischen Ereignis- und Ideengeschichte verbunden. Sein für ein englischsprachiges Publikum geschriebenes Buch „Austria“ (aus der Reihe „Nations of the Modern World“) umfasst den Zeitraum seit der Endphase der Monarchie bis zu den ersten Jahrzehnten der Zweiten Republik und legt den Schwerpunkt auf die Zeit des Nationalsozialismus - und widmet dabei dem österreichischen Widerstand, ganz im Geist der der Moskauer Deklaration von 1943, die eine eigene Leistung Österreichs zur Befreiung gefordert hatte, einen erheblichen Teil seiner Darstellung.

Repräsentativ für die Sicht auf die Erste Republik aber war nicht das unübersetzt gebliebene Buch von Stadler, sondern der immer wieder neu aufgelegte Abriss der politischen Geschichte der Zwischenkriegszeit, den Walter Goldinger erstmals im von Benedikt herausgegebenen Band veröffentlicht hatte und der seit 1992 in einer von Dieter Binder überarbeiteten Version eine weitere Auflage erlebte. ${ }^{11}$ Eine hohe Sichtbarkeit hat(te) auch die von Erika Weinzierl und Kurt Skalnik herausgegebene zweibändige „Geschichte der Ersten Republik. Österreich 1918-1938“,12 die mit zahlreichen Aufsätzen neben der politischen Geschichte auch der Wirtschafts-, Sozial- und Kulturgeschichte einen Platz gab. Die relative ,Ausgewogenheit' dieser Gesamtdarstellungen und die Betulichkeit, mit der Schlüsselereignisse auf dem Weg zur Zerstörung der Demokratie - vom Brand des Justizpalastes 1927 über die Ausschaltung des Parlaments 1933 bis zum Aufstand des Republikanischen Schutzbundes und seiner Niederschlagung 1934 - behandelt wurden, hat diesen Büchern (und anderen) das heute despektierlich gemeinte Prädikat "großkoalitionäre Geschichtsschreibung" eingetragen. ${ }^{13}$

Wirklich "großkoalitionär“ aber war ein Projekt, das 1971 von Bundeskanzler Bruno Kreisky (SPÖ) und dem zweiten Präsidenten des Nationalrats, Alfred Maleta (ÖVP), angestoßen wurde: Die Wissenschaftliche Kommission des TheodorKörner-Stiftungsfonds und des Leopold-Kunschak-Preises zur Erforschung der österreichischen Geschichte der Jahre 1918-1938 bestand von 1971 bis 1989 und

11 Walter Goldinger, Der geschichtliche Ablauf der Ereignisse in Österreich von 1918 bis 1945, in: Benedikt (Hg.), Österreich, 15-288; Walter Goldinger/Dieter Binder, Geschichte der Republik Österreich 1918-1938, Wien 1992 (auf 7-11 das Vorwort von Binder mit Ausführungen zur Publikationsgeschichte des Textes von Goldinger).

12 Erika Weinzierl/Kurt Skalnik (Hg.), Österreich 1918-1939. Geschichte der Ersten Republik, 2 Bde., Wien 1983.

13 Großkoalitionär: Günther Schefbeck (Hg.), Österreich 1934. Vorgeschichte - Ereignisse - Wirkungen, Wien 2004. Zum Schutzbundaufstand vgl. die Kontroverse zwischen Kurt Bauer (Der Februaraufstand 1934. Fakten und Mythen, Wien 2019) und Florian Wenninger (Rezension zu Kurt Bauer, Der Februaraufstand 1934. Fakten und Mythen, H-Soz-Kult, 13.03.2019, URL: www. hsozkult.de/publicationreview/id/reb-27953 (abgerufen 20.05.2020)). 
gab, neben der Edition der Ministerratsprotokolle der Ersten Republik, eine Schriftenreihe unter dem Titel „Studien und Quellen zur österreichischen Zeitgeschichte“ heraus. ${ }^{14}$ Vor allem aber dokumentierte die Kommission in insgesamt elf Bänden ihre Tagungen, die sich mit ausgewählten Etappen und Problemen der Ersten Republik beschäftigt hatten. Diese Bände, deren Themen von der Revolution 1918/1919 bis hin zum "Anschluss" 1938 reichten und in den Jahren zwischen 1973 und 1989 erschienen, versammelten aber nicht nur die auf den Tagungen gehaltenen Referate, sondern enthielten auch die protokollierten Diskussionen, die im Anschluss an die Referate geführt worden waren. Diese Protokolle geben einen faszinierenden Einblick in Diskussionen, an denen nicht nur Wissenschaftler - arrivierte und noch nicht arrivierte -, sondern auch Politiker-Zeitzeugen teilnahmen und die hoch kontrovers verliefen. ${ }^{15}$ Für die Zeit der Ersten Republik jedenfalls gibt es kein anderes Projekt, in dem man der Wissenschaft beim Diskutieren auf hohem Reflexionsniveau so ,zuhören' kann, wie es in diesen Bänden möglich war.

14 Die Bände in der Reihenfolge des Erscheinens: Everhard Holtmann, Zwischen Unterdrückung und Befriedung. Sozialistische Arbeiterbewegung und autoritäres Regime in Österreich 1933-1938, Wien 1978; Walter Goldinger (Hg.), Protokoll des Klubvorstands der Christlichsozialen Partei, Wien 1980; Hans von Hammerstein, Im Anfang war der Mord. Erlebnisse des Bezirkshauptmanns von Braunau am Inn und als Sicherheitsdirektor von Oberösterreich in den Jahren 1933 und 1934, Wien 1981; Charlotte Heidrich, Burgenländische Politik in der Ersten Republik. Deutschnationale Parteien und Verbände im Burgenland vom Zerfall der Habsburgermonarchie bis zum Beginn des autoritären Regimes (1918-1933), Wien 1982; Judit Garamvölgyi, Betriebsräte und sozialer Wandel in Österreich 1919/20. Studien zur Konstituierungsphase der österreichischen Betriebsräte, Wien 1983; Hans Löwenfeld-Russ, Im Kampf gegen den Hunger. Aus den Erinnerungen des Staatssekretärs für Volksernährung 1918-1920, Wien 1986; Walter Wiltschegg, Die Heimwehr eine unwiderstehliche Volksbewegung?, Wien 1985; Reinhard Owerdieck, Parteien und Verfassungsfrage in Österreich. Die Entstehung des Verfassungsprovisoriums der Ersten Republik, Wien 1987; Richard Schüller, Unterhändler des Vertrauens. Aus den nachgelassenen Schriften, Wien 1990. Ursprünglich sollte sich die Arbeit der Kommission auf die Jahre von 1927 bis 1938 beschränken, später wurde die Zeitspanne auf die Jahre 1918 bis 1938 erweitert. Als „Festgabe“ - de facto als Zwischenbilanz - des Körner-Kunschak Projekts erschien: Ludwig Jedlicka/Rudolf Neck (Hg.), Vom Justizpalast zum Heldenplatz. Studien und Dokumentationen 1927 bis 1938, Wien 1975.

15 Die Bände in der Reihenfolge des Erscheinens: Österreich 1927-1938, Wien 1973; Das Jahr 1934: 12. Februar, Wien 1975; Das Jahr 1934: 25. Juli, Wien 1975; Das Juliabkommen von 1936. Vorgeschichte, Hintergründe und Folgen, Wien 1977; Die Ereignisse des 15. Juli 1927, Wien 1979; Die österreichische Verfassung von 1918 bis 1938, Wien 1980; Anschluss 1938, Wien 1981; Koalitionsregierungen in Österreich: Ihr Ende 1920 und 1966, Wien 1985; Österreich November 1918, Wien 1986; Geistiges Leben im Österreich der Ersten Republik, Wien 1986; Saint-Germain 1919, Wien 1989. Vgl. auch die Auszüge aus den Diskussionen in: Jedlicka/Neck, Heldenplatz, 239-259. 
Gleichwohl stand auch im Körner-Kunschak-Projekt die politische Geschichte im Vordergrund, einzig dem "geistigen Leben“ war ein Tagungsband gewidmet, die Sozial- und Wirtschaftsgeschichte aber blieb außen vor. Wichtige Ergänzungen zum Bild der Ersten Republik aus diesem Feld aber kamen bald mit den Arbeiten von Ernst Bruckmüller ${ }^{16}$ und Roman Sandgruber. ${ }^{17}$ Singulär blieb das „Handbuch des politischen Systems Österreich. Erste Republik 1918-1933“, das mit einer Vielzahl von Autoren das politische Gefüge und seine Akteure analysierte. ${ }^{18}$ Mit der monumentalen Studie von Robert Kriechbaumer über die „Großen Erzählungen“ in der Politik gelang dann eine Rekonstruktion der sozialmoralischen Milieus und ihrer Politik in der Ersten Republik und damit eine Integration der politischen und der Sozialgeschichte. ${ }^{19}$ Ernst Hanischs Gesamtdarstellung der Geschichte Österreichs im 20. Jahrhundert, erschienen unter dem Titel „Der lange Schatten des Staates“, schließlich nutzte das Instrumentarium der Gesellschaftsgeschichte und gehört, gerade in den Kapiteln zur Ersten Republik, immer noch zum Besten, was man über diese Zeit lesen kann.

Im Jubiläumsjahr 2018 erschienen drei sehr unterschiedliche Gesamtdarstellungen zur Geschichte der Ersten Republik: Während das von Stefan Karner herausgegebene Buch „Die umkämpfte Republik. Österreich von 1918-1938“ aus Anlass der großen Ausstellung zur Geschichte der Zwischenkriegszeit im neu eröffneten Haus der Geschichte im Museum Niederösterreich in St. Pölten herauskam und handbuchähnlich über Parteien und Politik, aber auch über Gesellschaft und Wirtschaft Auskunft gibt, ${ }^{20}$ bieten die Bücher von Lothar Höbelt - „Die Erste Republik Österreich (1918-1938). Das Provisorium““21 - und von Anton Pelinka - „Die gescheiterte Republik. Kultur und Politik in Österreich 1918-1938“22 - Gesamtanalysen an. Höbelt schreibt auf Basis einer ungemein profunden Kenntnis des politischen Personals - er weiß sogar, wer mit wessen Schwester verheiratet ist - und wirft einen scharfen Blick auch auf den ländlichen Raum, auf Österreich abseits von Wien,

16 Ernst Bruckmüller, Sozialgeschichte Österreichs, Wien ${ }^{2} 2001$ (zur Ersten Republik vgl. 372-417).

17 Roman Sandgruber, Ökonomie und Politik. Österreichische Wirtschaftsgeschichte vom Mittelalter bis zur Gegenwart, Wien 1995 (zur Ersten Republik vgl. 335-402). Vgl. auch Eduard März, Österreichische Bankpolitik in der Zeit der großen Wende 1913-1923. Am Beispiel der Creditanstalt für Handel und Gewerbe, Wien 1981; Fritz Weber, Vor dem großen Krach. Österreichs Banken in der Zwischenkriegszeit am Beispiel der Credit-Anstalt für Handel und Gewerbe, Wien 2016.

18 Tálos/Dachs/Hanisch/Staudinger (Hg.), Handbuch.

19 Robert Kriechbaumer, Die großen Erzählungen der Politik. Politische Kultur und Parteien in Österreich von der Jahrhundertwende bis 1945, Wien 2001.

20 Stefan Karner (Hg.), Die umkämpfte Republik. Österreich von 1918-1938, Innsbruck 2017.

21 Lothar Höbelt, Die Erste Republik Österreich (1918-1939). Das Provisorium, Wien 2018.

22 Anton Pelinka, Die gescheiterte Republik. Kultur und Politik in Österreich 1918-1938, Wien 2017. 
was in den meisten Darstellungen der politischen Geschichte eher unterbelichtet bleibt. ${ }^{23}$ Er lässt die Erklärung der gewichtigen Probleme der Republik aber allzu oft in einer ironisch getönten Detailbeschreibung der Ereignisse aufgehen. Pelinka wiederum, dessen Buch eher ein Großessay als eine umfassende Darstellung ist, verharrt sehr oft in der Feststellung der Lager-Mentalität, die einen Konsens oder auch nur eine stabile Kooperation im politischen Feld unmöglich gemacht habe. Überdies leidet sein Buch - das „Kultur“ im Titel trägt - unter einer begrifflichen Unschärfe: Mal meint der Begriff die „Hochkultur“ und die Künstler werden nach ihrer Haltung zur Republik befragt, mal zieht sich der Politikwissenschaftler Pelinka auf die „politische Kultur“ zurück und fragt nach den mentalen und institutionellen Voraussetzungen gedeihlicher Zusammenarbeit über die Parteigrenzen hinweg, die allzu schwach entwickelt waren. So unterschiedlich die Bücher von Höbelt und Pelinka auch sein mögen, ${ }^{24}$ so umweht beide doch ein gewisser Traditionalismus - insoweit als die Infragestellung des Primats der Politikgeschichte, die in Österreich am deutlichsten in Hanischs Buch (dessen Titel „Der lange Schatten des Staates“ ja auch ironisch eine dominante Tendenz der Geschichtswissenschaft zu treffen suchte ${ }^{25}$ zum Ausdruck kam, anscheinend nicht mehr en vogue ist.

Zugegeben: Für die Analyse des rund zwanzig Jahre zählenden Zeitraums der Ersten Republik, der von politischen Zäsuren und der allmählichen Zerstörung der Demokratie bestimmt war, kann der Politikgeschichte kaum entkommen werden. Hat es signifikante Veränderungen im Bild der Ersten Republik gegeben? Tatsächlich ist die Einschätzung in der Forschung eher durch Kontinuität gekennzeichnet: Ian Kershaws jüngst geäußertes Diktum - „a democracy built on shaky ground“ ${ }^{26}$ - ist das Leitmotiv der meisten Darstellungen seit den 1950er-Jahren. Die Verantwortung für das Scheitern der Demokratie/Österreichs wird dabei auf viele Schultern verteilt, wenngleich die Christlichsozialen mit Dollfuß der Verantwortung für die Demokratiezerstörung in den Jahren 1933/1934 nicht entkommen können. Die österreichischen Nationalsozialisten aber traten in der Forschung erst spät ins Bild. ${ }^{27}$ Wandrus-

23 Vgl. Britta McEwen, New Work on the Austrian First Republic, in: Austrian History Yearbook 51 (2020), 317-323, 319 .

24 Vgl. auch ihr Streitgespräch in: Das Bestehende erschien absurd, Die Zeit, 03.05.2018, 10-11.

25 Vgl. Ernst Hanisch, Die Dominanz des Staates. Österreichische Zeitgeschichte im Drehkreuz von Politik und Wissenschaft, in: Alexander Nützenadel/Wolfgang Schieder (Hg.), Zeitgeschichte als Problem. Nationale Traditionen und Perspektiven in Europa, Göttingen 2004, 54-77.

26 Ian Kershaw, To Hell and Back: Europe 1914-1949, London 2015, 184.

27 Vgl. aus der inzwischen reichhaltigen Literatur Bruce F. Pauley, Hitler and the Forgotten Nazis: A History of Austrian National Socialism, Chapel Hill 1981; Kurt Bauer, Elementar-Ereignis. Die österreichischen Nationalsozialisten und der Juliputsch 1934, Wien 2003; ders., Hitlers Zweiter Putsch. Dollfuß, die Nazis und der 25. Juli 1934, St. Pölten 2014; Hans Schafranek, Söldner für den 
zkas Lagerparadigma - „Das freie Feld zwischen den befestigten weltanschaulichen Lagern wurde durch Laufgräben und Drahtverhaue immer mehr eingeengt, bis es fast völlig verschwand“" ${ }^{28}$ - erfuhr zahlreiche Variationen; Pelinka etwa nutzt dieses Deutungsmuster geradezu obsessiv. ${ }^{29}$ Es ist ein Zeichen der großen Kontinuität in der Forschung zur Ersten Republik, dass dieses Bild einer auf Konflikt und Unversöhnlichkeit ausgerichteten Fundamentalpolitisierung der Gesellschaft kaum je hinterfragt worden ist. Zum einen wird hier in mancher Hinsicht, zu viel' verlangt: In einer komplexen modernen Gesellschaft kann die Bürgergesamtheit zum einen gar nicht mehr durch einen substanziellen Wertekonsens weltanschaulicher Art zusammengehalten werden, sondern „nur noch durch einen Konsens über das Verfahren legitimer Rechtsetzung und Machtausübung “. ${ }^{30}$ Zum anderen ist die Vorstellung, dass der übergroße Teil der österreichischen Bevölkerung 24 Stunden am Tag und 7 Tage in der Woche Repräsentanten eines „Lagers“ gewesen seien, nicht plausibel. Die Zugehörigkeit zu einem durch Herkunft, Klassenlage, Landschaft und wohnräumliche Situation bestimmten „sozialmoralischen Milieu“ ${ }^{31}$ bedeutet nicht, dass man in geschlossenen Verkehrskreisen lebt. Milieu und „Lager“ können, müssen

Anschluss. Die Österreichische Legion 1933-1938, Wien 2011; Franz Schausberger, Ins Parlament, um es zu zerstören: Das parlamentarische Agi(ti)eren der Nationalsozialisten in den Landtagen von Wien, Niederösterreich, Salzburg und Vorarlberg nach den Landtagswahlen 1932, Wien ${ }^{2} 2012$ sowie immer noch Francis Carsten, Faschismus in Österreich, München 1978.

Wandruszka, Struktur, 30o. Eine frühe Ausprägung der Lagertheorie findet sich bei Borkenau, der die Christlichsozialen und die Sozialdemokraten als "two antagonistic camps" beschreibt (Borkenau, Austria, 214). Rührt der - als Kennzeichnung von politischen Gruppen und Milieus ohnehin seltsame - Begriff des Lagers her aus einer Übersetzung des englischen Begriffs „camp“?

Pelinka, Republik, 19-23, 26, 189-194. Auch Höbelt schließt sich eng an Wandruszkas Lagerparadigma an, vgl. Höbelt, Republik, 59.

30 Jürgen Habermas, Kampf um Anerkennung im demokratischen Rechtsstaat, in: ders., Die Einbeziehung des Anderen. Studien zur politischen Theorie, Frankfurt a. M. 1996, 237-276, 263.

31 Rainer M. Lepsius, Parteiensystem und Sozialstruktur. Zum Problem der Demokratisierung der deutschen Gesellschaft, in: ders., Demokratie in Deutschland. Soziologisch-historische Konstellationsanalysen. Ausgewählte Aufsätze, Göttingen 1993, 25-50. Mit einem modifizierten Milieubegriff arbeitet auch Ernst Hanisch, der um den Typus des „unpolitischen Österreichers“ weiß und in einer "Gesellschaftsgeschichte des politischen Verhaltens" ein "mannigfaltig gemischtes Stimmungspotential“ vorhanden sieht, gleichwohl aber in seinen Arbeiten auf die "große Erklärungskraft" des Lagerparadigmas vertraut (Ernst Hanisch, Bäuerliches Milieu und Arbeitermilieu in den Alpengauen: ein historischer Vergleich, in: Rudolf G. Ardelt/Hans Hautmann (Hg.), Arbeiterschaft und Nationalsozialismus in Österreich, Wien 1990, 583-598, 583 sowie ders., Schatten, $32,117)$. Unverwüstlich ist das Lagerparadigma vor allem als Narrativ, mit dem sich effektvoll eine Dramaturgie des Niedergangs der Demokratie erreichen lässt, vgl. etwa Marina Brandtner, Diskursverweigerung und Gewalt. Dimensionen der Radikalisierung des politischen Klimas in der obersteirischen Industrieregion 1927-1934, Innsbruck 2011. 
aber nicht deckungsgleich sein: Einem Milieu kann man kaum entkommen, einem Lager schon. Helmut Qualtingers „Herr Karl“ gehörte sicher zu einem Milieu, aber stand er in einem Lager? Es wird angenommen werden können, dass Flexibilität, Offenheit, Opportunismus, „situationselastisches“ Verhalten im Alltag vorherrschten: Wie sollte man sonst erklären, dass weder das Dollfuß/Schuschnigg-Regime noch die NS-Herrschaft nach 1938 auf massiven Widerstand stießen? Eben darum wird aber auch für die Jahre vor 1933/1934 ein Maß an latentem oder manifestem Desinteresse an der Politik unterstellt werden können. Es sind die wirklich Unbeteiligten, Uninteressierten, Unentschiedenen, die aus dem Blick geraten, wenn eine den Alltag konfigurierende ,Totalität' der politischen Haltung als Normalfall angenommen wird. ${ }^{32}$ Wohl blieb das Stimmverhalten bei den Wahlen in der Ersten Republik mindestens für die beiden großen Parteien - die Sozialdemokraten und die Christlichsozialen - stabil und offenbarte insofern ein hohes Maß an Loyalität zwischen Wählenden und Parteien. Aber auch dort, wo Überzeugung und Engagement vorhanden waren, darf bezweifelt werden, ob das Stimmverhalten oder selbst die Parteimitgliedschaft schon komplett den persönlichen Alltag dominierte. Das größte Problem des Lagerparadigmas besteht ohnehin darin, dass es aus sich heraus nicht erklären kann, unter welchen Umständen Lager sich verändern, auflösen, neu bilden können. Dem Lager haftet an, statisch zu sein - und das gilt auch für die modifizierte Variante („Integrationsmilieu und Orientierungslager“), die Detlef Lehnert vorgelegt hat. ${ }^{33}$

Freilich ist in dieser Kritik viel Spekulation enthalten - es gibt noch immer zu wenig Mikrostudien zum Alltag des Politischen, die Aufschluss darüber geben können, wie verpflichtend Stimmabgabe und Parteimitgliedschaft empfunden worden sind; es fehlt an Forschungen zu „contact zones“, zu Räumen, in denen eine Interaktion zwischen unterschiedlichen sozialen Milieus und politischen Organisationen mög-

32 Für die Erste Republik steht somit noch jene, Revision` aus, die Tara Zahra und Pieter Judson für die späte Habsburgermonarchie vorgenommen haben: die Entdeckung des „helpless nationalist“, der sich zwar prinzipiell im Nationalitätenkonflikt zuordnen kann, aber im Alltag, gerade in ethnisch gemischten Regionen und Grenzräumen auf die alltägliche Kooperation mit den ,Anderen in der Familie, der Gemeinde, am Arbeitsplatz etc. angewiesen waren. (Vgl. Pieter M. Judson/Tara Zahra, Introduction: Sites of Indifference to Nationhood, in: Austrian History Yearbook 43 (2012), 21-27.)

33 Vgl. Detlef Lehnert, Politisch-kulturelle Integrationsmilieus und Orientierungslager in einer polarisierten Massengesellschaft, in: Tálos/Dachs/Hanisch/Staudinger (Hg.), Handbuch, 431-443. Ähnlich differenziert, und ergänzt noch um die Dimension einer „Sakralisierung der Politik“, die Sicht auf die Lager in Kriechbaumer, Erzählungen, 19-42, 182-197. Für eine soziologische Umkreisung des Lagerparadigmas vgl. Walter B. Simon, Österreich 1918-1938. Ideologien und Politik, Wien 1984, vor allem 53-106. 
lich war ${ }^{34}$ - wie es überhaupt einen Mangel an genuin sozialgeschichtlichen Arbeiten zur Ersten Republik gibt: Kurze Zeiträume scheinen sich nicht gut zu eignen für das Studium von sozialen Klassen und Schichten, die eher einem langfristigen Wandel unterworfen sind. ${ }^{35}$ Immerhin zeigt der Blick auf die vielfältige Vereinslandschaft und die zahllosen Vorfeldorganisationen der „Lager“ (und des Katholizismus), dass auch Österreich nicht recht taugt für jene vor allem in der angelsächsischen Demokratieforschung verbreitete „neo-Tocquevillean thesis“, die - in Anlehnung an den Nexus von Assoziationswesen und Demokratie, den Alexis de Tocqueville in den USA im frühen 19. Jahrhundert beobachtet hatte - davon ausgeht, dass die Arbeit im Verein gleichsam in zwei Richtungen demokratieförderlich sei: Das Vereinsmitglied übe sich ein in Partizipation, Kooperation und Verantwortung (für die Belange des Vereins) und sei dann auch in der Lage, diese Tugenden als Staatsbürger zu leben, wobei die Fülle der Vereine für die Balance der Interessen in der Gesellschaft sorge. Tatsächlich hätte damit in Österreich wie in Deutschland die Demokratie ein

34 Vielversprechende Anfänge finden sich in den Studien von Ernst Langthaler und Stefan Eminger zu niederösterreichischen Dörfern und Kleinstädten, die gleichwohl auch von einer zunehmenden Polarisierung und einem Rückzug in die „Lager“ seit der zweiten Hälfte der 192oer-Jahre ausgehen, vgl. Ernst Langthaler, Wie aus Dörflern Parteigänger und Patrioten wurden. Identitätspolitik in einer Landgemeinde (1920er bis 1930er Jahre), in: Stefan Eminger/Ernst Langthaler (Hg.), Niederösterreich im 20. Jahrhundert, Bd. 1: Politik, Wien 2008, 371-386 sowie Stefan Eminger, Die Konkurrenz der „Clans“. Politik im Bauerndorf in der ersten Hälfte des 20. Jahrhunderts, in: ebd., 387-397. Auch die Spaltung des Dorfs in rivalisierende „Clans“ markiert bei Licht betrachtet freilich nur „factions“ im christlichsozialen „Lager“. Auf die Spannungslinien zwischen lokalem Eigensinn und überregionalen Deutungsmustern weist Eminger in einem anderen Aufsatz hin: „Reichsbündler“, „Marienkinder“ und Bauernburschen. Politischer Katholizismus und Jugend auf dem Dorfe in der Zwischenkriegszeit, in: Hanns Haas/Ewald Hiebl (Hg.), Politik vor Ort. Sinngebung in ländlichen und kleinstädtischen Lebenswelten, Innsbruck 2007, 31-53. Hier wird das Bild geschlossener Verkehrskreise eher noch bestärkt: „Die Gründung katholischer Jugendvereine ist [...] im Zusammenhang mit der zunehmenden Verschränkung von christlichsozialer Politik und Kirche sowie im Kontext der politischen Lagerbildung zu sehen“" (Eminger, „Reichsbündler“, 34). Eine Reihe von Aufsätzen zur Sozialgeschichte liegt vor, meist mit einem regionalgeschichtlichen Fokus, vgl. etwa Norbert Ortmayr, Ländliches Gesinde in Oberösterreich 1918-1938, in: Josef Ehmer/Michael Mitterauer (Hg.), Familienstruktur und Arbeitsorganisation in ländlichen Gesellschaften, Wien 1986, 325-416; ders., Demographischer Wandel in Oberösterreich 1918-1938. Verlauf - Komponenten - Kontexte, in: Oberösterreichiches Landesarchiv (Hg.), Oberösterreich 1918-1938, Bd. 4, Linz 2016, 11-61; Reinhard Sieder/Gottfried Pirhofer, Zur Konstitution der Arbeiterfamilie im Roten Wien. Familienpolitik, Kulturreform, Alltag und Ästhetik, in: Michael Mitterauer/Reinhard Sieder (Hg.), Historische Familienforschung, Frankfurt a. M. 1982, 326-368. Vgl. auch Gustav Otruba, „Bauer“ und „Arbeiter“ in der Ersten Republik. Betrachtungen zum Wandel ihres Wirtschafts- und Sozialstatus, in: Gerhard Botz/Hans Hautmann/Helmut Konrad (Hg.), Geschichte und Gesellschaft. Festschrift für Karl R. Stadler, Wien 1974, 57-98. 
gutes Fundament haben müssen - das Gegenteil war der Fall. ${ }^{36}$ Das starke Assoziationswesen führte im Fall von schwachen politischen Institutionen mit geringer Legitimität und geringen Anreizen zur Kooperation eher zu einer Entfremdung von Gesellschaft und Staat, zu einer Fragmentierung des politischen und sozialen Gefüges. ${ }^{37}$ Ein solches Bild eines wechselseitigen Prozesses aus Fragmentierung der Gesellschaft und Delegitimierung nicht der Politik, aber der staatlichen Institutionen trifft das Problem der österreichischen Demokratie in der Ersten Republik vielleicht präziser, als es die simple Feststellung der „Lager“ leisten kann; zumal in der Fragmentierung das politische Desinteresse und das Unbeteiligtsein eine Rolle spielen, die es im „Lager“ nie bekommt. Die Delegitimierung der Institutionen aber erfolgte auch aus der Politik heraus: Dollfuß’ Nutzung des Kriegswirtschaftlichen Ermächtigungsgesetzes und die Ausschaltung des Parlaments 1933 waren wesentliche Etappen auf diesem Weg - wer, wie er, demokratische Institutionen schwächte oder zerstörte, leistete sich die Illusion eines ,autoritären Staates', verschaffte aber tatsächlich nur jenen in der Gesellschaft einen Spielraum, denen an der Demokratie ebenso wenig lag wie am Staat von Dollfuß und Schuschnigg. ${ }^{8}$

\section{Fehlstellen und Desiderate}

Die Dominanz der Gesamtdarstellungen zur Geschichte der Ersten Republik war unvermeidlich, sie war dem Orientierungs- und Rechenschaftsbedürfnis der Zweiten Republik geschuldet. Der Logik der historischen Forschung entsprach dies nicht: Synthesen sollten auf Forschung beruhen und ihr nicht vorangehen, aber das ist meist ein frommer Wunsch. In Österreich lief die Forschung zu Parteien, Verbänden, Institutionen oder Personen eher parallel zum Genre der Gesamtdarstellung und floss erst in die nächste Generation der Gesamtdarstellungen ein. Gewiss: Vor allem die ersten Jahre der Republik haben in den letzten Jahren die Aufmerksamkeit der Forschung gefunden. ${ }^{39}$ Niemand hat jedoch die Bemerkung Karl Renners,

36 Vgl. Sheri Berman, Civil Society and the Collapse of the Weimar Republic, in: World Politics 49 (1997) 3, 401-429.

37 Zum Einbau des Begriffs Fragmentierung in einen modifizierten Lagerbegriff vgl. Lehnert, Integrationsmilieus, 433 .

38 Vgl. Peter Huemer, Sektionschef Robert Hecht und die Zerstörung der Demokratie in Österreich, Wien 1975 - immer noch grundlegend. Vgl. auch Parlamentsdirektion (Hg.), Staats- und Verfassungskrise 1933, Wien 2014 sowie, zum Fortgang der Gesetzgebungspraxis, Helmut Wohnout, Regierungsdiktatur oder Ständeparlament. Gesetzgebung im autoritären Österreich, Wien 1993.

39 Vgl. Helmut Konrad/Wolfgang Maderthaner (Hg.), ... der Rest ist Österreich. Das Werden der Ersten Republik, 2 Bde., Wien 2008; Alfred Pfoser/Andreas Weigl, Die erste Stunde Null. Gründungs- 
in der Verhandlung der Sanierungspläne des Bundeskanzlers Michael Mayr 1921 zwischen Parlament, Parteien und Ländern habe sich die „eigentliche Peripetie der inneren Entwicklung des Landes“ vollzogen, forschungspraktisch aufgegriffen. ${ }^{40}$ Die brillante Studie zur Kriegsopferversorgung in Österreich in den Jahren zwischen 1914 und 1938, die Verena Pawlowsky und Harald Wendelin vorgelegt haben, ${ }^{41}$ hat die Bedeutung der Wohlfahrtspolitik für die Legitimation einer neuen Demokratie offengelegt - und zugleich deutlich werden lassen, wie selten die Forschung den Nexus zwischen Demokratie und Wohlfahrtsstaat zum Gegenstand genommen hat. So groß die Bedeutung des Völkerbunds für die wirtschaftliche Stabilisierung Österreichs gewesen ist - durch die Anleihen von 1922 und 1931 -, so gering fällt die Aufmerksamkeit in der Forschung aus: In den Gesamtdarstellungen ist der Völkerbund oft nur eine Chiffre für die Außenpolitik vor allem Frankreichs und Großbritanniens. Ein institutioneller Eigensinn wird dem Völkerbund nicht zugestanden. Dabei war Österreich ein zentrales Bewährungsfeld für den neu geschaffenen Völkerbund und die mit ihm einhergehende neue Form der internationalen Beziehungen. ${ }^{42}$

Erstaunlich ist das geringe Interesse an Musik und Musikpolitik in der Ersten Republik, vor allem mit Blick auf die große Bedeutung, die der Musik in der Selbstwahrnehmung Österreichs in aller Regel zukommt. Ausführungen zur Musikgeschichte - verstanden nicht als Stil- und Formanalyse oder Biographie, sondern als Teil einer Gesellschafts- und Kulturgeschichte - findet man in den üblicherweise

jahre der österreichischen Republik, Salzburg 2017 (missverständlicher Titel: Die „Stunde Null“ ist immer eine Illusion); Robert Kriechbaumer/Michaela Maier/Maria Mesner/Helmut Wohnout (Hg.), Die junge Republik. Österreich 1918/19, Wien 2018; Marion Dotter/Stefan Wedrac, Der hohe Preis des Friedens. Die Geschichte der Teilung Tirols 1918-1922, Innsbruck ${ }^{2}$ 2019. Zur Frage der ,Revolution' in Österreich 1918/19 vgl. Otto Bauer, Die österreichische Revolution, Wien 1923; Marcus Gräser/Birgit Kirchmayr (Hg.), Die ,Österreichische Revolution' 1918/19. Zur Problematik einer alten Meistererzählung der Zeitgeschichte in Österreich, in: zeitgeschichte 41 (2014) 6 sowie die abwägenden Einschätzungen bei Ernst Bruckmüller, Österreichische Geschichte. Von der Urgeschichte bis zur Gegenwart, Wien 2019, 471-475 und Hanisch, Schatten, 263-278.

Karl Renner, Österreich von der Ersten zur Zweiten Republik, Wien 1953, 48. Vgl. zur Einschätzung dieser Vorgänge auch Bauer, Österreichische Revolution, 249-262. Vgl. auch Nathan Marcus, Austrian Reconstruction and the Collapse of Global Finance, 1921-1931, Cambridge 2018.

Verena Pawlowsky/Harald Wendelin, Die Wunden des Staates. Kriegsopfer und Sozialstaat in Österreich 1914-1939, Wien 2015.

42 Vgl. Tim B. Müller/Adam Tooze, Demokratie nach dem Ersten Weltkrieg, in: dies. (Hg.), Normalität und Fragilität. Demokratie nach dem Ersten Weltkrieg, Hamburg 2015, 9-33, 24; Peter Berger, Im Schatten der Diktatur. Die Finanzdiplomatie des Vertreters des Völkerbundes in Österreich Meinoud Marinus Rost van Tonningen 1931-1936, Wien 2000 sowie Patricia Clavin, Securing the World Economy: The Reinvention of the League of Nations, 1920-1946, Oxford 2013, 26-33, dort auch Hinweise auf weitere Literatur. 
politikzentrierten Gesamtdarstellungen der Geschichte der Ersten Republik nicht. Aber auch monographische Studien fehlen, sieht man von solchen zu den gut erforschten Salzburger Festspielen einmal ab. ${ }^{43}$ Die österreichische Musikwissenschaft hat hierzu wenig beigetragen, einen Dialog zwischen den Disziplinen gibt es nicht. Hingegen gibt es zur Literatur, zur Malerei und zur Architektur in der Zwischenkriegszeit wichtige Arbeiten, die Kunst als Teil der Gesellschaftsgeschichte begreifen. ${ }^{44}$

Auffällig sind auch die Lücken in der biographischen Forschung, die gewiss dem Umstand geschuldet sind, dass die Historikergeneration, die in den 1960er-Jahren mit dem Studium begann, die Form der Biographie als altmodisch ansah. Immerhin liegen inzwischen neuere Arbeiten zu Karl Renner, Otto Bauer, Otto Ender und

43 Vgl. Michael P. Steinberg, The Meaning of the Salzburg Festival: Austria as Theater and Ideology, 1890-1938, Ithaca 1990; Robert Kriechbaumer, Zwischen Österreich und Großdeutschland. Eine politische Geschichte der Salzburger Festspiele 1933-1944, Wien 2013; Norbert Christian Wolf, Eine Triumphpforte österreichischer Kunst. Hugo von Hofmannsthals Gründung der Salzburger Festspiele, Salzburg 2014. Was eine kulturwissenschaftlich ausgerichtete Geschichtswissenschaft in Sachen Musik leisten kann, hat Moritz Csaky für die Zeit vor 1914 gezeigt: Ideologie der Operette und Wiener Moderne. Ein kulturhistorischer Essay, Wien ${ }^{2}$ 1998. Eine eigenwillige, auf lebensgeschichtlichen Interviews basierende Deutung des Verhältnisses von Musik und Arbeit versucht Georg Schinko, Über die Produktion von Tönen. Beziehungen von Arbeit und Musizieren, Österreich 1918-1938, Wien 2019.

44 Vgl. aus der Fülle der Literatur: Franz Kadrnoska (Hg.), Aufbruch und Untergang. Österreichische Kultur zwischen 1918 und 1938, Wien 1981; Christoph Bertsch/Markus Neuwirth (Hg.), Die ungewisse Hoffnung. Österreichische Malerei und Graphik zwischen 1918 und 1938, Salzburg 1993; ders. (Hg.), Das ist Österreich! Bildstrategien und Raumkonzepte 1914-1938, Berlin 2015; Birgit Kirchmayr, Zeitwesen. Autobiographik österreichischer Künstlerinnen und Künstler im Spannungsfeld von Politik und Gesellschaft 1900-1945. Eine Studie zu Alfred Kubin, Oskar Kokoschka, Aloys Wach, Erika Giovanna Klien und Margret Bilger, Wien 2020; Andreas Nierhaus/ Eva-Maria Orosz (Hg.), Werkbundsiedlung Wien 1932. Ein Manifest des Neuen Wohnens, Wien 2012; Klaus Amann, Die Dichter und die Politik. Essays zur österreichischen Literatur nach 1918, Wien 1992; Friedrich Achberger, Fluchtpunkt 1938. Essays zur österreichischen Literatur zwischen 1918 und 1938, Wien 1994; Wendelin Schmidt-Dengler, Ohne Nostalgie. Zur österreichischen Literatur der Zwischenkriegszeit, Wien 2002; Primus-Heinz Kucher (Hg.), Verdrängte Moderne vergessene Avantgarde. Diskurskonstellationen zwischen Literatur, Theater, Kunst und Musik in Österreich 1918-1938, Göttingen 2016; Martin Erian/Primus-Heinz Kucher (Hg.), Exploration urbaner Räume - Wien 1918-38. (Alltags)kulturelle, künstlerische und literarische Vermessungen der Stadt in der Zwischenkriegszeit, Göttingen 2019; Evelyne Polt-Heinzel, Österreichische Literatur zwischen den Kriegen. Plädoyer für eine Kanonrevision, Wien 2012; Julia Bertschik/Primus-Heinz Kucher/Evelyne Polt-Heinzl/Rebecca Unterberger, 1928. Ein Jahr wird besichtigt, Wien 2014; Regina Thumser-Wöhs, „... zauberlacht Unlust in blaue Heiterkeit“. Sucht und Kunst im 19. und frühen 20. Jahrhundert, Innsbruck 2017; Pia Janke, Politische Massenfestspiele in Österreich zwischen 1918 und 1938, Wien 2010; vgl. auch die Aufsätze in Konrad/Maderthaner (Österreich, Bd. 2, 157-278), die der „kulturellen Redimensionierung“ nach 1918 gewidmet sind. 
Rudolf Ramek vor und die Frauen- und Geschlechterforschung hat nicht selten eine (kollektiv)biographische Perspektive eingenommen. ${ }^{45}$ Für zahlreiche Schlüsselfiguren der Ersten Republik - allen voran für Engelbert Dollfuß - aber gibt es keine wissenschaftlichen Ansprüchen genügende Biographien. ${ }^{46}$

Ein wesentliches Kennzeichen der Forschung zur Ersten Republik liegt in der ausschließlichen Fixierung auf Österreich. ${ }^{47}$ Eine Einbettung in die Zusammenhänge der europäischen Geschichte findet kaum statt. Freilich: Ohne Saint-Germain, ohne den Verweis auf den Völkerbund und die schwierige außenpolitische Situierung der Republik zwischen Deutschland, Italien, Ungarn und der Tschechoslowakei kommt keine Gesamtdarstellung aus. Meistens handelt es sich dabei aber um eine Einbettung in eine Kulissenlandschaft. Ein Vergleich, der auf den Zusammenhang Österreichs mit anderen europäischen Staaten und Gesellschaften durch die Rekonstruktion ähnlicher (oder unterschiedlicher) Probleme verweist und nur so klären kann, wie besonders - oder repräsentativ - der Fall Österreich gewesen ist, spielt in der Forschung keine Rolle. Naheliegend wäre ein Vergleich mit den anderen Nachfolge-

45 Richard Saage, Der erste Präsident. Karl Renner - eine politische Biographie, Wien 2016; Ernst Hanisch, Der große Illusionist. Otto Bauer (1881-1938), Wien 2011; Peter Melichar, Otto Ender 1875-1960. Landeshauptmann, Bundeskanzler, Minister. Untersuchungen zum Innenleben eines Ministers, Wien 2018; Franz Schausberger, Rudolf Ramek 1881-1941. Konsenskanzler im Österreich der Gegensätze, Wien 2017 und Gabriella Hauch, Vom Frauenstandpunkt aus. Frauen im Parlament 1919-1933, Wien 1995. Zur Schlüsselfigur Ignaz Seipel vgl. immer noch Klemens von Klemperer, Ignaz Seipel: Christian Statesman in a Time of Crisis, Princeton 1972.

Zu Dollfuß’ Nachleben vgl. Lucile Dreidemy, Der Dollfuß-Mythos. Eine Biographie des Posthumen, Wien 2014.

47 Diese Selbstbezogenheit spiegelt sich auch in der Forschung zum „Roten Wien“, die seit Jahrzehnten ohne Vergleich auskommt. Auch der umfängliche Katalog zur Ausstellung im Wien $\mathrm{Mu}$ seum 2019/2020 (Werner Michael Schwarz/Georg Spitaler/Elke Wikidal (Hg.), Das Rote Wien 1919-1934. Ideen, Debatten, Praxis, Basel 2019) beschränkt sich in einigen wenigen Aufsätzen auf die internationale Vorbildwirkung der Architektur. Hat es in Europa nicht auch andere "rote“ Städte gegeben - und somit Stoff für vergleichende Fragestellungen? Es ist das alte Lied der WienForschung: „Wien, nur Du allein ...“. Immerhin wird inzwischen das „nichtrote“ Wien stärker ins Blickfeld genommen, vgl. Janek Wasserman, Black Vienna: The Radical Right in the Red City, 1918-1938, Ithaca 2014 und Markus Benesch, Die Wiener Christlichsoziale Partei 1910-1934, Wien 2014. Ein Meisterwerk ist: Wolfgang Kos (Hg.), Kampf um die Stadt. Politik, Kunst und Alltag um 1930, Wien 2010. Zum „Roten Wien“ vgl. auch Alfred Georg Frei, Rotes Wien. Austromarxismus und Arbeiterkultur. Sozialdemokratische Wohnungs- und Kommunalpolitik 1919-1934, Berlin 1984; Anson Rabinbach, The Crisis of Austrian Socialism: From Red Vienna to Civil War, 1927-1934, Chicago 1983; Helmut Gruber, Red Vienna: Experiment in Working-Class Culture, 1919-1934, Oxford 1991; Helmut Konrad/Gabriella Hauch, Hundert Jahre Rotes Wien. Die Zukunft einer Geschichte, Wien 2019 sowie den voluminösen Quellenband von Rob McFarland/ Georg Spitaler/Ingo Zechner (Hg.), Das Rote Wien. Schlüsseltexte der zweiten Wiener Moderne 1919-1934, Berlin 2020. 
staaten der Habsburgermonarchie - allesamt ,neue' Staaten, die sich mit dem institutionellen Erbe der Monarchie auseinanderzusetzen und ihren Platz im Staatensystem zu finden hatten. Vielleicht noch naheliegender aber müsste der Vergleich mit Deutschland sein - nicht wegen der ,Anschluss'-Problematik, ${ }^{48}$ sondern aufgrund der analogen Situation von Demokratieaufbau und -zerstörung im selben Zeitraum. Aber ein solcher Vergleich findet in der Forschung nicht statt.

Diese Engführung der Zeitgeschichtsforschung auf die Nationalgeschichte steht im Widerspruch zur Aufgabenbestimmung, die der Tübinger Historiker Hans Rothfels in seinem berühmt gewordenen Einleitungsaufsatz zum ersten Jahrgang der „Vierteljahreshefte für Zeitgeschichte“ 1953 der Zeitgeschichtsforschung gestellt hatte: Sie solle nicht nur, so die bekannte Formel, die „Epoche der Mitlebenden“ zum Gegenstand nehmen, sondern auch die Zäsur 1917/1918 als Beginn einer neuen „universalgeschichtlichen Epoche“ begreifen. ${ }^{49}$ Auch wenn Rothfels' Begriff „universalgeschichtlich“ geschichtsphilosophisch aufgeladen scheint, so verbarg sich darin jedenfalls keine Ermunterung, die Zeitgeschichte als einen ausschließlich nationalgeschichtlichen Vorgang zu verstehen. Die Perspektive auf eine inter-, trans- oder supranationale Zeitgeschichte ist in Österreich kaum genutzt worden..$^{50}$

Die unbedingte Orientierung auf das eigene Land in der österreichischen Zeitgeschichtsforschung ist nicht schwer zu erklären und vor allem dem Umstand geschuldet, dass sich ein neuer Teilbereich der Geschichtswissenschaft am besten legitimiert (und durchsetzt), wenn er seine Kompetenz in dem Feld beweisen kann, das in den Augen der Öffentlichkeit traditionell das höchste Prestige aufweist: in der Nationalgeschichte. Unumstritten war die neue Zeitgeschichte nicht: „Denn für seriöse Historiker“, hielt Erika Weinzierl rückblickend fest, „war die Beschäftigung mit so junger Geschichte schon hart an der Grenze zum Journalismus.“ ${ }^{51}$ Die Forschung

48 Vgl. dazu Erin R. Hochman, Imagining a Greater Germany: Republican Nationalism and the Idea of Anschluss, Ithaca 2016 und Jan Vermeiren, The First World War and German National Identity: The Dual Alliance at War, Cambridge 2016.

49 Hans Rothfels, Zeitgeschichte als Aufgabe, in: Vierteljahreshefte für Zeitgeschichte 1 (1953) 1, 1-8, 2,6 .

50 Eine signifikante Ausnahme bildet Barry McLoughlin/Hannes Leidinger/Verena Moritz, Kommunismus in Österreich 1918-1938, Innsbruck 2009. In diesem Buch wird die Geschichte der KPÖ konsequent aus der Perspektive einer internationalen Geschichte des Kommunismus analysiert. Vgl. auch Hannes Leidinger/Verena Moritz, Gefangenschaft, Revolution, Heimkehr. Die Bedeutung der Kriegsgefangenenproblematik für die Geschichte des Kommunismus in Mittel- und Osteuropa 1917-1920, Wien 2003 sowie Verena Moritz/Julia Köstenberger/Aleksandr Vatlin/Hannes Leidinger/Karin Moser, Gegenwelten. Aspekte der österreichisch-sowjetischen Beziehungen 1918-1938, St. Pölten 2013.

51 Erika Weinzierl, Der Februar 1934 und die Folgen für Österreich, Wien 1995, 52. 
zur Geschichte der Ersten Republik hat dabei auch eine Schlagseite: Denn die Aufmerksamkeit lag lange - und oftmals immer noch - nicht auf dem Scheitern der Demokratie, sondern auf dem Österreichs. Das erklärt sich aus der engen Bindung der Zeitgeschichtsforschung an die Festigung eines österreichischen Nationalbewusstseins, dessen Mangel immer prominent in den Erklärungen für das Ende der Ersten Republik aufscheint. ${ }^{52}$ Erst die seit den 1970er-Jahren nicht mehr bestreitbare Nationswerdung Österreichs - die in Meinungsumfragen aufscheinende Zustimmung zur Nation Österreich ${ }^{53}$ - hat mit dazu beigetragen, dass die Aufmerksamkeit in der Forschung stärker auf die Fragen nach der Funktions(un)fähigkeit der Demokratie gelenkt werden konnte.

Die Verquickung von Forschung und Nationalgeschichte offenbarte im Fall der Zeitgeschichte ein Paradoxon: Eben weil die Erste Republik - ihre Bewohnerinnen und Bewohner - Schwierigkeiten damit hatte, sich als Nation und Nationalstaat mit unverrückbaren Grenzen verstehen zu können, wurde sie von den Historikerinnen und Historikern, die in der Zweiten Republik ihre Ausbildung erfuhren und mit einem Verständnis von der „Nation Österreich“ aufgewachsen waren, behandelt, als $o b$ sie ein Nationalstaat gewesen wäre. ${ }^{54}$ Das schloss eine vergleichende Perspektive nicht aus, aber just der Vergleich mit Deutschland musste als problematisch empfunden werden, da das hohe Maß an Ähnlichkeit, das hier gerade im Blick auf die Problemlagen der 1920er und frühen 1930er Jahre, etwa im Aufstieg des Nationalsozialismus, offensichtlich ist, den Abstand, der nach 1945 als konstitutiv für die österreichische Nationsbildung empfunden wurde, im Nachhinein noch beeinträchtigen musste.

Ein Vorwurf an die Zeitgeschichtsforschung in Österreich im Sinne eines „Versäumnisses“ ist das nicht. Die deutsche Zeitgeschichtsforschung hätte aus einem Vergleich zwischen beiden Staaten auch Erkenntnisgewinne ziehen können und hat diese Chance auch nicht genutzt. Österreich war und ist kein Feld der deutschen Geschichtswissenschaft, jedenfalls nicht für das 19. und 20. Jahrhundert. Die geringe Bereitschaft zur Beschäftigung mit der Geschichte des anderen Landes ging einher mit einer relativen Sprachlosigkeit der Historikerinnen und Historiker: Ein Dialog

52 Vgl. etwa Steven Beller, Geschichte Österreichs, Wien 2007, 187, der hier sogar zur Kategorie des „Versagens“ greift, weil es der Ersten Republik nicht gelang, eine österreichische Identität zu schaffen und sie ein „Land ohne Eigenschaften“ blieb.

53 Vgl. Ernst Bruckmüller, Nation Österreich. Kulturelles Bewußtsein und gesellschaftlich-politische Prozesse, Wien ${ }^{2} 1996,61-82$.

54 Die Übereinstimmung von zeithistorischer Forschung und Arbeit am österreichischen Nation Building dokumentiert - gewollt oder ungewollt, jedenfalls eindrücklich: Gerhard Botz/Gerald Sprengnagel (Hg.), Kontroversen um Österreichs Zeitgeschichte, Frankfurt a.M. ${ }^{2} 2008$. 
findet in der Zeitgeschichtsforschung kaum statt. ${ }^{55}$ Karl Dietrich Erdmanns Suche nach der „Spur Österreichs in der deutschen Geschichte“ und seine altertümelnde Konstruktion „Drei Staaten - zwei Nationen - ein Volk“, die just in den Jahren der Waldheim-Kontroverse in den späten 1980er-Jahren in Österreich Aufsehen erregten und überwiegend auf Ablehnung stießen, haben jedenfalls in Deutschland kein Interesse gefunden. ${ }^{6}$ Hans Mommsen und Everhard Holtmann waren Teil des Kunschak-Körner-Projekts, Ulrich Kluge, der aus dem Umfeld von Hans Rosenberg kam, forschte zur Agrarpolitik der Ersten Republik und legte eine immer noch sehr lesenswerte Darstellung des "Ständestaats" vor. ${ }^{57}$ Die historisch arbeitenden Politikwissenschaftler Detlef Lehnert, Dir Hänisch und Richard Saage haben zur Kommunalpolitik in Wien, zur Wahlanalyse und zu Karl Renner publiziert. ${ }^{8}$ War es das schon? Viel ist in dieser kurzen Aufzählung sicher nicht vergessen worden. Ein Name aber muss noch erwähnt werden: Karl Dietrich Bracher, der mit seinem 1955 erschienenen Buch über die Auflösung der Weimarer Republik ein Meisterwerk der Verschränkung von Struktur- und Prozessgeschichte vorgelegt hatte, lieferte wichtige typologische Versatzstücke für eine vergleichende Geschichte der europäischen Auseinandersetzungen zwischen Demokratie und Antidemokratie in der Zwischenkriegszeit und nahm dabei auch immer wieder Österreich in den Blick. 59

55 Entsprechend knapp ist der Raum für die Zeitgeschichte in: Robert A. Kann/Friedrich Prinz (Hg.), Deutschland und Österreich. Ein bilaterales Geschichtsbuch, Wien 1980.

56 Karl Dietrich Erdmann, Die Spur Österreichs in der deutschen Geschichte. Drei Staaten, zwei Nationen, ein Volk?, Zürich 1989. Erdmann hatte seine Dreistaatentheorie auch schon seinem Beitrag über „Das Ende des Reiches und die Entstehung der Republik Österreich, der Bundesrepublik Deutschland und der Deutschen Demokratischen Republik“ im „Gebhardt-Handbuch der deutschen Geschichte“ (Bd. 4,2, Stuttgart 1973) zugrunde gelegt. Vgl. auch die Debatte in Botz/Sprengnagel, Kontroversen, vor allem die Beiträge von Hanns Haas, 194-215 und Rudolf Ardelt, 266-286.

57 Ulrich Kluge, Der österreichische Ständestaat 1934-1938. Entstehung und Scheitern, München 1984; ders., Bauern, Agrarkrise und Volksernährung in der europäischen Zwischenkriegszeit. Studien zur Agrargesellschaft und wirtschaft der Republik Österreich 1918-1938, Stuttgart 1988.

58 Detlef Lehnert, Kommunale Politik, Parteiensystem und Interessenkonflikte in Berlin und Wien 1919-1932, Berlin 1991; Dirk Hänisch, Wahlentwicklung und Wahlverhalten in der Ersten Republik, in: Tálos/Dachs/Hanisch/Staudinger (Hg.), Handbuch, 488-503; ders., Die österreichischen NSDAP-Wähler. Eine empirische Analyse ihrer politischen Herkunft und ihres Sozialprofils, Wien 1998; Saage, Renner.

59 Karl Dietrich Bracher, Kritische Betrachtungen zum Faschismusbegriff, in: ders., Zeitgeschichtliche Kontroversen. Um Faschismus, Totalitarismus, Demokratie, München ${ }^{2} 1976$; ders., Autoritarismus und Totalitarismus. Die deutsche Diktatur und Österreich im Spannungsfeld der europäischen Nationalismen, in: ders., Wendezeiten der Geschichte. Historisch-politische Essays 1987-1992, Stuttgart 1992, 145-172. Zum europäischen Vergleich vgl. auch Juan J. Linz, The Breakdown of Democratic Regimes: Crisis, Breakdown, \& Reequilibration, Baltimore 1978 und Gregory M. Luebbert, 


\section{Erste Republik(en). Plädoyer für den Vergleich}

Was kann ein Vergleich mit Deutschland leisten? Wo und wie hilft er in der Erkenntnis von Zusammenhängen, die bei einem ausschließlich auf Österreich gerichteten Blick nicht in Sicht geraten? ${ }^{60}$ Wie und mit welcher Erklärungskraft ein Vergleich zwischen Österreich und Deutschland gezogen werden kann, hat kein Geringerer als Karl Renner vorgeführt. In einem Aufsatz, der 1929 in der „Gesellschaft", der Theoriezeitschrift der deutschen Sozialdemokratie, veröffentlicht wurde, nahm sich Renner die Christlichsoziale Partei des eigenen Landes und die deutsche Zentrumspartei vor. Vordergründig handelte es sich dabei um „dasselbe“ Phänomen ${ }^{61}$ : zwei Parteien des politischen Katholizismus mit Massenanhang und „im Grundzug“ demokratisch orientiert. Warum aber, so fragte Renner, ist dann das Verhältnis der Sozialdemokratie zu diesen Parteien in beiden Staaten so unterschiedlich? Während die deutsche Sozialdemokratie im Reich und in vielen Ländern mit der Zentrumspartei Koalitionen bilde, stünden die beiden Parteien in Österreich „,in schroffstem politischen Kampfe“. Die schnell bereitliegenden Erklärungen - die stärkere Linksorientierung der österreichischen Partei und die größere Kompromissbereitschaft der deutschen Sozialdemokratie - hielt Renner für wenig aufschlussreich. Tatsächlich bestünden gravierende Unterschiede zwischen den beiden katholischen Parteien, ,und deren Auswirkungen werden durch die verschiedene Struktur der beiden Länder noch verschärft".62

Die Unterschiede erläuterte Renner aus der Entstehungsgeschichte der beiden Parteien heraus: Das Zentrum sei aus der Opposition gegen den (preußischen) Staat entstanden, habe in der Zeit des Kulturkampfs seine eigentliche Gestalt angenommen und sehe im Protestantismus (und seiner politischen Dimension) den eigentlichen Widerpart. Mit den „alten Mächten“ aus der Vorkriegszeit habe sich das Zentrum nie identifiziert. Im Gegensatz dazu sei die Christlichsoziale Partei aus der Revolte Wiener Kleinbürger gegen Liberalismus und Kapitalismus heraus entstanden und habe erst mit der Eroberung der Dörfer nach 1900 zu einer Partei der Kirche und des Klerikalismus werden können. In einem fast ausschließlich ka-

Liberalism, Fascism, or Social Democracy: Social Classes and the Political Origins of Regimes in Interwar Europe, New York 1991.

60 Die Literatur zur Methode des Vergleichs ist umfänglich, eine nach wie vor schlüssige Einführung bietet Hartmut Kaelble, Der historische Vergleich. Eine Einführung zum 19. und 20. Jahrhundert, Frankfurt a. M. 1999.

61 Karl Renner, Die Christlichsozialen in Österreich und das Zentrum im Reich, in: Die Gesellschaft. Internationale Revue für Sozialismus und Politik 6 (1929, Bd. 2) 8, 137-148, 137.

62 Ebd. 
tholischen Land habe der Protestantismus als Widerlager keine Rolle gespielt und gegen den Staat sei die Partei auch nicht gerichtet gewesen. Vielmehr spiele der Antisemitismus als ideologischer Kitt eine große Rolle und die Sozialdemokratie sei zum zentralen politischen Feindbild avanciert. In den letzten Jahren vor dem Ersten Weltkrieg seien die Christlichsozialen dann auch zur „Hofpartei“ geworden. ${ }^{63}$

Einen Unterschied sah Renner auch in der sozialen Basis der beiden Parteien: Das Bündnis mit den Hausbesitzern und ihrer Kurie in Wien, das für die Erringung des Bürgermeisterpostens für Karl Lueger entscheidend gewesen war, habe die Christlichsozialen „schon in den Anfängen korrumpiert" ${ }^{\prime 64}$ und zur Verteidigung von Privilegien geführt. Darum sei die christliche Arbeiterbewegung klein geblieben, während das Zentrum weite Teile der katholischen Arbeiterschaft viel selbstverständlicher an die Partei habe binden können. Mit der österreichischen Wahlrechtsreform, dem Aufstieg der Sozialdemokratie und dem Reichsratswahlergebnis von 1907 sei Albert Geßmann, neben Lueger der wichtigste Politiker der Christlichsozialen, klargeworden, dass seine Partei nicht die alleinige Volkspartei sei und werden könne. Daraufhin habe eine Neuausrichtung als bürgerliche und als Regierungspartei stattgefunden - ein Prozess, der dann durch Seipels Bürgerblock-Politik fortgesetzt worden sei. Eine so dezidiert ,bürgerliche' Partei habe das Zentrum nicht sein wollen und können.

Schließlich hätten, war Renner überzeugt, diese Differenzen auch zu einem Unterschied nicht nur in der Haltung zur Sozialdemokratie, sondern auch im Verhältnis zur Demokratie überhaupt beigetragen. Hier gelangt seine Analyse dann auf den dramaturgischen Höhepunkt: Während Seipels Politik zum latenten Bündnis mit den "faschistischen Banden“ der Heimwehr führe, seien Zentrums-Anhänger Mitglieder im „Reichsbanner Schwarz-Rot-Gold“, der parteiübergreifenden Organisation, die sich dem Schutz der Republik und der Demokratie verschrieben hatte.

Gewiss hat Renner in seiner Analyse die Christlichsozialen aus der politischen Gegnerschaft heraus stark abwertend behandelt und das deutsche Zentrum um des Kontrasts willen in ein rosiges Licht getaucht. Die christliche Arbeiterbewegung in Österreich war nicht so schwach wie behauptet ${ }^{65}$ und auch in der Zentrumspartei gab es einen aristokratischen Flügel (Franz von Papen) der der Weimarer Demokratie ablehnend gegenüberstand. Gleichwohl interessiert an Renners Analyse nicht die Übereinstimmung mit dem heutigen Forschungsstand zu den beiden Parteien -

63 Ebd., 144 .

64 Ebd., 141.

65 Vgl. Anton Pelinka, Stand oder Klasse? Die christliche Arbeiterbewegung Österreichs 1933-1938, Wien 1972. Zur Situation in Deutschland vgl. Michael Schneider, Die Christlichen Gewerkschaften 1894-1933, Bonn 1982. 
von Bedeutung ist vielmehr die offenkundige Fruchtbarkeit des Vergleichs, zumal Renner nicht nur die Unterschiede der beiden Parteien aus ihrer Entstehungsgeschichte heraus beleuchtete, sondern auch die Rahmenbedingungen der politischen Regime mit ins Auge fasste: Während die Zentrumspartei von Anfang an mit dem allgemeinen Männerwahlrecht rechnen musste, das mit der Reichsgründung 1871 eingeführt wurde, war die Christlichsoziale Partei in Wien wie in Cisleithanien eine Partei, die das Kurienwahlrecht und damit die Verteidigung von Privilegien als konstitutiv wahrnahm. Die bürgerliche Frontstellung gegen ,unten', die daraus erwuchs, blieb als mentales Erbe auch in der Ersten Republik erhalten und wurde in ihrer konfliktiven Haltung durch die Existenz eines De-facto-Zweiparteiensystems in der Zeit der Bürgerblockpolitik noch verstärkt, während die Zentrumspartei sich in einem Mehrparteiensystem befand und in aller Regel mehrere Koalitionspartner zum Regieren benötigte. Mit der Verschränkung der beiden Betrachtungsebenen - Parteien und politische Regime - wird ein Wechselspiel in der Analyse möglich (was Renner in seinem kurzen Aufsatz nicht ausführte): Die Rahmenbedingungen helfen bei der Analyse der Unterschiede, zugleich tragen die Unterschiede zur Erklärung der Rahmenbedingungen bei.

Die typische Versuchsanordnung des Vergleichs rekurriert auf Gemeinsamkeiten und Unterschiede zugleich - und stößt dabei im Fall von Deutschland und Österreich auf ein reichhaltiges Setting. Die Gemeinsamkeiten sind offensichtlich: Sie reichen vom zeitlichen Zusammenfall von Demokratisierung und Niederlage im Krieg (mit den an der Legitimation der neuen Demokratien zehrenden Begleiterscheinungen wie Hunger, lebensweltlichen Ungewissheiten, unklaren Grenzverhältnissen, Gewalt) ${ }^{66}$ bis zu Demokratiezerfall und -zerstörung in den frühen 193oer Jahren, auch vor dem Hintergrund einer wirtschaftlichen Krise, deren Ursprünge ohne internationale Zusammenhänge nicht erklärbar sind. Die für einen Vergleich ebenso konstitutiven Unterschiede zwischen Deutschland und Österreich sind ebenso zahlreich, für eine ganze Reihe von Unterschieden lassen sich jedoch funktionale Äquivalente finden: Der Kampf von rechts gegen die Demokratie der „Novemberverbrecher“ und für die Revision des Versailler Vertrags unterscheidet auf den ersten Blick Deutschland von Österreich. In Österreich fiel die Identifizierung der handelnden Politiker mit einer stigmatisierten Revolution geringer aus, vor allem natürlich weil seit dem Zerbrechen der Großen Koalition 1920 Sozialdemokraten auf der Ebene des Bundesstaates keine Funktionen mehr innehatten, im Gegensatz zu Deutschland, wo Reichspräsident Friedrich Ebert die Rechte bis zu seinem Tod

66 Zur Gewaltgeschichte der Ersten Republik vgl. Gerhard Botz, Gewalt in der Politik. Attentate, Zusammenstöße, Putschversuche, Unruhen in Österreich 1918 bis 1938 , München ${ }^{2} 1983$. 
1925 an ihren Machtverlust erinnerte; der Kampf gegen St. Germain fiel im Übrigen aus, jedenfalls diente er keiner Partei, auch den österreichischen Nationalsozialisten nicht, als politische Mobilisierungsstrategie. Die Antwort auf die Frage, warum das so war, lenkt den Blick auf ein funktionales Äquivalent: Der Anschlusswunsch und die in diese Richtung betriebene Propaganda sind funktional äquivalent zum nationalistischen Furor in Deutschland und absorbieren die Energien der Rechten. Wer gegen das Anschlussverbot war, konnte genauso gut den Vertrag von Versailles, der ja auch, gewissermaßen von der anderen Seite der Grenze her ein Anschlussverbot enthielt, zu seinem Hassobjekt machen und zur deutschen Rechten aufschließen: Der „Anschluss“ wurde dann zur „Revanche für St. Germain“"67

Everhard Holtmann hat in einem 2017 erschienenen Aufsatz, der Belastungen und Spielräume der Ersten Republik in einem Vergleich mit dem Deutschen Reich auslotet, auf eine Reihe von Umständen hingewiesen, die Österreich nach 1918 in eine bessere Ausgangslage - mit Blick auf die Festigung der Demokratie - gebracht habe, als es in Deutschland der Fall gewesen war. ${ }^{68}$ Knapp zusammengefasst sind es folgende Umstände:

1. Im Unterschied zur „Schmach von Versailles“ hat es keine Stimulation eines Revanchismus in Österreich gegeben, ebenso sei die Verständigung über den Waffenstillstand im November noch eine Angelegenheit des Monarchen und der kaiserlichen Regierung gewesen, während in Deutschland das alte Regime diese undankbare Aufgabe bereits den Repräsentanten der Demokratie überließ - und diese sich und der Republik damit ein Stigma aufluden.

2. Das österreichische Heer wurde im Unterschied zur deutschen Reichswehr durch den sozialdemokratischen Einfluss (Julius Deutsch) fundamental demokratisiert. Auch wenn später „Umfärbungen“ stattfanden, wurde der Primat der Politik seitens der Heeresführung nicht herausgefordert, ein Staat im Staat entstand in Österreich nicht.

3. Die Sozialdemokratie repräsentierte fast unangefochten die Arbeiterschaft, eine Spaltung der Arbeiterbewegung fand nicht statt, die KPÖ blieb marginalisiert -

67 Arnold Suppan im Gespräch mit Cornelia Grobner, Die Presse, 28.09.2019, W4. Die Anschlussbewegung aus der deutschen wie aus der österreichischen Perspektive analysiert Norbert Schausberger, Der Griff nach Österreich. Der „Anschluß“, Wien ${ }^{3} 1988$.

68 Everhard Holtmann, Verpasste Konsolidierung. Das Scheitern der Demokratie in Österreich in der Zeit zwischen den Weltkriegen, in: Steffen Kailitz (Hg.), Nach dem „Großen Krieg“. Vom Triumph zum Desaster der Demokratie 1918/19 bis 1939, Göttingen 2017, 363-384, 373-378. Knapp und stichwortartig hat auch Ernst Hanisch Ähnlichkeiten und Unterschiede zwischen der Ersten Republik und der Weimarer Republik zusammengefasst: Ernst Hanisch, Einleitung, in: Tálos/Dachs/ Hanisch/Staudinger (Hg.), Handbuch, 1-7, 6-7. 
anders als in Deutschland, wo die Spaltung der Arbeiterbewegung bzw. Rivalität und Kampf zwischen SPD und KPD Energien band, die in der Verteidigung der Demokratie fehlten.

4. Die Kompaktheit der politischen Kräfte, die etwa gleiche Stärke der Christlichsozialen und der Sozialdemokraten, ermöglichte eine „wechselseitige Vetomacht“, die in der stärker fragmentierten Parteienlandschaft Deutschlands nicht herstellbar war. Zugleich waren die bürgerlichen Kräfte stark genug, Regierungskoalitionen ohne die Sozialdemokratie zu bilden, was zur Polarisierung beitrug, aber eben deshalb vor Zersplitterung schützte, die in Deutschland ja viel mit unbefriedigender Kompromissbildung und der Bereitwilligkeit kleiner Parteien, Partikularinteressen nachzugehen, zu tun hatte. Vor allem die Christlichsoziale Partei in Österreich wirkte als Integrationskraft in der Verbindung der unterschiedlichen ländlichen Räume, auch wenn sie in einigen wenigen Regionen vom deutschnationalen Landbund herausgefordert wurde. ${ }^{69}$ (Eine solche hohe Integrationskraft wies der politische Katholizismus in Deutschland nicht auf, der natürlich nicht zur vorherrschenden Partei im ländlichen Raum des evangelischen Deutschland wurde und zudem den bayrischen Partikularismus - mit der Bayerischen Volkspartei als eigenständiger Regionalpartei des politischen Katholizismus - nicht ausbalancieren konnte.) Die Balance zur Vorherrschaft der Christlichsozialen auf Bundesebene hielt das Rote Wien.

5. Das Bundes-Verfassungsgesetz von 1920 ließ, trotz der Erweiterung der Befugnisse des Bundespräsidenten in der Novelle von 1929, keinen Spielraum für „exekutive Führerschaft" und installierte eine Parlamentsherrschaft (auch über das Heer), während die Weimarer Reichsverfassung mit dem starken Reichspräsidenten („Ersatzkaiser“) und dem Notverordnungsrecht starke Elemente einer vom Parlament abgehobenen eigenmächtigen Exekutive enthielt (ohne die die Zertrümmerung der Weimarer Demokratie auch nicht möglich gewesen wäre). Zugleich verzichtete das Bundesverfassungs-Gesetz auf Elemente direkter Demokratie (Volksbegehren, Volksentscheid), die in Deutschland zur Mobilisierung gegen die Republik genutzt werden konnten.

6. Die Abhängigkeit des ausgeglichenen Staatshaushalts von Anleihen und Kreditzusagen durch den Völkerbund und die damit einhergehende Funktion der Demokratien von Frankreich und Großbritannien als De-facto-Garantiemächte übten einen Stabilisierungseffekt aus, da die kontrastierenden autoritären Regime in Ungarn und Italien zwar Einfluss auf Österreich hatten, aber keine Funktion für die Finanzpolitik der Republik einnehmen konnten.

69 Vgl. zum Landbund Kriechbaumer, Erzählungen, 494-544. 
Gleichwohl bewahrte keiner dieser Umstände die Erste Republik vor dem Scheitern; die Weltwirtschaftskrise und der Aufstieg des Nationalsozialismus reduzierten den ,Vorteil', den Österreich in diesen Umständen zu haben schien, recht bald. Im Rahmen einer vergleichenden Betrachtung müssen aber weitere Belastungen in Rechnung gestellt werden; tatsächlich lassen sich Umstände benennen, mit denen sich Österreich nach 1918 im Vergleich in einer schlechteren Ausgangskonstellation befand als das Deutsche Reich:

1. Während das Deutsche Reich als Rechtssubjekt noch existierte, wenn auch mit Gebietsverlusten, und die Frage der nationalen Identität beantwortbar blieb, war der neu geschaffene Staat Österreich ein Gebilde, das nicht selbstverständlich erschien. Tatsächlich war die neu geschaffene Republik ein Beispiel für das Auseinandertreten von „identity space“ und „decision space“70 - insoweit als der Horizont der deutschen Nation für viele Österreicherinnen und Österreicher relevant blieb, die Entscheidungen für die Republik aber entweder im neuen Staat oder durch die Siegermächte des Ersten Weltkriegs getroffen wurden. Eine nationalistische Revanchebewegung in Richtung der einstigen Größe der Monarchie löste der Vertrag von St. Germain nicht aus (tatsächlich war Österreich der einzige ,Verliererstaat', der etwas ,dazubekam': das Burgenland). Es bleibt aber zu diskutieren, ob nicht die Anschlussbewegung eine bestimmte Form der nationalistischen Revanche darstellte (im Sinne des Irredentismus). ${ }^{71}$ In jedem Fall fehlte in Österreich die in Deutschland selbstverständlich bleibende, auf das Staatsgebiet bezogene Loyalität.

2. Österreich war außenpolitisch ,uninteressant', da es für keinen Nachbar eine Gefahr mehr darstellte. Daher war es in kein Bündnissystem eingebunden, weder in jene, die von Frankreich ausgingen („Kleine Entente“), noch in jene verkappten Bündnissysteme, die die Verlierer zusammenbanden („Rapallo“, Deutschland-Sowjetunion). Das Völkerbundinteresse war rein finanzpolitisch begründet. Österreich hatte, zugespitzt formuliert, das ,Pech, keine Reparationen leisten zu müssen, was eben auch keinen außenpolitischen Regelungsbedarf schuf, der sich im deutschen Fall durch die amerikanischen Initiativen zur Regelung der Reparationen ergab.

3. Die wirtschaftliche Situation war eindeutig dramatischer als in Deutschland: Die Auflösung des traditionellen Wirtschaftsraums der Habsburgermonarchie

70 Charles S. Maier, Consigning the Twentieth Century to History: Alternative Narratives for the Modern Era, in: American Historical Review 105 (2000) 3, 807-831, 823.

71 Vgl. Werner Suppan, The Imperialist Peace Order in Central Europe: Saint Germain and Trianon, Wien 2019. 
führte zur Verkürzung der Spielräume in Österreich, das zwar durchaus über industrielle Substanz verfügte, gleichwohl aber die traditionellen Absatzmärkte verloren hatte, da die benachbarten Nachfolgestaaten der Monarchie dem Protektionismus frönten. ${ }^{72}$ Die Renner-Ideen vom Wirtschaftsraum Donau fanden keine Resonanz. Die Scheinblüte der Inflationszeit verdeckte nicht die enorme Zerrüttung der Vermögenslagen, vor allem im Bürgertum.

4. Die USA griffen in Österreich weniger ein, als es in Deutschland der Fall war, eine „Amerikanisierung“ (in welcher Hinsicht auch immer, kulturell wie wirtschaftlich) fand kaum statt. Vor allem gab es wenig amerikanische Kredite, die gern an deutsche Städte vergeben wurden, kaum aber nach Österreich flossen. Auch wenn das in Deutschland Teil der desaströsen Verflechtung der deutschen und der amerikanischen Ökonomie nach 1929 sein sollte, boten die amerikanischen Kredite schnelles Geld, die zur Modernisierung vieler Kommunen in der Stabilisierungsphase 1924-1929 genutzt wurden. Das Rote Wien genügte sich finanztechnisch selbst.

5. Die kulturelle Ausnahmestellung, die Wien vor dem Ersten Weltkrieg einnahm und die dem ganzen Staat ein kulturelles Prestige verlieh, brach nach $1919 \mathrm{ab}$; ein schwer zu erklärendes Faktum, da viele der Ausgangsbedingungen für kulturelle Innovation (oder jedenfalls für eine Bewahrung der Energien) nach wie vor gegeben waren. Während in Deutschland die „Weimar Culture“ Tendenzen, die vor 1914 vorhanden waren, zur Blüte brachte und das objektiv verarmte Berlin in einen Taumel versetzte, ruhte die internationale Bedeutung Wiens nach 1919 nur auf der politischen Transformation, nicht aber auf kultureller Neuerung. (Aber in beiden Fällen erwuchs aus der kulturpolitischen Situation kein „Stil“ der Republik.)

6. Die politische Polarisierung in der Ersten Republik kann nicht darüber hinwegtäuschen, dass es ein Defizit an Pluralität gab, die in Deutschland aus der Konfrontation von Tradition und Neuerung immer wieder neu erwuchs und Spielräume schuf, die auch für die Stabilisierung der Demokratie genutzt werden konnten. Wurde in Österreich abseits der Politik über etwas gestritten - mit dem Ergebnis der Durchsetzung des Neuen? Weder das Phänomen der Rationalisierung in der Industrie noch die Architektur des Neuen Bauens traten so prägnant auf, dass die Tradition herausgefordert wurde - und Schönberg ging nach Berlin.

Ein Vergleich mit Deutschland ist keineswegs der „Königsweg“. Es hängt von der Fragestellung und vom Interesse ab, welcher Vergleich - mit einem oder mit mehre-

72 Vgl. Sandgruber, Ökonomie, 335-343 und Bruckmüller, Österreichische Geschichte, 501-502. 
ren Staaten - am meisten Erkenntnis verspricht. Der Vergleich umfasst immer auch eine Analyse von Verflechtungen, mindestens auf der Ebene der Diskurse: Es wurde ja aufmerksam beobachtet, unter Politikern, in den Medien, unter Intellektuellen und Unternehmern wie in anderen Staaten auf Krisen reagiert und Politik gestaltet wurde. Diese Wahrnehmungen und der Diskurs, der daraus entstand, womöglich auch Lernprozesse, ebenso aber auch deren Verweigerung sind integraler Teil des Vergleichs. Für den Vergleich ist es nicht notwendig, die ,ganze 'Zeit und den ,ganzen' Staat in den Blick zu nehmen. Auch Regionen und Länder können miteinander vergleichen werden. ${ }^{73}$ Auch von Ereignissen kann ausgegangen werden: Auf welche Weise wurden dramatische, Spaltungslinien in der Gesellschaft offenlegende Phänomene wie der Justizpalastbrand in Wien 1927 und die große Streikbewegung im Ruhreisenstreit 1928 im politischen Prozess und im gesellschaftlichen Diskurs verarbeitet? 74

Ein Vergleich der nach dem Ersten Weltkrieg neu entstandenen Staaten kann der Frage nachgehen, warum und auf welche Weise Funktionsstörungen in der politischen Struktur, im Parteiwesen und im Parlamentarismus zu „nationalen Legitimationskrisen" 75 heranwuchsen. Der Vergleich mit funktionierenden, jedenfalls länger fortbestehenden Demokratien - wie etwa der Tschechoslowakei bis 1938 - kann den Sinn dafür schärfen, dass Fragilität und Krisen, die im Fall Österreichs (wie auch im deutschen Fall) immer auf das Ende hin interpretiert werden, zur Demokratie dazugehören. ${ }^{76}$ Der Vergleich der „ersten Republiken“ - ne-

73 Die Forschung zu den Ländern hat sich in den vergangenen Jahren vor allem auf die Zeit des Nationalsozialismus konzentriert. In Oberösterreich, wo früher als andernorts systematisch zur Zeit des Nationalsozialismus gearbeitet wurde (vgl. die Publikationsreihe „Oberösterreich in der Zeit des Nationalsozialismus“, die 2014 mit Band 13 abgeschlossen werden konnte), hat das Landesarchiv 2010 ein Forschungsprojekt zum Zeitraum 1918-1938 initiiert, inzwischen sind einige Monographien und Aufsatzbände aus diesem Projekt hervorgegangen. Wichtige Beiträge zur Zwischenkriegszeit in den Ländern finden sich in Wolfgang Weber/Walter Schuster (Hg.), Biographien und Zäsuren. Österreich und seine Länder 1918-1933-1938, Linz 2011 sowie in Herbert Dachs/Michael Dippelreiter/Franz Schausberger (Hg.), Radikale Phrase, Wahlbündnisse und Kontinuitäten. Landtagswahlkämpfe in Österreichs Bundesländern 1919 bis 1932, Wien 2017 (darin auch: Martin Dolezal, Landtagswahlkämpfe in der Ersten Republik. Ein vergleichendes Resümee, 559-596).

74 Zum Brand des Justizpalasts vgl. Norbert Leser/Paul Sailer-Wlasits (Hg.), Als die Republik brannte. Von Schattendorf bis Wien, Wien ${ }^{2} 2002$ und Bundesministerium für Justiz/Ludwig Boltzmann-Institut für Geschichte und Gesellschaft (Hg.), 80 Jahre Justizpalastbrand. Recht und gesellschaftliche Konflikte, Innsbruck 2008.

75 Bracher, Autoritarismus, 150.

76 Zur Situation der Demokratie in der Tschechoslowakei vgl. Andrea Orzoff, Das Personal und das Vokabular der Demokratie. Die Erste Tschechoslowakische Republik, in: Müller/Tooze, Demokratie, $436-462$. 
ben Österreich und Deutschland abermals die Tschechoslowakei - wiederum kann sich von Aufmerksamkeit dafür leiten lassen, vor welchen Problemen Demokratien standen, die einen Wechsel von der Monarchie zur Republik vollzogen hatten und wie sie mit den aus dem Ancien Régime übriggebliebenen Modernisierungsdefiziten umgingen. Solche Defizite erschließen sich freilich nicht in einer primär politikgeschichtlichen Analyse, sie bilden stets ein Ensemble, dem nur mit einer gesellschaftsgeschichtlichen Analyse, die nicht nur nach Institutionen, sondern auch nach Lebenswelten und Mentalitäten fragt, beizukommen ist.

Vergleichende Studien können auch klären, auf welche Weise Demokratien Probleme lösten und ähnlich gelagerte Krisen auf vielleicht unterschiedliche Weise in den Griff bekamen. Mit Blick auf das finale Scheitern bleiben immer noch genug Fragen übrig: Warum trugen die aus der Sicht der 1920er Jahre ausgesprochen erfolgreiche und populäre sozialpolitische Bewältigung der Nachkriegskrisen gerade in Österreich und in Deutschland und das Überstehen der Inflation nicht zu einer dauerhaften Stärkung der Legitimation der neuen Staaten und damit zu einer anhaltenden Stabilisierung der Demokratie bei? Was aber meint „Demokratie“? Wie kann dieser Begriff eingesetzt werden, wenn österreichische Geschichte in der Zwischenkriegszeit als Geschichte der Demokratie verstanden und analysiert werden soll? Eine normative Überfrachtung scheint ebenso wenig dienlich zu sein wie die simple Übernahme eines zeitgenössischen Alltagssprachgebrauchs. Eher wird man „democracy in the making“ zum Untersuchungsgegenstand nehmen können, was konkurrierende Deutungsmuster unter den Zeitgenossen ebenso einschließt wie eine inhaltliche Spurbreite, die autoritäre Tendenzen nicht von vornherein dichotomisch der Demokratie gegenüberstellt, sondern sie als Teil einer ,Konfusion' durchaus zulässt. ${ }^{77}$ Ganz ohne normatives Verständnis von Demokratie - im Sinne der definitorischen Setzung von Standards, die nicht unterschritten werden dürfen - geht es freilich auch nicht: Man wird unterscheiden müssen zwischen autoritären Tendenzen zum Schutz der Demokratie und solchen, die ihren Abbau betreiben, auch

77 Vgl. Tim B. Müller, Von der „Whig Interpretation“ zur Fragilität der Demokratie. Weimar als geschichtstheoretisches Problem, in: Geschichte und Gesellschaft 44 (2018) 3, 430-465, 441-442. Vgl. dazu auch Bracher, Autoritarismus, der die Konfrontation von Demokratie und Antidemokratie als Strukturmerkmal der Zwischenkriegszeit bezeichnet, aber gleichfalls damit keine klare Dichotomie benennen will, sondern auf den Umstand hinweist (Bracher, Autoritarismus, 147), dass die Demokratie erst den Freiraum für die Antidemokraten schaffe, vor allem dort, wo es sich um antidemokratische Massenbewegungen handle: Antidemokraten brauchten die Demokratie als Entfaltungsareal. Everhard Holtmann nutzt den Begriff der „defekten Demokratie“zur Kennzeichnung der Zeit zwischen dem Beginn des Notverordnungsregimes (auf der Basis des Kriegswirtschaftlichen Ermächtigungsgesetzes) und dem Februar 1934 (Holtmann, Verpasste Konsolidierung, 371). 
wenn diese Unterscheidung wiederum eine Grauzone offenlässt, in der ein ernst gemeinter Schutz der Demokratie zugleich an ihren Grundlagen nagt. Jedenfalls aber kann man zwischen autoritären Tendenzen in der Demokratie und einer autoritären Herrschaft passabel unterscheiden: Die Errichtung der Anhaltelager 1933 markiert diese Differenz. ${ }^{78}$

Eine begriffsscharfe Definition des politischen Autoritarismus - als Idealtyp im Weber'schen Sinne und damit als ein Tertium Comparationis für den Vergleich hätte dazu beitragen können, sich die eine oder andere aufgeregte Debatte um „Austrofaschismus“ und „Ständestaat“ zu ersparen. Autoritarismus lässt sich - in Anlehnung an Karl Dietrich Bracher - als Movens für ein antidemokratisches Regime fassen, das - im Unterschied zum Faschismus - reaktionär agiert und an Massenmobilisierung kein Interesse hat. Die Ursache für die Entstehung des Autoritarismus wiederum kann als Strukturproblem der politischen Modernisierung verstanden werden: Die Demokratie war eine Sturzgeburt (im österreichischen wie im deutschen Fall als Ergebnis der Niederlage im Krieg), ohne das wichtige soziale, ideelle und institutionelle Voraussetzungen dafür schon gegeben oder Blockaden aufgehoben waren. ${ }^{79}$ Das verschaffte jenen, die der Demokratie ablehnend oder indifferent gegenüberstanden, einen Spielraum - und verengte diesen zugleich für jene, die durch soziale Reformen der Demokratie eine populäre Basis verschaffen wollten. Im europäischen Vergleich jedenfalls war das Dollfuß/Schuschnigg-Regime ein autoritäres Regime, dessen Besonderheit im Abstand zu anderen autoritären Regimen zu klären ist. Ernst Hanischs gelungener Begriff des „Imitationsfaschismus“80 ist implizit das Ergebnis einer vergleichenden Betrachtung; noch präziser aber formuliert es wiederum Ian Kershaw, der Österreich zwischen 1934 und 1938 so charakterisiert: als „authoritarian regime - more repressive conservative-reactionary than fascist, or at any rate embracing a rather mild form of partial fascism compared with what was

78 Vgl. Gerhard Jagschitz, Die Anhaltelager in Österreich, in: Jedlicka/Neck (Hg.), Heldenplatz, 128151.

79 Bracher, Autoritarismus, 146. Zum Pfad der „konservativen Modernisierung“ und damit einer Demokratievermeidung vgl. Ernst Bruckmüller, Landwirtschaftliche Organisation und gesellschaftliche Modernisierung. Vereine, Genossenschaften und politische Mobilisierung der Landwirtschaft Österreichs vom Vormärz bis 1914, Salzburg 1977, 238-262 und ders., Die verzögerte Modernisierung. Mögliche Ursachen und Folgen des „österreichischen Weges“ im Wandel des Agrarbereiches, in: Herbert Knittler (Hg.), Wirtschafts- und sozialhistorische Beiträge. Festschrift für Alfred Hoffmann zum 75. Geburtstag, Wien 1979, 289-307.

80 Hanisch, Schatten, 313. Zum Ruhreisenstreit vgl. Gerald D. Feldman/Irmgard Steinisch, Notwendigkeit und Grenzen sozialstaatlicher Intervention. Eine vergleichende Fallstudie des Ruhreisenstreites in Deutschland und des Generalstreiks in England, in: Archiv für Sozialgeschichte 20 (1980), 57-117. 
to come“" ${ }^{81}$ Die Geschichte der Ersten Republik war eine Krisengeschichte und keine Erfolgsgeschichte, sie wird immer aus der Perspektive ihres Scheiterns her diskutiert werden, oder besser: aus der Perspektive ihres Endes her. Auch die vergleichende Forschung soll sich jedoch dem Paradoxon nicht entziehen, dass die Erste Republik nicht nur vom Scheitern her gedacht werden kann, aber ohne das Scheitern auch nicht verstanden werden kann. ${ }^{82}$

81 Kershaw, Hell, 242. Zur Forschung zu den Jahren 1933-1938 vgl. Emmerich Tálos, Das austrofaschistische Herrschaftssystem. Österreich 1933-1938, Wien 2013; Ilse Reiter-Zatloukal/Christiane Rothländer/Pia Schölnberger (Hg.), Österreich 1933-1938. Interdisziplinäre Annäherungen an das Dollfuß-/Schuschnigg-Regime, Wien 2012 und Florian Wenninger/Lucile Dreidemy (Hg.), Das Dollfuß/Schuschnigg-Regime 1933-1938. Vermessung eines Forschungsfeldes, Wien 2013. Vgl. auch die Einschätzung des Regimes als „traditional dictatorship“ bei Gregory M. Luebbert, Social Foundations of Political Order in Interwar Europe, in: World Politics 39 (1987) 4, 449-478, 462-463.

82 Vgl. Franka Maubach, Weimar (nicht) vom Ende her denken, in: Aus Politik und Zeitgeschichte 68 (2018) 18-20, 4-9. 


\title{
Austrofaschismus
}

\author{
Florian Wenninger
}

Vermutlich ist kein Thema in der österreichischen Geschichtswissenschaft so kontrovers diskutiert worden wie die Zwischenkriegszeit des 20. Jahrhunderts und hier besonders die Diktatur der Jahre 1933-1938. ${ }^{1}$ Zudem stießen wohl nur wenige historische Perioden auf ein vergleichbares öffentliches Interesse.

Die geschichtswissenschaftliche Bearbeitung des Austrofaschismus ${ }^{2}$ ist naturgemäß eng mit jener der Ersten Republik verschränkt, zumal das geschichtspolitisch heiße Eisen ja vor allem in den Gründen und Verantwortlichkeiten für das Zustandekommen der Diktatur besteht. Anliegen des vorliegenden Beitrags ist es, die Historiographie jener Jahre zu skizzieren, die sich durch eine - um einen Begriff der Organisationsforschung zu entlehnen - starke Pfadabhängigkeit auszeichnet. Gemeint ist damit, dass einmal etablierte Muster zwar eventuell modifiziert und weiterentwickelt, in ihrer Grundstruktur aber tradiert wurden. In der Retrospektive werden die entsprechenden Schwerpunkte und Paradigmen am besten anhand

1 Siegfried Mattl, Bestandsaufnahme zeitgeschichtlicher Forschung in Österreich, Wien 1983, 4850 .

2 Ernst Hanisch hat polemisch angemerkt, der "Theorieenthusiasmus“ der späten 1960er-Jahre habe, gepaart „mit der Arroganz der Jugend“, dazu geführt, „die Faschismustheorie der Zwischenkriegszeit aufzugreifen und sie relativ problemlos auf die Jahre 1934 bis 1938 als ,Austrofaschismus umzumünzen“, vgl. Ernst Hanisch, Die Dominanz des Staates. Österreichische Zeitgeschichte im Drehkreuz von Politik und Wissenschaft, in: Alexander Nützenadel/Wolfgang Schieder (Hg.), Zeitgeschichte als Problem. Nationale Tradition und Perspektiven der Forschung in Europa, Göttingen 2004, 54-77, 63. Diese Behauptung stimmte schon für den Theoriediskurs der 1960er-Jahre nur eingeschränkt und kann im Lichte der jüngeren internationalen Faschismusforschung als gänzlich überholt gelten. Wird daher im Weiteren der Begriff „Austrofaschismu“" gebraucht, so weniger, weil alle anderen gängigen Bezeichnungen für das Regime letztlich auf dessen Verharmlosung zielen, sondern weil man, Karl Vocelka zitierend, wohl „,beschönigende Worte für dieses Regierungssystem finden [... mag], doch [...] in einer ernsthaften wissenschaftlichen Analyse über die Tatsache, dass es ein faschistisches System war, nicht hinwegkommen"werde. Karl Vocelka, Geschichte Österreichs. Kultur - Gesellschaft - Politik, Graz/Wien/Köln 2002, 293. Anders formuliert: Es handelt sich schlicht um den historisch angemessensten und überdies theoretisch am hinreichendsten fundierten Terminus. Dabei ist „Austrofaschismus“ nicht als Kategorie sui generis zu verstehen, sondern bezeichnet ab 1933 die österreichische Spielart eines Diktaturtypus, der ideologisch primär negativ konstituiert war und sich neben einem Führerprinzip vor allem durch eine spezifische, nämlich aktivistische Form der Herrschaftsausübung auszeichnete. Eine ausführlichere inhaltliche Begründung durch den Autor findet sich in einem Sammelband von Carlo Moos, der 2021 erscheinen soll. 
der historiographischen Frühphase in den 1950er-Jahren deutlich, die deshalb das Zentrum der Darstellung bildet. Damals entstand jene Meistererzählung, die bis heute die wissenschaftliche wie auch die populäre Wahrnehmung der österreichischen Zwischenkriegszeit nachhaltig beeinflusst. Niedergelegt wurde diese folgenreiche Interpretation im meistgelesenen Werk zum gegenständlichen Zeitraum, in Heinrich Benedikts mehrfach aufgelegter „Geschichte der Republik Österreich“. Wie zu zeigen sein wird, verfolgte dieses Buch das erklärte Ziel, eine konservative Deutungshoheit über die Erste Republik und jene Diktatur zu erringen, die ihr ein Ende setzte. Auch ein solches Unterfangen kam nicht umhin, zentrale historische Fakten anzuerkennen. Es zeichnete sich daher letztlich vor allem durch eine spezifische interpretative Gewichtung aus, die massive Zerrbilder erzeugte, welche bis in die Gegenwart nachwirken.

Der zweite Abschnitt des Beitrags umreißt Themen und Konjunkturen der Forschung in den darauffolgenden Jahrzehnten bis in die Gegenwart und benennt Desiderate.

\section{Zeitgenössische Darstellungen}

Die Auseinandersetzung um die Deutung der Diktatur setzte nur wenige Tage nach der militärischen Konsolidierung des Dollfuß’schen Staatsstreiches im Februar 1934 ein. Die von den politischen bzw. militärischen Führungspersönlichkeiten der Sozialdemokratie, Otto Bauer und Julius Deutsch, unmittelbar nach ihrer Flucht in die ČSR in Brünn gegründete Exilorganisation, das Auslandsbüro der österreichischen Sozialdemokraten (ALÖS), entfaltete umgehend eine rege publizistische Tätigkeit, die sich in einer ersten Phase vor allem den Februarkämpfen widmete. Das Ziel war die Entwicklung einer neuen Gründungserzählung für die geschlagene Sozialdemokratie, die sich nach dem Ersten Weltkrieg als eine der wenigen Arbeiterparteien Europas nicht gespalten hatte, in der Endphase der Ersten Republik aber faktisch zerbrochen war. Zum Bezugspunkt der neuen Bewegung, die zwar in der Tradition der alten stehen, zugleich aber nicht mit dem Odium von deren Niederlage behaftet sein sollte, wurde der antifaschistische Widerstand auserkoren. ${ }^{3}$ Zugleich sollte außenpolitischer Druck auf das neue Regime in Wien aufgebaut und politische wie

3 Vgl. Ernst Hanisch, Der große Illusionist. Otto Bauer (1881-1938), Wien/Köln/Weimar 2011, 307-309; Florian Wenninger, Ein Gedächtnisort entsteht. Die Konstituierungsphase der sozialdemokratischen Erinnerung an den Austrofaschismus in den Jahren 1934-1938, Dipl.-Arb., Universität Wien 2008. 
finanzielle Unterstützung für die in die Illegalität abgedrängte Opposition initiiert werden. Auch in Exil und Untergrund blieb die Sozialdemokratie dabei ihrer theoretischen Diskussionskultur nach Möglichkeit treu. So erschienen 1934/1935 neben zahlreichen Heroisierungs- und Rechtfertigungsschriften ${ }^{4}$ im Umfeld des ALÖS und der tschechischen Sozialdemokratie auch mehrere Texte, die innerparteilich einen historiographischen Kontrapunkt setzten. ${ }^{5}$ Die Meinungsverschiedenheiten betrafen weniger das Wesen des Dollfuß-Regimes als vielmehr die Politik der sozialdemokratischen Parteiführung in der Endphase der Republik. In der Beurteilung des Charakters der Diktatur war man sich dagegen weitgehend einig, Beschreibungen und Analysen prangerten dessen repressiven Unrechtscharakter an und wiesen insbesondere auf seine negativen materiellen Folgen für die Industriearbeiterschaft hin. ${ }^{6}$

Gleichfalls überaus kritisch waren Darstellungen, die im Umfeld der KPÖ im Exil entstanden, und ebenfalls versuchten, die Februarkämpfe für die eigene Traditionspflege in Dienst zu nehmen. Noch stark geprägt von der „Sozialfaschismus“-These stand dabei der Verrat der sozialdemokratischen Führung an der kämpfenden Basis im Zentrum der Darstellung. ${ }^{7}$

Die Sieger des Februar 1934 unter ihrem nunmehrigen „Führer“ Dollfuß dürften die Heftigkeit der außenpolitischen Reaktionen auf das eigene gewaltsame Vorgehen anfangs unterschätzt haben, ebenso wie die lange nachwirkenden Aversionen in der Arbeiterschaft. Obwohl weder in Großbritannien noch in Frankreich sozialdemokratische Parteien die Regierung stellten, war das öffentliche Aufsehen, das die

4 Unter anderem: Otto Bauer, Der Aufstand der österreichischen Arbeiter. Seine Ursachen und Wirkung, Brünn 1934; Julius Deutsch, Der Bürgerkrieg in Österreich. Eine Darstellung von Mitkämpfern und Augenzeugen, Karlsbad 1934; ders., Putsch oder Revolution? Randbemerkungen über Strategie und Taktik im Bürgerkrieg, Karlsbad 1934.

5 Karl Kautsky, Grenzen der Gewalt. Aussichten und Wirkungen bewaffneter Erhebungen des Proletariats, Karlsbad 1934; Emil Franzel, Der Bürgerkrieg in Österreich. Eine politisch-militärische Betrachtung, Bodenbach 1934 .

6 Vgl. beispielhaft: Commission d'enquěte sur la situation des prisonniers politiques (Hg.), Livre noir de la dictature autrichienne, Brüssel 1934; Pertinax [d. i. Otto Leichter], Österreich 1934. Die Geschichte einer Konterrevolution, Zürich 1935; Karl Heinz, Nacht über Österreich, Karlsbad 1935.

7 Vgl. Bela Kun, The February Struggle in Austria and its Lessons, New York 1934; Jakow Mirow [d. i. Alexander Abromow]/Hans Fischhof [d. i. Hans Goldschmidt] (Hg.), Schutzbundkämpfer erzählen vom Februar 1934, Moskau 1936; Heinz Roscher, Die Februarkämpfe in Floridsdorf, Moskau/ Leningrad 1935; Ilja Ehrenburg, Der Bürgerkrieg in Österreich (Neue Deutsche Blätter 1), Prag 1934; für mehrere zeitgenössische Texte siehe die Anthologie von Erich Hackl/Evelyne Polt-Heinzl (Hg.), Im Kältefieber. Februargeschichten 1934, Wien 2014. 
Vorgänge in Österreich erzeugten, in beiden Ländern beträchtlich. ${ }^{8} \mathrm{Um}$ in diesem Umfeld die Agitation des ALÖS nicht unwidersprochen zu lassen, sah sich das Regime veranlasst, seine Sicht der Dinge darzulegen. Dabei wurde argumentativ weitgehend an gängige Versatzstücke der bürgerlichen Propaganda aus den vorangehenden Jahren angeknüpft, den Sozialdemokraten Putschabsichten unterstellt und das eigene Vorgehen als Präventivschlag gerechtfertigt. Die Darstellung des Staatsstreiches 1933/1934 als Ergebnis italienischen Drucks, dem man nur im Hinblick auf die Gefahren des immer aggressiveren Deutschen Reiches nachgegeben habe, letztlich als Akt des Widerstandes gegen den Nationalsozialismus also, sucht man in den Regimepublikationen bis 1938 vergeblich. Ganz im Gegenteil, wie ein prominenter Regimepropagandist ausdrücklich festhielt:

Allerdings wird behauptet, daß die Regierung Dollfuss sich nur unter dem Drucke der italienischen Regierung entschlossen habe, in Oesterreich den Faszismus einzuführen [...]. Glauben die, die derlei verbreiten, wirklich, daß man sich in Oesterreich nicht mehr der Parlamentswirtschaft seit 1919 erinnert? [...] Der mittelbare Anlaß zur Reform der österreichischen Bundesverfassung war durchaus innerpolitischer Natur, die Richtung aber, in der sie sich bewegte, war in der allgemeinen deutschen Entwicklung gegeben. ${ }^{9}$

Die Deutung des Austrofaschismus als „Abwehrdiktatur“ tauchte erst nach 1938 in Schriften exilierter Regimeträger ${ }^{10}$ und vor allem nach 1945 auf. Zuvor hatte die Selbstdarstellung ganz auf der angesprochenen Linie der ,allgemeinen deutschen Entwicklung" und der Funktion Österreichs als abendländisches Bollwerk gegen "den Marxismus“ gelegen. Der Juliputsch und der Tod von Engelbert Dollfuß 1934 taten der Propagierung der „Deutschen Sendung“ in Kombination mit scharf antimarxistischer Rhetorik keineswegs einen dauerhaften Abbruch. Erweitert wurde die Selbstverortung des Regimes aber um ein zusätzliches starkes Motiv, den Führerkult um den getöteten Kurzzeitdiktator. ${ }^{11}$

8 Wie Kurt Schuschnigg später auch beklagte, vgl. ders., Austrian Requiem, London 1947, 123-124, $136,140-141$.

9 Julius Patzelt, Unser Verhältnis zu Italien und die europäische Krise, Wien 1935, 30.

10 So verklärte ausgerechnet Ernst Rüdiger Starhemberg die Auseinandersetzung mit der Sozialdemokratie zur tragischen Episode und implizierte wenig glaubwürdig, dass für ihn die Abwehr des Nationalsozialismus durchweg Priorität gehabt habe, vgl. Ernst Rüdiger von Starhemberg, Between Hitler and Mussolini. Memoirs of Prince Starhemberg, New York 1942.

11 Für die zum Teil auch durch den Bundespressedienst 1934 verbreiteten Schriften siehe etwa Julius Patzelt, Sozialdemokratie in Österreich, Wien 1934; Josef Kuhnert, Die Mär vom Galgenland, Wien 1934; Josef Schneider/Carl Zell, Der Fall der Roten Festung, Wien 1934; den Grundstein für den Dollfuß-Kult legte maßgeblich der führende Ideologe des Ständestaates, Johannes Messner, vgl. 
Der Streit um die Jahre 1933-1938 setzte sich auch nach der Inkorporierung Österreichs in das Deutsche Reich im März 1938 fort. Während im Einflussbereich des NS-Regimes stark autobiographisch gefärbte Darstellungen des NS-Untergrundes 1933-1938 gegenüber systematischen Ansätzen überwogen, ${ }^{12}$ verfassten mehrere ehemalige Regimeträger, die vor den NS-Machthabern ins Ausland geflohen waren, gleich ihren exilierten sozialdemokratischen Gegenspielern Darstellungen und Analysen, die zum Teil freilich erst nach dem Krieg erschienen. ${ }^{13}$ Ganz abseits dieser Auseinandersetzungen entstanden speziell im englischsprachigen Raum bereits vor 1945 mehrere wissenschaftliche Arbeiten zu unterschiedlichen Aspekten der Diktatur, die im Weiteren aber weder in der angelsächsischen noch in der deutschsprachigen Historiographie ausführlicher rezipiert wurden. ${ }^{14}$

\section{Geschichte als Politikum nach 1945}

Unmittelbar mit der Wiederherstellung der Republik Österreich nach dem Ende des Zweiten Weltkrieges in Europa formierte sich auch erneut die Parteienlandschaft, wobei trotz formaler Distanzierung der Österreichischen Volkspartei von den Christlichsozialen wesentliche organisatorische und personelle Kontinuitäten gewahrt blieben: Nicht zufällig waren alle ÖVP-Bundeskanzler bis 1966 hochrangige Funktionäre des Austrofaschismus gewesen. ${ }^{15}$ Die Kooperation der beiden

ders., Dollfuß, Innsbruck 1935; zur stark mythologisierten Biographik Engelbert Dollfuß' vgl. Lucile Dreidemy, Der Dollfuß-Mythos. Eine Biographie des Posthumen, Wien/Köln/Weimar 2014.

12 Hertha Csepek-Schulz, Kämpfende Frau. Erlebnisberichte aus der Ostmark 1932-1938, Wien/ Leipzig 1940; Hans Bleyer-Härtl, Ringen um Reich und Recht. Zwei Jahrzehnte politischer Anwalt in Österreich, Berlin 1939; Walther Pembaur, Im letzten Kampf um Österreich, Wien/Leipzig 1939; Anton Rintelen, Erinnerungen an Österreichs Weg. Versailles - Berchtesgaden - Großdeutschland, München 1941; Hans [von] Frisch, Die Gewaltherrschaft in Österreich 1933-1938, Leipzig/Wien 1938; Frithjof Melzer (Hg.), Weltgeschichte miterlebt! 7 Tage Österreich, Berlin 1938.

13 Vgl. u. a. Robert Ingrim [d. i. Franz Robert Klein], Der Griff nach Österreich, Zürich 1938; Guido Zernatto, Die Wahrheit über Österreich, New York 1939; Martin Fuchs, Showdown in Vienna. The Death of Austria, New York 1939; Georg Wieser [d. i. Otto Leichter], Ein Staat stirbt. Österreich 1934-38, Paris 1938; Jakob Fried, Nationalsozialismus und Katholische Kirche in Österreich, Wien 1947; Julius Braunthal, The Tragedy of Austria, Suffolk 1948.

14 Vgl. Florian Wenninger, Austrian Missions - Das Problem der politischen Äquidistanz der Forschung am Beispiel Austrofaschismus, in: Ilse Reiter-Zatloukal/Christiane Rothländer/Pia Schölnberger (Hg.), Österreich 1933-1938. Interdisziplinäre Bestandsaufnahmen und Perspektiven, Wien/Köln/Weimar 2012, 257-272.

15 Vgl. Wolfgang C. Müller, Die Österreichische Volkspartei, in: Herbert Dachs/Peter Gerlich/Herbert Gottweis/Franz Horner/Helmut Kramer/Volkmar Lauber/Wolfgang C. Müller/Emmerich Tá- 
Großparteien wurde einerseits durch politische Kursänderungen begünstigt, andererseits durch die Etablierung einer Konkordanzdemokratie, die sich abseits von Wahlzeiten durch klar abgezirkelte Einflusssphären und niedrige Konfliktintensität auszeichnete. Wahlen selbst waren in erster Linie nicht Überzeugungs, sondern Mobilisierungskämpfe: Die Volatilität zwischen den politischen Blöcken war äußerst gering, über das Wahlergebnis entschied daher vor allem, wie weit es gelang, die eigene Klientel an die Urnen zu bringen. Bereits der Nationalratswahlkampf 1945 zeigte, dass die Bezugnahme auf die Jahre 1933 bis 1938 insbesondere auf Seiten der Sozialdemokratie als wesentliches Mobilisierungsinstrument betrachtet wurde. ${ }^{16}$ Die Volkspartei reagierte darauf anfangs mit dem Versuch, das Thema durch einen historischen Kompromiss aus der Welt zu schaffen. Bei einer Großveranstaltung im Wiener Konzerthaus, die auch im Radio übertragen wurde, erklärte ÖVP-Obmann und Bundeskanzler Leopold Figl:

Schauen wir nicht mehr nach rückwärts, sondern nur mehr nach vorwärts. Machen wir vor allem gemeinsam Schluß mit den Schlagworten vom Austromarxismus und Austrofaschismus [...]. Wir haben uns in diesen schweren Tagen des ersten Wiederaufbaues gemeinsam zusammengesetzt, um unser neues Haus zu bauen. Der Sozialist und der christliche Bauer, der Kommunist und der Heimwehrmann, der Schutzbündler und der Freiheitsbündler, ja, sagen wir es nur ganz offen und ehrlich, der Austromarxist und der Austrofaschist vom Jahre $1934 \cdot{ }^{17}$

Die erhoffe Resonanz blieb jedoch aus: Die SPÖ war an einem Kompromiss nicht interessiert und übernahm weitgehend die Erzählung des sozialdemokratischen Untergrundes und Exils von vor 1938. Die Folge war eine Verhärtung der geschichtspolitischen Fronten: Schon 1947 revidierte die ÖVP ihr durch Figl vorgebrachtes An-

los (Hg.), Handbuch des Politischen Systems Österreichs, Wien 1991, 227-246, 227-228.

16 Der entsprechende Befund von Norbert Hölzl, bezogen auf die Nationalratswahlkämpfe der Nachkriegszeit, bestätigt sich abgeschwächt auch in den Landtagswahlkämpfen dieser Zeit, vgl. ders., Propagandaschlachten, Die österreichischen Wahlkämpfe 1945-1971, Wien 1974, 17-19; vgl. die Beiträge in Herbert Dachs (Hg.), Zwischen Wettbewerb und Konsens. Landtagswahlkämpfe in Österreichs Bundesländern 1945-1970, Wien/Köln/Weimar 2006; siehe auch Isabella M. Poier, Landtagswahlkämpfe in der Steiermark 1945 bis 1953: eine historisch-politikwissenschaftliche Analyse anhand von Wahlkampfplakaten, phil. Diss., Universität Graz 2012; Karl Anderwald, Landtagswahlkämpfe in Kärnten 1945-1975, phil. Diss., Universität Salzburg 1992; Bernhard Glas, Landtagswahlkämpfe in Oberösterreich 1945-1973, phil. Diss., Universität Salzburg 1996.

17 Redemanuskript Leopold Figls im Programmheft „12. Februar 1934 - Stunde der Besinnung“, Wiener Konzerthaus, 12.02.1946, 6 . 
gebot eines Schlussstrichs und schwenkte auf das bereits angesprochene Paradigma der „Abwehrdiktatur“ ein:

Wenn von den Linksparteien seit Kriegsende immer wieder die Behauptung aufgestellt wird, der autoritäre Kurs in den Jahren 1933 bis 1938 hätte dem Nationalsozialismus in Österreich Vorspanndienste geleistet, [...] so ist dies eine große Ungerechtigkeit [...]. Eine solche Behauptung ist aber auch eine grobe Geschichtsfälschung, denn der autoritäre Kurs wurde nicht - wie von der Linken behauptet wird - eingeschlagen, um irgendeinen Teil der österreichischen Bevölkerung zu unterdrücken, sondern nur deshalb, weil der Bestand des Vaterlandes von außen her bedroht war. Es galt damals der braunen Gefahr Herr zu werden, und dies war mit normalen parlamentarischen Mitteln einfach nicht möglich. ${ }^{18}$

Erstmals ausführlicher begründet wurde diese Darstellung zwei Jahre später ${ }^{19}$ und noch in den 1980er- und 1990er-Jahren mit Publikationen und Ausstellungen im Umfeld der ÖVP verbreitet. ${ }^{20}$

Bis 1948 standen sich die jeweiligen Geschichtsinterpretationen in Österreich vornehmlich in Form dünner Broschüren und von Artikeln in den theoretischen Organen der Parteien, der „Zukunft", den „Monatsheften“ und „Weg und Ziel“, bzw. den Parteizeitungen gegenüber. ${ }^{21}$ Die Ausnahme von dieser Regel war der journalistische Bericht eines Korrespondenten des britischen „Daily Telegraph“, G. E. R. Gedye, der bereits 1939 auf Englisch publiziert worden war. ${ }^{22}$

18 Alfred Kasamas, Wir wollen Österreich. Die Grundsätze und Ziele der Österreichischen Volkspartei, Wien 1947, 32-33.

19 Hans Huebmer, Österreich 1933-1938. Der Abwehrkampf eines Volkes, Wien 1949.

20 Vgl. Dreidemy, Dollfuß-Mythos, 271-273. Als prominenter Apologet des Regimes trat in diesem Zusammenhang wiederholt der in München ansässige Politikwissenschafter Gottfried-Karl Kindermann auf den Plan, vgl. ders., Hitlers Niederlage in Österreich: bewaffneter NS-Putsch, Kanzlermord und Österreichs Abwehrsieg von 1934, Hamburg 1984.

21 Unter anderem SPÖ (Hg.), Die Wahrheit über den Februar 1934, Wien [1945]; Heinrich Schneidmadl, Grüner Weg in braune Hölle. Eine konfiszierte Landtagsrede: die letzte Warnung vor der Katastrophe, Wien 1946; Julius Deutsch, Alexander Eifler. Ein Soldat der Freiheit, Wien 1947; Ernst Fischer, der 12. Februar 1934, in: Weg und Ziel 4 (1946) 2, 65-83; Die ÖVP und der 12. Februar. Ein kurzer Tatsachenbericht des Hauptreferats für Presse und Publizistik der ÖVP, Wien 1946.

22 Vgl. George Eric Rowe Gedye, Betrayal in Central Europe. Austria and Czechoslovakia: the fallen bastions, New York 1939. Zu Gedyes Rolle im Zweiten Weltkrieg siehe Peter Pirker, Subversion deutscher Herrschaft. Der britische Kriegsgeheimdienst SOE und Österreich, Göttingen 2012. Zu Gedye als Zeitzeuge der Vorgänge in Österreich siehe Peter Pirker, Paradoxia. Wie G. E. R. Gedye Österreich den Anglo-Amerikanern erklärte, in: Joshua Parker/Ralph J. Poole (Hg.), Austria and America. Cross-cultural encounters 1865-1933, Wien/Münster 2014, 133-170. 


\section{Charles A. Gulicks „Austria from Habsburg to Hitler“}

Zum geschichtswissenschaftlichen Aufreger wurde Gedyes Arbeit wohl auch aufgrund ihres journalistischen Charakters nicht. Dieses Privileg blieb dem US-amerikanischen Nationalökonomen und Historiker Charles A. Gulick vorbehalten, dessen 1.900-seitiges Werk über die österreichische Zwischenkriegszeit nach fast 13-jähriger Arbeit 1948 erschien. ${ }^{23}$ Gulick war ursprünglich aufgrund seines Interesses an den im Aufbau befindlichen europäischen Sozialsystemen erstmals 1930 auch in Österreich gewesen. Die dabei gesammelten Eindrücke veranlassten ihn, seine künftige Forschung auf die Alpenrepublik zu konzentrieren. Er verbrachte 1936/1937 einen längeren Forschungsaufenthalt in Wien und knüpfte in dieser Zeit ein breites Netz an Kontakten sowohl zu Repräsentanten des austrofaschistischen Regimes als auch des sozialdemokratischen Untergrundes. Mithilfe eines jungen heimischen Nationalökonomen, Alexander Gerschenkron, sammelte er umfangreiches Material. Wenige Monate nachdem Gulick im September 1937 in die USA zurückgekehrt war, überschlugen sich in Österreich im März 1938 die Ereignisse. Gulick und seine Frau Esther gründeten in Berkeley gemeinsam mit Geistlichen ein Hilfskomitee, das besonders bedrohte Menschen dabei unterstützte, in die USA zu emigrieren. Als Ergebnis dieser Bemühungen gelangten neben Gerschenkron mehrere sozialdemokratische Funktionäre wie der Redakteur Ernst Winkler oder der ehemalige Nationalrat, Vorsitzende der Sozialistischen Arbeiterjugend und leitender Schutzbundfunktionär Karl Heinz nach Berkeley, wo Gulick sie als Forschungsassistenten in seinem Österreich-Projekt beschäftigte. ${ }^{24}$ Auch mehrere andere, eher

23 Charles A. Gulick, Austria from Habsburg to Hitler, 2 Bde., Berkeley 1948.

24 Die durch Quellen nicht näher belegte und von Historikern dennoch aufgegriffene Behauptung von Gerschenkrons Nachkommen, der wahre Verfasser der beiden Gulick-Bände sei Gerschenkron gewesen, erscheint schon aufgrund der zeitlichen Abfolge wenig wahrscheinlich: Gerschenkron war in Österreich ab Anfang 1937 für etwa ein Jahr mit der Sammlung von Material für Gulick beauftragt gewesen, hatte nach seiner Emigration in die USA aber zunächst nicht für Gulick, sondern für Howard S. Ellis und Jack Condliffe gearbeitet und war erst Ende 1939 in Gulicks Team gewechselt, wo er bis zu seinem abermaligen Wechsel an die Federal Reserve nach Washington 1944 blieb. Er war damit nur während der Hälfte des Durchführungszeitraumes in das Projekt involviert gewesen. Dass er gleichwohl eine wesentliche Rolle spielte, geht aus der Würdigung seines Beitrages in Gulicks Einleitung deutlich hervor. Vgl. die entsprechenden Angaben von Gerschenkrons Enkel, Nicholas Dawidoff, The Fly Swatter. Portrait of an Exceptional Character, New York 2002, 115-116; Albert Müller, Uses of Adversity. Considering Structures, Networks, and Coincidence in the Context of Alexander Gerschenkron's Emigrations and Career, in: Giuliana Gemelli (Hg.), The „Unacceptables". American Foundations and Refugee Scholars between the Two Wars and after, Bruxelles 2000, 299-306, 303; Marcel van der Linden, Gerschenkron's Secret: A Research Note, in: Critique 40 (2012) 4, 553-562, 560; Gulick, Austria, Bd. 1, XVI. 
liberale denn sozialdemokratische Exilanten unterstützten die Genese des Buches, vor allem die Verfassungsrechtler Hans Kelsen und Bruno Schönfeld sowie der vormalige Chefredakteur des „Österreichischen Volkswirt“, Walther Federn.

Das zweibändige Werk, das aus dem Projekt schließlich hervorging, fußte auf einer enormen bis heute unübertroffenen Fülle an Quellen, wie auch konservative Kritiker anerkennend einräumten. ${ }^{25}$ Die Arbeit zeichnete sich zudem durch eine innovative Methodik aus, die neben klassisch historiographischen Verfahren auch Zeitzeugeninterviews und teilnehmende Beobachtungen umfasste. Inhaltlich fokussierte Gulick auf zwei Aspekte der Ersten Republik: auf den „Gemeindesozialismus" des Roten Wien und auf die antirepublikanischen Umtriebe der politischen Rechten, die schließlich in Dollfuß' Staatsstreich und der anschließenden Diktatur mündeten. Im Ergebnis bestätigte Gulick die sozialdemokratische Überlieferung weitgehend, wenn auch keineswegs vollständig. ${ }^{26} \mathrm{Er}$ argumentierte entschieden gegen Interpretationen, denen zufolge die Errichtung der Diktatur das Resultat einer Verkettung unglücklicher Umstände gewesen sei. Auch wies er die später weit verbreitete Interpretation zurück, das Regime sei primär durch ausländischen Druck Italiens und dessen innerösterreichischer Vollstreckungsgehilfen, der Heimwehren, durchgesetzt worden. Vielmehr verortete er die Verantwortung für die Beseitigung der Demokratie vor allem in der Führung der Christlichsozialen Partei. Nicht zuletzt zerpflückte Gulick die Vorstellung vom Austrofaschismus als einer Abwehrdiktatur gegen den Nationalsozialismus. Er widmete sich ausführlich dysfunktionalen Seiten des Regimes, der verbreiteten Korruption und der sturen außenpolitischen Anlehnung an den italienischen Faschismus. ${ }^{27}$

25 Wie der ÖVP-nahe Verleger Wilhelm Cornides an den ihm bekannten Diplomaten Stephan Verosta schrieb, sei Gulicks Materialsammlung trotz der parteilichen Einseitigkeit des Gesamtwerkes „doch unbestreitbar wertvoll“, Wilhelm Cornides an Stephan Verosta, 12.07.1950. Wienbibliothek im Rathaus (WBR), Handschriftensammlung (HS), Archiv Verlag für Geschichte und Politik (AVGP), ZPH 1765, Box 1. Fragmente des ursprünglichen Materialkorpus von Gulick finden sich in der Bancroft Library in Berkeley.

26 Inwiefern das Werk, wie Peter Goller meint, „in wesentlichen Zügen den Anforderungen einer ,westorientierten', die linkssozialistischen Traditionen in das Abseits drängenden SPÖ“ gedient haben soll, erschließt sich allenfalls eingeschränkt, sieht man von Gulicks durchaus kritischen Anmerkungen zur Politik der KPÖ ab, vgl. Peter Goller, „Während der Schlacht ist es schwer, Kriegsgeschichte zu schreiben .... Geschichtsschreibung der österreichischen Arbeiterbewegung vor 1934, Wien 2009, 10.

$27 \mathrm{Zu}$ Gulick und seinen Forschungen über Österreich siehe Florian Wenninger, „The Duty to Express Value Judgments“. Charles Adams Gulick, Interwar Austria and the Question of Political Neutrality as a Scholarly Virtue, in: Günter Bischof/David M. Wineroither (Hg.), Democracy in Austria (Contemporary Austrian Studies 28), Innsbruck 2019, 241-270. 
Allgemein war die Arbeit vor allem durch eine tiefe Antipathie gegenüber dem Austrofaschismus gekennzeichnet, aus der Gulick, den das FBI während des Krieges als „liberal and mild pink“ charakterisiert hatte, ${ }^{28}$ auch gar keinen Hehl machte:

[...] I have no patience with the intellectual contortionist who apparently thinks he is "unscientific“ unless he tries to get a part of each foot on each side of every question that is faintly controversial. [...] To some readers the conclusions and judgements may, at times, seem to read more like a bill of indictment. As a matter of fact, they sum up to a bill of indictment. Moreover, no apology is required or offered for indicting Fascists [...].29

Die Übersetzung von Gulicks Arbeit wurde unter der Ägide des SPÖ-Parteihistorikers Jacques Hannak von einer Gruppe ehemaliger ExilantInnen innerhalb kurzer Zeit bewerkstelligt, wofür man offensichtlich auch bereit war, eine Fülle von Übersetzungsfehlern in Kauf zu nehmen. ${ }^{30}$ Der Coup gelang dennoch, das Buch wurde zum veritablen Aufreger. Während Konservative empört Abschied „von Professor Gulick als Wissenschafter“ nahmen ${ }^{31}$ und Bundeskanzler Figl sich weigerte, ihn zu empfangen, hofierte die SPÖ Gulick ${ }^{32}$ und war intensiv bestrebt, für eine größtmögliche Verbreitung seines Werkes zu sorgen. ${ }^{33}$

28 Report of FBI-Agent David C. Spencer, 02.12.1944, zit. n. Dokumentationsarchiv des Österreichischen Widerstandes (Hg.), Österreicher im Exil. USA 1938-1945, Bd. 2, Wien 1995, 624. Eine eigene FBI-Akte existiert laut Beantwortung einer entsprechenden Anfrage beim FBI offenbar nicht, vgl. Freedom of Information/Privacy Act (FOIPA) Request No. 1363152-00o on Gulick, Charles Adams, 14.12.2016.

29 Gulick, Austria, Bd. 1, 11.

30 Wie Gulick später an Bruno Kreisky schrieb: „the 1950 translation was a total disaster [...] I am convinced that in less than 2.400 pages there are 5.000 errors and that at least 100 of them exactly reverse the meaning of the English", Charles A. Gulick an Bruno Kreisky, 15.07.1975, Kreisky Archiv/Gulick, Bruno Kreisky, IX.3 Korrespondenzen, Box 2.

31 Österreich von Habsburg zu Hitler?, Die Furche, 05.08.1950, zit. n. Kurt Skalnik, Republikanische Mitte. Überlegungen und Überzeugungen, Wien/Zürich 1966, 163-168, 167.

32 Anlässlich von dessen Österreich-Besuch im Frühling 1952 bereitete die SPÖ Gulick einen prominenten Empfang, bei dem der Wiener Bürgermeister Franz Jonas und Vizekanzler Adolf Schärf die Festreden hielten, vgl. Gertrude Enderle-Burcel (Hg.), Adolf Schärf: Tagebuchnotizen des Jahres 1952, Innsbruck/Wien 2010, 115-116, 118-119.

33 So initiierte der ÖGB Ankaufaktionen durch Werksbüchereien, vgl. Entwurf eines Schreibens von Karl Cornides an die Industriellenvereinigung, 19.12.1950. WBR, HS, AVGP, ZPH 1765, Box 1; Karl Cornides an Georg Zimmer-Lehmann, 15.06.1951. WBR, HS, AVGP, ZPH 1765, Box 1. 


\section{Der „Anti-Gulick“:34 Die „Geschichte der Republik Österreich“}

Um den „außerordentlichen Gefahren für die gesamte österreichische Politik [durch] die Vernachlässigung der vaterländischen Geschichtsschreibung", die das „Pamphlet von Gulick weiten Kreisen“ vor Augen geführt habe, ${ }^{35}$ etwas entgegenzuhalten und zugleich einer „,bewusst österreichischen Politik ein festes Fundament zu geben“, ${ }^{36}$ kurz, um „Geschichte [zu] machen, indem wir Geschichte schreiben“",37 initiierte der Verlag für Geschichte und Politik 1950 eine publizistische Antwort auf „Austria from Habsburg to Hitler“. Dabei standen die katholisch-konservativen Verleger Wilhelm Cornides und sein Sohn Karl ${ }^{38}$ sowie der Diplomat und Jurist Stephan Verosta, der sie in ihrem Anliegen unterstützte, von Beginn an vor zwei Problemen: den Eindruck von Parteilichkeit zu vermeiden und Gulicks Mammutwerk zumindest in der Außenwahrnehmung auf Augenhöhe zu begegnen.

Die politische Nähe des Projektes zur Volkspartei war von Beginn an nicht nur inhaltlich, sondern auch personell klar: Neben dem Figl-Intimus Verosta ${ }^{39}$ gehörten zu den tatkräftigsten Förderern des Projektes neben Unterrichtsminister Felix Hurdes und dessen Pressereferent Raimund Poukar auch der Industrielle, ÖVP-Nationalratsabgeordnete und spätere Minister Josef Böck-Greissau sowie die VP-nahen Banker Georg Zimmer-Lehmann (CA) und Friedrich Maurig (Schoeller Bank). Sowohl Figl als auch Raab hatten dem Vorhaben außerdem frühzeitig umfangreiche

34 Die Bezeichnung „Anti-Gulick“ findet sich als Projekttitel in: Memo von Karl Cornides, 24.11.1954. WBR, HS, AVGP, ZPH 1765, Box 1.

35 „Bericht über die bisherigen Bemühungen zur Schaffung einer Geschichte der ersten Republik“ des Verlages für Geschichte und Politik an Unterrichtsminister Felix Hurdes, 09.12.1950. WBR, HS, AVGP, ZPH 1765, Box 1.

36 Ebd.

37 „Vorschläge für eine Einleitung“ als Beilage eines Schreibens Karl Cornides an Heinrich Benedikt, 30.07.1954. WBR, HS, AVGP, ZPH 1765, Box 1.

38 Wilhelm [von] Cornides (1886-1964), nicht identisch mit dem gleichnamigen 1920 geborenen Verfasser des Cornides-Berichtes über die Massenmorde in Belzec (vgl. Dokumentation, Zur „Umsiedlung“ der Juden im Generalgouvernement, in: Vierteljahreshefte für Zeitgeschichte 7 (1959) 3 , 333-336), heiratete in die Verlegerdynastie Oldenbourg ein und fungierte zwischen 1912 und 1941 als Gesellschafter, später als Verwaltungsrat des Oldenbourg-Verlages. 1947 gründete Wilhelm gemeinsam mit seinem Sohn Karl (1911-1989, bis dahin ebenfalls in der Verlagsbranche tätig und 1945-1947 Chefredakteur der „Tiroler Nachrichten“) den Verlag für Geschichte und Politik als Tochterunternehmen des Oldenbourg-Verlages in Wien.

39 Vgl. u. a. Heribert Franz Köck, The Impact of Francisco de Vitoria's International Legal Doctrine upon the „Vienna School of International Law and Legal Philosophy“ of the twentieth Century, in: José María Beneyto/Carmen Román Vaca (Hg.), New Perspectives on Francisco de Vitoria. Does International Law lie at the heart of the origin of the modern world?, Madrid 2014, O. S. (Kap. 4). 
finanzielle Unterstützung zugesichert. ${ }^{\circ 0} \mathrm{Zu}$ guter Letzt wurde seitens des Verlages auch die ÖVP direkt um Unterstützung ersucht. ${ }^{41}$ Umgekehrt sollte das zu erarbeitende Buch insbesondere die Arbeiterschaft erreichen, die „bisher einseitig im Sinne der SPÖ unterrichtet und verhetzt" worden sei. ${ }^{42}$

Zugleich waren sich die Initiatoren einig, dass historiographische Hegemoniearbeit im beabsichtigten Sinne nur erfolgreich sein könne, „wenn wir peinlich den Eindruck einer parteipolitischen Bindung vermeiden“. ${ }^{43}$ Eine Mitwirkung des ÖVPParteihistorikers Wilhelm Böhm, der sich zunächst Anfang 1951 über Poukar angetragen hatte, ${ }^{44}$ wurde daher vor allem im Hinblick auf dessen politisches Etikett dankend abgelehnt, allenfalls ,irgendwo unter ferner liefen jedoch könnte er bestimmt nützlich sein“. 45

Aus Zeit- und Kostengründen stand von Beginn an außer Frage, dass es kaum möglich sein würde, der wissenschaftlichen Abhandlung Gulicks ein Werk entgegenzusetzen, das sich mit diesem in puncto Quellenfundierung würde messen können..$^{46}$ Obwohl das kreierte Buch daher von Beginn an explizit „nicht für den Fachmann“ konzipiert war, ${ }^{47}$ aber dennoch ,sowohl den allgemein historisch interessierten Laien, als auch Lehrer und Studenten“ erreichen und „darüber hinaus im In- und Ausland die Kontinuität der österreichischen Politik und ihre Tradition herausstell[en]" wollte, ${ }^{48}$ musste es doch zumindest durch Fachleute verfasst sein. Allerdings bildete „das Fehlen überragender Persönlichkeiten auf dem Gebiet der österreichischen Geschichtsforschung, die auch politisch als für diese schwierige Aufgabe geeignet angesehen werden konnten “49 eine gewisse Herausforderung dar. Man entschied sich schließlich, zwei dezidiert bürgerliche Historiker mit der Leitung des Projektes zu betrauen, nämlich Heinrich Benedikt und Alphons Lhotsky. Der

40 Karl Cornides an Wilhelm Cornides, 05.12.1950. WBR, HS, AVGP, ZPH 1765, Box 1; Karl Cornides an Georg Zimmer-Lehmann, 15.06.1951. WBR, HS, AVGP, ZPH 1765, Box 1.

41 „Bericht über die bisherigen Bemühungen zur Schaffung einer Geschichte der ersten Republik“ des Verlages für Geschichte und Politik an Unterrichtsminister Felix Hurdes, 09.12.1950. WBR, HS, AVGP, ZPH 1765, Box 1.

Karl Cornides an die Österreichische Industriellenvereinigung, 01.02.1952. WBR, HS, AVGP, ZPH 1765, Box 1.

43 Karl Cornides an Wilhelm Böhm, 12.10.1951. WBR, HS, AVGP, ZPH 1765, Box 1.

44 Wilhelm Böhm an Karl Cornides, 22.09.1951. WBR, HS, AVGP, ZPH 1765, Box 1.

45 Raimund Poukar an Karl Cornides, 08.01.1951. WBR, HS, AVGP, ZPH 1765, Box 1.

46 Vgl. Karl Cornides an Stephan Verosta [erstes Halbjahr 1950]. WBR, HS, AVGP, ZPH 1765, Box 1.

47 Wilhelm Cornides an Karl Cornides, 26.12.1950. WBR, HS, AVGP, ZPH 1765, Box 1.

48 „Bericht über die bisherigen Bemühungen zur Schaffung einer Geschichte der ersten Republik“ des Verlages für Geschichte und Politik an Unterrichtsminister Felix Hurdes, 09.12.1950. WBR, HS, AVGP, ZPH 1765, Box 1.

49 Ebd. 
Neuzeithistoriker Benedikt, der zwar getauft war, nach nationalsozialistischen Kategorien aber als Jude galt, hatte den Krieg im englischen Exil überlebt. Mit der Unterstützung des Historikers und vormaligen Leiters der Arbeitsgemeinschaft für das Auslandsdeutschtum der Vaterländischen Front, des Geistlichen Hugo Hantsch, ${ }^{50}$ hatte er sich 1947 in Wien im Fach Geschichte habilitiert und arbeitete vor seiner Ernennung zum Extraordinarius 1950 unter anderem für die im Einflussbereich der ÖVP befindliche „Wiener Tageszeitung “. ${ }^{11}$

Wie Benedikt entstammte auch der Mediävist Alphons Lhotsky einem konservativen Umfeld und hatte den damaligen Machthabern jedenfalls als verlässlich genug gegolten, um nach den Februarkämpfen 1934 gemeinsam mit anderen mit der Säuberung der Wiener Arbeiterbibliotheken von missliebiger Literatur betraut zu werden. ${ }^{52}$ Unter dem NS-Regime hatte Lhotsky als Presse- und Propagandareferent des Kunsthistorischen Museums gewirkt, nach 1945 wurde er mit seinen Arbeiten zur österreichischen Staatsbildung im Mittelalter zu einem historischen Mitentwickler der österreichischen Nation. ${ }^{53}$

Während Benedikt von Stephan Verosta anfangs verdächtigt wurde, „dass er viel Geld verdienen, nicht zu viel arbeiten und überall dreinreden wollen wird“',54 erwies er sich im Sinne des Projektes rasch als die glücklichere Personalie als Lhotsky, der in den ersten Besprechungen auf inhaltliche Vorgaben mit „fast krankhafter Empfindlichkeit" reagierte und bei Benedikt und dem mittlerweile ebenfalls hinzugestoBenen Adam Wandruszka die Befürchtung weckte, eine ersprießliche Kooperation werde „wegen dessen grosser [...] Gewissenhaftigkeit schwierig werden“. ${ }^{55}$ Diese Einschätzung sollte sich als richtig erweisen, Lhotsky kehrte dem Projekt schließlich vorzeitig den Rücken. ${ }^{56}$ In weiterer Folge übernahm Benedikt die Leitung der

50 Vgl. Thomas Winkelbauer, Das Fach Geschichte an der Universität Wien. Von den Anfängen um 1500 bis etwa 1975, Göttingen 2018, 246. Hugo Hantsch hat auch selbst eine zweibändige Geschichte Österreichs vorgelegt, die inhaltlich jedoch mit der Proklamation der Ersten Republik und den Friedensverhandlungen nach dem Ersten Weltkrieg endete, vgl. ders., Die Geschichte Österreichs, 2 Bde., Graz/Wien 1947.

51 Zur Person Benedikt siehe Fritz Fellner/Doris A. Corradini, Österreichische Geschichtswissenschaft im 20. Jahrhundert, Wien/Köln/Weimar 2006, 54.

52 Zur Zensur der Wiener Arbeiterbüchereien und Lhotskys Beteiligung daran siehe Alfred Pfoser, Literatur und Austromarxismus, Wien 1980, 213-239.

53 Vgl. Winkelbauer, Geschichte, 258.

54 Karl Cornides an Wilhelm Cornides, 09.12.1950. WBR, HS, AVGP, ZPH 1765, Box 1.

55 Karl Cornides an Wilhelm Cornides, 30.12.1950. WBR, HS, AVGP, ZPH 1765, Box 1.

56 Der genaue Zeitpunkt von Lhotskys Ausscheiden ist aus den vorhandenen Unterlagen nicht zu rekonstruieren. Ab Anfang 1953 wird in den Korrespondenzen des Verlages jedoch nur noch Benedikt als Herausgeber genannt. 
Gruppe alleine. Im Autorenteam verblieben außerdem der Nationalökonom Friedrich Thalmann, der anstelle des ursprünglich vorgesehenen, politisch aber offenbar nicht ausreichend vertrauenswürdigen Kurt W. Rothschild den wirtschaftsgeschichtlichen Teil des Werkes abdecken sollte, der Archivar im Staatsarchiv, Walter Goldinger, der durch seinen Beruf Zugang zu den zu diesem Zeitpunkt an und für sich noch gesperrten Aktenbeständen hatte und dem der Ruf vorauseilte, „ein wahres Arbeitstier" $\mathrm{zu}$ sein, ${ }^{57}$ sowie der bereits erwähnte Historiker und Redakteur der Zeitungen „Die Presse“ und „Die Furche“, Adam Wandruszka, der als vormaliger SA-Obertruppführer als das völkische Element der Gruppe gelten durfte.

Es handelte sich zwar grundsätzlich um ein honoriertes Auftragswerk, dennoch brachte auch die endgültige Konstellation die Notwendigkeit mit sich, den Autoren gewisse Spielräume zu lassen, wie Karl Cornides seinem Vater zu erklären versuchte: „Ich habe den Eindruck, dass Du Dir bezüglich der Möglichkeit, die Autoren an ein Leitseil zu nehmen, ein falsches Bild machst. Die Möglichkeit besteht in ganz bescheidenem Ausmass [nur] bei Benedikt und Wandruszka“, Thalmann müsse man hingegen „wie ein rohes Ei“ behandeln. ${ }^{8}$ Die offenkundige Sensibilität mancher Autoren

erlegt uns [...] eine ausserordentliche Vorsicht bei dem Bestreben, die Sache entsprechend den eigenen Wünschen zu lenken, auf. Ich sehe hier keinen anderen Weg als den bereits von mir beschrittenen, der vorsichtigen Beeinflussung in Einzelbesprechungen und des geschickten Ausspielens der Ergebnisse dieser Einzelbesprechungen gegenüber den anderen, indem ich das, was ich durchzusetzen hoffe, als den Gedanken eines Mitarbeiters darstelle. Es muss der Anschein gewahrt bleiben, dass die Initiative bei den Herausgebern und Mitarbeitern liegt. ${ }^{59}$

\section{Stränge einer Meistererzählung}

Aber inwiefern wollten die Initiatoren des Projektes überhaupt Einfluss nehmen, was waren die grundlegenden argumentativen Linien, die das Buch verbreiten sollte? Gegenüber der Industriellenvereinigung, die er - schlussendlich erfolgreich als Geldgeber gewinnen wollte, legte Karl Cornides dar, das geplante Buch solle bei aller Sachlichkeit ein „patriotisches Werk sein, das nicht nur für die österreichische

57 Karl Cornides an Wilhelm Cornides, 05.12.1950. WBR, HS, AVGP, ZPH 1765, Box 1.

58 Karl an Wilhelm Cornides, 30.12.1950. WBR, HS, AVGP, ZPH 1765, Box 1.

59 Karl an Wilhelm Cornides, 30.12.1950. WBR, HS, AVGP, ZPH 1765, Box 1. 
Geschichtsforschung und staatsbürgerliche Erziehung, sondern auch für die eigentliche Politik von größtem Wert" sein werde. ${ }^{60}$ Die Darstellung solle letztlich darauf hinauslaufen, „zu zeigen, wie sich im Gegensatz zum Anschlussgedanken allmählich der Glaube an eine besondere staatliche und kulturelle Mission Österreichs und an seine wirtschaftliche Lebensfähigkeit festigt". ${ }^{61}$

Die Festigung eines österreichischen Nationalbewusstseins sollte demnach als historischer Lernprozess interpretiert werden. Im Zentrum des Buches müsse daher „vor allem [...] das Problem des ,Staats wider Willen“ stehen, wie die Initiatoren bereits in der Konzeptionsphase erklärten. ${ }^{62}$ Damit war das erste zentrale Narrativ der konservativen Historiographie formuliert, das durch den "Anti-Gulick“ erhebliche Breitenwirkung erlangte. Das Schlagwort vom „Staat, den keiner wollte“, war freilich keine Erfindung der Benedikt-Gruppe gewesen, sondern knüpfte an eine so oder so ähnlich bereits vor 1938 häufig gebrauchte Formel an, die der nationalsozialistische Historiker Reinhold Lorenz bereits 1940 als Titel eines Buches über die österreichische Zwischenkriegszeit verwendet hatte. ${ }^{63}$ Sie wertete die Erste Republik als solche $a b$, indem diese als gleichsam aufgezwungen erschien und ihre Errungenschaften weitestgehend ausgeblendet blieben. Vor allem aber wurde die Verantwortung für die euphemistisch als "Scheitern“ titulierte Beseitigung von Demokratie und Republik 1933/1934 allen politischen Richtungen zugewiesen: Wenn der Staat "ungeliebt“ gewesen war $^{64}$ und ihn ergo "niemand gewollt" hatte und er folglich "gescheitert" war, ${ }^{65}$ dann waren im Umkehrschluss für dessen Überwindung alle mehr oder weniger gleichermaßen verantwortlich zu machen. Zudem lenkte eine derartige Deutung den analytischen Fokus von der sozialen auf die kulturell-politische Ebene, indem sie unterstellte, im Zentrum der innenpolitischen Auseinandersetzungen zwischen 1918 und 1938 hätten nicht materielle Interessengegensätze und die Haltung zu Republik und Demokratie gestanden, sondern vielmehr die Haltung zur österreichischen Nation.

Das beschriebene Kernargument bezweckte demnach dreierlei: die Abwertung der Ersten Republik, die weiten Teilen des bürgerlichen Milieus retrospektiv nach

60 Karl Cornides an Österreichische Industriellenvereinigung, 13.07.1951. WBR, HS, AVGP, ZPH 1765, Box 1.

61 Karl Cornides an Friedrich Korger, 15.12.1951. WBR, HS, AVGP, ZPH 1765, Box 1.

62 Karl Cornides an Wilhelm Cornides, 05.12.1950. WBR, HS, AVGP, ZPH 1765, Box 1.

63 Reinhold Lorenz, Der Staat wider Willen. Österreich 1918-1938, Berlin 1940.

64 Friedrich Weissensteiner, Der ungeliebte Staat. Österreich zwischen 1918 und 1938, Wien 1990.

65 Anton Pelinka, Die gescheiterte Republik. Kultur und Politik in Österreich 1918-1938, Wien/Köln/ Weimar 2017. 
wie vor als „rotes“ Staatsexperiment galt; ${ }^{66}$ die Negierung der eigenen antidemokratischen Parteitradition samt Umdeutung der sozialen Verteilungskämpfe in einen ideologischen Gegensatz um die nationale Frage; und schließlich die Konstruktion eines historischen Bruches zwischen Erster und Zweiter Republik, den es zwar nicht real, im bürgerlichen Milieu aber sicherlich emotional gab, der also die Akkommodation mit dem demokratisch-republikanischen System der Gegenwart erleichtern sollte. ${ }^{67}$

Auch in anderer Hinsicht war die schließlich 1954 publizierte „Geschichte der Republik Österreich“ stilprägend. Besonders einflussreich war die von Adam Wandruszka in seinem Beitrag entworfene (vom Autor selbst unter Anführungszeichen gesetzte) „natur- oder gottgewollte Dreiteilung Österreichs“ in drei antagonistische Lager: ein christlichsoziales, ein sozialdemokratisches und ein deutschnationales. Diese Unterteilung habe das politische Leben Österreichs seit den 1880er-Jahren geprägt und allen Regimewechseln seither getrotzt. ${ }^{68}$ Es ist verschiedentlich auf die Schwächen dieser Theorie aufmerksam gemacht worden, ${ }^{69}$ gleichwohl wird sie bis in die Gegenwart gerne zur Charakterisierung der österreichischen Politik in der Ersten Republik bemüht. Es scheint daher lohnend, abermals einen kritischen Blick auf diese Interpretation zu werfen.

Unübersehbar ist einerseits die politische Motivation des Lagerparadigmas. Die historische Herleitung eines gleichsam „natürlichen“ eigenständigen nationalen Lagers fiel just in eine Phase, in der die ÖVP-Führung abermals - und diesmal, wie es schien, mit einigem Erfolg - versuchte zu realisieren, woran die Christlichsozialen von Seipel bis Schuschnigg stets gescheitert waren: die Zusammenfassung des gesamten, organisatorisch fragmentierten bürgerlichen Milieus in einer gemeinsa-

66 Ersichtlich unter anderem am Umgang mit dem 12. November als Datum der Republiksproklamation, vgl. Florian Wenninger, Von „Monarchenfressern“ und „Habsburg-Agenten“. Der 12. November als politischer Erinnerungsort der Zweiten Republik, in: zeitgeschichte 41 (2014) 6, 400-414.

67 Vgl. dazu im Detail Martin Reisacher, Die Konstruktion des „Staats, den keiner wollte“. Der Transformationsprozess des umstrittenen Gedächtnisorts „Erste Republik“ in einen negativen rhetorischen Topos, Dipl.-Arb., Universität Wien 2010.

68 Vgl. Adam Wandruszka, Die drei Lager, in: Heinrich Benedikt (Hg.), Geschichte der Republik Österreich, Wien 1954, 291-300, bes. 291-293.

69 Unter anderem durch Hermann Fritzl/Martin Uitz, Kritische Anmerkungen zur sogenannten Lagertheorie, in: Österreichische Zeitschrift für Politikwissenschaft 5 (1975) 4, 325-332; Rudolf Steininger, Polarisierung und Integration. Eine vergleichende Untersuchung der strukturellen Versäulung der Gesellschaft in den Niederlanden und in Österreich, Meisenheim/Glan 1975; Detlef Lehnert, Politisch-kulturelle Integrationsmilieus und Orientierungslager in einer polarisierten Massengesellschaft, in: Emmerich Tálos/Herbert Dachs/Ernst Hanisch/Anton Staudinger (Hg.), Handbuch des politischen Systems Österreichs. Erste Republik 1918-1933, Wien 1995, 431-443. 
men Parteiorganisation. Die entsprechende Botschaft lag nahe: Die Existenz zweier unvermeidlich in Konkurrenz zueinander stehender bürgerlicher Kräfte sei eine politische wie historische Anomalie. Der „nationale“ Adam Wandruszka, der Zeit seines Lebens der FPÖ eng verbunden blieb, entwarf demgegenüber eine eigenständige „nationale“ Traditionslinie. Wie bedeutsam die Lagertheorie für die FPÖ ist, unterstreicht der Umstand, dass sie bis heute in praktisch keiner historischen Verlautbarung der Partei fehlt. ${ }^{\circ 0}$ Wandruszkas Beitrag sorgte innerhalb der Projektgruppe für hitzige Debatten. Womöglich war die Ursache dafür, dass er schließlich dennoch ohne tiefgreifendere Modifikationen publiziert wurde, dass seine Deutung auch vom Standpunkt der ÖVP aus einen gewichtigen Vorteil hatte. Mit der Existenz eines seit jeher eigenständigen national-völkischen Sammelbeckens war eine retrospektive Abgrenzung zum Nationalsozialismus vollzogen, die es realiter so nicht gegeben hatte.

In der weiteren geschichtswissenschaftlichen Bearbeitung der Zwischenkriegszeit und speziell des Austrofaschismus evozierte die Lagertheorie weitverbreitete Fehldeutungen. Sowohl die Betonung weltanschaulicher - und nicht materieller Gegensätze als auch der Hang zu einer Geschichtsschreibung, die den historischen Prozess auf Aktivitäten und Gedanken „großer Männer“ reduzierte, ${ }^{71}$ verdeckte die entscheidenden Motive und Dynamiken, die letztlich in den Staatsstreich 1933/1934 mündeten. Wenn es nämlich zwei dezidiert bürgerliche Blöcke gegeben haben sollte, die sich in ihrer verteilungspolitischen Ausrichtung weitgehend einig waren, mussten die ideologischen und personellen Differenzen zwischen ihnen ähnlich unüberbrückbar gewesen sein wie jene mit der Linken in sozialen Fragen. Ein solcher Ansatz ignorierte freilich, dass programmatische Fragen bei der Rechten stets zuverlässig zurücktraten, sobald sich der gemeinsame Gegner, die Arbeiterbewegung, am Horizont zeigte. Bei näherer Betrachtung der Organisationspraxis sowohl in deutschnationalen wie in christlichsozialen Strukturen der 1920er-Jahre erweist sich zudem, dass einerseits der wütende Antiklerikalismus der Liberalen und später der Schönerianer in den 1920er-Jahren auf ein mehr oder weniger folkloristisches Niveau abgesunken war und eine gewisse identitäre Rolle spielen mochte, aber keine handlungsleitende Bedeutung mehr hatte. Umgekehrt hatten innerhalb des katholischen Milieus junge Intellektuelle erfolgreich nationalvölkische Vorstellungen po-

70 Vgl. Lothar Höbelt, Raab und Reinthaller. Die Stabilisierung der Zweiten Republik, in: Freiheitliches Bildungsinstitut (Hg.), Bericht der Historiker-Kommission. Analysen und Materialien zur Geschichte des Dritten Lagers und der FPÖ, Wien 2019, 93-124; desgl. in populärer Form etwa Andreas Mölzer, Die „Dritte Kraft“!?, in: Zur Zeit 17 (2013) 18, 4.

71 Prototypisch bei Viktor Reimann, Zu groß für Österreich. Seipel und Bauer im Kampf um die Erste Republik, Wien 1968. 
pularisiert, was die Differenzen zusätzlich reduzierte..$^{72}$ Ohnehin war die nationale Frage im österreichischen Kontext nie auf den Gegensatz groß- versus kleindeutsch zu reduzieren gewesen. Auch der vor allem im katholisch-legitimistischen Milieu (aber beileibe nicht nur da) verbreitete Reichsgedanke stand praktisch keineswegs im Widerspruch zum völkischen Deutschnationalismus. Vielmehr proklamierte er mehr oder minder selbstverständlich eine deutsche Suprematie über die anderen Volksgruppen. Der Austrofaschismus betonte das deutsche Element vor diesem Hintergrund nicht einfach, um dem Nationalsozialismus Wind aus den Segeln zu nehmen. Vielmehr setzte er schlicht eine Tradition fort, die schon das Habsburgerreich als Instrument zur Festigung der deutschen Vorherrschaft in Südosteuropa verstanden hatte. ${ }^{73}$ Und schließlich hatten zwischen den bürgerlichen Strömungen nicht nur Differenzen abgenommen, es gab auch zwei stark verbindende weltanschauliche Achsen zwischen „nationalen“ und „katholischen“ Kräften: einen „Antimarxismus“, der sich faktisch nicht nur gegen die Arbeiterbewegung, sondern auch gegen sämtliche anderen Ausdrucksformen der Moderne richtete, und den Antisemitismus, ${ }^{74}$ dessen Bedeutung als Brückenideologie Wandruszka lediglich am Rande ansprach. ${ }^{75}$

72 Vgl. Anton Staudinger, $\mathrm{Zu}$ den Bemühungen katholischer Jungakademiker um eine ständischantiparlamentarische und deutsch-völkische Orientierung der Christlichsozialen Partei, in: Erich Fröschl/Helge Zoitl (Hg.), Februar 1934. Ursachen - Fakten - Folgen. Beiträge zum wissenschaftlichen Symposion des Dr-Karl-Renner-Instituts, abgehalten vom 13. bis 15. Februar 1984 in Wien, Wien 1984, 221-231; ders., Kulturpolitik des Politischen Katholizismus, in: Hilde Haider-Pregler (Hg.), Verspielte Zeit. Österreichisches Theater der dreißiger Jahre, Wien 1997, 34-46.

73 Für die jüngere Zeit vgl. bes. die Arbeiten von Julie Thorpe, Pan-Germanism and the Austrofascist State 1933-1938, Manchester 2011 und Janek Wasserman, Österreichische Aktion: Monarchism, Authoritarianism and the Unity of the Austrian Conservative Ideological Field during the First Republic, in: Central European History 47 (2014) 1, 76-104. Unter den älteren Arbeiten siehe neben jenen Friedrich Heers besonders die Studie von Peter Eppel, Zwischen Kreuz und Hakenkreuz. Die Haltung der Zeitschrift „Schönere Zukunft“ zum Nationalsozialismus in Deutschland 19341938, Wien/Köln/Graz 1980; desgl. Anton Staudinger, Deutsch oder nicht-deutsch. Eine slowenische Übersetzung der österreichischen Bundeshymne und die Kriterien ihrer Ablehnung durch das ständestaatlich-autoritäre Österreich, in: Mladje. Literatura, umetnost, družbena vprašanja 12 (1976) 23, 88-98.

74 Siehe dazu ausführlich die Beiträge in Gertrude Enderle-Burcel/Ilse Reiter-Zatloukal (Hg.), Antisemitismus in Österreich 1933-1938, Wien/Köln/Weimar 2018; desgl. John Connelly, From Enemy to Brother. The Revolution in Catholic Teaching on the Jews, 1933-1965, Harvard 2012, bes. $72-74$.

75 Wandruszka, Lager, 387. 
Ideologische Schnittmengen waren demnach keineswegs auf Katholisch-Nationale vom Schlage Arthur Seyß-Inquarts, ${ }^{76}$ Alois Hudals ${ }^{77}$ oder Taras Borodajkewy$\mathrm{Cz}^{78}$ beschränkt. Die These von den zwei bürgerlichen Lagern wird auch unter einem weiteren Gesichtspunkt nicht glaubwürdiger. Rudolf Steininger und Detlev Lehnert haben darauf hingewiesen, dass eine nach politischen „Lagern“ bzw. „Säulen“ differenzierte Gesellschaft sich wesentlich durch „möglichst vollständige[...] Konzentration der Sozialbeziehungen auf die eigene Kategorie" auszeichne, die nach außen abschotte und nach innen homogenisiere. Ein so geschlossenes Integrationsmilieu existierte aber im Fall der nationalen Gruppierungen schlicht nicht. Ganz im Gegenteil war das Verhältnis der besonders in Sport, Schul- und Freizeitvereinen sozialisierten Nationalen zu ,ihren“ Parteien von Distanz, nicht selten von Abneigung geprägt und hatte den steten Niedergang, schließlich die Implosion der Partei zur Folge.

Zusammenfassend ist die Annahme eines stark fragmentierten Bürgerblocks, der sich vor allem in der Abgrenzung nach links, in antimodernen und antisemitischen Ressentiments einig war, wesentlich plausibler als die Unterteilung in zwei bürgerliche Lager. Unter den Bedingungen der Krise wirkten innerhalb der Rechten schließlich Zentrifugalkräfte, die eine Machtverschiebung anzudeuten begannen: weg von den traditionell dominanten Christlichsozialen hin zur NSDAP. Die Errichtung einer Diktatur 1933 war unter diesem Gesichtspunkt sowohl als Versuch zu verstehen, durch die Krise weiter verschärfte Verteilungskämpfe im Sinne der bürgerlichen (und großbäuerlichen) Seite zu entscheiden, wie auch als Bestreben der urbanen christlichsozialen Eliten, den eigenen Führungsanspruch gegen die immer selbstbewussteren Nationalsozialisten zu behaupten. Gut illustrierbar ist die These von zwei Lagern statt dreien am Beispiel jener Bewegung, die Wandruszka als gleichsam außerhalb aller Lagerzusammenhänge stehend verortete: der Heimwehren. ${ }^{79}$ Sie repräsentierten den radikalisiertesten Teil des immer instabileren bürgerlichen Lagers. Innerhalb der Verbände war die Verzahnung von „völkischen“ und "christlichsozialen“ Elementen so eng, dass spätere Versuche, bestimmte Strukturen

76 Zur Person Seyß-Inquarts hat Johannes Koll mit Fokus auf dessen Rolle im Nationalsozialismus eine umfassende, erhellende Studie vorgelegt, vgl. ders., Arthur Seyß-Inquart und die deutsche Besatzungspolitik in den Niederlanden (1940-1945), Wien/Köln/Weimar 2015.

77 Alois Hudal, Die Grundlagen des Nationalsozialismus. Eine ideengeschichtliche Untersuchung von katholischer Warte, Leipzig/Wien 1937.

78 Arbeiten zur Person Borodajkewycz nehmen bislang vornehmlich die öffentliche Auseinandersetzung um dessen judenfeindliche Ausfälle in den Fokus, untersuchen ihn aber nicht als recht prototypischen Vertreter der Katholisch-Nationalen in den 193oer-Jahren, vgl. u. a. Rafael Kropiunigg, Eine österreichische Affäre. Der Fall Borodajkewycz, Wien 2015.

79 Wandruszka, Lager, 359. 
der einen oder anderen Strömung zuzuschlagen, fast zwangsläufig zum Scheitern verurteilt waren. ${ }^{80}$

Wie widersprüchlich und für sich genommen wenig aussagekräftig programmatische Differenzen innerhalb des Bürgerblocks waren, vor allem aber, wie wenig sich aus diesen eine Abgrenzung zweier einigermaßen klar umrissener Lager ableiten ließ, veranschaulicht auch eine Episode in der Erarbeitung der „Geschichte der Republik Österreich“. Nachdem Wandruszka dem Verlag jenen Abschnitt seines Textes übermittelt hatte, der die Christlichsozialen behandelte, erhielt er einen wutentbrannten Brief des „erschütterten “ ${ }^{8_{1}}$ Karl Cornides, der ihm vorwarf, er, Wandruszka, glorifiziere zu Unrecht ihm nahestehende „nationale“ Intellektuellenzirkel und spreche diesen eine viel größere Bedeutung zu, als sie in Wirklichkeit gehabt hätten, während er "die eigentlich konservativen Kreise“ ignoriere. ${ }^{82}$ Dies werde "gerade in unseren eigenen Kreisen, für die wir doch in erster Linie die Arbeit gemacht haben, wenig Freude erwecken“. ${ }^{83}$ Die „liebevolle Interpretation des ,nationalen Lagers “" ${ }^{84}$ die Cornides seinem Autor also zum Vorwurf machte, bezog sich nun aber keineswegs auf die Großdeutsche Volkspartei oder den Nationalsozialismus, sondern Wandruszkas erkennbare Sympathien für einen Intellektuellen wie Heinrich Srbik ${ }^{85}$ und den Bund Neuland. Heinrich Srbik war durch sein Engagement im Nationalsozialismus nach 1945 belastet, vor 1938 allerdings war der Historiker mit seiner gesamtdeutschen Geschichtsauffassung ein geachteter Repräsentant eben jener Reichsidee gewesen, auf die sich auch der Austrofaschismus ideologisch stark stützte. ${ }^{86}$ Der Bund Neuland wiederum war zwar eine katholische Gründung, ver-

80 Siehe dazu: Ludger Rape, Die österreichischen Heimwehren und die bayerische Rechte 1920-1923, Wien 1977; Francis L. Carsten, Faschismus in Österreich. Von Schönerer zu Hitler, München 1978; Walter Wiltschegg, Die Heimwehr. Eine unwiderstehliche Volksbewegung?, Wien 1985; Franziska Schneeberger, Sozialstruktur der Heimwehr in Österreich. Eine vergleichend-politische Sozialgeschichte der Heimwehrbewegung, phil. Diss., Universität Salzburg 1988; John T. Lauridsen, Nazism and the Radical Right in Austria 1918-1934, Copenhagen 2007; Andreas Fraydenegg-Monzello, Volksstaat und Ständeordnung. Die Wirtschaftspolitik der steirischen Heimwehren 1927-1933, Wien/Köln/Weimar 2015; Lothar Höbelt, Die Heimwehren und die österreichische Politik 19271936. Vom politischen „Kettenhund“ zum „Austro-Fascismus“?, Graz 2016.

81 Karl Cornides an Adam Wandruszka, 23.08.1954. WBR, HS, AVGP, ZPH 1765, Box 1.

82 Karl Cornides an Adam Wandruszka, 10.08.1954. WBR, HS, AVGP, ZPH 1765, Box 1. Auf den Grad von Cornides' Aufgebrachtheit ließ abschließend der drohende Hinweis schließen, Wandruszka gefährde mit derlei Kapriolen seine „ganze Zukunft“.

83 Karl Cornides an Heinrich Benedikt, 20.08.1954. WBR, HS, AVGP, ZPH 1765, Box 1.

84 Ebd.

85 Srbik war Wandruszkas Doktorvater gewesen.

86 Zur Bedeutung der Reichsidee für die Ideologie des Austrofaschismus siehe Anton Staudinger, Austrofaschistische „Österreich“-Ideologie, in: Emmerich Tálos/Wolfgang Neugebauer (Hg.), 
einigte in sich aber starke völkische Strömungen und galt vor 1938 als die nationalkatholische Organisation schlechthin. ${ }^{87}$ Wandruszka hatte sich also keineswegs auf Personen und Ideologien außerhalb des katholischen, geschweige denn des bürgerlichen Milieus bezogen, sondern lediglich auf dessen rechten Flügel. Wie er zu seiner Verteidigung bitter bemerkte:

$\mathrm{Du}$ [Karl Cornides] bist einerseits auf die Neulaender boese und wirfst mir vor, sie zu gut zu behandeln und empfiehlst mir andererseits das Buch von Rudolf, ${ }^{88}$ dem Gruender und geistlichen Oberhaupt der Neuland-Bewegung und Gegner der christlichsozialen Richtung des „politischen Katholizismus“ des Praelaten Fried ${ }^{89}$. Es ist besser, wir stellen den Briefwechsel ueber dieses Thema ein, sonst kenne ich mich ueberhaupt nicht mehr aus $[\ldots] .9^{\circ}$

Die Verengung der Perspektive auf ideengeschichtliche und individualpsychologische Aspekte, die bis heute die Rezeption der Ersten Republik stark prägen, erleichterte auch die Tradierung eines anderen Elements der Benedikt'schen Republikgeschichte: die Errichtung des Austrofaschismus als historische Koinzidenz, als weitgehend zufälliges Resultat einer nicht minder zufälligen Abfolge von Ereignissen. In den Worten der Republikgeschichte: „Was niemand vorausgesehen hatte und was auch die Regierung nicht herbeizuführen dachte, war eingetreten, die Handlungsunfähigkeit des Parlaments. " ${ }^{11}$ Eine solche Interpretation negierte nicht nur er-

„Austrofaschismus“. Beiträge über Politik, Ökonomie und Kultur 1934-1938, Wien 1984, 287-316; zu Heinrich Srbik und seiner Involvierung in die gezielte Sabotage der Karrieren jüdischer und linksstehender Wissenschaftler vgl. Klaus Taschwer, Geheimsache Bärenhöhle. Wie ein antisemitisches Professorenkartell der Universität Wien nach 1918 jüdische und linke Forscherinnen und Forscher vertrieb, in: Regina Fritz/Grzegorz Rossolinski-Liebe/Jana Starek (Hg.), Alma mater antisemitica. Akademisches Milieu, Juden und Antisemitismus an den Universitäten Europas zwischen 1918 und 1939, Bd. 3, Wien 2016, 221-242.

87 Vgl. Gerhard Seewann, Österreichische Jugendbewegung in Österreich-Ungarn 1900 bis 1914 und die Fortsetzung in ihrem katholischen Zweig „Bund Neuland“ von 1918 bis 1938, 2 Bde., Frankfurt a. M. 1974; Maximilian Liebmann, „Heil Hitler“ - Pastoral bedingt. Vom Politischen Katholizismus zum Pastoralkatholizismus, Wien/Köln/Weimar 2009, 65-66.

88 Cornides hatte Wandruszka in seinem Brief vom 10. August 1954 das Buch von Karl Rudolf (Aufbau im Widerstand. Ein Seelsorge-Bericht aus Österreich 1938-1945, Salzburg 1947) mit dem Zusatz empfohlen, hier lasse sich vieles über die Wandlungen des Katholizismus ersehen, die Wandruszka unerwähnt gelassen habe.

89 Gemeint ist Jakob Fried, vgl. Fried, Nationalsozialismus.

90 Adam Wandruszka an Karl Cornides, 16.08.1954. WBR, HS, AVGP, ZPH 1765, Box 1.

91 Walter Goldinger, Der geschichtliche Ablauf der Ereignisse in Österreich von 1918 bis 1945, in: Heinrich Benedikt (Hg.), Geschichte der Republik Österreich, Wien 1954, 15-288, 199. 
kenntnistheoretisch die Prozesshaftigkeit von Geschichte, sondern verstellte vor allem die Sicht auf Vorgänge, die bereits in die Anfänge der Republik zurückreichten, so etwa auf den Umstand, dass innerhalb der Christlichsozialen Partei der demokratisch-republikanisch orientierte Flügel bereits seit Anfang der 1920er-Jahre eindeutig minoritär war, während sich die antidemokratische Haltung der Parteiführung konstant verstärkte. ${ }^{92}$ Es war nicht irgendein fanatisierter Hinterbänkler, sondern der Parteiobmann und präsumtive Bundeskanzler Ignaz Seipel selbst gewesen, der bereits im März 1920 in Vorbereitungen für einen Staatsstreich verwickelt gewesen war, ${ }^{93}$ maßgeblich den Aufbau paramilitärischer Verbände vorangetrieben, ${ }^{94}$ bereits in der Frühphase der Republik mit ausländischen Rechtsradikalen konspiriert hatte ${ }^{95}$ und schließlich Anfang 1927 auch in aller Öffentlichkeit erklärt hatte, er strebe ein Ständeparlament an, das „ohne langwierige Verfassungsänderungen in den Mechanismus der Gesetzgebung eingeschalten werden kann". ${ }^{66}$ Es war denn auch keine spontane Emotion des Augenblicks, die Seipel in seiner „Tübinger Rede“ die Reinigung „der Demokratie von der Parteienherrschaft" fordern ließ.97 In Kombination mit ganz ähnlichen Stimmungslagen in anderen Teilen der bürgerlichen Eliten ${ }^{98}$ kann darin der Ausdruck eines seit Jahren bestehenden autoritären Konsenses im bürgerlichen Milieu gesehen werden. Für dessen Realisierung hatte allerdings lange Zeit ausreichend forsches und dabei - im Unterschied zu den Heimwehrführern -

92 Vgl. Anton Staudinger, Christlichsoziale Partei und Errichtung des „Autoritären Ständestaates“ in Österreich, in: Ludwig Jedlicka/Rudolf Neck (Hg.), Vom Justizpalast zum Heldenplatz - Studien und Dokumentationen 1927 bis 1938 (Festgabe der Wissenschaftlichen Kommission des TheodorKörner-Stiftungsfonds und des Leopold-Kunschak-Preises zur Erforschung der österreichischen Geschichte der Jahre 1918 bis 1938 anlässlich des dreißigjährigen Bestands der Zweiten Republik Österreich und der zwanzigsten Wiederkehr des Jahrestages des Österreichischen Staatsvertrages), Wien 1975, 65-81.

93 Anton Staudinger, Christlichsoziale Partei, in: Erika Weinzierl/Kurt Skalnik, Österreich 19181938. Geschichte der Ersten Republik, Bd. 1, Graz/Wien/Köln 1983, 249-276, 259.

94 Vgl. Carsten, Faschismus, 59-60.

95 Vgl. Lajos Kerekes, Die „Weiße Allianz“ - bayrisch-österreichisch-ungarische Projekte gegen die Regierung Renner im Jahre 1920, in: Österreichische Osthefte 7 (1965) 5, 353-366; desgl. Rape, Heimwehren, 190-191, 294-296, 376-386; Lauridsen, Nazism, 111-112.

96 Straßenpolitik gegen Wirtschaftspolitik, Reichspost, 01.02.1927, 1-2.

97 Wie auch eine sechs Monate zuvor gehaltene, ähnlich gelagerte Rede in München ist „Die Tübinger Kritik der Demokratie“ abgedruckt in Ignaz Seipel, Der Kampf um die Österreichische Verfassung, Wien/Leipzig 1930, 177-188.

98 Vgl. Karl Haas, Industrielle Interessenspolitik in Österreich zur Zeit der Weltwirtschaftskrise, in: Österreichische Gesellschaft für Zeitgeschichte (Hg.), Jahrbuch für Zeitgeschichte, Wien 1978, 97-126. 
berechenbares Personal gefehlt. In den vormaligen Weltkriegsoffizieren Dollfuß und Schuschnigg war es schließlich gefunden.

Die Lagertheorie ist sicherlich der meistzitierte Inhalt der „Geschichte der Republik Österreich“, vielleicht fast ebenso bedeutsam war aber noch eine andere Deutung, genauer gesagt, Nichtdeutung. Der Fokus auf Parteipolitik und die getrennte Behandlung von Politik und Ökonomie, die selbst jüngste Darstellungen noch dominiert, ${ }^{99}$ führten dazu, dass materielle Interessengegensätze, die letztlich das ausschlaggebende Cleavage für die Beseitigung der Ersten Republik bildeten, weitgehend im Dunklen blieben. Als Schuschnigg bereits im Juni 1932 äußerte, „bei einem solchen Notstand sei ein Regieren mit dem Parlament nicht möglich", ${ }^{100}$ bezog er sich auf ein Problem, das sich unter den Bedingungen der Weltwirtschaftskrise zwar zugespitzt hatte, das aber keineswegs neu war: Die bürgerlichen Parteien vertraten ökonomisch vor allem Eliteninteressen. ${ }^{101}$ Sowohl ihre Haltung im Mietrecht, zum Wohlfahrtsstaat (und hier besonders zur Invalidenfürsorge und zur Arbeitslosenversicherung) als auch ihre Lohn, Beschäftigungs, Wirtschafts- und Fiskalpolitik widersprachen in weiten Teilen den wirtschaftlichen Interessen des Gros ihrer eigenen AnhängerInnen. ${ }^{102}$ Dieses banden die bürgerlichen Parteien daher kulturell an sich, das heißt mit unterschiedlichen Formen von Identitätspolitiken, vornehmlich negativen Abgrenzungen. Die rapide Polarisierung der bürgerlichen Klientel nach rechts fiel vor diesem Hintergrund nicht zufällig mit der Verschärfung der sozialen Lage ab 1930 zusammen. Sie war das Ergebnis des Eindrucks, „das System“, das hieß die bisherige Repräsentation durch die bürgerlichen Parteien, funktioniere endgültig nicht mehr. Kulturell tiefsitzende Vorbehalte, gepaart mit einem weitverbreiteten ausgeprägten Standesbewusstsein in kleinbürgerlichen und bäuerlichen Schichten,

99 Bertrand Michael Buchmann, Insel der Unseligen. Das autoritäre Österreich 1933-1938, Wien 2019; Pelinka, Die gescheiterte Republik.

100 Wortmeldung Schuschniggs in der Sitzung des Ministerrates vom 17.06.1932, zit. n. Rudolf Neck/ Adam Wandruszka (Hg.), Abteilung VIII. 20. Mai 1932 bis 25. Juli 1934. Kabinett Dr. Engelbert Dollfuß. 20. Mai 1932 bis 18. Oktober 1932 (Protokolle des Ministerrates der Ersten Republik 1918-1938 1), bearb. v. Gertrude Enderle-Burcel, Wien 1985, 244.

101 Vgl. Fritz Weber, Die wirtschaftliche Entwicklung, in: Tálos/Dachs/Hanisch/Staudinger (Hg.), Handbuch, 23-42; ders., Vor dem großen Krach. Österreichs Bankwesen der Zwischenkriegszeit am Beispiel der Credit-Anstalt für Handel und Gewerbe, Wien/Köln/Weimar 2016; Ernst Hanisch, Der lange Schatten des Staates. Österreichische Gesellschaftsgeschichte im 20. Jahrhundert (Österreichische Geschichte 1890-1990), Wien 1994, bes. 281-283.

102 Siehe dazu u. a. auch Dieter Stiefel, Arbeitslosigkeit. Soziale, politische und wirtschaftliche Auswirkungen - am Beispiel Österreich 1918-1938, Berlin 1979; ders., Die große Krise in einem kleinen Land, Wien 1988; Ernst Bruckmüller, Sozialstruktur und Sozialpolitik, in: Weinzierl/Skalnik, Österreich, Bd. 1, 381-436. 
verhinderten in dieser Situation ein Übergehen nach links und befeuerten stattdessen die immer rasantere Drift nach rechts. Die bürgerlichen Parteien, besonders die Christlichsozialen, standen vor der Wahl, ihre soziale Funktion gründlich zu revidieren oder die elektoralen Effekte ihrer eigenen Politik zu neutralisieren, indem sie keine Wahlen mehr abhielten. Sie entschieden sich einhellig für das Zweite. Der Leserschaft des Benedikt-Bandes wurde dieser Zusammenhang kaum angedeutet.

Abschließend soll noch auf zwei weitere Paradigmen eingegangen werden, die das Benedikt-Projekt nicht selbst entwarf, aber aufgriff und popularisierte.

Das Erste betraf die Rolle der Diktatoren. Wilhelm Cornides und Heinrich Benedikt waren beide „Voll Verachtung " ${ }^{103}$ für Schuschnigg und hielten seine Politik übereinstimmend für „himmelschreiend blöd und unbeholfen“"104. Als Goldingers Beitrag, wenn auch in wesentlich gesetzteren Worten, zu einem ähnlichen Ergebnis kam, befand man allerdings, seine Kritik sei „zu scharf“, ${ }^{105}$ und plädierte dafür, dem „Unglücksmann, [der] hier versagen musste“, zumindest zuzugestehen, „für sich [...] die Nachsicht [zu] beanspruchen [..., die dem zusteht, der das Beste gewollt hat". ${ }^{106}$

Ganz anders hingegen die Einschätzung der Person Dollfuß; Karl Cornides regte an, den Dollfuß-Kult des Austrofaschismus in modifizierter Form zu übernehmen:

Vor allem meine ich, dass man den Gedanken aufgreifen sollte, dass Dollfuss als Blutzeuge des politischen und weltanschaulichen Widerstandes gefallen sei. Vielleicht könnte man den Gedanken vertreten, dass das christlichsozial-konservative Lager vor allem von 1933-1938 seinen Widerstand gegen den Nationalsozialismus geleistet hat [...]. ${ }^{107}$

Diese Revision des ursprünglichen Dollfuß-Mythos der 1930er-Jahre war bemerkenswert. Während des Austrofaschismus war das Dollfuß-Vermächtnis als Auftrag zur inneren Befriedung, vor allem auch als Ausgleich mit den Nazis, interpretiert worden. Nun wurde Dollfuß zum Kopf eines Abwehrkampfes umgedeutet, der er in der Realität nie war, wie Wilhelm Cornides intern auch unumwunden erklärte: Dollfuß sei „ja immer verhandlungsbereit gewesen [mit den Nationalsozialisten] und Schuschnigg auch, was ihrer letzten Endes grossdeutschen Konzeption entsprach“. ${ }^{108}$

103 Karl an Wilhelm Cornides, 20.12.1950. WBR, HS, AVGP, ZPH 1765, Box 1.

104 Karl an Wilhelm Cornides, 30.12.1950. WBR, HS, AVGP, ZPH 1765, Box 1.

105 Karl Cornides an Heinrich Benedikt, 20.08.1954. WBR, HS, AVGP, ZPH 1765, Box 1.

106 „Bemerkungen zu den mir gestern zu Gesicht gekommenen Seiten 345-388 des Abschnittes Goldinger"von Wilhelm Cornides [Sommer 1954]. WBR, HS, AVGP, ZPH 1765, Box 1.

107 Karl Cornides an Adam Wandruszka, 10.08.1954. WBR, HS, AVGP, ZPH 1765, Box 1. 108 Wilhelm Cornides an Karl Cornides, 26.12.1950. WBR, HS, AVGP, ZPH 1765, Box 1. 
Vor allem Walter Goldinger war allerdings zu einer so weitreichenden biographischen Frisur nicht bereit und handelte sich damit prompt den Verdacht ein, ein verkappter politischer Gegner zu sein. Der Verlag hatte sich erbötig gemacht, Carl Karwinsky, dem ehemaligen austrofaschistischen Staatssekretär für Sicherheitswesen und in dieser Funktion einer der Hauptverantwortlichen für die militärische Flankierung des Staatsstreiches 1933/1934, das Manuskript des Buches vorab für allfällige Korrekturen vorzulegen. Nachdem er Goldingers Ereignisgeschichte erhalten hatte, reagierte Karwinsky umgehend:

[...] es ist insbesonders das Bild Dollfuss', in dem mir jene Züge zu fehlen scheinen, die durch sein selbstloses und heisses Bemühen um Oesterreichs Erhaltung [die] so charakteristisch für ihn waren. Dieses Bemühen war es, das ihm die Herzen der Massen zufliegen liess und eine Belebung des Oesterreichbewusstseins zur Folge hatte. ${ }^{109}$

Überdies verwahrte sich Karwinsky entschieden gegen die Klassifizierung einer Erschießung gefangener Schutzbündler während der Februarkämpfe 1934 durch das Bundesheer als „Untat" und monierte, Goldingers Kritik an Schuschniggs Agieren während des Juliputsches der Nazis 1934 sei aus einem ganz konkreten Grund hinderlich:

Wie Ihnen nicht unbekannt sein dürfte, waren und sind Bemühungen im Gange, Dr. v. Schuschnigg die Rückkehr in die Heimat und eine angemessene Tätigkeit hier zu ermöglichen. Der Widerstand seiner Gegner würde eine wesentliche Stärkung erfahren, wenn eine so arge Diskriminierung $[\ldots]$ publiziert würde. ${ }^{110}$

Er, Karwinsky, habe Bundeskanzler Raab daher auf die Darstellung „aufmerksam gemacht und gebeten, mit dem Autor, der ja einer dem Herrn Bundeskanzler unterstehenden Dienststelle angehört, im kurzen Wege sprechen zu lassen“. ${ }^{111}$ Während der Verlag keinen Hehl aus seiner Irritation über Karwinskys Versuch machte, Druck auszuüben, sagte Benedikt umgehend zumindest die Änderung der inkriminierten Darstellung der Februarkämpfe und (etwas zu voreilig) des Juliputsches zu. ${ }^{112}$

109 Carl Karwinsky an Heinrich Benedikt, 11.09.1954. WBR, HS, AVGP, ZPH 1765, Box 1.

110 Carl Karwinsky an Heinrich Benedikt, 14.09.1954. WBR, HS, AVGP, ZPH 1765, Box 1.

111 Carl Karwinsky an Heinrich Benedikt, 11.09.1954. WBR, HS, AVGP, ZPH 1765, Box 1.

112 Heinrich Benedikt an Carl Karwinsky, 13.09.1954. WBR, HS, AVGP, ZPH 1765, Box 1. Nach Rücksprache mit Goldinger zeigte sich dieser bereit, die Passage zur Ermordung der Schutzbündler durch das Bundesheer abzuändern und das Wort „Untat“ entfallen zu lassen: „Natürlich hat Herr Dr. Goldinger nicht das geringste Interesse, das Bundesheer zu belasten, obwohl nach seiner ge- 
Die Differenzen zwischen Goldinger und Karwinsky betrafen letztlich Details, jedoch bezeichnenderweise nicht die Rahmung der Februarereignisse. Hier hatte Goldinger einerseits den Einfluss Italiens auf das Geschehen hervorgehoben und andererseits vor allem einen Akt des Staatsnotstandes sehen wollen: „[... es] bestand auch für die Regierung, sobald die Würfel einmal gefallen waren, keine andere Möglichkeit als zurückzuschlagen und so den Bestand des Staates, der von außen schwer gefährdet war, zu sichern. " ${ }^{113}$

Das führt zum letzten Aspekt des Benedikt-Projektes, der historiographisch eine beträchtliche Langzeitwirkung entfalten sollte: zur Externalisierung der Verantwortung für die innenpolitische Entwicklung, die Darstellung Österreichs als Korken, der hilflos auf den wechselnden Gezeiten widerstrebender Großmachtinteressen zu treiben schien, bar jedes Gestaltungsspielraumes. Dass die Realität etwas anders gelagert gewesen war, wussten die Initiatoren des Projektes gleichwohl.

Für mich [Wilhelm Cornides] ist die Zeit nach Februar 1914 [sic!, gemeint ist 1934] nur mehr „Abgesang“. Nachdem man die Linke, die als Mitlerin [sic!] zur demokratischen Welt unentbehrlich geworden war, unterm Hund behandelt, misshandelt, hatte und sich aussenpolitisch den Faschisten anpasste, war es eben aus und kam es nur mehr darauf an, wie man zum Deutschtum - also zu den Nazis sich fand. ${ }^{1{ }^{14}}$

Andernorts notierte Wilhelm Cornides entgeistert, Schuschnigg schreibe sogar selbst, er sei

im Ausland - Prag, Paris, London - herumgereist, um zu verkünden, dass Österreich nie gegen Deutschland kämpfen werde. Nach den Ciano-Tagebüchern hat er Ciano gesagt, dass, wenn es zu einem zweiten Juli 1934 komme, der Versuch einer bewaffneten italienischen Intervention Österreich auf der Seite Deutschlands, also gegen Italien kämpfend finden würde. ${ }^{115}$

nauen Kenntnis des Tatbestandes die von Ihnen zur Entlastung vorgebrachten Argumente keinesfalls erwiesen sind.“ In puncto Juliputsch blieb Goldinger jedoch hart, hier sei „an dem Tatbestand [...] nicht zu zweifeln, und er blieb auch bei seiner Auffassung, daß er sich in der Darstellung desselben einer grossen Zurückhaltung befleissigt habe“. Karl Cornides an Carl Karwinsky, 24.09.1954. WBR, HS, AVGP, ZPH 1765, Box 1.

113 Vgl. Goldinger, Ablauf der Ereignisse, 217-218, 218. Siehe die entsprechenden Ausführungen von Wandruszka, Lager, 339.

114 Wilhelm Cornides an Karl Cornides, 26.12.1950. WBR, HS, AVGP, ZPH 1765, Box 1.

115 „Bemerkungen zu den mir gestern zu Gesicht gekommenen Seiten 345-388 des Abschnittes Goldinger" von Wilhelm Cornides [Sommer 1954]. WBR, HS, AVGP, ZPH 1765, Box 1. 
In der Benedikt'schen Republikgeschichte fand sich letztlich dennoch die Betonung der ungünstigen außenpolitischen Konstellation, während die innerösterreichischen Handlungsspielräume weitgehend unbeachtet blieben.

Nachdem man das Manuskript schließlich nach dreijähriger Arbeit abgeschlossen hatte, befanden „sich der Herausgeber und die hiesigen Autoren [Benedikt, Wandruszka, Goldinger und Verosta] in einer gewissen Euphorie“, die Vater und Sohn Cornides jedoch erklärtermaßen nicht teilten. ${ }^{116}$

Niemand könnte erleichterter sein als ich, wenn es uns gelungen wäre, die Epoche Dollfuss-Schuschnigg von allen gegen sie vorgebrachten Angriffen zu rechtfertigen. Sie dürfen überzeugt sein, daß der Gesandte Verosta [...] bereits das Möglichste versucht hat, dem Werk einen in diesem Sinn positiven Charakter zu geben. Er ist aber von einem gewissen Punkt an auf den unerbittlichen Widerstand der Sachbearbeiter gestossen, die als Wissenschafter auf dem Standpunkt stehen, daß das, was wahr sei, gesagt werden müsse. ${ }^{117}$

Der Rezensent der „Arbeiter-Zeitung“ traf damit buchstäblich ins Schwarze, als er spöttisch anmerkte, der Benedikt-Gruppe sei es gegangen

wie jenem Mann aus der Bibel, der auszog, um zu fluchen, aber am Ende segnen mußte. Sie zogen aus zu segnen, nämlich die bürgerliche Politik, müssen aber an allen entscheidenden Stellen ihres Antigulick, wenn auch verhalten und verlegen, genau das mißbilligen, was auch Gulick mißbilligt und verdammt hat. ${ }^{118}$

\section{Wesen und Grenzen der Koalitionsgeschichtsschreibung}

Wiewohl Adam Wandruszka später den Vorwurf strikt von sich weisen sollte, er und seine Kollegen aus dem Benedikt-Projekt hätten „Koalitionsgeschichtsschreibung" betrieben, ${ }^{119}$ war das ursprüngliche Anliegen des „Anti-Gulick“ doch genau

116 Karl Cornides an Friedrich Thalmann, 15.09.1954. WBR, HS, AVGP, ZPH 1765, Box 1.

117 Karl Cornides an Carl Karwinsky, 24.09.1954. WBR, HS, AVGP, ZPH 1765, Box 1.

118 Warum ging die Erste Republik zugrunde? Eine konservative Geschichte Österreichs, ArbeiterZeitung, 21.11.1954, 3.

119 Adam Wandruszka, Das „nationale Lager“ in der Ersten Republik, in: Rudolf Neck/Adam Wandruszka (Hg.), Anschluß 1938. Protokoll des Symposiums in Wien am 14. und 15. März 1978 (Wissenschaftliche Kommission des Theodor-Körner-Stiftungsfonds und des Leopold-KunschakPreises zur Erforschung der österreichischen Geschichte der Jahre 1918 bis 1938), Wien 1981, $164-172,164$. 
das: „mein [Wilhelm Cornides] Buch sollte verständlich machen, warum damals [in der Ersten Republik] nicht ging, was nun, zugegebenermaßen mehr schlecht als recht, aber eben doch geht: dass man in Gemeinschaft mit der Linken eine Art von österreichischer Politik treibt". ${ }^{120}$

Anhand der Genese des Benedikt-Bandes lassen sich beispielhaft die wesentlichen Charakteristika der Koalitionsgeschichte zeigen. Konstitutiv war die negative Abgrenzung der großkoalitionären Gegenwart zur Konfliktgeschichte der Ersten Republik. ${ }^{121}$ Die Erste Republik wurde als „Staat wider Willen“ denunziert, eingebettet zwischen zwei katastrophische Ereignisse, den Zusammenbruch der Monarchie 1918 und den „Anschluss“ 1938. Vor allem die konservative Variante der Koalitionsgeschichte interpretierte außerdem das gezielte Nation Building als historischen Lernprozess, in dem der Erfahrung des Nationalsozialismus eine katharsische Funktion zugeschrieben wurde. Argumentativ lief eine solche Deutung - alle haben gelitten, alle haben gelernt - indirekt also auf die Opferthese hinaus. Das Konzept der drei politischen Lager erleichterte es dabei, stillschweigend darüber hinwegzugehen, dass die Christlichsozialen in ihrer breiten Mehrheit eine durchaus ambivalente Haltung zur Deutschtumsideologie gehabt hatten und der Austrofaschismus eine innenpolitische Befriedung vor allem mit den Nationalsozialisten angestrebt hatte, kaum mit der Linken. Die heftigen Auseinandersetzungen mit den Nazis in den Jahren 1933/1934, zeitgenössisch meist noch als Bruderzwist bedauert, mutierten solcherart zur Zuspitzung eines gewachsenen, gewissermaßen natürlichen Gegensatzes, dem fundamentale ideologische Differenzen zugrunde gelegen hätten. Die Ableitungen für die Bewertung der Diktatur lagen auf der Hand. Generell wurden vor allem außenpolitische Faktoren betont. Wenn man auch selbst geirrt hatte, dann nur mit lauteren Motiven: der Verteidigung der Nation Österreich, der berechtigten Angst vor linken Diktaturbestrebungen und - vor allem - einer tiefsitzenden Aversion gegen den Nationalsozialismus. Als maßgebliche Hindernisse für eine Koalition mit der Linken erschienen retrospektiv neben kulturellen Differenzen deren Haltung zur österreichischen Nation. Die tatsächlich ausschlaggebenden Faktoren soziale Interessengegensätze und die innerhalb des fragmentierten Bürgerblocks weithin geteilte Abneigung gegen das System der parlamentarischen Demokratie blieben dagegen außen vor. Trotz unbestreitbarer Fehler habe die Geschichte mit der Wiedererrichtung der österreichischen Eigenstaatlichkeit letztlich jene bestätigt, die

120 Wilhelm Cornides an Karl Cornides, 26.12.1950. WBR, HS, AVGP, ZPH 1765, Box 1.

121 Vgl. Ernst Hanisch, Die Dominanz des Staates. Österreichische Zeitgeschichte im Drehkreuz von Politik und Wissenschaft, in: Alexander Nützenadel/Wolfgang Schieder (Hg.), Zeitgeschichte als Problem. Nationale Tradition und Perspektiven der Forschung in Europa, Göttingen 2004, 54-77. 
von Beginn an dem Gedanken einer österreichischen Nation verpflichtet gewesen seien - also die Christlichsozialen.

Die sozialdemokratische Variante dieser Erzählung wurde vor allem durch Adolf Schärfs Resümee der ersten zehn Jahre der Zweiten Republik popularisiert, das ein Jahr nach dem Benedikt-Band erschien. ${ }^{122}$ Auch Schärf betonte die Erfolgsgeschichte der Zweiten Republik, indem er sie dem „Scheitern“ der Ersten gegenüberstellte. Abseits dessen ergaben sich Schnittmengen über weite Strecken allerdings eher zwangsläufig - die Fakten waren nun einmal weitgehend eindeutig. Es wäre demnach verfehlt, die Koalitionsgeschichte als Suche nach einem retrospektiven Konsens zu deuten. Vielmehr adressierte sie primär das jeweils eigene Milieu und war bestrebt, diesem die Alternativlosigkeit des Nachkriegsproporzes zu veranschaulichen.

In weiterer Folge etablierte sich stillschweigend eine Art Arbeits- bzw. Thementeilung, die bis in die 1980er-Jahre eine prägende Tendenz blieb. So lag es nahe, dass sich die Biographik bevorzugt Persönlichkeiten der jeweils eigenen "Seite“ widmete $^{123}$ und auch die Organisationsgeschichte schon wegen des Quellenzugangs eher empathiegeleitet war. ${ }^{124}$ Während die rote historiographische Reichshälfte vor allem auf den Februar 1934 fokussiert war, erwärmten sich konservative AutorInnen eher für den Juliputsch $1934^{125}$ und den Zusammenbruch 1938, ${ }^{126}$ für Aspekte also, die geeignet waren, das „Abwehrkampf“-Paradigma zu stützen. ${ }^{127}$ Wiewohl

122 Adolf Schärf, Österreichs Erneuerung: 1945-1955. Das erste Jahrzehnt der Zweiten Republik, Wien 1955.

123 Vgl. u. a. Anton Hopfgartner, Kurt Schuschnigg. Ein Mann gegen Hitler, Graz/Wien 1989; Jacques Hannak, Karl Renner und seine Zeit. Versuch einer Biographie, Wien 1965; Otto Leichter, Otto Bauer. Tragödie oder Triumph, Wien 1970.

124 Vgl. etwa Harry Slapnicka, Christlichsoziale in Oberösterreich. Vom Katholikenverein 1848 bis zum Ende der Christlichsozialen 1934, Linz 1984; Ludwig Reichhold, Geschichte der Christlichen Gewerkschaften Österreichs, Wien 1987; Gerhard Hartmann, Für Gott und Vaterland. Geschichte und Wirken des CV in Österreich, Kevelaer 2006; Fritz Klenner, Die österreichischen Gewerkschaften. Vergangenheit und Gegenwartsprobleme, 3 Bde., Wien 1951; Jacques Hannak, Im Sturm eines Jahrhunderts. Volkstümliche Geschichte der Sozialistischen Partei Österreichs, Wien 1952; Kritische Ausnahmen von dieser Regel etwa: Anton Pelinka, Stand oder Klasse? Die christliche Arbeiterbewegung Österreichs 1933 bis 1938, Wien/München/Zürich 1972; desgl. die Arbeiten von Anton Staudinger zur Geschichte der Christlichsozialen Partei.

125 Vgl. Gerhard Jagschitz, Der Putsch. Die Nationalsozialisten 1934 in Österreich, Graz/Wien/Köln 1976; Kindermann, Hitlers Niederlage.

126 Vgl. Erwin Steinböck, Österreichs militärisches Potential im März 1938, Wien/München 1988.

127 Vgl. Ludwig Reichhold, Kampf um Österreich. Die Vaterländische Front und ihr Widerstand gegen den Anschluß 1933-1938. Eine Dokumentation, Wien 1984; Franz Schausberger, Letzte Chance für die Demokratie. Die Bildung der Regierung Dollfuß I im Mai 1932. Bruch der österreichischen Proporzdemokratie, Wien/Köln/Weimar 1993; ders., Ins Parlament, um es zu zerstören. Die Natio- 
ausländische WissenschaftlerInnen in der österreichischen Debatte häufig abseits der Links-Rechts-Achse verortet wurden, zeigt eine nähere Befassung, dass letztlich auch sie häufig in das skizzierte Schema passten. ${ }^{128}$

Eine wichtige Wendemarke innerhalb der gleichermaßen politisierten wie nach politischer Richtung isolierten Geschichtsschreibung bildete die 1971 gegründete Wissenschaftliche Kommission des Theodor-Körner-Stiftungsfonds und des Leopold-Kunschak-Preises zur Erforschung der österreichischen Geschichte der Jahre 1927 bis 1938. Der ehemalige Revolutionäre Sozialist Bruno Kreisky, der 1936 im Rahmen des „Großen Sozialistenprozesses“ vor Gericht gestanden hatte und mittlerweile zum Bundeskanzler avanciert war, gewann den einstigen oberösterreichischen Landessekretär der Vaterländischen Front und nachmaligen ÖVP-Nationalratspräsidenten Alfred Maleta für die Idee einer gemeinsamen Forschungsgruppe, die aus den beiden namensgebenden parteinahen Stiftungen sowie öffentlichen Mitteln finanziert wurde. ${ }^{129}$ In das kurz Körner-Kunschak-Kommission genannte Gremium nominierte neben beiden Großparteien auch die KPÖ (fast ausschließlich: männliche) Vertreter, bei denen es sich neben ZeitzeugInnen vor allem um Historiker handelte. Ganz im Sinne des Medienkanzlers Kreisky, der bei politischen Vorhaben stets auch deren massenmediale Kommunikation im Auge hatte, gehörten der Kommission außerdem mehrere Journalisten an. ${ }^{130}$ Unter dem Vorsitz des (sozialdemokratischen) Archivars und späteren Generaldirektors des Österreichi-

nalsozialisten in den österreichischen Landtagen 1932/33, Wien/Köln/Weimar 1995; zuletzt ders., Alle an den Galgen! Der politische „Takeoff“ der „Hitlerbewegung“ bei den Salzburger Gemeindewahlen 1931, Wien/Köln/Weimar 2005.

128 Vgl. Wenninger, Austrian Missions.

129 Vgl. Rudolf Neck, Die Wissenschaftliche Kommission des Theodor Körner-Stiftungsfonds und des Leopold-Kunschak-Preises zur Erforschung der österreichischen Geschichte der Jahre 1927 bis 1938, in: Jedlicka/Neck (Hg.), Justizpalast, 15-16.

130 Über die personelle Zusammensetzung der Kommission lässt sich Neck nicht näher aus. Die nachfolgenden Angaben beruhen daher auf Auskünften, für die der Autor Anton Staudinger herzlich dankt. Demnach nominierte die SPÖ Manfred Ackermann, Karl Ausch, Gerhard Botz, Julius Braunthal, Fritz Fellner, Hanns Haas, Josef Hindels, Rosa Jochmann, Robert A. Kann, Hans Kelsen, Ernst Koref, Felix Kreissler, Otto Leichter, Norbert Leser, John E. Leslie, Alfred Magaziner, Karl Maisel, Hans Mommsen, Oskar Morgenstern, Rudolfine Muhr, Vincenz Ludwig Ostry, Walter Pollak, Robert Prantner, Friedrich Scheu, Karl R. Stadler, Stefan Wirlandner, Walter Wodak und Hans Zeisel. Die ÖVP entsandte Fritz Bock, Alois Brusatti, Josef Dengler, Franz Gall, Heinrich Gleißner, Walter Goldinger, Alfons Gorbach, Alfred Hoffmann, Walter Jambor, Hans Leinkauf, Franz Loidl, Egbert Mannlicher, R. John Rath, Ludwig Reichhold, Rudolph von Salis, Kurt Skalnik, Herbert Schambeck, Anton Staudinger, Ludwig Strobl, Franco Valsechhi, Stephan Verosta und Adam Wandruszka. Für die KPÖ gehörten der Kommission Friedl Fürnberg, Ernst Fischer, Leopold Hornik, Lajos Kerekes, Josef Polisensky, Herbert Steiner und Vladimir Mihailovic Turok an. 
schen Staatsarchives, Rudolf Neck, und dem der ÖVP zugerechneten Vorstand des Instituts für Zeitgeschichte, Ludwig Jedlicka, ${ }^{131}$ hielt die Kommission mehrere Symposien ab, deren Vorträge und Diskussionen in Tagungsbänden umfassend dokumentiert und im Verlag für Geschichte und Politik von Karl Cornides sukzessive publiziert wurden, desgleichen die Reihe „Studien und Quellen zur österreichischen Zeitgeschichte“. Ihre höchste Produktivität erreichte die Gruppe in den 1970er-Jahren, formal bestand sie bis 1985 , wurde danach in einen Verein umgewandelt und stellte ihre Tätigkeit 1989 ein. ${ }^{132}$

\section{Forschungskonjunkturen seit 1970}

Offenbar im Hinblick auf die Arbeit der Körner-Kunschak-Kommission hatte die SPÖ Anfang der 1970er-Jahre das Thema Austrofaschismus nicht offensiv aufgegriffen. Sie hielt zwar parteiinterne Gedenkkundgebungen ab, widmete sich ansonsten aber nur im Jahr 1973 in einer knappen Publikation der Parteiakademie der Ausschaltung des Parlaments von $1933 .{ }^{133}$ Der Verlag der KPÖ gab hingegen zum vierzigsten Jahrestag der Februarkämpfe 1974 eine umfangreiche bebilderte Publikation heraus, in der ganz in der Tradition der Parteigeschichtsschreibung die Rolle der Sozialdemokratie scharf kritisiert und der kommunistische Wille und Beitrag zum Widerstand betont wurde. ${ }^{134}$ Dass die Erforschung der Jahre 1933-1938 in den 1970er-Jahren dennoch einen so jähen Aufschwung erlebte, war vor allem auf einen Generationswechsel innerhalb des Fachs zurückzuführen. Ab den frühen 197oerJahren trat insbesondere die „Linzer Schule“ des aus der Emigration zurückgekehrten Karl R. Stadler auf den Plan. Kennzeichnend für diese ,junge“ Zeitgeschichtsforschung waren einerseits methodologische und erkenntnistheoretische Innovationen (die Abkehr von der klassisch-positivistischen „Geschichte von oben“, das Interesse an Strukturen statt Individuen, die Erschließung neuer Quellentypen, allen voran der Oral History, die Einführung quantitativer Analyseverfahren und eine große

131 Vgl. Oliver Rathkolb, Ludwig Jedlicka. Vier Leben und ein typischer Österreicher. Biographische Skizze zu einem der Mitbegründer der Zeitgeschichtsforschung, in: zeitgeschichte 32 (2005) 6, 351-370.

132 Ein umfangreicher Bestand der Kommission harrt bis heute im Österreichischen Staatsarchiv, ein eigener Audiobestand in der Mediathek einer systematischen Bearbeitung.

133 Anton Benya/Gerhard Botz/Ernst Koref/Bruno Kreisky/Otto Probst, Vierzig Jahre danach. Der 4. März 1933 im Urteil von Zeitgenossen und Historikern (eine Veröffentlichung des Dr.-KarlRenner-Institutes), Wien 1973.

134 Arnold Reisberg, Februar 1934. Hintergründe und Folgen, Wien 1974. 
Aufgeschlossenheit für interdisziplinäre Ansätze und Kooperationen, um nur die wichtigsten zu nennen), andererseits und vor allem aber ein dezidiert politisches Selbstverständnis, das der Geschichtswissenschaft eine demokratisch-emanzipative Verantwortung zusprach. Die augenfälligsten Folgen für die Behandlung der österreichischen Zwischenkriegszeit waren ein bis dahin ungekanntes Interesse an organisations, ideen- und kulturgeschichtlichen Aspekten der Arbeiterbewegung, ${ }^{135}$ an politischer Militan $z^{136}$ und schließlich am Widerstand gegen diktatorische Transformationsprozesse. ${ }^{137}$ Ausdruck des neuen Sendungsbewusstseins waren neben einer regelrechten Flut an Publikationen auch mehrere großangelegte Ausstellungen. ${ }^{138}$

135 Neben zahlreichen Texteditionen siehe etwa die Beiträge in Gerhard Botz/Hans Hautmann/Helmut Konrad/Josef Weidenholzer (Hg.), Bewegung \& Klasse. Studien zur österreichischen Arbeitergeschichte, Wien 1978; Ernst Glaser, Im Umfeld des Austromarxismus. Ein Beitrag zur Geistesgeschichte des österreichischen Sozialismus, Wien/München/Zürich 1981; Peter Kulemann, Am Beispiel des Austromarxismus. Sozialdemokratische Arbeiterbewegung in Österreich von Hainfeld bis zur Dollfuß-Diktatur, Hamburg 1982; Raimund Löw/Siegfried Mattl/Alfred Pfabigan, Der Austromarxismus. Eine Autopsie. Drei Studien, Frankfurt a. M. 1986; Friedhelm Boll (Hg.), Arbeiterkulturen zwischen Alltag und Politik. Beiträge zum europäischen Vergleich in der Zwischenkriegszeit, Wien/München/Zürich 1986.

136 Unter anderem Christine Vlcek, Der Republikanische Schutzbund in Österreich. Geschichte, Aufbau und Organisation, phil. Diss., Universität Wien 1971; Ilona Duczynska, Der demokratische Bolschewik. Zur Theorie und Praxis der Gewalt, München 1975; Gerhard Botz, Gewalt in der Politik. Attentate, Zusammenstöße, Putschversuche, Unruhen in Österreich 1918-1934, München 1976; Irene Etzersdorfer/Hans Schafranek, Der Februar 1934 in Wien. Erzählte Geschichte, Wien 1984; Hans Safrian, Mobilisierte Basis ohne Waffen - Militanz und Resignation im Februar 1934 am Beispiel der Oberen und Unteren Leopoldstadt, in: Helmut Konrad/Wolfgang Maderthaner (Hg.), Neuere Studien zur Arbeitergeschichte. Zum fünfundzwanzigjährigen Bestehen des Vereins für Geschichte der Arbeiterbewegung, Wien, Bd. 2, Wien 1984, 471-49o; Hans Schafranek, „Die Führung sind wir selber" - Militanz und Resignation im Februar 1934 am Beispiel Kaisermühlen, in: ebd., 439-470; Winfried Garscha/Hans Hautmann, Februar 1934 in Österreich, Berlin 1984; Karl Haas, Austromarxismus und Wehrfrage. Zur militärpolitischen Pragmatik der österreichischen Sozialdemokratie in der ersten Republik, Habil., Universität Wien 1985; Finbarr McLoughlin, Der Republikanische Schutzbund und gewalttätige Auseinandersetzungen in Österreich 19231934, phil. Diss., Universität Wien 1990; siehe zuletzt auch Charlotte Rönchen, „Geistige Führer, Träger und Vermittler der Aufruhridee“? Eine Kollektivbiographie der mittleren Führungsebene des Republikanischen Schutzbundes Wien, MA-Arbeit, Universität Wien 2020.

137 Siehe u. a. die Reihe von Erika Weinzierl/Karl R. Stadler (Hg.), Justiz und Zeitgeschichte, Wien 1977-1991; ebenso die mehrbändige Quellenedition des Dokumentationsarchivs des Österreichischen Widerstandes (Hg.), Widerstand und Verfolgung, Wien 1984-2019; Karl R. Stadler (Hg.), Sozialistenprozesse. Politische Justiz in Österreich 1870-1936, Wien/München/Zürich 1986.

138 Vgl. Helene Maimann (Hg.), Mit uns zieht die neue Zeit. Arbeiterkultur in Österreich 1918, Wien 1981; Helene Maimann/Siegfried Mattl (Hg.), Die Kälte des Februar. Österreich 1933-1938, Wien 1984. 
Der ORF trug durch Produktionen wie die „Staatsoperette“139 1977 , einschlägige Diskussionsformate und schließlich mit der Dokumentarreihe „Österreich I“ 1989 maßgeblich dazu bei, das öffentliche Interesse am Thema wachzuhalten. Der Erforschung der Zwischenkriegszeit kam zusätzlich entgegen, dass die angesprochene Themenkonjunktur sich nicht auf Österreich beschränkte. Ausländische WissenschaftlerInnen trugen in weiterer Folge zentrale Werke bei. ${ }^{140}$

Den Höhepunkt der öffentlichen Befassung mit dem Austrofaschismus bildete das Jahr 1984. Die SPÖ hatte den Jahrestag der Februarkämpfe 1934 sorgfältig vorbereitet und beging ihn mit einer Vielzahl von Veranstaltungen, Gedenkkundgebungen und Denkmalenthüllungen, allem voran mit der Schau „Die Kälte des Februar“. ${ }^{141}$

Bereits ein Jahr später, 1985, markierte die Debatte um die Causa Reder-Frischenschlager den Anfang der bislang nachhaltigsten Themenverschiebung der österreichischen Zeitgeschichtsforschung: Hatte bis dahin die Zeit vor 1938 dominiert, rückten nun der Nationalsozialismus und die Involvierung Österreichs bzw. seiner Bevölkerung in den Fokus.

139 Vgl. Evelyne Polt-Heinzl, Staatsoperetten. Kunstverstörungen. Das kulturelle Klima der 1970er, Wien 2009.

140 Mehrere dieser ForscherInnen hatten freilich österreichische Wurzeln, so etwa Kurt L. Shell, Ilona Duczynska, Felix Kreissler oder Francis L. Carsten. Grundlegende Arbeiten beigesteuert haben auBerdem etwa Bruce Pauley, Hahnenschwanz and Swastika. The Styrian Heimatschutz and Austrian National Socialism 1918-1934, Rochester 1966; ders., From Prejudice to Persecution. A History of Austrian Anti-Semitism, Chapel Hill 1992; Clifton E. Edmondson, The Heimwehr and Austrian Politics 1918-1936, Athens 1978; Anson Rabinbach, Vom Roten Wien zum Bürgerkrieg, Wien 1989 sowie Charlie Jeffery, Beyond Red Vienna. Social Democracy in the Austrian Provinces, 1918-1934, London 1995; R. John Rath, The Dollfuß Ministry. The Intensification of Animosities and the Drift toward Authoritarianism, in: Austrian History Yearbook 30 (1999), 65-101; Felix Kreissler (Hg.), 50 Jahre danach. Der „Anschluß“ von innen und außen gesehen (Beiträge zum internationalen Symposion von Rouen, 29. Februar bis 4. März 1988), Wien/Zürich 1989; James W. Miller, Engelbert Dollfuß als Agrarfachmann. Eine Analyse bäuerlicher Führungsbegriffe und österreichischer Agrarpolitik 1918-1934, Wien/Graz/Köln 1989; Christoph Butterwegge, Austromarxismus und Staat. Politiktheorie und Praxis der österreichischen Sozialdemokratie zwischen den beiden Weltkriegen, Marburg 1991; zur Organisationsgeschichte siehe die Arbeiten Everhard Holtmanns, vgl. ders., Zwischen Unterdrückung und Befriedung. Sozialistische Arbeiterbewegung und autoritäres Regime in Österreich 1933-1938, München 1978; ders., Die Organisation der Sozialdemokratie in der Ersten Republik 1918-1934, in: Wolfgang Maderthaner/Wolfgang C. Müller (Hg.), Die Organisation der österreichischen Sozialdemokratie 1889-1995, Wien 1996, 93-167; ders., Die Sozialdemokratie in der Illegalität 1934-1945, in: ebd., 169-194; Jill Lewis, Fascism and the Working Class in Austria 1918-1934. The Failure of Labour in the First Republic, New York/ Oxford 1991; Kenneth Segar/John Warren (Hg.), Austria in the Thirties. Culture and Politics, Riverside 1991; Tim Kirk, Nazism and the Working Class in Austria. Industrial Unrest and Political Dissent in the ,National Community', Cambridge 1996.

141 Maimann/Mattl, Kälte. 
Es war maßgeblich das Interesse für die Frühphase des Nationalsozialismus, das Ende der 1990er-Jahre einer neuerlichen Beschäftigung mit der Zeit vor 1938 den Weg ebnete. ${ }^{142}$ Den Vorgängen rund um den Juliputsch 1934 widmeten sich Anfang der 200oer-Jahre gleich mehrere neue Studien, die nach dem Sozialprofil der illegalen NS-AktivistInnen fragten, ${ }^{143}$ die Ereignisse auf Mikroebene rekonstruierten ${ }^{144}$ und den durchaus merkwürdigen Ereignisablauf des Putsches stärker durch das Prisma der SA, ihrer Entmachtung in Deutschland und ihrer Rivalität mit der SS zu fassen versuchten. ${ }^{145}$

Die Aneignung der auf die Erste Republik und den Austrofaschismus rekurrierenden Tradition des Widerstandes gegen autoritäre Tendenzen seit 1945 ist bislang nicht näher untersucht worden. Als gesichert darf jedoch gelten, dass mit der Erosion der sozialdemokratischen Säule in den letzten Jahrzehnten entsprechende Versatzstücke auch jenseits des SP-Milieus aufgegriffen wurden. Es spricht einiges dafür anzunehmen, dass die politische Brisanz der Befassung mit dem Austrofaschismus zwar nachgelassen hat, aber keineswegs verschwunden ist. So war wohl nicht zuletzt dem Politisierungsschub durch die Bildung der schwarz-blauen Bundesregierung 2000 zuzuschreiben, dass die Austrofaschismusforschung seither einen neuerlichen Aufschwung erlebt hat.

Charakteristisch für diese jüngste historiographische Phase sind mehrere Neuerungen.

Auf thematischer Ebene augenfällig ist zunächst die stärkere Interdisziplinarität, gepaart mit einer methodischen Diversifikation. Beides drückt sich etwa im erhöhten Interesse an kulturhistorischen Aspekten der Diktatur aus, die zuvor kaum Beachtung gefunden hatten, hinzu kam eine vermehrte Bearbeitung audiovisueller Quellen. ${ }^{146}$ In diesem Zusammenhang erwähnenswert sind nicht nur kultur- und

142 Dirk Hänisch, Die österreichischen NSDAP-Wähler. Eine empirische Analyse ihrer politischen Herkunft und ihres Sozialprofils, Wien/Köln/Weimar 1998; Alfred Elste/Dirk Hänisch, Auf dem Weg zur Macht. Beiträge zur Geschichte der NSDAP in Kärnten von 1918 bis 1938, Wien 1997. Für eine aufschlussreiche Kommunalstudie siehe Laurenz Krisch, Zersprengt die Dollfußketten. Die Entwicklung des Nationalsozialismus in Bad Gastein bis 1983, Wien/Köln/Weimar 2003.

143 Kurt Bauer, Elementar-Ereignis. Die österreichischen Nationalsozialisten und der Juliputsch 1934, Wien 2003.

144 Christian Klösch, Des Führers heimliche Vasallen. Die Putschisten des Juli 1934 im Kärntner Lavanttal, Wien 2007.

145 Hans Schafranek, Sommerfest mit Preisschießen. Die unbekannte Geschichte des NS-Putsches im Juli 1934, Wien 2006.

146 Eine Ausnahme stellte vor allem die leider nie publizierte, ausgezeichnete Studie von Sirikit M. Amann dar, vgl. dies., Kulturpolitische Aspekte im Austrofaschismus (1934-1938). Unter besonderer Berücksichtigung des Bundesministeriums für Unterricht, phil. Diss., Universität Wien 
medienpolitische Untersuchungen, ${ }^{147}$ architektur- und städtebaugeschichtliche Arbeiten, ${ }^{148}$ sondern auch Studien zur Selbstinszenierung, ${ }^{149}$ zur Rolle der Kirche, ${ }^{150}$ zu den Ansätzen des Regimes, die Arbeiterschaft zu integrieren, ${ }^{151}$ und diverse Po-

1987; siehe außerdem Friedbert Aspetsbergers Untersuchung zum Österreichischen Staatspreis, vgl. ders., Literarisches Leben im Austrofaschismus. Der Staatspreis, Königstein 1980; schließlich Alexandra Vasak, Kulturpolitik im Austrofaschismus hinsichtlich der bildenden Künste. Architektur - Bildhauerei - Malerei, Dipl.-Arb., Universität Wien 1996.

147 Unter frühen Arbeiten zur Medienpolitik des Regimes vgl. besonders Walter Köhler, Amtliches Nachrichtenwesen und Nachrichtenpolitik im "Austrofaschismus“. Amtliche Nachrichtenstelle und „Politische Korrespondenz“ im Umfeld des „austrofaschistischen“ Mediensystems 1933 bis 1938, phil. Diss, Universität Wien 1985; für spätere Arbeiten siehe u. a. Verena Finkenstedt, Los Vieneses. Österreichische Kabarettkünstler im Spannungsfeld von Austrofaschismus, Nationalsozialismus und Franquismus, phil. Diss, Universität Wien 2018.

148 Vgl. Barbara Feller, Baupolitik in Wien im Austrofaschismus, Dipl.-Arb., Universität Wien 1991; Thomas Mitterecker, Großglockner-Hochalpenstraße. Ausstellungsbau im österreichischen Ständestaat, Dipl.-Arb., Technische Universität Wien 2012; Markus Mistelbauer, Architektur und Ideologie. Wohnbau im Austrofaschismus, Dipl.-Arb., Technische Universität Wien 2015; Anna Stuhlpfarrer, Das Wiener Hofburgareal. Architektur und Denkmal, Bühne politischer Machtdemonstration und geschichtlicher Legitimation. Über den Umgang mit dem imperialen Erbe im Zentrum Wiens in den Jahren des Austrofaschismus und Nationalsozialismus, phil. Diss., Universität Wien 2017; Andreas Suttner, Das schwarze Wien. Bautätigkeit im Ständestaat 1934-1938, Wien/Köln/Weimar 2017.

149 Vgl. Robert Kriechbaumer, Ein Vaterländisches Bilderbuch. Propaganda, Selbstinszenierung und Ästhetik der Vaterländischen Front 1933-1938, Wien/Köln/Weimar 2002; Julia Tinhof, Ihr Jungen schließt die Reihen gut, ein Toter führt uns an. Propaganda im Austrofaschismus; Schwerpunktthema Kinder und Jugendliche, Dipl.-Arb., Universität Wien 2010; Bettina Brunner, Die fotografische Repräsentation des österreichischen „Ständestaates“. Illustrierte Zeitungen und Bildchroniken als Träger der visuellen Geschichte des Dollfuß-Schuschnigg-Regimes, Dipl.-Arb., Universität Graz 2014; Dreidemy, Dollfuß-Mythos; Pia Janke, Politische Massenfestspiele in Österreich zwischen 1918 und 1938, Wien/Köln/Weimar 2010.

150 Vgl. u. a. Liebmann, „Heil Hitler“; Johannes Thonhauser, Die Kirche und die „Kärntner Seele“. Habitus, kulturelles Gedächtnis und katholische Kirche in Kärnten, insbesondere vor 1938, Wien/ Köln/Weimar 2019.

151 Vgl. Walter Göhring/Brigitte Pellar, Anpassung und Widerstand. Arbeiterkammern und Gewerkschaften im österreichischen Ständestaat, Wien 2001; Paul Pasteur, Unter dem Kruckenkreuz. Gewerkschafter und Gewerkschafterinnen in Österreich 1934-1938, Innsbruck 2008; Elisabeth Luif, „... daß die Arbeiterschaft als erster Waggon hinter der Lokomotive rangiert“. Integrationsstrategien im Austrofaschismus am Beispiel der „Sozialen Arbeitsgemeinschaft“, MA-Arbeit, Universität Wien 2020. 
litikfeldanalysen, etwa zur Wirtschafts- und Sozialpolitik, ${ }^{152}$ Schulpolitik ${ }^{153}$ und zur späteren Rezeption des Regimes. ${ }^{154}$ Neben den bereits genannten Arbeiten zum Juliputsch 1934 wurden auch die Februarkämpfe neuerlich zum Thema, allerdings mit unterschiedlicher Überzeugungskraft. ${ }^{155}$ Die internationale Faschismusforschung hat sich seit den 1990er-Jahren stark auf ideengeschichtliche Themen konzentriert, das hat seinen Niederschlag auch in Österreich gefunden, wenngleich die Auseinandersetzung mit der austrofaschistischen Ideologie per se kein Novum darstellt. ${ }^{156}$

152 Siehe bes. Peter Berger, Im Schatten der Diktatur: Die Finanzdiplomatie des Vertreters des Völkerbundes in Wien. Rost van Tonningen 1931-1936, Wien 2000; Gerhard Senft, Im Vorfeld der Katastrophe. Die Wirtschaftspolitik des Ständestaates. Österreich 1934 bis 1938, Wien 2002; Hansjörg Klausinger, Von Mises zu Morgenstern. Der Austroliberalismus und der „Ständestaat“, in: zeitgeschichte 32 (2005) 5, 323-335; außerdem die einschlägigen Beiträge in: Günter Bischof/ Anton Pelinka/Alexander Lassner (Hg.), The Dollfuss/Schuschnigg Era in Austria. A Reassessment (Contemporary Austrian Studies 11), Innsbruck 2003 sowie Fritz Weber, Vor dem großen Krach. Österreichs Banken in der Zwischenkriegszeit am Beispiel der Credit-Anstalt für Handel und Gewerbe, Wien/Köln/Weimar 2016.

153 Vgl. Christian Mathies, Im Zeichen von Herrgott und Vaterland. Die Tiroler Schule im Ständestaat 1933-1938, phil. Diss., Universität Innsbruck 2017.

154 Vgl. bes. Karl Klambauer, Österreichische Gedenkkultur zu Widerstand und Krieg. Denkmäler und Gedächtnisorte in Wien 1945-1986, Innsbruck/Wien/Bozen 2006; eine wichtige Grundlagenarbeit lieferte zuvor das Dokumentationsarchiv des Österreichischen Widerstandes (Hg.), Gedenken und Mahnen in Wien 1934-1945. Gedenkstätten zu Widerstand und Verfolgung, Exil, Befreiung. Eine Dokumentation, Wien 1998; siehe außerdem Lucile Dreidemy, „Aus der Geschichte lernen ... und gegen die Rotfront kämpfen!“ Das Dr. Engelbert Dollfuß-Museum in Texingtal, Niederösterreich, in: Dirk Rupnow/Heidemarie Uhl (Hg.), Zeitgeschichte ausstellen in Österreich. Museen - Gedenkstätten - Ausstellungen, Wien/Köln/Weimar 2011.

155 Substanziell Neues hatte besonders die Bundesländerstudie von Werner Anzenberger und Martin F. Polaschek zu bieten, vgl. dies., 12. Februar 1934. Widerstand für eine Demokratie, Graz 2004; Ähnliches gilt für die Arbeit von Peter Weingand zur KPÖ, vgl. ders., Die KPÖ und der Februar 1934. Mit den internen Berichten der KP-Bezirksgruppen und Karten des Bundesheeres, Graz 2020. An seinem Anspruch, Fakten und Mythen zu trennen und Erstere überzeugend zu analysieren, scheitert Kurt Bauer hingegen weitgehend, vgl. ders., Der Februar-Aufstand 1934. Fakten und Mythen, Wien/Köln/Weimar 2019. Zur ausführlicheren Begründung der Kritik siehe die Besprechung des Buches durch den Autor des vorliegenden Textes, Rezension zu Kurt Bauer, Der Februaraufstand 1934. Fakten und Mythen, H-Soz-Kult, 13.03.2019, URL: www.hsozkult.de/publicationreview/id/ reb-27953 (abgerufen 19.11.2020).

156 Für ältere einschlägige Arbeiten siehe neben den Arbeiten Anton Staudingers und Ernst Hanischs vor allem Heinrich Bußhoff, Das Dollfuß-Regime in Österreich als geistesgeschichtliches Problem unter besonderer Berücksichtigung der „Schöneren Zukunft“ und der „Reichspost“, Berlin 1968; Klaus-Jörg Siegfried, Universalismus und Faschismus. Das Gesellschaftsbild Othmar Spanns, Wien 1974; Eppel, Kreuz. Zu neueren Ansätzen siehe die voluminöse, inhaltlich aber nur streckenweise ergiebige Arbeit von Erika Kustatscher, „Berufsstand“ oder „Stand“. Ein politischer Schlüsselbegriff im Österreich der Zwischenkriegszeit, Wien/Köln/Weimar 2016; siehe außerdem die einschlägigen 
Neu sind auch stärker transnationale und komparatistisch orientierte Arbeiten, die den Fall Österreich sowohl im Kontext der großen Faschismen als auch der „kleinen“ europäischen Diktaturen untersuchen. ${ }^{157}$ Die austrofaschistische Repressionspolitik ist wieder stärker ins Zentrum gerückt, seit der österreichische Nationalrat im Februar 2012 auf eine Petition von 97 HistorikerInnen aus dem In- und Ausland hin eine (auf Betreiben der ÖVP allerdings rein symbolische) Rehabilitierung der demokratischen Opfer des Austrofaschismus beschloss. ${ }^{158}$ Direkt aus dieser Initiative hervorgegangen war im Januar 2011 auch eine Tagung der Institute für Rechts- und Zeitgeschichte, deren Ergebnisse in zwei umfangreichen Sammelbänden niedergelegt wurden. Ziel war dabei neben dem Eröffnen neuer Forschungsperspektiven besonders auch eine Bestandsaufnahme der bisherigen Forschungsarbeit und die Identifikation von Desideraten. ${ }^{159}$ Erheblich bemerkbar gemacht hat sich auch die Wissenschaftsgeschichte, die wesentliche Erkenntnisse zur Elitengeschichte beigesteuert hat. ${ }^{160}$ Deutliche Impulse kamen desgleichen aus der Frauen- und Ge-

Beiträge in Richard Faber/Elmar Locher (Hg.), Italienischer Faschismus und Deutscher Katholizismus, Würzburg 2013.

157 Katharina Ebner, Ideologietransfer des italienischen Faschismus nach Wien und Budapest unter Berücksichtigung der Rolle der römisch-katholischen Kirche, phil. Diss., Universität Wien 2016; Johannes Thaler, Faschismus, katholische Kirche und kleinstaatliche Diktaturen. Ein Vergleich von Litauen und Österreich in der Zwischenkriegszeit, phil. Diss., Universität Wien 2016; Linda Erker, Die Universität Wien im Austrofaschismus. Zur politischen Vereinnahmung einer Hochschule im Vergleich mit der Universität Madrid im Franco-Faschismus, phil. Diss., Universität Wien 2018.

158 Zur Repressionspolitik im Austrofaschismus siehe bisher vor allem Eva-Maria Sedlak, Politische Sanktionen gegen öffentliche Bedienstete im österreichischen „Ständestaat“, phil. Diss., Universität Wien 2004; Maria Mesner/Margit Reiter/Theodor Venus, Enteignung und Rückgabe. Das sozialdemokratische Parteivermögen in Österreich 1934 und nach 1945, Innsbruck/Wien/Bozen 2007; Pia Schölnberger, Das Anhaltelager Wöllersdorf 1933-1938. Strukturen, Brüche, Erinnerungen, Wien/ Köln/Weimar 2015; Amelie Berking, Linke Frauen hinter Gittern. Frauenspezifische Bedingungen der politischen Haft im Austrofaschismus, MA-Arbeit, Universität Wien 2018. Siehe insbesondere auch die umfangreichen rechtshistorischen Arbeiten Ilse Reiter-Zatloukals in diesem Themenkreis.

159 Reiter-Zatloukal/Rothländer/Schölnberger (Hg.), Österreich; Florian Wenninger/Lucile Dreidemy (Hg.), Das Dollfuß/Schuschnigg-Regime 1933-1938. Vermessung eines Forschungsfeldes, Wien/ Köln/Weimar 2013.

160 Vgl. u. a. Juliane Mikoletzky, „Von jeher ein Hort starker nationaler Gesinnung“. Die Technische Hochschule in Wien und der Nationalsozialismus, Wien 2003; Theresa Maria Kuen, Studien zu Geschichte und politischer Orientierung des Lehrkörpers der Tierärztlichen Hochschule Wiens während der Zeit des „Austrofaschismus“ (1933-1938), med. Diss., Wien 2012; Marianne Schlosser, Das Institut für Turnlehrerausbildung während des Austrofaschismus und das Hochschulinstitut für Leibesübungen während des Nationalsozialismus an der Universität Wien. Eine Analyse des Vorlesungsverzeichnisses, des Personalstandes, einer biographischen Darstellung ausgewählter Lehrer und Lehrerinnen und eine Beschreibung der Hochschullager, Dipl.-Arb., Universität 
schlechtergeschichte. ${ }^{161}$ Schließlich hat sich die Biographik nicht nur von den Führungspersönlichkeiten Dollfuß und Schuschnigg wegzubewegen begonnen, sondern ist insgesamt fühlbar kritischer geworden. ${ }^{162}$ Zugleich hat sich die Forschung auch stärker für personelle Kontinuitäten über die Regimebrüche hinweg zu interessieren begonnen. ${ }^{163}$ Der bisherige Wissensstand zur Praxis der Gesetzgebung ${ }^{164}$ und

Wien 2012; Alexander Freiberger, Die Universität Innsbruck im Austrofaschismus 1933-1938. Am Beispiel der Disziplinarverfahren gegen NS-Studierende, Dipl.-Arb., Universität Innsbruck 2014; Johannes Koll (Hg.), „Säuberungen an österreichischen Hochschulen 1934-1945“. Voraussetzungen, Prozesse, Folgen, Wien/Köln/Weimar 2017; Andreas Huber/Linda Erker/Klaus Taschwer, Der Deutsche Klub. Austro-Nazis in der Hofburg, Wien 2020.

161 Siehe u. a. Veronika Helfert, Geschlecht. Schreiben. Politik. Frauentagebücher im Februar 1934, Dipl.-Arb., Universität Wien 2010; Hanna Lichtenberger, Als die Schüsse fielen in der Analyse. Die Psychoanalytikerinnen Helene Deutsch, Muriel Gardiner und Marie Langer im Widerstand gegen den Austrofaschismus, Dipl.-Arb., Universität Wien 2012; Nina Kogler, GeschlechterGeschichte der Katholischen Aktion im Austrofaschismus. Diskurse - Strukturen - Relationen, Wien/ Münster 2014; Doreen Blake, Die weibliche Antimoderne im Austrofaschismus. Eine Analyse der katholischen Frauenzeitschrift „Elisabeth-Blatt“, 1934-1938, MA-Arbeit, Universität Wien 2015; Anna Battisti, Die „Frauenstunde“ der RAVAG. Radio von Frauen für Frauen in den letzten Jahren der ersten Republik bis zum Ende des Austrofaschismus, Dipl.-Arb., Universität Wien 2016; siehe auch die Beiträge in: Veronika Helfert/Veronika Duma/Hanna Lichtenberger/Linda Erker (Hg.), Perspektivenwechsel: Geschlechterverhältnisse im Austrofaschismus/Changing the Perspecives: Gender Relations in Austro-Fascism. Österreichische Zeitschrift für Geschichtswissenschaften 27 (2016) 3; Berking, Frauen.

162 Siehe besonders die Beiträge zu Joseph Buttinger, Therese Schlesinger und Arthur Seyß-Inquart in: Günter Bischof/Fritz Plasser/Eva Maltschnig (Hg.), Austrian Lives (Contemporary Austrian Studies 21), Innsbruck 2012; Franz Schausberger, Rudolf Ramek 1881-1941. Konsenskanzler im Österreich der Gegensätze, Wien/Köln/Weimar 2017; Peter Melichar, Otto Ender 1875-1960. Landeshauptmann, Bundeskanzler, Minister. Untersuchungen zum Innenleben eines Politikers, Wien/ Köln/Weimar 2018.

163 Rare, umso stärker hervorzuhebende Arbeiten aus der Zeit vor 1990 sind die Studien von Kurt L. Shell, Jenseits der Klassen? Österreichs Sozialdemokratie seit 1934, Wien 1969 sowie Helmut Wohnout, Die „Causa Starhemberg“ 1947-1954, Dipl.-Arb., Universität Wien. Zu den jüngeren Arbeiten siehe bes. Franziska Dzugan, Chamäleons im Blätterwald. Die Wurzeln der ÖVP-ParteijournalistInnen in Austrofaschismus, Nationalsozialismus, Demokratie und Widerstand. Eine kollektivbiografische Analyse an den Beispielen „Wiener Tageszeitung“ und „Linzer Volksblatt“ 1945 bzw. 1947 bis 1955, phil. Diss, Universität Wien 2011; Birgit Behal, Kontinuitäten und Diskontinuitäten deutsch-nationaler katholischer Eliten im Zeitraum 1930-1965. Ihr Weg und Wandel in diesen Jahren am Beispiel Dr. Anton Böhms, Dr. Theodor Veiters und ihrer katholischen und politischen Netzwerke, phil. Diss., Universität Wien 2009.

164 Vgl. Helmut Wohnout, Regierungsdiktatur oder Ständeparlament? Gesetzgebung im autoritären Österreich, Wien/Graz/Köln 1993. 
zu den involvierten Personengruppen ${ }^{165}$ hat ebenfalls eine fruchtbare Erweiterung erfahren. ${ }^{166}$

Begünstigt durch die Restitution von Aktenbeständen aus dem Moskauer Sonderarchiv, ${ }^{167} \mathrm{zu}$ denen vor allem die erhaltenen Quellen des Generalsekretariats der Vaterländischen Front zählten, hat schließlich Emmerich Tálos, der gemeinsam mit Wolfgang Neugebauer den erstmals 1984 erschienenen, später mehrfach ergänzten und wiederaufgelegten Sammelband "Austrofaschismus" verantwortet hatte, 2013 eine materialreiche Gesamtdarstellung des Regimes vorgelegt. ${ }^{168} \mathrm{Im}$ Unterschied zum einzigen bis dahin existierenden Versuch, das Regime in seiner Gesamtheit zu portraitieren, ${ }^{169}$ deckt Tálos' Arbeit ein wesentlich weiteres Spektrum als nur Politik- und Wirtschaftsgeschichte ab und widmet sich ausführlich dem Zustandekommen, den Trägern, der Ideologie, vor allem auch der sozialen Funktion des Regimes.

Die Frage nach der geeigneten Begrifflichkeit für das Regime $1933-1938^{170}$ birgt zwar nach wie vor eine gewisse politische Brisanz, ist mittlerweile aber immerhin konstruktiv diskutierbar geworden. ${ }^{171}$ Es bliebe zu wünschen, dass der gegenwärtig in Arbeit befindliche Sammelband unter der Ägide von Carlo Moos diesen Weg weiterführen und verbreitern wird.

165 Gertrude Enderle-Burcel/Johannes Kraus, Mandatare im Ständestaat 1934-1938. Biographisches Handbuch der Mitglieder des Staatsrates, Bundeskulturrates, Bundeswirtschaftsrates und Länderrates sowie des Bundestages, Wien 1991.

166 Maren Seliger, Scheinparlamentarismus im Führerstaat. „Gemeindevertretung“ im Austrofaschismus und Nationalsozialismus. Funktionen und politische Profile der Wiener Räte und Ratsherren 1934-1945 im Vergleich, Wien/Münster 2010.

167 Für eine vollständige Aufstellung der dortigen Beuteakten mit Österreichbezug siehe Gerhard Jagschitz/Stefan Karner, „Beuteakten aus Österreich“. Der Österreichbestand im russischen „Sonderarchiv" Moskau, Graz/Wien 1996.

168 Emmerich Tálos, Das austrofaschistische Herrschaftssystem. Österreich 1933-1938, Wien 2013. Eine gekürzte Studienversion erschien 2017.

169 Vgl. Ulrich Kluge, Der österreichische Ständestaat 1934-1938, Wien 1984. Der schmale Band von Roland Jezussek bleibt zu sehr an der Oberfläche, um in diese Reihe gestellt zu werden, vgl. ders., Der „Austrofaschismus“ - ein Modell autoritärer Staatsform. Ideologie, Entstehung und Scheitern des österreichischen Ständestaats, Saarbrücken 2009.

170 Für einen Überblick siehe Emmerich Tálos, Deutungen des Österreichischen Herrschaftssystems 1934-1938, in: Florian Wenninger/Paul Dvořak/Katharina Kuffner (Hg.), Geschichte macht Herrschaft. Zur Politik mit dem Vergangenen, Wien 2007, 199-213.

171 Vgl. die Beiträge zum Themenschwerpunkt in: Historicum N. F. III-IV (2017). 


\section{Conclusio und Ausblick}

Relativ am besten erforscht ist der Austrofaschismus in politikgeschichtlicher Perspektive. Bei näherer Betrachtung tun sich allerdings schon hier markante Lücken auf. So liegt auf Ebene der Parteiengeschichte der mit der Systemetablierung einhergehende Säuberungs- und Transformationsprozess der Christlichsozialen Partei weitgehend im Dunklen. Auch fehlen eingehendere Untersuchungen für das Elektorat der beiden Großparteien, wie sie Dirk Hänisch für die NSDAP vorgelegt hat. Desgleichen sind die Zerschlagung der - linken wie rechten - Oppositionsstrukturen und ihre Folgen bislang unzureichend untersucht worden. Vor diesem Hintergrund stützen sich Annahmen über politische Neugruppierungsprozesse auf ein dünnes Fundament. Offen ist vor allem, welche Strukturen und Netzwerke aktiv blieben, wie sie sich reorganisierten und in welcher Weise sie sich wo betätigten. Als Quellen sind hier bislang vor allem Unterlagen des Exils bzw. Korrespondenzen der deutschen Parteistellen und die Untergrundpublizistik ${ }^{172}$ herangezogen worden. Lohnend wären insbesondere systematischere Auswertungen von lokalen und regionalen Behördenwahrnehmungen. Solche Mikrostudien erlaubten wesentlich detailliertere Einschätzungen der tatsächlichen Verankerung, Sozialstruktur und Aktivitätsmuster der verschiedenen Gruppierungen. ${ }^{173}$ Vor allem wäre auch eine nähere Befassung mit der illegalen Betriebsarbeit interessant, wo nicht nur unterschiedliche Parteien miteinander konkurrierten, sondern auch innerhalb des sozialdemokratischen Untergrundes Revolutionäre Sozialisten und illegale Freie Gewerkschafter. Daran schließt unmittelbar an, dass eine befriedigende Geschichte der illegalen Richtungs- wie legalen Einheitsgewerkschaft weiterhin fehlt.

Im Bereich der Repressionspolitik deutet der bisherige Kenntnisstand eindeutig auf einen wesentlich stärkeren behördlichen und justiziellen Druck hin als bislang angenommen. Praktisch überhaupt noch nicht untersucht worden ist der flankierend ausgeübte sozialpolitische Druck durch die Streichung von Fürsorgeleistungen, Verlust von Gemeindewohnungen oder politisch motivierten Arbeitsplatzverlust. Zur Repressionspolitik wird man in einem weiteren Kreis auch die gewaltsame Durchsetzung der Diktatur in den militärischen Auseinandersetzungen 1934 zählen

172 Siehe zuletzt Harald Schodl, Trotzkistische Publikationen während der Zeit des Austrofaschismus. Ein Beitrag zur Geschichte der österreichischen ArbeiterInnenbewegung, Dipl.-Arb., Universität Wien 2007.

173 Vorbildhaft sind in diesem Zusammenhang Arbeiten wie jene von Valerie Limbach, „... es ist daher die erwähnte Behauptung über die Polizei eine reine Erfindung." Repression und Kommunistische Untergrundaktivitäten im Austrofaschismus am Beispiel des Kommunistischen Jugendverbandes Ottakring und Hernals, BA-Arbeit, Universität Wien 2020. 
müssen. Die regelrechte Flut von großteils hagiographischer Broschüren- und Erinnerungsliteratur täuscht darüber hinweg, dass die Februarkämpfe in ihrer Gesamtheit nach wie vor schlechter erforscht sind als die Niederringung des nationalsozialistischen Putschunternehmens im Juli desselben Jahres. Klar ist zwar der grobe Ereignisablauf der Kämpfe, künftige Untersuchungen müssten dies aber in Beziehung zu den entsprechenden Vorbereitungen der Exekutive und des Bundesheeres einerseits und der Sozialdemokratie andererseits setzen und den Motiven der am Aufstand Beteiligten Aufmerksamkeit widmen. ${ }^{174}$

Forschungslücken gibt es auch in anderen Bereichen. So sind die vielversprechenden Arbeiten zur Rolle des Staatsapparates in der Umbruchphase ${ }^{175}$ nicht weiter verfolgt worden und bleiben auch Gegensätze zwischen verschiedenen Trägergruppen des Regimes abseits des Heimatschutzes ungeklärt. Beispielsweise ist die Rolle der Katholischen Kirche während der Ersten Republik mehrfach Gegenstand fruchtbarer Untersuchungen gewesen, eine systematische Zusammenschau steht dagegen weiterhin aus. Ein Desiderat bleibt auch eine detaillierte Beschäftigung mit der Frage, weshalb die Aktivierung der Gesellschaft als Herrschaftsmittel trotz imposanter Strukturen der Vaterländischen Front als Monopolorganisation letztlich nur beschränkt gelang. Ein häufig bemühter Grund ist die soziale Funktion des Regimes zugunsten der Besitzenden, die im Großen und Ganzen klar erkennbar ist. Zum einen harrt jedoch die konkrete Entwicklung der Lebens- und Konsumverhältnisse in verschiedenen Bevölkerungsgruppen einer näheren Betrachtung. Zum anderen ist die Frage offen, weshalb das Regime - anders als die großen Faschismen in Deutschland und Italien - offenbar nicht in der Lage war, eine Prekarisierung der Lebensverhältnisse in weiten Teilen der arbeitenden Bevölkerung durch Propaganda und die bereits angesprochene Integration in das faschistische Organisationswesen aufzufangen. Nicht zuletzt bleibt hinsichtlich der diversen personellen und ideologischen Kontinuitäten und Brüche noch viel Arbeit.

$\mathrm{Zu}$ wünschen wäre abschließend ein stärkerer Mut zur Synthese, als dies bislang üblich ist. Denn erst durch verallgemeiner- und diskutierbare Ableitungen wird Zeitgeschichte insofern Gegenwartsgeschichte, als sie ihr emanzipatives Potenzial zu entfalten und gesellschaftliche Reflexionsprozesse jenseits der engen Grenzen der Zunft anzustoßen vermag.

174 Wie viel Arbeit hier noch zu tun bleibt, veranschaulichte jüngst das Beispiel von Weingand, KPÖ.

175 Siehe besonders Peter Huemer, Sektionschef Robert Hecht und die Zerstörung der Demokratie in Österreich, Wien 1975; desgl. Elisabeth Winkler, Die Polizei als Instrument der Etablierungsphase der austrofaschistischen Diktatur (1932-1934). Mit besonderer Berücksichtigung der Wiener Polizei, phil. Diss., Universität Wien 1983. 


\title{
NS-Zeit und Zweiter Weltkrieg
}

\author{
Georg Hoffmann
}

Das Gedenkjahr 2018 stand ganz im Zeichen der einhundertsten Wiederkehr der Ausrufung der Ersten Republik, wie auch des achtzig Jahre zurückliegenden „Anschlusses“ Österreichs an das nationalsozialistische Deutsche Reich. ${ }^{1}$ Aus allen Aktivitäten ragte dabei vor allem die Eröffnung des Hauses der Geschichte Österreich heraus. Für das aus jahrzehntelangen Diskussionen erwachsene zeithistorische Museum war mit dem Wiener Heldenplatz ein historisch aufgeladener Standort gewählt worden, der in unmittelbarer Verbindung mit dem Jahr 1938 stand. Die wissenschaftliche Community hatte bereits im Vorfeld Kernpunkte, aktuelle Fragestellungen und neue Ansätze der Forschung zu Österreichs 20. Jahrhundert diskutiert und definiert und dabei vor allem den Nationalsozialismus als das entscheidende Thema markiert. ${ }^{2}$ Dass sich aus dem Haus dennoch keine wahrzunehmende inhaltlichthematische, sondern fast ausschließlich eine institutionelle Debatte entwickelte, ${ }^{3}$ erstaunt in der Nachbetrachtung - nicht zuletzt aufgrund zahlreicher Ereignisse: So führte etwa die „Germania-Liederbuch-Affäre“ Anfang $2018 \mathrm{zu}$ einer breiten Diskussion um Antisemitismus und gipfelte letztlich in einer von der FPÖ eingesetzten Historikerkommission. ${ }^{4}$ Nahezu zeitgleich weihte die Republik Österreich im belarussischen Maly Trostinec eine neue Gedenkstätte für jüdisch-österreichische NSOpfer ein und stärkte damit auch die wissenschaftlich-öffentliche Diskussion rund

Ich möchte mich an dieser Stelle bei Daniel Brewing, Nicole-Melanie Goll, Birgit Johler, Pia Schölnberger und Dirk Rupnow für wertvolle Hinweise, Anregungen und Unterstützung bedanken.

1 Dazu u. a.: Heinz Fischer (Hg.), 100 Jahre Republik. Meilensteine und Wendepunkte in Österreich 1918-2018, Wien 2019.

2 Vgl. Thomas Winkelbauer (Hg.), Haus? Geschichte? Österreich?: Ergebnisse einer Enquete über das neue historische Museum in Wien, Wien 2016.

3 Als Beispiel der medialen Diskussion: Weiter „Aufbruch ins Ungewisse“ im Haus der Geschichte, Salzburger Nachrichten, 24.10.2019, URL: https://www.sn.at/kultur/allgemein/weiter-aufbruchins-ungewisse-im-haus-der-geschichte-78191812 (abgerufen 15.10.2020); Das Haus der Geschichte in Wien blickt in eine ungewisse Zukunft, Handelsblatt, 11.12.2019, URL: https://www. handelsblatt.com/politik/international/weltgeschichten/siebenhaar/weltgeschichte-das-haus-dergeschichte-in-wien-blickt-in-eine-ungewisse-zukunft/25314606.html (abgerufen 15.10.2020).

4 Vgl. Dirk Rupnow, Das Gedenk- und Erinnerungsjahr 2018 - eine Rückschau, in: zeitgeschichte 46 (2019) 4, 463-479, 464-466; Margit Reiter, Die Ehemaligen: Der Nationalsozialismus und die Anfänge der FPÖ, Göttingen 2019, 287. 
um internationale Dimensionen von Verantwortung, Erinnerung und Täterschaft. ${ }^{5}$ Im Jahr 2019 nahmen dann Kontroversen rund um das Heeresgeschichtliche $\mathrm{Mu}$ seum Wien ihren Anfang, das besonders mit veralteten und teils inkorrekten Darstellungen der NS-Zeit, des Krieges sowie der Belebung österreichischer Opferbilder in die Kritik geraten war. ${ }^{6}$ All diese Debatten fanden und finden zudem entlang einer Schwelle zwischen „Erfahrungs“ und vierter Nachkriegsgeneration statt, geprägt von neuen Fragestellungen und Zugängen, aber auch neuen transdisziplinären Verknüpfungen, die unmittelbaren Einfluss auf die zeitgeschichtliche Forschungslandschaft haben. ${ }^{7}$ Es ist also nicht übertrieben, von einem besonderen Jahr der österreichischen Zeitgeschichte und der NS-Forschung zu sprechen.

Dieser Befund wie auch die generationenbedingte Veränderung zeitgeschichtlicher Forschung bilden den Hintergrund der vorliegenden Ausführungen. Sie verstehen sich als Annäherung an die Entwicklung der österreichischen Zeitgeschichtsforschung, unter Betrachtung der zentralen Themen Nationalsozialismus und Zweiter Weltkrieg, ohne dabei einen Anspruch auf Vollständigkeit zu erheben. Die sehr stark national ausgerichtete NS-Forschung - die gleichzeitig einen transnationalen Impetus hat - lässt den Blick immer wieder nach Deutschland gleiten, das nicht nur in der zeitgeschichtlichen Forschung, sondern auch im öffentlichen Umgang mit der NS-Zeit Bezugspunkte auf mehreren Ebenen aufweist. Im Vergleich zeigen sich österreichische Spezifika, die letztlich eine wissenschaftliche Landschaft formten, auch weil sich - und das sei als Befund vorangestellt - in der österreichischen NSForschung zahlreiche internationale Debatten und neue Forschungsansätze nicht oder nur teilweise verstetigt haben. Der vorliegende Beitrag spürt den Ursachen dafür nach und skizziert neben der allgemeinen Entwicklung der NS-Forschung vor allem zwei international ausgeformte Themenfelder, die in gewisser Hinsicht Desiderate der österreichischen NS-Forschung sind: einerseits die NS-Täterforschung, die gleichzeitig aktuell die Frage nach einer „Volksgemeinschaft“ und damit eine Beleuchtung von Herrschaftsmechanismen aufwirft, andererseits die neuere Sozialund Kulturgeschichte von Krieg und Gewalt, die anhand des Beispiels des noch immer emotional diskutierten Bombenkrieges betrachtet wird.

5 Vgl. Pia Schölnberger (Hg.), Das Massiv der Namen. Ein Denkmal für die österreichischen Opfer der Shoa in Maly Trostinec, Wien 2019.

6 Als Beispiel: Nicole Scheyerer, Wo die Kanonen und Panzer friedlich ruhen, Der Falter, 28.08.2019, URL: https://www.falter.at/zeitung/20190828/wo-die-kanonen-und-panzer-friedlich-ruhen/ (abgerufen 15.10.2020).

7 Vgl. Heidemarie Uhl, Gedenkjahre. Editorial, in: zeitgeschichte 46 (2019) 4, 453-46o. 


\section{NS-Forschungen in der Zeit österreichischer Opferthesen}

„Ich habe im Krieg nichts anderes getan als hunderttausende Österreicher auch, nämlich meine Pflicht als Soldat erfüllt." ${ }^{\text {(8 }}$ Diese Worte des späteren Bundespräsidenten Kurt Waldheim im Wahlkampfjahr 1986 gelten wohl als zentraler Moment und Zäsur im Umgang Österreichs mit seiner NS-Vergangenheit. In der darauffolgenden sehr kontroversen Diskussion wurden verzerrte nationale Geschichtsbilder genauso sichtbar wie Konflikte zwischen der Kriegs- und der ersten Nachkriegsgeneration. Eine der Folgen war die Stärkung einer NS-Forschung, zu deren Leistungen es zählen sollte, Nationalsozialismus und Holocaust in die österreichische Geschichtsschreibung zu integrieren. Lange Jahre war das nicht der Fall gewesen. Aus einem in der unmittelbaren Nachkriegszeit entstandenen antifaschistischen Grundkonsens hatte sich eine nachhaltige Distanzierung der noch jungen Republik Österreich von der NS-Zeit entwickelt. Hintergrund waren der Prozess einer Nationswerdung sowie die Suche nach nationaler Identität, in die eine Abgrenzung von der NS-Vergangenheit und der damit einhergehenden Frage der Verantwortung eingeschrieben war. Die Geschichtswissenschaften, getragen von der nun an die Forschungseinrichtungen zurückkehrenden Kriegsgeneration, formten dieses Bild entscheidend mit. ${ }^{9}$ Neben einer weitgehenden Ausblendung der NS-Zeit fußte die aufgebaute Grunderzählung auf zwei Prämissen: zum einen auf der Auffassung der NS-Zeit als historische Diskontinuität, die jedenfalls nicht Teil der österreichischen Geschichte sei, auch weil nach staatsrechtlicher Definition Österreich als Staat zwischen 1938 und 1945 nicht existiert hatte. Das Jahr 1938 wurde so zum vorläufigen Endpunkt der österreichischen Geschichte, zu einer Grenze vor dem Abgrund einer "dunklen Zeit". ${ }^{10}$ Zum anderen galt die Annahme, dass Schuld und Verantwortung beim NS-Regime selbst zu suchen und allenfalls auf die Bundesrepublik Deutschland zu übertragen seien. Diese Externalisierung galt auch für den Zweiten Weltkrieg, der als „kein österreichischer Krieg ${ }^{{ }^{11}}$ definiert wurde. Beides waren Bausteine der vermeintlich rettenden nationalen Erzählung gegen den Schock über die kaum fassbaren NS-Verbrechen, aber auch gegen die aufkommende Frage der (Mit)

8 Zit. n. Michael Gehler, Die Affäre Waldheim. Eine Fallstudie zum Umgang mit der NS-Vergangenheit in den späten achtziger Jahren, in: Rolf Steininger/Michael Gehler (Hg.), Österreich im 20. Jahrhundert, Bd. 2: Vom Zweiten Weltkrieg bis zur Gegenwart, Wien 1997, 355-414, 358.

9 Vgl. Gerhard Botz, Nationalsozialismus in Wien. Machtübernahme, Herrschaftssicherung, Radikalisierung 1938/39, in: Historical Social Research, Supplement 28 (2016), 241-315, 242.

10 Vgl. Ernst Hanisch, Von der Opfererzählung zum schnellen Moralisieren. Interpretationen des Nationalsozialismus in Österreich, in: Geschichte und Gesellschaft 31 (2005) 2, 255-265, 256.

11 Ernst Joseph Görlich/Felix Romanik, Geschichte Österreichs, Innsbruck 1970, 551. 
Schuld: die Konstruktion einer These, nach der Österreich das „erste Opfer des Nationalsozialismus" geworden sei. ${ }^{12}$ Sie wurde zum Gründungsnarrativ der Zweiten Republik, das sich in das Geschichtsbild einschrieb, untermauert von staatlichen Auftragswerken. ${ }^{13}$

Die entsprechende geschichtswissenschaftliche Bearbeitung etablierte sich in den 1950er-Jahren im Rahmen einer Politikgeschichte, die positivistisch geprägt war und in Österreich die Form einer auf politischem Konsens basierenden Koalitionsgeschichtsschreibung annahm. Kernpunkte des Interesses waren dabei die problematische Zwischenkriegszeit sowie die Gegenerzählung einer Erfolgsgeschichte der Zweiten Republik. ${ }^{14}$ Die NS-Zeit wurde allenfalls unter dem Aspekt des betont österreichischen Widerstands und der Verfolgung von österreichischen Widerstandskämpfern - seltener Widerstandskämpferinnen - betrachtet. ${ }^{15}$ Antisemitismus, Holocaust und jüdische Opfer fanden in der Forschung keinen Platz. ${ }^{16}$ Diese Ausgrenzung galt auch für emigrierte österreichische HistorikerInnen, wie etwa Raul Hilberg, dem die Auswanderung im Jahr 1939 genauso zur Last gelegt wurde wie die „unerbetene Erinnerung “. ${ }^{17}$ Hilberg hatte in den USA bereits früh das erste umfassende Werk zur Verfolgung von Jüdinnen und Juden sowie zum Holocaust vorgelegt, ${ }^{18}$ das jedoch lange, auch in Österreich, nicht wahrgenommen wurde. ${ }^{19}$ Zudem wurde die Frage der Täterschaft, trotz einer intensiven Nachkriegsjustizdebatte, weitgehend nicht gestellt. Das lag auch am Wesen der frühen NS-Forschung, die in der Betrachtung von Herrschaft fast ausschließlich die nationalsozialistische

12 Vgl. Heidemarie Uhl, Vom Opfermythos zur Mitverantwortungsthese: Die Transformation des österreichischen Gedächtnisses, in: Monika Flacke (Hg.), Mythen der Nationen. 1945 - Arena der Erinnerungen, Berlin 2004, 481-509.

13 Siehe: Österreichische Bundesregierung (Hg.), Rot-Weiß-Rot-Buch. Gerechtigkeit für Österreich. Darstellungen, Dokumente und Nachweise zur Vorgeschichte und Geschichte der Okkupation Österreichs, Wien 1946; Ernst Marboe, Das Österreich-Buch, Wien 1948.

14 Siehe dazu als Beispiel: Heinrich Benedikt (Hg.), Geschichte der Republik Österreich, Wien 1954.

15 Vgl. Botz, Nationalsozialismus, 242. Als ein Beispiel: Otto Molden, Der Ruf des Gewissens. Der österreichische Freiheitskampf 1938-1945, Wien 1958.

16 Dazu u. a. Thomas Albrich, Holocaust und Schuldabwehr. Vom Judenmord zum kollektiven Opferstatus, in: Steininger/Gehler (Hg.), Österreich im 20. Jahrhundert, Bd. 2, 39-107, 54-56.

17 Raul Hilberg, Unerbetene Erinnerung. Der Weg eines Holocaust-Forschers, Frankfurt a. M. 1994.

18 Siehe: Raul Hilberg, The Destruction of the European Jews, Chicago 1961. Eines der frühen Werke ist auch: Jonny Moser, Die Judenverfolgung in Österreich 1938-1945, Wien 1966.

19 Vgl. Anna Corsten, „Unerbetene Erinnerer?“ Emigrationshistoriker in den USA als Impulsgeber für die Aufarbeitung von Nationalsozialismus und Holocaust in der Bundesrepublik, in: Dominik Groß/Julia Nebe (Hg.), Forschung zwischen Freiheit und Verantwortung. Die wissenschaftliche Perspektive, Kassel 2018, 199-231. Mit Dank an Anna Corsten für die Hinweise. 
Führungselite und das Umfeld Adolf Hitlers in den Blick nahm. ${ }^{20}$ Die Personifizierung des Bösen ${ }^{21}$ diente dabei als Erklärungsfolie für die Monstrosität der NSVerbrechen - und funktionierte gleichzeitig als Abgrenzung der Gesellschaft von Täterschaft und Schuld. ${ }^{22}$

Das österreichische Opferbild dehnte sich auch auf das Narrativ des Krieges selbst aus, wo letztlich die Erfahrungen hunderttausender ÖsterreicherInnen aufgefangen wurden. Lange vor allem über populärwissenschaftliche Autobiographien

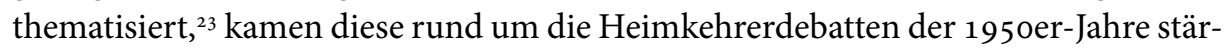
ker ins öffentliche Bewusstsein, wo sie neben dem Bild der „sauberen Wehrmacht“ ${ }^{24}$ eine zweite österreichische Opferthese schufen, wie Heidemarie Uhl attestiert: jene der ÖsterreicherInnen als Opfer des Krieges. ${ }^{25}$ Untermauert wurde dieses Bild etwa, mit Blick auf die ehemaligen Soldaten, durch den „Stalingrad-Mythos“, ${ }^{26}$ aber auch durch die Dienstpflichtargumentation, die in der Waldheim-Affäre so deutlich in Erscheinung treten sollte. Manifest wurde die zweite Opferthese etwa in Form von Kriegerdenkmälern für gefallene „österreichische“ Soldaten des Zweiten Weltkrieges, die ab den 196oer-Jahren in nahezu jeder Gemeinde - meist in Ergänzung von Gedenkzeichen des Ersten Weltkrieges - geschaffen wurden. ${ }^{27}$ Einen besonderen Aspekt stellte dabei die Thematisierung des alliierten Bombenkrieges dar. So wurden häufig in die entstehenden Kriegerdenkmäler auch die zivilen Bombenopfer integriert und damit als militärische Opfer markiert. Die wissenschaftliche Basis

20 Siehe dazu die zentrale Publikation: Joachim Fest, Hitler. Eine Biographie, Frankfurt a. M. 1973.

21 Siehe dazu auch die durchweg immer wieder missverständlich verwendete Formel Hannah Arendts von der „Banalität des Bösen“: Hannah Arendt, Eichmann in Jerusalem. Ein Bericht der Banalität des Bösen, München 1964 .

22 Dazu ausführlich: Klaus-Michael Mallmann/Gerhard Paul, Sozialisation, Milieu und Gewalt. Fortschritte und Probleme der neueren Täterforschung, in: Klaus-Michael Mallmann/Gerhard Paul (Hg.), Karrieren der Gewalt. Nationalsozialistische Täterbiographien, Darmstadt 2011, 1-33.

23 Als Beispiel: Lothar Rendulic, Gekämpft, gesiegt, geschlagen, Wels 1952.

24 Siehe eine der diesbezüglich zentralen Schriften: Siegfried Westphal, Der deutsche Generalstab auf der Anklagebank, Nürnberg 1945-1948, Mainz 1978.

25 Dazu ausführlich: Heidemarie Uhl, Das „erste Opfer“. Der österreichische Opfermythos und seine Transformation in der Zweiten Republik, in: Österreichische Zeitschrift für Politikwissenschaft 30 (2001) 1, 19-34.

26 Zur Stalingrad-Kontroverse, die bis in die 1990er-Jahre anhielt, siehe: Alexander Pollack, Die Wehrmachtslegende in Österreich. Das Bild der Wehrmacht im Spiegel der österreichischen Presse nach 1945, Wien 2002.

27 Dazu u. a.: Heidemarie Uhl, Erinnern und Vergessen. Denkmäler zur Erinnerung an die Opfer der nationalsozialistischen Gewaltherrschaft und an die Gefallenen des Zweiten Weltkriegs in Graz und der Steiermark, in: Stefan Riesenfellner/Heidemarie Uhl (Hg.), Todeszeichen. Zeitgeschichtliche Denkmalkultur in Graz und in der Steiermark vom Ende des 19. Jahrhunderts bis zur Gegenwart, Wien/Köln/Weimar 1994, 111-197. 
dafür bildeten die ersten Arbeiten zu diesem Teil des Krieges, die - und das sollte der deutschsprachigen Luftkriegsforschung bis in die 20ooer-Jahre generell inhärent sein - vor allem von Fragen nach der moralischen und völkerrechtlichen Legitimierung eines „Krieg[es] gegen die Zivilbevölkerung ${ }^{{ }_{28} 8}$ geprägt waren, basierend auf einer mit Zahlen unterfütterten Militär- und hier vor allem einer Operationsgeschichte. ${ }^{29}$

\section{NS-Forschung nach Waldheim}

Erste Änderungen in der geschichtswissenschaftlichen Betrachtung der NS-Zeit ergaben sich vor allem mit der 1968er-Generation, die ab den späten 1970er-Jahren in entsprechende Führungspositionen an den Universitäten aufrückte. Diese Generation war in der Koalitionsgeschichtsschreibung wissenschaftlich sozialisiert worden und diskutierte nun neue Zugänge. Einzelne Impulse kamen dabei auch aus Deutschland, wo etwa Martin Broszat der am Totalitarismuskonzept orientierten deutschen Forschung einen strukturfunktionalistischen Ansatz und damit einen stärker polyzentrischen Blick auf das „Dritte Reich“ entgegenstellte. ${ }^{30}$ Dennoch waren marxistische Faschismustheorien der Zwischenkriegszeit für Österreich prägender. ${ }^{31}$ „Austrofaschismus" und Nationalsozialismus rückten in der wissenschaftlichen Betrachtung und argumentativ nahe aneinander - entlang deutlicher politischer Gräben mit Blick auf die Jahre 1934 und 1938. Die Beschäftigung mit der NS-Zeit intensivierte sich zusehends. Träger dessen war die schrittweise an den Universitäten institutionalisierte Zeitgeschichte, die in den 1960er-Jahren in Wien mit Ludwig Jedlicka und Linz mit Karl R. Stadler sowie in Salzburg mit Erika Weinzierl begann und sich in den 1970er-Jahren in Klagenfurt und in den 1980er-Jahren in Innsbruck und durch Helmut Konrad auch in Graz verstetigte. Vermehrt rückte nun der „vergessene Widerstand“, ${ }^{32}$ nicht zuletzt durch die Schaffung des von Herbert Steiner geleiteten Dokumentationsarchivs des Österreichischen Widerstands (DÖW) im

28 Maximilian Czesany, Nie wieder Krieg gegen die Zivilbevölkerung. Eine völkerrechtliche Untersuchung des Luftkrieges 1939-1945, Graz 1964.

29 Siehe u. a.: Johann Ulrich, Der Luftkrieg über Österreich 1939-1945), Wien 1967.

30 Siehe: Martin Broszat, Der Staat Hitlers. Grundlegung und Entwicklung seiner inneren Verfassung, München 1969.

31 Siehe: Ernst Nolte, Der Faschismus in seiner Epoche, München 1963.

32 Peter Dusek, Der vergessene Widerstand, Wien 1978. 
Jahr 1963 sowie durch eine breite öffentliche Thematisierung, in den Fokus. ${ }^{33}$ Die Vielfalt und Offenheit zu anderen Disziplinen, die in der Zeitgeschichtsforschung Einzug hielten, spiegelten sich auch in der NS-Forschung: etwa in der Betonung der Regionalgeschichte ${ }^{34}$ oder beispielsweise anhand der Entstehung einer historischen Sozialwissenschaft. Der Schwerpunkt entwickelte sich tendenziell in Richtung einer Gesellschaftsgeschichte. ${ }^{35}$ Jedoch blieben Opferthese sowie die Externalisierung von Schuld und Täterschaft die dominanten Elemente und prägten auch den Blick auf die Funktionsweise von NS-Herrschaft, nun jedoch ergänzt um ein trügerisches Bild: Österreich habe seine Vergangenheit erfolgreich bewältigt.

Als Kurt Waldheim 1986 seine umstrittenen Aussagen tätigte, hatte sich eine NS-Forschung im Rahmen der Zeitgeschichte auch in Österreich bereits etabliert, wenn auch weitgehend abseits einer breiten Wahrnehmung. Die Folgewirkungen der Affäre lagen also vor allem im Zerfall der Opferthese, die nun als „Lebenslüge“ 36 identifiziert war. Der noch jungen Zeitgeschichtsforschung kam somit die Aufgabe des Aufbaus eines neuen Narrativs zur NS-Zeit zu. Entscheidend dafür war das „Bedenkjahr“ 1988, das nicht nur von zahlreichen Aktivitäten, Konferenzen und Ausstellungen geprägt war, sondern in dem sich durch das Ende von Archivsperren die Aktenlage zur NS-Zeit deutlich besserte. ${ }^{37}$ Erste Anstrengungen waren dabei vor allem struktur- und gesellschaftsgeschichtlicher Natur, in Form einer gesamtheitlichen Rekonstruktion der NS-Herrschaft in Österreich. ${ }^{8}$ Das war die entscheidende Voraussetzung für tiefergehende Betrachtungen und vor allem für die Integration der NS-Zeit in die österreichische Geschichtsschreibung. ${ }^{39}$ Der so lange dominanten Opferthese wurde etwa durch Gerhard Botz ein mehrschichtiges und multiperspektivisches Bild des „Anschlusses“ im Jahr 1938 auf mehreren Ebenen

33 Siehe dazu die Ausgaben der einzelnen Bundesländer. Exemplarisch: Dokumentationsarchiv des Österreichischen Widerstandes (DÖW) (Hg.), Widerstand und Verfolgung 1934-1945 in Niederösterreich, Wien 1987; Radomír Luža, Der Widerstand in Österreich 1938-1945, Wien 1985. Stellvertretend: Ernst Hanisch, Nationalsozialistische Herrschaft in der Provinz. Salzburg im Dritten Reich, Salzburg 1983.

35 Dazu v. a.: Ernst Hanisch, Der lange Schatten des Staates. Österreichische Gesellschaftsgeschichte im 20. Jahrhundert (Österreichische Geschichte 1890-1990), Wien 1994.

36 Gerhard Botz, Geschichte und kollektives Gedächtnis der Zweiten Republik. „Opferthese“, „Lebenslüge" und "Geschichtstabu“ in der Zeitgeschichtsschreibung, in: Wolfgang Kos/Georg Rigele (Hg.), Inventur 45/55. Österreich im ersten Jahrzehnt der Zweiten Republik, Wien 1996, 51-85.

37 Vgl. Heidemarie Uhl, Zwischen Versöhnung und Verstörung. Eine Kontroverse um Österreichs historische Identität fünfzig Jahre nach dem „Anschluß“, Wien 1992.

38 Siehe: Ernst Hanisch/Wolfgang Neugebauer/Emmerich Tálos (Hg.), NS-Herrschaft in Österreich 1938-1945, Wien 1988.

39 Siehe: Anton Pelinka/Erika Weinzierl (Hg.), Das große Tabu. Österreichs Umgang mit seiner NSVergangenheit, Wien 1987. 
entgegengesetzt, ${ }^{40}$ während die Frage nach Schuld und Verantwortung zaghaft auch zu einer stärkeren Beschäftigung mit Holocaust und Antisemitismus führte. ${ }^{41}$ Das entscheidende Thema dieser Phase blieb aber die Herrschaftsgeschichte. Die nachfolgende Generation von HistorikerInnen stieß sich daran, letztlich weil sie zwar die Opfer thematisiert, nicht aber zu Wort kommen sah. ${ }^{42}$ An dieser Erkenntnis weitete sich der Zugang zur NS-Forschung schrittweise. Aspekte von Zwangsarbeit und NS-Wirtschaft, ${ }^{43}$ die Verfolgung von Jüdinnen und Juden ${ }^{44}$ oder etwa eine kritische Analyse der Rolle und der Verbrechen der Deutschen Wehrmacht, die mit der Wehrmachtsausstellung einen Knalleffekt erleben sollte, ${ }^{45}$ rückten ins Zentrum. ZeitzeugInnen wurden Untersuchungsgegenstand, eine Oral History entwickelte sich, ${ }^{46}$ und der Blick begann sich auf die Basis der NS-Herrschaft und zaghaft auch auf den Alltag im „Dritten Reich“ zu richten. Von besonderer Bedeutung war die Stärkung einer Frauen- und Geschlechterperspektive in der NS-Forschung. ${ }^{47}$ NSVerbrechen wurden nun schrittweise in ihrer Dimension erfasst.

Diese Veränderungen schufen jedoch auch Diskussionspotenzial. International entwickelte sich 1987 eine Debatte zur Historisierung der NS-Zeit zwischen Martin

40 Siehe: Gerhard Botz, War der „Anschluss“ erzwungen?, in: Felix Kreissler (Hg.), Fünfzig Jahre danach - Der Anschluss von innen und außen gesehen, Wien/Zürich 1989, 97-119.

41 Siehe: Hans Safrian/Hans Witek, „Und keiner war dabei“. Dokumente des alltäglichen Antisemitismus in Wien 1938, Wien 1988.

42 Vgl. Hanisch, Opfererzählung, 258.

43 Siehe u. a.: Alice Teichova/Herbert Matis/Andreas Resch (Hg.), Business History. Wissenschaftliche Entwicklungstrends und Studien aus Zentraleuropa, Wien 1999; Florian Freund/Bertrand Perz, Fremdarbeiter und KZ-Häftlinge in der „Ostmark“, in: Ulrich Herbert (Hg.), Europa und der „Reichseinsatz“. Ausländische Zivilarbeiter, Kriegsgefangene und KZ-Häftlinge in Deutschland 1938-1945, Essen 1991, 317-350; Stefan Karner/Peter Ruggenthaler, Zwangsarbeit in der Landund Forstwirtschaft auf dem Gebiet Österreichs 1939 bis 1945, Wien/München 2002.

44 Dazu etwa das schon 1969 erschienene Werk von Erika Weinzierl, das in den 1980er-Jahren neu aufgelegt wurde: Erika Weinzierl, Zu wenig Gerechte. Österreicher und Judenverfolgung 19381945, Graz 1969.

45 Siehe: Walter Manoschek, Österreicher in der Wehrmacht. Zur Selektivität österreichischer Erinnerungsarbeit, in: Dan Diner/Frank Stern (Hg.), Nationalsozialismus aus heutiger Perspektive, Gerlingen 1994; Hannes Heer/Klaus Naumann (Hg.), Vernichtungskrieg. Verbrechen der Wehrmacht 1941-1944, Hamburg 1995. Später: Richard Germann, Österreichische Soldaten in Ost- und Südosteuropa 1941-1945. Deutsche Krieger - nationalsozialistische Verbrecher - österreichische Opfer?, Wien 2006.

46 Siehe exemplarisch: Gerhard Botz, Oral History in Austria, in: BIOS - Zeitschrift für Biographieforschung und Oral History (Sonderheft 1990), 97-106.

47 Siehe u. a. Johanna Gehmacher, „Völkische Frauenbewegung“. Deutschnationale und nationalsozialistische Geschlechterpolitik in Österreich, Wien 1998; Karin Schmidlechner-Lienhart, Frauenleben in Männerwelten. Kriegsende und Nachkriegszeit in der Steiermark, Graz 1997. 
Broszat und Saul Friedländer, getragen von wechselseitigen Befürchtungen der Verzerrungen des Gesamtbildes des Nationalsozialismus. ${ }^{48}$ Es war die Zeit der großen und polarisierenden Theoriedebatten - allen voran jener zwischen den VertreterInnen des Intentionalismus und des Funktionalismus/Strukturalismus, die sich 1996 in die Goldhagen-Debatte steigern sollten. ${ }^{49}$ Gleichzeitig entstand Kritik an beiden Richtungen. Das lag am Vorwurf der Entsubjektivierung und sogar des „apologetischen Reflexes",50 die etwa der Strukturgeschichte schon länger entgegengebracht wurde. Entscheidend war aber, dass beide Ansätze „Herrschaft“ und „Gesellschaft“ als Gegensatzpaare betrachteten. Die Folge waren stärkere Reflexionen der Positionen und Standpunkte der HistorikerInnen ${ }^{51}$ und eine Veränderung im Zugang zur NS-Forschung. Die Alltagsgeschichte etwa stellte genau diese Problematik ins Zentrum und hob in vielerlei Hinsicht die scharfe Trennlinie zwischen „Herrschenden“ und „Beherrschten“ auf. Wegweisend war dafür die Studie von Alf Lüdtke, der Herrschaft als „Kräftefeld“"52 definierte. An diesem Ansatz sollte sich eine beginnende NS-Täterforschung ausrichten, die auch Gegenstand der Goldhagen-Debatte wurde. Damit war ein Paradigmenwechsel eingetreten: Der Schwerpunkt der Betrachtung der NS-Herrschaft hatte sich von einer Beschäftigung mit Gegensatz, Opposition, Resistenz und Dissens hin zu Konsens, Zustimmung und Konformität innerhalb der nationalsozialistischen Gesellschaft verschoben.

Diese neuen Ansätze entwickelten sich auch vor dem Hintergrund des Endes des Kalten Krieges, der in ganz Europa Nachkriegsmythen zerfallen ließ und zu einer Neuverhandlung von Geschichtsbildern führte. Die zunehmend kulturgeschichtlich beeinflussten Fragestellungen gerade an die Gesellschaftsgeschichte formten in den 1990er-Jahren einen mehrschichtigen Cultural Turn aus. Nicht mehr „Ideologie“ oder „Struktur“ waren die vordringlichen Fragen der NS-Forschung, sondern „Erfahrungen“, „Wahrnehmungen“ oder etwa „Weltanschauungen“. Leitthema die-

48 Siehe: Martin Broszat/Saul Friedländer, Um die „Historisierung des Nationalsozialismus“. Ein Briefwechsel, in: Vierteljahreshefte für Zeitgeschichte 36 (1988) 2, 339-372.

49 Vgl. Hans-Ulrich Wehler, Intentionalisten, Strukturalisten und das Theoriedefizit der Zeitgeschichte, in: Norbert Frei (Hg.), Martin Broszat, der „Staat Hitlers“ und die Historisierung des Nationalsozialismus, Göttingen 2007, 71-76; Michael Schneider/Dieter Dowe, Die „GoldhagenDebatte“. Ein Historikerstreit in der Mediengesellschaft, Bonn 1997.

50 Nicolas Berg, Der Holocaust und die westdeutschen Historiker. Erforschung und Erinnerung, Göttingen 2003, 522.

51 Siehe zur Debatte rund um Martin Broszats Mitgliedschaft in der Hitlerjugend: Norbert Frei, NSForschung. Hitler-Junge 1926, Die Zeit, 11.09.2003, URL: https://www.zeit.de/2003/38/Martin_ Broszat (abgerufen 15.10.2020).

52 Alf Lüdtke (Hg.), Herrschaft als soziale Praxis. Historische und sozial-anthropologische Studien, Göttingen 1991, 12. 
ser Phase war, vor allem auch in Österreich, Erinnerung/Gedächtnis. Aufgebaut auf den Studien von Jan und Aleida Assmann, ${ }^{53}$ wurde diese Thematik unter anderem von Heidemarie Uhl in die österreichische NS-Forschung eingebracht. ${ }^{54} \mathrm{Im}$ Kern etablierte sich dabei die Nachgeschichte des Nationalsozialismus, festgemacht am Umgang der Zweiten Republik mit seiner NS-Vergangenheit,55 und dem „Zivilisationsbruch Auschwitz" als Dreh- und Angelpunkt, der gleichzeitig einen transnationalen Zugang öffnete. ${ }^{6} \mathrm{Im}$ Geschichtsbild war aus der Opfer- eine (Mit)Täternation geworden.

Gleichzeitig verankerte sich die Zeitgeschichte stärker in der Öffentlichkeit. Historikerkommissionen wurden eingesetzt, zunächst zur Waldheim-Affäre, dann 1998 zur Frage des Vermögensraubes, der Zwangsarbeit und der Opferentschädigung. ${ }^{57}$ Mit dem Vordringen in die Öffentlichkeit entwickelte sich die Zeitgeschichte mit der NS-Forschung zu einer gesellschaftskritischen Instanz, zu einem „Wächteramt ${ }^{\text {“, } 58}$ das auch in gesellschaftspolitische Bereiche vordrang, etwa in Fragen der Gedenkkultur oder beispielsweise der Museumslandschaft. Vor diesem Hintergrund wurde die Nachgeschichte der NS-Zeit so dominant, dass etwa Ernst Hanisch 1996 von einer „Obsession“ und gleichzeitig von einer „akkusatorisch moralisierenden Geschichtsschreibung " 59 sprach. Im deutschen Kontext war ein ähnlicher Vorwurf auch von Hans Mommsen an den Kulturalismus und an die Kritiker des struktura-

53 Siehe u. a.: Jan Assmann, Erinnerungsräume. Formen und Wandlungen des kulturellen Gedächtnisses, München 1992; Pierre Nora, Zwischen Geschichte und Gedächtnis, Berlin 1990.

54 Siehe u. a.: Uhl, Opfermythos, 481-509.

55 Vgl. Evan Burr Bukey, Hitler's Austria. Popular Sentiment in the Nazi Era 1938-1945, Chapel Hill/ London 2000, 232. Dabei wurden etwa auch Themen wie die Entnazifizierung aufgegriffen, siehe Dieter Stiefel, Entnazifizierung in Österreich, Wien 1981.

56 Vgl. Dan Diner, Zivilisationsbruch. Denken nach Auschwitz, Frankfurt a. M. 1988.

57 Vgl. Clemens Jabloner/Brigitte Bailer-Galanda/Eva Blimlinger/Georg Graf/Robert Knight/Lorenz Mikoletzky/Bertrand Perz/Roman Sandgruber/Karl Stuhlpfarrer/Alice Teichova, Schlussbericht der Historikerkommission der Republik Österreich, Vermögensentzug während der NS-Zeit sowie Rückstellungen und Entschädigungen seit 1945 in Österreich. Zusammenfassungen und Einschätzungen (Veröffentlichungen der Österreichischen Historikerkommission 1), Wien/München 2003.

58 Heidemarie Uhl, Gesellschaft - Gedächtnis - Kultur. Zu den Transformationen der österreichischen Zeitgeschichte, in: Margit Franz/Heimo Halbrainer/Gerald Lamprecht/Karin M. Schmidlechner/Eduard G. Staudinger/Monika Stromberger/Andrea Strutz/Werner Suppanz/Heidrun Zettelbauer (Hg.), Mapping Contemporary History. Zeitgeschichten im Diskurs, Wien 2008, 27-51, 41.

59 Ernst Hanisch, Die Präsenz des Dritten Reiches in der Zweiten Republik, in: Kos/Rigele (Hg.), Inventur, 33-50, 35 . 
listischen Ansatzes, allen voran Nicolas Berg, formuliert und mit der Befürchtung des Verlustes von Realgeschichte verknüpft worden. ${ }^{60}$

Neben Erinnerung/Gedächtnis formte sich in der kulturgeschichtlich geprägten NS-Forschung, zunächst vor allem in Deutschland und kaum in Österreich, schrittweise ein zweiter Schwerpunkt: eine neue Betrachtung von "Gesellschaft" im NSStaat. Aus diesem sollte sich später vor allem in Deutschland die Forschungsthematik der "Volksgemeinschaft“ entwickeln. Basis dessen war, neben der großen Synthese von NS-Herrschaft und Massenmord, die deutlich zunehmende Erschließung von weiteren Opfergruppen. Dies machte letztlich den ubiquitären Verfolgungscharakter des NS-Regimes sichtbar und warf gleichzeitig verstärkt Fragen nach Inklusionsund Exklusionsmechanismen, nach Konsens, Zustimmung und Belohnung innerhalb eines „Herrschaftssystems“ auf. Das brach freilich mit der Strukturgeschichte und ließ die alte Diskussion zwischen FunktionalistInnen und IntenionalistInnen beinahe obsolet erscheinen. 2006 entzündete sich am „Volksstaat"-Modell ${ }^{61}$ von Götz Aly eine neuerliche, internationale Debatte, festgemacht an dessen These einer wirtschaftlich fundierten "Gefälligkeitsdiktatur" ${ }^{62}$ In der Kritik daran wurde deutlich, dass sich ein neuer Paradigmenwechsel abzuzeichnen begann, mit dem Konzept der „Volksgemeinschaft“ als Drehpunkt. Das traf nicht überall auf Zustimmung. So lehnte Hans Mommsen „Volksgemeinschaft" als ursprünglich nationalsozialistisches Konstrukt einer neuen Gesellschaftsform ab. ${ }^{63}$ In der Diskussion vor allem zwischen Ian Kershaw und Michael Wildt wurde das Analysemodell geschärft, dem letztlich das Potenzial zur Neudeutung des Nationalsozialismus zugestanden wurde, ${ }^{64}$ nicht zuletzt durch die Beschäftigung mit der Frage der Normativität. ${ }^{65}$

In Österreich wirkte sich diese Debatte zuvorderst in einer anhaltenden Auffächerung der NS-Forschung auch mit kulturgeschichtlich geprägten Schwerpunk-

60 Siehe: Hans Mommsen, Täter und Opfer - ein Streit um die Historiker, Die Welt, 13.09.2003, URL: https://www.welt.de/print-welt/article259363/Taeter-und-Opfer-ein-Streit-um-die-Historiker. html (abgerufen 15.10.2020).

61 Götz Aly, Hitlers Volksstaat. Raub, Rassenkrieg und nationaler Sozialismus, Frankfurt a. M. 2006.

62 Ebd., 49.

63 Vgl. Hans Mommsen, Changing Historical Perspectives on the Nazi Dictatorship, in: European Review 17 (2009) 1, 73-80.

64 Zur Diskussion siehe: Ian Kershaw, „Volksgemeinschaft“. Potenzial und Grenzen eines neuen Forschungskonzepts, in: Vierteljahreshefte für Zeitgeschichte 59 (2011) 1, 1-17; Michael Wildt, Volksgemeinschaft. Eine Antwort auf Ian Kershaw, in: Zeithistorische Forschungen/Studies in Contemporary History 8 (2011) 1, 102-109.

65 Dazu u. a.: Raphael Gross, Anständig geblieben. Nationalsozialistische Moral, Frankfurt a. M. 2010 sowie Michael Wildt, Die Ambivalenz des Volkes: Der Nationalsozialismus als Gesellschaftsgeschichte, Berlin 2019. 
ten aus. Weitere Opfergruppen wurden erschlossen, Verbrechenskomplexe auch transnational betrachtet und ganze Themenbereiche freigelegt. ${ }^{66}$ Der Einsatz von Kriegsgefangenen und ZwangsarbeiterInnen in der NS-Kriegsindustrie, ${ }^{67}$ Österreicher in der Wehrmacht und als Kriegsgefangene wurden beleuchtet. ${ }^{68}$ "Arisierung“, Kunstraub - und verbunden mit der Nachgeschichte - Restitution waren und sind breitangelegte Themen ${ }^{69}$ wie auch eine Visual History. ${ }^{70}$ Erst jetzt wurden auch das Konzentrationslager Mauthausen ${ }^{71}$ und eine Frauen- und Geschlechterperspektive nachhaltig in die NS-Forschung integriert..$^{72}$ Forschungseinrichtungen begannen sich mit ihrer eigenen NS-Vergangenheit auseinanderzusetzen, ${ }^{73}$ Medizin und Sport kamen in den Fokus. ${ }^{74}$ Ein Schwerpunkt bildete sich, wenngleich auch nachhaltiger in Deutschland, mit der Forschung zur Kriegsendphase aus - durchweg und ursprünglich als Gegenentwurf zum „Stunde-null“-Mythos ${ }^{75}$ gedacht. In zunehmendem Maße gerieten die sogenannten Endphaseverbrechen, wie etwa die

66 Exemplarisch hervorgehoben: Helga Amesberger/Brigitte Halbmayer/Elke Rajal, „Arbeitsscheu und moralisch verkommen“. Verfolgung von Frauen als „Asoziale“ im Nationalsozialismus, Wien 2019.

67 Als ein Beispiel: Stefan Karner/Barbara Stelzl-Marx (Hg.), Kriegsgefangene des Zweiten Weltkrieges. Gefangennahme - Lagerleben - Rückkehr, Wien/München 2005; Oliver Rathkolb (Hg.), NSZwangsarbeit. Der Standort Linz der „Reichswerke Hermann Göring AG Berlin“ 1938-1945, 2 Bde., Wien/Köln/Weimar 2001.

68 Vgl. Günter Bischof/Fritz Plasser/Barbara Stelzl-Marx (Hg.), New Perspectives on Austrians and World War II, New Brunswick 2009; Richard Germann, „Österreichische“ Soldaten im deutschen Gleichschritt?; in: Harald Welzer/Sönke Neitzel/Christian Gudehus (Hg.), „Der Führer war wieder viel zu human, viel zu gefühlvoll“. Der Zweite Weltkrieg aus der Sicht deutscher und italienischer Soldaten, Frankfurt a. M. 2011, 217-233.

69 Siehe u. a. Gabriele Anderl/Alexandra Caruso (Hg.), NS-Kunstraub in Österreich und die Folgen, Wien 2005; Pia Schölnberger/Sabine Loitfellner (Hg.), Bergung von Kulturgut im Nationalsozialismus. Mythen - Hintergründe - Auswirkungen, Wien 2016.

70 Zuletzt: Ina Markova, Die NS-Zeit im Bildgedächtnis der Zweiten Republik, Wien 2018.

71 Siehe z. B.: Bertrand Perz/Florian Freund, Konzentrationslager in Oberösterreich 1938 bis 1945, Wien 2007.

72 Vgl. Sybille Steinbacher (Hg.), Frauen in der NS-Volksgemeinschaft, Göttingen 2007.

73 Siehe u. a. Mitchell G. Ash/Wolfram Nieß/Ramon Pils (Hg.), Geisteswissenschaften im Nationalsozialismus. Das Beispiel der Universität Wien, Wien 2010.

74 Exemplarisch: Herwig Czech/Paul Weindling (Hg.), Österreichische Ärzte und Ärztinnen im Nationalsozialismus. Zwischen Verfolgung, Verstrickung und Täterschaft, Wien 2017; Matthias Marschik/Agnes Meisinger/Rudolf Müllner/Johann Skocek/Georg Spitaler (Hg.), Images des Sports in Österreich. Innenansichten und Außenwahrnehmungen, Wien 2018.

75 Vgl. Gerald Stourzh, 1945 und 1955. Schlüsseljahre der Zweiten Republik. Gab es die Stunde Null? Wie kam es zum Staatsvertrag und Neutralität?, Wien 2005. 
Todesmärsche ungarisch-jüdischer ZwangsarbeiterInnen, ${ }^{76}$ in ihrer spezifischen Ausformung und Einhegung in eine NS-Herrschaft zu Kriegsende in den Fokus. ${ }^{77}$ Auch die Thematik der „Deserteure“ und „Standgerichte“ fand nun eingehende Beleuchtung..$^{8}$

Parallel zur steigenden Vielfalt innerhalb der NS-Forschung nahm auch die öffentliche Aufmerksamkeit zu. Vor allem die beiden Jubiläumsjahre 2005 und 2008 belegen deutlich, wie stark das offizielle Österreich abermals Positionen zur eigenen NS-Vergangenheit zu diskutieren begann - durchaus auch in einem Revival eines eigenen Opferbildes. ${ }^{79}$ Besonders auffallend war dabei die Ausstellung „25 Peaces“ im Jahr 2005, die unter anderem mit Lichtinstallationen den brennenden Stephansdom als Symbol eines österreichischen Opferganges im Krieg - und hier besonders im Bombenkrieg - in das Zentrum rückte. ${ }^{80}$ Im eher verhalten begangenen Jubiläumsjahr 2015 und im durch Diskussionen und die Schaffung eines Hauses der Geschichte Österreich geprägten Jahr 2018 zeigte sich, dass sich Debatten und Zugänge abermals verändert hatten. Diese Entwicklung machte auch vor der Forschung nicht Halt. Wenngleich ein neuerlicher Paradigmenwechsel bislang ausblieb, so zeichnen sich doch deutlich neue Tendenzen ab. ${ }^{81}$ Zaghaft lässt sich ein Rückgang der Forschungen zu Erinnerung und Gedächtnis erkennen - was zu einem Gutteil an einer lange nach Waldheim an die Universitäten gekommenen Generation von HistorikerInnen liegen mag. Gleichzeitig entwickeln sich in Österreich die Forschungen zur „Volksgemeinschaft“ erst und öffnen neue Blicke in das Feld von Täterschaft. Gesamtheitliche Darstellungen der NS-Herrschaft in Österreich stehen noch immer vor der Herausforderung der Zusammenführung einer Makro- mit einer Mikroebene. $^{82}$ Den jüngsten Versuch einer eingehenden Betrachtung unternahm 2017

76 Siehe dazu das bislang einzige umfassende Werk zu diesem Thema: Eleonore Lappin-Eppel, Ungarisch-Jüdische Zwangsarbeiter und Zwangsarbeiterinnen in Österreich 1944/45. Arbeitseinsatz Todesmärsche - Folgen, Wien 2010.

77 Vgl. Sven Keller, Volksgemeinschaft am Ende. Gesellschaft und Gewalt 1944/45, München 2013.

78 Vgl. Walter Manoschek (Hg.), Opfer der NS-Militärjustiz. Urteilspraxis - Strafvollzug - Entschädigungspolitik in Österreich, Wien 2003; Peter Pirker/Florian Wenninger (Hg.), Wehrmachtsjustiz. Kontext, Praxis, Nachwirkungen, Wien 2011.

79 Vgl. Ulrike Felber, Republiksgeschichte im Parlament. Die Jubiläumsausstellung 2008, in: Dirk Rupnow/Heidemarie Uhl (Hg.), Zeitgeschichte ausstellen in Österreich. Museen - Gedenkstätten Ausstellungen, Wien/Köln/Weimar 2011, 275-312.

80 Siehe dazu: Karin Liebhart, Menschen - Mythen - Meilensteine. Die österreichische Milleniumsausstellung 1996, in: Rupnow/Uhl (Hg.), Zeitgeschichte ausstellen, 255-275, 258.

81 Vgl. Birthe Kundrus/Sybille Steinbacher, Kontinuitäten und Diskontinuitäten. Der Nationalsozialismus in der Geschichte des 20. Jahrhunderts, Göttingen 2013.

82 Dazu schon früher: Michael Gehler, Zeitgeschichte im dynamischen Mehrebenensystem. Zwischen Regionalisierung, Nationalstaat, Europäisierung, internationaler Arena und Globalisierung, Bochum 2001. 
der Wiener Historiker Kurt Bauer in seinem Werk „Die dunklen Jahre“, ${ }^{8_{3}}$ in der eine Gesamterzählung der NS-Zeit in Österreich versucht wurde, unter Einbettung des Alltags und damit auch der Analyse der „österreichischen“ NS-Gesellschaft vor allem im Krieg. Die Publikation führte zu einer wissenschaftlichen Debatte, ${ }^{84}$ die wiederum die Frage nach einer Erzählung „,von unten“ in der Betrachtung der NSHerrschaft unter spezifisch „österreichischen“ Vorzeichen zum Thema hatte. Dabei zeigt sich deutlich, welche Möglichkeiten dieses Feld in Österreich bietet und wie stark eine Betrachtung von Alltag neue Blickwinkel evoziert, selbst wenn sie „Volksgemeinschaft" als Analysemodell nur am Rande aufgreift.

Einzelne Themenfelder, die sich international in das Zentrum der NS-Forschung und der zugehörigen Theoriedebatten geschoben haben, gelten jedoch in Österreich in mehrerlei Hinsicht noch immer als Desiderate. Zwei Beispiele seien nun exemplarisch herausgegriffen und näher untersucht.

\section{NS-Täterforschung, Akteure oder die Frage nach NS-Herrschaft}

Betrachtet man die internationale Entwicklung der NS-Forschung, so steht seit etlichen Jahren vor allem die Frage der Täterschaft im Zentrum der wissenschaftlichen Betrachtungen, und dies nicht nur in der Betrachtung der Genese von Verbrechen, sondern vielmehr als „Akteure ${ }^{\text {"85 }}$ auch mit Blick auf die Ausformung von NS-Herrschaft. Umrahmt von Debatten, die teilweise sehr kontrovers geführt wurden, spannte sich ein ganzes Forschungsfeld auf. In den 1970er- und 1980er-Jahren entwickelten sich neue Fragestellungen, aufbauend auf Vorstellungen von Täterschaft, die in der unmittelbaren Nachkriegszeit entstanden waren. Die Abgrenzung von NS-Massenverbrechen und dem Völkermord hatte das Bild prominenter NS-Funktionäre als Hauptakteure entstehen lassen, auf die sämtliche Schuld, aber auch die spezifische Funktionsweise einer NS-Herrschaft projiziert werden konnte. Der Eichmann-Prozess in Israel 1961 fügte dem die bald dominante Vorstellung von „Schreibtisch-

83 Kurt Bauer, Die dunklen Jahre. Politik und Alltag im nationalsozialistischen Österreich 1938-1945, Frankfurt a. M. 2017.

84 Dazu: Martin Tschiggerl/Thomas Wallach, Österreich in der NS-Zeit. Verbrechen ohne Täter?, Der Standard, 16.11.2017, URL: https://www.derstandard.at/story/2000067887091/oesterreich-in-derns-zeit-verbrechen-ohne-taeter? (abgerufen 15.10.2020).

85 Harald Welzer, Wer waren die Täter? Anmerkungen zur Täterforschung aus sozialpsychologischer Sicht, in: Gerhard Paul (Hg.), Täter der Shoah. Fanatische Nationalsozialisten oder ganz normale Deutsche?, Göttingen 2002, 237-253, 238. 
tätern“, „Bürokraten des Massenmordes“86 oder „Verwaltungsmassenmördern“87 hinzu, die wiederum mit der Definition des NS-Apparates, als streng hierarchisch und arbeitsteilig organisiert, unterfüttert wurde. Einzelne Personen erschienen darin als willenlose Erfüllungsgehilfen, die somit keine individuelle Schuld auf sich geladen hatten. Der zugehörige Begriff des „Befehlsnotstands“ wurde weitgehend auf die Kriegsgeneration übertragen und diente nicht nur der juristischen Rechtfertigung, sondern auch der Untermauerung der Opferthese wie auch der Abgrenzung in der Dichotomie „Opfer“ und „TäterIn“. Der entscheidende Punkt dieser Deutung war, dass sich TäterInnen und damit auch NS-FunktionärInnen vom Rest der Gesellschaft abhoben und als Ausnahmen erschienen. Gleichzeitig diente gerade die „Befehlsnotstand“-Argumentation auch als Erklärungsfolie der nachhaltigen Untermauerung des Narrativs von der „sauberen Wehrmacht“, wie sich später deutlich sowohl in der Waldheim- als auch in der Wehrmachtsausstellungsdebatte zeigte.

Schon in seinen ersten Studien in den 1960er-Jahren wies Raul Hilberg früh und ungehört auf ein unrealistisches Bild des NS-Systems hin, dem er die Ansicht entgegenstellte, dass TäterInnen nicht im Gegensatz, sondern als Teil der Gesellschaft aktiv geworden seien. ${ }^{88}$ Dieser Ansatz war geeignet, nicht nur bestehende Vorstellungen zu hinterfragen, sondern auch ein neues Bild der NS-Gesellschaft in den Fokus zu nehmen. In Österreich war es Simon Wiesenthal, der in der Suche nach NSVerbrechern Täterschaft zumindest zu einem öffentlichen Aufregerthema machte. ${ }^{89}$ Vor allem aber sprach er einen Aspekt an, der noch heute in Diskussion steht und etwa von Bertrand Perz und jüngst von Kurt Bauer aufgegriffen wurde: den überproportional hohen Anteil von "ÖsterreicherInnen“ unter den NS-TäterInnen.90 Jedoch standen Überlegungen zu Täterschaft der öffentlichen Meinung und der politikgeschichtlichen, strukturalistischen Schwerpunktsetzung in der Forschung entgegen. So entwickelte sich trotz erster Ansätze keine Täterforschung - vielmehr blieb Täterschaft lediglich ein Aspekt, der in der Widerstand- und Opferforschung mitgedacht wurde bzw. in der Betrachtung der Nachkriegsjustiz Erwähnung fand, jedenfalls aber nicht in eine Herrschaftsgeschichte integriert wurde.

86 Ulrike Jureit, Ein Rhythmus der Geschichte? Generationsgeschichtliche Deutungsmuster zum 20. Jahrhundert, in: Rüdiger Hachtmann/Sven Reichardt (Hg.), Detlev Peukert und die NS-Forschung, Göttingen 2015, 85-102, 97.

87 Arendt, Eichmann, 20.

88 Vgl. Hilberg, Destruction, 277.

89 Siehe: Simon Wiesenthal, Doch die Mörder leben, München 1967.

90 Vgl. Bertrand Perz, Der österreichische Anteil an den NS-Verbrechen. Anmerkungen zur Debatte, in: Helmut Kramer/Karin Liebhart/Friedrich Stadler (Hg.), Österreichische Nation - Kultur - Exil und Widerstand, Wien/Berlin 2006, 223-234. 
In Österreich selbst benötigte es die Waldheim-Debatte 1986 sowie die ein Jahr davor stattfindende Reder-Affäre, ${ }^{91}$ um die Frage der Täterschaft nachhaltig aufzuwerfen. Die nun auch in der NS-Forschung gestellte Frage der (Mit)Verantwortung brach das alte Bild der TäterInnen auf. Gleichzeitig evozierte es die Frage nach einer Definition von Täterschaft - durchaus auch in Erweiterung des Begriffs, etwa in Form des „Bystander" ${ }^{92}$ die in der deutschen Übersetzung mit "ZuschauerIn“ oder „MitläuferIn“ nur ungenügend erfasst wird, ${ }^{93}$ vor allem aber als „AkteurIn“. Über die Definition spannte sich die Frage der Betrachtungsebene auf, die etwa Christopher Browning 1993 in „Ordinary Men“94 mit der Fokussierung der zweiten und dritten Reihe der TäterInnen diskutierte. ${ }^{95}$ Mit „Eichmann-Männer“ publizierte Hans Safrian 1993 eine der ersten österreichischen Forschungen in diese Richtung. ${ }^{96}$ Allerdings, und trotz einer Beschäftigung mit dieser Thematik, entstand hier kein ausgewiesener Forschungsschwerpunkt. International antwortet der im Intentionalismus verankerte Daniel J. Goldhagen auf Browning und spitzte die bereits beschriebene Intentionalismus-Funktionalismus-Debatte zu, die in der Täterforschung zwischen AnhängerInnen eines situativen sowie eines kognitiven Ansatzes geführt wurde. ${ }^{97}$ Die Frage der „Normalität“ war dabei ein Diskussionsgegenstand, der sehr unterschiedlich interpretiert wurde und dabei auf die Beschaffenheit und Funktionsweisen der NS-Gesellschaft hindeutete. In den Ausführungen beider Denkschulen wurden gleichzeitig die „Killing Fields“ im Osten Europas, das Wechselspiel zwischen Zentrale und Peripherie und in weiterer Folge Rahmenbedingungen und Handlungsspielräume von AkteurInnen in unterschiedlichen Kontexten erschlossen, teilweise in sich ausschließenden Gegensatzpaaren..$^{98}$ Einer der

911985 war der in Italien als Kriegsverbrecher verurteilte Walter Reder, der in Österreich als „letzter Kriegsgefangener" galt, nach seiner Freilassung in Österreich von Verteidigungsminister Friedhelm Frischenschlager als „Heimkehrer“ empfangen worden. Vgl. Brigitte Bailer-Galanda/Christian S. Ortner, Am Beispiel Walter Reder: die SS-Verbrechen in Marzabotto und ihre „Bewältigung“, Wien 1985. Aktuell: Barbara Tóth, Der Handschlag. Die Affäre Frischenschlager-Reder, Wien 2018.

92 Victoria J. Barnett, Bystanders. Conscience and Complicity during the Holocaust, London 1999.

93 Siehe: Raul Hilberg, Täter, Opfer, Zuschauer. Die Vernichtung der Juden 1933-1945, Frankfurt a. M. 1996.

94 Christopher R. Browning, Ordinary Men. Reserve Police Battalion 101 and the Final Solution in Poland, New York 1993.

95 Siehe: Klaus-Michael Mallmann, Vom Fußvolk der „Endlösung“. Ordnungspolizei, Ostkrieg und Judenmord, in: Tel Aviver Jahrbuch für deutsche Geschichte 26 (1997), 355-391.

96 Vgl. Hans Safrian, Die Eichmann-Männer, Wien/Zürich 1993.

97 Dazu der Anstoß zur Debatte: Daniel J. Goldhagen, Hitler’s Willing Executioners. Ordinary Germans and the Holocaust, New York 1996.

98 Vgl. Peter Longerich, Tendenzen und Perspektiven der Täterforschung, in: Aus Politik und Zeitgeschichte 2007/14-15, URL: https://www.bpb.de/apuz/30537/tendenzen-und-perspektiven-dertaeterforschung-essay (abgerufen 12.04.2020). 
leitenden Publikationen dieser neuen Richtung innerhalb der NS-Forschung war dabei die von Ulrich Herbert verfasste Biographie zu Werner Best. ${ }^{99}$

Die Betrachtung „normaler“ Männer der zweiten und dritten Reihe verlieh dem Feld Tragkraft und breites wissenschaftliches Potenzial. Eine Erweiterung geschah rasch, etwa unter Integration beziehungsweise Diskussion sozialwissenschaftlicher und sozialpsychologischer Ansätze, der Referenzrahmentheorie von Harald Welzer, ${ }^{100}$ bis hin zu einer Sozial- und Kulturgeschichte von Gewalt, der verstärkten Frage nach „Bystanders“, nach Akteurinnen, ${ }^{101}$ nach Situationen sowie nach Organisationen. ${ }^{102}$ Entscheidend war dann in den 200oer-Jahren die unmittelbare Verquickung mit der aufkommenden Forschungsthematik der „Volksgemeinschaft“. Denn hier spannten sich die entscheidenden Fragen nach den Motiven, der „Moral“, aber eben auch der Funktion und den Narrativen von Gewalt auf und wurden in neue Betrachtungen zur Funktionsweise von NS-Herrschaft überführt. ${ }^{103}$ Jüngst wurde dieses Feld auch durch einen deutschen Beitrag zu „Räumen der Gewalt“"104 ergänzt, der jedoch kontrovers diskutiert wird und in Kritik steht. ${ }^{105}$

Österreich nahm auch an dieser und folgenden Debatten kaum oder nur am Rande Teil. Zwar gab es immer wieder Studien zu Täterkomplexen, auch eingebettet in eine Kollaborationsforschung ${ }^{106}$ - ein Forschungsfeld oder ein Forschungsschwerpunkt formten sich dabei jedoch nie aus, sieht man einmal von den Arbeiten des Dokumentationsarchivs des Österreichischen Widerstandes sowie einer wesentlich intensiveren Betrachtung der Nachkriegsjustiz ab. ${ }^{107}$ So sind bis heute, wie Ernst

99 Vgl. Ulrich Herbert, Best. Biographische Studien über Radikalismus, Weltanschauung und Vernunft 1903-1989, Bonn 1996.

100 Vgl. Harald Welzer, Täter. Wie aus ganz normalen Menschen Massenmörder werden, Frankfurt a. M. 2005.

101 Vgl. Kathrin Kompisch, Täterinnen. Frauen im Nationalsozialismus, Wien/Köln/Weimar 2008.

102 Vgl. Stefan Kühl, Ganz normale Organisationen. Zur Soziologie des Holocaust, Berlin 2014.

103 Exemplarisch: Detlef Schmiechen-Ackermann (Hg.), „Volksgemeinschaft“. Mythos, wirkungsmächtige soziale Verheißung oder soziale Realität im „Dritten Reich“? Propaganda und Selbstmobilisierung im NS-Staat, Paderborn 2012. Zu Gewaltnarrativen: Daniel Brewing, Im Schatten von Auschwitz. Deutsche Massaker an polnischen Zivilisten 1939-1945, Darmstadt 2016; Georg Hoffmann, Fliegerlynchjustiz. Gewalt gegen abgeschossene alliierte Flugzeugbesatzungen 1943-1945, Paderborn 2015.

104 Jörg Baberowski, Räume der Gewalt. Frankfurt a. M. 2015.

105 Vgl. Friedrich Lenger, Wenn Räume töten. Jörg Baberowski entgrenzt die Gewalt, in: Zeitschrift für Ideengeschichte 10 (2016) 2, 101-106.

106 Zuletzt mit einem europäischen Überblick: Klaus Kellmann, Dimensionen der Mittäterschaft. Die europäische Kollaboration mit dem Dritten Reich, Wien/Köln/Weimar 2019, 33-71.

107 Als Beispiel: Winfried R. Garscha/Claudia Kuretsidis-Haider, Justizielle „Diktaturfolgenbewältigung“ in Österreich nach 1945, in: DÖW (Hg.), Forschungen zum Nationalsozialismus und dessen Nachwirkungen in Österreich, Wien 2012, 223-246. 
Hanisch und Evan Burr Bukey attestiert haben, strukturierte Betrachtungen der NSDAP und SS in Österreich oder etwa Biographien zu „österreichischen“ Gauleitern ein Desiderat der österreichischen NS-Forschung. ${ }^{108}$ Die erst kürzlich einsetzende Betrachtung der Tätigkeiten und Handlungsspielräume von „ÖsterreicherInnen " in den Zentren des Massenmordes im Osten ${ }^{109}$ harrt dabei genauso noch einer umfassenden Analyse wie die Themen Herrschaft in der Endphase des Krieges ${ }^{110}$ und „Volksgemeinschaft“.

\section{Forschungen zum Bombenkrieg als Spiegel der Beschäftigung mit einer Kultur- und Sozialgeschichte des Krieges}

Ein durchaus ähnlicher Befund ist für die Forschungen zu Krieg und Kriegserfahrung zu ziehen, die sich in besonderem Maße, gerade für Österreich relevant, in der Thematik des Bombenkrieges ausdrücken. In Deutschland entwickelte sich 2002, wenige Jahre nach der Goldhagen-Debatte, eine emotional geführte Kontroverse unter HistorikerInnen. Ausgangspunkt war die umstrittene Publikation von Jörg Friedrich, in der der alliierte Bombenkrieg indirekt mit dem Holocaust verglichen wurde. ${ }^{111}$ In internationalen Reaktionen zeigte sich deutlich: Der Bombenkrieg hatte sich seit Kriegsende zum Refugium gesellschaftlicher Opferauffassungen entwickelt, die durchweg emotional besetzt den Täterdebatten entgegengestellt wurden. Dabei war die Verbindung zur NS-Forschung und zu ihren Schwerpunktthemen verlorengegangen. Die Bilder der Feuerstürme von Dresden und Hamburg waren dabei

108 Ausnahmen sind: Oliver Rathkolb, Schirach. Eine Generation zwischen Goethe und Hitler, Wien 2020; Ursula Mindler-Steiner, Tobias Portschy. Biographie eines Nationalsozialisten. Die Jahre bis 1945, Eisenstadt 2006.

109 Hier sei die Publikation „Massiv der Namen“ erwähnt, die zu Maly Trostinec zwei Artikel zu Täterschaft aufweist: Peter Stadlbauer, Österreich und die NS-Verbrechen in Maly Trostinec, in: Schölnberger (Hg.), Massiv, 92-102; René Bienert/Georg Hoffmann, Die Täter von Maly Trostinec. Betrachtungen zur Täterschaft und Nachkriegsjustiz im „österreichischen“ Kontext, in: Schölnberger (Hg.), Massiv, 102-114.

110 Dazu als Beispiel: Georg Hoffmann, „Vergeltung“ im Bombenkrieg. Lynchjustiz an alliierten Flugzeugbesatzungen in Deutschland, Österreich und Ungarn 1943-1945, in: Oliver von Wrochem (Hg.), Repressalien und Terror. „Vergeltungsaktionen“ im deutsch besetzten Europa 1939-1945, Paderborn 2017, 249-267.

111 Siehe: Jörg Friedrich, Der Brand. Deutschland im Bombenkrieg 1940-1945, Berlin/München 2002. 
omnipräsente Motive, die Emotionen zu wecken vermochten und sich auch tief in der Populärkultur verankerten. ${ }^{12}$

Basis all dessen waren frühe, sofort nach 1945 einsetzende Luftkriegsforschungen, die zu den ersten historischen Abhandlungen des Zweiten Weltkriegs zählten. ${ }^{113}$ Neben völkerrechtlichen und moralischen Betrachtungen war es vor allem der Zugang einer klassischen Militärgeschichte, die dieses Feld formte. Hier trafen sich operationsgeschichtliche Analysen mit Kriegserfahrungen, garniert mit noch aus der Feder Joseph Goebbels stammenden Deutungen von Krieg und darin eingeschriebenen Feindbildern. ${ }^{114}$

In der internationalen Reaktion auf Jörg Friedrich und der anhaltenden Debatte schärften sich zuvorderst in Deutschland neue Ansätze und Blickwinkel. Die Luftkriegsforschung wurde zu einem neuen Teilfeld einer „Militärgeschichte in der Erweiterung" mit stark sozial- und kulturgeschichtlicher Prägung. ${ }^{15}$ Diese integrierte sich in die NS-Forschung und nahm zunächst vor allem die Aspekte Erinnerung und Gedächtnis in den Fokus. ${ }^{116}$ Schrittweise dehnte sich die Betrachtung auf „Herrschaft“ und später auch auf „Volksgemeinschaft“ und Gewaltmechanismen aus; ${ }^{117}$ neue Standardwerke entstanden, die sich mit Fragen der angloamerikanischen Forschung verbanden. ${ }^{118}$

In Österreich wurde ein derartiger Schritt in ähnlichem Ausmaß nicht vollzogen. Betrachtungen des Bombenkrieges blieben in sich abgekapselt und integrierten sich kaum in die NS-Forschung, wurden von dieser aber auch selten aufgegriffen. Sie blieben häufig einseitige Betrachtungen, die nicht selten die gesellschaftliche Opferperspektive unreflektiert spiegelten. Die Zäsur des Jahres 1986 ging dabei an

112 Vgl. Nicole-Melanie Goll, „Terror Pilots“ and „Bombing Holocaust“. Discourses on Victimization and Remembrance in Austria in the Context of the Allied Aerial Bombardment, in: Marc Landry/ Patrick Kupper (Hg.), Austrian Environmental History (Contemporary Austrian Studies 27), Innsbruck 2018, 277-293.

113 Vgl. Dietmar Süß, Tod aus der Luft. Kriegsgesellschaft und Luftkrieg in Deutschland und England, München 2011, 22-24.

114 Siehe: Czesany, Zivilbevölkerung.

115 Siehe: Thomas Kühne/Benjamin Ziemann, Militärgeschichte in der Erweiterung. Konjunkturen, Interpretationen, Konzepte, in: dies. (Hg.), Was ist Militärgeschichte?, Paderborn/München/Wien/ Zürich 2000, 9-46.

116 Siehe: Jörg Arnold, The Allied Air War and Urban Memory. The Legacy of Strategic Bombing in Germany, Cambridge 2011; Malte Thießen, Eingebrannt ins Gedächtnis. Hamburgs Gedenken an Luftkrieg und Kriegsende 1943 bis 2005, Hamburg 2007.

117 Siehe dazu vor allem: Neil A. Gregor, A Schicksalsgemeinschaft? Allied Bombing, Civilian Morale, and Social Dissolution in Nuremberg 1942-1945, in: The Historical Journal 43 (2000) 4, 10511070; Hoffmann, Fliegerlynchjustiz.

118 Siehe: Süß, Tod. 
der österreichischen Betrachtung des Luftkrieges genauso spurlos vorüber wie etwa die Friedrich-Debatte. Das zeigt sich besonders am Desiderat einer erinnerungsgeschichtlichen Forschung, auch zum zentralen österreichischen Opfersymbol des Bombenkrieges: dem Philipphof. ${ }^{119}$ Die Forschung zum Luftkrieg blieb weitgehend auf militär- und hier auf operationsgeschichtliche Aspekte beschränkt und gleichzeitig regional und lokal begrenzt. ${ }^{120}$ Nur wenige Ausnahmen wiesen auf ein breiteres Spektrum hin. ${ }^{121}$ In kaum einem internationalen Standardwerk zum Luftkrieg sind österreichische Positionen erkennbar. Während in Deutschland Fragen nach Krieg und Gesellschaft, Herrschaftsmechanismen im Bombenkrieg sowie vor allem nach Erinnerung und Gedächtnis, gerade im Kontext von Dresden und Hamburg, ${ }^{122}$ gestellt wurden und werden, ist Ähnliches in Österreich bislang kaum zu erkennen. ${ }^{123}$ Das trifft auch auf Teilthemen wie etwa die Verquickung des Bombenkrieges mit dem Holocaust oder Fluchtbewegungen von „Ausgebombten“ in die Alpen-Donau-Reichsgaue und nationalsozialistische Konstrukte einer „Gemeinschaft unter Bomben" ${ }^{\text {" } u . ~}{ }^{124}$

Die Ursachen für diese Entwicklung liegen neben der stark populärhistorisch und öffentlich-medial getragenen Thematisierung zu einem Gutteil auch an der Militärgeschichte selbst, die noch immer den einbettenden Rahmen der Luftkriegsforschung stellt. In Deutschland hatte sich diese Ende der 1990er- und Anfang der 20ooer-Jahre in die NS-Forschung integriert, dabei die klassische Operationsgeschichte weitge-

119 Eine Ausnahme: Katrin Hammerstein, Weiße Flecken? Österreichische Erinnerungen an den Luftkrieg, in: Jörg Arnold/Dietmar Süß/Malte Thießen (Hg.), Luftkrieg. Erinnerungen in Deutschland und Europa, Göttingen 2009, 114-131.

120 Siehe exemplarisch: Walter Brunner, Bomben auf Graz. Die Dokumentation Weissmann, Graz 1989; Erich Marx (Hg.), Bomben auf Salzburg. Die „Gauhauptstadt“ im „Totalen Krieg“, Salzburg 1995; Marcello La Speranza, Bomben auf Wien. Zeitzeugen berichten, Wien 2003; Gerwin Strobl, Bomben auf Oberdonau. Luftkrieg und Lynchmorde an alliierten Fliegern im „Heimatgau des Führers", Wien 2014.

121 Vgl. Thomas Albrich, Luftkrieg über der Alpenfestung 1943-1945. Der Gau Tirol-Vorarlberg und die Operationszone Alpenvorland, Innsbruck 2014; Siegfried Beer/Stefan Karner, Der Krieg aus der Luft. Kärnten und Steiermark, Graz 1992.

122 Rolf-Dieter Müller/Nicole Schönherr/Thomas Widera (Hg.), Die Zerstörung Dresdens 13. bis 15. Februar 1945. Gutachten und Ergebnisse der Dresdner Historikerkommission zur Ermittlung der Opferzahlen, Göttingen 2010.

123 Siehe: Nicole-Melanie Goll, „Terror Pilots“ and „Bombing Holocaust“: Discourses on Victimization and Remembrance in Austria in the Context of the Allied Air War, in: Landry/Kupper (Hg.), Austrian Environmental History, 277-299.

$124 \mathrm{Zu}$ Gewaltmechanismen im Bombenkrieg und einer „Volksgemeinschaft unter Bomben“ siehe: Hoffmann, Fliegerlynchjustiz, 155-177. 
hend an den Rand gedrängt. ${ }^{125}$ Hier wurde rasch, in Verbindung mit der NS-Täterforschung, der „Referenzrahmen Krieg“ oder „Krieg als Gesellschaftszustand“" ${ }_{126}$ zum entsprechenden Untersuchungsgegenstand. In Österreich blieb die Militärgeschichte weitgehend eine Operationsgeschichte, die sich kaum integrierte und in der zeitgeschichtlichen Forschungslandschaft als zu einschlägig angesehen wurde. ${ }^{127}$ Zwar sind in den letzten Jahren immer wieder neue Ansätze erkennbar, das Fehlen einer modernen und an die NS-Forschung gekoppelten österreichischen Forschung zu Krieg und Militär spiegelt sich jedoch deutlich in der aktuellen Debatte rund um das Heeresgeschichtliche Museum ${ }^{128}$ und führt letztlich dazu, dass Themen wie der Bombenkrieg, vor allem in ihrer Tiefe, Leerstellen der österreichischen Forschung blieben.

\section{Schlussbetrachtungen und Ausblick}

Die Forschung zum Nationalsozialismus ist heute ein zentrales Feld der österreichischen Zeitgeschichte, mit breiter Themenvielfalt und einem entsprechenden gesellschaftlichen Nachhall. Der Weg bis dorthin war weit, beginnend bei politisch als opportun erachteten Geschichtsbildern, die Teil einer Nationswerdung nach Kriegsende sowie der Abgrenzung vom Nationalsozialismus waren, über eine Koalitionsgeschichtsschreibung und die österreichische Opferthese bis hin zu einem gänzlichen Bruch des Geschichtsnarrativs in den 1980er-Jahren. Die Zäsur der Waldheim-Debatte 1986 stellte an die noch junge Zeitgeschichte die Aufgabe, neue Herangehensweisen in der NS-Forschung und zum Umgang Österreichs mit seiner Vergangenheit zu finden. Sie lehnte sich dabei an internationale Debatten an, die ab den 1990er-Jahren gemeinsam mit dem Cultural Turn das Forschungsfeld prägen sollten. Erinnerung und Gedächtnis wurden rasch zu einem Forschungsparadigma, auch weil in Österreich die Frage des Umgangs mit der NS-Zeit virulent war. Parallel verstärkte sich das Interesse an der Thematik der „Herrschaft“, die sich allerdings

125 Siehe dazu exemplarisch: Horst Boog/Gerhard Krebs/Detlef Vogel (Hg.), Das Deutsche Reich und der Zweite Weltkrieg, Bd. 7: Das Deutsche Reich in der Defensive, Stuttgart 2001 sowie Sönke Neitzel/Harald Welzer, Soldaten. Protokolle vom Kämpfen, Töten und Sterben, Frankfurt a. M. 2011.

126 Jan-Philipp Reemtsma, Krieg ist ein Gesellschaftszustand. Zur Eröffnung der Ausstellung „Vernichtungskrieg. Verbrechen der Wehrmacht 1941-1944", in: Mittelweg 36 (1997) 2, 55-60.

127 Als Ausnahme siehe: Manfried Rauchensteiner, Der Krieg in Österreich 1945, Wien 1984.

128 Vgl. u. a. Hannes Leidinger/Verena Moritz, Last der Historie. Das Heeresgeschichtliche Museum in Wien und die Darstellung der Geschichte bis 1945, in: Rupnow/Uhl (Hg.), Zeitgeschichte ausstellen, 15-45. 
nur schrittweise mit der Betrachtung der Beschaffenheit einer NS-Gesellschaft und der Thematik Alltag verband. Die NS-Forschung fächerte sich dabei erheblich auf und ist heute durch eine sehr große Bandbreite und Themenvielfalt gekennzeichnet, die zunehmend international vernetzt ist und transnational gedacht wird. Und dennoch ergeben sich Desiderate der NS-Forschung, da sich theoretische und inhaltliche Debatten in Österreich anders verstetigt haben als im internationalen Vergleich. So erscheint der Zugang zum Bombenkrieg in der Zeit vor Waldheim zu verharren und noch immer als Refugium gesellschaftlicher Opferwahrnehmungen zu fungieren, während gerade die NS-Täterforschung zentrale österreichische Standpunkte und Themen genauso vermissen lässt wie die Forschungen zur „Volksgemeinschaft“. Auch der Zugang zum Zweiten Weltkrieg samt den darin eingeschriebenen Soldatenbildern weist noch erhebliches wissenschaftliches Potenzial der Entwicklung einer neueren österreichischen Militärgeschichte auf - darauf verweist nicht zuletzt die aktuelle Debatte rund um das Heeresgeschichtliche Museum.

In der NS-Forschung tritt nun eine neue Generation von HistorikerInnen auf den Plan, die an die NS-Zeit neue Fragen stellt und stellen wird. Wege sind gerade aufgrund der Vielfalt noch nicht definiert, auch ein neuerlicher Paradigmenwechsel ist noch nicht eingetreten. Es scheint jedoch sicher, dass sich Bilder wandeln werden, nicht zuletzt aufgrund von intensiveren Betrachtungen und neuen Möglichkeiten. Es bleibt auch abzuwarten, ob das Ende der „Erfahrungsgeneration“ zu einer verstärkten Historisierungsdebatte führen und ob die NS-Forschung in ihrer Bedeutung generell zurückgedrängt werden wird. Konzeptionell erscheint vor allem der in der Forschungslandschaft immer wieder diskutierte Analysegegenstand „Volksgemeinschaft" in die Zukunft zu führen - auch mit dem Anspruch, zu einem tieferen Verständnis der Beschaffenheit der nationalsozialistischen Gesellschaft, der Handlungs- und Bewegungsräume Einzelner und etwa der sie umgebenden Normvorstellungen beizutragen und so neue Sichtweisen auf „NS-Herrschaft“ zu ermöglichen. Dabei verspricht auch die Unterkategorie „Volksgemeinschaft im Krieg“ und vor allem zu Kriegsende und im Bombenkrieg neue Erkenntnisse. Die Vielfalt der Themen stellt dafür eine ideale Voraussetzung dar, weil sich die Eindringtiefe erhöht. Aspekte wie etwa "Alter im Nationalsozialismus“, die beispielsweise gleichzeitig NS-Ahnenkonstruktionen berühren, aber auch dem Bild der leistungsorientierten NS-Gesellschaft widersprechen, weisen auf neue Wege hin. Inklusions- und Exklusionsmechanismen sowie ihre Wandelbarkeiten, aber auch Selbstregulierungen sind dabei wichtige Betrachtungsfelder wie auch die Fragen zur Normativität und „Moral“.

Entscheidende Voraussetzung für die Zukunft der NS-Forschung wird jedoch sein, welche Umsetzungsmöglichkeiten eine nun tätige Generation von ForscherIn- 
nen vorfinden wird. Diese unterscheidet sich schon jetzt erheblich von der vorhergehenden. Zumeist von Prekarisierung betroffen und außerhalb einer institutionellen Karriere an den Forschungseinrichtungen angebunden, arbeitet diese Generation in einem anderen Rhythmus und mit ständigem Blick auf die Absicherung der eigenen Existenz. Der Wettlauf um Drittmittel lässt dabei weniger Diskussion, dafür umso mehr Konkurrenz entstehen. Das muss Einfluss auf thematische und wissenschaftstheoretische Entwicklungen haben. Wissenschaft ist in vielerlei Hinsicht zum Wettkampf geworden. Gleichzeitig aber stellen sich dieser Generation auch gänzlich neue Möglichkeiten. Es bleibt abzuwarten, wie diese genutzt werden können. 


\title{
Holocaust
}

\author{
Bertrand Perz
}

Die Forschung zum Holocaust, seit sie diese durch eine US-amerikanischen Fernsehserie popularisierte Bezeichnung für den nationalsozialistischen Massenmord an Juden und Jüdinnen trägt, ist immer wieder von Debatten über ihren Gegenstand und die Grenzen des Themas, ihre methodischen Zugriffe, ihre Perspektiven, ihre Versäumnisse und Ausblendungen begleitet. Das ist für Forschungsfelder per se nichts Besonderes, beim Thema Holocaust ist die wissenschaftliche Forschung aber wie bei wohl keinem anderen Thema von einem öffentlichen Diskurs begleitet, den sie selbst mit befördert hat, den sie allerdings nicht bestimmt. Dies verweist auch darauf, dass der Gegenstand selbst bei aller Historisierung kein abgeschlossener ist, man denke nur an die Restitutions- und Entschädigungsfragen, die uns bis heute begleiten, an letzte Gerichtsverfahren gegen Beteiligte am Massenmord, aber auch an Spuren und Prägungen, die der Holocaust etwa im kollektiven wie individuellen Gedächtnis hinterlassen hat. ${ }^{1}$

Zugleich lässt sich (nicht nur) für den deutschen Sprachraum in den letzten Jahren eine zunehmende Tendenz zur Historisierung der Forschung selbst beobachten, ${ }^{2}$ manche Befunde wie die Studie von Nicolas Berg über die Rolle der westdeutschen Nachkriegshistoriker lösen in der Scientific Community auch heftige Reaktionen aus. ${ }^{3}$ So formulierte Stefan Kühl in Bezug auf eine Raul Hilberg zu seinem zehnten Todestag gewidmeten Tagung ${ }^{4}$ mit kritischem Unterton: Die „Holocaustforschung

$1 \quad$ Karl Fallend, Unbewusste Zeitgeschichte. Psychoanalyse - Nationalsozialismus - Folgen, Wien 2016.

2 Michael Brenner/Maximilian Strnad (Hg.), Der Holocaust in der deutschsprachigen Geschichtswissenschaft. Bilanz und Perspektiven (Dachauer Symposien zur Zeitgeschichte 12), Göttingen 2012; Ulrich Herbert, Holocaust-Forschung in Deutschland: Geschichte und Perspektiven einer schwierigen Disziplin, in: Frank Bajohr/Andrea Löw (Hg.), Der Holocaust. Ergebnisse und neue Fragen der Forschung, Frankfurt a. M. 2015, 31-79. Weitere Literatur außerhalb des deutschen Sprachraums angeführt in Dirk Rupnow, Zeitgeschichte oder Holocaust-Studien? Zum Ort der Erforschung der nazistischen Massenverbrechen, in: Heinz Berger/Melanie Dejnega/Regina Fritz/ Alexander Prenninger (Hg.), Politische Gewalt und Machtausübung im 20. Jahrhundert. Zeitgeschichte, Zeitgeschehen und Kontroversen. Festschrift für Gerhard Botz, Wien/Köln/Weimar 2011, 575-583.

3 Nicolas Berg, Der Holocaust und die westdeutschen Historiker, Erforschung und Erinnerung, Göttingen 2003.

4 René Schlott (Hg.), Raul Hilberg und die Holocaust-Historiographie (Beiträge zur Geschichte des Nationalsozialismus 35), Göttingen 2019. 
befindet sich im Prozess der Selbsthistorisierung“. Es sei, so Kühl zuspitzend, nur eine Frage der Zeit, „bis Historiker beforschen werden, wie frühere Historiker beforscht haben, wie die ersten Forscher über den Holocaust geforscht haben".5

Angesichts der wissenschaftlichen wie medialen Präsenz des Themas mag es erstaunlich klingen, dass es bisher in dieser Form keine umfassendere Darstellung der Entwicklung der Holocaustforschung für Österreich gibt. ${ }^{6}$ Zwar widmete sich eine Tagung des Wiener Wiesenthal Instituts für Holocaust-Studien VWI der Frühgeschichte der Holocaustforschung, die österreichischen Beiträge zu diesem Forschungsfeld waren aber explizit nicht Gegenstand. ${ }^{7}$ Sucht man nach Literaturüberblicken zum Thema, so kann als rezente Darstellung am ehesten ein Sammelband des Dokumentationsarchivs des Österreichischen Widerstandes DÖW herangezogen werden. ${ }^{8}$

Der vorliegende Beitrag hat schon aus Platzgründen nicht den Anspruch, einen bis jetzt fehlenden umfassenden Überblick über die Forschungsgeschichte und -literatur seit $1945 \mathrm{zu}$ geben, vielmehr sollen skizzenhaft einige Überlegungen zur Entwicklung der Holocaustforschung in Österreich angestellt werden, wobei eine nationale Perspektive für sich schon die Frage aufwirft, welche der dafür möglichen Kriterien (wie Gegenstand der Forschung selbst; Diskurse und Debatten; verwendete Quellen; Verortung der ForscherInnen, Institutionen, Projekte; Finanzierung) als relevant für eine nationale Zuordnung angenommen werden.

Aufgeworfen ist aber auch die Frage nach der Reichweite des seit Ende der $1970 e r-$ Jahre verwendeten Begriffs „Holocaust“, um das entsprechende Forschungsfeld, das hier besprochen werden soll, überhaupt vermessen zu können. Der Begriff dient ja nicht nur der Benennung eines historischen Vorgangs, sondern ist durch kulturelle

5 Stefan Kühl, Die Holocaustforschung beforscht sich selbst. Soziologische Perspektiven auf die Probleme der Zeitgeschichtsforschung, Zeitgeschichte online, URL: https://zeitgeschichte-online.de/ kommentar/die-holocaustforschung-beforscht-sich-selbst (abgerufen 20.09.2020).

6 Hinweise auf die Entwicklung des Forschungsfeldes sine eher verstreut und finden sich z. B. in: Berger/Dejnega/Fritz/Prenninger (Hg.), Politische Gewalt; Zeitgeschichte(n) in Österreich. HistorikerInnen aus vier Generationen anlässlich "30 Jahre Zeitgeschichte“. zeitgeschichte 30 (2003) 6; Bertrand Perz/Ina Markova (Hg.), 50 Jahre Institut für Zeitgeschichte der Universität Wien 1966-2016, Wien 2017; Gerhard Botz/Gerald Sprengnagel (Hg.), Kontroversen um Österreichs Zeitgeschichte, Wien 1994 (2008 in der zweiten Auflage erweitert um einen Dokumentenanhang und ein umfängliches Nachwort von Gerhard Botz).

7 Regina Fritz/Éva Kovács/Béla Rásky (Hg.), Als der Holocaust noch keinen Namen hatte/Before the Holocaust had its Name. Zur frühen Aufarbeitung des NS-Massenmordes an Jüdinnen und Juden/ Early Confrontations of the Nazi Mass Murder of the Jews - Simon Wiesenthal Conference 2012, Wien 2016.

8 Brigitte Bailer, Forschungen zur Verfolgung der österreichischen Jüdinnen und Juden, in: DÖW (Hg.), Forschungen zu Vertreibung und Holocaust, Wien 2018, 53-79. 
Einschreibungen seit seiner Verwendung im öffentlichen Sprachgebrauch mit vielen Bedeutungen aufgeladen. ${ }^{9}$

Debatten über die Einbettung in eine Gewalt- und Genozidgeschichte des 20. Jahrhunderts, die Verbindungslinien zum Kolonialismus oder auch die Kontextualisierung in einem Jahrhundert der Lager, Trends der internationalen Forschungsentwicklung haben in Österreich erst in den letzten Jahren eine größere Bedeutung bekommen. Im öffentlichen Diskurs über den Holocaust erfährt der Begriff selbst eine zunehmend inflationäre Verwendung, in dem er auf andere Verbrechenskomplexe des Nationalsozialismus ausgeweitet wird, die nicht oder nur indirekt mit dem Mord an den europäischen Juden und Jüdinnen in Zusammenhang stehen. Überhaupt wird, wie zuletzt Nikolaus Wachsmann in seiner monumentalen Studie „KL“ konstatiert, die gesamte NS-Zeit zunehmend durch die Linse des Holocaust wahrgenommen, verstärkt durch die mediale Bilderverwendung, die "Auschwitz“ als Symbol für den Holocaust omnipräsent macht. ${ }^{10}$

Welche problematischen Effekte die inflationäre Begriffsverwendung für das öffentliche Geschichtsbewusstsein auch in Österreich hat, wird besonders dort deutlich, wo Differenzierung gefragt wäre. So empfehlen PolitikerInnen hierzulande einen Besuch der KZ-Gedenkstätte Mauthausen als Allheilmittel gegen Antisemitismus $^{11}$ oder erinnern an runden Jahrestagen der Befreiung des KZ Mauthausen vor allem an die sechs Millionen ermordeter Juden und Jüdinnen ${ }^{12}$ und erwecken damit der Eindruck, KZs seien vor allem für diese Gruppe von Verfolgten eingerichtet worden. ${ }^{13}$ Mauthausen steht als Konzentrationslager auch, aber eben nicht

9 Katja Köhr, Die vielen Gesichter des Holocaust. Museale Repräsentationen zwischen Individualisierung, Universalisierung und Nationalisierung, Göttingen 2012, 9.

10 Nikolaus Wachsmann, KL. Die Geschichte der nationalsozialistischen Konzentrationslager, München 2015, 23.

11 Bertrand Perz, Pflichtbesuche in der KZ-Gedenkstätte Mauthausen?, Museologien-Blog Gottfried Fliedl, URL: http://museologien.blogspot.com/2019/o4/pflichtbesuche-in-der-kz-gedenkstatte. html (abgerufen 20.07.2020).

1275 Jahre Mauthausen-Befreiung: „Ort gegen Vergessen“, ORF online, 10.05.2020, URL: https://orf. at/stories/3165124/ (abgerufen 20.09.2020).

13 Bis Ende 1940 wurden nach Mauthausen kaum mehr als 100 als Juden kategorisierte Personen eingewiesen. Erst 1941 wurde eine größere Zahl nach Mauthausen eingewiesen, hervor sticht die brutale Ermordung von hunderten niederländischer Juden 1941. Dennoch war der Lagerkomplex Mauthausen/Gusen bis Mitte 1944 eher von der Verfolgung als „politisch“ definierter Gegner des NS aus ganz Europa und von als „kriminell“ und „asozial“ definierten Personen sowie sowjetischen Kriegsgefangenen geprägt. Erst mit der Einweisung ungarischer und polnischer Juden 1944 wurde der Mauthausen/Gusen-Komplex unter quantitativen Perspektiven auch ein maßgeblicher, mit dem Holocaust verbundener Ort. Vgl. Andreas Kranebitter, Zahlen als Zeugen. Soziologische Analysen zur Häftlingsgesellschaft des KZ Mauthausen (Mauthausen-Studien 9), Wien 2014. Die 
zentral für den Massenmord an den europäischen Juden, wie das für die deutschen Vernichtungslager in Ostpolen oder für Auschwitz gilt. Feststellungen wie jene von Wachsmann, Konzentrationslager seien „nicht gleichbedeutend mit dem Holocaust, auch wenn die Geschichte der beiden eng zusammenhängt“, verlassen den fachwissenschaftlichen Diskurs meist nicht. ${ }^{14}$ Generell wird der öffentliche Diskurs über den Holocaust auch in Österreich nur mehr sehr begrenzt durch die (Geschichts) Wissenschaft bestimmt, wodurch eine Kluft zwischen einer enorm differenzierten und kritischen Forschung und einer (mit wenigen Ausnahmen wie den KZ-Gedenkstätten) auf Komplexitätsreduktion und Emotionalisierung, Zwecken wie Identitätsstiftung fixierten öffentlichen, medial vermittelten Verhandlung des Themas, vor allem in den Histotainment-Formaten, immer größer zu werden scheint. ${ }^{15}$

Der vorliegende Beitrag folgt nicht der Tendenz zur inflationären Verwendung des Holocaustbegriffs und damit seiner Entdifferenzierung und Entkontextualisierung, allerdings wird die Erforschung anderer Verbrechenskomplexe, soweit sie mit dem Holocaust strukturell, ereignisgeschichtlich oder von der Forschungsgeschichte her in einem engen Zusammenhang stehen, zum Teil mit in den Blick genommen.

Für die Entwicklung der Holocaustforschung in Österreich lassen sich aus heutiger Sicht vier Phasen ausmachen: In den ersten Nachkriegsjahren waren es Überlebende, die sich ihrer Geschichte bemächtigten und darüber autobiographisch geprägt schrieben, während die Geschichtswissenschaft durch Abwesenheit glänzte. In einer zweiten Phase, von den 1960er- bis Anfang der 1980er-Jahre, in die auch die Institutionalisierung von Zeitgeschichte als eigenem Fach in Österreich fällt, kamen im Rahmen einer entstehenden NS-Forschung beachtliche wissenschaftliche Studien zur Judenverfolgung dazu, sie blieben aber Einzelfälle. Erst ab den 1980erJahren, vor dem Hintergrund der internationalen Forschungsentwicklungen, der Waldheim-Debatte, des Endes des Kalten Krieges, des EU-Beitritts und kommissionell verhandelter Entschädigungs- und Restitutionsfragen, kann man von einer größeren Zahl genuin österreichischer Beiträge zur Holocaustforschung sprechen; eine Phase, die bis Anfang der 20ooer-Jahre reichte. Eine vierte Phase kann als Transund Internationalisierung der Forschung in Österreich, sowohl thematisch und methodisch als auch personell und institutionell, bezeichnet werden, womit aber

Wahrnehmung der Konzentrationslager als Orte der Judenvernichtung hatte allerdings schon durch die veröffentlichten Befreiungsbilder deutscher KZs begonnen, siehe allgemein dazu Cornelia Brink, Ikonen der Vernichtung. Öffentlicher Gebrauch von Fotografien aus nationalsozialistischen Konzentrationslagern nach 1945, Berlin 1998.

14 Wachsmann, KL, 22-23.

15 Jürgen Matthäus, Holocaustforschung in Deutschland, in: Brenner/Strnad (Hg.), Der Holocaust in der deutschsprachigen Geschichtswissenschaft, 28-29. 
zugleich die Frage aufgeworfen ist, was gemessen an den oben erwähnten möglichen Kriterien daran der spezifisch österreichische Beitrag in diesem Forschungsfeld ist.

\section{1. Überlebende schreiben ihre Geschichte - Die Abwesenheit der Geschichtswissenschaft in den ersten Nachkriegsjahrzehnten}

Die ersten zwei Nachkriegsjahrzehnte lassen sich in Bezug auf die historische Forschung zum Judenmord für Österreich in zweifacher Weise charakterisieren: auf der einen Seite die Bemühungen von Überlebenden und Exilanten, die Geschehnisse zu dokumentieren und darzustellen, auf der anderen Seite die Abwesenheit der akademischen Geschichtsforschung. ${ }^{16}$ So kann die Publikationstätigkeit vieler Überlebender als eine Art Selbstermächtigung als HistorikerInnen gesehen werden, deren Texte weit über Erinnerungsberichte hinausgingen. Hermann Langbein publizierte umfangreiche historische Darstellungen über das KZ Auschwitz und wurde dabei schon aufgrund der Spezifik dieses Lagers zu einem weithin bekannten Autor über den Holocaust, ${ }^{17}$ Simon Wiesenthal wiederum baute mit seinem Dokumentationszentrum nicht nur ein umfangreiches Archiv für den Holocaust auf. Sein „Memorandum" an die Bundesregierung in den 1960er-Jahren, gedacht als Aufforderung zu einer aktiveren Verfolgung von NS-Verbrechen durch die österreichische Justiz, beinhaltete ein komplettes, bis heute von der Geschichtswissenschaft nicht zur Gänze eingelöstes Programm für eine Holocaustforschung, die die österreichische Beteiligung im Fokus hatte. ${ }^{18}$ Einige wenige Überlebende verbanden ihre Auseinanderset-

16 Bailer, Forschungen; Regina Fritz/Éva Kovács/Béla Rásky, Der NS-Massenmord an den Juden. Perspektiven und Fragen der frühen Aufarbeitung, in: dies. (Hg.), Als der Holocaust noch keinen Namen hatte (Beiträge zur Holocaustforschung des Wiener Wiesenthal Instituts für HolocaustStudien 2), Wien 2016, 7-19.

17 Hermann Langbein, Die Stärkeren. Ein Bericht, Wien 1949; ders., Menschen in Auschwitz, Wien 1972. Darüber hinaus dokumentierte Langbein auch Gerichtsverfahren: ders., Der Auschwitz-Prozess, 2 Bde., Wien/Frankfurt a. M./Zürich 1965, später auch historische Studien zu Widerstand in den Konzentrationslagern und zu Massentötungen durch Giftgas. Vgl. Brigitte Halbmayr, Zeitlebens konsequent - Hermann Langbein - Eine politische Biographie, Wien 2012; Katharina Stengel (Hg.), Opfer als Akteure. Interventionen ehemaliger NS-Verfolgter in der Nachkriegszeit (Jahrbuch zur Geschichte und Wirkung des Holocaust 2008), Frankfurt a. M./New York 2008.

18 Bertrand Perz, Die österreichische Beteiligung an NS-Verbrechen. Anmerkungen zur Debatte, in: Helmut Kramer/Karin Liebhart/Friedrich Stadler (Hg.), Österreichische Nation - Kultur - Exil und Widerstand. In memoriam Felix Kreissler, Wien/Berlin 2006, 223-234; Gerhard Botz, Simon Wiesenthals Beitrag zur Aufarbeitung der Geschichte des österreichischen Nationalsozialismus. Sein (fast) vergessenes „Memorandum“ zur „Beteiligung von Österreichern an Nazi-Verbrechen“ und die „österreichische Täter-These“, in: Dokumentationsarchiv des österreichischen Wider- 
zung mit einem direkten Professionalisierungsschritt und wurden Historiker, wie Jonny Moser und Herbert Rosenkranz. ${ }^{19}$ Moser, Gründungsmitglied des 1963 entstandenen DÖW, sollte dann auch jener Historiker sein, der Mitte der 1960er-Jahre als Erster einen Gesamtüberblick über die Judenverfolgung in Österreich publizierte. ${ }^{20}$ Rosenkranz folgte in den 1970er-Jahren mit einer weiteren, stark auf Quellen der IKG Wien aufbauenden Darstellung, die lange Zeit als Standardwerk diente. ${ }^{21}$

Die Situation war in eng mit dem Thema Holocaust verknüpften Feldern ähnlich. So kamen die ersten Impulse zur Geschichtsschreibung über Konzentrationslager ausschließlich von KZ-Überlebenden, in Österreich war es neben Langbein Hans Maršálek für Mauthausen, der eine umfangreiche Quellensammlung anlegte, die erste Dauerausstellung in Mauthausen aufbaute und Anfang der 1970er-Jahre eine Dokumentation zur Geschichte des KZ Mauthausen vorlegte. ${ }^{22}$ Maršálek konnte sich dabei allerdings auch auf eine 1967 am neu gegründeten Wiener Institut für Zeitgeschichte vorgelegte ungedruckte Dissertation von Gisela Rabitsch stützen, eine bemerkenswert frühe geschichtswissenschaftliche Auseinandersetzung mit der Thematik, die wiederum von Maršálek in seinen Mauthausen-Publikationen weitgehend ausgeblendet wurde. ${ }^{23}$ Die Auseinandersetzung mit der Verfolgung von Sinti und Roma verlief in ähnlichen Bahnen wie bei Moser und Rosenkranz, eine Pionier-

standes (Hg.), Forschungen zum Nationalsozialismus und dessen Nachwirkungen in Österreich. Festschrift für Brigitte Bailer, Wien 2012, 169-199; allgemein Tom Segev, Simon Wiesenthal. Die Biographie, München 2010.

19 Moser, nach seiner Entlassung aus einem Internierungslager 1944 Mitarbeiter des schwedischen Diplomaten Raoul Wallenberg in Ungarn, begann in den 1950er-Jahren an der Universität Wien ein Geschichtsstudium und promovierte 1962 mit einer Dissertation zum Thema Antisemitismus. Jonny Moser, Von der Emanzipation zur antisemitischen Bewegung: Die Stellung Georg Ritter von Schönerers und Heinrich Friedjungs in der Entwicklungsgeschichte des Antisemitismus in Österreich (1848-1896), phil. Diss., Universität Wien 1962. Rosenkranz, der den Holocaust in einem Internierungslager in der Sowjetunion überlebt hatte, studierte ebenfalls in Wien und war später als Archivar und Historiker in Israel tätig.

20 Jonny Moser, Die Judenverfolgung in Österreich. 1938-1945 (Monographien zur Zeitgeschichte), Wien 1966.

21 Herbert Rosenkranz, Verfolgung und Selbstbehauptung. Die Juden in Österreich 1938-1945, Wien/München 1978.

22 Bertrand Perz, Die KZ-Gedenkstätte Mauthausen. 1945 bis zur Gegenwart, Innsbruck/Wien/Bozen 2006, 213-234.

23 Bertrand Perz, Ausgeblendete Anfänge. Die Dissertation von Gisela Rabitsch über Konzentrationslager in Österreich und ihre selektive Rezeption, in: Perz/Markova (Hg.), Institut für Zeitgeschichte, 334-349; Rabitsch konnte 1970 eine Zusammenfassung ihrer Dissertation veröffentlichen. Gisela Rabitsch, Das KL Mauthausen, in: Hans Rothfels/Theodor Eschenburg (Hg.), Studien zur Geschichte der Konzentrationslager (Schriftenreihe der Vierteljahreshefte für Zeitgeschichte 21), Stuttgart 1970, 50-92. 
studie stammte von der jüdischen kommunistischen Widerstandskämpferin Selma Steinmetz, die allerdings schon Ende der 1920er-Jahre Geschichte, Germanistik und Pädagogik studiert und 1931 promoviert hatte. ${ }^{24}$

Über die Gründe der lange vernachlässigten Auseinandersetzung der Geschichtswissenschaft mit dem Nationalsozialismus und insbesondere mit seinen Massenverbrechen ist ausführlich und viel geschrieben worden. ${ }^{25}$ Dazu zählen jedenfalls: die „Opferthese“ als Gründungspositionierung der Zweiten Republik und die damit verbundene Externalisierung ${ }^{26}$ von Nationalsozialismus und Holocaust, die Frage des österreichischen Nation Building und einer Österreich-Identitä ${ }^{27}$ und generell der Kalte Krieg. Viele der zahlreichen Beiträge zum österreichischen Umgang mit der NS-Zeit sind allerdings sehr auf innerösterreichische Gründe fokussiert und beachten wenig nicht unähnliche Trends in anderen Ländern. ${ }^{28}$

\section{Einzelstudien der 1960er- und 1970er-Jahre}

In den 1960er- und 1970er-Jahren sind für die Holocaustforschung in Österreich nur allmähliche Veränderungen zu bemerken. Trotz der Konjunktur von Zeitgeschichte als neue historische Disziplin, die in den 1960er-Jahren zur Gründung gleich mehrerer universitärer und außeruniversitärer Institutionen führte (DÖW 1963, Institut für kirchliche Zeitgeschichte in Salzburg 1964, Institut für Zeitgeschichte an

24 Selma Steinmetz, Österreichs Zigeuner im NS-Staat, Wien 1966.

25 Die Literatur dazu ist ausufernd, daher hier nur einige wenige Hinweise: Günter Fellner, Die österreichische Geschichtswissenschaft vom „Anschluß“ zum Wiederaufbau, in: Friedrich Stadler (Hg.), Kontinuität und Bruch 1938-1945-1955, Wien 1988, 113-155; Gerhard Botz, Eine deutsche Geschichte 1938 bis 1945 ? Österreichische Geschichte zwischen Exil, Widerstand und Verstrickung, in: zeitgeschichte 14 (1986/1987) 1, 19-38 bzw. Gerhard Botz, Zeitgeschichte in einer politisierten Geschichtskultur: Historiographie zum 20. Jahrhundert in Österreich, in: Historical Social Research, Supplement 28 (2016), 105-132 [der Aufsatz ist ursprünglich erschienen in: Konrad H. Jarausch/Jörn Rüsen/Hans Schleier (Hg.), Geschichtswissenschaft vor 200o. Perspektiven der Historiographiegeschichte, Geschichtstheorie, Sozial- und Kulturgeschichte. Festschrift für Georg G. Iggers zum 65. Geburtstag, Hagen 1991].

26 Heidemarie Uhl, Das „,erste Opfer“. Der österreichische Opfermythos und seine Transformationen in der Zweiten Republik, in: Österreichische Zeitschrift für Politikwissenschaft 30 (2001) 1, 19-34.

27 Johanna Gehmacher, „Österreichs Söhne“ und die „Töchter der Zeit“: Prolegomena zu einer Erfahrungsgeschichte nationaler Identitätspolitik, in: BIOS - Zeitschrift für Biographieforschung und Oral History 27 (2014) 1-2, 44-60.

28 Siehe dazu die Länderberichte zur Erinnerungskultur, wenn auch nicht speziell auf die Forschung gerichtet, in: Volkhard Knigge/Norbert Frei (Hg.), Verbrechen erinnern. Die Auseinandersetzung mit Holocaust und Völkermord, München 2002. 
der Universität Wien 1966, Lehrkanzel bzw. Institut für Neuere Geschichte und Zeitgeschichte an der Universität Linz 1968), ${ }^{29}$ dem rasch weitere zeitgeschichtliche Institute bzw. Abteilungen an anderen Universitätsstandorten folgen sollten, blieb das Thema randständig. Öffentlich breite Thematisierungen der NS-Verbrechen wie der Eichmann-Prozess in Jerusalem, der Frankfurter Auschwitz-Prozess, der der westdeutschen Zeitgeschichtsforschung über Gutachtenaufträge wichtige Impulse lieferte, ${ }^{30}$ und auch die Kreisky-Peter-Wiesenthal-Affäre änderten daran wenig.

Das forschungsleitende Interesse der Zeitgeschichte galt vor allem den Konflikten der Ersten Republik und in Bezug auf die Verfolgungspolitik im Nationalsozialismus zunächst vor allem dem (politischen) Widerstand. ${ }^{31}$ Auch wenn in dieser Phase eine ganze Reihe von Studien zum Nationalsozialismus entstand, blieben historische Arbeiten zur Judenverfolgung im Nationalsozialismus bis Ende der 1970erJahre eher die Ausnahme. Dennoch war die institutionelle Entwicklung von großer Bedeutung auch für die Holocaustforschung: Die wenigen, aber umso wichtigeren Forschungsarbeiten stammten durchweg von Personen, die in den neu gegründeten Institutionen tätig waren, die allerdings vielfältige Forschungsinteressen im Feld der Zeitgeschichte hatten und sich selbst nicht als Spezialisten für die Verfolgungsgeschichte sahen.

$\mathrm{Zu}$ nennen ist hier etwa Erika Weinzierls nach der Haltung der österreichischen Gesellschaft zur Judenverfolgung fragende Studie „Zu wenig Gerechte“, die sich mit von Yad Vashem ausgezeichneten Personen beschäftigte, die Juden und Jüdinnen geholfen hatten, ${ }^{32}$ sowie einschlägige Arbeiten von Gerhard Botz und Karl Stuhlpfarrer. Letzterer hatte bereits 1974 eine präzise Skizze der gesamten Diskriminierungs- und Verfolgungsgeschichte der jüdischen Bevölkerung Österreichs begin-

29 Siehe Zeitgeschichte(n) in Österreich. HistorikerInnen aus vier Generationen anlässlich „30 Jahre Zeitgeschichte". zeitgeschichte 30 (2003) 6.

30 Derartige große Justizverfahren hatten gerade in der Bundesrepublik Deutschland zu umfangreichen historischen Studien in Form von Gerichtsgutachten über NS-Verbrechen geführt. In Österreich wurden schon aufgrund der zögerlichen juristischen Verfolgung derartige Gutachten in dieser Intensität nicht nachgefragt.

31 Wolfgang Neugebauer, Ludwig Jedlicka, Herbert Steiner und die Widerstandsforschung. Aspekte der Frühgeschichte des Instituts für Zeitgeschichte und des Dokumentationsarchivs des österreichischen Widerstandes, in: Perz/Markova (Hg.), Institut für Zeitgeschichte, 62-84; Botz, Zeitgeschichte in einer politisierten Geschichtskultur, 111-115; Hans Safrian, Tabuisierte Täter. Staatliche Legitimationsdefizite und blinde Flecken der Zeitgeschichte in Österreich, in: Botz/Sprengnagel (Hg.), Kontroversen, 527-535, 531.

32 Erika Weinzierl, Zu wenig Gerechte. Österreicher und die Judenverfolgung 1938-1945, Graz/ Wien/Köln 1969. 
nend von der Zeit seit dem Ersten Weltkrieg und bis in die Nachkriegszeit reichend vorgelegt. ${ }^{33}$

Monographisch war es vor allem die Studie von Gerhard Botz über „Wien im Nationalsozialismus", die für den deutschen Sprachraum neue Maßstäbe für die Geschichte einer Großstadt im NS-Staat setzte. Als Stadt mit dem zahlenmäßig größten Anteil jüdischer Bevölkerung im NS-Staat 1938 war die Auseinandersetzung mit Wien von vornherein auch eine mit der Judenverfolgung, wobei vor allem die „Arisierungen" in Wien, hier vor allem die Wohnungspolitik, als eine Form "negativer Sozialpolitik" besondere Aufmerksamkeit erfuhr. ${ }^{34}$

Wie wenig die universitäre Forschung generell in diesem Feld engagiert war, zeigt ein Blick auf die Abschlussarbeiten des Instituts für Zeitgeschichte der Universität Wien. Im ersten Jahrzehnt nach seiner Gründung, also zwischen 1966 und 1975, entstanden zwar elf Studien zum Nationalsozialismus, aber keine explizit zum Thema Judenverfolgung. ${ }^{35}$

Als typische Einzelarbeit in dieser Phase ist auch die in Fortsetzung der Forschungen von Selma Steinmetz an der Universität Salzburg 1982 vorgelegte Dissertation von Erika Thurner über die Verfolgung von Sinti und Roma in Österreich zu sehen, die für längere Zeit einzige umfassende Auseinandersetzung mit diesem Thema. ${ }^{36}$

Kontinuierlich Beiträge zum Thema Judenverfolgung lieferten nicht die Universitäten, sondern in erster Linie das DÖW, in der eine Überlebenden- und Exilgeneration gemeinsam mit jüngeren HistorikerInnen eine dem Selbstverständnis der Institution entsprechende stark dokumentarisch geprägte Forschung betrieb. Mit seiner großen, 1970 gestarteten Quellenedition "Widerstand und Verfolgung" in den einzelnen österreichischen Bundesländern, das an das ältere Regierungsprojekt

33 Karl Stuhlpfarrer, Antisemitismus, Rassenpolitik und Judenverfolgung in Österreich, in: Anna Drabek/Wolfgang Häusler/Kurt Schubert/Karl Stuhlpfarrer/Nikolaus Vielmetti (Hg.), Das österreichische Judentum, Wien 1974, 141-164. In der 3. Auflage (1988) inhaltlich stark erweitert und unter Einbeziehung der neuen Literatur unter dem Titel: Karl Stuhlpfarrer, Judenfeindschaft und Judenverfolgung in Österreich seit dem Ersten Weltkrieg, in: Drabek/Häusler/Schubert/Stuhlpfarrer/Vielmetti (Hg.), Judentum, 141-204.

34 Gerhard Botz, Wien vom „Anschluß“ zum Krieg. Nationalsozialistische Machtübernahme und Politisch-soziale Umgestaltung am Beispiel der Stadt Wien 1938/39, Wien/München 1978 bzw. ders., Nationalsozialismus in Wien. Machtübernahme, Herrschaftssicherung, Radikalisierung, Kriegsvorbereitung 1938/39, Wien 2018.

35 Andreas Huber, Zeitgeschichte, quo vasisti? Forschungsschwerpunkte und Trends am Beispiel der Abschlussarbeiten 1965-2015, in: Perz/Markova (Hg.), Institut für Zeitgeschichte, 242-266.

36 Als Publikation erschienen als: Erika Thurner, Nationalsozialismus und Zigeuner in Österreich. (Veröffentlichungen zur Zeitgeschichte 2), Wien/Salzburg 1983. Als biographische, von Karin Berger herausgegebene Studie siehe auch Ceija Stojka, Wir leben im Verborgenen. Erinnerungen einer Rom-Zigeunerin, Wien 1988. 
anknüpfte, welches in der Formierungsphase des Wiener Zeitgeschichteinstituts durchgeführt, aber nie veröffentlicht worden war, ${ }^{37}$ wurden zahlreiche Dokumente zur Judenverfolgung erstmals publiziert. ${ }^{38}$ Die mit einem breiten Ansatz sowohl zum Widerstand als auch zur Verfolgung angelegte Buchreihe dokumentierte die verschiedensten Aspekte rassistischer Verfolgung von Juden und Jüdinnen, so auch Aspekte des Vermögensentzugs, die erst Jahre später wieder aufgegriffen werden sollten, in großem Umfang vor allem durch die Historikerkommission der Republik Österreich.

Waren die wissenschaftlichen Beiträge zum Holocaust in dieser Phase noch überschaubar, so stieg die Präsenz des Themas im öffentlichen Raum merklich an. Neben der Dauerausstellung im DÖW wurde 1970 die Dauerausstellung über die Geschichte des KZ Mauthausen in der KZ-Gedenkstätte Mauthausen eröffnet, die auch eine Grundlage für deren verstärkte Rezeption ab den 1980er-Jahren werden sollte. 1978 folgte die Österreich-Ausstellung in der KZ-Gedenkstätte Auschwitz, die schon aufgrund der realen wie imaginären Grenzen des Kalten Krieges nie die entsprechende Aufmerksamkeit in Österreich bekommen sollte, auch nicht für die staatlich geförderte politische Bildung. ${ }^{39}$ Allerdings stand in allen, stark an der Opferthese orientierten Ausstellungen der Holocaust nicht im Zentrum, auch nicht in Auschwitz, sondern die politische Verfolgungsgeschichte und der Widerstand. Die

37 Die Regierung hatte im Februar 1962 das Ministerkomitee für die Herausgabe einer geschichtlichen Darstellung über den Beitrag Österreichs zu seiner Befreiung im Sinne der Moskauer Deklaration gebildet. Ludwig Jedlicka, der zu dieser Zeit als Dozent bereits die Gründung des ersten, 1966 geschaffenen universitären Instituts für Zeitgeschichte an der Universität Wien betrieb, wurde gemeinsam mit Friedrich Heer mit der Leitung eines entsprechenden Forschungsprojektes beauftragt. Bis 1965 sollte eine Dokumentation erarbeitet werden, als Titel war „Die österreichische

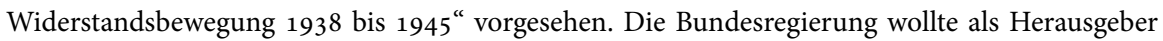
dieser Dokumentation fungieren. Vgl. Gerhard Oberkofler: Das Regierungsprojekt einer Dokumentation über den Beitrag Österreichs zu seiner Befreiung, in: Mitteilungen der Alfred KlahrGesellschaft 2003/3, URL: http://www.klahrgesellschaft.at/Mitteilungen/Oberkofler_3_03.html (abgerufen 20.07.2020) bzw. Neugebauer, Ludwig Jedlicka, Herbert Steiner und die Widerstandsforschung, 68-74.

38 Wolfgang Neugebauer, Widerstandsforschung im DÖW: Die Reihe „Widerstand und Verfolgung“, in: Dokumentationsarchiv des Österreichischen Widerstandes (Hg.), Bewahren - Erforschen Vermitteln, Wien 2008, 73-80; bzw. Wolfgang Neugebauer, Zur Geschichte der Widerstandsforschung, in: Dokumentationsarchiv des Österreichischen Widerstandes (Hg.), Opferschicksale. Widerstand und Verfolgung im Nationalsozialismus. 50 Jahre Dokumentationsarchiv des Österreichischen Widerstandes (Jahrbuch 2013), Wien 2013, 211-232, URL: https://www.doew.at/cms/ download/7os7n/Opferschicksale_Jahrbuch\%202013.pdf (abgerufen 07.11.2020).

39 Daran konnten auch die seit den 1970er-Jahren durchgeführten jährlichen sogenannten LangbeinSymposien mit der Zielgruppe Lehrkräfte, maßgeblich von Anton Pelinka mitgetragen, letztlich wenig ändern. Vgl. URL: http://www.langbeinsymposium.at/ (abgerufen 20.08.2020). 
Involvierung der Geschichtswissenschaft in die Einrichtung dieser Ausstellungen blieb eher bescheiden. ${ }^{\circ}$

\section{Von der Waldheim-Debatte bis zur Historikerkommission der Republik. Die kurze Phase einer „österreichischen" Holocaustforschung}

Die öffentlichen Debatten der 196oer- und 197oer-Jahre über antisemitische Äußerungen und NS-Involvierungen von Hochschulprofessoren, Parteiobmännern und Regierungsmitgliedern hatten wenige Effekte auf die geschichtswissenschaftlichen Forschungsprogramme hinsichtlich einer Holocaustforschung, das gilt auch für die (in Österreich erst mit Verzögerung erfolgte) Ausstrahlung des vierteiligen Fernsehfilms „Holocaust. Die Geschichte der Familie Weiss“ Anfang 1979, die zu einer groBen medialen Präsenz des Themas führte. ${ }^{41}$ Bestandsaufnahmen zeitgeschichtlicher Forschungen Anfang der 1980er-Jahre monierten aber eher fehlende theoretische wie methodische Zugriffe und Reflexionen über die Funktion der Zeitgeschichte und verabschiedeten thematisch die traditionelle Republikgeschichte wie auch die NS-Forschung, die zu diesem Zeitpunkt aus heutiger Sicht aber gerade erst begonnen hatte. ${ }^{42}$

Als mit der Waldheim-Debatte Mitte der 1980er-Jahre die Frage des Umgangs mit der NS-Vergangenheit schlagartig auch eine breite Öffentlichkeit erreichte und die Geschichtswissenschaft feststellen musste, dass ihre Beiträge zur Aufarbeitung der NS-Verbrechen und der österreichischen Beteiligung daran nur bescheiden waren, sahen manche Historiker, allen voran Gerhard Botz, die Zeitgeschichtsforschung in

40 Bertrand Perz, Die Ausstellungen in den KZ-Gedenkstätten Mauthausen, Gusen und Melk, in: Dirk Rupnow/Heidemarie Uhl (Hg.), Zeitgeschichte ausstellen in Österreich. Museen - Gedenkstätten Ausstellungen, Wien/Köln/Weimar 2011, 87-116; Brigitte Bailer/Bertrand Perz/Heidemarie Uhl, Die Österreichische Gedenkstätte in Auschwitz, in: Nationalfonds - Koordinierungsstelle zur Neugestaltung der österreichischen Länderausstellung im Staatlichen Museum Auschwitz-Birkenau (Hg.), Österreichische Gedenkstätte 1978-2013 Staatliches Museum Auschwitz Birkenau, Wien 2015, 114-127.

41 Unmittelbar zur Erstausstrahlung machte „Der Spiegel“ den Fernsehfilm zum Titelthema: „Holocaust. Der Judenmord bewegt die Deutschen“. Der Spiegel 33 (1979) 5, URL: https://www.spiegel. de/spiegel/print/index-1979-5.html (abgerufen 08.11.2020). Der ORF übernahm die Serie erst nach dem großen Publikumserfolg in der Bundesrepublik Deutschland und sendete sie im März 1979. Peter Diem, Antisemitismus.1979-2019: Das Fernsehereignis Holocaust und seine Wirkung, URL: https://austria-forum.org/attach/AEIOU/\%C3\%96sterreich_und_die_Shoa/Holocaust_im_ TV.pdf (abgerufen 30.06.2020).

42 Siegfried Mattl, Bestandsaufnahme zeitgeschichtlicher Forschung in Österreich, Wien 1983. Dazu auch Botz, Zeitgeschichte in einer politisierten Geschichtskultur, 121-122. 
Österreich personell wie inhaltlich in die Krise geraten. ${ }^{43}$ Botz meinte 1991 rückblickend:

Doch mit einem Mal sah sich die österreichische Zeitgeschichte von der Politik und von den Massenmedien wieder gefragt nach scheinbar ganz einfachen „Fakten“, die der strukturgeschichtlichen Sicht und der historisch-sozialwissenschaftlichen Theorieorientierung oft zu banal erschienen waren:

Fragen nach der Rolle von Österreichern in der deutschen Wehrmacht und von deren Rolle beim Massenmord an den Juden oder bei der antislawischen Vernichtungspolitik in Osten und Südosten des Dritten Reiches, nach der Einstellung der österreichischen Bevölkerung zum Nationalsozialismus und zum Antisemitismus, nach deren Rolle bei der Judenverfolgung, nach den Funktionsmechanismen der NS-Herrschaft im Großen und in kleinsten Räumen, alles Probleme, die bisher vernachläßigt worden waren. Dazu kamen grundsätzliche Einschätzungs- und Wertungsfragen, auf die, wenn überhaupt, nur in einem langfristigen kollektiven Dis-kussionsprozeß „Antworten“ gefunden werden konnten. Dies galt für Fragen wie „Österreich und die Österreicher - Täter oder Opfer im Dritten Reich?“ oder „War der „Anschluß“ von außen erzwungen oder nicht?“ oder auch „Hatte es viel oder wenig Widerstand in Österreich gegeben?“44

Bemerkenswert ist in diesem Zusammenhang eine doch sehr differente Wahrnehmung auch unter professionellen Zeithistorikern, was die Präsenz der NS- und Holocaustforschung vor der Waldheim-Debatte betrifft. So betonte etwa Helmut Konrad in einem 2011 formulierten Rückblick auf die Formierungsphase der österreichischen Zeitgeschichte im Konsens mit anderen Einschätzungen die lange Fokussierung auf die Erste Republik und auf Widerstand und Exil, um dann aber übergangslos Erstaunen darüber zum Ausdruck zu bringen, „wie sehr der Monolith Auschwitz für Jahrzehnte den Blick auf den Ersten Weltkrieg verstellte " und wie sehr die Zeitgeschichte diesen Krieg der Militärgeschichte überlassen habe. ${ }^{45}$ So richtig der zweite Teil der Feststellung war, so sehr beruhte die wenig plausible erste wohl auf einer Nichtunterscheidung zwischen öffentlicher und wissenschaftlicher Thematisierung. Anfang der 1980er-Jahre hatte es von Seiten der österreichischen

43 Dies führte $1987 \mathrm{zu}$ einer breiten Diskussion um das Selbstverständnis der österreichischen Zeitgeschichtsforschung: Gerhard Botz/Gerald Sprengnagel (Hg.), Kontroversen um Österreichs Zeitgeschichte, Wien 1994 (2008 in der zweiten Auflage erweitert um einen Dokumentenanhang und ein umfängliches Nachwort von Gerhard Botz).

44 Botz, Zeitgeschichte in einer politisierten Geschichtskultur, 127.

45 Helmut Konrad, Von Linz aus. Die Formierung der Österreichischen Zeitgeschichte, in: Berger/ Dejnega/Fritz/Prenninger (Hg.), Politische Gewalt, 47-58. 
Geschichtswissenschaft - im Unterschied zu den Medien - kaum Beiträge zum KZ Auschwitz gegeben, auch wenn man „Auschwitz“ nur als Chiffre nimmt. ${ }^{46}$

Allerdings erfolgten einzelne Anstöße zur Geschichtsschreibung über NS-Verbrechen durchaus schon vor der Waldheim-Debatte, wie an der Etablierung einer KZ-Forschung am Institut für Zeitgeschichte der Universität Wien deutlich wird, die auf die Außenlager des KZ Mauthausen in Zusammenhang mit Zwangsarbeit für die Kriegswirtschaft gerichtet war. So war Anfang der 1980er-Jahre in der Lehre durch entsprechende Veranstaltungen des Assistenten Karl Haas zwar bereits KZGeschichte präsent, die konkrete Anregung für derartige Forschungsprojekte wurde aber vom Auschwitz-Überlebenden Hermann Langbein an Erika Weinzierl als Vorständin des Instituts für Zeitgeschichte herangetragen. ${ }^{47}$ Die daraus entstandenen umfangreichen, die ökonomischen Hintergründe ihrer Errichtung einbeziehenden Außenlagerstudien waren in der KZ-Forschung in dieser Zeit noch Neuland, ein Forschungsfeld KZ-Geschichte wie auch zur Zwangsarbeit generell war erst im Entstehen begriffen. ${ }^{4}$

46 Von Seiten der österreichischen Geschichtswissenschaft gab es neben der Mitarbeit bei der Einrichtung der Österreich-Ausstellung in der Gedenkstätte Auschwitz 1978 nur vereinzelt Beiträge zu Auschwitz, etwa in der Zeitschrift „Zeitgeschichte“. Eine umfangreichere Studie zu Auschwitz, herausgegeben und kommentiert von Gerhard Botz, war die Publikation eines Interviews mit Margareta Glas-Larsson unter dem Titel: dies., Ich will reden. Tragik und Banalität des Überlebens in Theresienstadt und Auschwitz, Wien/München/Zürich/New York 1981. Zur Nachgeschichte von Auschwitz kann man die 1983 von Thomas Albrich vorgelegte Dissertation zählen, die als erste umfassende Studie über jüdische DPs in Österreich 1987 als Band 1 in der Reihe „Innsbrucker Forschungen zur Zeitgeschichte" publiziert wurde, vgl. Thomas Albrich, Exodus durch Österreich. Die jüdischen Flüchtlinge 1945-1948 (Innsbrucker Forschungen zur Zeitgeschichte 1), Innsbruck 1987.

47 Langbein hatte ursprünglich mit der Österreich-Ausstellung in Auschwitz große Hoffnungen für die politische Bildung verbunden, die sich nicht wirklich erfüllten. Mit dem Hinweis auf fehlende Forschungen zu Außenlagern des KZ Mauthausen fokussierte er nun aber stärker auf den Lagerkomplex Mauthausen. Daraus gingen die Studien von Florian Freund („Arbeitslager Zement“. Das KZ Ebensee und die Raketenrüstung, Wien 1989) sowie Bertrand Perz (Das Projekt „Quarz“ Der Bau einer unterirdischen Fabrik durch Häftlinge des KZ Melk für die Steyr-Daimler-Puch AG 1944-1945, Innsbruck 2014 (überarbeitete Neuauflage von Projekt Quarz. Steyr-DaimlerPuch und das Konzentrationslager Melk, Wien 1991)) hervor; als Nebenprodukt das vom KZÜberlebenden Karl Flanner initiierte Projekt zum Außenlager in Wiener Neustadt: Florian Freund/ Bertrand Perz, Das KZ in der Serbenhalle. Zur Kriegsindustrie in Wiener Neustadt, Wien 1988.

48 Karin Orth, Die Historiografie der Konzentrationslager und die neuere KZ-Forschung, in: Archiv für Sozialgeschichte 47 (2007), 579-598. Der wesentliche Impuls für eine breitere Zwangsarbeitsforschung auch in Österreich kam in den 1980er-Jahren vor allem durch die Rezeption der damals aufsehenerregenden Studie von Ulrich Herbert, Fremdarbeiter. Politik und Praxis des „AusländerEinsatzes" in der Kriegswirtschaft des Dritten Reiches, Berlin/Bonn 1985. 
Generell erfuhr die NS- und Holocaustforschung aber in den 1980er-Jahren durch die Waldheim-Debatte wichtige Impulse. So erschien wohl in direkter Reaktion darauf fünfzig Jahre nach dem „Anschluss“ erstmals ein Sammelband zum Thema NS-Herrschaft in Österreich, den die herausgebenden Historiker und Sozialwissenschaftler selbst als einen ersten Versuch einer Gesamtdarstellung dieser Phase bezeichneten. ${ }^{49}$ Der multiperspektivisch angelegte Band enthielt in Bezug auf NS-Verbrechen eine Reihe von Aufsätzen, darunter ganz neue aus Forschungsprojekten der 1980er-Jahre hervorgegangene Beiträge jüngerer HistorikerInnen zu „Arisierungen“ in Wien, zu Verbrechen der Wehrmacht und zur Zwangsarbeit von zivilen AusländerInnen, KZ-Häftlingen und ungarischen Juden und Jüdinnen..$^{\circ}$ Die HistorikerInnen des DÖW steuerten Beiträge zur Judenverfolgung und zum NSTerrorapparat bei. ${ }^{51}$

Im selben Jahr legten Hans Witek und Hans Safrian unter dem provokanten, von der Waldheim-Debatte deutlich beeinflussten Titel „Und keiner war dabei“ eine aufsehenerregende Quellensammlung vor, die die Frage der Mitverantwortung der österreichischen Gesellschaft bei der Terrorisierung und Verfolgung der jüdischen Bevölkerung, insbesondere bei der Beraubung in den Monaten nach dem "Anschluss“ stellte, ${ }^{52}$ weitere einschlägige Dokumente publizierte das DÖW in einer zum runden Jahrestag vorgelegten Dokumentation zum „Anschluss“.53

49 Emmerich Tálos/Ernst Hanisch/Wolfgang Neugebauer (Hg.), NS-Herrschaft in Österreich 19381945, Wien 1988.

50 Hans Witek, „Arisierungen“ in Wien. Aspekte nationalsozialistischer Enteignungspolitik 19381940, in: Tálos/Hanisch/Neugebauer (Hg.), NS-Herrschaft, 199-216; Walter Manoschek/Hans Safrian, Österreicher in der Wehrmacht, in: Tálos/Hanisch/Neugebauer (Hg.), NS-Herrschaft, 331-360; Florian Freund/Bertrand Perz, Industrialisierung durch Zwangsarbeit, in: Tálos/Hanisch/ Neugebauer (Hg.), NS-Herrschaft, 95-114; geschlechtergeschichtlich über Formen der Arbeit Karin Berger, „Hut ab vor Frau Sedlmayer“. Zur Militarisierung und Ausbeutung der Arbeit von Frauen im nationalsozialistischen Österreich, in: Tálos/Hanisch/Neugebauer (Hg.), NS-Herrschaft, 141-162.

51 Wolfgang Neugebauer, Das NS-Terrorsystem, in: Tálos/Hanisch/Neugebauer (Hg.), NS-Herrschaft, 163-184; Jonny Moser, Österreichs Juden unter der NS-Herrschaft, in: Tálos/Hanisch/Neugebauer (Hg.), NS-Herrschaft, 185-198. Bezeichnenderweise war die dem Band beigegebene Bibliographie keine Auflistung bisheriger österreichischer Forschungsbeiträge oder im Band hauptsächlicher verwendeter Literatur, sondern eine Zusammenstellung deutscher und internationaler Forschungsarbeiten, gedacht als Aufforderung zur Rezeption der deutschen und internationalen Forschungstrends.

Hans Safrian/Hans Witek, Und keiner war dabei. Dokumente des alltäglichen Antisemitismus in Wien 1938, Wien 1988; parallel dazu beschäftigte sich zu dieser Zeit auch Michael John in Linz mit Fragen des Vermögensentzuges, vgl. Michael John, Beschlagnahmte Vermögen und „Arisierungen“ in Linz, in: Verband Österreichischer Geschichtsvereine (Hg.), Bericht über den XVIII. Historikertag in Linz 1990, Wien 1991, 89-96.

53 Dokumentationsarchiv des österreichischen Widerstandes (Hg.), „Anschluß“ 1938. Eine Dokumentation, Wien 1988. 
Direkt als Folge der Waldheim-Debatte entstanden auch die ersten kritischen Studien zur Rolle von Österreichern in der Wehrmacht, ${ }^{54}$ die dann in den 199oerJahren zum Engagement von Walter Manoschek und Hans Safrian als Kuratoren der Hamburger Ausstellung über Verbrechen der Wehrmacht führten. ${ }^{55}$

Welchen Effekt die Waldheim-Debatte insgesamt auf die Geschichtsschreibung zu NS-Verbrechen in Österreich hatte, ist nicht wirklich zu bemessen, da Ende der 1980er-Jahre die globalen politischen Umbrüche mit dem Ende des Kalten Krieges (und dem darauffolgenden EU-Beitritt Österreichs) mindestens ebenso große Auswirkungen auf die Forschungslandschaft hatten, ganz praktisch etwa die Öffnung von vielen Archiven. Jedenfalls kann ab Ende der 1980er-Jahre eine doch erhebliche Zunahme an einschlägigen Projekten und Studien konstatiert werden. Allerdings blieb ein für Österreich charakteristische Phänomen bestehen, das nicht zuletzt auch mit der Kleinheit der Forschungs-Community und fehlender wissenschaftlicher Infrastruktur zu tun hatte. Einzelne Felder im Bereich Holocaustforschung wurden meist nur durch eine, teilweise herausragende Einzelstudie bearbeitet, das wenig austauschfördernde Nischendasein verschaffte aber den AutorInnen zugleich eine Pionierrolle im jeweiligen Spezialbereich. Ohne jeden Anspruch auf Vollständigkeit seien hier wesentliche Themenbereiche benannt, soweit sie nicht schon erwähnt wurden: erste Studien zur Täterforschung (noch ohne Perspektive auf Frauen), ${ }^{56}$ zur Judenverfol-

54 Unter der Leitung von Karl Stuhlpfarrer wurde das Forschungsprojekt „Der Balkan im Zweiten Weltkrieg als Teil der österreichischen Zeitgeschichte" (Projektbericht für das BMWuF, Wien 1989) durchgeführt, an dem u. a. Walter Manoschek und Hans Safrian mitwirkten. Manoschek schloss mit seiner Dissertation über Wehrmachtsverbrechen auf dem Balkan direkt an dieses Projekt an: ders., „Serbien ist judenfrei“. Militärische Besatzungspolitik und Judenvernichtung in Serbien 1941/42, München 1993; den damaligen Forschungsstand zusammenfassende, für die politische Bildung erstellte kritische Darstellung der Wehrmachtsgeschichte: Dokumentationsarchiv des österreichischen Widerstandes, Wolfgang Neugebauer/Bundesministerium für Unterricht, Kund und Sport, Elisabeth Morawek (Hg.), Österreicher und der Zweite Weltkrieg, Wien 1989.

55 Hamburger Institut für Sozialforschung (Hg.), Vernichtungskrieg. Verbrechen der Wehrmacht 1941 bis 1944 (Katalog zur Ausstellung „Vernichtungskrieg - Verbrechen der Wehrmacht 1941 bis 1944“), Hamburg 1996.

56 Hier vor allem für die vielbeachtete, von Hans Safrian vorgelegte Publikation: ders., Die EichmannMänner, Wien/Zürich 1993. Zwar war bereits vor Safrians Studie ein zentraler österreichischer Verantwortlicher für den Holocaust thematisiert worden, die Studie stammte aber vom US-amerikanischen Historiker Peter Black: ders., Ernst Kaltenbrunner: Vasall Himmlers, eine SS-Karriere, Paderborn/München/Wien/Zürich 1991. Später: Thomas Geldmacher-Musiol, „Wir Als Wiener waren ja bei der Bevölkerung beliebt“. Österreichische Schutzpolizisten und die Judenvernichtung in Ostgalizien 1941-1944, Wien 2002; Thomas Mang, „Gestapo-Leitstelle Wien - Mein Name ist Huber“. Wer trug die lokale Verantwortung für den Mord an den Juden Wiens?, Münster 2004. 
gung in einzelnen Städten, ${ }^{57}$ Studien zu Kultusgemeinden bzw. Judenräten, ${ }^{58} \mathrm{zu}$ Deportationen aus Österreich, ${ }^{59} \mathrm{zu}$ Ghettos ${ }^{60}$ und zum KZ Auschwitz-Birkenau, ${ }^{61}$ zur Deportation ungarischer Juden als ZwangsarbeiterInnen nach Ostösterreich. ${ }^{62}$

Der Schwerpunkt der meisten Forschungen lag aber weniger bei den konkreten Verbrechen selbst, sondern vielmehr bei Fragen von Vertreibung und Exil, ${ }^{63}$ der Entnazifizierung, ${ }^{64}$ der justiziellen Aufarbeitung, ${ }^{65}$ der Entschädigung und Restitution $^{66}$ sowie beim Umgang mit dem Holocaust. ${ }^{67}$

57 Robert Streibel, Plötzlich waren sie alle weg - Die Juden der ,Gauhauptstadt Krems` und ihre Mitbürger, Wien 1991.

58 Erstmal eine umfassende Analyse der Wiener Kultusgemeinde während der gesamten NS-Zeit: Doron Rabinovici, Instanzen der Ohnmacht. Wien 1938-1945. Der Weg zum Judenrat, Frankfurt a. M. 2000.

59 Gabriele Anderl/Walter Manoschek, Gescheiterte Flucht. Der Jüdische „Kladovo-Transport“ auf dem Weg nach Palästina 1939-42, Wien 1993.

60 Jüdisches Museum Frankfurt am Main (Hg.), „Unser einziger Weg ist Arbeit“. Das Getto in Lodz 1940-1944, Wien 1990 bzw. Florian Freund/Bertrand Perz/Karl Stuhlpfarrer, Das Ghetto in Lodz, Wien 1993, URL: http://phaidra.univie.ac.at/o:378879 (abgerufen 21.09.2020). Bereits $1971 \mathrm{war}$ ein Totenbuch Theresienstadt, wenn auch stark wegen der damaligen Quellenlage fehlerbehaftet, erschienen, vgl. Jüdisches Komitee Theresienstadt (Hg.), Totenbuch Theresienstadt. Deportierte aus Österreich, Wien 1971, das 2005 vom DÖW neu bearbeitet wieder aufgelegt wurde.

61 Florian Freund/Bertrand Perz/Karl Stuhlpfarrer, Der Bau des Vernichtungslagers Auschwitz-Birkenau. Die Aktenmappen der Zentralbauleitung Auschwitz. „Vorhaben: Kriegsgefangenenlager Auschwitz (Durchführung der Sonderbehandlung)“ im Militärhistorischen Archiv Prag, in: zeitgeschichte 20 (1993) 5/6, 187-214.

62 Michael Achenbach/Dieter Szorger, Der Einsatz ungarischer Juden am Südostwall im Abschnitt Niederdonau 1944/45, Dipl.-Arb., Universität Wien 1997; Harald Strassl/Wolfgang Vosko, Das Schicksal ungarisch-jüdischer Zwangsarbeiter am Beispiel des Südostwallbaus 1944/45 im Bezirk Oberwart. Unter besonderer Berücksichtigung der Massenverbrechen bei Rechnitz und Deutsch Schützen, Dipl.-Arb., Universität Wien 1999; zur selben Zeit erschien auf Deutsch auch die ungarische Studie von Szabolcs Szita, Verschleppt, verhungert, vernichtet. Die Deportation von ungarischen Juden auf das Gebiet des annektierten Österreich 1944-1945, Wien 1999.

63 Siehe etwa die vom DÖW zwischen 1984 und 2002 herausgegebene siebenbändige Dokumentationsreihe „Österreicher im Exil“; Friedrich Stadler, Vertriebene Vernunft. Emigration und Exil österreichischer Wissenschaft, 1930-1940, 2 Bde., Wien 1987/88.

64 Siehe den Forschungsüberblick von Dieter Stiefel, Forschungen zur Entnazifizierung in Österreich. Leistungen, Defizite, Perspektiven, in: Walter Schuster/Wolfgang Weber (Hg.), Entnazifizierung im regionalen Vergleich, Linz 2004, 43-57.

65 Zur Forschungsentwicklung siehe Thomas Albrich/Winfried R. Garscha/Martin F. Polaschek (Hg.), Holocaust und Kriegsverbrechen vor Gericht. Der Fall Österreich, Innsbruck/Wien/Bozen 2006. Ausführliche Literaturangaben unter URL: http://www.nachkriegsjustiz.at/service/biblio/gesamtbibliogr.php (abgerufen 22.08.2020).

66 Brigitte Bailer-Galanda, Wiedergutmachung kein Thema. Österreich und die Opfer des Nationalsozialismus, Wien 1993.

67 In vergleichender Perspektive unter Einbeziehung von Österreich etwa: Rolf Steininger (Hg.), Der Umgang mit dem Holocaust. Europa - USA - Israel, Wien/Köln/Weimar 1994. 
$\mathrm{Zu}$ den wichtigsten Dokumentationsprojekten zählte in dieser Phase das zeitlich unmittelbar an die Waldheim-Debatte anknüpfende DÖW-Projekt der „Namentlichen Erfassung der österreichischen Holocaust-Opfer“, das mit Verweis auf ähnliche bereits durchgeführte Projekte in der Bunderepublik Deutschland und anderen Ländern von der Gedenkstätte Yad Vashem angeregt worden war, die Teilfinanzierung durch die Bundesregierung erfolgte aber erst Anfang der 1990er-Jahre. Das DÖW sah darin eine konsequente Fortsetzung der von Jonny Moser bereits geleisteten Pionierarbeit in Bezug auf die Judenverfolgung und erfasste bis 2001 in einer online verfügbaren Datenbank über 62.00o Opfer namentlich. ${ }^{68}$

Auf universitärer Ebene betrieb das Innsbrucker Institut für Zeitgeschichte zu dieser Zeit ein nicht unähnliches Projekt unter der Leitung von Thomas Albrich. Ziel war eine umfassende biographische Erhebung zur Geschichte der Juden in Tirol und Vorarlberg in einer Datenbank. ${ }^{69}$ Biographischen Zugängen verpflichtet war auch das von Gerhard Botz initiierte international und interdisziplinär aufgestellte, in der österreichischen Zeitgeschichte bis dato größte Oral-History-Projekt mit ehemaligen Mauthausen-Häftlingen („Mauthausen Survivors Documentation Project"), darunter auch über 200 jüdische Überlebende..$^{70}$

68 Die namentliche Erfassung konnte später auf fast 64.000 Namen erweitert werden. Die ersten Hauptmitarbeiter wurden wiederum die jüngeren Historiker Florian Freund und Hans Safrian, die bereits in der KZ- bzw. Täterforschung Forschungserfahrung gesammelt hatten. Siehe Wolfgang Neugebauer, Vorwort, in: Florian Freund/Hans Safrian, Vertreibung und Ermordung. Zum Schicksal der österreichischen Juden 1938-1945. Das Projekt „Namentliche Erfassung der österreichischen Holocaustopfer", Wien 1993, 5; Brigitte Bailer/Gerhard Ungar, Die namentliche Erfassung der österreichischen Holocaustopfer, in: Dokumentationsarchiv des österreichischen Widerstandes (Hg.), Opferschicksale, 63-73.

69 Daraus u. a. hervorgegangen: Thomas Albrich, „Wir lebten wie sie ..... Jüdische Lebensgeschichten aus Tirol und Vorarlberg, Innsbruck 1999.

70 Das zwischen 2002 und 2003 durchgeführte und von Botz geleitete Interviewprojekt wurde maßgeblich von Brigitte Halbmayr, Helga Amesberger (beide Institut für Konfliktforschung) und Christine Schindler (DÖW) betreut. In insgesamt 23 Staaten wurden rund 860 Audiointerviews, 100 davon auch als Videointerviews, geführt. Gerhard Botz/Bernadette Dewald/Alexander Prenninger, Mauthausen erzählen - Narrating Mauthausen, in: Bundesministerium für Inneres (Hg.), Das Gedächtnis von Mauthausen, Wien 2004, 76-103 bzw. Helga Amesberger/Gerhard Botz/ Brigitte Halbmayr, „Mauthausen“ im Gedächtnis der Überlebenden. Das „Mauthausen Survivors Documentation Project“, in: Bundesministerium für Inneres (Hg.), Gedächtnis von Mauthausen, 104-123; Heinrich Berger, Quantitative Analyse der Datenbank des „Mauthausen Survivors Documentation Project“, URL: https://www.lbihs.at/BergerMauthQuant.pdf (abgerufen 10.06.2020). Zu den herausragenden Oral-History-Projekten mit Holocaustbezug zählt auch das in den 1990er-Jahren von Albert Lichtblau durchgeführte vielstündige biographische Narrativinterview mit Simon Wiesenthal, das in voller Läng erstmals 2020 im Rahmen einer VWI-Veranstaltungsserie 2020 unter dem Titel „ICh bin einer der 500 von 150.000؛ Simon Wiesenthal im Interview“ gezeigt wurde, 
Als im Jahr 2000 eine erweiterte Neuauflage des Sammelbands „NS-Herrschaft“ von 1988 erschien, der nun neben aktualisierten viele zusätzliche Beiträge versammelte, spiegelte dies die Forschungsentwicklung seit Ende der 1980er-Jahre gut wider. ${ }^{11}$ So wurden nun Beiträge zu Medizinverbrechen und zu den Deportationstransporten der österreichischen Juden integriert. ${ }^{72}$ Auch wurden stärker frauenund geschlechtergeschichtliche Untersuchungen aufgenommen, wobei hier zum Thema Holocaust aber selbst deutliche Forschungsdesiderate benannt wurden. ${ }^{73}$

Die stärkere öffentliche Thematisierung von NS-Verbrechen, weniger die Forschung selbst, führte in den 1980er- und 1990er-Jahren auch in Österreich zu einer Zunahme an Holocaustleugnung und Revisionismus, wozu vor allem das DÖW, das dauerhaft Rechtsextremismus beobachtete und beforschte, mit einschlägigen Analysen reagierte. ${ }^{74}$

URL: https://www.vwi.ac.at/index.php/veranstaltungen/icalrepeat.detail/2020/02/16/309/-/ichbin-einer-der-500-von-150-00o-simon-wiesenthal-im-interview (abgerufen 20.06.2020).

71 Emmerich Tálos/Ernst Hanisch/Wolfgang Neugebauer/Reinhard Sieder (Hg.), NS-Herrschaft in Österreich 1938-1945, Wien 2000.

72 Peter Malina/Wolfgang Neugebauer, NS-Gesundheitswesen und -Medizin, in: Tálos/Hanisch/Neugebauer/Sieder (Hg.), NS-Herrschaft, 696-720; Florian Freund/Hans Safrian, Die Verfolgung der österreichischen Juden 1938-1945. Vertreibung und Deportation, in: Tálos/Hanisch/Neugebauer/ Sieder (Hg.), NS-Herrschaft, 767-794.

73 So Ingrid Bauer im programmatischen Aufsatz: Eine frauen- und geschlechtergeschichtliche Perspektivierung des Nationalsozialismus, in: Tálos/Hanisch/Neugebauer/Sieder (Hg.), NS-Herrschaft, 409-443. Zuvor zur Frage von Täterinnen schon Johanna Gehmacher, Kein Historikerinnenstreit ... Fragen einer frauen- und geschlechtergeschichtlichen Erforschung des Nationalsozialismus in Österreich, in: zeitgeschichte 22 (1995) 3-4, 109-122. Zwar waren mit Gabriella Hauchs Untersuchungen zu Zwangsarbeiterinnen derartige Perspektiven bezüglich NS-Verbrechen deutlich angesprochen (vgl. Gabrielle Hauch, Zwangsarbeiterinnen und ihre Kinder. Zum Geschlecht der Zwangsarbeit, in: Oliver Rathkolb (Hg.), NS-Zwangsarbeit. Der Standort Linz der „Reichswerke Hermann Göring AG Berlin“ 1938-1945, Bd. 1: Christian Gonsa/Gabriella Hauch/Michael John/ Josef Moser/Bertrand Perz/Oliver Rathkolb/Michaela C. Schober, Zwangsarbeit - Sklavenarbeit: Politik-, sozial- und wirtschaftshistorische Studien, Wien/Köln/Weimar 2001, 355-448), direktere Bezüge zur Holocaustforschung wies aber erst die Studie auf von Helga Amesberger/Katrin Auer/ Brigitte Halbmayr, Sexualisierte Gewalt: weibliche Erfahrungen in NS-Konzentrationslagern, Wien 2004. Generell dazu: Johanna Gehmacher/Gabrielle Hauch (Hg.), Frauen- und Geschlechtergeschichte des Nationalsozialismus. Fragestellungen, Perspektiven, neue Forschungen (Querschnitte 23), Innsbruck/Wien/Bozen 2007.

74 In deutsch-österreichischer Coproduktion erschienen u. a. Brigitte Bailer-Galanda/Wolfgang Benz/Wolfgang Neugebauer (Hg.), Wahrheit und „Auschwitzlüge“: Zur Bekämpfung „revisionistischer“ Propaganda, Wien 1995. Brigitte Bailer steuerte auch den einschlägigen Aufsatz „Holocaust-Leugnung in Österreich“ im Sammelband von Günter Morsch und Bertrand Perz bei: Brigitte Bailer, Holocaust-Leugnung in Österreich, in: Günter Morsch/Bertrand Perz (Hg.), Neue Studien 
Insgesamt sollte die Konjunktur an NS- und Holocaustforschung dieser Jahre nicht überschätzt werden. Die von Wiesenthal in seinem Memorandum der 196oerJahre angeführten Verbrechenskomplexe waren um die Jahrtausendwende zu groBen Teilen nach wie vor nicht erforscht. Der US-amerikanische Historiker Evan B. Bukey, der selbst zu dieser Zeit ein Buch über die Einstellung und Stimmungslage der österreichischen Bevölkerung zum Nationalsozialismus zwischen 1938 und 1945 publizieren sollte, ${ }^{75}$ beklagte massive Lücken in der NS-Forschung. ${ }^{76}$ In Bezug auf die Holocaustforschung vermisste Bukey Studien zu dem Verhalten des österreichischen Klerus zum Holocaust, zur Einschätzung der österreichischen Beteiligung am Holocaust sowohl in quantitativer wie qualitativer Hinsicht sowie über das Wissen der Bevölkerung bezüglich der Vorgänge im KZ Mauthausen ${ }^{77}$ oder in den Vernichtungslagern im besetzten Polen.

Auch muss konstatiert werden, dass die wissenschaftliche Infrastruktur und Finanzierung dieses Forschungsfeldes in Österreich bis Ende der 1990er-Jahre äußerst bescheiden blieben und viele interessierte ForscherInnen eher in prekären Beschäftigungsverhältnissen ihren Studien nachgingen.

Die aus heutiger Sicht nach der Waldheim-Debatte naheliegende Idee, eine Professur mit der Denomination Nationalsozialismus oder Holocaust zu schaffen, war damals nicht existent und hätte einen Bruch mit dem Verständnis der inhaltlichen Bestimmung von Lehrstühlen in der Geschichtswissenschaft bedeutet, die für das 20. Jahrhundert eher durch „Neuzeit mit besonderer Berücksichtigung der Zeitgeschichte" oder maximal „Zeitgeschichte" benannt waren. Von den Stelleninhabern wäre eine Denomination Holocaust wohl als Einschränkung der Lehr- und Forschungsmöglichkeiten empfunden worden.

Die NS- und Holocaustforschung in Österreich in dieser Zeit hatte trotz ihres an sich transnationalen Gegenstandes einen starken nationalgeschichtlichen Fokus und war überdies weitgehend auf das Territorium der Republik Österreich beschränkt,

zu nationalsozialistischen Massentötungen durch Giftgas. Historische Bedeutung, technische Entwicklung, revisionistische Leugnung, Berlin 2011, 355-365.

75 Evan B. Bukey, Hitler's Austria. Popular Sentiment in the Nazi Era, 1938-1945, Chapel Hill (NC) 2000 (deutsche Ausgabe: ders., Hitlers Österreich. „Eine Bewegung und ein Volk“, Hamburg/Wien 2001).

76 Evan B. Bukey, Versäumnisse der österreichischen NS-Forschung, in: zeitgeschichte 30 (2003) 6 , 399-406.

77 Wobei Bukey offensichtlich die bereits 1991 erschienene Studie von Gordon J. Horwitz (In the Shadow of Death: Living Outside the Gates of Mauthausen, New York 1990) nicht kannte. 
soweit nicht die Themen von vornherein über die Grenzen Österreich hinausreichten..$^{8}$

Die institutionelle Verankerung der Holocaustforschung, ihrer personellen und finanziellen Ressourcen sollte sich Ende der 1990er-Jahre noch einmal erheblich verändern. Die nach Ende des Kalten Krieges einsetzenden internationalen Restitutions- und Entschädigungsdebatten in Bezug auf den Nationalsozialismus, nicht zuletzt befördert durch drohende US-amerikanische Sammelklagen gegen Industrieunternehmen und Banken, führten in einer Reihe von Ländern zur Etablierung von historischen Kommissionen, die sich nun mit Fragen des Vermögensentzuges, von Raub und Restitution ebenso auseinandersetzen mussten wie mit der Frage der Entschädigung von Zwangsarbeit.

Neben der großen - nach dem Vorbild der Unabhängigen Expertenkommission Schweiz-Zweiter Weltkrieg 1998 eingesetzten und bis 2003 tätigen, wenn auch etwas anders organisatorisch aufgestellten - Historikerkommission der Republik Österreich ${ }^{79}$ war es eine Vielzahl von kleineren Kommissionen und Forschungsgruppen, die zur Untersuchung der Rolle von einzelnen Industrieunternehmen und Banken währen der NS-Zeit etabliert wurden, so auch in Österreich. ${ }^{80}$ Zeitgleich mit der Einrichtung der Historikerkommission der Republik wurde Ende 1998 auch die

78 So bei Fragen nach der Beteiligung der Wehrmacht am Holocaust, der Geschichte der Konzentrationslager, der Geschichte von Ghettos oder österreichischer Akteure in den besetzten Gebieten. Eher die Ausnahme in der österreichischen Holocaustforschung bildeten Studien, deren Thematik vollkommen von Österreich entkoppelt waren, wie etwa Dirk Rupnow, Täter - Gedächtnis - Opfer. Das „Jüdische Zentralmuseum“ in Prag 1942-1945, Wien 2000. Auch Bukeys kritische Anmerkungen verließen diesen nationalgeschichtlichen Fokus nicht. Zwar setzte er das Forschungsfeld nicht gänzlich mit dem Gebiet des heutigen Österreichs gleich, dennoch weist seine darüber hinausgehende Aufzählung an Versäumnissen ausschließlich auf österreichische Akteure in den zentralen Institutionen, in den Besatzungsgebieten, in den Lagern wie auch bei der Wehrmacht hin; womit Bukey quasi eine natürliche Zuständigkeit für österreichische Themen bei der österreichischen Forschung annahm, ohne weitere Überlegungen zum Verhältnis von Forschungsstandort und Forschungsgegenstand anzustellen, die an sich durch seine eigenen Forschungen zu Österreich als US-Amerikaner nahegelegt waren.

79 Eva Blimlinger, „... das geht sich nie aus, das könnt ihr nicht verlangen, Wahnsinn!“ Konzeption und Organisation von Auftragsforschungsprojekten am Beispiel der Historikerkommission, in: zeitgeschichte 30 (2003) 5, 281-292; Clemens Jabloner, Die Historikerkommission der Republik Österreich, in: Forum Politische Bildung (Hg.), Gedächtnis und Gegenwart. HistorikerInnenkommissionen, Politik und Gesellschaft (Informationen zur Politischen Bildung 20), Innsbruck/Wien/ München/Bozen 2004, 15-20; Clemens Jabloner, Am Beispiel der Historikerkommission. Zeitgeschichtliche Forschung in juristischer Perspektive, in: Österreichische Zeitschrift für Geschichtswissenschaften 16 (2005) 1, 111-136.

80 Etwa zur Postsparkasse, zur Creditanstalt-Bankverein, zu den Reichswerken „Hermann Göring“ am Standort Linz, zur Elektrizitätswirtschaft oder (später) zu den Reichsforsten. Maßgeblich betei- 
Zentrale Forschungsstelle Nachkriegsjustiz gegründet, mit der durch die Erschließung von Gerichtsakten wesentliche Grundlagen für eine Holocaustforschung geschaffen wurden. ${ }^{81}$

Im Unterschied zur Waldheim-Debatte hatte die Etablierung von Kommissionen unmittelbare Auswirkungen auf die NS- und Holocaustforschung, da diese eine Vielzahl an vergleichsweise gut finanzierten Forschungsprojekten auf den Weg brachten. So war die Österreichische Historikerkommission das bis dahin größte Forschungsprojekt seit der Institutionalisierung der Zeitgeschichte in den 1960erJahren, sowohl finanziell wie personell. Eine ganze Reihe von Projekten der Historikerkommission hatte unmittelbaren Holocaustbezug oder befasste sich mit der Verfolgung von Minderheiten wie Roma und Slowenen, neben bereits bekannten HistorikerInnen im Bereich der NS- und Holocaustforschung wirkten auch bis dahin nicht mit diesen Themen befasste Personen, etwa aus der Sozial- und Rechtswissenschaft, mit. ${ }^{82}$

Der nationalgeschichtliche Fokus dominierte auch in der Phase der Historikerkommissionen, was nicht zuletzt auch an den Rahmenbedingungen lag, waren doch die jeweiligen Staaten in Bezug auf Entschädigungs- und Restitutionsforderungen in ihrer nationalen Verantwortung angesprochen worden, nicht viel anders war es auch bei den mit Klagen bedrohten Unternehmen. So waren die Untersuchungsfelder der Österreichischen Historikerkommission, auch jene mit Bezug zum Holocaust, fast vollständig an die heutigen nationalen Grenzen gebunden - auch wenn aufgrund der Tatsache, dass das Zentrum der Verwaltung für das österreichische Gebiet zwischen 1938 und 1945 in Berlin lag und Reichsgaugrenzen sich nicht völ-

ligt an vielen dieser Untersuchungen oder leitend dabei tätig war Oliver Rathkolb vom Institut für Zeitgeschichte der Universität Wien.

81 Als wesentlichste Aufgabe der am Sitz des DÖW mit Unterstützung des Justizministeriums und der Landesarchive geschaffenen Einrichtung wurde formuliert: „[...] die zentrale Dokumentation sämtlicher Akten der justiziellen Ahndung von nationalsozialistischen Verbrechen in Österreich. Mittelfristig sollen alle in Österreich durchgeführten staatsanwaltschaftlichen Untersuchungen und Gerichtsverfahren wegen NS-Verbrechen dokumentiert werden. Ein langfristiges Ziel ist die elektronische Vernetzung sämtlicher europäischer Gerichtsverfahren von NS-Verbrechen." Die gesammelten Unterlagen selbst sollten in Form von Mikrofilmen am Staatsarchiv aufbewahrt werden, Erschließung und Auswertung am DÖW erfolgen, URL: http://www.nachkriegsjustiz.at (abgerufen 12.06.2020).

82 Ein wesentliche Anzahl der 49 Bände der Historikerkommission beschäftigt sich mit dem Entzug und der Restitution/Entschädigung von Vermögen, Mobilien, Wohnungen, Liegenschaften und Unternehmen, mit Institutionen der Verfolgung und Beraubung wie der „Zentralstelle für jüdische Auswanderung“, dem „Stillhaltekommissar", mit der „Vermögensverkehrsstelle“ oder mit Zwangsarbeit auch von Juden und Jüdinnen. Vgl. URL: https://hiko.univie.ac.at/ (abgerufen 21.09.2020) inklusive Volltextsuche. 
lig mit heutigen Bundesländern deckten, diese thematischen Engführungen nicht völlig hermetisch waren.

Die Beschränkung auf österreichisches Territorium führte dazu, dass etwa die mit dem Massenmord in der "Aktion Reinhard(t)" einhergehenden Beraubungsaktionen unter der Leitung einer ganz Gruppe von ÖsterreicherInnen rund um den SS- und Polizeiführer Odilo Globocnik in Lublin ${ }^{83}$ ebenso wenig Gegenstand der Untersuchung waren wie die Beraubung von geflüchteten und vertriebenen ÖsterreicherInnen, die von der Deutschen Wehrmacht in Ländern wie Frankreich und auch von österreichischen NS-Funktionären in den Niederlanden ${ }^{84}$ wieder eingeholt wurden. Eine Ausweitung des Mandats, die die österreichische Beteiligung am Vermögensentzug in der NS-Zeit im gesamten europäischen Raum umfasst hätte, wäre aus methodischen wie arbeitspragmatischen Gründen nicht leicht in ein Forschungsprogramm übersetzbar gewesen, eine solche Vorgehensweise wurde aber auch bei der Formulierung des Untersuchungsauftrages nie ernsthaft diskutiert. ${ }^{85}$

\section{Trans- und Internationalisierung der Holocaustforschung in Österreich nach der Jahrtausendwende}

Welche Effekte die Konjunktur der historischen Kommissionen und unternehmensgeschichtlichen Projekte um die Jahrtausendwende zeitigte, kann man unterschiedlich beurteilen. Für den öffentlichen Diskurs war das Thema der Beraubung, Entschädigung und Restitution über ein halbes Jahrzehnt äußerst präsent, die Zeit des

83 Bertrand Perz, The Austrian Connection: SS and Police Leader Odilo Globocnik and His Staff in the Lublin District, in: Holocaust and Genocide Studies 29 (2015) 3, 400-430; ders., Warum Österreicher? Zum Personal der Dienststelle des SS- und Polizeiführers Odilo Globocnik in Lublin, in: Stephan Lehnstaedt/Robert Traba (Hg.), Die „Aktion Reinhardt“: Geschichte und Gedenken, Berlin 2019, 45-70; ders., Die Verwertung des Opfergoldes aus den Vernichtungslagern der „Aktion Reinhard“, in: Dokumentationsarchiv des österreichischen Widerstandes (Hg.), Forschungen zum Nationalsozialismus, 131-153; ders./Thomas Sandkühler, Auschwitz und die "Aktion Reinhard“ 1942-45. Judenmord und Raubpraxis in neuer Sicht, in: zeitgeschichte 26 (1999) 5, 283-316.

84 Johannes Koll, Arthur Seyß-Inquart und die deutsche Besatzungspolitik in den Niederlanden (1940-1945), Wien 2015.

85 Für die Unabhängige Expertenkommission Schweiz - Zweiter Weltkrieg dagegen war diese transnationale Perspektive schon wegen der spezifischen Rolle der Schweiz während des Zweiten Weltkrieges konstitutiv. Die Fokussierung auf Österreich birgt aber nicht nur methodische Problematiken in sich, sondern hat auch erheblichen Einfluss darauf, wie diese Forschungen wahrgenommen werden. Mögen sie in Österreich nicht zuletzt einer - durchaus kritischen - Identitätsbildung dienen, so werden sie in Deutschland, dem wohl wichtigsten ausländischen Markt österreichischer Publikationen, oft als regionaler Beitrag zur NS-Forschung wahrgenommen. 
Nationalsozialismus war, wenn man es salopp ausdrücken möchte, in den Wohnzimmern angekommen.

Für die österreichbezogene Geschichte der Judenverfolgung wurden unter anderem auch wichtige zusätzliche Erkenntnisse über Beraubungsvorgänge und Verfolgungsinstitutionen gewonnen, generell wurden viele neue Quellen erschlossen und zugänglich gemacht. Der größte Effekt in der Forschung war sicherlich die Entstehung einer breiten Provenienzforschung, die heute weit über die Frage von Kunstraub und Kunstrestitution hinausgeht und in vielfältiger Weise auch mit dem Forschungsfeld Holocaust verbunden ist. ${ }^{86}$ Allerdings ist die Provenienzforschung schon aufgrund ihres Gegenstandes und ihrer Beauftragung sehr auf den Einzelfall hin und weniger an Synthesen orientiert und dient meist außerwissenschaftlichen Zwecken wie als Entscheidungsgrundlage für politisches Handeln. Geschichtswissenschaftlich werden dabei vor allem die enorme Dimension des nationalsozialistischen Vermögensentzuges der jüdischen Bevölkerung und die lange problematische Restitutionspolitik der Zweiten Republik deutlich.

Was die weitere Entwicklung der Holocaustforschung in Österreich bis in die Gegenwart betrifft, kann man den von Ulrich Herbert getroffenen Befund für Deutschland begrenzt auf Österreich übertragen. Herbert sieht spätestens ab der Jahrtausendwende das Ende einer abgeschlossenen „deutschen“ Holocaustforschung angesichts der transnationalen Ansätze in Bezug auf den Gegenstand und der Internationalisierung der Scientific Community gekommen, wobei er dabei mehr oder weniger ausschließlich die geschichtswissenschaftliche Disziplin im Auge zu haben scheint. ${ }^{87}$ Nachdem man von einer abgeschlossenen „österreichischen“ Holocaustforschung für die 1980er- und 1990er-Jahre nur schwer sprechen kann, kommt es hier zwar zu keinem so deutlichen Umbruch, allerdings ist auch hier ein eindeutiger

86 Auf der Basis des Kunstrückgabegesetzes von 1998 wurde die Kommission für Provenienzforschung etabliert, die für den ebenfalls eingerichteten Kunstrückgabebeirat Dossiers erstellt. Dieser empfiehlt der zuständigen Bundesministerin oder dem zuständigen Bundesminister die Restitution von Objekten bei einem NS-verfolgungsbedingten Entzug. Analog dazu betreiben Bundesländer, Kommunen und einzelne Institutionen Provenienzforschung. Dieses österreichische Restitutionsverfahren hatte auch international eine Vorreiterrolle. Vgl. URL: http://www.provenienzforschung. gv.at/de/ (abgerufen 10.08.2020). Vgl. Eva Blimlinger/Heinz Schödl, ... (k)ein Ende in Sicht. 20 Jahre Kunstrückgabegesetz in Österreich (Schriftenreihe Der Kommission für Provenienzforschung 8), Wien/Köln/Weimar 2018. International hat Provenienzforschung, vor allem auch in der Frage kolonialer Beraubung, heute eine globale Dimension angenommen.

87 Ulrich Herbert, Holocaust-Forschung in Deutschland: Geschichte und Perspektiven einer schwierigen Disziplin, in: Bajohr/Löw (Hg.), Der Holocaust, 31-79, 61. 
Trend zur Trans- und Internationalisierung, aber auch zu einer stärkeren disziplinären Breite zu konstatieren. ${ }^{88}$

Am stärksten verbunden ist diese Entwicklung mit den nach der Jahrtausendwende einsetzenden Bemühungen einer größeren Gruppe von Wissenschaftlerinnen aus dem geschichts, politik, kultur- wie sprachwissenschaftlichen Bereich universitärer wie außeruniversitärer Institutionen, gemeinsam mit der Israelitischen Kultusgemeinde Wien eine eigenständige Holocaustforschungs, aber auch Dokumentations- und Vermittlungseinrichtung in Österreich zu etablieren.

Im 2002 von einem kleinen Steering Committee formulierten „Mission Statement" des zu gründenden Instituts, das nach Rücksprache mit dem Namensgeber den Namen „Wiener Wiesenthal Institut für Holocaust-Studien“ erhalten sollte, wird dieser Trend deutlich:

Der Holocaustforschung in Österreich fehlt es bisher an institutioneller Trägerschaft, finanziellen Ressourcen und Kooperation. Das Zentrum bietet national und international die Möglichkeit, bereits bestehende Einrichtungen, Projekte und Ansätze zu vernetzen, gemeinsam zu beraten und neue Vorhaben zu initiieren. Darüber hinaus will das Zentrum seine Einrichtungen als Plattform für einen internationalen Austausch von Forscherinnen und Forschern sowie für die Förderung von wissenschaftlichem Nachwuchs bereitstellen. ${ }^{89}$

Zwar wurde im „Mission Statement“ noch deutlich auf Österreich Bezug genommen - der langen jüdischen Geschichte Österreichs, des Antisemitismus, der radikalen Verfolgung nach 1938, der Nähe von Wien zu den Schauplätzen der Judenverfolgung und -vernichtung in Ost- und Südosteuropa wie zur günstigen Archivsituation. Das mit der 2009 erfolgten Aufnahme eines regulären Betriebs verbundene Forschungsprogramm war aber von Anfang an (im Unterschied zu der fast ausschließlich an eine österreichische Öffentlichkeit gerichteten Vermittlungstätig-

88 So z. B. Forschungsbeiträge der Anthropologie (wie Margit Berner, „Judentypologisierungen“ in der Anthropologie am Beispiel der Bestände des Naturhistorischen Museums Wien, in: zeitgeschichte 32 (2005) 2, 111-116); der Archäologie (wie Claudia Theune, Spuren von Krieg und Terror. Archäologische Forschungen an Tatorten des 20. Jahrhunderts, Wien 2020); der Soziologie (wie Andreas Kranebitter, Quantitative Auswertungen zur jüdischen Bevölkerung Österreichs zwischen 1938 und 1945, in: DÖW (Hg.), Forschungen zu Vertreibung und Holocaust, Wien 2018, 31-52).

89 Mission Statement, verfasst von Micha Brumlik, Dan Diner und Bertrand Perz gemeinsam mit Ingo Zechner, URL: https://www.vwi.ac.at/index.php/institut/institutsprofil/mission-statement (abgerufen 20.07.2020). 
keit) trans- und international, das gilt auch für die Zusammensetzung des Wissenschaftlichen Beirates und insbesondere für das Fellowship-Programm des Instituts. ${ }^{90}$ 2012 verabschiedete der Wissenschaftliche Beirat des VWI ein Positionspapier unter dem Label „Europäisierung des Holocaust“, das sechs Themenfelder für die künftige Ausrichtung des Instituts als ein „mitteuropäisches Kompetenzzentrum im Bereich der Holocaustforschung" festlegte: antijüdische Gesetzgebung in Europa 1919/1933 bis 1938/41; Judenmord und europäische Öffentlichkeit; indigene Organisationen und der Holocaust außerhalb des Reiches; Besatzungsverwaltungen, Achsenregime und der Holocaust; Reaktionen jüdischer Organisationen und Gemeinden; Reaktionen der neutralen Länder und internationalen Organisationen auf die Judenverfolgung in Deutschland. ${ }^{11}$ Zugleich wurden für die Zukunft erhebliche thematische Erweiterungen und Kontextualisierungen ausgemacht..$^{92}$ Die hier formulierten Ausrichtungen der Forschung korrespondieren weitgehend mit auch sonst beschriebenen allgemeinen Trends in der Holocaustforschung. ${ }^{93}$

Sieht man von der fast kompletten Finanzierung durch die Republik Österreich und die Stadt Wien sowie von den spezifischen und für Österreich wichtigen Umständen der Situierung des Instituts in Wien ab - etwa dem Konnex zur Tätigkeit von Wiesenthal in Wien und der Aufbewahrung und Pflege von Teilen seines Archives -, könnte das Institut tatsächlich auch an einem beliebigen anderen Standort in Europa seinen Forschungen nachgehen. Mit der Gründung des VWI, dessen Anfänge dann durchaus holprig verlaufen sollten, entstand so im letzten Jahrzehnt

90 Das VWI führt zwar auch Forschungsprojekte durch, die sich auf Österreich beziehen, etwa die Zwangsarbeit ungarischer Juden und Jüdinnen ab 1944 im Osten Österreichs, generell sind die Projekte aber nicht österreichspezifisch.

91 URL: https://www.vwi.ac.at/index.php/forschung/forschungsschwerpunkte (abgerufen 20.07.2020).

92 Dazu zählen die Rolle von frühem und lokalem Wissen über den Holocaust; Genozide/Nationalismen in vergleichender Perspektive; Fragen der Ethnisierung gesellschaftlicher Phänomene; Fragestellungen, die im weitesten Sinn der Ansatz der Jewish Studies stellt; die Verfolgung der Sinti und Roma und die Integration anderer Opfergruppen des NS; die digitale oder topographische Präsentation und Visualisierung von Forschungsergebnissen in Richtung Digital Humanities und das Thema Zwangsmigration.

93 Blick auf immer mehr unterschiedliche Beteiligte am Massenmord, Verschiebung des Fokus auf Osteuropa, stärkere Betonung eines gesamteuropäischen Genozids statt von Deutschland ausgehender Völkermord, stärkere Berücksichtigung der Perspektive der Opfer, Verbindung zu anderen Massenverbrechen, ökonomische Aspekte der Verfolgung, Rolle der deutschen Bevölkerung, Kenntnisse über Massenverbrechen, Geschichte der Überlebenden. Vgl. Ulrich Herbert, Holocaust-Forschung in Deutschland: Geschichte und Perspektiven einer schwierigen Disziplin, in: Bajohr/Löw (Hg.), Der Holocaust, 31-79. 
eine Forschungsinfrastruktur für Holocaustforschung, die auch international starke Aufmerksamkeit erfuhr.

Der damit verbundene Trend weg von einer auf Österreich fokussierten Holocaustforschung zeigt sich auch an den Universitäten. Mit der zunehmenden Präsenz ausländischer, vor allem deutscher WissenschaftlerInnen an den österreichischen Universitäten verschoben sich auch die Schwerpunkte. Dem Trend zur Einbettung des Holocaust in einen größeren historischen Zusammenhang und weg von der nationalen Fokussierung war etwa die am Institut für Zeitgeschichte der Universität Wien 2010 geschaffene Professur mit der Denomination „Vergleichende Diktaturen, Gewalt- und Genozidforschung “ geschuldet. Deren erste Inhaberin, Sybille Steinbacher, hatte einen starken Fokus auf Nationalsozialismus und Holocaust, nicht aber auf Österreich. ${ }^{94}$ An der Universität Klagenfurt wiederum wurde mit Dieter Pohl ein international renommierter Holocaustforscher auf einen Zeitgeschichteprofessur berufen, dessen Forschungsschwerpunkte von vornherein wenig Österreichbezüge hatten.

Insgesamt kann man bei den unzähligen holocaustrelevanten Projekten der letzten Jahre, viele an der Schnittstelle zwischen Forschung und Vermittlung, ${ }^{95}$ sowohl sehr deutliche Österreichbezüge wie völlige Losgelöstheit vom Standort finden. ${ }^{96}$ So sind methodisch durchaus an der internationalen Holocaustforschung orientierte Studien zu „Mischehen“, zu topographischen Projekten wie zu Sammellagern zum Zweck der Deportation oder zu einzelnen Berufsgruppen inhaltlich auf Österreich oder Wien bezogen, ${ }^{97}$ das gilt auch für viele Regionalstudien in diesem Feld, ${ }^{98}$ wäh-

94 Sybille Steinbacher ist seit 2017 Inhaberin der einzigen Holocaustprofessur in Deutschland und zugleich Direktorin des dem VWI nicht unähnlichen Fritz-Bauer-Instituts. Nachfolgerin in Wien ist Kerstin von Lingen.

95 Siehe etwa die zahlreichen Publikationen im Rahmen von „erinnern.at“.

96 Nationale wie transnationale Aspekte verknüpfen die Studien von Vida Bakondy, Montagen der Vergangenheit. Flucht, Exil und Holocaust in den Fotoalben der Wiener Hakoah-Schwimmerin Fritzi Löwy, Göttingen 2017 und von Margit Berner, Letzte Bilder. Die „,rassenkundliche“ Untersuchung jüdischer Familien im Ghetto Tarnów 1942, Berlin 2020.

97 Michaela Raggam-Blesch, Alltag unter prekärem Schutz. Mischlinge und Geltungsjuden im NSRegime in Wien, in: zeitgeschichte 43 (2016) 5, 292-307 bzw. dies., „Privileged“ under Nazi-Rule: The Fate of Three Intermarried Families in Vienna, in: Journal of Genocide Research 21 (2019) 3, 378-397; Dieter J. Hecht/Michaela Raggam-Blesch/Heidemarie Uhl, Letzte Orte. Die Wiener Sammellager und die Deportationen 1941/42, Wien/Berlin 2019; Barbar Sauer/Ilse Reiter-Zatloukal, Advokaten 1938. Das Schicksal der in den Jahren 1938 bis 1945 verfolgten österreichischen Rechtsanwältinnen und Rechtsanwälte, Wien 2010; Katharina Kniefacz/Herbert Posch, „... unter Vorbehalt des Widerrufes" - Jüdische Mischlinge an der Universität Wien 1938-1945, in: zeitgeschichte 43 (2016) 5, 275-291.

98 Stellvertretend für diese Studien: Werner Sulzgruber, Die Jüdische Gemeinde in Wiener Neustadt. Von ihren Anfängen bis zu ihrer Zerstörung, Wien 2005 oder die mehrbändige Studie zu 
rend wiederum Untersuchungen zur Repräsentation des Holocaust, etwa in der Kunst oder im Internet, keinen genuin nationalen oder regionalen Fokus aufweisen. ${ }^{99}$

Man könnte, was die Institutionenlandschaft betrifft, von einer gewissen Zweiteilung der Forschungen sprechen. Während das VWI trans- und international ausgerichtet arbeitet, findet zugleich weiterhin eine österreichspezifische Forschung statt, zum Teil bei universitären Abschlussarbeiten, vor allem im Bereich des DÖW, wenn auch in Bezug auf Deportationen zunehmend mit Perspektive auf die Zielorte, ${ }^{100}$ generell orientieren sich aber auch diese Forschungen heute an den internationalen Trends dieses Forschungsfeldes.

Die zunehmende und problematische Trennung von Forschungen zum Holocaust, zu den Mechaniken des Verfolgungs- und Vernichtungsprozesses und einer Erinnerungs- bzw. Repräsentationsforschung lässt sich auch für Österreich konstatieren, eine mit Berechtigung geforderte Integration dieser Bereiche ist derzeit nicht festzustellen. Ob dies durch Änderung des Labels der Forschungstätigkeit zu bewerkstelligen wäre, die auf stärkere Integration zielen, wie von Dirk Rupnow angedacht, ist ungewiss. ${ }^{101}$

Was die genuin österreichische Forschung betrifft, also außerhalb der FellowshipProgramme des VWI mit zeitlich begrenzter Vorortpräsenz meist internationaler ForscherInnen, fällt allerdings auf, dass zum Kernbereich ${ }^{102}$ des Holocaust, zu den

jüdischem Leben im Mostviertel von Johannes Kammerstätter unter dem Titel: Unsere jüdischen Landsleute und ihr tragbares Vaterland, Wieselburg 2012.

99 Eva Pfanzelter, Performing the Holocaust on social networks: digitality, transcultural memory and new forms of narrating, in: Kultura Popularna 51 (2017) 1, 136-151; Eva Pfanzelter, Inszenierung Vernetzung - Performanz: Holocaust Repräsentationen im Netz, in: Iris Roebling Grau/Dirk Rupnow (Hg.), Holocaust-Fiktion. Kunst jenseits der Authentizität, München/Paderborn 2015, 63-83 bzw. Dirk Rupnow, Jenseits der Grenzen. Die Geschichtswissenschaft, der Holocaust und die Literatur, in: Roebling Grau/Rupnow (Hg.), Holocaust-Fiktion, 85-102; Eva Pfanzelter, At the Crossroads with Public History: Mediating the Holocaust on the Internet, in: Holocaust Studies. A Journal of Culture and History 21 (2015) 4, 250-271.

100 Dokumentationsarchiv des österreichischen Widerstandes (Hg.), Deportation und Vernichtung Maly Trostinec (Jahrbuch 2019), Wien 2019; Christine Schindler im Auftrag des DÖW (Hg.), Nisko 1939. Das Schicksal der Juden aus Wien (Jahrbuch 2020), Wien 2020; zum österreichischen Maly-Trostinec-Bezug siehe auch: Waltraud Barton (Hg.), Ermordet in Maly Trostinec. Die österreichischen Opfer der Shoa in Weißrussland. Beiträge zur Konferenz „Maly Trostinec erinnern“. 28.-29. November 2011, Wien Museum, Wien 2012.

101 Rupnow, Zeitgeschichte oder Holocaust-Studien, 582.

102 Den Begriff des „Kerns“, wie er etwa von Stephan Lehnstaedt verwendet wird (ders., Der Kern des Holocaust. Bełżec, Sobibór, Treblinka und die Aktion Reinhardt, München 2017), kann man problematisch finden, ändert aber wenig am Befund. 
Ghettos und zum Massenmord in den besetzten Gebieten in Lagern und durch militärische Einheiten in Österreich durch FachhistorikerInnen weniger geforscht wird. ${ }^{103}$ Hier scheint unausgesprochen die Vorstellung, dass Deutschland für das gesamte NS-Herrschaftsgebiet zuständig ist, Österreich aber vor allem für sein eigenes Territorium, nachzuwirken. ${ }^{104}$

Die Mehrzahl der Studien befasst sich eher mit Fragen des Umgangs mit dem NSErbe, mit justizieller Aufarbeitung, ${ }^{105}$ in großer Zahl mit Erinnerungskultur und mit Repräsentationsformen des Holocaust ${ }^{106}$ und der schon erwähnten Provenienzforschung. Studien, die die Holocaustgeschichtsschreibung selbst zum Thema haben, sind in Österreich noch eher selten. ${ }^{107}$

Der Befund über den Zustand der Holocaustforschung in Österreich muss ambivalent bleiben. Die institutionelle Infrastruktur hat sich erheblich verbessert und verbreitert, ${ }^{108}$ die Schaffung von Spezialinstituten wie dem VWI dynamisiert den

103 Einschlägige Publikationen sind zum Teil aus erinnerungskulturellen Projekten heraus entstanden (z. B. Angelika Brechelmacher/Bertrand Perz/Regina Wonisch (Hg.), Post 41. Berichte aus dem Getto Litzmannstadt/Reports from Litzmannstadt Ghetto - Ein Gedenkbuch/A memorial book, Wien 2015) oder stammen zum Teil von den Rändern der Geschichtswissenschaft, siehe die auf breite Lesbarkeit hin konzipierten Studien im Bereich der Täterforschung von Johannes Sachslehner, Der Henker. Leben und Taten des SS-Hauptsturmführers Amon Leopold Göth, Wien/Graz/ Klagenfurt 2013; ders., „Zwei Millionen ham’ma erledigt“. Odilo Globocnik - Hitlers Manager des Todes, Wien/Graz/Klagenfurt 2014; ders., „,Rosen Für Den Mörder“. Die zwei Leben des NS-Täters Franz Murer, Wien/Graz/Klagenfurt 2017.

104 Ausgenommen werden kann hier das Feld der KZ-Forschung in Österreich, in dem beide Zugänge relativ ausgewogen nebeneinander existieren, siehe etwa die Publikationstätigkeit der KZ-Gedenkstätte Mauthausen in den letzten 15 Jahren, maßgeblich betreut von Andreas Kranebitter, Gregor Holzinger, Katharina Kniefacz, Ralf Lechner und Christian Dürr, URL: https://www.mauthausenmemorial.org/de (abgerufen 20.05.2020) oder auch die Publikationen des Mauthausen Komitee Österreich, URL: https://www.edition-mauthausen.at/ (abgerufen 20.05.2020).

105 Hier allerdings auch transnational, siehe Christian Rabl, Mauthausen vor Gericht. Nachkriegsprozesse im internationalen Vergleich, Wien 2019.

106 Zum Beispiel Ina Markova, Die NS-Zeit im Bildgedächtnis der Zweiten Republik (Der Nationalsozialismus und seine Folgen 6), Innsbruck/Wien/Bozen 2018.

107 Zum Beispiel Leo Gürtler, Unhinterfragte Schutzbehauptungen. Franz Stangls oberösterreichische Zeit im Werk von Gitta Sereny, in: Philipp Rohrbach/Florian Schwanninger (Hg.), Beyond Hartheim. Täterinnen und Täter im Kontext von „Aktion T4“ und „Aktion Reinhard“, Innsbruck/ Wien/Bozen, 2019, 73-88.

108 Neben dem VWI kommen Studien aus Institutionen wie der Zentralen Forschungsstelle Nachkriegsjustiz, den Instituten der Ludwig Boltzmann Gesellschaft (LBI für Kriegsfolgenforschung sowie LBI for Digital History), dem Zentrum für Jüdische Kulturgeschichte (ZJK) an der Universität Salzburg bzw. dem Centrum für jüdische Studien an der Universität Graz oder dem Institut für jüdische Geschichte Österreichs in St. Pölten, in den letzten 20 Jahren erfolgten spezifische Förderungen durch den Österreichischen Nationalfonds und den Zukunftsfonds der Republik. 
internationalen Austausch, birgt aber auch die Gefahr in sich, durch Spezialisierung desintegrierend zu wirken, etwa in der Trennung von universitärer und außeruniversitärer Forschung oder durch Schaffung eigener Publikationsorgane, deren Texte nicht mehr „zufällig“ in allgemeinen historischen Fachzeitschriften rezipiert werden. ${ }^{109}$ Die Einbettung des Holocaust in die Gewaltgeschichte des 20. Jahrhunderts, in die Diktaturen, Gewalt- und Genozidforschung, gerade auch im Lehrbetrieb der Universitäten eine Notwendigkeit, schafft zwar neue Einsichten, kann aber auch zu einer Marginalisierung des Gegenstandes führen. Zugleich birgt der breite öffentliche Diskurs der letzten Jahrzehnte über den Holocaust, in dem die Geschichtswissenschaft kaum mehr tonangebend ist, auch die Gefahr der Dekontextualisierung und Trivialisierung in sich, was sich auch an der Funktion der - immer weniger werdenden - Zeitzeugen, von Akteurinnen einer „Gegenerzählung“ zur Affirmation breitakzeptierten Wissens über den Holocaust ${ }^{110}$ deutlich machen lässt. Jedenfalls lässt sich konstatieren, dass die seit 1989/1990 weltweit und in Europa zu beobachtenden Prozesse der Renationalisierung auf die Holocaustforschung in Österreich nicht zutreffen, und das ist schon ein sehr positiver Befund.

109 Das VWI versucht dem durch seine umfangreichen Vermittlungsprogramme und gezielten Präsentationen von Fellows an anderen Institutionen (VWI goes to ...) entgegenzuwirken.

110 Marin Sabrow, Der Zeitzeuge als Wanderer zwischen zwei Welten, in: Martin Sabrow/Norbert Frei (Hg.), Die Geburt des Zeitzeugen nach 1945, Göttingen 2012, 13-32. 


\section{Zweite Republik}

Günter Bischof

\section{Einleitung: der globale Kontext}

Die Erste Republik Österreich dauerte 20 Jahre (1918-1938) und fand mit dem Einmarsch und der Besatzung durch Hitlers Wehrmacht („Anschluss“) ein unrühmliches Ende. Die Zweite Republik besteht nun bereits seit 75 Jahren (1945-2020) und wird deshalb auch oft als „Erfolgsstory“ gefeiert. ${ }^{1}$ Lothar Höbelt, eigentlich kein Zeithistoriker und im FPÖ-Fahrwasser, betrachtet sie in seinem neuen Buch „Die Zweite Republik Österreich und ihre Besonderheiten“ bereits als vergangen und verblüht und spricht von der „Zweieinhalbten Republik“.2 Ob sie nun eine „Erfolgsstory“ war ${ }^{3}$ oder als „paradoxe Republik“4 in die Geschichte eingehen wird, soll im Folgenden erörtert werden.

Österreich war nie isoliert und „sui generis“, sondern existierte in einem internationalen Umfeld, das das Land von außen bestimmte, war also nach Manfried Rauchensteiner immer „unter Beobachtung“. ${ }^{5}$ Es gibt mithin gute Gründe dafür, die Zweite Republik von diesem geopolitischen Umfeld aus zu betrachten, als Teil der europäischen Geschichte, mit der auftauchenden Globalisierung auch zunehmend als Teil der Weltgeschichte. Hier tut sich natürlich historiographisch gesehen ein weiter Bogen auf, der in dem vorliegenden kurzen Beitrag nicht gänzlich gemeistert werden kann. Einen Versuch ist es aber wert.

In der angloamerikanischen Historiker-Community gibt es zahlreiche Versuche, das Nachkriegseuropa und die Globalisierung der Welt in großen Überblicks-

1 Ernst Hanisch, Der lange Schatten des Staates. Österreichische Gesellschaftsgeschichte im 20. Jahrhundert (Österreichische Geschichte 1890-1990), Wien 1994, 395-489, immer noch der beste Überblick zur Zweiten Republik.

2 Lothar Höbelt, Die Zweite Republik und Ihre Besonderheiten (Schriftenreihe des Forschungsinstitutes für politisch-historische Studien der Dr.-Wilfried-Haslauer-Bibliothek 76), Wien 2020, 271-281.

3 Oliver Rathkolb, Die Zweite Republik (seit 1945), in: Thomas Winkelbauer (Hg.), Geschichte Österreichs, Stuttgart 2015, 525-594, 578, 579.

4 Oliver Rathkolb, Die paradoxe Republik. Österreich 1945 bis 2005, Wien 2005.

5 Dem Autor stand nur die englische Übersetzung zur Verfügung: Manfried Rauchensteiner, Under Observation. Austria since 1918, Wien 2018. 
darstellungen zu thematisieren. Tony Judt hat sich im Dezember 1989 am Wiener Westbahnhof entschlossen, eine Geschichte Nachkriegseuropas zu schreiben. In seinem Opus magnum „Postwar“ kommt er zu der Einsicht, dass „um legitim zu sein, um für sich die Autorität von rechtens errichteter Staaten in Anspruch zu nehmen, [...] die Regierungen des befreiten Europa zuallererst das Erbe der diskreditierten Kriegsregime" hätten in Angriff nehmen müssen. Er fügt hinzu, dass vor allem besetzte Länder, nicht nur Frankreich, mit dem „Vichy-Syndrom“ (Henry Rousso) zu kämpfen gehabt hätten, nämlich mit der jahrzehntelangen „Schwierigkeit, einzugestehen, was im Krieg wirklich passierte“, sowie dem „übermächtige[n] Wunsch, die Erinnerung zu blockieren bzw. als brauchbare Vergangenheit [usable past] einzuordnen, um nicht die zarten Bande der Nachkriegsgesellschaft zu zerstören“. Dabei seien viele Nachkriegsgesellschaften in eine „kollektive Amnesie“ gefallen. ${ }^{6}$ In seiner Geschichte Europas nach dem Krieg resümiert Ian Kershaw: „Es dauerte viel länger, die mentalen und moralischen Wunden zu heilen als die Gemeinden und Städte wiederaufzubauen".7

Eric Hobsbawm, der einen Teil seiner Kindheit in Wien verbrachte, hat in seinem Buch "The Age of Extremes" einen frühen und ambitionierten Versuch einer Gesamtdarstellung der Geschichte des 20. Jahrhunderts unternommen. Im zweiten Teil des Buches „The Golden Age“ behandelt er die Jahre vom Ende des Zweiten Weltkrieges bis zum Ende des Kalten Krieges, wobei er die Jahre 1950 bis 1973 als die "golden years" bezeichnet. ${ }^{8}$ Was kennzeichnete diese "goldenen Jahre“: ein gewaltiges wirtschaftliches Wachstum, relativer sozialer Frieden und Wohlstand, Massenkonsum, innovative Hochtechnologie sowie ein „reformierter Kapitalismus“. Das Laissez-faire der Zwischenkriegszeit, das zu Weltwirtschaftskrise und dem Zweiten Weltkrieg geführt hatte, wurde über Bord geworfen. Nach dem Krieg paarten sich ökonomischer Liberalismus und Sozialdemokratie. Es war die staatlich geplante Wirtschaft, die den Nachkriegswohlstand hervorzauberte. Die Mischung von „Märkten und Regierungen“ brachten die „goldenen Jahre" hervor. ${ }^{9}$ Ian Kershaw nennt diese "goldenen Jahre" ganz einfach "the good times". ${ }^{10}$

Mark Mazower, der an der Columbia University lehrt, weist in seiner Geschichte Europas im 20. Jahrhundert darauf hin, dass die „Pläne für das goldene Zeitalter“ bereits während des Zweiten Weltkrieges vor allem in der angloamerikanischen Welt

6 Tony Judt, Postwar. A History of Europe Since 1945, New York 2005, 41, 61, 808.

7 Ian Kershaw, The Global Age. Europe 1950-2017, New York 2020, Xxv.

8 Eric Hobsbawm, The Age of Extremes. A History of the World, 1914-1991, New York 1994, 257286.

9 Ebd., 268-274.

10 Kershaw, The Global Age, 131-168. 
geschmiedet worden seien. Dazu gehörte die Wiederherstellung demokratischer Regime, die vor allem sozialdemokratische sein würden. Dazu gehörten auch der Beveridge-Plan und die Vorstellung einer Sozialversicherung für alle. Der Zusammenbruch von ganzen Volkswirtschaften im Krieg rufe nach staatlicher Lenkung in Friedenszeiten. Nach der Hitler-Diktatur würden Individuen sich gegen einen starken Staat durchsetzen und Menschenrechte einfordern. Der Exilösterreicher Hans Kelsen meinte, dass das Völkerrecht sich gegenüber staatlicher Souveränität durchsetzen werde. Friedrich von Hayek, ein anderer prominenter Exilösterreicher, konnte sich mit seinen Ideen von laissez faire und Wirtschaftsliberalismus nicht durchsetzen. ${ }^{11}$

David Reynolds, Historiker in Cambridge, geht in seiner Globalgeschichte auf die Globalisierung ein. Die rapide Entwicklung des Welthandels und die Technologisierung und Digitalisierung der Welt in der Kommunikationsindustrie (Fernsehen, Computer, Internet) hätten diese Entwicklungen vorangetrieben. Gerade die Deregulierung der Welt- und Finanzmärkte habe den Prozess der Globalisierung beschleunigt und den spekulativen „Casino-Kapitalismus“ aufblühen lassen. Auch im Kulturbereich sei es bereits seit den 1950er-Jahren zur „Amerikanisierung“ - zum Massenkonsum und „McWorld“ - gekommen. Die Globalisierung habe aber nicht erst in den 1990er-Jahren eingesetzt, sondern habe ihre Wurzeln im späten 19. Jahrhundert. ${ }^{12}$

\section{Historiographie und die frühen Jahre der Zweiten Republik}

Der erste Versuch, die Geschichte der Zweiten Republik in den Griff zu bekommen, findet sich in der von Erika Weinzierl und Kurt Skalnik herausgegebenen Darstellung in zwei Bänden. ${ }^{13}$ Karl Gutkas schrieb bald darauf eine erste monographische Zusammenfassung der Geschichte der Zweiten Republik. ${ }^{14}$ Ernst Hanisch betont, dass die „Erfolgsgeschichte“ der Zweiten Republik ein zentraler Punkt der „Konsensgeschichtsschreibung“ sei. Die Skalnik/Weinzierl-Bände sind gewissermaßen

11 Vgl. das Kapitel „Blueprints for the Golden Age“, in: Mark Mazower, Dark Continent. Europe’s Twentieth Century, New York 1998, 182-211.

12 David Reynolds, One World Divisible. A Global History since 1945, New York 2000, 290-301, 650-657.

13 Erika Weinzierl/Kurt Skalnik (Hg.), Die Zweite Republik, 2 Bde., Graz 1972, später dann in einer einbändigen Edition neu aufgelegt, dies. (Hg.), Das neue Österreich. Geschichte der Zweiten Republik, Graz 1976.

14 Karl Gutkas, Die Zweite Republik. Österreich 1945-1985, Wien 1985. 
eine Summa dieser Schule. ${ }^{15}$ Alfred Ableitinger fasste die innenpolitische Entwicklung der Zweiten Republik dann in einem Sammelband in einem langen monographischen Essay zusammen. ${ }^{16}$ Überhaupt wurde anfangs die Zweite Republik in Sammelbänden abgehandelt und erst in den letzten zwanzig Jahren kamen monographische Analysen dazu. ${ }^{17}$ Seit 1992 habe ich mit Anton Pelinka (und anderen Mitherausgebern) immer wieder versucht, die Geschichte der Zweiten Republik in den Mittelpunkt der Jahresschrift „Contemporary Austrian Studies“ zu stellen (wir arbeiten gerade am Band 30 zum Thema „A Visual History of Austria“, in dem die Zweite Republik wiederum viel Aufmerksamkeit erhalten wird). ${ }^{18}$ Bereits vor zwanzig Jahren habe ich einen historiographischen Aufsatz zu neuerer Literatur zur Zweiten Republik verfasst. ${ }^{19}$ Im Folgenden sollen zuerst innenpolitische und dann außenpolitische Entwicklungen verfolgt und einige Forschungsdesiderata genannt werden.

Der Anfang der Zweiten Republik stand unter denkbar ungünstigen Vorzeichen. Die Provisorische Regierung Renner (zusammengesetzt aus einer breiten Koalition zwischen der SPÖ, ÖVP, und KPÖ), die von der russischen Besatzungsmacht eingesetzt wurde und am 27. April 1945 die Unabhängigkeit Österreichs verkündete, wurde von den Westmächten nicht anerkannt und regierte nur in der Sowjetzone.

15 Ernst Hanisch spricht von vier Schulen, die die Geschichte Österreichs im 20. Jahrhundert dominierten: 1) die „deutschnationale“ Schule (1918-1945); 2) die versöhnliche Schule der „Konsensgeschichtsschreibung“ (1945-1970); 3 ) die revisionistische Schule der „neuen Linken“ (1970-1990); 4) eine lose „postmodernistische“ Schule, die von der Fragmentierung und der Atomisierung der Geschichtswissenschaften gekennzeichnet ist (1990-?); vgl. Ernst Hanisch, Der forschende Blick. Österreich im 20. Jahrhundert: Interpretationen und Kontroversen, in: Carinthia 189 (1999), 567583 .

16 Alfred Ableitinger, Die innenpolitische Entwicklung, in: Wolfgang Mantl (Hg.), Politik in Österreich. Die Zweite Republik: Bestand und Wandel, Wien 1992, 119-203; Helmut Konrad, nennt diesen Essay eine „definitve“ Erzählung, Helmut Konrad, Austria on the Path to Western Europe: The Political Culture of the Second Republic, in: Austrian History Yearbook 26 (1995), 1-15, 3.

17 Etwa Reinhard Sieder/Heinz Steiner/Emmerich Tálos (Hg.), Österreich 1945-1995. Gesellschaft Politik - Kultur, Wien ${ }^{2}$ 1996; Rolf Steininger/Michael Gehler (Hg.), Österreich im 20. Jahrhundert, 2 Bde., Wien 1997; Robert Kriechbaumer (Hg.), Österreichische Nationalgeschichte nach 1945: Die Spiegel der Erinnerung. Die Sicht von innen, Bd. 1, Wien 1998; Oliver Rathkolb/Otto M. Maschke/Stefan August Lütgenau (Hg.), Österreichs Nationalgeschichte nach 1945: Mit anderen Augen gesehen. Internationale Perzeptionen Österreichs 1955-1990, Bd. 2, Wien 2002.

18 Vom Band 1 weg zu „Thema Austria in the New Europe“ (1992) zum Band 2 „Kreisky Era in Austria“ (1993) und Band 3 „Austria in the Nineteen Fifities“ (1994) bis hin zu Band 27 „Austrian Environmental History“ (2018) sowie Band 29 "Myths in Austrian History“ (2020).

19 Günter Bischof, Austria after 1945 - Success Story? Heroic Age? Review of Recent Literature, in: ders./Anton Pelinka/Ruth Wodak (Hg.), Neutrality in Austria (Contemporary Austrian Studies 9), New Brunswick 2001, 293-318. 
Ernst Hanisch spricht von den restaurativen Tendenzen eines „Rückbruches“, nämlich einer Kontinuität von der Ersten zur Zweiten Republik (etwa in der Verfassung, aber auch in einer Kontinuität zum gerade untergehenden „Dritten Reich“). ${ }^{20}$ Das westliche Österreich war zu diesem Zeitpunkt noch nicht von den Nazis befreit. Fühlten sich die ÖsterreicherInnen befreit oder besiegt? Oliver Rathkolb meint, dass sich der 13. April (Befreiung Wiens) nie in ganz Österreich als Befreiungstag durchgesetzt habe und in der Öffentlichkeit nicht mehr präsent sei. ${ }^{21}$ Hannes Leidinger und Verena Moritz konstatieren: „Aus der ,Niederlage` erwuchs weniger das Gefühl der ,Befreiung‘ als der ,Entmündigung.“ “22 Aber zum siebzigsten Jahrestag der Gründung der Zweiten Republik und des Endes des Krieges 2015 sprach Bundespräsident Heinz Fischer ähnlich klare Worte wie der deutsche Präsident Richard von Weizsäcker dreißig Jahre zuvor:

Hat es nicht lange Zeit Streit über die Frage gegeben, ob Österreich 1945 tatsächlich befreit wurde oder ob es nicht eher aus der Unfreiheit in Großdeutschland in die Unfreiheit durch die Besatzungsmächte geraten ist? Die klare Antwort lautet wie folgt: Österreich ist 1945 von einer unmenschlichen verbrecherischen Diktatur befreit worden.23

Erst nachdem sich die Amerikaner, Briten und Franzosen in ihren Zonen eingerichtet hatten, der Alliierte Rat Anfang September zum ersten Mal in Wien als höchste Autorität im Land zusammentrat und die Regierung Renner nach Länderkonferenzen mit Vertretern aus dem Westen ausgeweitet wurde, anerkannten die Westmächte die Renner-Regierung Ende Oktober. Am 25. November 1945 schon wurde in Österreich gewählt. Die ÖVP ging als klarer Wahlsieger hervor, Leopold Figl wurde Bundeskanzler und etablierte eine breite Koalitionsregierung mit SPÖ und KPÖ.

Die meisten Historiker stimmen in diesem Grundnarrativ zu den Ereignissen 1945 überein. Unterschiedliche Bewertungen gibt es in der Frage, warum die KPÖ bei den Wahlen nur 5 Prozent und nicht - wie erwartet - 20 Prozent der Stimmen gewinnen konnte. Bei den Wahlen 1945 waren gut 6o Prozent der WählerInnen Frauen (ca. eine halbe Million Österreicher befand sich noch in Kriegsgefangenschaft). Die

20 Hanisch, Schatten des Staates, 395-398.

21 Rathkolb, Die Zweite Republik (seit 1945), 525-594, 540.

22 Hannes Leidinger/Verena Moritz, Umstritten, verspielt, gefeiert, Die Republik Österreich 1918/2018, Innsbruck 2018.

23 Rede des Bundespräsidenten zum 70. Jahrestag der Gründung der Zweiten Republik im Wortlaut (Hervorhebung vom Autor), APA OTS, 27.04.2015, URL: https://www.ots.at/presseaussendung/ OTS_20150427_OTSo059/rede-des-bundespraesidenten-zum-70-jahrestag-der-gruendung-derzweiten-republik-im-wortlaut (abgerufen 13.05.2020). 
Angst der Frauen vor den Sowjets war besonders groß, da die Rote Armee nach der Befreiung plünderte und viele Frauen und Mädchen vergewaltigte. Die Österreicher dämmten den Kommunismus in ihrem eigenen Land ein, Monate bevor die USA die Eindämmungsdoktrin erfand. Trotzdem wurde ein KPÖ-Minister in die Regierungskoalition aufgenommen, wohl um die Sowjets zu beschwichtigen. ${ }^{24}$ Die Nähe der KPÖ zur sowjetischen Besatzungsmacht trug ihr den Ruf ein, die „fünfte Besatzungsmacht“ zu sein. ${ }^{25}$ In seinem Buch zur KPÖ meint Manfred Mugrauer: „Durch das enttäuschende Wahlergebnis erschwerten sich die Rahmenbedingungen kommunistischer Politik in Österreich“. ${ }^{26}$ Die als „Russenpartei“ bekannte KPÖ litt unter der „schwersten Hypothek“ der „sowjetischen Besatzungspraxis“: „Neben den Demontagen und Beschlagnahmungen waren es die Übergriffe von Angehörigen der Roten Armee auf die Zivilbevölkerung - Plünderungen, Vergewaltigungen und Verschleppungen -, welche die KPÖ in der öffentlichen Meinung in Misskredit brachten“. ${ }^{27}$ Auf jeden Fall - und auf Verlangen der Briten und der Amerikaner sollte eine große Koalition die politischen Verhältnisse im Land stabilisieren und den permanenten Streit der politischen Lager der Ersten Republik verhindern. ${ }^{28}$

Nachdem eine wichtige Weichenstellung im demokratischen Wiederaufbau des Landes erfolgt war, wurde in den folgenden Jahren der wirtschaftliche Wiederaufbau des Landes in Angriff genommen. Wurde dieser durch die harte Arbeit der ÖsterreicherInnen veranlasst oder durch die ausländische Hilfe vor allem der Amerikaner? Trotz der massiven Zerstörungen in ihrem Land war die Grundstimmung der ÖsterreicherInnen weit optimistischer als nach 1918. Der „Anschluss“ und der Zweite Weltkrieg hatten die ÖsterreicherInnen von der „deutschen Versuchung“ geheilt. Die „wirtschaftliche Lebensfähigkeit“ des Landes wurde nicht mehr angezweifelt. Das Land hatte von der Wirtschaftspolitik des Nationalsozialismus und den Investitionen vor allem in die Grundstoffindustrie profitiert und stand trotze massiver Bombardements durch die Alliierten nach dem Krieg in der wirtschaftlichen Substanz gestärkt da. Die große Frage war nur, was würde mit dem „deutschen Eigentum“ nach dem Krieg passieren? Was die Sowjets nicht 1945 geplündert und

24 Hanisch, Schatten des Staates, 406-407; Höbelt, Zweite Republik, 12-14; Rauchensteiner, Under Observation, 262; Josef Leidenfrost, Die Nationalratswahlen 1945 und 1949, in: Günter Bischof/ Josef Leidenfrost (Hg.), Die bevormundete Nation. Österreich und die Alliierten 1945-1949 (Innsbrucker Forschungen zur Zeitgeschichte 4), Innsbruck 1988, 127-137; Günter Bischof, Austria in the First Cold War, 1945-55. The Leverage of the Weak, Houndmills/New York 1999, 69-70.

25 Höbelt, Zweite Republik, 13.

26 Manfred Mugrauer, Die Politik der KPÖ 1945-1955, Wien 2020, 123.

27 Ebd., 492.

28 Bischof, Austria in the First Cold War, 90, 127-128; Manfried Rauchensteiner, Die Zwei. Die Grosse Koalition in Österreich 1945-1966, Wien 1987. 
weggeführt hatten, beschlagnahmten sie 1946 und überführten es in ihre Holding USIA, immerhin vierhundert Firmen (inklusive der Ölindustrie und der Donaudampfschifffahrtsgesellschaft). Die Westmächte übertrugen das „deutsche Eigentum“ an die österreichische Regierung „in trust“. Diese Betriebe wurden verstaatlicht (auch die ÖVP und die Amerikaner unterstützten das, ironischerweise nicht aber die Sowjets), womit Österreich einen ähnlich hohen Anteil verstaatlichter Industrien besaß wie Frankreich. ${ }^{29}$ Eben diese Mischung von „Markt und Regierung“ zauberten auch in Österreich die "goldenen Jahre“ herbei, wie Hobsbawm betont. Alle diese Faktoren werden von Autoren, die jene Zeit noch persönlich miterlebten, ignoriert. Josef Taus spricht vom „heroischen Zeitalter“ der Nachkriegszeit, in der die ÖsterreicherInnen das Land wiederaufgebaut hätten. Auch Hannes Androsch meint, die ÖsterreicherInnen hätten an die wirtschaftliche Lebensfähigkeit ihres Landes geglaubt, betont aber die Auslandshilfe kaum. ${ }^{30}$ Helmut Konrad erwähnt in seiner „Kann Lecture“ den Anteil des Marshall-Plans beim Wiederaufbau Österreichs nicht. ${ }^{31}$ Damit gerät der Beitrag der ausländischen Hilfe im österreichischen Wiederaufbau langsam in Vergessenheit.

Ohne die deutschen Investitionen während des Krieges und die wirtschaftliche Hilfe des Auslandes nach dem Krieg wäre der Wiederaufbau zu raschem Nachkriegswohlstand und Österreichs Teilhabe an den "goldenen Jahren“ wohl kaum möglich gewesen, auf jeden Fall nicht so rasch. Die US-Armee 1945 und die UNRRA (United Nations Relief and Rehabilitation Administration) 1946 retteten die ÖsterreicherInnen vor dem Verhungern. Dann gab es Überbrückungshilfsaktionen des US-Kongresses, vor dem Einsetzen des European Recovery Program (ERP). Der Marshall-Plan schaffte nicht nur Lebensmittel und die notwendigen Güter ins Land (zwischen 1948 und 1952), sondern generierte auch die notwendigen Investitionsmittel mit den ERP-Gegenwertkonten für die großen staatlichen Prestigeprojekte wie das Großwasserkraftwerk Kaprun, das bereits während des Krieges mit Zwangsarbeitern begonnen worden war, und den Ausbau der VOEST. Wirtschaftshistoriker haben errechnet, dass die USA ungefähr so viele Hilfsmittel im Land ausgeschüt-

29 Dieter Stiefel, „Fünf Thesen zu den sozioökonomischen Folgen der Ostmark“, in: Mantl (Hg.), Politik in Österreich, 49-61; Günter Bischof/Peter Berger, „Nicht lebensfähig?“. Austria’s Economic Viability after the Two World Wars, in: Günter Bischof/Marc Landry/Christian Karner (Hg.), Myths in Austrian History. Construction and Deconstruction (Contemporary Austrian Studies 29), New Orleans/Innsbruck 2020, 193-210; Günter Bischof/Hans Petschar, Der Marshallplan - Seit 1947. Die Rettung Europas \& der Wiederaufbau Österreichs, Wien 2017.

30 Josef Taus, Österreich über Alles, wann es nur will, in: Kriechbaumer (Hg.), Österreichische Nationalgeschichte, 519-558, 520-523; Hannes Androsch, Wirtschaft und Gesellschaft. Österreich 1945-2005, Innsbruck 2005, 34-37.

31 Konrad, Austria on the Path to Western Europe, 10-11. 
tet wie die Sowjets an Reparationen aus dem Land abgesaugt hätten. Ohne diese Auslandshilfen hätte sich das Land viel langsamer von den Kriegszerstörungen erholt (auch weil keine Investitionsmittel zur Verfügung standen). ${ }^{32}$ Oliver Rathkolb nennt die Entwicklung der österreichischen Volkwirtschaft, basierend auf „engen korporatistischen Strukturen, globalem Wachstum [und] Marshall-Plan-Hilfe im Kalten Krieg“ nach 1945 „die wohl größte Erfolgstory“.33

Auslandshilfe sowie Konkordanzdemokratie („consociational democracy“) und die Sozialpartnerschaft („Austro-corporatism“) erzeugten den sozialen Frieden und den Wohlstand, der die Zweite Republik bis in die 1990er-Jahre, im großen Unterschied zur gewaltbereiten „Konkurrenzdemokratie“ und Armut der Ersten Republik, charakterisierte. Die Konkordanzdemokratie der Großen Koalition von ÖVP und SPÖ integrierte die unterschiedlichen Interessen und Identitäten nach dem Krieg. Auch die Alleinregierungen Klaus und Kreisky führten die informelle Sozialpartnerschaft weiter. Die Klaus- und Kreisky-Regierungen bescherten dem Land einen Modernisierungsschub. Kreisky musste sich zunehmend mit wirtschaftlichen Einbrüchen in den krisengeschüttelten 1970er-Jahren herumschlagen. Das Ende des "goldenen Zeitalters“ der Konsumgesellschaft und des unaufhörlichen Wirtschaftswachstums, das zu breitem Wohlstand geführt hatte, war gekommen. Kreisky versuchte den so wichtigen Wirtschaftssektor der maroden verstaatlichten Industrie mit „deficit spending“ und massiven staatlichen Stützungsaktionen über die Runden zu bringen (Austro-Keynesianismus). Trotz massiver Kritik der Opposition gaben dem „Sonnenkönig“ die Wähler vielleicht gerade deshalb immer wieder das Vertrauen in seiner 13-jährigen Regierungszeit. ${ }^{34}$

Die Konkordanzdemokratie „heilte die Wunden, die Geschichte dem Land bescherte“. „Die Errichtung von Konsens durch die Machtaufteilung“ intensivierte das

32 Bischof/Petschar, Der Marshallplan; Hans Seidel, Österreichs Wirtschaft und Wirtschaftspolitik nach dem Zeiten Weltkrieg, Wien 2005; Roman Sandgruber, Ökonomie und Politik. Österreichs Wirtschaftsgeschichte vom Mittelalter bis zur Gegenwart (Österreichische Geschichte), Wien 1995, 451-452; Franz Mathis, Die österreichische Wirtschaft - Grundlagen und Entwicklungen, in: Steininger/Gehler (Hg.), Österreich im 20. Jahrhundert, Bd. 2: Vom Zweiten Weltkrieg bis zur Gegenwart, 415-453.

33 Oliver Rathkolb, Die Zweite Republik (seit 1945), 579.

34 Die Literatur zur „Kreisky Ära“ ist inzwischen umfangreich geworden, neben der zahlreichen Memoirenliteratur Kreiskys und seiner engsten Mitarbeiter, angefangen mit Günter Bischof und Anton Pelinka ((Hg.), The Kreisky Era in Austria (Contemporary Austrian Studies 2), New Brunswick 1994) bis hin zum kritischen Band von Robert Kriechbaumer (Die Ära Kreisky. Österreich 19701983, Wien 2004); vgl. auch Rathkolb, Die paradoxe Republik, 135-139, 184-195, 274-277; zum „Zeitalter des Sonnenkönigs“ vgl. Höbelt, Zweite Republik, 231-270. 
Proporzsystem. ${ }^{35}$ Auch in Österreich setzten sich der liberale demokratische Neuanfang und die Ideen des Sozialstaates (nach dem Beveridge-Plan) wie im restlichen Westeuropa durch (Mazower). Oliver Rathkolb scheint der einzige Zeithistoriker zu sein, der dabei immer wieder das ,autoritäre Potential“ der österreichischen Demokratie herauskehrt. ${ }^{36}$

Der demokratische Wiederaufbau war vor viele Herausforderungen gestellt, vor allem die des Umgangs mit dem Erbe des Nationalsozialismus. Die politischen Lager der Ersten Republik formierten sich rasch wieder nach der Befreiung Wiens, abgesehen von den Deutschnationalen, die sich durch ihre „Anschluss"-Politik und die Unterstützung des Nazi-Regimes ins Abseits manövriert hatten. Ihre Gruppenbiographie, wie es Dieter Binder formuliert, habe in einem „krassen Gegensatz zur Idee von Österreich als erstem Opfer der deutschen Aggression" gestanden. ${ }^{37}$ Gut eine halbe Million NS-Parteimitglieder verlor ihr Wahlrecht 1945 und musste mit diversen „Sühnefolgen“ rechnen. Die Entnazifizierung setzte ein. Bereits die provisorische Renner-Regierung erließ mit dem Verbotsgesetz vom 6. Mai ein strenges Gesetz gegen die „Nazis“, die sich zuerst einmal registrieren lassen mussten. Der FPÖ-nahe Historiker Lothar Höbelt meint etwas süffisant dazu: „Freilich deshalb drohte keineswegs jedem Nazi der Galgen“..$^{38}$ Die strenge Volksgerichtsbarkeit der unmittelbaren Nachkriegszeit brachte aber immerhin dreißig mörderische Nationalsozialisten, die in den letzten Tagen des Krieges Kapitalverbrechen begangen hatten, an den Galgen. Die Besatzungsmächte trieben 1945 die Entnazifizierung zügig voran (vor allem die Amerikaner), scheiterten dann aber an der großen Zahl der Parteigänger, besonders der vielen „Mitläufer“. 1946 übergaben die Besatzungsmächte das Ruder an die österreichische Regierung, die kein Interesse an einer strengen Entnazifizierung hatte und früh um das „Buhlen“ der Stimmen der Nazis begann, die dann 1949 auch wieder wählen durften. Bereits 1948 fiel die „Entnazifizierung“ dem Kalten Krieg zum Opfer. Den Westmächten erschien die „rote Gefahr“ des Kommunismus größer als die „braune“. Die Figl-Regierung erließ prompt Amnestierungen

35 Anton Pelinka, Austria. Out of the Shadow of the Past, Boulder 1998, 15-30; Rathkolb, Die Zweite Republik (seit 1945), 534-543, 546-550; Günter Bischof/Anton Pelinka/Ferdinand Karlhofer (Hg.), Austro-Corporatism. Past - Present - Future (Contemporary Austrian Studies 4), New Brunswick 1995; Günter Bischof/David M. Wineroither (Hg.), Democracy in Austria (Contemporary Austrian Studies 28), New Orleans/Innsbruck 2019.

36 Rathkolb, Die paradoxe Republik, 64-73; Rathkolb, Die Zweite Republik (seit 1945), 546.

37 Dieter Binder, The Second Republic: Austria Seen as a Continuum, in: Austrian History Yearbook 26 (1995), 17-43, 18.

38 Höbelt, Zweite Republik, 50. 
der Mitläufer, die dann auch rasch in die Gesellschaft integriert wurden. Die Volksgerichtsbarkeit zeigte keine Zähne mehr und lief 1957 aus. ${ }^{39}$

Die meisten Historiker betrachten die Entnazifizierung als Fehlschlag - oder wie Helmut Konrad es ausdrückt: „kein besonders rühmliches Kapitel in der Geschichte der jungen Republik““.40 Höbelt scheint eher davon auszugehen, dass die Entnazifizierung - wie etwa in der Borodajkewycz-Affäre 1965 - ein „Sturm im Wasserglas" gewesen sei, da das „Wiederaufleben des nazistischen Ungeistes“ meist von den Kommunisten im Abseits beschworen worden sei, während sich die Regierungsparteien ÖVP und SPÖ schon 1945 „bewusst alle Optionen offengelassen“ hätten, um dann 1949 um die Nazistimmen zu „buhlen“.41 Auch die Freilassung des Kriegsverbrechers Walter Reder 1985 während der „kleinen SPÖ/FPÖ-Koalition“ schiebt er in die Schuhe der SPÖ, da die Rückkehr „Chefsache“ gewesen sei. ${ }^{42}$ Auch Österreich konstruierte nach dem Krieg eine „usable past“ (Judt), um sich vom Schatten des Zweiten Weltkrieges zu lösen (Kershaw).

Die fehlende Konfrontation mit der Nazivergangenheit war ein schweres Manko in der Nachkriegsentwicklung der österreichischen Demokratie. Bis hin zur Wahl von Kurt Waldheim als Bundespräsident 1986 versteiften sich die ÖsterreicherInnen auf die Doktrin, das Land sei das ,erste Opfer Hitlers“ gewesen. Die Alliierten machten es ihnen mit ihrer Vorgabe der „Moskauer Deklaration“ vom 1. November 1943 nach dem Krieg allerdings leicht, sich in diesen Mythos zurückzuziehen. Der Opferstatus der ÖsterreicherInnen (inklusiver einer guten Million von Wehrmachtssoldaten) ignorierte den Opferstatus der Juden und anderer verfolgter Gruppen. Er sollte Österreich Reparationen ersparen, welche die Sowjetunion trotzdem aus dem einkassierten „deutschen Eigentum“ in ihrer Zone presste. Auch Restitutionszahlungen an die verfolgten Juden sollten so auf die lange Bank geschoben werden. ${ }^{43}$ In jüngerer Zeit haben Gerald Stourzh und Michael Gehler diese zum Großteil akzeptierte

39 Den besten Überblick bietet nach wie vor Dieter Stiefel, Entnazifizierung in Österreich, Wien 1981; vgl. auch Walter Schuster/Wolfgang Weber (Hg.), Entnazifizierung im regionalen Vergleich, Linz 2004. Konrad, Austria on the Path to Western Europe, 15.

41 Höbelt, Zweite Republik, 45-78.

42 Höbelt, Zweite Republik, 262-263.

43 Die Literatur zur Erinnerung und Geschichtspolitik Österreichs zum Zweiten Weltkrieg ist immens, vgl. Günter Bischof, Victims? Perpetrators? „Punching Bags“ of European Historical Memory? The Austrians and Their World War II Legacies, in: German Studies Review 27 (2004) 1, 17-32; neuere Arbeiten sind Cornelius Lehnguth, Waldheim und die Folgen. Der parteipolitische Umgang mit dem Nationalsozialismus in Österreich, Frankfurt a. M. 2013; Katrin Hammerstein, Gemeinsame Vergangenheit - getrennte Erinnerung? Der Nationalsozialismus in Gedächtnisdiskursen und Identitätskonstruktionen von Bundesrepublik Deutschland, DDR und Österreich, Göt- 
Kritik an der Opferdoktrin in Frage gestellt. Natürlich habe Österreich die „advokatorische Funktion" für sich in Anspruch genommen, das Beste aus der Moskauer Deklaration herauszuholen, behauptet Stourzh. ${ }^{44}$ Eine Debatte über die Täterrolle der ÖsterreicherInnen im Krieg 1945 und danach, meint Gehler, sei, wenn nicht „ein mutwillig selbstzerstörerisches Akt“, so doch eine „außen- wie innenpolitisch sehr riskante Gratwanderung " gewesen. ${ }^{45}$

Nach der Wahl Waldheims zum Bundespräsidenten erhöhte sich der Druck aus dem Ausland, sich endlich der Opferdoktrin zu entledigen. Das Jubiläum zum fünfzigsten Jahrestag des „Anschlusses“ wurde zum Anlass genommen, den Opfermythos von der politischen und zivilgesellschaftlichen Seite her zu hinterfragen. Reden von Waldheim 1988, Bundeskanzler Franz Vranitzky 1991 und Präsident Thomas Klestil 1994 erinnerten zum ersten Mal an österreichische TäterInnen im Zweiten Weltkrieg und gaben das neue Paradigma der österreichischen Erinnerung von „Opfern und Tätern“ vor, Österreich habe eine Verantwortung für die Verbrechen des Zweiten Weltkrieges zu tragen, die von „OstmärkerInnen“ verübt worden seinen. Im Folgenden kam es dann zu einer gründlichen Aufarbeitung der österreichischen „Tätergeschichte“ durch die Historikerkommission sowie durch vom Nationalfonds und vom Zukunftsfonds geförderte Projekte. ${ }^{46}$ Sehr verspätet ist Österreich vom „Watschenmann der europäischen Erinnerung“ zu einem Vorzeigemodell geworden. Es wäre auch die These zu diskutieren, ob nicht ein heimlicher, vielleicht unausgesprochener Teil des Aquis communautaire zu Österreichs Beitritt zur Europäischen Union 1995 ein offener Umgang mit der Vergangenheit des Zweiten Weltkriegs (inklusive der Rolle von ÖsterreicherInnen im Holocaust) war, ähnlich wie Präsident Klestil bei der Angelobung der schwarz-blauen Regierung von Wolfgang Schüssel diese dazu zwang, die neue Geschichtspolitik (die „Opfer-und-

tingen 2017; Heidemarie Uhl, Opferthesen, revisited. Österreichs ambivalenter Umgang mit der NS-Vergangenheit, in: Aus Politik und Zeitgeschichte 68 (2018) 34-35, 47-54.

Gerald Stourzh, Um Einheit und Freiheit. Staatsvertrag, Neutralität und das Ende der Ost-WestBesetzung Österreichs 1945-1955 (Studien zu Politik und Verwaltung 62), Wien ${ }^{4} 1998,26$.

45 Michael Gehler, Österreichs Außenpolitik der Zweiten Republik. Von der alliierten Besatzung bis zum Europa des 21. Jahrhunderts, Bd. 1, Innsbruck 2005, 28.

46 Günter Bischof/Barbara Stelzl-Marx/Katharina Bergmann-Pfleger, Auftrag Zukunft: 3000 Zeichen für Gedenken, Toleranz und Demokratie. 15 Jahre Zukunftsfonds der Republik Österreich, Wien 2020; vgl. auch Günter Bischof/Michael Maier, Reinventing Tradition and the Politics of History. Schüssel's Restitution and Commemoration Policies, in: Günter Bischof/Fritz Plasser (Hg.), The Schüssel Era in Austria (Contemporary Austrian Studies 18), New Orleans/Innsbruck 2010, 206234. 
Täter"-Doktrin) des Landes anzuerkennen. ${ }^{47}$ Auch die ehemals kommunistischen Nachbarn Österreichs mussten vor ihrem EU-Beitritt 2004 mit ihrer Geschichte ins Reine kommen.

\section{Außenpolitik}

Die österreichische Außenpolitik wurde während der Besatzungszeit von den Besatzungsmächten mitbestimmt. Die antikommunistische Ausrichtung des Landes führte früh zu einer klaren Westorientierung. Dabei war überraschend, dass die SPÖ mit den Amerikanern besser ins Gespräch kam als die ÖVP, was mit ihrem rigiden Antikommunismus zu tun hatte. ${ }^{48}$ Aber auch die "kapitalistischen“ Amerikaner zeigten sich von der pragmatischen Seite, als sie die Verstaatlichung des „deutschen Eigentums" (Industrie und Banken) in ihrer Zone erlaubten, der Investition von ERP-Gegenwertmitteln in die verstaatlichte Industrie zustimmten sowie überhaupt das Fließen von Marshall-Plan-Mitteln in die Sowjetzone gegenüber Washington durchsetzten, um eine Teilung des Landes zu verhindern. ${ }^{49}$ Nach dem „Oktoberstreik“ 1950 nahmen die Amerikaner zügig die Wiederbewaffnung Österreichs in Angriff. ${ }^{\circ}$ Nachdem die Staatsvertragsverhandlungen im Zuge des Koreakrieges von den Besatzungsmächten eingefroren worden waren, kam die Neutralität Österreich zunehmend ins Gespräch. Nach dem Kanzlerwechsel von Figl zu Raab 1953 wurde Raab rasch den westorientierten Außenminister Karl Gruber los und baute ein besseres Verhältnis zur sowjetischen Besatzungsmacht auf. Bei der Berliner Außenministerkonferenz schwankten dann auch die Amerikaner auf eine „österreichische Neutralität nach Schweizer Muster" ein. Im Kreml kam Nikita Chruschtschow nach Stalins Tod als Parteichef zum Zuge und er wollte Fortschritte in der Österreichfrage

47 Günter Bischof, „Watschenmann der europäischen Erinnerung“? Internationales Image und Vergangenheitspolitik der Schüssel/Riess-Passer-ÖVP/FPÖ-Koalitionsregierung, in: Günter Bischof/ Michael Gehler/Anton Pelinka (Hg.), Österreich in der EU. Bilanz einer Mitgliedschaft (Historische Forschungen des Arbeitskreises europäische Integration 5), Wien 2003, 445-478.

48 Oliver Rathkolb meint sogar, der Antikommunismus sei ein Teil der österreichischen Nachkriegsidentität geworden, vgl. Rathkolb, Die paradoxe Republik, 31-34.

49 Bischof, Austria in the First Cold War, 52-103; Bischof/Petschar, Der Marshallplan.

50 Zur geheimen Wiederbewaffnung nach dem als „Putsch“ verrufenen Oktoberstreik 1950, vgl. Günter Bischof, „Austria looks to the West“. Kommunistische Putschgefahr, geheime Wiederbewaffnung und Westorientierung am Anfang der fünfziger Jahre, in: Thomas Albrich/Klaus Eisterer/ Michael Gehler/Rolf Steininger (Hg.), Österreich in den Fünfzigern, Innsbruck 1995, 183-210; zu Österreichs Sicherheitspolitik nach dem Krieg, vgl. Manfried Rauchensteiner (Hg.), Zwischen den Blöcken. Nato, Warschauer Pakt und Österreich, Wien 2010. 
in die Wege leiten, als ein Entspannungszeichen zur „friedlichen Koexistenz“ mit dem Westen. Die Regierung Raab verhandelte mit den Sowjets direkt und bilateral in Moskau und erzielte den Durchbruch in der Staatsvertragsfrage, was zur Unterzeichnung am 15. Mai 1955 führte. Bis Ende Oktober zogen die Besatzungsmächte ihre Truppen aus Österreich ab und das Parlament erließ das Gesetz zur „immerwährenden Neutralität“. Österreich war wieder souverän..$^{51}$

In den folgenden Jahren definierte Österreich seine Neutralität zwischen Ost und West, ohne jedoch seine ideologische Westorientierung aufzugeben. Zahlreiche junge ÖsterreicherInnen wurden bereits seit der Besatzungszeit zunehmend „amerikanisiert“ - der amerikanische Lebensstil und die Populärkultur zogen die jungen Leute in ihren Bann, auch als Protestform gegen die Generation ihrer „Nazieltern“. 52 Österreich wurde Teil der „McWorld“ (Reynolds). In seiner Diplomatie und Sicherheitspolitik konnte das Land nicht an der europäischen Integration teilnehmen (EWG und NATO). Es gerierte sich vielmehr als „Brückenbauer“ zwischen Ost und West: Wien wurde im Kalten Krieg wiederholt Schauplatz von Gipfelgesprächen und hochgradigen Ost-West-Verhandlungen. Wien holte darüber hinaus verschiedene UN-Organisationen in die Stadt (International Atomic Energy Agency IAEA, United Nations Industrial Development Organization UNIDO) und avancierte in den 1970er-Jahren zum dritten Zentrum der Vereinten Nationen. ${ }^{53}$

Bruno Kreisky, der Vollblutaußenpolitiker, betrieb eine sehr eigenwillige und kontroverse Außenpolitik während seiner Zeit als Regierungschef. Seine „aktive Neutralitätspolitik“ verlegte er zunehmend in die „Dritte Welt“ und den Nahen Osten. Er liebäugelte mit den „blockfreien“ Staaten. Als Vizepräsident der Sozialistischen Internationale reiste er dreimal zu „fact finding missions“ nach Nordafrika und in den Nahen Osten, um im Dauerstreit zwischen Israelis und Palästinensern zu vermitteln. Er verhandelte mit Jassir Arafat; Österreich war die erste Regierung, die die PLO offiziell als legitime Vertretung der Palästinenser anerkannte. Das führte

51 Stourzh, Um Einheit und Freiheit; Gehler, Östereichs Außenpolitik, Bd. 1, 63-140; Bischof, Austria in the First Cold War, 130-149; Rathkolb, Die paradoxe Republik, 263-274.

52 Reinhold Wagnleitner, Coca-Colonisation und Kalter Krieg. Die Kulturmission der USA in Österreich nach dem Zweiten Weltkrieg, Wien 1991; Günter Bischof, Two Sides of the Coin: The Americanization of Austria and Austrian Anti-Americanism, in: Alexander Stephan (Hg.), The Americanization of Europe: Culture, Diplomacy, and Anti-Americanism after 1945, New York 2006, 147-181.

53 Oliver Rathkolb, Internationalisierung Österreichs seit 1945 (Österreich - Zweite Republik), Innsbruck 2006, 38; Franz Cede/Christian Prosl, Ambition and Reality. Austria’s Foreign Policy since 1945, Innsbruck 2017, 52-56; Günter Bischof/Stefan Maurer, ,One hour east of Vienna ...' At the Crossroads of Europe. Vienna - Bridgehead and Bridge in the Cold War, in: Katia Pizzi/Marjatta Hietala (Hg.), Cold War Cities: History, Culture and Memory, Oxford 2016, 45-74. 
zu argen Verstimmungen mit Israel und den USA. ${ }^{54}$ Nach der Geiselnahme von Marchegg 1973 verhandelte er mit Terroristen und schloss das Lager Schönau, das vielen russischen jüdischen Flüchtlingen als Durchgangslager auf dem Weg meist nach Israel diente. ${ }^{55}$ In der Folge gab es weitere terroristische Attentate von radikalen Palästinensern in Wien. Dabei wurde Kreisky auch heftig von der Opposition kritisiert: Er zeige keine Zurückhaltung in seiner Außenpolitik, attackierte ihn ÖVPChef Alois Mock, dafür aber „Sprunghaftigkeit, persönlichen Interessen und Neigung zum diplomatischen Spektakel“. Ludwig Steiner, der außenpolitische Sprecher der ÖVP, sprach von „Kreisky’scher Effekthascherei“. Auch wurde er des „Neutralismus“ und des „Antiamerikanismus“ bezichtigt. ${ }^{56}$ Im Rückblick attackierte Mock Kreiskys gesamte Außenpolitik: „Kreisky verwechselte Neutralitätspolitik mit ständiger Einmischung in internationale Konflikte“. Seine Nahostpolitik, meinte Mock, der in den frühen 1990er-Jahre selbst Außenminister war, habe „weniger den österreichischen Interessen als denen der Sozialistischen Internationale " gedient. ${ }^{57}$

Nach dem Ende des Kalten Krieges verlor Österreich seinen Sonderstatus als neutraler Staat am Rande des Eisernen Vorhangs zwischen Ost und West. Zudem trat Österreich 1995 der Europäischen Union bei und beendete damit seinen „langen Weg“ in die europäische Einigung, nachdem die russischen Bedenken eines versteckten neuen "Anschlusses“ aus dem Weg geräumt worden waren. ${ }^{58}$ Das habe einen „Paradigmenwechsel“ in der österreichischen Außenpolitik hin zur „Europäisierung“ eingeleitet, betonte Schüssels Außenministerin Ursula Plassnik.59 Am Ende der 1990er-Jahre wurde sogar ein NATO-Beitritt in Erwägung gezogen. Die

54 Ausführlich dazu Michael Gehler, Österreichs Außenpolitik, Bd. 1, 388-417; Kriechbaumer, Ära Kreisky, 261-283; Rathkolb, Internationalisierung Österreichs, 62-67; Cede/Prosl, Ambition and Reality, 62-82; Otmar Höll, The Foreign Policy of the Kreisky Era, in: Bischof/Pelinka (Hg.), Kreisky Era in Austria, 32-77.

55 Kreiskys komplexe jüdische Identität, der Marchegg-Anschlag und die Schließung von Schönau sowie seine Beziehungen zu Israel werden analysiert von Daniel Aschheim, The Complex Dynamics of Post-World War Two Jewish Identity and Politics: The Perplexing Case of Bruno Kreisky, phil. Diss., Hebräische Universität Jerusalem 2020.

56 Mock, zit. n. Kriechbaumer, Ära Kreisky, 267; Steiner, zit. n. Höll, Foreign Policy of the Kreisky Era, 49-51.

57 Alois Mock in einem langen Interview mit Kriechbaumer, ders., Ära Kreisky, 304, 306.

58 Michael Gehler, Der lange Weg nach Europa. Österreich vom Ende der Monarchie bis zur EU, 2 Bde., Innsbruck 2002.

59 Dabei betont sie auch, dass die österreichische Außenpolitik keineswegs ihr eigenständiges Profil verloren habe, wie Michael Gehler meint, vgl. Ursula Plassnik, On the Road to a Modern Identity. Austrian Foreign Policy from the Cold War to the European Union, in: Günter Bischof/Ferdinand Karlhofer (Hg.), Austria's International Position after the End of the Cold War (Contemporary Austrian Studies 22), New Orleans/Innsbruck 2013, 55-94, 55-56. 
neue außenpolitische Ausrichtung nach Brüssel, die mit gemeinsamen europäischen Verteidigungsanstrengungen einherging, führte auch zu einer Erosion der Neutralität. Da die Neutralität aber ein zentraler Teil der österreichischen Identität geworden war, kam es zu keiner militärischen Westintegration. ${ }^{60}$ Die österreichische Neutralität ist bereits gut erforscht. ${ }^{61}$ Daneben gibt es aber noch eine große Forschungsagenda zu erledigen.

\section{Forschungsdefizite}

Ein kurzer Abriss wie dieser soll nicht verhehlen, dass Historiker noch viel Arbeit zur Erforschung dieser Republik zu leisten haben. Die Frage der Folgen des Zweiten Weltkriegs auf Österreichs Nachkriegsstatus müsste endlich in einer Zusammenschau behandelt werden (Entnazifizierung, wirtschaftliche Folgen, inklusive Reparationen und Restitutionen, die mentalen und sozialen Folgen von Krieg und Kriegsgefangenschaft für die Betroffenen und ihre Familien, Geschichts- und Erinnerungspolitik). Gab es zu viel oder zu wenig „Bevormundung“ durch die Besatzer? Die Geschichte der österreichischen Neutralität im Kalten Krieg sowie Kreiskys Rolle darin sind noch nicht endgültig geklärt. Für die Zeit der Kreisky-Jahre und die Folgen des Endes des Kalten Krieges für Österreich sind noch viele Fragen offen. Überhaupt seien die „Durchführungs- und Folgegeschichte“ des Staatsvertrages nach dessen Abschluss 1955 noch zu untersuchen, verlangt Gerald Stourzh. ${ }^{62}$ Was waren die wirtschaftlichen Folgen von Kreiskys massiven Unterstützungsaktionen der verstaatlichten Industrie? War Kreiskys Nahostpolitik zu aggressiv für einen neutralen Kleinstaat wie Österreich? Lockte er damit den palästinensischen Terrorismus ins Land? Führte Kreisky mit seiner gewagten Außenpolitik das kleine Land aus seiner Isolation und Selbstzufriedenheit als „Insel der Seligen“ zurück in die Weltpolitik? Gab es einen Paradigmenwechsel in der österreichischen Außenpolitik mit dem EU-Beitritt? Führte die Fortsetzung der „großkoalitionären“ Politik nach der Regierung Schüssel I zu Stillstand im Politikbetrieb? Gibt es seit den „goldenen

60 Günter Bischof, Of Dwarfs and Giants. From Cold War Mediator to Bad Boy of Europe: Austria and the U.S. in the Transatlantic Arena (1990-2013), in: Bischof/Karlhofer (Hg.), Austria's International Position, 13-52; Gehler, Österreichs Außenpolitik, Bd. 2, 664-918; Rathkolb, Internationalisierung Österreichs, 86-89.

61 Ernst Bruckmüller, Nation Österreich. Sozialhistorische Aspekte ihrer Entwicklung, Wien 1984; Rathkolb, Die paradoxe Republik, 17-6o; Hanisch, Schatten des Staates, 427-437.

62 Gerald Stourzh, Um Einheit und Freiheit. Staatsvertrag, Neutralität und das Ende der Ost-WestBesetzung Österreichs 1945-1955 (Studien zu Politik und Verwaltung 62), Wien ${ }^{5}$ 2005, 828. 
Jahren" und in der Zukunft weniger Wirtschaftswachstum und somit kaum noch eine „Steigerung in den Lebenschancen“, wie sie Ernst Hanisch für die Geschichte des 20. Jahrhunderts konstatiert? ${ }^{63}$

Das vielleicht größte Manko der Geschichtswissenschaft für die Zweite Republik ist vielleicht die Weigerung, den Hauptakteuren biographisch näherzukommen. Bereits auf dem ersten Zeitgeschichtetag in Innsbruck 1993 habe ich das Fehlen akademischer biographischer Studien angemahnt. Im angloamerikanischen Publikationsbetrieb verkaufen sich Biographien von Präsidenten wie Roosevelt, Truman, Eisenhower, Kennedy, Johnson, Nixon besonders gut. Selbst George H. W. Bush hat bereits eine biographische Studie von einem bekannten Historiker erhalten. ${ }^{64}$ In Großbritannien gehört es zur guten Reputation eines bekannten Historikers, eine Churchill-Biographie zu wagen. In Österreich gibt es abgesehen von ernsthaften Versuchen zu Renner ${ }^{65}$ und Kreisky ${ }^{66}$ zu den Bundeskanzlern und Präsidenten der Zweiten Republik keine nennenswerten biographischen Studien. ${ }^{67}$ Lothar Höbelt hat zu Jörg Haider eine biographische Arbeit verfasst, die auf Englisch erschienen ist. ${ }^{68}$ Veronika Duma hat eine bemerkenswerte Biographie zur KZ-Überlebenden und Parlamentarierin Rosa Jochmann vorgelegt. ${ }^{69}$

Hanisch behauptet auch, dass es in der Geschichtswissenschaft seit den 1990erJahren zu einer „Atomisierung“ gekommen sei. Jeder geht seinen eigenen Interessen nach, seien es nun die Frauen- oder Einwanderungsgeschichte, die Kulturwissenschaften, Umweltgeschichte, Public History, digitale oder visuelle Geschichte. Die "Felder" und "Themengeschichten" in dem vorliegenden Band reflektieren auch diese neue Vielfalt. Wird diese „Fragmentierung“ dazu führen, dass sich niemand mehr trauen wird, die große Zusammenschau zu schreiben, wie das in diesem Auf-

63 Hanisch, Schatten des Staates, 13.

64 Jon Meacham, Destiny and Power. The American Odyssey of George Herbert Walker Bush, New York 2015.

65 Walter Rauscher, Karl Renner. Ein österreichischer Mythos, Wien 2015; Richard Saage, Der erste Präsident. Karl Renner - eine politische Biographie, Wien 2016.

66 Kreisky hat ein eigenes Archiv hinterlassen und drei Memoirenbände vorgelegt, auf denen jeder Biograph aufbauen kann, trotzdem wagen sich bisher nur engste Mitarbeiter an seinen Lebensweg heran, vgl. Wolfgang Petritsch, Bruno Kreisky. Ein biographischer Essay, Wien 2000; lediglich zu Kreiskys Außenpolitik gibt es eine solide akademische Studie, vgl. Elisabeth Röhrlich, Kreiskys Außenpolitik. Zwischen österreichischer Identität und internationalem Programm, Göttingen 2009.

67 Lediglich Journalisten haben biographische (Vor)Studien unternommen, allerdings ohne Einsicht der Archive, vgl. Ernst Trost, Figl von Österreich. Der Weg zum Staatsvertrag, Wien 1985; Peter Pelinka, Wolfgang Schüssel. Eine politische Biographie, Wien 2003.

68 Lothar Höbelt, Defiant Populist. Jörg Haider and the Politics of Austria, West Lafayette 2003.

69 Veronika Duma, Rosa Jochmann. Politische Akteurin und Zeitzeugin, Wien 2019. 
satz die vielzitierten Historiker Hanisch, Rathkolb, Höbelt und Gehler gewagt haben?

Auch die größere Frage wäre zu diskutieren, ob die Zweite Republik wirklich zwischen 1985 und 1995 ihrem Ende entgegenging und zur "Zweieinhalbten“ oder zur „Dritten“ Republik mutierte. Die „Europäisierung der Politik“ und die „Globalisierung der Volkswirtschaft" haben diese Transformation in die Wege geleitet. Der Politologe Anton Pelinka sprach von den „vier farewells“ der 1980er Jahre. Österreich hat sich vom Katholizismus, Sozialismus, Korporatismus und der Neutralität verabschiedet. Das hat zu einem „anderen Österreich“ geführt, in dem das „Inselder-Seligen “-Syndrom verschwand. ${ }^{70}$

In der Rückschau sieht Ernst Hanisch die Krisenzeiten bereits 1973/1975 deutlich hereinbrechen, es war aber die Zäsur von 1985/1986, die in eine neue Republik führte. Der Ölpreisschock von 1973 sowie der „ökologisch bedingte Pessimismus über die Grenzen des Wachstums“ führten zu sinkenden Bruttonationalprodukten. Die lange Wachstumsperiode der Nachkriegszeit lief aus, obwohl die Kreisky-Regierung die Krise mit hohen Budgetdefiziten gut überstand. Aber 1984/1985 ging das „goldene Zeitalter der Parteien“ ihrem Ende entgegen. Der Zwentendorf-Volksentscheid 1978 und die Besetzung der Hainburger Auen 1984 ersetzten die „Logik der Sozialpartner“, die durch Wirtschaftswachstum gekennzeichnet war, durch die „Logik der ökologischen Bewegung“, die von einer „postmaterialistischen Lebensphilosophie getragen wurde“. War das die „Generalprobe der Dritten Republik“ (A. Pelinka)? Dazu kamen die Krise der verstaatlichen Industrie, die Krise des Sozialsystems und die Budgetkrise sowie zahlreiche Skandale. ${ }^{71}$ Bereits Emmerich Tálos hat von einem „Rückzug des Sozialstaats“ seit den 1980er-Jahren gesprochen. ${ }^{72}$

Lothar Höbelt meint, das Ende der Republik habe sich zwischen 1985 und 1995 „mit dem Zusammenbruch des realen Sozialismus“ und dem Fall der Berliner Mauer als gemeinsamer Nenner vollzogen. Auch er sieht, ähnlich wie Pelinka, vier Faktoren, die zum Ende der Zweiten Republik geführt hätten: 1. das Ende der „Inselder-Seligen“-Mentalität und der Neutralität, die nur mehr als „lokale Marotte weiter gepflegt wird“; 2. das „Zweieinhalb-Parteiensystem [...] mit seinem abnormen Konzentrationsgrad und seiner Organisationsdichte“ sei ans Ende gekommen und

70 Pelinka, Out of the Shadow of the Past, 228-232; zur „Insel der Seligen“, vgl. auch Konrad Paul Liessmann, Austria, Insel der Seligen. Fortunate Isle, in: Bischof/Landry/Karner (Hg.), Myths in Austrian History, 211-224.

71 Hanisch, Schatten des Staates, 458-459, 473-474.

72 Emmerich Tálos, Der Sozialstaat - Vom ,goldenen Zeitalter ${ }^{`}$ zur Krise, in: Sieder/Steiner/Tálos (Hg.), Österreich 1945-1995, 537-551; ders., Vom Siegeszug zum Rückzug. Sozialstaat Österreich 1945-2005 (Österreich - Zweite Republik 3), Innsbruck 2005. 
selbst der Proporz sei auf Widerspruch gestoßen; 3. die Entstehung und das Wachstum „rechtspopulistischer" und „grün-alternativer" Parteien - hier habe Österreich in Europa sogar eine „Pionierrolle“ eingenommen; 4. die verstaatlichte Industrie habe sich nicht mehr von der Krise von 1975 erholt und „schleppe sich weidwund aber noch zwei Jahrzehnte weiter“. Ohne Kreisky zu nennen, fügt er hinzu: „[...] die Verstaatlichte wurde mit der politischen Vorgabe der Arbeitsplatzsicherung überfrachtet".73

Höbelt meint weiter, von der „Dritten Republik“ sei oft die Rede gewesen, nachdem Theodor Piffl-Perčević sie bereits 1974 habe kommen sehen und Bernd Schilcher in den 1980er-Jahren von der „Dritten Republik“ gesprochen habe. Jörg Haiders Idee von der „Dritten Republik“ in den 199oer-Jahren habe, so Höbelt salopp, „alle anderen Bewerber bis auf weiteres in die Flucht" geschlagen, keiner habe sich mehr getraut, von der „Dritten Republik“ zu reden. ${ }^{74}$ Die Veränderungen der Zweiten Republik seit den 1980er-Jahren in Politik und Gesellschaft scheinen still und heimlich zu einer neuen Republik geführt zu haben, die noch keinen Namen hat, die aber in der Zukunft von den Historikern zu definieren sein wird.

73 Höbelt, Die Zweite Republik, 272-277.

74 Ders., 272. 


\title{
Kalter Krieg
}

\author{
Maximilian Graf
}

\section{Elend oder Aufbruch?}

Im Jahr 2010 hat Günter Bischof vom „Elend der österreichischen Geschichtsschreibung zum Kalten Krieg“ gesprochen und seine seit Jahren punktuell formulierte Kritik in gesammelter Form vorgetragen. Er konstatierte eine Beschränkung auf das Thema „Österreich und der Kalte Krieg“ und bemängelte die über den österreichischen „Tellerrand“ kaum hinausreichende Forschung. Als Ausnahme nannte Bischof die großen Konferenzen und Publikationen des Ludwig Boltzmann Instituts für Kriegsfolgenforschung (BIK). ${ }^{1}$ Dieses hatte damals ein internationales Forschungsprojekt zum „Prager Frühling“ im Kontext des Krisenjahres 1968 abgeschlossen. ${ }^{2}$ Seither folgten weitere Großprojekte zum „Wiener Gipfel 1961“ zwischen Nikita S. Chruschtschow und John F. Kennedy ${ }^{3}$ sowie zum „Kreml und Osteuropa 1989 bis 1991“.4 Ausgewählte Beiträge der Sammelbände werden auch in der renommierten „Harvard Cold War Studies Book Series“ publiziert. ${ }^{5}$ Parallel dazu schwang sich auch

1 Günter Bischof, Vom Elend der österreichischen Geschichtsschreibung zum Kalten Krieg, in: Reinhard Krammer/Christoph Kühberger/Franz Schausberger (Hg.), Der forschende Blick. Beiträge zur Geschichte Österreichs im 20. Jahrhundert. Festschrift für Ernst Hanisch zum 70. Geburtstag, Wien/Köln/Weimar 2010, 371-390. Für einen gewichtigen Beitrag Bischofs zur internationalen Geschichte des Kalten Kriegs vor seiner Mitarbeit an den Projekten des BIK siehe: Günter Bischof/ Saki Dockrill (Hg.), Cold War Respite, The Geneva Summit of 1955, Baton Rouge 2000.

2 Stefan Karner/Natalja Tomilina/Alexander Tschubarjan/Viktor Iščenko/Michail Prozumenščikov/ Peter Ruggenthaler/Oldřich Tůma/Manfred Wilke (Hg.), Prager Frühling. Das internationale Krisenjahr 1968, 2 Bde., Köln/Weimar/Wien 2008.

3 Stefan Karner/Barbara Stelzl-Marx/Natalja Tomilina/Alexander Tschubarjan/Günter Bischof/Viktor Iščenko/Michail Prozumenščikov/Peter Ruggenthaler/Gerhard Wettig/Manfred Wilke (Hg.), Der Wiener Gipfel 1961. Kennedy - Chruschtschow, Innsbruck/Wien/Bozen 2011.

4 Stefan Karner/Mark Kramer/Peter Ruggenthaler/Manfred Wilke/Alexander Bezborodov/Viktor Iščenko/Olga Pavlenko/Efim Pivovar/Michail Prozumenščikov/Natalja Tomilina/Alexander Tschubjarjan (Hg.), Der Kreml und die „Wende“ 1989. Interne Analysen der sowjetischen Führung zum Fall der kommunistischen Regime. Dokumente, Innsbruck/Wien/Bozen 2014; dies. (Hg.), Der Kreml und die deutsche Wiedervereinigung 1990. Interne sowjetische Analysen, Berlin 2015.

5 Günter Bischof/Stefan Karner/Peter Ruggenthaler (Hg.), The Prague Spring and the Warsaw Pact Invasion of Czechoslovakia in 1968, Lanham 2010; Günther Bischof/Stefan Karner/Barbara StelzlMarx (Hg.), The Vienna Summit and Its Importance in International History, Lanham 2014. 
die Österreichische Akademie der Wissenschaften (ÖAW) zu Initiativen auf und legte basierend auf Großkonferenzen mit „Der österreichische Staatsvertrag“6 und „The Revolutions of ${ }^{1989}$ “ zwei umfassende Handbücher vor.7 Es folgte der Band „Europa und die deutsche Einheit“. ${ }^{8}$ Neben Projekten zur Besatzungszeit (auf die weiter unten eingegangen wird) wurden durch international vernetzte Forschungen zu den Beziehungen kommunistischer Parteien im Kalten Krieg ${ }^{9}$ weitere Akzente gesetzt. Auch vom Beispiel Österreich ausgehende Forschungen fanden international Beachtung. Dies war für Studierende anregend und das Institut für Zeitgeschichte der Universität Wien bot ihnen durch das Erasmus Intensive Program „Cold War \& Society “10 und fortgesetzte Mitwirkung an solchen Initiativen eine Möglichkeit zur internationalen Vernetzung.

Gemeinsam mit Agnes Meisinger hat der Autor der vorliegenden Standortbestimmung 2016 einen Sammelband zum Thema „Österreich im Kalten Krieg“ herausgegeben, in dem einleitend der Forschungsstand eingehend besprochen wird. Die folgenden Ausführungen fußen darauf. Die Beiträge des Bandes präsentieren international ausgerichtete und thematisch breitgefächerte Forschungen zu Diplomatie, Kultur, NGOs, Politik, Sport, Wissenschaft und der atomaren Herausforderung. ${ }^{11}$ Es handelte sich um den Aufbruch einer jungen Generation, die bestrebt war, das von Bischof überspitzt konstatierte „Elend“ zu überwinden und Österreich verstärkt in die internationale Diskussion einzubringen. Leider erfuhr dieser keine Verstetigung. Im Gegenteil, institutionell wurde der Rückwärtsgang eingeschlagen: Die im außeruniversitären Bereich neben dem BIK führende ÖAW „hat sogar - entgegen der jüngeren internationalen Entwicklung und ihrer aktuellen Erklärungsnotwendigkeit - die Zeitgeschichtsforschung weitgehend marginalisiert und dafür

6 Arnold Suppan/Gerald Stourzh/Wolfgang Mueller (Hg.), Der österreichische Staatsvertrag 1955. Internationale Strategie, rechtliche Relevanz, nationale Identität, Wien 2005.

7 Wolfgang Mueller/Michael Gehler/Arnold Suppan (Hg.), The Revolutions of 1989. A Handbook, Wien 2015.

8 Michael Gehler/Maximilian Graf (Hg.), Europa und die deutsche Einheit. Beobachtungen, Entscheidungen und Folgen, Göttingen 2017.

9 Francesco Di Palma/Wolfgang Mueller (Hg.), Kommunismus und Europa. Europapolitik und -vorstellungen europäischer kommunistischer Parteien im Kalten Krieg, Paderborn 2016 sowie das Themenheft: Journal of European Integration History 20 (2014) 2.

10 In diesem Rahmen wurden 2010-2012 jeweils zweiwöchige Winter Schools in Wien, Budapest und Berlin organisiert. Für die Resultate siehe die Themenhefte: Cold War Reloaded. zeitgeschichte 37 (2010) 6; From Cold War to Détente. zeitgeschichte 38 (2011) 6.

11 Maximilian Graf/Agnes Meisinger (Hg.), Österreich im Kalten Krieg. Neue Forschungen im internationalen Kontext, Göttingen 2016. 
eine frühneuzeitliche Habsburg-Retro-Schau priorisiert“. ${ }^{12}$ Diesem Befund Michael Gehlers ist nichts hinzuzufügen - es gilt aber, dieser Tendenz entgegenzuwirken und die international vorhandene Wertschätzung der geleisteten Arbeit auch in Österreich konsequent einzufordern.

Lange konzentrierte sich die Geschichtsschreibung zu Österreich im Kalten Krieg vor allem auf die detaillierte und multiperspektivische Erforschung der Besatzungszeit. Über das Jahr 1955 hinausgehende Forschungen waren nicht zuletzt wegen der Unzugänglichkeit der Quellen eine Seltenheit. Mittlerweile macht sich eine Schwerpunktverlagerung bemerkbar. Ein besonderer Fokus lag zuletzt auf dem Ende des Kalten Kriegs. Dazwischen klaffen Lücken. Abgesehen von einigen Ausnahmen wird hier auf die seit dem Jahr 2000 publizierten Editionen, Monographien und Sammelwerke Bezug genommen. Vollständigkeit ist in diesem Rahmen nicht möglich. Aufsätze, unveröffentlichte Diplomarbeiten und Dissertationen können nur in Einzelfällen zitiert werden. Alle angeführten Werke enthalten umfangreiche weiterführende Literaturverweise. Da dieser Band keinen separaten Beitrag zu den internationalen Beziehungen Österreichs vorsieht, wird diesem zentralen Aspekt besondere Aufmerksamkeit zuteil. Kritikern altbackener Diplomatiegeschichte sei versichert, dass auch die Erforschung der internationalen Position Österreichs im Kalten Krieg zunehmend im Sinne einer zeitgemäßen Internationalen Geschichte erfolgt.

\section{Die Besatzungszeit: Neue Erkenntnisse trotz hohen Erforschungsgrads}

Den am besten erforschten Abschnitt stellt die vergleichsweise geschlossene Periode der Besatzungszeit (1945-1955) dar, in der Österreich als Nebenschauplatz des frühen Kalten Kriegs auch international eine nicht unwesentliche Rolle einnahm. Im Mittelpunkt des Forschungsinteresses standen die längste Zeit die westlichen Besatzungspolitiken ${ }^{13}$ und die Geschichte des österreichischen Staatsvertrags. ${ }^{14}$

12 Michael Gehler, Unter Aufsicht, Frankfurter Allgemeine Zeitung, 07.02.2018.

13 Günter Bischof, Austria in the First Cold War, 1945-55. The Leverage of the Weak, Basingstoke 1999; Manfried Rauchensteiner, Stalinplatz 4. Österreich unter alliierter Besatzung, Wien 2005. Stellvertretend für frühere Wellen der Forschung: Alfred Ableitinger/Siegfried Beer/Eduard G. Staudinger (Hg.), Österreich unter alliierter Besatzung 1945-1955, Wien/Köln/Graz 1998; Günter Bischof/Josef Leidenfrost (Hg.), Die bevormundete Nation. Österreich und die Alliierten 19451949, Innsbruck 1988.

14 Gerald Stourzh, Um Einheit und Freiheit. Staatsvertrag, Neutralität und das Ende der Ost-WestBesetzung Österreichs 1945-1955, Wien/Köln/Graz ${ }^{5} 2005$. 
Durch den im Gefolge der Archivrevolution in Osteuropa erweiterten Zugang zu Aktenmaterial erfolgten seither vor allem intensive Forschungen zur sowjetischen Österreichpolitik. ${ }^{15}$ Diese wurde auch konsequent in den Kontext der sowjetischen Deutschland- ${ }^{16}$ und Osteuropapolitik ${ }^{17}$ eingebettet. Zur sowjetischen Neutralitätskonzeption im Kalten Krieg haben insbesondere Peter Ruggenthaler ${ }^{18}$ und Wolfgang Mueller ${ }^{19}$ Beiträge zur internationalen Forschungsdiskussion geleistet. Seither wurden diese Arbeiten durch monographische Studien zu Aspekten der Wirtschaftspolitik, ${ }^{20}$ den Repressionen der Besatzungsmacht ${ }^{21}$ und zum Innenleben der sowjetischen Besatzung in Österreich erweitert. ${ }^{22}$ Eher vernachlässigt wurde bisher die sowjetische Kultur- und Wissenschaftspolitik. ${ }^{23}$ Bei der amerikanischen ist

15 Wolfgang Mueller, Die sowjetische Besatzung in Österreich 1945-1955 und ihre politische Mission, Wien 2005; Wolfgang Mueller/Arnold Suppan/Norman Naimark/Gennadij Bordjugov (Hg.), Sowjetische Politik in Österreich 1945-1955: Dokumente aus russischen Archiven, Wien 2005; Stefan Karner/Barbara Stelzl-Marx (Hg.), Die Rote Armee in Österreich. Sowjetische Besatzung 1945-1955, 2 Bde., Graz/Wien/München 2005.

16 Michael Gehler, Modellfall für Deutschland? Die Österreichlösung mit Staatsvertrag und Neutralität 1945-1955, Innsbruck/Wien/Bozen 2015; Wolfgang Mueller, Sowjetische Deutschland- und Österreichpolitik 1941 bis 1955 im Vergleich: Die Fragen der staatlichen Einheit und des Friedensvertrages, in: Michael Gehler/Ingrid Böhler (Hg.) Verschiedene europäische Wege im Vergleich: Österreich und die Bundesrepublik Deutschland 1945/49 bis zur Gegenwart. Festschrift für Rolf Steininger zum 65. Geburtstag, Innsbruck/Wien/Bozen 2007, 121-152.

17 Csaba Békés/László Borhi/Peter Ruggenthaler/Ottmar Traşcă (Hg.), Soviet Occupation of Romania, Hungary, and Austria 1944/45-1948/49, Budapest/New York 2015; Wolfgang Mueller, Soviet Policy, Political Parties, and the Preparation for Communist Takeovers in Hungary, Germany, and Austria, 1944-1946, in: East European Politics and Societies 24 (2010) 1, 90-115.

18 Peter Ruggenthaler, The Concept of Neutrality in Stalin's Foreign Policy, 1945-1953, Lanham 2015; ders., Stalins großer Bluff. Die Geschichte der Stalin-Note in Dokumenten der sowjetischen Führung (Schriftenreihe der Vierteljahrshefte für Zeitgeschichte 95), München 2007.

19 Wolfgang Mueller, A Good Example of Peaceful Coexistence? The Soviet Union, Austria, and Neutrality, 1955-1991, Wien 2011.

20 Walter M. Iber, Die sowjetische Mineralölverwaltung in Österreich. Zur Vorgeschichte der OMV 1945-1955, Innsbruck/Wien 2011; Otto Klambauer, Die sowjetische Wirtschaftspolitik in Österreich 1945-1955, in: Andreas Hilger/Mike Schmeitzner/Clemens Vollnhals (Hg.), Sowjetisierung oder Neutralität? Optionen sowjetischer Besatzungspolitik in Deutschland und Österreich 19451955, Göttingen 2006, 435-450; Hans Seidel, Österreichs Wirtschaft und Wirtschaftspolitik nach dem Zweiten Weltkrieg, Wien 2005.

21 Stefan Karner/Barbara Stelzl-Marx, Stalins letzte Opfer. Verschleppte und erschossene Österreicher in Moskau 1950-1953, Wien/Köln/Weimar 2009.

22 Barbara Stelzl-Marx, Stalins Soldaten in Österreich. Innensicht der sowjetischen Besatzung, Wien/ München 2012.

23 Ausnahmen bestätigen die Regel: Michael Kraus, „Kultura“. Der Einfluss der sowjetischen Besatzung auf die österreichische Kultur 1945-1955, Dipl.-Arb., Universität Wien 2008. 
man hier weiter. ${ }^{24}$ Der Fokus auf die Sowjetunion ließ das Interesse an Arbeiten zu den westlichen Besatzungsmächten aber generell zurückgehen. Günter Bischof und Helmut Petschar haben uns jüngst die Geschichte des Marshall-Plans in Österreich inklusive seines Nachwirkens bis heute ins Gedächtnis zurückgerufen. ${ }^{25}$

Einen Schwerpunkt der Außenpolitikforschung zum Besatzungsjahrzehnt stellte neben dem Staatsvertrag die österreichische Südtirolpolitik dar, ${ }^{26}$ deren stärkere multilaterale Kontextualisierung inzwischen in Angriff genommen wurde. Neuere Forschungen zur Alpen-Adria-Region zeigen, wie eng sämtliche Konflikte und Interaktionen zwischen Italien, Jugoslawien und Österreich verflochten waren. ${ }^{27}$ Bis dato wenig beachtet wurden globale Blickpunkte. Nunmehr liegt aber eine von Gerald Stourzh und Wolfgang Mueller verfasste umfassende englischsprachige Darstellung zur Geschichte des Staatsvertrags vor. ${ }^{28}$

24 Reinhold Wagnleitner, Coca-Colonization and the Cold War, Chapel Hill 2008; Christian H. Stifter, Zwischen geistiger Erneuerung und Restauration. US-amerikanische Planungen zur Entnazifizierung und demokratischen Neuorientierung österreichischer Wissenschaft, Wien/Köln/Weimar 2014.

25 Günter Bischof/Hans Petschar, The Marshall Plan in Austria - since 1947. Saving Europe Rebuilding Austria, Wien 2017.

26 Rolf Steininger, Autonomie oder Selbstbestimmung? Die Südtirolfrage 1945/46 und das GruberDe Gasperi-Abkommen (Innsbrucker Forschungen zur Zeitgeschichte 2), Innsbruck/Wien/Bozen 2006 (Neuauflage von Rolf Steininger, Los von Rom? Die Südtirolfrage 1945/46 und das Gruber-De Gasperi-Abkommen, Innsbruck 1987); Viktoria Stadlmayer, Kein Kleingeld im Länderschacher. Südtirol, Triest und Alcide Degasperi 1945/1946, Innsbruck 2002. Als Quellenausgaben hierzu: Michael Gehler (Hg.), Akten zur Südtirol-Politik 1945-1958, 6 Bde., Innsbruck/Wien/Bozen 2011-2021 (bisher sind 3 Bde. zum Zeitraum 1945-1948 erschienen); ders., Verspielte Selbstbestimmung? Die Südtirolfrage 1945/46 in US-Geheimdienstberichten und österreichischen Akten, Innsbruck 1996. Auch für die Zeit nach 1955 wurden auf dem Gebiet der Südtirol-Forschung enorme Leistungen erbracht. Die umfangreichen Quellenpublikationen werden eine künftig noch stärker multiarchivarisch ausgerichtete und analytischere Forschung beleben. Rolf Steininger, Südtirol zwischen Diplomatie und Terror 1947-1969, 3 Bde., Bozen 1999; Rolf Steininger, Akten zur Südtirol-Politik 1959-1969, 7 Bde., Innsbruck/Wien/Bozen 2005-2013. Siehe auch die Publikationen von Hubert Speckner basierend auf den sicherheitsdienstlichen Akten.

27 Wolfgang Mueller/Karlo Ruzicic-Kessler/Philipp Greilinger (Hg.), The Alps-Adriatic Region 19451955. International and Transnational Perspectives on a Conflicted European Region, Wien 2018.

28 Gerald Stourzh/Wolfgang Mueller, A Cold War over Austria. The Struggle for the State Treaty, Neutrality, and the End of East-West Occupation, 1945-1955, Lanham 2018; Gerald Stourzh/Wolfgang Mueller, Der Kampf um den Staatsvertrag 1945-1955. Ost-West-Besetzung, Staatsvertrag und Neutralität Österreichs, Wien/Köln/Weimar 2020. 


\section{Keine Gesamtdarstellungen und kaum globale Fragestellungen}

Während zur Besatzungszeit bereits Synthesen vorliegen, fehlt zur weiteren Geschichte Österreichs im Kalten Krieg eine fundierte Gesamtdarstellung. ${ }^{29}$ Diese Feststellung soll jedoch nicht die Leistungen der bisher publizierten Längsschnittstudien schmälern. Michael Gehler legte 2005 den ersten Überblick zur Außenpolitik der Zweiten Republik vor..$^{\circ}$ Österreichs „langer Weg nach Europa“, der über mehrere Annäherungsversuche und -schritte schlussendlich erst nach dem Ende des Kalten Kriegs 1995 im Beitritt zur Europäischen Union mündete, wurde von Gehler in mehreren Monographien dargelegt. ${ }^{31}$ Elisabeth Röhrlich hat Kreiskys Außenpolitik mit einem biographischen Zugang analysiert. Die Darstellung thematisiert jedoch seine außenpolitischen Interessen und deren Umsetzung eingehender als das Tagesgeschäft. ${ }^{32}$ Aufgrund der geographischen Lage des Landes spielte sich dieses im Kalten Krieg nun einmal stärker in einer Ost-West-Dimension als entlang der NordSüd-Achse oder im Nahen Osten ab.

In globaler Perspektive ${ }^{33}$ war die österreichische Forschung bisher eher zurückhaltend. Dabei bergen gerade die Dekolonisierung und Stellvertreterkriege in der damals so genannten „Dritten Welt“ großes Forschungspotenzial. Erwin A. Schmidl hat eine Studie zum österreichischen „Blauhelmkontingent“ im Kongo 1960-1963 vorgelegt. ${ }^{34}$ Die österreichische „Algeriensolidarität“ ist von Fritz Keller vor allem entlang innenpolitischer Divergenzen und vor dem Hintergrund der Dekolonisierung untersucht worden. ${ }^{35}$ Überraschend ist für den Autor, dass Österreich 1968

29 Lediglich ein schmales, auf Zeitzeugeninterviews basierendes Buch liegt vor: Otto Klambauer, Der Kalte Krieg in Österreich. Vom Dritten Mann zum Fall des Eisernen Vorhangs, Wien 2000.

30 Michael Gehler, Österreichs Außenpolitik der Zweiten Republik. Von der alliierten Besatzung bis zum Europa des 21. Jahrhunderts, 2 Bde., Innsbruck/Wien/Bozen 2005. Weiters: Günter Bischof/ Anton Pelinka/Michael Gehler (Hg.), Austrian Foreign Policy in Historical Context (Contemporary Austrian Studies 14), New Brunswick 2006; zuletzt zusammenfassend ohne neue Erkenntnisse: Franz Cede/Christian Prosl, Anspruch und Wirklichkeit. Österreichs Außenpolitik seit 1945 , Innsbruck/Wien/Bozen 2015.

31 Zuletzt: Michael Gehler, From Saint Germain to Lisbon. Austria's Long Road from Disintegrated to United Europe 1919-2009, Wien 2020.

32 Elisabeth Röhrlich, Kreiskys Außenpolitik. Zwischen österreichischer Identität und internationalem Programm, Göttingen 2009.

33 Als prägendste Darstellung hierzu: Odd Arne Westad, The Global Cold War. Third World Interventions and the Making of Our Times, Cambridge 2005.

34 Erwin A. Schmidl, Blaue Helme, Rotes Kreuz. Das österreichische Sanitätskontingent im Kongo, 1960 bis 1963, Innsbruck/Wien/Bozen ${ }^{2} 2010$.

35 Fritz Keller, Gelebter Internationalismus. Österreichs Linke und der algerische Widerstand (19581963), Wien 2010. 
einen eher dubiosen „Vermittlungsversuch“ im Vietnamkrieg unternahm, der sowohl im Kreml als auch im Weißen Haus Gesprächsthema war. ${ }^{36}$ Wie im Falle Vietnams dominierte auch im Verhältnis zu China lange Zeit vor allem die Frage der diplomatischen Anerkennung der kommunistischen Hälfte eines geteilten Staates. ${ }^{37}$ Interesse besteht zum Beispiel auch an den österreichischen Interaktionen mit dem sandinistischen Nicaragua der 1980er-Jahre..$^{38}$ Diese vermeintlichen Randthemen der österreichischen Forschung stellen international höchst willkommene Beträge zur globalen Geschichte des Kalten Kriegs dar und für die Zukunft bleibt viel zu tun: Wie wurde die in Lateinamerika (Guatemala, Chile, El Salvador, Kuba etc.), ${ }^{39}$ Afrika (Kongo, Angola etc.) und Asien (Vietnam, Korea, Kambodscha etc.) ausgetragene Blockkonfrontation wahrgenommen, und wie veränderte sie den österreichischen Blick und den Umgang mit diesen Teilen der Welt? Von mindestens ebenso großer Bedeutung ist die Außenperspektive auf Österreich, ${ }^{40}$ weil sie das Selbstbild relativiert und dabei hilft, tradierte Mythen zu hinterfragen. Den gelungensten diesbezüglichen Versuch hat Manfried Rauchensteiner mit seinem Werk „Unter Beobachtung " unternommen. ${ }^{41}$

36 Wolfgang Mueller/Maximilian Graf, An Austrian Mediation in Vietnam? The Superpowers, Neutrality, and Kurt Waldheim's Good Offices, in: Sandra Bott/Jussi Hanhimaki/Janick Schaufelbuehl/Marco Wyss (Hg.), Neutrality and Neutralism in the Global Cold War. Between or within the blocs?, London 2016, 127-143.

37 Maximilian Graf/Wolfgang Mueller, Austria and China 1949-89: A Slow Rapprochement, in: Janick Marina Schaufelbuehl/Marco Wyss/Valeria Zanier (Hg.), Europe and China in the Cold War: Exchanges Beyond the Bloc Logic and the Sino-Soviet Split, Leiden 2019, 17-41.

38 Laurin Blecha, Von Ottakring nach Cuatro Esquinas. Beziehungen und Kooperationen zwischen Nicaragua und Österreich von 1979 bis 1990, in: Albert Manke/Kateřina Březinová (Hg.), Kleinstaaten und sekundäre Akteure im Kalten Krieg. Politische, wirtschaftliche, militärische und kulturelle Wechselbeziehungen zwischen Europa und Lateinamerika, Bielefeld 2016, 275-302.

39 Siehe auch: Günter Bischof/Klaus Eisterer (Hg.), Transatlantic Relations. Austria and Latin America in the 19th and 2oth Centuries, Innsbruck/Wien/Bozen 2006.

40 Oliver Rathkolb/Otto M. Maschke/Stefan August Lütgenau (Hg.), Mit anderen Augen gesehen. Internationale Perzeptionen Österreichs 1955-1990, Wien/Köln/Weimar 2002; Oliver Rathkolb (Hg.), Außenansichten. Europäische (Be)Wertungen zur Geschichte Österreichs im 20. Jahrhundert, Innsbruck/Wien/München/Bozen 2003. Diese verdienstvollen, weitestgehend auf Beiträgen von aufmerksamen Beobachtern und ehemaligen Diplomaten basierenden Bände sollten jedoch um auf breiter Quellenbasis fußende Studien ergänzt werden.

41 Manfried Rauchensteiner, Unter Beobachtung. Österreich seit 1918, Wien/Köln/Weimar 2017. 


\section{Krisen und Entspannung: \\ Politik, Wirtschaft und Grenzen zwischen Ost und West}

In Anlehnung an die Untergliederung der "Cambridge History of the Cold War“42 ist es für die Zeit vom Spätherbst 1955 bis Anfang der 1980er-Jahre angebracht, von „Krisen und Entspannung“ zu sprechen. Österreich strebte erfolgreich nach einer Entspannung mit dem Ostblock, jedoch wurde diese in gewisser Regelmäßigkeit durch Krisen belastet. Dies sollte nicht ausgeblendet werden, wenn leichtfertig von einer langen Phase der Entspannung ${ }^{43}$ ausgegangen wird. Neben der Besatzungszeit gelten die „Krisen an Österreichs Grenzen“44 als am besten erforscht. So liegen zahlreiche Publikationen zu Österreich im Zusammenhang mit der Niederschlagung des ungarischen Volksaufstandes $1956^{45}$ und des „Prager Frühlings“ $1968^{46}$ vor. Österreichs Umgang mit den einhergehenden Fluchtbewegungen wird aktuell einer Neubewertung unterzogen. ${ }^{47}$ Auch die „Vermittlungstätigkeit“ österreichischer Politiker während der Zweiten Berlin-Krise (1958-1961/1963) hat Aufmerksamkeit erregt. ${ }^{4}$

Ein relativ stark bespieltes Forschungsfeld stellen die Beziehungen Österreichs zu Ländern unterschiedlicher Blockzugehörigkeit dar. Mit Fokus auf den Westen sind die Publikationen zum Verhältnis zwischen Österreich und der Bundesrepublik

42 Melvyn P. Leffler/Odd Arne Westad (Hg.), The Cambridge History of the Cold War, Bd. 2: Crises and Détente, Cambridge 2010.

43 Oliver Bange/Poul Villaume (Hg.), The Long Détente: Changing Concepts of Security and Cooperation in Europe, 1950s-1980s, Budapest/New York 2017.

44 Reiner Eger, Krisen an Österreichs Grenzen. Das Verhalten Österreichs während des Ungarnaufstandes 1956 und der tschechoslowakischen Krise 1968. Ein Vergleich, Wien 1981.

45 Andreas Gémes, Austria and the 1956 Hungarian Revolution: Between Solidarity and Neutrality, Pisa 2008; Ibolya Murber/Zoltán Fónagy (Hg.), Die ungarische Revolution und Österreich 1956, Wien 2006; Erwin A. Schmidl (Hg.), Die Ungarnkrise 1956 und Österreich, Wien/Köln/Weimar 2003; Manfried Rauchensteiner, Spätherbst 1956. Die Neutralität auf dem Prüfstand, Wien 1981.

46 Hierzu zuletzt die Beiträge von Peter Ruggenthaler, Horst Pleiner und Hubert Speckner, Silke Stern, Manfred Mugrauer, Dieter Bacher und Harald Knoll, in: Karner/Tomilina/Tschubarjan/ Iščenko/Prozumenščikov/Ruggenthaler/Tůma/Wilke (Hg.), Frühling, Bd. 1.

47 Maximilian Graf/Sarah Knoll, In Transit or Asylum Seekers? Austria and the Cold War Refugees from the Communist Bloc, in: Günter Bischof/Dirk Rupnow (Hg.), Migration in Austria (Contemporary Austrian Studies 26), Innsbruck/New Orleans 2017, 91-111. Knoll arbeitet an einer Dissertation zum Thema.

48 Zum Beispiel Martin Kofler, Kreisky - Brandt - Khrushchev: The United States and Austrian Mediation during the Berlin Crisis, 1958-1963, in: Günter Bischof/Anton Pelinka/Michael Gehler (Hg.), Austrian Foreign Policy in Historical Context (Contemporary Austrian Studies 14), New Brunswick 2006, 170-185. 
Deutschland ${ }^{49}$ und Oliver Rathkolbs Arbeit zur amerikanischen Österreichpolitik bis 1963 erwähnenswert. ${ }^{\circ}$ Eine Studie über die Beziehungen zu den südeuropäischen Diktaturen macht deutlich, dass diese nicht nur von der jüngeren österreichischen Vergangenheit, sondern auch durch den Kontext des Kalten Kriegs geprägt waren. ${ }^{51}$ Darüber hinaus liegen keine umfassend quellengestützten Arbeiten jüngeren Datums vor, umso dringlicher wäre es, solche in Angriff zu nehmen. Über die 1960er-Jahre hinausreichende Analysen würden neue Erkenntnisse zur Wahrnehmung der Neutralität vor dem Hintergrund veränderter internationaler Rahmenbedingungen liefern. Dies betrifft nicht nur die USA, ${ }^{52}$ sondern auch Westeuropa. Der Vergleich mit anderen neutralen Staaten sollte fortgesetzt werden. ${ }^{53}$ Forschungen zu den Interaktionen und Wahrnehmungen unter den Neutralen stehen erst am Anfang. In diesem Zusammenhang sollte auch die Frage der österreichischen Teilhabe an der Europäischen Integration erneut thematisiert werden. ${ }^{54}$

Transnationale Fragestellungen stehen international hoch im Kurs. Dazu gehören auch Parteiennetzwerke. Mit Blick auf die europäische Integration liegen Dokumentationen zur Kooperation christdemokratischer Parteien vor. ${ }^{55} \mathrm{Zu}$ den so-

49 Matthias Pape, Ungleiche Brüder. Österreich und Deutschland 1945-1965, Köln/Weimar/Wien 2000; Rolf Pfeiffer, Eine schwierige und konfliktreiche Nachbarschaft - Österreich und das Deutschland Adenauers 1953-1963, Münster/Hamburg/London 2003; Böhler/Gehler (Hg.), Wege; Michael Gehler/Rudolf Agstner (Hg.), Einheit und Teilung. Österreich und die Deutschlandfrage 1945-1960. Festgabe für Rolf Steininger zum 70. Geburtstag, Innsbruck/Wien/Bozen 2013.

50 Oliver Rathkolb, Washington ruft Wien. US-Großmachtpolitik und Österreich 1953-1963, Wien 1997. Viertiefend zu den österreichisch-amerikanischen Beziehungen unter Präsident Kennedy siehe Martin Kofler, Kennedy und Österreich. Neutralität im Kalten Krieg, Innsbruck/Wien/München/Bozen 2003.

51 Stefan A. Müller/David Schriffl/Adamantios T. Skordos, Heimliche Freunde. Die Beziehungen Österreichs zu den Diktaturen Südeuropas nach 1945: Spanien, Portugal, Griechenland, Wien 2016.

52 Oliver Rathkolb, Bruno Kreisky: Perspectives of Top Level U. S. Foreign Policy Decision Makers, 1959-1983, in: Günter Bischof/Anton Pelinka/Oliver Rathkolb (Hg.), The Kreisky Era in Austria (Contemporary Austrian Studies 2), New Brunswick 1994, 130-151.

53 Johanna Rainio-Niemi, The Ideological Cold War. The Politics of Neutrality in Austria and Finland, New York 2014; Wolfgang Mueller, A Special Relationship with Neutrals? Khrushchev's Coexistence, Austria and Switzerland, 1955-60, in: zeitgeschichte 41 (2014) 5, 279-295.

54 Michael Gehler/Rolf Steininger (Hg.), Die Neutralen und die Europäische Integration 1945-1995/ The Neutrals and the European Integration 1945-1995, Wien/Köln/Weimar 2000.

55 Zuletzt: Michael Gehler/Piotr H. Kosicki/Helmut Wohnout (Hg.), Christian Democracy and the Fall of Communism, Leiden 2019; Michael Gehler/Markus Gonschor/Hinnerk Meyer/Hannes Schönner (Hg.), Transnationale Parteienkooperation der europäischen Christdemokraten und Konservativen: Dokumente 1965-1979, Berlin 2016; Michael Gehler/Wolfram Kaiser (Hg.), Transnationale Parteienkooperation der europäischen Christdemokraten: Dokumente 1945-1965, München 2004. 
zialdemokratischen Interaktionen ist in Österreich vergleichsweise wenig geforscht worden. Dies ist angesichts der Zusammenarbeit prägender Repräsentanten der Sozialistischen Internationale wie Willy Brandt, Bruno Kreisky und Olof Palme umso erstaunlicher. ${ }^{56}$ Künftige quellengestützte Forschungen zur Politikabstimmung europäischer sozialdemokratischer Regierungen wären hochgradig wünschenswert. Selbst innenpolitisch weitgehend bedeutungslose Kleinparteien, wie die KPÖ, können international eine überraschend große Rolle spielen. Die Erforschung ihrer Geschichte ist lange Zeit auf das Besatzungsjahrzehnt beschränkt geblieben. ${ }^{57}$ Eine Perspektivenerweiterung auf den Reformweg der KPÖ (etwa 1963-1969) in internationaler Vergleichsperspektive sowie auf Konflikte mit den östlichen und Interaktionen mit den westlichen „Bruderparteien“ offenbart einen lohnenswerten Forschungsgegenstand..$^{58}$ Darüber hinaus wäre eine intensivere Erforschung der Rolle der KPÖ im Ost-West-Handel wünschenswert. ${ }^{59}$

Zur Wirtschaftsgeschichte der Zweiten Republik liegen bereits Überblicke vor. ${ }^{60}$ Obwohl die Forschung zum Osthandel eine gewisse Vertiefung erfahren hat, ${ }^{61}$ bleibt in diesem Feld viel zu tun. Nur unzureichend sind bisher die Wechselwirkungen zwischen Innen-, Außen- und Wirtschaftspolitik herausgearbeitet worden (Embargos,

56 Oliver Rathkolb, Sozialdemokratische Netzwerke in der europäischen Nahostpolitik - Brandt, Kreisky und Palme als politische Unternehmer, in: Michael Gehler/Wolfram Kaiser/Brigitte Leucht (Hg.), Netzwerke im europäischen Mehrebenensystem. Von 1945 bis zur Gegenwart, Wien/Köln/ Weimar 2008, 121-137.

57 Als umfassenden Überblick unter Berücksichtigung der aus der „Parteigeschichtsschreibung“ hervorgegangenen Werke siehe: Manfred Mugrauer, Die Kommunistische Partei Österreichs. Zum Stand der Forschung über die Geschichte der KPÖ, in: Jahrbuch für historische Kommunismusforschung 2013, 211-234.

58 Maximilian Graf, Frühstart des „Eurokommunismus“? Das Experiment der KPÖ und die Konferenzen westeuropäischer kommunistischer Parteien im Kontext der europäischen Reformkommunismen der 1960er-Jahre, in: Jahrbuch für historische Kommunismusforschung 2017, 217-232.

59 Maximilian Graf, Parteifinanzierung oder Devisenerwirtschaftung? Zu den Wirtschaftsbeziehungen von KPÖ und SED, 1946-1989, in: Jahrbuch für historische Kommunismusforschung 2014, 229-247.

60 Felix Butschek, Vom Staatsvertrag zur Europäischen Union. Österreichische Wirtschaftsgeschichte von 1955 bis zur Gegenwart, Wien 2004. Zur „Ära Kreisky“ siehe zuletzt: Hans Seidel, Wirtschaft und Wirtschaftspolitik in der Kreisky-Ära, Wien/Köln/Weimar 2017.

61 Zum Osthandel siehe: Andreas Resch, Der österreichische Osthandel im Spannungsfeld der Blöcke, in: Manfried Rauchensteiner (Hg.), Zwischen den Blöcken. NATO, Warschauer Pakt und Österreich, Wien 2010, 497-556; Gertrude Enderle-Burcel/Piotr Franaszek/Dieter Stiefel/Alice Teichova (Hg.), Gaps in the Iron Curtain. Economic relations between neutral and socialist countries in Cold War Europe, Kraków 2009; Gertrude Enderle-Burcel/Dieter Stiefel/Alice Teichova (Hg.), „Zarte Bande“. Österreich und die europäischen planwirtschaftlichen Länder/„Delicate Relationships“. Austria and Europe’s Planned Economies, Innsbruck/Wien/Bozen 2006. 
Osthandelsboom, Exportförderungskredite, Arbeitsplatzsicherung und schließlich die Krise der Verstaatlichten). Ohne Kenntnis dieser Zusammenhänge wird man insbesondere die Ostpolitik Österreichs seit den 1970er-Jahren nicht adäquat analysieren können.

Die Erforschung der Beziehungen zu den sozialistischen Staaten Europas hat insbesondere seit der Jahrtausendwende große Fortschritte gemacht. ${ }^{62}$ Mittlerweile liegen Monographien zur Tschechoslowakei, ${ }^{63}$ zum slowakischen Landesteil, ${ }^{64}$ zur DDR, $^{65}$ zu Rumänien ${ }^{66}$ und zur Sowjetunion vor. ${ }^{67}$ Nur jene zur UdSSR und zur DDR decken den gesamten Zeitraum des Kalten Kriegs ab. Zu Polen ist in den letzten Jahren verstärkt gearbeitet worden. ${ }^{68}$ Am belastetsten waren die Beziehungen zu den Nachbarstaaten hinter dem Eisernen Vorhang. Wie dramatisch und häufig die Zwischenfälle an der österreichisch-tschechoslowakischen Grenze insgesamt waren, hat Stefan Karner anhand von Fallbeispielen aufgezeigt. ${ }^{69}$ Den zunächst blutigsten Grenzabschnitt stellte jener zu Jugoslawien dar. Nach dem Bruch Stalins mit Tito 1948 und der darauffolgenden Westwendung Belgrads entspannte sich das Verhältnis zu Österreich und die Lage an der Grenze normalisierte sich..$^{\circ}$ In den 196oerJahren wurde ein Abkommen über den kleinen Grenzverkehr geschlossen. Der Tourismus in Richtung Jugoslawien sowie die Arbeitsmigration in Richtung Österreich begannen zu boomen. Petra Mayrhofer widmet sich der Aufarbeitung der österrei-

62 Arnold Suppan/Wolfgang Mueller (Hg.), Peaceful Coexistence or Iron Curtain? Austria, Neutrality and Eastern Europe in the Cold War and Détente, 1955-1989, Wien 2009.

63 Paul Ullmann, Eine schwierige Nachbarschaft. Die Geschichte der diplomatischen Beziehungen zwischen Österreich und der Tschechoslowakei 1945-1968, Wien 2006; Martin David, Österreichisch-tschechoslowakische Beziehungen 1945 bis 1974 unter besonderer Berücksichtigung aktueller Themen, phil. Diss., Universität Wien 2002.

64 David Schriffl, Tote Grenze oder lebendige Nachbarschaft? Österreichisch-slowakische Beziehungen 1945-1968, Wien 2012.

65 Maximilian Graf, Österreich und die DDR 1949-1990. Politik und Wirtschaft im Schatten der deutschen Teilung, Wien 2016; Rolf Pfeiffer, Die DDR und Österreich 1949-1972. Beziehungen in den Jahren offizieller Beziehungslosigkeit, Aachen 2015.

66 Paul Ullmann, Relațiile diplomatice austro-române între 1945-1997/Die österreichisch-rumänischen diplomatischen Beziehungen zwischen 1945 und 1997, Iaşi 2010.

67 Mueller, Example.

68 Siehe dazu die Beiträge von Maximilian Graf, Sarah Knoll und Peter Ruggenthaler in: Peter Ruggenthaler/Wanda Jarząbek (Hg.), Österreich - Polen. Stationen gemeinsamer Geschichte im 20. Jahrhundert, Graz 2021 (im Druck).

69 Stefan Karner, Halt! Tragödien am Eisernen Vorhang. Die Verschlussakten, Salzburg 2013.

70 Petar Dragišić, Österreichisch-jugoslawische Beziehungen 1945-1955, phil. Diss., Universität Wien 2007; ders., Odnosi Jugoslavije i Austrije 1945-1955, Belgrad 2013. 
chisch-jugoslawischen Beziehungen unter besonderer Berücksichtigung Kärntens. ${ }^{71}$ 1978 wurde die über den bilateralen Kontext hinausweisende Arbeitsgemeinschaft Alpen-Adria gegründet, deren Erforschung von Karlo Ruzicic-Kessler vorangetrieben wird. Ungeachtet der unterschiedlichen politischen, wirtschaftlichen und militärischen Ausrichtung Österreichs, Italiens und Jugoslawiens zeigt sich ein hoher Grad interregionaler Integration. $7^{2}$

Am Beispiel Ungarns lassen sich Erfolge der österreichischen Entspannungspolitik am besten illustrieren. Nach den Tiefpunkten im Gefolge des Zweiten Weltkriegs und der kommunistischen Machtübernahme sowie erneut nach 1956 begann eine langsame Entspannung der Beziehungen. Diese trug ab Mitte der 1960er-Jahre erste Früchte $^{73}$ und führte zu einer kontinuierlichen Entschärfung der Lage am Eisernen Vorhang. Das Verhältnis entwickelte sich zu einem Musterbeispiel der europäischen Entspannung, und die gemeinsame Grenze wurde sukzessive durchlässiger. Einen Markstein stellte die Aufhebung der gegenseitigen Visapflicht 1979 dar. Grenzüberschreitende Kontakte und Kooperationen intensivierten sich. Im Westen wurden die Beziehungen zwischen Österreich und Ungarn sogar als wünschenswertes Modell für die Ost-West-Beziehungen gesehen. Im Osten hingegen blickte man mit Sorge auf die Entwicklung. ${ }^{74}$ Selbst die 1988 von Ungarn gewährte Reisefreiheit (Weltpass) war zumindest indirekt dem österreichischen Streben nach einer durchlässigeren Grenze geschuldet. Es folgte ein Reiseboom von Ost nach West und 1989 gehörte der Eiserne Vorhang endgültig der Geschichte an. Weniger mit Blick auf die Ereignisgeschichte des Jahres $1989^{75}$ als in Langzeitperspektive liegt mit dem erfolgreichen Streben nach größerer Durchlässigkeit des Eisernen Vorhangs ein echter österreichischer Beitrag zur Überwindung der Blockteilung - der auch inhärenter Bestandteil der internationalen Geschichte des Kalten Kriegs ist. ${ }^{76}$

71 Petra Mayrhofer, Hans Sima. Ein politisches Leben. Kärntner Landeshauptmann (1965-1974), Wien/Köln/Weimar 2015. Mayrhofer forscht zu den bilateralen Beziehungen in den 1960er- und 1970er-Jahren.

72 Karlo Ruzicic-Kessler, Avvicinamento e cooperazione interregionale: La Jugoslavia nei rapporti di vicinato con l'Austria e l'Italia (1968-1978), in: Acta Histriae 26 (2018) 3, 787-806.

73 Andreas Gémes, „Wie zwei geschiedene Eheleute“. Österreichisch-ungarische Beziehungen in den 1950er Jahren, Graz 2010.

74 Tamás Baranyi/Maximilian Graf/Melinda Krajczar/Isabella Lehner, A Masterpiece of European Détente? Austrian-Hungarian Relations from 1964 until the Peaceful End of the Cold War, in: zeitgeschichte 41 (2014) 5, 311-338.

75 Dazu zuletzt: Stefan Karner/Philipp Lesiak (Hg.), Der erste Stein aus der Berliner Mauer. Das Paneuropäische Picknick 1989, Graz 2019.

76 Maximilian Graf, The opening of the Austrian-Hungarian border revisited: How European détente contributed to overcoming the „Iron Curtain“, in: Bernhard Blumenau/Jussi M. Hanhimäki/ 
Transfers und transnationale Interaktionen über den Eisernen Vorhang hinweg verdienen eine tiefschürfende Analyse. Sie vermögen es, die gesellschaftlichen Dimensionen der Ost-West-Teilung und ihrer Überwindung fassbarer zu machen. Der Tourismus böte ein spannendes Experimentierfeld. Die Archive der östlichen Staatssicherheitsdienste horten umfangreiches Quellenmaterial zu diesem und weiteren Themen. Die Arbeit an anschlussfähigen Feldern (wie Wirtschaft, Kirchen, Kultur, Sport, Medien, Spionage) bietet beste Voraussetzungen zur internationalen Sichtbarmachung österreichischer Forschungen zum Kalten Krieg.

\section{Interaktionsfelder: Kultur, Sport, Medien, Wissenschaft, Militär, Geheimdienste}

Zu kulturellen Themen haben Vertreter der Germanistik den Anfang gemacht und sich zunächst im Rahmen eines von Michael Hansel und Michael Rohrwasser herausgegebenen Sammelbandes dem kulturellen Kalten Krieg in Österreich angenommen, der zwar erneut auf die Besatzungszeit fokussiert, aber bereits darüber hinausweisende Beiträge enthält. ${ }^{77}$ Ein von Günther Stocker initiiertes Projekt hat neben zahlreichen Spezialstudien eine umfassende Monographie zu den Diskursen des Kalten Kriegs in der österreichischen Nachkriegsliteratur bis in die Mitte der 196oer-Jahre vorgelegt. ${ }^{78}$ Neben transnationalen Akteuren der Kulturszene ${ }^{79}$ ist auch die österreichische Kulturaußenpolitik gegenüber den sozialistischen Staaten Gegenstand der jüngeren Forschung gewesen. Während wir bereits viel über das Zustandekommen von Kulturabkommen und die Errichtung von Kulturinstituten wissen ${ }^{80}$ stellt die Wirkungsgeschichte der österreichischen Bemühungen weiterhin ein Desiderat dar. Spannend wären Studien zur Rezeption jenseits des Eisernen Vorhangs. Welche Wirkung konnte das kulturelle Engagement Österreichs in den sozi-

Barbara Zanchetta (Hg.), New Perspectives on the End of the Cold War. Unexpected Transformations?, London 2018, 138-158.

77 Michael Hansel/Michael Rohrwasser (Hg.), Kalter Krieg in Österreich. Literatur - Kunst - Kultur, Wien 2010.

78 Stefan Maurer/Doris Neumann-Rieser/Günter Stocker, Diskurse des Kalten Krieges. Eine andere österreichische Nachkriegsliteratur, Wien/Köln/Weimar 2017.

79 Stefan Maurer, „Der Boden des neutralen Österreichs scheint uns besonders für eine Auseinandersetzung zwischen Ost und West geeignet zu sein. “ Wolfgang Kraus' Netzwerke im kulturellen Kalten Krieg, in: Graf/Meisinger (Hg.), Österreich, 209-229.

80 Andrea Brait, „die große Trennungslinie, die an unserer Haustür vorbeiführt, überbauen“. Zur Vermittlerfunktion der österreichischen Kulturaußenpolitik zwischen Ost und West, in: ebd., 259295. 
alistischen Staaten entfalten und welchen Einfluss hatten Rundfunk und Fernsehen aus Österreich ebendort?

Der Sport wurde spätestens ab den 1950er-Jahren zu einer von ideologischen Interessen geprägten und politischen Interventionen begleiteten Projektionsfläche des Ost-West-Gegensatzes. Die Cold War Studies widmen sich verstärkt den transnationalen Dimensionen des Sports. Ein Themenheft der "zeitgeschichte" hat den Anfang in Österreich gemacht. ${ }^{81}$ Auch im Bereich der Wissenschaftskontakte ${ }^{82}$ und zu Fragen der Technologie ${ }^{8_{3}}$ sind zuletzt Initiativen gestartet.

Oftmals vernachlässigte militärische Fragestellungen dominieren den von Rauchensteiner 2010 herausgegebenen Band „Zwischen den Blöcken“, der neben der österreichischen Landesverteidigung insbesondere den Umgang mit den Supermächten und den Militärbündnissen in den Blick nimmt. Darüber hinaus beinhaltet er auch eine eingehende Analyse der österreichischen Medien im Kalten Krieg durch Berthold Molden. ${ }^{84}$

Medial stets präsent und mythenbeladen ist die Rolle der Geheimdienste im Österreich des Kalten Kriegs. Eine tiefgehende Beschäftigung ist aber erst in den letzten Jahren in Angriff genommen worden. ${ }^{85}$ Unter der Ägide von Siegfried Beer entstand das Austrian Center for Intelligence, Propaganda and Security Studies, das seit 2007 das „Journal for Intelligence, Propaganda and Security Studies“ (JIPSS) herausgibt. Dessen Inhalte weisen weit über den österreichischen „Tellerrand“ hinaus, bieten aber dennoch ausreichend Raum für eine Analyse des österreichischen Szenarios. In den letzten Jahren hat sich auch das BIK stärker der Erforschung des Agierens der Nachrichtendienste in Österreich verschrieben. Diese Forschungen sollten fortgesetzt und vertieft werden. Dabei geht es nicht darum, Sensationen zutage zu fördern, sondern darum, aus den Unmengen an Aktenmaterial, die das nachrichten-

81 Sport in Kalten Krieg. zeitgeschichte 42 (2015) 4.

82 Johannes Feichtinger/Heidemarie Uhl (Hg.), Die Akademien der Wissenschaften in Zentraleuropa im Kalten Krieg. Transformationsprozesse im Spannungsfeld von Abgrenzung und Annäherung, Wien 2018.

832018 fand die Tagung "Technological Innovation and the Spread of Globalization in the Cold War" statt. Siehe URL: https://iog.univie.ac.at/fileadmin/user_upload/i_iog/news/Programm_Technoligical_Conference_K3.pdf (abgerufen 23.11.2020).

84 Manfried Rauchensteiner (Hg.), Zwischen den Blöcken. NATO, Warschauer Pakt und Österreich, Wien/Köln/Weimar 2010.

85 Als gewichtige Beiträge hierzu sowie auch zu militärischen Fragestellungen des frühen Kalten Kriegs siehe: Erwin A. Schmidl (Hg.), Österreich im frühen Kalten Krieg 1945-1958. Spione, Partisanen, Kriegsplane, Wien/Köln/Weimar 2000; Walter Blasi/Erwin A. Schmidl/Felix Schneider (Hg.), B-Gendarmerie, Waffenlager und Nachrichtendienste. Der militärische Weg zum Staatsvertrag, Wien/Köln/Weimar 2005. 
dienstliche Tagesgeschäft produzierte, ein Narrativ zu den tatsächlichen Aktivitäten $\mathrm{zu}$ schaffen und diese angemessen zu kontextualisieren. Kürzlich hat der Experte zur Geschichte der österreichischen Geheimdienste Thomas Riegler eine über den Kalten Krieg hinausweisende Monographie vorgelegt. ${ }^{86}$

\section{Internationale Organisationen, das atomare Zeitalter und der Terrorismus}

Auch wenn in der Fachwelt keine Einigkeit darüber besteht, inwiefern der Nahostkonflikt in die Geschichte des Kalten Kriegs zu integrieren ist, ist jedenfalls klar, dass der daraus resultierende Terrorismus durch den Ost-West-Konflikt beeinflusst wurde. In den 1970er- und 1980er-Jahren geriet Österreich in dessen „Fadenkreuz“, wie es Thomas Riegler formuliert hat. ${ }^{87}$ Erstmals wurde dies mit der Geiselnahme von Marchegg/Schwechat offenkundig, die darauf abzielte, die über Österreich abgewickelte jüdische Emigration aus der Sowjetunion zum Erliegen zu bringen. ${ }^{88}$ Den aufsehenerregendsten Fall stellte aber die Geiselnahme am Sitz der Organization of the Petroleum Exporting Countries (OPEC) 1975 dar. Sie zeigt, dass die Ansiedelung internationaler Organisation in Wien - entgegen der Behauptungen der Politik - nicht unbedingt eine Erhöhung der Sicherheit Österreichs bedeutete.

Nicht nur die OPEC hatte ihren Sitz in Wien. 1979 wurde die Bundeshauptstadt zum dritten ständigen Sitz der United Nations Organisation (UNO). Seither beherbergt die Wiener UNO-City auch die seit 1957 in der Stadt ansässige International Atomic Energy Agency (IAEA). ${ }^{89}$ Ihre Geschichte wird von Elisabeth Röhrlich erforscht. Sie hat in ihren Forschungen unter anderem nachweisen können, dass die Gründung der IAEA nicht nur von den Ost-West-Beziehungen, sondern in entscheidender Weise auch von Nord-Süd-Fragen bestimmt wurde. Ihr „IAEA History Research Project" ist Partner des am Woodrow Wilson International Center for Scholars angesiedelten „Nuclear Proliferation International History Project“ und ein

86 Thomas Riegler, Österreichs geheime Dienste. Vom Dritten Mann bis zur BVT-Affäre, Wien 2019.

87 Thomas Riegler, Im Fadenkreuz: Österreich und der Nahost-Terrorismus 1973-1985, Göttingen 2011.

88 Dazu rezent: Gabriele Anderl/Viktor Iščenko, Die jüdische Emigration aus der Sowjetunion via Österreich, in: Stefan Karner/Alexander Tschubarjan (Hg.), Österreich - Russland. Stationen gemeinsamer Geschichte, Graz/Wien 2018, 241-251.

89 Siehe als Einführung: Erwin A. Schmidl, Wien als internationales Zentrum, in: Michael Dippelreiter (Hg.), Wien. Die Metamorphose einer Stadt, Wien/Köln/Weimar 2013, 703-730. 
weiteres Beispiel für die Internationalität von Forschungen, die in Österreich ihren Ausgangspunkt haben..$^{\circ 0}$

Die atomare Dimension umfasste aber nicht nur Diplomatie, Politik, Wissenschaft und Technik, ${ }^{91}$ sondern auch die Geschichte der Emotionen. Die Angst vor der atomaren Auslöschung war ein globales Phänomen, das auch vor Österreich nicht Halt machte ${ }^{92}$ und dessen weitere Erforschung wünschenswert wäre. Das Thema Abrüstung steht in engem Zusammenhang damit: Wien war Gastgeber für die im Endeffekt erfolglosen - fast 16 Jahre dauernden - Verhandlungen über die gegenseitige Verminderung von Streitkräften und Rüstungen und damit zusammenhängende Maßnahmen in Europa (MBFR). Zudem wurde der niemals ratifizierte zweite Vertrag zur nuklearen Rüstungsbegrenzung (SALT II) 1979 durch den USPräsidenten Jimmy Carter und den sowjetischen Staats- und Parteichef Leonid I. Breschnew in der österreichischen Hauptstadt unterzeichnet, wodurch Wien zum zweiten Mal nach 1961 als Gastgeber eines Gipfeltreffens der Supermächte fungierte. ${ }^{93}$ Bald darauf trübte sich die internationale Lage erheblich ein.

\section{Die KSZE und das Ende des Kalten Kriegs}

Die letzte Hochphase des Kalten Kriegs an der Wende von den 1970er- zu den 1980er-Jahren zeigte in Teilen Europas und insbesondere in Österreich weniger starke Auswirkungen als in globaler Betrachtung. Während auch die „Détente in Europe“ in Mitleidenschaft gezogen war, scheint die „European Détente“ überlebt $\mathrm{zu}$ haben. Als sowjetische Raketenstationierungen, die Nachrüstungsdebatte und der sowjetische Einmarsch in Afghanistan sowie die „polnische Krise“ Anfang der 1980er-Jahre das internationale Klima massiv verschärften, bemühten sich viele

90 Für Ergebnisse des Projekts siehe u. a.: Elisabeth Röhrlich, The Cold War, the developing world, and the creation of the International Atomic Energy Agency (IAEA), 1953-1957, in: Cold War History 16 (2016) 2, 195-212 und das Themenheft: Nuclear Modernity and Western Societies: From the Creation of Euratom to the Three Mile Island Accident. zeitgeschichte 42 (2015) 5. Die Monographie ist in Arbeit.

91 Zuletzt: Christian Forstner, Kernphysik, Forschungsreaktoren und Atomenergie. Transnationale Wissensströme und das Scheitern einer Innovation in Österreich, Wiesbaden 2019.

92 Doris Neumann-Rieser, Atomangst in österreichischer Literatur zwischen 1945 und 1966, in: Graf/ Meisinger (Hg.), Österreich, 97-120.

93 Anlässlich des 40. Jahrestags fand eine Konferenz des BIK statt: URL: http://bik.ac.at/konferenz1979-stpoelten/ (abgerufen 23.11.2020). 
europäische Staaten, die Ost-West-Entspannung aufrechtzuerhalten. ${ }^{94}$ Österreichs Beziehungen zum Osten überstanden diese Phase ebenfalls relativ unbeschadet, was mitunter die westliche Skepsis gegenüber Wiens Ostpolitik verstärkte.

In diesen Jahren rückten militärische Fragestellungen und Kriegsängste zurück in den Fokus der Öffentlichkeit. Nachrüstungsdebatte und Friedensbewegung sind international intensiv beforscht worden, ${ }^{95}$ vergleichbare Arbeiten zu Österreich stehen aus. ${ }^{96}$ Die Haltung Österreichs zum sowjetischen Einmarsch in Afghanistan ist bis dato nur am Rande thematisiert worden, beispielsweise durch Agnes Meisinger im Zusammenhang mit der Frage eines Boykotts der Olympischen Sommerspiele in Moskau 1980.97 Oliver Rathkolb hat einen Aufsatz zum ambivalenten Umgang von Gewerkschaften und politischen Parteien mit der Solidarność verfasst. ${ }^{8}$ Weitere Forschungen sollten zeitnah in Angriff genommen werden. Zu den 1970er- und 1980er-Jahren besteht für die österreichische Zeitgeschichtsforschung im internationalen Vergleich zweifelsohne der größte Aufholbedarf.

Die schärfste Kontroverse der Cold War Studies zur Détente wird aktuell über die Bedeutung der KSZE für das Ende des Kalten Kriegs geführt.99 Mit der Rolle Öster-

94 Poul Villaume/Odd Arne Westad (Hg.), Perforating the Iron Curtain. European Détente, Transatlantic Relations and the Cold War, 1965-1985, Kopenhagen 2010, 7-17.

95 Philipp Gassert/Tim Geiger/Hermann Wentker (Hg.), Zweiter Kalter Krieg und Friedensbewegung. Der NATO-Doppelbeschluss in deutsch-deutscher und internationaler Perspektive, München 2011; Leopoldo Nuti (Hg.), The Crisis of Détente in Europe. From Helsinki to Gorbachev, 1975-1985, London/New York 2009.

96 Während europaweit massenhaft Menschen auf die Straßen gingen, blieb es im neutralen Österreich, das von der Nachrüstung nicht direkt betroffen war, vergleichsweise ruhig. Dennoch wurde bei Großveranstaltungen - die mitunter den Eindruck der einseitigen Parteinahme gegen die NATO-Nachrüstung erweckten - Solidarität mit der westeuropäischen Bewegung bekundet. Die Teilhabe von Parteien und Vorfeldorganisationen war innenpolitisch umstritten. Ein interessanter Aspekt des österreichischen Falls ist, dass die Friedensbewegung ihre Wurzeln auch im Protest gegen Waffenexporte hatte. Zeitgenössisch dazu: Andreas Maislinger, Friedensbewegung in einem neutralen Land. Zur neuen Friedensbewegung in Österreich, in: Reiner Steinweg/Jörg Becker (Red.), Medienmacht im Nord-Süd-Konflikt: Die Neue Internationale Informationsordnung, Frankfurt a. M. 1984, 392-415.

97 Agnes Meisinger, Die österreichische Haltung zum Boykott der Olympischen Sommerspiele in Moskau 1980 unter besonderer Berücksichtigung der Rolle Bruno Kreiskys, Dipl.-Arb., Universität Wien 2012.

98 Oliver Rathkolb, Austria: An Ambivalent Attitude of Trade Unions and Political Parties, in: Idesbald Goddeeris (Hg.), Solidarity with Solidarity. Western European Trade Unions and the Polish Crisis, 1980-1982, Maryland 2010, 269-288.

99 Siehe dazu als jüngsten Höhepunkt die Beiträge von Gottfried Niedhart und Oliver Bange zur Intentionalität des Wandels durch die KSZE sowie die Vorbemerkungen des Herausgebers Mark Kramer, der ihre Interpretationen als „teleological nonsense“ bezeichnete: Mark Kramer, Editor’s Note, 
reichs im KSZE-Prozess haben sich in erster Linie ein Schweizer und ein deutscher Historiker befasst. Thomas Fischer hat im Kontext der europäischen Neutralen die Rolle Österreichs im KSZE-Prozess erstmals wissenschaftlich beleuchtet. ${ }^{100}$ Er wurde dadurch zu einem Pionier der in den vergangenen Jahren boomenden KSZEForschungen. ${ }^{101}$ Benjamin Gilde hat Österreichs Rolle mit Blick auf die humanitäre Dimension der KSZE eingehend analysiert. Die Ballhausplatzdiplomatie hatte maßgeblichen Anteil daran, den KSZE-Prozess auch über das weitgehend ergebnislose erste Folgetreffen in Belgrad (1977/1978) und das sogar für sieben Monate unterbrochene zweite Folgetreffen in Madrid (1980-1983) hinwegzuretten. ${ }^{102}$ Auch hier folgen nun im Rahmen eines FWF-Projekts von Österreich ausgehende vergleichende Forschungen zur Rolle der neutralen Staaten in der sowjetischen KSZEPolitik. Das Wiener Folgetreffen (1986-1990) stellt nicht nur ein österreichisches, sondern ein internationales Forschungsdesiderat dar, das nun ebenfalls im Rahmen eines FWF-Projekts in Angriff genommen wurde. Damit erfahren die in den letzten Jahren intensiven Arbeiten zur Rolle Österreichs am Ende des Kalten Kriegs eine Fortsetzung. Andrea Brait, Michael Gehler und Wolfgang Mueller haben bereits Sammelbände $\mathrm{e}^{103}$ und einen Zeitzeugenband ${ }^{104}$ vorgelegt; eine umfangreiche Ausgabe diplomatischer Dokumente zu den Umbruchsjahren 1985-1991 wird folgen. Gemeinsam mit Gehler hat der Autor des vorliegenden Beitrags die Aktenedition „Österreich und die deutsche Frage 1987-1990“ erarbeitet und zur Aufarbeitung der Haltung Österreichs zur deutschen Einheit beigetragen. ${ }^{105}$

in: Journal of Cold War Studies 18 (2016) 3, 1-2; Gottfried Niedhart, Introduction: CSCE, the German Question, and the Eastern Bloc, in: ebd., 3-13; ders., Ostpolitik: Transformation through Communication and the Quest for Peaceful Change, in: ebd., 14-59; Oliver Bange, Onto the Slippery Slope: East Germany and East-West Détente under Ulbricht and Honecker, 1965-1975, in: ebd., 60-94.

100 Thomas Fischer, Neutral Power in the CSCE. The N+N States and the Making of the Helsinki Accords 1975, Baden-Baden 2009.

101 Zuletzt: Nicolas Badalassi/Sarah B. Snyder (Hg.), The CSCE and the End of the Cold War. Diplomacy, Societies and Human Rights, 1972-1990, New York 2019.

102 Benjamin Gilde, Österreich im KSZE-Prozess 1969-1983. Neutraler Vermittler in humanitärer Mission, München 2013.

103 Andrea Brait/Michael Gehler (Hg.), Grenzöffnung 1989: Innen- und Außenperspektiven und die Folgen für Österreich, Wien/Köln/Weimar 2014; Wolfgang Mueller (Hg.), 1989: Die Samtenen Revolutionen, Österreich und die Transformation Europas, Wien 2017.

104 Andrea Brait/Michael Gehler (Hg.), Am Ort des Geschehens in Zeiten des Umbruchs. Lebensgeschichtliche Erinnerungen aus Politik und Ballhausplatzdiplomatie vor und nach 1989, Hildesheim 2017.

105 Michael Gehler/Maximilian Graf, Österreich und die deutsche Frage 1987-90. Vom HoneckerBesuch in Bonn zur Einheit, Göttingen 2018. 


\section{Fazit und Ausblick}

Trotz des hohen Bearbeitungsgrads der Besatzungszeit und der großen Fortschritte zum Ende des Kalten Kriegs bleibt für die österreichische Forschung viel zu tun und es wäre wünschenswert, wenn sich angehende Historiker und Historikerinnen in ihren Qualifikationsarbeiten verstärkt den zahlreichen bestehenden Desiderata zuwenden würden. Dafür wird es aber einer entsprechenden Heranführung an die Themen in der Lehre und ihrer stärkeren und nachhaltigeren institutionellen Verankerung in der universitären und außeruniversitären Forschung bedürfen. Der Blick sollte dabei nicht nur auf das europäische Szenario und die Rolle der Supermächte beschränkt bleiben, sondern auch die globale Dimension umfassen. ${ }^{106}$ Im internationalen Rahmen verortete Forschungen können dabei weiterhin von Österreich ausgehen. Sie werden nationale Forschungslücken schließen und bei entsprechender Relevanz und Qualität internationale Aufmerksamkeit erfahren. Zeitlich wäre ein stärkerer Fokus auf die 1970er- und 1980er-Jahre wünschenswert. Österreich wäre dadurch Teil der internationalen Forschungsdebatte und würde ihre Ergebnisse nicht - wie bisher so oft - erst im Nachhinein auf das eigene Fallbeispiel anwenden. Eine Intensivierung der Forschung wäre auch mit Blick auf die Wirtschaft sowie zu den weiteren genannten Themenfeldern und darüber hinaus angezeigt. Auch die Rolle der Kirche stellt kaum bearbeitetes Desiderat dar. Trotz aller rezenten Trends und wichtiger Perspektivenerweiterungen sind Forschungen zu Politik und Diplomatie im Sinne einer zeitgemäßen International History in der internationalen Scientific Community keineswegs verpönt. Im Gegenteil, eine fundierte historische Kenntnis des internationalen Systems und seiner Wechselwirkungen ist essenziell, um unsere Gegenwart zu verstehen. Der Kalte Krieg wirkt nach - auch auf Österreich im vermeintlich geeinten Europa. ${ }^{107}$

106 Dazu wurde an der Universität Wien jüngst eine Initiative gesetzt: https://newcoldwarstudies-hist. univie.ac.at/ (abgerufen 07.03.2021).

107 Zur Position Österreichs nach dem Kalten Krieg generell: Günter Bischof/Ferdinand Karlhofer (Hg.), Austria's International Position after the End of the Cold War (Contemporary Austrian Studies 22), New Orleans 2013; zu den Implikationen der „Ostöffnung“: Dieter Stiefel (Hg.), Der „Ostfaktor“. Österreichs Wirtschaft und die Ostöffnung 1989 bis 2009, Wien/Köln/Weimar 2010. 


\section{EU und Europa}

Anita Ziegerhofer

Ist die österreichische Zeitgeschichte europäisch? Ist Europa in der österreichischen Zeitgeschichte ein Thema? Welche Folgen haben der EU-Beitritt und die EU-Mitgliedschaft Österreichs für die österreichische Zeitgeschichte? Und welche Beachtung findet die europäische Integration in der Zeitgeschichtsforschung unseres Landes? Kann man den Anfang der europäischen Integration als Zäsur, als Epochenbeginn innerhalb der österreichischen Zeitgeschichte darstellen?

In den vorliegenden Betrachtungen wird, ohne Anspruch auf Vollständigkeit, der Versuch unternommen, diese Fragen zu beantworten. Zunächst erfolgt eine Begriffsdefinition, in einem weiteren Abschnitt der Versuch einer Standortbestimmung der Zeitgeschichte in Bezug auf Europa/EU-Europa, um in einem abschließenden Schritt die Forschungsdesiderata zu diskutieren.

\section{Zeitgeschichte und EU-Europa}

Die Zeitgeschichte entwickelte sich als eigenständige Disziplin der Geschichtswissenschaft erst mit der Erfahrung der „deutschen Katastrophe“: 1947 entstand in München das Institut zur Erforschung der nationalsozialistischen Politik, das 1952 in Institut für Zeitgeschichte umbenannt wurde. ${ }^{1}$ In Österreich erfolgte die Anerkennung der Zeitgeschichte als eigenständiges akademisches Fach erst durch die von Ludwig Jedlicka initiierte Expertentagung im Dezember 1960 und wenig später, im März 1961, konnte Alphons Lhotsky feststellen: „Die Zeitgeschichte, nach der so heftig und mit größter Berechtigung verlangt wurde, ist kein Wunschtraum mehr“.2 Demnach entwickelte sich die Zeitgeschichte als eigenständiges Fach in Österreich im Vergleich mit Deutschland mit einiger Verspätung. Diese Tatsache erklärt wohl, dass Österreich erstens an die deutsche „Geschichtskultur angebunden [ist]“ und zweitens „deren geschichtstheoretische und methodische, zum Teil auch inhaltliche

1 Norbert Frei, Zeitgeschichte, in: Stefan Jordan (Hg.), Lexikon Geschichtswissenschaft. Hundert Grundbegriffe, Stuttgart 2002, 336-339, 336-337.

2 Erika Weinzierl, Zeitgeschichte - Programm einer Zeitschrift, in: zeitgeschichte $1(1973)$ 1, 3. 
,Konjunkturen' $[\ldots]$ seit den sechziger Jahren mit gebührender Verzögerung regelmäßig mitmacht". 3

Zwölf Jahre nach der Anerkennung der Zeitgeschichte als eigenständige Disziplin erschien 1973 die erste Nummer der „Zeitgeschichte“. Eine Intention der damaligen Herausgeberin, der Grande Dame der österreichischen Zeitgeschichte, Erika Weinzierl, war, „immer wieder über die Grenzen Österreichs und auch Europas hinauszublicken“. ${ }^{4}$ Erst elf Jahre später erfüllte sich der Wunsch Weinzierls, als 1984 mit Helmut Konrad der erste Ordinarius für „,Allgemeine Zeitgeschichte unter Berücksichtigung außereuropäischer Länder und Kulturen" nach Graz berufen wurde. 5 Die Bezeichnung „Allgemeine Zeitgeschichte“ implizierte damals wohl auch Europa!

1993 formulierte Gerhard Botz am Zeitgeschichtetag in Innsbruck „Zwölf Thesen zur Zeitgeschichte Österreichs." ${ }^{6}$ Damals - vor über einem Vierteljahrhundert konstatierte er allerdings noch immer einen Österreichzentrismus in der hiesigen Zeitgeschichte. Darüber hinaus stellte er fest, dass sich Zeitgeschichte in Österreich größtenteils als eine politisierte Geschichte, aber auch eine Geschichte des Politischen verstand:

Heute steht durch die EU-Orientierung und die Öffnung Osteuropas offensichtlich eine neuerliche Umorientierung von österreichischer Geschichtsmentalität und Zeitgeschichte bevor, parallel zu einer Neudefinition von Österreichs internationaler Rolle und nationaler Identität. ${ }^{7}$

In Bezug auf die damals bevorstehende Ostöffnung 1988/89 formulierte Botz folgende Vermutung:

Inwiefern die 1988/89 begonnene Öffnung Österreichs gegen Osten und zur EG (EU) auch eine echte thematische Weitung des bisher überwiegend nationalstaatlich limitier-

3 Gerhard Botz, Zwölf Thesen zur Zeitgeschichte in Österreich, in: Ingrid Böhler/Rolf Steininger (Hg.), Österreichischer Zeitgeschichtetag 1993 (24. bis 27. Mai 1993 in Innsbruck), Innsbruck 1995, 19-33, 26.

4 Weinzierl, Zeitgeschichte, 3.

5 Vielen Dank an Helmut Konrad für diese Auskunft (E-Mail vom 25. März 2019) sowie Walter Höflechner, Das Fach „Geschichte“ an der philosophischen resp. Geisteswissenschaftlichen Fakultät der Universität Graz. Vertretung und Institution. Von den Anfängen bis zur Gegenwart (Publikationen aus dem Archiv der Universität Graz 44/1), Graz 2015, 536-538.

6 Botz, Zwölf Thesen, 19-33.

7 Ebd., 25. 
ten zeitgeschichtlichen Horizonts mit sich bringen wird, ist nicht abzusehen, jedoch nicht auszuschließen. ${ }^{8}$

Bevor die Frage nach der „thematischen Weitung“ zu beantworten versucht wird, soll zunächst die Frage „Was ist Europa?“ und die im Zusammenhang mit den Begriffen Europa und Europäische Union stehenden Termini im geschichtswissenschaftlichen Kontext geklärt werden.

Was ist Europa? Ein Kontinent, ein Anhängsel von Asien, ein Halbkontinent oder ist Europa die Europäische Union, der Europarat oder die OEEC? Es zeigt sich, dass die Frage nach Europa eine Vielzahl an Antworten provoziert. Als ZeithistorikerIn sich nur auf die EU zu beschränken, die Timothy Garton Ash in einem Interview anlässlich der Verleihung des Aachener Karlspreises im Mai 2013 als „schlechteste Form Europas ausgenommen alle anderen, die in der Geschichte ausprobiert wurden“, bezeichnete, ${ }^{9}$ wäre zu wenig: Europa ist mehr als eine geographische Größe, ist mehr als EU oder Europarat - Europa ist ein Komplex an Werten, kollektiven Identitäten, ist Einheit in der Vielfalt, war aber auch bis 1989 Spaltung in der Vielfalt. Und auch Integration von europäischen Staaten bedeutet nicht ausschließlich EU, sondern auch Europarat, OECD, OSZE, EFTA ...

Die wissenschaftliche Auseinandersetzung mit dem komplexen Europa wird unter dem Begriff Europastudien subsumiert, von denen einen Kernbereich die europäische Integrationsgeschichte bildet. Die Europastudien eröffnen ein inter- und multidisziplinäres Feld der Zusammenarbeit: Geschichte, Kulturwissenschaft, Politikwissenschaft, Soziologie und Rechtswissenschaften finden hier ihren Platz. ${ }^{10}$ Europastudien werden etwa an der Universität Bremen ${ }^{11}$ am eigens dafür eingerichteten Institut für Integrierte Europastudien angeboten wie auch an der Europa-Universität Viadrina in Frankfurt an der Oder, wo es ein eigenes Institut für Europastudien gibt. ${ }^{12}$

8 Ebd., 28-29.

9 Zit. n. Ulrike Liebert, Was ist Europa? Zur Einführung in die interdisziplinären Europastudien, in: Ulrike Liebert/Janna Wolff (Hg.), Interdisziplinäre Europastudien. Eine Einführung, Wiesbaden $2015,1-28,1$.

10 Vgl. dazu etwa Timm Beichelt/Bożena Chołuj/Gerald C. Rowe/Hans-Jürgen Wagener/Thekla Lange, Einleitung: Was heißt und zu welchem Ende studiert man Europastudien?, in: Timm Beichelt/Bożena Chołuj/Gerard Rowe/Hans-Jürgen Wagener (Hg.), Europa-Studien. Eine Einführung, Wiesbaden 2006, 7-44.

11 Institut für Europastudien, Universität Bremen, URL: https://www.ies.uni-bremen.de/ (abgerufen 26.08.2020).

12 Viadrina Institut für Europastudien (IFES), Europa-Universität Viadrina Frankfurt (Oder), URL: https://www.europa-uni.de/de/forschung/institut/institut_europastudien/index.html (abgerufen 26.08.2020). 
In dem vielbeachteten Sammelband von Michael Gehler und Silvio Vietta erfolgt die Auseinandersetzung mit den Begriffen „Europa - Europäisierung - Europäistik“ für die Geschichtswissenschaften. ${ }^{13}$ In unterschiedlichen Disziplinen hat sich gegen Ende der 1970er-Jahre ein neuer europäischer Wissenschaftsdiskurs herausgebildet, den die oben genannten Herausgeber unter dem Sammelbegriff „Europäisierung“ erfassen. ${ }^{14}$ Mit „Europäisieren“ bzw. „Europäisiertwerden“ ist hier das Angleichen und Anpassen an die europäische Lebensart gemeint, aber auch der ,jahrhundertelange Export europäischer kultureller Werte und politischer Vorstellungen in andere Kontinente bis hin zu Akzeptanz und Übernahme europäischer Richtlinien und Politikinhalte durch einzelne Mitgliedstaaten der Europäischen Union". ${ }^{15}$ Nicht der Gedanke, Europa zu reflektieren und zu hinterfragen, sei neu, sondern, so Gehler und Vietta, vielmehr die Suche nach einer disziplinenübergreifenden Europawissenschaft. Anfang des 21. Jahrhunderts hat man sich diesem Novum vor allem mit staats- und verfassungsrechtlichen, europarechtlichen und politikwissenschaftlichen Fragestellungen genähert, wie dementsprechende Publikationen belegen. ${ }^{16}$ „Europäisierung" meint Europawissenschaft und dient als Etikett für ForscherInnen, die über Themen mit umfassenden Europabezug auch interdisziplinär forschen. ${ }^{17}$ Der Prozess der „Europäisierung“ bedeutet aber nicht nur europäische Integrationspolitik, sondern reicht historisch weit zurück bzw. auch räumlich über das EU-Europa hinaus. ${ }^{18}$ Für Florian Bieber bedeutet Europäisierung

die grenzüberscheitende Konstruktion und Diffusion von Institutionen, Regeln, Haltungen und Überzeugungen. Diese Prozesse sind multidirektional und werden oft von unterschiedlichen AkteurInnen angetrieben. Die Implementierung von Vereinheitlichungskonzepten und -diskursen, wenn auch in ihrem Ursprung verschieden, war schon immer mit Machtverhältnissen verbunden - von der Antike bis in die Gegenwart. ${ }^{19}$

13 Michael Gehler/Silvio Vietta (Hg.), Europa - Europäisierung - Europäistik. Neue wissenschaftliche Ansätze, Methoden und Inhalte (Arbeitskreis Europäische Integration. Historische Forschungen. Veröffentlichungen 7), Wien 2010.

14 Ebd., 9 .

15 Ebd.

16 Gehler und Vietta führen exemplarisch an Gunnar Folke Schuppert/Ingolf Pernice/Ulrich Haltern (Hg.), Europawissenschaft, Baden-Baden 2005: Gehler/Vietta (Hg.), Europa - Europäisierung Europäistik, 11.

Wolfgang Schmale, Die Bedeutung der Europäistik für die Geschichtswissenschaften, in: Gehler/ Vietta (Hg.), Europa - Europäisierung - Europäistik, 111-120, 112.

18 Gehler/Vietta (Hg.), Europa - Europäisierung - Europäistik, 9.

19 Florian Bieber, URL: file:///C:/Users/zieger/AppData/Local/Microsoft/Windows/INetCache/Content.Outlook/VIH19UPJ/DimensionsEuropeanization_folder_eng_longversion.pdf (abgerufen 27.08.2020). 
Unter dem Begriff „Europäistik“ versteht der Kulturwissenschaftler und Germanist Silvio Vietta

eine Wissenschaft von einer eigenen Struktur und besonderen Form der europäischen Kulturgeschichte (European turn). Sie definiert damit Europa wesentlich über den Kulturbegriff und als einen eigenen Kulturraum gegenüber anderen Kulturen. Die Europäistik ist insbesondere befasst mit der Entstehung und Entwicklung der Leitkodierungen der europäischen Kulturgeschichte wie auch mit den nationalen und epochalen Varianten dieser Leitkodierungen. ${ }^{20}$

Europäistik umfasst Europastudien, -forschungen und -wissenschaft, die aber in erster Linie das geographisch eingegrenzte Europa zum Gegenstand haben. In diesem Kontext sei auf Paul Michael Lützeler verwiesen, der von der Kontinentalisierung spricht. $^{21}$

Bereits in den 1990er-Jahren führte Wolfgang Schmale den Begriff Europäistik in die Historiographie ein. ${ }^{22}$ Schmale zeichnet Europa in seiner "longue durée“ unter dem Blickwinkel der Kulturgeschichte nach und beginnt beim Mythos vom Raub der Europa, zeigt Europakonzepte in unterschiedlichen Epochen auf oder analysiert Europakarten und -bilder. ${ }^{23}$

An dieser Stelle sei kurz auf die Frage der Zäsur in der Zeitgeschichte eingegangen: Eine Zäsur trennt das Vorher von seinem Nachher, um so die „Sinneinheit zu konstituieren, die aus Begebenheiten ein Ereignis macht“. ${ }^{24}$ Folgende Begebenheiten bildeten Einschnitte und gelten in der Zeitgeschichte als unumstrittene Zäsuren: 1917 (Ausbruch der Russischen Revolution), 1918 (Ende des Ersten Weltkrieges), 1945 (Ende des Zweiten Weltkrieges) sowie 1989 (Zerfall des Kommunismus). ${ }^{25}$ Doch Zäsuren sind fluide, so wird etwa die „Osterweiterung“ 2004 als Ende des

20 Silvio Vietta, Europäische Kulturgeschichte. Eine Einführung, Paderborn 2007, 469. Es sei hier nochmals auf Liebert/Wolff (Hg.), Interdisziplinäre Europastudien bzw. Beichelt/Chołuj/Rowe/ Wagener (Hg.), Europa-Studien hingewiesen.

21 Paul Michael Lützeler, Kontinentalisierung. Das Europa der Schriftsteller, Bielefeld 2007.

22 Gehler/Vietta (Hg.), Europa - Europäisierung - Europäistik, 11.

23 Hier gilt es das Standardwerk von Wolfgang Schmale zu erwähnen: Wolfgang Schmale, Geschichte Europas, Wien 2000 oder ders., Geschichte und Zukunft der Europäischen Identität, Stuttgart 2008.

24 Martin Sabrow, Zäsuren in der Zeitgeschichte, in: Frank Bösch/Jürgen Danyel (Hg.), Zeitgeschichte. Konzepte und Methoden, Göttingen 2012, 109-130, 113.

25 Ebd., 109-130. Allgemein Michael Gehler/Andrea Brait (Hg.), Am Ort des Geschehens in Zeiten des Umbruchs. Lebensgeschichtliche Erfahrungen aus Politik und Ballhausplatzdiplomatie vor und nach 1989 (Historische Europa-Studien 17), Hildesheim 2018; Peter Pichler, Zeitgeschichte als Le- 
Ostblocks gefeiert und als europäisches Narrativ erzählt, aber entgleitet dann bald wieder dem Gedächtnis. Bleiben wir bei der europäischen Integrationsgeschichte, hier markieren der EGKS- wie auch der EWG-Vertrag eine neue Dimension der beginnenden Transnationalisierung Europas, doch gelten weder 1950/1952 noch 1957/1958 als Zäsuren, Selbiges kann auch für den Vertrag von Maastricht (1993) gesagt werden: Die europäische Integration erfuhr damals eine weitere, tiefergehende Dimension durch die politische Vereinigung, als Zäsur gilt das Jahr 1993 wohl dennoch nicht. Ob die Migrationsthematik 2015 oder der (harte oder weiche) Brexit feste Zäsuren in der Zeitgeschichte bilden werden, bleibt abzuwarten. Das Jahr 2020, in dem Corona als Pandemie nicht nur die gesamte Menschheit, sondern auch Politik und Wirtschaft zu beherrschen begann, besitzt zweifelsohne das Potenzial, eine zeithistorische Zäsur zu werden. Francis Fukuyama meinte im Jahr 1989, das Ende der Geschichte und somit den Sieg des liberalen Westens erblicken zu können. ${ }^{26}$ Wir wissen, dass Fukuyamas These falsch war, allein die Niederschlagung des Aufstandes am Platz zum Tor des Himmlischen Reiches, am Tiananmen-Platz in Peking 1989 machte seine These obsolet. Eine Wende in der (Politik- und Zeit-)Geschichte könnte die Präsidentschaft Donald Trumps ab 2016 bilden, dadurch wurde ein markanter Anfangspunkt eines neuen Politikstils gesetzt, ich nenne es „TwitterPolitik“, der sich relativ rasch auch über Europa ergoss. Es scheint wohl so, dass Samuel Huntingtons These vom „Kampf der Kulturen ${ }^{{ }^{27}}$ im Sinne des „Kampfes zwischen Kultur und Unkultur des Regierens" eher realisiert wird als Fukuyamas Ende der Geschichte.

Fasst man das Geschriebene zusammen, kann für die Zeitgeschichte (und europäische Integrationsgeschichte) festgehalten werden, dass sie über ein wesentliches Merkmal verfügt: Sie unterliegt aufgrund des permanenten Wechsels und der Ablöse von Zeitzeugen sowie durch das Auftauchen ständig neuer Quellenarten einer ständigen Dynamik, die sie als Geschichtswissenschaft zeitlich nicht exakt eingrenzbar macht und man so gesehen versuchen muss, die Zeitgeschichte immer neu zu datieren bzw. neu zu definieren. ${ }^{28}$

bensgeschichte. Überlegungen zu einer emanzipativen und aktuellen Zeithistoriographie (Gesellschafen und Staaten im Epochenwandel 23), Frankfurt a. M. 2017.

26 Francis Fukuyama, The end of history and the last man, London 1992.

27 Samuel P. Huntington, Kampf der Kulturen. Die Neugestaltung der Weltpolitik im 21. Jahrhundert, München 1996.

28 Michael Gehler, Zeitgeschichte im dynamischen Mehrebenensystem. Zwischen Regionalisierung, Nationalstaat, Europäisierung, internationaler Arena und Globalisierung (Herausforderungen 12), Bochum 2001, 14. 


\section{2. „Europäisierung“ in der Zeitgeschichte}

Wie bereits oben festgestellt, lässt sich eine europäische Geschichtsschreibung nicht allein auf die Epoche der Zeitgeschichte reduzieren. Europäische Geschichte ist komplex, es geht um transnationale und raumübergreifende Phänomene, um Vernetzungen, um Ideen, Begriffe, Vorstellungen und Konstruktionen, die auf Europa bezogen sind. Es geht dabei in erster Linie um einen eurozentrischen Blick - Europa im Zentrum. Es ist Schmale beizupflichten, dass sich europäische Geschichte als Vernetzungsgeschichte versteht und Europäistik als Dachbegriff für die unterschiedlichen Methoden und Konzepte, wie europäische Geschichte geschrieben werden kann. ${ }^{29}$

Als ein Beispiel für die europäische Geschichte als Vernetzungsgeschichte möchte ich die Pariser Vorortverträge 1919-1923 anführen, die in den letzten Jahren aus globalgeschichtlicher Perspektive Beachtung gefunden haben. ${ }^{30}$ Anhand dieser Verträge werde ich versuchen, Transnationalität, raumübergreifende Phänomene und Vernetzungen darzustellen. ${ }^{31}$ Die Vorortverträge, die den Ersten Weltkrieg beendeten, stellen das Produkt der Pariser Friedensverhandlungen dar; sie begannen am 18. Januar 1919 und endeten am 21. Januar 1920. Diese genaue zeitliche Festlegung gilt auch für die fünf Verträge: 28. Juni 1919 Vertrag von Versailles, 10. September 1919 Vertrag von St. Germain, 27. November 1919 Vertrag von Neuilly, 4. Juni 1920 Vertrag von Trianon, 10. August 1920 Vertrag von Sèvres (24. Juli 1923 Vertrag von Lausanne).

So wie die Friedenskonferenz als Endpunkt des "Großen Krieges" terminlich festgemacht werden kann (oder je nach Sichtweise auch als Ausgangspunkt eines weiteren Weltkrieges), gilt diese terminliche Fixierung auch für den Zeitraum des Ersten Weltkriegs. ${ }^{32}$ Um allerdings den Ausbruch des Ersten Weltkrieges verstehen

29 Wolfgang Schmale, Europäistik und österreichische Geschichte, in: Martin Scheutz/Arno Strohmeyer (Hg.), Was heißt „österreichische“ Geschichte? Probleme, Perspektiven und Räume der Neuzeitforschung (Wiener Schriften zur Geschichte der Neuzeit 6), Wien 2008, 149-166, 152.

30 Vgl. etwa Margaret MacMillan, Die Friedensmacher. Wie der Versailler Vertrag die Welt veränderte, München 2018; Jörn Leonhard, Der überforderte Frieden. Versailles und die Welt 19181923, München 2018; Emily S. Rosenberg, Transnationale Strömungen in einer Welt, die zusammenrückt, in: Akira Iriye/Jürgen Osterhammel (Hg.), Geschichte der Welt 1870-1945. Weltmärkte und Weltkriege, München 2012, 815-998.

31 An dieser Stelle sei auf das FWF-Projekt P-29774-G16 „Die rechtliche Bedeutung des Vertrages von St. Germain“ hingewiesen, das von Anita Ziegerhofer geleitet wird, gemeinsam mit Thomas Olechowski, Herbert Kalb, unter Mitarbeit von Laura Rathmanner und Stefan Wedrac.

32 Wobei auch die Frage nach dem Ende des Krieges sich nicht mehr genau beantworten lässt, vgl. dazu etwa Wlodzimierz Borodziej/Maciej Górny, Der vergessene Krieg: Europas Osten 1912-1923, 
zu können, muss man die zeitgeschichtliche Zäsur überschreiten und den Vorabend des Ersten Weltkrieges vielleicht auch im Sinne des Schlafwandelns ${ }^{33}$ darstellen. Im Verlauf des Krieges entwickelte sich dieser europäische Krieg zum Weltkrieg, den die Pariser Peacemaker mit einem Weltfrieden besiegeln wollten: Die alliierten und assoziierten Mächte waren nicht mehr ausschließlich europäische Mächte, erstmals unterzeichnete beinahe die gesamte Welt die Friedensverträge. Der „ewige Friede“ sollte durch Ersetzung der bisherigen (europäischen) Hegemonialpolitik durch eine internationale Politik erlangt werden. Einer der berühmtesten Proponenten dieser Idee war der amerikanische Präsident Woodrow Wilson. Auf seinen Einsatz hin wurden sowohl die Satzung des Völkerbundes wie auch die Statuten der International Labour Organization (ILO) Bestandteil der Vorortverträge: Sie bildeten den ersten und vorletzten/letzten Teil, quasi die Klammer aller fünf Vorortverträge und sollten Garant für den politischen bzw. sozialen Frieden sein. Beide internationale Organisationen wurden am 28. Juni 1919 gegründet, an dem Tag, an dem Deutschland den Vertrag von Versailles unterzeichnete. Im Januar 1920 nahm der Völkerbund als erste weltumspannende politische Staatenorganisation seine Arbeit auf. ${ }^{34}$ Sehr rasch sollte sich herausstellen, dass es sich um eine europazentrierte Organisation handelte, nicht nur aufgrund des Fernbleibens der USA von dieser Organisation, sondern wohl auch deshalb, weil sie ihren Sitz in Genf hatte und der Großteil der MitarbeiterInnen europäisch war - so kamen unter anderem die drei Generalsekretäre allesamt aus Europa: der Brite Eric Drummond, der Franzose Joseph Avenol und der Ire Sean Lester. Von 1923 bis 1946 war der Brite Lord Robert Cecil Völkerbundpräsident. Die Arbeiten des Völkerbundes, die seiner Organisationen sowie die Genfer Tagungen, bieten sich als Forschungsgegenstand der Europäisierung im Sinne eines „europäisch gefärbten Webmusters internationaler Beziehungen“" ${ }^{35}$ an. Der Interna-

Darmstadt 2018 oder Roland Banken, Die Verträge von Sévres 1920 und Lausanne 1923. Eine völkerrechtliche Untersuchung zur Beendigung des Ersten Weltkrieges und zur Auflösung der sogenannten „Orientalischen Frage“ durch die Friedensverträge zwischen den alliierten Mächten und der Türkei (Geschichte der internationalen Beziehungen im 20. Jahrhundert 5), München 2014.

33 Vgl. dazu Christopher Clark, Die Schlafwandler. Wie Europa in den Ersten Weltkrieg zog, München 2013 oder Kersten Knipp, Im Taumel. 1918 - Ein europäisches Schicksalsjahr, Darmstadt 2018.

34 Anita Ziegerhofer, League of Nations, in: Ute Daniel/Peter Gatrell/Oliver Janz/Heather Jones/Jennifer Keene/Alan Kramer/Bill Nasson (Hg.), 1914-1918-online. International Encyclopedia of the First World War, Berlin 2019, URL: https://encyclopedia.1914-1918-online.net/article/league_of_ nations (abgerufen 27.08.2020).

35 Madeleine Herren, Der Völkerbund - Erinnerung an ein globales Europa, in: Pin de Boer/Heinz Duchhardt/Georg Kreis/Wolfgang Schmale (Hg.), Europäische Erinnerungsorte 3. Europa und die Welt, München 2012, 271-280, 272. 
tionalismus der Zwischenkriegszeit besaß das Potenzial, Europa als neues, als ein globales Europa schaffen zu können. ${ }^{36}$ Er besaß aber auch das Potenzial, Europa als ein „vereintes“ Europa zu kreieren. So diente der Völkerbund für Aristide Briand als jene Organisation, mit welcher er die Idee von der Vereinigung europäischer Staaten für realisierbar hielt. Auf der 10. Völkerbundtagung im September 1929 hielt der französische Politiker eine Rede, in der er die europäischen Mitgliedstaaten des Völkerbundes aufforderte, eine „Europäische Union“ zu errichten. ${ }^{37}$ Europäisch war auch das Konzept des „ewigen Friedens“, wonach sich nicht nur der südamerikanische Politiker Jan Smuts, sondern auch Woodrow Wilson orientierten. ${ }^{38}$ Wenngleich dem Völkerbund in den letzten Jahren von wissenschaftlicher Seite wieder mehr Beachtung geschenkt wird, ${ }^{39}$ bieten die Rolle Europas in der Entwicklung dieser Weltorganisation und jene Europas zu einem vereinten bzw. globalen Europa Basis weiterer zeitgeschichtlicher Forschungen. Wesentliches Augenmerk sollte auch den nationalen Völkerbundligen geschenkt werden und deren Bedeutung für die Verwirklichung des vereinten Europas bzw. des Weltfriedens. ${ }^{40}$

Die globalen Verflechtungen finden nicht nur in Bezug auf den Völkerbund und die ILO in den Vorortverträgen ihren Niederschlag: So mussten die Verliererstaaten nicht nur dem Völkerbund und der ILO beitreten, sondern auch eine Liste von internationalen Übereinkommen unterzeichnen, die ihnen von den Siegermächten diktiert wurden..$^{41}$ Diese Übereinkommen geben Zeugnis von den wirtschaftlichen und technischen Verflechtungen europäischer Staaten im globalen Kontext. Betrachtet man die Friedensverträge, die auf dem Gedanken des Selbstbestimmungsdogmas fußten, zeigt sich, dass die Selbstbestimmung einzelner Völker den Nationalismus befeuerte und schließlich direkt in die zweite Katastrophe des 20. Jahrhunderts

36 Vgl. Herren, Der Völkerbund, 272. Herren bezeichnet den Internationalismus nach dem Ende des Ersten Weltkrieges als Potenzial für ein neues, globales Europa.

37 Vgl. Thomas Neumann, Die europäische Integrationsbestimmungen in der Zwischenkriegszeit, Wien 1999 oder Anita Ziegerhofer, Austria and Aristide Briand's 1930 Memorandum, in: Austrian History Yearbook 29 (1998), 139-159.

38 Herren, Der Völkerbund, 272.

39 Vgl. Patricia Clavin, Securing the World Economy: The Reinvention of the League of Nations 1920-1946, Oxford 2016 oder Susan Pedersen, The Guardians. The League of Nations and the Crisis of Empire, Oxford 2015.

40 Vgl. Wolfgang Schmale/Christopher Treiblmayr (Hg.), Human Rights Leagues in Europe (18982016), Stuttgart 2017 (Historische Mitteilungen der Ranke Gesellschaft 98).

41 Vgl. Art. 234 Vertrag von St. Germain. 
führte. Eine Minderheitenpolitik, wie sie die Siegerstaaten vorsahen, wurde von den Verliererstaaten als konträr zum Selbstbestimmungsrecht erachtet. ${ }^{42}$

Die Pariser Friedensverhandlungen wecken darüber hinaus die Frage nach dem Verhältnis „Europäisierung und Amerikanisierung“, ihre Beantwortung könnte den eurozentrischen Blick überwinden. Dies gilt umso mehr für die Zeit nach dem Ende des Zweiten Weltkrieges: Wie stark beförderte oder bremste etwa der Marshall-Plan eine Europäisierung bzw. Amerikanisierung Europas? Der Marshall-Plan war an die europäische Integration gekoppelt - der österreichische Politikwissenschaftler Heinrich Schneider macht die Verwendung des Begriffes Integration ab 1948 fest, ${ }^{43}$ als die ersten europäischen Institutionen wie die OEEC (später OECD) für die Umsetzung des Marshall-Plans gegründet wurde.

Aus dieser knappen Darstellung der Vorortverträge und des Völkerbundes als ein Teil dieser Verträge ergeben sich für ZeithistorikerInnen viele neue Forschungsmöglichkeiten im Kontext von Europäisierung und auch für die europäische Integrationsgeschichte. Dies führt nun zu der Frage, ob die Botz'sche „thematischen Weitung der Zeitgeschichte“ stattgefunden hat.

\section{Standortbestimmung: EU-ropa in der Zeitgeschichte}

Richtet man das Augenmerk auf die Stellung der europäischen Integrationsgeschichte innerhalb der Zeitgeschichte und auf die Frage, ob die europäische Integrationsgeschichte als Forschungsbereich und als mögliche Zäsur in der Zeitgeschichte angekommen ist, kann zunächst festgehalten werden, dass die „Angebundenheit“ Österreichs an die deutsche Zeitgeschichtsschreibung für die Europäistik Gültigkeit besitzt.

Hierüber gibt ein Blick in die Inhaltsverzeichnisse der „Zeitgeschichte“ ab 1973 Aufschluss: Es fällt auf, dass Europa im Sinne der europäischen Integration unterrepräsentiert ist, was an der Österreichzentriertheit liegen mag, da die EG damals für das Nichtmitglied Österreich keine unmittelbare Bedeutung hatte. Erst 1980 findet man einen Beitrag, der sich mit der EWG beschäftigte, ${ }^{44}$ dem Marshall-Plan wird

42 Vgl. Herbert Kalb, Minderheitenschutzrechte und der Vertrag von St. Germain-en-laye - ein (rechts)historischer Überblick in: zeitgeschichte 46 (2019) 3, 343-370; Herbert Kalb/Thomas Olechowski/Anita Ziegerhofer (Hg.), Der Vertrag von St. Germain, Wien 2019. So wird z. B. der Minderheitenvertrag zwischen Deutschland und Polen als Kleiner Vertrag von Versailles angesehen.

43 Heinrich Schneider, Leitbilder der Europapolitik 1. Der Weg zur Integration, Bonn 1977.

44 Wolfgang Immerschitt, Die Verhandlungen zur Gründung der Europäischen Wirtschaftsgemeinschaft, in: zeitgeschichte 7 (1980) 9/10, 327-345. 
anlässlich seines vierzigsten Geburtstages 1987 eine eigene Nummer gewidmet. ${ }^{45}$ Weder Österreichs EU-Beitritt noch die Ratspräsidentschaften noch die Maßnahmen der EU-14 (als Sanktionspolitik gegen Österreich bekannt) fanden Beachtung. Überraschend ist auch die Tatsache, dass weder der 20-jährigen noch der 25-jährigen Mitgliedschaft Österreichs in der EU ein eigenes Themenheft gewidmet wurde.

Überblickt man die Literatur, die sich mit dem europäischen Integrationsprozess beschäftigt, zeigt sich - eingeschränkt auf den deutschsprachigen Raum - eine beinahe unüberblickbare Fülle an Büchern, die die Vereinigung Europas ab dem Mittelalter bzw. ab 1945 zum Inhalt hat. ${ }^{46}$

In der österreichischen Zeitgeschichte gilt Michael Gehler als unbestrittener Pionier auf dem Gebiet der Darstellung der Geschichte der europäischen Integration. Gehler lehrte bis 2006 als außerordentlicher Professor für Zeitgeschichte an der Universität Innsbruck, seit 2006 leitet er als Professor das Institut für Geschichte an der Universität Hildesheim und ist Inhaber des Jean-Monnet-Lehrstuhls. Gehler verfasste eine Reihe von Publikationen, wovon einige bereits Standardwerke der europäischen Integrationsgeschichte sind. ${ }^{47}$ Jüngst erschien ein zweibändiges Werk, das sich dem Visual Turn der Integrationsgeschichte Europas zuordnen lässt, ${ }^{48}$ und eine umfassende Monographie über Österreichs Weg in die EU ab dem Vertrag von St. Germain. ${ }^{49}$ Neben der europäischen Integrationsgeschichte widmet sich Gehler

45 Der Marshall-Plan. zeitgeschichte 15 (1987) 3.

46 Beispielsweise: Michael Gehler, Europa. Ideen - Institutionen - Vereinigung - Zusammenhalt,

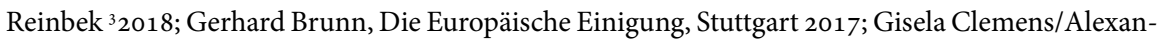
der Reinfeldt/Gerhard Wille, Geschichte der europäischen Integration, Paderborn 2008; Wilfried Loth, Europas Einigung. Eine unvollendete Geschichte, Frankfurt 2014 oder Hartmut Kälble, Der verkannte Bürger. Eine andere Geschichte der europäischen Integration seit 1950, Frankfurt a. M. 2019; Rainer Hudemann/Hartmut Kälble/Klaus Schwabe (Hg.), Europa im Blick der Historiker (Historische Zeitschrift. Beihefte 21), München 1995.

47 Zum Beispiel mit Österreich-Bezug: Michael Gehler, Der lange Weg nach Europa. Österreich vom Ende der Monarchie bis zur EU, ein Band Darstellung, ein Band Dokumente, Innsbruck 2002; Michael Gehler, Vom Marshall-Plan bis zur EU. Österreich und die europäische Integration von 1945 bis zur Gegenwart, Innsbruck/Wien 2006.

48 Michael Gehler/Otto May, „Motiv Europa. Postalische Dokumente zur Geschichte und Einigungsidee von 1789 bis $1945^{\prime}$ ", Hildesheim 2017 sowie Michael Gehler/Otto May, „Motiv Europa. Postalische Dokumente zur Geschichte und Einigungsidee von 1789 bis $1945^{“}$. Begleitband zur Ausstellung an der Universität Hildesheim, Hildesheim 2019.

49 Michael Gehler, From Saint-Germain to Lisbon: Austria’s long road from disintegrated to united Europe 1919-2009, Wien 2020. 
den internationalen Beziehungen, so ist er Mitherausgeber eines Handbuchs über das Revolutionsjahr $1989 . .^{50}$

Seit dem Abgang von Michael Gehler nach Deutschland ist in Innsbruck die europäische Integrationsgeschichte „verwaist“. Nicht am Institut für Geschichte, sondern am Institut für Politikwissenschaft forscht und lehrt Andreas Maurer als ausgewiesener Europaexperte. Er ist seit 2013 Professor für Politikwissenschaften und Europäische Integration und leitet das Innsbruck Center for European Research (ICER) ${ }^{51}$ als Jean-Monnet-Lehrstuhl. An der Rechtswissenschaftlichen Fakultät befindet sich das Center for European Integration Innsbruck (CEI) unter der Leitung von Walter Obwexer. ${ }^{52}$

Ähnlich wie in Innsbruck verhält es sich mit „EU-Europa“ an der Universität Wien. Das Institut für Zeitgeschichte hat unter anderem als Schwerpunkt die österreichische Republiksgeschichte im internationalen Vergleich. ${ }^{33}$ Die „Europäistik“ ist am Institut für Geschichte/Neuzeit bei Wolfgang Schmale angesiedelt. Schmale gehört zu den einflussreichsten und bedeutendsten „Europäisten“ in der internationalen Scientific Community. Der Professor für Geschichte der Neuzeit führte, wie bereits erwähnt, den Begriff der Europäistik in die Geschichtswissenschaft ein, und er gilt als Pionier der europäischen Kulturgeschichte. Seine Werke sind Standardwerke, die einen Überblick über die europäische Integration ab dem Mittelalter bis in die Gegenwart bieten. ${ }^{54}$ Neben Wolfgang Schmale forscht auch Thomas Angerer im Bereich europäische Integration vorwiegend aus französischer Perspektive.

So wie in Innsbruck, ist auch die Politikwissenschaft an der Universität Wien in Bezug auf europäische Integrationsgeschichte sehr gut aufgestellt. Es sei hier stell-

50 Wolfgang Müller/Michael Gehler/Arnold Suppan (Hg.), The Revolutions of 1989. A Handbook (Internationale Geschichte 2), Wien 2015. Auch folgendes zweibändige Werk zählt als Standardwerk: Michael Gehler, Österreichs Außenpolitik der Zweiten Republik. Von der alliierten Besatzung bis zum Europa des 21. Jahrhunderts, 2 Bde., Innsbruck 2005.

51 URL: https://www.icer.at/ (abgerufen 26.08.2020). Von Andreas Maurer stammt u. a. folgendes Buch: Andreas Maurer/Heinrich Neisser/Johannes Pollak (Hg.), 20 Jahre EU-Mitgliedschaft Österreichs, Wien 2015. Es ist eines der wenigen Sammelbände, die anlässlich des Gedenkens der 20-jährigen Mitgliedschaft Österreichs in der EU herausgegeben wurde.

52 URL: https://www.uibk.ac.at/cei/ (abgerufen 26.08.2020).

53 Oliver Rathkolb, Internationalisierung Österreichs seit 1945 (Österreich - Zweite Republik. Befund, Kritik, Perspektive 15), Innsbruck 2006; Oliver Rathkolb (Hg.), How to re(write) European History. History and Text Book Projects in Retrospect, Innsbruck 2010.

54 Vgl. etwa Schmale, Europa. 
vertretend auf das Centre for European Integration Research (EIF) hingewiesen, das Gerda Falkner leitet. 55

Ein Blick nach Salzburg zeigt, dass die dort angesiedelte Zeitgeschichte eine eigene Abteilung Europäische Regionalgeschichte hat, die sich aber in erster Linie auf Antisemitismus, Holocaust, Migration, Vertreibung spezialisiert hat. Allerdings wird an der Universität Salzburg ein Masterlehrgang European Union Studies angeboten, mit politikwissenschaftlichem Schwerpunkt. ${ }^{56}$

An dieser Stelle sei auf die jährlich stattfindende Summer School der Universität Wien mit dem Titel International and European Studies in St. Wolfgang/Wolfgangsee hingewiesen. ${ }^{57}$ Der Schwerpunkt der Summer School unter Leitung des Professors für Römisches Recht, Stefan Meissl, liegt in der Darstellung der rechtlichen und politikwissenschaftlichen Perspektive.

Weder an der Johannes-Kepler-Universität Linz noch an der Alpen-Adria-Universität in Klagenfurt ${ }^{58}$ wird explizit europäische Integrationsgeschichte gelehrt bzw. dazu geforscht. Dies gilt ebenfalls für den Fachbereich Allgemeine Zeitgeschichte an der Karl-Franzens-Universität. EU-ropa wird in Graz vielmehr an der Rechtswissenschaftlichen Fakultät erforscht und gelehrt.

An der Schnittstelle zwischen Politik, Geistes- und Rechtswissenschaften erfolgte die Gründung des interdisziplinären Zentrums für Südosteuropaforschungen unter der Leitung des Politikwissenschaftlers Florian Bieber. Die traditionellen und sehr guten Kontakte der Universität Graz in den ost- bzw. südosteuropäischen Raum führten unter anderem zu dessen Gründung. Seit Oktober 2019 leitet Bieber für drei Jahre den Jean Monnet Chair in the Europeanisation of Southeastern Europe. Im Rahmen des Lehrstuhls werden zusätzliche Lehrveranstaltungen im Bereich der EU-Integration Südosteuropas angeboten. Florian Bieber ist auch der Aufbau eines Profilbildenden Forschungsbereichs (PBB) zum Thema Dimensionen der Europäisierung seitens des Rektorats der Universität Graz überantwortet worden. Das interdisziplinär zusammengesetzte Forschungsteam wird gesellschaftliche Transformationsprozesse in Südosteuropa aus einer vergleichenden Perspektive betrachten und Europäisierungsdiskurse im Kontext von Macht und Kommunikationsräu-

55 Centre for European Integration Research, Universität Wien, URL: https://eif.univie.ac.at/ (abgerufen 26.08.2020).

56 European Union Studies (Masterstudium), Universität Salzburg, URL: https://www.masterstudies. ng/universities/Austria/University-of-Salzburg-Centre-of-European-Union-Studies/ (abgerufen 26.08.2020).

57 URL: https://shs.univie.ac.at/summer-school/ (abgerufen 26.08.2020); URL: https://shs.univie. ac.at/summer-school/ (abgerufen 26.08.2020).

58 Eine Ausnahme stellt Johannes Dafinger dar, er forscht über Europakonzepte im 20. Jahrhundert. 
men beschreiben. Dabei werden kulturelle, wirtschaftliche, rechtliche, politische und soziale Aspekte sowie weitere Kategorien wie Gender, Ethnizität, Klasse und Generation berücksichtigt und konventionelle Dichotomien - wie Ost/West oder Zentrum/Peripherie - in Frage gestellt. Aufbauend auf der historisch gewachsenen Südosteuropaexpertise der Universität Graz widmet sich der Profilbildende Bereich dieser Region, um Europäisierung zu erforschen und zu verstehen. Als eine Region, die seit der Antike an Europäisierungsprozessen teilnimmt, ist sie der ideale Ort, um Dimensionen der Europäisierung durch multiperspektivische Vergleiche zu erforschen - Lehrveranstaltungen, Ringvorlesungen und auch die Installation eines Doktorratsprogrammes dienen der Erforschung dieses Prozesses. ${ }^{59}$ Ein Mitglied des Forschungsbereichs Dimensionen der Europäisierung ist die Zeithistorikerin Anita Ziegerhofer. Sie beschäftigt sich am Fachbereich Rechtsgeschichte und Europäische Rechtsentwicklung/Institut für Rechtswissenschaftliche Grundlagen seit den 1990er-Jahren mit EU-Europa und nähert sich der Darstellung des europäischen Integrationsprozesses mit einem ideengeschichtlichen und rechtshistorischen Ansatz. ${ }^{60}$ Anlässlich der 20-jährigen Mitgliedschaft Österreichs in der EU hat sie einen MOOC $^{61}$ gestaltet, der aufgrund der zahlreichen Interviews mit den wesentlichen Entscheidungsträgern aus Politik, Wirtschaft und Kultur ein wichtiges zeitgeschichtliches Dokument des Weges Österreichs in die EU darstellt. ${ }^{62}$ Ein weiterer MOOC anlässlich von 25 Jahren EU-Mitgliedschaft Österreichs, allerdings mit Schwerpunkt auf die Darstellung der Beziehung zwischen dem Bundesland Steiermark und der EU, wurde 2020 erstellt. ${ }^{63}$ Es darf nicht unerwähnt bleiben, dass der ehemalige Assistent am Institut für Rechtsgeschichte und Europäische Rechtsentwicklung (jetzt Fachbereich Rechtsgeschichte und Europäische Rechtsentwicklung am Institut für Rechtswissenschaftliche Grundlagen), Peter Pichler, als freischaffender Wissenschaftler den kulturhistorischen Diskurs, der von Wolfgang Schmale losgetreten wurde, mit einigen Monographien vorantreibt und erstmals konsequent danach

59 URL: file:///C:/Users/zieger/AppData/Local/Microsoft/Windows/INetCache/Content.Outlook/ VIH19UPJ/DimensionsEuropeanization_folder_eng_longversion.pdf (abgerufen 27.08.2020).

60 Auswahl Monographien: Anita Ziegerhofer/Reinhard Likar/Johannes W. Pichler, Die „Vereinigten Staaten von Europa“. Dokumente eines Werdens, Wien 1999; Anita Ziegerhofer-Prettenthaler, Botschafter Europas. Richard Nikolaus Coudenhove-Kalergi und die Paneuropa-Bewegung, Wien 2004; Anita Prettenthaler-Ziegerhofer, Europäische Integrationsrechtsgeschichte, Innsbruck ${ }^{32012 .}$

$61 \mathrm{MOOC}=$ Massive Open Online Course.

62 iMooX Kurs „Österreich und die Europäische Union“, Historische Vorläufer und die „Idee Europa“, 08.09.2015, iMooX at, URL: https://www.youtube.com/watch?v=uwoq5xLe2-\&list=PLhy2nHJciT EAq5xayVGtdHipUJl6FHbdN (abgerufen 27.08.2020).

63 URL: https://imoox.at/mooc/local/courseintro/views/startpage.php?id=111 (abgerufen 27.08.2020). 
fragt, was genau die EU - jenseits von „ever closer union“ und EU-Zentrismus - als Kulturgemeinschaft eigenen Typs ausmacht. ${ }^{64}$

Schließlich sei auf die 2010 erfolgte Gründung des Zentrums für Osteuropäisches Recht (ZOR) an der Rechtswissenschaftlichen Fakultät hingewiesen. ${ }^{65}$ Hierbei handelt es sich um eine institutsübergreifende Einrichtung, deren Ziel die Optimierung und Koordinierung vorhandener Forschungspotenziale und Fachkompetenzen im Bereich von rechtsvergleichenden sowie transnationalen Rechtsfragen darstellt, im Kontext von Internationalen Beziehungen, Politik und historischen Interpretationen. Für ZeithistorikerInnen würde sich ein weiterer Forschungsbereich anbieten, etwa im Zusammenhang mit separatistischen Konflikten im postsowjetischen Raum - eine Kooperation ist bis dato (leider) noch nicht angedacht worden. ${ }^{66}$

Abschließend sei noch angemerkt, dass anlässlich der Feierlichkeiten rund um die Gründung der Republik Österreich entsprechende Sammelbände erschienen sind, die in erster Linie Ereignisgeschichte darstellen. Aus Anlass des neunzigsten Geburtstages der Republik Österreich erschien ein Sammelband, ${ }^{67}$ in dem sich ein Beitrag mit Europa und Integration beschäftigt. ${ }^{68}$ Im Sammelband anlässlich des

64 Peter Pichler, Acht Geschichten über die Integrationsgeschichte. Zur Grundlegung der Geschichte der europäischen Integration als ein episodisches historiographisches Erzählen, Innsbruck 2011; Peter Pichler, Leben und Tod in der Europäischen Union, Innsbruck 2014; Peter Pichler, EUropa. Was die Europäische Union ist, was sie nicht ist und was sie einmal werden könnte, Graz 2016; Peter Pichler, Zeitgeschichte als Lebensgeschichte. Überlegungen zu einer emanzipativen und aktuellen Zeithistoriographie (Gesellschaften und Staaten im Epochenwandel 23), Frankfurt a. M. 2017; Peter Pichler, European Union cultural history: introducing the theory of ,paradoxical coherence to start mapping a field of research, in: Journal of European Integration 40 (2018) 1, 1-16. Peter Pichler ist im Vorstand, Anita Ziegerhofer Mitglied des Institute for the Study of the History of Ideas of Europe an der University of East Anglia/Norwich: Ideas of Europe. An Initiative of the Institute for the Study of Ideas of Europe, URL: http://www.ideasofeurope.org (abgerufen 27.08.2020).

65 Das ZOR wurde 2012 mit dem Namen Russian East and European \& Eurasian Studies Centre gegründet und mit 1. April 2020 in ZOR umbenannt (englisch: Centre for East European Law and Eurasian Studies, CEELES). Grundsätzlich bewegen sich die MitarbeiterInnen des ZOR im Bereich der Rechtsvergleichung mit Fokus auf das öffentliche Recht des osteuropäischen bzw. postsowjetischen Raums. Ganz aktuell sind dabei die Verfassungsreform in Russland sowie der Fokus auf das Recht anderer postsowjetischer Republiken (wie etwa der Ukraine).

66 Herrn Dr. Benedikt Harzl sei für das Gespräch herzlichst gedankt.

67 Stefan Karner/Lorenz Mikoletzky (Hg.), Österreich. 90 Jahre Republik. Beitragsband der Ausstellung im Parlament, Wien 2008.

68 Michael Gehler, Österreichs Europa- und Integrationspolitik im Spannungsfeld von Findung und Wahrung seiner Neutralität von 1918 bis zur Gegenwart, in: Karner/Mikoletzky (Hg.), Österreich, $571-582$. 
einhundertsten Geburtstages der Republik Österreich ${ }^{69}$ thematisiert man sowohl den Fall des Eisernen Vorhangs wie auch Österreichs Weg in die EU als Meilensteine und Wendepunkte. In Ernst Bruckmüllers „Europäische Dimensionen österreichischer Geschichte“ findet man drei Beiträge, die unter anderem Österreichs Weg in die EU aufzeigen..$^{70}$ In Bruckmüllers jüngstem Werk über „Österreichische Geschichte “ wird dem Beitritt Österreichs zur EU ein kurzer Abschnitt gewidmet. ${ }^{71}$ Vocelkas „Geschichte Österreichs“ streift den Bereich Österreich und EU ${ }^{72}$ wie auch Steven Bellers „Geschichte Österreichs“.73 Ernst Hanischs Standardwerk für ZeithistorikerInnen „Der lange Schatten des Staates“ endet mit 1990.74 Eine Zeitgeschichte Österreichs als eigenständige Monographie unter Berücksichtigung des österreichischen EU-Integrationsprozesses liefert Michael Gehler mit „From Saint-Germain to Lisbon: Austria’s Long Road from Disintegrated to United Europe 1919-2009“. Abschließend sei hier die Steiermark exemplarisch für die Landesgeschichtsschreibung der weiteren Bundesländer hervorgehoben: Die Geschichte der Steiermark von Stefan Karner, ${ }^{75}$ jene von Alfred Ableitinger und Dieter A. Binder ${ }^{76}$ sowie Joseph F. Desput ${ }^{77}$ und auch die von Josef Riegler, dem ehemaligen Leiter des Steiermärkischen Landesarchivs, verfasste Geschichte der Steiermark ${ }^{78}$ - alle im Zeitraum von 2000 bis 2005 erschienen - räumen der Darstellung der Steiermark in Bezug auf die europäische Integration Platz ein. Im Januar 2020 war Österreich 25 Jahre Mitglied in der EU. Aus diesem Anlass verfasste Anita Ziegerhofer eine Geschichte der Steiermark ab 1918. Neben der politischen Geschichte erfolgt die Darstellung des Anteils der Steiermark am europäischen Integrationsprozess. Als Innovation kann die Tatsache hervorgehoben werden, dass die Geschichtsschreibung nicht nur ana-

69 Heinz Fischer (Hg.), 100 Jahre Republik: Meilensteine und Wendepunkte in Österreich 1918-2018, Wien 2018.

70 Ernst Bruckmüller, Europäische Dimensionen österreichischer Geschichte (Schriften des Instituts für Österreichkunde 65), Wien 2002.

71 Von Vranitzky und Schüssel. Österreich und Europa, in: Ernst Bruckmüller, Österreichische Geschichte. Von der Urgeschichte bis zur Gegenwart, Wien 2019, 604-618.

72 Karl Vocelka, Geschichte Österreichs. Kultur - Gesellschaft - Politik, Wien 2005.

73 Steve Beller, Geschichte Österreichs, Wien 2007.

74 Ernst Hanisch, Der lange Schatten des Staates. Österreichische Gesellschaftsgeschichte im 20. Jahrhundert (Österreichische Geschichte 1890-1990), Wien 1994.

75 Stefan Karner, Die Steiermark im 20. Jahrhundert. Politik - Wirtschaft - Gesellschaft - Kultur, Graz 2000.

76 Alfred Ableitner/Dieter A. Binder, Geschichte der österreichischen Bundesländer seit 1945. Steiermark (Geschichte der österreichischen Bundesländer seit 1945 6/7), Wien 2002.

77 Joseph F. Desput (Hg.), Vom Bundesland zur europäischen Region. Die Steiermark von 1945 bis heute (Geschichte der Steiermark 10), Graz 2004.

78 Josef Riegler (Hg.), Die Neue Steiermark. Unser Weg 1945-2005, Graz 2005. 
log, sondern auch digital erzählt wird: Anhand von QR-Codes sind Interviews von WissenschaftlerInnen und PolitikerInnen sowie ZeitzeugInnen und SchülerInnen abrufbar. ${ }^{79}$

Hinsichtlich der eingangs aufgeworfenen Frage, ob der Beitritt Österreichs zur EU eine Zäsur darstellt, kann dies zumindest für die Darstellung in den Geschichtsbüchern (teilweise in Form von Kapiteln) bejaht werden.

\section{Forschungsdesiderata - Europäistik goes Zeitgeschichte}

Aus dem Überblick, der keinen Anspruch auf Vollständigkeit erhebt, kann der Schluss gezogen werden, dass die Zeitgeschichte den von Gerhard Botz eingangs konstatierten „Österreichzentrismus“ überwunden hat. Die „thematische Weitung", die sich Botz durch die Öffnung Österreichs gegen Osten und zur EG erhoffte, erfolgte zwar, wenngleich die europäische Integrationsgeschichte in der österreichischen Zeitgeschichte (leider) unterrepräsentiert ist. Es ist vor allem die Politikwissenschaft, der die Zeitgeschichte das weite Feld der europäischen Integration überlässt, Fächer wie „Europastudien“ oder „Europäische Integration“ werden in der österreichischen Zeitgeschichte nicht angeboten. Diese Feststellung ist wohl der Tatsache geschuldet, dass sich „Europa“ nicht auf die Zeitgeschichte allein begrenzen lässt, was im Speziellen auch für die europäische Integration gilt. Sie kann zwar zeitlich von den Politik- und RechtswissenschaftlerInnen nach dem Ende des Zweiten Weltkrieges festgemacht werden, die HistorikerInnen verfolgen deren Wurzeln allerdings bis ins Mittelalter zurück. ${ }^{80}$ Die europäische Integrationsgeschichte ab 1945 allein aus der rechts, sozial- und politikwissenschaftlichen Perspektive zu beleuchten, ist zu wenig. Die wissenschaftliche Auseinandersetzung mit der europäischen Integrationsgeschichte kann jedoch sowohl im Kontext einer allumfassenden Geschichte geschrieben werden als auch ab 1945. Die Politikgeschichte oder auch die Auseinandersetzung mit Biographien ${ }^{81}$ liefern ein großes wissenschaftliches Betätigungsfeld für „EuropäistikerInnen der Zeitgeschichte“.

79 Anita Ziegerhofer, Vom Rand ins Zentrum EUropas. Die Geschichte der Steiermark ab 1918 analog und digital erzählt, Graz 2020.

80 Welcome to HEIRS, History of European Integration Research Society, URL: https://heirsweb. wordpress.com/ (abgerufen 27.08.2020). Wünschenswert wäre es, wenn auch österreichische ZeithistorikerInnen sich dem Netzwerk History of European Integration Research Society anschließen würden.

81 Vgl. etwa Ziegerhofer-Prettenthaler, Botschafter Europas; siehe auch diese drei Biographien von Anita Prettenthaler-Ziegerhofer, entnommen Winfried Böttcher: Anita Prettenthaler-Ziegerhofer, 
Die Europäistik bietet für österreichische HistorikerInnen bzw. ZeithistorikerInnen ein schier unendlich weites Forschungsfeld, das nicht nur Aktualität, sondern auch viel Charme besitzt. Beginnend mit der klassischen Erzählung ab der Antike bis hin zur Frage nach dem Anteil Österreichs am europäischen Integrationsprozess. Wichtig wäre auch der Blick von außen auf Europa bzw. auch auf Österreich innerhalb von Europa und die Überwindung der eurozentrierten und auch österreichzentrierten Sichtweise, die Überwindung des nationalstaatlichen Narrativs. Als ein weiteres zu beforschendes Feld bietet sich das „organisierte“ Europa an: das Europa der OEEC/OECD, des Europarates, der KSZE/OSZE - auch unter dem Blickwinkel österreichischer Politik- und Diplomatiegeschichte. Wie anhand der Pariser Vorortverträge exemplifiziert wurde, erheben sich trotz der bereits erfolgten Einbettung der Pariser Vororteverträge in die Globalgeschichte viele neue Forschungsfragen etwa in Bezug auf die Stellung Österreichs im Völkerbund. ${ }^{82}$

Gerade für ZeithistorikerInnen ergeben sich Herausforderungen bei der Betrachtung des sich immer schneller wandelnden Europas - Europa ist nicht mehr alleine beforschbar: Die Forderung nach Interdisziplinarität, wie sie seit Jahren von ZeithistorikerInnen erhoben wird, drängt sich immer mehr auf. Es bedarf einer „integralen Europäistik“: Alle Wissenschaftsbereiche sollen ihr Methoden- und Kompetenzenpotenzial nutzen und davon profitieren; dies umso mehr, als Europa immer en vogue ist - ob in einem großen Überblick oder unter Heranziehung neuer Quellen im Zuge der Digitalisierung wie Blogs, ${ }^{{ }^{3}}$ unter Zuhilfenahme von Social Medias wie Facebook, Instagram oder Twitter. ZeithistorikerInnen müssen sich mehr in die Europastudien einbringen - die europäische Integrationsgeschichte muss eine institutionalisierte Zeitgeschichte werden.

Wir brauchen, um mit Peter Pichler zu sprechen, eine europäische Zeitgeschichte als Lebensgeschichte, und wir müssen „weg von der Nationalgeschichte hin zur Europäisierung“. Dies ist im Europa 2021 umso aktueller und brennender denn je.

Georg von Podiebrad (1420-1471), in: Winfried Böttcher (Hg.), Klassiker des europäischen Denkens, Baden-Baden 2014, 89-95; Anita Prettenthaler-Ziegerhofer, Richard Nikolaus CoudenhoveKalergi (1894-1972), in: Böttcher, Klassiker, 592-597; Anita Prettenthaler-Ziegerhofer, Altiero Spinelli (1907-1986), in: Böttcher, Klassiker, 661-667 oder Anita Ziegerhofer, Hans Wehberg, Otto Umfried, in: Winfried Böttcher (Hg.), Europabilder vergessener Europäer, Baden-Baden 2019. Allgemein Michael Gehler, Europa, Europäisierung, Europäistik, europäische Integration und die Folgen für die Biographieforschung, in: Àgoston Zénó Bernád/Christine Gruber/Maximilian Kaiser (Hg.), Europa baut auf Biographie. Aspekte, Bausteine, Normen und Standards für eine europäische Biographik, Wien 2017, 13-20.

82 Vgl. Peter Becker/Natasha Wheatley (eds.), Remaking Central Europe: The League of Nations and the Former Habsburg Lands, Oxford 2020.

83 Wolfgang Schmale, Mein Europa, URL: https://wolfgangschmale.eu (abgerufen 27.08.2020). 


\section{FELDER UND THEMEN}


(c) 2021 Böhlau Verlag | Brill Österreich GmbH https://doi.org/10.7767/9783205209980 | CC BY-NC 4.0 


\section{Geschlecht}

Martina Gugglberger

Zentral und marginal zugleich? Zeithistorische Frauen- und Geschlechterforschung in Österreich

Der Frauen- und Geschlechtergeschichte müsse „ein bemerkenswerter Erfolg zugesprochen werden, denn sie hat erhebliche Veränderungen in der Geschichtswissenschaft bewirkt", befand die deutsche Zeithistorikerin Christiane Eifert vor gut zehn Jahren. Sie bezog sich dabei auf die deutsche Geschichtswissenschaft und begründete ihre Einschätzung sowohl auf die tiefgreifenden inhaltlichen Impulse des geschlechterhistorischen Forschungsfeldes als auch auf der Institutionalisierung, wie sie anhand von Professuren, Studienangeboten und Publikationen abzulesen ist. ${ }^{1}$

Die Frauen- und Geschlechtergeschichte etablierte sich in den letzten vierzig Jahren auch in Österreich an den Universitäten und in der historischen Forschungslandschaft. Inwiefern auch hierzulande von einem anhaltenden Erfolg gesprochen werden kann, insbesondere mit Blick auf die zeithistorische Forschung und Lehre, soll im Folgenden diskutiert werden.

Ein Rückblick auf die Entwicklung der Frauen- und Geschlechtergeschichte in Österreich kann auf eine Reihe von vorausgegangenen „Bestandsaufnahmen“ bzw. „Standortbestimmungen“ zurückgreifen. Anfang der 1990er-Jahre resümierten sowohl Ingrid Bauer als auch Edith Saurer mehrfach über Lage und Verortung der feministischen Geschichtsforschung in Österreich. ${ }^{2}$ Ein Jahrzehnt später reflektierte Johanna Gehmacher über das Verhältnis von Zeitgeschichte und Geschlechterge-

1 Christiane Eifert, Standortbestimmung: Wo befindet sich die Frauen- und Geschlechtergeschichte innerhalb der Geschichtswissenschaft?, in: querelles-net 24 (2008), URL: http://www.querelles-net. de/index.php/qn/article/view/618/626== (abgerufen 18.06.2020).

2 Vgl. Edith Saurer, Frauengeschichte in Österreich. Eine fast kritische Bestandsaufnahme, in: L'Homme Z. F. G. 4 (1993) 2, 37-63; in erweiterter Form: Edith Saurer, Skizze einer Geschichte der historischen Frauenforschung in Österreich, in: Barbara Hey (Hg.), Innovationen 2. Standpunkte feministischer Forschung und Lehre (Materialien zur Förderung von Frauen in der Wissenschaft 9), Wien 1999, 319-377; Ingrid Bauer, Der Blick macht die Geschichte. Eine frauenforschende (nach den Frauen forschende) Rückschau auf „20 Jahre Zeitgeschichte“, in: zeitgeschichte 21 (1994) 1, 14-28. 
schichte. ${ }^{3}$ Ihrer Leitfrage nach Zentralität und Marginalität in der Beziehung von Frauen- bzw. Geschlechtergeschichte und der Zeitgeschichte ist auch der Untertitel des vorliegenden Beitrags entnommen. Schließlich motivierten verschiedene Jubiläen in den letzten Jahren eine Rückschau auf die Entwicklung des Faches in Österreich. ${ }^{4}$ Die aktuellsten Bestandsaufnahmen lieferten 2016 ein Nachwuchsautorinnenkollektiv rund um die Studierendengruppe fernetzt an der Universität Wien und 2017 die Historikerin Maria Mesner 5 .

Vorauszuschicken ist, dass eine derartige Standortbestimmung nur bedingt auf die Zeitgeschichte fokussiert bleiben kann. Die historische Frauenforschung und die daraus in den 1990er-Jahren hervorgegangene Geschlechterforschung waren von Beginn an ein epochenübergreifendes und vor allem ein interdisziplinäres Projekt. $\mathrm{Ab}$ den 1990er-Jahren sind nichtsdestotrotz Tendenzen einer „Redisziplinierung“ $\mathrm{zu}$ erkennen, als Beispiel kann die Gründung der Zeitschrift „L'Homme“ herangezogen werden, die als fachspezifisches Medium Frauen- und Geschlechterforschung auch innerhalb der Disziplin positionieren wollte. ${ }^{6}$ Themen und Inhalte der feministischen Geschichtswissenschaft hatten und haben in der österreichischen Forschung einen starken Bezug zum 20. Jahrhundert,7 insofern besonders zur Zeitgeschichte.

3 Vgl. Johanna Gehmacher, Am Rand der Geschichte. Zeitgeschichte und ihre Marginalisierungen Anmerkungen aus österreichischer Perspektive, in: zeitgeschichte 32 (2005) 5, 301-322.

4 Vgl. Karin Schmidlechner, 25 Jahre zeitgeschichtliche Frauen- und Geschlechtergeschichte. Eine Bestandsaufnahme, in: Helmut Konrad/Stefan Benedik (Hg.), Mapping Contemporary History II. Exemplary fields of research in 25 years of Contemporary History Studies at Graz University. Exemplarische Forschungsfelder aus 25 Jahren Zeitgeschichte an der Universität Graz, Wien/Köln/ Weimar 2010, 211-218.

5 Vgl. Veronika Helfert/Jessica Richter/Brigitte Semanek/Alexia Bumbaris/Karolina Sigmund, Bestandsaufnahmen und Herausforderungen. Blicke auf die gegenwärtige Frauen- und Geschlechtergeschichte, in: dies. (Hg.), Frauen- und Geschlechtergeschichte un/diszipliniert? Aktuelle Beiträge aus der jungen Forschung (Studien zur Frauen- und Geschlechtergeschichte 11), Innsbruck 2016, 7-22; Maria Mesner, Nachhaltige Ambivalenzen. Frauen- und Geschlechtergeschichte am Institut für Zeitgeschichte, in: Bertrand Perz/Ina Markova (Hg.), 50 Jahre Institut für Zeitgeschichte der Universität Wien 1966-2016, Wien 2017, 267-283; dieser Beitrag ist eine Adaptierung von: Maria Mesner, Disziplinäre Verwerfungen und verquere Verhältnisse: Frauen- und Geschlechtergeschichtsforschung in der österreichischen Zeitgeschichte, in: Jirí Pesek/Oliver Rathkolb/Nina Lohmann/Jan Horsky/Thomas Walter (Hg.), Zeitgeschichte in Bewegung. Die österreichische Erforschung des 20. Jahrhunderts, Prag 2013, 55-70.

6 Diese „Redisziplinierung“ lag im internationalen Trend, wie zahlreiche zeitgleiche Zeitschriftengründungen belegen, z. B.: Gender \& History 1989, vgl. Edith Saurer, Eine Zeitschrift gründen (Rede anlässlich 20 Jahre L'HOMME Fest), Wien 2009, 3, URL: https://www.univie.ac.at/Geschichte/salon21/ (abgerufen 18.06.2020).

7 Vgl. Saurer, Skizze, 348-349. 
Die „Epoche der Mitlebenden ${ }^{\text {“8 }}$ konnte in spezifischer Weise mit neuen methodischen Herangehensweisen, wie der Oral History, erforscht werden. Diese waren gerade für die (zeit)historische Frauenforschung, die teilweise mit schwer oder gar nicht zugänglichen Quellen umzugehen hat, willkommene (neue) Instrumentarien. Darüber hinaus ergaben sich zeithistorische Schnittmengen mit Studien der Frauen- und Geschlechterforschung aus Nachbardisziplinen (Politikwissenschaft, Soziologie, Rechtswissenschaften etc.). Dieser Zentralität der Epoche steht nichtsdestotrotz eine nur zögerliche, teilweise marginale Wahrnehmung von Ergebnissen der Frauen- und Geschlechtergeschichte seitens der institutionellen Zeitgeschichte gegenüber. ${ }^{9}$ Der vorliegende Beitrag versucht, wo es möglich ist, auf die zeithistorischen Forschungen und Institutionen in Österreich einzugehen, kann aber auf eine breite Darstellung nicht verzichten.

\section{Neue Perspektiven: Frauen- und Geschlechterforschung}

Die historische Frauenforschung ist eine Forschungsperspektive, die im Kontext der Neuen Frauenbewegung in den 1970er-Jahren von Studentinnen in die Universitäten getragen wurde. Frauen und ihre Lebenszusammenhänge waren bis dahin in der historischen Forschung blinde Flecken gewesen. Neben dem Sichtbarmachen der Geschichte des ,anderen" Geschlechts ging es vor allem darum, den Ursachen für die ungleichen sozialen, rechtlichen und ökonomischen Positionen von Männern und Frauen auf den Grund zu gehen. Nicht zuletzt trat die (historische) Frauenforschung an, den (Geschichts-)Wissenschaften den feministischen Spiegel vorzuhalten und Universitäten als Terrain zu demaskieren, auf dem Wissenschaftlerinnen diskriminiert wurden. Scheinbar objektive Wahrheiten und Fragestellungen, Theorien und Methoden, aber vor allem die bisherigen Ergebnisse der von Männern dominierten Wissenschaft wurden als unzureichend und lückenhaft kritisiert. Die ersten Forschungen widmeten sich überwiegend Gesellschaftsbereichen, die als "frauenspezifisch" galten wie Familie, Reproduktion oder Frauenarbeit und Frauenbewegungen. ${ }^{10}$ Ende der $1980 e r-J a h r e$ führte zunehmende Kritik an der Konzeptualisierung von „Frauen“ als homogener Gruppe zu einer grundlegenden Neuausrichtung der Forschungsrichtung hin zur Geschlechtergeschichte. Dieser Ansatz rückt

8 Hans Rothfels, Zeitgeschichte als Aufgabe, in: Vierteljahreshefte für Zeitgeschichte 1 (1953) 1, 1-8, 2.

9 Vgl. Gehmacher, Rand, 314.

10 Claudia Opitz-Belakhal, Geschlechtergeschichte (Historische Einführungen), Frankfurt a. M. 2010, 10-12; Andrea Griesebner, Feministische Geschichtswissenschaft. Eine Einführung, Wien ${ }^{2} 2012,97$. 
Geschlecht als Kategorie und Geschlechterverhältnisse ins Zentrum und geht von der Notwendigkeit einer Verknüpfung von Ungleichheitskategorien aus. Der Begriff Gender, der Geschlecht als soziale und historisch gewachsene Konstruktion auffasst und nicht als biologisch determinierte Konstante, förderte Analysen, die nach der Wirkmächtigkeit von vergeschlechtlichten Diskursen und Normen fragten. ${ }^{11}$ Das Forschungsfeld wurde damit erheblich verbreitet. Nicht nur die Historizität und soziale Konstruktion von Weiblichkeit, sondern auch von Männlichkeit rückte ins Visier. Die Historische Männerforschung hat seither wichtige Beiträge geleistet, Normen und Facetten von Männlichkeit auszudifferenzieren. ${ }^{12}$ Weitere kritische Impulse kamen Ende der 1990er-Jahre von Seiten der Queer History, die sich radikal gegen eindeutige (Geschlechter)Identifikationen richtete, die Vorstellung einer binären Zweigeschlechtlichkeit sprengte und historische wie gegenwärtige Gesellschaften als heteronormativ entlarvte. ${ }^{13}$ Damit ging nicht nur eine kritische Haltung gegenüber dem Genderkonzept einher, auch (Geschlechts)Körper und Sexualität(en) wurden intensiv und neu verhandelt. Verstärkt wurden diese Neuauslotungen durch die kulturgeschichtliche Wende, von der die (Zeit)Geschichtsforschung seit den 1990erJahren erfasst wurde und die mit der Geschlechterforschung eng verschränkt ist.

\section{Große Bandbreite an Themen und Inhalten}

Die Frauen- und Geschlechtergeschichte kann, was ihre Beiträge zur Geschichtswissenschaft betrifft, auch in Österreich auf eine Vielfalt an Projekten und Publikationen verweisen. Eine umfassende Darstellung von Arbeiten und Schwerpunkten kann an dieser Stelle nicht geleistet und die große Bandbreite entsprechend nur kursorisch umrissen werden.

Thematisch hatten ab Ende der 1970er-Jahre vor allem die neue Sozialgeschichte bzw. die ArbeiterInnen(bewegungs)geschichte eine wichtige Impulsfunktion und brachten Ansätze einer Alltagsgeschichte und Erfahrungsgeschichte genauso ins Rollen wie historisch anthropologische und mikrohistorische Fragestellungen. Die historische Frauenforschung war und ist mit diesen paradigmatischen Neubefra-

11 Vgl. Joan W. Scott, Gender: A Useful Category of Historical Analysis, in: The American Historical Review 91 (1986) 5, 1053-1075.

12 Vgl. Jürgen Martschukat/Olaf Stieglitz, Geschichte der Männlichkeiten, Frankfurt a. M. ${ }^{22018}$; Raewyn Connell, Masculinities, Cambridge ${ }^{2} 2005$.

13 Vgl. Norbert Finzsch/Marcus Velke, Queer, Gender, Historiographie. Aktuelle Tendenzen und Projekte (Geschlecht - Kultur - Gesellschaft), Münster 2016. 
gungen der Geschichte verwoben und thematisch verknüpft. ${ }^{14}$ Der Zugang, Frauen in der Geschichte sichtbar zu machen, wie er in der Frühphase der Frauengeschichte verfolgt wurde, rückte zudem biographische Ansätze in den Vordergrund. Die Biographieforschung, als „erster Ort“ der Frauengeschichtsschreibung ${ }^{15}$ lässt sich zweifelsfrei als Konstante in der zeithistorischen Geschlechtergeschichte in Österreich bezeichnen und besitzt nach wie vor einen wichtigen Stellenwert, insbesondere in der Zeitgeschichte. ${ }^{16}$

Dieses biographische Interesse war gepaart mit der grundlegenden Haltung, Frauen als historische Subjekte respektvoll wahrzunehmen, und schlug sich - wie bereits erwähnt - auch in der Wahl der Methoden nieder. Lebensgeschichtliche Interviews gewannen eine zentrale Bedeutung gerade für die Bearbeitung von zeithistorischen Themen. Der quellenkritische Umgang mit Oral History und die Nutzung qualitativer Analyseinstrumente aus den Sozialwissenschaften zeichnete viele dieser Projekte aus. ${ }^{17}$ Die Frauen- und Geschlechtergeschichte profitierte im Verlauf ihrer Genese von den interdisziplinären Methoden- und Theoriediskussionen der feministischen Wissenschaften und bezog in den letzten Jahren verstärkt diskurstheoretische und intersektionale Ansätze ein. Einen breiten Widerhall in der ,allgemeinen“ Zeitgeschichtsschreibung fanden die methodischen wie theoretischen Perspektiven jedoch kaum. ${ }^{18}$

Die Themenpalette war von Beginn an sehr breit und reichte von der Erforschung von (Frauen)Bewegungen und Organisationen, Geschlechterverhältnissen in der Politik, Studien zu Arbeit und Erwerbsleben, Bildung, Sexualität, Reproduktion, Formen des Zusammenlebens, Ausschlüssen, Kriminalität bis zu einem Schwerpunkt an Arbeiten einerseits zu Nationalsozialismus, Shoah und Widerstand, andererseits zur Nachkriegszeit bis in die 1950er-Jahre. ${ }^{19}$ Im Gegensatz dazu setzte die Auseinandersetzung mit dem austrofaschistischen Ständestaat wesentlich später und mit weniger Verve ein. Zuletzt beschäftigte sich 2016 eine Nummer der „Öster-

14 Vgl. Ingrid Bauer, Kontinuitäten und Transformationen. Die österreichische Zeitgeschichtsforschung im Generationenvergleich, in: zeitgeschichte 30 (2003) 6, 320-340.

15 Vgl. Bauer, Blick, 17.

16 Zum Beispiel Veronika Duma, Rosa Jochmann. Politische Akteurin und Zeitzeugin, Wien 22020; vgl. biografiA, biografische Datenbank und Lexikon österreichischer Frauen, URL: http://www. biografia.at/ (abgerufen 18.06.2020).

17 Zum Beispiel Ela Hornung-Ichikawa, Warten und Heimkehren. Eine Ehe während und nach dem Zweiten Weltkrieg, Wien 2005.

18 Vgl. Christa Hämmerle, Traditionen, Trends und Perspektiven. Zur Frauen- und Geschlechtergeschichte des Ersten Weltkriegs in Österreich, in: Geschichte und Region/Storia e regione 23 (2014) 2, 21-48.

19 Ausführlichere bibliographische Hinweise vgl. Saurer, Frauengeschichte; Mesner, Ambivalenzen. 
reichischen Zeitschrift für Geschichtswissenschaften“" mit den Geschlechterverhältnissen im Austrofaschismus. ${ }^{20}$

Im Zusammenhang mit dem Nationalsozialismus und den folgenden Nachkriegsjahrzehnten stehen auch einige regionalgeschichtliche Studien, wie sie für einige Bundesländer vorliegen. ${ }^{21}$ Ein Forschungsungleichgewicht besteht noch deutlich, was das Stadt-Land-Gefälle betrifft. Wien, aber auch die Landeshauptstädte, bzw. städtischer Alltag, Politik und Berufsleben wurden bisher wesentlich intensiver nach Geschlechterverhältnissen befragt als bäuerliche bzw. ländliche Gesellschaften.

Ein seit den 200oer-Jahren sich entwickelndes Thema ist auch in Österreich das der Männergeschichte, das wie in Deutschland vor allem Studien zu Männlichkeitskonstruktionen im Zusammenhang mit Krieg bzw. Militär anregte. ${ }^{22}$ Interessanterweise motivierte gerade dieses Themenfeld auch Historiker - mit mehr oder weniger theoretischen Anschlüssen zur Geschlechterforschung -, über Männlichkeit(en) nachzudenken. ${ }^{23}$ Eine analytische wie historiographische Neuorientierung ermöglichte unter anderem das Konzept einer „Krise der Männlichkeit“, wie sie für das 2o. Jahrhundert als Konsequenz der sich verändernden Geschlechterordnung diskutiert wird. ${ }^{24}$

Bereits 2012 behandelte Heft 2 der Zeitschrift „L'Homme“ das Verhältnis von Globalgeschichte und Geschlechtergeschichte. Die geforderte Überwindung von eurozentrischen Perspektiven und die Notwendigkeit einer Verflechtungsgeschichte (Entangled History) sind Ansprüche, die in der zeithistorischen Geschlechtergeschichte bisher erst wenig aufgegriffen wurden. Die globalhistorische Ausweitung

20 Zum Beispiel Perspektivenwechsel: Geschlechterverhältnisse im Austrofaschismus/Changing the Perspectives: Gender Relations in Austro-Fascism. Österreichische Zeitschrift für Geschichtswissenschaften 27 (2016) 3.

21 Vgl. Brigitte Mazohl-Wallnig/Erika Thurner/Dagmar Stranzinger, Die andere Geschichte II (Lesebücher zur Geschichte Salzburgs 5), Salzburg 1996; Gabriella Hauch (Hg.), Frauen im Reichsgau Oberdonau. Geschlechtsspezifische Bruchlinien im Nationalsozialismus (Oberösterreich in der Zeit des Nationalsozialismus 5), Linz 2006; Karin Maria Schmidlechner, Aus dem Blickfeld. Eine biographische Annäherung an ambivalente Lebensszenarien steirischer Frauen in der Kriegs- und Nachkriegszeit (1939-1955) (Grazer Gender Studies 11), Graz 2008.

22 Zum Beispiel Christa Hämmerle, ,Vor vierzig Monaten waren wir Soldaten, vor einem halben Jahr noch Männer ...'Zum historischen Kontext einer „Krise der Männlichkeit“ in Österreich nach dem Ersten Weltkrieg, in: L'Homme F. Z. G. 19 (2008) 2, 51-73.

23 Vgl. Wolfgang Schmale, Geschichte der Männlichkeit in Europa (1450-2000), Wien 2003; Ernst Hanisch, Männlichkeiten. Eine andere Geschichte des 20. Jahrhunderts, Köln/Wien 2005.

24 Christa Hämmerle/Claudia Opitz-Belakhal (Hg.), Krise(n) der Männlichkeit. L'Homme Z. F. G. 19 (2008) 2; Gerhard Baumgartner/Markus Cerman/Franz X. Eder (Hg.), Im Inneren der Männlichkeit. Österreichische Zeitschrift für Geschichtswissenschaften 11 (2000) 3. 
des Forschungsblicks unter verstärktem Einbezug postkolonialer Theorien stellt sich als weitere Aufgabe für zukünftige Forschungen dar. ${ }^{25}$

Dass jedoch auch „traditionelle“ Themen mit nationalen Bezügen lohnende Felder sind, die kombiniert mit Ausstellungsformaten ein breiteres Publikum ansprechen, bewiesen jüngste Publikationen, die anlässlich der Einhundert-Jahr-Jubiläen des Frauentages bzw. der Einführung des Frauenwahlrechts in Österreich veröffentlicht wurden. ${ }^{26}$

\section{Einzelerscheinungen im luftleeren Raum: Aufbruch in den 1970er-Jahren}

Wiewohl vereinzelte frauenhistorische Ansätze und Arbeiten bereits in der ersten Hälfte des 20. Jahrhunderts auszumachen sind, ${ }^{27}$ taucht ein Name mit dem Beginn der österreichischen zeithistorischen Frauenforschung in allen Rückblicken verlässlich auf: Erika Weinzierl. Sie hatte 1971 an der Universität Salzburg die erste Lehrveranstaltung zur Geschichte von Frauen angeboten.$^{28} 1975$ veröffentlichte die damals einzige österreichische Universitätsprofessorin im Fach Geschichte eine der ersten frauenhistorischen Publikation nach 1945 mit dem Titel „Emanzipation? Österreichische Frauen im 20. Jahrhundert“.29 Damit leitete Weinzierl, die Ende der 1970er-Jahre an das Institut für Zeitgeschichte der Universität Wien wechselte, jedoch noch keine kontinuierliche Entwicklung der frauenhistorischen Forschung in Österreich ein. Ihr „engagierter Nonkonformismus“30 blieb in den 1970er-Jahren „eine Einzelerscheinung“. ${ }^{11}$ Weiterhin zeigten sich die österreichischen Universitä-

25 Vgl. Angelika Epple, Globalgeschichte und Geschlechtergeschichte: Eine Beziehung mit Zukunft, in: L'Homme Z. F. G. 23 (2012) 2, 87-100.

26 Vgl. Heidi Niederkofler/Maria Mesner/Johanna Zechner, Frauentag! Erfindung und Karriere einer Tradition, Wien 2011; Ahoi Blaustrumpf (Hg.), „Sie meinen es politisch!“ 100 Jahre Frauenwahlrecht in Österreich. Geschlechterdemokratie als gesellschaftspolitische Herausforderung, Wien 2019; aus regionalhistorischer Perspektive: Andrea Lauritsch (Hg.), „An uns, ihr Frauen, ist die Reihe“. 100 Jahre Frauenwahlrecht: historische Streifzüge durch Kärntens Geschichte, Klagenfurt 2018.

27 Zum Beispiel Emma Adlers 1906 erschienenes Werk zu den Frauen der Französischen Revolution, vgl. Saurer, Frauengeschichte, 45.

28 Das Thema lautete „Die soziale und politische Stellung der Frauen in Österreich 1848-1970“, vgl. Bauer, Blick, 14.

29 Erika Weinzierl, Emanzipation? Österreichische Frauen im 20. Jahrhundert, Wien 1975.

30 Bauer, Kontinuitäten, 329.

31 Mesner, Ambivalenzen, 270. 
ten in Bezug auf die Frauengeschichte als „luftleerer Raum“, wie Ingrid Bauer 1993 feststellte. ${ }^{32}$

Auf der Ebene der Lehrangebote gesellten sich 1975 Edith Saurer, damals Assistentin am Institut für Geschichte, und 1979 Michael Mitterauer, Professor am Institut für Wirtschafts- und Sozialgeschichte, beide Universität Wien, hinzu. ${ }^{33}$ Lehrveranstaltungen zur Frauengeschichte durchzusetzen war in dieser Aufbruchsphase kein friktionsfreier Prozess, jene Wissenschaftlerinnen, die sich dafür einsetzten, hatten zahlreiche Widerstände zu überwinden. ${ }^{34}$ Edith Saurer, seit 1970 Assistentin und ab 1992 Professorin für Geschichte der Neuzeit an der Universität Wien, avancierte im Laufe ihrer universitären Karriere zu einer zentralen Vertreterin der österreichischen Frauen- und Geschlechtergeschichte. ${ }^{35}$ Sie legte selbst rückblickend den Beginn der österreichischen Frauengeschichtsforschung mit den späten 1970erJahren fest. ${ }^{36}$

\section{Ausbreitung und ...}

Bezeichnenderweise kamen in dieser ersten Phase der frauen- und geschlechterhistorischen Forschung in Österreich maßgebliche Impulse und Debatten aus außeruniversitären feministischen Räumen. ${ }^{37}$ Dieses „Ineinandergreifen von (geschlechter)politischen, sozialen, kulturellen und wissenschaftlichen Kontexten" war charakteristisch für das entstehende Forschungsfeld. ${ }^{38}$ Vielfach waren es Studierende, die Frauenforschung als Inhalt der universitären Ausbildung forderten. ${ }^{39}$ Deren Interesse an einer Geschichtswissenschaft, die neue Fragen stellte und bisher marginalisierte Gruppen ins Zentrum rückte, war von gesellschaftspolitischen An-

32 Bauer, Blick, 14.

33 Saurers Proseminar trug den Titel „Zur Geschichte des Frauenwahlrechts: die Suffragetten“, Mitterauer lehrte zur „Frau im Mittelalter“, vgl. Mesner, Verwerfungen, 60.

34 Vgl. Christa Hämmerle/Gabriella Hauch, „Auch die österreichische Frauenforschung sollte Wege der Beteiligung finden ..." Zur Institutionalisierung der Frauen- und Geschlechtergeschichte an der Universität Wien, in: Karl Anton Fröschl (Hg.), Reflexive Innensichten aus der Universität. Disziplinengeschichten zwischen Wissenschaft, Gesellschaft und Politik, Göttingen 2015, 97-109. Vgl. Margarethe Lanzinger/Erich Landsteiner, Edith Saurer. Historikerin und Kämpferin für (Geschlechter-) Demokratie, in: Mitchell G. Ash/Josef Ehmer (Hg.), Universität - Politik - Gesellschaft, Wien 2015, 349-354.

36 Vgl. Saurer, Frauengeschichte, 45.

37 Vgl. Bauer, Blick, 14.

38 Vgl. Hämmerle/Hauch, Frauenforschung, 97.

39 Vgl. Mesner, Ambivalenzen, 273. 
sprüchen getrieben und zielte auf eine forschungsgestützte Veränderung der Geschlechterverhältnisse in der Gesellschaft.

Bevor noch ein entsprechendes Lehrangebot bestand, sorgten selbstorganisierte Initiativen von Studierenden und aus dem Mittelbau für eine Zunahme an frauenund geschlechterhistorischen Abschlussarbeiten. Bereits Ende der 1970er-Jahre hatte sich an der Universität Wien eine interdisziplinäre Studentinnengruppe formiert, aus der 1982 die Arbeitsgruppe Frauengeschichte entstand, der Edith Saurer genauso angehörte wie die Philosophin Herta Nagl-Docekal..$^{40}$ Deren Programm bestand vor allem in der Anregung frauenhistorischer Lehre. Daneben wurden Diskussionsgruppen und Ringvorlesungen organisiert. Die 1996 in Arbeitsgruppe Frauen- und Geschlechtergeschichte umbenannte und bis zur Gegenwart aktive Initiative entwickelte sich zum „Zentrum auf dem Weg der Institutionalisierung der Frauen- und Geschlechterforschung" an der geisteswissenschaftlichen Fakultät in Wien. ${ }^{41}$

Auf Initiative von Irene (Bandhauer)Schöffmann trafen sich zudem Geschichtsstudentinnen außerhalb der universitären Strukturen, um einander zu unterstützen. ${ }^{42}$ Aus diesem Netzwerk ging 1984 die Gruppe der "Wiener Historikerinnen“ hervor, die das 5. Historikerinnentreffen im selben Jahr nach Wien holten. ${ }^{43}$ Unter den 76 Referentinnen befand sich auch die Doyenne der frauenhistorischen Forschung Gerda Lerner. Die amerikanische Professorin - eine geborene Wienerin, die 1938 als Jüdin in die USA hatte emigrieren müssen - sprach zum Thema „A Feminist Theory of History“".44 Die internationale Tagung mit sechshundert Teilnehmenden aus zwölf Ländern war ein starkes Signal an die universitäre Geschichtswissenschaft und verhalf der im Tagungsband als ,ungeschriebene Geschichte" bezeichneten feministischen Geschichtswissenschaft in Österreich zu einem Auftrieb.

Nur wenige Monate später veranstaltete das Frauenreferat der Österreichischen Hochschülerschaft die erste Österreichische Frauensommeruniversität in Wien, die der Auftakt für weitere jährlich an wechselnden Standorten stattfindende Sommer-

40 Vgl. Edith Saurer, Die Arbeitsgruppe Frauengeschichte am Institut für Geschichte der Universität Wien, in: Gertraud Seiser/Eva Knollmayr (Hg.), Von den Bemühungen der Frauen, in der Wissenschaft Fuß zu fassen (Materialien zur Förderung von Frauen in der Wissenschaft 3), Wien 1994, 177.

41 Vgl. Hämmerle/Hauch, Frauenforschung, 101.

42 Vgl. Mesner, Ambivalenzen, 272.

43 Bis dahin fanden die Treffen in Städten der Bundesrepublik Deutschland statt, vgl. Hämmerle/ Hauch, Frauenforschung, 101.

44 Vgl. Gerda Lerner, Eine feministische Theorie der Historie, in: Wiener Historikerinnen (Hg.), Die ungeschriebene Geschichte. Historische Frauenforschung. Dokumentation des 5. Historikerinnentreffens in Wien, Wien 1985, 404-411. 
universitäten war. ${ }^{45}$ Diese Initiative veranschaulicht einmal mehr die wichtige Rolle von Studierenden und ihren Vertreterinnen für die Entwicklung des Forschungsbereichs an den österreichischen Universitäten.

\section{... österreichweite Durchsetzung in den 1980er- und 1990er-Jahren}

Mitte der 1980er-Jahre kann schließlich von einer ersten Etablierung des Faches im Lehrangebot gesprochen werden. Besonders das unter Wissenschaftsministerin Hertha Firnberg 1982 eingerichtete „Sonderkontingent“ von Lehrveranstaltungen „zur Förderung der Frauenforschung“ trug österreichweit zu einer Ankurbelung eines interdisziplinären Lehrangebotes bei. ${ }^{46}$ Auch an den Universitäten in Salzburg, Linz, Innsbruck, Graz und Klagenfurt bildete diese Maßnahme die Grundlage für die Finanzierung von Lehrveranstaltungen zur Frauenforschung, zunehmend auch im Bereich der Frauengeschichte.

Verstärkt wurde das Vorantreiben der feministischen Forschung und Lehre durch zahlreiche Arbeitsgruppen, die sich in den 1980er-Jahren auch an den Universitäten der Bundesländer formierten. In diesen Gruppen schlossen sich überwiegend junge Wissenschaftlerinnen zusammen, die durch Veranstaltungen, Tagungen und universitätspolitische Interventionen energisch für einen Platz der Frauenforschung an den Universitäten kämpften. Viele dieser Aktivistinnen finden sich später unter den (außerordentlichen) Professorinnen wieder, die ab Mitte der 1990er-Jahre das Fach vertraten. Interdisziplinär ausgerichtet und unter prekären und hürdenreichen Bedingungen arbeitend, leisteten diese Arbeitsgruppen einen wichtigen Beitrag zur Verstetigung der Forschungsperspektive an den diversen Universitäten. Veranstaltungsformate wie Ringvorlesungen, Ausstellungen, ${ }^{47}$ Tagungen und Diskussionsabende, teilweise von Studierenden organisiert, waren wichtige Medien, um die Fachrichtung universitätsintern, aber auch in der Öffentlichkeit voranzutreiben.

Ab Beginn der 1990er-Jahre beförderte zudem die Novellierung des Universitätsorganisationsgesetzes (UOG) eine Etablierung von Frauenforschung und Frauen-

45 Bis 1990 fanden die Sommeruniversitäten regelmäßig statt. Danach wurden sie erst 2007 wiederaufgenommen, die letzte Veranstaltung fand 2012 statt.

46 Andrea Griesebner, Die Wiener Initiative für die Stärkung der Frauenforschung und ihre Verankerung in der Lehre. Ein Bericht, in: Gertraud Seiser/Eva Knollmayr (Hg.), Von den Bemühungen der Frauen, in der Wissenschaft Fuß zu fassen (Materialien zur Förderung von Frauen in der Wissenschaft 3), Wien 1994, 64-66.

47 Zum Beispiel die Ausstellung „Sieg der Waffen, Sieg der Wiegen - Frauenalltag im Nationalsozialismus“ der „Historikerinnengruppe der Universität Salzburg“ 1988. 
förderung. Zentrale Einrichtungen an den österreichischen Universitäten sind seither die Arbeitskreise für Gleichbehandlungsfragen und die Koordinationsstellen für Frauen- und Geschlechterforschung.

An der Aufbauphase der Frauen- und Geschlechterforschung in den 1980erJahren waren die zeithistorischen Abteilungen der einzelnen Universitäten mit unterschiedlichem Gewicht beteiligt. Während in Graz und Salzburg bereits im Wintersemester 1986/1987 entsprechende Lehrveranstaltungen angeboten wurden, integrierte die Wiener Zeitgeschichte frauen- und geschlechterhistorische Inhalte etwas zögerlich erst Anfang der 1990er-Jahre..$^{48} 1998$ wurde schließlich mit Johanna Gehmacher am Institut für Zeitgeschichte der Universität Wien erstmals eine Stelle mit einer Geschlechterforscherin besetzt.

Am Fachbereich Zeitgeschichte der Universität Graz war ab 1984 Karin Schmidlechner als Universitätsassistentin tätig. Ihre Arbeit „Frauenleben in Männerwelten. Ein Beitrag zur Geschichte der steirischen Frauen in der Nachkriegszeit (19451951)" war 1995 die österreichweit erste Habilitationsschrift in Zeitgeschichte zu einem frauengeschichtlichen Thema. In der Folge intensivierte Schmidlechner als außerordentliche Professorin kontinuierlich in der eigenen Lehre und Forschung Themen der Frauen- und Geschlechtergeschichte mit einem speziellen regionalhistorischen Fokus. ${ }^{49}$

An der Universität Salzburg war es nach dem bereits erwähnten Auftakt durch Erika Weinzierl geraume Zeit ruhig um die historische Frauenforschung im Lehrangebot. Die erste frauen- und geschlechterhistorische Lehrveranstaltung am Institut für Geschichte wurde im Wintersemester 1986 von den Zeithistorikerinnen Ingrid Bauer und Helga Embacher (damals Dissertantinnen) angeboten. ${ }^{50}$ Am Institut für Geschichte wurde ab den späten 1980er-Jahren Frauengeschichte mit Schwerpunkt auf das 19. Jahrhundert vor allem von der Neuzeithistorikerin Brigitte Mazohl (-Wallnig) vorangetrieben, die 1993 die Professur für Österreichische Geschichte an der Universität Innsbruck annahm.

Erst 1995 bekam mit Ingrid Bauer die zeithistorische Frauen- und Geschlechterforschung am Institut für Geschichte der Universität Salzburg einen fixen Platz. Bauer hatte zuvor den Schwerpunkt „Historische Frauenforschung“ am Ludwig Boltzmann Institut für Geschichte der Arbeiterbewegung (LBI) in Salzburg auf-

48 Vgl. Mesner, Ambivalenzen, 271.

49 Zum Beispiel Anita Ziegerhofer-Prettenthaler/Karin M. Schmidlechner/Ute Sonnleitner, „Haustochter gesucht". Steirische Arbeitsmigrantinnen in der Schweiz (Grazer Gender Studies 13), Graz 2010.

$50 \quad$ Vgl. Gespräch mit Ingrid Bauer, 02.12.2019. 
gebaut $^{51}$ und mit ihren Forschungen zu den Halleiner Tabakarbeiterinnen einen wichtigen Beitrag zur österreichischen Arbeiterinnengeschichte geleistet. ${ }^{52}$

An der Universität Linz kamen erste Impulse für eine Frauenforschung aus der Soziologie und der Rechtsgeschichte. ${ }^{53}$ Ursula Floßmann, Doyenne der feministischen Rechtswissenschaft in Österreich, entwickelte in Linz den Studienzweig Frauenrecht und betrieb die inhaltliche Neuausrichtung der Legal Gender Studies an der Juristischen Fakultät. Am Linzer Institut für Zeitgeschichte habilitierte sich 1996 Gabriella Hauch mit einer Arbeit zu den ersten Parlamentarierinnen in der Zwischenkriegszeit ${ }^{54}$ und verfestigte die Frauen- und Geschlechtergeschichte am Standort Linz.

An den Universitäten Innsbruck und Klagenfurt fand die Geschlechtergeschichte zunächst weniger Anbindung an den zeithistorischen Instituten. Einschlägige Angebote in der Lehre wurden hier vorwiegend von externen Lehrbeauftragten bespielt und von universitären Einrichtungen organisiert, die die interdisziplinäre Geschlechterforschung vorantrieben.55 In Innsbruck entwickelte sich ab Ende der 1980er-Jahre eine lebendige politikwissenschaftliche Frauen- und Geschlechterforschung mit starken zeithistorischen Bezügen, vertreten durch Erna Appelt und Sieglinde Rosenbauer. In Klagenfurt setzten sich vor allem Studierende im Rahmen von Veranstaltungen und Projekten mit zeithistorischen Themen der Frauen- und Geschlechtergeschichte auseinander. Die spätere Historikerin Andrea Lauritsch organisierte als Vorsitzende des ÖH-Frauenreferats beispielsweise 1991 die erste Österreichische Historikerinnentagung $1991 .^{56}$

51 Vgl. Lebenslauf, URL: https://www.uni-salzburg.at/fileadmin/oracle_file_imports/1521206.PDF (abgerufen 18.06.2020).

52 Ingrid Bauer, „Tschikweiber haums uns g’nennt .... “. Die Zigarrenfabriksarbeiterinnen von Hallein (Frauen, Arbeit, Geschichte), Berlin ${ }^{2} 2016$.

53 Vgl. zum Beginn der Frauenforschung an der JKU: Edeltraud Ranftl, Vom Nebenwiderspruch zur Institutionalisierung, in: Gertraud Seiser/Eva Knollmayr (Hg.), Von den Bemühungen der Frauen, in der Wissenschaft Fuß zu fassen (Materialien zur Förderung von Frauen in der Wissenschaft 3), Wien 1994, 411-431.

54 Vgl. Gabriella Hauch, Vom Frauenstandpunkt aus. Frauen im Parlament 1919-1933 (Studien zur Gesellschafts- und Kulturgeschichte 7), Wien 1995.

55 An der Universität Innsbruck ausgehend vom Büro für Gleichstellung und Gender Studies, ab 2005 Forschungsplattform Center Interdisziplinäre Geschlechterforschung; an der Universität Klagenfurt: ab 2001 Universitätszentrum für Frauen- und Geschlechterstudien.

56 Vgl. Andrea Lauritsch, Am Anfang war Klagenfurt. Zur Geschichte des ÖH-Frauenreferats an der UBW, in: Gertraud Seiser/Eva Knollmayr (Hg.), Von den Bemühungen der Frauen, in der Wissenschaft Fuß zu fassen (Materialien zur Förderung von Frauen in der Wissenschaft 3), Wien 1994, 448; seit Mitte der 1990er-Jahre forscht Tina Bahovec an der Abteilung für die Geschichte Ost- und Südosteuropa u. a. auch zu geschlechterhistorischen Themen. 
Zeitschriftengründungen, Professuren und Studiengänge - Institutionalisierung in den 1990er- und 2000er-Jahren

Eine österreichweite Zusammenarbeit unter Frauen- und Geschlechterhistorikerinnen anzuregen, gelang nur zögerlich. Für ein paar Jahre informierte ab 1986 ein jährlicher „Rundbrief“ über österreichweite Aktivitäten und Forschungen. Die Herausgeberschaft wechselte zwischen den Standorten, doch war dies offensichtlich nicht ausreichend, um „latente Spannungen zwischen Bundes- und Landeshauptstädten entgegenzuwirken". ${ }^{57}$ Regionalgeschichtliche Studien und Aktivitäten in den Bundesländern wurden teilweise andernorts nur wenig wahrgenommen oder rezipiert..$^{58}$

Als nachhaltiges Vernetzungsprojekt, das 1996 auch international erweitert wurde, kann die 1990 erstmals herausgegebene Zeitschrift „L'Homme“ bezeichnet werden. Acht Wissenschaftlerinnen aus Wien, Salzburg und Innsbruck, die meisten von ihnen Historikerinnen, begründeten diese erste deutschsprachige Zeitschrift für feministische Geschichtswissenschaften. Damit beabsichtigten sie, ein Forum zu schaffen, das das ,innovative Potential“ und die gänzlich neue Perspektive der feministischen Geschichtsschreibung bündeln und artikulieren konnte. ${ }^{59}$ Zweierlei Anschlüsse wurden mit "L’Homme“ angestrebt: einerseits an eine internationale Forschungs-Community und andererseits an die eigene Disziplin im Lande. Nach einem Beginn, der geprägt war von interdisziplinärer Zusammenarbeit, stand nun auch die Auseinandersetzung mit der eigenen Disziplin verstärkt im Fokus. ${ }^{60}$

Trotz dieser Initiativen, der kontinuierlichen Präsenz in der Lehre und einer regen Forschungslandschaft fand eine Institutionalisierung der Frauen- und Geschlechterforschung in Form von Professuren und Stellen relativ spät statt. ${ }^{61}$ An der Universität Wien werden als deutschsprachiges Novum seit 1991 Gastprofessuren (seit 1999 als Käthe-Leichter-Gastprofessuren) für Frauen- und Geschlechterforschung ausgeschrieben, die teilweise auch von (Zeit)Historikerinnen ausgefüllt wurden. ${ }^{62}$ Mit Edith Saurer erhielt 1992 die erste prononcierte Frauenhistorikerin eine Professur (für Neuere Geschichte). Erst zwölf Jahre später (2004) wurde Carola Sachse auf die erste Professur mit Schwerpunkt Frauen- und Geschlechterforschung am Institut

57 Hämmerle/Hauch, Frauenforschung, 102.

58 Vgl. Mesner, Verwerfungen, 66.

59 Vgl. Brigitte Mazohl-Wallnig, Women's History in Austria, in: Karen Offen/Ruth Roach Pierson/ Jane Rendall (Hg.), Writing women's history. International perspectives, Basingstoke 1991, 287.

60 Vgl. Hämmerle/Hauch, Frauenforschung, 103.

61 Vgl. Mesner, Ambivalenzen, 282.

62 Eine Liste ist verfügbar unter URL: https://genderausschuss.univie.ac.at//kaethe-leichter-gastprofessur/ (abgerufen 18.06.2020). 
für Zeitgeschichte der Universität Wien berufen. 2004 war in puncto Geschlechtergeschichteprofessuren ein erfolgreiches Jahr: An der Universität Linz trat auch Gabriella Hauch die erste interdisziplinäre Professur für Frauen- und Geschlechterforschung an. Daneben haben sich seit den 1990er-Jahren weitere ZeithistorikerInnen habilitiert, die sich in ihren Arbeiten schwerpunktmäßig mit der Kategorie Geschlecht beschäftigten. ${ }^{63}$ Hier zeigt sich ein strukturelles Problem, da habilitierte Wissenschaftlerinnen zwar als Lehrbeauftragte und Dozentinnen maßgeblich an der Ausgestaltung der Forschung und Lehre beteiligt waren, dieses Engagement meist jedoch keine nachhaltige inhaltliche Verankerung des Forschungsschwerpunkts an den Instituten bewirkte. Mittelbaustellen sind im Gegensatz zu Professuren nur selten mit Denominationen, sprich festgelegten Forschungsschwerpunkten verknüpft und verfügen im Normalfall über keine AssistentInnenstellen, die ein Forschungsgebiet mit- und weitertragen können. Im Falle von Pensionierungen oder eines Wechsels an andere Universitäten ist demgemäß das Weiterbestehen von Forschungsschwerpunkten nicht gesichert, wie die folgenden Beispiele verdeutlichen.

\section{Nachhaltigkeit und individuelles Engagement - Die 2010er-Jahre}

Geschlecht als Kategorie bzw. Geschlechtergeschichte tauchen zwar bei der Beschreibung von Institutsschwerpunkten mittlerweile gerne auf, generell ist die Geschlechtergeschichte jedoch nach wie vor kein selbstverständlicher Bestandteil der Zeitgeschichte in Österreich. „Dass es sie gab und gibt, ist ausschließlich auf individuelles Engagement zurückzuführen. " ${ }^{64}$ Diese Feststellung traf Karin Schmidlechner vor 10 Jahren anlässlich des 25-Jahr-Jubiläums der Grazer Zeitgeschichte. Wie Recht sie mit dieser Feststellung hatte, zeigt sich an den Konsequenzen, die durch Pensionierungen und Stellenwechsel gleich an mehreren Standorten sichtbar wurden. Während in Graz nach der Pensionierung von Schmidlechner 2019 der Forschungs- und Lehrschwerpunkt nun allein von Heidrun Zettelbauer als assoziierter Professorin gestemmt wird, hinterließ in Salzburg das Ausscheiden von Ingrid Bauer eine große inhaltliche Lücke im Kernfach Zeitgeschichte. Auch an der Universität Linz veränderte sich die inhaltliche Ausrichtung des Instituts für Frauen- und Geschlechterforschung mit dem Wechsel von Gabriella Hauch an die Universität Wien kom-

63 Z. B. Karin Schmidlechner (1986), Erika Thurner (1991), Susan Zimmermann (1999), Ingrid Bauer (2001), Johanna Gehmacher (2001), Mathias Marschik (2003), Irene Bandhauer-Schöffmann (2004), Maria Mesner (2004), Ela Hornung (2007), Heidrun Zettelbauer (2017), Martina Gugglberger (2017), die Auflistung erhebt keinen Anspruch auf Vollständigkeit.

64 Schmidlechner, 25 Jahre, 212. 
plett. Nur ebendort ist es gelungen, (zeithistorische) Geschlechtergeschichte auch jenseits von Stellen beispielsweise als Pflichtfachbereich im Studienplan Geschichte bzw. seit 2006 in Form des Masters „Frauen- und Geschlechtergeschichte“ oder „MATILDA - European Master in Women's and Gender History“ zu verankern. Mehrere Einrichtungen wie die Sammlung Frauennachlässe oder die universitäre Forschungsplattform zur „Neuverortung der Frauen- und Geschlechtergeschichte im veränderten europäischen Kontext" (bestehend von 2006 bis 2012) bzw. der gesamtuniversitäre Forschungsverbund „Geschlecht und Handlungsmacht (Gender and Agency)" lassen hier aktuell eine nachhaltigere Institutionalisierung erkennen. ${ }^{65}$

Dieser zumindest partiellen Verankerung auf institutioneller Ebene steht allerdings seit den 1990er-Jahren eine zunehmende Präkarisierung der akademischen Forschung gegenüber. Dies stellt vor allem NachwuchswissenschaftlerInnen vor große Hürden und betrifft besonders Forschungsbereiche, die eine randständige Perspektive vertreten. ${ }^{66}$ An der Universität Wien haben sich deshalb Studierende 2010 zum Verein fernetzt zusammengeschlossen, um gemeinsam auf die spezifische Situation von jungen ForscherInnen im Bereich Frauen- und Geschlechtergeschichte hinzuweisen. ${ }^{67}$ Trotz spezifischer Förderprogramme beispielsweise des Fonds für Wissenschaft und Forschung (seit 1998 Herta-Firnberg- und seit 2005 Elise-Richter-Programm) entsteht ein großer Anteil der zahlreichen Projekte in zeitlich befristeten oder gar nicht bezahlten Projektarbeiten, also von „marginalisierten Positionen" aus. ${ }^{68}$

\section{Zeitschriften als Gradmesser der Integration}

Die Bedeutungskurve von Ansätzen und Perspektiven der historischen Forschung lässt sich unter anderem an der Präsenz von einschlägigen Artikeln in Fachzeitschriften ablesen. In der österreichischen Zeitgeschichte gehören hierzu die „zeitgeschichte“ (seit 1973), die „Österreichische Zeitschrift für Geschichtswissenschaften“ (seit 1990) und „L'Homme“ (seit 1990). Ingrid Bauer hat sich 1993 - anlässlich des zwanzigjährigen Bestehens der "zeitgeschichte“ - die Mühe gemacht, den Anteil der Autorinnen im Vergleich zu den männlichen Kollegen zu erheben. ${ }^{69}$ Sie eruierte eine Frauenquote von 19 Prozent von insgesamt 624 AutorInnen. Führt man ihre statis-

65 Vgl. Hämmerle/Hauch, Frauenforschung, 106.

66 Vgl Mesner, Ambivalenzen, 281.

67 Vgl. URL: fernetzt.univie.ac.at (abgerufen 18.06.2020).

68 Gehmacher, Rand, 314.

69 Bauer, Blick, 14-28. 
tische Auswertung für die darauffolgenden Jahrgänge fort, so zeigt sich ein eindeutiger Anstieg bei den Autorinnen seit 1993. Von 642 AutorInnen, die von 1994 bis Mitte $2019^{70}$ für die Zeitschrift Texte (mit)verfassten, waren 42 Prozent Frauen, was mehr als einer Verdopplung gleichkommt. Bauer konstatierte vor allem eine Diskrepanz zwischen der Rubrik Buchbesprechungen - mit einem sehr geringen Autorinnenanteil von nur 12 Prozent - und den wissenschaftlichen Aufsätzen (23 Prozent). Rezensionen interpretierte sie folglich als „Männerterrain“, da diese den „Gestus des Überblicks über das Fach“ repräsentierten und besser in die „community of science “ integriert seien. Die Bedeutung der Männerbastion Buchbesprechung nahm interessanterweise innerhalb der „zeitgeschichte“ ab Mitte der 1990er-Jahre sukzessive ab, in einzelnen Ausgaben wurden schließlich gar keine Rezensionen mehr aufgenommen. Hinsichtlich der Aufsätze, die von Frauen zumindest in MitautorInnenschaft verfasst wurden, ist jedenfalls ein auffälliger Anstieg bemerkbar: von 23 Prozent 1993 auf 41 Prozent in den Jahren 1994 bis 2019. Anhaltend hoch ist der Autorinnenanteil vor allem ab 2005. In einigen dieser Jahrgänge ist das Geschlechterverhältnis ausgeglichen $(2008,2011,2012,2018)$ bzw. überwiegen teilweise sogar die Autorinnen $(2016,2017)$.

Eine Analyse von "gender in science“ betrifft immer zwei Ebenen. Neben der Präsenz von Wissenschaftlerinnen in einem Forschungsfeld stellt sich auch die Frage nach der inhaltlichen Bedeutung der Kategorie Geschlecht. Hat sich das Geschlechterverhältnis bei den BeiträgerInnen wie gezeigt eindeutig verbessert, so veranschaulicht ein Blick auf die Inhalte der Beiträge, dass dies nicht in gleichem Maße für die Geschlechtergeschichte bzw. Frauengeschichte als Thema bzw. Forschungsperspektive zutrifft. In den ersten zwanzig Jahren filtert Ingrid Bauer 39 Beiträge heraus, die sich frauen- bzw. geschlechterhistorischen Fragestellungen widmen. ${ }^{71}$ Zwei Hefte (1987/1988 und 1990/1991) erschienen dabei als Schwerpunkthefte mit dem Titel „Historische Frauenforschung“ bzw. versammelte ein Heft (1988/1989) Beiträge zum Überthema „Frauen - Macht - Disziplin“.

In den darauffolgenden 25 Jahren können lediglich 32 Beiträge identifiziert werden, die frauen- bzw. geschlechtergeschichtlichen Themen bzw. Fragestellungen nachgehen. Zwanzig Jahre lang erschien kein geschlechtergeschichtliches Schwerpunktheft, erst 2010 widmete sich Heft 2 dem Thema „Politische Gewalt - Terrorismus - Geschlecht“. Im Folgejahr erschien das nächste Schwerpunktheft zu „Migration von Frauen aus/nach Österreich“ und fünf Jahre darauf, 2016, präsentierten die

70 Von 2019 wurden Heft 1 und Heft 2 in die Auszählung einbezogen. Heft 3 und Heft 4 lagen noch nicht vor.

71 Vgl. Auflistung in: Bauer, Blick, 26-28. 
bislang letzten Schwerpunkthefte Beiträge zu einerseits „Geschlechtergeschichte(n)

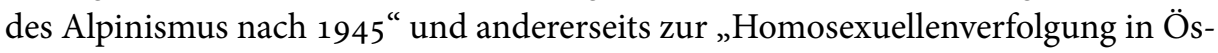
terreich".

Als Kontrast bot es sich an, auch die vorliegende Reihe „Böhlaus Zeitgeschichtlicher Bibliothek" einem kurzen Gender-Close-up zu unterziehen. Die Reihe hat seit 197642 Bände hervorgebracht, nur 12 Bände wurden bisher von Frauen (mit)verfasst bzw. herausgegeben, das sind 28,5 Prozent - was deutlich unter dem Wert der „zeitgeschichte“ liegt. Den Auftakt machte zwar ein Band aus der Feder der Politologin Margarete Mommsen zur österreichischen Proporzdemokratie, doch sollte die nächste Autorin, Irene Matyas, erst 14 Jahre später folgen. Nur marginal lassen sich in der Reihe frauen- und geschlechterhistorische Beiträge verorten. Nach mehreren Bänden zu Biographien von Männern konzentrierte sich erst 1996 der 33. Band von Waltraud (Kannonier)Finster und Meinrad Ziegler auf Biographien von Frauen im Exil - noch immer ein zentrales Werk für die methodisch und interpretative Auseinandersetzung mit Lebensgeschichten..$^{72} 2001$ folgte Band 38 mit der Herausgabe der Erinnerungen von Paula von Rosthorn zum Pekinger Boxeraufstand..$^{73}$ Der jüngst erschienene 42. Band von Birgit Kirchmayr bezieht dezidiert geschlechterhistorische Fragestellungen in die Analyse von Biographien von KünstlerInnen mit ein. ${ }^{74}$ Zuvor hatten lediglich zwei Sammelbände (Band 22, 1992 und Band 32, 1996) einige wenige frauen- bzw. geschlechterhistorische Aufsätze enthalten. ${ }^{75}$

72 Vgl. Waltraud Kannonier-Finster/Meinrad Ziegler, Frauen-Leben im Exil. Biographische Fallgeschichten (Böhlaus zeitgeschichtliche Bibliothek 33), Wien 1996.

73 Vgl. Paula von Rosthorn/Alexander Pechmann (Hg.), Peking 1900. Paula von Rosthorns Erinnerungen an den Boxeraufstand, März bis August 1900 (Böhlaus zeitgeschichtliche Bibliothek 38), Wien 2001.

74 Vgl. Birgit Kirchmayr, Zeitwesen. Autobiographik österreichischer Künstlerinnen und Künstler im Spannungsfeld von Politik und Gesellschaft 1900-1945: eine Studie zu Alfred Kubin, Oskar Kokoschka, Aloys Wach, Erika Giovanna Klien und Margret Bilger (Böhlaus zeitgeschichtliche Bibliothek 42), Wien/Köln/Weimar 2020.

75 Karl Kaser (Hg.), Clios Rache: neue Aspekte strukturgeschichtlicher und theoriegeleiteter Geschichtsforschung in Österreich (Böhlaus zeitgeschichtliche Bibliothek 22), Wien 1992; Klaus Hödl (Hg.), Der Umgang mit dem „Anderen“: Juden, Frauen, Fremde ... (Böhlaus zeitgeschichtliche Bibliothek 32), Wien 1996. 


\section{Resümee}

Das Verhältnis von Zeitgeschichte und Frauen- bzw. Geschlechtergeschichte sei ein „ungeordnetes“ bzw. „ambivalentes“, so resümierte Maria Mesner 2013. ${ }^{76}$ Dem ist noch immer zuzustimmen. Zwar kann von einer basalen Integration sowohl auf institutioneller Ebene als auch in die Zeitgeschichte als Fach gesprochen werden. Darauf deutet ein kontinuierliches Lehrangebot seit den 1990er-Jahren an allen Standorten ebenso hin wie letztlich auch die Aufnahme der Kategorie Geschlecht in den vorliegenden Band. Während in rezenten einführenden Lehrwerken zu Geschichte, Frauen- und Geschlechtergeschichte als Teilbereich, Thema, Perspektive oder Konzeptualisierung Aufnahme gefunden haben, ${ }^{77}$ trifft dies für einführende Werke der Zeitgeschichte verhaltener zu. Geschlechterverhältnisse werden unter anderem im Zuge eines „Wertewandels“ in den Jahrzehnten nach $1945^{78}$ thematisiert bzw. erst 2012 als explizites Themenfeld aufgenommen.79 Politische Zeitgeschichte, Fragen der Periodisierung, aber auch Erinnerungspolitiken bleiben nach wie vor von geschlechterhistorischen Fragestellungen und Forschungsergebnissen weitgehend unberührt. ${ }^{80}$

Bisher war von Geschlecht als Kategorie, als Forschungsperspektive bzw. -feld oder -richtung die Rede. Die Debatten, ob Geschlechterforschung ein eigenes Fach bzw. eine Disziplin sein kann oder will, führten 2012 bei der Gründung der Gesellschaft für Geschlechterforschung in Österreich zum Verzicht auf die Bezeichnung „Fachgesellschaft“. ${ }^{81}$ Als interdisziplinäres Projekt, das offen in viele Richtungen bleiben soll und einer Kanonisierung immer einen größtmöglichen Spielraum für Widerstände und Widersprüche entgegenhalten möchte, war und ist Geschlechter-

76 Mesner, Verwerfungen, 70 .

77 Zum Beispiel Ulinka Rublack (Hg.), Die Neue Geschichte. Eine Einführung in 16 Kapiteln, Frankfurt a. M. 2013; Hans-Jürgen Goertz, Geschichte. Ein Grundkurs (Rororo Rowohlts Enzyklopädie 55688), Reinbek bei Hamburg ${ }^{3} 2007$.

78 Vgl. Constantin Goschler/Rüdiger Graf, Europäische Zeitgeschichte seit 1945 (Akademie Studienbücher - Geschichte), Berlin 2010.

79 Vgl. Frank Bösch/Jürgen Danyel (Hg.), Zeitgeschichte. Konzepte und Methoden, Göttingen 2012.

80 Vgl. Zeitenschwellen. L'Homme Z. F. G. 25 (2014) 2; Maria Mesner, Zäsuren und Bögen, Grenzen und Brüche, Zeit- und Geschlechtergeschichte. Österreich in den 1970er Jahren, in: Lucile Dreidemy/Richard Hufschmied/Agnes Meisiner/Berthold Molden/Eugen Pfister/Katharina Prager/ Elisabeth Röhrlich/Florian Wenninger/Maria Wirth (Hg.), Bananen, Cola, Zeitgeschichte. Oliver Rathkolb und das lange 20. Jahrhundert, Wien/Köln/Weimar 2015, 1003-1012.

81 Vgl. Martina Gugglberger/Kristina Pia Hofer, Die Gründung der Österreichischen Gesellschaft für Geschlechterforschung/Gender Studies Association (ÖGGF) - ein Bericht, in: L'Homme Z. F. G. 24 (2013) 2, 125-129. 
forschung gedacht. Dabei kann auf einen erfolgreichen Weg zurückgeblickt werden, der nicht frei von Anwürfen und Verwerfungen war. Das kritische Potenzial und gleichsam die programmatische Widerständigkeit der Frauen- und Geschlechtergeschichte hat die "allgemeine“ Zeitgeschichte noch nicht zur Genüge ausgeschöpft. Mehrdeutigkeit und Widerspruch als paradigmatische Begriffe in den "Mainstream“ der zeithistorischen Forschung zu bringen und damit geschlechterhistorische Perspektiven gleichrangig und zentral zu integrieren, ist noch nicht ausreichend gelungen. ${ }^{82}$

82 Kirsten Heinsohn, Kommentar: Nachkriegszeit und Geschlechterordnung, in: Julia Paulus/Eva-Maria Silies/Kerstin Wolff (Hg.), Zeitgeschichte als Geschlechtergeschichte. Neue Perspektiven auf die Bundesrepublik (Geschichte und Geschlechter 62), Frankfurt a. M. 2012, 99; Saurer, Zeitschrift, 2. 


\title{
Migration
}

\author{
Dirk Rupnow
}

Die Fixierung von Medien und Öffentlichkeit auf historische Jahrestage und Jubiläen ist für HistorikerInnen Fluch und Segen zugleich: Sie läuft der Logik der wissenschaftlichen Forschung zuwider, bietet aber jeweils die Chance, bestimmte Themen der Vergessenheit zu entreißen, sichtbar zu machen und breit zu diskutieren. Doch diese Chance wird jeweils sehr unterschiedlich wahrgenommen. So verstrich etwa 2012 der fünfzigste Jahrestag der Unterzeichnung des ersten österreichischen Anwerbeabkommens mit Spanien ebenso wie zuvor schon der des Raab-Olah-Abkommens, ohne dass dem in Österreich große öffentliche oder mediale Aufmerksamkeit gewidmet worden wäre. ${ }^{1}$ Tatsächlich kamen auch nur wenige spanische „Gastarbeiter" ins Land, weil Österreich für sie weniger attraktiv war als Frankreich oder Deutschland, aber immerhin ermöglichte die (geheime) Vereinbarung zwischen Wirtschaftskammer und ÖGB im Dezember 1961 durch den Ausgleich der Interessen von Arbeitgebern und Arbeitnehmern überhaupt erst die strukturierte Anwerbung von ausländischen Arbeitskräften (und stellt darüber hinaus einen Grundstein für die Institutionalisierung der Sozialpartnerschaft dar).

Im Jubiläumsjahr 2014 wurde jedoch gleich von verschiedenen Seiten der Unterzeichnung des Anwerbeabkommens zwischen Österreich und der Türkei 1964 gedacht: Das Bundesministerium für Europa, Integration und Äußeres veranstaltete ein wissenschaftliches Symposium „50 Jahre türkische Migration nach Österreich Gestern, heute und in der Zukunft" an der österreichischen Botschaft in Ankara sowie ein weiteres in Wien an der Diplomatischen Akademie. Um das Unterzeichnungsdatum im Mai herum kam es außerdem zu einer dichten Medienberichterstattung. ${ }^{2}$ Die Stadt Wien lud 1.000 ehemalige türkische und jugoslawische „GastarbeiterInnen“ unter dem Motto „Gerufen und gekommen“ zu einem Festakt ins Rathaus,

Der Text basiert auf Dirk Rupnow, Geschichte, Gedächtnis, Migration. Über einige Herausforderungen für die österreichische Zeitgeschichte, in: Lucile Dreidemy/Richard Hufschmied/Agnes Meisinger/Berthold Molden/Eugen Pfister/Katharina Prager/Elisabeth Röhrlich/Florian Wenninger/Maria Wirth (Hg.), Bananen, Cola, Zeitgeschichte. Oliver Rathkolb und das lange 20. Jahrhundert, Wien/Köln/Weimar 2015, 903-913, wurde aber für den vorliegenden Band grundlegend überarbeitet, aktualisiert und erweitert.

1 Vgl. 50 Jahre Gastarbeiter in Österreich. Von Anwerbeabkommen und Integration, orf.at, URL: http://www.orf.at/stories/2090725/2090744 (abgerufen 02.09.2014).

2 Vgl. etwa die zahlreichen Beiträge in: Die Presse, 11.05.2014 sowie in: Der Standard, 15.05.2014. 
wo ihnen Bundespräsident Heinz Fischer, Bürgermeister Michael Häupl und Integrationsstadträtin Sandra Frauenberger Anerkennung und Dank aussprachen. Ein österreichweiter symbolischer Akt blieb jedoch signifikanterweise aus. ${ }^{3}$ Hinzu kam allerdings eine ganze Reihe von lokalen Projekten, hauptsächlich Ausstellungen (etwa in St. Pölten, Salzburg, Hall i. T., Telfs sowie zwei Wanderausstellungen), aber auch Performances und sonstige Veranstaltungen, die aus sehr unterschiedlichen Kontexten hervorgingen (von Universitäten und Forschungseinrichtungen über NGOs und Vereinen bis hin zu Lokalmuseen), aber allesamt nicht an große Kulturinstitutionen angebunden waren. ${ }^{4}$

Im Jubiläumsjahr 2016, zum fünfzigsten Jahrestag der Unterzeichnung des Anwerbeabkommens mit Jugoslawien, wurden von offizieller politischer Seite keine Veranstaltungen, Festakte oder Projekte an die Öffentlichkeit getragen. In Wien erinnerte eine Tagung des Innsbrucker Instituts für Zeitgeschichte in Kooperation mit der Initiative Minderheiten, dem Arbeitskreis Archiv der Migration und der ÖBB, flankiert von einer Ausstellung über die jugoslawische Vereinsszene in Österreich in den 1980er-Jahren und Videointerventionen am Haupt- und Westbahnhof, an das Inkrafttreten des Anwerbeabkommens 1966. Das Bundesministerium für Europa, Integration und Äußeres und der Österreichische Integrationsfonds unterstützten währenddessen eine Kunstausstellung zum Thema „Gastarbeit in Österreich“ im Museumsquartier in Wien („Ajnhajtclub“), die von dem in Belgrad geborenen und in Amsterdam arbeitenden Künstler und Kurator Bogomir Doringer konzipiert

3 Als Auftragsforschung im Rahmen der Wiener Tagung des BMEIA vgl. Sylvia Hahn/Georg Stöger, 50 Jahre österreichisch-türkisches Anwerbeabkommen, Salzburg 2014.

4 Stadtmuseum St. Pölten/Zentrum für Migrationsforschung am Institut für die Geschichte des ländlichen Raumes und NÖ Landesarchiv/Bernhard Gamsjäger/Österreichisch-Türkischer Freundschaftsverein/Betriebsseelsorge Traisental: „Angeworben! Hiergeblieben! 50 Jahre ,Gastarbeit in der Region St. Pölten“; Stadtarchiv Salzburg/Universität Salzburg: „Kommen - Gehen - Bleiben. Migrationsstadt Salzburg 1960-1990"; Institut für Zeitgeschichte der Universität Innsbruck/Stadtmuseum und -archiv Hall i. T.: „Hall in Bewegung. Spuren der Migration in Tirol“; Integrationsbeauftragte der Marktgemeinde Telfs/Migrationsarchiv Telfs: „Alte Neue TelferInnen“; Verein Jukus zur Förderung von Jugend, Kultur und Sport: „Avusturya! Österreich - 50 Jahre türkische Gastarbeit in Österreich“; migrare/Volkshilfe/Universität Linz: „Gekommen und geblieben. 50 Jahre Arbeitsmigration“; Wiener Institut für internationalen Dialog/Wienwoche: „Gaygusuz gegen Österreich oder von der Nützlichkeit der ,Gast'-arbeiter_innen." Eine weitere wissenschaftliche Konferenz wurde von Christiane Hintermann und vom Autor, gemeinsam mit dem Karl-RennerInstitut, der Grünen Bildungswerkstatt und der Initiative Minderheiten veranstaltet: „Orte, Räume und das Gedächtnis der Migration“. Vgl. auch Dirk Rupnow/Verena Sauermann/Veronika Settele, „Hall in Bewegung“. Ein kleinstädtisches Ausstellungsprojekt im österreichischen Jubiläumsjahr 2014, in: Christoph A. Rass (Hg.), Die Szenographie der Migration in stadt- und regionalgeschichtlicher Ausstellungspraxis (IMIS-Beiträge 51), Osnabrück 2017, 81-101. 
wurde. Der Grazer Verein Jukus trat erneut mit einer Ausstellung hervor, die zunächst im Wiener Volkskundemuseum präsentiert wurde („Unter fremdem Himmel. Aus dem Leben jugoslawischer GastarbeiterInnen“). Die Fragmentierung der Community seit dem Zerfall Jugoslawiens und den Kriegen in den 1990er-Jahren scheint den Umgang mit dem Jubiläum in jedem Fall beeinflusst zu haben.

Dazwischen wurde im Sommer 2015 allein durch den Begriff der „Flüchtlingskrise“ deutlich, wie verzerrt und auf die Gegenwart beschränkt die Wahrnehmung in Österreich und in weiten Teilen Europas ist, wenn es um Migration geht: Das soll freilich nicht heißen, dass es keine Probleme und keine Herausforderungen gegeben hätte bzw. gäbe, aber sie wurden in Europa erst als „Krise“ wahrgenommen, als eine große Zahl von Flüchtlingen in der EU angekommen bzw. in der EU gestorben ist (wie Ende August 2015, als 71 Flüchtlinge, darunter 4 Kinder, erstickt in einem Lastwagen auf der österreichischen Autobahn nahe der ungarischen Grenze gefunden wurden), aber nicht, solange die Mehrzahl im Mittelmeer ums Leben kam bzw. die Türkei mehr als drei Millionen syrische Flüchtlinge aufgenommen hatte.

Was blieb im bezugsreichen und geradezu übervollen „Gedenk- und Erinnerungsjahr“ 2018 von all dem übrig?5 Migration war das eigentliche Jahresthema (und, damit verbunden, die Angst vor Diversität), das von ÖVP und FPÖ schon ausgiebig für den Wahlkampf im Jahr 2017 benutzt worden war. Über das gesamte Jahr verteilt kam es praktisch im Wochenrhythmus zu rechtsextremen und rassistischen Aussagen und Aktionen von Politikern: Im FPÖ-nahen, rechtsradikalen Magazin „Aula“ wurde der österreichische Teilnehmer beim Eurovision Song Contest als „Quotenmohr“ bezeichnet, die FPÖ Vöcklamarkt forderte in einem Posting „Schütze Deine Rasse, es ist das Blut Deiner Ahnen!“, ein Amstettner FPÖ-Stadtrat bezeichnete die Protagonisten einer ÖBB-Werbung als „Schwuchteln und Neger“, Hakenkreuze wurden gepostet, rassistische Karikaturen geteilt usw. Der FPÖ-Innenminister, der in der Vergangenheit für zahlreiche rassistische Wahlkämpfe der Partei verantwortlich gewesen war, forderte, Asylbewerber „konzentriert“ an einem Ort zu halten. Der FPÖ-Klubchef behauptete, es gebe „stichhaltige Gerüchte“, dass der US-amerikanische Philanthrop George Soros „Migrantenströme nach Europa unterstützte“.6 Die diversen Jahrestage (Republikgründung 1918, „Anschluss“ und Novemberpogrom 1938, Allgemeine Erklärung der Menschenrechte 1948, Ratifi-

52018 - 100 Jahre Republik, Republik Österreich, URL: http://www.oesterreich1oo.at (abgerufen 14.02.2019). Ausführlich zum Gedenk- und Erinnerungsjahr 2018 vgl. Dirk Rupnow, Das Gedenkund Erinnerungsjahr 2018 - Eine Rückschau, in: zeitgeschichte 46 (2019) 4, 463-477.

6 Vgl. Das war doch nur ein Einzelfall, Der Standard, 07./08./09.12.2018, URL: https://www.derstandard.at/story/2000072943520/nur-einzelfaelle-die-lange-liste-rechter-ausrutscher (abgerufen 14.09.2020). 
kation der Europäischen Menschenrechtskonvention durch Österreich 1958, 1968) hätten praktisch alle ins Feld geführt werden können, um die grundlegende Bedeutung von Menschenrechten und Asyl und vielleicht auch eine diesbezügliche historische Verantwortlichkeit zu unterstreichen, stattdessen wurde die diskursive Illegalisierung und Kriminalisierung jeglicher Form von Migration und aller MigrantInnen konsequent fortgesetzt. Inhaltlich blieb es währenddessen an den Jahrestagen sehr intern-österreichisch, daran konnte auch das Team des am 10. November 2018 in der Neuen Hofburg am Heldenplatz eröffneten Hauses der Geschichte Österreich nichts ändern, obwohl es in seiner Eröffnungsausstellung „Aufbruch ins Ungewisse.

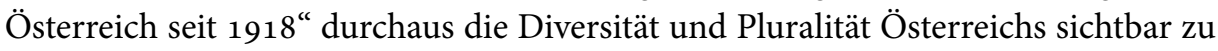
machen versuchte.

Die offiziellen Gedenkreden der Repräsentanten des Staates hielten mit ihren wiederholten Beschwörungen von Demokratie und Gemeinsamkeit wenig Überraschendes und praktisch keine Höhepunkte bereit. Sie werden nur interessant, wenn man sie vor dem Hintergrund der realpolitischen Verhältnisse und der unterschiedlichen politischen Positionen liest, in Verbindung setzt mit ansonsten populistischen, antisemitischen oder rassistischen Aussagen, einer strikten Antimigrationspolitik und beständigen Stimmungsmache gegen Muslime sowie dem gleichzeitigen Angriff auf sozialstaatliche Einrichtungen und Errungenschaften. Die zu den verschiedenen Anlässen geladenen GastrednerInnen, signifikanterweise in den meisten Fällen KünstlerInnen, scherten allerdings regelmäßig aus der staatstragenden Gedenkroutine aus. Die wichtigste Rede des Jahres wurde wohl vom Schriftsteller Michael Köhlmeier gehalten, beim Gedenktag gegen Gewalt und Rassismus am 4. Mai auf Einladung des Nationalratspräsidenten. Sie dauerte zwar nicht einmal sieben Minuten, in ihr entlarvte er aber treffsicher den heuchlerischen Philosemitismus vor allem der FPÖ ebenso wie die Betroffenheitsroutine des Holocaustgedenkens vor dem Hintergrund einer menschenfeindlichen Antimigrationspolitik und rassistischen antimuslimischen Stimmungsmache. ${ }^{7}$ Der Schriftsteller Daniel Kehlmann positionierte sich bei der Eröffnung des Brucknerfests in Linz im September ähnlich, vor allem im Hinblick auf die restriktive Flüchtlingspolitik der Bundesregierung. Er erinnerte daran, dass vor achtzig Jahren auch aus Österreich hilfesuchend Flüchtlinge aufgebrochen seien, die heute erinnert und betrauert würden, während gleich-

7 Michael Köhlmeier, Rede beim Gedenktag gegen Gewalt und Rassismus im Gedenken an die Opfer des Nationalsozialismus, erinnern.at, URL: http://www.erinnern.at/bundeslaender/oesterreich/gedenktage/5.-mai-gedenktag-gegen-gewalt-und-rassismus-im-gedenken-an-die-opfer-desnationalsozialismus/michael-koehlmeiers-gedenkrede-die-dinge-beim-name-nennen/Rede\%20 Michael\%20Koehlmeier.pdf (abgerufen 14.02.2019). 
zeitig eine Abschottungspolitik betrieben werde. ${ }^{8}$ Der Universalkünstler André Heller beschrieb bei der Gedenkfeier zum „Anschluss“ am 12. März das Schicksal seines Vaters, sprach über österreichische NS-Täter, die Befreiung, den Widerstand und schlug von dort einen Bogen zum Engagement gegen Rassismus und Fremdenhass heute - auch indem er daran erinnerte, dass nicht Auschwitz und der Holocaust am Beginn der NS-Herrschaft gestanden hätten, sondern die Ausgrenzung von als „störend“ und „schädlich“ empfundenen Menschen. Nach Bemerkungen zum politischen Populismus, zum gegenwärtigen Fluchtgeschehen und zu globaler Gerechtigkeit plädierte er am Ende für die Anerkennung von Diversität und Mitgefühl. ${ }^{9}$ Beim Staatsakt zur Republikgründung in der Staatsoper begrüßte die Schriftstellerin und Kärntner Slowenin Maja Haderlap zu Beginn ihrer Festrede auf Deutsch und in ihrer Muttersprache Slowenisch. Nach einem Durchgang durch die vergangenen hundert Jahre sprach sie über die Gefahren einer zunehmenden Ökonomisierung des Lebens und das integrative Potenzial der Demokratie - zur Einbindung und auch zum Schutz von Minderheiten:

Demokratie ist nicht zuletzt auch die einzige Herrschaftsform, die den Anderen und die Minderheiten mit einbezieht, und wäre als einzige Ordnung imstande, Menschen, die aus anderen Ländern und Traditionen, aus unterschiedlichen Motiven zu uns kommen, einzubinden und zwar als Mitverantwortliche für das Gemeinwesen und die Werte der Demokratie. $^{10}$

1.

Nun wäre es tatsächlich falsch, den „Gastarbeiter“-Anwerbeabkommen zu viel Bedeutung zuzumessen und sie als Beginn der (Arbeits)Migration nach Österreich darzustellen. Sie sollten nur regulieren, was längst begonnen hatte. Dennoch erinnern sie daran, dass Österreich in der zweiten Hälfte des 20. Jahrhunderts zu einem

8 Daniel Kehlmann, Im Steinbruch. Festrede zur feierlichen Eröffnung des Internationalen Brucknerfestes Linz 2018, OÖ Nachrichten, 09.09.2018, URL: https:/www.nachrichten.at/nachrichten/ kultur/Daniel-Kehlmann-Im-Steinbruch;art16,3001741 (abgerufen 14.02.2019).

9 André Heller, Gedenkrede zum 80. Jahrestag des 12. März 1938, bundespraesident.at, URL: http:// www.bundespraesident.at/fileadmin/user_upload/Gedenkrede_Andre_Heller.pdf (abgerufen 14.02. 2019).

10 Maja Haderlap, Festrede. Im langen Atem der Geschichte, bundespraesident.at, URL: https://www. bundespraesident.at/fileadmin/user_upload/Festrede_von_Maja_Haderlap_-_Staatsakt_100_ Jahre_Republik_OEsterreich.pdf (abgerufen 14.02.2019). 
Einwanderungsland wurde - und es im österreichischen Interesse lag, ausländische Arbeitskräfte ins Land zu holen, die wesentlich dazu beitrugen, Wohlstand zu schaffen und abzusichern. ${ }^{11}$ Freilich scheiterten das staatliche Regelwerk und die involvierten Institutionen auch immer wieder dabei, Migration vollständig kontrollieren und steuern zu können. ${ }^{12}$ Die schnelle Abfolge von Jubiläen der Anwerbeabkommen rückte aber nicht nur die Geschichte der „Gastarbeitermigration“ ins Licht, sondern vor allem die gegenwärtige Pluralität der österreichischen Gesellschaft, die unleugbar Realität und Alltag ist. In der politischen Arena ist dies immer noch nicht allseits anerkannt und unumstritten, vielfach wird immer noch eine - freilich nie da gewesene - homogene Nation imaginiert oder sogar gewalthaft zu realisieren gefordert.

Mehrfach ist festgestellt worden, dass die Geschichte der Arbeitsmigration nicht im kollektiven Gedächtnis der ÖsterreicherInnen angekommen sei. ${ }^{13}$ Die Leerstelle ist offensichtlich. Der lange Zeit verwendete, übrigens (entgegen landläufiger Annahmen) aus der NS-Zeit (und nicht aus der Nachkriegszeit, in Abgrenzung zur NS-Terminologie) herrührende Begriff des „Gastarbeiters“, der das Land wieder zu verlassen habe, sobald seine Arbeitskraft nicht mehr benötigt werde, ist Ausdruck dieser Tatsache wie auch Mitursache für die gegenwärtige Situation. ${ }^{14}$

11 Darauf haben auf Seiten der Historiker schon früh in ihrem wichtigen Sammelband hingewiesen: Gernot Heiss/Oliver Rathkolb, Vorwort der Herausgeber, in: Gernot Heiss/Oliver Rathkolb (Hg.), Asylland wider Willen. Flüchtlinge in Österreich im europäischen Kontext seit 1914 (Veröffentlichungen des Ludwig Boltzmann-Institutes für Geschichte und Gesellschaft 25), Wien 1995, 7-17, 13. Vgl. in diesem Zusammenhang auch Andreas Weigl, Migration und Integration. Eine widersprüchliche Geschichte (Österreich - Zweite Republik: Befund, Kritik, Perspektive 20), Innsbruck/Wien/Bozen 2009, 14-15; Heinz Fassmann/Rainer Münz, Einwanderungsland Österreich? Historische Migrationsmuster, aktuelle Trends und politische Maßnahmen, Wien 1995. Zu den Anwerbeabkommen allgemein vgl. Christoph Rass, Institutionalisierungsprozesse auf einem internationalen Arbeitsmarkt: Bilaterale Wanderungsverträge in Europa zwischen 1919 und 1974 (Studien zur historischen Migrationsforschung 19), Paderborn/München/Wien/Zürich 2010, 121-128, 380-383 (zu Österreich).

12 Vgl. in diesem Zusammenhang das Konzept der „Autonomie der Migration“, das sich in der sogenannten Kritischen Migrationsforschung etabliert hat: Manuela Bojadžijev/Serhat Karakayal,, Autonomie der Migration. 10 Thesen zu einer Methode, in: Transit Migration Forschungsgruppe (Hg.), Turbulente Ränder. Neue Perspektiven auf Migration an den Grenzen Europas, Bielefeld 2007, 203-209.

13 Christiane Hintermann, Gedächtnislücke Migration? Betrachtungen über eine nationale Amnesie, in: zeitgeschichte 40 (2013) 3, 149-165; Dirk Rupnow, Deprovincializing Contemporary Austrian History. Plädoyer für eine transnationale Geschichte Österreichs als Migrationsgesellschaft, in: zeitgeschichte 40 (2013) 1, 5-21; Christiane Hintermann/Dirk Rupnow, Orte, Räume und das Gedächtnis der Migration. Erinnern in der (post)migrantischen Gesellschaft, in: Mitteilungen der Österreichischen Geographischen Gesellschaft 158 (2016), 59-83.

14 Thomas Schiller, NS-Propaganda für den Arbeitseinsatz, Hamburg 1997, 6. 
Tatsächlich hat sich auch die institutionalisierte österreichische Zeitgeschichte lange Zeit kaum des Themas angenommen. ${ }^{15}$ Unter den ZeithistorikerInnen schenkte ihm einzig Oliver Rathkolb breite Aufmerksamkeit, so etwa in seiner Geschichte der „paradoxen“ Zweiten Republik. ${ }^{16}$ Folgerichtig etablierte Rathkolb am 2005 von ihm gegründeten und aufgebauten, 2013 leider geschlossenen Ludwig Boltzmann Institut für europäische Geschichte und Öffentlichkeit einen Arbeitsbereich zu Migration und Gedächtnis, der von der Geographin und Migrationsforscherin Christiane Hintermann betreut wurde. ${ }^{17}$

Die Vernachlässigung der Geschichte Österreichs als Migrationsgesellschaft erklärt sich wohl zu einem großen Teil aus der generellen Scheu der österreichischen Zeitgeschichte, vor allem Wiener Prägung, vor der Geschichte der Zweiten Republik seit den 1960er-Jahren. ${ }^{18}$ Thomas Angerer, Mitarbeiter am Institut für Geschichte der Universität Wien, hatte bereits Mitte der 1990er-Jahre im Zuge seiner Kritik an der zeitlichen und thematischen Beschränktheit der österreichischen Zeitgeschichtsforschung und mit Blick auf die seinerzeitigen Debatten über Einwanderung, vor allem über das sogenannte Antiausländervolksbegehren „Österreich zuerst“ der Haider-FPÖ 1992/1993, das in der Verfassung festzuschreiben forderte, dass Österreich kein Einwanderungsland sei, schon auf das „historiographic vacuum“ hingewiesen:

15 Vgl. etwa die kurzen Erwähnungen in Karl Vocelka, Geschichte Österreichs. Kultur - Gesellschaft - Politik, München 2004, 345-347 sowie Peter Berger, Kurze Geschichte Österreichs im 20. Jahrhundert, Wien 2008, 294, 347. Ernst Hanisch, Der lange Schatten des Staates. Österreichische Gesellschaftsgeschichte im 20. Jahrhundert (Österreichische Geschichte 1890-1990), Wien 1994, 448, kommt ausschließlich auf Flüchtlingsmigration am Beispiel Ungarns zu sprechen.

16 Oliver Rathkolb, Die paradoxe Republik. Österreich 1945 und 2005, Wien 2005, 40-41, 44, 49-52, 207, 415-416.

17 Vgl. die daraus hervorgegangenen Sammelbände: Stefanie Mayer/Mikael Spang (Hg.), Debating Migration. Political Discourses on Labor Immigration in Historical Perspective (Studies in European History and Public Spheres 1), Innsbruck/Wien/Bozen 2009; Christiane Hintermann/Christina Johansson (Hg.), Migration and Memory. Representations of Migration in Europe since 1960 (Studies in European History and Public Spheres 3), Innsbruck/Wien/Bozen 2010.

18 Ernst Hanisch, Die Dominanz des Staates. Österreichische Zeitgeschichte im Drehkreuz von Politik und Wissenschaft, in: Alexander Nützenadel/Wolfgang Schieder (Hg.), Zeitgeschichte als Problem. Nationale Traditionen und Perspektiven der Forschung in Europa (Geschichte und Gesellschaft, Sonderheft 20), Göttingen 2004, 54-77, 70. Gleichzeitig wird eine Öffnung der Zeitgeschichte nach hinten, zum langen 19. Jahrhundert, betrieben, um vor diesem Hintergrund die Konflikte des kurzen 20. Jahrhunderts zu analysieren. Vgl. Zeitgeschichte im Krebsgang ins 19. Jahrhundert zurückschreiben. Am Beispiel der Demokratie-Diktatur-Debatte: die universitaet-online, 28.01.2009, sowie Universität Wien, Online Portal, URL: http://stream.univie.ac.at/media/geschichte/2008WS/ vranitzky/070113_090113?res=320 (abgerufen 03.09.2014). 
das Fehlen einer „recent history of Austrian immigration - from the call for foreign man power in the 1960 s to the actual quasi-closing of the borders". ${ }^{19}$

Der öffentliche Diskurs wird angesichts dieses „historiographischen Vakuums“ neben Polemiken und Rassismen - weiterhin bestimmt von sozialwissenschaftlichen Analysen, weitaus weniger aber von historischem Wissen und Geschichte(n). Die vornehmlich quantitativen und normative Aspekte fokussierenden Arbeiten, die häufig auch von einer politikberatenden Absicht getragen sind, sind nicht selten voll von problematischen Kategorisierungen und Zuschreibungen sowie letztlich Verkürzungen der Realität. ${ }^{20}$

Allerdings deutet sich in den vergangenen Jahren ein verstärkter Trend zur Historisierung der („Gastarbeiter“-)Migration in einem breiteren Kontext an. ${ }^{21}$ Medienberichte weisen ebenso in diese Richtung wie die bereits genannten Ausstellungsaktivitäten und Veranstaltungen angesichts der vergangenen Jahrestage, die häufig einen historischen Zugang in den Mittelpunkt gestellt haben. Befördert wird dies durch die sehr dynamische internationale Forschung.

19 Thomas Angerer, An Imcomplete Discipline. Austrian Zeitgeschichte and Recent History, in: Günter Bischof/Anton Pelinka/Rolf Steininger (Hg.), Austria in the Nineteen Fifties (Contemporary Austrian Studies 3), New Brunswick/London 1995, 207-251, 227. Dazu auch Thomas Angerer, „Gegenwartsgeschichte"? Für eine Zeitgeschichte ohne Ausflüchte, in: Gertraud Diendorfer/Gerhard Jagschitz/Oliver Rathkolb (Hg.), Zeitgeschichte im Wandel. 3. österreichische Zeitgeschichtetage 1997, Innsbruck/Wien 1998, 46-53.

20 Der Wiener Sozialhistoriker Josef Ehmer konstatierte kürzlich eine Fokussierung der etablierten Zeitgeschichte auf die NS-Zeit und ihre Folgen sowie gleichzeitig eine Vernachlässigung anderer, rezenterer Themen und Aspekte, die den Sozialwissenschaften überlassen blieben: Josef Ehmer, Sozialwissenschaftler/innen oder Zeithistoriker/innen. Wer schreibt die Geschichte des 20. Jahrhunderts?, in: Heinrich Berger/Melanie Dejnega/Regina Fritz/Alexander Prenninger (Hg.), Politische Gewalt und Machtausübung im 20. Jahrhundert. Zeitgeschichte, Zeitgeschehen und Kontroversen. Festschrift für Gerhard Botz, Wien/Köln/Weimar 2011, 59-71, 64. Vgl. in diesem Zusammenhang auch Lena Karasz (Hg.), Migration und die Macht der Forschung. Kritische Wissenschaft in der Migrationsgesellschaft, Wien 2017.

21 Vgl. Günter Bischof/Dirk Rupnow (Hg.), Migration in Austria (Contemporary Austrian Studies 26), New Orleans/Innsbruck 2017; Senol Grasl-Akkilic/Marcus Schober/Regina Wonisch (Hg.), Aspekte der österreichischen Migrationsgeschichte, Wien 2019; Stefan Karner/Barbara Stelzl-Marx (Hg.), Migration. Flucht - Vertreibung - Integration (Veröffentlichungen des Ludwig BoltzmannInstituts für Kriegsfolgenforschung, Sonderband 21), Graz 2019; Lisa Grösel, Fremde von Staats wegen: 50 Jahre „Fremdenpolitik“ in Österreich, Wien 2016; Verena Lorber, Angeworben. GastarbeiterInnen in Österreich in den 1960er und 1970er Jahren (Transkulturelle Perspektiven 14), Göttingen 2017. 
2.

Das Forschungsfeld wurde in Österreich in den frühen 1970er-Jahren begründet, in einer Phase entscheidender Umbrüche, in vielen gesellschaftlichen Bereichen auch für das „Gastarbeiter“-Regime und damit für Migration und Diversität in Österreich. ${ }^{22}$ Nach den Anwerbeabkommen mit der Türkei und Jugoslawien zogen zunächst jährlich zwischen 10.000 und 20.000 Personen nach Österreich, Anfang der 1970er-Jahre waren es sogar jährlich 25.00o bis 40.00o. Auf dem Höhepunkt arbeiteten 1973 über eine Viertelmillion ausländische Arbeitskräfte im Land, die 10 Prozent der Beschäftigten ausmachten. Etwa 8o Prozent von ihnen stammten aus Jugoslawien, etwa 12 Prozent aus der Türkei. Den Bedarf hatte eine rasant wachsende Wirtschaft erzeugt, die im Inland ihren Arbeitskräftebedarf nicht mehr ausreichend befriedigen konnte. Die Gewerkschaften, die der Öffnung des österreichischen Arbeitsmarkts ablehnend gegenüberstanden, sich aber den Forderungen der Wirtschaft nicht ganz entziehen konnten, sorgten dafür, dass durch die Zulassung von Kontingenten für ausländische Arbeitnehmer ein in Teilen zwar liberalisiertes, insgesamt aber mit Inländerprimat und Rotationsprinzip für die betroffenen ausländischen Arbeitnehmer äußerst restriktives Regime für "Gastarbeit“ installiert wurde. ${ }^{23}$

Ende der 1960er- bzw. Anfang der 1970er-Jahre verstärkten sich die Debatten über die Beschäftigung von Ausländern und ihre gesellschaftlichen Folgen. Die Ölkrise und das verlangsamte Wirtschaftswachstum wurden im März 1974 für eine Einschränkung der Touristenbeschäftigung und ein Einfrieren der Gastarbeiterbeschäftigung auf dem Stand von Oktober 1973 genutzt, parallel zum Anwerbestopp in der Bundesrepublik Deutschland, der bereits im November 1973 verfügt worden war. Während in Österreich einem Viertel der ausländischen Arbeitskräfte die Aufenthalts- und Arbeitsbewilligungen entzogen wurde, kam es jedoch gleichzeitig - als unbeabsichtigte Nebeneffekte - vielfach zur Verstetigung des Aufenthalts und zu verstärktem Familiennachzug. In diese Zeit ihres Höchststandes und ihrer Drosselung fiel auch das Aufkommen einer intensiven sozialwissenschaftlichen

22 Vgl. dazu ausführlich Dirk Rupnow, Ausländerforschung. Frühe Studien zu den „Gastarbeitern“ in den 1970er Jahren, in: Johannes Feichtinger/Marianne Klemun/Jan Surman/Petra Svatek (Hg.), Wandlungen und Brüche. Wissenschaftsgeschichte als politische Geschichte (Festschrift für Mitchell Ash), Göttingen 2018, 363-370.

23 Helga Matuschek, Ausländerpolitik in Österreich 1962-1985. Der Kampf um und gegen die ausländische Arbeitskraft, in: Journal für Sozialforschung 25 (1985) 2, 159-198; Eveline Wollner, Die Reform der Beschäftigung ausländischer Arbeitskräfte Anfang der 196oer Jahre in Österreich, in: zeitgeschichte 34 (2007) 4, 213-225. 
Forschungstätigkeit zu den gesellschaftlichen Folgen der Ausländerbeschäftigung. Czarina Wilpert hat (am Beispiel der Bundesrepublik Deutschland) schon früh die zweite Hälfte der 1970er-Jahre - nach einer ersten Phase der Anwerbung bis 1973 als Phase der Infrastrukturdebatten und der auf soziale Probleme orientierten Forschung bezeichnet. ${ }^{24}$ Sie kann auch als „Entdeckung der Einwanderung" verstanden werden. ${ }^{25}$

Die Sozialpartner als die maßgeblichen Akteure auf dem Feld der Ausländerbeschäftigung in Österreich (Wirtschaftskammer, Arbeiterkammer, Industriellenvereinigung, Gewerkschaftsbund) gründeten 1971 den Arbeitskreis für ökonomische und soziologische Studien, um "rechtzeitig fundiertes Wissen über die auftauchenden wesentlichen Schwierigkeiten bei der Ausländer-Beschäftigung zu gewinnen und entsprechende Maßnahmen vorzuschlagen “.26 Durchgeführt wurden zunächst vier Studien: über die Einstellung der österreichischen Bevölkerung zu den Gastarbeitern, über Erfahrungen und Meinungen der Österreicher in Wohngebieten mit hohem Gastarbeiteranteil, über Probleme und Erfahrungen von österreichischen Industriebetrieben mit Gastarbeiterbeschäftigung und über den Prozess der Eingliederung von Gastarbeitern in Österreich. Die wesentlichen Ergebnisse daraus wurden 1973 zusammenfassend publiziert.

1977 veröffentlichte der damalige Leiter der österreichischen Anwerbestelle in Istanbul, Siegfried Pflegerl, eine Studie, in der er die „Vielzahl der relevanten Faktoren, die für den Gastarbeiter eine einheitliche soziale Realität darstellt", zusammenzufassen und vor allem auch bereits "die Rolle der Bevölkerung des Gastlandes und ihr Einfluß auf die Integration" in den Blick zu nehmen versuchte. ${ }^{27}$ Es folgten in den frühen 1980er-Jahren eine im Auftrag des Bundesministeriums für Soziale Verwaltung und des Bundesministeriums für Wissenschaft und Forschung vom Institut für Höhere Studien in Wien durchgeführte Untersuchung über „Ausländische Arbeitskräfte in Österreich“ (1983) sowie die umfangreiche Monographie „Gastarbeiter. Leben in zwei Gesellschaften“ (1984) von der Wiener Geographin

24 Czarina Wilpert, International Migration and Ethnic Minorities. New Fields for Post-War Sociology in the Federal Republic of Germany, in: Current Sociology 32 (1984) 3, 305-352, 306.

25 Marcel Berlinghoff, Das Ende der „Gastarbeit“. Europäische Anwerbestopps 1970-1974 (Studien zur Historischen Migrationsforschung 27), Paderborn/München/Wien/Zürich 2013.

26 Arbeitskreis für ökonomische und soziologische Studien Wien (Hg.), Gastarbeiter. Wirtschaftliche und soziale Herausforderung, Wien 1973, 8.

27 Siegfried Pflegerl, Gastarbeiter. Zwischen Integration und Abstoßung, Wien/München 1977, 7. Pflegerl leitete von 1965 bis zur Schließung im Jahre 1993 die Österreichische Kommission für die Anwerbung türkischer Arbeitskräfte in Istanbul. 
Elisabeth Lichtenberger. ${ }^{28}$ Lichtenberger hatte 1974, nach ihrer Rückkehr von einer zweijährigen Gastprofessur in Nordamerika, in Wien eine Erhebung über jugoslawische Gastarbeiter durchgeführt - um zu überprüfen, ob die Stadtentwicklungen in Nordamerika und Europa im Hinblick auf ethnische, ökonomische und demographische Segregationsvorgänge vergleichbar waren. ${ }^{29} 1981$ erfolgte ein erneutes Forschungsprojekt mit einem modifizierten theoretischen Konzept. Mit ihrem Titel wies Lichtenberger - im Hinblick auf die spezifische Unsicherheit aufgrund der Arbeitsmarktpolitik der Aufnahmeländer - bereits auf eine besondere transnationale Verfasstheit migrantischer Lebensräume hin, die durch das einfache Schema Auswanderung - Einwanderung verfehlt werde und vielmehr Herkunfts- und Aufnahmeraum miteinander verbinde. ${ }^{30}$

Die Studie des Instituts für Höhere Studien IHS in Wien setzte sich aus einem sozial- und einem wirtschaftswissenschaftlichen Teil zusammen. Während der ökonomische Teil (unter der Leitung von Gudrun Biffl) betriebs- und volkswirtschaftliche Aspekte der Ausländerbeschäftigung (Auswirkungen auf den Arbeitsmarkt, Arbeitslosigkeit ausländischer Arbeitskräfte und Einfluss auf die Entwicklung der Gesamtarbeitslosigkeit, Einkommensverteilung) einschließlich der Frage nach Möglichkeiten und Grenzen der Substituierbarkeit fokussierte, beschäftigte sich der sozialwissenschaftliche Teil (unter der Leitung von Hannes Wimmer) mit der sozialen Lage jugoslawischer und türkischer StaatsbürgerInnen in Österreich (soziale Struktur, Arbeitswelt, Wohnverhältnisse, zweite Generation, türkische Frauen, rechtliche Stellung, Freizeit, Motive, Selbstbeurteilung). ${ }^{31}$ Gearbeitet wurde mit einer Repräsentativbefragung von neunhundert zufällig ausgewählten Gastarbeiterhaushalten. Der damalige SPÖ-Sozialminister Alfred Dallinger verband mit dem von seinem Haus vergebenen Forschungsauftrag die Hoffnung, dass dessen Ergebnis „die öffentliche Diskussion zum Thema ,Ausländer in Österreich ' positiv beeinflußt“. In seinem Vorwort zur Veröffentlichung konstatiert Dallinger, dass die Mehrheit der „Gastarbeiter“ nicht die Absicht habe, ständig in Österreich zu bleiben, betonte aber gleichzeitig:

28 Elisabeth Lichtenberger, Gastarbeiter. Leben in zwei Gesellschaften, Wien/Köln/Graz 1984; Bundesministerium für Soziale Verwaltung (Hg.), Ausländische Arbeitnehmer in Österreich (Forschungsberichte aus Sozial- und Arbeitsmarktpolitik 9), Wien [1985]; Hannes Wimmer (Hg.), Ausländische Arbeitskräfte in Österreich, Frankfurt a. M./New York 1986.

29 Vgl. die daraus entwickelte Arbeit von Helga Leitner, Gastarbeiter in der städtischen Gesellschaft. Segregation, Integration und Assimilation von Arbeitsmigranten am Beispiel jugoslawischer Gastarbeiter in Wien, Frankfurt a. M. 1983.

30 Vgl. Lichtenberger, Gastarbeiter, 24, 30.

31 Wimmer (Hg.), Ausländische Arbeitskräfte, 1-4. 
Die ausländischen Arbeitnehmer in Österreich sind längst ein integraler Bestandteil unserer Gesellschaft geworden. [...] Die in Österreich lebenden ausländischen Arbeitskräfte und ihre Familien haben aus allen diesen Gründen ein Recht, als gleichberechtigte Mitbürger anerkannt zu werden. ${ }^{32}$

Vor allem der Geograph Heinz Fassmann, der bereits an Lichtenbergers Studie mitgearbeitet hatte, und der Demograph Rainer Münz legten im Weiteren wichtige Arbeiten vor, aber auch der Politologe Rainer Bauböck, der bereits an der IHS-Studie beteiligt gewesen war. ${ }^{33} 2003$ wurde schließlich von Heinz Fassmann und Irene Stacher der erste österreichische Migrations- und Integrationsbericht publiziert, der sich sehr breit demographischen und sozioökonomischen Strukturen, Lebenssituationen und -formen und rechtlichen Rahmenbedingungen, aber auch Fremdenfeindlichkeit und Organisationsformen von MigrantInnen widmete. ${ }^{34}$

In Österreich differenziert sich die Forschungslandschaft zum Thema Migration immer mehr, das Thema wird jedoch weiterhin hauptsächlich den SoziologInnen und PolitologInnen, GeographInnen und DemographInnen überlassen. ${ }^{35}$ Dementsprechend stehen sozialwissenschaftliche und quantifizierende Zugänge im Vordergrund. Der Schwerpunkt liegt auf den Migrationsbewegungen und deren legistischen Rahmenbedingungen. Die Absicht des Großteils dieser Forschung ist, Wissen bereitzustellen, das politikberatend und sozialtechnisch eingesetzt werden kann. Ökonomische Aspekte und der/die MigrantIn als Arbeitskraft stehen häufig im Vor-

32 Alfred Dallinger, Vorwort, in: ebd., 5-6.

33 Heinz Fassmann/Rainer Münz (Hg.), European Migration in the Late Twentieth Century. Historical Patterns, Actual Trends, and Social Implications, Aldershot/Brookfield 1994; Fassmann/ Münz, Einwanderungsland Österreich; Rainer Bauböck, „Nach Rasse und Sprache verschieden“. Migrationspolitik in Österreich von der Monarchie bis heute (IHS Reihe Politikwissenschaft 31), Wien 1996. Signifikanterweise unpubliziert blieb die umfangreiche Arbeit von Eugène Richard Sensenig-Dabbous, Reichsfremde, Staatsfremde und Drittausländer. Immigration und Einwanderungspolitik in Österreich (Ludwig Boltzmann-Institut für Gesellschafts- und Kulturgeschichte), Salzburg 1998.

34 Heinz Fassmann/Irene Stacher (Hg.), Österreichischer Migrations- und Integrationsbericht. Demographische Entwicklungen - sozioökonomische Strukturen - rechtliche Rahmenbedingungen, Klagenfurt/Celovec 2003. Der zweite Migrations- und Integrationsbericht erschien 2007.

35 Vgl. etwa aus der neueren Literatur: Stefanie Mayer/Mikael Spang (Hg.), Debating Migration. Political Discourse on Labor Immigration in Historical Perspective (European History and Public Spheres 1), Innsbruck/Wien/Bozen 2009; Ferdinand Karlhofer/Günther Pallaver (Hg.), Politik in Tirol. Jahrbuch 2011, Zuwanderung - Herausforderung für Gesellschaft und Politik, Innsbruck/ Wien/Bozen 2011; Julia Dahlvik/Heinz Fassmann/Wiebke Sievers (Hg.), Migration und Integration - wissenschaftliche Perspektiven aus Österreich. Jahrbuch 1/2011 (Migrations- und Integrationsforschung 2), Wien/Göttingen 2012. 
dergrund. Wie in den medialen Diskursen wird hierbei häufig, wenn auch nur implizit, Migration in Zusammenhang mit „Problemen“ bzw. als „Problem“ zum Thema („Gastarbeiter-“, „Ausländerproblem“). ${ }^{36}$ Individuelle Erfahrungen werden meistens ausgeblendet, alltagsgeschichtliche Fragestellungen setzen sich erst langsam durch. ${ }^{37}$ Demgegenüber stehen Minderheitengeschichten, auch aus aktivistischer Perspektive, die wichtige Grundlagen und Anknüpfungspunkte bieten. ${ }^{38} \mathrm{Oft}$ bleiben sie allerdings sehr kleinteilig, sodass eine Kontextualisierung und Integration in die allgemeine Politik, Sozial- und Kulturgeschichte Herausforderungen darstellen. ${ }^{39}$

Der (sozial)historische Blick richtet sich vornehmlich auf Arbeitsmigration bis in die erste Hälfte des 20. Jahrhunderts hinein, aber nur sehr selten darüber hinaus. ${ }^{40}$ Auf dem ersten österreichischen Zeitgeschichtetag, veranstaltet 1993 in Innsbruck, war das Thema Arbeitsmigration vor allem in Verbindung mit der NS-Zwangsarbeit präsent. Neben den Wiener Zeithistorikern Bertrand Perz und Florian Freund, die sich der Zwangsarbeit im Nationalsozialismus widmeten, beklagte der Geograph Heinz Fassmann in seinem Beitrag das Verdrängen historischer Bezüge - namentlich zur NS-Zwangsarbeit - bei der Etablierung der strukturierten Arbeitsmigration in den 1950er- und 1960er-Jahren sowie das Fehlen einer konsensfähigen Integrationspolitik; der Linzer Sozial- und Wirtschaftshistoriker Michael John beschäftigte sich mit Migration und Multikulturalität in Österreich in der zweiten Hälfte des 19.

36 Vgl. etwa Peter Zuser, Die Konstruktion der Ausländerfrage in Österreich. Eine Analyse des öffentlichen Diskurses 1990 (Institut für Höhere Studien, Wien - Reihe Politikwissenschaft/Political Science Series 35), Wien 1996.

37 Vgl. etwa Peter Payer, „Gehen Sie an die Arbeit“. Zur Geschichte der „Gastarbeiter“ in Wien 19641989, in: Wiener Geschichtsblätter 59 (2004) 1, 1-19.

38 Vgl. etwa die wichtigen Arbeiten von Ljubomir Bratić, Soziopolitische Organisationen der MigrantInnen in Österreich, in: Kurswechsel 2000/1, 6-20; Ljubomir Bratić, Soziopolitische Netzwerke der MigrantInnen aus der ehemaligen Sozialistischen Föderativen Republik Jugoslawien (SFRJ) in Österreich, in: Fassmann/Stacher (Hg.), Österreichischer Migrations- und Integrationsbericht, 395-409.

39 Zum Stand der österreichischen Migrationsforschung vgl. Bernhard Perchninig, Migration Studies in Austria - Research at the Margins? (KMI Working Paper 4), Wien [2002]; Heinz Fassmann, Migrations- und Integrationsforschung in Österreich, Institutionelle Verankerung, Fragestellungen und Finanzierungen (KMI Working Paper 15), Wien [2009]; Sabine Strasser, Migrationsforschung in Österreich, ein [KriMi]? Kommentar zur Kritischen Migrationsforschung, in: Stimme 75/2010, 22-23.

40 Vgl. etwa auch Josef Ehmer, Migrationen in der historischen Forschung - Themen und Perspektiven, in: Heinz Fassmann/Julia Dahlvik (Hg.), Migrations- und Integrationsforschung - interdisziplinäre Perspektiven. Ein Reader (Migrations- und Integrationsforschung 1), Göttingen 2011, 89-101, der Transhumanz, landwirtschaftliche Saisonarbeit und Gesellenwanderung sowie Migrationen des 19. Jahrhunderts anspricht, signifikanterweise in seinem Beitrag zu einem grundlegenden Reader zur Migrationsforschung aber nicht darüber hinausgeht. 
und in der ersten Hälfte des 20. Jahrhundert; und die Salzburger Soziologin Brunhilde Scheuringer skizzierte den Integrationsprozess der volksdeutschen Flüchtlinge und Vertriebenen in Österreich nach $1945 .^{41}$

3.

In einer Pilotstudie zum „Impact of Immigration on Europe’s Societies“ hielt das European Migration Network, das von der EU-Kommission als ein System zum Austausch von Informationen über Asyl und Migration eingerichtet wurde, 2006 fest: „The effect on European societies has received less published attention than topics such as migration flows and settlements or on policies towards immigration populations. “42 Ein originär historischer Zugang, der überhaupt erst einmal die Archive auslotet, ist (trotz der Entwicklungen der letzten Jahre) weiterhin ein Desiderat - und dies gilt nicht nur für Österreich, sondern cum grano salis für die meisten europäischen Einwanderungsländer. ${ }^{43}$

41 Vgl. den Abschnitt „Zwangsarbeit und Arbeitsmigration“, in: Ingrid Böhler/Rolf Steininger (Hg.), Österreichischer Zeitgeschichtetage 1993. 24. bis 27. Mai 1993 in Innsbruck, Innsbruck/Wien 1995, 191-288. Zur NS-Zwangsarbeit in Österreich vgl. in der Folge vor allem Florian Freund/ Bertrand Perz/Mark Spoerer, Zwangsarbeiter und Zwangsarbeiterinnen auf dem Gebiet der Republik Österreich 1938-1945 (Veröffentlichungen der Österreichischen Historikerkommission 26/1), München 2004. Vgl. außerdem: Michael John, Vom nationalen Hort zur postmodernen City. Zur Migrations- und Identitätsgeschichte der Stadt Linz im 20. und 21. Jahrhundert, Linz 2015; Michael John, Bevölkerung in der Stadt. „Einheimische“ und „Fremde“ in Linz (19. und 20. Jahrhundert), Linz 2000.

42 European Migration Network, The Impact of Immigration on Europe's Societies (2006), URL: http://emn.intrasoft-intl.com/Downloads/prepareShowFiles.do?directoryID=16 (abgerufen 22.06. 2012).

43 Grundsätzliche methodische Überlegungen zu Perspektiven historischer Migrationsforschung finden sich bei Michael G. Esch/Patrice G. Poutrus, Zeitgeschichte und Migrationsforschung. Eine Einführung, in: Zeithistorische Forschungen/Studies in Contemporary History 2 (2005) 3, 338344; Michael G. Esch, Historisch-sozialwissenschaftliche Migrationsforschung als Delegitimationswissenschaft, in: Österreichische Zeitschrift für Geschichtswissenschaften 19 (2008) 1, 60-78; Sigrid Wadauer, Historische Migrationsforschung. Überlegungen zu Möglichkeiten und Hindernissen, in: Österreichische Zeitschrift für Geschichtswissenschaften 19 (2008) 1, 6-14. Wichtige Anknüpfungspunkte für einen originär historischen Zugang zu Arbeitsmigration in Österreich bieten die Arbeiten von Wladimir Fischer, Of Crescents and Essence, or: Why Migrants' History Matters to the Question of 'Central European Colonialism', in: Andrew Colin Gow (Hg.), Hyphenated Histories. Articulations of Central European Bildung and Slavic Studies in the Contemporary Academy, Leiden/Boston 2007, 61-101; Wladimir Fischer, „Ich haaß Vocelka - du haaßt Vocelka“. Der Diskurs über ,Gastarbeiter' in den 1960er- bis 1980er-Jahren und der unhistorische Vergleich 
Darüber hinaus sind die Geschichten der Migration und der MigrantInnen in den etablierten Archiven nur unzureichend präsent. Systematisch ist zu dem Thema praktisch nicht gesammelt worden, wichtige Bestände sind verstreut und auch weitgehend unbekannt oder - absichtlich oder nicht - bereits vernichtet worden, historisches Erfahrungswissen und private Überlieferungen drohen durch den generationellen Wandel verlorenzugehen. Für einen neuen historischen Zugang ist es tatsächlich eine wichtige und grundlegende Voraussetzung, dass Geschichten und Erfahrungen der Migration erst einmal im Archiv ankommen, der grundlegendsten Infrastruktur des „kollektiven Gedächtnisses“. Es darf schließlich nicht übersehen werden, dass die staatlichen Archive die Hegemonialstrukturen in der Gesellschaft nur abbilden bzw. sie selbst mit herstellen und absichern: Sie sammeln nicht einfach, sondern sind Machtmaschinen des Staates, die Wissen produzieren und Spuren verwischen. Diese Einsicht, die die amerikanische Anthropologin und Historikerin Laura Ann Stoler im Zuge ihrer Beschäftigung mit den kolonialen Archiven formuliert hat, hat auch hier ihre Gültigkeit. ${ }^{44}$

Bereits im September 2012, bezugnehmend auf die Unterzeichnung des Anwerbeabkommens mit Spanien, wurde daher im Rahmen der „Wienwoche“ eine von Arif Akkılıç und Ljubomir Bratić konzipierte Plakatkampagne durchgeführt, die drei zentrale Forderungen in den öffentlichen Raum trug: „50 Jahre Arbeitsmigration Geschichtsschreibung jetzt / Gleichheit jetzt / Archiv jetzt“.45 Der Arbeitskreis Archiv der Migration, der sich daraufhin gründete, erarbeitete ein Konzeptpapier für ein

mit der Wiener Arbeitsmigration um 1900, in: Martin Scheutz/Vlasta Valeš (Hg.), Wien und seine Wienerinnen. Ein historischer Streifzug durch Wien über Jahrhunderte, Wien/Köln/Weimar 2008, 327-353; Wladimir Fischer, Vom ,Gastarbeiter zum, Ausländer'. Die Entstehung und Entwicklung des Diskurses über ArbeitsmigrantInnen in Österreich, in: Österreich in Geschichte und Literatur 53 (2009), 248-266; Wladimir Fischer, Von Einschusslöchern und Gesäßabdrücken. Spuren von MigrantInnen aus der südöstlichen Peripherie in Wiens Großstadttextur um 1900, in: Wladimir Fischer/Waltraud Heindl/Alexandra Millner/Wolfgang Müller-Funk (Hg.), Räume und Grenzen in Österreich-Ungarn 1867-1918. Kulturwissenschaftliche Annäherungen, Tübingen 2010, 141-172. Vgl. in diesem Zusammenhang auch Ingo Haar, Jüdische Migration und Integration in Wien. Vom Toleranzpatent Josephs II. bis in den Vormärz 1790-1830/47, in: Annemarie Steidl/Thomas Buchner/Werner Lausecker/Alexander Pinwinkler/Sigrid Wadauer/Hermann Zeitlhofer (Hg.), Übergänge und Schnittmengen. Arbeit, Migration, Bevölkerung und Wissenschaftsgeschichte in der Diskussion, Wien/Köln/Weimar 2008, 457-484.

44 Laura Ann Stoler, Colonial Archives and the Arts of Governance, in: Archival Science 2 (2002) 1-2, 87-109.

45 Vgl. Wienwoche 2012, URL: http://www.wienwoche.org (abgerufen 10.04.2013) sowie Arbeitskreis „Archiv der Migration“, URL: http://www.archivdermigration.at (abgerufen 08.09.2014). Die Plakate wurden gestaltet von Toledo i Dertschei (Eva Dertschei, Carlos Toledo), Wien. Dazu auch Arif Akkılıç/Ljubomir Bratić, Aufruf für ein Archiv der Migration, in: Stimme 84/2012, 27. 
Migrationsarchiv in Österreich. ${ }^{46}$ Erneuert wurde die Forderung nach Historisierung und einem Archiv der Migration mit einer Plakataktion des Arbeitskreises im Mai 2014, die unter dem Titel „50 Jahre Anwerbeabkommen Österreich-Türkei, 15. Mai 1964 - 15. Mai 2014“ gemeinsam mit der Initiative Minderheiten durchgeführt wurde: Mit historischen Zitaten wurden einige zentrale Aspekte der Anwerbung von „Gastarbeitern“ (Österreichs ursprüngliche geringe Attraktivität für ausländische Arbeitskräfte im Vergleich zu anderen Anwerbeländern wie Deutschland und der Schweiz, vor allem wegen schlechter Lohnverhältnisse; die Lebensbedingungen von Migranten der ersten Generation; die Interessen der österreichischen Unternehmen) zu thematisieren versucht. Den logischen Schlusspunkt bildete ein Plakat mit einem Zitat aus einem Interview (2012) mit einem Migranten, der 1967 als „Gastarbeiter“ nach Österreich gekommen war: „Ob Türken oder Jugoslawen, die Gastarbeiter haben das Land aufgebaut. Das muss man feiern! Das ist ja die Geschichte von Österreich. “47

Ebenfalls im Jahr 2012 wurde in St. Pölten das Zentrum für Migrationsforschung am Institut für die Geschichte des ländlichen Raumes am niederösterreichischen Landesarchiv eingerichtet, zunächst noch als ein befristetes Projekt. ${ }^{8}$ Es begann seine Arbeit mit einer Ausstellung über deutschsprachige Vertriebene aus der Tschechoslowakei in Niederösterreich, widmete sich aber danach breiter und allgemeiner der Migrationsgeschichte. Im Juli 2013 gründete sich dann eine entsprechende regionale Initiative in Vorarlberg: das Vielfaltenarchiv - Dokumentationsstelle zur Migrationsgeschichte Vorarlbergs mit Sitz in Dornbirn, aufbauend auf die bereits laufenden Sammlungs- und Ausstellungsaktivitäten der Bodensee Amateur Fotografen BAF. ${ }^{49}$ Von einer Gruppe postmigrantischer Vorarlberger aus türkischen

46 Der Arbeitskreis bestand aus Arif Akkılıç, Vida Bakondy, Ljubomir Bratić, Wladimir Fischer, Li Gerhalter, Dirk Rupnow. Eine Zeit lang gehörte ihm auch Belinda Kazeem an. Vgl. Archiv der Migration, URL: http://www.archivdermigration.at (abgerufen 03.10.2020). Vgl. dazu auch die Beiträge von Natalie Bayer, Ljubomir Bratić, Li Gerhalter, Zara Pfeiffer und Hannes Sulzenbacher sowie das Interview von Gerd Valchars mit Arif Akkılıç/Vida Bakondy/Ljubomir Bratić/Dirk Rupnow, in: Kulturrisse 2013/4: „AArchiv der Migration, jetzt!“ sowie Dirk Rupnow, Beschäftigung mit Geschichte ist kein Luxus. Wieso Österreich ein „Archiv der Migration“ braucht, in: Stimme 89/2013, 8-9 (sowie die weiteren Beiträge ebd. von Vida Bakondy, Wladimir Fischer, Vladimir Ivanović, Dirk Rupnow, Verena Sauermann/Veronika Settele, Theresa Weitzhofer-Yurtişik) und „... Prozesse und Logiken, die vor allem die privilegierte Mehrheit verlernen muss.“ Gespräch mit Marissa Lôbo/Dirk Rupnow, in: Bildpunkt 31/2014, 10-12.

47 Die Plakate sind ebenfalls zugänglich über www.archivdermigration.at. Sie wurden gestaltet von Beatrix Bakondy, Wien. Abgedruckt finden sie sich in: Der Standard, 15.05.2014.

48 Vgl. URL: http://www.migrationsforschung.at (abgerufen 08.09.2014).

49 Vgl. URL: http://www.vielfaltenarchiv.at und URL: http://www.bafart.com (abgerufen 08.09.2014) sowie die Ausstellung „Arbeyter. Bodensee Amateur Fotografen, Fotografien“, Emsiana 2013, Hohenems. 
Familien initiiert und betrieben, ist sein Ziel „die Dokumentation, Erforschung und Vermittlung der Migrationsgeschichte Österreichs, insbesondere Vorarlbergs, mit einem besonderen Fokus auf die Arbeitsmigration seit der Industrialisierung“. Durch die Zusammenarbeit mit Kommunalarchiven, Bildungsinstitutionen und Kultureinrichtungen soll „ein wesentlicher Teil der österreichischen, insbesondere der Vorarlberger Geschichte, dokumentiert und vermittelt werden“. Eine besondere Bedeutung kommt dabei der engen Kooperation mit dem vorarlberg museum zu.

Auch die Stadt Salzburg kündigte im Jubiläumsjahr 2014 an, im Stadtarchiv in Zusammenarbeit mit der Universität Salzburg Materialien, Fotos und Dokumente von MigrantInnen sammeln und eine Interviewsammlung anlegen zu wollen. ${ }^{50}$ Neben der Arbeitsmigration nach Salzburg soll es dabei um die Binnenwanderung innerhalb Salzburgs, Österreichs und Europas, aber auch um die Auswanderung aus Salzburg gehen. Schließlich schrieb im September 2017 auch die Magistratsabteilung 17 für Integration und Diversität der Stadt Wien gemeinsam mit dem Wien Museum ein Projekt „Migration sammeln“ aus. Mit ihm wurden allerdings nur temporär bis Sommer 2016 Objekte zur Geschichte der „Gastarbeitermigration“ gesichert und in die Sammlungen des Wien Museums aufgenommen. ${ }^{51}$ In Tirol gelang es im Rahmen der Vorbereitungen für die Ausstellung „Hier Zuhause. Migrationsgeschichte aus Tirol“ (2017) am Tiroler Volkskunstmuseum in Innsbruck ein Dokumentationsarchiv Migration Tirol (DAM) am Zentrum für MigrantInnen in Tirol (ZeMiT) zu etablieren, als Kooperationsprojekt von NGO/Beratungsstelle, Tiroler Landesmuseen und Universität Innsbruck. Im Wissenschaftlichen Beirat sind zudem die regionalen Archive eingebunden..$^{52}$

Ob es einer österreichweiten Einrichtung bedarf oder regionale Initiativen ohnehin sinnvoller und effektiver sind, bleibt zunächst noch eine offene Frage. Entscheidend ist jedenfalls, nicht aus dem Blick zu verlieren, dass es sich um eine Aufgabe handelt, die keinesfalls nur die Bundeshauptstadt Wien, sondern alle Bundesländer

50 Aussendung der Stadt Salzburg, Kommen - Gehen - Bleiben. Migrationsstadt Salzburg 1960-1990. Pressegespräch Stadt \& Uni zur Ausstellung am Makartsteg vom 23. Mai bis 6. Juli, 22.05.2014.

51 Arif Akkılıç/Vida Bakondy/Ljubomir Bratić/Regina Wonisch (Hg.), Schere Topf Papier. Objekte zur Migrationsgeschichte, Wien 2016 sowie URL: http://www.migrationsammeln.info/ (abgerufen 16.07.2020). Das Sammlungsprojekt wurde durch die Ausstellung „Geteilte Geschichte. Viyana Beč - Wien“ abgeschlossen, die vom 5. Oktober 2017 bis 11. Februar 2018 im Wien Museum zu sehen war, kuratiert von Vida Bakondy und Gerhard Milchram. Vgl. auch Vida Bakondy, Objekte der Erinnerung - Erzählungen zur Migration, in: Österreichische Zeitschrift für Geschichtswissenschaft 29 (2018) 3, 189-201.

52 Vgl. URL: https://www.zemit.at/de/dam.html und URL: https://hier-zuhause.at/ (abgerufen 24.09.2018) sowie Hier zuhause. Migrationsgeschichten aus Tirol (Kat. Tiroler Volkskunstmuseum), Innsbruck 2017. 
gleichermaßen betrifft, die Städte wie auch den ländlichen Raum. Zudem bedarf es wohl - wie in der gesamten Gesellschaft - eines generellen Bewusstseinswandels und Umdenkens in den bestehenden Institutionen (Archiven, Museen usw.) auf allen Ebenen und einer kritischen Evaluation und gegebenenfalls Erweiterung bzw. Veränderung bisheriger Sammlungspraxen und -bestände.

Das Vorarlberger Landesmuseum - vorarlberg museum - hat bereits 2013 einen wichtigen Schritt in diese Richtung gesetzt: In den anlässlich seiner Neueröffnung neu eingerichteten Ausstellungen „buchstäblich vorarlberg“, „vorarlberg. ein making-of" und "Sein \& Mein. Ein Land als akustische Passage“, die sich der Landesgeschichte auf sehr unterschiedliche Art und Weise annäherten und dabei auch verstärkt die jüngste Vergangenheit in den Blick nahmen, waren Erfahrungen und Geschichten der Migration jeweils ein integraler Bestandteil der Erzählung. Damit gibt es einen neuen Standard, den andere Häuser im Land in Zukunft zu berücksichtigen haben werden. Erschwerend kommt freilich hinzu, dass die Zeitgeschichte in den österreichischen Landesmuseen generell stark unterrepräsentiert ist.

Zwar widmete sich bereits 1996 das damalige Historische Museum der Stadt Wien (heute: Wien Museum) in einer Sonderausstellung dem Thema unter dem Titel „Wir. Zur Geschichte und Gegenwart der Zuwanderung nach Wien".53 Explizit wurde hier die Arbeitsmigration nach 1945 mit in die lange und vielfältige Geschichte der Zuwanderung nach Wien einbezogen. Auch bei der Ausstellung „Migration. Eine Zeitreise nach Europa“, 2003 im Museum Arbeitswelt im oberösterreichischen Steyr gezeigt, wurden im Rahmen der internationalen Wanderausstellung „Crossing Borders" Geschichte, Ausmaß und Bedeutung von Migration für Österreich beschrieben. Toleranz und Verständnis waren das erklärte Ziel der Präsentation. ${ }^{54}$ Nachhaltig waren diese Projekte jedoch nicht. Vorbildhaft und maßstabsetzend ist allerdings immer noch die von der Initiative Minderheiten konzipierte und 2004 im Wien Museum gezeigte Ausstellung „Gastarbajteri. 40 Jahre Arbeitsmigration“. Sie hatte es sich - angesichts des vierzigsten Jahrestags der Unterzeichnung des Anwerbeabkommens mit der Türkei - zur Aufgabe gemacht, „das Leben der Einwanderer und Einwanderinnen, die seit den 1960er- und 1970er-Jahren zunehmend einen relevanten Teil der Bevölkerung in diesem Land bilden, ebenso als einen wichtigen Teil

53 Wir. Zur Geschichte und Gegenwart der Zuwanderung nach Wien (217. Sonderausstellung des Historischen Museums der Stadt Wien, 19. September bis 29. Dezember 1996), Kat. Wien 1996. Vgl. auch Michael John/Albert Lichtblau, Schmelztiegel Wien - einst und jetzt. Zur Geschichte und Gegenwart von Zuwanderung und Minderheiten, Wien/Köln/Weimar 1993.

54 Migration. Eine Zeitreise nach Europa, Kat. Steyr 2003. 
der sozialen Geschichte dieses Landes zu betrachten“.55 Mit „Gastarbajteri“ war in Österreich bereits ein erster Anlauf zur Sammlung und Darstellung der Geschichte der Arbeitsmigration gemacht worden. Nicht zuletzt als Bottom-up-Initiative der Initiative Minderheiten, in die auch migrantische AkteurInnen eingebunden waren, war sie wegweisend, aber leider ebenfalls nicht nachhaltig, da es nicht gelang, die zusammengetragenen Bestände langfristig an einem Ort zu bewahren und zugänglich zu machen.

4.

Der neue Trend zur Historisierung der Migration ist jedenfalls offensichtlich, wenn auch nicht immer HistorikerInnen und/oder wissenschaftliche Einrichtungen daran beteiligt sind, sondern häufig NGOs, Vereine und AktivistInnen. ${ }^{56}$ Auch der Antrag der grünen Nationalratsabgeordneten Alev Korun im Jahr 2013, ein Migrationsmuseum einzurichten, wies in diese Richtung. ${ }^{57}$ Für die Zeitgeschichte öffnet sich damit ein Arbeitsfeld, das dem gegenwärtigen Bedarf nach transnationalen europäischen und globalen Geschichten, in denen das Regionale und Lokale sichtbar bleiben, entgegenkommt. ${ }^{58}$ Angeschlossen werden kann dabei an eine ganze Reihe von Traditionen und Diskussionen, etwa über Gesellschaftsgeschichte von den Rändern her, die von Minoritäten und Marginalisierten ausgeht. ${ }^{59}$ Die Erschließung neuer Quellen - schon immer eine Kernaufgabe der Zeitgeschichte ${ }^{60}$ - ist in jedem Fall von zentraler Bedeutung für eine Bearbeitung des Themas. Nicht nur in den bestehenden Archiven wird relevantes Material geborgen werden müssen, sondern vor allem jenseits davon gilt es, mögliche Überlieferungen $\mathrm{zu}$ suchen und $\mathrm{zu}$ sichern

55 Vgl. Hakan Gürses/Cornelia Kogoj/Sylvia Mattl (Hg.), Gastarbajteri. 40 Jahre Arbeitsmigration, Ausstellungskatalog, Wien 2004, 23. Vgl. auch die Online-Version, URL: http://www.gastarbajteri. at (abgerufen 22.06.2012).

56 Ljubomir Bratić, Politischer Antirassismus. Selbstorganisation, Historisierung als Strategie und diskursive Interventionen, Wien 2010, 137-139.

57 2244/A(E) XXIV. GP - Entschließungsantrag, 21.03.2013.

58 Vgl. Michael Gehler, Zeitgeschichte im Mehrebenensystem. Zwischen Regionalisierung, Nationalstaat, Europäisierung, internationaler Arena und Globalisierung (Herausforderungen 12), Bochum 2001 sowie Hanisch, Die Dominanz des Staates, 76.

59 Ingrid Bauer, Von den Autobahnen der Erkenntnis - und versäumten Ausfahrten, in: L'Homme F. Z. G. 7 (1996), 206-211.

60 Vgl. den Stellenwert der Quellenerschließung bei Hans Rothfels, Zeitgeschichte als Aufgabe, in: Vierteljahrshefte für Zeitgeschichte 1 (1953) 1, 1-8, 3-4 sowie vorher schon bei Justus Hashagen, Das Studium der Zeitgeschichte, Bonn 1915, 25-32. 
(etwa von Beratungsorganisationen, migrantischen Vereinen usw.). ${ }^{61}$ Darüber hinaus wird es notwendig sein, Interviews mit Zeitzeugen $\mathrm{zu}$ generieren, um deren Erfahrungen und Erinnerungen zu bewahren. Ohne sie wird ein neuer, multiperspektivischer Blick auf die österreichische Geschichte nicht möglich sein.

Mit der Archivierung ist es freilich nicht getan. Das Sammeln und Bewahren ist jedoch ein erster entscheidender und grundlegender Schritt, eine Voraussetzung für alles weitere: ohne Archiv keine Geschichtsschreibung. Letztlich geht es aber natürlich darum, die Geschichte der Migration zu schreiben - oder besser: Migration und MigrantInnen in die Geschichte einzuschreiben, allerdings ohne sie einfach zu vereinnahmen. Letztlich geht es um eine Veränderung der allgemeinen Wahrnehmung: Migration und MigrantInnen als ein selbstverständlicher, sicht- und hörbarer Teil der Gegenwart und Geschichte.

Damit wird eine Reihe von Fragen aufgeworfen, die für jede Beschäftigung mit Geschichte grundlegend sind, aber häufig nicht explizit thematisiert werden: Wessen Geschichte(n) wird/werden erzählt? Wer erzählt Geschichte(n)? Wer darf Geschichte(n) erzählen? Wessen Geschichte(n) wird/werden gehört? Migration muss als gelebte Realität, nicht nur als Ausnahme und Problem erzählt werden, das Marginalisierte in die Mitte rücken. MigrantInnen selbst müssen diese Geschichte erzählen und (mit)schreiben können. Letztlich geht es aber nicht um eine segregierte Geschichte der Migration und der MigrantInnen, sondern um eine inklusive Geschichte, die der alläglichen Pluralität und dem Wandel des gegenwärtigen Österreich gerecht wird. Eine Geschichte der Migration und der MigrantInnen ist allerdings eine unverzichtbare Voraussetzung dafür. Der Begriff der Migrationsgeschichte kann gleichzeitig nur ein Behelfsausdruck sein, denn es geht um wesentlich mehr als um den Vorgang der Migration im engeren Sinne, sondern um Pluralität und Gesellschaftswandel (sowie den Umgang damit, bis hin zur Ausblendung und Ablehnung). Dies geht einher mit den Debatten über eine „Entmigrantisierung“ der Migrationsforschung und gleichzeitige „Migrantisierung“ der Gesellschaftsforschung, die derzeit in der sozialwissenschaftlichen Migrationsforschung geführt wird. ${ }^{62}$ Wie immer sind dabei die Begriffe, mit denen wir unseren Forschungsgegenstand beschreiben, von zentraler Bedeutung und keineswegs nur peripher rele-

61 Problematisch ist in diesem Zusammenhang die Tatsache, dass zentrale Akteure der „Gastarbeiterbeschäftigung“ in Österreich - Wirtschaftskammer und Gewerkschaftsbund - als Vereine keiner Aufbewahrungspflicht unterliegen. Gerade in diesem Bereich ist bereits viel wichtiges Material vernichtet worden bzw. nur schwer zugänglich.

62 Manuela Bojadžijev/Regina Römhild, Was kommt nach dem „transnational turn“? Perspektiven für eine kritische Migrationsforschung, in: Labor Migration (Hg.), Vom Rand ins Zentrum. Perspektiven einer kritischen Migrationsforschung (Berliner Blätter 65), Berlin 2014, 10-24. 
vant. Entscheidend wird es sein, keine neuen Unsichtbarkeiten zu erzeugen, aber auch nicht die Konstruktion eines „Anderen“ im Zuge einer „Migrantologie“ zu befördern. ${ }^{63}$

Daraus ergeben sich vielfältige Chancen für die österreichische Zeitgeschichte: eine Öffnung und Perspektivenerweiterung, eine Verknüpfung mit anderen Räumen und Geschichten, Möglichkeiten des Vergleichs, neue historische Erzählstränge, Erinnerungsbezüge und zeitliche Zusammenhänge. Die herkömmliche, implizit ethnisch formatierte Nationalgeschichte der Zweiten Republik mit ihren etablierten Narrativen von Wohlstand und Sozialstaat oder Neutralität und dem Weg in die EU, aber auch vom „ersten Opfer“ oder (Mit)Schuldigen an den Verbrechen des „Dritten Reiches“ und den daraus resultierenden erinnerungskulturellen bzw. geschichtspolitischen Verwerfungen kann dies jedenfalls nicht mehr leisten. Dies heißt natürlich nicht, dass diese Kernerzählungen ihre Bedeutung verloren hätten. Sie werden jedoch nicht nur ergänzt, sondern vor allem transformiert durch den Blick auf Migration und die Perspektiven von MigrantInnen.

Wie eigentlich jede, wird auch diese (neue) Geschichte nie vollständig zu erzählen sein, sondern höchstens in Ausschnitten und Fragmenten. Die meisten historischen Darstellungen verschweigen dies freilich gern und versuchen, den Eindruck einer abgerundeten und abgeschlossenen „Geschichte“ zu erwecken. Vor allem die „Nation“ bot dafür Rahmen und Bezugsgröße, aber auch Legitimation. Was sich nicht problemlos und sauber einfügte, wurde und wird gerne ausgeblendet und geradezu „herausgeschrieben“ (dethematisiert). In der Realität jenseits der Geschichtsschreibung wurde diese Abgeschlossen- und Reinheit nicht selten auch gewalthaft zu realisieren versucht - dort ebenfalls unter Beteiligung von HistorikerInnen und häufig mit Geschichte als Argument.

Migration stellt das Format der nationalen Geschichte und die etablierten Großnarrative radikal und nachhaltig in Frage. Sie als solche klar zu benennen und zu fokussieren, hat daher eine strategische Funktion. Es handelt sich um eine transnationale Geschichte par excellence: Globalisierung findet alltäglich vor Ort statt, das Überschreiten oder Unterlaufen von Grenzen wird ständig praktiziert. ${ }^{64}$ Es handelt sich im besten Sinne um eine „geteilte Geschichte“ im Sinne von „divided“ und

63 Vgl. in diesem Zusammenhang auch Stephan Lanz, Berlin aufgemischt: Abendländisch - multikulturell - kosmopolitisch? Die politische Konstruktion einer Einwanderungsstadt, Bielefeld 2007, 86-96 und seine Beschreibung und Kritik einer „Ausländerforschung“.

64 Erol Yildiz, Die weltoffene Stadt. Wie Migration Globalisierung zum urbanen Alltag macht, Bielefeld 2013; Regina Römhild, Global Heimat Germany. Migration and the Transnationalization of the Nation-State, in: Transit 1 (2004) 1, URL: http://escholarship.org/uc/item/57Z247op (abgerufen 22.06.2012). 
„shared“ zugleich, um eine „entangled history“ und „histoire croisée“, wie es eigentlich jede Geschichte schon immer ist - mit all den Ambivalenzen, die Austausch und Interaktion mit sich bringen, einschließlich der immer wieder hergestellten $\mathrm{Ab}$ - und Ausgrenzungen. ${ }^{65}$ Geschichte ist dementsprechend nur noch transnational zu verstehen: im Sinne des Wortes, die Grenzen unterminierend und durchlöchernd, ohne sie freilich vollständig aufzulösen. ${ }^{66}$ Der nicht nur methodische Nationalismus der Geschichtswissenschaften verhindert aber immer noch weitgehend, dass dies entsprechend wahrgenommen wird.

Mit dem Blick auf Migration sollte endlich Abschied genommen werden von der irrigen Vorstellung einer vollständigen und geschlossenen Geschichte. Eine fragmentierte wäre wohl auch eine ehrlichere Geschichte, die keinesfalls nur an den Rändern zerfasert, sondern immer schon auf allen Ebenen. Sie wäre vielleicht auch gefeit davor, zur Legitimationsgeschichte für immer neue, immer wieder exkludierende Projekte zu werden, ob auf der nationalen oder - wie neuerdings häufiger - auf der internationalen Ebene. Ein Verständnis von Geschichte bleibt allerdings ebenfalls strategisch bedeutsam. Aus dem Blick auf die Vergangenheit können Vorstellung vom Möglichen und von Veränderung entwickelt werden. Ein kritisches Erinnern ist ein notwendiges Instrument, um verhärtete Perspektiven zu verschieben und zu „verlernen“.67 Gefordert ist freilich eine Geschichte, die ihr Potenzial zur Inklusion

65 Shalini Randeria, Geteilte Geschichte und verwobene Moderne, in: Jörn Rüsen/Hannah Leitgeb/ Norbert Jegelka (Hg.), Zukunftsentwürfe. Ideen für eine Kultur der Veränderung, Frankfurt a. M./ New York 1999, 87-96; Sebastian Conrad/Shalini Randeria, Einleitung. Geteilte Geschichten Europa in einer postkolonialen Welt, in: Sebastian Conrad/Shalini Randeria (Hg.), Jenseits des Eurozentrismus. Postkoloniale Perspektiven in den Geschichte- und Kulturwissenschaften, Frankfurt a. M./New York 2002, 9-49, 17.

66 Aus der Fülle der Literatur vgl. - mit durchaus unterschiedlichen Positionen und Akzentuierungen - beispielhaft Nina Glick Schiller/Linda Basch/Cristina Szanton Blanc, From Immigrant to Transmigrant. Theorizing Transnational Migration, in: Anthropological Quaterly 68 (1995) 1, 48-63; Ludger Pries, Migration und Integration in Zeiten der Transnationalisierung - oder: Warum braucht Deutschland eine ,Kulturrevolution'?, in: iza. Zeitschrift für Migration und soziale Arbeit 2001/1, 14-19; Andreas Wimmer/Nina Glick Schiller, Methodological Nationalism, the Social Sciences, and the Study of Migration. An Essay in Historical Epistemology, in: International Migration Review 37 (2003) 3, 576-610; Michael Bommes, Der Mythos des transnationalen Raumes. Oder: Worin besteht die Herausforderung des Transnationalismus für die Migrationsforschung, in: Dietrich Thränhardt/Uwe Hunger (Hg.), Migration im Spannungsfeld von Globalisierung und Nationalstaat (Leviathan, Sonderheft 22), Wiesbaden 2003, 90-116; Michael Bommes, Transnationalism or Assimilation, in: Journal of Social Science Education 4 (2005) 1, 14-30.

67 María Do Mar Castro Varela, Interkulturelle Kompetenz, Integration und Ausgrenzung, in: Matthias Otten/Alexander Scheitza/Andrea Cnyrim (Hg.), Interkulturelle Kompetenz im Wandel, Bd. 1: Grundlegungen, Konzepte und Diskurse (SIETAR Deutschland - Beiträge zur interkulturellen Zusammenarbeit 1), Frankfurt a. M. 2007, 155-169, 167. 
zur Geltung bringt und diese nicht gleichzeitig wieder mit neuen Ausgrenzungen erkauft.

Das Fach Zeitgeschichte ist heute - wie schon immer, aber vielleicht in erhöhtem Maße - mit einer ganzen Reihe von Herausforderungen konfrontiert: Immer unklarer wird die zeitliche Abgrenzung ihres Zuständigkeitsbereichs; eine Vielzahl von ErzählerInnen und AkteurInnen, nicht zuletzt ZeitzeugInnen, steht in der Öffentlichkeit in Konkurrenz zu professionellen HistorikerInnen; gleichzeitig konkurrenzieren sich vermehrt unterschiedliche Medien und Genres bei der Darstellung der jüngsten Vergangenheit, bis hin zu fiktionalen Annäherungen an die Geschichte; sie ist Teil der Erinnerungskultur wie auch ihr kritisches Gegenüber und damit in einer komplexen Verstrickung gefangen, die es immer wieder zu reflektieren gilt. ${ }^{6}{ }^{8} \mathrm{Hinzu}$ kommt, dass die Realität der Migrationsgesellschaft nicht nur Gegenstand der Zeitgeschichte sein muss, sondern bereits ihre Bedingung und ihr Rahmen ist. Dieser Tatsache mit allen ihren Konsequenzen muss sie sich aber erst noch bewusst stellen, in Österreich wie in anderen Ländern. Damit wird auch noch einmal das normativhomogene Konzept eines „kollektiven Gedächtnisses“ in Frage gestellt. An die Stelle von „collective memories“ müssen wohl plurale und heterogene „collected memories“ gestellt werden, die es auszutauschen, zu teilen und anzuerkennen gilt. ${ }^{69}$

\section{5.}

Mit den „Gastarbeitern“ aus der Türkei und Jugoslawien wurde die Republik Österreich Anfang der 1960er-Jahre zum Einwanderungsland - und damit zu einer immer pluraleren und diverseren Gesellschaft. Natürlich war die Bevölkerung bis dahin keinesfalls homogen, aber es überwog statistisch die Auswanderung. Für die ungarischen (wie auch die späteren) Flüchtlinge des „Kalten Krieges“ war Österreich 1956 mehrheitlich Durchgangsstation, nicht Zielland. Die letzte Phase intensiver Zuwanderung lag in der Hauptstadt Wien bereits mehr als fünf Jahrzehnte zurück: In der Habsburgermonarchie kamen hunderttausende von Menschen aus den böhmischen Ländern, der ungarischen Reichshälfte, den österreichischen Erbländern, Galizien, der Bukowina und Dalmatien in die Haupt- und Residenzstadt..$^{\circ}$ Der Verweis auf

68 Vgl. Martin Sabrow, Zeitgeschichte schreiben. Von der Verständigung über die Vergangenheit in der Gegenwart, Göttingen 2014, vor allem 133-146.

69 Michele Barricelli, Collected Memories statt kollektives Gedächtnis. Zeitgeschichte in der Migrationsgesellschaft, in: Markus Furrer/Kurt Messmer (Hg.), Handbuch Zeitgeschichte im Geschichtsunterricht, Schwalbach 2013, 89-118.

70 Für einen Überblick vgl. Fassmann/Münz, Einwanderungsland Österreich. 
die slawischen Namen im Wiener Telefonbuch wurde ja geradezu sprichwörtlich auch für eine Normalisierung nach wenigen Generationen. Dazwischen lag allerdings der wohl systematischste Versuch, die Bevölkerung als „Volksgemeinschaft“ zu homogenisieren - während des „Dritten Reichs“ mit der exzessiv-gewalthaften Ausgrenzung, Vertreibung und Ermordung von denen, die als „anders“ gekennzeichnet wurden, vor allem der jüdischen Bevölkerung. Die unmittelbare Nachkriegszeit war wiederum von einer Vielzahl von Flüchtlingen, Displaced Persons und Vertriebenen auf dem Gebiet Österreichs geprägt.

Während im Jahr 1961 der Anteil der Menschen mit ausländischer Staatsangehörigkeit in Österreich bei 1,4 Prozent lag, kam es in den 1960er- und 1970er-Jahren durch die Anwerbung von „Gastarbeitern“ aus Jugoslawien und der Türkei zu einem Anstieg auf einen vorläufigen Höchstwert von 4,1 Prozent im Jahr 1974 (über 310.000 Personen von einer Gesamtbevölkerung von etwa 7,6 Millionen). Erst die Jugoslawienkriege in den 199oer-Jahren führten dann zu einem neuerlichen signifikanten Ansteigen auf über 8 Prozent im Jahr 1993. Seit der Jahrtausendwende kam es erneut zu einem markanten Anstieg, 2008 wurde erstmals die 10-Prozent-Marke überschritten (etwa 845.00o Personen bei einer Gesamtbevölkerung von ungefähr 8,3 Millionen)..$^{71}$ Im Jahr 2015 wurden über 88.00o Asylanträge gestellt, vor allem von Menschen aus Afghanistan, Syrien und dem Irak (in EU-Ländern insgesamt über 1,3 Millionen). ${ }^{72}$ Österreich hat damit die zweithöchste Pro-Kopf-Quote von Asylbewerbern in Europa (10 Asylbewerber auf 1.00o Einwohner) nach Schweden (17 auf 1.000).

Gegenwärtig haben mehr als 23 Prozent der Wohnbevölkerung Österreichs einen sogenannten Migrationshintergrund (2 Millionen von 8,7 Millionen), in Wien sind es sogar über 45 Prozent.73 Die größte Gruppe darunter sind Menschen aus dem ehemaligen Jugoslawien (über eine halbe Million) und aus der Türkei (mehr als eine Viertelmillion). Am 1. Januar 2020 lebten knapp 17 Prozent der Bevölkerung mit einer nichtösterreichischen Staatsbürgerschaft im Lande, in Wien waren es über 30 Prozent. ${ }^{74}$ Die größte Gruppe sind dabei wiederum Menschen aus dem ehema-

71 Fact Sheet 24: Staatsbürgerschaft und Einbürgerung (Oktober 2016), ÖIF, URL: http://www.integrationsfonds.at/themen/publikationen/oeif-fact-sheets/ (abgerufen 25.10.2016).

72 Integrationsbericht 2016, BMEIA, URL: https://www.bmeia.gv.at/integration/integrationsbericht/ (abgerufen 25.10.2016).

73 Bevölkerung mit Migrationshintergrund nach Bundesländern (Jahresdurchschnitt 2019), Statistik Austria, URL: http://www.statistik.at/web_de/statistiken/menschen_und_gesellschaft/bevoelkerung/bevoelkerungsstruktur/bevoelkerung_nach_migrationshintergrund/index.html (abgerufen 16.07.2020).

74 Bevölkerung am 01.01.2020 nach detaillierter Staatsbürgerschaft und Bundesland, Statistik Austria, URL: http://www.statistik.at/web_de/statistiken/menschen_und_gesellschaft/bevoelkerung/ 
ligen Jugoslawien, gefolgt von Deutschen und Türken. Österreich ist damit europaund weltweit an der Spitze angekommen. Das österreichische Nachrichtenmagazin "profil“ hat dementsprechend schon formuliert: „Österreich ist geworden, was es nie sein wollte: eines der führenden Einwanderungsländer der Welt“" ${ }^{75}$

Die gegenwärtige Situation in Österreich ist äußerst komplex und widersprüchlich: Zum einen ist in der vergangenen Dekade das Interesse an der Migrationsgeschichte der Zweiten Republik erwacht, mit einem Fokus auf die „Gastarbeitermigration" in den 196oer- und 1970er-Jahren. Gleichzeitig absorbiert die als „Flüchtlingskrise“ wahrgenommene Entwicklung alle Aufmerksamkeit und delegitimiert geradezu jeglichen Blick in die Geschichte, wenn es um Migration geht. Im Mittelpunkt stehen die Notwendigkeiten der Gegenwart und Pläne für die Zukunft. Die strukturierte Arbeitsmigration gilt oft auch als irrelevant für einen Vergleich, wenn es um Flucht geht. Dabei dürfte im Angesicht der aktuellen Situation ein vertiefter Blick in die Geschichte durchaus sinnvoll sein: Die Unterschiede zwischen Flucht- und Arbeitsmigration scheinen offensichtlich, werden aber wohl überschätzt. Beide Phänomene sind oft miteinander verschränkt und nicht leicht voneinander zu trennen. Die Fluchtbewegungen ins Nachkriegsösterreich - allen voran die ungarischen Flüchtlinge des Jahres 1956, aber auch die tschechoslowakischen 1968 und die polnischen 1980 - sind fester Bestandteil des etablierten historischen Narrativs der Zweiten Republik, eine nachhaltige Herausforderung und Transformation Österreichs brachten sie allerdings nicht mit sich: Der Großteil der Flüchtlinge verließ das Land bald wieder und nutzte es nur als Durchgangsstation. Dementsprechend hatten sie nur einen sehr kleinen Effekt auf die Demographie, konnten aber umso leichter zu einem Symbol für Offenheit und Solidarität werden, denen - bei genauerem Hinsehen - auch in diesen Fällen sehr enge Grenzen gesteckt waren. Die Kriege in Jugoslawien in den 1990er-Jahren und die dadurch bedingte Ankunft von vielen tausenden bosnischen Flüchtlingen waren daher eine ganz neue Realität für Österreich. Viele sind im Zuge dessen durch Österreich hindurchgereist, aber mehr als 90.00o sind auch im Land geblieben. ${ }^{76}$ Österreich war nicht mehr nur Transitland, sondern wurde auch Zielland für die Flüchtlinge. Im Kontext der „Flüchtlingskrise“ 2015 wurde daher immer wieder auf die historischen Erfahrungen der jugoslawischen, vor allem bosnischen Flüchtlinge in den 1990er-Jahren verwiesen.

bevoelkerungsstruktur/bevoelkerung_nach_staatsangehoerigkeit_geburtsland/index.html (abgerufen 16.07.2020).

75 Clemens Neuhold, Lebenslüge der Nation, profil 44/2016, 31.10.2016, 14-21.

76 Barabara Franz, Bosnian refugees and socio-economic realities. Changes in refugee and settlement policies in Austria and the United States, in: Journal of Ethnic and Migration Studies 29 (2002) 1, $5^{-25}$. 
Hier wird in Zukunft sicherlich ein Schwerpunkt der Forschung liegen, womit die Zeitgeschichte auch so weit in Richtung Gegenwart vordrängen würde, wie es die Archivsperre derzeit erlaubt.

Mittlerweile sehen drei Viertel der ÖsterreicherInnen ihr Land als Einwanderungsland: 33 Prozent sagen, das treffe "ganz sicher“ zu, 43 Prozent sehen das zumindest „eher“ so, während für nur 8 Prozent Österreich „ganz sicher kein“ bzw. für 14 Prozent „eher nicht“ ein Einwanderungsland ist. ${ }^{77}$ Migration und MigrantInnen zum integralen Teil österreichischer Geschichte zu machen und diese als plural und transnational zu begreifen und neu zu erzählen, ist aber keine einfache Aufgabe, wenn Rassismus im Wachsen begriffen ist und angeblich klare Unterscheidungen zwischen verschiedenen Kulturen als unhinterfragbar gelten. Bedauerlicherweise hat auch die erste Bundesregierung mit grüner Beteiligung (Kurz II) kein Bekenntnis zu einer notwendigen neuen, zeitgemäßen transnationalen Perspektive auf Geschichte und Erinnerungskultur, die der Tatsache Rechnung trägt, dass Österreich ein Einwanderungsland ist, abgelegt. Obwohl nicht zuletzt in der Corona-Krise deutlich wurde, dass der Anteil von MigrantInnen in systemrelevanten Berufen besonders groß ist, adressierte Bundeskanzler Kurz in seinen Ansprachen konsequent nur die „lieben Österreicherinnen und Österreicher“. Und auch die Rassismusdebatten im Gefolge der „Black-Lives-Matter“-Proteste in den USA in Reaktion auf den Tod von George Floyd im Mai 2020 machten sichtbar, wie weit der Weg noch ist. Schließlich hätte auch Österreich eine Geschichte rassistischer Polizeigewalt gegenüber MigrantInnen aufzuarbeiten (Marcus Omofuma 1999, Richard Ibekwe 2000, Cheibani Wague 2003, Edwin Ndupu 2004, Yankuba Ceesay 2005).

77 Unique Research, Wien 2016 (500 Befragte), profil 44/2016, 31.10.2016, URL: http://www.profil.at/oesterreich/umfrage-oesterreich-einwanderungsland-7663079 (abgerufen 31.10.2016). Im FPÖ-Parteiprogramm „Österreich zuerst“ von 2011 wird währenddessen weiterhin darauf beharrt: „Österreich ist kein Einwanderungsland“, URL: https://www.fpoe.at/fileadmin/user_upload/www. fpoe.at/dokumente/2015/2011_graz_parteiprogramm_web.pdf (abgerufen 02.11.2016). Die ÖVP bekennt sich währenddessen in ihrem Programm aus dem Jahr 2015 zur qualifizierten Zuwanderung und zu einer Leitkultur, URL: https://www.oevp.at/die-partei/Die-OeVP.psp (abgerufen 02.11.2016). Im SPÖ-Parteiprogramm aus dem Jahr 1998 wird gegen Fremdenfeindlichkeit, Rassismus und Antisemitismus und für ein solidarisches Miteinander Position bezogen, URL: https:// spoe.at/sites/default/files/das_spoe_parteiprogramm.pdf (abgerufen 02.11.2016). Allein das Parteiprogramm der Grünen von 2001 hielt bereits fest: „Trotz der Anwerbung von ausländischen Arbeitskräften ab Anfang der Sechzigerjahre fehlt bis heute das Bekenntnis, dass Österreich ein Einwanderungsland ist. Ganz im Gegenteil hat Österreich bis heute die Tatsache, dass ImmigrantInnen ein Teil der Gesellschaft geworden sind und langfristig hier bleiben werden, einfach ignoriert und die Betroffenen jahrzehntelang als ,GastarbeiterInnen behandelt", URL: https://www. gruene.at/partei/programm/parteiprogramm (abgerufen 02.11.2016). 
Der Blick auf die gesetzlichen Rahmenbedingungen des „Gastarbeiter“-Regimes macht deutlich, welche weitreichenden Kontinuitäten in Österreich den Umgang mit Menschen bestimmen, die zeitweise als nützlich gelten, aber nicht als zugehörig betrachtet werden - über die unterschiedlichen historischen Brüche hinweg, noch hinter die NS-Zeit zurück, diese aber durchaus einschließend. ${ }^{78}$ Die österreichische Politik wurde von Anfang an von einem äußerst restriktiven Umgang mit MigrantInnen dominiert: Eine selektive Einwanderung unter dem Vorbehalt ökonomischen Nutzens für das Land und eine dezidierte Abwehrpolitik, vor allem durch hohe Barrieren für eine permanente Niederlassung und die Übernahme der Staatsbürgerschaft, waren stets eng miteinander verschränkt. Diese Doppelstrategie hat sich lange erhalten. Der belgisch-amerikanische Migrationsforscher Aristide Zolberg hat die grundsätzliche Ambivalenz gegenüber „fremden“ Arbeitskräften in praktisch allen Kontexten und über einige Jahrhunderte hinweg, seit der Kolonisierung der Welt durch europäische Nationen, prägnant zusammengefasst: „Wanted but not Welcome“.79

78 Vida Bakondy/Renée Winter, Marginalisierte Perspektiven. Kontinuitäten der Arbeitsmigrationspolitik in Österreich, in: zeitgeschichte 40 (2013) 1, 22-34; Dirk Rupnow, Recht und Differenz. Das „Gastarbeiter“-Regime in Österreich, in: Hier zuhause. Migrationsgeschichten aus Tirol (Kat. Tiroler Volkskunstmuseum), Innsbruck 2017, 43-47; Dirk Rupnow, Von der „Gastarbeit“ zum „Migrationshintergrund“. Logiken der Nützlichkeit, Kontinuitäten und Wandlungen der Ausgrenzung, in: Andreas Brunner/Barbara Staudinger/Hannes Sulzenbacher (Hg.), Die Stadt ohne Juden/ Flüchtlinge/Muslime/Ausländer, Wien 2018, 82-86.

79 Aristide Zolberg, Wanted but not Welcome. Alien Labor in Western Development, in: William Alonso (Hg.), Population in an Interacting World, Cambridge 1987, 36-73, 37: „Of particular interest in this respect is that imported labor tends to be alien in the deep sense - that, not merely foreign, but representing for the receiving society an undesirable ,otherness. This is by no means happenstance, as it is precisely the alien character of the labor that makes its importation profitable in the first place; and it is also the case that the people involved remain alien afterward as a consequence of the role to which they are confined in the receiving society. It follows that by using alien labor a hegemonic society tends to foster an increase in its own heterogeneity, an outcome that commonly gives rise to severe political strains pertaining to issues of societal identity and cohesion." Vgl. in diesem Zusammenhang auch Kien Nghi Ha, Die kolonialen Muster deutscher Arbeitsmigrationspolitik, in: Hito Steyerl/Encarnación Gutiérrez Rodriguez (Hg.), Spricht die Subalterne deutsch?, Münster 2003, 56-107, 67: „Abwehrpolitik‘ und selektive Zuwanderung unter Nützlichkeitsvorbehalt als Gegensätze anzusehen, wäre eine zu vordergründige Sichtweise, die übersieht, dass diese sich ergänzenden Positionen die moderne Ambivalenz des Rassismus widerspiegeln." 


\title{
Gedächtnis und Erinnerungskultur
}

\author{
Ljiljana Radonići und Heidemarie Uhl
}

1993 hielt der Gedächtnisbegriff mit dem Buch „Österreichisches Gedächtnis“ in Österreich Einzug. „Gedächtnis“ wurde damit zum Synonym für die „Verdrängungsgeschichte“ der Zweiten Republik, für die „spezifisch österreichische Kultur des Erinnerns und Vergessens" des Nationalsozialismus. ${ }^{2}$ Der vorliegende Beitrag geht der Frage nach, wie Österreich als ehemaliger integraler Bestandteil des Deutschen Reichs im europäischen Mainstream der Entwicklung von der Verdrängung zur Aufarbeitung zu verorten ist.

\section{1. „Memory boom“ und Europäisierung der Erinnerung}

Folgten erinnerungspolitische Debatten bis zum Ende der 1980er-Jahre mit wenigen Ausnahmen wie dem Eichmann-Prozess 1961 oder den Diskussionen um die Ausstrahlung der Fernsehserie „Holocaust“ 1978/1979 unter anderem in den USA, Frankreich, Italien, Deutschland und Österreich vorwiegend nationalen Prozessen, so setzen sich ausgehend von den USA seither im Zuge der "Universalisierung", "Amerikanisierung“ und „Europäisierung des Holocaust" verstärkt transnationale Erinnerungspraktiken durch, die keinesfalls frei von Opferkonkurrenzen und Erinnerungskonflikten sind.

Nachdem Ende der 1980er-Jahre der „memory boom“ eingesetzt hat, gerät leicht aus dem Blick, dass dies ein vergleichsweise neuer Trend ist. So verfolgte etwa die Europäische Union keinesfalls von Anfang an eine geschichtspolitische Agenda. Bis in die 1970er-Jahre lag der Fokus auf der gemeinsamen Zukunft und erst in den 1980er-Jahren begann man, sich auf das europäische historische Erbe zu „besinnen“. Doch war hier zunächst ein positives Erbe gemeint - die Akropolis in Athen wurde etwa als erstes europäisches Kulturerbe gefördert und 1985 symbolträchtig zur Vorstellung der Initiative „Kulturhauptstadt Europas“ genutzt. Wenn heute vielfach von

1 Der Beitrag entstand im Rahmen des Projektes „Globalized Memorial Museums. Exhibiting Atrocities in the Era of Claims for Moral Universals“ (GMM), gefördert vom Europäischen Forschungsrat (ERC) im Rahmen des Forschungs- und Innovationsprogramms der EU „Horizon 2020“ (GMMgrant agreement No 816784).

2 Meinrad Ziegler/Waltraud Kannonier-Finster, Einleitung und Ausgangspunkte, in: dies. (Hg.), Österreichisches Gedächtnis. Über Erinnern und Vergessen der NS-Vergangenheit, Wien 1993, 11. 
der in der 1990er-Jahren einsetzenden Europäisierung des Holocaust als negativem europäischem Gründungsmythos die Rede ist, so lässt dies außer Acht, dass 1993 die erste diesbezügliche Maßnahme auf europäischer Ebene (die vom Europäischen Parlament verabschiedete „Entschließung zum europäischen und internationalen Schutz der Stätten der von den Nationalsozialisten errichteten Konzentrationslager als historische Mahnmale“) die NS-Lager im Allgemeinen betraf und das Wort „Holocaust" noch gar nicht enthielt.

In diese Zeit fallen auch die ersten Gründungstexte dessen, was wir heute als Gedächtnistheorie einerseits und als Geschichtspolitik andererseits bezeichnen. 1988 hatte Jan Assmann unter Rückgriff auf Maurice Halbwachs' Theorie des „mémoire collective“ (1939) das „kollektive Gedächtnis“ in das „kommunikative“ und das „kulturelle Gedächtnis“ unterteilt und damit die Gedächtnistheorie im deutschen Sprachraum begründet. Schon Halbwachs hatte betont, Erinnerungen seien nie „authentisch“, sondern auf die Bedürfnisse der Gegenwart zugeschnitten: Das kollektive Gedächtnis „,bewahrt nicht die Vergangenheit auf, sondern es rekonstruiert sie mit Hilfe materieller Spuren, Riten, Texte und Traditionen und mit Hilfe von neuerlichen psychischen und sozialen Gegebenheiten, das heißt mit der Gegenwart“. ${ }^{3}$

Ungefähr zur selben Zeit wurde im westdeutschen Historikerstreit das Wort Geschichtspolitik zunächst als politischer Kampfbegriff und unter anderem von Peter Steinbach und Peter Reichel bald auch als wissenschaftliches Konzept geprägt. Während Jan Assmann „die negativen Formen eines Vergessens durch Auslagerung und eines Verdrängens durch Manipulation, Zensur, Vernichtung, Umschreibung und Ersetzung “4 in seinem kulturwissenschaftlichen Konzept nur in einem Satz erwähnte, lag der Fokus bei der Geschichtspolitik von Anfang an auf Deutungskämpfen. ${ }^{5}$ Die Begriffe Erinnerungskultur, kulturelles Gedächtnis, Geschichts- und Vergangenheitspolitik versuchten also, die Anfang der 1990er sich abzeichnenden transnationalen Erinnerungspraktiken einzufangen, die vor allem durch die Universalisierung des Holocaust ausgelöst und den Zusammenbruch des „Ostblocks“ nochmals intensiviert wurden.

In der Europäischen Union schlägt sich dies als „Europäisierung der Erinnerung“ nieder - verstanden als „Prozess der relativierenden Transformation der nationalen Perspektiven, als strukturelle Veränderung und Angleichung der Geschichtsbilder

3 Maurice Halbwachs, Das Gedächtnis und seine sozialen Bedingungen, Berlin 1985, 296.

4 Jan Assmann, Kollektives Gedächtnis und kulturelle Identität, in: Jan Assmann/Tonio Hölscher, Kultur und Gedächtnis, Frankfurt a. M. 1988, 9-19, 23.

5 Edgar Wolfrum, Geschichtspolitik in der Bundesrepublik Deutschland. Der Weg zur bundesrepublikanischen Erinnerung 1948-1990, Darmstadt 1999, 25-26. 
im Sinne einer Anreicherung mit europäischen Bezügen“6 ${ }^{6}$ Das entscheidende Jahr hierfür war 1995, als sich das Ende des Zweiten Weltkriegs zum fünfzigsten Mal jährte. Zunächst sprach bei der ersten europäischen Gedenkveranstaltung im Februar 1995 der Präsident des Europäischen Parlaments Klaus Hänsch - ein deutscher Sozialdemokrat und schlagender Burschenschafter, dessen Familie 1945 aus Schlesien geflohen war - anlässlich des Bombardements von Dresden davon, dass das Leiden deutscher Zivilisten mit jenem der Bevölkerung von Coventry, Leningrad oder Rotterdam zu vergleichen sei.7 Doch Mitte des Jahres setzte im Europäischen Parlament eine Entwicklung ein, die zu Beginn des neuen Millenniums ihren Höhepunkt erreichen sollte: die „Europäisierung des Holocaust“, die Vorstellung, dass der Holocaust der negative Gründungsmythos Europas sei und dass, wie Tony Judt es formulierte, auf den Krematorien von Auschwitz ein neues Europa erbaut werde. ${ }^{8}$

Diese Europäisierung des Holocaust schlug sich in der Zeit zwischen 1995 und 2000 in sechs holocaustbezogenen Resolutionen des Europäischen Parlaments nieder: von jener zur Einführung eines Holocaustgedenktags 1995 bis zu jener zur Erinnerung an den Holocaust im Jahr 200o. Offenbar war 1995 die Zeit für ein gemeinsames Holocaustgedenken auf EU-Ebene jedoch noch nicht gekommen, denn es sollte bis 2000 dauern, bis sich die Idee eines europaweiten Gedenktags durchsetzte und 2005 schließlich auch von der UNO eingeführt wurde.

In der zweiten Hälfte der 1990er-Jahre lag der Schwerpunkt noch auf „harten“ Fragen von Entschädigung und der Restitution von Raubkunst, Raubgold usw., etwa bei der Londoner Konferenz über NS-Raubgold 1997 und der Washingtoner Konferenz über geraubte Vermögenswerte 1998. In diesen Kontext fällt auch die einzige explizite Aufforderung der EU an die ostmittel- und südosteuropäischen Beitrittskandidaten: In der Resolution über die Rückgabe geraubten jüdischen Eigentums von 1995 forderte das Europäische Parlament insbesondere die osteuropäischen Länder zum Handeln auf.

Zeitgleich mit dem Skandal um das Schweizer Raubgold wurde 1998 in Schweden das ExpertInnennetzwerk Task Force for International Cooperation on Holocaust Education, Remembrance, and Research (ITF) gegründet, dem heute - umbenannt in International Holocaust Remembrance Alliance (IHRA) - 34 Länder angehören.

6 Harald Schmid, Europäisierung des Auschwitzgedenkens? Zum Aufstieg des 27. Januar 1945 als „Holocaustgedenktag“ in Europa, in: Jan Eckel/Claudia Moisel (Hg.), Universalisierung des Holocaust? Erinnerungskultur und Geschichtspolitik in internationaler Perspektive, Göttingen 2008, 174-202, 178.

7 Oriane Calligaro, Legitimation Through Remembrance? The Changing Regimes of Historicity of European Integration, in: Journal of Contemporary European Studies 23 (2015) 3, 330-343, 338.

8 Tony Judt, Geschichte Europas. Von 1945 bis zur Gegenwart, München/Wien 2006. 
Die schwedische Initiative verschob den Fokus von der Entschädigungs- auf symbolische Politik: Die Gründung der ITF und ihre enorme Aufwertung bei der Holocaustkonferenz in Stockholm im Jahr 2000 läuteten jedenfalls eine Verlagerung von Fragen der Enteignung und geraubten Vermögens hin zu Holocaust Education und symbolischen Erinnerungsakten ein.

Das in Stockholm im Jahr 2000 abgehaltene International Forum on the Holocaust war ein Schlüsselereignis für die „Europäisierung des Holocaust“. Erstmals nahmen hochrangige PolitikerInnen, PräsidentInnen und RegierungschefInnen, renommierte WissenschaftlerInnen, GedenkstättenmitarbeiterInnen und ZeitzeugInnen aus 46 Ländern an einer Konferenz zum Thema Holocaust teil. Als Ergebnis wurde eine Deklaration verabschiedet, in der zwar auch andere Opfer des Nationalsozialismus gewürdigt wurden, der Begriff Holocaust jedoch der Vernichtung der europäischen Jüdinnen und Juden vorbehalten blieb. Sie resultierte in der Empfehlung, alle Staaten sollten den 27. Januar, den Jahrestag der Befreiung von Auschwitz-Birkenau, oder ein anderes, national bedeutsames Datum als Holocaustgedenktag einführen.

Auf wissenschaftlicher Ebene fand diese Entwicklung ihre Entsprechung einerseits in Deutschland in der Forderung nach einem „negativen Gedächtnis“, das die „politics of regret" ${ }^{\text {"9 }}$ als leere Hülse von Gedenkritualen überwinden sollte, andererseits in der These von der „Kosmopolitisierung des Holocaust“, wie sie in dem vielzitierten Werk „Erinnerungen im globalen Zeitalter: Der Holocaust“ von Daniel Levy und Natan Sznaider vertreten wurde. In „Formen und Traditionen des negativen Gedächtnisses“ führt Reinhart Koselleck aus: „Die Täterschaft und ihre Taten müssen in die Erinnerung einbezogen und nicht nur die Opfer als solche und allein erinnert werden. "10 Charakteristisch für dieses historische Erinnern sei Volkhard Knigge zufolge,

dass Schuld und Verantwortung nicht mehr verleugnet, abgeschoben oder überdeckt werden, sondern dass sie zu Anlässen kritischer gesellschaftlicher Selbstreflexion und Selbstvergewisserung gemacht werden. [...] Der Rückbezug auf die negative Vergangenheit muss umfassend und konkret sein, muss Opfer, Täter und gesellschaftliche wie indivi-

9 Jeffrey K. Olick, The Politics of Regret: On Collective Memory and Historical Responsibility, New York 2007.

10 Reinhart Koselleck, Formen und Traditionen des negativen Gedächtnisses, in: Volkhard Knigge/ Norbert Frei (Hg.), Die Auseinandersetzung mit Holocaust und Völkermord, München 2002, 2132,27 . 
duelle Tatvoraussetzungen einschließen; er darf auch Ambivalenzen und Grauzonen, die sich eindeutigen Opfer-Täter-Schemata widersetzen, nicht ausweichen. ${ }^{11}$

Diese „heiklen“ Fragen wurden im Zuge der „Europäisierung des Holocaust“ auch in Bezug auf die Kollaboration außerhalb NS-Deutschlands gestellt.

Was die These von der Kosmopolitisierung des Holocaust angeht, so erlaubt die hier vorgenommene verschränkende Periodisierung politischer und wissenschaftlicher Entwicklungen, das Werk von Levy und Sznaider von 2001 als „Kind seiner Zeit“ in der zu diesem Zeitpunkt noch kaum hinterfragten Universalisierung des Holocaust einzuordnen. Levy und Sznaider bewerten das „Zeitalter der Globalisierung" optimistisch und sehen einen Wandel von nationalen zu kosmopolitischen Erinnerungskulturen - auch im Sinne einer „Kampfansage an die versteinerte Wissenschaft, die nicht imstande ist, sich vom Nationalstaat zu verabschieden“. Die Erinnerung an den Holocaust mache die „Katastrophe Europas zum Ausgangspunkt neuer grenzüberschreitender Solidarität" ${ }^{12}$ denn der Umgang mit dem Holocaust öffne das Verständnis für neue Erinnerungskulturen in der „Zweiten Moderne“. Die Erinnerung an den Holocaust werde in einer Epoche ideologischer Ungewissheiten $\mathrm{zu}$ einem Maßstab für humanistische und universalistische Identifikationen. Dadurch würden national übergreifende Gedenkkulturen zur Grundlage für eine globale Menschenrechtspolitik. Paradoxerweise trage gerade das Unvorstellbare des Holocaust zu seiner Entkontextualisierung bei, was Levy und Sznaider positiv bewerten - von ihm aus entwickle sich ein Modell für Gut und Böse, Schuld und Unschuld. Die so neu entstandene „Schicksalsgemeinschaft“ definiere sich nicht mehr durch nationale Erfahrungen, sondern nehme den Holocaust zum Anlass, neue gemeinsame Bezüge jenseits des Nationalstaats herzustellen. „Die neuen Erinnerungen gelten den Opfern und nicht den Tätern oder Helden. Damit ist der Holocaust zu einem universalen ,Container' für Erinnerungen an unterschiedliche Opfer geworden." ${ }^{13}$

2002 diagnostizierte auch der amerikanische Soziologe Jeffrey C. Alexander, dass der Holocaust zu einem universalisierten Symbol geworden sei. Doch diese Uni-

11 Volkhard Knigge, Europäische Erinnerungskultur. Identitätspolitik oder kritisch-kommunikative historische Selbstvergewisserung, in: Kulturpolitische Gesellschaft e.V. (Hg.), kultur.macht.europa - europa.macht.kultur. Begründungen und Perspektiven europäischer Kulturpolitik, Bonn 2008, 150-161, 157.

12 Daniel Levy/Natan Sznaider, Erinnerung im globalen Zeitalter: Der Holocaust, Frankfurt a. M. 2001, 10.

13 Ebd., 223. 
versalisierung habe zwei sehr verschiedene Gesichter. ${ }^{14}$ Universalisierung könne sowohl heißen, den Holocaust als „Zivilisationsbruch“ anzuerkennen, als auch, dass verschiedene Opfergruppen explizit oder implizit betonten, sie hätten „wie die Juden“ gelitten. Während der Begriff „Kosmopolitisierung des Holocaust“ die positive Bewertung dieser Entwicklung impliziert, ist „Universalisierung“ der neutralere Begriff, mit dem sich das Phänomen in seinen verschiedenen Ausprägungen erfassen lässt, ohne die Entwicklung normativ aufzuladen.

Auch Levy und Sznaider besserten im Vorwort zur Neuauflage ihres Buches fünf Jahre später ihre zunächst ungebrochen positive Einschätzung gewissermaßen nach, wenn sie 2007 kritischer schrieben:

Die Erinnerung an den Holocaust wird zu einer europäischen Erinnerung, die Europa dazu verhelfen kann, ein eigenes (wenn auch negatives) Wertesystem zu entwickeln. Der Preis, der dafür gezahlt wird, ist die Entkontextualisierung der Geschichte. Wenn aus ehemaligen Feinden nun Freunde werden, muss der alte historische Kontext verdrängt werden. ${ }^{15}$

Der Preis der Entkontextualisierung sei, dass es

in diesem Diskurs keine Juden und keine Deutschen mehr geben darf. Es gibt nur Menschen und Menschheit, wie auch aus dem Begriff der „Verbrechen gegen die Menschheit“ und der Entstehung eines moralischen und legalen Kodex gegen „Völkermord“ hervorgeht. ${ }^{16}$

Auch in seiner 2008 erschienenen Monographie kritisierte Sznaider: „Das jüdische Gedächtnis ist aus dem europäischen Diskurs verschwunden. Und das trotz aller Rituale und Gedenktage! Oder vielleicht auch deswegen. “"

Laut Dan Diner tritt an die Stelle des verlorengegangenen historischen Urteilsvermögens

14 Jeffrey Alexander, On the Social Construction of Moral Universals. The „Holocaust“ from War Crime to Trauma Drama, in: European Journal of Social Theory 5 (2002) 1, 5-85, 51.

15 Daniel Levy/Natan Sznaider, Erinnerung im globalen Zeitalter: Der Holocaust, Frankfurt a. M. 2007, 11.

16 Ebd., 15.

17 Natan Sznaider, Gedächtnisraum Europa. Die Visionen des europäischen Kosmopolitismus. Eine jüdische Perspektive, Bielefeld 2008, 7. 
ein universell drapierter moralisierender Diskurs über unterschiedslose Opferschaft. Ein solcher Diskurs wird in letzter Konsequenz vor einer Dekonstruktion des Gedächtnisses an den Zweiten Weltkrieg ebenso wenig halt machen wie vor der Geltung und Bedeutung des Holocaust. ${ }^{18}$

Auch in Deutschland, dem Land des „negativen Gedächtnisses“, trifft dies für Aufrechnungsdiskurse über Bombenopfer und Vertriebene zu. Der französische Zeithistoriker Henry Rousso diagnostiziert im Zusammenhang damit einen sich beschleunigenden Prozess der „Viktimisierung“ bzw. der „Geschichtsbetrachtung aus der Opferperspektive“ nach der Wende vom 20. zum 21. Jahrhundert:

Es ist erstaunlich, wie sehr historische Erfahrungen wie der Widerstand gegen den Nationalsozialismus oder die antikolonialen Befreiungskämpfe heute den Opferstatus hervorkehren, während sie in der Vergangenheit eher die Figur des Helden bevorzugten (des Märtyrers, der für eine Sache stirbt und sich für die Gemeinschaft opfert). [...] Allerdings hat die Identifikation mit den Opfern, die in der traditionellen Geschichtsbetrachtung der Staaten, Sieger, Gelehrten usw. ja tatsächlich vergessen wurden, heute zur Überbewertung dieser Perspektive geführt. ${ }^{19}$

Diese Entkontextualisierung der historischen Ereignisse im Zuge der Universalisierung des Holocaust als „negative Ikone“ (Dan Diner) der Menschheit und „Container" für andere Erinnerungen ist nur eines der Probleme, die die wissenschaftliche Literatur thematisiert.

Das Verständnis des Holocaust als einzigartigem Ereignis führt zu einem Konflikt mit anderen Opfererfahrungen. Im Zuge der EU-Beitrittsbemühungen der postsozialistischen Länder trat die Erinnerung an die stalinistischen und sozialistischen Verbrechen, insbesondere den Gulag, in Konkurrenz zur Holocausterinnerung. Während amerikanische PolitikerInnen beispielsweise gegenüber NATO-Beitrittskandidaten auf die Bedeutung der ITF hinwiesen, um sich gemeinsamer Werte und Ziele zu versichern, finden sich keine Belege dafür, dass EU-Gremien einen bestimmten Umgang mit dem Holocaust offiziell zum Beitrittskriterium für postsozialistische Länder gemacht hätten. Die meisten Beitrittskandidaten traten aber vor

18 Dan Diner, Gegenläufige Gedächtnisse. Über Geltung und Wirkung des Holocaust, Göttingen $2007,8$.

19 Henry Rousso, Das Dilemma eines europäischen Gedächtnisses, in: Zeithistorische Forschungen 1 (2004) 3, 363-378, 374. 
oder rund um ihren EU-Beitritt der ITF bei, die sich 2013 in International Holocaust Remembrance Alliance (IHRA) umbenannte.

Anlässlich des sechzigsten Jahrestags des Kriegsendes wurden auf EU-Ebene die letzten Deklarationen verabschiedet, die noch als ungebrochener Ausdruck der „Europäisierung des Holocaust“ gedeutet werden können. In der „European Parliament resolution on the 6oth anniversary of the end of the Second World War in Europe on 8 May 1945" wird hervorgehoben, dass für manche Nationen das Ende des Zweiten Weltkrieges eine neue Tyrannei durch die Sowjetunion nach sich gezogen habe. Es folgte 2008 die „Erklärung des 23. August zum Europäischen Tag des Gedenkens an die Opfer von Stalinismus und Nazismus“ und seitdem noch einige weitere Entschließungen in ähnlichem Stil. ${ }^{20}$ Den postsozialistischen Mitgliedstaaten gelang es unmittelbar nach dem EU-Beitritt, den Fokus von der „Europäisierung des Holocaust“ auf eine „Europäisierung der Erinnerung“ zu verschieben. Letztere impliziert aber nicht einfach die Erinnerung an die Verbrechen von Stalinismus und Staatssozialismus als eine weitere unverzichtbare Komponente, sondern betreibt eine Gleichsetzung von Nationalsozialismus und Stalinismus als "gleichermaßen“ verbrecherisch.

\section{2. Österreichisches Gedächtnis - Verdrängung und Aufarbeitung}

Auch in Österreich verstärkte sich im ausgehenden 20. Jahrhundert die Tendenz einer transnationalen Synchronisierung bzw. Europäisierung der Erinnerungskultur. ${ }^{21}$ Dabei ist ebenso wie in anderen EU-Ländern seit Mitte der 198oer-Jahre eine Verschränkung von drei Prozessen zu beobachten.

1. Konfliktreiche Grundsatzdebatten über den Umgang mit der bislang ausgeblendeten NS-Vergangenheit brechen auf. Wie im Historikerstreit in der Bundesrepublik Deutschland wurden in der Waldheim-Debatte in Österreich die jeweiligen „Nachkriegsmythen“ - die Relativierung der deutschen Schuld durch den Vergleich mit den Verbrechen der „anderen“, die These von Österreich als „erstem Opfer“ - entscheidend relativiert. In vielen europäischen Ländern, seit 1989 auch in postkommunistischen Staaten, gewannen Fragen von Kollabora-

20 Marek Kucia, The Europeanization of Holocaust Memory and Eastern Europe, in: East European Politics and Societies and Cultures 30 (2016) 1, 97-119, 106.

21 Vgl. dazu im Überblick: Heidemarie Uhl, Opferthesen, revisited. Österreichs ambivalenter Umgang mit der NS-Vergangenheit, in: Aus Politik und Zeitgeschichte 68 (2018) 34-35, 47-54. 
tion und insbesondere der Mitverantwortung für die Deportation und Ermordung der jüdischen Bevölkerung an Relevanz. ${ }^{22}$

2. Eine neue Erinnerungskultur für bislang ausgeblendete Opfergruppen, vor allem die Opfer der Shoah, etabliert sich. Nationale Holocaustgedenktage werden eingerichtet, angestoßen durch zivilgesellschaftliches Engagement entstehen nun die oft ersten Denkmäler für die deportierten und ermordeten jüdischen BürgerInnen, von nationalen Flaggschiffprojekten in den Hauptstädten bis hin zu „Stolpersteinen“ vor ehemaligen Wohnhäusern.

3. Die wissenschaftliche Reflexion über Geschichtspolitik und Erinnerungskultur verläuft parallel zur Entfaltung des gesellschaftlichen Interesses an der NSVergangenheit. Darauf ist wohl auch zurückzuführen, dass „Gedächtnis“ im deutschsprachigen Raum zu dem Leitbegriff des Cultural Turn ${ }^{23}$ wurde, während im angloamerikanischen Raum die Frage nach Identitätskonstruktionen in Bezug auf „race, class, gender“ im Vordergrund stand. In Österreich erschien 1993 mit „Österreichisches Gedächtnis“ von Meinrad Ziegler und Waltraud Kannonier-Finster die erste wissenschaftliche Arbeit, die mit dem Gedächtnisbegriff operierte. „Gedächtnis“ wurde damit zum Synonym für die „Verdrängungsgeschichte“ der Zweiten Republik, für die „spezifisch österreichisch[e] Kultur des Erinnerns und Vergessens“ des Nationalsozialismus. ${ }^{24}$

Die Waldheim-Debatte führte zu einem Perspektivenwechsel im Forschungsfeld. Bis zur Zäsur 1986 standen der Austrofaschismus und der Widerstand 1934 bis 1945 im Zentrum der Zeitgeschichtsforschung. Nun wurde erstmals die „NS-Herrschaft in Österreich“ - so der Titel eines 1988 publizierten Sammelbandes - breit thematisiert. Im wissenschaftlichen wie auch im intellektuellen Diskurs richtete sich die Kritik zentral auf die Opferthese, ${ }^{25}$ die durch die Präambel zur Unabhängigkeitserklärung vom 27. April 1945 zur Staatsdoktrin erhoben worden war. Robert Menasse sprach in einem vielbeachteten Essay etwa davon, dass die Zweite Republik „auf

22 Vgl. die Beiträge zu den nationalen Ausprägungen europäischer Erinnerung in Monika Flacke (Hg.), Mythen der Nationen. 1945 - Arena der Erinnerungen, Mainz 2004.

23 Vgl. Ljiljana Radonić/Heidemarie Uhl, Zwischen Pathosformel und neuen Erinnerungskonkurrenzen. Das Gedächtnis-Paradigma zu Beginn des 21. Jahrhunderts. Zur Einleitung, in: dies. (Hg.), Gedächtnis im 21. Jahrhundert. Zur Neuverhandlung eines kulturwissenschaftlichen Leitbegriffs, Bielefeld 2016, 7-25.

24 Waltraud Kannonier-Finster/Meinrad Ziegler, Einleitung und Ausgangspunkte, in: dies., Österreichisches Gedächtnis. Über Erinnern und Vergessen der NS-Vergangenheit, Wien 1993, 35-39, 39.

25 Vgl. Peter Pirker, The Victim Myth Revisited. Politics of History in Austria up until the Waldheim Affair, in: Günter Bischof/Marc Landry/Christian Karner, Myths in Austrian History. Construction and Deconstruction (Contemporary Austrian Studies 29), Innsbruck 2020, 153-174. 
einer Geschichtslüge begründet wurde, auf der Lüge, dass Österreich ausschließlich Opfer der Nazi-Aggression gewesen sei““ ${ }^{26}$

In Bezug auf die Frage, inwieweit Österreich tatsächlich eine Sonderstellung einnimmt oder aber im europäischen Mainstream der Entwicklung von der Verdrängung zur Aufarbeitung zu verorten ist, wies Tony Judt auf die europäischen Gemeinsamkeiten im Umgang mit der NS-Vergangenheit hin. Er zeigte auf, dass die politischen Mythen Nachkriegseuropas trotz der unterschiedlichen ereignisgeschichtlichen Hintergründe ein gemeinsames narratives Muster aufwiesen: Die NSZeit werde als eine von außen aufgezwungene Fremdherrschaft und das eigene Volk als unschuldiges Opfer eines brutalen Okkupationsregimes dargestellt, gegen das sich die mutigen Helden und Märtyrer des Widerstands aufgelehnt hätten. Bemerkenswert ist, dass die Ermordung der jüdischen Bevölkerung in den Nachkriegsjahrzehnten insgesamt nur eine marginale Rolle spielte. ${ }^{27}$ Die Darstellung der Nation als Opfer und des Widerstands als nationaler Freiheitskampf ermöglichte es den europäischen Nachkriegsgesellschaften, die Frage der Mitwirkung von Teilen der eigenen Bevölkerung am NS-Terrorregime zu „externalisieren“. Für die NS-Verbrechen und insbesondere den Holocaust wurde allein Nazideutschland (bzw. die Bundesrepublik als Rechtsnachfolgerin) verantwortlich gemacht. ${ }^{28}$

Im Unterschied zu besetzten bzw. kollaborierenden Ländern war Österreich aber von 1938 bis 1945 integraler Bestandteil des Deutschen Reiches, die ÖsterreicherInnen waren deutsche StaatsbürgerInnen, rund 1,3 Millionen waren als Soldaten der Deutschen Wehrmacht am Kriegsgeschehen beteiligt. Nach 1945 waren mehr als 500.000 als ehemalige Mitglieder der NSDAP von der Entnazifizierung betroffen. Wenn selbst Österreich seine NS-Vergangenheit negieren konnte, dann hatten andere Länder weitaus mehr Anrecht auf einen Opferstatus. Tony Judt resümiert: „War

26 Robert Menasse, Das Land ohne Eigenschaften. Essay zur österreichischen Identität, Wien ${ }^{3} 1993$, 15.

27 Vgl. Tony Judt, Die Vergangenheit ist ein anderes Land. Politische Mythen im Nachkriegseuropa, in: Transit. Europäische Revue 6/1993, 87-120.

28 Aber auch in der Nachkriegsbundesrepublik stand das „eigene Leid“ - Opfer der Vertreibung und des Bombenkriegs - vielfach im Vordergrund. Der Schuldabwehr diente auch die Vorstellung, dass nur Hitler und die NS-Führungsspitzen für die Verbrechen des Regimes verantwortlich zu machen seien. Vgl. Katrin Hammerstein, Gemeinsame Vergangenheit - getrennte Erinnerung? Der Nationalsozialismus in Gedächtnisdiskursen und Identitätskonstruktionen von Bundesrepublik Deutschland, DDR und Österreich, Göttingen 2017, 68-70; zur Kritik der deutschen Aufarbeitungskultur vgl. zuletzt Samuel Salzborn, Kollektive Unschuld. Die Abwehr der Shoah im deutschen Erinnern, Leipzig/Berlin 2020. 
Österreich schon schuldlos, so bedurfte offenbar auch die besondere Verantwortung anderer Nicht-Deutscher in anderen Ländern keiner genaueren Überprüfung. “29

Der österreichische Fall ist allerdings weitaus komplexer, als es die von 1945 bis zur Waldheim-Debatte und darüber hinaus auf offizieller Ebene vertretene Opferthese und ihre kritische Entlegitimierung seit 1986 nahelegen. Das Selbstverständnis als „,erstes Opfer" hat keineswegs durchgängig die Haltung zur NS-Vergangenheit in der Zweiten Republik bestimmt. Dies war nur in der ersten Nachkriegszeit, während der kurzen Phase des antinazistischen Grundkonsenses aller politisch-gesellschaftlichen Kräfte der Fall. Ab Ende der 1940er-Jahre erlangten wirkungsmächtige Gegenerzählungen vielfach eine hegemoniale Position, vor allem im Zusammenhang mit dem „Heldengedenken“ für die gefallenen österreichischen Wehrmachtssoldaten. Die Widersprüche zwischen den konträren Sichtweisen auf die NS-Zeit führten, wie im Folgenden gezeigt wird, immer wieder zu Konflikten. Aber erst die Waldheim-Debatte 1986 sollte Österreich nachhaltig mit seiner NS-Vergangenheit konfrontieren und den Auftakt zum Europäisierungsprozess des österreichischen Gedächtnisses bilden.

\subsection{Die offizielle These: „Erstes Opfer" des Nationalsozialismus}

Im August 1945 fand am Wiener Schwarzenbergplatz die Enthüllung des von der sowjetischen Besatzungsmacht errichteten Denkmals für die Rote Armee statt, die Wien im April 1945 befreit hatte. Bei dieser Feier erklärte der damalige Staatssekretär und spätere Bundeskanzler Leopold Figl (ÖVP):

Sieben Jahre schmachtete das österreichische Volk unter dem Hitlerbarbarismus. Sieben Jahre wurde das österreichische Volk unterjocht und unterdrückt, kein freies Wort der Meinung, kein Bekenntnis zu einer Idee war möglich, brutaler Terror und Gewalt zwangen die Menschen zu blindem Untertanentum..$^{30}$

Figls Rede ist ein typisches Beispiel für die parteienübergreifende , antifaschistische Haltung der ersten Nachkriegszeit. Die Basis dafür wurde in der Proklamation über die Selbständigkeit Österreichs vom 27. April 1945 gelegt. Die vielzitierte Formulierung „das erste freie Land, das der Hitlerschen Aggression zum Opfer gefallen ist“

29 Judt, Die Vergangenheit, 91 (Hervorhebung im Original).

30 Zit. n. Mahnmal unerbittlicher Gerechtigkeit, Das Kleine Volksblatt, 21.08.1945, 1-2. 
wurde wörtlich aus der Moskauer Deklaration der alliierten Außenminister vom 30. Oktober 1943 übernommen. ${ }^{31}$

Aus gegenwärtiger Sicht wird die Moskauer Deklaration instrumentalisiert, denn die mit der Formulierung „erstes Opfer“ verbundene Aussicht auf eine Wiederherstellung Österreichs diente nicht nur, aber auch der psychologischen Kriegsführung bzw. dem weitgehend erfolglosen Versuch, einen österreichischen Widerstand zu motivieren. ${ }^{32}$ Der Vorwurf, die Opferthese sei eine „Geschichtslüge“,33 greift jedoch zu kurz. Zum einen eröffnete sich damit in der prekären Lage zu Kriegsende die Möglichkeit der Distanzierung von NS-Deutschland, die von den Gründungsvätern der Zweiten Republik naturgemäß aufgegriffen wurde. Zum anderen durchdrang in der ersten Nachkriegszeit das damit verbundene antinationalsozialistische, österreichpatriotische Bekenntnis die politische Symbolik und Rhetorik in allen Bereichen des öffentlichen Lebens. Im neuen Staatswappen, proklamiert mit dem 1. Mai 1945, wurde der aus der Ersten Republik übernommene Adler mit einer gesprengten Eisenkette „zur Erinnerung an die Wiedererringung der Unabhängigkeit Österreichs und den Wiederaufbau des Staatswesens“ versehen. ${ }^{34}$ Das 1946 von der Bundesregierung herausgegebene „Rot-Weiß-Rot-Buch“ präsentierte amtliche Belege für den Widerstand und forderte daher „Gerechtigkeit für Österreich“.35 Die Errichtung von monumentalen Widerstandsdenkmälern in Wien und in den Bundesländern wurde beschlossen - allerdings sollten nur wenige davon realisiert werden. Einen Höhepunkt der Auseinandersetzung mit dem Nationalsozialismus bildete die offiziöse „Antifaschistische Ausstellung“ mit dem Titel „Niemals vergessen!“, 1946 im Wiener Künstlerhaus gezeigt. NS-Terror, Krieg, auch die Judenverfolgung wurden eindrucksvoll angeprangert, aber zugleich dem deutschen Faschismus bzw. dem preußischen Militarismus zugeschrieben. ${ }^{36}$ Dass es sich dabei um eine „unösterreichische“, im Widerspruch zum österreichischen „Volkscharakter“ stehende

31 Proklamation über die Selbständigkeit Österreichs, Staatsgesetzblatt für die Republik Österreich, 1/1945, 01.05.1945, 2.

Vgl. Robert H. Keyserlingk, Austria in World War II. An Anglo-American Dilemma, Kingston/ Montreal 1988; dazu kritisch: Gerald Stourzh, Um Einheit und Freiheit. Staatsvertrag, Neutralität und das Ende der Ost-West-Besetzung Österreichs 1945-1955, Wien/Köln/Graz 2005, 24-25.

33 Menasse, Land ohne Eigenschaften, 15.

34 Staatsgesetzblatt für die Republik Österreich, 2/1945, 01.05.1945, 13.

35 Bundeskanzleramt (Hg.), Rot-Weiß-Rot-Buch. Gerechtigkeit für Österreich! Darstellungen, Dokumente und Nachweise zur Vorgeschichte und Geschichte der Okkupation Österreichs. Nach amtlichen Quellen. Erster Teil, Wien 1946, 3. - Ein geplanter zweiter Band wurde nicht publiziert.

36 Vgl. Wolfgang Kos, Die Schau mit dem Hammer. Zur Planung, Ideologie und Gestaltung der antifaschistischen Ausstellung „Niemals vergessen!“, in: ders., Eigenheim Österreich. Zu Politik, Kultur und Alltag nach 1945, Wien 1994, 7-58. 
Ideologie gehandelt habe, wurde zu einem Grundpfeiler des österreichischen Nationalbewusstseins. ${ }^{37}$

Die Ausstellung „Niemals vergessen!“ bildete den Höhe, aber auch den Endpunkt der Gründungserzählung eines aus dem Geist des Antifaschismus wiedererstandenen Österreich. Spätestens 1948, mit dem Beginn des Kaltes Krieges und der Reintegration der ehemaligen NationalsozialistInnen, zeichnete sich ein Richtungswechsel ab. Durch das Nationalsozialistengesetz 1947 erlangten rund 487.000 „Minderbelastete" (ca. 92 Prozent der ehemaligen österreichischen NSDAP-Mitglieder) wieder das Wahlrecht. ${ }^{38}$ Die Konkurrenz um das beträchtliche Stimmenpotenzial der „Ehemaligen“ wurde ab nun zur Signatur der politischen Kultur in der Zweiten Republik. Umworben wurde diese Wählerschicht sowohl von den beiden Großparteien SPÖ und ÖVP als auch von dem 1949 als Sammelbecken für ehemalige NationalsozialstInnen gegründeten Verband der Unabhängigen (VdU), aus dem 1956 die FPÖ hervorging. ${ }^{39}$

Die veränderte Situation hatte entscheidende Auswirkungen auf die Semantik der Opferthese. Die Würdigung des Widerstands, zentrales Argument zur Untermauerung des in der Moskauer Deklaration von Österreich geforderten „eigenen Beitrags zu seiner Befreiung", fand Ende der 1940er-Jahre ein abruptes Ende. Der Widerstand stand nun unter Kommunismusverdacht, Denkmäler waren im antikommunistischen Klima der 1950er- und 1960er-Jahre kaum noch realisierbar.

Vor diesem Hintergrund beriefen sich österreichische Politiker - auch und gerade jene, die in der NS-Zeit als Regimegegner inhaftiert waren - auf die Opferthese nur noch in der Selbstdarstellung nach außen, vor allem als Argument in den Verhandlungen um den Staatsvertrag und zur Abwehr von Wiedergutmachungsansprüchen jüdischer Organisationen. In Österreich selbst wurde sie zunehmend auf den Minimalkonsens reduziert: dass das Land mit dem Nationalsozialismus nichts zu tun gehabt habe. Die österreichische Geschichte endete am 13. März 1938 mit dem Gesetz über die „Wiedervereinigung Österreichs mit dem Deutschen Reich“ und begann wieder am 27. April 1945. Die Jahre dazwischen bildeten eine Leerstelle, denn sie gehörten zur deutschen Geschichte (Nationalsozialismus) oder zur Weltgeschichte

37 Vgl. Werner Suppanz, Österreichische Geschichtsbilder. Historische Legitimation in Ständestaat und Zweiter Republik, Wien 1998.

38 Vgl. Winfried R. Garscha, Entnazifizierung und gerichtliche Ahndung von NS-Verbrechen, in: Emmerich Tálos/Ernst Hanisch/Wolfgang Neugebauer/Reinhard Sieder (Hg.), NS-Herrschaft in Österreich. Ein Handbuch, Wien 2000, 852-883, 859.

39 Vgl. Margit Reiter, Die Ehemaligen. Der Nationalsozialismus und die Anfänge der FPÖ, Göttingen 2019. 
(Zweiter Weltkrieg). Der Staat Österreich, so die Begründung, habe nicht existiert und sei somit an beiden nicht beteiligt gewesen.

\subsection{Die populistische Antithese: Opfer des Krieges gegen den Nationalsozialismus}

In dieser Leerstelle konnte sich eine gegenläufige Opfererzählung etablieren, die jahrzehntelang innerhalb Österreichs weitaus wirkmächtiger war als die offizielle Selbstdarstellung als „erstes Opfer“. Die populistische Antithese zum antifaschistischen Geist von 1945 manifestiert sich im „Heldengedenken“ an die Gefallenen. In der Unabhängigkeitserklärung waren die österreichischen Wehrmachtssoldaten als Opfer eines „sinn- und aussichtslosen Eroberungskrieg[es]“ betrauert worden. Wenige Jahre später wurden sie als Helden der „Pflichterfüllung“ und der „Tapferkeit“ gewürdigt, die die „Heimat“ gegen die „Feinde aus dem Osten“ verteidigt hätten. Ab Beginn der 1950er-Jahre wurden Kriegerdenkmäler für den Ersten Weltkrieg um die Namen der Toten erweitert oder neu errichtet. Die Aufmärsche und „Heldengedenkfeiern" des ab 1952 wieder zugelassenen Kameradschaftsbundes machten deutlich, dass es nicht allein um das Totengedenken, sondern auch um die symbolische Rehabilitierung der überlebenden Wehrmachtssoldaten ging. Bei der Weihe des 1951 errichteten Denkmals auf dem Soldatenfriedhof des Zentralfriedhofs von Graz kommentierte die führende regionale Tageszeitung:

Es war eines der traurigsten Zeichen der Nachkriegszeit, daß die Überlebenden das Andenken ihrer Gefallenen auslöschen sollten in selbstzerfleischender Anklage und grausamer Selbstbeschuldigung. Wir können uns nur freuen, daß diese Zeit überwunden ist und daß sich die Heimat durch die Erneuerung und Neugestaltung von Kriegerdenkmälern wieder zu ihren im härtesten Kampf gefallenen Söhnen bekennt. ${ }^{40}$

Die Denkmallandschaft ist ein Indikator für die Durchdringung der österreichischen Gesellschaft mit einem Geschichtsbild, das im Widerspruch zur Opferthese steht. Kriegerdenkmäler zählen zum selbstverständlichen Inventar praktisch jeder Gemeinde. Das Gefallenengedenken zu Allerseelen, gemeinsam getragen von Kirche und Kameradschaftsbund, wurde Bestandteil der lokalen Folklore. Die öffentliche Präsenz von Gedenkstätten für die Opfer der NS-Gewaltherrschaft blieb - außerhalb Wiens - hingegen marginal. Das Gedenken an die mehr als 66.00o jüdischen

40 Dem Andenken der Gefallenen, Kleine Zeitung, 05.06.1951, 4. 
ÖsterreicherInnen, die der Shoah zum Opfer gefallen waren, sollte aber auch in der Bundeshauptstadt bis in die 1980er-Jahre eine Leerstelle bleiben. ${ }^{41}$

Die machtvolle, auf regionaler und lokaler Ebene vielfach hegemoniale Gegenthese zur offiziellen Sprachregelung sah die ÖsterreicherInnen somit nicht als Opfer des Nationalsozialismus, sondern als Opfer des Krieges gegen den Nationalsozialismus - zivile und militärische Opfer der alliierten Armeen, Opfer des Bombenkrieges, Opfer von Vergewaltigungen durch Rotarmisten.

Die gegensätzlichen Sichtweisen brachen fallweise in Denkmalkonflikten auf. So weigerte sich der niederösterreichische Kameradschaftsbund 1963, an der Weihe einer Gedenkstätte für Priester im niederösterreichischen Wallfahrtsort Maria Langegg teilzunehmen, weil namentlich neben den Gefallenen des Ersten und Zweiten Weltkriegs auch drei im KZ ermordete Geistliche geehrt wurden. Begründet wurde der Boykott folgendermaßen: Die „ehrlichen Soldaten, die das Priesterkleid trugen, ihren Eid hielten und dafür starben“, sollten nicht „mit den verschiedenen Erscheinungen gegensätzlicher Art" gleichgestellt werden. ${ }^{42}$

Kontrovers war insbesondere die Beurteilung des Kriegsendes - für die offizielle Opferthese bedeutete das Jahr 1945 die Befreiung vom Nationalsozialismus, für die populistische Gegenthese Bomben, Chaos, Not, Zusammenbruch, Übergriffe der sowjetischen Besatzungssoldaten und den Beginn der zehnjährigen Besatzungszeit. Allerdings war dieses Konfliktpotenzial insofern entschärft, als „1945“ seit der Unterzeichnung des Staatsvertrages mit „1955“ ̈̈berschrieben wurde. Bis in die jüngste Zeit war es eine österreichische Besonderheit, dass die "runden“ Jahrestage des Kriegsendes in der österreichischen Geschichtskultur praktisch keine Rolle spielten. Denn in den „5er-Jahren“ wurde das Jubiläum des Staatsvertrages begangen, als Reinszenierung des eigentlichen Gründungsmythos der Zweiten Republik: der Erfolgsgeschichte eines kleinen Landes zwischen den Blöcken, das den übermächtigen Alliierten seine Freiheit abgetrotzt hatte. Damit unterblieb aber auch die Auseinandersetzung mit der Bedeutung des Jahres 1945. Eine Meinungsumfrage aus dem Jahr 1998 zeigt jedenfalls, dass nicht die Gründung der Zweiten Republik, sondern der 15. Mai 1955 als eigentlicher Tag der Freiheit galt. 20 Prozent der Befragten waren „stolz“ auf diesen Tag, nur 1 Prozent votierte für den 27. April 1945.43

41 Heidemarie Uhl, From the Periphery to the Center of Memory: Holocaust Memorials in Vienna, in: Dapim. Studies on the Holocaust 30 (2016) 3, 221-242.

42 NÖ. Landzeitung, F.37, 12.09.1963, zit. n. Am Beispiel Maria - Langegg, Die Furche, 14.09.1963, abgedruckt in: Walter Hacker (Hg.), Warnung an Österreich. Neonazismus: Die Vergangenheit bedroht die Zukunft, Wien/Frankfurt a. M./Zürich 1966, 170-171.

43 Vgl. Emil Brix/Ernst Bruckmüller/Hannes Stekl, Einleitung, in: dies. (Hg.), Memoria Austriae, 14. 


\subsection{Von der Entlegitimierung zur Reaktivierung - Transformationen der Opferthese}

In der Waldheim-Debatte stand die Formulierung vom „ersten Opfer“ als Angelpunkt der österreichischen „Lebenslüge“ im Zentrum der Kritik. Dem wäre entgegenzuhalten, dass - wie gezeigt - die Opferthese keineswegs durchgängig den Umgang mit der NS-Vergangenheit bestimmte. Insbesondere nach der Wiedererlangung der vollen Souveränität erschien die Berufung auf den Widerstand, die seit Kriegsende zur Erlangung des Staatsvertrags ins Treffen geführt worden war, vielfach obsolet. Nach 1955 mehrten sich deutschnationale und „neonazistische“ Manifestationen. Als Fanal für das Wiedererstarken der alten und neuen „Unbelehrbaren“ gilt die Schillerfeier 1959, als Burschenschaften und deutschnationale Organisationen auf der Wiener Ringstraße einen machtvollen Fackelzug veranstalteten. Zu den zahlreichen „Naziaktivitäten“ kamen skandalöse Freisprüche hochrangiger NSTäter (etwa 1963 im Prozess gegen Franz Murer, den „Schlächter von Vilnius“).44 Wie bedrohlich die Tendenz einer „Renazifizierung“ ${ }^{45}$ war, wurde 1965 in der Affäre Borodajkewycz evident. Taras Borodajkewycz, Professor für Neuere Geschichte an der Wiener Hochschule für Welthandel, war durch deutschnationale und antisemitische Äußerungen aufgefallen, sein provokantes Auftreten in einer vom Fernsehen übertragenen Pressekonferenz löste Demonstrationen von GegnerInnen und AnhängerInnen aus (unter anderem wurde dabei „Hoch Auschwitz!“ gerufen), bei denen ein Demonstrant, der ehemalige kommunistische Widerstandskämpfer Ernst Kirchweger, von einem einschlägig vorbestraften Rechtsradikalen tödlich verletzt wurde. ${ }^{46}$ Die „chronique scandaleuse“ setzte sich 1975 fort, mit dem Konflikt zwischen Bundeskanzler Kreisky und Simon Wiesenthal, als dieser den Einsatz von FPÖ-Parteiobmann Friedrich Peter in einer berüchtigten SS-Einheit aufdeckte.

Die offizielle Opferthese blieb von diesen Skandalen und Konflikten nicht unberührt, vielmehr: Sie bezog daraus neue semantische Impulse. In den medial ausgetragenen Kontroversen über das Wiedererstarken von Deutschnationalismus, Antisemitismus und NS-nahem Gedankengut formierte sich eine Verteidigungsposition, getragen von konservativ-katholischen PatriotInnen, ehemaligen WiderstandskämpferInnen aller politischen Richtungen und jungen HistorikerInnen

44 Vgl. Thomas Albrich/Winfried R. Garscha/Martin F. Polaschek (Hg.), Holocaust und Kriegsverbrechen vor Gericht. Der Fall Österreich, Innsbruck/Wien/Bozen 2006.

45 Walter Hacker (Hg.), Warnung an Österreich. Neonazismus: Die Vergangenheit bedroht die Zukunft, Wien/Frankfurt a. M./Zürich 1966.

46 Vgl. Gerard Kasemir, Spätes Ende für „wissenschaftlich“ vorgetragenen Rassismus. Die Affäre Borodajkewycz, in: Michael Gehler/Hubert Sickinger (Hg.), Politische Affären und Skandale in Österreich. Von Mayerling bis Waldheim, Thaur/Wien/München 1995, 486-501. 
der 1968er-Generation. Ihre Kritik richtete sich allerdings nicht - wie später in der Waldheim-Debatte - auf die Opferthese, sondern, im Gegenteil, auf deren Bedeutungsverlust in der politischen Kultur, vor allem auf die mangelnde Anerkennung des Widerstands als Grundlage für das Wiedererstehen Österreichs 1945. Es zählt zu den Verdiensten der in der Kreisky-Ära verstärkt institutionalisierten wissenschaftlichen Zeitgeschichte, den vielfach geleugneten oder als kommunistisch diffamierten „österreichischen Widerstand“ neu im Geschichtsbewusstsein verankert und vor allem in die Schulbücher gebracht zu haben. Erst durch die historisch-politische Bildungsinitiative der 1970er-Jahre (unter anderem durch den Grundsatzerlass „Politische Bildung" 1978) wurde die Opferthese des Jahres 1945 in ihrem ursprünglichen antinationalsozialistischen Geist nachhaltig reaktiviert. Einen weiteren kaum zu unterschätzenden Einfluss hatte die emotionale Erschütterung durch die Serie „Holocaust“, 1979 kurz nach der Ausstrahlung in der Bundesrepublik auch im ORF gesendet. Dieser Wissenshorizont war prägend für jene Generation, die 1986 den Kampf gegen das Geschichtsbild der Verharmlosung und Verdrängung aufnehmen sollte, das von Kurt Waldheim symbolisiert wurde.

2.4 Waldheim-Affäre 1986 - Das Zerbrechen des Opfermythos und die Europäisierung des österreichischen Gedächtnisses

Im Epizentrum der Waldheim-Affäre stand der berühmte Satz, mit dem sich der ÖVP-Präsidentschaftskandidat gegen den Vorwurf der Beteiligung an Kriegsverbrechen auf dem Balkan rechtfertigte: „Ich habe im Krieg nichts anderes getan als Hunderttausende andere Österreicher, nämlich meine Pflicht als Soldat erfüllt" ${ }^{47}$ Das Ausmaß an Unverständnis und Ablehnung, auf das Waldheims Aussage über die „Pflichterfüllung“ in der Wehrmacht stieß, war durchaus bemerkenswert. Ein Jahrzehnt zuvor hatte dieses Argument noch keinen Anstoß erweckt. 1975 hatte sich FPÖ-Parteiobmann Friedrich Peter mit den Worten ,Ich habe lediglich meine Pflicht erfüllt" gegen Simon Wiesenthals Aufdeckung seiner SS-Vergangenheit verteidigt. ${ }^{8}$ Kurt Waldheims Rechtfertigung, dass er „nach vielen Jahren im Ausland

47 Kurt Waldheim in einer Wahlbroschüre vom April 1986, zit. n. Neues Österreich (Hg.), Pflichterfüllung. Ein Bericht über Kurt Waldheim, Wien 1986, Einband. - Waldheim verwendete dieses Argument erstmals in der ORF-Pressestunde am 09.03.1986, vgl. Cornelius Lehnguth, Waldheim und die Folgen. Der parteipolitische Umgang mit dem Nationalsozialismus in Österreich, Frankfurt a. M. 2013, 94.

48 Vgl. Ingrid Böhler, „Wenn die Juden ein Volk sind, so ist es ein mieses Volk.“ Die Kreisky-PeterWiesenthal-Affäre 1975, in: Michael Gehler/Hubert Sickinger (Hg.), Politische Affären und Skandale in Österreich. Von Mayerling bis Waldheim, Thaur/Wien/München 1996, 502-531. 
nicht wissen habe können, daß sich mittlerweile das geistige Klima in Österreich dahingehend verändert habe, daß ein solcher Satz nicht mehr selbstverständlich von allen akzeptiert werde“,49 kann insofern eine gewisse Schlüssigkeit nicht abgesprochen werden.

Der Waldheim-Skandal und das zwei Jahre danach anlässlich der fünfzigjährigen Wiederkehr des „Anschlusses“ begangene „Gedenkjahr 1938/1988“ brachten für Österreich jene kathartische Grundsatzdebatte um die verdrängte NS-Vergangenheit, ${ }^{\circ}$ die charakteristisch für die europäischen „memory wars“" ${ }^{5_{1}} \mathrm{im}$ ausgehenden 20 . Jahrhundert ist. Auch das traditionelle Gefallenengedenken wurde nun in neuem Licht gesehen: als machtvolles Symbol für die nach wie vor ungebrochene Präsenz der „unbewältigten Vergangenheit“ in der regionalen und lokalen Erinnerungskultur. Kriegerdenkmäler repräsentierten jenen „braunen, unterirdischen Fluß“,52 aus dem sich die gefühlsmäßigen Bindungen an die NS-Zeit speisten, sie wurden zum Indikator für die Verbreitung eines Geschichtsbewusstseins, das „eindeutig und unversöhnlich“ im Widerspruch zur „Philosophie“ der Zweiten Republik - der Opferthese - steht, wie Anton Pelinka in der ersten Studie zum problematischen „Heldengedenken“ für die Wehrmachtssoldaten schrieb: „Nichts von der Befreiung Österreichs durch die Alliierten und durch den österreichischen Widerstand, nichts von der Besetzung Österreichs durch Deutschland. " ${ }^{33}$ Die auch in österreichischen Städten gezeigte „Wehrmachtsausstellung“ sollte wenige Jahre später die Legende von der „sauberen Wehrmacht“ grundsätzlich in Frage stellen.

In den 1990er-Jahren entwickelte sich eine „Synchronisierung der Gedächtnislandschaften",54 nicht allein mit der Bundesrepublik Deutschland, sondern analog zur Neuausrichtung der europäischen Erinnerungskultur. 1991 erfolgte die offizielle Distanzierung von der Opferthese. Bundeskanzler Franz Vranitzky bekannte sich in seiner Rede vor dem Parlament zur „Mitverantwortung für das Leid, das zwar nicht Österreich als Staat, wohl aber Bürger dieses Landes über andere Menschen und Völker gebracht haben“.55 1997 wurde - nach einer Empfehlung des EU-Parlaments 1995,

49 Menasse, Land ohne Eigenschaften, 14-15.

50 Vgl. Heidemarie Uhl, Zwischen Versöhnung und Verstörung. Eine Kontroverse um Österreichs historische Identität fünfzig Jahre nach dem „Anschluß“, Wien/Köln/Weimar 1992.

51 Vgl. Dan Stone, Memory Wars in the „New Europe“, in: ders. (Hg.), The Oxford Handbook of Postwar European History, Oxford 2012, 715-731.

52 Josef Haslinger, Politik der Gefühle. Ein Essay über Österreich. Darmstadt/Neuwied 1987, 65.

53 Anton Pelinka, Vorwort, in: Reinhold Gärtner/Sieglinde Rosenberger, Kriegerdenkmäler. Vergangenheit in der Gegenwart, Innsbruck 1991, 7-8.

54 Hammerstein, Gemeinsame Vergangenheit - getrennte Erinnerung, 458-46o.

55 Zit. n. Gerhard Botz/Gerald Sprengnagel (Hg.), Kontroversen um Österreichs Zeitgeschichte. Verdrängte Vergangenheit, Österreich-Identität, Waldheim und die Historiker, Frankfurt a. M./New York ${ }^{2} 2008,575-576$. 
aber auch nach deutschem Vorbild - ein Gedenktag für die Opfer des Nationalsozialismus beschlossen, mit Zustimmung aller Parlamentsparteien. Allerdings fiel die Wahl nicht auf den 27. Januar, sondern auf den 5. Mai, den Tag der Befreiung des Konzentrationslagers Mauthausen - wohl auch um eine Differenz zur Bundesrepublik zu markieren. Am 26. Oktober 2000, dem Nationalfeiertag, wurde das Holocaustdenkmal am Wiener Judenplatz enthüllt.

Im Februar 2000 war Wolfgang Schüssel (ÖVP) eine Koalition mit der FPÖ eingegangen. Die erstmalige Regierungsbeteiligung einer rechtspopulistischen Partei in einem Land der EU galt als Verletzung des europäischen Wertekonsenses und führte zu Protesten in ganz Europa. Der Versuch der EU-Mitgliedstaaten, diesen Tabubruch durch „Sanktionen“ zu begegnen, war zwar rasch zum Scheitern verurteilt, führte aber doch dazu, dass sich FPÖ-Obmann Jörg Haider und der ÖVP-Vorsitzende und Bundeskanzler Wolfgang Schüssel auf Verlangen von Bundespräsident Thomas Klestil in einer Präambel zum Regierungsprogramm zu den „grundlegenden Werten der Demokratie in Europa" bekennen mussten. Dazu zählte vor allem auch die Selbstverpflichtung zur „kritischen Auseinandersetzung mit der NS-Vergangenheit“.

Österreich stellt sich seiner Verantwortung aus der [...] Geschichte des 20. Jahrhunderts und den ungeheuerlichen Verbrechen des nationalsozialistischen Regimes [...]. Die Einmaligkeit und Unvergleichbarkeit des Verbrechens des Holocaust sind Mahnung zu [...] Wachsamkeit gegen alle Formen von Diktatur und Totalitarismus. Die Bundesregierung [...] wird für vorbehaltlose Aufklärung, Freilegung der Strukturen des Unrechts und Weitergabe dieses Wissens an nachkommende Generationen als Mahnung für die Zukunft sorgen..$^{6}$

Es ist wohl kein Zufall, dass der Ton dieses Bekenntnisses an die Stockholm Declaration vom 27. Januar 2000 erinnert. 57

Angesichts der Orientierung der österreichischen Erinnerungskultur am europäischen bzw. globalen Holocaustgedächtnis ist es bemerkenswert, dass das Jahr 1945 erst spät in Diskussion geriet. Die berühmte Rede des deutschen Bundespräsidenten Richard von Weizsäcker anlässlich des vierzigsten Jahrestages des Kriegsendes hatte in Österreich praktisch keine Resonanz - 1985 wurde wieder die traditionelle Staats-

56 Präambel des Regierungsprogramms, zit. n. Die Präambel des Regierungsprogramms, Die Welt, 04.02.2000, URL: http://www.welt.de/print-welt/article500574/Die_Praeambel_des_Regierungsprogramms.html (abgerufen 20.05.2020).

57 Erklärung des Stockholmer Internationalen Forums über den Holocaust, URL: https://www.holocaustremembrance.com/stockholm-declaration (abgerufen 20.05.2020). 
vertragsfeier zelebriert. „1945“ war aber nach wie vor ein subkutanes geschichtspolitisches Minenfeld: Wurde Österreich besetzt oder befreit? Auf die Agenda geriet dieses Datum paradoxerweise durch die seit 2002 von schlagenden deutschnationalen Burschenschaften abgehaltene Totenehrung am 8. Mai in der Krypta des Österreichischen Heldendenkmals für die Gefallenen des Ersten und Zweiten Weltkriegs im Äußeren Burgtor der Wiener Hofburg. Im April 2002 hatten Rechtsextreme und Burschenschaften auf dem Heldenplatz gegen die Wehrmachtsausstellung demonstriert, mit Plakaten, auf denen „Großvater wir danken dir“ und „Wehrmachtssoldaten - wir gedenken Eurer Heldentaten“ zu lesen war. Am 8. Mai 2002 wurde von schlagenden Burschenschaften erstmals eine Gedenkfeier für die Wehrmachtssoldaten abgehalten, die auf starke öffentliche Kritik stieß. Bis 2012 wiederholte sich jährlich das gleiche Schauspiel: Der Heldenplatz wurde am 8. Mai weiträumig abgesperrt, Gegendemonstrationen der Zugang zum Platz verweigert. Die Burschenschaften wurden durch ein massives Polizeiaufgebot abgeschirmt und konnten den Platz exklusiv für ihre provokante Totenehrung nutzen. 2012 organisierte eine Plattform zivilgesellschaftlicher Initiativen ein „Fest der Freiheit“, dem ein Teil des Heldenplatzes zugestanden wurde. Seit 2013 wird der Tag des Kriegsendes mit einem „Fest der Freude“ auf dem ganzen Heldenplatz gefeiert, das Bundesheer beteiligt sich daran mit einer Mahnwache für die Opfer des Nationalsozialismus. ${ }^{58}$

Der Konflikt um den 8. Mai am Heldenplatz mag dazu beigetragen haben, dass 2015 nicht der Staatsvertrag, sondern erstmals das Kriegsende im Vordergrund stand. Der Festakt zum siebzigsten Jahrestag der Gründung der Republik Österreich eröffnete den Rahmen für eine Grundsatzerklärung von Bundespräsident Heinz Fischer:

Hat es nicht lange Zeit Streit über die Frage gegeben, ob Österreich 1945 tatsächlich befreit wurde, oder ob es nicht eher aus der Unfreiheit in Großdeutschland in die Unfreiheit durch die Besatzungsmächte geraten ist? Die klare Antwort lautet wie folgt: Österreich ist 1945 von einer unmenschlichen verbrecherischen Diktatur befreit worden. ${ }^{59}$

Im Gedenkjahr 2020 hat sich in der politischen Rhetorik und in der medialen Berichterstattung das Verständnis von 1945 als Befreiung von der nationalsozialisti-

58 Heidemarie Uhl, Von Helden und Opfern, in: Peter Stachel, Mythos Heldenplatz. Hauptplatz und Schauplatz der Republik, Wien 2018, 174-179.

59 Rede des Bundespräsidenten zum 70. Jahrestag der Gründung der Zweiten Republik im Wortlaut, APA-OTS, 27.04.2015, URL: https://www.ots.at/presseaussendung/OTS_20150427_OTSoo59/ rede-des-bundespraesidenten-zum-70-jahrestag-der-gruendung-der-zweiten-republik-im-wortlaut (abgerufen 20.05.2020). 
schen Gewaltherrschaft weitestgehend durchgesetzt. Der Staatsvertrag 1955 fand nur geringe mediale Resonanz, die Gewichtung zwischen der weltpolitischen Zäsur 1945 und dem vor allem national relevanten Datum 1955 wurde offenkundig neu austariert. ${ }^{60}$ Die österreichische Erinnerungskultur scheint in Europa angekommen zu sein.

60 Vgl. Heidemarie Uhl, 1945 versus 1955. Wie man Gedenken austariert, Die Presse, 09.05.2020. 


\title{
Justiz und Strafverfolgung
}

\author{
Christian Rabl
}

Eine "Standortbestimmung in Zeiten des Umbruchs“ erscheint beim Thema Justiz und Strafverfolgung besonders berechtigt zu sein, immerhin jährt sich 2020 das Ende des Zweiten Weltkriegs bereits zum 75. Mal und das letzte Urteil eines Geschworenengerichts wegen NS-Verbrechen in Österreich liegt ebenfalls bereits 45 Jahre zurück. Am 2. Dezember 1975 wurde der ehemalige SS-Angehörige Johann Gogl, der im KZ-Komplex Mauthausen als Kommandanturstabsmitglied der Abteilung Schutzhaftlager sowohl im Haupt- als auch im Außenlager Ebensee eingesetzt gewesen war, einstimmig freigesprochen. Die Geschworenen beim Landesgericht Wien waren trotz zahlreicher belastender Aussagen ${ }^{1}$ ehemaliger KZ-Häftlinge zu Gogls Tätigkeit im KZ nicht von der Schuld des Angeklagten zu überzeugen gewesen. ${ }^{2}$ Obgleich die juristische Ahndung in Österreich bereits Mitte der 1970er-Jahre zum Erliegen gekommen war, hat sich die hiesige Zeitgeschichtsforschung dieses Themas erst relativ spät angenommen. ${ }^{3}$ Der vorliegende Beitrag versteht sich als Versuch einer Bestandsaufnahme der österreichischen Forschung betreffend der Ahndung von NS-Verbrechen. Eine lückenlose Darstellung des Forschungsstandes zur Thematik wäre freilich an dieser Stelle nicht zu leisten, weshalb im Folgenden

$1 \quad$ KZ- und Holocaust-Überlebende berichteten im Zeugenstand vielfach unter Aufbietung ihres gesamten Mutes von ihren traumatischen Erlebnissen und mussten - nicht nur, vor allem aber auch in Österreich - die Erfahrung machen, dass von Strafverteidigern der Versuch unternommen wurde, sie als unglaubwürdig darzustellen, sodass ihnen vor Gericht oft tatsächlich nicht geglaubt wurde. Mit zunehmendem Zeitabstand zu den NS-Verbrechen weigerten sich daher viele AugenzeugInnen, sich dieser erniedrigenden und letztlich auch nutzlosen Retraumatisierung auszusetzen und als Zeugen in NS-Prozessen aufzutreten. So war beispielsweise der ehemalige 2. Lagerschreiber des KZ Mauthausen, Hans Maršálek, im Vorfeld der Neuauflage des Gogl-Verfahrens nicht dazu bereit, an einer Gegenüberstellung mit dem Angeklagten teilzunehmen. Vgl. Christian Rabl, Mauthausen vor Gericht. Nachkriegsprozesse im internationalen Vergleich (Mauthausen-Studien 13), Wien 2019, 286, Fn 1621.

2 Zum Gogl-Verfahren vgl. ausführlich: Gregor Holzinger, Das letzte Urteil. Die beiden Prozesse gegen Johann Vinzenz Gogl, in: ders. (Hg.), Die zweite Reihe. Täterbiografien aus dem Konzentrationslager Mauthausen (Mauthausen-Studien 10), Wien 2016, 295-307 sowie zuletzt: Rabl, Mauthausen vor Gericht, 285-288.

3 Ein wesentlicher Grund für die verspätete Beschäftigung der Zeitgeschichtsforschung mit den Quellen der Nachkriegsjustiz ist sicherlich die Tatsache, dass die Prozessakten zunächst nicht zugänglich waren. 
eine Annäherung an das Thema am Beispiel eines zentralen österreichischen Verbrechensortes, des KZ-Komplexes Mauthausen, gewählt wird. ${ }^{4}$

Ehe jedoch im dritten Abschnitt auf die österreichische und internationale juristische Ahndung zum Verbrechenskomplex Mauthausen eingegangen wird, erfolgt einführend eine kurze Darstellung zur Entwicklung der österreichischen Nachkriegsjustiz seit 1945 und daran anschließend ein allgemeiner Abriss zur bisherigen zeitgeschichtlichen Forschungstätigkeit.

\section{1. Österreichische Nachkriegsjustiz - Ein kurzer Abriss}

Die österreichische Konzentrationsregierung handelte nach ihrer Konstituierung Ende April 1945 in Wien sehr rasch und brachte binnen weniger Tage ein Kriegsverbrechergesetz auf den Weg, welches bereits am 8. Mai 1945 beschlossen wurde und das konkrete Maßnahmen zur Entnazifizierung sowie zur Ahndung von NSVerbrechen beinhaltete. ${ }^{5}$ Die österreichische Volksgerichtsbarkeit nahm in Wien bereits im Spätsommer 1945 ihre Arbeit auf, weitere Gerichtsstandorte folgten in Linz, Graz ${ }^{6}$ und Innsbruck. Die Arbeit der Volksgerichte wird von der zeithistorischen Forschung zumindest bis zum Jahr 1948 als überwiegend ambitioniert und zielgerichtet eingeschätzt. Obgleich teilweise selektiv vorgegangen wurde, sei laut Hellmut Butterweck doch eine „erhebliche Zahl von Schuldigen zur Verantwortung gezogen“ und „teilweise mit großer Härte“7 abgeurteilt worden: Von 1945 bis zur Außerkraftsetzung des Kriegsverbrechergesetzes 1957 wurden Verfahren gegen 136.829 Personen angestrengt, von denen wiederum 23.477 mit einem Urteil ende-

4 Die Ausführungen folgen hier im Wesentlichen den zuletzt publizierten Forschungsergebnissen des Autors: Christian Rabl, Der KZ-Komplex Mauthausen vor Gericht, phil. Diss., Universität Wien 2017; ders., Am Strang. Die österreichischen Angeklagten in den Dachauer MauthausenProzessen, Wien 2018; ders., Mauthausen vor Gericht.

5 Claudia Kuretsidis-Haider hat mit ihrer Dissertation über die „Engerau-Prozesse“ die erste detaillierte Analyse zu einigen der frühesten österreichischen Nachkriegsprozesse vorgelegt, die sich vor dem Landesgericht Wien mit den Verbrechen gegen ungarisch-jüdische ZwangsarbeiterInnen im Zuge des Südostwallbaus beschäftigten. Überdies zeichnet Kuretsidis-Haider aber auch die Entwicklung der österreichischen Nachkriegsgesetzgebung nach und geht ausführlich auf die Entstehung von Verbots- und Kriegsverbrechergesetz ein. Die Dissertation ist im Jahr 2006 als Band 2 der Reihe „Österreichische Justizgeschichte“ erschienen. Vgl. Claudia Kuretsidis-Haider, „Das Volk sitzt zu Gericht“. Österreichische Justiz und NS-Verbrechen am Beispiel der Engerau-Prozesse 1945-1954 (Österreichische Justizgeschichte 2), Innsbruck/Wien/Bozen 2006.

6 Das Volksgericht Graz hatte überdies Dependancen in Leoben und Klagenfurt.

7 Hellmut Butterweck, Verurteilt und begnadigt. Österreich und seine NS-Straftäter, Wien 2003, 11. 
ten. Davon wiederum wurden 13.607 Angeklagte für schuldig befunden. ${ }^{8}$ Die Strafen fielen durchaus streng aus: Von 43 durch österreichische Volksgerichte zum Tod verurteilten Männern wurden 30 tatsächlich hingerichtet, ${ }^{9} 29$ Angeklagte erhielten lebenslängliche Kerkerstrafen. Gleichzeitig zeigt sich aber auch, dass die Staatsanwaltschaften kaum aus eigener Wahrnehmung Ermittlungen zu NS-Verbrechen einleiteten, sondern lediglich auf Strafanzeigen reagierten. Bei einigen österreichspezifischen Tatkomplexen blieben die Behörden untätig oder ließen Verdächtigen gegenüber Milde walten. So wurde etwa in Bezug auf den Verbrechenskomplex Mauthausen mit den mehr als vierzig Außenlagern schon im Zuge der Ermittlungen wenig Eifer gezeigt, wenn es darum ging, potenzieller TäterInnen habhaft zu werden und sie vor Gericht zu bringen. Hingegen waren insbesondere Angeklagte aus der Gruppe der ehemaligen Funktionshäftlinge vor Gericht wiederholt mit klassischen nationalsozialistischen Stereotypen konfrontiert. ${ }^{10}$

Ab 1948 geriet die juristische Ahndung von NS-Verbrechen in Österreich ins Stocken. Die zuständigen Behörden sahen immer häufiger von einer Anklage ab, die Gerichte sprachen zusehends mildere Urteile aus und wählten die Haftstrafen so, dass diese bereits am Tag der Urteilsverkündung durch die U-Haft abgesessen waren. Verurteilten NS-TäterInnen wurden seitens des OGH mittels Wiederaufnahme - vielfach auch mit Unterstützung prominenter FürsprecherInnen aus höchsten politischen Kreisen, kirchlicher Würdenträger und aus dem privaten Umfeld - erhebliche Strafreduktionen oder vorzeitige Entlassungen ermöglicht. ${ }^{11}$ Von

8 Alle Zahlen nach Forschungsstelle Nachkriegsjustiz, URL: http://www.nachkriegsjustiz.at/prozesse/volksg/index.php (abgerufen 30.03.2020).

9 Vgl. Karl Marschall, Volksgerichtsbarkeit und Verfolgung von nationalsozialistischen Gewaltverbrechen in Österreich 1945-1972. Dokumentation, Wien 1977, 1; zum Phänomen der Todesstrafe vgl. auch Claudia Kuretsidis-Haider/Heimo Halbrainer/Elisabeth Ebner (Hg.), „Mit dem Tode bestraft." Historische und rechtspolitische Aspekte zur Todesstrafe in Österreich im 2o. Jahrhundert und der Kampf um ihre weltweite Abschaffung (Veröffentlichungen der Forschungsstelle Nachkriegsjustiz 2), Graz 2008.

10 Solche Stereotype finden sich sowohl in Urteilsbegründungen österreichischer Gerichte zu Angeklagten, die Funktionshäftlinge gewesen waren, als auch in den Gerichtsakten der US-amerikanischen Militärgerichtsprozesse sowie den Urteilen westdeutscher Gerichte. Nicht selten wirkte sich das direkt auf das Strafmaß, in weiterer Folge aber auch auf die Haftdauer verurteilter ehemaliger Funktionshäftlinge aus, denen seitens der Behörden nicht zugetraut wurde, sich in die Nachkriegsgesellschaft zu reintegrieren. Vgl. ausführlich: Rabl, Mauthausen vor Gericht, 276-277, 316-319.

11 Vgl. beispielsweise das Verfahren gegen den ehemaligen Schutzpolizisten und Führer der Wachmannschaften des KZ-Außenlagers Peggau, Franz Weber, der sich vor dem Volksgericht Graz verantworten musste und zu dessen Gunsten im Jahr 1949 neben mehreren steirischen Landespolitikern auch der damalige Vizekanzler Adolf Schärf bei Justizminister Josef Gerö intervenierte. Vgl. Rabl, Mauthausen vor Gericht, 250-252. 
Relevanz war in diesem Kontext auch das Gnadenrecht der österreichischen Bundespräsidenten, welches verstärkt ab Anfang der 1950er-Jahre von den amtierenden Bundespräsidenten Theodor Körner bzw. Adolf Schärf selbst in schwerwiegenden Fällen gewährt wurde. ${ }^{12}$ Mit der Amnestiegesetzgebung wurde per 14. März 1957 das Kriegsverbrechergesetz endgültig außer Kraft gesetzt, zahlreiche Reststrafen nachgesehen und Urteile vieler NS-Täter wurden getilgt. ${ }^{13} \mathrm{Ab} 1955$ wurden alle offenen Strafverfahren zu NS-Tatbeständen den österreichischen Geschworenen- bzw. ganz vereinzelt Schöffengerichten übertragen, die jedoch bis 1975 nur vierzig Hauptverhandlungen ${ }^{14}$ führten, von denen wiederum viele mit - vor allem international heftig kritisierten - Freisprüchen endeten. ${ }^{15}$

\section{Die österreichische Nachkriegsjustiz als zeithistorisches Forschungsfeld}

Eine erste Bilanz zur Arbeit der österreichischen Nachkriegsjustiz stellte der damalige Generalanwalt Karl Marschall im Auftrag des Bundesministeriums für Justiz mit der Dokumentation über die „Volks-Gerichtsbarkeit und Verfolgung von nationalsozialistischen Gewaltverbrechen in Österreich“ für den Zeitraum 1945 bis 1972 zusammen. Hier noch nicht berücksichtigt ist das bereits erwähnte Urteil gegen Johann Gogl, welches das Kapitel österreichische Nachkriegsjustiz am 2. Dezember 1975 in Österreich - bezeichnenderweise mit einem einstimmigen Freispruch - de facto abgeschlossen hatte. Im gleichen Jahr hatte der Holocaustüberlebende Simon Wiesenthal, der sich seit dem Tag seiner Befreiung aus dem KZ Mauthausen am

12 Allein verurteilte NS-Täter aus dem Mauthausen-Komplex betreffend sprach Bundespräsident Theodor Körner zwischen 1951 und 1955 sieben Begnadigungen aus, eine weitere sprach sein Nachfolger Adolf Schärf aus. Zum Vergleich: Insgesamt wurden zwischen 1946 und 1954 nur 42 Personen im Zusammenhang mit dem Mauthausen-Komplex abgeurteilt, 13 davon wurden freigesprochen. Vgl. Rabl, Mauthausen vor Gericht, 272-278.

13 Vgl. Winfried Garscha, Chronik der gerichtlichen Ahndung von NS-Verbrechen nach der Abschaffung der Volksgerichte (1956 bis 200o), in: Justiz und Erinnerung 4/2001, 25-31, 27.

14 Vgl. ebd., 31.

15 Kürzlich widmete sich der österreichische Spielfilm „Murer“ einem jener Skandalurteile, die in den 1960er-Jahren vor allem international für Empörung bis hin zu öffentlichen Protestkundgebungen gesorgt und gleichzeitig auch das Versagen der österreichischen Geschworenengerichtsbarkeit bei der Ahndung von schweren NS-Massenverbrechern aufgezeigt hatten. Die Reaktionen auf den Murer-Freispruch - bis hin zu Applaus zahlreicher Prozessbeobachter nach der Urteilsverkündung - zeigen überdies die Weigerung großer Teile der österreichischen Bevölkerung, die direkte und massive Mitschuld österreichischer Täter an NS-Verbrechen anzuerkennen. Zur Biographie des ehemaligen Chefs des Ghettos von Wilna Franz Murer vgl. Johannes Sachslehner, „Rosen für den Mörder“. Die zwei Leben des SS-Mannes Franz Murer, Graz 2017. 
5. Mai 1945 intensiv darum bemüht hatte, flüchtige NS-Täter vor Gericht zu bringen, medial bekannt gemacht, dass der damalige FPÖ-Bundesparteiobmann Friedrich Peter Mitglied einer an Kriegsverbrechen beteiligten SS-Einsatzgruppe an der Ostfront gewesen war. ${ }^{16}$ Die Reaktion - insbesondere des damaligen Bundeskanzlers Bruno Kreisky, der massiv zugunsten Peters Partei ergriff - machte überdeutlich, dass österreichische Justiz und Politik in Sachen (Nicht)Ahndung von NS-Verbrechen weitestgehend auf Linie waren. Es verwundert also nicht, dass es nach dem Gogl-Freispruch 1975 in Österreich zu keinem weiteren Urteil kam. ${ }^{17}$

Im selben Jahr traf der ehemalige Spiegelgrund-Insasse Friedrich Zawrel in Wien erneut auf seinen Peiniger, den früheren NS-Euthanasiearzt und nunmehrigen Gerichtspsychiater Heinrich Groß. ${ }^{18}$ Zawrel machte Groß’ Tätigkeit am Spiegelgrund öffentlich und in den folgenden Jahren wurde die Rolle des inzwischen hochangesehen und politisch bestens vernetzten Groß mehrfach medial thematisiert und seine Beteiligung an der hundertfachen Ermordung von Kindern während der NS-Zeit nachgewiesen. Es dauerte dennoch rund zwanzig Jahre, bis sich die Staatsanwaltschaft 1997 endlich zu einer Mordanklage gegen Groß durchrang. Weitere drei Jahre vergingen, ehe am 21. März 2000 die Hauptverhandlung vor dem Landesgericht Wien eröffnet wurde. Noch am selben Tag wurde die Verhandlung aufgrund des schlechten Gesundheitszustands des Angeklagten wieder abgebrochen und nicht mehr aufgenommen, Groß starb fünf Jahre später in Hollabrunn. ${ }^{19}$

In den 1980er-Jahren hatten Teile der österreichischen Gesellschaft damit begonnen, am österreichischen Mythos der Opferthese zu rütteln. Angetrieben wurden sie nicht zuletzt von den öffentlichen Auseinandersetzungen rund um die Rederund wenig später die Waldheim-Affäre, von den kontroversiellen Diskussionen um das Hrdlicka-Denkmal gegen Krieg und Faschismus am Wiener Albertinaplatz und die Uraufführung von Thomas Bernhards Theaterstück „Heldenplatz“ (beides 1988) sowie die Reden des österreichischen Bundeskanzlers Franz Vranitzky im Nationalrat (1991) sowie an der Hebräischen Universität in Jerusalem (1993) - die Liste ließe sich zweifelsohne noch verlängern. Dieser neue, offenere Diskurs war auch

16 Vgl. Simon Wiesenthal, Recht, nicht Rache. Erinnerungen, Berlin 1988.

17 Es kam lediglich zu einigen Einstellungen laufender Verfahren, etwa am 11. Mai 1976 im Verfahren gegen Ernst Lerch und Helmut Pohl, beide Beteiligte an der „Aktion Reinhard“ im Distrikt Lublin. Vgl. Garscha, Chronik, 30-31.

18 Zur Geschichte des Friedrich Zawrel vgl. Oliver Lehmann/Traudl Schmidt, In den Fängen des Dr. Gross. Das misshandelte Leben des Friedrich Zawrel, Wien 2001.

19 Die Rolle von Heinrich Groß bei der Ermordung von Kindern als Arzt in der psychiatrischen Klinik Am Spiegelgrund war in den letzten Jahren Gegenstand zahlreicher zeitgeschichtlicher, medien- und medizinwissenschaftlicher Studien, wurde in Ausstellungen thematisiert und überdies auch in mehreren Film- und Theaterproduktionen künstlerisch aufgegriffen. 
der Beginn einer - überwiegend aus zivilgesellschaftlichem Engagement erwachsenden - Gedenkkultur. Die skizzierten Entwicklungen führten freilich nicht dazu, dass die österreichische Justiz ihre Bemühungen verstärkt hätte, flüchtige NS-Verbrecher bzw. auch solche mit bekanntem Aufenthaltsort - spät aber doch - juristisch zu belangen.

Mitte der 1980er-Jahre begann die systematische zeitgeschichtliche Aufarbeitung zentraler österreichischer Tatorte der NS-Zeit, wie beispielsweise der Geschichte einiger früherer Mauthausen-Außenlager ${ }^{20}$ durch die Historiker Bertrand Perz und Florian Freund. In ihren Studien griffen sie auch substanziell auf Akten der Nachkriegsjustiz als Quellengattung zurück, die Mitte der 1980er-Jahre - unter strengen datenschutzrechtlichen Auflagen - erstmals für die wissenschaftliche Forschung zugänglich waren. Freilich war das Gros der Akten zu dieser Zeit noch nicht erschlossen und in den Aktenspeichern der zuständigen Gerichte verwahrt. Zur Darstellung der Lagergeschichte zogen die Forscher sowohl das als Beweismaterial in den Gerichtsakten (oft nur spärlich) vorhandene Schriftgut aus der KZ-Verwaltung als auch ZeugInnenaussagen - etwa ehemaliger KZ-Häftlinge, SS-Angehöriger und ZivilistInnen - heran. Der logische nächste Schritt war die systematische Erschließung der Prozessakten, bei der das Dokumentationsarchiv des österreichischen Widerstandes (DÖW) von Beginn an eine zentrale Rolle einnahm. Mit der Zugänglichmachung von Justizakten als Quelle für die Zeitgeschichtsforschung ging auch die erstmalige tiefergehende Erforschung der Geschichte der österreichischen Nachkriegsjustiz einher. Dies äußerte sich durch zwei beim DÖW angesiedelte Forschungsprojekte: „Die Verfahren vor dem Volksgericht Wien (1945-1955) als Geschichtsquelle“ (1993-1996) sowie „Die Nachkriegsjustiz als nicht-bürokratische Form der Entnazifizierung: Österreichische Justizakten im europäischen Vergleich“ (1996-1998). Im Dezember 1998 erfolgte schließlich die Gründung der Forschungsstelle Nachkriegsjustiz, welche die justizgeschichtliche Aufarbeitung in Bezug auf die Ahndung von NS-Verbrechen durch dokumentarisch angelegte Vorstudien sowie zahlreiche wissenschaftliche Detailstudien entscheidend vorantrieb. ${ }^{21}$ Neben der Webseite,

20 Vgl. Florian Freund, Arbeitslager Zement. Das Konzentrationslager Ebensee und die Raketenrüstung, Wien 1991; Bertrand Perz, Projekt Quarz. Steyr-Daimler-Puch und das Konzentrationslager Melk, Wien 1991; Florian Freund/Bertrand Perz, Das KZ in der Serbenhalle. Zur Kriegsindustrie in Wiener Neustadt, Wien 1987.

21 Neben der bereits zitierten langjährigen leitenden wissenschaftlichen Mitarbeiterin der Forschungsstelle Nachkriegsjustiz, Claudia Kuretsidis-Haider, ist hier besonders auf die herausragende Rolle von Winfried R. Garscha zu verweisen, dessen Verdienste um die Erforschung der österreichischen Nachkriegsjustiz jüngst auch in einer Festschrift im Auftrag des DÖW gewürdigt worden sind: Claudia Kuretsidis-Haider/Christine Schindler (Hg.), Zeithistoriker - Archivar - Aufklärer. Festschrift für Winfried R. Garscha, Wien 2017. 
die umfangreiche Informationen zur Thematik sowie kostenlose Downloads von Findbehelfen, Quellen und Literatur bietet, ${ }^{22}$ bildete die zwischen Juni 1999 und Dezember 2006 erscheinende Schriftenreihe „Justiz und Erinnerung“ ein wichtiges Informationsmedium über den Fortgang der Forschungen. Die Publikation bot zahlreichen österreichischen und internationalen ForscherInnen eine Plattform zur Präsentation ihrer Forschungsergebnisse. ${ }^{23}$ Aus der primär dokumentarisch angelegten Arbeit, deren Zielsetzung zunächst „die zentrale Dokumentation sämtlicher Akten der justiziellen Ahndung von nationalsozialistischen Verbrechen in Österreich“" ${ }^{24}$ war, entstanden über die Jahre viele Studien zur Geschichte der österreichischen Nachkriegsjustiz. Darüber kam es zu einer kontinuierlichen Vernetzung mit österreichischen ForscherInnen und zu internationalen Forschungskooperationen, die wichtige komparative Studien ermöglichten. ${ }^{25}$ Einige dieser Studien fokussierten explizit auf einzelne Verbrechenskomplexe, wie etwa auf die juristische Ahndung der NS-Verbrechen zum KZ- und Vernichtungslager Lublin-Majdanek durch polnische, deutsche und österreichische Gerichte. ${ }^{26}$

22 Vgl. Forschungsstelle Nachkriegsjustiz, URL: http://www.nachkriegsjustiz.at (abgerufen 30.03. 2020).

23 Die Reihe „Justiz und Erinnerung“ steht auf der Webseite der Forschungsstelle Nachkriegsjustiz zum kostenlosen Download zur Verfügung, URL: http://www.nachkriegsjustiz.at/service/archiv/ index.php (abgerufen 23.02.2020).

24 Forschungsstelle Nachkriegsjustiz, URL: http://www.nachkriegsjustiz.at/fstn/index.php (abgerufen 31.03.2020).

25 An dieser Stelle können nur einige wenige dieser Publikationen angeführt werden, welche die Breite des Forschungsfeldes skizzieren sollen: Claudia Kuretsidis-Haider/Winfried Garscha (Hg.), Keine „Abrechnung“. NS-Verbrechen, Justiz und Gesellschaft in Europa nach 1945, Leipzig/Wien 1998; Martin F. Polaschek, Im Namen der Republik Österreich! Die Volksgerichte in der Steiermark 1945 bis 1955, Graz 1998; Thomas Albrich/Winfried R. Garscha/Martin F. Polaschek (Hg.), Holocaust und Kriegsverbrechen vor Gericht. Der Fall Österreich, Innsbruck 2006; Heimo Halbrainer/ Claudia Kuretsidis-Haider (Hg.), Kriegsverbrechen, NS-Gewaltverbrechen und die europäische Strafjustiz von Nürnberg bis Den Haag (Veröffentlichungen der Forschungsstelle Nachkriegsjustiz 1), Graz 2007; Wolfgang Stadler, „... Juristisch bin ich nicht zu fassen. “ Die Verfahren des Volksgerichts Wien gegen Richter und Staatsanwälte. 1945-1955, Wien 2007; Claudia Kuretsidis-Haider/ Winfried R. Garscha (Hg.), Gerechtigkeit nach Diktatur und Krieg. Transitional Justice 1945 bis heute: Strafverfahren und ihre Quellen (Veröffentlichungen der Forschungsstelle Nachkriegsjustiz 3), Graz 2010; Hellmut Butterweck, Nationalsozialisten vor dem Volksgericht Wien. Österreichs Ringen um Gerechtigkeit 1945-1955 in der zeitgenössischen Wahrnehmung, Innsbruck 2016.

26 Vgl. Claudia Kuretsidis-Haider/Irmgard Nöbauer/Winfried R. Garscha/Siegfried Sanwald/Andrzej Selerowicz (Hg.), Das KZ Lublin-Majdanek und die Justiz. Strafverfolgung und verweigerte Gerechtigkeit: Polen, Deutschland und Österreich im Vergleich, Graz 2011. 


\section{Der Verbrechenskomplex Mauthausen-Gusen - Forschungsstand zur juristischen Ahndung}

Das Konzentrationslager Mauthausen-Gusen erstreckte sich zwischen August 1938 und Mai 1945 auf über vierzig Außenlager in ganz Österreich sowie Nordslowenien (Außenlager Loiblpass Süd) und Süddeutschland (Außenlager Passau I-III). ${ }^{27}$ Der verbrecherische und gewaltvolle Charakter des Systems Mauthausen manifestierte sich überdies auch in den unzähligen Evakuierungstransporten von KZ-Häftlingen, die im Frühjahr 1945 auf ihrem Weg Richtung Mauthausen in weiten Teilen Ostund Südösterreichs eine Spur der Gewalt und der Vernichtung hinterließen. ${ }^{28}$ Von den rund $200.000 \mathrm{KZ}$-Häftlingen, die insgesamt im Mauthausen-Komplex inhaftiert waren, wurden weit über 90.000 ermordet. Sie fielen zu rund einem Drittel direkten Gewalttaten zum Opfer, etwa zwei Drittel starben infolge indirekter bzw. struktureller Gewalt, die sich in mangelnder Ernährung, Ausrüstung und Unterbringung sowie in auszehrender Zwangsarbeit - im Sinne der „Vernichtung durch Arbeit“ äußerte. ${ }^{29}$

Die juristische Ahndung der Verbrechen, die im Komplex Mauthausen begangen wurden, unterscheidet sich in mehreren Punkten von anderen Verbrechenskomplexen, die einen vergleichsweise überschaubaren TäterInnenkreis aufweisen, wie etwa den Euthanasiemorden. Als potenzielle TäterInnen kommen neben Mitgliedern der Lager-SS Mauthausen auch ZivilistInnen und KZ-Häftlinge in Betracht. In Summe versahen zwischen 1938 und 1945 rund 12.00o bis 15.000 SS-Angehörige

27 Es kann hier nicht auf weitere große Verbrechenskomplexe der NS-Zeit in Österreich eingegangen werden, wie etwa auf die Euthanasieverbrechen - etwa in Hartheim, am Steinhof oder in Gugging und Mauer-Öhling. Hier sei auf das umfangreiche Werk von Gerhard Fürstler und Peter Malina verwiesen, welches die wesentlichen österreichischen Nachkriegsprozesse zu diesem Verbrechenskomplex behandelt: Gerhard Fürstler/Peter Malina, „Ich tat nur meinen Dienst.“ Zur Geschichte der Krankenpflege in Österreich in der NS-Zeit, Wien 2004; auch auf die massiven Endphaseverbrechen gegen ungarisch-jüdische ZwangsarbeiterInnen, die sich in zahlreichen Massakern - etwa in Rechnitz, am Präbichl, in Graz, Hofamt-Priel, Leiben, Göstling oder Randegg - äußerten, kann hier nicht näher eingegangen werden. Das umfangreichste Werk zu diesen Massenverbrechen hat Eleonore Lappin-Eppel vorgelegt: dies., Ungarisch-Jüdische Zwangsarbeiter und Zwangsarbeiterinnen in Österreich 1944/45. Arbeitseinsatz - Todesmärsche - Folgen (Austria: Forschung und Wissenschaft. Geschichte 3), Wien 2010.

28 Dem Gesamtphänomen der Todesmärsche am Ende des Zweiten Weltkriegs widmet sich etwa Daniel Blatman, Die Todesmärsche 1944/45. Das letzte Kapitel des nationalsozialistischen Massenmords, Reinbek bei Hamburg 2011.

29 Vgl. zu dieser Einschätzung Bertrand Perz/Jörg Skriebeleit, Den Tod ausstellen, in: Gregor Holzinger/Andreas Kranebitter (Red.), Der Tatort Mauthausen/The Crime Scenes of Mauthausen. Eine Spurensuche/Searching for Traces, Wien 2014, 117-134, 125. 
im Kommandanturstab bzw. in den Wachkompanien der SS-Totenkopfsturmbanne Mauthausen bzw. Mauthausen-Gusen ihren Dienst. ${ }^{30}$ Sowohl in der inneren als auch in der äußeren Bewachung waren schwere Gewalttaten gegen KZ-Häftlinge an der Tagesordnung. Eine weitere Gruppe von TäterInnen waren ZivilistInnen, wobei hier wiederum zwischen mehreren Arten zu unterscheiden ist. Erstens waren dies Personen, die beispielsweise als zivile (Vor-)ArbeiterInnen oder HandwerkerInnen auf Baustellen für Rüstungs- oder Untertage-Verlagerungsprojekte regelmäßig in direktem Kontakt mit KZ-Häftlingen waren und sie in nicht wenigen Fällen mit brutaler Gewalt zur Arbeit antrieben; zweitens waren dies ZivilistInnen, die in leitenden Positionen in Rüstungsbetrieben oder in diversen Führungsstäben an der Ausbeutung und der dramatischen Unterversorgung der KZ-ZwangsarbeiterInnen mitbeteiligt waren; drittens schließlich begingen in den letzten Wochen vor Ende des Zweiten Weltkrieges insbesondere im Zuge von Evakuierungstransporten oder -märschen zahlreiche Angehörige regionaler Volkssturm-, HJ- oder Polizeieinheiten sowie Zivilisten ohne institutionelle Zugehörigkeit teils brutale Verbrechen an KZ-Häftlingen. ${ }^{31}$ Neben der Lager-SS und ZivilistInnen waren es schließlich auch KZ-Häftlinge selbst - hauptsächlich im Rahmen des von der Lager-SS etablierten Systems der Funktionshäftlinge als Kapos -, die ebenfalls teils schwere Verbrechen an ihren Kameraden verübten.

Neben der enormen Breite und Quantität potenzieller TäterInnen im KZ-Komplex Mauthausen ist überdies auch die Herkunft der KZ-Häftlinge ein relevanter Aspekt. Die Tatsache, dass die Mauthausen-Häftlinge aus vielen dutzend Ländern nach Mauthausen deportiert wurden, ist von entscheidender Bedeutung, wenn es um die Frage geht, welche Länder und Behörden überhaupt ein Interesse an einer juristischen Ahndung von NS-Verbrechen haben, die im System Mauthausen verübt wurden.

Zusammenfassend zeigt sich, dass unter Berücksichtigung der Lager-SS Mauthausen sowie von einigen tausend ZivilistInnen und Funktionshäftlingen in Summe von rund 20.000 potenziellen Tatverdächtigen auszugehen ist, die an Verbrechen im KZ-Komplex Mauthausen beteiligt waren.

Doch in welchem Ausmaß wurde der Verbrechenkomplex Mauthausen tatsächlich vor Gericht behandelt? Welche Behörden und Länder führten Mauthausen-Pro-

30 Vgl. Rabl, Mauthausen vor Gericht, 15.

31 Einen weiteren Sonderfall stellt die sogenannte Mühlviertler Hasenjagd dar, an der sich im Februar 1945 im regionalen Umfeld von Mauthausen zahlreiche Menschen beteiligten. Vgl. Matthias Kaltenbrunner, Flucht aus dem Todesblock. Der Massenausbruch sowjetischer Offiziere aus dem Block 20 des KZ Mauthausen und die „Mühlviertler Hasenjagd“. Hintergründe, Folgen, Aufarbeitung (Der Nationalsozialismus und seine Folgen 5), Innsbruck 2012. 
zesse? Gegen welche der oben genannten Gruppen von TäterInnen richteten sich diese und gegen welche nicht? Welche Urteile wurden gefällt und welche Strafen verhängt? Viele dieser Fragen hat die zeithistorische Forschung lange unbeantwortet gelassen. Lediglich vereinzelt entstanden seit Ende der 1990er-Jahre Studien zu einzelnen Prozessen oder Prozessgruppen. Florian Freund etwa legte 1997 in den „Dachauer Heften“ eine erste Analyse des Mauthausen-Hauptverfahrens (Parent Case) vor, in dem sich im ehemaligen KZ Dachau zwischen März und Mai 1946 insgesamt 61 Männer aus dem Mauthausen-Komplex vor einem US-Militärgericht verantworten mussten. ${ }^{32}$ Rund 15 Jahre später widmete sich Tomaz Jardim neuerlich dem Mauthausen-Parent-Case in einer ausführlichen Analyse. ${ }^{33}$ Die 62 USamerikanischen Mauthausen-Nachfolgeverfahren, die sich 1947 gegen weitere 240 Täter aus dem Mauthausen-Umfeld gerichtet hatten, blieben zunächst - mit wenigen Ausnahmen ${ }^{34}$ - von der Forschung unbeachtet.

Anfang der 200oer-Jahre legte die Forschungsstelle Nachkriegsjustiz im Zuge ihrer dokumentarischen Arbeit auch einen ersten quantitativen Überblick zu den in Österreich geführten Mauthausen-Prozessen vor Volks- und Geschworenengerichten vor. ${ }^{35}$ Außerdem waren in der schon in den 1960er-Jahren begonnenen Reihe „Justiz und NS-Verbrechen“ bzw. der später folgenden Reihe „DDR-Justiz und NSVerbrechen“, welche sämtliche Urteile zu NS-Tötungsverbrechen beinhalteten, auch die Urteile zu einige umfangreichen Mauthausen-Verfahren enthalten. ${ }^{36}$ Einen ersten Überblick über die in ganz Mitteleuropa unternommenen Anstrengungen zur juristischen Ahndung von Verbrechen im Mauthausen-System legte Bertrand Perz im Jahr 2007 vor und verwies dabei auch auf kaum oder gar nicht bekannte Pro-

32 Vgl. Florian Freund, Der Mauthausen-Prozeß. Zum amerikanischen Militärgerichtsverfahren in Dachau im Frühjahr 1946, in: Dachauer Hefte 13 (1997), 99-118.

33 Vgl. Tomaz Jardim, Mauthausen Trial: American Military Justice in Germany, Harvard 2012.

34 Vgl. Nina Höllinger, „I never saw any humanity in the accused Schilling ... “. Andreas Schilling vor dem Dachauer Tribunal, in: Gregor Holzinger (Hg.), Die zweite Reihe. Täterbiografien aus dem Konzentrationslager Mauthausen (Mauthausen-Studien 10), Wien 2016, 263-275.

35 Vgl. Justiz und Erinnerung 5-9/2002-2004 sowie ausführlicher: Peter Eigelsberger, „Mauthausen vor Gericht“. Die österreichischen Prozesse wegen Tötungsdelikten im KZ Mauthausen und seinen Außenlagern, in: Albrich/Garscha/Polaschek (Hg.), Holocaust und Kriegsverbrechen, 11-56.

36 Vgl. die Serien „Justiz und NS-Verbrechen. Sammlung deutscher Strafurteile wegen nationalsozialistischer Tötungsverbrechen 1945-1999“ sowie „DDR-Justiz und NS-Verbrechen. Sammlung ostdeutscher Strafurteile wegen nationalsozialistischer Tötungsverbrechen. “ Die Sammlung ist auch online verfügbar, die Urteile können auf der Webseite der Foundation for Research on NationalSocialist Crimes, Amsterdam einzeln als Digitalisate erworben werden, URL: https://www.junsv. $\mathrm{nl} /$ (abgerufen 01.04.2020). 
zessgruppen. ${ }^{37}$ Dazu zählten etwa die von den drei alliierten Mächten Frankreich, Großbritannien und Sowjetunion geführten Verfahren, aber auch mögliche weitere Mauthausen-Verfahren in Polen und der Tschechoslowakei.

Der Autor des vorliegenden Beitrags hat sich ab 2011 im Rahmen seiner Dissertation mit dem Titel „Der KZ-Komplex Mauthausen vor Gericht“ ebendiesen Desideraten gewidmet und nach mehreren Jahren der Recherche im Jahr 2017 eine umfassende Analyse zu der Frage vorgelegt, in welchem Umfang der Verbrechensort Mauthausen vor Gericht behandelt wurde.

\section{Mauthausen vor Gericht - Ein Überblick}

In Summe wurden im Rahmen von Nachkriegsprozessen zum Mauthausen-Komplex 506 Urteile gegen 498 Personen gefällt. ${ }^{38}$ Diese Verfahren erstreckten sich auf einen Zeitraum von mehr als 45 Jahren, beginnend im Herbst 1945 und endend mit dem bislang letzten Mauthausen-Urteil vor dem Landgericht Duisburg im März 1993. Die Verfahren wurden einerseits vor Militärgerichten aller vier Besatzungsmächte geführt, andererseits von mehreren „Opferländern“ sowie Nachfolgestaaten des Dritten Reichs. Ein Blick auf die unterschiedlichen Gerichtsstandorte zeigt die große räumliche Ausdehnung von Mauthausen-Verfahren über weite Teile Mittelund Osteuropas.

\subsection{Alliierte Verfahren zum Mauthausen-Komplex}

Die umfangreichsten Verfahren führten - nicht zuletzt aufgrund der Tatsache, dass US-Truppen das KZ Mauthausen am 5. Mai 1945 befreit und das dramatische Ausmaß der dort begangenen Verbrechen ganz unmittelbar zu Gesicht bekommen hatten ${ }^{39}$ - US-amerikanische Militärgerichte in den Jahren 1946 und 1947

37 Bertrand Perz, Prozesse zum KZ Mauthausen, in: Ludwig Eiber/Robert Sigel (Hg.), Dachauer Prozesse: NS-Verbrechen vor amerikanischen Militärgerichten in Dachau 1945-1948. Verfahren, Ergebnisse, Nachwirkungen, Göttingen 2007, 174-191.

$38 \mathrm{Zu}$ den Zahlen vgl. Rabl, Mauthausen vor Gericht, 291-311; die Diskrepanz in den Zahlen ergibt sich aus der Tatsache, dass sich einige Personen wegen mehrerer getrennt verhandelter Delikte bzw. vor unterschiedlichen Justizbehörden verantworten mussten.

39 Unmittelbar nach der Befreiung des KZ Mauthausen nahm ein US-Ermittlerteam die Arbeit auf, um Beweise für spätere Kriegsverbrecherprozesse zu sammeln und Augenzeugen zu befragen. In dieser Phase war die massive Unterstützung durch KZ-Überlebende von entscheidender Bedeutung für die Ermittlungsarbeit. Vgl. Rabl, Mauthausen vor Gericht, 45-49. 
auf dem Gelände des ehemaligen KZ Dachau durch. Insgesamt 305 Männer standen im Haupt- und den 62 Nachfolgeverfahren vor Gericht, wobei nicht weniger als 116 Todesurteile $^{40}$ und weitere 47 Mal lebenslange Haft verhängt, hingegen nur 26 Freisprüche ausgesprochen wurden. ${ }^{41}$ Unter den 86 tatsächlich hingerichteten Mauthausen-Tätern ${ }^{42}$ befanden sich auch 18 der in Summe 38 Angeklagten österreichischer Herkunft, darunter auch der ehemalige Gauleiter des Gaues Oberdonau, August Eigruber. ${ }^{43}$ Abgesehen von Eigrubers Rolle im Zusammenhang mit dem KZ Mauthausen, welche auch in österreichischen Printmedien thematisiert wurde, kamen die weiteren 37 angeklagten Österreicher, bei denen es sich überwiegend um ehemalige Kommandanturstabsmitglieder und Funktionshäftlinge gehandelt hatte, medial nicht vor. Es zeigt sich, dass die Entscheidung der US-Militärbehörden, die Mauthausen-Prozesse außerhalb Österreichs durchzuführen, einer Externalisierung der Verantwortung für die im Mauthausen-Komplex begangenen Verbrechen Vorschub leistete. ${ }^{44}$ Ganz im Sinne der österreichischen Opferthese konnte die alleinige Schuld an der Ermordung von rund 90.000 Menschen im Mauthausen-Komplex „den Deutschen“ angelastet werden, während die direkte Verbrechensbeteiligung österreichischer Täter nicht zur Kenntnis genommen wurde.

Neben den US-Behörden widmeten sich auch die drei weiteren alliierten Mächte innerhalb ihrer Besatzungszonen der juristischen Ahndung von NS-Verbrechen wenn auch betreffend den Mauthausen-Komplex in wesentlich überschaubarerer Quantität. Über die sowjetischen Militärtribunale ist aufgrund der schwierigen Quellenlage, aber auch aufgrund der Tatsache, dass sie meist unter Ausschluss der Öffentlichkeit geführt wurden, nur wenig bekannt. Die sechs (bislang bekannten) Mauthausen-Verfahren entsprachen nicht den gängigen rechtsstaatlichen Kriterien. ${ }^{45}$ Den Angeklagten wurden zentrale Rechte vorenthalten, etwa die Bereitstellung

40 Letztlich wurden 86 dieser 116 Todesstrafen von den US-Behörden im Kriegsverbrechergefängnis Landsberg am Lech in den Jahren 1947 bis 1949 auch tatsächlich durch den Strang vollstreckt. Vgl. ebd., 81 .

41 Vgl. ebd., 82.

42 Die hohe Zahl von 86 Hinrichtungen zeigt deutlich, dass die US-Militärgerichte in Bezug auf den Mauthausen-Komplex besonders hart urteilten. Zum Vergleich: Die 86 vollstreckten Todesurteile stellen 32 Prozent der Gesamtzahl der Hinrichtungen (286) in allen Dachauer Prozessen dar, darunter etwa sämtliche KZ-Prozesse zu Dachau, Buchenwald und Flossenbürg. Dies wiegt umso schwerer, wenn man berücksichtigt, dass nur rund 17 Prozent der in sämtlichen Dachauer Prozessen angeklagten 1.786 Männer Angeklagte in den Mauthausen-Prozessen waren, vgl. ebd.

43 Vgl. Rabl, Am Strang, 53, 114-117.

44 Vgl. Bertrand Perz, Vorwort, in: Rabl, Am Strang, 13.

45 Das erste bekannte Mauthausen-Verfahren überhaupt richtete sich gegen den ehemaligen Funktionshäftling Johann von Loosen, der am 9. Oktober 1945 aufgrund seiner Tätigkeit als Kapo bzw. 
eines Rechtsvertreters oder die Übersetzung der Protokolle der Beweisführung bzw. der eigentlichen Verhandlung ins Deutsche. Während bis 1946 noch Todesurteile verhängt worden waren, knüpfte sich später an die Verurteilung durch ein sowjetisches Militärtribunal jeweils die Deportation in ein sowjetisches Arbeitslager. Dies zeigt etwa das Beispiel des ehemaligen Gusener Rapportführers Kurt Gagstädter, der von einem sowjetischen Militärgericht für schuldig befunden und in ein Straflager bei Irkutsk deportiert wurde. Nach seiner Rückkehr nach Oberösterreich im Sommer 1957 wurde Gagstädter mit Triumphbogen und finanziellen Zuwendungen seitens Bund und Land Oberösterreich in der Heimat willkommen geheißen. Die Lokalmedien berichteten über Gagstädter als unschuldiges Opfer der sowjetischen Militärjustiz, der lediglich aufgrund seiner Körpergröße der Waffen-SS zugeteilt worden sei. Gagstädters Vergangenheit als Rapportführer in Gusen und seine sehr wahrscheinliche Beteiligung an den dortigen „Todbadeaktionen“ wird freilich mit keinem Wort erwähnt. ${ }^{46}$

Die britischen Militärbehörden führten in ihrer Zone in Klagenfurt im Herbst 1947 zwei Prozesse gegen insgesamt 14 Angeklagte durch, die sich mit den beiden Mauthausen-Außenlagern südlich und nördlich des Loiblpass an der kärntnerischslowenischen Grenze befassten. Im größeren der beiden Verfahren ${ }^{47}$ stand auch der österreichische Lagerarzt am Loiblpass, Sigbert Ramsauer, vor Gericht. Im Gegensatz zu Lagerführer Jakob Winkler und Kommandoführer Walter Brietzke, die zum Tode verurteilt und 1948 in Graz-Karlau erhängt wurden, erhielt Ramsauer lebenslange Haft. Er wurde aber schon im April 1954 - angeblich aus gesundheitlichen Gründen - freigelassen ${ }^{48}$ und arbeitete danach bis zu seinem Tod im Jahr 1991 jahrzehntelang als Chefarzt im Landeskrankenhaus Klagenfurt sowie in seiner eigenen Arztpraxis. ${ }^{49}$

Lagerältester von Gusen II zum Tode verurteilt und im Dezember 1945 hingerichtet wurde. Vgl. Rabl, Mauthausen vor Gericht, 140.

46 Vgl. ebd., 144-147.

47 Aufgrund der hohen Zahl französischer KZ-Häftlinge, die am Loiblpass als Zwangsarbeiter eingesetzt gewesen waren, gewährten die britischen Militärbehörden zwei französischen Militärangehörigen die Teilnahme am Verfahren im fünfköpfigen Richtergremium. Vgl. Lisa Rettl/Peter Pirker, „Ich war mit Freuden dabei.“ Der KZ-Arzt Sigbert Ramsauer. Eine österreichische Geschichte, Wien 2010, 121.

48 Die Entlassung Ramsauers war von massiven politischen Interventionen zu dessen Gunsten begleitet. Vgl. ebd., 266-285.

$49 \mathrm{Zu}$ den Loibl-Verfahren vgl. neben Rettl/Pirker, Ramsauer auch Josef Villa, Die Verfolgung von Kriegsverbrechen im KZ Loibl durch ein britisches Militärgericht in Klagenfurt (1947). Eine Analyse der interalliierten Spannungsfelder in institutioneller und rechtlicher Hinsicht sowie die me- 
Die französischen Besatzungsbehörden widmeten sich im Rahmen ihrer NS-Prozesse - wohl nicht zuletzt mangels Mauthausen-Außenlagerstandorten innerhalb ihrer Zone - nur punktuell ehemaligen SS-Angehörigen und Funktionshäftlingen. Dabei fokussierten sie auf Außenlagerstandorte Mauthausens, an denen besonders viele KZ-Häftlinge französischer Herkunft zur KZ-Zwangsarbeit herangezogen und ermordet worden waren. Neben den Außenlagern am Loiblpass zählten dazu das unter dem Decknamen „Projekt Quarz“ eingerichtete Außenlager Melk sowie die Wiener Außenlager. Drei der sechs französischen Mauthausen-Verfahren wurden im westdeutschen Rastatt vor dem Tribunale Générale verhandelt und führten letztlich zu Todesurteilen und der Hinrichtung der drei Angeklagten. Es handelte sich dabei um zwei ehemalige Kapos des Außenlagers Melk - den aus Spanien stammenden Fidel Balbas und den Deutschen Uli Schmidt - sowie den ehemaligen SS-Wachposten und späteren Rapportführer Hans Bühner. Die weiteren Verfahren fanden in Koblenz und Innsbruck statt und endeten mit kurzen Haftstrafen..$^{50}$

\subsection{Mauthausen-Prozesse in „Opferländern“}

Abgesehen von den alliierten Militärbehörden führten bis 1948 auch mehrere „Opferländer“, wie etwa Polen, die Tschechoslowakei oder Slowenien, ${ }^{11}$ NS-Prozesse gegen Mauthausen-Täter durch, wobei hier - ähnlich der Volksgerichtsbarkeit in Österreich - jeweils ganz spezifische rechtliche Rahmenbedingungen im Sinne von Sondergesetzgebungen geschaffen wurden. KZ-Häftlinge polnischer Herkunft waren die mit Abstand größte Häftlingsgruppe im Mauthausen-Komplex gewesen und stellten auch die größte Opfergruppe dar. ${ }^{52}$ Ungeachtet dessen standen, den Vereinbarungen der Moskauer Deklaration folgend, ${ }^{53}$ in den polnischen Verfahren hauptsächlich jene Tatorte im Zentrum, die sich auf polnischem Gebiet befunden hatten. Besonders in den Fokus der polnischen Gerichte fielen jene Verbrechen, die im KZ- und Vernichtungslager Auschwitz-Birkenau begangen worden waren. In ins-

dial-gesellschaftliche Wirkung des britischen Militärgerichtsverfahrens zu den NS-Verbrechen im KZ Loibl, phil. Diss., Universität Wien 2017; Rabl, Mauthausen vor Gericht, 118-129.

50 Vgl. Rabl, Mauthausen vor Gericht, 129-137.

51 Das einzige slowenische Verfahren richtete sich im Herbst 1957 in Ljubljana gegen den ehemaligen SS-Wachmann Jože Vavpotič, der am Loiblpass eingesetzt gewesen war. Vgl. ebd., 184-186.

52 Vgl. Andreas Kranebitter, Zahlen als Zeugen. Soziologische Analysen zur Häftlingsgesellschaft des KZ Mauthausen (Mauthausen-Studien 9), Wien 2015, 186.

53 Die Moskauer Deklaration vom 30. Oktober 1943 sah unter anderem vor, dass NS-Täter jeweils in jenen Ländern vor Gericht gestellt werden sollten, in denen sie ihre Verbrechen begangen hatten. Vgl. Rabl, Mauthausen vor Gericht, 55-59. 
gesamt 83 Urteilsausfertigungen polnischer Volksgerichte zu Auschwitz-Birkenau wurde aber auch der Mauthausen-Komplex als weiterer Tatort angeführt und kann somit als urteilsrelevant erachtet werden. ${ }^{54}$ In 61 dieser 83 Fälle kamen die verurteilten SS-Angehörigen jedoch glimpflich davon und waren mit niedrigen Haftstrafen bis zu fünf Jahren konfrontiert.55 Sie konnten - sofern sie die extrem schlechten Haftbedingungen in den polnischen Gefängnissen überlebten - mit der baldigen Heimkehr nach Deutschland rechnen. ${ }^{56}$ Doch weshalb verhängten die polnischen Volksgerichte derart niedrige Haftstrafen? Die polnische Justiz sah sich von Beginn an auf mehreren Ebenen mit Problemen konfrontiert: Erstens befanden sich viele potenzielle NS-Täter in alliiertem Gewahrsam (im Falle Mauthausens meist im USamerikanischen „War Crimes Enclosure“ von Dachau) und zweitens fehlte es den polnischen Ermittlungsbehörden an den notwendigen finanziellen und personellen Ressourcen. ${ }^{57}$ Daraus resultierte vielfach das Fehlen stichhaltiger Beweise oder Augenzeugen für konkrete Gewaltverbrechen. Die Arbeit der polnischen Behörden war daher primär davon abhängig, dass die alliierten Behörden einer Auslieferung potenzieller NS-Täter nach Polen zustimmten. ${ }^{8}$ Im Zuge der Prozessführung konnten sie mangels eigener Ermittlungsresultate oft einzig die bisherigen Ermittlungsergebnisse der US-Behörden als Beweismittel heranziehen. Insofern verwundert es nicht, dass viele Mauthausen-Urteile relativ mild ausfielen und sich auf wenige Jahre Haft beschränkten. Die Schuldsprüche bezogen sich einzig auf das Delikt der SSMitgliedschaft sowie auf die Anwesenheit in einem Konzentrationslager.

Die Volksgerichte in der Tschechoslowakei widmeten sich hauptsächlich der Frage der Kollaboration und nur ganz am Rande den Verbrechen, die von SS-Angehörigen (darunter auch zahlreichen Sudetendeutsche) im Mauthausen-Komplex gegen KZHäftlinge begangen worden waren. Im tschechischen Cheb kam es zum einzigen Todesurteil gegen Josef Stowasser, einen ehemaligen Angehörigen der Verwaltungsabteilung des Mauthausener Kommandanturstabes. Stowasser wurde (unter anderem) die Ermordung eines sowjetischen Kriegsgefangenen während der „Mühlviertler Hasenjagd“ vorgeworfen, weshalb er am 8. Juli 1948 zum Tode verurteilt und noch am gleichen Tag hingerichtet wurde. ${ }^{59}$ In Summe wurde an verschiedenen Gerichts-

54 Vgl. ebd., 174.

55 Vgl. ebd., 180.

56 Vgl. ebd., 181-182.

57 In diesem Kontext muss ganz besonders auf die Auswirkungen der deutschen Intelligenzaktion bzw. der AB-Aktion hingewiesen werden. Im Zuge dieser Vernichtungsaktionen waren auch zahlreiche Polen mit juristischen Fachkenntnissen ermordet worden.

58 Vgl. Rabl, Mauthausen vor Gericht, 55-59.

59 Vgl. ebd., 161-162. 
standorten in Tschechien rund ein Dutzend Prozesse mit Bezug zum MauthausenKomplex geführt, wobei auch hier die Urteile überwiegend mild ausfielen und die Verurteilten oft - ohne ihre Haft zur Gänze verbüßt zu haben - frühzeitig wieder des Landes verwiesen wurden. Ebenso wie die polnischen Prozesse richteten sich die tschechischen Verfahren hauptsächlich gegen SS-Angehörige, die von den USBehörden aus dem Dachauer Kriegsgefangenenlager nach Tschechien überstellt worden waren. Da es aber auch den tschechischen Behörden oft an stichhaltigen Beweisen für eine Verurteilung vor dem Volksgericht fehlte, gaben die Behörden im Zweifelsfall der Vertreibung der Verdächtigen den Vorzug vor deren Anklage. ${ }^{60}$

\subsection{Mauthausen-Prozesse in den Nachfolgestatten des Dritten Reichs}

Auf den - besonders von internationalen Opferorganisationen heftig kritisierten Umgang der österreichischen Justiz mit NS-Verbrechen wurde eingangs bereits verwiesen. Ganz besonders was die Geschworenengerichtsbarkeit nach 1955 anbelangt, ist die Bilanz ernüchternd. Das erste Verfahren gegen den ehemaligen SS-Mann Johann Gogl endete zunächst vor dem Landesgericht Linz 1972 mit einem Freispruch, wurde vom OGH aufgehoben und an das Landesgericht Wien verwiesen. Dort kam es bei der Neuauflage drei Jahre später neuerlich zu einem einstimmigen Freispruch. Ganz ähnlich verlief auch das zweite Mauthausen-Verfahren, das sich 1969 in Klagenfurt gegen Andreas Vogel gerichtet hatte. Der ehemalige „Volksdeutsche“, SSMann und Kriegsversehrte hatte vor Gericht offen zugegeben, aus Hass gegen den Kommunismus im Außenlager Loiblpass-Nord einen sowjetischen Kriegsgefangenen erschossen zu haben. Dennoch verneinten die Geschworenen die Frage nach Mordlust und niedrigen Beweggründen und sprachen Vogel frei. Auch hier hob der OGH zwar das Urteil auf, die Neuaustragung des Verfahrens am 16. April 1970 brachte jedoch mit acht neuen Geschworenen das gleiche Ergebnis: Freispruch. ${ }^{61}$

Immerhin: Zwischen 1946 und 1955 waren vor österreichischen Volksgerichtsgerichten in Wien, Linz und Graz in Summe 42 SS-Angehörige, Zivilisten und Funktionshäftlinge abgeurteilt ${ }^{62}$ und - zumindest teilweise - zu langjährigen Ker-

60 Vgl. ebd., 155 .

61 Vgl. ebd., 279-288.

62 Vor dem Volksgericht Wien wurden 18 Verfahren gegen 17 Personen verhandelt (der ehemalige Rapportführer des KZ-Außenlagers St. Aegyd, Anton Perschl, sah sich mit zwei getrennten Verfahren konfrontiert), das Volksgericht Linz führte 19 Verfahren zum Mauthausen-Komplex (darunter ein Sammelverfahren gegen 7 zivile Angestellte der Steyr-Werke Gusen), ein weiteres Verfahren 
kerstrafen oder gar zum Tod verurteilt worden ${ }^{63}$. Betrachtet man die Angeklagten näher, so zeigt sich bei den österreichischen Volksgerichtsverfahren ein zentraler Unterschied zu allen anderen größeren Prozessgruppen: Während sowohl alliierte Militärgerichte als auch polnische, tschechische oder westdeutsche Gerichte überwiegend ehemalige SS-Angehörige, jedoch nur vereinzelt ehemalige KZ-Häftlinge sowie wenige ZivilistInnen zur Verantwortung zogen, hielt sich in Österreich die Zahl angeklagter SS-Angehöriger (13 Männer), ZivilistInnen (15 Männer) und ehemaliger KZ-Häftlinge (11 Männer, 1 Frau $)^{64}$ nahezu die Waage.

In den besetzten Westzonen Deutschlands sowie in der Sowjetischen Besatzungszone (SBZ) und der DDR spielte der Mauthausen-Komplex vor Gericht zunächst eine marginale Rolle. In den Westzonen fanden lediglich fünf Verfahren statt, die mit niedrigen Haftstrafen oder Freisprüchen endeten. In der SBZ und DDR kam es zwischen 1949 und 1955 zu weiteren vier Mauthausen-Verfahren. Drei behandelten die Verbrechen ehemaliger SS-Angehöriger, eines den Fall eines früheren Funktionshäftlings. Insbesondere die Urteilsbegründungen der DDR-Verfahren weisen oft starke Züge der SED-Propaganda auf, die gezielt versuchte, die DDR als „,antifaschistischen Modellstaat“ zu positionieren. In der DDR wurde auch das letzte Todesurteil betreffend den Mauthausen-Komplex verhängt. Es richtete sich gegen den ehemaligen SS-Sanitätsdienstgrad Karl Theiner, der unter anderem in Gusen durch „Abspritzungen“ rund neunzig kranke KZ-Häftlinge mit tödlichen Injektionen ermordet hatte. Das Urteil wurde beim Stadtgericht Berlin am 4. Februar 1955 verkündet und die Todesstrafe am 10. Juni 1955 vollstreckt. ${ }^{65}$

Nach der Gründung der Bundesrepublik Deutschland standen dort - nicht zuletzt aufgrund massiven Drucks der deutschen Öffentlichkeit - die Zeichen zunächst ganz

fand vor dem Volksgericht Graz gegen den schon erwähnten Schutzpolizisten Franz Weber statt. Vgl. ebd., 244-277.

63 Die Todesstrafe gegen den ehemaligen SS-Mann und Angehörigen der Politischen Abteilung von Mauthausen, Franz Doppelreiter, wurde später in lebenslange Haft umgewandelt. Vollstreckt wurde hingegen das Linzer Todesurteil gegen den ehemaligen KZ-Häftling und „Halbjuden“ Johann Ludwig, der erst im Januar 1945 nach Mauthausen gekommen und in Gusen II als „Stubendienst" eingesetzt worden war. Vgl. ebd., 255-256.

64 Das einzige bekannte Mauthausen-Verfahren gegen eine Frau betraf die aus dem burgenländische Spitzzicken stammende Hermine Horvath, die im KZ Mauthausen als „Zigeunerin“ kategorisiert worden war. Die fünffache Mutter Horvath wurde vom Volksgericht Linz für schuldig befunden, in ihrer Funktion als Stubendienst im April 1945 einen weiblichen Mithäftling mit einem Besenstiel geschlagen zu haben. Horvath musste die verhängten 18 Monate Haft vollständig absitzen, eine bedingte Entlassung wurde ihr - im Gegensatz zu so gut wie allen anderen verurteilten MauthausenTätern - verwehrt. Vgl. ebd., 253-254.

65 Vgl. ebd., 195-197. 
auf „Schlussstrich“ und „Amnestie“. Erst ab Mitte der 1950er-Jahre gerieten mehrere bedeutsame Akteure aus dem Mauthausen-Komplex, die sich über viele Jahre erfolgreich der Justiz entzogen hatten, in den Fokus der Ermittler. Dies lag nicht zuletzt an den Aussagen des ehemaligen Gusener Block- und Lagerältesten Johann Kammerer, der 1950 beim Landgericht Augsburg zu lebenslanger Haft verurteilt worden war. Kammerer nannte vor Gericht mehrere Namen ehemaliger SS-Angehöriger, die in Gusen an schweren Verbrechen beteiligt gewesen waren. ${ }^{66}$ Gegen viele dieser Männer wurde in den folgenden Jahren - noch verstärkt ab der Gründung der Zentralen Stelle der Landesjustizverwaltungen in Ludwigsburg im Dezember 1958 - ermittelt. Einige von ihnen mussten sich schließlich auch vor Gericht verantworten, darunter mehrere ehemalige Lagerführer, wie etwa Karl Chmielewski (Gusen), Anton Ganz (Ebensee) oder Anton Streitwieser (Melk, Wiener Außenlager) sowie leitende Mitarbeiter des Kommandanturstabes, wie etwa Karl Schulz (Leiter Politische Abteilung), Werner Fassel (Stellvertretender Leiter Politische Abteilung) oder Martin Roth (Kommandoführer im Krematorium) ${ }^{67}$ Während die genannten Lagerführer durchweg wegen vielfachen Mordes zu lebenslangen Haftstrafen verurteilt wurden, kam das Gros der betreffend KZ Mauthausen Angeklagten, darunter auch Schulz, Fassel und Roth, mit vergleichsweise niedrigen Haftstrafen davon. ${ }^{68}$

\section{Fazit und Ausblick}

Die österreichische Zeitgeschichtsforschung hat sich seit Mitte der 1980er-Jahre und besonders ab der Gründung der Forschungsstelle Nachkriegsjustiz intensiv mit der juristischen Ahndung bzw. der Strafverfolgung der österreichischen Justiz in Bezug auf NS-Verbrechen beschäftigt. Ungeachtet dessen stehen weiterhin einige interessante Aspekte zur Diskussion, von denen zwei hier kurz umrissen werden sollen:

Nach wie vor umstritten ist etwa die Frage des Anteils österreichischer TäterInnen an den Verbrechen des NS-Regimes. Während Simon Wiesenthal seit den 1960erJahren wiederholt auf den überproportionalen Anteil österreichischer TäterInnen

66 Vgl. ebd., 208-209.

$67 \mathrm{Zu}$ den jeweiligen Verfahren vgl. ebd., 219-233.

68 Zur Kritik an der westdeutschen „Beihilfe-Rechtsprechung“ vgl. etwa Kerstin Freudiger, Die juristische Aufarbeitung von NS-Verbrechen (Beiträge zur Rechtsgeschichte des 20. Jahrhunderts 33), Tübingen 2002 sowie Michael Greve, Täter oder Gehilfen? Zum strafrechtlichen Umgang mit NSGewaltverbrechern in der Bundesrepublik Deutschland, in: Ulrike Weckel/Edgar Wolfrum (Hg.), „Bestien“ und „Befehlsempfänger“. Frauen und Männer in NS-Prozessen nach 1945, Göttingen 2003, 194-221. 
an den NS-Verbrechen hingewiesen hat, ${ }^{69}$ hat Kurt Bauer zuletzt argumentiert, diese „Täterthese“ Wiesenthals sei ebenso ein Mythos wie die jahrzehntelang als Staatsdoktrin geltende Opferthese. Österreicher seien unter den TäterInnen in Relation zu ihrem Anteil an der Gesamtbevölkerung des Deutschen Reichs vermutlich eher unterrepräsentiert gewesen. ${ }^{70}$ Bertrand Perz hat in diesem Zusammenhang zu Recht darauf hingewiesen, dass allein die Frage, an welchen Kriterien festgemacht werden solle, ob jemand ÖsterreicherIn sei oder nicht, methodisch schwierig und somit nur von Fall zu Fall zu klären sei.71 Perz plädiert daher dafür, sich dieser Frage anhand von Einzelfallstudien zu bestimmten Verbrechenskomplexen kontinuierlich anzunähern, um letztlich zu einer belastbaren Gesamteinschätzung zu gelangen..$^{72}$

Eine weitere offene Frage ist jene nach dem Lebensverlauf verurteilter NS-TäterInnen nach ihrer Haftentlassung. Der Autor des vorliegenden Beitrags hat in seiner Studie „Mauthausen vor Gericht" die These vertreten, dass das Gros ehemaliger SS-Angehöriger und ZivilistInnen - im Gegensatz zu verurteilten Funktionshäftlingen - nach der (meist frühzeitigen) Haftentlassung im Gegensatz zu „gewöhnlichen Verbrechern" keiner Reintegration in die österreichische bzw. deutsche Nachkriegsgesellschaft bedurfte. Denn - so zeigt die enorme Zahl wohlmeinender Petitionen und Gnadengesuche politischer und konfessioneller VertreterInnen sowie des sozialen Umfelds der inhaftierten NS-TäterInnen - die verurteilten NS-TäterInnen standen selbst während der Verbüßung ihrer Haft nicht außerhalb der Gesellschaft, sondern blieben stets eng vernetzt und gut integriert. ${ }^{73}$ Zur Untermauerung dieser These bedarf es freilich noch weiterer Studien, die den weiteren Lebensverlauf verurteilter NS-TäterInnen anderer Verbrechenskomplexe nach ihrer Haftentlassung im Detail beleuchten.

69 Vgl. Anton Pelinka, Simon Wiesenthal und die österreichische Innenpolitik (Referat im Rahmen der Tagung „Österreichs Umgang mit der NS-Täterschaft“ anlässlich des 9o. Geburtstags von Simon Wiesenthal, Wien, 02. und 03.12.1998), 3, URL: https://www.doew.at $/ \mathrm{cms} /$ download $/ 5 \mathrm{kmjc} /$ pelinka_wiesenthal.pdf (abgerufen 01.04.2020).

70 Vgl. Kurt Bauer, Die dunklen Jahre. Politik und Alltag im nationalsozialistischen Österreich $1938-$ 1945, Wien 2017, 406-407.

71 Zu dieser Frage vgl. auch Rabl, Am Strang, 19-21.

72 Vgl. Perz, Vorwort, in: Rabl, Am Strang, 11-13.

73 Vgl. Rabl, Mauthausen vor Gericht, 319; ders., Am Strang, 76-78. 


\title{
Zwangsarbeit
}

\author{
Kerstin von Lingen
}

Für das nationalsozialistische Deutsche Reich, und dies schließt das Gebiet des heutigen Österreich ein, mussten während des Zweiten Weltkriegs zwanzig Millionen Menschen sowohl auf dem Reichsgebiete als auch in den besetzten und kontrollierten Ländern Europas Zwangsarbeit leisten. ${ }^{1}$ Damit war Zwangsarbeit ein Massenphänomen. Der Zwangsarbeitereinsat $Z^{2}$ war niemals nur ein bloßes Regimeverbrechen, für das sich später allein die herrschende Clique verantwortlich machen ließ. Kein anderes Kriegsverbrechen wurde mit einer derart breiten Teilhabe der Bevölkerung begangen. ${ }^{3}$ Die "Vergesellschaftung" des Zwangsarbeitereinsatzes geschah im Spanungsfeld vom bereitwilligen und überzeugten Mitmachen über Formen der passiven Hinnahme und Duldung bis hin zu vereinzelter Distanzierung. Dabei gab es deutlich mehr Profiteure, Akteure und Mitläufer des Systems Zwangsarbeit als Verweigerer und Widerständler. ${ }^{4}$

Seit dem Ersten Weltkrieg lässt sich das Phänomen der „,verwalteten Massen“ "nachweisen, gemeint ist hier die industriemäßig betriebene Erfassung, Internierung und wirtschaftliche Ausbeutung der Kriegsgefangenen. ${ }^{5} \mathrm{Zu}$ den technisch-organisatorischen Neuerungen zählten vor allem Stacheldraht, Wachtürme, elektrische Zäune und Flutlicht, Telegramme, Eisenbahntransport, Karteikarten, Bezugsscheine, eine

1 Zu dieser Zahl vgl. Volker Knigge/Rikola-Gunnar Lüttgenau, Jens-Christian Wagner, Einleitung, in: Volkhard Knigge/Rikola-Gunnar Lüttgenau/Jens-Christian Wagner (Hg.), Zwangsarbeit. Die Deutschen, die Zwangsarbeiter und der Krieg, Weimar 2010, 6-11, 6.

2 Zur besseren Lesbarkeit wurde im Text durchgängig der Begriff "Zwangsarbeiter" verwendet, der Zwangsarbeiter und Zwangsarbeiterinnen einschließt. An einigen Stellen wurde darüber hinaus auf geschlechterspezifische Unterschiede deutlich hingewiesen, etwa in der unterschiedlichen Behandlung von Zwangsarbeiterinnen, insbesondere jener mit Kindern.

3 Das galt im nationalsozialistischen Deutschland insbesondere für die Zwangsarbeit von Juden und Jüdinnen. Vgl. Wolf Gruner, Der geschlossene Arbeitseinsatz deutscher Juden. Zur Zwangsarbeit als Element der Verfolgung, 1938-1943, Berlin 1997; Wolf Gruner, Zwangsarbeit und Verfolgung. Österreichische Juden im NS-Staat 1938-1945, Innsbruck 2000.

4 Dies hat 2010 die große Ausstellung im Jüdischen Museum Berlin zum Thema eindrucksvoll gezeigt. Vgl. den Ausstellungskatalog von Volkhard Knigge/Rikola-Gunnar Lüttgenau/Jens-Christian Wagner (im Auftr. der Stiftung Gedenkstätten Buchenwald und Mittelbau-Dora) (Hg.), Zwangsarbeit. Die Deutschen, die Zwangsarbeiter und der Krieg, Weimar 2010.

5 Vgl. Hannes Leidinger/Verena Moritz, Verwaltete Massen. Kriegsgefangene in der Donaumonarchie 1914-1918, in: Jochen Oltmer (Hg.), Kriegsgefangene im Europa des Ersten Weltkriegs, Paderborn/München/Wien/Zürich 2006, 35-66. 
normierte Lagerarchitektur und neue Formen der Massendesinfektion. Die gigantischen Kriegsgefangenenlager waren zum einen der sichtbare Ausdruck dafür, dass der Krieg total geworden war; zum anderen schufen sie Präzedenzfälle für Grausamkeiten, die späteren Häftlingen in der totalitären Lagerwelt bedenkenlos zugemutet wurden. Durch die Repressalien gegen Kriegsgefangene „bewegte sich der Krieg geradezu in mehreren Zeitaltern der Kriegsführung zugleich - einerseits durch den Rückschritt zu längst veralteten, an Sklaverei grenzende Methoden, begleitet andererseits von der Umsetzung modernster Techniken der Zwangsausübung “6

Im Zweiten Weltkrieg kam es durch die Verschmelzung von Kriegsgewalt, Zwangsarbeit und Lagerhaft dann zu einer ungeahnten Radikalisierung und Brutalisierung.7 Kein anderer militärischer Konflikt hat so viele Ressourcen vernichtet und Menschenleben gekostet. Mehr als fünfzig Millionen Menschen waren global gesehen gezwungen - oftmals fern ihrer Heimat -, ihre Arbeitskraft in die Kriegswirtschaft einzubringen. Während auf den Schlachtfeldern und bei den mörderischen Angriffen auf die Heimatfronten die moderne Kriegstechnik ihre enormen Zerstörungskräfte entfaltete, schufen Helfer aus Staat und Wirtschaft gleichzeitig unmenschliche Lagersysteme und Zwangsarbeitsregime, die erbarmungslos die Terror- und Tötungsmacht moderner Organisationen unter Beweis stellten. Japan beutete gleichfalls zwanzig Millionen Kriegsgefangenen und Zivilpersonen aus, um die Schlagkraft seiner Streitkräfte aufrechtzuerhalten. ${ }^{8}$ In der Sowjetunion bildeten während der gesamten Weltkriegsjahre Kriegsgefangene, Gulag-Häftlinge, Arbeitssoldaten und Sondersiedler ein Heer von insgesamt zehn Millionen Zwangsarbeitern. ${ }^{9}$

Für die Kriegsführung Deutschlands, Japans und der Sowjetunion erwies sich der verbrecherische Zwangsarbeitereinsatz bald als unverzichtbar. Dies ist sowohl

6 Annette Becker, Paradoxien in der Situation der Kriegsgefangenen 1914-1918, in: Jochen Oltmer (Hg.), Kriegsgefangene im Europa des Ersten Weltkriegs, 24-31, 30.

7 Auch im Folgenden vgl. Kerstin von Lingen/Klaus Gestwa, Zwangsarbeit als Kriegsressource. Systematische Überlegungen zur Beziehungsgeschichte von Krieg und Zwangsarbeit, in: dies. (Hg.), Zwangsarbeit als Kriegsressource in Europa und Asien (Krieg in der Geschichte 77), Paderborn 2014, 15-56, 17.

8 Vgl. Andreas Heusler/Mark Spoerer/Helmuth Trischler, Rüstung und Zwangsarbeit im „Dritten Reich“: eine Einführung, in: dies. (Hg.), Rüstung, Kriegswirtschaft und Zwangsarbeit im „Dritten Reich“, München 2010, 1-14, 1.

9 Vgl. Edwin Bacon, The Gulag at War. Stalin's Forced Labour System in the Light of the Archives, Houndmills 1994; Steven Barnes, All for the Front - All for the Victory! The Mobilization of Forced Labor in the Soviet Union during World War Two, in: International Labor and Working-Class History 58 (2000), 239-260; Vladimir Nikolaevič Trjachov, Gulag i vojna. Žestokaja pravda dokumentov, Perm 2005. 
vor dem Hintergrund des kriegsbedingten Ausnahmezustands als auch im Kontext der ideologiegeleiteten Vereinnahmung von Gesellschaft für die Forschung von Interesse. Der totalitäre Rassenstaat gründete sich genauso wie der stalinistische Parteistaat mit seinem wachstumsorientierten Produktionsregime vor allem auf Gewalt und Unterwerfung. Die organisierte Eliminierung von Millionen Menschen durch entwürdigende Sklavenarbeit führte zur Deformation von Menschlichkeit und zur Verrohung der Gesellschaft und verlängerte den Krieg.

Einen interessanten Sonderfall stellt in dieser Hinsicht das heutige Österreich dar, wo der Zwangsarbeitereinsatz während des Zweiten Weltkriegs gleichzeitig einen Industrialisierungs- und Technisierungsschub der Wirtschaft insgesamt bewirkte. Diese These, prononciert vorgetragen von Bertrand Perz und Florian Freund, ${ }^{10}$ besagt, dass insbesondere in der Rüstungsindustrie anhand der Zahlen nachzuweisen ist, dass die Zahl der Industriebeschäftigten von 530.000 auf 730.000 anstieg. Während im übrigen Deutschen Reich die Zahl der ausländischen Zwangsarbeiter nur in etwa den Ausfall deutscher Industriearbeiter kompensierte, stiegen die Zahlen in Österreich kontinuierlich an, begünstigt durch die Erweiterung von bestehenden Fabriken, aber auch durch die Verlagerung von bombengefährdeten Industriestandorten aus Deutschland in die „Donaugaue“. Der Anteil der Zwangsarbeiter blieb auffällig hoch: 1944 waren in der „Ostmark“ 36 Prozent ausländischer Zivilarbeiter in der Industrie beschäftigt. Bis 1944 verdoppelten sich die Zahlen der in der Industrie beschäftigten Kriegsgefangenen und die Zahlen der Zwangsarbeiter (Männer wie Frauen) vervierfachte sich. ${ }^{11}$

Generell ist zu sagen, dass das Thema Zwangsarbeit zunächst in Deutschland wie in Österreich nur wenig Beachtung fand und sich dies erst mit der Studie von Ulrich Herbert und den großen Konferenzen zum „Reichseinsatz“ der Zwangsarbeiter ab 1989 grundlegend änderte. ${ }^{12}$ Auf Herbert folgten die breiter angelegten Studien von

10 Florian Freund/Bertrand Perz, Zwangsarbeiter und Zwangsarbeiterinnen auf dem Gebiet der Republik Österreich 1939-1945, Bd. 2, Wien/München 2004, 644-695; Florian Freund/Bertrand Perz, Die Zahlenentwicklung der ausländischen Zwangsarbeiter und Zwangsarbeiterinnen auf dem Gebiet der Republik Österreich 1939-1945, in: Florian Freund/Bertrand Perz/Mark Spoerer, Zwangsarbeiter und Zwangsarbeiterinnen auf dem Gebiet der Republik Österreich 1939-1945 (Veröffentlichungen der Österreichischen Historikerkommission 26/1), Wien/München 2004, 7-273.

11 Vgl. Felix Butschek, Österreichische Wirtschaftsgeschichte. Von der Antike bis zur Gegenwart, Wien 2011, 91.

12 Als Initialzündung für die neuere geschichtswissenschaftliche Erforschung der Zwangsarbeit in der NS-Kriegswirtschaft gilt die Studie von Ulrich Herbert, Fremdarbeiter. Politik und Praxis des „Ausländereinsatzes“ in der Kriegswirtschaft des Dritten Reiches, Bonn 1985; Vgl. auch Ulrich 
Overy (1994), Schulte (2001), Spörer (2003) und Tooze (2006). ${ }^{13} 2014$ verbreiterte der vergleichende Sammelband von Lingen und Gestwa zu Asien und Europa das

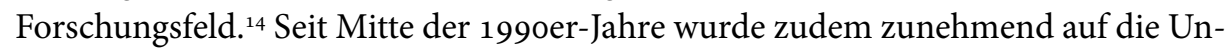
terschiede in der Behandlung männlicher und weiblicher Zwangsarbeiter verwiesen und die Kategorie Geschlecht in diese Forschungen eingeführt, hier sind vor allem die Arbeiten Carola Sachses und Gabriella Hauchs zu nennen, sowie, speziell auf die Kinder der „Ostarbeiterinnen“ bezogen, Bernhild Vögels. ${ }^{15}$ Darauf aufbauend bildete sich ein besonderer Schwerpunkt im Bereich sexualisierte Gewalt gegen (Häftlings)Zwangsarbeiterinnen heraus. ${ }^{16}$

Herbert (Hg.), Europa und der „Reichseinsatz“. Ausländische Zivilarbeiter, Kriegsgefangene und KZ-Häftlinge in Deutschland 1938-1945, Essen 1991.

13 Richard J. Overy, War and Economy in the Third Reich, Oxford 1994; Jan Erik Schulte, Zwangsarbeit und Vernichtung. Das Wirtschaftsimperium der SS, Paderborn 2001; Mark Spoerer, Zwangsarbeit unter dem Hakenkreuz. Ausländische Zivilarbeiter, Kriegsgefangene und Häftlinge im Dritten Reich und im besetzten Europa 1939-1945, Stuttgart 2003; Adam Tooze, The Wages of Destruction. The Making and Breaking of Nazi Economy, London 2006.

14 Von Lingen/Gestwa (Hg.), Zwangsarbeit als Kriegsressource. Vgl. hierin auch die allgemeinen Einführungen von von Lingen/Gestwa, Zwangsarbeit als Kriegsressource, 15-56.

15 Carola Sachse (Hg.), Als Zwangsarbeiterin 1941 in Berlin. Die Aufzeichnungen der Volkswirtin Elisabeth Freund (Selbstzeugnisse der Neuzeit 5), Berlin 1996; Carola Sachse, Siemens, der Nationalsozialismus und die moderne Familie. Eine Untersuchung zur sozialen Rationalisierung in Deutschland im 20. Jahrhundert, Hamburg 1990; Gabriella Hauch, Zwangsarbeiterinnen und ihre Kinder: Zum Geschlecht der Zwangsarbeit, in: Christian Gonsa/Gabriella Hauch/Michael John/Josef Moser/Bertrand Perz/Oliver Rathkolb/Michael C. Schober, Zwangsarbeit-Sklavenarbeit: Politik-, sozial- und wirtschaftshistorische Studien (NS-Zwangsarbeit: Der Standort Linz der „Reichswerke Hermann Göring AG Berlin“, 1938-1945 1), Wien/Köln/Graz 2001, 355-448; Gabriella Hauch, Ostarbeiterinnen. Vergessene Frauen und ihre Kinder, in: Fritz Mayrhofer/Walter Schuster (Hg.), Nationalsozialismus in Linz, Bd. 2, Linz ²002, 1271-1310; Bernhild Vögel, Das „Entbindungsheim für Ostarbeiterinnen.“: Braunschweig, Broitzemer Straße 200 (Kleine Historische Bibliothek 3), Hamburg 1989, URL: http://www.birdstage.net/images/entbindungsheim. pdf (abgerufen 10.11.2020); Bernhild Vögel, Säuglingslager - „ein Massenexperiment allergrößten Stiles"?, in: Andreas Frewer/Günther Siedbürger (Hg.), Medizin und Zwangsarbeit im Nationalsozialismus. Einsatz und Behandlung von "Ausländern“ im Gesundheitswesen, Frankfurt a. M./ New York 2004, 309-340; Bernhild Vögel, „Rassisch unerwünscht“. Sowjetische und polnische Zwangsarbeiterinnen und ihre Kinder, in: KZ-Gedenkstätte Neuengamme (Hg.), Zwangsarbeit und Gesellschaft (Beiträge zur Geschichte der nationalsozialistischen Verfolgung in Norddeutschland 8), Bremen 2004, 125-144. Vgl. auch Raimund Reiter, Tötungsstätten für ausländische Kinder im Zweiten Weltkrieg - Zum Spannungsverhältnis von kriegswirtschaftlichem Arbeitseinsatz und nationalsozialistischer Rassenpolitik in Niedersachsen, Hannover 1993.

Vgl. Brigitte Halbmayr/Helga Amesberger/Katrin Auer, Sexualisierte Gewalt. Weibliche Erfahrungen in NS- Konzentrationslagern, Wien 2004; Brigitte Halbmayr/Elke Frietsch/Christina Herkommer, Sexualisierte Gewalt gegen Frauen während der NS-Verfolgung, in: Elke Frietsch/Christina Herkommer (Hg.), Nationalsozialismus und Geschlecht. Zur Politisierung und Ästhetisierung von 
Das Forschungsinteresse zur Zwangsarbeit generierte sich also zunächst aus Studien, die die KZ-Zwangsarbeit besonders in den Blick nahmen und auf deren systematischen Charakter hinwiesen. In Deutschland war dies die Studie von Falk Pingel, ${ }^{17}$ in Österreich zählten Florian Freund und Bertrand Perz mit ihren Arbeiten zu den KZ-Außenlagern Ebensee, Melk und Wiener Neustadt zu den Vorreitern. ${ }^{18}$ Die Forschung zu Österreich hat in den letzten Jahrzehnten viele Aspekte dieses Zwangseinsatzes genauer beleuchtet, ${ }^{19}$ insbesondere den Zusammenhang von $\mathrm{KZ}$ Außenlagern, Industrie und Zwangsarbeit. Doch erst mit den Sammelklagen Ende der 1990er-Jahre und der Frage der Entschädigung, befeuert nicht zuletzt durch die Forschungsarbeit der österreichischen Historikerkommission, wurde Zwangsarbeit ein in der Öffentlichkeit diskutiertes Thema.

Eine einheitlich verwendete wissenschaftliche Definition von Zwangsarbeit gibt es nicht. ${ }^{20}$ Einen wichtigen Anhaltspunkt bietet der 1930 als Reaktion auf koloniale Zwangsarbeitsregime vage formulierte Bestimmungsversuch der Internationalen Arbeitsorganisation (ILO). Demnach ist unter Zwangsarbeit zu verstehen „[j]ede Art von Arbeit oder Dienstleistung, die von einer Person unter Androhung irgendwelcher Strafe verlangt wird und für die sie sich nicht freiwillig zur Verfügung gestellt hat“. ${ }^{21}$ Besonders die Definition von „Zwang“ bleibt umstritten. Ulrich Herbert hat vorgeschlagen, den Begriff Zwangsarbeit nicht auf jede Form von unfreier Arbeit

Körper, „Rasse“ und Sexualität im „Dritten Reich“ und nach 1945, Bielefeld 2008, 141-154; Brigitte Halbmayr, Sex-Zwangsarbeit in NS-Konzentrationslagern. Fakten, Mythen und Positionen, in: Insa Eschebach/Regina Mühlhäuser (Hg.), Krieg und Geschlecht. Sexuelle Gewalt im Krieg und Sex-Zwangsarbeit in NS-Konzentrationslagern, Berlin 2008, 127-145.

17 Falk Pingel, Häftlinge unter SS-Herrschaft. Widerstand, Selbstbehauptung und Vernichtung im Konzentrationslager, Hamburg 1978.

18 Florian Freund, Arbeitslager Zement. Das KZ Ebensee und die Raketenrüstung, Wien 1989; Bertrand Perz, Projekt Quarz. Steyr-Daimler Puch und das Konzentrationslager Melk, Wien 1991; Florian Freund/Bertrand Perz, Das KZ in der Serbenhalle. Zur Kriegsindustrie in Wiener Neustadt, Wien 1987.

19 Als Überblick vgl. Florian Freund/Bertrand Perz, Fremdarbeiter und KZ-Häftlinge in der „Ostmark“, in: Ulrich Herbert (Hg.), Europa und der „Reichseinsatz“. Ausländische Zivilarbeiter, Kriegsgefangene und KZ-Häftlinge in Deutschland 1938-1945, Essen 1991, 317-350; Bertrand Perz/Florian Freund, Zwangsarbeit von zivilen AusländerInnen, Kriegsgefangenen, KZ-Häftlingen und ungarischen Juden in Österreich, in: Emmerich Tálos/Ernst Hanisch/Wolfgang Neugebauer/ Reinhard Sieder (Hg.), NS-Herrschaft in Österreich. Ein Handbuch, Wien 2000, 644-695.

20 Dies betonte zuletzt Christian Westerhoff, Zwangsarbeit im Ersten Weltkrieg. Deutsche Arbeitskräftepolitik im besetzten Polen und Litauen 1914-1918 (Studien zur Historischen Migrationsforschung 25), Paderborn 2012, 10.

21 Hartwig Bülck, Die Zwangsarbeit im Friedensvölkerrecht. Untersuchung über die Möglichkeit und Grenzen allgemeiner Menschenrechte, Göttingen 1953; Hartwig Bülck, Zwangsarbeit, in: HansJürgen Schlochauer (Hg.), Wörterbuch des Völkerrecht, Berlin 1960, 893-894. 
auszudehnen und darauf zu achten, den Begriff von der oftmals auch erzwungenen Dienstpflicht deutscher Reichsbürger zum Landjahr, Arbeitsdienst oder zu anderen Dienstverpflichtungen abzugrenzen..$^{22}$ Freund und Perz betonen den ,außerökonomischen Zwang " für die Aufnahme des Dienstverhältnisses eines Zwangsarbeiters" ${ }^{23}$ und Spoerer fügt dem noch die Kategorie der prekären Lebensumstände und verminderten Überlebenschancen hinzu. ${ }^{24}$ Hornung, Langthaler und Schweitzer grenzen in ihrer Studie für die österreichische Historikerkommission die Zwangsarbeit unter Zuhilfenahme des Konzepts von Peter Imbusch (der repressiven, konditionierten und kompensatorischen Zwang unterscheidet ${ }^{25}$ noch weiter ein. ${ }^{26}$

\section{Opfer, Formen, Ursachen und Ziele von Zwangsarbeit}

Die Zusammensetzung der ausländischen Zwangsarbeiter und Zwangsarbeiterinnen unterschied sich in Österreich vom restlichen Deutschen Reich: Perz und Freund unterscheiden die Opfer von Zwangsarbeit grob in vier große Gruppen: erstens zivile Arbeitskräfte, die mit „Anwerbung“, Zwangsrekrutierung oder Deportation zur Arbeit herangezogen wurden; zweitens Kriegsgefangene, die grundsätzlich durch die Genfer Konvention nur unter besonderen Bedingungen zu Arbeiten herangezogen werden durften - gegen diese Vorgaben verstieß man oder man ordnete die Gefangenen anderen Kategorien zu, die diesen Schutz nicht genossen; drittens KZ-Häftlinge, deren Arbeit bzw. Ausbeutung nicht nur zu ihrer eigenen „Vernichtung" führen sollte, sondern mit Fortschreiten des Krieges immer mehr nach den Bedürfnissen und Wünschen der Wirtschaft organisiert wurde (Stichwort Anlage oder Verlegung von Konzentrationslagern auf „Bestellung“ zum Beispiel seitens der Steyr-Daimler-Puch AG); und viertens ungarische Juden, die angesichts der eingetretenen Notlage mangelnder Arbeitskräfte unter mörderischen Bedingungen unter anderem zur Errichtung des "Südostwalls“ herangezogen wurden..$^{27}$

22 Vgl. Ulrich Herbert, Geschichte der Ausländerbeschäftigung in Deutschland 1880 bis 1980. Saisonarbeiter, Fremdarbeiter, Gastarbeiter, Berlin/Bonn 1986, 82.

23 Freund/Perz, Zwangsarbeit, 646.

24 Vgl. Spoerer, Zwangsarbeit unter dem Hakenkreuz, 15-18.

25 Vgl. Peter Imbusch, Macht und Herrschaft. Sozialwissenschaftliche Theorien und Konzeptionen, Opladen 1998, 12.

26 Ela Hornung/Ernst Langthaler/Sabine Schweitzer, Zwangsarbeit in der Landwirtschaft in Niederösterreich und dem nördlichen Burgenland (Veröffentlichungen der Österreichischen Historikerkommission 26/3), Wien 2004, 25-26.

27 Vgl. Freund/Perz, Zwangsarbeit, 644-695. 
Der Krieg konnte sowohl als Katalysator als auch als Initiator die Entwicklung der Zwangsarbeit wesentlich beeinflussen. ${ }^{28}$ Angesichts der Mobilisierung aller verfügbaren Ressourcen wurden bereits Formen von Zwangsarbeit durch die forcierte Anwendung von Zwang und Terror verstärkt, um eine höhere Intensität der wirtschaftlichen Ausbeutung zu erreichen. Zugleich bildeten sich unter den Vorzeichen des Kriegs oftmals neue Formen der Zwangsarbeit heraus. Trotz einzelner Weiterentwicklungen entstand damit häufig ein grundlegend verändertes Zwangsarbeitsregime, das sich mit dem Kriegsende keineswegs immer auflöste. Zu Zwangsarbeit wurden nicht nur Kriegsgefangene und verschleppte Zivilisten aus den besetzten und beherrschten Gebieten verpflichtet, sondern oftmals auch die eigenen Staatsbürger.

Wie Andreas Heusler betont, aber auch Studien zum Gulag belegen, stellte Zwangsarbeit kriegswirtschaftlich gesehen durchaus ein Erfolgsmodell dar:

Einerseits diente die mit Hilfe der Zwangsarbeiter realisierte Aufrechterhaltung bzw. Ausweitung der gesamtwirtschaftlichen Produktivität den militärischen Zielen. Andererseits wurde die durch Mobilmachung und überhitzte Produktivität ausgelöste, für Unternehmen bedrohliche strukturelle Verknappung der Ressource „Arbeit“ mit Hilfe der unfreien Arbeit zu einem großen Teil aufgefangen und abgefedert. So trug die Nutzung unfreier Arbeit zur Befriedung latenter Binnenkonflikte zwischen öffentlichem und privatwirtschaftlichem Sektor bei. Dies ist insbesondere zu beobachten beim massenhaften Einsatz von weiblichen Zwangsarbeitern; bei der Anwerbung und Verschleppung der Zwangsarbeiterinnen ging es dem NS-Staat nämlich ganz wesentlich um die Entlastung inländischer Frauen, deren Arbeitseinsatz zwar kriegswirtschaftlich gesehen nötig war, aber nicht mit den ideologischen Vorstellungen von der „Hausfrau und Mutter“ zur Deckung zu bringen war. Insgesamt konnten kriegsbedingte Belastungen für die deutsche Zivilund Arbeitsbevölkerung durch den millionenfachen Einsatz ausländischer Zwangsarbeiter, KZ-Häftlinge und Kriegsgefangener spürbar reduziert werden - was sich innergesellschaftlich loyalitätsbildend auswirkte. ${ }^{29}$

Im Arbeitsalltag wurde Zwang unterschiedlich - oftmals nach rassistischen oder politischen Kriterien gestaffelt - ausgeübt; er entschied maßgeblich über die Lebensbedingungen der zwangsrekrutierten Arbeitskräfte. In enger Verbindung damit gab es

28 Auch im Folgenden vgl. von Lingen/Gestwa, Zwangsarbeit als Kriegsressource, 41-44.

29 Andreas Heusler, Zwangsarbeit in der deutschen Kriegswirtschaft 1939 bis 1945 als Faktor der Interessenkongruenz zwischen Wirtschaft und Staat, in: von Lingen/Gestwa (Hg.), Zwangsarbeit als Kriegsressource, 233-245. 
für die einzelnen Zwangsarbeitergruppen auch verschiedene rechtliche Bestimmungen, die sie deutlich voneinander trennten und nicht zuletzt dadurch verhindern konnten, dass sich dauerhafte und starke Formen gruppenübergreifender Solidarität herausbildeten. Das erschien in den Augen der Machthaber als besonders wichtig, weil die oft kaum mehr zu übersehende Masse von Zwangsarbeitern ein Unruheund Aufstandspotenzial darstellte und unter Kontrolle gehalten werden musste. ${ }^{30}$

Das augenscheinlichste Beispiel dafür ist die nationalsozialistische Arbeitskräftepolitik. Sie unterschied zwischen dem „Arbeitseinsatz“ ausländischer Zivilarbeiter, der "Zwangsarbeit“ von Kriegsgefangenen und verschleppten Zivilisten auf Reichsgebiet, der „Ghettoarbeit“ jüdischer Zivilisten und der „KZ-Häftlingsarbeit“ für deutsche Industrieunternehmen. Darüber hinaus gab es „Arbeitserziehungslager“ und „Polizeihaftlager“, dessen Insassen nicht selten gleichfalls mörderische Arbeitsleistung zu erbringen hatten, und insbesondere die Lager-SS verfolgte klar die Linie einer „Vernichtung durch Arbeit“. ${ }^{11}$ Der Staat griff allerdings meist nicht in die jeweilige unternehmerische Strategie direkt ein, sondern verhandelte mit der Betriebsleitung vor allem Produktionsziele. Dabei nutzten viele Unternehmen die sich ihnen ergebenden Handlungsspielräume; doch auch wenn grundsätzlich ein Interesse erkennbar war, die Arbeitskraft eines Häftlings so lange wie möglich zu erhalten, so wurde deren Vernichtung zur schnelleren Erreichung von Produktionszielen doch billigend in Kauf genommen. Dies trifft insbesondere für die letzten zwölf Kriegsmonate zu, als es angesichts der beschlossenen Untertageverlagerung der Produktion und durch Evakuierungen von anderen Lagern ins Reichsinnere zu expandierenden Zahlen an KZ-Häftlingen sowie einer enormen Überbelegung kam, die logistisch kaum noch zu bewältigen war und zu enorm hohen Todesraten führte.

Eines der Phänomene des NS-Staates war die freiwillige Anwerbung bzw. der Versuch, die Zwangsarbeiter mit Versprechungen auf eine bevorzugte Behandlung zu guten Arbeitsleistungen zu motivieren und ihnen zugleich ihre Besserstellung gegenüber anderen Gruppen zu veranschaulichen. Zu diesem Maßnahmenpaket zählte ebenfalls, dass bei der Organisation der Zwangsarbeit bestimmte Kompetenzen und Aufgaben an (qualifizierte) Zwangsarbeiter übertragen wurden, die bereit waren, Führungspositionen zu übernehmen. Im Heer der zwangsverpflichteten Arbeitskräfte formierte sich auf diese Weise eine „Funktionselite“, deren Arbeitseinsatz mit Vergünstigungen „belohnt“ wurde. Die Hierarchisierung der Zwangsarbeiter erwies

30 Zum Thema Kriegsgefangene und Zwangsarbeiter als sicherheits- und innenpolitische Probleme vgl. Jochen Oltmer, Einführung. Funktionen und Erfahrungen von Kriegsgefangenschaft im Europa des Ersten Weltkriegs, in: ders. (Hg.), Kriegsgefangene im Europa des Ersten Weltkriegs, 1123, 17.

31 Vgl. Heusler/Spoerer/Trischler, Rüstung und Zwangsarbeit, 1-8. 
sich damit vielfach als effizientes Organisations- und Herrschaftsmittel. Sie stellte zum einen eine thematische Klammer zwischen den unterschiedlichen Zwangsarbeitsregimen dar; zum anderen eröffnete ihre Untersuchung aufschlussreiche Einblicke in die Praxis, Bedeutung und Erfahrung von Zwangsarbeit und ermöglichte es, wichtige Merkmale des jeweiligen Zwangsarbeitsregimes näher zu bestimmen. ${ }^{32}$ Der massenhafte Zwangsarbeitereinsatz erforderte einen speziellen Kontroll- und Verwaltungsapparat. Deshalb übernahmen vereinzelt schon bestehende Institutionen bestimmte Aufgaben; in den meisten Fällen bildeten sich aber neue Institutionen, die dem Zwangsarbeiterregime einen festen administrativen Rahmen gaben und durch die Organisation des Arbeitseinsatzes nicht nur an Personal, sondern bald auch an Einfluss und Ansehen gewannen.

Eine Schlüsselrolle kommt daher dem Begriff Lager zu. Vielbeachtet wurden die Überlegungen des italienischen Philosophen Giorgio Agamben. Er bezeichnet das Lager als den Raum, „der sich öffnet, wenn der Ausnahmezustand zur Regel zu werden beginnt“. Das Wesen des Lagers liege „in der Materialisierung des Ausnahmezustands“.33 Noch weiter geht der Soziologe Zygmunt Bauman; er versteht das Lager als den Inbegriff der „Ambivalenz der Moderne“. Diese „Welt des tödlichen Ernstes“ zähle zu den „furchtbarsten Tributen an die Überzeugung, dass eine neue und bessere Ordnung auf der Erde installiert und solch eine Ordnung gleichsam auf Befehl eingerichtet werden kann". ${ }^{34}$ Nicht übersehen werden sollte jedoch bei den Definitionsversuchen des Begriffs Lager die in der NS-Zeit ebenfalls massenhafte Lagererfahrungen für Deutsche, etwa in HJ oder Reichsarbeitsdienst, wie Patel betont: Das NS-Regime habe ein zweites, fast ebenso komplexes Konglomerat von Lagern geschaffen, das sich an die Mitglieder der „Volksgemeinschaft“ wandte und als eine Art soziales Experiment Tendenzen zur Ersetzung der Familie durch neue Formen der Vergemeinschaftung in sich trug. ${ }^{35}$

32 Vgl. Ulrich Herbert. Zwangsarbeit im „Dritten Reich“. Kenntnisstand, offene Fragen, Forschungsprobleme, in: Wilfried Reininghaus/Norbert Reimann (Hg.), Zwangsarbeit in Deutschland 19391945. Archiv und Sammlungsgut, Topographie und Erschließungsstrategien, Bielefeld 2001, 16$37,17$.

33 Giorgio Agamben, Homo Sacer. Die souveräne Macht und das nackte Leben, Frankfurt a. M. 2002, 178,183 .

34 Zygmunt Bauman, Die Lager - östliche, westliche, moderne, in: Dittmar Dahlmann/Gerhard Hirschfeld (Hg.), Lager, Zwangsarbeit und Deportation. Dimensionen der Massenverbrechen in der Sowjetunion und in Deutschland, 1933 bis 1945, 53-65, 54-55, 61. Von der Lagergeschichte als das „Horrormärchen der Moderne“ sprach schon Gerd Amanski, Maschinen des Terrors, Das Lager (KZ und GULAG) in der Moderne, Münster 1993, 26.

35 Vgl. Kiran Klaus Patel, Auslese und Ausmerze. Das Janusgesicht der nationalsozialistischen Lager, in: Zeitschrift für Geschichtswissenschaft 54 (2006), 339-365, 339. 


\section{Aufarbeitung und Entschädigungspolitik}

Schon bei den unter US-Ägide geführten Nürnberger Nachfolgeprozessen von 1946 bis 1949 wurde der nationalsozialistische Zwangsarbeitereinsatz als „Crime against Humanity" verhandelt. Ungeachtet dieser unmittelbar nach Kriegsende einsetzenden internationalen Debatten und Normsetzung hat das politische Feld der Zwangsarbeiterentschädigung lange Zeit jedoch nicht die gebührende Aufmerksamkeit der Politik erhalten. Das änderte sich gegen Ende der 1980er-Jahre. Bald ging es nicht mehr nur um Themen der Anerkennung und Entschädigung, sondern auch um wichtige Fragen der Geschichtspolitik und der Verortung von Gewalterfahrung im Rahmen trans- und internationaler Beziehungen.

Anfänglich spielten bei der Aufarbeitung der Zwangsarbeit Kriegsverbrecherprozesse eine große Rolle. Doch nur wenige erhielten die Möglichkeit, als Zeugen über ihr Leid zu sprechen. Deshalb suchten manche die literarische Bühne, um das Erlebte zu verarbeiten. ${ }^{36}$ Ihre Erinnerungen galten in der Forschung als wichtige Quellen und bestimmten den wissenschaftlichen Blick auf das Phänomen Zwangsarbeit lange Zeit.

Diese Erinnerungen und die neuen Forschungsergebnisse haben seit Mitte der 1990er-Jahre das Phänomen der Zwangsarbeit in den Mittelpunkt des öffentlichen Interesses gerückt und darüber ehemalige Kriegsgegner ins Gespräch gebracht. NGOs haben verschiedene Opfergruppen miteinander vernetzt und die Thematik mit der Frage nach Entschädigungen zurück auf die politische Bühne gebracht. ${ }^{37}$ In den letzten zwanzig Jahren hat sich deshalb eine immer stärker werdende transnationale Versöhnungspolitik entwickelt, die von zahlreichen lokalen Geschichtsinitiativen flankiert und unterstützt worden ist. Deren Protagonisten geht es darum, die Spuren des Zwangsarbeitereinsatzes vor Ort zu sichten und zu den noch lebenden Zwangsarbeitern in Kontakt zu treten. Viele Bürgerinitiativen seit den 1980erJahren haben es als zunehmend beschämend empfunden, dass den nationalsozialistischen Zwangsarbeitern kein gebührender Platz in der Geschichte des Zweiten Weltkriegs eingeräumt worden sei und deren tragisches Schicksal im Schatten anderer Opfernarrative stehe. Einzelne Unternehmen, Städte und Kreise, zunächst in Deutschland, dann auch in Österreich, finanzierten Studien zur Aufarbeitung ihrer

36 Viele dieser Zeitzeugenberichte sind als wichtiges Quellenmaterial für erste wissenschaftliche Studien genutzt worden. Vgl. Eugen Kogon, Der SS-Staat, München 1946; Hermann Langbein, Der Auschwitzprozess. Dokumentation, 2 Bde., Wien 1965.

37 Auch im Folgenden vgl. von Lingen/Gestwa, Zwangsarbeit als Kriegsressource, 35-37. 
Zwangsarbeitergeschichte; sie stellten sich ihrer historischen Verantwortung und bemühten sich mit vielerlei Maßnahmen öffentlichkeitswirksam um Aussöhnung. ${ }^{38}$

Eine besondere Rolle bei der Aufarbeitung nationalsozialistischen Unrechts kommt den sogenannten Historikerkommissionen zu, also staatlich eingesetzten Gremien aus Fachleuten, die sich bestimmten Aspekten der nationalsozialistischen Terrorpolitik widmen und die Ergebnisse veröffentlichen. ${ }^{39}$ Die österreichische Historikerkommission hat in dieser Hinsicht vielbeachtete Arbeit geleistet. Mit dem Thema Zwangsarbeit beschäftigen sich die Bände 26/1-3, wobei der Zwangswirtschaft in der Land- und Forstwirtschaft besondere Aufmerksamkeit zukam, da diese in Österreich die zweitgrößte Form der Ausbeutung darstellte. ${ }^{40}$ Inzwischen gibt es umfangreiche neuere Studien zu Einzelaspekten, etwa zum Zwangsarbeitereinsatz in der Landwirtschaft, ${ }^{41}$ zur Arbeitskräftepolitik, ${ }^{42}$ in Elektrizitätswerken, ${ }^{43}$ zur

38 Ein Beispiel hierfür stellen Initiativen der Stadt Marburg dar, die die Aufarbeitung mit Entschädigungszahlungen und Begegnungsreisen verknüpfte; vgl. hier Karin Brandes/Fritz BrinkmannFrisch/Wolfgang Form/Lydia Hartleben/Ulrich Hussong/Albrecht Kirschner/Heinrich Löwer/ Dirk Richhardt/Theo Schiller/Barbara Wagner/Thomas Werther, Zwangsarbeit in Marburg 1939 bis 1945. Geschichte, Entschädigung, Begegnung, Marburg 2005.

39 Vgl. Norbert Frei/Dirk van Laak/Michael Stolleis (Hg.), Geschichte vor Gericht. Historiker, Richter und die Suche nach Gerechtigkeit, München 200o. Hierin besonders der Beitrag von Raphael Gross, Mächtiger als die Gerichte? Geschichte und historische Gerechtigkeit, in: Frei/van Laak/ Stolleis (Hg.), Geschichte vor Gericht, 164-172.

40 Freund/Perz/Spoerer, Zwangsarbeiter und Zwangsarbeiterinnen; Stefan Karner/Peter Ruggenthaler, Zwangsarbeit in der Land- und Forstwirtschaft auf dem Gebiet Österreichs 1939-1945 (Veröffentlichungen der Österreichischen Historikerkommission 26/2), Wien/München 2004; Ela Hornung/Ernst Langthaler/Sabine Schweitzer, Zwangsarbeit in der Landwirtschaft in Niederösterreich und dem nördlichen Burgenland (Veröffentlichungen der Österreichischen Historikerkommission 26/3), Wien/München 2004 sowie Hubert Feichtlbauer, Zwangsarbeit in Österreich 1938-1945. Fonds für Versöhnung, Frieden und Zusammenarbeit, Wien 2005.

41 Ernst Langthaler, Nationalsozialistische,(Land)Volksgemeinschaft' als gesellschaftliches Kräftefeld am Beispiel der Zwangsarbeit, in: Detlef Schmiechen-Ackermann (Hg.), Der Ort der ,Volksgemeinschaft' in der deutschen Gesellschaftsgeschichte, Paderborn 2017, 287-301.

42 Florian Freund, NS-Arbeitskräftepolitik in der „Ostmark“, in: Oliver Rathkolb/Florian Freund (Hg.), NS-Zwangsarbeit in der Elektrizitätswirtschaft der „Ostmark“, 1938-1945. Ennstalwerke Kaprun - Draukraftwerke - Ybbs-Persenbeug - Ernsthofen, Köln/Wien ${ }^{2} 2014$, 8-26.

43 Oliver Rathkolb/Florian Freund (Hg.), NS-Zwangsarbeit in der Elektrizitätswirtschaft der „Ostmark“, 1938-1945. Ennstalwerke - Kaprun - Draukraftwerke -Ybbs-Persenbeug - Ernsthofen, Köln/Wien ${ }^{2} 2014$. 
Situation der Befreiung ${ }^{44}$ und zu der Frage der späten Entschädigungen, also des „Preises“ dieser Zwangsarbeit. ${ }^{45}$

Der dabei verwandte Begriff Wiedergutmachung ist insofern problematisch, weil er zum einen suggeriert, dass man Unrecht und Mord auf eine materielle Weise ungeschehen machen könnte, ${ }^{46}$ zum anderen, weil der Begriff durch die daraus folgende finanzielle Kompensation eine Art Wertigkeit des Verlusts herstellt, die selten den Gerechtigkeitserwartungen der einstigen Verfolgten entspricht. ${ }^{47}$ Wiedergutmachung ist daher ein Synonym für eine bürokratisch-juristische Vergangenheitsbewältigung; sie ist oft auch die Geschichte einer erneuten Enttäuschung, ${ }^{48}$ die sich aus der nicht aufgelösten Spannung zwischen „lebensweltlichen Gerechtigkeitsvorstellungen und rechtsstaatlichem Normierungsbedürfnis“ ergibt. ${ }^{49}$ In Abgrenzung zum Begriff Reparationen, der einen zwischenstaatlichen Ausgleich beschreibt, versucht der Begriff Wiedergutmachung auch die „emphatisch-moralisch verpflichtende" Ebene deutlich zu machen. ${ }^{50}$

Das Thema Zwangsarbeit findet seit Jahren, insbesondere im kulturellen Bereich, durchaus Interesse in der Öffentlichkeit. Zu nennen sind hier nicht zuletzt die beiden (Wander)Ausstellungen „Zwangsarbeit. Die Deutschen, die Zwangsarbeiter und der Krieg“, die die Verflechtung zwischen mörderischen Lagersystemen und den Profiteuren in Politik und Wirtschaft augenfällig machten. Die Ausstellung, die zunächst $2010 \mathrm{im}$ Jüdischen Museum in Berlin eröffnet und in der Folge durch viele deutsche Städte tourte, wurde danach adaptiert unter dem Titel „Zwangsarbeit im

44 Dieter Bacher, Das Kriegsende 1945 als „Zäsur“ in der Biografie ziviler Zwangsarbeiter in Österreich, in: Stefan Karner/Gerhard Botz/Helmut Konrad (Hg.), Epochenbrüche im 2o. Jahrhundert, Wien/Köln/Weimar 2017.

45 Hermann Rafetseder, „Der Preis der Vergangenheit“: NS-Zwangsarbeit und Österreich im Rahmen des „Entschädigung“-Diskurses, im Auftr. des Museums Arbeitswelt Steyr, anlässlich der Internationalen Wanderausstellung „Zwangsarbeit im Nationalsozialismus“, Linz 2016.

46 Zur Kritik des Begriffs Hans Günter Hockerts, Wiedergutmachung in Deutschland 1945-2000. Eine historische Bilanz, in: Vierteljahreshefte für Zeitgeschichte 49 (2001) 2, 167-214, 167.

Vgl. Constantin Goschler, Schuld und Schulden. Die Politik der Wiedergutmachung für NS-Verfolgte seit 1945, 11; Vgl. auch Jakob Tanner/Sigrid Weigel (Hg.), Gedächtnis, Geld und Gesetz. Vom Umgang mit der Vergangenheit des Zweiten Weltkrieges, Zürich 2002.

48 Vgl. Norbert Frei/José Brunner/Constantin Goschler (Hg.), Die Praxis der Wiedergutmachung. Geschichte, Erfahrung und Wirkung in Deutschland und Israel, Göttingen 2009; Hans Günter Hockerts/Claudia Moisel/Tobias Winstel (Hg.), Grenzen der Wiedergutmachung. Die Entschädigung für NS-Verfolgte in West- und Osteuropa 1945-2000, Göttingen 2006.

49 Vgl. José Brunner/Norbert Frei/Constantin Goschler, Komplizierte Lernprozesse. Zur Geschichte und Aktualität der Wiedergutmachung, in: dies. (Hg.), Praxis der Wiedergutmachung, 9-47, 23.

50 Hans Günter Hockerts, Wiedergutmachung in Deutschland 1945-200o. Eine historische Bilanz, München 2001, 93. 
Nationalsozialismus“ 2016 auch in Österreich gezeigt. ${ }^{51}$ Seitdem gab es weitere Ausstellungsprojekte, um bestimmte Opfergruppen in den Fokus zu rücken, zuletzt war dies die Ausstellung „Im Totaleinsatz. Zwangsarbeit der tschechischen Bevölkerung für das Dritte Reich mit Erweiterung um Zwangsarbeit auf österreichischem Gebiet “ (2018/2019 in Wien); ${ }^{2}$ zudem gibt es unzählige regionale Wanderausstellungen, zum Beispiel zur Zwangsarbeit in Vorarlberg oder im Burgenland, oder Ausstellungen auf dem Werksgelände von Firmen, die damals von Zwangsarbeit profitierten (ein Beispiel sind die Voestalpine, die in Linz als Hermann-Göring-Werke 1938 errichtet worden war, die Ausstellung wurde 2014 eröffnet) ${ }^{53}$.

Dem Versöhnungsaspekt und der interkulturellen Begegnung wird in interessanten Gedenkinitiativen Raum gegeben, etwa im Projekt „Brücken schlagen“.54 Dabei ging es auch immer wieder um die regionalgeschichtliche Dimension des Aspektes des „Beitrags“ der Zwangsarbeit zur Wirtschaftskraft der Region, etwa im Pinzgau oder in Tirol, ${ }^{55}$ oder zur Ausbeutung ungarischer Zwangsarbeiter in Mauthau-

51 So wurde die Ausstellung 2016 auch im Museum Arbeitswelt in Steyr gezeigt, um die Verzahnung zwischen Arbeitseinsatz und Profiteuren aus der Wirtschaft noch deutlicher zu unterstreichen. In Steyr erinnert eine kleine Dauerausstellung im "Stollen der Erinnerung" auch weiterhin an die ZwangsarbeiterInnen, vgl. URL: http://museum-steyr.at/ausstellung-2/stollen-der-erinnerung/ (abgerufen 30.01.2020).

52 URL: http://www.erinnern.at/bundeslaender/wien/termine/ausstellung-201eim-totaleinsatz.zwangsarbeit-der-tschechischen-bevoelkerung-fuer-das-dritte-reich-mit-erweiterung-umzwangsarbeit-auf-oesterreichischem-gebiet201c (abgerufen 03.12.2019).

53 NS-Zwangsarbeit, URL: https://www.voestalpine.com/group/de/konzern/historie/ns-zwangsarbeit/ (abgerufen 30.01.2020).

54 Das Projekt „Brücken schlagen - ehemalige Zwangsarbeiter und Zwangsarbeiterinnen aus der Ukraine zwischen Rückkehr und neuer Heimat" (2007/2008): Margarethe Ruff und Werner Bundschuh besuchten u. a. ehemalige ZwangsarbeiterInnen, die in Vorarlberg waren. Schwerpunkt der Initiative waren zum einen die Rekonstruktion der Lebenswege, insbesondere der „verlorenen Jugend" (vgl. Margarethe Ruff, Um ihre Jugend betrogen. Ukrainische Zwangsarbeiter/innen in Vorarlberg 1942-1945 (Studien zur Geschichte und Gesellschaft Vorarlbergs 13), Bregenz 1996), zum anderen ein Begegnungsfest. Am 8. Dezember 2008 wurden in der Stadt Rowenki alle noch lebenden ZwangsarbeiterInnen zu einem „Fest der Versöhnung" eingeladen, URL: http://www.erinnern. at/bundeslaender/oesterreich/bundeslaender/vorarlberg/bibliothek/dokumente/das-projekt-brucken-schlagen-ehemalige-zwangsarbeiter-und-zwangsarbeiterinnen-aus-der-ukraine-zwischenruckkehr-und-neuer-heimat-margarethe-ruff-und-werner-bundschuh (abgerufen 04.12.2019).

55 Alois Nußbaumer, ,Fremdarbeiter' im Pinzgau. Zwangsarbeit, Lebensgeschichten, Salzburg 2011. Besprechung von Lisa Aigner, Die vergessenen Zwangsarbeiter der Bergbauernhöfe, Der Standard, 09.02.2012, URL: https://www.derstandard.at/story/1328507112492/die-vergessenen-zwangsarbeiter-der-bergbauernhoefe (abgerufen am 30.01.2020); Carola Mair, Die Kinder von Etzelsdorf ein Zeitdokument über ein oberösterreichisches Schicksal von Zwangsarbeiterinnen und deren Kinder um 1945, Österreich 2006/2007. Zum Thema: Kinder von Ostarbeiterinnen in Oberösterreich. „Eine [sic!] Zeitdokument über die Situation von Zwangsarbeiterinnen im Gau Oberdonau - 
sen. ${ }^{56}$ Zuletzt wurde die Geschichte des Nationalsozialismus in Österreich mit der der Profiteure verbunden, was zu interessanten Mikrostudien geführt hat. ${ }^{57}$ Im Entstehen ist zudem eine Studie des Wiener Wiesenthal Instituts inklusive einer Datenbank zum Komplex der ungarischen jüdischen Zwangsarbeit in Österreich, die ebenfalls einen Sonderfall darstellt verglichen zum restlichen Deutschen Reich und der geographischen Lage sowie der Situation bei Kriegsende geschuldet war. ${ }^{58}$

Die Versuche künstlerischer Darstellung von Zwangsarbeit wurden mit Literaturnobelpreisen, Oscars und anderen international bekannten Auszeichnungen gewürdigt. Hollywoodfilme wie „Schindlers Liste“ (1993) sowie literarische Werke wie Primo Levis „Ist das ein Mensch?“ (1947), Imre Kertész’ „Roman eines Schicksalslosen“ (1975) und Herta Müllers „Atemschaukel“ (2009) haben die beispielslose Leiderfahrungen mit Lagerhaft und Zwangsarbeit im Fokus der Weltöffentlichkeit gehalten und sie zu einem lebendigen Kern der Erinnerungen an den Zweiten Weltkrieg gemacht. In Österreich sind an literarischen Verarbeitungen zu nennen Hans Leberts Roman „Die Wolfshaut“, der sich um einen ungesühnten Zwangsarbeitermord in einer Ziegelei dreht ${ }^{59}$ und erst mit der Neuauflage 1991 für Diskussionen sorgte, Christoph Ransmeiers dystopischer Roman „Morbus Kithahara"60 und Elfriede Jelineks Theaterstück „Rechnitz“ (2008), das von dem Schweigen eines

und die Geschehnisse gegen Kriegsende 1945 in der Ostarbeiterinnen-Baracke der Frauenklinik in Linz und den ehemaligen Kinderheimen Lindenhof in Spital am Phyrn und im Schloß Etzelsdorf in Pichl bei Wels. In ihrem Film dokumentiert Carola Mair das Schicksal von ostslawischen Zwangsarbeiterinnen und deren Kindern in Oberösterreich. Nach 1945 wurde ihr Schicksal verdrängt und vergessen“, URL: http://www.erinnern.at/bundeslaender/oesterreich/e_bibliothek/videos/diekinder-von-etzelsdorf (abgerufen 04.12.2019).

56 Szabolcs Szita, Ungarn in Mauthausen. Ungarische Häftlinge in SS-Lagern auf dem Territorium Österreich (Mauthausen Studien 4), Wien 2006.

57 Michael John, Zwangsarbeit in der oberösterreichischen Großindustrie 1941-1945. Ein sozial- und wirtschaftshistorischer Überblick, in: Gabriella Hauch (Hg.), Industrie und Zwangsarbeit im Nationalsozialismus. Mercedes Benz - VW - Reichswerke Hermann Göring in Linz und Salzgitter, Wien 2003, 141-167; vgl. auch jeweils das Kapitel zu Zwangsarbeit bei: Horst Schreiber, Nationalsozialismus und Faschismus in Tirol und Südtirol. Opfer. Täter. Gegner (Tiroler Studien zu Geschichte und Politik 8/Nationalsozialismus in den österreichischen Bundesländern 1), Innsbruck/ Wien/Bozen 2008; Herbert Brettl, „Nationalsozialismus im Burgenland. Opfer. Täter. Gegner“. Die Geschichte des Nationalsozialismus im Burgenland neu erzählt (Nationalsozialismus in den österreichischen Bundesländern 2), Innsbruck 2012; Meinrad Pichler, Nationalsozialismus in Vorarlberg. Opfer - Täter - Gegner (Nationalsozialismus in den österreichischen Bundesländern 3), Innsbruck 2012.

58 Eva Kovacs, Ungarische Zwangsarbeit in Wien, Projekthomepage, URL: http://ungarische-zwangsarbeit-in-wien.at/ (abgerufen 30.01.2020).

59 Hans Lebert, Die Wolfshaut, Leipzig ${ }^{2}$ 1991. (Die erste Erscheinung war bereits 1960).

60 Christoph Ransmayr, Morbus Kitahara, Frankfurt a. M. 1995. 
ganzen Ortes zum ungeklärten Mord an ca. 170 Zwangsarbeitern handelt, die am 24. März 1945 im Zuge einer Feier im Schloss des Grafen Battyány erschossen worden waren, wobei die Leichen bis heute nicht gefunden worden sind, ${ }^{61}$ sowie Bruno Schernhammers Roman zur Entstehung der Reichsautobahn und der schwierigen Vergangenheitsbewältigung nach $1945 .{ }^{62}$ Dabei wurden so unterschiedliche Opfergruppen wie verschleppte Jüdinnen und Juden, osteuropäische Zwangsarbeiterinnen, Kriegsgefangene, aber auch zur Zwangsarbeit verschleppte Volksdeutsche nach 1945 thematisiert.

\section{Forschungsdebatten und -felder}

Die aktuelle Debatte zur vergleichenden Lagergeschichte eröffnete Ende 2011 ein Themenheft der Zeitschrift des Hamburger Instituts für Sozialforschung. Im Herbst 2013 erschienen zwei komparativ angelegte Sammelbände, die mit ihren transnationalen Perspektiven der weiteren Forschung neue Impulse gaben. ${ }^{63}$ Bei ihren Querschnitten durch die erschreckende Welt der Lager wird das Thema der kriegsbedingten Zwangsarbeit kompetent mit behandelt; diese steht aber nicht im Zentrum. Die politischen Initiativen der Stiftung „Erinnerung, Verantwortung und Zukunft“ (EVZ) führten ebenfalls, aufgrund der dadurch zugänglichen Dokumentationen, zu neuen Forschungsergebnissen. ${ }^{64}$ Dazu kamen viele Studien zu Nutznießern der Zwangsarbeiterpolitik, neben Arbeitsämtern natürlich vor allem Firmen. ${ }^{65}$ Hier sind auch die mehrbändigen Arbeiten zu den Hermann-Göring-Werken Linz, herausgegeben von Oliver Rathkolb, zu nennen. ${ }^{66}$ Zudem gibt es Einzelstudien zu Opfer-

61 Vgl. auch mehrere Volksgerichtsprozesse zum Thema, Wiener Stadt- und Landesarchiv (WStLA), $\operatorname{Vg} 12$ Vr 2832/45 und Vg 5 b Vr 190/48.

62 Bruno Schernhammer, Und alle winkten. Im Schatten der Autobahn, Wien 2018.

63 Christoph Jahr/Jens Thiel (Hg.), Lager vor Auschwitz. Orte von Internierung, Zwang und Gewalt im 20. Jahrhundert, Berlin 2013; Bettina Greiner/Alan Kramer (Hg.), Welt der Lager. Zur „Erfolgsgeschichte“ einer Institution, Hamburg 2013.

64 Dieter Bacher/Stefan Karner (Hg.), Zwangsarbeiter in Österreich 1939-1945 und ihr Nachkriegsschicksal. Ergebnisse der Auswertung des Aktenbestandes des „Österreichischen Versöhnungsfonds“, Innsbruck 2013.

65 Silvia Rief, Rüstungsproduktion und Zwangsarbeit. Die Steyrer-Werke und das KZ Gusen (Der Nationalsozialismus und seine Folgen 2), Innsbruck 2005.

66 Oliver Rathkolb (Hg.), NS-Zwangsarbeit. Der Standort Linz der „Reichswerke Hermann Göring AG Berlin“ 1938-1945, Bd. 1: Christian Gonsa/Gabriella Hauch/Michael John/Josef Moser/ Bertrand Perz/Oliver Rathkolb/Michael C. Schober, Zwangsarbeit - Sklavenarbeit: Politik-, sozialund wirtschaftshistorische Studien, Wien/Köln/Weimar 2001; Bd. 2: Karl Fallend, Zwangsarbeit - 
gruppen, etwa aus Weißrussland, ${ }^{67}$ sowie zu lokalen Besonderheiten, in denen es um die Unterdrückung regionaler Minderheiten ging, hier ist besonders Kärnten zu nennen. ${ }^{68}$

Als es nach Ende des Kalten Kriegs zu einem „Boom in der Erforschung der verborgenen ,Opfer-Geschichte des Zweiten Weltkriegs“ kam, richtete sich das öffentliche und wissenschaftliche Interesse verstärkt auch auf die Geschichte der Kriegsgefangenschaft als zentrales militärisches, ökonomisches und politisches Massenphänomen. ${ }^{69}$ Die unmenschliche Behandlung der 5,2 Millionen sowjetischen Kriegsgefangen, von denen im deutschen Gewahrsam mehr als 3 Millionen starben, wurde als größtes Kriegsverbrechen der Wehrmacht und als „unbekannter Holocaust“ nun intensiv untersucht. Schon bald ging es der historischen Forschung aber nicht mehr nur um den deutschen Fall in der Zeit von 1939 bis 1945, sondern darüber hinaus um die Anatomie der europäischen Erfahrungen von Kriegsgefangenschaft im Zeitalter der Weltkriege. Ziel war es, das Phänomen der Kriegsgefangenschaft im Gesamtzusammenhang von Zwangsmigrationen und Zwangsarbeit während der ersten Hälfte des 20. Jahrhunderts zu verorten und die miteinander verflochtenen Problemdimensionen in den Situationen des totalen Kriegs zu erläutern.

Dabei galt es, generell die globale vergleichende Forschungsperspektive zu forcieren, um wichtige strukturelle Kontinuitäten, aber auch Diskontinuitäten offenzulegen und herauszuarbeiten, inwiefern die Feindstaaten bei ihrer Behandlung von Kriegsgefangenen aufeinander Bezug nahmen und es zu Interaktionen und Resonanzen kam - nicht selten auch in Form von Vergeltungsmaßnahmen. Vergleichende Untersuchungen gibt es ferner zur Entschädigungspolitik in Ost- und Westeuropa. Sie verdeutlichen, dass es in Europa während des Kalten Krieges viele politische Verwerfungen gab. Der transnationale Zugriff auf den ost- und westeuropäischen Umgang mit Zwangsarbeit und auf die damit verbundene sehr divergente Entschädigungspraxis stellte damit eine große methodische Herausforderung dar. Diese Problematik hat die Stiftung EVZ seit 2000 wiederholt thematisiert. Zugleich

Sklavenarbeit in den Reichswerken Hermann Göring am Standort Linz. (Auto-)Biographische Einsichten, Wien 2001.

67 Ludwig Boltzmann-Institut für Kriegsfolgen-Forschung/Weißrussisches Nationalarchiv (Hg.), Ostarbeiter. Weißrussische Zwangsarbeiter in Österreich 1941-1945. Dokumente und Materialien/ Ostarbajtery. Prinuditel nyjtrudbelorusskogonaselenija v Avstrii. (Veröffentlichungen des Ludwig Boltzmann-Instituts für Kriegsfolgen-Forschung, Sonderband 2), Graz/Minsk 2003.

68 Tomaž Ogris, Anisja - Zwangsarbeiterin in Kärnten. Erinnerungen/Anisja - prisilna delavka na Koroškem, Zweisprachige Ausgabe, Klagenfurt/Wien 2012, 140.

69 Hubert Speckner, In der Gewalt des Feindes. Kriegsgefangenenlager in der „Ostmark“ 1939 bis 1945, Wien/München 2003. 
mit dem Abschluss des Entschädigungsprogramms kam es zur Öffnung der Archive des Internationalen Suchdienstes (ITS) in Bad Arolsen, seit 2019 Arolsen Archives. Damit sind der Forschung neue umfangreiche Quellenbestände erstmals zugänglich, die es - zumindest auf Europa bezogen - ermöglichen, näher auf transnationale Kontexte und Bezüge einzugehen. Publikationen im Umfeld der Wanderausstellung von 2010 zur Zwangsarbeit, organisiert von der Stiftung Gedenkstätten Buchenwald und Mittelbau-Dora, haben dieses Quellenmaterial erstmals vorgestellt und erste Hypothesen formuliert. Aus den vergleichenden Beobachtungen lassen sich keine historischen Gesetzmäßigkeiten ableiten; sie lassen sich aber systematisieren, um so das weite Forschungsfeld der Beziehungsgeschichte zwischen Krieg und Zwangsarbeit $\mathrm{zu}$ ordnen und aufschlussreiche Problemorientierung für weitergehende Forschungen zu vermitteln.

Zuletzt ist das Forschungsfeld der Folgen von Zwangsmigration stark angewachsen, das 1985 von Wolfgang Jacobmayer angestoßen worden war. ${ }^{70}$ Hier geht es um die Frage, was nach der Befreiung der Lager 1945 mit den Verschleppten passierte, und insbesondere steht im Fokus, wie vielen der ehemaligen Zwangsarbeiter und Zwangsarbeiterinnen ein Neuanfang außerhalb Europas gelang. ${ }^{71}$ Jochen Oltmer hat 2018 neuere Forschungsergebnisse zu den Migrationsregimen herausgegeben ${ }^{72}$ und Christoph Rass mit Frank Wolff der Migrationsforschung neue Richtungen aufgezeigt $^{73}$. Für die Forschung stehen hier die Themenfelder Repatriierung und DPLager im Mittelpunkt. ${ }^{74}$ Hier sind in den nächsten Jahren, insbesondere in Bezug auf den Ausgangspunkt österreichischer DP-Lager ${ }^{75}$ und Österreich als Transit-

70 Wolfgang Jacobmeyer, Vom Zwangsarbeiter zum Heimatlosen Ausländer. Die Displaced Persons in Westdeutschland 1945-1951 (Kritische Studien zur Geschichtswissenschaft 65), Göttingen 1985.

71 Pertti Ahonen/Gustavo Corni/Jerzy Kochanowski/Rainer Schulze/Tamás Stark/Barbara StelzlMarx (Hg.), People on the Move. Forced Population Movements in Europe in the Second World War and Its Aftermath, Oxford/New York 2008.

72 Jochen Oltmer (Hg.), Migrationsregime vor Ort und lokales Aushandeln von Migration, Wiesbaden 2018.

73 Christoph Rass/Frank Wolff, ,What Is a Migration Regime?', in: Andreas Pott/Christoph Rass/ Frank Wolff (Hg.), Was ist ein Migrationsregime? What Is a Migration Regime?, Wiesbaden 2018, $19-64$.

74 Rebecca Boehling/Susanne Urban/Rene Bienert (Hg.), Displaced Persons. Leben im Transit. Überlebende zwischen Repatriierung, Rehabilitation und Neuanfang (Freilegungen. Jahrbuch des International Tracing Service 3), Gottingen 2014.

75 Thomas Albrich, Exodus durch Österreich. Die jüdischen Flüchtlinge 1945-1948 (Innsbrucker Forschungen zur Zeitgeschichte 1), Innsbruck 1987; Thomas Albrich, Von der Zwangsarbeit ins DP-Lager. Fremde in Österreich in der unmittelbaren Nachkriegszeit nach 1945, in: Neujahrsblätter des Historischen Archivs der Marktgemeinde Lustenau 3 (2012), 86-106; Michael John/Albert Lichtblau, Schmelztiegel Wien - einst und jetzt. Geschichte und Gegenwart der Zuwanderung 
land ${ }^{76}$ noch neue Arbeiten zu erwarten, die die globale Dimension berücksichtigen, insbesondere auch von der Verfasserin des vorliegenden Beitrags selbst ${ }^{77}$.

nach Wien. Aufsätze, Quellen, Kommentare, Wien ${ }^{2} 1993$; Michael John, Bevölkerung in der Stadt. ,Einheimische und ,Fremde in Linz (19. und 20. Jahrhundert), Linz 2000; Michael John, Displaced Persons in Linz. ,Versetzte Personen ' und Flüchtlinge der Nachkriegszeit, in: Willibald Katzinger (Hg.), Prinzip Hoffnung. Linz zwischen Befreiung und Freiheit, Linz 1995, 213-230; Michael John, Zwischenstation Oberösterreich. Die Auffanglager und Wohnsiedlungen für jüdische DPs und Infiltrees in Oberösterreich, in: Thomas Albrich (Hg.), Flucht nach Eretz Israel. Die Bricha und der jüdische Exodus durch Österreich nach 1945, Innsbruck 1998, 67-92; Michael John, Post-War Conflicts in Austria (1945-50). Remembering the Relations between Displaced Persons and the Indigenous Population, in: Crossroads of History: Experience, Memory, Orality 11 th International Oral History Conference. Bogaziçi University Printhouse, Istanbul 2000, 550-553.

76 Börries Kuzmany/Rita Garstenauer (Hg.), Aufnahmeland Österreich, Wien 2017; Ingrid Böhler/ Nikolaus Hagen/Philipp Strobl (Hg.), Displaced-Persons-Forschung in Österreich und Deutschland. Bestandsaufnahme und Ausblicke. zeitgeschichte 47 (2020) 2.

77 Kerstin von Lingen/Milinda Banerjee (Hg.), Forced Migration and Refugee Resettlement in the Long 1940s. A Connected and Global History (Special Issue, under review 2020). 


\section{Postkolonialismus}

Eric Burton

\section{Einleitung ${ }^{1}$}

Im September 2018 forderte Reinhard Bösch als amtierender Wehrsprecher der FPÖ und Vorsitzender des Parlamentarischen Verteidigungsausschusses in einem Interview mit den „Vorarlberger Neuen Nachrichten“, in Nordafrika „einen Raum in Besitz zu nehmen“, um dort „Anlandezentren“ für Asylsuchende einzurichten beispielsweise in Libyen. Diese Maßnahme, so Bösch, sei notfalls auch gegen den Willen nordafrikanischer Regierungen mit „verschiedensten militärischen und polizeilichen Kräften einfach durchzuführen“.2 VertreterInnen von Oppositionsparteien und Medien kritisierten Böschs Äußerungen scharf. Böschs Ideen erinnerten an die Kolonialzeit, sagte Alma Zadić (Liste Pilz), während SPÖ-Bundesgeschäftsführer Max Lercher Bösch zum Rücktritt aufforderte und meinte, dessen „Kolonialphantasien gehören ins 19. Jahrhundert". ${ }^{3}$ Die Bezüge auf den Kolonialismus in der Kritik an Bösch blieben allgemein, sie bezogen sich nicht auf eine spezifisch österreichische Kolonialvergangenheit. Dieser Geschichte gilt es jedoch mehr Beachtung beizumessen. Der vorliegende Beitrag befasst sich mit postkolonialistischen Perspektiven in der Zeitgeschichte und Forschungen zu Österreichs „Kolonialismus ohne Kolonien“, ${ }^{4}$ der mit einem etablierten Orientalismus und tiefverankerten Vorstellungen eines „weißen“ Österreichs einherging - also Elemente, die auch in Böschs Äußerungen mitschwingen. Im Zentrum stehen dabei Kontinuitäten und Rekonfigurationen im Verhältnis zum Globalen Süden mit einem besonderen Fokus auf Kolonialismus und Antikolonialismus.

1 Ich danke Marcel Amoser, Lucile Dreidemy, Katharina Föger, Immanuel Harisch, Clemens Pfeffer, Walter Sauer und den Herausgebern für ihre Kommentare zu vorherigen Entwürfen dieses Aufrisses.

2 Kurz zu Causa Bösch: „Nicht meine Angelegenheit“, Kleine Zeitung, 05.09.2018, URL: https:// www.kleinezeitung.at/politik/aussenpolitik/5491402/AfrikaAussagen_Kurz-zu-Causa-Boesch_ Nicht-meine-Angelegenheit (abgerufen 15.10.2020).

3 Soldaten in Afrika: „FPÖ fordert ganz offen Krieg“, Heute, 04.09.2018, URL: https://www.heute. at/s/soldaten-in-afrika-fp-fordert-ganz-offen-krieg-54649470 (abgerufen 15.10.2020).

4 Vgl. für die Schweiz: Patricia Purtschert/Barbara Lüthi/Francesca Falk (Hg.), Postkoloniale Schweiz. Formen und Folgen eines Kolonialismus ohne Kolonien, Bielefeld ${ }^{2} 2013$. 
Der historische Wandel in der österreichischen Haltung zum Kolonialismus lässt sich anschaulich am Beispiel der bis heute von Marokko völkerrechtswidrig besetzten West-Sahara aufzeigen: einst Ziel kolonialer Ambitionen expansionistisch denkender Kreise Österreich-Ungarns in der zweiten Hälfte des 19. Jahrhunderts, ${ }^{5}$ wurde die West-Sahara nach der Unabhängigkeit von Spanien und der folgenden Besetzung durch Marokko 1975/1976 zu einem Kristallisationspunkt außenpolitischer Debatten der Kreisky-Ära. Die SPÖ unterstützte die saharauische Befreiungsbewegung Polisario mit Hilfsgütern. Die ÖVP hingegen drängte darauf, den Verkauf weiterer Panzer aus der Produktion des kriselnden österreichischen Waffenherstellers Steyr Daimler Puch an Marokko zu genehmigen, während die erste Lieferung bereits im Kampf gegen die Aufständischen eingesetzt worden war. ${ }^{6}$ In der Gegenwart werden Unterstützungserklärungen für die Polisario nicht mehr im Nationalrat oder gar in der Bundesregierung diskutiert, sondern nur noch in zivilgesellschaftlichen Solidaritätsgruppen, die die fehlende Aufmerksamkeit für diesen seit Jahrzehnten schwelenden Konflikt in Medien und Politik beklagen.7 Die Schlagzeilen gehören heutzutage denen, die eine neue Besetzung Nordafrikas vorschlagen. Die Äußerungen zogen für Bösch keine weiteren Konsequenzen nach sich. Wie schon 2017 zog die FPÖ Vorarlberg im Herbst 2019 mit dem gelernten Historiker Bösch als Spitzenkandidat in den Wahlkampf und in den Nationalrat. ${ }^{8}$

Die österreichische Zeitgeschichte hat sich in den letzten zwei Dekaden den Herausforderungen und Forschungsprogrammen postkolonialistischer Ansätze - im Sinne einer breiten theoretischen und methodologischen Strömung ${ }^{9}$ - nur zögerlich genähert; eine Aneignung fand eher in anderen Disziplinen wie den Literaturund Kulturwissenschaften, der Kritischen Entwicklungsforschung und den Gender Studies statt. In der Zeitgeschichte sind postkolonialistische Theorien noch am ehes-

5 Walter Sauer, Expeditionen ins afrikanische Österreich. Ein Reisekaleidoskop, Wien 2014, 46-47.

6 Politik und Panzer, Die Zeit, 21.06.1985, URL: https://www.zeit.de/1985/26/politik-und-panzer (abgerufen 15.10.2020).

7 Eva M. Huber, (Re-)Konstruktionen nationaler Identität in der Solidaritätsbewegung für die Westsahara, Dipl.-Arb., Universität Wien 2014.

8 FPÖ Vorarlberg zieht wieder mit Bösch in den Wahlkampf, Der Standard, 21.06.2019, URL: https://www.derstandard.at/story/2000105221302/fpoe-vorarlberg-zieht-wieder-mit-boesch-inden-wahlkampf (abgerufen 15.10.2020).

9 Die theoretischen Perspektiven bezeichne ich hier als „postkolonialistisch“, in Abgrenzung zu "postkolonial“ als epochal und z. T. auch räumlich definierenden Begriff. Einen Einstieg in das postkolonialistische Theorieangebot bieten etwa Ina Kerner, Postkoloniale Theorien zur Einführung, Hamburg ${ }^{32017}$; María do Mar Castro Varela/Nikita Dhawan, Postkoloniale Theorie. Eine Kritische Einführung, Bielefeld ${ }^{2} 2015$. Eine exzellente und umfassende historische Einbettung der Theorien bietet Robert Young, Postcolonialism. An Historical Introduction, Chichester 2016. 
ten für kulturhistorische Fragestellungen in Anspruch genommen worden, um die Machtaspekte von Sinn- und Bedeutungssystemen oder Differenzkonstruktionen zu untersuchen. Bereits bei grundlegenden Fragen besteht keinerlei Einigkeit, etwa inwiefern Österreich als postkolonialer Raum zu begreifen ist und auf eine koloniale Vergangenheit zurückblickt oder inwiefern imperialistische Überseeambitionen und Binnenkolonialismus der K.-u.-k.-Ära Teil historisch konstitutiver Prozesse oder nur punktuell relevante Phänomene waren. ${ }^{10}$ Es gilt zu diskutieren, welchen Erkenntnisgewinn es bringt, wenn Österreich und die außereuropäische Welt in einen gemeinsamen Analyserahmen integriert werden und der Fokus dabei auf kolonialen und postkolonialen Verhältnissen liegt.

Der vorliegende Beitrag skizziert - ohne Anspruch auf Vollständigkeit - zuerst drei Ansätze, Österreich als Teil (post)kolonialer Verhältnisse zu fassen. Im Anschluss folgt ein Abriss rezenter Forschungen zu bestimmten Themenfeldern, in denen die transnationalen Verflechtungen Österreichs im Rahmen von Nord-SüdVerhältnissen und (De)Kolonisierungsbestrebungen beleuchtet werden. Der Gegenstand bringt es mit sich, dass die Grenzen einer eng gefassten österreichischen Zeitgeschichtsforschung hier in dreierlei Hinsicht überschritten werden: erstens durch Rückgriffe auf koloniale Dimensionen der Habsburgermonarchie, zweitens durch die Einbeziehung der Wissensproduktion in anderen Disziplinen sowie im Rahmen von Ausstellungsprojekten und aktivistischen Kontexten und drittens in Bezug auf Forschungen, die an österreichischen Universitäten angesiedelt sind, aber auch Räume jenseits Ostmitteleuropas in den Blick nehmen. Erkennbar werden somit die Konturen einer österreichischen Zeitgeschichtsforschung, die sich nicht durch eindeutige nationalstaatliche Bezüge oder disziplinäre Trennlinien, sondern in erster Linie durch die Wahl des Gegenstandes sowie eine spezifische Form der Problemorientierung auszeichnet. Der vorliegende Beitrag zielt in erster Linie auf eine Einordnung verschiedener Ansätze ab und plädiert erstens für eine stärkere Artikulation der hier präsentierten Perspektiven mit global- und verflechtungsgeschichtlichen Ansätzen, die ebenfalls eine Überwindung eurozentrischer Perspektiven und Kategorien anstreben, sowie im Zusammenhang damit zweitens, die gegenseitige Konstituierung von Diskursen und Praktiken, von „innen“ und „außen“ stärker im Rahmen von Nord-Süd-Beziehungen zu thematisieren. ${ }^{11}$ In diesem Sinne werden

10 Für einen pointierten und überblicksartigen Einstieg in die Thematik eignen sich Berthold Molden, Decolonizing the Second Republic. Austria and the Global South from the 1950 s to the 1970s, in: Journal of Austrian Studies 48 (2015) 3, 109-128; Walter Sauer (Hg.), k.u.k. kolonial - Habsburgermonarchie und Europäische Herrschaft in Afrika, Wien 2002.

11 Kerner, Postkoloniale Theorien, 80-84; Sebastian Conrad/Shalini Randeria (Hg.), Jenseits des Eurozentrismus. Postkoloniale Perspektiven in den Geschichts- und Kulturwissenschaften, Frankfurt a. M. 2002. 
hier auch Forschungen rezipiert, die zur Bearbeitung dieser Fragenstellungen beitragen, ohne selbst explizit auf postkolonialistische Ansätze zu rekurrieren.

\section{Ansätze}

Drei Ansätze, die Anfang der 2oooer-Jahre entstanden, haben die Frage nach Österreichs kolonialen Verflechtungen in den Mittelpunkt gerückt. Ihnen allen ist gemein, dass sie für zentrale Argumente auf „präzeitgeschichtliche“ Epochen Bezug nehmen; gleichzeitig unterscheiden sie sich in ihren methodologischen Herangehensweisen ebenso wie im Erkenntnisinteresse und in den normativen Ansprüchen.

\subsection{Das imperialistische Habsburg: Kolonialismus ohne Kolonien}

In einem ersten Ansatz steht die Frage, ob Habsburg eine Kolonialmacht war, im Mittelpunkt. Bis vor kurzem wurde die Frage „Hat Österreich eine koloniale Vergangenheit?" klar verneint. Die erfolglosen Bemühungen des Staates, zwischen 1857 und 1913 Kolonien zu erwerben (Suquatra, Nikobaren, Salomonen, Westsahara und Südostanatolien), werden weithin ebenso als Randepisoden gewertet wie die zwei Fälle, in denen die Monarchie tatsächlich als Kolonialmacht agierte (die Etablierung einer Handelsstation in Mosambik 1777-1781 sowie die Besetzung eines ca. 6 Quadratkilometer großen Stück Landes in China 1901-1914). 1871 hatte Ministerpräsident Friedrich Beust den Balkan, nicht Afrika oder andere Überseeterritorien, als wichtigstes Interessengebiet Österreich-Ungarns definiert. ${ }^{12}$ War das Habsburgerreich also überhaupt ein Imperium, das sich mit Kolonialmächten wie Frankreich, Großbritannien, Spanien oder dem Deutschen Reich vergleichen lässt? Kolonialismus, so die Grundannahme des Sozialhistorikers Walter Sauer, konnte auch ohne Kolonialherrschaft existieren, anderen Abhängigkeitsbeziehungen (oder dem Kolonialismus anderer Staaten) den Weg bahnen und Spuren hinterlassen, die das Bewusstsein bis heute prägen: Das sei in Österreich der Fall. ${ }^{13}$ Auf dieser Ebene herrscht eine klare Übereinstimmung mit postkolonialistischen Ansätzen, die (ins-

12 Sauer, Expeditionen ins afrikanische Österreich, 45.

13 Walter Sauer, Schwarz-Gelb in Afrika. Habsburgermonarchie und koloniale Frage, in: ders. (Hg.), k.u.k. kolonial - Habsburgermonarchie und Europäische Herrschaft in Afrika, Wien 2002, 17-78; Johann Wagner, Österreichische Kolonialversuche in der zweiten Hälfte des neunzehnten Jahrhunderts, phil. Diss., Universität Wien 1955. 
besondere kulturelle) Manifestationen des Kolonialismus auch dort orten, wo sich dieser nicht zwangsläufig in territorialer Herrschaft niederschlug.

Für Österreich ist diese These eines Kolonialismus ohne Kolonien in den letzten zwei Jahrzehnten untermauert worden, oft aufbauend auf älteren Studien und Archivrecherchen und in der Regel ohne Bezug auf postkolonialistische Theorieangebote. Insbesondere im 19. und frühen 20. Jahrhundert lassen sich koloniale Ambitionen nachweisen, die über reine Symbolpolitik hinaus- und mit hierarchisierenden (und zum Teil bereits länger tradierten) Repräsentationen einhergingen. Anhand mannigfaltiger Beispiele sind wirtschaftliche Verflechtungen durch Ressourcengewinnung und Absatzmärkte nachgewiesen worden; ebenso eine koloniale Konsumkultur, die sich etwa in exotistischen Völkerschauen im Prater niederschlug und sich auch langfristig in Stadtbildern, Imaginationen und Gewohnheiten eingeschrieben hat; ${ }^{14}$ die Wissensproduktion im Windschatten und bisweilen auch im Dienste anderer europäischer Imperien; die damit verbundenen Reisepraktiken - und andere Formen der Partizipation an einem gesamteuropäischen Phänomen des Expansionismus. ${ }^{15}$

Gut belegt sind etwa die Vorstöße österreichischer Händler und Missionare, die Mitte des 19. Jahrhunderts einer österreichischen Kolonisierung des Sudan den Weg ebnen wollten und eine Vormachtstellung im Handel zwischen Triest und Asien anstrebten. ${ }^{16}$ Dabei blieb der Staat keinesfalls immer unbeteiligt, insbesondere wenn es um die Wahrung ökonomischer Interessen ging. Das Interesse der Habsburger am Überseehandel hatte sich bereits im frühen 17. Jahrhundert intensiviert; um Exportmärkte zu erschließen und abzusichern, intervenierte das Kaisertum Österreich im 19. Jahrhundert mit seiner Kriegsmarine unter anderem in Syrien (1840) sowie

14 Sauer, Expeditionen ins afrikanische Österreich; ders., Exotische Schaustellungen im Wiener Vormärz. Zwischen Voyeurismus und Früher Rassentheorie, in: Mitteilungen des Instituts für Österreichische Geschichtsforschung 124 (2016) 2, 391-417.

15 Gabriele Habinger, Frauen reisen in die Fremde. Diskurse und Repräsentationen von reisenden Europäerinnen im 19. und beginnenden 20. Jahrhundert, Wien 2006; Franz Kotrba, k.u.k. in Ostafrika. Die Habsburgermonarchie im „Scramble for East Africa“, Wien 2015; Sauer (Hg.), k.u.k. kolonial.

16 Michael Zach, Österreicher im Sudan von 1820 bis 1914, Wien 1985; Walter Sauer, Ein Jesuitenstaat in Afrika? Habsburgische Kolonialpolitik in Ägypten, dem Sudan und Äthiopien in der ersten Hälfte des 19. Jahrhunderts, in: Österreich in Geschichte und Literatur 55 (2011) 1, 6-27; Markus Kaiserseder, Die österreichischen Missionsstationen im Sudan zur Mitte des 19. Jahrhunderts Wegbereiter eines Kolonialismus?, Dipl.-Arb., Universität Wien 2013; Philipp Weingartshofer, Imperialismus-Strategien am Beispiel der Österreicher im Sudan. Das Zusammenspiel kolonialer Akteure in Peripherie und Metropole am Beispiel der Österreicher im Sudan im 19. Jahrhundert, Dipl.-Arb., Universität Wien 2013. 
gemeinsam mit anderen Imperialmächten im Libanon (1867) und im chinesischen „Boxeraufstand“ (1900). ${ }^{17}$ Derartige militärische Unterdrückungsmaßnahmen zur Durchsetzung ökonomischer Interessen hat Walter Sauer auch als Teilnahme an einem „kollektiven Imperialismus“ der Großmächte gedeutet. ${ }^{18}$ Die Frage, warum es (zumindest in Bezug auf Übersee) grosso modo bei einem informellem Imperialismus blieb, der sich nicht in Eroberung und territorialer Herrschaft niederschlug, stößt nach wie vor auf Interesse. James Callaway argumentiert etwa, dass die kolonialen Ambitionen Wiens in den fünf Jahrzehnten vor dem Ersten Weltkrieg nicht zuletzt durch den ungarischen Staat gebremst worden seien, der an stabilen Handelsbeziehungen mit Indien, Südamerika, Japan oder China mehr interessiert gewesen sei als an kolonialen Abenteuern:

Hungarian and Austrian colonial enthusiasts, which included a significant portion of the public, imperial bureaucrats, and Emperor Franz Josef, never outweighed the Hungarian state's perception that Africa offered little economic opportunity and numerous risks. ${ }^{19}$

Ab Ende des 19. Jahrhunderts hatten Lobbygruppen für eine Popularisierung und breitere Akzeptanz kolonialer Vorstellungen gesorgt. Simon Loidls Arbeiten zur 1894 gegründeten Österreichisch-Ungarischen Kolonialgesellschaft illustrieren, wie nützlich der Fokus auf spezifische Akteursgruppen ist, um den Habsburger Protokolonialismus konkret zu verorten und in seinen Charakteristika zu spezifizieren. Die Gesellschaft befasste sich in ihrer Tätigkeit viel mit der Emigrationsfrage: Die Behörden sollten die Auswanderung in neu erworbene Territorien in Übersee unterstützen, um so die soziale Frage zu lösen und Habsburg zu Glanz und Größe einer Kolonialmacht zu verhelfen. ${ }^{20}$ Sauer regt zudem an, auch zionistische Emig-

17 Robert-Tarek Fischer, Österreich im Nahen Osten. Die Großmachtpolitik der Habsburgermonarchie im arabischen Orient 1633-1918, Wien 2006; Andreas Bilgeri, Österreich-Ungarn im Konzert der Kolonialmächte: Die militärischen Interventionen der Kriegsmarine, in: Kakanien Revisited 2012, URL: http://www.kakanien-revisited.at/beitr/fallstudie/ABilgeri1/ (abgerufen 15.10.2020); Georg Lehner/Monika Lehner, Österreich-Ungarn und der „Boxeraufstand“ in China, Innsbruck 2002.

18 So etwa bei Sauer, Schwarz-Gelb in Afrika, 19.

19 James Callaway, The Battle over Information and Transportation: Extra-European Conflicts between the Hungarian State and the Austro-Hungarian Foreign Ministry, in: The Hungarian Historical Review 7 (2018) 2, 274-302, 296.

20 Simon Loidl, Colonialism through Emigration: Publications and Activities of the ÖsterreichischUngarische Kolonialgesellschaft (1894-1918), in: Austrian Studies 20 (2012), 161-175; Simon Loidl, „Europa ist zu enge geworden“ - Kolonialpropaganda in Österreich-Ungarn 1885-1918, Wien 2017. 
rationsprojekte mit Zielen wie Angola und Uganda (und erst später Palästina) im „fruchtbare[n] kolonialistische[n] Nährboden Österreich-Ungarns“ zu verorten, da sich diese - wenngleich mit gänzlich anderen und fraglos legitimen Motiven für die Auswanderung - in Hinblick auf die Diskriminierung außereuropäischer Völker im „Einklang mit der siedlerkolonialistischen Tradition des europäischen Imperialismus “ befunden hätten. ${ }^{21}$ In dieser Perspektive, die es noch empirisch zu unterfüttern gilt, wäre der Kolonialismus ohne Kolonien der Habsburgerära also lang und weit über die Grenzen Österreichs hinaus wirksam.

\subsection{Das orientalistische Kakanien: Multikulturalität und Zivilisierungsmission im} Binnenkolonialismus

Parallel zu Sauer, Loidl und anderen, die österreichische Beziehungen in die Welt und koloniale Ambitionen untersuchen, ohne sich auf postkolonialistische Theorien zu stützen, haben sich KulturhistorikerInnen explizit mit der Frage auseinandergesetzt, inwiefern Theoreme wie die Orientalismusthese Edward Saids ${ }^{22}$ oder das Hybriditätskonzept von Homi K. Bhabha auf den Fall des Habsburgerreiches anwendbar sind. Die Sammelbände „Kakanien revisited“ (2002) und „Habsburg Postcolonial“ (2003) stehen paradigmatisch für einen zweiten Ansatz, nämlich eine Anwendung der Postcolonial Studies, die sich auf die (imaginierte wie reale) Geographie Mittelost- und Südosteuropas beschränkt und die „quasi-kolonialen Machtverhältnisse" vor allem in Hinblick auf ihre kulturellen Dimensionen analysiert. ${ }^{23}$ Im Zentrum stehen hier, unter Rückgriff auf den Theoretiker Edward Said, „Orientalismen“ der Habsburgermonarchie ${ }^{24}$ sowie der „innere Kolonialismus“, der insbesondere in

21 Walter Sauer, Rezension zu Simon Loidl, „Europa ist zu enge geworden“ - Kolonialpropaganda in Österreich-Ungarn 1885-1918, Wien 2017, in: Mitteilungen der Alfred Klahr Gesellschaft 24 (2017) 4, 28-29.

22 Said selbst behandelte anfangs Habsburg nicht. Nahm er die deutschsprachige Wissenschaftslandschaft anfangs noch explizit von seiner Orientalismusthese aus, betonte er später, dass Habsburg keinesfalls als „weniger imperialistisch“ einzustufen sei. Edward W. Said, Culture and Imperialism, New York 1994, xxii.

23 Wolfgang Müller-Funk/Peter Plener/Clemens Ruthner (Hg.), Kakanien revisited. Das Eigene und das Fremde (in) der österreichisch-ungarischen Monarchie, Tübingen 2002; Johannes Feichtinger/ Ursula Prutsch/Moritz Csáky (Hg.), Habsburg postcolonial: Machtstrukturen und kollektives Gedächtnis, Innsbruck 2003.

24 Siehe hierzu die Beiträge in Robert Born/Sarah Lemmen (Hg.), Orientalismen in Ostmitteleuropa: Diskurse, Akteure und Disziplinen vom 19. Jahrhundert bis zum Zweiten Weltkrieg, Bielefeld 2014. 
Bezug auf Bosnien und die Herzegowina konstatiert wird, die 1878 (teilweise) besetzt und 1908 schließlich annektiert wurden. Die Verschränkungen zwischen Binnenkolonialismus und Ambitionen in Übersee werden hier über Äußerungen wie jene des Außenhandelsexperten Moritz von Engel dargestellt, der 1902 meinte, dass sich Österreich-Ungarn gerade durch die Abwesenheit von Überseekolonien „mit Genugtuung [...] nun seiner eigentlichen Aufgabe, der kolonisatorischen Tätigkeit“ in Südosteuropa widmen könne. ${ }^{25}$

Manche ImperialismushistorikerInnen betonen im Fall des Habsburgerreiches eine pluralistische, multiethnische und multilinguale Kulturpolitik, die sich positiv von den Kolonialverbrechen und Assimilationspolitiken anderer europäischer Großmächte unterscheide. ${ }^{26}$ Dieses Bild revidieren die Beiträge in „Habsburg postcolonial“ und weitere Publikationen in dieser Tradition nur teilweise. ${ }^{27}$ Während das Argument rassistisch motivierter Überlegenheits- und Zivilisierungsdiskurse ${ }^{28}$ und die These eines „Binnenkolonialismus“ für den Fall Bosniens und Herzegowinas in mehreren Fällen Bestätigung erfährt, werden die tschechoslowakischen Bemühungen zur „Entösterreicherung“ („odrakouštěni“) in der Zwischenkriegszeit vom Historiker Robert Luft als Pseudodekolonisierung dargestellt. Die Nützlichkeit postkolonialistischer Theorien für den Fall der Tschechoslowakei anzweifelnd, räumt Luft dennoch ein, dass der von vereinzelten Intellektuellen konstruierte „Dekolonialisierungsmythos“ zwar wenig „mit dem politischen und gesellschaftlichen Geschehen“ zu tun gehabt, aber dennoch enorme Bedeutsamkeit für das nationale Selbstbild in der Tschechoslowakei erlangt habe. ${ }^{29}$ Postkolonialistische Theorien werden in dieser zweiten Strömung bisweilen nur als Anregung, der Kolonialbegriff gar nur als „heuristische Metapher“ verstanden, was auch bedeutetet, dass zentrale normative Annahmen und konstitutive Elemente der Selbstreflexion nicht direkt übernommen werden. So empfindet der Germanist Clemens Ruthner die in postkolonialistischen

25 Zit. n. Ursula Prutsch, Habsburg postcolonial, in: Feichtinger/Prutsch/Csáky (Hg.), Habsburg postcolonial, $33-43,36$.

26 Stephen Howe, Empire. A Very Short Introduction, Oxford 2002, 55.

27 Siehe auch die zahlreichen Debattenbeiträge auf der Forschungsplattform „Kakanien revisited“, URL: http://www.kakanien-revisited.at/ (abgerufen 15.10.2020).

28 Siehe hierzu auch die an Edward Said anschließende Forschung zur Konstruktion des Balkans als negativen Spiegel des westliche(re)n Europas: Marija Todorova, Die Erfindung des Balkans. Europas bequemes Vorurteil, Darmstadt 1999.

29 Robert Luft, Machtansprüche und kulturelle Muster nichtperipherer Regionen. Die Kernlande Böhmen, Mähren und Schlesien in der späten Habsburgermonarchie, in: Feichtinger/Prutsch/ Csáky (Hg.), Habsburg postcolonial, 165-187, 184-185. 
Texten oft ausgedrückten „prinzipiellen Vorbehalte gegen akademische Aktivitäten als Machtpraktiken“ als „etwas angestaubt" und wenig praktikabel. ${ }^{\circ \circ}$

Für die Zeitgeschichte nach 1918 bieten diese Forschungen zahlreiche Anknüpfungspunkte: etwa in Bezug auf die Frage nach einem „halb-kolonial[en] und halborientalisch[en]“ Tourismus zwischen Österreich und den anderen Nachfolgeländern der Habsburgermonarchie ${ }^{31}$ oder Migrations- und Minorisierungsprozesse im Rahmen von „Gastarbeit", Beschäftigungs- und Asylpolitik, in deren Konzipierung und Ausgestaltung manche AutorInnen ein koloniales Erbe identifizieren. ${ }^{32}$ Einige dieser Arbeiten könnten aufgrund ihrer Haltung und ihres direkten Gegenwartsbezugs alternativ auch der dritten Strömung zugeordnet werden.

\subsection{Das postkoloniale Österreich: „Mia san net in Ameriga!"}

AutorInnen einer dritten Strömung in der Literatur verorten sich explizit in diasporischen, künstlerischen und/oder aktivistischen Kontexten. ${ }^{33}$ Ihre Arbeiten zeichnen sich dadurch aus, dass sie die (Re)Konstruktion von Geschichte mit einem expliziten Gegenwartsbezug und emanzipatorischen Ansprüchen verbinden: Die bestehende Historiographie ebenso wie die eigenen Interventionen werden mit einer Problematisierung von Rassismen in Österreich und darüber hinaus verknüpft, um Emanzipationsprozesse in Gang zu setzen. ${ }^{34}$ Wie in der zweiten Strömung werden postko-

30 Clemens Ruthner, k.u.k. Kolonialismus als Befund, Befindlichkeit und Metapher. Versuch einer weiteren Klärung, in: Feichtinger/Prutsch/Csáky (Hg.), Habsburg postcolonial, 111-128, 121.

31 Peter Stachel, Halb-kolonial und halb-orientalisch? Dalmatien als Reiseziel im 19. und frühen 2o. Jahrhundert, in: Peter Stachel/Martina Thomsen (Hg.), Zwischen Exotik und Vertrautem. Zum Tourismus in der Habsburgermonarchie und ihren Nachfolgestaaten, Berlin/Bielefeld 2014, 165200.

32 Renée Winter, Post/Koloniale Verbindungen?, in: Context XXI 2004/4-5, 42-45; Brigitte Hipfl/ Daniela Gronold, Asylum Seekers as Austria’s Other. The Re-Emergence of Austria's Colonial Past in a State-of-Exception, in: Social Identities: Journal for the Study of Race, Nation and Culture 17 (2011) 1, 27-40.

33 Der Zusammenhang mit aktivistischen Kontexten ist freilich kein Alleinstellungsmerkmal, aber im Gegensatz zu Autoren wie Walter Sauer (um nur ein Beispiel zu nennen), dessen akademisches Schaffen ebenfalls eng mit seinem Engagement für die Anti-Apartheid-Bewegung und Solidaritätsarbeit verknüpft war und ist, werden die Bezüge und die eigenen politischen Positionen in dieser Strömung meist explizit gemacht.

34 Eine der frühesten Arbeiten in dieser Perspektive ist Araba Evelyn Johnston-Arthur, Über die Konstruktion des môren und der moerin im Kontext „epistemischer Gewalt" und den traumatischen Charakter neokolonialer Erfahrungen in der modernen afrikanischen Diaspora in Österreich, Dipl.-Arb., Universität Wien 2004. Siehe auch dies., „Es ist Zeit, der Geschichte selbst eine Gestalt 
lonialistische Theorien rezipiert (aber in der Regel affirmativer angewendet); ${ }^{35}$ hinzu kommt bisweilen die explizite Verortung in feministischen Epistemologien wie zum Beispiel Standpunkttheorien. Ein wichtiges Referenzwerk in diesem Unterfangen ist das 1986 erschienene „Farbe bekennen. Afro-deutsche Frauen auf den Spuren ihrer Geschichte“..36

AutorInnen wie die Germanistin und Sozialwissenschaftlerin Araba Evelyn Johnston-Arthur, der Kunsthistoriker Christian Kravagna, die Künstlerin Belinda Kazeem-Kamiński oder die Historikerin Vida Bakondy überbrücken in der Wissensproduktion und -diskussion nicht nur die Kluft zwischen akademischen Institutionen und aktivistischen Kontexten, sondern nutzen auch Ausstellungen, Kunstprojekte und andere Formate zur Auseinandersetzung mit der (post-)kolonialen Geschichte Österreichs. Der Impetus hinter Publikationen und Initiativen ist ein umfassender Reflexions- und Bildungsanspruch als Antwort auf Rassismen und andere Herrschaftsmechanismen der Gegenwart. ${ }^{37}$ Die Befassung mit Geschichte gewinnt ihre Bedeutung dabei in besonders hohem Maße durch gesellschaftliche Missstände der Gegenwart. So nennen Vida Bakondy und Renée Winter etwa den Erstickungstod des Nigerianers Marcus Omofuma in Polizeigewahrsam 1999 und die Kriminalisierung von AfrikanerInnen unter der Regierungskoalition von ÖVP und FPÖ als Anstoß für ihre Studie über Afrikarepräsentationen im Österreich der 1950er-Jahre anhand des Films „Omaru. Eine afrikanische Liebesgeschichte“..38 Auch in der Ausstellung „Naija Akatarians“ („Nigerian Migrants in Vienna since the 1960s", Wien 2016), die darauf abzielte, nigerianische Migrationsnarrative in die

zu geben ...". Strategien der Entkolonisierung und Ermächtigung im Kontext der modernen afrikanischen Diaspora in Österreich, in: Kien Nghi Ha/Nicola Lauré al-Samarai/Sheila Mysorekar (Hg.), re/visionen. Postkoloniale Perspektiven von People of Color auf Rassismus, Kulturpolitik und Widerstand in Deutschland, Münster 2007, 423-444.

Siehe etwa Sophie Schasiepen, Schreiben über Dr. Rudolf Pöchs „Forschungsreisen“. Postkoloniale Kritiken und die österreichische Rezeption eines k.u.k. Anthropologen, Dipl.-Arb., Akademie für bildende Künste Wien 2013.

36 Katharina Oguntoye/May Ayim/Dagmar Schultz (Hg.), Farbe bekennen: Afro-deutsche Frauen auf den Spuren ihrer Geschichte, Berlin 1986. Siehe auch Katharina Oguntoye, Eine afro-deutsche Geschichte: Zur Lebenssituation von Afrikanern und Afro-Deutschen in Deutschland von 1884 bis 1950, Berlin 1997.

37 Belinda Kazeem-Kamiński, Engaged Pedagogy. Antidiskriminatorisches Lehren und Lernen bei Bell Hooks, Wien 2016.

38 Vida Bakondy/Renée Winter, „Nicht alle Weißen schießen. “ Afrikarepräsentationen im Österreich der 1950er Jahre im Kontext von (Post-)Kolonialismus und (Post-)Nationalsozialismus, Innsbruck 2007. 
Wiener Stadtgeschichte einzuschreiben, stellte Omofumas Tod einen zentralen Bezugspunkt dar. ${ }^{39}$

Johnston-Arthur problematisiert die kollektive Amnesie, die Themen wie Rassismus, Versklavung und österreichische Mitwirkung im Kolonialismus im hegemonialen österreichischen Kontext ausblendet. ${ }^{40}$ Integraler Bestandteil dieser Strömung ist „Testimonialliteratur", in der persönliche Erfahrungen mit einem Exemplaritätsanspruch geschildert werden. ${ }^{41}$ So berichtet Johnston-Arthur, wie sie im „[i]m Zuge der Vereinsgründung von Pamoja - Bewegung der jungen afrikanischen Diaspora in Österreich [...] als Obfrau des Vereins in die Sicherheitsdirektion der Bundespolizei zitiert“ und dort „vom zuständigen Sachverständigen“ [sic!] mit den Worten konfrontiert worden sei: „Mia san net in Ameriga! Es gibt ka afriganische Diaspora in Österreich, de gibt's nua bei die Juden - ihr seid’s a Völkerwanderung!“42 Basierend auf Erfahrungen dieser Art sehen Johnston-Arthur und andere Mitglieder der 2006 gegründeten Recherchegruppe zu Schwarzer Österreichischer Geschichte die Notwendigkeit, an einer „Geschichtsschreibung [mitzuwirken], die Schwarze Menschen nicht mehr als exotische Objekte und Ausnahmeerscheinungen, sondern vielmehr als Subjekte und als Bestandteil österreichischer Geschichte neu verortet" und sichtbar mache - so die Historikerin und Journalistin Claudia Unterweger, selbst aktive Teilnehmerin der Recherchegruppe, retrospektiv. ${ }^{43}$ Gerade eine Bearbeitung, Neu- und Umdeutung der Geschichte soll dabei „entkolonisierte“ Formen des Wis-

39 Siehe auch die Materialien und Interviews auf der Webseite Naija Akatarians, URL: https://naijaakatarians.wordpress.com/ (abgerufen 15.10.2020). Weitere Ausstellungen, in denen Verhältnisse zwischen der österreichischen Mehrheitsgesellschaft und minorisierten Gruppen, Rassismus und Widerstandsformen ebenfalls thematisiert werden, sind u. a. SchwarzÖsterreich. Die Kinder afroamerikanischer Besatzungssoldaten (Volkskundemuseum Wien 2016; Ausstellungskatalog: Niko Wahl/Tal Adler/Philipp Rohrbach, SchwarzÖsterreich: Die Kinder afro-amerikanischer Besatzungssoldaten, Wien 2016) und Multiversität. Internationale Studierende in Innsbruck 1955-1995 (Innsbruck 2019).

40 Johnston-Arthur, „Es ist Zeit“, 425. Siehe auch diese Analyse aktueller Geschichtslehrbücher: Leonie Valesca Haaf, Die Darstellung des Kolonialismus und Imperialismus im österreichischen Geschichtsschulbuch, Dipl.-Arb., Universität Wien 2017.

41 Zum Begriff Testimonialliteratur: Kerner, Postkoloniale Theorien, 17.

42 Araba Evelyn Johnston-Arthur, Schwarze Erfahrungen der jungen Afrikanischen Diaspora in Österreich, in: Karl A. Kumpfmüller (Hg.), Europas Langer Schatten. Afrikanische Identitäten Zwischen Selbst- und Fremdbestimmung, Frankfurt a. M. 2000, 153-159, 156. Siehe auch Michaela Obemeata-Gimoh, Andere Österreicher. Die Kinder der afrikanischen Diaspora in Wien, Dipl.Arb., Universität Wien 2014.

43 Claudia Unterweger, Talking Back Strategien Schwarzer österreichischer Geschichtsschreibung, Wien 2016, 63. Ein ähnliches Anliegen der Sichtbarmachung verfolgt Walter Sauer (Hg.), Von Soliman zu Omofuma. Afrikanische Diaspora in Österreich 17. bis 20. Jahrhundert, Innsbruck 2007. Siehe auch, mit einem breiteren geographischen Fokus, die Webseite des 2014 gegründeten His- 
sens ermöglichen. Arbeiten aus den beiden erstgenannten Strömungen werden hier ebenfalls rezipiert - bisweilen stellen sie den empirischen Unterbau für die Umdeutungen dar -, aber als zu unkritisch eingeschätzt, da die Auseinandersetzung mit eigenen Privilegien und „,,der eigenen spezifisch österreichischen Weiß-heit“ dort nur unzureichend geführt werde. ${ }^{44}$

Die Recherchegruppe formierte sich anlässlich des Mozart-Jahres 2006, um die Ausstellung „remapping Mozart“ zu realisieren. Hier finden sich Umdeutungen, mittels derer die „lange zurückreichende Anwesenheit Schwarzer Menschen in Österreich“ sowie die historische „Tradition ihrer Kämpfe gegen Ausgrenzung“ belegt wird und den Fremdbestimmungen Selbstdefinitionen entgegensetzt werden sollen. ${ }^{45}$ Paradigmatisch für diese Strategie steht die Umdeutung von Angelo Soliman (1721-1796), dessen Leichnam unter Kaiser Franz II. ausgestopft wurde, um ihn als halbnackten „Wilden“ im Kaiserlichen Naturalienkabinett auszustellen. In der Ausstellung wurde er zu einem „Vorkämpfer für die Bürgerrechte“ (Unterweger) namens „Angelo X“; erwähnt wird auch das Bemühen von Solimans Tochter, Josephine Soliman, um eine Rückgabe und würdige Bestattung der sterblichen Überreste ihres Vaters. ${ }^{46}$

\section{Themenfelder}

Eine zentrale These, die insbesondere Werke des dritten Ansatzes, aber zum Teil auch der ersten beiden Ansätze kennzeichnet, konstatiert die fortgesetzte Wirkmächtigkeit kolonialer, rassistischer und orientalistischer Denkmuster von der Vorbzw. Zwischenkriegszeit bis in die Zweite Republik. Diese These ist empirisch noch weiter zu untersuchen und auszudifferenzieren. Brüche und Kontinuitäten gilt es dabei ebenso zu beachten wie Umdeutungen und die Wirkung auf verschiedene gesellschaftliche Gruppen jenseits politischer Eliten. Im Folgenden werden fünf Themenfelder bzw. Problemstellungen skizziert, die Möglichkeiten aufzeigen, wie diese Fragen bearbeitet werden können.

torikernetzwerks Black Central European Studies Network, URL: https://blackcentraleurope.com/ (abgerufen 15.10.2020).

44 Araba Evelyn Johnston-Arthur, Weiß-heit, in: Büro für ungewöhnliche Maßnahmen (Hg.), Historisierung als Strategie. Positionen - Macht - Kritik. Eine Publikation im Rahmen des antirassistischen Archivs, Wien 2004, 10-11, 10.

45 Unterweger, Talking Back, 63.

46 Ebd., 130, 188-190. 
3.1 Kolonialistische Projekte und Antikolonialismus in der

Zwischenkriegs- und NS-Zeit

Eine der zentralen Fragen in Bezug auf historische Kontinuitäten und Brüche betrifft die Konfiguration vom Erbe des Habsburger „Kolonialismus ohne Kolonien“ mit dem Kolonialrevisionismus bzw. neuen kolonialistischen Projekten der Zwischenkriegszeit bis hin zum Nationalsozialismus. Zusätzlich gilt es auch, antikoloniale Netzwerke stärker in den Blick zu nehmen. Welche Visionen und tatsächlichen Institutionalisierungen und Praktiken gab es in diesen Jahrzehnten? Hier ist einerseits für die Zwischenkriegszeit festzuhalten (und weiter zu erforschen), wie in Kreisen der Kommunistischen Partei (KPÖ) und der Sozialdemokratischen Arbeiterpartei (SDAP) antiimperialistische Kampagnen (zum Beispiel „Hände weg von China und Marokko“, 1925) zum integralen Teil der internationalen Solidarität wurden und Leitfiguren internationaler Aktivistennetzwerke, wie zum Beispiel der erste schwarze Gewerkschaftsführer Südafrikas, Clements Kadalie im Jahr 1927, in Österreich Station machten und Vorträge hielten. ${ }^{47}$ Andererseits blieb der Glaube an die Richtigkeit einer „zivilisatorischen Mission“ in weiten Teilen der Linken bestehen. ${ }^{48}$

Ganz prononciert war der Zivilisierungsgedanke in einer neu formulierten politischen Vision mit explizit kolonialistischem Gehalt: der antikommunistisch und katholisch geprägten Paneuropabewegung, die sich wenige Jahre nach dem Ende des Habsburgerreiches in der Ersten Republik konstituierte. Im 1923 veröffentlichten Manifest dieser Bewegung verstand der österreichisch-japanische Schriftsteller, Politiker und spätere Dollfuß-Anhänger Richard Coudenhove-Kalergi die europäische Kultur als „Kultur der weißen Rasse“, die auf „dem Boden der Antike und des Christentums entstanden“ sei. ${ }^{49}$ Das zukünftig zu errichtende Paneuropa sah er jedoch auf Ressourcen und Siedlungsraum und damit auf eine „einheitliche Organisation und rationelle Erschließung seines afrikanischen Kolonialreiches“ angewiesen.50 1929 schrieb Coudenhove-Kalergi, dass Paneuropa von „Lappland bis nach Angola“ reiche; dieses „Eurafrika“ vereine „die höchsten Kulturvölker der weißen Rasse mit

47 Sauer, Expeditionen ins afrikanische Österreich, 58.

48 Dabei spielten auch wirtschaftliche Argumente eine Rolle. Zu Handelsbeziehungen der Zwischenkriegszeit siehe Gerald Kitter, Der Österreichisch-Afrikanische Außenhandel 1918-1938, Dipl.Arb., Universität Wien 2000.

49 Richard Coudenhove-Kalergi, Paneuropa, Wien/Leipzig 1923, 38. Zu Coudenhove-Kalergi als Anhänger des Austrofaschisten Engelbert Dollfuß siehe Lucile Dreidemy, Der Dollfuß-Mythos. Eine Biographie des Posthumen, Wien 2014, 236-237. Ich danke Lucile Dreidemy für den Hinweis auf diese Bewegung und ihr Manifest. Siehe auch Sauer, Expeditionen ins afrikanische Österreich, 56.

50 Coudenhove-Kalergi, Paneuropa, 38. 
den primitivsten Naturvölkern der schwarzen“.51 „[D]er Tatsache der Ungleichheit der Menschenrassen“ entsprechend sollte „die Beziehung zu Afrika [...] in den kommenden Jahrzehnten nicht auf Gleichberechtigung“, sondern auf „Herrschaft, Erziehung und Führung" aufgebaut sein..$^{52}$ Das Paneuropaprojekt wurde nicht nur von Intellektuellen wie Albert Einstein oder Heinrich Mann, sondern auch von politischen Führungsfiguren wie Bundeskanzler Ignaz Seipel (zugleich Präsident der Paneuropäischen Union in Österreich), Karl Renner, Otto von Habsburg oder Konrad Adenauer unterstützt. In der Nachkriegszeit war das neoimperiale Projekt Eurafrika ein Faktor für das Gelingen der (west)europäischen Integration in den 1950er-Jahren, die keineswegs eine klare Abkehr vom Kolonialismus oder von Afrika darstellte: Frankreich etwa nutzte den Einigungsprozess zu einer Konsolidierung des eigenen Einflusses. ${ }^{53}$ Die europäische Integration hat also auch Wurzeln im paneuropäisch-imperialistischen Projekt der Zwischenkriegszeit, das unter anderem in Wien ausformuliert wurde und Afrika in interdependenter, aber gleichzeitig rassistisch separierender und hierarchischer Manier als „,Siedlungsraum“, „Plantage“ und "tropische Ergänzung Europas“ einbezog. ${ }^{54}$

Schon mit den frühen Jahren des Austrofaschismus lässt sich auch wieder eine österreichische Teilhabe und Initiierung kolonialpolitischer Projekte von Seiten staatlicher Stellen konstatieren. So stimmten Österreich und Ungarn 1935, also bereits unter faschistischen Regierungen, im Völkerbund gegen eine Verurteilung und Sanktionierung Italiens als Antwort auf dessen Invasion in Abessinien (heutiges Äthiopien). Im Gegenzug für italienische Garantien, „Wünschen der österreichischen und ungarischen Regierung [...] an der wirtschaftlichen Ausbeutung Abessiniens gebührend Rechnung zu tragen“, gewährte Österreich Rom sogar das Prägerecht für Maria-Theresien-Taler, um die äthiopische Währung zu schwächen und den italienischen Truppen ein Zahlungsmittel zu verschaffen. ${ }^{55}$ Eine dezidiert postkolonialistische Perspektive auf die italienische Invasion in Abessinien eröffnet Markus Wurzer durch die Analyse von Differenzkonstruktionen und hybriden

51 Richard Coudenhove-Kalergi, Afrika, in: Paneuropa 5 (1929) 2, 1-19, 4.

52 Ebd., 4-5.

53 Peo Hansen/Stefan Jonsson, Eurafrica. The Untold History of European Integration and Colonialism, London 2015, 24-25, 28, 35. Die Ideen der Bewegung spiegeln sich in der gegenwärtigen Migrations- und Wirtschaftspolitik der EU gegenüber Afrika. Die Bewegung existiert unter dem Namen der Paneuropaunion bis heute.

54 Coudenhove-Kalergi, Afrika, 3, 19.

55 Lorenz Mikoletzky, Österreich, Italien und der abessinische Krieg 1935/36. Politik, Meldungen und Streiflichter, in: Mitteilungen des österreichischen Staatsarchivs 31 (1978), 487-501, zit. n. Sauer, Expeditionen ins afrikanische Österreich, 58. 
Identitäten in Tagebüchern und Fotografien (deutschsprachiger) Soldaten aus Südtirol in Diensten Mussolinis. ${ }^{56}$

Durch Bezüge auf Italien und Deutschland wird das Verständnis für die österreichische Implikation in Kolonialprojekten besonders deutlich. Wie Gregory Weeks zeigt, konnte die deutsche kolonialrevisionistische Bewegung (welche die „Rückgabe" der Kolonien forderte, die Deutschland nach Kriegsende an andere europäische Mächte abtreten musste) in Österreich Fuß fassen. Imperiale Ambitionen und „Entdeckungsreisen" aus der Habsburgerära wurden in den späten 193oer- und frühen 1940er-Jahren zum Vorläufer des deutschen Imperialismus stilisiert; neu gegründete Kolonialvereine bildeten Sammelbecken für deutschnationale und nationalsozialistische Kreise, die größtenteils für eine Kolonisierung des Ostens, teils aber auch für die Wiederinbesitznahme der Überseekolonien warben, die das Deutsche Reich mit den Versailler Verträgen abtreten musste. Nach dem „Anschluss“ 1938 folgten Kolonialausstellungen 1939 und 1940 sowie 1941 die Eröffnung einer spezifisch auf den Kolonialdienst in Übersee ausgerichteten Polizeischule in Wien-Strebersdorf. Zahlreiche österreichische Beamte aus anderen Ressorts hatten sich bereits freiwillig zum Kolonialdienst gemeldet. ${ }^{57}$ Die meisten staatlichen Planungen und praktischen Vorbereitungen für die Renaissance des deutschen Kolonialreiches nahmen aufgrund der angeordneten Konzentration von Ressourcen zur Kriegsführung 1942 ein jähes Ende. ${ }^{8}$

Die Verquickung von Machtansprüchen und Wissenschaft erreichte ihren Höhepunkt in der ersten Hälfte der 1940er-Jahre, wirkte dann aber noch lange nach. Die Verschränkungen „(post)nazistischer" und „(post)kolonialer" Dimensionen stehen im Zentrum von Vida Bakondys und Renée Winters Betrachtung österreichischer Afrikarepräsentationen der 1950er-Jahre am Beispiel des Spielfilms „Omaru - eine

56 Markus Wurzer, „Nachts hörten wir Hyänen und Schakale heulen“. Das Tagebuch eines Südtirolers aus dem italienisch-abessinischen Krieg 1935-1936, Innsbruck 2016; Markus Wurzer, Betwixt and Between. The Hybrid Identity of a South Tyrolean Bersagliere in the 1935-1936 Italo-Abyssinian War, in: Tabula 14 (2016) 1, 165-179; ders., Die sozialen Leben kolonialer Bilder. Italienischer Kolonialismus in visuellen Alltagskulturen und Familiengedächtnissen in Südtirol/Alto Adige 1935-2015, phil. Diss., Universität Graz 2020. Siehe auch Markus Wurzer/Birgit Kirchmayr (Hg.), Krieg und Fotografie: Neue Aspekte einer alten Beziehung in transnationaler und postkolonialer Perspektive. zeitgeschichte 45 (2018) 2.

57 Gregory Weeks, Hitlers österreichische Kolonialisten. Erste Republik - Ständestaat - „Drittes Reich“ 1918-1945, Wien 2016; Paul Sauer, Kamerun und Österreich 1918-1938. Vom Großwildjäger Ernst Zwilling, dem Ringer Jim Louis und dem Kolonialrevisionisten Gustave Hervé, Dipl.Arb., Universität Wien 2017.

58 Karsten Linne, Deutschland jenseits des Äquators? Die NS-Kolonialplanungen für Afrika, Berlin 2008. 
afrikanische Liebesgeschichte“ (1955), den der Wiener Regisseur Albert Quendler in (der ehemaligen deutschen Kolonie) Kamerun drehte.59 In diesen Jahren, geprägt durch die Dynamik der Dekolonisierung in Asien und Afrika, wuchs mit der wiedererlangten Souveränität auch Österreichs diplomatisches und wirtschaftliches Interesse an der „Dritten Welt“.

\section{2 Österreichs „Entdeckung der Dritten Welt"}

Während an zeitgeschichtlichen Forschungen, die Österreich in den Ost-WestKonflikt einordnen, ${ }^{60}$ kein Mangel herrscht, lässt der Forschungsstand zu österreichischen Positionen in Bezug auf den Nord-Süd-Konflikt sowie die De- und Rekolonisierung schon in grundlegender Hinsicht zu wünschen übrig. Bisher haben sich zu Gerald Hödls Standardwerk „Österreich und die Dritte Welt“ nur wenige substanzielle Arbeiten, größtenteils mit dem Schwerpunkt auf der Dekade nach Abschluss des Staatsvertrages 1955, hinzugesellt. ${ }^{61}$ Österreichs „Entdeckung der Dritten Welt“62 nach dem Zweiten Weltkrieg, so argumentieren Paula Pfoser und Clemens Pfeffer in postkolonialistisch angelegten Arbeiten zu Nationalratsdebatten bzw. der ORF-Berichterstattung über die afrikanische Dekolonisierung, sei eng mit dem Aufbau einer eigenen, nationalen Identität verknüpft gewesen. ${ }^{63}$ Ähnlich wie politische und diplomatische Kreise in der Schweiz oder (die Kolonialgeschichte besonders effektiv verdrängend) der Bundesrepublik Deutschland ${ }^{64}$ pflegten auch österreichische VolksvertreterInnen von der SPÖ-Abgeordneten Herta Firnberg bis zur FPÖ den Mythos der kolonialen „Unbeflecktheit“, um bei Regierungen gerade

59 Bakondy/Winter, „Nicht alle Weißen Schießen“.

60 Rezent etwa der anregende Überblick von Maximilian Graf/Agnes Meisinger (Hg.), Österreich im Kalten Krieg. Neue Forschungen im internationalen Kontext, Göttingen 2016.

61 Eine nennenswerte frühere Studie ist Michael Thomas Neugebauer, Die österreichisch-afrikanischen Beziehungen seit 1955, Wien/Köln/Weimar 1992.

62 Gerald Hödl, Österreich und die Dritte Welt: Außen- und Entwicklungspolitik der Zweiten Republik bis zum EU-Beitritt 1995, Wien 2004, 68.

63 Paula Pfoser, Modernisierung, Paternalismus, Partnerschaftlichkeit. Repräsentationen afrikanischer Dekolonisation im frühen österreichischen Fernsehen (1957-1965), in: Stichproben. Wiener Zeitschrift für kritische Afrikastudien 29/2015, 91-111; Clemens Pfeffer, Koloniale Fantasien Made in Austria. Koloniale Afrikarepräsentationen im österreichischen Nationalrat am Wendepunkt zum Postkolonialismus 1955-1965, in: Manuel Menrath (Hg.), Afrika im Blick. Afrikabilder im deutschsprachigen Europa, 1870-1970, Zürich 2012, 99-122.

64 Purtschert/Lüthi/Falk (Hg.), Postkoloniale Schweiz; Andreas Eckert/Albert Wirz, Wir nicht, die Anderen auch. Deutschland und der Kolonialismus, in: Conrad/Randeria (Hg.), Jenseits des Eurozentrismus, 372-392, 377 . 
unabhängig gewordener Staaten Vertrauen zu gewinnen und die eigenen wirtschaftlichen und politischen Bestrebungen als harmlos, wohltäterisch und weit entfernt von jedem Neokolonialismus darzustellen. ${ }^{65}$ Wenn auch der Grundtenor für die Kooperation und Exportmöglichkeiten positiv war, so galt die „Dritte Welt" doch auch als Bedrohung weißer Vorherrschaft. Ein ÖVP-Abgeordneter zeigte sich angesichts der rapide steigenden Zahl postkolonialer Staaten in den Vereinten Nationen „[a]ls Europäer [...] etwas erschüttert", dass in dieser „Organisation die weiße Rasse nur mehr in einem sehr geringen Maße vertreten war" ${ }^{\text {"66 }}$

Über alle politischen Parteigrenzen hinweg erhofften sich österreichische PolitikerInnen ab Ende der 1950er-Jahre durch Beziehungen zur „Dritten Welt“ einen besseren Zugang zu Ressourcen und Absatzmärkten. ${ }^{67}$ Hinzu kam die Hoffnung auf Prestige durch Teilnahme an internationalen Einsätzen, wie etwa durch die von Erwin Schmidl untersuchte Entsendung von Österreichs ersten UN-„Blauhelmen“, die 1960-1963 im Kongo stationiert waren - einer der entscheidenden Knotenpunkte von Dekolonisation und Kaltem Krieg. ${ }^{68}$ Die Meinungen zur Dekolonisierung in Österreich waren durchaus divers und widersprüchlich. Einerseits wurden ab den 1960er-Jahren antikoloniale Emanzipationsbestrebungen als legitim erachtet und das Festhalten Portugals an der Kolonialherrschaft bzw. Südafrikas an der Apartheid kritisiert, andererseits am Bild vom zivilisatorischen Entwicklungskolonialismus, der den Kolonien historischen Fortschritt "gebracht" habe, festgehalten. Konkrete Schritte auf internationaler Ebene, wie etwa UN-Abstimmungen über den Stopp von Waffenexporten an das Kolonialkriege führende NATO-Mitglied Portugal oder wirtschaftliche Sanktionen gegen Südafrika, wurden von der Regierung in Wien lange Zeit nicht unterstützt. Das antikommunistische Grundrauschen, wirtschaftliche Eigeninteressen sowie die De-facto-Einbindung in das westliche Lager wogen menschenrechtliche Bedenken auf. ${ }^{69}$

Ein Spezifikum in den Bezugnahmen auf den Kolonialismus stellt die gelegentliche Autoviktimisierung dar, in deren Rahmen die Besetzung Österreichs im Anschluss an das Ende des Zweiten Weltkrieges tendenziell zur Kolonialherrschaft umgedeutet wurde. Österreich teile ein Schicksal mit der kolonisierten Welt, man

65 Pfeffer, Koloniale Fantasien, 103.

66 Hödl, Österreich und die Dritte Welt, 72.

67 Ebd.

68 Erwin A. Schmidl, Blaue Helme, rotes Kreuz. Das österreichische UN-Sanitätskontingent im Kongo, 1960 bis 1963 , Innsbruck ${ }^{2} 2010$.

69 Hödl, Österreich und die Dritte Welt, 78, 91-104; Stefan A. Müller/Adamantios Skordos/David Schriffl, Heimliche Freunde. Die Beziehungen Österreichs zu den Diktaturen Südeuropas nach 1945. Spanien, Portugal, Griechenland, Wien 2016. 
schneide in Bezug auf die eigenen Rechte „kaum viel besser als ein Kolonialvolk ab", wie Ernst Koref 1950 im Nationalrat meinte. ${ }^{70}$ Auch Osteuropa wurde noch über 1955 hinaus und mit deutlich antikommunistischer Schlagseite als Opfer eines sowjetischen Kolonialismus gezeichnet - was die Aufmerksamkeit von antikolonialen Emanzipationskämpfen im Globalen Süden ablenkte und deren spezifische Charakteristika wie Antirassismus in den Hintergrund treten ließ. Die Stilisierung Österreichs zum (nunmehr befreiten) Kolonialopfer ging dabei nicht mit einer Solidarisierung mit dem Globalen Süden einher, wie Berthold Molden durch das Artikulieren der Innen- und Außendimensionen in den Diskursen gezeigt hat. ${ }^{11}$ Reichweite und Effekte dieser Denkweisen für die ersten zwei Jahrzehnte der Zweiten Republik sind noch weiter zu untersuchen; denkbar sind neben Studien von Nationalratsdebatten und Kontakten auf Regierungsebene auch Arbeiten zu Kirchen, Partei- und Gewerkschaftsbeziehungen in den Globalen Süden, die Thematisierung von Kolonialismus und Befreiungsbewegungen in Medien und der Populärkultur. ${ }^{72}$

\subsection{Entwicklung und Export}

In der ersten Hälfte der 1960er-Jahre bildete sich die „Entwicklungshilfe“ in Österreich als ein spezifisches außenpolitisches Instrument heraus, um die Beziehungen zu postkolonialen Staaten zu gestalten. Das war kein Sonderfall, tatsächlich wurden Entwicklungspolitik und Entwicklungsarbeit in diesen Jahren dies- und jenseits des Eisernen Vorhangs ein dominanter Gestaltungsmodus in den bilateralen Beziehungen zu Ländern des Globalen Südens. Globalgeschichtlich betrachtet ist Österreich sowohl in Hinblick auf die Institutionalisierung als auch in Bezug auf die diskursive Rahmung der Entwicklungspolitik Teil einer größeren Strömung. Nicht nur in Frankreich oder Großbritannien, auch in westlichen wie kommunistischen Ländern ohne eine unmittelbare Vorgeschichte als Kolonialmacht etablierten sich mehr oder minder autonome entwicklungspolitische Strukturen und Instrumente. Kennzeichnend für die österreichische Frühphase der Entwicklungspolitik ist dabei die besonders enge Anbindung an Missionsstrukturen und katholische Aktivitäten,

70 Zit. n. Molden, Decolonizing the Second Republic, 113.

71 Molden, Decolonizing the Second Republic.

72 Methodische Anregungen, Hinweise auf Quellenkorpora und einige ansprechend ausgeführte Beispiele dazu finden sich in ebd. 
die den staatlichen oft vorausgingen; mit Abstrichen gilt das wohl auch für das internationale Engagement von Gewerkschaften. ${ }^{73}$

Postkolonialistische Perspektiven auf Entwicklungsdenken und -praktiken gehören mittlerweile zum Kanon der Kritischen Entwicklungsforschung. ${ }^{74}$ Gemeinsam mit PraktikerInnen der Entwicklungszusammenarbeit sowie Studierenden und anderen Lehrenden der Internationalen Entwicklung in Wien arbeitet der Afrikanist Walter Schicho am Aufbau eines digitalen „Archivs des Helfens“ (ArchE) sowie eines „Archivs der Entwicklungszusammenarbeit“ (ArchEZA). Bereits online ist ein reicher Fundus studentischer Arbeiten, von denen einige - insbesondere jene, die sich mit Repräsentationspraktiken befassen - auf postkolonialistische Ansätze zurückgreifen. ${ }^{75}$

Ökonomie- und diskurszentrierte Perspektiven stehen jedoch nach wie vor in einem Spannungsverhältnis, selbst wenn sie von ein und demselben Autor vertreten werden. So hat Gerald Hödl Oral-History-Interviews mit österreichischen "EntwicklungshelferInnen" mithilfe postkolonialistischer Theoreme analysiert und festgestellt, dass deren Erinnerungen an Einsätze in den 196oer- und 1970er-Jahren nicht den proklamierten Nord-Süd-Transfer von Know-how, sondern ganz im Gegenteil den Fluss von „Wissen, Erfahrungen und Emotionen vom ,Süden in den ,Norden“ ins Zentrum stellten; die erwarteten Differenzkonstruktionen (fortschrittlich - rückständig; entwickelt - unterentwickelt, europäisch - nichteuropäisch) spielten hingegen kaum eine Rolle oder wurden von den Interviewten mit Gegenbeispielen unterlaufen. ${ }^{76}$ In seiner früheren Arbeit hatte Hödl hingegen die österreichische „Entwicklungshilfe“ als neues und spezifisches Instrument für die Beziehung zu postkolonialen Staaten dargestellt, das - in Zusammenarbeit mit anderen westlichen Gebern und Institutionen - der Kontrolle weiter Teile der außereuropäischen Peripherie und der Stabilisierung des kapitalistischen Weltsystems diente.77

73 Zeynep Sagun, Die Anfänge der öffentlichen Entwicklungshilfe Österreichs, Dipl.-Arb., Universität Wien 2013. Siehe auch das Habilitationsprojekt von Lucile Dreidemy, Internationale Politik ohne staatliche Akteure? Das Beispiel der Entwicklungspolitik in Deutschland und Österreich ab den $1960 e r$ Jahren, Universität Wien.

74 Lukas Schmidt/Sabine Schröder (Hg.), Entwicklungstheorien. Klassiker, Kritik und Alternativen, Wien 2016; Aram Ziai, Development Discourse and Global History. From Colonialism to the Sustainable Development Goals, Abington 2017.

75 Archive des Helfens (ArchE), Universität Wien, URL: https://archeza.univie.ac.at/beitraege-zurgeschichte-der-oesterreichischen-eh-eza/arbeiten-aus-dem-forschungsseminar-arche/ (abgerufen 15.10.2020).

76 Gerald Hödl, „Es tut mir nicht leid, dass ich’s gemacht hab.“ Eine „Oral History“ der österreichischen Entwicklungshilfe, in: Journal für Entwicklungspolitik XXVI (2010) 3, 95-118, 113.

77 Hödl, Österreich und die Dritte Welt. 
Die wohlwollende Interpretation der mikrohistorischen Oral-History-Interviews unterscheidet sich von der systemkritischen Makroperspektive jedoch in einem Grad, dass es unmöglich scheint, hier ein allgemeingültiges Narrativ zu konstruieren. Stattdessen wird gerade auf diese Art der Wert der Methodenvielfalt deutlich.

Eine Neubetrachtung verdienen die bereits vor drei Jahrzehnten offengelegten Verbindungen zwischen Exportinteressen (vor allem der verstaatlichten Industrie) und entwicklungspolitischen Fragen. ${ }^{78}$ Impulse zur Bearbeitung weiterer Quellentypen jenseits offizieller Akten und Diskurse liefert auch Hanna Hackers Lektüre der autobiographischen Development-Kontaktliteratur, also von Erfahrungsberichten, in denen Pädagogisierung und Disziplinierung als charakteristische Elemente der Entwicklungsarbeit hervortreten und Erfahrungsdimensionen wie Körperlichkeit und Begehren breiten Raum einnehmen. ${ }^{79}$

\subsection{Postkolonialismus avant la lettre}

Die Rezeption postkolonialistischer Ansätze im deutschsprachigen Raum wird oft als Übernahme eines Trends von angloamerikanischen Universitäten gedeutet. Es gab allerdings auch andere beachtenswerte Transmissionsriemen, Netzwerke und Ansätze, teils jenseits des heute etablierten postkolonialistischen Kanons, die Beachtung verdienen - wie einige rezente Arbeiten zeigen. Österreich tritt in diesen wissen(schaft)s- und ideengeschichtlichen Arbeiten bisher noch nicht prominent auf, aber einige österreichische HistorikerInnen haben sich dem Aufspüren und der Neubewertung solcher oft verschütteter Kreuzungs- und Traditionslinien kolonialismuskritischen Denkens im deutschsprachigen Raum wie auch darüber hinaus verschrieben.

Neben den klassischen Imperialismustheorien marxistischer Tradition bildete sich zum Beispiel auch in der Theologie ein Ansatz aus, der - so der Historiker Cle-

78 Walter Pohl/Guido Rüthemann/Hans Steiner, Geschäfte mit der Entwicklung. Österreich und die Dritte Welt, Wien ${ }^{2}$ 1986; Martin Frimmel/Helmut Haberl/Alexis Wiederstein, Katastrophen-Hilfe. Österreichische Kraftwerke in der Dritten Welt, Wien 1991; Bernhard Rogl, Österreichische Industrieanlagenexporte nach Afrika 1945-1993, in: Journal für Entwicklungspolitik XII (1996) 2, 143-164; Elisabeth Prinz, Berufliche Einschulung als Element des Industrieanlagenverkaufs an Entwicklungsländer, dargestellt am „Projekt Nigeria“ der VOEST-Alpine, Dipl.-Arb., JKU Linz 1981. Zu Waffenexporten siehe Peter Pilz, Die Panzermacher. Die österreichische Rüstungsindustrie und ihre Exporte, Wien 1982.

79 Hanna Hacker, Queer entwickeln. Feministische und postkoloniale Analysen, Wien 2012. 
mens Pfeffer - „postkoloniale Perspektiven avant la lettre“ vertrat. ${ }^{80}$ Pfeffer bezieht sich auf Perspektiven, die sich in den 1970er-Jahren im Umfeld der EvangelischTheologischen Fakultät Hamburg entfalteten: Beeinflusst durch die Studentenbewegung (und die Rezeption von antikolonialen Denkern wie Frantz Fanon) und im Austausch mit den zahlreichen Studierenden aus Asien, Afrika und Lateinamerika an der Fakultät, erarbeiteten Theologen wie Hans Jochen Margull hier ein Verständnis von Kolonialismus als politischer Ideologie, die Mission und Missionshistoriographie entscheidend prägte. Eine kritische Missionshistoriographie sollte helfen, die eurozentrischen Dimensionen von Christentum und Mission zu überwinden und eine neue Grundlage für gleichberechtigte Beziehungen in der Gegenwart schaffen. Wie Pfeffer hervorhebt, entstanden diese Ansätze keineswegs in einem intellektuellen Vakuum: Ihre Herausbildung steht selbst exemplarisch für eine verflochtene und geteilte Geschichte. Die westdeutschen Autoren setzten sich mit außereuropäischen Emanzipationsbewegungen und Positionen wie jenen von Frantz Fanon auseinander und waren im steten Austausch mit den vielen internationalen Studierenden an der Fakultät - nur unter Beachtung dieser (schwach institutionalisierten) Zirkulationen sind auch die (weitgehend in Vergessenheit geratenen) theoretischen Innovationen erklärbar.

Ähnlich rahmt der Historiker David Mayer die Auseinandersetzung des DDRHistorikers Manfred Kossok mit marxistischen Strömungen in Lateinamerika, und hier insbesondere dem Werk des Peruaners José Carlos Mariátegui. Mariátegui hatte in seinem Versuch, den Marxismus an lateinamerikanische Realitäten anzupassen, auch indigene kommunalistische Traditionen eingeflochten. ${ }^{81}$ Mayer zufolge war Kossok der Erste, der Mariáteguis Ansätze im deutschen Sprachraum rezipierte und somit eine Art Vorläufer für postkolonialistische oder „dekoloniale“ Debatten. Mayer lenkt somit den Blick auf die Pluralität von Marxismen und die Multidirektionalität der Ideenzirkulation: Hier handelte es sich keinesfalls um die Diffusion von einem (angloamerikanischen) Zentrum, sondern um einen „Süd“-„Ost“-Transfer zwischen der kommunistischen und der postkolonialen Welt, der etablierten Ideengeschichten, in deren Zentrum der „Westen“ steht, zuwiderläuft.

Hinzu kommen weitere Beiträge zu einer Ideengeschichte, in der die Artikulation von Ideen immer auch als politischer Akt verstanden wird. Hierzu zählen etwa die

80 Clemens Pfeffer, Missionshistoriographie post 1968. Postkoloniale Perspektiven avant la lettre, in: Sebastian Pittl (Hg.), Theologie und Postkolonialismus. Ansätze - Herausforderungen - Perspektiven, Regensburg 2018, 191-218.

81 David Mayer, Coming to Terms with the Past, Getting a Grip on the Future. Manfred Kossok's Interventions into Historiographical Debates about Latin America during the Radicalized 196os, in: Review (Fernand Braudel Center) 38 (2015) 1-2, 15-39. 
Beiträge des Afrikahistorikers Arno Sonderegger zur Geschichte des panafrikanischen Denkens, zu den Biographien antikolonialer Intellektueller aus Afrika und der Diaspora sowie seine umfassende Eurozentrismuskritik, die er mit einer Geschichte des Despotiebegriffs von der Antike bis in die Gegenwart leistet. ${ }^{82}$ Mit Blick auf die transnationale Mobilität und verschiedene soziale Kontexte zeichnet Immanuel Harisch das Denken des Historikers Walter Rodney (1942-1980) nach, dessen Schaffen zwischen seinem Heimatland Guyana, Jamaika, Tansania und Hamburg zu einem zentralen, wenngleich nicht kanonisierten Referenzpunkt postkolonialistischer Theoriebildung zählt. ${ }^{83}$ Rodneys Arbeiten werden oft den neomarxistischen Dependenztheorien zugeordnet, sind allerdings keinesfalls ökonomistisch und dadurch ein Beleg für das spannungsreiche Nahverhältnis von Marxismus und Postkolonialismus. ${ }^{84}$ Es ist eine offene Frage, ob auch in Österreich derartige Zirkulationen und Auseinandersetzungen nachzuweisen sind, wie sie Pfeffer, Mayer, Sonderegger und Harisch herausgearbeitet haben. Anknüpfen ließe sich hier aber fraglos bei den Forschungen zu Österreichs „1968“.

\subsection{Das lange „1968“ im Zeichen von Aktivismus und Antisolidarität}

Das „österreichische“ „1968“ wird in der Zeitgeschichte bisher eher belächelt und als provinziell und marginal eingeschätzt - paradigmatisch gefasst in den Bonmots des Historikers Fritz Keller über das „Mailüfterl“, das nicht länger als eine „heiße Viertelstunde" dauerte. ${ }^{85}$ Der Blick auf die Austauschprozesse mit dem Globalen Süden kann jedoch zu einem transnational erweiterten Verständnis nicht nur der österreichischen Linken, sondern auch breiterer gesellschaftlicher Kreise führen. Während es für linke Solidaritätspraktiken bereits einige Studien gibt, sind Praktiken, die sich

82 Arno Sonderegger (Hg.), African Thoughts on Colonial and Neo-Colonial Worlds - Facets of an Intellectual History of Africa, Berlin 2015; ders., Die Dämonisierung Afrikas. Zum Despotiebegriff und zur Geschichte der afrikanischen Despotie, Saarbrücken 2008.

83 Immanuel Harisch, Walter Rodney's Dar es Salaam Years, 1966-1974. How Europe Underdeveloped Africa, Tanzania’s ujamaa, and Student Radicalism at „the Hill“, MA-Arbeit, Universität Wien 2017.

84 Siehe als Beleg für diese Spannungen den Sammelband von Felix Wemheuer, zum Zeitpunkt der Veröffentlichung Sinologe an der Universität Wien: Felix Wemheuer (Hg.), Marx und der Globale Süden, Köln 2016.

85 Fritz Keller, Mailüfterl über Krähwinkel, in: Bärbel Danneberg/Fritz Keller/Aly Machalicky/Julius Mende (Hg.), Die 68er. Eine Generation und ihr Erbe, Wien 1998, 36-42. Siehe auch die Beiträge von Oliver Rathkolb und Karl Vocelka in: Oliver Rathkolb/Friedrich Stadler (Hg.), Das Jahr 1968 Ereignis, Symbol, Chiffre, Göttingen 2010. 
explizit gegen diese Solidaritätspraktiken wendeten, ein Desiderat der Forschung. Exklusionsprozesse ,innen“ wie „außen“ sollten auch dabei wieder in einen gemeinsamen Analyserahmen gestellt, Pro-Apartheid-Haltungen in Wirtschaft, Politik und Presse mit Exklusionsprozessen, Identitätsdebatten und materiellen Interessenlagen im „Inneren“ artikuliert werden. Zu deutendes Material, das eine feste Haltung der Antisolidarität ausdrückt, gäbe es zu Genüge. So hieß es, um ein konkretes Beispiel zu nennen, in der Tiroler Tageszeitung am 4. November 1983 polemisch:

So unbefriedigend die Diskriminierung der Schwarzen für europäische Gleichheitsfanatiker sein mag, die weißen Südafrikaner müssen die Last der Reformen selber tragen [...] (D)a ist es relativ belanglos, was die Besserwisser in aller Welt meinen. Die schimpfen auf die Buren und kommen nicht einmal mit ihrem Haustürken klar. ${ }^{86}$

Mit mehr Einsichten in Lobbynetzwerke und mehrheitsösterreichische Positionen gegenüber Emanzipationsforderungen im Globalen Süden ließe sich auch verdeutlichen, warum viele Aspekte der transnationalen Solidaritätsdiskurse in Österreich einerseits nur ein geringes Echo fanden und andererseits tausende ÖsterreicherInnen dem Lockruf des Apartheid-Regimes nach qualifizierten - weißen - Fachkräften folgten und nach Südafrika auswanderten. ${ }^{87}$

Zu beachten sind dabei auch Wechselwirkungen und der Einfluss ,ausländischer" Studierender und Intellektueller auf theoretische Debatten und Aktivismus. In einer Untersuchung zu studentischem Aktivismus an der Universität Innsbruck zeigt Marcel Amoser vielfältige Bezugnahmen, darunter nicht nur die Zusammenarbeit von in- und ausländischen Studierenden im Rahmen der Solidarität mit politisch Verfolgten aus Griechenland, dem Iran oder der Türkei, sondern auch die antikommunistischen Motive der Behörden und Strategien in konservativen Medien und auf Seiten der Polizei, bevorzugt ausländische Studierende zu „Rädelsführern“ zu erklären - oft ohne haltbare Belege - und somit die Ursachen von politischem Aktivismus zu exterritorialisieren. ${ }^{88}$ Mit einem solchen gezielten Blick auf die Interak-

86 Zit. n. Eva Enichlmayr/Walter Sauer, Apartheid-Propaganda in Österreich, in: Walter Sauer/Theresia Zeschin (Hg.), Die Apartheid-Connection. Österreichs Bedeutung für Südafrika, Wien 1984, $163-172,167$.

87 Andrea Heuberger (Hg.), Rot-Weiß-Rot in der Regenbogennation. Geschichte und Geschichten österreichischer Auswanderer in Südafrika, Wien 2012.

88 Marcel Amoser, Studentischer Protest an der Universität Innsbruck von den 1960ern bis in die 1980er, in: Margret Friedrich/Dirk Rupnow (Hg.), Geschichte der Universität Innsbruck 16692019, Bd. II: Aspekte der Universitätsgeschichte, Innsbruck 2019, 337-389, 344, 367-368, 384385 . 
tionen von in- und ausländischen Studierenden muss auch die übliche analytische Trennung der „transnationalen“ und „lokalen“ Dimensionen von 1968 hinterfragt werden. ${ }^{89}$

Instruktiv in dieser Hinsicht ist auch Hanna Hackers Blick auf die Pan-African Students Union of Austria (PASUA), die von 1961 bis 1965 existierte. Der sozialistische und antirassistische Aktivismus der PASUA-Mitglieder geriet schnell ins Visier der Behörden, die PASUA als kommunistische Organisation brandmarkten gleichzeitig sind die Überwachungsakten, Erinnerungen und weitere Dokumente in Privatbesitz, wie Hacker andeutet, als Teil eines „postkolonialen Archivs“ in Österreich zu lesen. ${ }^{\circ 0}$ Oral History bietet weitere Einblicke in die Verflechtung lokaler und transnationaler Dimensionen. Andrea Sommerauer hat eine Studie über junge Männer vorgelegt, die durch Initiative des Kennedyhauses in Innsbruck - einem Hort der schon vor 1968 knospenden Gegenkultur - als Missionshelfer der Marianischen Kongregation nach Rhodesien entsendet wurden. Die zwischen 1964 und 1976 entsandten Männer fanden sich dabei inmitten der Auseinandersetzungen zwischen weißem Siedlerregime und Widerstandsbewegungen wieder. $\mathrm{Ob}$ es sich bei Letzteren um „Befreiungskämpfer“ oder, wie das rassistische Regime behauptete, „Terroristen“ handelte, war für die wenigsten Missionshelfer eindeutig. ${ }^{91}$

Wünschenswert wären auch Untersuchungen, die Alternativen zum dominanten methodologischen Bilateralismus (Solidaritätsbeziehungen zwischen ÖsterreicherInnen und einzelnen Ländern wie zum Beispiel Chile) bieten und etwa danach fragen, wie hier verschiedene Generationen (vom Exil der Zwischenkriegszeit bis in die Gegenwart) und Milieus von Algerien- bis Vietnamsolidarität überlappen oder unabhängig voneinander existierten, wie Gruppen zeitlich, lokal und auch transnational verortet waren. Verknüpfungen und Vergleiche über die nationalstaatlichen Grenzen hinaus bieten weiteres Erkenntnispotenzial. Für den Fall der österreichischen Anti-Apartheid-Bewegung (1977-1993) etwa liegt die Deutungshoheit derzeit noch weitgehend bei Selbstdarstellungen, die nahelegen, dass Ziele wie Bewusstseinsbildung und Politisierung im Land selbst in durchaus beachtlichem Umfang erreicht wurden - obwohl sich die Bewegung im internationalen Vergleich eher spät

$89 \mathrm{Zu}$ dieser Unterscheidung siehe etwa Martin Klimke, 1968 als transnationales Ereignis, in: Oliver Rathkolb/Friedrich Stadler (Hg.), Das Jahr 1968 - Ereignis, Symbol, Chiffre, Göttingen 2010, 21-30, 26.

90 Hanna Hacker, Transnational Assemblages, Pan-African Activism, and Cold War Politics in the 1960s, or, Is There A Feminist Post-colonial Archive in Austria? (unveröffentlichtes Manuskript), VAD-Konferenz Leipzig 2018, 5.

91 Andrea Sommerauer, Gewagte Mission. Der Missionshilfeeinsatz von Jugendlichen aus der Marianischen Kongregation (MK) Innsbruck in Rhodesien (1964-1976), Innsbruck 2019. 
formierte. ${ }^{92}$ Die Solidarität mit der algerischen Nationalen Befreiungsfront (FLN), die gegen Frankreich kämpfte, war schon ab den späten 1950er-Jahren relevant wenn auch nur in kleinen Kreisen. Im Algerienkrieg kämpften Österreicher in der Fremdenlegion auf Seiten Frankreichs ebenso wie auf Seiten der algerischen Befreiungsbewegung FLN. ${ }^{93}$ Fritz Keller argumentiert, dass das Algerien-Engagement der (zum Teil späteren) SPÖ-Führungskräfte wie Bruno Kreisky, Karl Blecha, Erwin Lanc und Peter Jankowitsch den Impuls für die österreichische Nahostpolitik der 1970er-Jahre gegeben habe. Bemerkenswert war unter anderem die Anerkennung der PLO 1980 - vor jedem anderen westlichen Land. Gleichzeitig habe Keller zufolge die Quasimonopolisierung der Beziehungen durch sozialdemokratische „Funktionärskampagnen“ die breitere Verankerung der Solidarität in der Zivilgesellschaft sowie auch eine Auseinandersetzung mit antikolonialen Intellektuellen wie zum Beispiel Frantz Fanon verhindert. ${ }^{94}$ Tatsächlich wurden bisher nur wenige Belege zur Rezeption von Werken Frantz Fanons oder Aimé Césaires in Österreich vorgebracht. ${ }^{95}$

Solidarität in einem breiten Spektrum der österreichischen Linken gab es auch im Falle Lateinamerikas, insbesondere Chiles und Nicaraguas. Die Revolution der Sandinisten etwa eignete sich als Projektionsfläche eigener Ideale, schien hier doch eine sozialistische Alternative gefunden zu werden zu den Sackgassen, in die westliche Industriegesellschaft einerseits und der Realsozialismus in Osteuropa andererseits zu münden schienen. ${ }^{96}$ Solche Perspektiven ließen sich durch Oral History, Privatarchive oder gegenhegemoniale Publikationsprojekten noch weiter erschließen, um

92 Walter Sauer, Austria and South Africa during Apartheid, in: SADET (Hg.), The Road to Democracy in South Africa, Bd. 3: International Solidarity, Part I, Pretoria 2008, 630-640.

93 Friedrich Keller, Solidarität der österreichischen Linken mit der algerischen Widerstandsbewegung, phil. Diss., Universität Amsterdam 2010.

94 Fritz Keller, Gelebter Internationalismus. Österreichs Linke und der algerische Widerstand (19581963), Wien 2010, 195, 261.

95 Eine ambivalente Fanon-Rezeption findet sich etwa beim österreichischen Widerstandskämpfer und Auschwitz-Überlebenden Jean Améry (1912-1978): Lutz Fiedler, „Schicksalsverwandtschaft"? Jean Amérys Fanon-Lektüren über Gewalt, Gegengewalt und Tod, in: Naharaim 11 (2017) $1-2,133-165$.

96 Laurin Blecha, Von Ottakring nach Cuatro Esquinas. Beziehungen und Kooperationen zwischen Nicaragua und Österreich von 1979 bis 1990, in: Albert Manke/Kateřina Březinová (Hg), Kleinstaaten und sekundäre Akteure im Kalten Krieg. Politische, wirtschaftliche, militärische und kulturelle Wechselbeziehungen zwischen Europa und Lateinamerika, Bielefeld 2016, 275-302; Jan Rybak, Eine sehr besondere Revolution, die ich kennenlernen wollte. Die österreichische Nicaragua-Solidaritätsbewegung 1979-1990, Bremen 2015. 
über Selbstdarstellungen hinauszugehen. ${ }^{97}$ Österreichische Stimmen dominieren bisher; durch die Einbeziehung weiterer Perspektiven von „außen“ und „von den Rändern“ wären produktive Dezentrierungen und Revisionen zeitgeschichtlicher Darstellungen zu erwarten.

\section{Ausblick}

Die Habsburger Kolonialpolitik lässt sich, bezieht man kulturelle Wechselwirkungen und die zwangsweise ökonomische Durchdringung außereuropäischer Gesellschaften im Rahmen einer internationalen Arbeitsteilung mit ein, über dreihundert Jahre zurückverfolgen. Während die Überseephantasien und -praktiken der K.-u.-k.-Periode wie auch kolonialrevisionistische Forderungen deutschnationaler Kreise im Österreich der Zwischenkriegszeit im kollektiven Gedächtnis weitgehend verblasst sind, aber in weitgehend unreflektierten Vorstellungswelten und Konsumkulturen fortexistieren, ist die „innere Kolonisierung“ des Reiches nicht zuletzt durch ihre mannigfaltigen Auswirkungen bis in die Gegenwart noch in vielerlei Hinsicht präsent. Die Erkenntnislücke zwischen Gegenwart und Habsburgermonarchie ist dabei allerdings noch eklatant.

Um hier Abhilfe zu schaffen, scheint es lohnend, erstens Quellenbestände in Staats-, Diözesen- oder Firmenarchiven sowie mediale Diskurse als Österreichs „postkoloniales Archiv“98 sowohl mit als auch gegen den Strich zu lesen, um Österreichs Verhältnis zu Kolonialismus, Antikolonialismus und Postkolonialismus zu ergründen. Zweitens wird es notwendig sein, ,außereuropäische“ Perspektiven und private Quellenbestände sowie Verflechtungen zwischen „innen“ und „außen“ stärker in den Blick zu nehmen. Für alle oben genannten Themenfelder gilt, dass (post-) migrantische, diasporische und externe Perspektiven auf Österreich marginalisiert sind - hier könnte die stärkere Beachtung der Testimonial-Literatur sowie die gezielte Anwendung von Oral History mit Beteiligten Abhilfe schaffen und weitere Dimensionen eines „postkolonialen Archivs“ zutage fördern. Eine Nachverfolgung dieser Zirkulationen und Lebensläufe dürfte zu Ergebnissen führen, die etablierte

97 Siehe etwa aus dem Umkreis der Chile-Solidaritätsbewegung: Sigrun Berger/Herbert Berger (Hg.), Chilenische Flüchtlinge und Österreich, Wien 2002. Im Hinblick auf Nicaragua siehe die Oral-History-Dokumentation von Jan Pirker, Narraciones de la Revolución. Erzählungen der Revolution, Österreich/Nicaragua 2013.

98 Hacker, Transnational Assemblages; allgemeiner dazu Hanna Hacker, archivescapes. Diskurse zum Archiv im Postkolonialen, in: Österreichische Zeitschrift für Geschichtswissenschaften 16 (2005) $1,36-58$. 
Deutungen der österreichischen Zeitgeschichte im nationalstaatlichen Rahmen oder im Ost-West-Verhältnis nicht nur bereichern, sondern ihnen womöglich auch entgegenlaufen.

Postkolonialistische Theorien wurden bisher vor allem zur Analyse von Repräsentationsregimen und Identitäts- und Differenzkonstruktionen herangezogen, sie bleiben damit stark dem kulturhistorischen Diskurs verhaftet und werden nur selten für die Deutung politischer und wirtschaftlicher Praktiken - über die Ebene der Sinnstrukturen hinaus - angewendet. Sie können über ihre derzeitige Anwendung in kulturhistorischen Fragestellungen hinaus stärkere Impulse zur Neudeutung politischer Prozesse oder wirtschaftlicher Dynamiken in der Zeitgeschichte sein. ${ }^{99}$ Die drängenden Fragen, wie Repräsentationsmechanismen mit materiellen Ungleichheiten und wirtschaftlichen Außenbeziehungen zusammenhängen, wie sie diskriminierende Praktiken legitimieren oder gar hervorbringen und mit einer stetigen Aktualisierung und Neukonfigurierung kolonialistischen Denkens einhergehen, sind jedenfalls noch zu beantworten.

99 Differenzkonstruktionen und politische Schwerpunktsetzungen werden explizit miteinander artikuliert in Pfeffer, Koloniale Fantasien. 


\title{
Transnationalismus
}

\author{
Claudia Kraft
}

\section{Zeitgeschichte als nationale Geschichte?}

In seiner Bestandsaufnahme zur österreichischen Zeitgeschichte aus dem Jahr 2004 formuliert Ernst Hanisch ganz am Ende seines Beitrags:

Die nationale Geschichte wird ein Schwerpunkt bleiben müssen, in möglichst vielen Dimensionen, auf möglichst vielen Ebenen und bis nahe an die Gegenwart heranreichend. Doch die Herausforderung einer „transnationalen Zeitgeschichte" liegt für Österreich entschieden im zentraleuropäischen Raum.

Diese Herausforderung untermauert er mit einem Blick auf das zu analysierende Erbe der Habsburgermonarchie. Dass der Autor seinen Text gerade mit einem Verweis auf eine transnationale Zeitgeschichte abschließt, erstaunt etwas, denn auf den vorangegangenen Seiten spielen Überlegungen zur räumlichen und verflechtungsgeschichtlichen Verortung der österreichischen Zeitgeschichte so gut wie keine Rolle. Vielmehr dominiert ein Narrativ, das man als typisch für Reflexionen über Methoden und Perspektiven der Zeitgeschichtsschreibung betrachten kann: Es geht um die langjährige Dominanz traditioneller Politikgeschichte, um die Kritik allzu großer Politisierung bzw. normativer Tendenzen in der Zeitgeschichte und vor allem um Fragen der thematischen Reichweiten und Perspektivierungen, also ob eine gesellschaftsgeschichtliche Makroperspektive einer kulturgeschichtlichen Mikroperspektive vorzuziehen sei. ${ }^{2}$ Hanisch rekurriert hier auf die kritische Aufnahme, die seine zehn Jahre zuvor erschienene Gesellschaftsgeschichte Österreichs ${ }^{3}$

1 Ernst Hanisch, Die Dominanz des Staates. Österreichische Zeitgeschichte im Drehkreuz von Politik und Wissenschaft, in: Alexander Nützenadel/Wolfgang Schieder (Hg.), Zeitgeschichte als Problem. Nationale Traditionen und Perspektiven in Europa, Göttingen 2004, 54-77, 76-77.

2 Letzteres bejaht Hanisch ganz eindeutig und recht polemisch, wenn er auf die postmoderne Unfähigkeit bzw. Unwilligkeit hinweist, „Geschichte“ zu schreiben, und Themen der Neuen Kulturgeschichte zeithistorische Relevanz abspricht, ebd., 66, 71.

3 Ernst Hanisch, Der lange Schatten des Staates. Österreichische Gesellschaftsgeschichte im 20. Jahrhundert (Österreichische Geschichte: 1890-1990), Wien 1994. 
in Teilen der österreichischen Geschichtswissenschaft gefunden hatte. In einer vor allem in der „Österreichischen Zeitschrift für Geschichtswissenschaften“ (OeZG) geführten Debatte wurde Hanisch unter vielen anderen Kritikpunkten vorgeworfen, einen habsburgisch-österreichischen Mythos fortzuschreiben, sich selbst als „Österreicher-Macher“ zu betätigen und zwecks „Kohärenzkonstitution“ „ein sehr altes historiographisches Konstrukt, nämlich das der Nationalgeschichtsschreibung“" zu bemühen. ${ }^{4}$ Die Redaktion der OeZG legte damit eine Schwachstelle der Gesellschaftsgeschichtsschreibung à la Bielefeld offen, die auch dem Zentralblatt dieser Forschungsrichtung, der Zeitschrift "Geschichte und Gesellschaft“ im Jahr $2000 \mathrm{zu}$ seinem 25-jährigen Bestehen vorgehalten wurde, nämlich „nationalzentrierte Sozialgeschichte in programmatischer Absicht“" ${ }^{\text {" }} \mathrm{zu}$ sein. Auf das sich im Folgejahr anschließende Diskussionsforum ${ }^{6}$ nahm 2004 auch Ernst Hanisch Bezug, jedoch ohne daraus weiterreichende Überlegungen anzustellen, was das nun für eine österreichische Zeitgeschichte bedeute.7 Es wird hier deutlich, dass in den 1990er- und frühen 200oer-Jahren für die Zeitgeschichte im deutschsprachigen Raum deren unreflektierte Verwendung des Nationalstaats als quasi natürlicher Rahmen zeithistorischer Problemstellungen zunehmend kritisch gesehen wurde, dass die Zeitgeschichte jedoch eher zögerlich an die aktive Problematisierung und Operationalisierung alternativer Forschungsparadigmen heranging. Ich möchte im Folgenden aufzeigen, inwieweit in den letzten zwei Jahrzehnten transnationale Forschungsansätze in der österreichischen Zeitgeschichtsforschung Eingang fanden, wie Transnationalität verstanden bzw. auch zum Teil anders umschrieben wurde, und auf einige Themenfelder verweisen, die entweder bereits in transnationaler Perspektive bearbeitet wurden bzw. die gerade für eine solche neue Herangehensweise ins Blickfeld der Forschenden rücken. Dabei kann und will dieser kurze Beitrag - geschrieben von

4 OeZG-Redaktion, Der lange Schatten der Historiographie oder: Barocke Aufklärung. Ernst Hanischs „Der lange Schatten des Staates“. Eine Kritik, in: Österreichische Zeitschrift für Geschichtswissenschaften 6 (1995) 1, 85-118; siehe Hanischs Replik, ders., Anklagesache: Österreichische Gesellschaftsgeschichte, in: Österreichische Zeitschrift für Geschichtswissenschaften 6 (1995) 3, 457-466 sowie einen weiteren Debattenbeitrag von Dieter Groh und Martin Zürn, dies., Der lange Schatten der ,Gesellschaftsgeschichte. Zur Problematik einer Konzeption, in: Österreichische Zeitschrift für Geschichtswissenschaften 6 (1995) 4, 569-608.

5 Lutz Raphael, Anstelle eines Editorials: Nationalzentrierte Sozialgeschichte in programmatischer Absicht: Die Zeitschrift „Geschichte und Gesellschaft. Zeitschrift für historische Sozialwissenschaft" in den ersten 25 Jahren ihres Bestehens, in: Geschichte und Gesellschaft 26 (2000) 1, 5-37.

6 Jürgen Kocka, Einladung zur Diskussion, in: Geschichte und Gesellschaft 27 (2001) 3, 463 (das Heft enthält weitere Beiträge von Jürgen Osterhammel, Susanne-Sophia Spiliotis und Albert Wirtz).

7 Hanisch, Dominanz, 76. 
einer Autorin, die noch immer eher als Außenstehende auf die österreichische Zeitgeschichte blickt - keinen Anspruch auf Vollständigkeit erheben.

\section{Transnationale Geschichte - der „Austrian Approach“?}

Seit inzwischen etlichen Jahren ist das Paradigma der transnationalen Geschichte aus den methodischen Debatten der Geschichtswissenschaft nicht mehr wegzudenken. Dieses Paradigma steht in einem engen Zusammenhang mit dem Nachdenken über Vergleich, Transfer und Verflechtung als historiographische Operationen, die nationalgeschichtliche Engführungen überwinden sollen. Nicht ohne Grund ist in der Debatte über die Methoden von Vergleich und Transfer auf die Bedeutung von Raumvorstellungen und die Wandelbarkeit und Situativität von Räumen hingewiesen worden sowie darauf, dass Akteure Räume herstellen, diese jedoch auch wieder das Akteurshandeln beeinflussen. ${ }^{8}$ Die gesamte seit etwa Mitte der 1990erJahre geführte Debatte über den heuristischen Wert einer eher auf Vergleiche bzw. Transfers und Verflechtungen fokussierenden Geschichtsschreibung blieb dennoch stark auf die USA und Großbritannien (als moderne Schrittmacher) bzw. auf Frankreich und Deutschland (als Paradebeispiele für eine antagonistische Verflechtungsgeschichte) beschränkt. ${ }^{9}$ Inzwischen ist hinsichtlich der vergleichs-, transfer- bzw. verflechtungsgeschichtlichen Perspektive ein gewisser Konsens erzielt worden, der sich für die reflektierte Koppelung dieser Zugänge ausspricht, nicht zuletzt, um auf diese Weise konventionelle Hierarchisierungen in „Pionierländer“ und „Nachzügler“ zu vermeiden. ${ }^{10}$ Gerade die imperial überformten sowie ethnisch, konfessionell

8 Hannes Siegrist, Perspektiven der vergleichenden Geschichtswissenschaft. Gesellschaft, Kultur und Raum, in: Hartmut Kaelble/Jürgen Schriewer (Hg.), Vergleich und Transfer. Komparatistik in den Sozial-, Geschichts- und Kulturwissenschaften, Frankfurt a. M./New York 2003, 305-339, 321-332.

9 Heinz-Gerhard Haupt/Jürgen Kocka (Hg.), Geschichte und Vergleich. Ansätze und Ergebnisse international vergleichender Geschichtsschreibung, Frankfurt a. M. 1996; Michael Werner/Bénédicte Zimmermann, Vergleich, Transfer, Verflechtung. Der Ansatz der Histoire croisée und die Herausforderung des Transnationalen, in: Geschichte und Gesellschaft 28 (2002) 4, 607-637; Kaelble/ Schriewer, Vergleich und Transfer.

10 Hartmut Kaelble, Die Debatte über Vergleich und Transfer und was jetzt?, Transnational, CrossRegional and Global Connections, URL: https://www.connections.clio-online.net/article/id/artikel-574 (abgerufen 08.05.2020); bereits 1998 plädierte Johannes Paulmann für einen Methodenmix, ders., Internationaler Vergleich und interkultureller Transfer. Zwei Forschungsansätze zur europäischen Geschichte des 18. bis 20. Jahrhunderts, in: Historische Zeitschrift 267 (1998) 3, $649-685,684-685$. 
und kulturell heterogenen Gebiete des mittleren und östlichen Europas bieten dabei einen interessanten Untersuchungsgegenstand. Deutlich wird das an Forschungsansätzen, die etwa am Beispiel der Habsburgermonarchie ein sensibles Begriffsinstrumentarium für das Nebeneinander politischer und territorialer Ordnungsentwürfe entwickelt haben, das von "Zentraleuropa“ ausgehend seine heuristische Validität aber auch für andere Regionen - sowohl in europäischer als auch in globalgeschichtlicher Perspektive - unter Beweis gestellt hat. ${ }^{11}$ Es ist sicher kein Zufall, dass in letzter Zeit innovative Überlegungen zu Fragen der Verflechtungsgeschichte und des Transfers von Theorien in unterschiedliche Teilbereiche der Geschichtswissenschaft vor allem auch anhand von Beispielen des östlichen Europas geliefert worden sind. ${ }^{12}$

Die auf den Nationalstaat fokussierte Untersuchungsperspektive ist im Rahmen der Debatten über die transnationale Geschichte selbstverständlich nicht einfach ad acta gelegt worden. Vielmehr wurde das Bewusstsein dafür geschärft, dass die Nation nur einer von zahlreichen Parametern für Territorialisierungsregime ist. Um einer Essenzialisierung von Raumvorstellungen entgegenzuwirken, erweisen sich gerade quellengestützte Forschungen, welche die Vielzahl von möglichen territorialen Bezügen herausarbeiten, als besonders wünschenswert. ${ }^{13}$ Blickt man auf das 19. und 20. Jahrhundert, so erscheint die Sensibilität für unterschiedliche räumliche Untersuchungsebenen unerlässlich. Charles S. Maier hat die Jahrzehnte zwischen 1860 und 1960/1970 als Zeitalter der „high territoriality“ bezeichnet und damit vor allem auf nationalstaatliche Praktiken der Raumdurchdringung hingewiesen, bei denen „Identitätsräume“ („identity spaces“) mit „Entscheidungsräumen“ („decision spaces") mehr oder weniger kongruent zu sein schienen. ${ }^{14}$ Zugleich wird in

11 Gregor Kokorz/Helga Mitterbauer (Hg.), Übergänge und Verflechtungen. Kulturelle Transfers in Europa, Bern/Berlin/Bruxelles/Frankfurt a. M./New York/Oxford/Wien 2004; Moritz Csáky, Pluralitäten, Heterogenitäten, Differenzen. Zentraleuropas Paradigmen für die Moderne, in: Moritz Csáky/Astrid Kury/Ulrich Tragatschnig (Hg.), Kultur - Identität - Differenz. Wien und Zentraleuropa in der Moderne, Innsbruck 2004, 13-44; Philipp Ther, Comparisons, Transfers, and the Study of Networks: Toward a Transnational History of Europe, in: Jürgen Kocka/Heinz-Gerhard Haupt (Hg.), Comparative and Transnational History: Central European Approaches and New Perspectives, New York 2009, 204-225.

12 Agnes Arndt/Joachim C. Häberle/Christiane Reinecke (Hg.), Vergleichen, verflechten, verwirren? Europäische Geschichtsschreibung zwischen Theorie und Praxis, Göttingen 2011; Dietlind Hüchtker/Alfrun Kliems (Hg.), Überbringen - Überformen - Überblenden. Theorietransfer im 20. Jahrhundert, Köln/Weimar/Wien 2011.

13 Siehe dazu etwa Matthias Middell, Transnationale Geschichte als transnationales Projekt. Zur Einführung in die Diskussion, in: Historical Social Research/Historische Sozialforschung 31 (2006) 2, 110-117.

14 Charles S. Maier, Consigning the Twentieth Century to History: Alternative Narratives for the Modern Era, in: American Historical Review 105 (2000) 3, 807-831, 816. 
Reflexionen zur transnationalen Geschichte betont, dass erst für die Zeit ab der Mitte des 19. Jahrhunderts sinnvollerweise von transnationaler Geschichte als Forschungsperspektive gesprochen werden könne, allerdings nicht nur, weil bis weit ins 19. Jahrhundert auch imperiale Raumordnungen dominant gewesen seien, sondern vor allem auch, weil transnationale Geschichte gerade die Prozesse des Grenzenüberschreitens und des Austauschs fokussiere, die das moderne Konstrukt „Nation“ erst historiographisch konturierten. ${ }^{15}$ Weiter gefasst kann somit konstatiert werden, dass Prozesse der Territorialisierung und Globalisierung sich nicht einander ausschließend gegenüberstanden, sondern einander bedingten. ${ }^{16}$ Hier bietet gerade das mittlere und östliche Europa, das im 19. und 20. Jahrhundert sowohl durch imperiale Überschichtung als auch durch nationale und regionale Diskurse und Ordnungspraktiken gekennzeichnet war, ein geeignetes Untersuchungsfeld, will man der Gleichzeitigkeit von Raumordnungen im Sinne eines „Spiels mit den Maßstäben“ („jeux d'échelles“), von dem Jacques Revel gesprochen hat, ${ }^{17}$ gerecht werden. In mit globalgeschichtlichem Anspruch entworfenen Werken wie dem „Palgrave Dictionary of Transnational History“ spielt diese Region, die für die konzeptuelle Konturierung transnationaler Geschichte erwiesenermaßen Potenzial besitzt, keine herausgehobene Rolle. ${ }^{18}$ Aber vielleicht könnte es doch lohnenswert sein, über die Zeit von der Mitte des 19. Jahrhunderts bis zur Gegenwart, die das „Palgrave Dictionary“ betrachtet und die auch in den oben erwähnten grundsätzlichen Erwägungen zu modernen Raumkonzepten zentral ist, genauer am Beispiel der österreichischen Zeitgeschichte nachzudenken, hat sie doch alle Zutaten zu bieten, die die bereits erwähnten Spannungsfelder von nationaler und transnationaler Geschichtsbetrachtung stimulieren: eine imperiale Vergangenheit, die über das Jahr 1918 hinaus in die Zeitgeschichte hineinragt, unterschiedlich verortete Nationalstaatsprojekte im 20. Jahrhundert sowie eine geopolitische Lage, die einen Fokus auf Austausch- und Verflechtungsprozesse unabdingbar zu machen scheint.

Geht man von der Gliederung des vorliegenden Sammelbandes aus, so beginnt österreichische Zeitgeschichte mit der Republikgeschichte seit 1918, die dann in die krisenhafte Phase von Diktaturen (Austrofaschismus und Nationalsozialismus) und

15 So etwa die Diskussionsbeiträge von Christopher Bayly in der AHR Conversation, vgl. C. A. Bayly/ Sven Beckert/Matthew Connelly/Isabel Hofmeyr/Wendy Kozol/Patricia Seed, AHR Conversation: On Transnational History, in: American Historical Review 111 (2006) 5, 1441-1464, 1442, 1449. Michael G. Müller/Cornelius Torp, Conceptualising Transnational Spaces in History, in: European Review of History 16 (2009) 5, 609-617, 612.

17 Jacques Revel, Jeux déchelles. La micro-analyse à l'expérience, Paris 1996.

18 Akira Iriye/Pierre-Yves Saunier (Hg.), The Palgrave Dictionary of Transnational History. From the Mid- $19^{\text {th }}$ Century to the Present Day, Basingstoke 2009. 
Krieg übergeht, um dann in einer erneuten (zweiten) Republikgeschichte zunächst im Kalten Krieg und dann im sich nach Osten erweiternden Europa weitererzählt zu werden. Diese klassische politikgeschichtliche Gliederung, die generell zeitgeschichtliche Forschungszusammenhänge - auch außerhalb Österreichs - prägt, muss nicht zwangsläufig quer zu transnationalen und verflechtungsgeschichtlichen Ansätzen stehen, die nicht entlang nationalstaatlicher Periodisierungen erzählen. Vielmehr ergeben sich aus der Reibung nationalgeschichtlicher und transnationaler Perspektiven innovative Fragestellungen, die „Österreich“ immer wieder neu positionieren und aus diesen Positionierungen heuristisches Potenzial generieren. Man könnte etwa mit der Frage beginnen, wo die sowohl die Habsburgermonarchie als auch die österreichischen Republiken stark prägende Metropole Wien eigentlich liegt, wenn man sie in einer Moderne zu positionieren versucht, für die die Forschung wie oben dargestellt die immense Relevanz von (nationalstaatlichen) Territorialisierungsprozessen einerseits und Grenzen überschreitenden Austauschprozessen andererseits konstatiert hat. Greift man zu dem instruktiven Sammelband „Laboratorien der Moderne. Orte und Räume des Wissens in Mittel- und Osteuropa“, wird man mit Erstaunen feststellen, dass Wien in der Einleitung als eine Maßstäbe setzende Metropole des „Westens“ an die Seite von Berlin, London und Paris gerückt und somit als Teil einer hegemonialen Moderne fixiert wird, in deren Schatten kleinere Zentren der Habsburgermonarchie standen. ${ }^{19}$ Einige Seiten darauf macht Moritz Csáky eindrücklich deutlich, dass erst die Austausch- und Verflechtungsbeziehungen mit diesen peripheren Orten die zum Topos gewordene Wiener Moderne um 1900 hervorgebracht hätten. ${ }^{20}$ Der gesamte Band kann als ein Plädoyer gelesen werden, Geschichte nicht in starren Konzepten wie dem der „Moderne“ stillzustellen, sondern nachzuvollziehen, wie sich Konzepte in dynamischen Austausch- und Verflechtungsprozessen überhaupt erst herausbildeten.

Der maßgeblich von Moritz Csáky mitgestaltete Grazer Spezialforschungsbereich zu „Moderne - Wien und Zentraleuropa um 1900“ (Laufzeit 1994-2004) leistete wichtige Beiträge zu einer solchen Ausdifferenzierung der Diskussion über die Moderne. Zugleich entwickelte Csáky am Beispiel der durch Multiethnizität und Mehrsprachigkeit geprägten Habsburgermonarchie ein konzeptuelles Instrumentarium, das zwar nicht unter dem Label transnationale Geschichte figuriert, aber das Interesse an Austausch- und Verflechtungsgeschichte eng am Forschungsmaterial sehr

19 Bernd Stiegler/Sylwia Werner, Einleitung, in: dies. (Hg.), Laboratorien der Moderne. Orte und Räume des Wissens in Mittel- und Osteuropa, Paderborn 2016, 7-12, 7-8.

20 Moritz Csáky, Die Stadt in Zentraleuropa - ein hybrider Kommunikationsraum, in: Stiegler/Werner (Hg.), Laboratorien, 31-59. 
viel überzeugender operationalisiert, als dies viele andere Texte tun, die das Transnationale explizit im Titel führen. Für die Zeitgeschichtsforschung, die das 20. und 21. Jahrhundert in den Blick nimmt, gibt es hier einiges zu lernen. So weist Csáky in seinem Buch „Das Gedächtnis der Städte“, das die Heterogenität zentraleuropäischer Ballungsräume und hier vor allem Wien in den Jahren um 1900 fokussiert, darauf hin, dass die Fragestellungen zu von Migration und kulturellen Hybridisierungsprozessen geprägten Städten Zentraleuropas auch auf die Nachfolgestaaten unter ihnen die Republik(en) Österreich - zu übertragen seien. Er macht darauf aufmerksam, wie sehr sich Konstellationen von Fremdheits- und Abgrenzungserfahrungen bei gleichzeitigen Überlappungs- und Vermischungsprozessen auch für die Ballungsräume des 21. Jahrhunderts beobachten ließen, und resümiert in einem Ausblick auf die Gegenwart:

Zentraleuropa und vor allem seine urbanen Milieus zur Zeit der Moderne könnten aufgrund ihrer soziokulturellen Differenziertheit, aufgrund ihrer Funktion als „Zwischenräume“, in denen sich unterschiedliche kulturelle Kommunikationsräume performativ verschränkten, als ,Laboratorien' angesehen werden, in denen Prozesse stattgefunden haben und sichtbar wurden, die heute, im Zeitalter der Globalisierung und der kulturellen Vernetzungen von allgemeiner, weltweiter Relevanz geworden sind. ${ }^{21}$

Es liegt auf der Hand, dass die Migrationsgeschichte, die an anderer Stelle dieses Bandes genauer behandelt wird, für die Republik Österreich, die „at a European crossroads, an intersection of developed and less developed regions, the junction of East and West “22 platziert ist, zentral erscheint, um die Entstehung und die Wirkungen der von Csáky angesprochenen „Laboratorien“ für das 20. und 21. Jahrhundert zu untersuchen. ${ }^{23}$

Es lassen sich noch weitere Forschungsfelder benennen, für die ein Blick auf die Habsburgermonarchie und ihre Nachgeschichte neue Impulse für die Behandlung zeitgeschichtlicher Fragestellungen liefert. Auch für das sich zurzeit ausgesprochen

21 Moritz Csáky, Das Gedächtnis der Städte. Kulturelle Verflechtungen - Wien und die urbanen Milieus in Zentraleuropa, Wien/Köln/Weimar 2010, 365; zur Migrationsgeschichte Wiens um 1900, siehe auch Elisabeth Röhrlich (Hg.), Migration und Innovation um 1900. Perspektiven auf das Wien der Jahrhundertwende, Wien/Köln/Weimar 2016.

22 Michael John, Migration in Austria: An Overview of the 1920 s to 2002, in: Johannes Feichtinger (Hg.), Understanding Multiculturalism: the Habsburg Central European experience, New York 2014, 122-157, 122.

23 Programmatisch dazu Dirk Rupnow, Deprovincializing Contemporary Austrian History. Plädoyer für eine transnationale Geschichte Österreichs als Migrationsgesellschaft, in: zeitgeschichte 40 (2013) 1, 5-21. 
dynamisch entwickelnde Feld der Wissensgeschichte wird die Habsburgermonarchie als ein Raum wahrgenommen, an dem innovative Forschungskonzepte zu entwickeln sind. So schlägt Johannes Feichtinger einen „Austrian approach“ vor, der anders als ein „Saidian approach“ nicht die Repräsentationen von Differenz, sondern stärker akteurszentriert „entangled spheres of knowledge making which where occluded by imperial colonialism, nationalism, cold war epistemology and the post-colonial approach and its representations" in den Blick nehmen solle. ${ }^{24} \mathrm{An}$ ders als die bei Edward Said im Mittelpunkt stehenden Unterschiede, die hierarchisch gedacht und in Form fester Wissensbestände diskursgeschichtlich untersucht werden, betont Feichtinger den Prozess der Wissensproduktion als einen zentralen wissensgeschichtlichen Forschungsgegenstand. Es sind nicht zuletzt die vielfältigen Raumbezüge und Untersuchungsebenen des Imperiums und seiner Nachfolgestaaten, vor deren Hintergrund innovative Fragestellungen entwickelt werden können. Aus wissensgeschichtlicher Perspektive lädt etwa die Historisierung ökonomischen Denkens ein, Raumkonzepte genauer zu betrachten und Austauschprozessen größere Aufmerksamkeit zu schenken. Es waren aus der Habsburgermonarchie stammende Wirtschaftswissenschaftler wie Friedrich August von Hayek und Ludwig von Mises, die zu Vordenkern neuer ökonomischer Ordnungskonzepte wurden, die heute unter dem allgegenwärtigen Begriff Neoliberalismus gefasst werden. Die neuere Forschung hat herausgearbeitet, dass mit dem Habsburgerreich in den Augen dieser Ökonomen nicht ein hoffnungslos rückständiger „Völkerkerker" untergegangen sei. Vielmehr sahen sie im Imperium ein zukunftweisendes Modell, in dem politische und ökonomische Räume nicht kongruent waren und nationalstaatliche Interessen (anders als nach 1918) den freien Fluss von Waren und Kapital nicht behinderten. Nicht nur die Nachfolgestaaten der Habsburgermonarchie betrachteten sie kritisch als Akteure, die die Ressource Eigentum für eine Volkswirtschaft unter nationalen Vorzeichen kontrollieren und bei Bedarf einschränken konnten. ${ }^{25}$ Für Hayek und Mises standen internationale Rahmenbedingungen für eine möglichst ungehinderte Entwicklung weltwirtschaftlicher Kooperation im Mittelpunkt, so-

24 Johannes Feichtinger, Introduction: Interaction, Circulation and the Transgression of Cultural Differences in the History of Knowledge Making, in: Johannes Feichtinger/Anil Bhatti/Cornelia Hülmbauer (Hg.), How to Write the Global History of Knowledge-Making. Interaction, Circulation and the Transgression of Cultural Differences, Cham 2020, 1-26, 15.

25 Quinn Slobodian, Globalists: The End of Empire and the Birth of Neoliberalism, Cambridge (MA) 2019; für ausgewählte „postimperiale“ Territorien im mittleren und östlichen Europa diskutiert Dietmar Müller den nationalstaatlichen Zugriff auf das Privateigentum, vgl. ders., Bodeneigentum und Nation. Rumänien, Jugoslawien und Polen im europäischen Vergleich, 1918-1948, Göttingen 2020. 
wohl dem Nationalstaat als auch Forderungen nach nationaler und demokratischer Selbstbestimmung standen sie skeptisch gegenüber. Sie imaginierten eine Wirtschaftsordnung, in der die „Identitätsräume“ nicht mit den „Entscheidungsräumen“ kongruent waren, um nochmals Charles S. Maier zu zitieren. Für diesen endet dieses Zeitalter in den 1960er-/1970er-Jahren in der westlichen Hemisphäre sowie in den 1980er-Jahren im „sozialistischen Block“. ${ }^{26}$ Ein Blick auf das Wirtschaftsdenken der 1920er-Jahre zeigt allerdings, dass das letzte Drittel des 20. Jahrhunderts auch vor dem Hintergrund des Erfahrungsraums der Habsburgermonarchie gelesen werden sollte: Neue ökonomische, aber auch gesellschaftspolitische Modelle können nicht nur aus der unmittelbaren Vorgeschichte der 1970er-Jahren erklärt werden, sie weisen auch Wissensbestände auf, die aus einer Zeit stammen, die nicht überall von „high territoriality“ geprägt war. Damit lohnt es sich, auch noch einmal anders über die These nachzudenken, die Habsburgermonarchie sei vielleicht im Hinblick auf ihren kulturellen Reichtum als modern, im Hinblick auf die Wirtschaftsordnung jedoch unbedingt als rückständig zu charakterisieren. Folgt man Konzepten durch Raum und Zeit, wird deutlich, dass der Erfahrungsraum der Habsburgermonarchie Wirtschafts- und Gesellschaftsentwürfe produzierte, die in jeweils adaptierter Form bis heute Relevanz behalten haben. Dass der Blick auf ältere Raumordnungen dabei zum Teil zu zweifelhaften politischen Schlussfolgerungen führte, mag aus normativer Sicht bedauerlich sein; aus historischer Perspektive ist es umso interessanter, was etwa ein Brief Ludwig von Hayeks an die Londoner „Times“ aus dem Jahr 1978 zeigt, in dem er die Migrationsbeschränkungen der Regierung Thatcher gegenüber den EinwohnerInnen früherer Teile des Commonwealth begrüßte und dies mit dem Verweis auf den Antisemitismus der 1920er-Jahre in Wien begründete, den er durch die Einwanderung von Jüdinnen und Juden aus den ehemaligen Territorien der Monarchie stimuliert sah. ${ }^{27}$

\section{3. Österreich im Kalten Krieg}

Auf ganz andere Art und Weise lädt die räumliche und geopolitische Neupositionierung Österreichs nach dem Zweiten Weltkrieg dazu ein, über den Mehrwert transnationaler Forschungsperspektiven nachzudenken. Während eine „posthabsburgische“ Perspektive Transfers und die Grenzüberschreitungen von Ideen über

26 Maier, Consigning, 823.

27 Friedrich August Hayek, Origins of Racialism, The Times, 01.03.1978, 13, zit. n. Slobodian, Globalists, 330, Anm. 159. 
zeitliche und räumliche Grenzen hinweg in den Blick nimmt, kann auch eine spezifische Verortung von AkteurInnen und Institutionen Ausgangspunkt innovativer transnationaler Forschung werden. Im österreichischen Fall erscheint hier die Verortung an einer Schnittstelle der geopolitischen Ordnung des Kalten Krieges besonders produktiv zu sein. Die politische Neutralität des Landes, aber schlicht auch die geographische Nähe zu den Ländern hinter dem „Eisernen Vorhang“, machen die Zweite Republik zu einem Raum, an dessen Beispiel die häufig durch ein „Containerdenken“ der Staaten und Blöcke geprägte Kalte-Krieg-Forschung neue Impulse erhalten kann. ${ }^{28}$

Mit der Figur des „go-between“ hat der Wissenschaftshistoriker Kapil Raj für die globale Wissensgeschichte einen Akteur konzeptualisiert, den er nicht nur als Vermittler, sondern auch als aktiven Mitgestalter von (Austausch)Beziehungen beschreibt. Auch wenn Raj sich vor allem für kolonialgeschichtliche Interaktionsprozesse interessiert, in denen die Entfernung zwischen (kolonialem) Zentrum und Peripherien eine zentrale Rolle spielt, betont er, dass es sich bei diesen Interaktionen um keine reinen Diffusionsprozesse handle und dass gerade auch die lokale Verortung der "go-betweens" relevant sei. ${ }^{29}$ Überträgt man seine Beobachtungen auf die Situation des Kalten Krieges, wird deutlich, dass Österreichs räumliche Nähe einerseits und seine antikommunistische Prägung andererseits einen hochinteressanten Kontext für die Betrachtung von Austauschprozessen über den Eisernen Vorhang hinweg darstellen. Hier sei etwa auf das Beispiel des britischen Journalisten G. E. R. Geyde verwiesen, der als Redakteur von Radio Free Europe exemplarisch einen solchen „go-between“ verkörperte. Seine langjährigen Erfahrungen in Mitteleuropa, die ihn in der Zwischenkriegszeit zu einem überzeugten Antifaschisten, zugleich durch seine Erfahrungen mit sowjetischer Politik in der Kriegs- und Nachkriegszeit zu einem ebenso überzeugten Antikommunisten hatten werden lassen, trugen dazu bei, dass er in der jungen Zweiten Republik sehr erfolgreich zwischen US-amerikanischem Antikommunismus und der österreichischen Suche nach Eigenständigkeit im Kalten Krieg vermitteln konnte. ${ }^{30}$ Neben der Neutralität waren auch die alten kulturpolitischen Verbindungslinien, die noch aus der Habsburgermonarchie stammten und auf die eher symbolisch verwiesen wurde, ein wichtiges

28 Umfassend gebündelt die Desiderata zuletzt von Maximilian Graf/Agnes Meisinger, Österreich und der Kalte Krieg. Forschungsstand und Desiderata, in: dies. (Hg.), Österreich im Kalten Krieg: Neue Forschungen im internationalen Kontext, Wien 2016, 9-48.

29 Kapil Raj, Go-Betweens, Travelers, and Cultural Translators, in: Bernard Lightman (Hg.), A Companion to the History of Science, Chichester 2016, 39-57.

30 Peter Pirker, Broker des transnationalen Antikommunismus. G.E.R. Geyde und Radio Free Europe in Österreich, in: zeitgeschichte 43 (2016) 6, 379-394. 
Instrument, mit dem es österreichischen „Brokern“ wie etwa dem einflussreichen Literaturwissenschaftler und Kulturjournalisten Wolfgang Kraus, die an der Schnittstelle von Außenpolitik, kulturellem Kalten Krieg und Kulturvermittlung wirkten, gelang, die intellektuelle Distanz zu den östlichen Nachbarn nicht zu groß werden zu lassen. Obwohl von dem mit klarer antikommunistischer Agenda auftretenden Congress for Cultural Freedom finanziert, gestaltete Kraus seit den frühen 1960erJahren mit der von ihm geleiteten Österreichischen Gesellschaft für Literatur (ÖGL) Kultur- und Literaturbeziehungen aktiv mit und verhinderte somit auch, dass diese zu einem bloßen Instrument der kulturellen Propaganda im Kalten Krieg wurden. ${ }^{31}$ Schließlich trugen auch die seit Ende der 1950er-Jahre verstärkten Bestrebungen, das neutrale Österreich zu einem aktiven Vermittler zwischen Ost und West zu machen, dazu bei, dass das Land trotz seines dezidierten Antikommunismus zu einem zentralen Ort wurde, an dem sich Kommunikation zwischen den Blöcken auf internationalen Konferenzen - etwa den Pugwash-Konferenzen in den Jahren $1958 / 1959^{32}$ - und in internationalen Organisationen, die ihren Sitz in Wien hatten, materialisieren konnte. ${ }^{33}$

Aus transnationaler Perspektive erscheint es besonders ergiebig, die geopolitische Lage Österreichs nach dem Zweiten Weltkrieg noch stärker aus einer akteurszentrierten Perspektive zu thematisieren. Hatten an anderer Stelle des vorliegenden Beitrags weltbekannte Protagonisten des Neoliberalismus ihren Auftritt, richtet sich der Blick nun auf österreichische VertreterInnen einer stärker interventionistischen und nachfrageorientierten Wirtschaftspolitik. Diese hatten vielfach ihre Karrieren bereits in der Zwischenkriegszeit in Österreich begonnen, waren in den 1930er-Jahren nach Großbritannien und in die USA emigriert und nach dem Krieg nach Österreich zurückgekehrt (so etwa Kurt Wilhelm Rothschild, Josef Steindl, Maria Szécsi oder

31 Stefan Maurer, „Der Boden des neutralen Österreichs scheint uns besonders für eine Auseinandersetzung zwischen Ost und West geeignet zu sein." Wolfgang Kraus' Netzwerke im kulturellen Kalten Krieg, in: Graf/Meisinger (Hg.), Österreich, 209-230.

32 Siehe dazu etwa die beiden Pugwash-Konferenzen, die 1958 und 1959 in Österreich stattfanden: Silke Fengler, „Salonbolschewiken“: Pugwash in Austria, 1955-1965, in: Alison Kraft/Carola Sachse (Hg.), Science, (Anti)Communism and Diplomacy. The Pugwash Conferences on Science and World Affairs in Early Cold War, Leiden/Boston 2019, 221-258; Elisabeth Röhrlich, An Attitude of Caution: The IAEA, the United Nations, and the 1958 Pugwash Conference in Austria, in: Journal of Cold War Studies 20 (2018) 1, 31-57.

33 Erwin A. Schmidl, Wien als internationales Zentrum, in: Michael Dippelreiter (Hg.), Wien - Metamorphose einer Stadt, Wien/Köln/Weimar 2013, 703-730; Christian Ehalt/Oliver Rathkolb (Hg.), Wissens- und Universitätsstadt Wien: Eine Entwicklungsgeschichte seit 1945, Wien 2015. 
Stefan Wirlandner). ${ }^{34}$ Nicht nur ihre Exilerfahrungen waren relevant, sondern auch die engen Kontakte etwa zu polnischen Wirtschaftswissenschaftlern, die wie Michał Kalecki als Vordenker des Keynesianismus galten, oder wie Kazimierz Łaski, der, aus dem Umfeld von Kalecki stammend, aufgrund der antisemitischen Kampagne im Jahr 1968 in Polen nach Österreich emigrierte und das 1973 gegründete Wiener Institut für Internationale Wirtschaftsvergleiche (wiiw), das in der Hochzeit der Konvergenztheorie die ökonomischen Entwicklungen in Osteuropa beobachtete, maßgeblich mitprägte. ${ }^{35}$ Das wiiw ist ein weiteres Beispiel für die Ergiebigkeit einer verflechtungsgeschichtlichen Betrachtung des Kalten Krieges: Es wurde von der USamerikanischen Ford Foundation finanziert und bot zugleich österreichischen WissenschaftlerInnen, die sich aus konvergenztheoretischer Perspektive für das östliche Europa interessierten, einen Ort, an dem der Austausch über wirtschaftspolitische Konzepte mit osteuropäischen KollegInnen im Rahmen von Gastaufenthalten und Workshopreihen intensiv geführt werden konnte. ${ }^{36}$ In der Rückschau betrachteten die beteiligten historischen AkteurInnen das wiiw als „Begegnungszentrum“, dem gleichzeitig "Zersetzungsstrategien des Ostens“ zugeschrieben wurden. ${ }^{37}$ Anhand des Spannungsbogens, den diese Bewertungen entfalten, wird schlaglichtartig deutlich, wie ergiebig eine genauere Erforschung transnationaler Netzwerke und transnationaler Wissensvermittlung für eine genauere Perspektivierung dessen sein kann, was mit „Kalter Krieg“ nur unzureichend beschrieben werden kann. Weitere Einrichtungen wie das Institut für Höhere Studien (IHS, geründet 1963), das International Institute for Applied System Analysis (IIASA, gegründet 1972) oder das Institut für die Wissenschaften vom Menschen (IWM, gegründet 1982) unterstreichen die Bedeutung Österreichs und insbesondere Wiens als Ort transnationaler

34 Günther Chaloupek, Die Emigration von Ökonomen in die USA und nach Großbritannien und der Einfluss der Rückwanderer auf Wirtschaftspolitik und Wirtschaftsdenken, in: Michael Mesch (Hg.), Wie kam der Keynesianismus nach Österreich? Wien 2016, 13-44.

35 Jan Toporowski, Kazimierz Łaski, 15 December 1921 - 20 October 2015, in: The Economic and Labour Relations Review 28 (2017) 3, 474-480.

36 Petra Mayrhofer, Rolle der Oesterreichischen Nationalbank bei West-Ost-Transfers im Rahmen des Wiener Instituts für Wirtschaftsvergleiche 1972/73-1991 - Pilot-Recherche, Wien 2015, URL: file:///C:/Users/Admin/Downloads/rolle-der_oesterreichischen_nationalbank_bei_west-osttransfers_mayrhofer\%20(1).pdf (abgerufen 08.05.2020); dies., Forty-five years of wiiw. A look at the founding history of the Vienna Institute for International Economic Studies (wiiw), in: wiiw (Hg.), Monthly Report May 2018, Wien 2018, 2-5, URL: https://wiiw.ac.at/monthly-report-no-52018-dlp-4527.pdf (abgerufen 08.05.2020).

37 Mayrhofer, Rolle, 43. Die Autorin dieser informativen Pilotstudie hat Interviews mit einer Vielzahl mit am wiiw Tätigen geführt, diese Zitate stammen von der ehemaligen wiiw-Geschäftsführerin Ingrid Gazzari und dem seit 1973 mit dem wiiw verbundenen (von 1991-1996 als dessen Direktor) Kazimierz Łaski. 
Austauschbeziehungen. ${ }^{38}$ Im engeren Bereich der Geschichtswissenschaft ist auch die 1964 gegründete International Conference of Social and Labour History (ITH) zu nennen, die es sich zum Ziel gesetzt hatte, den Austausch zwischen HistorikerInnen aus Ost und West zu stärken, die zur Arbeitergeschichte forschten. In methodischer Hinsicht ist hier besonders interessant, dass sich die ITH in den letzten Jahren konsequent einer globalen verflechtungsgeschichtlichen und transnationalen Perspektive verpflichtet hat, die den Eurozentrismus ihrer Entstehungszeit überwunden hat. 39

\section{Transnationalität der Erinnerungskulturen}

Österreichische Zeitgeschichte war seit den 1980er-Jahren zunehmend auch eine Geschichte der Aufarbeitung von Austrofaschismus und Nationalsozialismus sowie der Historisierung dieser Aufarbeitung. Nach 1989 kam eine vergleichende Perspektive in Bezug auf den Umgang mit der kommunistischen Vergangenheit im mittleren und östlichen Europa (aber zum Teil auch mit der Kollaborationsgeschichte und der Geschichte der autoritären Regime in der Zwischenkriegszeit) hinzu und resultierte in Forschungen, die man als "Aufarbeitung der Aufarbeitung“40 bezeichnen kann. Dabei dominierte zunächst vor allem ein vergleichendes, weniger transnationales Forschungsinteresse, das sich in den 200oer-Jahren auch in einer Reihe von Graduiertenkollegs und Forschungsprojekten niederschlug. ${ }^{41}$ In diesem Umfeld sind wichtige Werke entstanden, wie etwas Katrin Hammersteins Arbeit zu den Erinne-

38 Am Institut für Zeitgeschichte der Universität Wien wird seit September 2020 das Projekt „Ideentransfers durch ,Expert Clearing Houses' in Wien" unter der Leitung von Oliver Rathkolb durchgeführt, das sich mit IIASA und IWM beschäftigen wird, URL: https://www.univie.ac.at/zeitgeschichte/ideentransfers-durch-expert-clearing-houses-in-wien/ (abgerufen 08.05.2020).

39 David Mayer/Berthold Unfried, Marcel von der Linden and the International Conference of Social and Labour History (ITH), in: Karl-Heinz Roth (Hg.), On the Road to Global Labour History. A Festschrift for Marcel van der Linden, Leiden/Boston 2017, 17-21. Siehe dazu auch die Zusammenstellung der Konferenzthemen seit 1964 auf der Webseite der ITH, URL: https://www.ith.or.at/ de/themen-ith-konferenzen/?highlight=1964 (abgerufen 27.07.2020).

40 So zuletzt Ilko-Sascha Kowalczuk, Die Aufarbeitung der Aufarbeitung: Welche Zukunft hat die DDR-Geschichte?, in: Indes 2019/1, 107-116.

41 Zu nennen wären hier das Initiativkolleg „Europäische historische Diktatur- und Transformationsforschung" an der Universität Wien sowie das Graduiertenkolleg zu „Diktaturüberwindung und Zivilgesellschaft in Europe“, das an den Universitäten Heidelberg und Wien verankert war, oder das Projekt zu Erinnerungsmustern im Kalten Krieg und zum Zusammenhang von Autoritarismus und demokratischen Dispositionen am Ludwig-Boltzmann-Institut für Europäische Geschichte und Öffentlichkeit, vgl. Oliver Rathkolb/Günther Ogris (Hg.), Authoritarianism, History and De- 
rungsdiskursen in Westdeutschland, der DDR und in Österreich. In einer transnationalen Perspektive gelingt es ihr, bisherige, oftmals holzschnittartige Darstellungen des Umgangs in den drei „Nachfolgestaaten“ sehr viel differenzierter darzustellen und einen Beitrag zu einer Verflechtungsgeschichte im Kalten Krieg zu leisten. ${ }^{42}$ Der Holocaust ist inzwischen vielfach als zentraler Erinnerungsort einer nicht mehr nationalstaatlich segregierten, sondern zunehmend als europäisch bzw. global verfassten Erinnerungslandschaft beschrieben worden. ${ }^{43}$ Dabei sollte bedacht werden, dass nicht nur Erinnerungspraktiken transnationalen Dynamiken unterliegen, sondern dass der Faschismus und der Nationalsozialismus selbst in ihren transnationalen Dimensionen beschrieben werden können. Neuere Forschungen zeigen, dass gerade das Ausgreifen des Nationalsozialismus in das östliche und südöstliche Europa an ältere deutsche/deutsch-österreichische Raumkonzepte anschließen und diese etwa in Form eines „Großwirtschaftsraumes“ für die nationalsozialistische Kriegsführung adaptieren konnte. ${ }^{44}$ Hier ist Philipp Gassert zuzustimmen, dass die transnationale Geschichte die negativen Seiten transnationaler Netzwerke und Verflechtungen nicht aus den Augen verlieren dürfe und dass neben der Transnationalität der Erinnerungen an den Holocaust auch die Transnationalität seiner Durchführung und deren Folgen reflektiert werden müssten. ${ }^{45}$

Das Ende des Kalten Krieges brachte auch die Rückkehr vorsozialistischer Gedächtnismuster. Hier hat die Forschung zeigen können, dass gerade die Aufeinan-

mocratic Dispositions in Austria, Poland, Hungary and the Czech Republic, Innsbruck/Wien/Bozen 2010.

42 Katrin Hammerstein, Gemeinsame Vergangenheit - getrennte Erinnerung? Der Nationalsozialismus in Gedächtnisdiskursen und Erinnerungskonstruktionen von Bundesrepublik Deutschland, DDR und Österreich, Göttingen 2017.

43 Zuletzt dazu etwa Heidemarie Uhl, Der Holocaust als europäischer Erinnerungsort. Alte und neue Konflikte um eine gemeinsame EU-Gedächtniskultur, in: Barbara Mariacher/Jattie Enklaar/Evelyne Tax (Hg.), Eurovisionen: Europa zwischen Globalisierung und Polarisation: Innen- und AuBenansichten von Europa in Literatur, Geschichte und Philologie, Würzburg 2019, 61-70.

44 Carola Sachse (Hg.), „Mitteleuropa“ und „Südosteuropa“ als Planungsraum: wirtschafts- und kulturpolitische Expertisen im Zeitalter der Weltkriege, Göttingen 2010; Johannes Dafinger/Dieter Pohl (Hg.), A New Nationalist Europe Under Hitler. Transnational Networks in the National Socialist Sphere of Influence, 1939-1945, London/New York 2019; zu diesem sich dynamisch entwickelnden Forschungsfeld siehe auch die Sammelrezension von Angel Alcalde, The Transnational Consensus: Fascism and Nazism in Current Research, in: Contemporary European History 29 (2020) 2, 243-252.

45 Philipp Gassert, Rezension von Akira Iriye/Pierre-Yves Saunier (Hg.), The Palgrave Dictionary of Transnational History. From the Mid-19th Century to the Present Day, Basingstoke 2009, in: sehepunkte 11 (2011) 4, URL: https://www.recensio.net/rezensionen/zeitschriften/sehepunkte/11/o4/ the-palgrave-dictionary-of-transnational-history (abgerufen 08.05.2020). 
derbezogenheit von Erinnerungen im durch den Kalten Krieg getrennten Europa und die fortdauernde Valenz von Stereotypen, die aus der Zeit vor dem Zweiten Weltkrieg herrührten, transnationale Geschichte, die auch auf die Verschränkung von Zeitebenen eingeht, zu einem interessanten Unterfangen machen. ${ }^{46}$ Besonders überzeugend wird der Ansatz einer transnationalen Geschichte erprobt, wenn die lokalen, nationalen und transnationalen Bezugsebenen in ihren Austauschbeziehungen dargestellt werden, etwa wenn die Gedenkpraktiken im Wiener öffentlichen Raum als Teil von transnationalen Akteurs- und Wissensnetzwerken verstanden und lokale Aktionen mit übernationalen Erinnerungsformen „synthetisiert“ werden. ${ }^{47}$ Hier wird auch deutlich, dass Transnationalisierungsprozesse nicht per se an progressive politische Praktiken geknüpft sein müssen. So etablierte sich seit 1950 eine sich vom Faschismus abgrenzende österreichische Erinnerungskultur, die den Nationalstaat als zentralen Bezugsrahmen entdeckte. Dagegen huldigen rechtsnationalistische Akteure einer großdeutschen Erinnerungskultur, die in Widerspruch zur nationalstaatlich gerahmten offiziellen Gedenkkultur steht. In Reaktion wiederum auf das reaktivierte Paradigma der ,Volksgemeinschaft“ transformiert sich die offizielle Gedenkkultur, indem nun stärker als zuvor nicht die Kriegsopfer und die Wiederaufbauleistung der ÖsterreicherInnen betont werden, sondern das sich integrierende Europa als Fluchtpunkt der Nachkriegsentwicklung perspektiviert wird. ${ }^{4}$

Ebenfalls ,verortet" und gleichermaßen transnationalisiert wird die Erinnerungskultur in den zahlreichen Beiträgen zu Ausstellungspraktiken im gegenwärtigen Österreich. Stellvertretend für eine Vielzahl von Publikationen sei hier eine der neuesten von Heidemarie Uhl und Liljana Radonic genannt, die dieses Forschungsfeld kartiert und methodisch unterfüttert haben. Ihr jüngst erschienener Sammelband, dessen BeiträgerInnen sich mit zeithistorischen Ausstellungen beschäftigen, macht eindrücklich deutlich, wie stark im 21. Jahrhundert Museumsnarrative durch die Wechselwirkungen von lokalen und nationalen Erinnerungskulturen, durch transnationale Netzwerke und nicht zuletzt durch die erinnerungskulturellen Folgen von

46 Berthold Molden, Transnationale Repräsentationsmuster im Gedächtnis des Kalten Krieges. Fünf Thesen zur europäischen Zeitgeschichtsforschung, in: Linda Erker/Alexander Salzmann/Lucile Dreidemy/Klaudija Sabo (Hg.), Update! Perspektiven der Zeitgeschichte. Zeitgeschichtetage 2010, Innsbruck/Wien/Bozen 2012, 443-448 und Gerbel, Christian, Transnationale vs. nationale Erinnerungsmodi an den Zweiten Weltkrieg und den Holocaust in Österreich, Polen, Ungarn und Tschechien, in: Erker/Salzmann/Dreidemy/Sabo (Hg.), Update, 449-455.

47 Peter Pirker/Johannes Kramer/Mathias Lichtenwagner, Transnational Memory Spaces in the Making: World War II and Holocaust Remembrance in Vienna, in: International Journal of Politics, Culture, and Society 32 (2019) 2, 439-458.

48 Ebd., 456. 
umfassenden Migrationsprozessen geprägt sind. ${ }^{49}$ Auch hier könnte man sich wünschen, dass diese Forschungen auch auf konzeptuelle Anregungen zurückgreifen, die am Beispiel der Habsburgermonarchie entwickelt wurden und Fragen nach deren Nachwirkung in Gedächtniskulturen in einer postkolonialen Perspektive stellen. ${ }^{50}$

\section{Rück- und Ausblick}

In seinem Zwischenfazit zum Standort der transnationalen Geschichte nach einem guten Vierteljahrhundert erinnert Kiran Patel daran, dass Geschichtsschreibung immer auch politische Implikationen habe. In den USA etwa positionierte sich die transnationale Geschichte gerade in ihren Anfängen in den 1990er-Jahren deutlich gegen das Paradigma des Exzeptionalismus, vor dessen Hintergrund die US-amerikanische Geschichte losgelöst von ihren globalen Verflechtungen als selbstbezogene nationale Heilsgeschichte erzählt werde, auch wenn diese Heilsgeschichte gerade durch eine vergleichende (aber eben nicht verflechtende) Perspektive genauer konturiert werde. Zudem betont Patel, dass für die transnationale Geschichte Territorialität als Kategorie, die historisches Wissen ordne, weniger wichtig sei als andere fluidere Raumkonzepte. ${ }^{51}$ Beide Beobachtungen laden dazu ein, über die Verfasstheit der österreichischen Zeitgeschichte nachzudenken. Bei dieser fällt auf, dass lange der Fokus auf Periodisierungen dominierte, die 1933/1934-1945 einhegten.52 Befördert wurde diese Fixierung durch den Wunsch nach 1945, eine österreichische Nationalität zu schaffen, die es ermöglichte, als demokratische, in die Zukunft ausschreitende Nation bzw. als „österreichisches“ Opfer eines „deutschen“ Aggressors Teile der eigenen Geschichte hinter sich zu lassen. Die Dominanz einer sich vor diesem

49 Ljiljana Radonic/Heidemarie Uhl (Hg.), Das umkämpfte Museum: Zeitgeschichte ausstellen zwischen Rekonstruktion und Sinnstiftung (Erinnerungskulturen/Memory Cultures 8), Bielefeld 2020; zur Verknüpfung von Migrationen und Transformation von Erinnerungskulturen siehe auch die unveröffentlichte Doktorarbeit von Linda L. Jakubowicz, Auf dem Weg zu einer transnationalen Erinnerungskultur: zur historischen Sichtbarkeit von (Arbeits-)MigrantInnen am Beispiel der „GastarbeiterInnen“ aus dem ehemaligen Jugoslawien, phil. Diss., Universität Wien 2017.

50 Johannes Feichtinger/Ursula Prutsch/Moritz Csáky (Hg.), Habsburg Postcolonial: Machtstrukturen und Kollektives Gedächtnis, Innsbruck/Wien/München/Bozen 2003.

51 Kiran Klaus Patel, An Emperor Without Clothes? The Debate About Transnational History Twentyfive Years on, in: Histoire@Politique 26/2015, 1-16, 8-9, URL: https://www.histoire-politique.fr/ documents/26/pistes/pdf/HP26-Pistesetdebats_Kiran_Patel_def.pdf (abgerufen 08.05.2020).

52 Thomas Angerer, An Incomplete Discipline: Austrian Zeitgeschichte and Recent History, in: Günter Bischof/Anton Pelinka/Rolf Steininger (Hg.), Austria in the Nineteen Fifties (Contemporary Austrian Studies 3), New Brunswick 1995, 207-251, 208-211. 
spezifischen Hintergrund herausbildenden, auf das Territorium der Zweiten Republik fixierten Perspektive hatte somit zunächst außerwissenschaftliche Ursachen. Wenn Räume adressiert wurden, dann eher als feststehende „Untersuchungsebenen“ bzw. als von Vertretern der transnationalen Geschichte kritisierte „Container".53 So nimmt sich etwa Michael Gehler in seiner „Zeitgeschichte im Mehrebenensystem“ vor, „Zeitgeschichte im Verhältnis von Region, Nationalstaat, internationalen Beziehungen, europäischer Dimension und Globalisierung “ zu untersuchen, ${ }^{54}$ aber wie diese Ebenen erst durch Interaktionen hergestellt werden und wie der Begriff des Transnationalen dabei zu konzeptualisieren ist, bleibt offen. ${ }^{55}$ Folgerichtig spielt in dieser Studie aus dem Jahr 2001 Transnationalität als Forschungsperspektive keine Rolle. ${ }^{56}$ Einige Jahre später jedoch hat unter anderem die historische Netzwerkforschung den Blick für die Bedeutung für die Offenheit von Räumen und die Bedeutung von Akteurshandeln geschärft, wie man deutlich an den auf österreichische AkteurInnen bezogenen Beiträgen in einem Band zur regionalen europäischen Integration nachlesen kann. ${ }^{57}$

Interessanterweise wurde seit den 1990er-Jahren, als die über vierzig Jahre lang stabilen Grenzen in Europa durch den Zusammenbruch des Ostblocks in Bewegung gerieten, auch in der Politik eine verkürzte Perspektive auf nationalstaatliche Territorialität seit 1945 bzw. seit der Wiedererlangung der Souveränität 1955 kritisch betrachtet. So konstatiert etwa Erhard Busek, dass das nationalstaatliche Denken in der Gegenwart „jegliche politische Handlungskompetenz“ eingebüßt habe. Er verweist darauf, dass nach dem Ende der Blockkonfrontation sich alte Raumordnungen aufgelöst hätten und dass daher dringend eine Selbstverständigung über den Ort Österreichs, dem er eine „Schnittpunkt-Identität“ bescheinigt, geführt werden müsse. ${ }^{88}$

53 Patel, Emperor, 6; Bernhard Struck/Kate Ferris/Jacques Revel, Introduction: Space and Scale in Transnational History, in: The International History Review 33 (2011) 4, 573-584, 573-574.

54 Michael Gehler, Zeitgeschichte im Mehrebenensystem, Zwischen Regionalisierung, Nationalstaat, Europäisierung, internationaler Arena und Globalisierung, Bochum 2001, 11-12.

$55 \mathrm{Zu}$ den Interaktionen zwischen den räumlichen Ebenen und der Konturierung von Raumkonzepten durch Interaktion vgl. Struck/Ferris/Revel, Introduction, 576.

56 Der Begriff Transnationalismus taucht nur einmal im Zusammenhang mit ,transnationaler Parteienkooperation“" auf, wird aber nicht erläutert, vgl. Gehler, Zeitgeschichte, 154.

57 Oliver Rathkolb, Brandt, Kreisky and Palme as Policy Entrepreneurs: Social Democratic Networks in Europe's Policy Towards the Middle East, in: Wolfram Kaiser/Brigitte Leucht/Michael Gehler (Hg.), Transnational Networks in Regional Integration: Governing Europe, 1945-1983, Houndsmill 2010, 152-175; Michael Gehler, On the Long and Winding Road to European Union Membership: Austrian Party Elites in Transnational Political Networks, in: Kaiser/Leucht/Gehler (Hg.), Networks, 199-220.

58 Erhard Busek, Gedanken zur Europäischen Identität Österreichs, in: Bundesministerium für Wissenschaft und Forschung (Hg.), Grenzenloses Österreich. Symposium, April 1994. Dokumentation 1, Wien 1994, 9-14, 10, 12. 
Die Forschungsergebnisse aus diesem Projekt behandeln jedoch weniger die historischen Voraussetzungen und Konstruktionsprozesse dieser "Schnittpunkt-Identität“, sondern eher das „Österreichische" in sich wandelnden historischen (und erneut recht statischen) Kontexten nach $1945 . .^{59}$ Wenn man auf die eingangs erwähnte Kontroverse um die österreichische Zeitgeschichte, die sich um Ernst Hanischs Gesellschaftsgeschichte Mitte der 1990er-Jahre entzündet hatte, zurückkommt, könnte man Albert Müller zitieren, für den „Staats- und Nationalgeschichte“ nicht mehr "paradigmatisierbar" zu sein schienen bzw. nur insoweit weiter Nationalgeschichte geschrieben werden könne, wenn durch sie wie im Falle der Bundesrepublik Deutschland mit der Sonderwegsdebatte eine konsensfähige Problembeschreibung vorliege. ${ }^{60}$ Diese Stellungnahme ist hochinteressant für das Thema des vorliegenden Beitrags: Gerade die Perspektivierung der deutschen Geschichte als transnationale Geschichte hat deutlich gemacht, dass der „Sonderweg“ viel von seiner „konsensfähigen“"Erklärungskraft eingebüßt hat. Indem das Deutsche Reich vor 1914 sowohl in seinen globalgeschichtlichen als auch europäischen Austausch- und Verflechtungsbeziehungen in den Blick genommen wurde, erschien seine Sonderstellung sehr viel weniger evident. ${ }^{61}$ Der Abschied von der Sonderwegsthese erfolgte tatsächlich in einer Zeit, als das Paradigma der Nationalgeschichte seinen Alleinstellungscharakter verloren hatte und andere Paradigmen - wie etwa die transnationale Geschichte an Bedeutung gewannen. Heute, etwa zwei Jahrzehnte später, ist die vor allem in der Politik nach 1989 verbreitete Euphorie über ein zusammenwachsendes Europa, in dem die Nation an Bedeutung verlieren werde, verflogen. Gleichzeitig hat aber eine transnationale Zeitgeschichtsschreibung in den vergangenen Jahren deutlich gemacht, dass innovative Fragestellungen vor allem im variablen Spiel mit unterschiedlichen räumlichen Bezugsebenen entwickelt werden können, die sich weniger an festen Räumen als an raumschaffenden Praktiken und Prozessen orientieren. So könnte man abschließend die Frage stellen, ob die Perspektive einer transnationalen Geschichte Österreichs überhaupt noch sinnvoll gestellt werden kann - und ob nicht vielmehr die Geschichte historischer Gegenstände zum Ausgangspunkt genommen

59 Max Haller (Hg.), Identität und Nationalstolz der Österreicher. Gesellschaftliche Ursachen und Funktionen. Herausbildung und Transformation seit 1945. Internationaler Vergleich, Wien 1996.

60 OeZG-Redaktion, Schatten, 116.

61 Siehe dazu etwa Sebastian Conrad, Doppelte Marginalisierung. Plädoyer für eine transnationale Perspektive auf die deutsche Geschichte, in: Geschichte und Gesellschaft 28 (2002) 1, 145-169; Philipp Ther, Deutsche Geschichte als imperiale Geschichte. Polen, slawophone Minderheiten und das Kaiserreich als kontinentales Empire, in: Sebastian Conrad/Jürgen Osterhammel (Hg.), Das Kaiserreich transnational. Deutschland in der Welt 1871-1914, Göttingen 2004, 129-148. 
werden sollte, die dann in relationale räumliche Gefüge eingebettet werden, unter denen auch irgendeine Form von Österreich sein kann. ${ }^{62}$

62 Diese grundsätzliche Erwägung verdanke ich der klugen Kommentierung dieses Textes durch meine Wiener Kollegin Katharina Kreuder-Sonnen. 


\section{Public History}

Stefan Benedik und Lisbeth Matzer

Ein Historienprofessor, der jeden Tag sein vegetarisches Jausenpaket auspackt und darin nach Eßbarem wühlt, kann sich das natürlich nicht vorstellen. ${ }^{1}$

Wenn in allen Bereichen der Verhandlung von gesellschaftlich-kulturellem Wissen gerade ein Gerangel um die Buzzwords „Transfer“, „Public Outreach“ oder „Science to Public" entsteht, könnten sich ZeithistorikerInnen besonders in Österreich eigentlich entspannt zurücklehnen, haben sie doch viele Vermittlungsoptionen etabliert und die Agenda der Kommunikation an breite Öffentlichkeiten als eine der Kernaufgaben seit Beginn der Fachentwicklung verfolgt. Dennoch kommt das Konzept Public History unter diesem Namen erst in jüngster Zeit hier an. ${ }^{2}$ In diesem Beitrag fragen wir, ob dieser Widerspruch mit österreichischen Spezifika zu tun hat, die wir anhand von wenigen Beispielen oft aus den produktiven Rändern von Wissenschaft und/oder öffentlicher Auseinandersetzung diskutieren.

Dabei ist für uns ein radikal multiperspektivisches, offenes und demokratisches Verständnis von Public History leitend, ${ }^{3}$ das nicht entweder die Forschung über oder die Praxis von Geschichtsvermittlung durch ausgebildete HistorikerInnen meint. ${ }^{4}$ Vielmehr verstehen wir unter Public History sämtliche an nichtfachwissen-

$1 \quad$ Elfriede Jelinek, Die Kontrakte des Kaufmanns/Rechnitz (Der Würgeengel)/Über Tiere. Drei Theaterstücke, Hamburg 2009, 94.

2 Vgl. Christoph Kühberger (Hg.), Vergangenheitsbewirtschaftung, Public History zwischen Wirtschaft und Wissenschaft, Innsbruck/Wien 2012 sowie den 2017 veröffentlichten Call für einen Sammelband, der von Marion Großmann, Thomas Hellmuth und Thomas Walach herausgegeben werden wird, URL: https://www.hsozkult.de/event/id/termine-34234 (abgerufen 14.05.2020).

3 Vgl. Frank Bösch/Constantin Goschler, Der Nationalsozialismus und die deutsche Public History, in: Frank Bösch/Constantin Goschler (Hg.), Public History. Öffentliche Darstellungen des Nationalsozialismus jenseits der Geschichtswissenschaft, Frankfurt a. M./New York 2009, 8-10; David Dean (Hg.), A Companion to Public History, Hoboken 2018; Martin Lücke/Irmgard Zündorf, Einführung in die Public History, Göttingen 2018; IFPH-FIHP, URL: https://ifph.hypotheses.org/ (abgerufen 14.06.2020).

4 Vgl. Lücke/Zündorf, Einführung, 21-24. Bereits am Österreichischen Zeitgeschichtetag 1995 waren außeruniversitäre Beschäftigungsfelder ein Thema, vgl. Gerhard Botz/Paul Kellermann/Ulrike 
schaftliche und sehr unterschiedliche Öffentlichkeiten gerichtete (institutionelle wie temporäre, experimentelle wie etablierte) geschichtsvermittelnde Formate und Prozesse, deren AkteurInnen, Zugangsweisen und Zielsetzungen implizit oder explizit immer die Abgrenzung von akademischen zu außeruniversitären Feldern überwinden und damit konstruktiv irritieren - gerade auch, weil Menschen unabhängig von ihrem Verhältnis zum Wissenschaftsbetrieb Sprecherpositionen einnehmen können. ${ }^{5}$ Idealerweise sind Projekte der Public History für uns somit auch möglichst demokratische und partizipative Prozesse, die ihre eigenen Intentionen offenlegen und den TeilnehmerInnen Möglichkeiten erschließen, analytische Werkzeuge zur Kontextualisierung historischer wie gegenwärtiger Strukturen und Ereignisse sowie zur Decodierung von deren Medialisierung zu entwickeln bzw. zu schärfen und Repräsentationen von Geschichte damit zu hinterfragen. Dass solche Ansprüche zur Demokratisierung in unlösbarem Konflikt zu hegemonialen Wissenschaftsverständnissen stehen, deren konstitutive Hierarchisierung durch die stärker interaktiven Medien der Public History teils erschüttert werden, zeigt das Eingangszitat Elfriede Jelineks, das als Destabilisierung der aus Neutralität und Distanz gewonnenen Autorität der Figur des Historikers durch die Konfrontation mit einer (durch Authentifizierung vermeintlich abgesicherten) Erfahrung oder Emotion verstanden werden kann. Referenziert wird damit der Konflikt um Deutungshoheit zwischen Wissenschaft und (Zeit)ZeugInnen, zwischen akademischer und erfahrungsbasierter Expertise, der dem Feld der Public History eingeschrieben ist. Das Zitat spricht auch die Ungleichheit der Werkzeuge, Agenden und Perspektiven an, wenn FachwissenschaftlerInnen einer nicht selten auf Effekt und Voyeurismus bis hin zur Gewaltpornographie getrimmten Geschichtsindustrie gegenüberstehen.

Von der Institutionalisierung von Zeitgeschichte an den Universitäten ab Mitte der 1960er-Jahre ${ }^{6}$ bis zur Ausschreibung der ersten Professur für Public History in

Gschwandtner/Peter Lachnit/Karl Stocker, „Geschichte als Beruf“. ZeitgeschichtlerInnen und neue Berufsfelder, in: Rudolf G. Ardelt/Christian Gerbel (Hg.), Österreichischer Zeitgeschichtetag 1995. Österreich - 50 Jahre Zweite Republik, Innsbruck/Wien 1997, 521-544; Gerhard Botz/Ulrike Gschwandtner, Angewandte Geschichte, Wien 2001, URL: https://bit.ly/2 $\mathrm{C}_{35} \mathrm{Ihz}$ (abgerufen 14.06.2020).

5 David Dean formulierte diese Irritation im Zusammenhang mit Machtverhältnissen in der Wissensproduktion folgendermaßen: „Public history is not only about the history that publics receive and consume; it is also about the history that publics make." David Dean, Introduction, in: David Dean (Hg.), A Companion to Public History, Hoboken 2018, 1-11, 4. Als AutorInnen sprechen wir in diesem Beitrag als ZeithistorikerInnen auch aus der Position von Museumsarbeit im Haus der Geschichte Österreich (Benedik) und der historischen Erwachsenenbildung (Matzer).

6 Zur Entwicklung des Faches Zeitgeschichte in Österreich vgl. etwa: Helmut Konrad, Von Linz aus. Die Formierung der österreichischen Zeitgeschichte, in: Heinrich Berger/Melanie Dejnega/Regina 
Österreich an der Universität Wien $2018^{7}$ und noch weiter sind Überschneidungen und Widersprüche zwischen dem öffentlichem Anspruch der Zeitgeschichtsforschung in Österreich und ihren marginalisierenden Tendenzen zu verfolgen; unser Beitrag greift im Folgenden einige Entwicklungsstränge heraus, wobei wir eine nicht auf Vollständigkeit, sondern auf Vielfalt zielende Auswahl aus verschiedenen, an breite Öffentlichkeiten gerichtete Formate getroffen haben und fragen, was „öffentliche Zeitgeschichte" in Österreich bedeuten kann bzw. was ihre ermächtigenden und demokratisierenden Potenziale sind - und warum sie so selten (wirksam) genutzt werden.

\section{These 1: Public History war in Österreich oft eine Leistung der Zeitgeschichtsforschung}

Das Verhältnis zwischen (universitärer) Zeitgeschichtsforschung und Öffentlichkeiten im Sinne einer Public-History-Praxis ist mit Irritation und Produktivität beschreibbar. Es unterscheidet sich wesentlich von der von gegenseitiger Abwertung und gleichzeitiger Notwendigkeit der Koexistenz gekennzeichneten Beziehung zwischen Wissenschaft und Öffentlichkeiten allgemein. ${ }^{8}$ Eines der Distinktionsmerkmale des Fachs - besonders in Österreich - und teils auch des Selbstverständnisses einzelner ForscherInnen ist die Haltung, Forschung wiederholt einer Öffentlichkeit auszusetzen und dadurch legitimieren zu lassen. ${ }^{9}$ Trotzdem bleibt durch die kennzeichnende Hierarchiedifferenz zwischen ForscherInnen und Publikum das Potenzial einer breiten Diskussion über Wissenschaft meist ungenutzt.

Darin spiegeln sich die gegensätzlichen Paradigmen des aufklärerisch-erzieherischen Anspruchs einerseits und des revolutionär-demokratisierenden andererseits, die tief in die Entwicklungsgeschichte von Zeitgeschichtsforschung in Österreich

Fritz/Alexander Prenninger (Hg.), Politische Gewalt und Machtausübung im 20. Jahrhundert. Zeitgeschichte, Zeitgeschehen und Kontroversen. Festschrift für Gerhard Botz, Wien 2011, 47-57 oder den 30. Jubiläumsband der Zeitschrift „zeitgeschichte“: zeitgeschichte 30 (2003) 6.

7 Vgl. Ausschreibung der Universitätsprofessur für Public History, Universität Wien, URL: https:// bit.ly/2W9dMUQ (abgerufen 25.11.2018). Zum Zeitpunkt der Fertigstellung des vorliegenden Beitrags war die Professur noch nicht besetzt.

8 Vgl. Lücke/Zündorf, Einführung.

9 Vgl. Institut für Zeitgeschichte, Public History, Universität Innsbruck, URL: https://www.uibk.ac.at/ zeitgeschichte/medienspiegel/ (abgerufen 15.06.2020); Institut für Zeitgeschichte, Medienspiegel, Universität Wien, URL: https://www.univie.ac.at/zeitgeschichte/aktuell/medienspiegel/ (abgerufen 15.06.2020). Oder Pars pro Toto: Curated by ... Oliver Rathkolb, Österreichische Mediathek, URL: https://www.mediathek.at/meine-mediathek-curated-by/oliver-rathkolb/ (abgerufen 15.06.2020). 
eingeschrieben sind. Das zuerst genannte Paradigma ist im Verständnis von Zeitgeschichte als unidirektionale, top-down angelegte, universitäre Erziehungsinstanz abgebildet, die besonders in der Zeit ihrer Institutionalisierung der 196oer- bis 1980er-Jahre als elitäres, aufklärendes Korrektiv einer irregeleiteten postfaschistischen Mehrheitsgesellschaft eingerichtet wurde.

Daneben trat spätestens ab den 1980er-Jahren der in der Traditionslinie der Arbeitergeschichtsschreibung verhaftete Anspruch, Zeitgeschichtsforschung als Sprachrohr einer breiten, aber ignorierten Gesellschaftsschicht zu verstehen und demokratisch(er) zu praktizieren. ${ }^{10}$ Plakativ ausgedrückt wurde daraus nie ein $\mathrm{Pa}$ radigmenwechsel, befinden sich ZeithistorikerInnen öffentlich doch weiterhin meist in der Rolle von ExpertInnen oder ziehen sich auf diese zurück - die durch Oral History und Geschichtswerkstätten entwickelten Funktionen als ModeratorInnen und Zuhörende bleiben weitgehend ungenutzt. Der in einem breiten Verständnis von Public History integral verhafteten Auffassung, dass diese auch eine von einer nichtuniversitären Öffentlichkeit (mit)geschriebene Geschichte ${ }^{11}$ sein könnte, stehen in der Wissenschaft Vorbehalte entgegen, die aus dem aufklärerischen Anspruch stammen, aber durch damit verbundenen Elitismus und Hierarchiedenken im Kern antidemokratisch sind.

Wir beginnen hier mit dieser Reflexion, weil wir im Folgenden behaupten, dass Zugänge, die bereits ab den 1970er-Jahren im US-amerikanischen Wissenschaftsbetrieb und ab den 2oooer-Jahren auch außerhalb des angloamerikanischen Sprachraums mit dem Neologismus der Public History ${ }^{12}$ beschrieben wurden und werden, ebenso früh in den wissenschaftlichen Aktivitäten zu zeithistorischen Themen in Österreich, wo dieses Fach als öffentliches Projekt verstanden wurde und wird, präsent waren. ${ }^{13}$ Immerhin gründet die Legitimation des Fachs Zeitgeschichte vor allem für dessen „dritte Generation“ wesentlich in einem Aufklärungs- oder sogar

10 Vgl. Konrad, Linz; Erika Weinzierl, Aufgaben und Methoden der österreichischen Zeitgeschichte, in: Erich Zöllner (Hg.), Österreichs Erste und Zweite Republik. Kontinuität und Wandel ihrer Strukturen und Probleme, Wien 1985, 5-16; Ingrid Bauer, Kontinuitäten und Transformation. Die österreichische Zeitgeschichtsforschung im Generationenvergleich, in: zeitgeschichte 30 (2003) 6, 320-340.

11 Vgl. Dean, Introduction, 4.

12 Für einen Abriss der Begriffs- und Fachgeschichte der Public History vgl. Lücke/Zündorf, Einführung.

13 Vgl. Weinzierl, Aufgaben; Johanna Gehmacher, Am Rand der Geschichte. Zeitgeschichte und ihre Marginalisierungen - Anmerkungen aus der österreichischen Perspektive, in: zeitgeschichte 32 (2005) 5, 301-322. Für eine Übersicht vgl. Alexander Nützenadel/Wolfgang Schieder (Hg.), Zeitgeschichte als Problem. Nationale Traditionen und Perspektiven der Forschung in Europa, Göttingen 2004. 
Dienstleistungsverständnis gegenüber einer breiten Bevölkerung. ${ }^{14}$ Öffentlichkeitswirksame Formate von Public History, die außerhalb von Universitäten entstanden, wurden hingegen in der Forschungs-Community unter ihrem Wert verkauft oder kaum zum Gegenstand von wissenschaftlicher Auseinandersetzung gemacht, wie die Rezeption der ikonischen Fernsehdokumentationsreihen „Österreich II“ (19821986) und „Österreich I“ (1987-1989) von Hugo Portisch und Sepp Riff vor Augen führt. ${ }^{15}$ Dieser Meilenstein der Public History in Österreich ist nur vereinzelt wissenschaftlich untersucht worden, ${ }^{16}$ obwohl andere Fernseh- und Filmproduktionen äußerst ertragreich bearbeitet worden sind. ${ }^{17}$ Ein analoges Beispiel sind die Publikationen Brigitte Hamanns, deren Forschungsergebnisse von der österreichischen Scientific Community umso weniger wahrgenommen geworden zu sein scheinen, je größer die populäre Rezeption ihres Werks per se wurde. ${ }^{18}$ Diese Missachtung scheint vor allem kommerzielle Public History zu betreffen, denn neue Formen der Geschichtsvermittlung im Film- und Fernseh-, Literatur-, Tourismus- und Marke-

14 Vgl. Siegfried Mattl, Nicht eine, sondern viele Zeitgeschichten. In Annahme einer „dritten“ Generation, in: zeitgeschichte 30 (2003) 6, 357-366, 357 .

15 Dahinter steht keine grundsätzliche Skepsis gegenüber den Formaten, wie Kooperationsprojekte von ORF und Universität schon früh zeigen, etwa "Zeitgeschichte im Aufriß" zu 25 Jahren Staatsvertrag, vgl. Peter Dusek/Anton Pelinka/Erika Weinzierl, Zeitgeschichte im Aufriß. Österreich von 1918 bis in die achtziger Jahre, Wien 1981. Dazu grundsätzlich: Renée Winter, Mediale Öffentlichkeit und Legitimierung. Kooperationen des frühen Instituts für Zeitgeschichte mit dem österreichischen Fernsehen, in: Bertrand Perz/Ina Markova (Hg.), 50 Jahre Institut für Zeitgeschichte der Universität Wien 1966-2016, Wien 2017, 137-148.

16 Vgl. Renée Winter, Geschichtspolitiken im Fernsehen. Repräsentationen des Nationalsozialismus im frühen österreichischen TV (1955-1970), Bielefeld 2014, 16-17.

17 Vgl. etwa: Johanna Gehmacher, Frauen, Männer, Untergänge. Geschlechterbilder und Gedächtnispolitiken in Darstellungen zum Ende des ,Dritten Reiches, in: Johanna Gehmacher/Gabriella Hauch (Hg.), Frauen- und Geschlechtergeschichte des Nationalsozialismus. Fragestellungen, Perspektiven, neue Forschungen, Innsbruck/Wien/Bozen 2007, 240-256; Renée Winter, Interventions. Options for Action Against Antisemitic Violence in the 1965 TV Play An der schönen blauen Donau, in: Judith Keilbach/Béla Rásky/Jana Starek (Hg.), Völkermord zur Prime-Time. Der Holocaust im Fernsehen, Wien/Hamburg 2019, 193-203; Drehli Robnik, What shall the history books read?' Zur politischen Geschichtsästhetik von Tarantinos ,Inglourious Basterds', in: Hermann Kappelhoff/David Gaertner/Cilli Pogodda (Hg.), Mobilisierung der Sinne. Der Hollywood-Kriegsfilm zwischen Genrekino und Historie, Berlin 2013, 43-60; Tobias Ebbrecht-Hartmann, Blind Spots, in the Present. The National Socialist past in recent Austrian films, in: zeitgeschichte 46 (2019) 4 , 535-555.

18 Deutsche Kollegen hingegen lobten Hamanns Buch „Hitlers Wien - Lehrjahre eines Diktators“ als „Standardwerk“, das sich durch „größte [...] quellenkritische [...] Sorgfalt“ auszeichne, vgl. Andreas Wirsching, Hitlers Authentizität, Eine funktionalistische Deutung, in: Vierteljahreshefte für Zeitgeschichte 64 (2016) 3, 388-417; Brigitte Hamann, Hitlers Wien. Lehrjahre eines Diktators, München/Zürich 1998. 
tingbereich oder Spiel ${ }^{19}$ nimmt die österreichische Zeitgeschichte einerseits nur begrenzt wahr, während sie andererseits im nichtkommerziellen Bereich entscheidend zur Weiterentwicklung von Public History beiträgt. ${ }^{20}$

Dieses innovative Potenzial des Fachs zeigt sich schon seit den 1960er-Jahren in der Herausbildung neuer publizistischer, musealer und vortragsartiger Formate allesamt nichtkommerziell und ausgerichtet am erzieherisch-aufklärerischen $\mathrm{Pa}$ radigma. Das für die Public History so ertragreiche Dokumentationsarchiv des österreichischen Widerstandes (DÖW) wurde noch vor der Etablierung der universitären Zeitgeschichte gegründet und entwarf mit seinem vielschichtigen Charakter als Forschungsinstitution, Sammlung, Museum, Serviceeinrichtung, ja sogar Selbst- und Interessensvertretung, zeitgeschichtlich orientiertes Handeln als sich ständig entwickelnden Möglichkeitsraum. ${ }^{21}$ Die Konjunktur historischer Themen in der sich zur gleichen Zeit neu positionierenden Erwachsenenbildungslandschaft Österreichs, getragen von verschiedenen (politischen und/oder konfessionell orientierten) Einrichtungen, brachte hingegen ein stabiles, bestimmendes Format hervor: den Vortrag zeithistorischer ExpertInnen mit anschließender Diskussion. ${ }^{22}$ Als sich die Zeitgeschichtsforschung ab den frühen 1980er-Jahren zunehmend im Sinne des demokratischen Paradigmas positionierte, wurden neue Formate in Österreich vor allem aufbauend auf die Erwachsenenbildung entworfen: die Geschichtswerk-

19 Vgl. zum internationalen Kontext: Jerome de Groot, Consuming History. Historians and heritage in contemporary popular culture, New York 2009; Charlotte Linde, Working the Past. Narrative and Institutional Memory, New York 2009; Rulf Jürgen Treidel, Historische Erfahrungen im Urlaub. Vom Tagesausflug zur Studienreise, in: Sabine Horn/Michael Sauer (Hg.), Geschichte und Öffentlichkeit. Orte - Medien - Institutionen, Göttingen 2009, 103-111.

20 Vgl. Blaustrumpf ahoi! (Hg.), „Sie meinen es politisch!“, 100 Jahre Frauenwahlrecht in Österreich: Geschlechterdemokratie als gesellschaftspolitische Herausforderung, Wien 2018; Lexikon zur österreichischen Zeitgeschichte, hdgö, URL: https://lexikon.hdgoe.at/ (abgerufen 28.06.2020); zur langen Tradition solcher Kooperationen vgl. exemplarisch Andreas Novak/Oliver Rathkolb (Hg.), Die Macht der Bilder. 50 Jahre Rundfunkreform, Berndorf 2017; Winter, Öffentlichkeit; einzig im Feld der Unternehmensgeschichte hat sich mit History Marketing bisher auch ein weiteres universitär akzeptiertes, praktisches Betätigungsfeld von ZeithistorikerInnen etabliert. Vgl. exemplarisch: Kühberger, Vergangenheitsbewirtschaftung.

21 Vgl. Brigitte Bailer, 50 Jahre Dokumentationsarchiv des österreichischen Widerstandes, in: Dokumentationsarchiv des österreichischen Widerstandes (Hg.), Opferschicksale. Widerstand und Verfolgung im Nationalsozialismus. Jahrbuch 2013, Wien 2013, 9-30.

22 Zu dieser Zeit reichten zeithistorische Themen teils noch weit zurück bis in die Mitte des 19. Jahrhunderts, 1966 wurde beispielsweise 1866 unter dem Ansatzpunkt einer Urkatastrophe behandelt. Vgl. Programmblätter und hefte des Volksbildungsheimes Schloss Retzhof 1964-1974, Archiv des Bildungshauses Retzhof. 
stätten. ${ }^{23}$ Aus diesen Initiativen der „Geschichte von unten“ heraus entwickelte sich beispielsweise die Dokumentation lebensgeschichtlicher Aufzeichnungen sowie die mit dieser Einrichtung in Verbindung stehenden monatlich durchgeführten Gesprächskreise. Getragen haben diese Entwicklung universitär verankerte ForscherInnen und deren Institutionen, nur in die Produktion sind Verlage oder Museen involviert. ${ }^{24} \mathrm{Ab}$ den $1990 e r-J a h r e n$ rückte das aufklärerische Paradigma noch stärker in den Vordergrund, als Fördergelder für politisch-demokratische Bildungsarbeit im zeithistorischen Bereich vermehrt vergeben wurden, vor allem an Projekte, die lokale oder regionale NS-Geschichte in den Blick nahmen. ${ }^{25}$

In Summe lässt sich also erstens mit Siegfried Mattl konstatieren, dass Public History in den 1980er- und 1990er-Jahren nicht nur zum außeruniversitären Beschäftigungsfeld wurde, sondern sich daraus auch Forschungsfragen entwickelten, ${ }^{26}$ die von kommerziellen Projekten stets ignoriert wurden. Zweitens ist für das Feld der Public History in Österreich eine im internationalen Trend stehende Diversifizierung der Formate zu beobachten, mit der eine Reduktion auf unidirektionale Kommunikation einhergeht, die auch mit einer Professionalisierung und Institutionalisierung von Public History außerhalb von Forschungsinstitutionen zu tun hat:

23 Vgl. Helmut Konrad, Geschichtswerkstätten, in: Kurt Aufderklamm/Wilhelm Filla/Erich Leichtenmüller/Judita Löderer (Hg.), Demokratische Bildung. Realität und Anspruch (Schriftenreihe des Verbandes Österreichischer Volkshochschulen 10), Wien 1996, 57-62.

24 Vgl. Konrad, Geschichtswerkstätten, 59; Die Entstehung der Textsammlung, Doku Lebensgeschichten, URL: https://bit.ly/3gLitw7 (abgerufen 16.06.2020); Gesprächskreise im Wien Museum, Wien Museum/Doku Lebensgeschichten, URL: https://bit.ly/3foUpig (abgerufen 16.06.2020). Zur Verbindung von (der Sammlung von) Egodokumenten als Aspekte der Public History vgl. Li Gerhalter, Collecting Ego-Documents and Democratisation, in: Public History Weekly 8 (2020) 3 , URL: dx.doi.org/10.1515/phw-2020-15175 (abgerufen 25.06.2020).

25 Vgl. Gerhard Baumgartner, Wagnis Demokratie. 30 Jahre Österreichische Gesellschaft für Politische Bildung, Wien 2007; Förderstatistiken und Schwerpunktthemen 2004-2019, Österreichische Gesellschaft für Politische Bildung, URL: https://bit.ly/3gNEYAp (abgerufen 16.06.2020).

26 Vgl. Mattl, Zeitgeschichten, 360; zeitgeschichte 3 (1975/76) 4; zeitgeschichte 9 (1981/82) 3; zeitgeschichte 11 (1983/84) 8; zeitgeschichte $12(1984 / 85)$ 1, 5; zeitgeschichte 21 (1994) 9-10; zeitgeschichte 24 (1997) 7-8; zeitgeschichte 28 (2001) 1, 4; zeitgeschichte 29 (2002) 2; zeitgeschichte 31 (2004) 3; zeitgeschichte 42 (2015) 1; Die wissenschaftliche Untersuchung öffentlicher Darstellungen von Zeitgeschichte in Bildpraktiken ist dabei noch ein junges Phänomen, wie beispielsweise die bahnbrechenden Arbeiten von Ina Markova zeigen, vgl. etwa: Ina Markova, Kollektives Gedächtnis und visuelle Repräsentation. Bedeutungsproduktion durch fotografische Bilddiskurse über die NS-Zeit, in: Gernot Gruber/Monika Mokre (Hg.), Repräsentation(en). Interdisziplinäre Annäherungen an einen umstrittenen Begriff (Österreichische Akademie der Wissenschaften. Philosophisch-historische Klasse Denkschriften 485/Kulturforschungen 2), Wien 2016, 151-166; Ina Markova, Visualizing Waldheim: Mediale Schlüsselbilder der „Affäre Waldheim“, in: Journal of Austrian Studies 49 (2016) 1/2, 71-90. 
Wenige große AkteurInnen (vor allem Medienhäuser) bestimmen das Feld mit einer Vielzahl an Produkten, die meist Blockbusterstil haben. Die in den letzten Jahren bzw. Jahrzehnten entstandenen zeithistorischen Museen richten ihre Aktivitäten vielfach in Antizipation der Agenda kommerzieller Player aus und sind auf die Kooperation mit diesen angewiesen. ${ }^{27}$ Nur ein Schattendasein führen daneben partizipativer angelegte Vermittlungsformate wie etwa Rundgänge; ${ }^{28}$ tatsächlich offene Diskussions- und Erzählformate sind praktisch verschwunden oder erhalten vergleichsweise wenig mediales Echo. Das Praxisfeld der Public History besteht somit fast ausschließlich aus journalistischen Medien einschließlich Fernsehen und Social Media sowie Sachbüchern, Ausstellungen, Denkmälern, Vortrags- und Diskussionsformaten und unidirektional angelegten Führungen. So groß die Rolle ist, die Interventionen im öffentlichen Raum, künstlerische Arbeiten und Performances für die Innovation von Form und Inhalt öffentlicher Debatten einnehmen, so nebensächlich ist ihre Position in hegemonialen Debatten innerhalb der Forschung. Bis zur Missachtung reicht der akademische Umgang mit Populärkultur, wo Belletristik (exklusive der nun auch in Österreich angekommenen zeithistorischen Graphic $\mathrm{Nove}^{29}$ ) und Kinofilm noch eher Aufmerksamkeit finden als andere Videoformate, digitale oder analoge Spiele, Mode, Musik oder Ähnliches.

Unbestreitbar ist im Feld der Vermittlung von Zeitgeschichte ein Schub der Konsolidierung bzw. Institutionalisierung - aber auch Kommerzialisierung - zu beobachten, der eine Professionalisierung der Produktion von geschichtsvermittelnden Formaten nach sich zieht. Das Aufkommen des Buzzword Public History könnte somit für die österreichische Zeitgeschichte als Chance interpretiert werden, den Fokus auf im bildungsbürgerlichen Kanon akzeptierte Medien zu überdenken, in-

27 Vgl. als nur ein Beispiel für die wechselseitige Verstärkung von Public-History-Formaten die Sonderausstellung „Der junge Hitler - Prägende Jahre eines Diktators 1889-1914“, die im Haus der Geschichte des Museum Niederösterreich 2020 gezeigt wurde. Ihr Thema basiert nicht nur auf dem ähnlich betitelten und kürzlich erschienenen Buch von Hannes Leidinger und Christian Rapp, sondern wurde in zahlreichen journalistischen Produktionen wieder aufgegriffen und in einer eigens produzierten ORF-Dokumentation gespiegelt, vgl. exemplarisch Hannes Leidinger/Christian Rapp, Hitler - Prägende Jahre. Kindheit und Jugend 1889-1914, Salzburg/Wien 2020; Gerhard Jelinek/Birgit Mosser-Schuöcker, Der junge Hitler, Fernsehdokumentation von ORF III, 28.03.2020.

28 Vgl. CLIO - Verein für Geschichts- und Bildungsarbeit, URL: http://www.clio-graz.net (abgerufen 16.06.2020); Theresa Högler, Zeitgeschichtliche Stadtwanderung durch Salzburg, Salzburg Museum, URL: https://bit.ly/3ffCoUb (abgerufen 28.06.2020); Termine - Lokale Agenda 21 plus Alsergrund, Lokale Agenda 21 plus Wien, URL: https://bit.ly/2ZZhYHZ (abgerufen 12.05.2020).

29 Vgl. Pedro J. Colombo/Aintzane Landa/Salva Rubio, Der Fotograf von Mauthausen, Wien 2019; Evelyn Steinthaler/Verena Loisel, Peršmanhof, 25. April 1945, Wien 2018; Fritz Schindlecker/Reinhard Trinkler, Heinz Fischer und die Zweite Republik, Eine Graphic Novel, Wien 2018. 
haltlich die Beschränkung auf das Projekt eines „nationalen Gedächtnisses“ hinter sich zu lassen und zeithistorische Auseinandersetzung für breite Öffentlichkeiten transnational, global oder jedenfalls nicht mehr ausschließlich gruppenbezogen zu denken. Solange deren universitäre Institutionalisierung und die damit notwendigen Richtungsdebatten, die zum Beispiel in Deutschland mit der Reduktion auf die Studierendenausbildung für Praxisfelder historischen Arbeitens außerhalb der Wissenschaft ausgegangen sind, in Österreich nicht abgeschlossen sind, ist also ein Window of Opportunity offen. ${ }^{30}$

These 2: Public History schränkt die Wahrnehmung von Zeitgeschichte stark auf Nationalsozialismus und NS-Herrschaft ein

Die schon erwähnte prägende Rolle des DÖW und der thematische Schwerpunkt der Geschichtswerkstättenbewegung weisen paradigmatisch darauf hin, dass Public History in Österreich zur Legitimation des Fachs Zeitgeschichte und zugleich zur Konzentration auf die NS-Forschung beiträgt. ${ }^{31}$ Wir behaupten darüber hinausgehend, dass die Herausbildung eines spezifischen und immer homogener werdenden "nationalen“ Gedächtnisses sowie die Popularisierung von Themen der NS-Herrschaft parallel laufen, was durch zwei transnationale, europäische Entwicklungen vorangetrieben wurde: erstens auf Ebene populärkultureller Entwicklungen durch

30 Vgl. Lücke/Zündorf, Einführung, 17-21.

31 Kritik an der Dominanz von NS-Themen in der Zeitgeschichtsforschung wurde im Fach bereits um die Jahrtausendwende diskutiert und auch dem Programm des Österreichischen Zeitgeschichtetages 2008 attestiert. Vgl. Heidemarie Uhl, Gesellschaft - Gedächtnis - Kultur. Zu den Transformationen der österreichischen Zeitgeschichtsforschung, in: Margit Franz/Heimo Halbrainer/Gerald Lamprecht/Karin M. Schmidlechner/Eduard G. Staudinger/Monika Stromberger/Andrea Strutz/ Werner Suppanz/Heidrun Zettelbauer (Hg.), Mapping Contemporary History. Zeitgeschichten im Diskurs, Wien/Köln/Weimar 2008, 27-48, 46; Ingrid Böhler/Eva Pfanzelter/Thomas Spielbüchler/ Rolf Steininger, Vorwort, in: Ingrid Böhler/Eva Pfanzelter/Thomas Spielbüchler/Rolf Steininger (Hg.), 7. Österreichischer Zeitgeschichtetag 2008. 1968 - Vorgeschichten - Folgen. Bestandsaufnahme der österreichischen Zeitgeschichte. Innsbruck/Wien/Bozen 2010, 13-14. Während die NS-Forschung für die Etablierung der Zeitgeschichte an westdeutschen Universitäten als konstitutiv gewertet wird, wurden diese Prozesse in Österreich - abseits des DÖW - von einer auf konsensorientierten Koalitions- und Republiksgeschichtsschreibung dominiert. NS-Forschung etablierte sich dabei erst Ende der 1970er-Jahre als Themengebiet des noch jungen Faches. Vgl. Alexander Nützenadel/Wolfgang Schieder, Zeitgeschichtsforschung in Europa. Einleitende Überlegungen, in: Alexander Nützenadel/Wolfgang Schieder (Hg.), Zeitgeschichte als Problem. Nationale Traditionen und Perspektiven der Forschung in Europa, Göttingen 2004, 7-24, 11-12; Weinzierl, Aufgaben, 11-12. 
unterhaltsame und somit leicht konsumierbare - vor allem deutsche - Fernsehproduktionen ${ }^{32}$ und zweitens durch die Hegemonialisierung der Shoa-Erinnerung und die Herausbildung eines umstritten bleibenden „Europäischen Gedächtnisses“, das um diesen Kern kreist. ${ }^{33}$ Daraus entspringt ein Charakteristikum österreichischer Public History, das gleichzeitig die Differenzen zwischen dieser und der österreichischen Zeitgeschichtsforschung offenlegt, nämlich die (nur für die Public History gültige) Verkürzung des Signifikanten „Zeitgeschichte“ auf die Bedeutung NS-Herrschaft bzw. Zweiter Weltkrieg. Die wissenschaftliche Zeitgeschichte, die sich in verschiedenen Phasen unterschiedlich stark, aber niemals ausschließlich nur mit NSForschung beschäftigt(e), ${ }^{34}$ tritt überwiegend zur Vermittlung von NS-Themen an eine breite Öffentlichkeit. ${ }^{35}$

32 Vgl. etwa Axel Bangert, The Nazi Past in Contemporary German Film: Viewing Experiences of Intimacy and Immersion, New York 2014, bes. 58-61, 127-135; Lutz Klinkel, Viele Taten, wenig Täter, Die Wehrmacht als Sujet neuerer Dokumentationsserien des öffentlich-rechtlichen Rundfunks, in: Michael Th. Greven/Oliver von Wrochem (Hg.), Der Krieg in der Nachkriegszeit, Der Zweite Weltkrieg in Politik und Gesellschaft der Bundesrepublik, Opladen 2000, 113-130; Vrääth Öhner, Fernsehen - Geschichte - Gedächtnis. Zur Transformation dokumentarischer Inszenierungsweisen der Historie, in: Christian Gerbel/Manfred Lechner/Dagmar C. G. Lorenz/Oliver Marchart/ Vrääth Öhner/Ines Steiner/Andrea Strutz/Heidemarie Uhl (Hg.), Transformationen gesellschaftlicher Erinnerung. Studien zur Gedächtnisgeschichte der Zweiten Republik (Kultur.Wissenschaften 9), Wien 2005, 131-157.

33 Vgl. u. a. Daniel Levy/Natan Sznaider, The Cosmopolitization of Holocaust Memory. From Jewish to Human Experience, in: Judith M. Gerson/Diane L. Wolf (Hg.), Sociology Confronts the Holocaust, Memories and Identities in Jewish Diasporas, Durham 2007, 313-330; Éva Kovács, Innocent Culprits - Silent Communities, On the Europeanisation of the Memory of the Shoah in Austria, in: Totalitarian Movements and Political Religions 9 (2008) 2-3, 225-236; Johanna Ray Vollhardt, "Crime against Humanity“ or „Crime against Jews"? Acknowledgment in Construals of the Holocaust and its Importance for Intergroup Relations, in: Journal of Social Issues 69 (2013) 1, 144-161.

34 Weinzierl und Uhl attestieren der österreichischen Zeitgeschichtsforschung bis ca. 1986 einen Schwerpunkt auf die Zeit vor 1938 und eine Einschränkung von NS-Geschichte auf Widerstand, Exil und Verfolgung, vgl. Uhl, Gesellschaft; Weinzierl, Aufgaben. Als prominente Ausnahmen vgl. etwa: Karl R. Stadler/Maria Szécsi, Die NS-Justiz in Österreich und ihre Opfer, Wien/München 1962; Karl R. Stadler, Österreich 1938-1945 im Spiegel der NS-Akten, Wien/München 1966.

Paradigmatisch zeigt sich das in der aktuellen „Braunau“-Kontroverse, in der Zeithistoriker (sic) Wortführer sind, vgl. Dirk Rupnow, Als wäre nichts gewesen? Zu den Umbauplänen für das Hitler-Geburtshaus, Die Presse/Spectrum, 12.06.2020, IV; Oliver Rathkolb, Hitler-Geburtshaus in Braunau: Verdrängter „Neonazi-Tourismus“, Der Standard, 13.06.2020, URL: https://www. derstandard.de/story/2000118040037/hitler-geburtshaus-in-braunau-verdraengter-neonazitourismus (abgerufen 13.10.2020). Als Nachweis der NS-Konturierung von Public History in Österreich nur einige wichtige Beispiele im digitalen Raum: Weiter erzählen, Videoausstellung von erinnern.at, URL: www.weitererzaehlen.at (abgerufen 08.06.2020); Plattform erinnern.at, URL: www.erinnern.at (abgerufen 08.06.2020); Virtuelles Museum Oberösterreich, URL: https://www. ooegeschichte.at/epochen/nationalsozialismus/ (abgerufen 08.06.2020). Auch im zentralen Oral- 
Die Auseinandersetzung mit NS-Geschichte ist durch den seit 1988 auf die Jahre 1918/1938/1945/1955 fokussierten Gedächtniskanon zyklisch alternierend strukturiert, wobei auch Erzählungen von „Staatsgründung“ - früher 1955, jetzt vermehrt 1918/1945 - immer stärker NS-Kontexte referenzieren. Daneben sind nur Themen präsent, die kurzfristiger Jahrestagslogik entspringen, ${ }^{36}$ während die Konfliktgeschichte der Ersten Republik durch das Verständnis von Public History als Projekt eines konsensualen „nationalen“ Gedächtnisses verdrängt worden ist. ${ }^{37}$ Dabei waren, wie Heidemarie Uhl festhält, die regelmäßig wiederkehrenden NS-bezogenen Gedenkjahre ursprünglich als Auseinandersetzung mit einer „unbequemen Vergangenheit" zentral geworden, ${ }^{38}$ sind aber unter den Prämissen eines moralischen, erkalteten „non-committal memory“ zum Rahmen für Performanzen historischer Selbstvergewisserung geworden. ${ }^{39}$ In der Gegenwart sichern Medienunternehmen und Museen/Gedenkstätten, Bildungseinrichtungen und Verlage mit der Positionierung ihrer Produkte ihre Interessen im Bereich der Aufmerksamkeits- und Verkaufsökonomie ab. Erscheinen die 1990er-Jahre noch von einer stark reagierenden, flexiblen und oft improvisierten Public-History-Landschaft in Österreich bestimmt, so hat sich im Laufe der 2oooer-Jahre die Szene professionalisiert und deren Produktion verstetigt. Erstens bereiten große Verlagshäuser - vor allem im konservativen, nicht im linken Spektrum - nicht nur Themenschwerpunkte in Wochen- und Tageszeitungen, sondern auch Sonderhefte und spezielle Aktionen vor, die oft durch

History-Projekt „MenschenLeben“ dominieren bislang veröffentlichte Ausschnitte mit Bezug auf NS-Geschichte, vgl. MenschenLeben, Österreichische Mediathek, URL: https://bit.ly/2WaPOIV (abgerufen 08.06.2020). Unter den breiten digitalen Angeboten des hdgö werden jene mit NSBezug am stärksten frequentiert, vgl. etwa die Webausstellung Zwischen den Zeiten. Frühjahr und Sommer 1945 in Fotos, hdgö, URL: https://www.hdgoe.at/zwischen_den_zeiten_1945 (abgerufen 08.06.2020) oder die partizipative Webausstellung „Der Balkon“, eine Baustelle, hdgö, URL: heldenplatz.hdgoe.at (abgerufen: 08.06.2020).

36 Der Erste Weltkrieg war - wie der Vergleich seiner Rezeption 2014, als alles bestimmendes Thema, und 2018, als Randnotiz, beweist - nur im Sinne einer solchen Logik relevant.

37 Bis 1988 stand die Geschichte der Ersten Republik im Mittelpunkt von Public-History-Projekten, worunter besonders innovative, mehr noch als von der runden Zahl von einer Historisierung gesellschaftspolitisch relevanter Fragen der Gegenwart angetrieben waren und sich etwa durch das Bespielen von Zugwaggons neuer Instrumentarien bedienten sowie Möglichkeiten zur personalen Vermittlung von Zeitgeschichte reflektierten. Vgl. Hildegund Amanshauser/Elisabeth Wiesbauer, Er-lebte Geschichte. Animationsprogramm zur Ausstellung „Die Kälte des Februar“, in: zeitgeschichte 12 (1984) 1, 19-25; Gerhard Buzeczki/Klarissa Guzei (Hg.), Abschlussbericht zur Ausstellung „Die Kälte des Februar“, Österreich 1933-1938, Wien 1984.

38 Vgl. Heidemarie Uhl, Gedenkjahre. Editorial, in: zeitgeschichte 46 (2019) 4, 453-46o.

39 Vgl. Stefan Benedik, Non-committal memory: The ambivalent inclusion of Romani suffering under National Socialism in hegemonic cultural memory, in: Memory Studies 13 (2018) 6, 1097-1112, URL: https://doi.org/10.1177/1750698018818220 (abgerufen 26.06.2020). 
die Zusammenarbeit mit universitären FachhistorikerInnen zustande kommen bzw. von diesen bespielt werden. ${ }^{40}$

Der zweite große Player ist der ORF, der seine zeithistorischen Schwerpunkte in den letzten Jahren erheblich ausgebaut hat, unterstützt unter anderem durch die nutzungsrechtlichen Rahmenbedingungen, die es ihm erlauben, eigene Produktionen aus dem Bereich „History“ im Gegensatz zu praktisch allen anderen Inhalten dauerhaft online zugänglich zu machen. Fernsehformate haben sich von der klassischen Dokumentation über Spieldokus bis hin zu Infotainment und Sendungen, in denen der Aktuelle Dienst das Kommentieren von Zeitgeschichte übernimmt, ausdifferenziert. Die zuletzt genannte Entwicklung treibt dabei die Logik der ereignisbezogenen Darstellung damit auf die Spitze, dass dieses Format historische Inhalte wie aktuelle Nachrichten behandelt und vermittelt. ${ }^{41}$ Das Themenspektrum wird entweder von NS-Geschichte dominiert, oder Narrative entwickeln sich vor dem implizit bleibenden Hintergrund der NS-Herrschaft als zentrale Erzählung. Ähnliches ließe sich vom dritten Bereich, jenem der in den letzten zwei Jahrzehnten entstandenen oder neu entwickelten Zeitgeschichtemuseen, sagen, deren zahlreiche Aufgaben in Ausstellung, Vermittlung und Sammlung von jüngerer und jüngster Geschichte vor allem unter dem Aspekt der historisch-politischen Bildung im Kontext der NS-Herrschaft Aufmerksamkeit bekommen. ${ }^{42}$

40 Siehe etwa die besonders prominenten Beispiele von Geschichte-Beilagen, Webangeboten oder Broschüren/Büchern, die Verlagshäuser mithilfe großer Tageszeitungen bewerben oder letztere auch selbständig für die eigenen AbonnentInnen aufbereiten oder frei zum Kauf anbieten, vgl. exemplarisch Die Presse Geschichte Magazine, URL: https://bit.ly/2W5W98j (abgerufen 29.06.2020); Die Stunde Null, Oberösterreichische Nachrichten, URL: https://bit.ly/2ZnACKJ (abgerufen 29.06.2020); Dossier 75 Jahre Österreich, Kleine Zeitung, URL: https://bit.ly/326jryN (abgerufen 29.06.2020).

41 Beispielhaft sind dazu etwa die Nachrichtensendungen des ORF, ZIB 2, vom 15.03.2018 oder 08.05.2020, die sich als Spezialausgaben auf historische Themen beschränkten, aber ihre Ausdrucksmittel kaum veränderten. Vgl. grundsätzlich Winter, Geschichtspolitiken, 46-47.

42 Diese strukturelle und historisch-institutionelle Verbindung wird deutlich etwa in der Zusammenfassung von „Museen“ und „Gedenkstätten“ im Untertitel von Dirk Rupnow/Heidemarie Uhl (Hg.), Zeitgeschichte ausstellen in Österreich, Museen - Gedenkstätten - Ausstellungen, Wien/ Köln 2011; Ljiljana Radonić/Heidemarie Uhl, Das zeithistorische Museum und seine theoretische Verortung. Zur Einleitung, in: Ljiljana Radonić/Heidemarie Uhl (Hg.), Das umkämpfte Museum. Zeitgeschichte ausstellen zwischen Dekonstruktion und Sinnstiftung, Bielefeld 2020, 7-25. 
These 3: Das politikwissenschaftliche Paradigma der Zeitgeschichtsforschung erschwert den Austausch mit künstlerischen Formaten von Public History

Für die Forschung zur Zeitgeschichte ist - besonders in Österreich - eine Differenz zwischen politikwissenschaftlichen, personen- oder ereigniszentrierten einerseits, und kulturwissenschaftlichen, auf Metaebenen fokussierenden Zugängen andererseits kennzeichnend, ${ }^{43}$ in der Public History aber sind politikwissenschaftliche Prämissen, Fragen und Themen hegemonial. Eine Ursache dafür vermuten wir darin, dass für das Sprechen von JournalistInnen und ForscherInnen im Feld der Public History primär Vokabular und Zugänge aus den politikwissenschaftlich geprägten Fachperspektiven zur Verfügung stehen. Auch legen die Massenformate von Public History zwischen Gastbeitrag, Interview und Podiumsdiskussion einen ereignis- oder strukturhistorischen, teils positivistischen Fokus nahe, weil angenommen wird, dass so gerahmte Inhalte niederschwelliger vermittelt werden können. Die damit verbundene Deutungshoheit wird vor allem durch künstlerische Auseinandersetzungen mit Fragen der Darstellung bzw. Darstellbarkeit von Geschichte herausgefordert. Besonders die vielen regionalen Initiativen, die für die Konfrontation mit zeithistorischen Fragen künstlerische Methoden einsetzen, tragen durch kreativ weiterentwickelte Zugänge viel zum selbstreflexiven Charakter zeithistorischer Auseinandersetzungen bei, ${ }^{44}$ während Fachwissenschaft, Journalismus, aber auch Museen $^{45}$ hinterherhinken.

43 Vgl. Uhl, Gesellschaft; Bauer, Kontinuitäten.

44 Um nur einige wenige zu nennen, sei hier auf die folgenden Initiativen und ihre Orte verwiesen: Interferenzen/Loibltal, URL: www.interferenzen.at; rož/St. Jakob im Rosental-Šentjakob v Rožu, URL: http://www.roz.si/nc/de/aktuell/; RE.F.U.G.I.U.S./Rechnitz-Rohonc, URL: www.refugius.at; $<$ rotor $>$ /Graz, URL: rotor.mur.at; Verein der Freunde des Deserteursdenkmal in Goldegg/Goldegg, URL: www.goldeggerdeserteure.at; Die Chronisten/Innsbruck, URL: www.virtuelles-haus-dergeschichte-tirol.eu; Pavelhaus-Pavlova hiša/Bad Radkersburg, URL: www.pavelhaus.at; IN SITU, Linzog/Linz, URL: http://www.insitu-linzog.at/; Steingeschichten Projekt Linz/Linz, URL: https:// steingeschichten.at (alle abgerufen 10.05.2020).

45 Historische Museen spiegeln den Gegensatz zwischen politik- und kulturwissenschaftlichen Zugängen im Konflikt zwischen dem Primat von Ereignisgeschichte und ihrer Kontextualisierung durch Metafragen von Repräsentation und Ausstellungs- bzw. Sammlungspraxis. Der in Österreich wohl symbolischste Moment in diesem Zusammenhang war die Kontroverse um die Zerstörung der Hologramme der alten Dauerausstellung im Jüdischen Museum Wien 2010, vgl. Sabine Offe, Ausstellungen, Einstellungen, Entstellungen, Jüdische Museen in Deutschland und Österreich, Berlin/Wien 2000; Kristiane Janeke, Rezension zu Tobias Natter/Michael Fehr/Bettina HabsburgLothringen (Hg.), Die Praxis der Ausstellung. Über museale Konzepte auf Zeit und auf Dauer, H-Soz-Kult, 21.12.2012, URL: https://bit.ly/2W6p38j (abgerufen 01.05.2020). 
Während für institutionell stabilisierte Formate des Austauschs zwischen Zeitgeschichtsforschung und Öffentlichkeiten Modi der Übersetzung existieren (Verknappung im Journalismus, musealer Fokus auf Materielles und Inszenierung, erzählerischer Duktus im mündlichen Vortrag), bleibt die Begegnung von fachwissenschaftlichen und künstlerischen Bearbeitungen von Zeitgeschichte voller Missverständnisse. Ein beredtes Beispiel dafür ist ein 2010 in der Tageszeitung „Die Presse" veröffentlichter bizarrer Kommentar von Nachfahren einer in ungeklärter Weise in Endphaseverbrechen verstrickten Adeligen auf das Theaterstück „Rechnitz (Der Würgeengel)" von Elfriede Jelinek. Insinuierend, dass mit der in Jelineks dramatischem Text ${ }^{46}$ literarisch deutlich überformten Hauptfigur der Gräfin ihre Urahnin quasi realistisch darzustellen beabsichtigt worden wäre, versuchen die Erben die literarische Erzählung durch die Gegenüberstellung mit Passagen eines Vortrags des Historikers Walter Manoschek als Fiktion zu enttarnen. ${ }^{47}$

Ironischerweise reflektiert Jelinek in genau diesem Text bereits über die Frage nach der Autorität wissenschaftlicher ExpertInnen in der Öffentlichkeit. Jelineks Erzähler klagt direkt die neutrale Stimme des Historikers als Komplizin von Entschuldungsdiskursen moralisch an und legt das ethische Versagen hinter der Forderung nach Differenzierung und der Verweigerung von Positionierung offen..$^{4}$ Die am Beginn zitierte Passage lässt sich eben nicht als Delegitimierung der Fachwissenschaft lesen, sondern als Kritik an der Herstellung einer scheinbar "unpolitischen“ historischen Wahrheit, die eine hierarchisch überlegene Position absichert - und vice versa. Nur künstlerischen Medien steht für derartige Kritik die Option der satirischen Wendung zur Verfügung. Ein Beispiel unter wenigen dafür ist die Mockumentary des österreichischen Filmemachers Walter Wippersberg, die für den ORF 2001 unter dem Titel „Die Wahrheit über Österreich oder: Wie man uns belogen hat" nicht nur Geschichtsmythen, sondern vor allem deren autoritative Vermittlung und die Legitimationsstrategien von HistorikerInnen (etwa den Bezug auf gleichzeitig symbolisch für sich selbst reklamierte, ja inkorporierte Archivbestände) dekonstruiert. ${ }^{49}$

Dass künstlerische Medien im Feld der Public History im Allgemeinen und literarische Texte im Besonderen problematische Klischees - wie die für die Zeit-

46 Vgl. Jelinek, Theaterstücke.

47 Vgl. Sehr geehrte Frau Jelinek!, Die Presse, 23.05.2010, URL: https://bit.ly/2ZiboPo (abgerufen 07.06.2020).

48 Jelinek, Theaterstücke, 58-59.

49 Vgl. Nikhil Sathe, Resistance Against Itself, Austrian Cinema's Responses to the Far Right, in: James Harvey (Hg.), Nationalism in Contemporary Western European Cinema, Basingstoke 2018, 191214, 205. 
geschichtsforschung dichotome Codierung von Opfer- und TäterInnenschaft oder deren vergeschlechtlichte Logik - herausfordern und eine öffentliche Auseinandersetzung mit den Bedingungen des Sprechens darüber anregen können, zeigt das oben genannte Drama von Elfriede Jelinek prototypisch..$^{50}$ Mit Bezug auf den Begriff "Sündenstolz" des Philosophen Hermann Lübbe ${ }^{51}$ wies die Schriftstellerin bereits Anfang der 200oer-Jahre darauf hin, dass das Ritualisieren von Erinnerung auch zum fortgesetzten Silencing der Opfer führen könne, ${ }^{52}$ eine Tendenz, der gerade künstlerische Formate entgegenwirken. Breit rezipiert wurde etwa das 2012 uraufgeführte Stück „F. Zawrel. Erbbiologisch und sozial minderwertig“ von Nikolaus Habjan und Simon Meusburger. Durch die Übersetzung in ein Puppentheater wurde die biografische Erzählung des NS-Psychiatrie-Opfers Friedrich Zawrel dabei vielfach gebrochen..$^{53}$ Abseits der größeren Institutionen wurden historische Narrative durch künstlerische Formate schon seit den 1990er-Jahren auf Modi der Repräsentation hin befragt, wie Programme in künstlerischen Häusern, im Rahmen von Festivals und von kleineren Kunstinitiativen zeigen. ${ }^{54}$

These 4: Public-History-Formate bieten Ausnahmen von der Regel des Silencing marginalisierter Gruppen in und durch Zeitgeschichtsforschung

Während Public History also erlauben kann, bislang unterdrückte Geschichten zu erzählen, müssen sowohl die politikwissenschaftlichen als auch die kulturwissenschaftlichen Forschungstraditionen österreichischer Zeitgeschichte als Projekte des Silencing kritisch betrachtet werden. ${ }^{55}$ Gerade durch den aufklärerischen Anspruch

50 Vgl. Elfriede Jelinek, Die Kinder der Toten: Roman, Reinbek bei Hamburg 1995.

51 Vgl. Hermann Lübbe, Vom Parteigenossen zum Bundesbürger, Über beschwiegene und historisierte Vergangenheiten, Paderborn 2007.

52 Vgl. Martin Krumbholz, Der Assistentin ins Gesicht gespuckt, Süddeutsche Zeitung, 04.11.2010, 11.

53 Vgl. Nikolaus Habjan/Simon Meusburger, F. Zawrel - Erbbiologisch und sozial minderwertig, Aufführung im Akademietheater Wien vom 11.11.2014, DVD, 109 min., Wien 2015.

54 Vgl. als nur eines der vielen dafür bahnbrechenden Ausstellungs- und Performanceprojekte die Maßstäbe setzende „Anthropophagische Woche“ des Linzer Vereins maiz 2014, URL: https://bit. ly/2W5YyQn (abgerufen 01.07.2020).

55 Johanna Gehmachers Analyse, dass kulturwissenschaftliche Zugänge sehr wohl kritisches Potenzial hätten, ist zuzustimmen, wenn auch eine Wirkung verspätet bzw. sehr vereinzelt zu bemerken ist. Gehmacher schreibt dazu: „Ihre [der Zeitgeschichte] Ausblendungen und Marginalisierungen sind besonders schwer aufzuheben, weil sie sich so sehr decken mit den Ausblendungen und Marginalisierungen einer spezifischen Gegenwart, aus der der Forscher/die Forscherin schreibt." Gehmacher, Marginalisierungen, 312 . 
in einer als homogen gedachten Gesellschaft beteiligten sich ZeithistorikerInnen lange an Diskriminierung und Ausgrenzung. Erst durch die Rezeption von politischen und wissenschaftlich-konzeptionellen Paradigmenwechseln kam es auch in der österreichischen Zeitgeschichte zur „Vervielfältigung der möglichen/zu schreibenden Geschichten". ${ }^{56}$

Gerade in den Anfangsjahren österreichischer Zeitgeschichtsforschung und -vermittlung wurde beispielsweise Migration auf den Zusammenhang von NS-Vertreibung, -Verfolgung und Exil beschränkt ${ }^{57}$ und wurden genau jene Teile der Gesellschaft damit ausgeschlossen, deren Geschichte von Migrationen geprägt war..$^{58}$ Aber auch andere Gewalterfahrungen - wie jene Friedrich Zawrels - wurden durch die Engführung von Erinnerung im Rahmen der Universalisierung der Shoa lange Zeit wissenschaftlich wie öffentlich marginalisiert und der Begriff der Überlebenden selbst für NS-Opfer stark national ausgelegt. ${ }^{59}$

Parallel zu diesen marginalisierenden Tendenzen durch Forschungsaufmerksamkeit zeigen auch die Programmatik musealer Institutionen und deren Sammlungs- und Ausstellungspraktiken die Reproduktion von Mythen „ethnischer“ Homogenität und Abgrenzung. ${ }^{60}$ Inhalte, Institutionen und AkteurInnen der Public History sind somit nicht neutral, sondern geprägt von (Einzel-)Interessen, (Erzähl-) Absichten und spezifischen Zugangsweisen, die mehrheitlich nach wie vor von einer (unreflektierten) vorgestellten Norm eines ökonomisch abgesicherten, „inländischen“, weißen Mannes als Referenzgröße der repräsentierten Erzählung ausgehen, wodurch von dieser Position abweichenden Erfahrungen eine Historisierung lange

56 Ebd., 308.

57 Vgl. hierzu die Thematisierungen in folgenden Heften der zeitgeschichte: zeitgeschichte $4(1976 / 77)$ 2; zeitgeschichte 4 (1976/77) 8; zeitgeschichte 14 (1986/87) 1; zeitgeschichte 18 (1990/91) 7/8.

58 Vgl. Arif Akkiliç/Vida Bakondy/Ljubomir Bratić/Regina Wonisch (Hg.), Schere, Topf, Papier. Objekte zur Migrationsgeschichte, Wien 2016; Regina Wonisch, Ausstellungskonzepte zur Arbeitsmigration in Österreich, in: Ali Özbaş/Joachim Hainzl/Handan Özbaş (Hg.), 50 Jahre jugoslawische Gastarbeit in Österreich, Graz 2016, 144-157; Vida Bakondy, Objekte der Erinnerung, Erzählungen zur Migration, Ein Sammlungsprojekt und eine Ausstellung zur Migrationsgeschichte im Wien Museum, in: Österreichische Zeitschrift für Geschichtswissenschaften 31 (2018) 3, 189-201.

59 Dass die Repräsentation von NS-Opferschaft in Public History-Formaten die Geschichte von nach 1945 migrierten Menschen per se ausschließt, macht deren Ermächtigung auf Basis der Verfolgung ihrer Community kaum möglich. Vgl. Benedik, Non-committal memory; Sonia Misak, The Jewish Communities of Vienna and Cracow, Communities Against All Odds, in: S. Ilan Troen (Hg.), Jewish Centers and Peripheries, Europe between America and Israel Fifty Years after World War II, New Brunswick/London 1999, 157-177.

60 Vgl. hierzu für den Museumsbereich: Laura-Edythe Coleman, Understanding and Implementing Inclusion in Museums, Lanham 2018; Johnnetta Betsch Cole/Laura L. Lott (Hg.), Diversity, Equity, Accessibility, and Inclusion in Museums, Washington 2019. 
verweigert wurde und teilweise noch wird. Zum Beispiel wurden auch in (kultur) historischen Ausstellungen erst jüngst Themen wie MigrantInnen, Romani ÖsterreicherInnen oder AfroösterreicherInnen behandelt. ${ }^{61}$

In diesen Beispielen aus dem Museumsbereich dominiert deutlich eine Kompensations- oder noch häufiger Kontributionserzählung. Zumal diese Projekte von den Communitys selbst eingefordert, initiiert und oft auch durchgeführt wurden, sind diese Ausstellungs- und Sammlungsaktivitäten - allen voran jene des Wien $\mathrm{Mu}$ seums $^{62}$ - Leuchtturmprojekte, weil die Deutungshoheit über das, was im Museumsraum gezeigt werden kann, tatsächlich zur Verhandlung gestellt wurde und die Dynamiken von Silencing und Voice teils transparent gemacht wurden. Das liegt auch an der Rolle künstlerischer Intervention in der Katalysierung dieses Paradigmenwechsels hin zur Berücksichtigung migrantischer Positionen in der Praxis des Ausstellens. Ein Vorzeigebeispiel dafür ist wohl die Programmschiene „Moving Museum“ des Kunstfestivals „WienWoche“ 2014, die den Rassismus von Sammlungsund Ausstellungspolitiken offenlegte, ohne ihn aufzulösen. ${ }^{63}$

Der grundsätzliche Wermutstropfen ist aber die internationale Entwicklung, dass solche Aktivitäten von Institutionen zur reinen Bewerbung eines symbolischen Wandels, der die Machtverhältnisse in der Institution aber unangetastet lässt, missbraucht werden könnten. Diese Formulierung liegt in Österreich am ehesten für das 2017 neu aufgestellte Weltmuseum Wien nahe, dem von kritischen Stimmen die Legitimation von rassistischen Praktiken des Ausstellens und der Institutionenpolitik vorgeworfen wurde und dessen weitgehende Entkoppelung von Public History per se als diskriminierende Praxis im Sinne des rassistischen Stereotyps der Geschichtslosigkeit der zu kolonisierenden Welt gewertet werden kann. ${ }^{64}$

61 Vgl. entsprechende Listen von Initiative Minderheiten, Ausstellungen, URL: https://bit.ly/3244duh (abgerufen 28.06.2020); Ausstellungen zu Migration und Integration, okay. Integration und Vielfalt in Vorarlberg, URL: https://bit.ly/2CsRTsx (abgerufen 28.06.2020); Philipp Blom, Wolfgang Kos (Hg.), Angelo Soliman, ein Afrikaner in Wien, Wien 2011.

62 Vgl. dazu besonders folgende bahnbrechenden Ausstellungen: Gastarbajteri. 40 Jahre Arbeitsmigration, Wien Museum 2004; Romane Thana. Orte der Roma und Sinti, Wien Museum und Landesmuseum Burgenland (anschließend auch im Vorarlberg Museum zu sehen) 2015; Geteilte Geschichte. Viyana - Beč - Wien, Wien Museum 2017. Vgl. Akkiliç/Bakondy/Bratić/Wonisch (Hg.), Schere; Bakondy, Objekte.

63 Neonpinkfarbige Überschriften brachten palimpsestartige Kommentare auf Vitrinen - aber eben auch an Leerstellen daneben, vgl. Barbara Staudinger, Moving Museum, WienWoche 2014, URL: https://bit.ly/3 foZgEA (abgerufen 03.06.2020) und URL: https://bit.ly/3ehguoY (abgerufen 02.06.2020).

64 Vgl. Christian Kravagna, Vom ethnologischen Museum zum unmöglichen Kolonialmuseum, in: Zeitschrift für Kulturwissenschaften 2015/1, 95-118; Jonas Jahns, Antidiskriminatorische Museumsarbeit, Eine Analyse des Weltmuseums Wien, Dipl.-Arb., Universität Wien 2019. 
Diese beiden Entwicklungen waren die Voraussetzung dafür, dass das Haus der Geschichte Österreich (hdgö) als (in diesem Sinn glücklicherweise) spät (2018) gegründetes, erstes zeithistorisches Museum des Bundes Migrations-, aber auch Rassismusgeschichte als integralen Bestandteil einer österreichischen (Zeit)Geschichte zu zeigen beanspruchen kann. Dass das Verweben und Konfrontieren der Erzählung eines „Nationalmuseums“ mit diskriminierten Positionen in Rezensionen jedoch nicht thematisiert wurde ${ }^{65}$ lässt auf eine Verlängerung von Marginalisierung in medialen Öffentlichkeiten schließen. Gerade hier können Social Media - allen voran Twitter - zu wichtigen Sprachrohren gegenhegemonialer Geschichtserzählungen werden. Dass international eine noch immer steigende Zahl von HistorikerInnen diesen Kanal zur Wissenschaftskommunikation jenseits des Public-History-Mainstreams nutzt, ${ }^{66}$ scheint in der österreichischen Zeitgeschichtsforschung noch nicht (ganz) angekommen.

These 5: Das demokratisierende und pluralisierende Potenzial von Public History vor allem im digitalen Raum ist weitgehend unausgeschöpft

Wir schreiben diesen Beitrag in Zeiten zweier einschneidender globaler Entwicklungen, gerade für die Geschichtsvermittlung: der Krise des Fortschritts- und Wachstumsparadigmas im Zuge von Klima- und Pandemie-Katastrophen einerseits und der Krise von rassistischen und patriarchalen Gesellschaftsordnungen angesichts der feministischen und Black-Lives-Matter-Bewegungen. Mit großer Verzögerung kommt der Postcolonial Turn (und daran angelagert Fragen nach Repräsentation und Agency) auch in der österreichischen Geschichtsforschung an und er könnte vor allem in der Public History zum leitenden Ansatz werden, ${ }^{67}$ eine Reflexion über gewaltvolle Strukturen, welche Institutionen der Public History befördern oder le-

65 Vgl. nur Pars pro Toto Anne-Catherine Simon, Ausstellung: Haus der verkopften Geschichte, Die Presse, 07.11.2018, URL: https://www.diepresse.com/5525990/ausstellung-haus-der-verkopftengeschichte (abgerufen 13.10.2020); Stephan Löwenstein, Zankapfel „Haus der Geschichte Österreich" eröffnet, Frankfurter Allgemeine Zeitung, 13.11.2018, URL: https://www.faz.net/aktuell/ feuilleton/haus-der-geschichte-oesterreich-eroeffnet-15885295.html (abgerufen 13.10.2020); Peter Münch, Zeitreise ohne Hitler-Balkon, Süddeutsche Zeitung, 08.11.2018, 11.

66 Vgl. Serge Noiret, Public History with Tweets, in: Public History Weekly 5 (2017) 24, URL: dx.doi. org/10.1515/phw-2017-9568 (abgerufen 28.06.2020).

67 Für das Feld des Museums wurde das schon vor 15 Jahren in der hellsichtigen Frage auf den Punkt gebracht, „Wer spricht?“, vgl. Beatrice Jaschke/Charlotte Martinz-Turek/Nora Sternfeld (Hg.), Wer spricht? Autorität und Autorschaft in Ausstellungen, Wien 2005. 
gitimieren, vorausgesetzt. ${ }^{68}$ Solche Auseinandersetzungen mit der eigenen Komplizenschaft sind in vielen Institutionen, besonders im musealen und jüngst journalistischen Bereich, angelaufen, und auch wenn damit die strukturell-konzeptionellen Grundlagen von Institution in Frage stehen, zeigt sich doch, dass „accessibility“, „inclusion“ und auch „participation“ wenigstens Symbolwörter auch in Kriterienkatalogen geworden sind. ${ }^{69}$

Trotzdem bleibt aufgrund des oben skizzierten Widerspruchs zwischen der aufklärerischen und demokratisierenden Agenda von Zeitgeschichte eine tendenziell skeptische Haltung universitärer Zeitgeschichtsforschung gegenüber $z u$ offenen Formaten bestehen. Dies zeigt sich etwa beispielhaft an dem 2008 bis 2014 in der Steiermark umgesetzten Projekt „63 Jahre danach“ des Künstlers Jochen Gerz. ${ }^{70}$ Das durch die Kooperation mit der regional auflagenstärksten „Kleinen Zeitung“ durchgeführte Projekt war einerseits radikal demokratisch gedacht, andererseits war es als kommerzielles Format, das einem privaten Medienunternehmen die Möglichkeit gab, den öffentlichen Raum mit dem eigenen Corporate Design zu überschreiben, und einer (Teil)Öffentlichkeit, die Themen zu bestimmen, nicht ohne Problematik. Letztlich bestimmten LeserInnen der Zeitung per Mehrheitsvoting über Inhalte und Aufstellungsorte von Displays mit NS-bezogenen historischen Fotos und aktuellen Texten. Wir führen dieses Beispiel nicht nur wegen seines Hybridcharakters zwischen Denkmal, Journalismus und Ausstellung an, sondern vor allem wegen des Verhältnisses der institutionellen Zeitgeschichtsforschung ihm gegenüber: Die Absenz universitärer ForscherInnen - mit einer prominenten Ausnahme - und professioneller zeithistorischer Vereine deuten wir als Zeichen einer akademischen Skepsis gegenüber der durch eine demokratische Öffnung - und fehlende Kontrolle - hervorgerufenen Beliebigkeit.

Daraus auf eine im Grunde autoritäre Haltung der Wissenschaft zu schließen, greift als Erklärungsmodell allerdings zu kurz. Gerade die Einschränkung dessen,

68 Vgl. Regina Wonisch, Der verantwortliche Blick. Museum und Ethik, in: Universalmuseum Joanneum (Hg.), Wem gehört die Geschichte?/Komu pripada zgodovina?, Graz 2014, 124-157. Larissa Förster/Iris Edenheiser/Sarah Fründt/Heike Hartmann (Hg.), Provenienzforschung zu ethnografischen Sammlungen der Kolonialzeit, Positionen in der aktuellen Debatte, Berlin 2017; Sophie Schönberger, Was heilt Kunst?, Die späte Rückgabe von NS-Raubkunst als Mittel der Vergangenheitspolitik, Göttingen 2019.

69 Vgl. BKA Projektaufruf: Das inklusive Museum, ICOM Österreich, URL: https://bit.ly/ 3 flvhsC (abgerufen 28.06.2020); David H. Lempert, Taking People's History Back to the People. An Approach to Making History Popular, Relevant, and Intellectual, in: Democracy \& Education 21 (2013) 2, 1-15, URL: https://bit.ly/2ZjkTwb (abgerufen 28.06.2020). Kriterienkatalog des Museumsbund Österreich, URL: https://bit.ly/3elpBh9 (abgerufen 28.06.2020).

70 Vgl. Werner Fenz (Hg.), Arbeit mit der Öffentlichkeit. 63 Jahre danach. Jochen Gerz, Wien 2016. 
wie Science to Public im produktions- und outputorientierten Universitätsbetrieb verstanden wird, reduziert schlicht die Freiräume für einen ergebnisoffenen Dialog und erschwert sukzessive gleichzeitig ein Engagement von ForscherInnen in der Öffentlichkeit, deren Planung von Aktivität weitgehend der Logik von Ziel- und Leistungsvereinbarungen unterliegt. Was das für den demokratischen Anspruch, aber alleine schon für die Kommunikationsaspekte von geschichtsvermittelnden Formaten bedeutet, zeigt ein einfacher Vergleich. Während Forderungen nach Partizipation und Reflexion in der historischen Fachdidaktik wie der Erwachsenenbildung immer zentraler werden, bleibt das Design von öffentlichen geschichtsvermittelnden Formaten zum Großteil auf unidirektionale Formen der Top-down-Vermittlung durch universitär ausgebildete ExpertInnen beschränkt. ${ }^{71}$ Das ist insofern besonders erstaunlich, als dies völlig gegenläufig zum Prozess der Digitalisierung zu stehen scheint. Während die Deutungs- und Repräsentationshoheiten von Journalismus, Politik und Wissenschaft weitgehend eingebrochen sind, finden die partizipativen Formen im Bereich der Public History - wie Geschichtswerkstätten, Bottom-upAusstellungen oder Grätzelinitiativen - keine virtuelle Erweiterung oder Äquivalente. ${ }^{72}$ Webausstellungen gehören zwar inzwischen zum guten Ton der allermeisten Museen, jedoch wird nach wie vor in den digital gezeigten Inhalten das digitale Medium selbst nicht reflektiert oder dessen Spezifika in Hinblick auf (demokratisierende) Potenziale nicht genutzt. ${ }^{73}$ Dieses Desiderat ist eine Folge dessen, dass sich ExpertInnen kaum in Formatentwicklungen einbringen (können), sondern diese nur verwenden.

Neben den genannten Ursachen ist dafür sicherlich auch die geringe Aufmerksamkeit verantwortlich zu machen, die öffentlich-historische Auseinandersetzung im digitalen Raum bekommt. Ein Beispiel hierfür ist die am Technischen Museum Wien angesiedelte „Österreichische Mediathek“, die durch visuelle und akustische Ausstellungen (teils sogar als Interventionen im öffentlichen Raum) seit Jahren eine Politik der (kostenfreien) Zugänglichkeit im Web verfolgt, aber viel zu oft übersehen

71 Vgl. beispielhaft: Programme 2008-2019, CLIO - Verein für Geschichts- und Bildungsarbeit, URL: http://www.clio-graz.net (abgerufen 16.06.2020).

72 Als eine lange schon im digitalen Bereich tätige Institution ist die Holocaust Education Initiative erinnern.at zu nennen. Vgl. Thomas Hellmuth, Late Awareness, Vigorous Remembrance: Austria Today, in: Public History Weekly 6 (2018) 38, URL: dx.doi.org/10.1515/phw-2018-13048 (abgerufen 26.06.2020).

73 Dies wird beispielsweise an folgenden Webausstellungen - trotz ihrer inhaltlichen Stärken - sichtbar: Werner Koroschitz/Slowenischer Kulturverein Rož, Vermessung/Meritev, URL: https://vermessung-meritev.at/ (abgerufen 28.06.2020); Kulturgeschichte online, Museum für Geschichte, URL: https://www.museum-joanneum.at/kulturgeschichte-online (abgerufen 28.06.2020). 
wird. ${ }^{74}$ Auch das DÖW hat unlängst ein Angebot in der digitalen Vermittlung etabliert, das smartphonebasiert ist, aber nicht breit rezipiert wurde. ${ }^{75}$ Ähnlich unter Wert verkauft werden auch Projekte, die konzeptionell noch innovativer angelegt sind, etwa die Citizen-Science-Aktivitäten der Österreichischen Nationalbibliothek ${ }^{76}$ oder die kommerzielle Fotosharingwebanwendung „Topothek“.77 Ersteres besticht durch ein konzeptionell durchdachtes Design des Austauschprozesses und bringt daher einen hohen Wissensgewinn nicht trotz, sondern durch Demokratisierung, indem UserInnen in Form der Zuordnung bzw. Prüfung von Luftbildern Forschungsarbeiten überhaupt erst ermöglichen. Im zweitgenannten Projekt zeigen sich hingegen deutlich die Probleme des Wechselspiels von fehlender Konsequenz der Moderation und Kommerzialisierung, etwa in der Überbetonung extremer Tendenzen wie digitalem Exhibitionismus, in Dekontextualisierungen, Falschdarstellungen oder Rechtsverletzungen (Urheberrecht, Datenschutz, Persönlichkeitsrechte). Wie auch bei Wikipedia gilt hier, dass breite Öffentlichkeiten einbindende, digitale Formate dieser Art nur mehr für ExpertInnen (mit entsprechend quellenkritisch geschultem Blick) wertvoll und tatsächlich "game changing" sein können, ${ }^{78}$ aber weder demokratisierend noch pluralisierend wirken, sondern die Unterdrückung von innovativen oder „unterlegenen“ Inhalten durch die simple Mehrheit der Masse fortschreiben. ${ }^{79}$

Angebote der digitalen Public History brauchen somit einen breiten Konzeptionsprozess und Moderation, Transparenz und präzise Aufgabenstellungen. Wenn Public History ein gesellschaftspolitisches Projekt ist, hat sie auch die Aufgabe, Komplexität und Pluralität sichtbar zu machen und Widersprüche zuzulassen. Marginalisierende, undemokratische oder auch wahrheitsfeindliche Positionen können für sich nicht die Ägide der Demokratisierung in Anspruch nehmen. Aus den knapp zweijährigen Erfahrungen des hdgö ist in diesem Zusammenhang zu berichten, dass es sich nicht nur symbolisch, sondern auch inhaltlich bezahlt macht, eigene Res-

74 Vgl. Österreichische Mediathek, Audiovisuelles Archiv, Technisches Museum Wien, URL: www. mediathek.at (abgerufen 16.06.2020).

75 Vgl. Memento Wien, Dokumentationsarchiv des Österreichischen Widerstandes, URL: https:// www.memento.wien (abgerufen 25.06.2020).

76 Vgl. Österreich aus der Luft, Österreichische Nationalbibliothek, URL: crowdsourcing.onb.ac.at (abgerufen 18.06.2020).

77 Vgl. Topothek, ICARUS - Internationales Zentrum für Archivforschung, URL: https://www.topothek.at/de/ (abgerufen 27.06.2020).

78 Vgl. Thomas Wozniak/Jürgen Nemitz/Uwe Rohwedder (Hg.), Wikipedia und Geschichtswissenschaft, Oldenbourg 2015.

79 Andererseits stellt die Topothek aber auch das einzige große Public-History-Format dar, das tatsächlich regional und per se dezentriert ist. 
sourcen für Öffentlichkeiten zur Verfügung zu stellen. Die partizipativen Ausstellungsmodule des Museums, die vom Web aus ohne Registrierung bespielt werden können, werden im realen Ausstellungsraum sichtbar und wurden ganz im Gegensatz zu anfangs geäußerten Befürchtungen - auch bei umstrittenen Themen - bisher nie durch digitalen Vandalismus attackiert. ${ }^{80}$ Partizipative Initiativen gibt es vor allem international einige zu nennen ${ }^{81}$ - Projekte, die eine Institution über den digitalen Raum öffnen, sind aber selbst inmitten der Corona-Krise selten, da Institutionen kein Interesse am tatsächlichen Abbau der Hierarchien in der Auseinandersetzung mit Geschichte generell haben können. Welche Möglichkeiten BürgerInnen im Sinne einer ernst gemeinten Citizen Science zur Involvierung in die Zeitgeschichte als Prozess geboten werden können, bleibt daher unbeantwortet. Die Schere, die sich hier beobachten lässt, ist jene zwischen einer Digitalisierung und Partizipation betonenden Rhetorik und einer form- und strukturkonservativen Praxis, in der sich erneut der Konflikt zwischen aufklärerischen und demokratisierenden Ansprüchen österreichischer Zeitgeschichte spiegelt.

\section{Resümee und Ausblick}

Aufgrund der (wenigstens implizit vorausgesetzten) öffentlichen Rolle von ZeitgeschichtsforscherInnen und der innerhalb ihrer Disziplin etablierten analytischen Auseinandersetzung mit heute unter eine breite Definition von Public History fallenden Formaten kann Public History von Beginn an als Teil der österreichischen Zeitgeschichtsforschung beschrieben werden - wenn auch nicht unter diesem begrifflichen Mantel. Der Fokus auf NS-Themen, der für die österreichische Zeitgeschichtsforschung per se nicht kennzeichnend wäre, wurde durch die Verschränkung mit Public History zum öffentlichen Signifikanten von „Zeitgeschichte“. Das dadurch verstärkte Spannungsfeld zwischen politik- und kulturwissenschaftlichen Prämissen in der Disziplin wird vor allem in der von Missverständnissen oder Ignoranz geprägten Beziehung von Zeitgeschichte gegenüber künstlerischen Formaten der Public History sichtbar. Gerade die Irritationen der Abgrenzungen zwischen

80 Vgl. „Der Balkon“, eine Baustelle, hdgö, URL: heldenplatz.hdgoe.at (abgerufen 28.06.2020); Geschichte (mit)schreiben, hdgö, URL: mitschreiben.hdgoe.at (abgerufen 28.06.2020).

81 Vgl. etwa die prominentesten Beispiele in der digitalen Museumsarbeit: Make your Story Part of History, Write Your Stories About Europe, Partizipative Webausstellung, Haus der Europäischen Geschichte, URL: https://my-european-history.ep.eu/myhouse/myheh_project (abgerufen 29.06.2020); Museum of Broken Relationships, URL: https://brokenships.com/ (abgerufen 29.06.2020). 
Wissenschaft und Nicht-Wissenschaft, ExpertInnentum und Publikum, Erklärenden und Betroffenen offenbaren das große demokratische wie pluralisierende Potenzial von Public History, dessen Nutzung aber in großen Teilen aussteht. Eine Weiterentwicklung und Öffnung von Zeitgeschichtsvermittlung (wie auch -forschung) erscheint uns aber gerade in Hinblick darauf unabdinglich, dass ihr demokratisches Versprechen in Zeiten politischer Entwicklungen, die die Grundprinzipien einer liberalen, offenen, demokratischen und gerechteren Gesellschaft bedrohen, eingelöst werden muss.

Geschichte ist eine Entscheidung. Deshalb ist der Blick auf die Metaebene des Ein- und Ausschließens in den Prozess der Herstellung von Geschichte angezeigt auch, weil der Aufstieg von Public History zum primären Ort der Verhandlung „nationaler" Gedächtnisse die Entwicklung neuer Sprechweisen in partizipativ angelegten, experimentellen und ergebnisoffenen Prozessen und so von vielstimmigerer Geschichte ermöglichen könnte: Wenn die Inhalte von Public History den Wert von Demokratie betonen, ist nicht zu rechtfertigen, wenn Inhalte und Formate in Strukturen entwickelt werden, die dieses Prinzip nicht widerspiegeln. Dazu müssen die Machtpositionen von AkteurInnen der Public History im Allgemeinen und HistorikerInnen im Speziellen sichtbar(er) gemacht und Strategien entwickelt werden, um Geschichtsvermittlung zu einem dezentrierten Prozess mit breiter Beteiligung und Bestärkung von marginalisierten Stimmen umzugestalten. 


\title{
Kriegsfolgenforschung
}

\author{
Barbara Stelzl-Marx
}

Kriege hören nicht auf, wenn die Waffen schweigen. Kriege haben Vorgeschichten, und sie haben Folgen: im privaten Leben und in der Gesellschaft, in der Politik und Wirtschaft, in sozialen, humanitären oder kulturellen Bereichen. Kriege beschädigen die menschliche Seele und die unterschiedlichsten Beziehungen, oft über Generationen hinweg. Ihre Spuren sind häufig - auf den ersten Blick - unsichtbar, doch nichtsdestotrotz vorhanden, gleichsam subkutan, eingebrannt in Biographien ebenso wie in Orte. „Kontaminierte Landschaften“" nennt Martin Pollack die zahllosen Flecken Mitteleuropas, an denen namenlos gewordene, heimlich begrabene Tote bis heute liegen. Parallel dazu gibt es kaum ein Dorf in Österreich, in dem nicht ein Kriegerdenkmal an die Gefallenen des Ersten und Zweiten Weltkrieges erinnert. Weitaus seltener finden sich Erinnerungszeichen an die Opfer des NS-Regimes. Dass militärische Auseinandersetzungen $\mathrm{zu}$ allen Zeiten vor allem Tod und Leid hervorbrachten, ist die einfachste Erkenntnis; inwiefern die Folgen noch Jahrzehnte später spürbar sind, ist Gegenstand zeithistorischer, aber auch interdisziplinärer Forschung.

„Was bleibt vom Krieg?“ ist die zentrale Frage, die sich die Forschung in Zusammenhang mit den Auswirkungen von Kriegen und Konflikten stellt. Dazu gehören staatliche, gesellschaftliche, ökonomische sowie soziale, humanitäre und kulturelle Folgen von Kriegen und Konflikten im 20. Jahrhundert. Der vorliegende Beitrag skizziert die Genese und aktuelle sowie einige offene Fragenstellungen der Kriegsfolgenforschung in Österreich im Rahmen der vier Themenkomplexe Weltkriege, Kalter Krieg, Kinder des Krieges und Zwangsmigration. Diese stellen zugleich die Programmlinien des 1993 gegründeten Ludwig Boltzmann Instituts für Kriegsfolgenforschung (BIK), Graz - Wien - Raabs, dar, das die Forschung in diesem Bereich sowohl national als auch international prägte und nach wie vor vorantreibt. ${ }^{2}$

1 Martin Pollack, Kontaminierte Landschaften, St. Pölten/Salzburg/Wien 2014. Die Arbeiten zum vorliegenden Beitrag wurden in Kooperation mit der Universität Graz und der Stadt Graz am Ludwig Boltzmann Institut für Kriegsfolgenforschung, Graz - Wien - Raabs, durchgeführt. Für Unterstützung bei der Erstellung dieses Beitrages gebührt Dieter Bacher, Bernhard Bachinger, Harald Knoll, Philipp Lesiak, Peter Ruggenthaler, Lukas Schretter, Andrea Strutz und Kornel Trojan besonderer Dank.

2 Vgl. URL: https://bik.ac.at/ (abgerufen 30.09.2020). 


\section{Weltkriege}

Die Zeitspanne von 1914 bis 1991 gilt als das „Zeitalter der Extreme“.3 Spezifisch für das „Extreme“ waren die zwei Weltkriege genauso wie der Aufstieg und Fall der „beiden Totalitarismen“ - Nationalsozialismus und Stalinismus. Als zentrales Ereignis am Beginn steht der Erste Weltkrieg und dessen Ende: Die Umstürze brachten eine neue Gesellschafts- und Weltordnung mit sich; der Untergang der Monarchie in mehreren europäischen Ländern resultierte in einer politischen Neuordnung von Teilen Mittel-, Ost- und Südosteuropas. Das wirtschaftliche und politische Chaos führte zum Aufstieg von totalitären Regimen. Das nationalsozialistisch regierte Deutschland sollte später den Zweiten Weltkrieg verursachen. In einer übergreifenden Erforschung der beiden Weltkriege und deren Folgen werden historische Zusammenhänge und Wechselwirkungen sichtbar. Die Erforschung von Nationalsozialismus und Stalinismus untersucht Herrschaftsstrukturen und -praktiken totalitärer Regime, ohne die Systeme oder deren Verbrechen gleichzusetzen. Im Zusammenhang mit der Etablierung der Kriegsfolgenforschung in Österreich bildeten, wie im Folgenden gezeigt wird, die Recherchen zu österreichischen Kriegsgefangenen in der Sowjetunion einen wesentlichen Schwerpunkt, gefolgt von Untersuchungen zu Kriegsgefangenschaft und Zwangsarbeit in der „Ostmark“. Somit soll dieser Bereich im Zusammenhang mit den unterschiedlichsten Folgen der Weltkriege besonders beleuchtet werden.

\subsection{Kriegsgefangenschaft und Zwangsarbeit}

„Sibirien“ gilt als Synonym für die Kriegsgefangenschaft der deutschen und österreichischen Wehrmachtsangehörigen im Zweiten Weltkrieg. ${ }^{4}$ Neben den harten Lebens- und Überlebensbedingungen dominiert die Kriegsgefangenschaft der rund 3 Millionen ${ }^{5}$ deutschen und 135.000 österreichischen Soldaten in der Sowjetunion

3 Eric Hobsbawm, Das Zeitalter der Extreme. Weltgeschichte des 20. Jahrhunderts, München 1998.

4 Zur Kriegsgefangenschaft in Russland im Ersten Weltkrieg vgl. insbesondere Hannes Leidinger/ Verena Moritz (Hg.), In russischer Gefangenschaft. Erlebnisse österreichischer Soldaten im Ersten Weltkrieg, Wien/Köln/Weimar 2008; Verena Moritz/Julia Wallececk-Fritz (Hg.), Kriegsgefangenschaft in Österreich-Ungarn 1914-1918. Historiographien, Kontext, Themen (im Druck).

5 Vgl. Rüdiger Overmans, „In der Hand des Feindes“. Geschichtsschreibung zur Kriegsgefangenschaft von der Antike bis zum Zweiten Weltkrieg, in: Rüdiger Overmans (Hg.), In der Hand des Feindes. Kriegsgefangenschaft von der Antike bis zum Zweiten Weltkrieg, Köln/Weimar/Wien 1999, 1-40, 14. 
noch aus einem weiteren Grund die Erinnerung an diese Extremsituation: Die letzten Österreicher kehrten erst nach der Unterzeichnung des Staatsvertrages 1955 in die Heimat zurück; die letzten Deutschen im März 1956. Damit war die Repatriierung der Spätheimkehrer mehr als zehn Jahre nach Kriegsende abgeschlossen. ${ }^{6}$ Bilder von tränenüberströmten und zugleich freudestrahlenden Menschen, die sich am Bahnhof von Wiener Neustadt in den Armen liegen, haben sich in das nationale Langzeitgedächtnis eingebrannt; daneben aber zugleich auch die Aufnahmen jener Frauen und Kinder, die vergeblich auf den Bahnsteig gekommen waren. ${ }^{7}$

Kriegsgefangenschaft im Zweiten Weltkrieg stellte ein Massenphänomen dar. Rund ein Drittel der elf Millionen gefangenen Wehrmachtssoldaten befand sich in sowjetischem Gewahrsam; die übrigen in westalliierter Hand. ${ }^{8}$ Sie alle verbindet die Erfahrung der Gefangennahme, des Abtransports in Lager, der Alltag hinter Stacheldraht mit seinen unterschiedlichsten Facetten, die Monate und Jahre der Ungewissheit, das lange Warten auf die Heimkehr und schließlich die Rückkehr in eine fremd gewordene Heimat oder - wie im Falle von 16.00o Österreichern in der Sowjetunion - der Tod. ${ }^{9}$ Mindestens 70.000 Österreicher, die bereits vor ihrer Registrierung in den sowjetischen Lagern verstorben waren, gelten bis heute als vermisst. ${ }^{10}$ Für die Angehörigen stellt die Ungewissheit über ihren Verbleib eine Lücke in der

6 Vgl. dazu insbesondere Stefan Karner, Im Archipel GUPVI. Kriegsgefangenschaft und Internierung in der Sowjetunion 1941-1956, Wien/München 1995. In den darauffolgenden Jahren entstanden unter der Leitung von Stefan Karner zahlreiche Publikationen zur Kriegsgefangenschaft in der Sowjetunion, darunter etwa auch zu Gefangenen aus einzelnen Bundesländern. Vgl. insbesondere Stefan Karner (Hg.), „Gefangen in Russland“. Die Beiträge des Symposions auf der Schallaburg 1995, Graz/Wien 1995; Edda Engelke, Niederösterreicher in sowjetischer Kriegsgefangenschaft während und nach dem Zweiten Weltkrieg, Graz 1998; Sabine Elisabeth Gollmann, Kärntner in sowjetischer Kriegsgefangenschaft während und nach dem Zweiten Weltkrieg, Graz 1999; Felix Schneider, Oberösterreicher in sowjetischer Kriegsgefangenschaft 1941 bis 1956, Graz 2004; Wolfram Dornik/Michael Hess/Harald Knoll, Burgenländische Kriegsgefangene und Zivilverurteilte in der Sowjetunion 1941-1956, Eisenstadt 2007. Aktuell werden Forschungen zu Kriegsgefangenen in Zentralasien, gefördert vom Zukunftsfonds der Republik Österreich und dem Land Kärnten, und in Moldawien, gefördert von der GRAWE, am BIK durchgeführt.

7 Vgl. Karner, Im Archipel GUPVI, 187-234.

8 Günter Bischof/Stefan Karner/Barbara Stelzl-Marx, Einleitung, in: Günter Bischof/Stefan Karner/ Barbara Stelzl-Marx (Hg.), Kriegsgefangenschaft des Zweiten Weltkrieges. Gefangennahme - Lagerleben - Rückkehr. Zehn Jahre Ludwig Boltzmann Institut für Kriegsfolgen-Forschung, Wien/ München 2005, 9-19, 9.

9 Archiv des Ludwig Boltzmann Instituts für Kriegsfolgenforschung, Graz - Wien - Raabs (AdBIK), Datenbank österreichischer Kriegsgefangener in der Sowjetunion.

10 Stefan Karner, Die Rückkehr der österreichischen Kriegsgefangenen aus der Sowjetunion, in: Stefan Karner/Gottfried Stangler (Hg.), „Österreich ist frei!“ Der Österreichische Staatsvertrag 1955. Beitragsband zur Ausstellung auf Schloss Schallaburg 2005, Horn/Wien 2005, 139-142, 139. 
Familiengeschichte dar, die teilweise durch Archivrecherchen und umfangreiche Forschungen geschlossen werden kann. Die Öffnung der sowjetischen Archive mit den Akten zu österreichischen Kriegsgefangenen in der Sowjetunion bildete zugleich den Grundstein des 1993 unter der Leitung von Stefan Karner gegründeten Ludwig Boltzmann Instituts für Kriegsfolgenforschung. ${ }^{11}$

Lange hinkte auch die Forschung zur Kriegsgefangenschaft bzw. Zwangsarbeit im „Dritten Reich“ und insbesondere in der „Ostmark“ nach. Beinahe ein Boom entstand allerdings im Zusammenhang mit der NS-Zwangsarbeiterentschädigung um die Jahrtausendwende, die mit Studien im Auftrag der Österreichischen Historikerkommission ${ }^{12}$ und zahlreichen nachfolgenden Publikationen einherging. Wesentlich in diesem Kontext ist der Zukunftsfonds der Republik Österreich (ÖZF), der Ende 2005 aus Mitteln des Fonds für Versöhnung, Frieden und Zusammenarbeit gegründet wurde. Gemäß dem Motto „Niemals wieder!“ verpflichtete sich der Fonds zur Förderung von Projekten,

die den Interessen und dem Gedenken der Opfer des NS-Regimes, der Erinnerung an die Bedrohung durch totalitäre Systeme und Gewaltherrschaft sowie der internationalen Zusammenarbeit dienen und zur Achtung der Menschenrechte und der gegenseitigen Toleranz beitragen..$^{13}$

So widmete sich das erste geförderte Projekt Aspekten der Repression an „Hitlers Sklaven und Stalins ,Verrätern“', sprich NS-Zwangsarbeitern und Kriegsgefangenen im „Dritten Reich“. ${ }^{14}$ Zahlreiche weitere Projekte zu diesem Schwerpunkt folgten. ${ }^{15}$

11 Stefan Karner gelang als erstem westlichen Historiker 1991 der Zutritt zu sowjetischen Archiven.

12 Vgl. insbesondere: Clemens Jabloner/Brigitte Bailer-Galanda/Eva Blimlinger/Georg Graf/Robert Knight/Lorenz Mikoletzky/Bertrand Perz/Roman Sandgruber/Karl Stuhlpfarrer/Alice Teichova, Schlussbericht der Historikerkommission der Republik Österreich. Vermögensentzug während der NS-Zeit sowie Rückstellungen und Entschädigungen seit 1945 in Österreich. Zusammenfassungen und Einschätzungen (Veröffentlichungen der Österreichischen Historikerkommission 1), Wien/ München 2003; Stefan Karner/Peter Ruggenthaler, Zwangsarbeit in der Land- und Forstwirtschaft auf dem Gebiet Österreichs 1939 bis 1945 (Veröffentlichungen der Österreichischen Historikerkommission 26/2), Wien/München 2004; Ela Hornung/Ernst Langthaler/Sabine Schweitzer, Zwangsarbeit in der Landwirtschaft in Niederösterreich und dem nördlichen Burgenland (Veröffentlichungen der Österreichischen Historikerkommission 26/3), Wien/München 2004.

13 Günter Bischof/Barbara Stelzl-Marx/Alexandra Kofler, Zukunftsfonds der Republik Österreich. Entstehung, Entwicklung und Bedeutung, Wien/Köln/Weimar 2015, 7.

14 Peter Ruggenthaler/Walter M. Iber (Hg.), Hitlers Sklaven - Stalins „Verräter“. Aspekte der Repression an Zwangsarbeitern und Kriegsgefangenen, Innsbruck/Wien/Bozen 2010.

15 Vgl. dazu die Liste der geförderten Projekte unter: Projekte 2006-2019, Zukunftsfonds der Republik Österreich, URL: http://www.zukunftsfonds-austria.at/projects.php (abgerufen 29.09.2020). 
Ein Charakteristikum fällt dabei besonders auf: die ideologisch-rassistisch geprägte Hierarchie unter zivilen Zwangsarbeitern und Kriegsgefangenen. So waren sowjetische Kriegsgefangene als slawische „Untermenschen“ neben den Juden jene Opfergruppe, die im nationalsozialistischen Deutschland das schlimmste Schicksal erleiden sollte: Von 5,7 Millionen gefangenen Rotarmisten verstarben bis Kriegsende rund 3,3 Millionen, beinahe 6o Prozent. Ein Teil von ihnen wurde zum Arbeitseinsatz oder zur Exekution in die Konzentrationslager der SS übermittelt, darunter Mauthausen. ${ }^{16}$

Auch im vergleichsweise ausführlich erforschten Stalag XVII B Krems-Gneixendorf, dem größten Kriegsgefangenenlager auf dem Gebiet des heutigen Österreichs, lag die Todesrate der sowjetischen Kriegsgefangenen ein Vielfaches über jener aller übrigen Nationalitäten. Mangelnde medizinische Versorgung, Seuchen und ihr schlechter körperlicher Zustand beim Eintreffen waren die Hauptursachen. Ein Lager - zwei Systeme: Sämtliche Bereiche des Lebens hinter Stacheldraht waren von dieser Gefangenenhierarchie geprägt. Es gab ein eigenes „Russenbrot“, das vorwiegend aus Sägemehl und Rübenschnitzel bestand und innerhalb kürzester Zeit Ruhrepidemien auslöste. Ihre Uniformen wurden mit „S.U.“ gekennzeichnet. „Skoro ubegu“ - „Bald werde ich fliehen“ dechiffrierten die gefangenen Rotarmisten selbst diese Abkürzung. Starben sowjetische Kriegsgefangene, wurden sie „bei gleichzeitigem Anfall mehrerer Leichen“ in Papier gewickelt in einem Massengrab beigesetzt. Nicht von ungefähr erhielt der Waldfriedhof des Lagers bald die Bezeichnung „Russenwäudl“. 83 Prozent der im Totenbuch des Lagers zwischen 1943 und April 1945 verzeichneten Verstorbenen waren Sowjets; wobei in diesem Zeitraum ihre Todesrate bereits stark zurückgegangen war. ${ }^{17}$

Für die sowjetischen Kriegsgefangenen, von Stalin bereits 1941 als „Vaterlandsverräter“ und „Deserteure“ gebrandmarkt, bedeuteten Kriegsende und Repatriierung den Beginn einer jahrzehntelangen Diskriminierung, die vielfach harte Repressionen beinhaltete. ${ }^{18}$ Den Befreiten wurde jedoch zunächst vorgespielt, dass sie

16 Zur gezielten Vernichtung sowjetischer Kriegsgefangener vgl. Reinhard Otto/Rolf Keller, Sowjetische Kriegsgefangene im System der Konzentrationslager, Wien 2019.

17 Vgl. dazu insbesondere Barbara Stelzl-Marx, Zwischen Fiktion und Zeitzeugenschaft. Amerikanische und sowjetische Kriegsgefangene im Stalag XVII B Krems-Gneixendorf, Tübingen 2000; Hubert Speckner, In der Gewalt des Feindes. Kriegsgefangenenlager in der „Ostmark“ 1939-1945, Wien/München 2001; Robert Streibel, Stalag 17 B - mehr als nur ein Hollywoodschinken, in: Das Waldviertel. Zeitschrift für Heimat- und Regionalkunde des Waldviertels und der Wachau 38 (1989) 3, 197-217; Igor Pucker/Christian Klösch, Lagerstadt Wolfsberg. Flüchtlinge - Gefangene Internierte, Wolfsberg 2013.

18 Vgl. etwa Dieter Bacher/Stefan Karner (Hg.), Zwangsarbeiter in Österreich 1939-1945 und ihr Nachkriegsschicksal. Ergebnisse der Auswertung des Aktenbestandes des „Österreichischen Ver- 
straffrei bleiben würden. „Die Heimat hat verziehen! Die Heimat ruft euch!“, lockten Zeitungen, Plakate und andere Medien. Mit allen zur Verfügung stehenden Mitteln versuchte eine eigens bei der Repatriierungsverwaltung eingerichtete Propagandaabteilung, ,jeden Sowjetbürger bis zum letzten“ zu einer Rückkehr in die UdSSR zu bewegen. Erst in den 1990er-Jahren fand eine vollständige Rehabilitierung dieser „Opfer zweier Diktaturen“ statt. ${ }^{19}$

Wenig überraschend stellten die Erinnerungen ehemaliger sowjetischer Kriegsgefangener und Zwangsarbeiter in der (ehemaligen) UdSSR bis vor wenigen Jahren ein Tabu dar, das nur die wenigsten zu durchbrechen wagten. Sie galten pauschal als Vaterlandsverräter, die für den Feind gekämpft bzw. gearbeitet und überlebt hatten. Lediglich jene, die im deutschen Gewahrsam ihr Leben verloren hatten, wurden posthum - analog zu gefallenen Rotarmisten - gewürdigt. ${ }^{20}$ Im Gegensatz etwa zu den USA, Großbritannien oder Frankreich lassen sich die Autobiographien ehemaliger Kriegsgefangener aus der Sowjetunion an einer Hand abzählen. Wenngleich viele ehemalige Kriegsgefangene und Zwangsarbeiter - ungeachtet ihrer Nationalität und ihrer Erfahrungen im Gewahrsam des Feindes - ihr Leben lang darüber schwiegen, prägte diese Extremsituation ihre weiteren Biographien. Wie erging es ihnen damit, die „besten Jahre“ durch Krieg und Lagerhaft verloren zu haben? Manche begannen erst im hohen Alter, ihre Erinnerungen zu Papier zu bringen; andere hatten gleich nach der Heimkehr autobiographische Texte verfasst, die im Familienarchiv verblieben oder auch an die Öffentlichkeit gelangten. Einige nutzten die Chance, die sich durch die Öffnung der sowjetischen/russischen Archive Anfang der 1990er-Jahre ergab, um einen Einblick in ihre Personalakte zu bekommen, den rund ein halbes Jahrhundert zuvor das Volkskommissariat für Innere Angelegenheiten (NKVD) angelegt hatte. „Streng geheim“ und „Aufbewahren auf ewig“ war auf jeder dieser Akte gedruckt worden.

\subsection{Forschungsdesiderata}

Während sich im Kontext der Kriegsfolgenforschung seit Anfang der 1990er-Jahre ein international anerkannter und auch vernetzter Forschungsschwerpunkt zur Kriegsgefangenschaft in der Sowjetunion während des Zweiten Weltkrieges etab-

söhnungsfonds“. Ein Zwischenbericht, Innsbruck/Wien/Bozen 2013.

19 Barbara Stelzl-Marx, „Kommt schnellstens in die Heimat zurück!“ Broschüren und Plakate für sowjetische Repatrianten, in: Annali dell'Instituto italo-germanico in Trento 29 (2003), 517-540.

20 Peter Sixl, Sowjetische Kriegsgräber in Österreich/Sovetskie mogily Vtoroj mirovoj vojny v Avstrii, Graz/Wien/Klagenfurt 2005. 
lieren konnte, stellen (österreichische) Kriegsgefangene in westalliierter Hand vergleichsweise ein Desiderat dar. Hier wären weiterführende Forschungen wichtig.

Ein anderer Fokus wäre auf „Kriegsfolgengenerationen“ zu richten, zu denen die ehemaligen Kriegsteilnehmer und noch mehr Kriegskinder zählen. ${ }^{21}$ Jene Soldaten, die in Gefangenschaft gerieten und oft Jahre fern der Heimat verbrachten, bilden hier sicherlich eine eigene Untergruppe. Trotz generationaler Gemeinsamkeiten und ähnlicher Erfahrungen ist jede Biographie in ihrer Individualität einzigartig. In den vergangenen Jahren entstand ein regelrechter „,historiographischer Boom “ ${ }^{\text {"2 }}$ im Bereich der Biographik. Es wäre lohnenswert, die Erinnerungen von Zwangsarbeitern und Kriegsgefangenen des Zweiten Weltkrieges im internationalen Vergleich zu analysieren.

Ein weiteres Desiderat, das an dieser Stelle erwähnt werden soll, sind vergleichende Forschungen zu Lagern im 20. Jahrhundert. Lager werden oft als Signum nicht nur des Nationalsozialismus, sondern totalitärer Systeme schlechthin gesehen, spielten aber auch in demokratischen Systemen eine durchaus wichtige Rolle. Zunächst hauptsächlich im militärischen Bereich relevant, entfalteten Lager im 20. Jahrhundert eine ungeahnte Dynamik und wurden zunehmend zu einem gesamtgesellschaftlichen Phänomen. In empirischer Hinsicht erscheint die von Zygmunt Bauman geprägte Bezeichnung des 20. Jahrhunderts als „Jahrhundert der Lager“ durchaus berechtigt. ${ }^{23}$ Auch im 21. Jahrhundert bleiben Lager allgegenwärtig. Sie sind auf das Engste mit den Kriegen und totalitären Systemen des 20. Jahrhunderts, aber auch mit weiteren Faktoren wie sozialen Problemen wie Wohnungsnot oder Flucht- sowie Migrationsbewegungen verknüpft. Allerdings sind die Lagerwelten des 20. Jahrhunderts im Hinblick auf die unterschiedlichen Funktionen noch weit diverser und umfassen etwa auch „Inklusionslager“. Diese zielten darauf ab, „Menschen durch Verlockung oder Zwang in ein national, politisch, sozial, religiös oder weltanschaulich definiertes Kollektiv zu integrieren“.24 Gerade während der NS-Zeit trugen solche erzieherischen und „subjektumformenden Inklusionslager“

21 Lutz Niethammer, Sind Generationen identisch?, in: Jürgen Reulecke (Hg.), Generationalität und Lebensgeschichte im 20. Jahrhundert (Schriften des Historischen Kollegs. Kolloquien 58), München $2003,1-16,3$.

22 Lucile Dreidemy/Katharina Prager/Elisabeth Röhrlich, Editorial, in: zeitgeschichte 37 (2010) 3, 152; Christian Klein (Hg.), Grundlagen der Biographik. Theorie und Praxis des biographischen Schreibens, Stuttgart/Weimar 2002.

23 Zygmunt Bauman, Das Jahrhundert der Lager?, in: Mihran Dabag/Kristin Platt (Hg.), Genozid und Moderne, Opladen 1998, 81-99.

24 Christoph Jahr/Jens Thiel (Hg.), Lager vor Ausschwitz, Berlin 2013, Klappentext. 
gemeinsam mit den Repressions- und Vernichtungslagern zu einer umfassenden „Lagerisierung" des gesamten Lebens bei.

Österreichweit lassen sich viele Lager und lagerähnliche Einrichtungen noch als „unsichtbar“ charakterisieren, etwa wenn es kein oder nur ein fragmentiertes Wissen über diese Orte gibt. Zwar wäre das lokale Wissen, das materielle und immaterielle Erbe oftmals durchaus vorhanden, allerdings ist dieses häufig noch nicht gesichert worden. Das Bundesdenkmalamt strebt eine vertiefte Erfassung von NSLagern an, was eine wichtige Grundlage darstellen und weitere Forschungen ermöglichen würde. Vielfach ist eine umfassende Aufarbeitung und Memorialisierung verhindert oder verzögert worden, was sich indes etwa häufig dann beobachten lässt, wenn solche Orte die (nationale bzw. lokale) Meistererzählung herausfordern oder quer zu dieser stehen. ${ }^{25}$

\section{Kalter Krieg}

Als Folge des Zweiten Weltkrieges standen sich in der „bipolaren Welt“ jahrzehntelang die Westmächte und der sogenannte Ostblock gegenüber, die mit politischen, wirtschaftlichen, technischen und militärischen Mitteln den Einfluss des jeweils anderen Lagers zurückzudrängen versuchten. Österreich nahm auf der Landkarte des Kalten Krieges eine besondere Stellung ein. Seit 1955 politisch und militärisch neutral, war das Land im „Herzen Europas“ mit über 1.100 Kilometern gemeinsamer Grenze mit kommunistischen Nachbarstaaten ein Vorposten und „Schaufenster“ der westlichen Welt aber auch direkt an der Front dieses Konflikts zwischen den Westmächten unter der Führung der USA und dem sogenannten Ostblock unter der Führung der Sowjetunion. Das Land wurde zu einem der bedeutendsten „Tummelplätze" für Nachrichtendienste. Unmittelbar war Österreich durch den Kalten Krieg bei der Niederschlagung des Ungarn-Aufstands 1956 und bei der Niederschlagung des „Prager Frühlings“ 1968 betroffen. In beiden Fällen nahm Österreich - zumindest vorübergehend - zahlreiche Geflüchtete auf; in beiden Fällen war das österreichische Bundesheer in Alarmbereitschaft, um die Grenzen vor einem möglichen sowjetischen Einmarsch zu schützen. Die Lage Österreichs begünstigte aber auch die Weiterentwicklung einer neutralen Politik: Der Kalte Krieg trat als Systemkonfrontation zwischen Kapitalismus und Kommunismus in Erscheinung und bestimmte in der zweiten Hälfte des 20. Jahrhunderts weltweit die Außen- und Sicherheitspolitik.

25 Vgl. etwa Stefan Karner/Heide Gsell/Philipp Lesiak (Hg.), Schloss Lannach 1938-1949, Graz 2008. 
Österreich fiel die Rolle als Eisbrecher und „Brückenbauer“ zwischen Ost und West zu, Wien wurde als Verhandlungsort auf neutralem Boden genutzt.

\section{1 Österreich als Eisbrecher und „Brückenbauer"}

Zahlreiche Projekte beschäftigten sich mit der Teilung Europas und Deutschlands nach dem Zweiten Weltkrieg sowie Österreichs Rolle in diesem Kontext. Im Zusammenhang mit der Kriegsfolgenforschung sollen insbesondere mehrere Arbeiten zur sowjetischen Besatzung Österreichs genannt werden, die Grundlage für weitere Forschungen in diesem Kontext werden könnten, etwa zu wirtschaftlichen Fragestellungen, ${ }^{26}$ Verhaftungen und Verschleppungen insbesondere auch im Kontext antisowjetischer Spionage ${ }^{27}$ oder zur Mikrogeschichte von Stalins Soldaten in Österreich: ${ }^{28}$ Um die Jahrtausendwende wurde es erstmals möglich, auf einer breiten Basis von Dokumenten aus Moskauer Archiven die zehnjährige sowjetische Besatzung Österreichs umfassend darzustellen. ${ }^{29}$

Hinsichtlich einer Vertiefung der Beziehungen mit ehemals sowjetischen Archiven und Forschungseinrichtungen war in weiterer Folge das internationale Forschungsprojekt zum Wiener Gipfel 1961 wesentlich, als sich die beiden mächtigsten Männer der Welt, John F. Kennedy und Nikita Chruschtschow, in Wien trafen. Der Kalte Krieg schien eine Atempause einzulegen, doch die Hoffnungen erfüllten sich

26 Walter M. Iber, Die Sowjetische Mineralölverwaltung (SMV). Zur Vorgeschichte der OMV 19451955, Innsbruck/Wien/Bozen 2010.

27 Stefan Karner/Barbara Stelzl-Marx (Hg.), Stalins letzte Opfer. Verschleppte und erschossene Österreicher in Moskau 1950-1953, Wien/München 2009; Stefan Karner (Hg.), Geheime Akten des KGB „Margarita Ottilinger“, Graz 1992; Stefan Karner, Im Kalten Krieg der Spionage. Margarethe Ottillinger in sowjetischer Haft 1948-1955, Innsbruck/Wien/Bozen 2016.

28 Barbara Stelzl-Marx, Stalins Soldaten in Österreich. Die Innensicht der sowjetischen Besatzung 1945-1955, Wien/München 2012.

29 Wolfgang Wagner, Die Besatzungszeit aus sowjetischer Sicht. Die Errichtung der sowjetischen Besatzungsmacht in Österreich von 1945 bis 1946 im Spiegel ihrer Lageberichte, Dipl.-Arb., Universität Wien 1998; Stefan Karner/Barbara Stelzl-Marx (Hg.), Die Rote Armee in Österreich. Sowjetische Besatzung 1945-1955. Beiträge, Graz/Wien/München 2005; Stefan Karner/Barbara Stelzl-Marx/Alexander Tschubarjan (Hg.), Die Rote Armee in Österreich. Sowjetische Besatzung 1945-1955. Dokumente/Krasnaja Armija v Avstrii. Sovetskaja okkupacija 1945-1955. Dokumenty, Graz/Wien/München 2005; Wolfgang Mueller, Die sowjetische Besatzung in Österreich 1945-1955 und ihre politische Mission, Wien/Köln/Weimar 2005. Zum Überblick über Forschungen zur sowjetischen Besatzung in Österreich bis zur Jahrtausendwende vgl. Wolfgang Mueller, Die sowjetische Besatzungsmacht in Österreich 1945-1955. Forschungsstand, Quellenlage und Fragestellungen, in: zeitgeschichte 28 (2001) 2, 114-129. 
nicht. Binnen Monaten wurde der Kalte Krieg heiß: In Berlin ließ Chruschtschow die Mauer bauen. Und im Jahr darauf schickte er Raketen nach Kuba, um die USA direkt zu bedrohen. Österreich stellte jedoch bei dem Treffen seine neue Rolle als neutraler Staat und Gastgeber erfolgreich unter Beweis, sodass Wien zum Ort der Begegnung im Kalten Krieg wurde. Auch hier hat der Zugang zu Dokumenten in ehemals sowjetischen Archiven neue Einblicke in das Thema erlaubt. ${ }^{30}$

Dank der engen Kooperation mit russischen Archiven und Forschungseinrichtungen, allen voran der Akademie der Wissenschaften in Moskau, der Russischen Staatlichen Geisteswissenschaftlichen Universität, dem Russischen Staatsarchiv für Zeitgeschichte und der Österreichisch-Russischen Historikerkommission folgten weitere Forschungen in diesem Bereich, insbesondere zur Niederschlagung des „Prager Frühlings" $1968,^{31}$ zum Revolutionsjahr $1989^{32}$ und zum Zerfall der Sowjetunion $1991^{33}$. Ein aktuelles Projekt zum Thema „Die Rolle der neutralen Staaten in der sowjetischen Außenpolitik, 1969-1975" widmet sich der Entstehungsgeschichte des KSZE-Prozesses. Es geht im Besonderen der Frage nach, wie die Sowjetunion die neutralen Staaten Österreich, Schweden, Finnland und die Schweiz für ihre Interessen nutzte bzw. inwiefern sich die Aktivitäten dieser neutralen Staaten in den Entscheidungen Moskaus manifestierten. ${ }^{34}$

30 Stefan Karner/Barbara Stelzl-Marx/Natalja Tomilina/Alexander Tschubarjan/Günter Bischof/Viktor Iščenko/Michail Prozumenščikov/Peter Ruggenthaler/Gerhard Wettig/Manfred Wilke (Hg.), Der Wiener Gipfel 1961. Kennedy - Chruschtschow, Innsbruck/Wien/Bozen 2011.

31 Günter Bischof/Stefan Karner/Peter Ruggenthaler (Hg.), The Prague Spring and the Warsaw Pact Invasion of Czechoslovakia in 1968 (Harvard Cold War Studies Book Series), Lanham/Boulder/ New York/Toronto/Plymouth (UK) 2010; Stefan Karner/Natalja Tomilina/Alexander Tschubarjan/ Viktor Iščenko/Michail Prozumenščikov/Peter Ruggenthaler/Oldřich Tůma/Manfred Wilke (Hg.), Prager Frühling. Das internationale Krisenjahr 1968. Beiträge (Veröffentlichungen des Ludwig Boltzmann Instituts für Kriegsfolgen-Forschung/Sonderband 9/1), Köln/Weimar/Wien 2008.

32 Stefan Karner/Mark Kramer/Peter Ruggenthaler/Manfred Wilke (Hg.), Der Kreml und die Wende 1989 (Veröffentlichungen des Ludwig Boltzmann Instituts für Kriegsfolgen-Forschung, Sonderband 15), Innsbruck/Wien/Bozen 2014; Stefan Karner/Philipp Lesiak (Hg.), Der erste Stein aus der Berliner Mauer. Das paneuropäische Picknick 1989 (Veröffentlichungen des Ludwig Boltzmann Instituts für Kriegsfolgen-Forschung 30), Graz/Wien 2015.

33 Mark Kramer/Stefan Karner/Peter Ruggenthaler/Manfred Wilke (Hg.), The Fate of Communist Regimes, 1989-1991, Bd. 1: East-Central Europe and the Warsaw Pact (Harvard Cold War Studies Book Series), Lanham 2016.

34 Vgl. FWF-Projekt P 31869: „Die Rolle der neutralen Staaten (Österreich, Schweden, Finnland, Schweiz) in der sowjetischen Außenpolitik, 1969-1975“, Projektleitung: Peter Ruggenthaler (20192022); Die Rolle der neutralen Staaten 1969-1975, Ludwig Boltzmann Institut für Kriegsfolgenforschung, URL: https://bik.ac.at/neues-fwf-projekt-zur-sowjetischen-aussenpolitik (abgerufen 30.09.2020). 


\subsection{Desiderata}

Durch die Öffnung der ehemals sowjetischen Archive Anfang der 1990er-Jahre konnten in den letzten zwei Jahrzehnten internationale Forschungsprojekte zum Ost-West-Konflikt unter Einbeziehung der sowjetischen Perspektive durchgeführt werden. Dabei lag der Fokus aufgrund des Aktenzugangs in Moskauer Archiven auf der ersten Hälfte und dem Ende des Kalten Krieges. Die Akten der obersten Entscheidungsinstanzen für den Zeitraum 1975 bis 1985 sind nach wie vor nicht systematisch deklassifiziert. Dementsprechend wäre ein Fokus künftig auf diese Zeit zu legen.

Desiderata liegen zudem im Bereich der Kulturdiplomatie im Kalten Krieg vor. Wie etwa Alexander Golovlev mit seiner Dissertation zur Musikdiplomatie gezeigt hat, eröffnen sich in diesem Kontext lohnenswerte Forschungsfragen. ${ }^{35}$

Von Interesse wäre weiter, Wien als Spionagedrehscheibe im Kalten Krieg und generell die Rolle der Nachrichtendienste in Bezug auf Österreich noch genauer zu beleuchten. ${ }^{36}$ Eine Basis dafür bilden unter anderem die Kooperationen mit den relevanten Archiven des ehemaligen „Ostblocks“ und ein aktuelles Forschungsprojekt zur Rolle tschechoslowakischer Geheimdienste in Österreich im Kalten Krieg. ${ }^{37}$

\section{Kinder des Krieges}

Kinder leiden besonders unter den Folgen von Kriegen. Als Zeugen und Opfer von Gewalt sind sie in wichtigen Lebensbereichen - wie der körperlichen und mentalen Gesundheit - durch Kriege geprägt. Vor allem Kinder auf der Flucht oder in Lagern sind extremen Belastungen ausgesetzt. Zu den indirekten Folgen von Kriegen gehören mangelnde Versorgung, fehlende Ausbildungschancen und Beeinträchtigungen in den sozialen und familiären Beziehungen. Besondere Lebenserfahrungen

35 Alexander Golovlev, Tchaikovsky Meets Debussy: French and Soviet Musical Diplomacy in Occupied Austria, 1945-1955, phil. Diss., Europäisches Hochschulinstitut Florenz 2017.

36 Vgl. etwa Erwin Schmidl (Hg.), Österreich im frühen Kalten Krieg 1945-1958. Spione, Partisanen, Kriegspläne, Wien/Köln/Weimar 2000; Siegfried Beer/Linda Jakubowicz (Hg.), Austria’s secret and intelligence services, Wien 2009; Stefan Karner, Halt! Tragödien am Eisernen Vorhang. Die Verschlussakten, Salzburg 2013. Siehe dazu insbesondere auch: URL: http://www.acipss.org (abgerufen 30.09.2020).

37 Vgl. FWF-Projekt P 33220-G: „Activities of Czechoslovak intelligence services in Austria in the Central European context 1948-1960. Networks - operations - impact“, Projektleitung: Barbara Stelzl-Marx (2020-2023). Durchgeführt an der Universität Graz in Kooperation mit dem Ludwig Boltzmann Institut für Kriegsfolgenforschung und der Stadt Graz. 
machen jene Kinder, die als Folge von Kriegen geboren wurden: Dazu zählen Besatzungskinder der alliierten Truppen in Österreich, die im ersten Jahrzehnt nach Ende des Zweiten Weltkrieges zur Welt kamen. Auch „Wehrmachtskinder“ deutscher und österreichischer Soldaten mit einheimischen Frauen in den vom „Dritten Reich“ besetzten Gebieten zählen zu diesen „Kindern des Krieges“.

Die Folgen von Kriegen bleiben für Kinder oft Jahrzehnte spürbar, wachsen mit zunehmenden Alter wieder an und werden „stumm" an die nachfolgenden Generationen weitergegeben. Trotzdem stehen Kinder nicht im Zentrum der gesellschaftlichen Aufmerksamkeit, wenn es um Kriegsopfer und die Auswirkungen von Kriegen geht; sie bleiben meist außerhalb des auf politische und materielle Kriegsfolgen gerichteten Fokus.

Die Kriegsfolgenforschung widmet sich der geschichtswissenschaftlichen Untersuchung von Kriegs- und Nachkriegskindheiten: Sie zeigt Faktoren auf, welche die Lebens- und Sozialisationsbedingungen, die Erinnerungen an Kriegs- und Kindheitserlebnisse, aber auch gesellschaftliche Normen und Vorstellungen einer „normalen" Kindheit beeinflussten. Zentral hierbei ist die Mitarbeit in Netzwerken und Bündnissen, um Kinder in der Folge von Kriegen zu schützen, zu stärken und zu fördern.

Wie im Folgenden gezeigt, wurden jüngere österreichische Forschungen in diesem Bereich insbesondere im Zusammenhang mit Besatzungskindern vorangetrieben. Dabei erfolgte auch eine Anbindung an das EU-Projekt „Children Born of War. Past - Present - Future“, wodurch das Thema vermehrt international und interdisziplinär verankert werden konnte. ${ }^{38}$

\subsection{Besatzungskinder}

Geschätzte $30.000^{39}$ uneheliche Kinder wurden nach 1945 in Liebesbeziehungen, Affären und sogenannten Versorgungspartnerschaften zwischen alliierten Soldaten und österreichischen Frauen geboren oder kamen infolge von Vergewaltigungen zur

38 Vgl. zum EU-geförderten „Horizon 2020“ Marie Skłodowska-Curie Actions Innovative Training Network „Children Born of War - Past, Present, Future“: Children born of war, CHIBOW, URL: https://www.chibow.org/ (abgerufen 30.09.2020). Im Rahmen dieses Projektes entstand: Lukas Schretter, Britische Besatzungskinder. Die Nachkommen britischer Soldaten und österreichischer Frauen nach dem Zweiten Weltkrieg, phil. Diss., Karl-Franzens-Universität Graz 2020.

39 Vgl. Silke Satjukow/Barbara Stelzl-Marx, Besatzungskinder in Vergangenheit und Gegenwart, in: Barbara Stelzl-Marx/Silke Satjukow (Hg.), Besatzungskinder. Die Nachkommen alliierter Soldaten in Österreich und Deutschland, Wien/Köln/Weimar 2015, 11-14, 11. 
Welt. Die meisten dieser Kinder kannten ihre leiblichen Väter nicht oder wurden von ihnen verlassen. Bis heute sind viele auf der - oft aussichtslosen - Suche nach ihren „Wurzeln“. Gleichzeitig wurde während der Besatzungszeit eine unbekannte Zahl von Kindern in Ehen zwischen österreichischen Frauen und westlichen Besatzungssoldaten geboren.

Nachdem Besatzungskinder in Österreich jahrzehntelang aus dem kollektiven Gedächtnis der Nachkriegszeit verdrängt worden waren und kaum wissenschaftliche Beachtung gefunden hatten, erschienen in jüngerer Vergangenheit fundierte Arbeiten zur Thematik. 2016 widmete sich eine Ausstellung den Kindern schwarzer GIs und österreichischer Frauen. ${ }^{40}$ Transdisziplinäre Forschungsprojekte, insbesondere der Geschichts- und Kulturwissenschaften, aber auch der Sozialwissenschaften und der Psychologie, zeugen von dem steigenden wissenschaftlichem Interesse an den zwischen 1945 und 1956 geborenen Kindern: Zu den umfangreichsten Forschungsprojekten zählt die Untersuchung „Besatzungskinder in Österreich. Eine sozial, diskurs- und biografiegeschichtliche Analyse“, die - ausgehend zu den Forschungen zu sowjetischen Besatzungskindern - am Ludwig Boltzmann Institut für Kriegsfolgenforschung angesiedelt war und vom Zukunftsfonds der Republik Österreich von 2011 bis 2014 gefördert wurde. Zeitgleich wurden Projekte zum psychosozialen Empfinden von Besatzungskindern in Österreich und Deutschland, zu ihren Erfahrungen mit Vorurteilen und zur Identitätsentwicklung von der Universität Leipzig in den Jahren 2012 bis 2016 in Kooperation mit der Universität Greifswald und in den Jahren 2013 bis 2016 in Kooperation mit dem BIK durchgeführt. ${ }^{41}$

Ein seit 2013 laufendes Projekt zu den Nachkommen afroamerikanischer Besatzungssoldaten in Österreich mit dem Titel „Lost in Administration. Afro-Austrian GI Children - A Research Project“ ist an der Universität Salzburg angesiedelt. ${ }^{42}$ Erwähnt sei auch das seit 2015 laufende Projekt „,Gefühlserbschaften'. Von den Besatzungskindern zu den Besatzungsenkeln“ an der Sigmund-Freud-Privatuniversität

40 Die von Philipp Rohrbach und Niko Wahl kuratierte Ausstellung "SchwarzÖsterreich“ wurde ab April 2016 im Österreichischen Museum für Volkskunde in Wien gezeigt.

$41 \mathrm{Zu}$ den Hintergründen des Forschungsprojektes und den Ergebnissen vgl. u. a. Anna-Lena Aßmann/Marie Kaiser/Georg Schomerus/Philipp Kuwert/Heide Glaesmer, Stigmatisierungserfahrungen deutscher Besatzungskinder des Zweiten Weltkrieges, in: Trauma \& Gewalt 9 (2015) 4, 294-303; Marie Kaiser/Philipp Kuwert/Elmar Braehler/Heide Glaesmer, Depression, Somatization, and Posttraumatic Stress Disorder in Children Born of Occupation After World War II in Comparison With a General Population, in: Journal of Nervous and Mental Disease 203 (2015) 10, $742-748$.

42 URL: www.lostinadministration.at (abgerufen 30.09.2020). Vgl. Ingrid Bauer/Philipp Rohrbach (Hg.), Black GI Children in Post-World War II Europe (zeitgeschichte 48 [2021] Heft 1). 
in Wien. ${ }^{43}$ Seit 2019 erforscht ein Projekt die Geschichte der Besatzungskinder in Tirol. ${ }^{44}$

Auch internationale Tagungen, wie die im Jahr 2012 vom BIK und der Universität Magdeburg an der Diplomatischen Akademie Wien veranstaltete Konferenz „Besatzungskinder in Österreich und Deutschland“, sowie wissenschaftliche Publikationen, vor allem der Sammelband „Besatzungskinder. Die Nachkommen alliierter Soldaten in Österreich und Deutschland“,45 und nicht zuletzt das vermehrte Erscheinen autobiographischer Texte von Betroffenen ${ }^{46}$ können nunmehr als Befund für das wachsende Bewusstsein und eine erhöhte Aufmerksamkeit dem Thema gegenüber gelten.

So liegen inzwischen zahlreiche Arbeiten zu den Nachkommen österreichischer Frauen und sowjetischer, ${ }^{47}$ amerikanischer, ${ }^{48}$ britischer ${ }^{49}$ oder französischer ${ }^{50}$

43 Vgl. Projekt: „,Gefühlserbschaften. Von den Besatzungskindern zu den Besatzungsenkeln“, Projektleitung: Rainer Gries (2016-2020), URL: https://franzvranitzkychair.univie.ac.at/forschung/ gefuehlserbschaften (abgerufen 30.09.2020).

44 Projekt: „Besatzungskinder in Tirol. Individuelle Lebensgestaltung und intergenerationale Verarbeitung einer besonderen Herkunft", Projektleitung: Flavia Guerrini (laufend), URL: https:// www.uibk.ac.at/iezw/mitarbeiterinnen/univ.-ass./guerrini/index/forschung.html (abgerufen 14.12.2020).

45 Vgl. Stelzl-Marx/Satjukow (Hg.), Besatzungskinder.

46 Vgl. dazu die autobiografischen Texte in: ebd., 411-493; Eleonore Dupuis, Befreiungskind, Wien 2015.

47 Vgl. u. a. Barbara Stelzl-Marx, Die unsichtbare Generation: Kinder sowjetischer Besatzungssoldaten in Österreich und Deutschland, in: Historical Social Research 34 (2009) 3, 352-372; Barbara Stelzl-Marx, „Ich bin stolz, ein Besatzungskind zu sein.“ Ressourcen und Resilienzfaktoren von Nachkommen sowjetischer Soldaten in Österreich, in: Elke Kleinau/Ingvill C. Mochmann (Hg.), Kinder des Zweiten Weltkrieges. Stigmatisierung, Ausgrenzung, Bewältigungsstrategien, Frankfurt a. M./New York 2016, 73-92.

48 Vgl. etwa Ingrid Bauer, „Austria’s Prestige Dragged into the Dirt?“ The GI-Brides and Postwar Austrian Society (1945-1955), in: Günter Bischof/Anton Pelinka/Erika Thurner (Hg.), Women in Austria, New Brunswick/New York 1998, 41-55; Ingrid Bauer, „Besatzungsbräute“. Diskurs und Praxen einer Ausgrenzung der österreichischen Nachkriegsgeschichte 1945-1955, in: Irene Bandauer-Schöffmann/Claire Duchen (Hg.), Nach dem Krieg. Frauenleben und Geschlechterkonstruktionen in Europa nach dem Zweiten Weltkrieg, Herbholzheim 2000, 261-276.

49 Vgl. u. a. Schretter, Nachkommen britischer Besatzungssoldaten; Karin Schmidlechner, Kinder und Enkelkinder britischer Besatzungssoldaten in Österreich, in: Stelzl-Marx/Satjukow (Hg.), Besatzungskinder, $238-258$.

50 Vgl. u. a. Klaus Eisterer, Fraternisierung 1945, in: Dornbirner Schriften. Beiträge zur Stadtkunde 14/1993, 21-33; Renate Huber, Französische und marokkanische Besatzungskinder in Vorarlberg. Historisches Phänomen und diskursiver Nachhall, in: Stelzl-Marx/Satjukow (Hg.), Besatzungskinder, 355-379; Hamid Lechhab, Marokkanische Besatzungskinder in Vorarlberg nach 1945, in: Walter Sauer (Hg.), Von Soliman bis Omofuma. Afrikanische Diaspora in Österreich, 17. bis 
Besatzungssoldaten vor. Afroamerikanische Besatzungskinder waren hingegen vor allem mit rassistischer Diskriminierung konfrontiert, zusätzlich zu dem ihnen anhaftenden Stigma, „unehelich“ und Kinder des ehemaligen Feindes zu sein, wie die entsprechenden Studien zeigen. ${ }^{51}$

Die Selbstsicht der unehelichen Kinder von österreichischen oder deutschen Frauen und alliierten Besatzungssoldaten hängt von der Persönlichkeitsstruktur, den Lebensbedingungen in Kindheit und Jugend und dem sozialen Umgang mit ihnen in den jeweiligen lokalen Gemeinschaften ab. Dies wird deutlich in den publizierten autobiographischen Texten und in öffentlichen Redebeiträgen von Betroffenen. ${ }^{52}$ Einige Besatzungskinder betonen, dass sie trotz oder wegen ihrer Kindheitsprobleme eine besondere Stärke entwickelt hätten. Von Forscherinnen und Forschern wird in diesem Zusammenhang von „resilienten“ Persönlichkeitsstrukturen gesprochen. ${ }^{53}$ Im Gegensatz dazu berichten andere Besatzungskinder über psychische, psychosomatische und physische Probleme.

Parallel zur Veröffentlichung einzelner Lebensgeschichten entstanden in den letzten Jahren private und institutionalisierte Netzwerke und Selbsthilfegruppen von Besatzungskindern, vielfach vor dem Hintergrund gegenseitiger Unterstützungsleistungen bei der Suche nach den absenten Vätern oder zum Austausch über die Lebensbedingungen im Kindesalter. ${ }^{54}$ Die Netzwerke, die die Betroffenen zudem aus ihrer Vereinzelung herausführen, arbeiten zum Teil eng mit der Wissenschaft zusammen und tragen zur Erforschung dieses Aspekts der Nachkriegszeit bei. Gleichzeitig fungieren Forschende als Vernetzungspunkte und unterstützen Betroffene mit Auskünften, Übersetzungen oder bei der Organisation von Netzwerktreffen. Gerade

20. Jahrhundert, Wien 2007, 177-186; Clément Mutombo, Les Damnés innocents du Vorarlberg. Parianisme envers les enfants historiques (1946), Frankfurt a. M. 2007.

51 Vgl. etwa Ingrid Bauer, „Leiblicher Vater: Amerikaner (Neger)“. Besatzungskinder österreichischafroamerikanischer Herkunft, in: Helmuth A. Niederle/Ulrike Davis Sulikowski/Thomas Fillitz (Hg.), Früchte der Zeit. Afrika, Diaspora, Literatur und Migration, Wien 2001, 49-67; Regina Fritz/Marion Krammer/Philipp Rohrbach, Diskriminiert - Abgelehnt - Vergessen. Kinder afroamerikanischer GIs und österreichischer Frauen nach 1945. Ein Projektbericht, in: Österreichische Zeitschrift für Geschichtswissenschaften 25 (2014) 1-2, 359-367; Niko Wahl/Philipp Rohrbach/Tal Adler, SchwarzÖsterreich. Die Kinder afroamerikanischer Besatzungssoldaten. Katalog zur Ausstellung im Österreichischen Volkskundemuseum von April bis August 2016, Wien 2016; Bauer/Rohrbach, Black GI Children.

52 Vgl. beispielsweise Dupuis, Befreiungskind; Rosa Schwarzkopf/Christian Mader, „So war mein Leben“ - Die Wahrheit über das Leben eines „Russenbankerts“, Wien 2016.

53 Vgl. Stelzl-Marx, Ressourcen und Resilienzfaktoren.

54 Genannt seien vor allem die folgenden Plattformen: URL: www.russenkinder.de; URL: www.russenkinder-distelblueten.de; URL: www.coeurssansfrontieres.com; URL: www.gitrace.org und URL: www.abgaengig-vermisst.at (alle abgerufen 30.09.2020). 
in den Vernetzungstreffen und Anfragen - beispielsweise an das Ludwig Boltzmann Institut für Kriegsfolgenforschung - wird deutlich, dass es sich bei der Geschichte der Besatzungskinder um keinen abgeschlossenen Themenkomplex handelt, sondern dass dieser für die Betroffenen von großer Relevanz ist und transgenerationell auch deren Kinder und Enkelkinder in der Auseinandersetzung mit den familiären „Wurzeln" berührt.

\subsection{Desiderata}

Viele Fragestellungen zu Kindern des Krieges stellen nach wie vor ein Desiderat dar oder konnten nur ansatzweise beleuchtet werden, darunter etwa die Kinder von Zwangsarbeitern bzw. Zwangsarbeiterinnen oder Kriegsgefangenen, die in der "Ostmark" geboren worden waren, ${ }^{55}$ oder auch die Nachkommen österreichischer Wehrmachtssoldaten in den besetzten Gebieten, insbesondere in Polen oder in der Sowjetunion, ${ }^{56}$ oder auch Nachkommen von (österreichischen) UNO-Friedenstruppen und einheimischen Frauen an den jeweiligen Einsatzorten.

Lücken gibt es in diesem Zusammenhang etwa auch hinsichtlich der Geschichte des Lebensborn in Österreich zwischen 1938 und 1945, insbesondere des größten Lebensborn-Heimes Wienerwald in Feichtenbach. Generell verfolgte die NSSexualpolitik das Ziel der "Reinhaltung des deutschen Blutes“ als Bestandteil der Erb- und Rassenpflege, gerichtet gegen Menschen, die nicht „deutschen oder artverwandten Blutes" waren. ${ }^{57}$ Die nationalsozialistische Rassenpolitik beschränkte sich nicht nur auf die Vernichtung „unwerten“ Lebens, sondern umfasste auch die

55 Vgl. Gabriella Hauch, Zwangsarbeiterinnen und ihre Kinder: Zum Geschlecht der Zwangsarbeit, in: Oliver Rathkolb (Hg.), NS-Zwangsarbeit. Der Standort Linz der „Reichswerke Hermann Göring AG Berlin“ 1938-1945, Bd. 1: Christian Gonsa/Gabriella Hauch/Michael John/Josef Moser/ Bertrand Perz/Oliver Rathkolb/Michael C. Schober, Zwangsarbeit - Sklavenarbeit: Politik-, sozial- und wirtschaftshistorische Studien, Wien/Köln/Weimar 2001, 355-448; Barbara Stelzl-Marx, „B-Baracke“. Das Lagerbordell für NS-Zwangsarbeiter in Graz, in: Friedrich Bouvier/Wolfram Dornik/Otto Hochreiter/Nikolaus Reisinger/Karin Maria Schmidlechner (Hg.), GeschlechterGeschichten (Historisches Jahrbuch der Stadt Graz 47), Graz 2017, 229-246.

56 Vgl. den Forschungsüberblick in: Barbara Stelzl-Marx, Wehrmachtskinder in der Sowjetunion. Die vergessenen Sekundäropfer des Zweiten Weltkrieges, in: Gisela Heidenreich (Hg.), Born of War Vom Krieg geboren. Europas verleugnete Kinder, Berlin 2017, 338-359.

57 Birgit Poier, „Erbbiologisch unerwünscht“. Die Umsetzung rassenhygienisch motivierter Gesundheits- und Sozialpolitik in der Steiermark 1938-1945, in: Wolfgang Freidl/Werner Sauer (Hg.), NSWissenschaft als Vernichtungsinstrument. Rassenhygiene. Zwangssterilisation, Menschenversuche und NS-Euthanasie in der Steiermark, Wien 2004, 177-224, 187. 
Förderung „erbgesunden“ Nachwuchses. Eine zentrale Rolle spielte der 1935 gegründete Lebensborn e. V. Mit dem Ziel, auf Grundlage der NS-Rassenhygiene und Gesundheitsideologie die Geburtenziffer „,arischer“ Kinder zu erhöhen, unterhielt der Verein Entbindungsanstalten im Deutschen Reich und in den besetzten Gebieten. Der Lebensborn war außerdem für die Verschleppung von Kindern aus den von Hitler-Deutschland besetzten Gebieten verantwortlich. Ein aktuelles Projekt zum „Lebensbornheim Wienerwald: Tabu und Projektion“, gefördert vom Jubiläumsfonds der Österreichischen Nationalbank und dem Land Niederösterreich, soll sich diesem Desiderat auf Grundlage bislang nicht berücksichtigter Quellen widmen. ${ }^{58}$

\section{Zwangsmigration}

Räumliche Mobilität und damit verknüpfte gesellschaftliche, politische und sozioökonomische Veränderungen stellen in der Kriegsfolgenforschung wichtige Forschungsthemen dar. Migrationsprozesse sind in unterschiedlichen Formen und Ausprägungen durch alle historischen Epochen hinweg beobachtbar. Unabhängig von ihrem Ausmaß werden räumliche Bevölkerungsbewegungen - seien es Binnenwanderungen innerhalb von Regionen oder Auswanderungen über Staatsgrenzen hinweg in andere Länder oder auf andere Kontinente - durch unterschiedlichste Faktoren ausgelöst. Besonders häufig liegen Migrationen ökonomische, politische oder religiöse Motive zugrunde; neben Kriegen und politischen Konflikten stellen auch (Natur)Katastrophen oder klimatische Veränderungen zentrale Auslöser für räumliche Mobilität und Fluchtbewegungen dar.

Die Zeitgeschichts- und Kriegsfolgenforschung in Österreich widmet sich speziell auch der Untersuchung von erzwungenen Migrationen und ihren Folgen auf gesellschaftlicher und individueller Ebene. ${ }^{59}$ Dazu gehören unter anderem Flucht und Vertreibung aus Österreich unter nationalsozialistischer Herrschaft, ${ }^{60}$ Flücht-

58 Vgl. URL: www.bik.ac.at (abgerufen 30.09.2020).

59 Stefan Karner/Barbara Stelzl Marx (Hg.), Migration. Flucht - Vertreibung - Integration, Graz/ Wien 2019.

60 Von den zahlreichen Publikationen seien stellvertretend genannt: Die vom Dokumentationsarchiv des österreichischen Widerstands zwischen 1984 und 2002 herausgegebene Serie „Österreicher im Exil“ (Frankreich, Spanien, Belgien, Großbritannien, USA, Sowjetunion und Mexiko); Erika Weinzierl/Otto D. Kulka (Hg.), Vertreibung und Neubeginn. Israelische Bürger österreichischer Herkunft, Wien 1992; Friedrich Stadler (Hg.), Vertriebene Vernunft, Emigration und Exil österreichischer Wissenschaft 1930-1940, 2 Bde., Münster 22004; Andrea Strutz, Split Lives: Memories and Narratives of Austrian Jewish Refugees, in: Günter Bischof/Fritz Plasser/Barbara Stelzl-Marx (Hg.), New Perspectives on Austrians and World War II (Contemporary Austrian Studies 57), New 
linge und Displaced Persons (DPs) nach dem Zweiten Weltkrieg, ${ }^{61}$ aber auch die Erforschung rezenter Migrationsprozesse aufgrund von Kriegen und Konflikten. ${ }^{62}$

\subsection{Flucht und Vertreibung}

Der Terminus Migration umfasst unterschiedlichste Formen von Wanderungen und Mobilität und deren Auslöser. Die Typologien von Migrationsbewegungen orientieren sich häufig an Faktoren wie dem Motiv, der räumlichen Distanz, dem Richtungsverlauf oder der Dauer. ${ }^{63}$ Die Erscheinungsformen von Migration sind vielfältig, und sie inkludieren neben Arbeits- und Siedlungswanderungen, Bildungs, Ausbildungs- und Kulturwanderungen, Heiratsmigrationen und Wohlstandswanderungen auch Gewaltmigrationen, also Migrationen, die aus einer Nötigung zur Abwanderung aus politischen, religiösen, rassistischen oder ethnonationalen Gründen erfolgen wie Flucht, Vertreibung, Umsiedlung oder Deportation. ${ }^{64}$

Im Bereich von Gewaltmigrationen erfolgten etwa Recherchen zu nach Lettland geflohenen österreichischen Juden ${ }^{65}$ oder das Projekt „(Nicht) im Gepäck? Über mitgebrachte, zurückgelassene und neu erworbene Dinge des Hausrats im Kontext von Flucht und Vertreibung (1945/2015)“ der Untersuchung von Objekten, die im Zuge von Fluchtbewegungen mitgebracht bzw. zurückgelassen wurden. Im Zentrum des

Brunswick/London 2009, 182-199; Christian Fleck, Editorial: Vertreibung von Wissenschaft, in: Österreichische Zeitschrift für Geschichtswissenschaften 21 (2010) 3, 5-9; Stefan Karner/Philipp Lesiak/Heinrihs Strods (Hg.), Die Flucht österreichischer Juden nach Lettland 1938-1941, Innsbruck/Wien/Bozen 2010; Philipp Mettauer, Erzwungene Emigration nach Argentinien. Österreichisch-jüdische Lebensgeschichten, Münster 2010; Margit Franz/Heimo Halbrainer (Hg.), Going East - Going South. Österreichisches Exil in Asien und Afrika, Graz 2014.

61 Vgl. dazu u. a. Thomas Albrich, Exodus durch Österreich. Die jüdischen Flüchtlinge 1945-1948, Innsbruck 1987; Gernot Heiss (Hg.), Asylland wider Willen. Flüchtlinge in Österreich im europäischen Kontext seit 1914, Wien 1995; Gabriela Stieber, Nachkriegsflüchtlinge in Kärnten und der Steiermark, Graz 1997; Sabine Aschauer-Smolik (Hg.), Tamid Kadima - immer vorwärts: Der jüdische Exodus aus Europa 1945-1948, Innsbruck/Wien 2010; Philipp Ther, Die Außenseiter: Flucht, Flüchtlinge und Integration im modernen Europa, Berlin 2017; Heribert Macher-Kroisenbrunner, „We hope to go to Palestine“. Das jüdische DP-Lager Admont 1946-1949, Graz 2018.

62 Vgl. etwa Karner/Stelzl-Marx (Hg.), Migration.

63 Vgl. Dirk Hoerder/Jan Lucassen/Leo Lucassen, Terminologien und Konzepte, in: Klaus J. Bade/ Pieter C. Emmer/Leo Lucassen/Jochen Oltmer (Hg.), Enzyklopädie Migration in Europa. Vom 17. Jahrhundert bis zur Gegenwart, Paderborn 2007, 36-39.

64 Vgl. Jochen Oltmer, Globale Migration. Geschichte und Gegenwart, München 2012, 18-19.

65 Stefan Karner/Philipp Lesiak/Heinrichs Strods (Hg.), Österreichische Juden in Lettland. Flucht Asyl - Internierung (Veröffentlichungen des Ludwig Boltzmann Instituts für Kriegsfolgen-Forschung 16), Innsbruck/Wien/Bozen 2010. 
Teilprojekts „Mobile Dinge“ steht die Frage, welche Bedeutung die mitgebrachten, zurückgelassenen und neu erworbenen Dinge des Hausrats im Migrationsprozess bzw. im Alltag des neuen sozialen Kontextes für Geflüchtete haben. Untersucht wird dabei sowohl die „Mobilität von Dingen“ als auch die „Mobilität an Dingen“, zum Beispiel inwiefern sich im Laufe des Migrationsprozesses die Verwendung und Bedeutung der betrachteten Dinge veränderten. ${ }^{66}$

Zur Lage von Displaced Persons und Flüchtlingen, die sich nach dem Kriegsende in unterschiedlichen Regionen Österreichs aufhielten und zum Teil in Österreich verblieben, bzw. zur Rolle Österreichs als Transitland für Flüchtlinge und DPs in der Nachkriegszeit existieren bereits etliche Publikationen, die diese Thematik am Beispiel unterschiedlicher Flüchtlingsgruppen (wie jüdische DPs, „Volksdeutsche“) und auch in unterschiedlichen Regionen beleuchten. ${ }^{67}$

Auch das Projekt „Niederösterreich: Zwangsmigrations- und Integrations/Inklusionsraum in der Nachkriegszeit, 1945-1956" setzte sich mit Flüchtlingen und Displaced Persons und deren Lebensbedingungen auseinander. Österreich war und ist Transit- und Zielland von Fluchtbewegungen. Allein in der zweiten Hälfte des 20. Jahrhunderts erlebte Österreich einige große Flüchtlingswellen. Mit 1,4 bis 1,6 Millionen Displaced Persons, Flüchtlingen und Vertriebenen als Folge der NSAggression stellte die Besatzungszeit die mit Abstand größten humanitären und inklusiven/integrativen Herausforderungen an die österreichische Gesellschaft im 20. Jahrhundert, gefolgt von den Fluchtbewegungen infolge der Ungarn-Krise 1956 mit rund 170.000 Betroffenen. Niederösterreich spielte für diese Migrationsbewegungen eine bedeutende und auch vielfältige Rolle. Es war gleichzeitig Ausgangs, Transfer- und Zielland der Fluchtbewegungen dieses Zeitraumes. Die Vertreibung der deutschsprachigen Minderheit aus der Tschechoslowakei 1945/1946 sowie die

66 Vgl. (Nicht) im Gepäck: Über mitgebrachte, zurückgelassene und neu erworbene Dinge im Kontext von Flucht und Vertreibung, FH St. Pölten, URL: https://research.fhstp.ac.at/projekte/nichtim-gepaeck-ueber-mitgebrachte-zurueckgelassene-und-neu-erworbene-dinge-im-kontext-vonflucht-und-vertreibung (abgerufen 30.09.2020); Mobile Dinge, Menschen und Ideen, mobile dinge, URL: https://www.mobiledinge.at (abgerufen 30.09.2020).

67 Vgl. z. B. Susanne Rolinek, Jüdische Lebenswelten 1945-1955. Flüchtlinge in der amerikanische Zone Österreichs, Innsbruck/Wien/Bozen 2007; Michael John, Flüchtlinge und Baracken - „Wartesaal“ und „Neue Heimat“. Linz nach dem Zweiten Weltkrieg, in: Nordico Stadtmuseum Linz (Hg.), Geteilte Stadt. Linz 1945-55, Salzburg 2015, 159-169; Dieter Bacher/Niklas Perzi, Chance auf eine neue Heimat. Zwangsarbeiter, DPs und Vertriebene auf dem Gebiet der Republik Österreich 19441950, in: Börries Kuzmany/Rita Garstenauer (Hg.), Aufnahmeland Österreich. Über den Umgang mit Massenflucht seit dem 18. Jahrhundert, Wien 2017, 175-205; Melanie Dejnega, „Heimat“ im Gepäck? Die Bedeutung der Migrationserfahrung in Lebensgeschichten „deutscher Vertriebener“ in Österreich, phil. Diss., Universität Bielefeld 2020. 
von Deutschen aus anderen Regionen Zentral- und Südosteuropas, von ZwangsarbeiterInnen sowie Kriegsgefangenen aus ganz Europa, aber auch von Flüchtlingen aus der Tschechoslowakei ab 1948 machte aus Niederösterreich einen Migrations, aber auch Integrations/Inklusionshotspot. ${ }^{68}$

Die Untersuchung „Flucht, Deportation, Internierung. Auf den Spuren österreichischer NS-Flüchtlinge in Kanada“, gefördert vom Zukunftsfonds der Republik Österreich und dem Land Niederösterreich, setzt sich mit einem wenig rezipierten Aspekt der Exilforschung ${ }^{69}$ auseinander und verfolgt das Ziel, jene aus Österreich vertriebenen Männer zu identifizieren, die 1940 als „enemy aliens“ in einer Gruppe von etwa 2.000 deutschsprachigen NS-Flüchtlingen von Großbritannien nach Kanada deportiert und dort bis zu drei Jahre in Lagern im Osten des Landes interniert wurden. Aus verschiedenen historischen Quellenbeständen werden die Namen, biographische Grunddaten sowie weitere biographische Informationen der internierten Flüchtlinge eruiert, aufbereitet und systematisch in eine eigens kreierte Datenbank eingepflegt. Dabei sind aber nicht nur Daten über Flucht und Verfolgung, die Internierung und die Entlassung von Interesse, sondern es sollen auch Informationen über verschiedene Stationen des Weiterlebens dieser NS-Flüchtlinge - soweit dies heute noch möglich ist - erfasst werden. ${ }^{70}$

\subsection{Desiderata}

Im Zusammenhang mit Zwangsmigration als Kriegsfolge sind noch zahlreiche Themen offen. Von Interesse wären etwa vergleichende Studien von Migration als Folge des Zweiten Weltkrieges und aktueller Konflikte. Desiderata liegen etwa auch bei der

68 Vgl. Forschungsverbund Migration, first, URL: http://first-research.ac.at/forschungsverbundmigration/ (abgerufen 30.09.2020); Dieter Bacher, Niederösterreich: Zwangsmigrations- und Integrations-/Inklusionsraum in der Nachkriegszeit 1945-1956, Ludwig Boltzmann Institut für Kriegsfolgenforschung, URL: http://first-research.ac.at/wp-content/uploads/2016/og/Bacher.pdf (abgerufen 30.09.2020).

69 Vgl. etwa Patrick Farges, Bindestrich-Identitäten? Sudetendeutsche Sozialdemokraten und deutsche Juden als Exilanten in Kanada, Bremen 2015, 115-153; Andrea Strutz, Flucht und Vertreibung nach Kanada: Ein Forschungsdesiderat der österreichischen Exilgeschichte, in: Evelyn Adunka/ Primavera Driessen Gruber/Simon Usaty (Hg.), Exilforschung Österreich: Leistungen, Defizite \& Perspektiven, Wien 2018, 114-130.

70 Vgl. dazu Andrea Strutz, Interned as „enemy aliens“: Jewish Refugees from Austria, Germany and Italy in Canada, in: Swen Steinberg/Anthony Grenville (Hg.), Refugees from Nazi-occupied Europe in British Overseas Territories (Yearbook of the Research Centre for German and Austrian Exile Studies 20), Leiden/Boston 2020, 46-67. 
Wahrnehmung von Flüchtlingen und DPs in den städtischen und ländlichen Regionen Österreichs durch die ansässige Wohnbevölkerung bzw. der unterschiedlichen Zuschreibungen in den Medien vor.

Wie das Beispiel des in Ansätzen erforschten deutschsprachigen Exils in Kanada zeigt, ${ }^{71}$ fehlt eine systematische Untersuchung der Erinnerungen von Flüchtlingen sowohl in Bezug auf Flucht und Vertreibung aus Europa als auch hinsichtlich ihrer Aufnahme und Integration in einer neuen, anderssprachigen Gesellschaft. ${ }^{72}$ Ebenso sind Untersuchungen über geschlechterspezifische Erfahrungen etwa hinsichtlich der Integrationserfahrungen oder der Veränderung von Geschlechterbeziehungen durch das Exil ausständig. ${ }^{73}$ Weitere offene Fragen betreffen etwa Weitermigrationen von ehemaligen Flüchtlingen nach $1945 .{ }^{74}$

\section{Resümee}

Mit den Worten „Der Krieg ist nie ein isolierter Akt“ ergänzte der bedeutende preuBische Militärtheoretiker Carl von Clausewitz das Zitat Heraklits, nach dem der Krieg der „Vater aller Dinge“ sei. Die beiden Weltkriege und der Kalte Krieg prägten das 20. Jahrhundert, ihre Folgen sind vielfach bis heute spürbar. Der Forschung gelang es, in diesem Bereich vieles sichtbar zu machen, was jahrzehntelang im Verborgenen geschwelt hatte. Zahlreiche Fragen sind aber auch noch offen, müssen erst gestellt und bearbeitet werden. Ein beachtlicher Teil der Themen hat bis heute große gesellschaftspolitische Relevanz, zeigt das Zusammenspiel von Mikro- und Makrogeschichte sowie die Konsequenzen der Weltpolitik in diesem Bereich der äl-

71 Vgl. dazu etwa Annette Puckhaber, Ein Privileg für wenige. Die deutschsprachige Migration nach Kanada im Schatten des Nationalsozialismus, Münster/Hamburg/London 2002; Genevieve Susemihl, „... and it became my home." Die Assimilation und Integration der deutsch-jüdischen Hitlerflüchtlinge in New York und Toronto, Münster 2004.

72 Beispielsweise prägten NS-Vertriebene die Entwicklung der kanadischen Musikwissenschaft und der kanadischen E-Musik ganz entscheidend durch transferiertes Wissen, das sie in ihren Herkunftsländern z. B. an Universitäten oder Akademien erworben hatten; vgl. Paul Helmer, Growing with Canada. The Émigré Tradition in Canadian Music, Montreal/Kingston/London 2009.

73 Vgl. zur Veränderung des Rollenbildes bei Frauen im Exil u. a. Genevieve Susemihl, „Wir bauen auf." Deutsch-jüdische Frauen in der amerikanischen Emigration, in: Ulla Kriebernegg/Gerald Lamprecht/Roberta Maierhofer/Andrea Strutz (Hg.), „Nach Amerika nämlich!“ Jüdische Migrationen in die Amerikas im 19. und 20. Jahrhundert, Göttingen 2012, 157-180.

74 Vgl. zu den Forschungen zu Israel/Palästina etwa: Thomas Albrich/Ronald W. Zweig (Hg.), Escape through Austria. Jewish Refugees and the Austrian Route to Palestine, London/Portland (OR) 2002. 
testen Form organisierter Gewalt auf individuelle Biographien. Wenngleich bewaffnete Auseinandersetzungen, das legitimierte Töten von als Feinden bezeichneten Menschen in der Prioritätsskala der zu vermeidenden Ereignisse in der modernen Agenda - zumindest offiziell - ganz oben stehen, wird die Forschung zu den Folgen von Kriegen wohl nicht so rasch obsolet werden. 


\section{Film}

\section{Christina Wieder}

Bereits in der dritten Ausgabe der von Erika Weinzierl begründeten Zeitschrift „zeitgeschichte“, im Dezemberheft des Jahres 1973, veröffentliche Georg E. Schmid einen Aufsatz mit dem Titel „Die cinéastische Avantgarde Frankreichs 1958-1968. Ein Beitrag zur französischen Kulturgeschichte“. Schmid - später außerordentlicher Professor an der Universität Salzburg und, wie Thomas Ballhausen und Alessandro Barberi schreiben, „der Doyen der österreichischen Filmgeschichtsschreibung “ widmete sich darin der Frage, ob das Kino der Nouvelle Vague durch filmisch-ästhetische Interventionen eine Entwicklung vorweggenommen habe, die sich später in der Auflehnung der studentischen Proteste von 1968 politisch manifestierten sollte. ${ }^{2}$ Er behandelt folglich den Stellenwert des Kinos innerhalb kultureller und sozialer Entwicklungen und erörtert die Bedeutung der Beteiligten rund um die Filmzeitschrift „Cahiers du Cinéma“ (darunter Claude Chabrol, Jean-Luc Godard, Jacques Rivette, Éric Rohmer und François Truffaut), die, von der theoretischen Auseinandersetzung mit dem Film kommend, den Sprung in die cineastische Praxis wagen sollten. Obgleich aus heutiger Sicht kaum Zweifel daran bestehen kann, dass die Nouvelle Vague das französische - wenn nicht sogar das internationale - Kino revolutionierte, schrieb Schmid 1973 noch etwas vorsichtig, dass „die Veränderung des französischen Kinos, die, wie die Auflehnung von 1968 bewiesen hat, die bei weitem überwiegende Majorität der französischen Cinéasten will, nur erfolgen kann, wenn die französische Gesellschaft verändert wird“.3

Schmids Aufsatz steht nun deshalb zu Beginn meiner Ausführungen, da es sich hierbei einerseits um eine der ersten geschichtswissenschaftlichen Auseinandersetzungen mit Film(bewegungen) im österreichischen Zeitgeschichtekontext handelt und er andererseits erlaubt, eine Gliederung für meinen Beitrag vorzunehmen. Retrospektiv betrachtet, scheint es kein Zufall gewesen zu sein, dass Schmid sich in seinen Ausführungen einer französischen Filmbewegung widmete und anhand dieser einen Beitrag zur kulturwissenschaftlichen Zeitgeschichtsforschung leistete, waren es doch vor allem französische HistorikerInnen, die markant dazu beitrugen, Film

1 Thomas Ballhausen/Alessandro Barberi, editorial: die wahrheit des film/cinema’s truth, in: Österreichische Zeitschrift für Geschichtswissenschaften 24 (2013) 3, 7.

2 Georg E. Schmid, Die cinéastische Avantgarde Frankreichs 1958-1968. Ein Beitrag zur französischen Kulturgeschichte, in: zeitgeschichte $1(1973 / 1974)$ 3, 51-63.

3 Ebd., 59 . 
als Quelle für die Geschichtswissenschaften zu etablieren. ${ }^{4}$ Zwar stellen Schmids Ausführungen eher eine Verhandlung von Produktionsumständen und strukturellen Veränderungen innerhalb eines kulturpolitischen Kontexts dar als eine analytische Auseinandersetzung mit dem filmischen Erbe selbst, wohl aber wird dem Film hier eine zentrale gesellschaftspolitische Funktion zugesprochen. Daran anschließende, an österreichischen Geschichtsinstituten geführte Debatten zum Umgang mit Film als historische Quelle und zu dessen gesellschaftlicher, politischer und kultureller Stellung sollen im Zentrum meiner Ausführungen stehen. In diesem Prozess spielten neben universitären Einrichtungen vor allem das Filmarchiv Austria und das Österreichische Filmmuseums eine essenzielle Rolle, weshalb die Besprechung dieser Institutionen den ersten Teil füllen wird. Ein zweiter Schwerpunkt wird dem Einsatz von Film zur Geschichtsvermittlung gewidmet sein sowie jenen Prozessen innerhalb der Zeitgeschichtsforschung, die, beeinflusst durch die sogenannten Pictorial, Iconic oder Visual Turns, ${ }^{5}$ zur Entwicklung der Visual History ${ }^{6}$ und einer Ausdifferenzierung des historischen Quellenkorpus geführt bzw. den Film von seiner Reduktion auf reine Illustrationsoptionen befreit haben. Drittens und abschließend sollen Herausforderungen, Desiderate und Perspektiven im Forschungsfeld Film und Zeitgeschichte besprochen werden.

4 Beispielsweise: Marc Ferro, Le film, une contre-analyse de la société?, in: Annnales 28 (1973), 109-124; Marc Ferro, The Fiction Film and Historical Analysis, in: Paul Smith (Hg.), The Historian and Film, Cambridge 1976, 80-94; Marc Ferro, Cinéma et Histoire, Paris 1976; Michéle Lagny, De l'histoire du cinéma: méthode historique et histoire du cinéma, Paris 1992; Pierre Sorin, Clio à lècran ou l'historien dans le noir, in: Revue d'histoire moderne et contemporaine 21 (1974), 252-278.

5 Zentrale Vertreter sind: W. J. T. Mitchell, The Pictorial Turn, in: Artforum 30 (1992) 7, 89-94; W. J. T. Mitchell, Bildtheorie, Frankfurt a. M. 2008; Gottfried Boehm, Die Wiederkehr der Bilder, in: Gottfried Boehm (Hg.), Was ist ein Bild?, München 1994, 11-38; Gottfried Boehm, Wie Bilder Sinn erzeugen. Die Macht des Zeigens, Berlin 2007; Klaus Sachs-Hombach, Das Bild als kommunikatives Medium. Elemente einer allgemeinen Bildwissenschaft, Köln 1993.

6 Gerhard Jagschitz, ab 1966 am Wiener Institut für Zeitgeschichte tätig, gilt als Begründer der Visual History in Österreich, jedoch blieben seine Ausführungen dazu primär auf das Medium Fotografie beschränkt. Vgl.: Gerhard Jagschitz, Visual History, in: Das audiovisuelle Archiv 29-30/1991, 23-51; dass der Begriff der Visual History weitere Verbreitung fand, ist v. a. der Forschungsaktivität Gerhard Pauls zu verdanken, der entscheidend das Spektrum an für die Geschichtsforschung relevanten Bildquellen erweiterte. Obgleich Paul stets die Bedeutung des Films betont, bleibt seine Forschung jedoch auch primär auf nichtbewegte Bilder beschränkt. Vgl.: Gerhard Paul (Hg.), Visual History. Ein Studienbuch, Göttingen 2006; siehe auch: Klaudija Sabo/Christina Wieder, Visual History in Bewegung. Bildliche Quellen in der historischen Forschung, in: Bertrand Perz/Ina Markova (Hg.), 50 Jahre Institut für Zeitgeschichte der Universität Wien 1966-2016, Wien 2017, 299-311. 


\section{Unverfälscht und ungekürzt - Vom Archiv auf die Leinwand und ins Lehrbuch}

Obgleich sich erst ab Mitte bis Ende der 1990er-Jahre eine intensivere Auseinandersetzung mit dem Medium Film in der österreichischen Geschichtswissenschaft verzeichnen lässt, 7 ist es notwendig, historisch weiter auszuholen, um vor allem jenen Institutionen Beachtung zu schenken, die noch bevor intensivere akademische Debatten zum Film entfachten, dessen besonderen Quellenwert erkannt hatten - allen voran das Filmarchiv Austria und das Österreichische Filmmuseum.

Auf Initiative des Direktors der Theatersammlung der Österreichischen Nationalbibliothek Joseph Gregor wurde 1929 erstmals in Österreich ein Archiv für Filmkunde begründet. Gregor war einer der Ersten, der erkannte, dass man die österreichische Filmkultur, die in den 1920er-Jahren durch aufwändige Produktionen von zahlreichen Monumentalfilmen einen Höhepunkt erreichte, schützen und bewahren musste - ein Gedanke, der nach Jahren der nationalsozialistischen Kulturund Film(kultur)vernichtung erst 1945 wieder aufgenommen wurde. Mit wiederentdecktem Bewusstsein für das Medium Film und dessen Konservierung wurden 1945 die Gesellschaft der Filmfreunde Österreichs sowie die Zeitschrift „Filmkunst“ gegründet. Als Basis wissenschaftlicher Filmforschung folgte 1952 die Gründung der Österreichischen filmwissenschaftlichen Gesellschaft. Im Jahr 1954, während der Ersten Internationalen filmwissenschaftlichen Woche in Wien, wurde erstmals die Forderung laut, dass Österreich ein eigenes Filmarchiv brauche, woraufhin am 17. Oktober 1955 das Österreichische Filmarchiv (ÖFA) gegründet wurde. Anfänglich als Verein geführt, sammelte das ÖFA neben Spiel, Dokumentar- und Wochen-

7 Diese Entwicklung lässt sich v. a. nachzeichnen, sieht man sich die Beiträge der Österreichischen Zeitgeschichtetage seit 1993 an. Während die Zeitgeschichtetage 1993 und 1995 nur jeweils ein Panel zu „Inszenierung der Geschichte - Museen und Ausstellungen als ,Massenmedien' der Zeitgeschichte" anboten, jedoch noch keines, das sich explizit mit Film befasste, änderte sich das ab 1999. Neben dem Panel "Cultural Expression in European Post-Authoritorian Regimes“ mit Beiträgen zum spanischen und portugiesischen Film von Linda Materna und Ana Soares fand am 27. Mai 1999 ein Gespräch zwischen Georg Seeßlen und Marcel Ophüls, moderiert von Wolfgang Kos, zu „Geschichte und Film: Mythos gegen Erinnerung“ sowie am 29. Mai 1999 ein Filmscreening von „Jud Süß“ mit anschließender Podiumsdiskussion statt: Veit Harlan, Jud Süß, Deutschland 1940; außerdem präsentierte Albert Lichtblau in der begleitenden Publikation sowie im Panel „Imaging History" den Video-History Lehrgang an der Universität Salzburg, siehe: Albert Lichtblau, Audiovisuelle Geschichte? Der „Video-History“-Lehrgang an der Universität Salzburg, in: Manfred Lechner/Dietmar Seiler (Hg.), zeitgeschichte.at, 4. Österreichischer Zeitgeschichtetag, Innsbruck 1999, 241-249; bei den folgenden Zeitgeschichtetagen 2003-2018 finden sich dann diverse Panels und Beiträge, die sich mit Film befassen. 
schaufilmen weitere filmrelevante Materialien. ${ }^{8}$ Neben dieser Sammeltätigkeit fokussierte es auf Restaurierungs- und Konservierungstätigkeiten und verfolgte die Zielsetzung, diese durch Filmscreenings, Retrospektiven und Ausstellungen in die Öffentlichkeit zu tragen. ${ }^{9}$ Im Jahr 1997 erfolgte nicht nur die Umbenennung des Österreichischen Filmarchivs in Filmarchiv Austria, sondern auch eine inhaltliche Umorientierung. Durch die im selben Jahr gestartete DVD-Edition „Österreich in historischen Filmdokumenten" sowie die Publikationstätigkeit wissenschaftlicher Arbeiten ${ }^{10}$ im Jahr 1999 ist das Filmarchiv Austria nicht mehr rein auf eine Sammelund Konservierungstätigkeit zu reduzieren, sondern verfolgt ebenso eine zeithistorische Forschungsarbeit, die markant zur Etablierung des Films als Geschichtsquelle beigetragen hat.

Eine ähnlich zentrale Rolle in diesem Prozess spielte das von Peter Konlechner und Peter Kubelka im Jahr 1964 gegründete Österreichische Filmmuseum. Auch das Filmmuseum machte es sich zur Aufgabe zu bewahren, zu restaurieren und zu vermitteln und orientierte sich hierfür an internationalen Vorbildern wie der Cinémathèque Française oder der Filmabteilung des Museum of Modern Art in New York. Inhaltlich standen vor allem in der Anfangsphase des Museums der Avantgar-

8 Geschichte des Filmarchiv Austria, Filmarchiv Austria, URL: https://www.filmarchiv.at/about/history/ (abgerufen 15.02.2020).

9 Bereits 1961 erfolgte die Rekonstruktion des Stummfilms „Der Rosenkavalier“ (Robert Wiene, Der Rosenkavalier, Österreich 1926), 1963 dann erstmals die Beteiligung am Programm der Viennale durch die Retrospektive „Festival der Heiterkeit“, 1971 wurde die Filmlageranlage im Alten Schloss in Laxenburg eröffnet mit der Ausstellung „Wien - Berlin - Hollywood. Richard Oswalt“. In den Jahren darauf folgten Ausstellungen und Retrospektiven zu G. W. Pabst, Hans Moser und Fred Astaire. Siehe: Geschichte des Filmarchiv Austria, Filmarchiv Austria, URL: https://www.filmarchiv. at/about/task/ (abgerufen 15.02.2020).

10 Die erste Publikation des Filmarchiv Austria beschäftigt sich mit dem österreichischen Stummfilm: Francesco Bono/Paolo Caneppele/Günter Krenn (Hg.), Elektrische Schatten. Beiträge zur österreichischen Stummfilmgeschichte, Wien 1999. Zahlreiche weitere Publikationen folgten. Exemplarisch: Armin Loacker (Hg.), Unerwünschtes Kino - der deutschsprachige Emigrantenfilm 1934-1937, Wien 2000; Armin Loacker (Hg.), Imaginierte Antike: österreichische MonumentalStummfilme, Historienbilder und Geschichtskonstruktionen in Sodom und Gomorrah, Samson und Delila, Die Sklavenkönigin und Salammbô, Wien 2002; Michael Aschenbach/Karin Moser (Hg.), „Österreich in Bild und Ton“. Die Wochenschau des austrofaschistischen Ständestaates, Wien 2002; Karin Moser (Hg.), Besetzte Bilder. Film, Kultur und Propaganda in Österreich 1945-1955, Wien 2005; Thomas Ballhausen/Barbara Eichinger/Karin Moser/Frank Stern (Hg.), Tatsachen der Seele. Arthur Schnitzler und der Film, Wien 2006; Verena Moritz/Karin Moser/Hannes Leidinger (Hg.), Kampfzone Kino. Film in Österreich 1918-1938, Wien 2008; Michael Achenbach/Thomas Ballhausen/Nikolaus Wostry (Hg.), Saturn. Wiener Filmerotik 1906-1910, Wien 2009. 
defilm, die Filmkomik der 1920er- und 1930er-Jahre sowie der sowjetische Film ${ }^{11}$ im Zentrum der Aufmerksamkeit. Dem (geschichts)wissenschaftlichen Anspruch des Filmmuseums ${ }^{12}$ könnte kaum deutlicher Ausdruck verliehen werden als mit dem Anliegen, dass der Film ,auch in Österreich als wichtigste Ausdrucksform der Moderne und als wichtigste zeitgeschichtliche Quelle des 20. Jahrhunderts verstanden werden [sollte] “. ${ }^{13}$ Dass dem Film als historische Quelle ebenso eine ästhetische Komponente innewohnt, geht aus folgendem Grundsatz hervor:

Filme sind mit gleicher Obhut und gleichem Respekt wie Gemälde oder Plastiken zu sammeln, zu bewahren und zu präsentieren. Filmen gebührt der Stellenwert und die Behandlung von Kunstwerken. Filme sind spezifische Produkte des geschichtlichen Gedächtnisses. Sie müssen wie historisches Quellenmaterial, wie Dokumente bewahrt und gezeigt werden: unverfälscht, ungekürzt, unkommentiert, unsynchronisiert. ${ }^{14}$

Dieser Grundsatz fand auch Anerkennung in der Programmreihe „Filmdokumente der Zeitgeschichte“, die 2008 im Filmmuseum zu sehen war und sich mit dem dokumentarischen Film sowie „rohen“ Filmdokumenten befasste.

Schon bevor akademische Debatten zum Umgang mit dem Medium Film als Quelle für die zeithistorische Forschung in Gang gesetzt wurden, hatten also außeruniversitäre Institutionen wie das Filmarchiv Austria und das Österreichische Filmmuseum die Grundlage dafür bereitet, Film in den historischen Quellenkorpus integrieren zu können, ohne ihn dabei seiner spezifischen Materialität zu berauben - keine Selbstverständlichkeit in diesem Moment, wie Michael Derndarskys

11 Von besonderer Bedeutung ist beispielsweise die Sammlung Dziga Vertov des Österreichischen Filmmuseums, die Filme, Fotos, Plakate und andere Dokumente von und über den Filmemacher versammelt und durch ihren Umfang immer wieder internationale ForscherInnen nach Wien bringt, zuletzt beispielsweise John MacKay, Professor für Film and Media Studies an der Yale University und IFK Senior_Fellow im Wintersemester 2019.

12 Auch das Filmmuseum hat eine Reihe von filmwissenschaftlichen und -historischen Publikationen herausgebracht, beginnend mit der Gründung in den 1960er-Jahren. Seit 2002 existieren die Reihen „KINO“ (Zsylnay-Verlag) sowie die Reihe „FilmmuseumSynemaPublikationen“, die sich bedeutenden Filmschaffenden widmen. Siehe beispielsweise: Alexander Horwath/Lisl Ponger/ Gottfried Schlemmer (Hg.), Avantgardefilm. Österreich. 1950 bis heute, Wien 1995; Alexander Horwath/Michael Loebenstein (Hg.), Peter Tscherkassky, Wien 2005; Michael Omasta/Olaf Möller (Hg.), John Cook. Viennese by Choice, Filmemacher von Beruf, Wien 2006; Thomas Tode/Barbara Wurm (Hg.), Dziga Vertov. Die Vertov-Sammlung im Österreichischen Filmmuseum, Wien 2006; Claudia Preschl (Hg.), Lachende Körper. Komikerinnen im Kino der $1910 e r$ Jahre, Wien 2008.

13 Über uns: Geschichte, Österreichisches Filmmuseum, URL: https://www.filmmuseum.at/ueber_ uns/geschichte (abgerufen 15.02.2020).

14 Ebd. 
„Quellenkritische Betrachtungen über den Film“ von 1977/1978 beweisen. Derndarsky kritisierte schon früh, dass der Film in den meisten geschichtswissenschaftlichen Einführungswerken und Methodendiskussionen als Quelle übersehen ${ }^{15}$ oder höchstens als „ebenfalls noch zu erwähnen“" ${ }^{16}$ angeführt werde. Derndarsky scheint schon fast vorwegzunehmen, was W. J. T. Mitchell später als Bildängste ${ }^{17}$ bezeichnet oder Gerhard Paul noch präziser als „diffuse Angst vor den laufenden Bildern des Films“"18 beschreibt. Denn Derndarsky hält fest, dass „ein Desinteresse seitens der Geschichtswissenschaft“, ja sogar „innere[r] Widerstand, Mißtrauen oder Furcht“ festgestellt werden könne, welche „sich in Oberflächlichkeit oder latenter Abneigung “19 im Umgang mit dem Medium Film manifestieren würden. Der Grund dafür, so Derndarsky, sei das unter HistorikerInnen vorherrschende konservative Quellenverständnis, das schriftlichen Dokumenten in der „soziale[n] Hierarchie der Quellen“2o eine deutlich höhere Position zuspreche.

\section{Neuorientierung und Ausdifferenzierung}

Zwar brachte die österreichische Zeitgeschichtsforschung schon in den frühen 1990er-Jahre Beiträge hervor, die sich dem Film annäherten und für eine Erweiterung des historischen Quellenkorpus plädierten, ${ }^{21}$ jedoch blieben dies meist

15 Michael Derndarsky, Quellenkritische Betrachtungen über den Film, in: zeitgeschichte 5 (1977/1978) 11/12, 441-462.

16 Egon Boshoff/Kurt Düwell/Hans Kloft, Grundlagen des Studiums der Geschichte. Eine Einführung, Köln/Wien 1973, 262, zit. n. Derndarsky, Quellenkritische Betrachtungen, 433.

17 Mitchell, Bildtheorie.

18 Gerhard Paul, Visual History, Version: 3.o, Docupedia-Zeitgeschichte, URL: http://docupedia.de/ zg/Visual_History_Version_3.o_Gerhard_Paul (abgerufen 15.02.2020).

19 Derndarsky, Quellenkritische Betrachtungen, 443.

20 Ebd.

21 Neben den bereits genannten Artikeln von Schmid und Derndarsky finden sich in der „zeitgeschichte" beispielsweise noch: Gerhard Botz, „Shoa“. Das Undarstellbare und Darstellbare in Claude Lanzmanns Film über den Holocaust, in: zeitgeschichte 14 (1986/1987) 6, 259-265; Georg E. Schmid, Zur Geschichte asymmetrischer Kulturbeziehungen am Bespiel des französischen und österreichischen Films, in: zeitgeschichte 15 (1987/1988) 1, 27-36; das 9./10. Heft des 16. Jahrgangs (1988/89), herausgegeben von Georg E. Schmid, widmete sich allgemein der zeitgeschichtlichen Auseinandersetzung mit visuellen Quellen, darunter: Mirko Herzog, Invasion statt Kollision. Ein Untergang der Titanic („Titanic“. Ein Film. USA 1953), in: zeitgeschichte 16 (1988/1989) 9/10, 335-349; des Weiteren gilt es zu nennen: Georg E. Schmid, Die Figuren des Kaleidoskops. Über Geschichte(n) im Film, Salzburg 1983; Gerhard Botz, Fernsehen ist Macht - macht das Fernsehen die Geschichte?, in: Walter Blumberger/Josef Weidenholzer (Hg.), Ist Wissen Macht? Macht Bildung frei? Max Lotteraner zum 6o. Geburtstag (Gesellschafts- und sozialpolitische Texte 7), Linz 
Einzelfälle mit kritischen Anmerkungen, die schnell wieder verhallten. Wie Monika Bernold herausstellt, dominieren seit den 1990er-Jahren innerhalb der Geschichtsforschung zwei Positionen im Umgang mit visuellen Quellen, einerseits eine kunst- und kulturwissenschaftliche, an „ästhetischen Konzeptionen“ orientierte, die allerdings „zumeist an dem unbewegten Bild, selten am Film“22 interessiert sei, andererseits eine medien, politik- und kommunikationswissenschaftlich geprägte. Diese Kategorisierung nach Bernold macht nicht nur inhaltlich und methodisch divergierende Ausformungen deutlich, sondern vor allem, dass eine zeithistorische Auseinandersetzung mit visuellen Medien, damit auch mit dem Film, stets ein inter- bzw. transdisziplinäres Unterfangen ist. Irit Rogoff hält fest, dass „images do not stay within discrete disciplinary fields“, ${ }^{23}$ weshalb auch Klaus Sachs-Hombach berechtigterweise fordert, die Bildwissenschaft als eigenständige „Trans-Disziplin“24 zu etablieren. Die Filmwissenschaft eröffnet unzählige Schnittstellen mit anderen Forschungsbereichen und Disziplinen, von der Didaktik und Pädagogik über die Politik, Medien- und Kommunikationswissenschaft bis hin zur Kunst, Kultur- und Bildwissenschaft. Einem interdisziplinären Anspruch folgend, existierte von 2006 bis 2010 beispielsweise das Initiativkolleg "Sinne - Technik - Inszenierung“, das Dissertationen der Disziplinen Film- und Medienwissenschaft, Kunstgeschichte, Philosophie, Theaterwissenschaft und visuelle Zeitgeschichte förderte. ${ }^{25}$ Auch von Seiten anderer Fachbereiche gibt es Bestrebungen zur Vernetzung innerhalb der Visual Studies, beispielsweise mit dem Erweiterungscurriculum „Jüdische Kulturgeschichte in Film und Medien “ ${ }^{26}$ des Instituts für Judaistik, dem Forschungsschwerpunkt „Visual Studies in den Sozialwissenschaften“" ${ }^{27}$ an der Universität Wien oder

1988; Hans Heinz Fabris/Kurt Luger (Hg.), Medienkultur in Österreich. Film, Fotografie, Fernsehen und Video in der Zweiten Republik, Wien/Köln/Graz 1988; Gabriele Jutz, Geschichtsbilder im französischen Kino, phil. Diss., Universität Salzburg 1988.

22 Monika Bernold, Medien- und Geschlechterdiskurse im 20. und 21. Jahrhundert. Kulturwissenschaftliche und zeithistorische Studien, Habil., Universität Wien 2012, 6.

23 Irit Rogoff, Studying Visual Culture, in: Nicolas Mirzoeff (Hg.), The Visual Culture Reader, London/New York 2001, 16.

24 Klaus Sachs Hombach/Jörg R. J. Schirra, Bild und Wort. Ein Vergleich aus bildwissenschaftlicher Sicht, in: ELiSe Essener Linguistische Skripte 6 (2006) 1, 51-72, 51.

25 Initiativkolleg „Sinne - Technik - Inszenierung“, Über das IK, Universität Wien, URL: https://iksti.univie.ac.at/home/ (abgerufen 23.02.2020).

26 Institut für Judaistik, Erweiterungscurriculum „Jüdische Kulturgeschichte und Film und Medien“, Universität Wien, URL: https://judaistik.univie.ac.at/studium/erweiterungscurricula/ (abgerufen 23.02.2020).

27 Visual Studies in den Sozialwissenschaften, Mission Statement, Universität Wien, URL: https:// visualstudies.univie.ac.at/ueber-uns/ (abgerufen 23.02.2020). 
dem Forschungsbereich „Visuelle Kultur ${ }^{{ }^{28} 8}$ an der Alpen-Adria-Universität Klagenfurt. Nicht zuletzt sei an dieser Stelle auch der noch neue, interdisziplinäre Masterlehrgang der Universität Wien „Zeitgeschichte und Medien“"29 genannt.

Besonders kultur- und bildwissenschaftliche Ansätze in der zeithistorischen Filmforschung haben jedoch gemein, dass sie einem mehrdimensionalen Bildbegriff folgen, der stark von den theoretischen Auseinandersetzungen im Zuge der bereits eingangs genannten Turns geprägt ist. Dies bedeutet, dass sich die Auseinandersetzung mit (bewegten) Bildern in der Zeitgeschichtsforschung von der „historischen Bildwissenschaft" und deren Position als Hilfswissenschaft hin zur Visual History weiterentwickeln konnte und damit bildästhetische Bestrebungen zentral wurden..$^{30}$ Wie W. J. T. Mitchell festhält, wohne Bildern stets eine soziale und politische Dimension inne und sie wiesen damit einen gesellschaftsprägenden Charakter auf. Frank Stern, Gründer und Leiter des Schwerpunkts Visuelle Zeit- und Kulturgeschichte, bringt es auf den Punkt, wenn er schreibt:

Film stellt nicht nur Geschichte dar, Film ist auch Geschichte und nicht wenige Filme haben das Geschichtsbewusstsein und gesellschaftliche Auseinandersetzungen beeinflusst. Es sei nur an Panzerkreuzer Potemkin, Im Westen nichts Neues, La Grande Illusion, Die Mörder sind unter uns und Apokalypse Now erinnert. ${ }^{31}$

Mitchell betont jedoch auch, dass der Pictorial Turn „keine Antwort auf irgendetwas" sei, sondern „eine Art und Weise die Frage zu formulieren“.32 Dies bedeutet, dass diese bildwissenschaftlichen Ansätze auch für die Visual History keine eindeutigen Antworten auf methodische Fragen zum Umgang mit Film geben konnten, ${ }^{33}$ allerdings wirkten sie sich fundamental auf das Verständnis von Bildern als historische Quellen aus.

28 Abteilung Visuelle Kultur, Über uns, Alpen-Adria-Universität Klagenfurt, URL: https://www.aau. at/kulturanalyse/abteilungen/abteilung-visuelle-kultur/ (abgerufen 23.02.2020).

29 Zeitgeschichte und Medien (Master), Universität Wien, URL: https://studienservice-lehrwesen. univie.ac.at/studieren/masterstudien/zeitgeschichte-und-medien-master/ (abgerufen 23.02.2020).

30 Franz X. Eder/Oliver Kühschelm, Bilder - Geschichtswissenschaft - Diskurse, in: Franz X. Eder/ Oliver Kühlschelm/Christina Linsboth (Hg.), Bilder in historischen Diskursen, Wiesbaden 2014, 3.

31 Frank Stern, Die siebte Kunst als Kulturgeschichte. Film als Zeitbewusstsein und visuelles Archiv. Eine Einführung, in: Frank Stern/Julia B. Köhne/Karin Moser/Thomas Ballhausen/Barbara Eichinger (Hg.), Filmische Gedächtnisse. Geschichte - Archiv - Riss, Wien 2007, 18 (Hervorhebungen im Original).

32 Mitchell, Bildtheorie, 108.

33 Selbst Gerhard Paul bemängelte zu Recht, dass die Visual History „keine fertige Methode“ zur Verfügung stelle. Siehe: Paul, Visual History. 
Die bereits in den späten 1970er- und frühen 1980er-Jahren beginnende Diskussion, ${ }^{34}$ wie filmisches Material im Geschichtsunterricht eingesetzt werden könne, blieb zwar anfänglich oberflächlich bzw. verstärkte jenes Verständnis des Films, welches ihm rein illustrative Möglichkeiten zugestand, scheint jedoch ebenso auf längere Sicht „Bildängsten“ von HistorikerInnen entgegengewirkt zu haben. Heide Schlüpmann hielt richtig fest, dass sich „,vom Kino in Bildungseinrichtungen und von einer Film-Bildung“ ohne Weiteres sprechen lasse, „[n]icht so leicht zu fassen ist es, wie das Kino bildet“. ${ }^{35}$ Ein Meilenstein in der didaktischen Auseinandersetzung mit Film stellt Alain Bergalas „Kino als Kunst. Filmvermittlung an der Schule und Anderswo“ dar, dessen pädagogisches Konzept sich nicht nur im Kontext der Film, Kultur- und Kunstgeschichte bewegt, sondern ebenfalls die Kategorie der ästhetischen Bildung zentral stellt. ${ }^{36}$ Dieser wiederum aus der französischen Filmwissenschaft kommende, stark praxisorientierte Ansatz Bergalas' prägte auch maßgeblich die österreichische Geschichtsvermittlung durch Film. ${ }^{37}$ Dass das

34 Diskussionen zum Umgang mit (Bewegt)Bildern im Unterricht wurden v. a. durch die Ausstrahlung der Fernsehserie „Holocaust“ (Marvin J. Chomsky, Holocaust, USA 1978), im österreichischen Fernsehen ab 1979 zu sehen, eingeleitet. Als TV-Serie konzipiert, löste „Holocaust“ ähnliche Debatten innerhalb der Geschichtsdidaktik aus wie einige Jahre später "Shoah“ (Claude Lanzmann, Shoah, Frankreich 1985) als Dokumentarfilm und „Schindlers Liste“ (Steven Spielberg, Schindlers Liste, USA 1993) als Spielfilm. Das bedeutet, die frühe geschichtsdidaktische Auseinandersetzung mit dem Medium Film steht in engem Zusammenhang mit Erinnerungsdiskursen und der Auseinandersetzung mit der nationalsozialistischen Vergangenheit.

35 Heide Schlüpmann, Dritter Bildungsweg: Ausgang Kino, in: Bettina Henzler/Winfried Pauleit/ Christine Rüffert/Karl-Heinz Schmid/Alfred Tews (Hg.), Vom Kino lernen. Internationale Perspektiven der Filmvermittlung, Berlin 2010, 11-17, 11.

36 Alain Bergala, Kino als Kunst. Filmvermittlung an der Schule und Anderswo, Marburg 2006.

37 Siehe beispielsweise: Wilfried Pauleit, Film - Geschichte - Vermittlung. Ein Dreiecksverhältnis, in: zeitgeschichte 40 (2013) 4, 214-218; im selben Heft (Geschichte und Filmvermittlung: Neue Perspektiven) stellten Karin Fest und Marie-Noëlle Yazdanpanah das vom BMWF geförderte, an das Ludwig Boltzmann Institut für Geschichte und Gesellschaft angebundene Projekt „Like Seen on the Screen. Die Medien und unsere Lebenswelten des" vor, Karin Fest/Marie-Noëlle Yazdanpanah, „Was hat das mit mir und meiner Vergangenheit zu tun?" Geschichte, ephemere Filme und deren Vermittlung, in: zeitgeschichte 40 (2013) 4, 227-235; auch das Vermittlungsprogramm des Österreichischen Filmmuseums schließt etwa durch die Reihen „Schule im Kino“ und „Fokus Film“ sowie eine Summer School, die sich an LehrerInnen richtet, an Bergalas Überlegungen an. Siehe dazu beispielsweise Publikationen von Alejandro Bachmann, 2010-2019 wissenschaftlicher Mitarbeiter, später Leiter des Bereichs „Vermittlung, Forschung und Publikationen“ des Österreichischen Filmmuseum: Alejandro Bachmann, Sequenziell denken. Zur Historizität von Filmvermittlung Zwei Aspekte, in: zeitgeschichte 40 (2013) 4, 219-226; Alejandro Bachmann, To Talk and to Write about Films and to Teach Cinema are the Last and Only Forms of Resistance Against Consumption and Amnesia. A Conversation with Alain Bergala, in: Alejandro Bachmann/Alain Bergala (Hg.), The Cinema Hypothesis. Teaching Cinema in the Classroom and Beyond. A Conversation, Wien 
Verhältnis von Film, (Bewegt)Bildern, Verbildlichung und Bildung allerdings eine Tradition aufweist, die noch viel weiter zurückreicht, zeichnet ein aktuelles Forschungsprojekt von Joachim Schätz (Institut für Theater, Film- und Medienwissenschaften der Universität Wien) in Kooperation mit dem Ludwig Boltzmann Institute for Digital History (LBIDH) nach, das „Praktiken des Lehr- und Unterrichtsfilms in Österreich“ ${ }^{38}$ zwischen 1918 und den 1960er-Jahren untersucht. Generell hat sich das Ludwig Boltzmann Institut für Geschichte und Gesellschaft (LBIGG) - 2019 umbenannt in Ludwig Boltzmann Institute for Digital History - als zentrale Einrichtung für die filmbezogene Zeitgeschichtsforschung erwiesen, nicht zuletzt aufgrund des besonderen Engagements von Siegfried Mattl, Institutsleiter von 2005 bis 2015. Mattl führte nicht nur diverse Forschungsprojekte zur Wiener Stadt- und Filmgeschichte durch, ${ }^{39}$ machte gemeinsam mit seinem Team das LBIGG zu einer wichtigen Plattform für die Beschäftigung mit Amateurfilmen und ephemeren Filmen, ${ }^{40}$ sondern forcierte überdies eine kulturwissenschaftliche Ausrichtung der zeithistorischen Filmforschung. ${ }^{41}$

2016, 119-131; Alejandro Bachmann/Manuel Zahn, Film-Education as a Multiplicity of Practices: A Media Ecological Perspective, in: Film Education Journal 1 (2018) 1, 78-89.

38 Praktiken des Lehr- und Unterrichtsfilms in Österreich, Zum Projekt, Universität Wien, URL: https://lehrfilmpraktiken.univie.ac.at/ (abgerufen 17.02.2020).

39 Beispielsweise von 2009 bis 2011 in Kooperation mit dem Österreichischen Filmmuseum und Regisseur Gustav Deutsch das Projekt: Film.Stadt.Wien: A Transdisciplinary Exploration of Vienna as a Cinematic City, Ludwig Boltzmann Institute for Digital History, URL: https://geschichte.lbg. ac.at/filmstadtwien/projekt-filmstadtwien (abgerufen 20.02.2020) oder 2011-2017 das Projekt: Sichtung und Aufarbeitung des Filmarchivbestandes media wien, Ludwig Boltzmann Institute for Digital History, URL: https://geschichte.lbg.ac.at/media-wien/projekt-media-wien (abgerufen 20.02.2020).

40 Beispielsweise 2011-2013 das Projekt: Archäologie des Amateurfilms. Ausgrabungen zur visuellen Kultur der Moderne, Ludwig Boltzmann Institute for Digital History, URL: https://geschichte.lbg. ac.at/tags/archaeologie-des-amateurfilms (abgerufen 20.02.2020); 2011-2016 das Projekt in Kooperation mit dem Österreichischen Filmmuseum und dem United States Holocaust Memorial Museum: Ephemere Filme: Nationalsozialismus in Österreich, Ludwig Boltzmann Institute for Digital History, URL: https://geschichtellbg.ac.at/tags/ephemere-filme-nationalsozialismus-inoesterreich (abgerufen 20.02.2020); 2016-2019 das ÖAW-Doc-Team-Projekt von Sandra Ladwig, Sarah Lauß und Michaela Scharf: Doing Amateur Film. Soziale und ästhetische Praktiken im österreichischen Amateurfilm der 1920er- bis 1980er-Jahre, Ludwig Boltzmann Institute for Digital History, URL: https://geschichte.lbg.ac.at/doing-amateur-film/projekt-doing-amateur-film-soziale-und-asthetische-praktiken-osterreichischen (abgerufen 20.02.2020).

41 Exemplarisch: Siegfried Mattl, Die Geschichte, der Film und ihr gemeinsamer Vorraum: Eine spannungsreiche Beziehung, in: Friedrich Edelmayer/Margarete Grandner/Jiri Pesek/Oliver Rathkolb (Hg.), Über die österreichische Geschichte hinaus. Festschrift für Gernot Heiss zum 7o. Geburtstag, Münster 2012, 229-240; Siegfried Mattl/Elisabeth Timm/Birgit Wagner (Hg.), Filmwissenschaft als Kulturwissenschaft. Zeitschrift für Kulturwissenschaften 2007/2; Siegfried Mattl/Drehli 
Neben dem LBIGG bzw. LBIDH hat sich das Institut für Zeitgeschichte der Universität Wien als richtungsweisend in der Forschung an der Schnittstelle Film und Zeitgeschichte erwiesen. Visual History, die durch Gerhard Jagschitz vor allem sozialwissenschaftlich ausgerichtet war und primär die Fotografie als Quelle etablierte, war bereits früh am IfZ der Universität Wien angekommen, ${ }^{42}$ erlaubte folglich jedoch auch, den Film und das Fernsehen präsent in die Forschung einzubeziehen. ${ }^{43}$ Mit der Berufung von Frank Stern und der Gründung des Schwerpunkts Visuelle Zeit- und Kulturgeschichte am Institut für Zeitgeschichte der Universität Wien im Jahr 2004 erlebte der Film als historische Quelle zentrale Anerkennung. Dies führte schließlich zu einer inhaltlichen und methodischen Ausdifferenzierung, die sich unter anderem in den zahlreichen Abschlussarbeiten widerspiegelt, die in den Jahren seit 2004 entstanden sind und die sich mit Film zeithistorisch beschäftigen.

Ähnlich wie Siegfried Mattl verfolgt Stern in seiner Forschung und Lehre einen kulturwissenschaftlichen Ansatz, der in der Tradition der französischen, israelischen und US-amerikanischen Filmforschung steht. ${ }^{44}$ Stern argumentiert, dass sich historisch-kontextualisierte Filmanalyse „nicht allein auf die Repräsentation der

Robnik (Hg.), Und das Kino geht weiter. Vergangenheit im Hollywood der Gegenwart, in: zeitgeschichte 29 (2002) 6; Siegfried Mattl/Karl Stuhlpfarrer/Georg Tillner (Hg.), Bild und Geschichte, Innsbruck/Wien 1997; Siegfried Mattl/Karl Stuhlpfarrer, Film und Geschichte. Ein Beiprogramm, in: zeitgeschichte 21 (1994) 9/10, 269-279.

42 Schon Ende der 1990er-Jahre sind erste Abschlussarbeiten zum Film entstanden, darunter: Doris Bachmüller, Die Mafia im Film. Eine Untersuchung italienischer und amerikanischer Mafia-Filme vor dem Hintergrund zeitgeschichtlicher Erkenntnisse in der Mafia Foschung, phil. Diss., Universität Wien 1998; Anna Schober, Blue Jeans. Vom Leben in Stoffen und Bildern, Frankfurt a. M. 2001; außerdem veranstaltete Dirk Rupnow von 1999 bis 2001 die kommentierte Reihe „Film in der Zeitgeschichte" beispielsweise zu antisemitischen Propagandafilmen, Paula Wessely oder NS-Euthanasie. 2001 fand des Weiteren das Symposium „Zwischen Dokumentation und Propaganda: ,Euthanasie im NS-Film“, ebenfalls von Dirk Rupnow organisiert, statt, wozu außerdem ein „zeitgeschichte“-Heft publiziert wurde, Dirk Rupnow/Claudia Spring (Hg.), Zwischen Dokumentation und Propaganda: „Euthanasie“ im NS-Film, in: zeitgeschichte 28 (2001) 4.

43 An dieser Stelle gilt es v. a. Monika Bernolds Forschung zu erwähnen, die schon früh mit visuellen Quellen gearbeitet hat und v. a. eine geschlechtergeschichtliche Orientierung forcierte, siehe: Monika Bernold/Siegfried Mattl (Hg.), TV-Time. Konzepte zur Fernsehgeschichte. zeitgeschichte 24 (1997) 7/8; Monika Bernold/Sylvia Szely (Hg.), TeleVisionen. Historiografien des Fernsehens. Österreichische Zeitschrift für Geschichtswissenschaften 12 (2001) 4; Monika Bernold/Andrea Braidt/Claudia Preschl (Hg.), SCREENWISE. Film, Fernsehen, Feminismus, Marburg 2004; Monika Bernold, Das Private Sehen. Fernsehfamilie Leitner, mediale Konsumkultur und nationale Identitätskonstruktion in Österreich nach 1955, Münster 2007; außerdem zum Fernsehen siehe: Renée Winter, Geschichtspolitiken und Fernsehen. Repräsentationen des Nationalsozialismus im österreichischen TV (1955-1970), Bielefeld 2017.

44 Siehe: Sabo/Wieder, Visual History, 306-307. 
historischen Ereignisse, auf das was, beziehen [kann], sondern primär auf das wie, sie ist kulturhistorische Filmanalyse“.45 Wiederholt plädierte Stern für ein Verständnis des Films, vor allem des Spielfilms, als historische Quelle, die nicht nur ein visuelles und kulturelles Gedächtnis aufweise, sondern ebenso Einblick in politische und kulturelle Entwicklungen geben könne. Während lange Zeit fälschlich argumentiert wurde, dass Film die Realität abbilden könne, argumentiert Stern hingegen, dass Film

eines nie sein [kann] - Wirklichkeit, außer eben die Wirklichkeit des Films und seiner Geschichte(n). Das Besondere des historischen Films ist, dass er dabei aus der Perspektive der Vergangenheit Mythen in die Gegenwart - und umgekehrt Mythen der Gegenwart in die Geschichte - projiziert: das Imaginäre, das Reale und das Symbolische..$^{46}$

Geprägt von diesem Filmverständnis, welches bewegte Bilder weder auf Illustrationsoptionen reduziert noch sie ihrer sozialen, politischen und ästhetischen Funktion beraubt, welches eine historisch-kontextualisierte Filmanalyse ${ }^{47}$ forciert und dabei die diversen Bedeutungsebenen von Bildern berücksichtigt, ist eine neue Generation von Forschenden entstanden, die sich dem Film als zentrale Quelle der Zeitgeschichte widmet. Ihre wiederum oft interdisziplinär angelegten Studien zeigen neben ihrer inhaltlichen Diversität vor allem eines, nämlich dass eine Auseinandersetzung mit visuellen Quellen bzw. dem Film ebenso für andere Forschungsschwerpunkte innerhalb der Geschichtswissenschaften neue Erkenntnisse bringen und Perspektiven eröffnen kann, beispielsweise für die Medizingeschichte und Traumaforschung, ${ }^{48}$ für

45 Frank Stern, Clio geht ins Kino oder Geschichte(n) des Films, in: Ingrid Bauer/Helga Embacher/ Ernst Hanisch/Albert Lichtblau/Gerald Sprengnagel (Hg.), >kunst >kommunikation >macht: Sechster Österreichischer Zeitgeschichtetag 2003, Innsbruck/Wien 2003, 108.

46 Frank Stern, Durch Clios Brille: Kino als zeit- und kulturgeschichtliche Herausforderung, in: Österreichische Zeitschrift für Geschichtswissenschaften 16 (2005) 1, 74.

47 Angelehnt an Helmut Kortes systematische Filmanalyse und seine Dimensionen der Filmanalyse, siehe: Helmut Korte, Einführung in die Systematische Filmanalyse, Berlin 2010, 19-29.

48 Siehe beispielsweise: Julia B. Köhne, Kriegshysteriker. Strategische Bilder und mediale Techniken militärpsychiatrischen Wissens, 1914-1920 (Abhandlungen zur Geschichte der Medizin und der Naturwissenschaften 106), Husum 2009; dies. (Hg.), Trauma und Film. Inszenierungen eines Nicht-Repräsentierbaren, Berlin 2012; siehe auch Katrin Pilz' laufendes Forschungsprojekt am Institut für Zeitgeschichte Wien und der Université libre de Bruxelles, welches sich unter dem Titel „Medicine in Motion. Early Medical Filmmaking as Cultural Scientific Practice Shaping Clinical Specialisation, Public Health and Visual Modernity in Vienna and Brussels (1900-1938)" mit Medizinlehrfilmen auseinandersetzt. 
die Frauen- und Geschlechtergeschichte, ${ }^{49}$ die Faschismus- und Genozidforschung ${ }^{50}$ oder die Antisemitismusforschung ${ }^{51}$.

Obgleich in meinen bisherigen Ausführungen eine Konzentration auf Spiel- und Amateurfilm zu verzeichnen ist, hat es auch einige progressive Annäherungen an das Thema des Dokumentarfilms gegeben, beispielsweise durch die 2010 vom Schwerpunkt Visuelle Zeit- und Kulturgeschichte in Kooperation mit dem Filmarchiv Austria und dem METRO Kinokulturhaus veranstaltete Dokumentarfilmreihe „Kunst Film - Dokument. In die Nähe“ oder das 2012 abgehaltene Symposium „Zooming In and Out. Produktionen des Politischen im neueren Dokumentarfilm“, organisiert von Julia B. Köhne, Klaudija Sabo und Alyin Basaran, und die daraus entstandene gleichnamige Publikation, die in diversen Beiträgen Narrationen, Symboliken und Ästhetiken des deutschen und österreichischen Dokumentarfilms analysiert. ${ }^{52}$ Auch Marietta Kesting, wie Sabo und Basaran neben ihrer akademischen Tätigkeit selbst als (Dokumentar)Filmemacherin tätig, ${ }^{53}$ widmete sich in ihrem Dissertationsprojekt fotografischen und filmischen Quellen, die den Kampf gegen die Apartheid in Südafrika dokumentieren bzw. nachfolgende Konflikte verhandeln. ${ }^{54}$ Wie Fiktion und Realität oder Bild und Stimme im Dokumentarfilm miteinander interagieren

49 Monika Bernold, Medien- und Geschlechterdiskurse; Monika Bernold/Andrea Braidt/Claudia Preschl (Hg.), SCREENWISE; Anna Schober, Repräsentationen von Geschlecht und feministische Interventionen, in: Johanna Gehmacher/Maria Mesner (Hg.), Frauen- und Geschlechtergeschichte. Positionen - Perspektiven, Innsbruck/Wien/München/Bozen 2003, 145-164; Vera Apfelthaler/Julia B. Köhne (Hg.), Gendered Memories. Transgressions in German and Israeli Film and Theater, Wien 2007; Aylin Basaran/Julia B. Köhne/Klaudija Sabo/Christina Wieder (Hg.), Sexualität und Widerstand. Internationale Filmkulturen, Wien 2018.

50 Michael Aschenbach/Karin Moser (Hg.), „Österreich in Bild und Ton“, Wien 2002; Armin Loacker, Anschluss im 3/4 Takt: Filmproduktion und Filmpolitik in Österreich 1930-1938, Trier 1999; Frank Stern, Voyeure der Vernichtung. Verbildlichung und Zeitbewusstsein, in: Helgard Kramer (Hg.), NS-Täter aus interdisziplinärer Perspektive, München 2006, 45-66; am 14. und 15. Mai 2015 fand beispielsweise die Konferenz „Film and Fascism. Comparing Southern and Central Europe“ an der Universität Wien statt, organisiert von Klaudija Sabo und Frank Stern.

51 Frank Stern, Bilder des Jüdischen vor und nach der Schoah, in: John D. Pattillo-Hess/Mario R. Smole (Hg.), Die Juden. Eine unbekannte Nation, Wien 2008, 73-76; Karin Stögner, Antisemitismus und Sexismus. Historisch-gesellschaftliche Konstellationen, Baden-Baden 2014.

52 Aylin Basaran/Julia B. Köhne/Klaudija Sabo (Hg.), ZOOMING IN AND OUT. Produktionen des Politischen im neueren deutschsprachigen Dokumentarfilm, Wien 2013.

53 Auch die Historikerin und Filmemacherin Helene Maimann soll an dieser Stelle erwähnt werden, denn sie hat schon früh damit begonnen, zeitgeschichtliche Themen im Dokumentarfilm zu behandeln. In ihren Filmen widmete sie sich beispielsweise zentralen Figuren der österreichischen Zeitgeschichte, darunter Bruno Kreisky, Hannes Androsch und Käthe Leichter, sowie jüdischen Themen, Persönlichkeiten und Überlebenden der Shoah.

54 Marietta Kesting, Affective Images, Post-Apartheid Documentary Perspectives, Albany 2017. 
oder konkurrieren, behandeln auch diverse Beiträge des Sammelbandes „Sichtbar Machen. Politiken des Dokumentarfilms“, herausgegeben von Vrääth Öhner, Elisabeth Büttner und Lena Stölzl. ${ }^{55}$ Herausragend an diesen Arbeiten ist, dass sie den Dokumentarfilm nicht darauf reduzieren, dass er schlicht abbilden würde, „wie es gewesen ist", ${ }^{66}$ sondern den Dokumentarfilm als nichtfiktionalen Film verstehen, der ebenso wie der Spielfilm eigene Narrative und ästhetische Strategien entwickelt, um gewisse Inhalte zu vermitteln bzw. ,imaginierte Realitäten“ 57 schafft.

Während also die 1990er-Jahre noch dominiert waren von Debatten, ob und wie das Medium Film den historischen Quellenkorpus ergänzen konnte, hat sich ab den 2oooer-Jahren das Forschungsfeld „Film und Zeitgeschichte“ sowohl inhaltlich als auch methodisch ausdifferenziert. Neben bereits genannten Arbeiten im Bereich der Medizingeschichte oder der Frauen- und Geschlechtergeschichte wurden Filmproduktionen unterschiedlicher kultureller Zusammenhänge und geographischer Regionen beforscht, etwa der (post)jugoslawische, ${ }^{58}$ israelische und palästinensische Film, ${ }^{59}$ die tansanische Filmproduktion ${ }^{60}$ oder das argentinische Kino ${ }^{61}$. Phänomene

55 Vräth Öhner/Elisabeth Büttner/Lena Stölzl (Hg.), Sichtbar Machen. Politiken des Dokumentarfilms, Berlin 2017.

56 Gabriele Metzler, Zeitgeschichte: Begriff - Disziplin - Problem, Version: 1.o, DocupediaZeitgeschichte, URL: http://docupedia.de/zg/metzler_zeitgeschichte_v1_de_2014 (abgerufen 20.02.2020).

57 Aylin Basaran/Julia B. Köhne/Klaudija Sabo, Zooming In and Out. Dokumentarische Strategien und Effekte des Politischen, in: Aylin Basaran/Julia B. Köhne/Klaudija Sabo (Hg.), ZOOMING IN AND OUT. Produktionen des Politischen im neueren deutschsprachigen Dokumentarfilm, Wien 2013, 7-22, 9 .

58 Beispielsweise: Andreas Filipovic, Debates on society and socialism in the Yugoslav film of the 1960s: the partisan issue, phil Diss., Universität Wien 2017; Klaudija Sabo, Ikonen der Nationen. Heldendarstellungen im „post“-sozialistischen Kroatien und Serbien, Berlin 2017; Anna Schober, The Cinema Makers. Public Life and the Exhibition of Difference in South-Eastern and Central Europe Since the 1960s, Bristol 2013.

59 Peter Grabher, Hier und Anderswo. Palästina-Israel im essayistischen Film (1960-2010), Marburg 2020; Frank Stern, Filmische Visionen: Deutsch-österreichisch-jüdische Metamorphosen im israelischen Kino, Graz 2017.

60 Laufendes Forschungsprojekt von Aylin Basaran, „Filmproduktion in Tansania nach der Unabhängigkeit“, am Institut für Zeitgeschichte der Universität Wien.

61 Laufendes Forschungsprojekt von Christina Wieder, „Visuelle Selbstermächtigungsstrategien im Exil. Jüdische Künstlerinnen von Mitteleuropa nach Argentinien“, am Institut für Zeitgeschichte der Universität Wien. 
wie Langeweile, ${ }^{62}$ Schmutz und Schund ${ }^{63}$ oder Geniekult ${ }^{64}$ wurden in ihren filmischen Repräsentationen untersucht. Auch der österreichische Werbefilm wurde als Forschungsgegenstand herangezogen. ${ }^{65}$

\section{Perspektiven und Herausforderungen}

Trotz dieser Diversität an zeitgeschichtlichen Arbeiten zum Film gilt es festzuhalten, dass immer noch ein Ungleichgewicht besteht, stellt man etwa der Forschung zum Film die Vielzahl an Arbeiten zur Fotografie bzw. zu nichtbewegten Bildern gegenüber. Auch existiert im österreichischen Kontext keine gleichbedeutende wissenschaftliche Zeitschrift für die historische Arbeit mit Film wie beispielsweise die von Anton Holzer herausgegebene Zeitschrift „Fotogeschichte“ für die Fotografie. Obgleich in den letzten Jahren intensive Forschung zu Film im Nationalsozialismus bzw. Repräsentationen des Nationalsozialismus im Film betrieben wurde, existiert bis dato auch noch keine umfassende Studie zur NS-Zeit im österreichischen Filmgedächtnis. ${ }^{66}$ Es gibt also sowohl was die akademische Institutionalisierung - beispielsweise in Form einer wissenschaftlichen Zeitschrift - als auch zentrale Themenfelder der Zeitgeschichtsforschung betrifft noch deutlichen Nachholbedarf.

Methodisch wird für kommende Studien eine Herausforderung sein, einen gemeinsamen Analyserahmen für Film und andere Bildquellen, sowohl statische als auch bewegte, zu schaffen. Gerhard Paul hat bereits festgestellt, dass ein Forschungsinteresse innerhalb der Visual History sei, „wie bestimmte Sujets und Motive mit anderen Bildern kommunizieren und durch die Bilderwelt wandern bzw. in andere Medien eingehen und in diesem Transfer ihre ursprüngliche Bedeutung verändern" ${ }^{67}$ Er spricht hier intervisuelle Zusammenhänge an, also Bild-Bild-Kontexte, die Kom-

62 Barbara Eichinger, Langeweile, Film, Jugend. Zur Historizität einer Projektion, phil. Diss., Universität Wien 2010.

63 Edith Blaschitz, Der „Kampf gegen Schmutz und Schund“: Film, Gesellschaft und die Konstruktion nationaler Identität in Österreich (1946-1970), Wien 2014.

64 Julia Köhne, Geniekult in Geisteswissenschaften und Literaturen um 1900 und seine filmischen Adaptionen, Wien 2014.

65 Karin Moser, Der österreichische Werbefilm. Die Genese eines Genres von seinen Anfängen bis 1938, Berlin/Boston 2019.

66 Für das österreichische Bildgedächtnis und den TV existieren solche Studien bereits, siehe: Ina Markova, Die NS-Zeit im Bildgedächtnis der Zweiten Republik, Innsbruck 2018; Renée Winter, Geschichtspolitiken und Fernsehen. Repräsentationen des Nationalsozialismus im frühen österreichischen TV (1955-1970), Bielefeld 2014.

67 Paul, Visual History. 
munikationsstrukturen innerhalb von Bildwelten in den Fokus nehmen und sowohl statischen als auch bewegten Bildern damit einen aktiven Gestaltungscharakter zusprechen, sie also als eigenständige Bildakte verstehen. ${ }^{68}$ Vereinzelt sind in den letzten Jahren bereits Arbeiten mit intervisueller Methodik ${ }^{69}$ entstanden, die sich vor allem durch ihre interdisziplinäre Herangehensweise auszeichnen und verstärkt aus der Bildwissenschaften kommende Ansätze rezipieren. Solche interdisziplinären Ansätze sowie neue methodische Vorgehensweisen werden ebenso bei jenen Forschungsprojekten zentral werden, die sich beispielsweise mit neuen Streamingformaten befassen..$^{70}$ Netflix, Amazon und Co. produzieren am laufenden Band Filme, aber auch hochwertige und kostenintensive Serien, die neue Ästhetiken, Narrative und Darstellungsweisen schaffen und damit nicht mehr schlicht in ein klassisches TV-Format eingeordnet werden können. Nicht umsonst warb HBO jahrelang mit dem Slogan „It's not TV, it's HBO“ und rief damit das Post-TV-Zeitalter aus. Dies bedeutet allerdings für neue Forschungsprojekte, dass sich durch Streaminganbieter wie Netflix, Amazon und HBO neue Forschungsgebiete auftun, die derzeit noch eine weitgehend methodisch unerkundete Grauzone darstellen.

Anschließend an die Annahme, dass Filme selbst einen aktiven Gestaltungscharakter aufweisen, soll zum Schluss noch eine potenzielle Entwicklungslinie des Forschungsgebietes angesprochen werden, nämlich der Ausbau filmpraktischen Arbeitens. Filmpraktische Arbeit als zeitgeschichtliche Arbeit wird bereits seit einigen Jahren an unterschiedlichen Instituten betrieben, beispielsweise am Video-HistoryLehrgang an der Universität Salzburg oder am Schwerpunkt Visuelle Zeit- und Kulturgeschichte an der Universität Wien. Durch begleitende Kamera- und Schnitttechnikkurse sind filmische Abschlussarbeiten von Studierenden (sowohl in Form von Seminar-, aber auch Diplom- und Masterarbeiten) vor allem am Schwerpunkt Visuelle Zeit- und Kulturgeschichte intensiv vorangetrieben worden. Filmpraktisches Arbeiten erfordert nicht nur ein analytisch geschultes Auge, was Dramaturgie, Bildsprache und -komposition betrifft, sondern ist überdies eine Möglichkeit, Wissen filmisch aufzuarbeiten, Wissen zu generieren, letztendlich auch eigene Quellen zu

68 Der Ansatz, dass Bilder selbst als Akteure der Geschichte auftreten können, wurde zentral geprägt von: Horst Bredekamp, Theorie des Bildakts, Berlin 2010.

69 Siehe: Klaudija Sabo, Ikonen der Nationen; Anna Schober, Ironie, Montage, Verfremdung. Ästhetische Taktiken und die politische Gestalt der Demokratie, München 2009; Christina Wieder, Montages of exile. Photographic techniques and spatial dimensions in the artwork of Grete Stern, in: Jewish Culture and History 21 (2019) 1, 41-65.

70 Beispielsweise die laufenden Dissertationsprojekte von Sarah Kanawin über die Konstruktion von Geschichte in Retro/Serien (Institut für Zeitgeschichte, Universität Wien) und von Verena Hanna zu neuen Israelischen (TV-)Serien (Institut für Zeitgeschichte, Universität Wien). 
schaffen - ähnlich wie es die Oral History betreibt. Eine solche filmpraktische Auseinandersetzung mit dem Visuellen fördert einen kritischen Umgang mit Filmen, positioniert sich gegen ein rezeptives, rein illustratives Verständnis von filmischen Quellen und zielt damit auf einen emanzipativen Mediengebrauch ab. Obgleich in den letzten Jahren zahlreiche Studierendenproduktionen entstanden sind, ${ }^{71}$ stellt ein solcher filmpraktischer Ansatz in der Zeitgeschichtsforschung und -lehre immer noch ein Novum dar. Eine breitere Etablierung von filmpraktischen Arbeiten, etwa indem sie als gleichwertige Qualifikationsarbeiten für Master- oder Doktoratstu$\operatorname{dien}^{72}$ anerkannt würden, wäre äußerst wünschenswert und gewinnbringend und würde letzten Endes dazu beitragen, die Kluft zwischen kultur- und kunstwissenschaftlicher Zeitgeschichtsforschung und zeitgeschichtlich interessierter Kunstpraxis zu schließen.

71 Gemeinsam mit Sonja Gassner und Frank Stern haben wir in den letzten Jahren diverse Filmabende im METRO Kinokulturhaus veranstaltet, bei denen Studierendenfilme gezeigt wurden, die im Zuge der Seminare des Schwerpunktes Visuelle Zeit- und Kulturgeschichte entstanden sind, „FILM NOIR - The Next Generation“ (2015-2019).

72 Ähnliche Ansätze existieren bereits, beispielsweise an der Akademie der bildenden Künste mit dem Programm „PhD in Practice“. 


\section{Fernsehen und Video}

Renée Winter

Fernsehen und Video in der Zeitgeschichte - bedeutet das ein, zwei oder viele Forschungsfelder? Und in welcher Weise hat sich die österreichische Zeitgeschichte bisher damit auseinandergesetzt? Der vorliegende Beitrag handelt auch vom langen Übersehen der audiovisuellen Medien in der Geschichtswissenschaft und damit von vielen Lücken. Die Benennung von Auslassungen kann und soll jedoch auch Perspektiven und mögliche Forschungsfragen zukünftiger Forschungen aufzeigen.

\section{Fernsehen und Video - Vorabüberlegungen}

Video - als Aufnahme- und Wiedergabetechnik - ist Grundlage der Fernsehproduktion. Im österreichischen Fernsehen, das seinen Sendebetrieb 1955 aufnahm, wurde nach anfänglicher Verwendung von Film seit 1961 (auch) auf Video aufgenommen. ${ }^{1}$ Somit ist Videogeschichte zu einem Teil auch Fernsehgeschichte und vice versa. Demgegenüber verstanden sich viele Videogruppen der 1970er- und 1980erJahre explizit als Gegenöffentlichkeit und Alternative und grenzten sich gegen das als vereinzelnd und entpolitisierend verstandene Fernsehen ab. ${ }^{2}$ Andere Projekte hatte den Anspruch, mittels Videotechnik ein anderes, ein lokales und selbstproduziertes Fernsehen zu schaffen. ${ }^{3}$ Ein intertextuelles Verhältnis gehen Fernsehen und Video außerdem dort ein, wo Home- und Amateurvideos sich einerseits an Fernsehformaten orientieren, andererseits Homevideos oder ihre Ästhetik in Pro-

1 Herbert Hayduck, Bewegte Bilder sprengen den Rahmen. Audiovisuelles Kulturgut in Fernseharchiven - hochwertiges Produktionsmittel und zeitgeschichtliche Quellensammlung, Dipl.-Arb., Universität Wien 2012, 64, 137. Laut anderen Darstellungen wurde schon 1960 auf Magnetband aufgenommen. Vgl. Camillo Foramitti, Chronik, in: Andreas Novak/Oliver Rathkolb (Hg.), Die Macht der Bilder, Berndorf 2017, 633-651, 634.

2 Garleff Zacharias-Langhans, Bürgermedium Video. Ein Bericht über alternative Medienarbeit, Berlin 1977, 17.

3 Leo Kellermann/Projektgruppe „Lokales Fernsehen“ im Institut für Informationsentwicklung (IFIWien), Lokales Fernsehen. Projekt Burgenland, Projekt Steiermark, Modell zur Sammlung von Daten für die Einrichtung lokaler Fernsehstudios, ein Medienversuch der Projektgruppe „Lokales Fernsehen“ im Institut für Informationsentwicklung (IFI-Wien), Wien 1977; Sepp Auer/Peter Hueber/Hans Kronberger, Arbeiter machen Fernsehen. Eine Projektstudie der Österreichischen Gesellschaft für Kommunikationsfragen, Graz 1980. 
gramme des Fernsehens Eingang finden. ${ }^{4}$ Ende der 1970er-Jahre war Fernsehen in Österreich schließlich „massenhaft und konkurrenzlos verfügbar",5 die Verbreitung des Videorekorders in privaten Haushalten ab den 1980er-Jahren hatte massiven Einfluss auf Fernsehgewohnheiten: Die ZuschauerInnen waren durch die Bedienung der „Zeitmaschine“" Videorekorder nicht mehr gezwungen, ihr Sehverhalten den zeitlichen Programmvorgaben des Fernsehens anzupassen. Forschenden wiederum ermöglichte der Videorekorder einen Zugang zu Material, das entweder aufgrund der Archivpolitiken der Fernsehanstalten nicht zugänglich war oder in dieser Form nicht archiviert wurde. ${ }^{7}$

\section{Mediengeschichte - Kultur-, sozial- und geschlechtergeschichtliche Zugänge}

In Forschungsüberblicken ist wiederkehrend auf die Vernachlässigung des Fernsehens durch die Geschichtswissenschaft hingewiesen worden. ${ }^{8}$ Video hingegen wurde nicht nur vernachlässigt, sondern kaum beachtet und erscheint bisher meist nur in Randnotizen von Untersuchungen zu TV, Film oder sozialen Bewegungen.

Einen ausführlichen, an theoretischen Herangehensweisen und Begriffsbildungen interessierten Überblick zur historischen Medienforschung gibt Monika

4 So hat zum Beispiel Liis Jõhvik in ihrem Beitrag „Get a reel life! Memory and gender in Soviet Estonian home movies and amateur films“ am Zeitgeschichtetag 2018 in Wien über einen vom Fernsehen ausgehenden Sammelaufruf für Homemovies und Homevideos gesprochen, siehe Österreichischer Zeitgeschichtetag, Wien 2018 (Programm), URL: https://backend.univie.ac.at/fileadmin/ user_upload/k_zgt18/ZGT18_Programmbuch_digital_.pdf (abgerufen 28.08.2020).

5 Monika Bernold, Geschichtsproduktion und mediale Selbstreflexivität im Fernsehen, in: Frank Stern/Julia B. Köhne/Karin Moser/Thomas Ballhausen/Barbara Eichinger (Hg.), Filmische Gedächtnisse. Geschichte - Archiv - Riss, Wien 2007, 136-154, 148.

6 Siegfried Zielinski, Audiovisuelle Zeitmaschine. Thesen zur Kulturtechnik des Videorecorders, in: ders. (Hg.), Video. Apparat/Medium, Kunst, Kultur. Ein internationaler Reader, Frankfurt a. M./ Bern/New York/Paris 1992, 91-114.

7 Judith Keilbach/Matthias Thiele, Für eine experimentelle Fernsehgeschichte, in: Hamburger Hefte zur Medienkultur 2/2003, 59-75, 69-70; Monika Bernold, Medien- und Geschlechterdiskurse im 20. und 21. Jahrhundert. Kulturwissenschaftliche und zeithistorische Studien, Habil., Universität Wien 2012, 98-99.

8 Siehe Bernold, Medien- und Geschlechterdiskurse, 6, 45. Vgl. auch Frank Bösch, Mediengeschichte. Vom asiatischen Buchdruck zum Fernsehen, Frankfurt a. M./New York 2011, 212. Zur Verstreutheit und Lückenhaftigkeit der Forschung zu geschlechtergeschichtlichen Aspekten siehe auch Renée Winter, Geschichte im Fernsehen und Geschlecht, in: Johanna Dorer/Brigitte Geiger/ Brigitte Hipfl/Viktorija Ratković (Hg.), Handbuch Medien und Geschlecht. Perspektiven und Befunde der feministischen Kommunikations- und Medienforschung, Wiesbaden 2019, URL: https:// doi.org/10.1007/978-3-658-20712-0_30-1 (abgerufen 28.08.2020). 
Bernold 2012 in ihrer Habilitationsschrift. So lassen sich laut Bernold seit den späten 1990er-Jahren zwei dominante Zugänge zu (visuellen) Medien in der Geschichtswissenschaft feststellen: erstens ein „eher am Bildbegriff und an kunst- und kulturwissenschaftlichen Methoden“9 interessierter Zugang, zweitens die „medien- oder politik- und kommunikationswissenschaftlich inspirierte[...]“ Frage nach „Medien und Mediengeschichte, nach visueller Kommunikation und damit verbunden nach den Konstitutionsmechanismen von Öffentlichkeit". ${ }^{10}$ Demgegenüber stehen Ausblendungen, die die Beschäftigung mit dem „Medium Fernsehen in seiner historischen Relevanz für die Neuordnungen des Alltags, der Geschlechterverhältnisse, des Wissens und auch des Geschichtsverständnisses im 20. Jahrhundert ${ }^{{ }_{111}}$ und die „der fehlende[...] Verbindung von Bild/Mediengeschichte [und ...] Frauen- und Geschlechtergeschichte "12 betreffen. Beide Leerstellen berühren Bereiche, denen Monika Bernold in ihrer langjährigen Auseinandersetzung mit historischen Medien- und Geschlechterdiskursen viel Aufmerksamkeit hat zukommen lassen. So veröffentlichte sie 2007 unter dem mehrdeutigen Titel „Das Private Sehen“ eine kultur, medien- und geschlechterhistorisch angelegte Studie zum frühen Fernsehen in Österreich, die zeigt, wie im und durch privaten Fernsehkonsum nationale $\mathrm{Zu}$ gehörigkeiten und Identitätskonstruktionen ebenso verhandelt wie geschlechtlich codierte Differenzen und Familie diskursiv her- und dargestellt wurden. ${ }^{13}$ Zahlreiche weitere Veröffentlichungen von Bernold befassen sich mit (österreichischer) Fernsehgeschichte aus geschlechterhistorischen und postkolonialen Perspektiven auf Basis medientheoretischer und kulturwissenschaftlicher Zugänge. ${ }^{14}$ Für die

9 Bernold, Medien- und Geschlechterdiskurse, 58.

10 Ebd.

11 Ebd., 45 .

12 Ebd.

13 Monika Bernold, Das Private Sehen. Fernsehfamilie Leitner, mediale Konsumkultur und nationale Identitätskonstruktion in Österreich nach 1955, Wien/Berlin 2007.

14 Siehe zum Beispiel: Monika Bernold, ein paar österreich. Von den „Leitners“ zu „Wünsch dir was“. Mediale Bausteine der Zweiten Republik, in: Österreichische Zeitschrift für Geschichtswissenschaften 7 (1996) 4, 517-532; Monika Bernold, Fernsehen ist gestern. Medienhistorische Transformationen und televisuelles Dabeisein nach 1945, in: Österreichische Zeitschrift für Geschichtswissenschaften 12 (2001) 4, 8-29; Monika Bernold, Fernsehen im Fernsehen. Mediale Selbstreflexivität und Meta-Narrative des ORF, in: Sylvia Szely (Hg.), Spiele und Wirklichkeiten. Rund um 50 Jahre Fernsehspiel und Fernsehfilm in Österreich, Wien 2005, 239-256; Monika Bernold, Whiteness, Österreich und Afrikanismus am Beispiel der ORF-Produktion Abenteuer Afrika, in: Medienimpulse. Beiträge zur Medienpädagogik 56/2006, 33-38; Monika Bernold, Falsche Fährte als Fahndungsobjekt. Televisuelle Wahrnehmungsmodi und audiovisuelle Evidenz in Aktenzeichen XY ... ungelöst, in: Maske und Kothurn. Internationale Beiträge zur Theater-, Film- und Medienwissenschaft 53 (2007) 2-3, 297-307; Monika Bernold, 9/11 als transnationales Medienereignis. Wissen- 
Etablierung von Fernsehforschung und Forschung zu audiovisuellen ${ }^{15}$ Medien in der österreichischen Zeitgeschichtsforschung sind Bernolds Arbeiten zentral, nicht zuletzt die von ihr gemeinsam mit Siegfried Mattl herausgegebene erste und einzige Ausgabe der Zeitschrift „zeitgeschichte“ zur Fernsehgeschichte, ${ }^{16}$ die mit Sylvia Szely publizierte Nummer der „Österreichischen Zeitschrift für Geschichtswissenschaften“ $\mathrm{zu}$ „Historiographien des Fernsehens“ ${ }^{\text {“17 }}$ und die Mitkonzeption der internationalen Tagung „screenwise. Standorte und Szenarien der zeitgenössischen feministischen Film- und TV-Wissenschaften “ 2003 in Wien. ${ }^{18}$

Elemente einer Kulturgeschichte des österreichischen Fernsehens finden sich beispielsweise in einer von Kurt Luger veröffentlichten Studie auf Basis von biographischen Interviews zu Alltag und Medienereignissen in der Zweiten Republik ${ }^{19}$ oder in Anton Tantners Bearbeitung der medialen Debatte rund um den Ausschluss des Skifahrers Karl Schranz von den Olympischen Spielen 1972. ${ }^{20}$

Weitere wichtige Arbeiten zur Geschichte des (österreichischen) Fernsehens sind in anderen Disziplinen entstanden, in der Publizistik- und Kommunikationswissenschaft, in Film- und Kulturwissenschaften. Exemplarisch sei hier verwiesen auf die im Umfeld der umtriebigen Gruppe kriTFM in den Theater-, Film- und Medienwissenschaften erschienenen Sammelbände zu Fernsehserien ${ }^{21}$ und zur Geschichte des

sproduktionen und Diskursstränge 2001-2010, in: Margit Reiter/Helga Embacher (Hg.), Europa und der 11. September 2001, Wien/Köln/Weimar 2011, 249-270; Monika Bernold, „Aber das heißt nicht, dass Sie eine Frauenrechtlerin sind!“ Gegenderte Wissens-Ökonomien im Fernsehen der 1970er Jahre, in: Andrea Seier/Thomas Waitz (Hg.), Klassenproduktion. Fernsehen als Agentur des Sozialen, Münster 2014, 87-99.

15 Zur Wichtigkeit des Tons und dessen Wegfallen in der Bezeichnung Visual History siehe Bernold, Medien- und Geschlechterdiskurse, 4-5.

16 Monika Bernold/Siegfried Mattl (Hg.), TV-Time. Konzepte zur Fernsehgeschichte. zeitgeschichte 24 (1997) $7 / 8$.

17 Monika Bernold/Sylvia Szely (Hg.), TeleVisionen. Historiographien des Fernsehens. Österreichische Zeitschrift für Geschichtswissenschaften 12 (2001) 4.

18 Zur Dokumentation der Tagung siehe den Band: Monika Bernold/Andrea B. Braidt/Claudia Preschl (Hg.), Screenwise. Film. Fernsehen. Feminismus, Marburg 2004.

19 Kurt Luger, „Es ist alles irgendwie so vorbeigezogen“. Erinnerungen an den Alltag, Medienereignisse und Bilder der Zweiten Republik, in: Hans Heinz Fabris/Kurt Luger (Hg.), Medienkultur in Österreich. Film, Fotografie, Fernsehen und Video in der Zweiten Republik, Wien/Köln/Graz 1988, 45-101.

20 Anton Tantner, Der „Schranz-Rummel“ von 1972. Geschichte, Sport, Krieg und Konstruktion von Nation, in: ZeitRaum 1995/1, 8-33. Online wiederveröffentlicht vom Demokratiezentrum Wien, URL: http://www.demokratiezentrum.org/fileadmin/media/pdf/schranz.pdf (abgerufen 28.08.2020).

21 Sarah Binder/Sarah Kanawin/Simon Sailer/Florian Wagner (Hg.), How I Got Lost Six Feet Under Your Mother. Ein Serienbuch, Wien 2013. 
Eurovision Songcontests ${ }^{22}$ sowie auf Paula Pfosers an der Akademie der Bildenden Künste entstandene Untersuchung zu Repräsentationen von Afrika im frühen österreichischen $\mathrm{TV}^{23}$. Einen Überblick zur Geschichte von Rundfunk und Fernsehen in Österreich unter Berücksichtigung von technik, kultur- und programmgeschichtlichen Aspekten bietet eine 2018 am Technischen Museum Wien verfasste Längsschnittstudie. ${ }^{24}$

\section{Zeitgeschichte im Fernsehen -}

Fernsehen und Video in der österreichischen Zeitgeschichte

Während geschlechter, kultur- und sozialgeschichtliche Perspektiven, wie Bernold sie in ihren Arbeiten eingenommen hat, eher die Ausnahme blieben, äußerten sich österreichische ZeithistorikerInnen regelmäßig zur Frage der Darstellung von Zeitgeschichte im Fernsehen. Zudem kam es seit Beginn der Institutionalisierung der Zeitgeschichte an österreichischen Universitäten zu Kooperationen zwischen der Institution Fernsehen und HistorikerInnen. ${ }^{25}$ In den durchaus konfliktreichen Auseinandersetzungen $\mathrm{zu}$ - vor allem im öffentlich-rechtlichen Fernsehen - gesendeten Inhalten drückt sich eine Kontroverse über die Deutungshoheit über die Geschichte einerseits und um die Mittel ihrer Darstellung andererseits aus. ${ }^{26}$

Die Fokussierung auf die Frage der Geschichte im Fernsehen zeigte sich auch auf den Zeitgeschichtetagen, den österreichweiten Tagungen, die seit 1993 in etwa alle zwei Jahre abgehalten werden. Schon auf dem ersten Zeitgeschichtetag 1993 an der Universität Innsbruck fand eine prominent besetzte ${ }^{27}$ abendliche Podiumsdiskus-

22 Christine Ehardt/Georg Vogt/Florian Wagner (Hg.), Eurovision Song Contest. Eine kleine Geschichte zwischen Camp, Trash, Geschlecht und Nation, Wien 2015.

23 Paula Pfoser, Bilder der Dekolonisation. Afrika-Repräsentationen im frühen österreichischen TV, Wien 2016.

24 Wolfgang Pensold, Zur Geschichte des Rundfunks in Österreich. Programm für die Nation, Wiesbaden 2018.

25 Renée Winter, Mediale Öffentlichkeit und Legitimierung. Kooperationen des frühen Instituts für Zeitgeschichte mit dem österreichischen Fernsehen, in: Bertrand Perz/Ina Markova (Hg.), 50 Jahre Institut für Zeitgeschichte der Universität Wien 1966-2016, Wien 2017, 137-148.

26 Die Distanz der Geschichtswissenschaft gegenüber Fernsehen, Film und Video hat Helene Maimann 1983 pointiert beschrieben: Helene Maimann, Geschichts-Bilder. Zum Verhältnis von Geschichte und Bild-Medien, in: Helmut Konrad (Hg.), Geschichte als demokratischer Auftrag. Karl R. Stadler zum 70. Geburtstag, Wien/München/Zürich 1983, 277-299.

27 An der Diskussion nahmen laut Programm teil: Ruth Beckermann, Gerhard Botz, Peter Dusek, Gerhard Jagschitz, Wilhelm van Kampen, Rolf Steininger und Rainer Wagner. Moderiert hat Helmut Konrad. Siehe: Institut für Zeitgeschichte der Universität Innsbruck (Hg.), Zeitgeschichte-Tag 
sion zum Thema „Zeitgeschichte im Fernsehen“ statt. Diskutiert werden sollte dabei laut Programmheft über Konfliktfelder und Kooperationsmöglichkeiten zwischen Wissenschaft und Medium. ${ }^{28}$ Wenige einzelne Beiträge der übrigen Zeitgeschichtetage der 1990er-Jahre (1995 in Linz, 1997 in Wien und 1999 in Graz ${ }^{29}$ ) befassten sich mit Fernsehen. Neben Monika Bernold, die einen konsum- und geschlechtergeschichtlichen Zugang zum frühen österreichischen Fernsehen präsentierte (1995), beschäftigten sich insbesondere Beiträge der Österreichischen Mediathek (Rainer Hubert 1997) und Beiträge von Seiten des historischen Archivs des ORFs (Gerhard Stanz und Johannes Kraus 1997, Peter Dusek und Siegfried Steinlechner 1999) mit Aspekten der Digitalisierung. Von einer spannungsgeladenen Diskussion zwischen HistorikerInnen und FernsehmacherInnen berichtet Werner Suppanz in seinem Kommentar zum 5. Österreichischen Zeitgeschichtetag 2001 in Klagenfurt und benennt das Verhältnis zwischen Zeitgeschichte und Medien als „prekär, konfliktbeladen und von gegenseitigen Missverständnissen geprägt “. . $^{\circ}$ Mit über zehn Beiträgen zu Fernsehen und Video versammelten die Zeitgeschichtetage 2003 in Salzburg ungewöhnlich viele Beiträge zu audio-visuellen Themen - was auch ein Ergebnis der titelgebenden Begriffe „kunst kommunikation macht“ darstellt. ${ }^{31}$ Die Schwerpunktsetzung 2003 kann als Ausdruck dessen angesehen werden, dem Visual Turn nun auch in der österreichischen Zeitgeschichtsforschung Rechnung zu tragen. ${ }^{32}$

Die meisten Beiträge 2003 (wie auch der nachfolgenden Zeitgeschichtetage 2008 in Innsbruck und 2010 in Wien) zu Fernsehen setzten sich tendenziell mit Dar-

'93 mit Symposium. University of New Orleans - Universität Innsbruck vom 24. bis 27. Mai 1993 in Innsbruck (Programmheft), Innsbruck 1993, 29.

28 Ebd.

29 Rudolf G. Ardelt/Christian Gerbel (Hg.), Österreichischer Zeitgeschichtetag 1995. Österreich - 50 Jahre Zweite Republik. 22. bis 24. Mai 1995 in Linz, Innsbruck/Wien 1996; Gertraud Diendorfer/ Gerhard Jagschitz/Oliver Rathkolb (Hg.), Zeitgeschichte im Wandel. 3. Österreichische Zeitgeschichtetage 1997, Innsbruck/Wien 1998; Manfred Lechner/Dietmar Seiler (Hg.), zeitgeschichte. at. 4. Österreichischer Zeitgeschichtetag '99, Innsbruck/Wien/München 1999.

30 Werner Suppanz, 5. Österreichischer Zeitgeschichtetag 2001, 4.-6. Oktober 2001 in Klagenfurt. Demokratie - Zivilgesellschaft - Menschenrechte - ein Kommentar, in: eForum zeitGeschichte 2001/3-4, URL: http://www.eforum-zeitgeschichte.at/set3_01a1.html (abgerufen 28.08.2020).

31 Ingrid Bauer/Helga Embacher/Ernst Hanisch/Albert Lichtblau/Gerald Sprengnagel (Hg.), > kunst $>$ kommunikation >macht. Sechster Österreichischer Zeitgeschichtetag 2003, Innsbruck/Wien/ München/Bozen 2004.

32 Für die Bundesrepublik Deutschland weist Monika Bernold darauf hin, dass das Ankommen des Visual Turn in der Geschichtswissenschaft anlässlich des deutschen Historikertages 2006 konstatiert worden sei. Bernold, Medien- und Geschlechterdiskurse, 43. 
stellungen der Geschichte im Fernsehen auseinander. ${ }^{33}$ Auf den Zeitgeschichtetagen der 2010er-Jahre (2012 in Linz, 2014 Klagenfurt, 2016 Graz und 2018 Wien) wurden wiederholt auch archivarische Perspektiven eingebracht, beispielsweise von MitarbeiterInnen der Österreichischen Mediathek ${ }^{34}$ oder 2016 in einer gemeinsamen Diskussion von ORF-Archiv und Fachbereichsbibliothek für Zeitgeschichte der Universität Wien. ${ }^{35}$ Beiträge zum Fernsehen selbst jedoch gingen signifikant zurück. Deutlich wird bei einer retrospektiven Betrachtung der Zeitgeschichtetage auch, dass von Beginn an MitarbeiterInnen des ORF - meist des historischen Archivs - eingebunden waren und zu Fernseh, Archiv- und anderen Themen sprachen. ${ }^{36}$

Das Medium Video wurde in den Beiträgen bisheriger Zeitgeschichtetage vor allem hinsichtlich seiner Möglichkeiten in Bezug auf Oral History - die Erstellung von Videointerviews und Fragen der Vermittlung von Zeitgeschichte über Video thematisiert. ${ }^{37}$ Über die Beschäftigung in wissenschaftlichen Beiträgen hinaus fanden wiederholt Videos Eingang in die Begleitprogramme der Zeitgeschichtetage, so vor allem 1999 in Graz, wo die Programmschiene „Media Night“ „den Umgang der Geschichtswissenschaft mit den sogenannten ,neuen Medien ' - Internet, CDRom,

33 So sprach etwa Heidemarie Uhl 2003 zur Krimiserie „Tatort“, Valentin Sima und Brigitte Entner 2003 zu Repräsentationen von PartisanInnen, Renée Winter 2008 und 2010 zur Darstellung von Nationalsozialismus im frühen TV. Bauer/Embacher/Hanisch/Lichtblau/Sprengnagel (Hg.), Zeitgeschichtetag 2003; Ingrid Böhler/Eva Pflanzelter/Thomas Spielbücher/Rolf Steininger (Hg.), 7. Österreichischer Zeitgeschichtetag 2008. 1968 - Vorgeschichten - Folgen. Bestandsaufnahme der österreichischen Zeitgeschichte, Innsbruck/Wien/Bozen 2010; Linda Erker/Alexander Salzmann/ Lucile Dreidemy/Klaudija Sabo (Hg.), Update! Perspektiven der Zeitgeschichte. Zeitgeschichtetage 2010, Innsbruck/Wien/Bozen 2012.

34 So die Beiträge von Gabriele Fröschl sowie Robert Pfundner 2012. Siehe: Institut für Neuere Geschichte und Zeitgeschichte (Hg.), grenzenlos. zeitgeschichtetag 2012. linz/donau 03.-05.10.2012 (Programmheft), JKU Linz, Linz 2012, 20, 26.

35 Stefan Benedik/Lisbeth Matzer/Markus Wurzer, Constructive Unrest. Österreichischer Zeitgeschichtetag 2016 (Programmheft), Universität Graz, Graz 2016, 135.

36 So besonders prominent auch beim Zeitgeschichtetag 2008 in Innsbruck, auf dem Hugo Portisch in einem einstündigen moderierten Gespräch gleichermaßen als Zeitzeuge und als Experte sprach.

37 So zum Beispiel kontinuierlich (1997, 1999, 2003, 2008) von Albert Lichtblau, der sich theoretisch und praktisch mit den Möglichkeiten von Video History auseinandersetzt, Andrea Strutz, die sich gemeinsam mit Manfred Lechner (1999) und gemeinsam mit Leonhard Weidinger und Ernst Langthaler (2003) mit audiovisueller Geschichtsvermittlung beschäftigt hat. 2016 wurde ein gemeinsames Forschungsprojekt von der Universität Innsbruck, FU Berlin und der Pädagogischen Hochschule Luzern zum Einsatz von Videointerviews mit Holocaustüberlebenden im Geschichtsunterricht präsentiert. 
Video ${ }^{\text {38 }}$ thematisierte, eine Video-History-Installation stattfand, und 2010 in Wien, wo im Rahmen der Schiene „Kunst und Zeitgeschichte“ Videoarbeiten gezeigt und diskutiert wurden. Analysen historischer Videopraktiken waren nur vereinzelt Thema, so sprach Barbara Sabitzer 2001 über die Arbeit der Medienwerkstatt Wien 1978-1996 ${ }^{39}$ und Renée Winter 2016 über Videoaktivismus und 2018 über Video als Selbsttechnologie. ${ }^{40}$

\section{Geschichtsfernsehen und Erinnerungspolitiken}

Die Schwerpunktsetzungen der Zeitgeschichtetage spiegeln zu einem großen Teil auch den Fokus publizierter Arbeiten zu Fernsehen und Video wider. Umfassend von ZeithistorikerInnen analysiert und kritisiert wurden beispielsweise die großen Geschichtsprojekte des ORF der 1980er-Jahre „Österreich I“ und „Österreich II“ (Gestaltung: Hugo Portisch, Sepp Riff, 1987-1989 bzw. 1982-1986, 1995)..11

38 Lechner/Seiler (Hg.), Zeitgeschichtetag '99, 509. Auf der die Dokumentation des Zeitgeschichtetages 1999 begleitenden CD-Rom befindet sich sogar ein fünfminütiges Video mit Aufnahmen der Tagung.

39 Siehe: Zeitgeschichtetag 2001. Demokratie - Zivilgesellschaft - Menschenrechte, 4.-6. Oktober 2001 (Programmheft), Universität Klagenfurt, Klagenfurt 2001, 9. Für den Scan des Programmheftes danke ich Brigitte Entner sehr herzlich.

40 Benedik/Matzer/Wurzer, Constructive Unrest, 86; Geschichte wird gemacht, Österreichischer Zeitgeschichtetag 2018 Wien (Programmheft), Universität Wien, Wien 2018, 69, URL: https://backend.univie.ac.at/fileadmin/user_upload/k_zgt18/ZGT18_Programmbuch_digital_.pdf (abgerufen 28.08.2020).

41 Siehe zum Beispiel: Gerhard Botz, Fernsehen ist Macht - macht das Fernsehen die Geschichte?, in: Walter Blumberger/Josef Weidenholzer (Hg.), Ist Wissen Macht? Macht Bildung frei? Max Lotteraner zum 6o. Geburtstag (Gesellschafts- und sozialpolitische Texte 7), Linz 1988, 66-74; Susanne Eybl/Peter Malina, Österreich II: Kuschelweiche Zeitgeschichte, in: schulheft 49/1988, 55-67; Susanne Eybl, Das Geschichtsbild in den österreichischen Medien: die historischen Dokumentarserien Österreich II und Österreich I von Hugo Portisch und Sepp Riff als Paradigma medial aufbereiteter Geschichtsschreibung, phil. Diss., Universität Wien 1993; Susanne Eybl/Elke Renner, Überlegungen zu einem ideologiekritischen Einsatz von "Österreich II" im Unterricht, in: zeitgeschichte 17 (1989) 1, 33-43; Susanne Eybl, Schnurstracks in den Krieg. Der Zweite Weltkrieg in Österreich I und Österreich II von Hugo Portisch und Sepp Riff, in: schulheft 56/1989, 23-38; Eduard Fuchs, Die Ö-II-Macher und ihre Opfer. Einige Thesen zur Instrumentalisierbarkeit von Zeitzeugenaussagen am Beispiel der Fernsehserie Ö II, in: Politische Bildung 11 (1989) 1, 20-25; Peter Malina/Gustav Spann, Geschichte als Bilderbogen der Vergangenheit. Kritische Notizen zur Fernsehserie „Österreich II“, in: Politische Bildung 11 (1989) 1, 12-19. 
Neben diesen prestigeträchtigen, im Schulunterricht eingesetzten und bis heute vom ORF wiederverwerteten Geschichtsproduktionen ${ }^{42}$ zogen auch einige andere Fernsehproduktionen die Aufmerksamkeit von ZeithistorikerInnen auf sich: „Der Herr Karl“ (Drehbuch: Carl Merz, Helmut Qualtinger, Regie: Erich Neuberg 1961), dessen Ausstrahlung am 15. November 1961 im Fernsehprogramm des ORF als Referenzpunkt des österreichischen Umgangs mit seiner nationalsozialistischen Vergangenheit erwähnt wird, ${ }^{43}$ die Ausstrahlung der Fernsehserie „Holocaust“ (Marvin J. Chomsky, NBC 1978) im österreichischen Fernsehen 1979, ${ }^{44}$ die, so Oliver Marchart, Vrääth Öhner und Heidemarie Uhl, eine „Intervention [...] in den narrativen Haushalt des nationalen Gedächtnisses“45 bedeutet habe, oder „Die Zweite Republik. Eine unglaubliche Geschichte" (vier Folgen, Hugo Portisch, ORF 2005) im Jahr $2005^{46}$. Das Wiener Wiesenthal Institut für Holocaust-Studien (VWI) widmete der Darstellung des Holocaust im Fernsehen 2014 eine mehrtägige Konferenz. Die Bei-

422013 sendete der ORF eine digitalisierte und minimal veränderte Version von Österreich I und II, siehe Renée Winter, Geschichtspolitische Bildung im ORF. Ein Blick auf das frühe Fernsehen, in: schulheft 153/2014, 63-76, 74-76.

43 Siehe zum Beispiel Winfried Garscha, Die verhinderte Re-Nazifizierung. Herbert Steiner und das Österreich des Herrn Karl, in: Herbert Arlt (Hg.), Erinnern und Vergessen als Denkprinzipien, St. Ingbert 2002, 27-44; Heidemarie Uhl, Vom Opfermythos zur Mitverantwortungsthese: NSHerrschaft, Krieg und Holocaust im „österreichischen Gedächtnis“, in: Christian Gerbel/Manfred Lechner/Dagmar C.G. Lorenz/Oliver Marchart/Vrääth Öhner/Ines Steiner/Andrea Strutz/ Heidemarie Uhl (Hg.), Transformationen gesellschaftlicher Erinnerung. Studien zur „Gedächtnisgeschichte" der Zweiten Republik, Wien 2005, 50-85, 65; Fiona Steinert/Heinz Steinert, Reflexive Menschenverachtung: die Wienerische Variante von Herrschaftskritik: Der Herr Karl - ein echter Wiener geht nicht unter, in: Reinhard Sieder/Heinz Steinert/Emmerich Tálos (Hg.), Österreich 1945-1995. Gesellschaft Politik Kultur, Wien ${ }^{2} 1996$, 236-249; Katharina Wegan, Monument. Macht. Mythos. Frankreich und Österreich im Vergleich nach 1945, Innsbruck/Wien/Bozen 2005, 311. Siehe auch den Sammelband zu Helmut Qualtingers Film- und Fernseharbeiten: Günter Krenn (Hg.), Helmut Qualtinger. Die Arbeiten für Film und Fernsehen, Wien 2003.

44 Oliver Marchart/Vrääth Öhner/Heidemarie Uhl, Holocaust revisited - Lesarten eines Medienereignisses zwischen globaler Erinnerungskultur und nationaler Vergangenheitsbewältigung, in: Moshe Zuckermann (Hg.), Medien - Politik - Geschichte, Göttingen 2003, 307-334; Heidemarie Uhl, Von „Endlösung“ zu „holocaust“. Die TV-Ausstrahlung von „Holocaust“ und die Transformationen des österreichischen Gedächtnisses, in: dies. (Hg.), Zivilisationsbruch und Gedächtniskultur. Das 20. Jahrhundert in der Erinnerung des beginnenden 21. Jahrhunderts, Innsbruck/Wien/München/Bozen 2003, 153-179; Vrääth Öhner, Fernsehen - Geschichte - Gedächtnis. Zur Transformation dokumentarischer Inszenierungsweisen der Historie, in: Gerbel/Lechner/Lorenz/Marchart/ Öhner/Steiner/Strutz/Uhl (Hg.), Transformationen, 131-157.

45 Marchart/Öhner/Uhl, Holocaust revisited, 317.

46 Vrääth Öhner, Perspektive 1982? Zwölf Anmerkungen zu „Die Zweite Republik“ von Hugo Portisch, in: Martin Wassermair/Katharina Wegan (Hg.), rebranding images. Ein streitbares Lesebuch zu Geschichtspolitik und Erinnerungskultur in Österreich, Innsbruck/Wien/Bozen 2006, 139-146; 
träge thematisierten ein breites Spektrum von Fernsehproduktionen verschiedener historischer und nationaler (Österreich, Bundesrepublik Deutschland, DDR, Italien, Israel, Serbien, Belgien, Tschechoslowakei, Rumänien, Polen, Ungarn, USA) Kontexte. ${ }^{47}$

Televisuelle Bearbeitungen spielen eine Rolle in übergreifenden Studien zur Repräsentation bestimmter historischer Figuren und Ereignisse wie in Drehli Robniks Längsschnittanalyse zur filmischen Behandlung von Graf von Stauffenberg 1948-2008 oder Alexander Pollaks Untersuchung der Darstellung der „Schlacht von Stalingrad“ im Fernsehen seit den 1970er-Jahren. ${ }^{48}$ Judith Keilbach, die ausführlich zum deutschen Geschichtsfernsehen geforscht hat, ${ }^{49}$ untersuchte das (marginale) Interesse des österreichischen Fernsehens am Prozess gegen Adolf Eichmann 1961..$^{\circ}$ Auch aus geschichtsdidaktischer Perspektive sind Fernsehen und seine Rezeption mehrfach behandelt worden. ${ }^{51}$

Geschichte im Fernsehen mit einer Geschichte des Fernsehens (insbesondere des ORF) verbindet der von Sylvia Szely herausgegebene Sammelband „Spiele und Wirklichkeiten“, der sich mit der Geschichte von Fernsehspielen beschäftigt. ${ }^{52}$ Die bezeichnenderweise erste umfassende Publikation zur ORF-Geschichte, die nicht aus einer Innensicht der Fernsehanstalt verfasst war, wurde von einer Filmreihe in Zusammenarbeit mit dem Filmarchiv Austria begleitet, die unter dem Titel „ORF 3 “ den Blick dahin lenken sollte, „wo es [das öffentlich-rechtliche Fernsehen] sich selbst

Ramón Reichert, Fernsehen im Staatsapparat. Die Zweite Republik von Hugo Portisch, in: kolik. film 4/2005, 106-111.

47 Siehe den Konferenzband: Judith Keilbach/Béla Rásky/Jana Starek (Hg.), Völkermord zur PrimeTime. Der Holocaust im Fernsehen, Wien/Hamburg 2019.

48 Drehli Robnik, Geschichtsästhetik und Affektpolitik. Stauffenberg und der 20. Juli im Film 19482008, Wien 2009; Alexander Pollak, Was vom Zweiten Weltkrieg übrig blieb. „Stalingrad“ und Wehrmachtsmythos im Fernsehdokumentarfilm, in: Hannes Heer/Walter Manoschek/Alexander Pollak/Ruth Wodak (Hg.), Wie Geschichte gemacht wird. Zur Konstruktion von Erinnerungen an Wehrmacht und Zweiten Weltkrieg, Wien 2003, 192-224.

49 Siehe zum Beispiel: Judith Keilbach, Geschichtsbilder und Zeitzeugen. Zur Darstellung des Nationalsozialismus im bundesdeutschen Fernsehen, Münster 2008.

50 Judith Keilbach, Der Eichmann-Prozess im österreichischen Fernsehen. Ein Medienereignis mit geringer Resonanz, in: S:I.M.O.N. - Shoah: Intervention. Methods. Documentation. 5 (2018) 1, 4-20.

51 Siehe zum Beispiel zuletzt: Alois Ecker/Alexander Sperl (Hg.), Österreichbilder von Jugendlichen. Zum Einfluss audiovisueller Medien, Wien 2018.

52 Sylvia Szely (Hg.), Spiele und Wirklichkeiten. Rund um 50 Jahre Fernsehspiel und Fernsehfilm in Österreich, Wien 2005. 
nicht (mehr) erinnert“.53 Theoretisch orientierte Überlegungen anhand von (österreichischen) Geschichtsfernsehproduktionen haben beispielsweise Vrääth Öhner ${ }^{54}$ und Monika Bernold ${ }^{55}$ angestellt. Eine Untersuchung der Repräsentationen des Nationalsozialismus im frühen österreichischen Fernsehen mit einer Analyse der an das neue Medium geknüpften Demokratisierungsversprechen zu verbinden und gleichzeitig geschichtspolitische Handlungsfelder in und um das Fernsehen sichtbar zu machen, war das Ziel der 2014 veröffentlichten Studie von Renée Winter. ${ }^{56}$ Auf Basis eines medientheoretischen Verständnisses des Fernsehens als Dispositiv betont die Untersuchung einerseits die Relevanz von Anordnungen, technischen und formalen Aspekten des Mediums für die Bedeutungsproduktionen des Fernsehens und verknüpft andererseits institutionen, programm, technik, genre, geschlechter, rezeptions- und repräsentationsgeschichtliche Perspektiven des Fernsehens.

Neben diesen an Geschichtspolitiken und Perspektiven des kulturellen Gedächtnisses interessierten Untersuchungen existieren verstreut Arbeiten zur Institutionen, Programm- und Wirtschaftsgeschichte des ORF,57 zum Rundfunkvolksbegehren $1964,{ }^{58} \mathrm{zu}$ regionalem Fernsehen, ${ }^{59}$ zur historischer Sportberichterstattung, ${ }^{60}$

53 Dietmar Schwärzler/Sylvia Szely, ORF 3: Film. Fernsehen. Österreich, in: filmarchiv 27/2005, 2833, 29. Der Titel „ORF 3 “verwies auf einen fiktiven Ort des Sendens, sechs Jahre bevor mit ORF III der Spartenkanal für „Kultur und Information“ den Betrieb aufnahm.

54 Vrääth Öhner, Fernsehen oder die Repräsentation der Vergangenheit in seinen Bildern, in: zeitgeschichte 24 (1997) 7/8, 228-240; Öhner, Transformation, 131-157; Vräth Öhner, Von „Endlösung“ zu „Holokaust“. Fernseh-Dokumentationen und die Grenzen des Wahrnehmbaren, in: zeitgeschichte 31 (2004) 3, 179-188.

55 Bernold, Geschichtsproduktion.

56 Renée Winter, Geschichtspolitiken und Fernsehen. Repräsentationen des Nationalsozialismus im frühen österreichischen TV (1955-1970), Bielefeld 2014.

57 Theodor Venus, Fernsehpioniere. Eine empirisch-historische Studie zur ,ersten Generation österreichischer Fernsehmitarbeiter, in: Hans Heinz Fabris/Fritz Hausjell (Hg.), Die vierte Macht. Zu Geschichte und Kultur des Journalismus in Österreich seit 1945, Wien 1991, 107-138; Franz Rest, Die Explosion der Bilder. Entwicklung der Programmstrukturen im österreichischen Fernsehen, in: Hans Heinz Fabris/Kurt Luger (Hg.), Medienkultur in Österreich. Film, Fotografie, Fernsehen und Video in der Zweiten Republik, Wien/Köln/Graz 1988, 265-315; Andreas Resch, Das Geschäft mit Wort und Bild. Wirtschaftsgeschichte der Massenmedien und der Werbebranche in Wien, Wien/Berlin/Münster 2008.

58 Dieter Fischer, Das Rundfunk-Volksbegehren 1964, phil. Diss., Universität Wien 2005.

59 Christiane Dorner/Daniel Pfurtscheller, Lokales Fernsehen in Tirol, in: Valentin Dander/Veronika Gründhammer/Heike Ortner/Daniel Pfurtscheller/Michaela Rizzoli (Hg.), Medienräume. Materialität und Regionalität, Innsbruck 2013, 131-146.

60 Martin Tschiggerl, Parteiische Neutralität. Österreichische Sportberichterstattung im Kalten Krieg, in: zeitgeschichte 42 (2015) 4, 250-266. 
zur Idee eines europäischen Fernsehsenders, ${ }^{61}$ zum Frauentag im $\mathrm{ORF}^{62}$ sowie vor allem im letzten Jahrzehnt entstandene Qualifikationsarbeiten zu einzelnen Aspekten der Programmentwicklung (Kinderfernsehen, ${ }^{63}$ Filmberichterstattung ${ }^{64}$ ) sowie Repräsentationen spezifischer politischer Prozesse und Institutionen ${ }^{65}$.

\section{Selbsthistorisierungen des ORF}

Eine ganze Reihe an Historisierungen des Fernsehens wurde vom Österreichischen Rundfunk selbst geleistet. Eine Möglichkeit des Fernsehens, seine eigene Vergangenheit zu erinnern, besteht in der Ausstrahlung vergangener Sendungen, zum Teil in eigenen Formaten wie etwa in den vergangenen Jahren die Sendungen „Panorama“ oder „16mm - Schätze aus dem Fernseharchiv“ auf ORF III. Neben diesen Wiederaufführungen fand die Selbsthistorisierung kontinuierlich in Publikationen - auch unter Beteiligung von ZeithistorikerInnen - statt. ${ }^{66}$ Die Veröffentlichungen und

61 Simone Paoli, The long path to a European Television Channel. Democracy, Broadcasting and European Union at the time of the Communication Satellites (1976-1986), in: zeitgeschichte 38 (2011) 4, 251-264.

62 Johanna Zechner, Über die mediale Rezeption eines Rituals. Der Frauentag im ORF-Fernsehen zwischen 1977 und 2009, in: Heidi Niederkofler/Maria Mesner/Johanna Zechner (Hg.), Frauentag! Erfindung und Karriere einer Tradition (Begleitbuch zur Ausstellung „Feste. Kämpfe. 100 Jahre Frauentag"), Wien 2001, 274-293.

63 Katharina Hörmann, „Disse malle pumperness - am dam des“. Aufbau und Auswirkungen des österreichischen Kinderfernsehens sowie eine Analyse unterschiedlicher Mitmach-Formate in der Geschichte des ORF, MA-Arbeit, Universität Wien 2016.

64 Karoline Rieder, Apropos Film! Apropos ...? Eine erste Bestandsaufnahme der Filmberichterstattung im ORF von den Anfängen bis 1976, Dipl.-Arb., Universität Wien 2008.

65 Petra Dobersberger, Arena-Besetzung revisited - Die Besetzung des Auslandsschlachthofs St. Marx 1976 als Erinnerungsort einer „verspäteten“ 68er-Bewegung, Dipl.-Arb., Universität Wien 2017; Jakob Zacharias Steiner, Rot-weiß-rote Integration in schwarz-weiß. EWG und EFTA in den Nachrichten des ORF 1959-1967, Dipl.-Arb., Universität Wien 2010; Markus Loose-Einfalt, Die öffentliche Repräsentation der Katholischen Kirche und ihre Rezeption in Politik und Medien analysiert anhand der Fernsehberichterstattung des ORF in den Jahren 1945 bis 1985, phil. Diss., Universität Wien 2017; David Christopher Jaklin, Von Wildgänsen und PMCs. Der Wandel in der gesellschaftlichen Wahrnehmung von Söldnern in Film und Fernsehen, phil. Diss., Universität Graz 2017.

66 Siehe die vierbände Rundfunkgeschichte von Viktor Ergert, 50 Jahre Rundfunk in Österreich, Bd. 1: 1924-1945, Bd. 2: 1945-1955, Bd. 3: 1955-1967, Bd. 4: 1967-1974, Salzburg 1974/1975/1977/1985; Franz Ferdinand Wolf, 25 Jahre ORF 1975-2000, Salzburg 2001; Kurt Tozzer/Martin Majnaric, Achtung Sendung. Höhepunkt, Stars und exklusive Bilder aus 50 Jahren Fernsehen, Wien 2005; Andreas Novak/Oliver Rathkolb (Hg.), Die Macht der Bilder, Berndorf 2017. 1980 gab der ORF außerdem eine breitangelegte Studienreihe heraus, die sich auch mit historischen Aspekten be- 
Wiederaufführungen könnten selbst Quellen für künftige Forschungsarbeiten sein: Wie erzählt die Fernsehanstalt ihre eigene Geschichte? Welche Narrative sind dominant, welche Auslassungen bestehen? Die Fernsehhistorikerin Lynn Spigel beispielsweise schreibt der Selbsthistorisierung des Fernsehens ein Fortschrittsparadigma zu: „television engages in a kind of historical consciousness that remembers the past in order to believe in the progress of the present ${ }^{\text {" }}{ }^{67}$

\section{Video und/in Geschichtswissenschaft}

Parallel zur breiten Verfügbarkeit von Videotechnik in den 1980er-Jahren erschienen Überlegungen zum methodischen Einsatz von Video in der Geschichtswissenschaft, insbesondere der Oral History. ${ }^{68}$ Mittlerweile existieren zahlreiche Onlinearchive mit Videointerviews, von denen das aus der von Steven Spielberg gegründeten Shoah Foundation hervorgegangene Visual History Archive das umfangreichste ist. ${ }^{69}$ Während Amateurfilme in Österreich von geschichtswissenschaftlicher Seite her im letzten Jahrzehnt gut beforscht (und archiviert) wurden, vor allem in Kooperationen des 2005-2015 von Siegfried Mattl geleiteten Ludwig Boltzmann Instituts für Geschichte und Gesellschaft (seit 2019: LBI for Digital History) mit dem Öster-

fasste. Zusammenfassung der Ergebnisse der Teilstudien in: Franz Simbürger/Karin Steiner (Hg.), Synopse der Forschungsberichte (Berichte zur Medienforschung 28), Wien 1980.

67 Lynn Spigel, From the dark ages to the golden age: women's memories and television reruns, in: Screen 36 (1995) 1, 16-33, 20.

68 Karin Berger, „Video-History“ - Vor den Grenzen die Möglichkeit. Zu Entstehungsbedingungen und Verwendung von Video-History als Methode in der Geschichtswissenschaft, in: Gerhard Botz/Christian Fleck/Albert Müller/Manfred Thaller (Hg.), „Qualität und Quantität“. Zur Praxis der Methoden der Historischen Sozialwissenschaft (Studien zur Historischen Sozialwissenschaft 10), Frankfurt a. M./New York 1988, 253-267; Gerhard Botz, Fernsehen in der Zeitgeschichte. „Zeitgeschichte im Fernsehen“ - „Video History“ in der „Zeitgeschichte“: drei Perspektiven, in: medien \& zeit 8 (1993) 4, 2-5; Andrea Strutz, Geteilte Leben. Erinnerungen jüdischer Vertriebener in den USA an NS-Verfolgung, Krieg und Österreich, in: Siegfried Mattl/Gerhard Botz/Stefan Karner/Helmut Konrad (Hg.), Krieg. Erinnerung. Geschichtswissenschaft, Wien/Köln/Weimar 2009; Gerda Klingenböck, Im Spannungsfeld von Erinnerung und audiovisueller Repräsentation. Historisches Konzept und filmische Realisation einer Video-Dokumentation von Lebensgeschichten aus dem Frauenkonzentrationslager Ravensbrück, Dipl.-Arb., Universität Wien 2003.

69 Siehe USC Shoah Foundation, Visual History Archive Online, URL: http://vhaonline.usc.edu. Weitere Sammlungen befinden sich zum Beispiel in der Österreichischen Mediathek, URL: https://www.mediathek.at/; auf Stiftung Erinnerung, Verantwortung und Zukunft, Interview-Archiv Zwangsarbeit 1939-1945, URL: https://archiv.zwangsarbeit-archiv.de/ oder auf: erinnern.at, weiter_erzaehlen; URL: https://www.weitererzaehlen.at/ (alle abgerufen 28.08.2020). 
reichischen Filmmuseum ${ }^{70}$ sind bisherige Forschungen zum Home- und Amateurvideobereich eher verstreut. So existieren vereinzelt Texte und Arbeiten zu Video als Gegenkultur, ${ }^{71}$ zur Ankunft von Video im Klub der Kinoamateure Österreichs, ${ }^{72}$ zur Geschichte der Medienwerkstatt Wien, ${ }^{73}$ zur Auswirkung von Digitalisierung auf das Amateurfilmschaffen, ${ }^{74} \mathrm{zu}$ Videokunst ${ }^{75}$ und $\mathrm{zu}$ Homevideo $^{76}$. Darüber hinaus werden in geschichtsdidaktischer Perspektive Möglichkeiten des Einsatzes von Videoclips oder der Videoproduktion durch SchülerInnen ausgelotet. ${ }^{77}$ Ein am Institut für Zeitgeschichte der Universität Wien angesiedeltes Forschungsprojekt widmet sich aktuell der Geschichte des Mediums Video 1960 bis 2000 unter dem Blickwinkel von Technologien des Selbst: Anhand verschiedener Anwendungsbereiche von Video (Psychotherapie, Coaching, Aktivismus, (auto)biographischer Gebrauch)

70 Siegfried Mattl/Carina Lesky/Vrääth Öhner/Ingo Zechner (Hg.), Abenteuer Alltag. Zur Archäologie des Amateurfilms, Wien 2015.

71 Manfred Neuwirth, Gegenkultur durch Video, in: Hans Heinz Fabris/Kurt Luger (Hg.), Medienkultur in Österreich. Film, Fotografie, Fernsehen und Video in der Zweiten Republik, Wien/Köln/ Graz 1988, 251-263.

72 Renée Winter, Video-Aufnahme. Die Ankunft von Video im Klub der Kinoamateure Österreichs, in: Renée Winter/Christina Waraschitz/Gabriele Fröschl (Hg.), Aufnahme läuft. Private Aufnahmen - Öffentliche Archive?, Wien 2016, 85-96.

73 Barbara Sabitzer, Die Medienwerkstatt Wien. Politisch-ästhetische Medienarbeit mit Video 19781996, Dipl.-Arb., Universität Wien 2001.

74 Karin Schuh, Die Auswirkungen der digitalen Videotechnik auf das Amateur- und Independentfilmschaffen in Österreich mit Schwerpunkt Wien. Eine Bestandsaufnahme anhand von ExpertInnengesprächen, Dipl.-Arb., Universität Wien 2004.

75 Gerda Lampalzer, Videokunst. Historischer Überblick und theoretische Zugänge, Wien 1992; Ana Karaminova, „Fresh“ von Adelina Popnedeleva - ein Produkt seiner Zeit. Oder: Wie Videokunstwerke Zeitgeschichte reflektieren, in: zeitgeschichte 39 (2012) 5, 308-325.

76 Winter/Waraschitz/Fröschl (Hg.), Aufnahme läuft; Renée Winter, „Wo ist zuhause, Mama?“ Home Videos und Mobilität, in: Günther Friesinger/Judith Schoßböck/Thomas Ballhausen (Hg.), Digital Migration. Konstruktionen - Strategien - Bewegungen, Wien 2016, 61-71; Renée Winter, Zuhause im Archiv. Video als Übergangsmedium, in: Ute Holfelder/Klaus Schönberger (Hg.), Bewegtbilder und Alltagskultur(en). Von Super 8 über Video zum Handyfilm. Praktiken von Amateuren im Prozess der gesellschaftlichen Ästhetisierung, Köln 2017, 106-117.

77 Simone Ofner, Geschichte einfach erklärt auf Youtube. Zum Einsatz von Erklär- bzw. Lernvideos im Geschichtsunterricht am Beispiel des Kanals The Simple History, Dipl.-Arb., Universität Graz 2017; Matthias Bollmann, Videoproduktion als Unterrichtsmethode im Geschichtsunterricht in der kooperativen Mittelschule. Eine Annäherung an neue Unterrichtskulturen mittels audiovisueller Beobachtung im Blick auf die professionalisierte medienpädagogische Praxis, phil. Diss., Universität Wien 2013. 
werden mediale Praktiken in Hinblick auf ihre subjektivierenden Funktionen analysiert. ${ }^{78}$

\section{Zur Archivsituation}

Das Historische Archiv des ORF wurde erst 1984, knapp dreißig Jahre nach Aufnahme des Fernsehbetriebs, eingerichtet. Die Lücken des Archivs seien, so Vrääth Öhner, nicht nur dieser verzögerten Archivierung geschuldet, sondern „auch direktes Resultat einer Erschließungspraxis, die Material zunächst nach der programmlichen Relevanz für zukünftige Ausstrahlung bewertet“.79 Diese Praxis betrifft nicht nur die auf Wiederverwendung ausgerichtete Indizierung und Beschlagwortung der Bestände, sondern auch deren Zerlegung und Fragmentierung, die die Rekonstruktion des Fernsehflows ${ }^{80}$ allein auf Basis des Fernseharchivs unmöglich macht. ${ }^{81}$

Der Zugang zum ORF-Archiv für ForscherInnen war lange Zeit nicht oder nur unter äußerst restriktiven Bedingungen gegeben. ${ }^{82} 2011$ wurde nach jahrzehntelangen Forderungen nach einer Öffnung des Archivs von FernsehforscherInnen, Studierenden und anderen an der Fachbereichsbibliothek Zeitgeschichte der Universität Wien eine Außenstelle des ORF-Archivs eröffnet. 2016 folgte eine weitere Recherchestation an der Universität Innsbruck, 2017 an der Universität Graz. Die Recherchestationen, die einen Zugang zum digitalisierten ORF-Material sowie zu Metadaten nichtdigitalisierten Materials bieten, stellen zweifellos eine Verbesserung der Forschungssituation dar. Inwieweit sich diese in einer steigenden Forschungs-

78 FWF-Projekt V-633: „Video als Selbsttechnologie. Selbst-Konfrontation, Selbst-Ermächtigung und Auto/biographische Praktiken“, Projektleitung: Renée Winter (2018-2022), Institut für Zeitgeschichte der Universität Wien, URL: https://zeitgeschichte.univie.ac.at/forschung/drittmittelprojekte/video-als-selbsttechnologie-selbst-konfrontation-selbst-ermaechtigung-und-autobiographische-praktiken/ (abgerufen 28.08.2020).

79 Vrääth Öhner, Wiedersehen macht Freude. Über Archivierung und Rekonstruktion von Fernsehprogrammen, in: Österreichische Zeitschrift für Geschichtswissenschaften 12 (2001) 4, 30-41, 35.

80 Der Flow bezeichnet ein in den Fernsehwissenschaften einflussreiches Konzept des Cultural-Studies-Theoretikers Raymond Williams, das die Erfahrung des Fernsehens als ununterbrochener Fluss von Sendungen, Werbung und Programmvorschauen beschreibt. Raymond Williams, Programmstruktur als Sequenz oder flow, in: Ralf Adelmann/Jan-Otmar Hesse/Judith Keilbach/Markus Stauff/Matthias Thiele (Hg.), Grundlagentexte zur Fernsehwissenschaft. Theorie, Geschichte, Analyse, Konstanz 2001, 33-43 (ursprünglich ist der Artikel bereits 1975 erschienen).

81 Öhner, Wiedersehen, 35.

82 Vgl. Bernold, Medien- und Geschlechterdiskurse, 95-98. 
tätigkeit, insbesondere in universitären Abschlussarbeiten zum Fernsehen, ausdrücken wird, werden die nächsten Jahre zeigen.

Das Modell der Archivaußenstellen an universitären Bibliotheken birgt jedoch weiterhin Hindernisse für Fernsehforschende: Die Logik des ORF-Archivs entspricht nach wie vor der eines Produktionsarchivs. Überleitungen, Programmansagen, Werbeblöcke etc. sind nicht oder nur im Ausnahmefall archiviert, stellen jedoch einen wesentlichen Teil der (historischen) Fernseherfahrung dar. Auch können Sendungen - so sie digital verfügbar sind - nur vor Ort gestreamt werden. Eine Kopie der Files für die Forschenden ist aus urheber- und datenschutzrechtlichen Gründen nicht erlaubt. Für filmanalytische Methoden wie Close Reading, Mikroanalyse oder Sequenzanalyse ist es jedoch erforderlich, Sequenzen gründlich und wiederholt anzusehen, sie anzuhalten, detaillierte Transkriptionen und Einstellungsprotokolle anzufertigen und bei Bedarf zu bestimmten Stellen zurückzukehren; ein Arbeitsprozess, der mit einer digitalen Kopie (zum Beispiel inklusive einer Verpflichtungserklärung, die Daten ausschließlich zu Forschungszwecken zu nutzen) wesentlich erleichtert würde. Zudem ist der Zugang zur Recherchestation in seiner aktuellen Form lediglich für Studierende und MitarbeiterInnen der jeweiligen Universitäten vorgesehen. Diese Regelung schließt prekarisierte, selbständige oder von Kettenvertragsregelungen betroffene ForscherInnen sowie Studierende anderer Universitäten, SchülerInnen oder alle sonstigen interessierten Personen aus bzw. macht diese vom - jedoch glücklicherweise oft vorhandenen - Wohlwollen der Bibliotheksleitung abhängig. $\mathrm{Zu}$ wünschen wäre ein wirklich öffentlicher Zugang zum Archiv des ORF, wie es auch andere öffentlich-rechtliche Rundfunkanstalten handhaben (wie zum Beispiel das Institute for Sound and Vision in Hilversum in den Niederlanden).

Öffentlichen Zugang, jedoch kein vollständiges Fernseharchiv gewährleistet die Österreichische Mediathek. Das Archiv der Mediathek geht zurück auf den gesetzlichen Auftrag, das „audiovisuelle Kulturerbe“ Österreichs zu sammeln, zu bewahren und zugänglich zu machen. Seit $1984^{83}$ werden ausgewählte Fernsehsendungen aufgenommen, regelmäßig auch mit einigen Minuten Vorlauf- und Nachspielzeit. Auch das Programm privater Fernsehsender ${ }^{84}$ wird selektiv erfasst und in den Bestand übernommen - so seit 2000 Sendungen von ATV, seit 2004 von Puls4 (vor 2008:

83 Laut Auskunft von Gabriele Fröschl, Leiterin der Österreichischen Mediathek.

84 Der Zugang zu den Archiven privater Fernsehsender ist von den Fernsehanstalten selbst per se nicht vorgesehen. Eine dementsprechende Anfrage an ATV, Servus TV, gotv und Puls4 wurde lediglich von ATV und Puls4 mit dem Hinweis beantwortet, dass ,aus rechtlichen und administrativen Gründen“ keine Einsicht gewährt werden könne (E-Mail vom 03.05.2019 an die Autorin). Der Community-Sender Okto arbeitet an der Onlinestellung seines gesamten Programms. Siehe URL: https://www.okto.tv/de/page/faq (abgerufen 28.08.2020). 
PulsTV), seit 2005 von Okto, seit 2009 von Servus TV sowie vereinzelte Sendungen von LT1 und GoTV. ${ }^{85}$ Außerdem wurden vereinzelt Fernsehmitschnitte externer Herkunft in den Bestand übernommen. 2014-2016 wurden in einem dreijährigen Projekt Home- und Amateurvideos gesammelt und digitalisiert. Mit ca. 3.00o Videokassetten unterschiedlichster Formate wurde damit ein großer Bestand privater Aufnahmen (vor allem der 1970er- bis 1990er-Jahre) zugänglich gemacht und für die Forschung erschlossen. ${ }^{86}$ Digitalisierung und Internet erleichtern den Zugang zu vielen bisher vor allem in Filmarchiven zugänglichen Quellen. Neben biographischen Videointerviews ${ }^{87}$ sind online beispielsweise ephemere Filme zum Nationalsozialismus in Österreich oder audio-visuelle Quellen zur Wiener Stadtgeschichte ${ }^{88}$ verfügbar.

Mit den Veränderungen von Fernseh- und Videopraktiken in Zusammenhang mit Digitalisierung und Social Media stellen sich auch neue Fragen für die Archivierung. Wie können aktuelle, fragmentierte Fernseherfahrungen für zukünftige ForscherInnen zugänglich gemacht werden? Diese bestehen nicht mehr nur aus dem Fernsehen vom TV-Gerät, sondern haben sich vervielfältigt und sind zusammengesetzt aus Sendungen in Mediatheken der Fernsehanstalten, von UserInnen archivierten Ausschnitten auf YouTube, für Facebook optimierten Clips von Nachrichtensendungen oder für Social Media aufbereiteten schriftlichen Teasern, vorgeschlagenen Lieblingsserien auf Netflix oder Amazon Prime und dem nicht erlaubten, aber weitverbreiteten Herunterladen oder Streamen von Serien.

Prekärer noch ist die Frage nach Selbstzeugnissen: Wie und von welchen Institutionen werden audiovisuelle Praktiken der Selbstdarstellung und Erzählung des eigenen Lebens archiviert - wenn das Aufheben und Speichern für die Filmenden

85 Siehe den Katalog der Österreichischen Mediathek, URL: https://www.mediathek.at/katalogsuche/ (abgerufen 28.08.2020). Danke für die Informationen zum aktuellen Aufnahmemodus an Robert Pfundner.

86 Wiener Videorekorder, Österreichische Mediathek, URL: https://www.mediathek.at/wienervideorekorder/ (abgerufen 28.08.2020).

87 Siehe Fußnote 69.

88 Siehe Ephemeral Films Project - National Socialism in Austria, United States Holocaust Memorial Museum/Österreichisches Filmmuseum/Ludwig Boltzmann Institut für Geschichte und Gesellschaft, URL: http://efilms.ushmm.org/ oder StadtFilmWien, Ludwig Boltzmann Institut für Geschichte und Gesellschaft, URL: http://stadtfilm-wien.at/, Filmarchiv der media Wien, URL: http// mediawien-film.at/ oder den Wiener Videorekorder der Österreichischen Mediathek, URL: https:// www.mediathek.at/wienervideorekorder/ (alle abgerufen 28.08.2020). 
selbst einen geringen Stellenwert hat und gegenüber den Möglichkeiten des sofortigen Anschauens und Teilens zurücktritt? ${ }^{89}$

\section{Ausblick}

Medien im historischen Kontext zu betrachten bedeutet, sie sowohl als Ausdruck und Produkt der jeweiligen historischen Anordnung zu begreifen als auch historische Wahrnehmungen und Vorstellungen von der Welt als medial bedingt zu verstehen. Monika Bernold schlägt vor, den Begriff der „historischen Medienkonstellation" $\mathrm{zu}$ verwenden,

weil in ihm die jeweiligen Veränderungen, Koppelungsprozesse und Dynamiken zwischen den unterschiedlichen Medien in den Blick geraten und die Stellung der verschiedenen Medien zueinander als potenziell veränderlich und offen konzipierbar ist. Die jeweilige historische Medienkonstellation wirkt in dieser Perspektive auf die historischen Artikulationen der jeweiligen Medien selbst ebenso zurück wie auf deren Lage und Verhältnis zueinander. ${ }^{90}$

Was diese Momentaufnahme zur zeitgeschichtlichen Fernseh- und Videoforschung zeigt, ist, dass es vieles noch zu erforschen und zu schreiben gibt: eine umfassende Programmgeschichte des ORF, Untersuchungen zu den privaten Fernsehsendern und zu experimentellen Fernsehzugängen, zur Bedeutung des Fernsehens für und seine verschiedenen historischen Ausprägungen als Ausdruck von gesellschaftliche/n Veränderungen. Eine weitere Leerstelle stellt eine historische Rezeptionsforschung, die über Modelle der medialen Beeinflussung von ZuschauerInnen hinausgeht, dar. Welche Rolle spielten zum Beispiel US-amerikanische Sitcoms für die Wahrnehmung von Differenzen für ein österreichisches Publikum? Wie hat beispielsweise die „Bill Cosby Show“ das Bild österreichischer FernsehzuschauerInnen geprägt in

89 So halten Ute Holfelder und Christian Ritter auf Basis einer Studie von Handyfilmen von Jugendlichen fest: „Die Tatsache, dass die meisten Handyfilme nur im Handyfilmarchiv der Akteure verbleiben und nicht auf anderen Speichermedien archiviert werden, ist ein Hinweis darauf, dass Handyfilme mehr noch als herkömmliche Bildmedien relativ zeitnah und direkt in soziale Interaktionen integriert und weniger aus der Retrospektive betrachtet werden." Ute Holfelder/Christian Ritter, Filmen im Alltag. Handyfilme in der Perspektive einer medienweltlichen Ethnografie, in: kommunikation@gesellschaft 14 (2013), 1-27, 21. Online unter URL: http://nbn-resolving.de/ urn:nbn:de:0168-ssoar-361878 (abgerufen 28.08.2020).

Bernold, Medien- und Geschlechterdiskurse, 94. 
einer Zeit, in der Arabella Kiesbauer bei „X-Large“ rassistischen Anfeindungen entgegentreten musste und andere Darstellungen Schwarzer Menschen in Österreich über Exotizismus nicht hinauskamen? Wie wurden jüdische Serienfiguren wie Fran Fine aus der Serie „Die Nanny“ im postnazistischen Österreich rezipiert? Wesentlich wären intersektionale, interdisziplinäre, historische Perspektiven auf die audiovisuellen Medien Fernsehen und Video als Elemente sich verändernder historischer Medienkonstellationen in ihren vielfältigen Erscheinungsformen (Videokassette, YouTube, Handyvideo, Stream ...), auf die mit den medialen Dispositiven verknüpften technischen Geräte (Rekorder, Überwachungskamera, Kameradrohne, Smartphone ...), auf ihr Zusammenspiel mit ökonomischen Sphären ((Re)Produktion, Landwirtschaft, Militär und Krieg, Konsum ...), auf ihre Repräsentationen und ihre Anordnungen, auf die Rezeptionssituationen (im Gasthaus, im Wohnzimmer, auf der Toilette ...) und auf die Frage der SenderInnen (Wer gibt etwas zu sehen: die Fernsehanstalt, die beste Freundin, das Kollektiv, die Firma ...?).

Was für die Zukunft der zeithistorischen Forschungen zu Fernsehen und Video jedenfalls notwendig erscheint, sind interdisziplinäre Zugänge und Kooperationen, ${ }^{91}$ eine Offenheit für (Medien)Theorie und ein Verständnis für das Politische der Medien, das über ein institutionelles Politikverständnis hinausgeht.

91 Studiengänge wie der an der Universität Wien seit 2016 angebotene interdisziplinäre Master Zeitgeschichte und Medien bilden hier sicher eine wichtige Grundlage für ein zukünftiges interdisziplinäres (Selbst-)Verständnis. 


\title{
Fotografie
}

\author{
Markus Wurzer
}

Die „Zeitgeschichte ist die Geschichte der ubiquitären (bewegten) Bilder“, ${ }^{1}$ und die „Entdeckung“ der Fotografie in den 1980er-Jahren hat die Quellenbasis der Disziplin erheblich erweitert. Aber auch wenn ZeithistorikerInnen Fotografien zunehmend in ihre Praxis einbeziehen, sei - Jens Jäger zufolge - der quellenkritische Umgang mit ihnen nichtsdestotrotz „immer noch unbefriedigend“. ${ }^{2}$ Man hat sich zwar von der Naivität verabschiedet, dass Fotos zeigten, wie es gewesen ist, ${ }^{3}$ doch bleibt - vielleicht gerade deswegen - methodisches Unbehagen. ${ }^{4}$ Die Frage nach ihrem Quellenwert wird - etwa in Studienbüchern - oft nur mit dem Hinweis auf eine eingeschränkte Quellentauglichkeit beantwortet, ergänzt um einen Appell für eine quellenkritische Herangehensweise. ${ }^{5}$ Der Fotografie wohnt allerdings auch ein ungeheures analytisches Potenzial inne, dessen Nutzung durch den Visual Turn in den Geschichtswissenschaften erst in den letzten Jahren in Entfaltung begriffen ist. ${ }^{6}$

Diese zwei Perspektiven auf Fotografie - methodologisch herausfordernd, inhaltlich vielversprechend - räumen ihr innerhalb der österreichischen Zeitgeschichte eine spezielle Position ein und mögen dafür verantwortlich sein, dass sie - nach wie vor - als (verhältnismäßig) „neue“ Quellengattung wahrgenommen wird. Die Absicht des vorliegenden Beitrages ist es, diese unter Verweis auf internationale Forschungszusammenhänge zu erörtern. Dabei wird einerseits - erstmalig - ein Überblick über fotobezogene zeithistorische Forschungen in Österreich geliefert.

1 Gabriele Metzler, Zeitgeschichte: Begriff - Disziplin - Problem, Version: 1.o, DocupediaZeitgeschichte, URL: http://docupedia.de/zg/metzler_zeitgeschichte_v1_de_2014 (abgerufen 15.08.2020).

2 Jens Jäger, Fotografie und Geschichte (Historische Einführungen 7), Frankfurt a. M. $2009,41$.

3 Metzler, Zeitgeschichte.

4 Daniela Kneissl, Einleitung, in: Daniela Kneissl (Hg.), Fotografie als Quelle der Zeitgeschichte: Kategorien, Schauplätze, Akteure, München 2009, 7-10.

5 Beispielsweise: Matthias Peter/Hans-Jürgen Schröder, Einführung in das Studium der Zeitgeschichte, Paderborn/München/Wien/Zürich 1994, 49, 256; Gabriele Metzler, Einführung in das Studium der Zeitgeschichte, Paderborn/München/Wien/Zürich 2004, 53; Gunilla Budde, Quellen, Quellen, Quellen..., in: Gunilla Budde/Dagmar Freist/Hilke Günther-Arndt (Hg.), Geschichte. Studium - Wissenschaft - Beruf, Berlin 2008, 52-69, 58; keine Erwähnung von Fotografie als Quelle in: Gerhard Schulz, Einführung in die Zeitgeschichte, Darmstadt 1997; Horst Möller/Udo Wengst (Hg.), Einführung in die Zeitgeschichte, München 2003.

6 Jens Jäger, Geschichtswissenschaft, in: Klaus Sachs-Hombach (Hg.), Bildwissenschaften. Disziplinen, Themen, Methoden, Frankfurt a. M. 2005, 185-195. 
Andererseits versammelt der Beitrag aktuelle Forschungsperspektiven und ist dementsprechend zweigeteilt.

\section{Entwicklungslinien}

Wenngleich Fotografie heute ein fixer Bestandteil des zeithistorischen Quellenkanons ist, war dies lange Zeit nicht so. Nach der Formierung der Zeitgeschichte als Disziplin in den 1960er-Jahren wurde das Interesse an historischer Fotografie von ,außen', vor allem durch ihre Verwendung in musealen und populärwissenschaftlichen Bereichen angeregt. 7 Erika Weinzierl veröffentlichte beispielsweise 1968 - auf Initiative des Tyrolia-Verlags - den populärwissenschaftlichen Band „Österreich. Zeitgeschichte in Bildern 1918-1968“. Dieser sollte neueste politikgeschichtliche Forschungsergebnisse zusammenfassen und einem größeren, jüngeren Leserkreis zugänglich machen. Beigegebene Fotografien sollten dabei - so die Autorin im Vorwort - „sachliche Informationen über die Geschichte der Republik" ${ }^{\text {“8 }}$ vermitteln. Diesen Impulsen entsprechend richteten sich erste fotobezogene Arbeiten nicht nach historischem Erkenntnisinteresse, sondern stellten Überlegungen über den Einsatz von Fotografien in der Geschichtsvermittlung an. ${ }^{9}$ Dazu sollte sich die Fotografie im Besonderen deshalb eignen, weil - so die populäre Annahme dieser Zeit - sie qua der ihr zugesprochenen indexikalischen Qualität unverfälscht zeigen könne, was gewesen sei. ${ }^{10}$

Erst in den 1980er-Jahren setzte innerhalb der deutschsprachigen Zeitgeschichte eine erste theoretische und methodologische Debatte über die „Fotografie als Quelle, ihre Aussagekraft, ihren Charakter und letztlich ihre Verwendbarkeit für die Forschung " ${ }^{11}$ ein. Wesentlicher „Ort" dieser Debatten war (und ist bis heute)

7 Markus Cerman, Die Fotografie als (sozial-)historische Quelle - Möglichkeiten und Grenzen eines „neuen“ Quellentyps, in: zeitgeschichte 20 (1993) 9/10, 271-296, 271.

8 Erika Weinzierl, Österreich. Zeitgeschichte in Bildern 1918-1968, in Zusammenarbeit mit Peter Hofrichter (Bilddokumentation), Innsbruck/Wien/München 1968, 7 .

9 Etwa für den schulischen Geschichtsunterricht: Gerhard Jagschitz, Möglichkeiten des Einsatzes von audiovisuellen Medien für Zeitgeschichte und politische Bildung im Unterricht, in: Peter Schneck/Karl Sretenovic (Hg.), Zeitgeschichte als Auftrag politischer Bildung. Lehren aus der Vergangenheit, Wien/München 1979, 157-162.

10 Roland Barthes, Die helle Kammer. Bemerkungen zur Photographie, Frankfurt a. M. 1985, 92; innerhalb der zeithistorischen Disziplin wurde diese indexikalische Qualität vor allem im Zuge der Debatten rund um die sog. „Wehrmachtsausstellung“ Ende der 1990er-Jahre in Zweifel gezogen; siehe dazu Abschnitt 1.1.

11 Cerman, Fotografie, 271. 
die Zeitschrift „FOTOGESCHICHTE“, die 1981 vom Wiener Fotohistoriker Timm Starl in Frankfurt am Main gegründet wurde. ${ }^{12} 2001$ „übersiedelte“ die Zeitschrift nach Wien, wo sie seither von Anton Holzer herausgegeben wird. ${ }^{13}$

Im österreichischen Kontext war es Gerhard Jagschitz, der den Diskurs prägte. ${ }^{14}$ Er ersann bereits zu dieser Zeit, was heute beinahe vergessen ist - in Analogie zur damals bereits etablierten Oral History -, als Erster im deutschsprachigen Raum den Begriff der Visual History. ${ }^{15}$ In einem programmatischen Aufsatz 1991 definierte er diesen wie folgt:

„Visual history“ ist nicht nur ein System eines theoretischen und methodologischen Zugangs zur Photographie. Der Begriff ist gleichzeitig ein Programm, ein längst bekanntes Medium endlich auch in die Historiographie und in die wissenschaftliche Arbeit einzubeziehen. „Visual history“ ist dafür hinaus auch noch ein Aufruf zur interdisziplinären Zusammenarbeit, denn es bedarf vieler verschiedener Zugänge und Kenntnisse, um der Photographie ihre Botschaften und Geheimnisse zu entreissen. ${ }^{16}$

FachkollegInnen knüpften kaum an dieses Programm an. Erst 15 Jahre später griff der deutsche Historiker Gerhard Paul auf den Begriff zurück. ${ }^{17}$ Im internationalen Vergleich war Jagschitz jedenfalls ein Vorreiter. Zur selben Zeit sinnierte etwa auch der deutsche Historiker Alf Lüdtke über das Potenzial einer „visuellen Geschichte“"18 - ohne sie jedoch zu konkretisieren.

Resultat der Auseinandersetzungen der 1980er-Jahre war die Erkenntnis, dass „es in Hinkunft ohne die Berücksichtigung visueller Quellen nicht gehen wird“. ${ }^{19}$ Nichtsdestotrotz war die Entwicklung kein Selbstläufer: Die 1989 von Jagschitz ins Leben gerufene Zeitschrift „Photographie und Gesellschaft. Zeitschrift für Imagolo-

12 Aus der regen Publikationstätigkeit Timm Starls sei seine Pionierarbeit zur „Knipser“-Fotografie hervorgehoben: Timm Starl, Knipser. Die Bildgeschichte der privaten Fotografie in Deutschland und Österreich von 1880 bis 1980, München 1995.

13 FOTOGESCHICHTE. Beiträge zur Geschichte und Ästhetik der Fotografie, URL: http://www. fotogeschichte.info/die-zeitschrift/ (abgerufen 15.08.2020); zur Geschichte der Zeitschrift siehe: Anton Holzer, Kein Stern. Die Geschichte der Fotogeschichte, in: Fotogeschichte 40 (2020) 157, 7-52.

14 Etwa seine Pionierarbeit: Gerhard Jagschitz, Zeitaufnahmen, Österreich im Bild. 1945 bis heute, Wien 1982.

15 Erstmals in: Georg E. Schmid, Geleit, in: zeitgeschichte 16 (1988) 9/10, 309-317, 315.

16 Gerhard Jagschitz, Visual History, in: Das audiovisuelle Archiv 29-30/1991, 23-51, 46.

17 Gerhard Paul (Hg.), Visual History. Ein Studienbuch, Göttingen 2006.

18 Alf Lüdtke, Zu den Chancen einer „visuellen Geschichte“, in: Journal für Geschichte 1986/3, 26-39.

19 Schmid, Geleit, 315. 
gie“, die als „Forum für fotografische Forschungsprobleme“ dem Ziel dienen sollte, „die speziell in Österreich vernachlässigte wissenschaftliche Diskussionskultur zumindest im audio-visuellen Bereich zu fördern“, ${ }^{20}$ musste bereits nach einem Jahrgang eingestellt werden. Vielleicht auch aufgrund dieser Erfahrung hielt Jagschitz noch 1991 fest, dass „Träger optischer Information weitgehend aus der Historiographie ausgeklammert" blieben. Dass ihr Quellenwert ob ihrer gesellschaftlichen Relevanz nicht beachtet werde, veranlasste Jagschitz gar, der österreichischen Zeitgeschichte eine „Abkoppelung von sozialer Realität“" ${ }^{21} \mathrm{zu}$ attestieren. Er forderte, „das Bild - und infolge ihrer Dominanz vor allem die Photographie - verstärkt in die Geschichtswissenschaft einzubringen".22

Im Rahmen des 1. Österreichischen Zeitgeschichtetags 1993 in Innsbruck griff Gerhard Botz, damals Professor für Österreichische Geschichte mit besonderer Berücksichtigung der Zeitgeschichte in Salzburg, die Appelle und Rufe nach Anerkennung und Integration von Bildern in den Quellenkanon auf. In seinen „zwölf Thesen zur Zeitgeschichte in Österreich“ erkannte er in Fotografien gar ein Charakteristikum der Disziplin: „Zeitgeschichte [ist] durch ein spezifisches Ensemble von epochenzentrierten Quellen und Methoden sowie inhaltlichen Schwerpunkten und Analyseproblemen charakterisiert“, die sich nicht nur, aber nun eben auch „aus dem Auftreten von [...] (massenhaften) fotografischen Bildquellen [...] ergeben", „die neue Methoden, etwa in Form von [...] Bildanalyse und semiologischen Deutungen, geradezu herausgefordert haben“. ${ }^{23}$

Auch wenn Markus Cerman Ende der 1980er- und Anfang der 1990er-Jahre glaubte, dass „der Gebrauch von fotografischen oder filmischen Quellen innerhalb der Geschichte einen ,Boom “" ${ }^{24}$ erlebt habe, so blieben explizit fotobezogene Studien rar gesät. Die wenigen schlossen sich inhaltlich an bestehende Forschungsschwerpunkte wie NS-Herrschaft in Österreich, Zweiter Weltkrieg und Holocaust an. Im Jahr 1988 erschienen beispielsweise Studien, die sich nicht zufällig Lichtbildern des "Anschlusses“ 1938 widmeten. ${ }^{25}$ Diese Arbeiten hingen mit den geschichtspoliti-

20 Gerhard Jagschitz, Editorial, in: Photographie und Gesellschaft. Zeitschrift für photographische Imagologie 1 (1989) 1, 2-4, 3.

21 Ebd., 24.

22 Ebd.

23 Gerhard Botz, Zwölf Thesen zur Zeitgeschichte in Österreich, in: Ingrid Böhler/Rudolf Steininger (Hg.), Österreichischer Zeitgeschichtetag 1993: 24. bis 27. Mai 1993 in Innsbruck, Innsbruck 1995, 19-33, 22.

24 Cerman, Fotografie, 271.

25 Gerhard Jagschitz, Photographie und ,Anschluß im März 1938, in: Oliver Rathkolb/Wolfgang Duchkowitsch/Fritz Hausjell (Hg.), Die veruntreute Wahrheit. Hitlers Propagandisten in Österreichs Medien (Schriftenreihe des Arbeitskreises für historische Kommunikationsforschung 1), 
schen Debatten rund um das „Gedenkjahr“ 1988 sowie die Waldheim-Affäre 1986 zusammen, die Fragen nach der Verantwortung Österreichs aufwarfen und die „Opferthese“ endgültig widerlegten. ${ }^{26}$ In diesen Kontexten erfüllten Fotografien vom "Anschluss“ mitunter die Funktion von Beweisen, die - so Heinz Grell - unwiderlegbar dokumentierten, dass die Bevölkerung Österreichs diesen bejubelt habe. ${ }^{27}$ Jagschitz legte dagegen eine Studie vor, in der er auf die Entstehungsbedingungen der Bilder als NS-Propagandamedien aufmerksam machte. ${ }^{28}$

Das Wiener Zeitgeschichteinstitut, an dem Jagschitz ab 1968 tätig war, bildete einen wichtigen Ort für fotobezogene Forschungen. Neben dem bereits Erwähnten verantwortete Jagschitz die Einrichtung eines Bildarchivs sowie die datenbankmäßige Erfassung von Fotosammlungen in Österreich. ${ }^{29}$ Daneben betrieben Institutsangehörige ebenso fotobezogene Projekte: Karl Stuhlpfarrer, Florian Freund und Bertrand Perz beschäftigten sich mit einem Bestand von fünfhundert Farbdiapositiven aus dem Ghetto Lodz. Dieser diente ihnen dabei eher noch als Impuls zur Erforschung konkreter Abläufe der Deportation, des strukturellen Zusammenhangs von Juden- und „Zigeunerverfolgung“ denn als Quelle. ${ }^{30}$ Unter der Leitung von Oliver Rathkolb wurde anhand der Bestände des Fotoarchivs des Dr.-Karl-RennerInstituts und des Bruno-Kreisky-Archivs die „Bildkultur in Österreich 1900-1983“ erforscht. ${ }^{31}$ Bertrand Perz beschäftigte sich mit Fotografien aus dem Kontext der NS-Zwangsarbeit. ${ }^{32}$

Salzburg 1988, 52-87; Heinz Grell, Der Österreich-Anschluss 1938. Zeitgeschichte im Bild, Leoni am Starnberger See ${ }^{3} 1988$.

Heidemarie Uhl, Zwischen Versöhnung und Verstörung. Eine Kontroverse um Österreichs historische Identität fünfzig Jahre nach dem „Anschluß“, Wien/Köln/Weimar 1992.

27 Grell, Österreich-Anschluss, 7-8.

28 Jagschitz, Photographie, 52-87.

292009 wurden die Bestände an das Bildarchiv der ÖNB übergeben; Archivbestände am Institut für Zeitgeschichte Wien, URL: https://www.univie.ac.at/zeitgeschichte/forschung/archivbestande/ (abgerufen 15.08.2020); Datenbank und Handbuch photographischer Quellen Österreichs, URL: https://www.univie.ac.at/zeitgeschichte/handbuch-photographischer-quellen-osterreichs/ (abgerufen 15.08.2020).

30 Bertrand Perz, Das Ghetto Lodz und die Einrichtung des Vernichtungslagers in Chelmno/Kulmhof, in: Rudolf G. Ardelt (Hg.), Österreich - 50 Jahre Zweite Republik: Österreichischer Zeitgeschichtetag 1995: 22. bis 24. Mai 1995 in Linz, Innsbruck/Wien 1997, 220-224, 223; siehe auch: Florian Freund/Bertrand Perz/Karl Stuhlpfarrer, Farbdias aus dem Ghetto Lodz, in: zeitgeschichte $18(1990 / 1991)$ 9/10, 271-303.

31 Projekt 3675 des Jubiläumsfonds der OeNB: „Bildkultur in Österreich 1900-1983“, Projektleitung: Oliver Rathkolb (1991-1992), vgl. dazu: Cerman, Fotografie, 271.

32 Bertrand Perz, „Neue Höhlenmenschen“. Eine von KZ-Häftlingen errichtete unterirdische Rüstungsfabrik bei Melk an der Donau, fotografiert von Michael Wrobel, in: Fotogeschichte 14 (1994) $54,45-56$. 
Fotobezogene Arbeiten wurden zu dieser Zeit aber auch schon anderswo betrieben: Der Historiker und Fotograf Arno Gisinger gründete beispielsweise 1997 in Innsbruck ein „Atelier für Fotografie und Visual History“ und widmete sich unter anderem der Rolle von Fotografien für das kulturelle Gedächtnis des Holocaust. ${ }^{33}$ Am Institut für Wirtschafts- und Sozialgeschichte in Wien reichte 1995 Ernst Langthaler eine Diplomarbeit ein, die sich mit Fotografien eines Wehrmachtssoldaten aus dem Zweiten Weltkrieg beschäftigte. ${ }^{34}$

\subsection{Die „Wehrmachtsausstellung" als methodologischer Katalysator}

Gerade diese Quellengattung von Fotografien von Wehrmachtsangehörigen aus dem Zweiten Weltkrieg sorgte Ende der 1990er-Jahre nicht nur innerhalb der Zeitgeschichtsforschung, sondern auch in der Öffentlichkeit für Aufregung: Die zwischen 1995 und 1999 in 34 Städten Deutschlands und Österreichs ${ }^{35}$ gezeigte Wanderausstellung „Vernichtungskrieg. Verbrechen der Wehrmacht 1941 bis $1944^{\text {“36 }}$ stützte sich nämlich intensiv auf „Knipser“-Fotografien. Ihre massenhafte Präsentation sorgte - in den Worten Dirk Rupnows - für einen regelrechten „Bilderbruch“, 37 der sowohl die bis dahin derealisierten Verbrechen endgültig sichtbar machen und die zuvor anonymen Täter als "ganz normale Männer“ entlarven konnte; auf diese Weise destabilisierte die Ausstellung die lange Zeit nicht in Frage gestellten Deutungsrahmen des Zweiten Weltkriegs. ${ }^{38}$

33 Arno Gisinger, Für eine Kulturgeschichte der fotografischen Erinnerung am Beispiel visueller Darstellungen des Holocaust, in: Gertraud Diendorfer (Hg.), Zeitgeschichte im Wandel: 3. Österreichischer Zeitgeschichtetag 1997: 26. bis 28. Mai 1997, Wien 1998, 472-477, 473.

34 Ernst Langthaler, Lebens-Zeichen. Zum Design einer Semio-Hermeneutik am Beispiel der Biographie eines Soldaten im Zweiten Weltkrieg, Dipl.-Arb., Universität Wien 1995; siehe auch: Ernst Langthaler, Heinrich, die Kamera und die Militärzeit. Ein Versuch, die Kriegs-Bilder eines jugendlichen Dorfbewohners zu verstehen, in: Österreichische Zeitschrift für Geschichtswissenschaften 5 (1994) 4, 517-546.

35 In Österreich wurde die Ausstellung in Wien, Innsbruck, Klagenfurt, Linz, Graz und Salzburg gezeigt.

36 Hamburger Institut für Sozialforschung (Hg.), Vernichtungskrieg. Verbrechen der Wehrmacht 1941 bis 1944, Hamburg 1996.

37 Dirk Rupnow, Das unsichtbare Verbrechen. Beobachtungen zur Darstellung des NS-Massenmordes, in: zeitgeschichte 29 (2002) 2, 87-97, 88.

38 Rupnow, Verbrechen, 93; für die Auswirkungen der Ausstellung auf den österreichischen Bilderkanon über die NS-Zeit siehe: Ina Markova, Die NS-Zeit im Bildgedächtnis der Zweiten Republik, Innsbruck/Wien/Bozen 2018, 149-168. 
Im Jahr 1999 entspann sich eine intensive Debatte rund um die in der Ausstellung gezeigten Fotografien, die sich im Speziellen an der Frage nach deren Authentizität und an der Interpretation einzelner Fotografien entzündete. ${ }^{39}$ Infolge dieser Kritik wurde die Schau im November 1999 ausgesetzt und eine Kommission beauftragt, die erhobenen Vorwürfe zu prüfen. Ihr Bericht ${ }^{40}$ widerlegte diese weitgehend und bestätigte die grundlegenden Aussagen der Ausstellung sowie - abgesehen von einige Ausnahmen - die Authentizität und die Inhalte gezeigter Fotografien. ${ }^{41}$ Die Ausstellung wurde daraufhin in überarbeiteter Form nochmals von 2001 bis 2004 gezeigt, ${ }^{42}$ wobei dieser „als Antwort auf den kritischen Diskurs um das erste Ausstellungsprojekt“ nun „das visuelle Schockerlebnis“ fehlte. ${ }^{43}$

Für die fotobezogene Zeitgeschichtsforschung in Deutschland und Österreich stellte die Ausstellung vor allem deshalb ein signifikantes Ereignis dar, weil sie die Disziplin für die methodologischen Herausforderungen im Umfang mit Fotografien als Quelle sensibilisierte. ${ }^{44}$ Wenngleich die Bilddebatte fast ausschließlich in Deutschland ausgetragen wurde, ${ }^{45}$ beteiligte sich auch - zwar nur vereinzelt und mit Verzögerung - die österreichische Zeitgeschichte. ${ }^{46}$ Gerald Lamprecht zeigte an einem Fallbeispiel, dass die Rekontextualisierung der „Landser“-Bilder in die

39 Miriam Y. Arani, „Und an den Fotos entzündete sich die Kritik“. Die „Wehrmachtsausstellung“, deren Kritiker und die Neukonzeption. Ein Beitrag aus fotohistorisch-quellenkritischer Sicht, in: Fotogeschichte 22 (2002) 85/86, 96-124; für die Ausstellungsdebatte im Allgemeinen siehe Christian Hartmann/Johannes Hürter/Ulrike Jureit, Verbrechen der Wehrmacht. Bilanz einer Debatte, München 2005.

40 Omer Bartov/Cornelia Brink/Gerhard Hirschfeld/Friedrich P. Kahlenberg/Manfred Messerschmidt/Reinhard Rürup/Christian Streit/Hans-Ulrich Thamer, Bericht der Kommission zur Überprüfung der Ausstellung „Vernichtungskrieg. Verbrechen der Wehrmacht 1941 bis 1944“, URL: https://web.archive.org/web/20131021095032/https://www.his-online.de//fileadmin/user_ upload/pdf/veranstaltungen/Ausstellungen/Kommissionsbericht.pdf (abgerufen 15.08.2020).

41 Rupnow, Verbrechen, 87.

42 Hamburger Institut für Sozialforschung (Hg.), Verbrechen der Wehrmacht. Dimensionen des Vernichtungskrieges 1941-1944, Hamburg 2002.

43 Heidemarie Uhl, Neue Wehrmachtausstellung macht Geschichte, Der Standard, 29.05.2002, URL: https://derstandard.at/961997/Neue-Wehrmachtsausstellung-macht-Geschichte (abgerufen 15.08.2020).

44 Hans-Ulrich Thamer, Eine Ausstellung und ihre Folgen. Impulse der „Wehrmachtsausstellung “ für die historische Forschung, in: Ulrich Bielefeld/Heinz Bude/Bernd Greiner (Hg.), Gesellschaft - Gewalt - Vertrauen. Jan Philipp Reemtsma zum 60. Geburtstag, Hamburg 2012, 489-503.

45 Lukas Grossberger, Die Wehrmachtausstellung in Deutschland und Österreich. Ein Vergleich. Dipl.-Arb., Universität Wien 2011, 85.

46 Andere Aspekte - etwa rund um das Verhältnis von Politik und Gedächtnis - diskutierte die österreichische Zeitgeschichte intensiver: Helga Embacher (Hg.), Umkämpfte Erinnerung. Die Wehrmachtsausstellung in Salzburg, Salzburg 1999; Walter Manoschek/Alexander Pollak/Ruth Wodak/ 
NS-Verbrechen autobiographische Narrationen von Ex-Wehrmachtsangehörigen destabilisiere. ${ }^{47}$ Im Januar 2001, kurz nach der Veröffentlichung des Kommissionsberichts zur Wehrmachtsausstellung, fand am Internationalen Forschungszentrum Kulturwissenschaften (IFK) in Wien eine Tagung statt, auf der Fragen fotografischer Authentizität und die Rolle von Lichtbildern im Spannungsfeld zwischen privatem und öffentlichem Erinnern ausgelotet wurden. ${ }^{48}$

\subsection{Inhaltliche Ausdifferenzierung ab den 2000er-Jahren}

Auch nach der „Wehrmachtsausstellung“blieben der Zweite Weltkrieg, die NS-Herrschaft und der Holocaust - wie auch in der deutschen Zeitgeschichtsforschung ${ }^{49}$ zentrale Themen fotobezogener Zeitgeschichtsforschungen in Österreich. Beispielsweise widmete sich Hans Petschar, seit 2002 Direktor des ÖNB-Bildarchivs, siebzig Jahre nach dem „Anschluss“ dessen fotografischen (und filmischen) Repräsentationen. ${ }^{50}$ Rosemarie Burgstaller beschäftigte sich mit den visuellen Darstellungen Österreichs nach dem März 1938 in NS-Ausstellungen. ${ }^{51}$ Wieder andere Arbeiten befassten sich mit Ikonisierungsprozessen einzelner Lichtbilder, die sich noch heute im Bilderkanon über die NS-Zeit finden..$^{52}$ Um die Jahrtausendwende wurden in Deutschland auch Fotografien aus den Konzentrationslagern Gegenstände histori-

Hannes Heer (Hg.), Wie Geschichte gemacht wird. Zur Konstruktion von Erinnerungen an Wehrmacht und Zweiten Weltkrieg, Wien 2003.

47 Gerald Lamprecht, Kriegsphotographie als Ort der Erinnerung. Photographie zwischen privat und öffentlich am Beispiel eines Kriegserinnerungsalbums und des Diskurses um die Photographien der Wanderausstellung „Vernichtungskrieg. Verbrechen der Wehrmacht 1941 bis 1944“, in: eForum zeitGeschichte 1 (2002) 2/3, 1-21.

48 Dirk Rupnow/Heidemarie Uhl, Editorial, in: zeitgeschichte 29 (2002) 2, 55; aus der Tagung entstand ein ,zeitgeschichte“-Sonderheft: zeitgeschichte 29 (2002) 2, 55-97.

49 Jäger, Fotografie, 44.

50 Hans Petschar, Anschluss: „Ich hole Euch heim“. Der „Anschluss“ Österreichs an das Deutsche Reich. Fotografie und Wochenschau im Dienst der NS-Propaganda. Eine Bildchronologie, Wien 2008.

51 Rosemarie Burgstaller, „Das befreite Land“. Österreich-Bilder im Nationalsozialismus, in: zeitgeschichte 42 (2015) 2, 116-130.

52 Werner Dreier/Eduard Fuchs/Verena Radkau/Hans Utz (Hg.), Schlüsselbilder des Nationalsozialismus. Fotohistorische und didaktische Überlegungen (Konzepte und Kontroversen 6), Innsbruck/ Wien/Bozen 2008; Johannes Breit, „Im Hintergrund: Abendwolken vor den Stubaier Alpen - im Vordergrund: Ostarbeiter“. Fotografien als Zugang zur NS-Geschichte - dargestellt mit Bildquellen des Molybdänbergbaus im Tiroler Valsertal 1941-1945, in: Oliver Rathkolb (Hg.), Update! Perspektiven der Zeitgeschichte. Österreichische Zeitgeschichtetage 2010, 25. bis 28. Mai 2010, Wien 2010, 225-234. 
scher Analysen. ${ }^{53}$ In Österreich gab es 2005 eine Fotoausstellung über das KZ Mauthausen. ${ }^{54} 2016$ folgte eine Konferenz am Grazer Centrum für jüdische Studien, aus der ein Band hervorging, der sich mit der Ästhetik und Evidenzfunktion von eben solchen Fotografien beschäftigt. ${ }^{55}$ Auf ganz andere Weise untersuchte Maria PohnLauggas Erinnerung an NS-Verbrechen: In ihrem am Wiener Institut für Soziologie betriebenen Forschungsprojekt widmete sie sich der intergenerationalen Tradierung von widerständigem Handeln gegen das NS-Regime durch visuelle Medien in österreichischen Familien. ${ }^{56}$

$\mathrm{Ab}$ den 200oer-Jahren begann sich das Erkenntnisinteresse fotobezogener Zeitgeschichtsforschungen auch anderen Kriegen zuzuwenden. Maßgeblich daran beteiligt war der Wiener Fotohistoriker Anton Holzer, der 2002/2003 sowohl einen international vielbeachteten Sammelband als auch ein „Fotogeschichte“-Sonderheft herausgab, die beide verschiedenste Aspekte von Krieg und Fotografie adressierten. Sie nahmen sowohl Propaganda- als auch „Knipser“-Bilder in den Blick und spannten den zeitlichen Bogen vom Krimkrieg (1853-1856) bis hin zum Krieg in Afghanistan (seit 2001), wobei der Schwerpunkt eindeutig - und das gilt allgemein für fotobezogene Zeitgeschichtsforschung - auf dem Ersten und Zweiten Weltkrieg lag. ${ }^{57}$ Die Anschläge vom 11. September 2001 regten unterdessen zu Studien über „Terrorbilder“ und ihre Wirkungen in historischen Perspektiven an. ${ }^{58}$

Holzer, der als Herausgeber der Zeitschrift „Fotogeschichte“ das Forschungsfeld in den letzten zwei Jahrzehnten substanziell mitgeprägt hat, beschäftigte sich selbst lange Zeit mit Fotografien des Ersten Weltkriegs. Er führte ein vielbeachtetes Forschungsprojekt über die Propagandafotografie der Habsburgerarmee durch und

53 Cornelia Brink, Ikonen der Vernichtung. Öffentlicher Gebrauch von Fotografien aus nationalsozialistischen Konzentrationslagern nach 1945, Berlin 1998; Habbo Knoch, Die Tat als Bild. Fotografien des Holocaust in der deutschen Erinnerungskultur, Hamburg 2001.

54 Gabriele Pflug/Ilsen About (Hg.), Das sichtbare Unfassbare. Fotografien vom Konzentrationslager Mauthausen, Wien 2005.

55 Hildegard Frübis/Clara Oberle/Agnieszka Pufelska (Hg.), Photographien aus den Lagern des NSRegimes. Beweissicherung und ästhetische Praxis, Wien 2018.

56 Maria Pohn-Lauggas, In Worten erinnern, mit Bildern sprechen. Zum Unterschied zwischen visuellen und mündlichen Erinnerungspraktiken, in: Zeitschrift für Qualitative Forschung 17 (2016) 1/2, 59-80.

57 Anton Holzer (Hg.), Krieg und Fotografie, in: Fotogeschichte 22 (2002) 85/86, 7-124; Anton Holzer (Hg.), Mit der Kamera bewaffnet. Krieg und Fotografie, Marburg 2003.

58 Werner Telesko, 11. September 2001: „Bilder des Terrors - Ikonographie des Untergangs“, in: Ingrid Bauer (Hg.), Kunst - Kommunikation - Macht. 6. Österreichischer Zeitgeschichtetag 2003, Innsbruck/Wien 2004, 197-200; Petra Bernhardt, Terrorbilder, in: Politik und Zeitgeschichte 66 (2016) 24/25, 3-10. 
schloss daran ein Projekt an, das sich mit der visualisierten Gewalt gegen die Zivilbevölkerung beschäftigte. ${ }^{59}$

Ein weiterer Forschungsschwerpunkt Holzers betraf die Zwischenkriegszeit. Er beschäftigte sich sowohl mit der Geschichte der Pressefotografie ${ }^{60}$ als auch mit Fotografiegeschichte im Allgemeinen und einzelnen FotografInnen, wie Robert Haas, im Speziellen. ${ }^{61}$ Zuletzt widmete sich Holzer - anlässlich des einhundertjährigen Jubiläums der Ausrufung der Republik - aus foto- und mediengeschichtlicher Perspektive dem Epochenjahr 1918/1919. ${ }^{62}$

Weitere fotobezogene Arbeiten zur österreichischen Zwischenkriegszeit konzentrieren sich auf die Bildpolitiken des Dollfuß-Schuschnigg-Regimes: Während sich Elizabeth Cronin beispielsweise der Instrumentalisierung des Genres der Heimatfotografie widmete, ${ }^{63}$ untersuchte Bettina Brunner den Gebrauch von zeitgenössischen illustrierten Zeitungen und Bildchroniken durch die Kanzlerdiktatur. ${ }^{64}$

Neben den bereits genannten Themen sind in den letzten Jahren zu einem weiteren Kernthema der österreichischen Zeitgeschichtsforschung, nämlich der Geschichte der Zweiten Republik und im Speziellen der „Besatzungszeit“, fotobezogene Arbeiten, wie etwa über die Fotografien von Dora Kallmus, die sie in den Flüchtlingslagern Österreichs zwischen 1946 und 1949 geschossen hatte, durchgeführt worden. ${ }^{65}$ Kathrin Wegan untersuchte dagegen eine der bekanntesten Bildikonen der Zeitgeschichte: die Präsentation des Staatsvertrags am Belvedere-Balkon. ${ }^{66}$ Daneben haben die alliierten Bilderdienste Aufmerksamkeit auf sich gezogen. Georg Schmid und Hans Petschar widmeten sich zum Beispiel US-amerikanischen Bild-

59 Anton Holzer, Die andere Front. Fotografie und Propaganda im Ersten Weltkrieg, Darmstadt 32012; Anton Holzer, Das Lächeln der Henker. Der unbekannte Krieg gegen die Zivilbevölkerung 1914-1918, Darmstadt ${ }^{2} 2014$.

60 Anton Holzer, Rasende Reporter. Eine Kulturgeschichte des Fotojournalismus, Darmstadt 2014.

61 Anton Holzer, Fotografie in Österreich: Geschichte, Entwicklungen, Protagonisten 1890-1955, Wien 2013; Anton Holzer/Frank Kreutler (Hg.), Robert Haas. Der Blick auf zwei Welten, Berlin 2016.

62 Anton Holzer, Krieg nach dem Krieg. Revolution und Umbruch 1918/19, Darmstadt 2017; Anton Holzer, Die erkämpfte Republik. 1918/19 in Fotografien, Salzburg/Wien 2018.

63 Elizabeth Cronin, Heimatfotografie in Österreich. Eine politisierte Sicht von Bauern und Skifahrern (Beiträge zur Geschichte der Fotografie in Österreich 10), Wien/Salzburg 2015.

64 Bettina Brunner, Die fotografische Repräsentation des österreichischen „Ständestaates“. Illustrierte Zeitungen und Bildchroniken als Träger der visuellen Geschichte des Dollfuß-Schuschnigg-Regimes, Dipl.-Arb., Universität Graz 2014.

65 Magdalena Vuković (Hg.), Porträts der Entwurzelung. D’Oras Fotografien in österreichischen Flüchtlingslagern 1946-1949 (Beiträge zur Geschichte der Fotografie in Österreich 17), Wien/ Salzburg 2018.

66 Katharina Wegan, „Staatsvertrag im Bild“, in: Bauer (Hg.), Kunst, 170-176. 
produktionen. ${ }^{67}$ Die alliierten Bilderdienste und ihr Zusammenspiel mit den nationalen Bildagenturen sind unterdessen auch Gegenstand eines Projekts, das Fritz Hausjell, Margarethe Szeless und Marion Krammer am Wiener Institut für Publizistik und Kommunikationswissenschaften unlängst durchführten. ${ }^{68}$

Zuletzt ist ein Forschungsstrang zu identifizieren, der sich mit visuellen Repräsentationen von Minderheiten, des ,Anderen' und ,Fremden' auseinandersetzte und an internationale Forschungen über rassistische Diskurse anschloss. Beispielhaft dafür sind etwa die Arbeiten, die im Wiener Photoinstitut Bonartes entstanden, ${ }^{69}$ sowie die Studien von Gerhard Baumgartner über die Darstellungen von Roma und Sinti im 19. und 20. Jahrhundert, ${ }^{70}$ von Katharina Stornig über Missionsfotografie ${ }^{71}$ sowie von Karl Kaser über visuellen Kulturen auf dem Balkan und Visualisierungen der Balkankriege (1912-1913) ${ }^{72}$ zu nennen.

Während die österreichische Zeitgeschichte in methodisch-theoretischen Fragen - bis auf Jagschitz und einige Ausnahmen, deren Einfluss allerdings eingeschränkt geblieben ist ${ }^{73}$ - eher Zuhörerin der im deutschen und angloamerikanischen Raum betriebenen Debatten war, haben sich andere Disziplinen daran sehr

67 Georg Schmid, Photographien und Information. Amerikanische Panoramen von Nachkriegsösterreich, in: zeitgeschichte 32 (2005) 4, 250-268; Hans Petschar, Der fremde, der eigene Blick. Amerikanisch-österreichische Bilddokumente 1945-1955, in: zeitgeschichte 32 (2005) 4, 269-274; siehe auch Hans Petschar, Die Junge Republik. Alltagsbilder aus Österreich 1945-1955, Wien 2005.

68 Marion Krammer/Margarethe Szeless/Fritz Hausjell (Hg.), Alliierte Bildpolitik in Österreich 19451955. Medien \& Zeit 32 (2017) 1.

69 Siehe etwa: Monika Faber/Martin Pfitscher (Hg.), „Die herrlichen schwarzen Menschen“. Hugo Bernatziks fotojournalistische Beutezüge in den Sudan 1925-1927 (Beiträge zur Geschichte der Fotografie in Österreich 8), Wien 2014; Magdalena Vuković (Hg.), „Im Dienst der Rassenfrage“. Anna Koppitz’ Fotografien für Reichsminister R. Walther Darré (Beiträge zur Geschichte der Fotografie in Österreich 12), Wien 2016.

70 Gerhard Baumgartner, „Zigeuner“-Fotografie aus den Ländern der Habsburgermonarchie im 19. und frühen 2o. Jahrhundert, in: Frank Reuter/Silvio Peritore (Hg.), Inszenierung des Fremden. Fotografische Darstellung von Sinti und Roma im Kontext der historischen Bildforschung, Heidelberg 2011, 133-162.

71 Katharina Stornig, Vielfache Bedeutungen. Missionsfotografie zwischen Neuguinea und Europa, 1896 - ca. 1930, in: Österreichische Zeitschrift für Geschichtswissenschaften 24 (2013) 2, 113-138.

72 Karl Kaser, Andere Blicke. Religion und visuelle Kulturen auf dem Balkan und im Nahen Osten, Wien/Köln/Weimar 2013; Karl Kaser, Gibt es den Balkan doch? Krieg und visuelle Revolution zu Beginn des 20. Jahrhunderts, in: Martina Baleva/Boris Prevesic (Hg.), „Den Balkan gibt es nicht“. Erbschaften im südöstlichen Europa, Wien/Köln/Weimar 2016, 142-157.

73 Cerman, Fotografie, 271-296; Gerald Trimmel, Das digitale Bild als historische Quelle, in: Diendorfer (Hg.), Zeitgeschichte, 478-483; Wolfgang Kos, Der öffentliche Raum der Bilder - Bemerkungen zur kulturgeschichtlichen Arbeit mit Bildquellen, in: Diendorfer (Hg.), Zeitgeschichte, 484-492. 
wohl beteiligt. Roswitha Breckner vom Wiener Institut für Soziologie legte 2010 zum Beispiel eine Sozialtheorie des Bildes vor; ${ }^{74}$ Franz X. Eder, Oliver Kühschelm und Christina Linsboth vom Wiener Institut für Wirtschafts- und Sozialgeschichte veröffentlichten 2014 einen Band zur historischen Bilddiskursanalyse. ${ }^{75}$

\section{Visual Turn in der österreichischen Zeitgeschichte?}

Das vorangegangene Kapitel hat vor Augen geführt, dass das lange Zeit vernachlässigte Bild mittlerweile endlich auch „ein vollwertiges Mitglied der historiografischen Familie geworden " 76 ist: Fotobezogene zeithistorische Forschungen widmen sich beileibe nicht mehr nur der NS-Geschichte, sondern auch anderen Themen; zusätzlich gilt: Arbeiten zur visuellen Zeitgeschichte entstehen nicht nur an den universitären Zeitgeschichteeinrichtungen. Sie stellt auch für andere geistes- und kulturwissenschaftliche Disziplinen ein produktives Feld dar.

Damit wird auch hinlänglich deutlich, dass die österreichische Zeitgeschichte über die letzten Jahrzehnte in vielfältiger Weise am seit den 1990er-Jahren für die Kultur- und Geisteswissenschaften postulierten Visual Turn ${ }^{77}$ partizipierte. ${ }^{78}$ Grund dafür sind mehrere parallel ablaufende und einander verstärkende Entwicklungen: Erstens: Die Geschichtswissenschaften transformierten sich - angestoßen vom Cultural Turn 79 - von einer textorientierten Disziplin zu einer multimedialen Kulturwissenschaft. Und gerade im Zuge des ebenso davon beeinflussten und in der Zeitgeschichte einflussreichen Memory-Booms der 1990er-Jahre „entdeckte“ die Erinnerungsforschung Bilder als Quellen. ${ }^{80}$

74 Roswitha Breckner, Sozialtheorie des Bildes. Zur interpretativen Analyse von Bildern und Fotografien, Bielefeld 2010.

75 Franz X. Eder/Oliver Kühschelm/Christina Linsboth (Hg.), Bilder in historischen Diskursen, Wiesbaden 2014.

76 Franz X. Eder/Oliver Kühschelm, Einleitung, in: Eder/Kühschelm/Linsboth (Hg.), Bilder, 3-44, 3.

77 Matthias Wieser, Visual Turn und Visual Culture Studies, in: Jörg Helbig (Hg.), Visuelle Medien, Köln 2014, 13-31.

78 Andrea Strutz, Geteilte Leben. Erinnerungen jüdischer Vertriebener in den USA an NS-Verfolgung, Krieg und Österreich, in: Siegfried Mattl (Hg.), Krieg. Erinnerung. Geschichtswissenschaft, Wien 2009, 111-142, 112.

79 Doris Bachmann-Medick, Cultural Turns. Neuorientierungen in den Kulturwissenschaften, Reinbek bei Hamburg 2006.

80 Jay Winter, The Generation of Memory: Reflections on the ,Memory Boom' in Contemporary Historical Studies, in: Archives \& Social Studies 1 (2007), 363-397. 
Zweitens: ZeithistorikerInnen standen in etwa seit der Jahrtausendwende mit dem Internet ganze neue Möglichkeiten der Bildrecherche offen, die die Arbeitspraxis nachhaltig verändert haben. Handelte es sich bis dahin um zeitaufwändige und kostspielige Unterfangen, konnten nun Quellenrecherchen vergleichsweise rasch und unkompliziert durchgeführt werden. Dies hat die Bereitschaft, mit Bildquellen zu arbeiten, zweifelsohne befördert. ${ }^{81}$

Drittens: Die Relevanz der Bilddebatte rund um die bereits erwähnten „Wehrmachtsausstellungen“ kann nicht genug gewürdigt werden, da sie den methodischen Nachholbedarf im Hinblick auf fotografische Quellen sichtbar machte. ${ }^{82} \mathrm{Zu}$ diesem Prozess passt, dass sich der Deutsche Historikertag 2006 dem Thema Geschichtsbilder widmete, was für Gerhard Paul den „Beginn des ,Visual Turn“ in der deutschsprachigen Geschichtswissenschaft " ${ }_{33}$ markiert habe. Er selbst war daran maßgeblich beteiligt: Noch im selben Jahr gab er das Studienbuch „Visual History“ ${ }^{4}$ heraus, das den Grundstein für ein Konzept bildete, das sich theoretisch eng an die Visual Culture Studies anlehnte und sich wie dieses auf den Visual Turn bezieht. ${ }^{85}$

Innerhalb der österreichischen Zeitgeschichte ist das Konzept der Visual History in den letzten 15 Jahren breit rezipiert worden, sodass sich die visuelle Wende nicht nur in der Forschung, sondern gerade auch in der universitären Lehre niedergeschlagen hat. In der Lehre sind Bilder als Quellen und der Umgang mit ihnen mittlerweile fest verankert. Ein stichprobenartiger Blick in die Onlinelehrveranstaltungsverzeichnisse der österreichischen Zeitgeschichteinstitutionen zeigt, dass zum Beispiel an den Standorten Wien, Graz, Innsbruck und Linz 2019/2020 einschlägige Lehrveranstaltungen angeboten wurden.

81 Gerhard Paul, Visual History, Version: 3.o, Docupedia-Zeitgeschichte, URL: http://docupedia.de/ zg/Visual_History_Version_3.o_Gerhard_Paul (abgerufen 15.08.2020).

82 Jürgen Danyel/Gerhard Paul/Annette Vowinckel, Visual History als Praxis: Eine Einleitung, in: dies. (Hg.), Arbeit am Bild. Visual History als Praxis (Visual History: Bilder und Bildpraxen in der Geschichte 3), Göttingen 2017, 7-14, 7.

83 Gerhard Paul, Vom Bild her denken. Visual History 2.o.1.6., in: Danyel/Paul/Vowinckel (Hg.), Arbeit, 15-74, 17; für den Visual Turn in den Geschichtswissenschaften siehe: Jens Jäger, Geschichtswissenschaft, in: Klaus Sachs-Hombach (Hg.), Bildwissenschaften. Disziplinen, Themen, Methoden, Frankfurt a. M. 2005, 185-195.

84 Paul (Hg.), Visual History.

85 Jagschitz' Konzeption von Visual History bezog sich ausschließlich auf Fotografie; Paul erweitert das Feld um sämtliche visuelle Medien; Gerhard Paul, Die aktuelle historische Bildforschung in Deutschland. Themen - Methoden - Probleme - Perspektiven, in: Jens Jäger/Martin Knauer (Hg.), Bilder als historische Quellen? Dimension der Debatten um historische Bildforschung, München 2009, 125-148, 138. 
Neben dem Lehrangebot sind noch weitere Tendenzen der Institutionalisierung zu beobachten: Mit dem Wintersemester 2016/2017 wurde am Wiener Institut für Zeitgeschichte das Masterstudium "Zeitgeschichte und Medien“ eingerichtet. ${ }^{86}$ Ebendort widmet sich einer von fünf Forschungsschwerpunkten auch der „visuellen Zeit- und Kulturgeschichte ${ }^{\text {" }}{ }^{87}$ Während in Graz ein Doktoratsprogramm zu visuellen Kulturen installiert wurde, ${ }^{88}$ gibt es in Klagenfurt einen gleichnamigen Forschungsschwerpunkt. ${ }^{89}$ Die Einrichtung dieser interdisziplinären Strukturen, an denen auch ZeithistorikerInnen teilhaben, sowie die selbstverständlich gewordene Integration von Bildern in die zeithistorische Lehre haben in den letzten Jahren eine große Zahl studentischer Qualifikationsschriften hervorgebracht.90

Der Visual Turn hat also bereits auf verschiedenen Ebenen Wirkung gezeigt, weshalb bekräftigt werden kann: Die österreichische Zeitgeschichte hat in den letzten Jahren eine visuelle Wende erlebt, die sich in Forschung und Lehre manifestiert hat. Wie aber geht es weiter? Hat die Arbeit an visuellem Material weiterhin Konjunktur? Oder befindet sich die am Visuellen interessierte Zeitgeschichtsforschung

86 Masterstudium Zeitgeschichte und Medien, Institut für Zeitgeschichte, Universität Wien, URL: https://www.univie.ac.at/zeitgeschichte/cms/uploads/16-o6-15_folder_zeitgeschichte-medien_web. pdf (abgerufen 15.08.2020).

87 Klaudija Sabo/Christina Wieder, Visual History in Bewegung. Bildliche Quellen in der historischen Forschung, in: Bertrand Perz/Ina Markova (Hg.), 50 Jahre Institut für Zeitgeschichte der Universität Wien 1966-2016, Wien 2017, 299-311.

88 Doktoratsprogramm Visuelle Kulturen, Geisteswissenschaftliche Fakultät, Universität Graz, URL: https://huk.uni-graz.at/de/profil/visuelle-kulturen/ (abgerufen 15.08.2020).

89 Forschungsschwerpunkt Visuelle Kultur, Universität Klagenfurt, URL: https://www.aau.at/forschung/forschungsprofil/forschungsschwerpunkte/visuelle-kultur/ (abgerufen 15.08.2020).

90 Auswahl: Martin Reichstam, Fotografisch-mediale Repräsentationen von Freikörperkultur während der Zwischenkriegszeit: Visual History - Freikörperkultur - Geschichtsdidaktik, Dipl.-Arb., Universität Graz 2016; Eva Tropper, Raum An/ordnen. Postkartensammeln als Raumpraxis um 1900, phil. Diss., Universität Graz 2017; Lisa Payr, Bilder vom Obersalzberg. Führermythos und Erinnerungskultur im Führersperrgebiet anhand zeitgenössischer Fotografien des Nationalsozialismus, Dipl.-Arb., Universität Graz 2018; Rosemarie Burgstaller, NS-Feindbild-Ausstellungen 19331945. Propaganda, „Volksgemeinschaft“ und visuelle Gewalt, phil. Diss., Universität Wien 2012; Ina Markova, Die NS-Zeit im Bildgedächtnis der Zweiten Republik. Bildstrategien, Geschichtspolitiken und der österreichische Bilderkanon 1945-2013, phil. Diss., Universität Wien 2015; Lukas Meißel, Mauthausen im Bild. Fotografien der Lager-SS. Entstehung - Motive - Deutungen, MAArbeit, Universität Wien 2015; Maria Buck, „Der Bahnhof war der Sonntag für die Gastarbeiter“. Bilder von Arbeitsmigranten im fotografischen Werk Erika Sulzer-Kleinemeiers von 1969 bis 1972, MA-Arbeit, Universität Innsbruck 2017; Sabine Dalvai, Historisches Lernen mit Fotografien als historische Quellen im kompetenzorientierten Geschichtsunterricht der Sekundarstufe II. Fotografien zum Personenkult Mussolinis in der Zeit des italienischen Faschismus zwischen 1922 und 1943, Dipl.-Arb., Universität Innsbruck 2018. 
bereits wieder in der Ermüdung? Die Kulturwissenschaftlerin Aleida Assmann meint, dass der "Wende-Enthusiasmus“ im Allgemeinen im Abflauen begriffen sei, appelliert aber, dass es im nächsten Schritt darum gehe, die Turns im Sinne ihrer kritischen Weiterentfaltung zu „übersetzen“. ${ }^{11}$ Aufschluss darüber, wie das in der fotobezogenen Zeitgeschichtsforschung aussehen könne, gebe - Gerhard Paul zufolge - eine neue, von modernen Bildmedien sozialisierte Generation von exzellenten ZeithistorikerInnen, ${ }^{92}$ die sich - als "Produkt“ entsprechender Anstrengungen in der Lehre - bereits in ihren Qualifikationsschriften mit großer Selbstverständlichkeit visuellen Beständen zuwandte und nun zusehends in das zeithistorische Feld drängt. Sie sind es auch, die die Impulse des Visual Turns endlich auch in die Forschungspraxis bringen, womit sie beweisen, dass fotobezogene zeithistorische Forschung in Österreich erst dabei ist, Fahrt aufzunehmen und ihr Potenzial auszuschöpfen.

\subsection{Aktuelle Perspektiven}

Ina Markova ist eine Vertreterin dieser neuen Generation. Sie setzte sich in ihrer Dissertation mit der NS-Herrschaft im Bilderkanon der Zweiten Republik auseinander und untersuchte dessen Wandel, wobei sie nach den Funktionalisierungen "geschichtsmächtiger" Bilder auf sozialer, historischer und politischer Ebene fragte. ${ }^{93}$ Der Bilderkanon ist auch Thema der von Stefan Benedik kuratierten Bildinstallation, die Teil der ersten HdGÖ-Ausstellung ist. Diese fordert das hegemoniale Bildgedächtnis heraus und unterläuft es, indem nicht nur vom Kanon abweichende Bilder Eingang in dieses fanden, sondern BesucherInnen über ein interaktives Webformat aufgefordert wurden, die Inhalte des kollektiven Gedächtnisses durch das Hochladen eigener Bilder mitzubestimmen. ${ }^{94}$

Eine weitere vielversprechende Perspektive bieten Projekte, die Prozesse der Intermedialität und -visualität untersuchen. Solche Studien sind nach wie vor rar;95

91 Aleida Assmann, Die Grenzenlosigkeit der Kulturwissenschaften, in: Kulturwissenschaftliche Zeitschrift 1 (2016) 1, 39-48, 41.

92 Paul, Version: 3.o.

93 Markova, Bildgedächtnis, 7-8, 11, 14.

94 Geschichte (mit)schreiben, Haus der Geschichte Österreich, URL: https://www.hdgoe.at/category/ Geschichte+\%28 mit\%29+schreiben (abgerufen 15.08.2020).

95 Paul, Bild, 57. 
Beispiele sind Klaudija Sabos Studie über Ikonisierungsprozesse in Ex-Jugoslawien ${ }^{96}$ und Christina Wieders Analyse visueller Selbstermächtigungsstrategien jüdischer Künstlerinnen im argentinischen Exil. ${ }^{97}$

Lukas Meißel und Vida Bakondy gehen ihrerseits neue Wege in der Erinnerungsforschung zu Holocaust und Shoah. Während sich Meißel mit Bildproduktionen des „Erkennungsdienstes“ in NS-Konzentrationslagern beschäftigt und das Anliegen verfolgt, das visuelle Täternarrativ durch die Integration von Opferperspektiven zu brechen, ${ }^{98}$ nahm Bakondy mit den Fotoalben der Wiener Hakoah-Schwimmerin Fritzi Löwy die Erinnerungsproduktion eines verfolgten Individuums in den Blick. In der Analyse ging sie über die Lektüre des arrangierten Narrativs hinaus und rekonstruierte auf Ebene einzelner Fotografien durch die eingehende historische Kontextualisierung deren soziale Biographien. ${ }^{99}$

In ganz ähnlicher Weise beschäftigt sich mein Dissertationsprojekt mit dem italienischen Kolonialkrieg gegen Äthiopien (1935-1941) in den visuellen Gedächtnissen Südtiroler Familien. Die Qualifikationsschrift untersucht die Konstruktion und Diffusion kolonialistischer und faschistischer visueller Kulturen durch private Bildpraktiken. Es geht also um die Frage, wie sich politisch marginalisierte Individuen durch den Bildgebrauch zu totalitären Regimen verhielten und wie koloniale Bilder in Familiengedächtnissen nachwirken. ${ }^{100}$

Zuletzt sei auch noch auf Eva Tropper verwiesen, die sich besonders in Bezug auf die Analyse von Bildpostkarten profiliert hat. Zudem leistet sie wichtige methodische Impulse, etwa im Hinblick darauf, was performative Zugänge in der Bildanalyse leisten können. ${ }^{101}$

96 Klaudija Sabo, Ikonen der Nationen. Heldendarstellungen im „post“-sozialistischen Kroatien und Serbien, Berlin 2017.

97 Christina Wieder, Montages of Exile. Photographic Techniques and Spatial Dimensions in the Artwork of Grete Stern, in: Jewish Culture and History 21 (2020) 1, 42-65.

98 Lukas Meissel, Mauthausen im Bild. Fotografien der Lager-SS. Entstehung - Motive - Deutungen, Wien 2019.

99 Vida Bakondy, Montagen der Vergangenheit. Flucht, Exil und Holocaust in den Fotoalben der Wiener Hakoah-Schwimmerin Fritzi Löwy, Göttingen 2017.

100 Markus Wurzer, Die sozialen Leben kolonialer Bilder. Italienischer Kolonialismus in visuellen Alltagskulturen und Familiengedächtnissen in Südtirol/Alto Adige 1935-2015, phil. Diss., Universität Graz 2020.

101 Tropper, Raum; Eva Tropper, Medialität und Gebrauch oder Was leistet der Begriff des Performativen für den Umgang mit Bildern?, in: Lutz Musner/Heidemarie Uhl (Hg.), Wie wir uns aufführen. Performanz als Thema der Kulturwissenschaften, Wien 2006, 103-130. 


\subsection{Fazit}

Erstens: Aus den aufgezählten Forschungsperspektiven wird ersichtlich, dass sich seit den 1990er-Jahren in methodisch-theoretischer Hinsicht viel getan hat. Wurden Fotografien lange nur als Beweise wahrgenommen und Bildmotive realienkundlich oder ikonologisch-ikonographisch interpretiert, haben sich bildanalytische Zugänge im Zuge des Visual Turns erweitert. ${ }^{102}$ Heute ist es ein Allgemeinplatz, dass es keinen methodischen „Königsweg“ gibt und die Bildanalyse ein interdisziplinäres Unterfangen ist. ${ }^{103}$ Richtungsweisend wären integrative Zugänge, die ikonographische Untersuchungen mit der Analyse von Bilderpraktiken und Wirkungsgeschichte verknüpfen. ${ }^{104}$ Um das methodische Unbehagen auszuräumen, wären Standards für Recherche und Bildanalyse dringend nötig. ${ }^{105}$

Zweitens: Wenngleich auf inhaltlicher Ebene die Schwerpunkte auf dem Ersten und Zweiten Weltkrieg liegen, hat sich die fotobezogene Zeitgeschichtsforschung seit den 1990er-Jahren sowohl in zeitlicher als auch räumlicher Hinsicht stark ausdifferenziert: So beschäftigen sich Studien mittlerweile nicht nur mit anderen Jahrzehnten, sondern auch mit „neuen“ Räumen. Deren „Entdeckung“ hängt auch mit dem Bedeutungsverlust nationalstaatlicher Deutungsrahmen innerhalb der Zeitgeschichtsforschung in den letzten zwei Jahrzehnten zusammen, statt derer transnationale und globalgeschichtliche Zugänge reüssieren. Trotz dieser Erweiterungen sollte nicht aus den Augen verloren werden, dass österreichspezifische Themen ebenso ihrer Bearbeitung harren: Zum Beispiel bieten die Geschichte der Umweltund Jugendbewegungen, der GastarbeiterInnen sowie von Ikonisierungsprozessen politischer Ereignisse, wie dem Fall des Eisernen Vorhangs, vielversprechende Desiderata. Das trifft auch auf die private Fotopraxis zu, die abseits der beiden Weltkriege nicht erforscht ist.

Das Feld ist nicht nur in räumlich-zeitlicher Perspektive erweitert worden. Aus dem Einfluss des Visual Turns resultierten auch neue Fragen, die Zusammenhänge von Wissen und Macht, die Artikulation von Differenz und Erinnerung, den sozialen und politischen Bildgebrauch oder die Bildwirkung und -rezeption adressierten. ${ }^{106}$ Die Bildaktforschung würde ebenso mehr Aufmerksamkeit verdienen. ${ }^{107}$

\footnotetext{
102 Paul, Bild, 26.

103 Jens Jäger/Martin Knauer, Bilder als historische Quellen? Ein Problemaufriss, in: Jäger/Knauer (Hg.), Bilder, 15.

104 Paul, Bild, 15-74, 71.

105 Danyel/Paul/Vowinckel, Visual History, 8.

106 Paul, Bild, 62, 68-69.

107 Ebd., 63.
} 
Diese neuen Fragestellungen ermöglichten es, in vergleichsweise „alten“ Themenfeldern wie der NS-Geschichte innovative Wege zu gehen. Der inhaltliche Paradigmenwechsel drückt sich auch dadurch aus, dass Bilder nicht mehr nur als Beweise, sondern auch als Medien und bedeutungsgenerierende Kräfte analysiert werden.

Drittens: Die Frage, in welche Richtungen sich das Feld inhaltlich entwickeln wird, hängt auch mit der Frage nach der Verfügbarkeit von Bildquellen zusammen. Wenngleich Archive in Österreich über umfangreiche Bilderbestände verfügen (und diese zum Teil online zugänglich sind), liegen diese - sowohl was ihre archivarische Erschließung als auch Erforschung anbelangt - oft noch brach. Ein Beispiel für das Potenzial, das in Archiven „schlummert“, ist das bereits erwähnte Projekt Holzers zur Propagandafotografie im Ersten Weltkrieg, in dem er - erstmalig - entsprechende Bestände des ÖNB-Bildarchivs als Quellengrundlage heranzog. ${ }^{108}$ Das Beforschen privater Bildpraktiken steht wiederum vor dem Problem, dass benötigte Quellen überhaupt selten in Archive gelangen und eher im privaten Bereich verbleiben. Vielversprechende Bestände, die ihrer Bearbeitung harren, finden sich aber nicht nur in den größeren Staats- und Landesarchiven und -museen, sondern auch in kleineren - oft spezialisierten - Einrichtungen. Ein Beispiel für ein solches ist das Tiroler Archiv für Photographische Dokumentation und Kunst (TAP) in Lienz, das Fotografien aus privater wie professioneller Praxis aus Tirol/Südtirol sammelt. ${ }^{109}$ Um von den archivierten, nicht beforschten Bildbeständen aus neue Themenfelder zu erschließen, wäre eine verstärkte Kooperation zwischen ZeithistorikerInnen und Archiven ausgesprochen erstrebenswert.

Viertens: Gerhard Botz hat schon 1993 darauf verwiesen, dass die österreichische Zeitgeschichte seit jeher in theoretischer und methodischer - sowie zum Teil auch in inhaltlicher - Hinsicht Entwicklungen der angloamerikanischen und (west) deutschen Geschichtswissenschaften mit einiger Verzögerung mitmache. ${ }^{110}$ Das gilt auch im Hinblick auf den Visual Turn, der sich innerhalb der letzten zwei Jahrzehnte gewissermaßen im Schlepptau auch in der österreichischen Zeitgeschichte etabliert hat. Während fotobezogenes Arbeiten in der Lehre mittlerweile ganz selbstverständlich implementiert ist, ist in der Forschungspraxis - getragen von einer jungen Historikergeneration - inzwischen auch ein Aufbruch zu konstatieren. Dieser sollte vom Gespräch mit anderen Disziplinen, die ebenso anhand fotografischer Bestände österreichspezifische Forschungen betreiben, geprägt sein. Während die Zeitge-

\footnotetext{
108 Holzer, Front.

109 Beispiel aus der TAP-Publikationstätigkeit: Martin Kofler/Katia Malatesta (Hg.), Frauenbilder/ Signora fotograf(i)a. Historische Fotografien/Collezioni storiche. Tirol - Südtirol/Alto Adige Trentino, Lienz/Bruneck/Bozen/Trento 2019.

110 Botz, Thesen, 26-27.
} 
schichte aus solchen Debatten wertvolle methodische und theoretische Anregungen ziehen könnte, würden andere kulturwissenschaftliche Disziplinen wiederum von (zeit)historischen Kernkompetenzen, wie der Quellenkritik und historischen/historiographischen Kontextualisierung profitieren. 


\section{Digital History und Digitalisierung}

Eva Pfanzelter und Sarah Oberbichler

\section{Einleitung}

2014 wurde in Deutschland das Hochschulforum Digitalisierung (HFD) ins Leben gerufen. Es sollte als Thinktank der Hochschulbildung im digitalen Zeitalter AkteurInnen aus Hochschule, Politik, Wirtschaft und Gesellschaft vernetzen und beraten. Initiiert vom Centrum für Hochschulentwicklung (CHE), der Hochschulrektorenkonferenz (HRK) und dem Stifterverband sowie gefördert vom Bundesministerium für Bildung und Forschung entstehen im Rahmen des Forums seitdem zahlreiche Arbeitsgruppen, Publikationen, Blogs, Podcasts und Studien, die den Digital Turn in der Hochschule zum Inhalt haben. ${ }^{1}$ Digital Literacy, also das Fitmachen für den Umgang mit der digitalen Welt, wird als zentrale Zukunftskompetenz für das 21. Jahrhundert genannt. Gefördert werden soll die Fähigkeit, „Daten auf kritische Art und Weise zu sammeln, zu managen, zu bewerten und anzuwenden“.2 Damit tritt die deutsche Hochschullandschaft in die Phase des Second Digital Turn ein, jener Entwicklungsstufe, in der Digitalisierung nicht allein durch die im ersten Turn vollzogene Transformation der Werkzeuge des Analogen Platz in unseren Gesellschaften findet, sondern in der Digitalität unsere Art zu Denken verändert, wie Architekturhistoriker und -theoretiker Mario Carpo $2017^{3}$ argumentiert hat.

Die Chiffren „Digitales Zeitalter“ und Digital Turn oder Computational Turn beschreiben diesen alle Lebensbereiche umfassenden Wandel der letzten Jahrzehnte. Umfangreich ist die einschlägige Theorieliteratur - das Definitionsbedürfnis ist

1 Das Hochschulforum Digitalisierung: Über uns, Hochschulforum Digitalisierung, URL: https:// web.archive.org/web/20190716113213/https://hochschulforumdigitalisierung.de/de/wir/dashochschulforum (abgerufen 06.11.2019).

2 Chantel Ridsdale/James Rothwell/Mike Smit/Hossam Ali-Hassan/Michael Bliemel/Dean Irvine/ Daniel Kelley/Stan Matwin/Brad Wuetherick, Strategies and Best Practices for Data Literacy Education. Knowledge Synthesis Report, o. O. 2015, 1-123, 8, URL: http://www.mikesmit.com/wpcontent/papercite-data/pdf/data_literacy.pdf (abgerufen 11.11.2020).

3 Mario Carpo, The Second Digital Turn. Design Beyond Intelligence (Writing Architecture Series), Cambridge (MA) 2017. 
groß. ${ }^{4}$ Ähnlich verhält es sich mit Digital History, denn wie der Historiker Adam Crymble meint, sei bereits der Begriff falsch, da es sich bei digitaler Geschichtswissenschaft weniger um ein Fach oder eine Disziplin, sondern vielmehr um ein breites transdisziplinäres und multidisziplinäres Forschungs- und Lehrfeld handle, ${ }^{5}$ das die historischen bzw. philologischen Wissenschaften ebenso betreffe wie das Bibliothekars- und Archivwesen oder die Medien- und Informationswissenschaft.

Ähnlich komplex gestaltet sich das Feld der österreichischen Zeitgeschichte - dem Untersuchungsgegenstand des vorliegenden Beitrages -, wenn es um digitale Diskurse geht. Es wird sich zeigen, dass die institutionalisierte österreichische Zeitgeschichte, wie sie seit den späten 196oer-Jahren im Hochschulbereich anzutreffen ist, internationalen Trends der (geistes-)wissenschaftlichen Community früh folgte und zeitweise sogar Pionierarbeit leistete, dieses Engagement jedoch wegen mangelnder Grundfinanzierung und der international rasant voranschreitenden Technologisierung in Lehre und Forschung nicht permanent aufrechterhalten werden konnte. Obwohl es auch nicht gelang, komplexe interdisziplinäre digitale Forschungsmethoden und -werkzeuge im wissenschaftlichen Alltag zu etablieren oder etwa personell zu institutionalisieren, sind Informations- und Kommunikationstechnologien heute dennoch nicht mehr aus zeithistorischen Untersuchungen und Vermittlungsvorhaben wegzudenken. Ebenso entstanden zahllose Projekte, die ohne die Möglichkeiten der Onlinetechnologien nicht durchführbar gewesen wären und die oft in enger disziplinübergreifender und transnationaler Zusammenarbeit entstanden. Der Computer ist auch für ZeithistorikerInnen zum primären Handwerkzeug geworden, das Internet zum alltäglichen Informations- und Kommunikationsmittel sowie, nicht selten, zum unerschöpflichen Archiv auch für historische Information. ${ }^{6}$

4 Siehe beispielsweise: Dave M. Berry, The Computational Turn: Thinking About the Digital Humanities, in: Culture Machine 12 (2011), 1-22 oder die zahlreichen Debatten in: Matthew K. Gold/ Lauren F. Klein (Hg.), Debates in the digital humanities, Minneapolis 2016.

5 Adam Crymble, Do you need digital history?, in: Historia 61 (2016) 2, 134-138.

6 Den Archival Turn der Geschichts- und Erinnerungsforschung beschreibt etwa auch Marianne Hirsch: Marianne Hirsch, The Generation of Postmemory. Writing and Visual Culture after the Holocaust, New York 2012, 242. 


\section{Die Entwicklung einer digitalen (Zeit-)Geschichtswissenschaft in Österreich}

2.1 UOG 1975, EARN, BIBOS, Internet und die nichtnumerische Datenverarbeitung

Der Einstieg der österreichischen Zeitgeschichte in die elektronische Datenverarbeitung erfolgte indirekt in den 1980er- und frühen 1990er-Jahren durch die Bibliotheken und durch die Nutzung von E-Mail und Internet. Diese Entwicklungen wiederum sind den von der Bundesregierung vorgegebenen Universitätsorganisationsgesetzen zu verdanken. Der tiefgreifende gesellschaftliche und soziale Wandel, der unter der Chiffre „1968“ subsumiert werden kann, wurde mit dem Universitätsorganisationsgesetz von 1975 (UOG 1975) in der Universitätslandschaft sichtbar und spürbar. Entstanden unter Hertha Firnberg als Bundesministerin für Wissenschaft und Forschung, kam es einer völligen Umgestaltung der Universitäten gleich und war somit die größte Reform der Hochschulen seit 1873..$^{7}$ Teil der Änderungen war eine Verwaltungsreform, in der als „besondere Universitätseinrichtungen“ Universitätsbibliotheken, EDV-Zentren, Großgeräteabteilungen und Abteilungen für Hochschuldidaktik oder auch Universitätssportinstitute vorgegeben waren. ${ }^{8}$

Als die zentralen Organisationseinheiten im Bereich der elektronischen Daten wurden mit dem UOG 1975 Zentren für elektronische Datenverarbeitung (EDVZentren) eingerichtet, was schon bald im Bereich der Netzwerktechnologien sichtbar wurde. Für Österreich bedeutete dies zunächst einmal eine notwendige Zusammenarbeit der unterschiedlichen EDV-Zentren mit dem BMfWF und der Post als Telekommunikationsfirma. 1979 entstand die Grundstruktur des späteren ACOnet (Austrian Academic Computer Network), mit welchem 1985 die österreichischen Universitäten erstmals Anschluss an internationale Datennetze erhielten, wie das European Academic and Research Network (EARN) und EUnet. Als nationaler EARN-Knoten wurde AEARN an der Universität Linz beheimatet. ${ }^{9}$

Ein österreichweit vorhandenes Netz war die Voraussetzung für eine Entwicklung, die auch für die Geschichtswissenschaften von weitreichender Bedeutung

7 Ebd., 612-614; zum UOG 1975 siehe ausführlich Manfried Welan/Heribert Wulz, Grundzüge des österreichischen Universitätsrechts 1. Teil, in: WPR-Diskussionspapier 52-R-96 (1996), URL: https://wpr.boku.ac.at/wpr_dp/dp-52.pdf (abgerufen 06.11.2020).

8 Bundesgesetz vom 11. April 1975 über die Organisation der Universitäten (Universitäts-Organisationsgesetz - UOG), BGBl. Nr. 258/1975.

9 Eva Pfanzelter, Von der elektronischen Datenverarbeitung 1958 zum Informatikstudium an der Universität Innsbruck 2002, in: Margret Friedrich/Dirk Rupnow (Hg.), Geschichte der Universität Innsbruck 1669-2019. Band II: Aspekte der Universitätsgeschichte, Innsbruck 2019, 601-645, $620-622$. 
war. Im UOG 1975 hatten die Universitätsbibliotheken bzw. das „wissenschaftliche Dokumentations- und Informationswesen“ einen besonderen Stellenwert erhalten. Die durch das Gesetz bestimmte Teilnahme an "gemeinsamen Einrichtungen des wissenschaftlichen Bibliothekswesens" und die dadurch gestärkte Zusammenarbeit mit anderen Bibliotheken im Österreichischen Bibliotheksverbund führten zur sehr frühen, von zentraler Stelle vorgegebenen Adaptierung elektronischer Datenverarbeitungsmaßnahmen. So entstanden bereits in den 1970er-Jahren erste gemeinsame Bibliothekskatalogsysteme, wie das Entlehnverbuchungssystem GRIBS und die Österreichische Zeitschriftendatenbank (ÖZDB). ${ }^{10}$

1979 begann die Entwicklung von BIBOS durch die EDV GmbH, ein Anfang der 1980er-Jahre in Österreich entwickeltes und an der Arbeiterkammer bzw. Arbeiterkammer-Bibliothek in Wien 1982 erstmals verwendetes sogenanntes integriertes Bibliothekssystem. Die mit dem System arbeitenden Bibliotheken waren im BIBOSVerbund zusammengeschlossen, der sich damit bis zum Ende des Jahrzehnts als wichtigster wissenschaftlicher Bibliotheksverbund etablieren konnte. BIBOS in der Version 2.1 lief 1988 erstmals auch im Onlinebetrieb. Bis 1996 waren in Österreich insgesamt 15 Bibliotheken in einem gemeinsamen Bibliotheksnetz verbunden. ${ }^{11}$ BIBOS und die Nachfolgesysteme BIBOS2, die 1998 angekaufte und ab 1999 verwendete Bibliothekssoftware ALEPH bzw. die 2008 eingeführte Software Primo und schließlich ab 2015 Alma stellten somit ab den 1990er-Jahren den Zugangspunkt für WissenschaftlerInnen dar. ${ }^{12}$ Bis Anfang 2019 war der Österreichische Bibliotheksverbund mit 70 Teilnehmenden als Vertretungsorgan von 91 Einzelinstitutionen somit der größte Verbund an wissenschaftlichen und administrativen Bibliotheken Österreichs. ${ }^{13}$

Der große Durchbruch im Bereich der Netzwerktechnologie und somit auch die alle Disziplinen betreffende wissenschaftliche Nutzung des Netzes als Kommunikations- und Arbeitswerkzeug kam jedoch erst mit der weltweiten Verbreitung des Internets in den frühen 1990er-Jahren. Dabei war die Geburtsstunde dessen, was heute als Internet bezeichnet wird, eng mit dem Kalten Krieg verknüpft, nämlich mit dem „Sputnik-Schock“ 1957: Der Start des ersten Satelliten Sputnik 1 durch die Sowjetunion am 4. Oktober 1957 führte in den USA zu einer technischen Aufholjagd. In der Folge wurde die (Defense) Advanced Research Projects Agency (D/

10 Pfanzelter, Datenverarbeitung, 625-629.

11 Ebd.

12 Die Österreichische Bibliothekenverbund und Service Gesellschaft m. b. H - Geschichte, Die Österreichische Bibliothekenverbund und Service GmbH, URL: https://www.obvsg.at/wir-ueber-uns/ geschichte/ (abgerufen 01.02.2019).

13 Ebd. 
ARPA) eingerichtet, um in Kooperation mit Universitäten und Wirtschaft den technischen Rückstand auf die UdSSR aufzuholen und neue Technologien im Bereich der Kommunikation und Datenübertragung zu entwickeln. Mit der Konzeption des ARPANET gelang es 1969 erstmals, digitale Daten zwischen Computern an unterschiedlichen ARPA-Standorten auszutauschen. ${ }^{14}$ Bis Ende 1969 waren vier ARPAForschungszentren miteinander verbunden. Bald folgten Universitäten und weitere Forschungseinrichtungen: 1971 waren bereits über dreißig Computerzentren in den USA vernetzt. Der erste Schritt in die „Informationsrevolution“ war damit vollzogen. ${ }^{15}$

Die breitenwirksame Akzeptanz der neuen Technologie wurde allerdings erst durch die Erfindung der E-Mail erreicht. ${ }^{16}$ Als „Killerapplikation“, also eine jener Anwendungen, die einer bestehenden Technologie zum Durchbruch verhelfen, sollte sie nicht nur die wissenschaftliche Kommunikation verändern. ${ }^{17}$ Spätestens 1973 wurde E-Mail im 2.00o-Rechner-starken ARPANET breit genutzt und bald avancierte die Anwendung zum beliebtesten Kommunikationsmedium in der wissenschaftlichen Community. ${ }^{18}$ Daneben waren nicht zuletzt die Erfindung und verhältnismäßig kostengünstige Verfügbarkeit von Personal Computern ausschlaggebend für die breite Anwendung der elektronischen bzw. automatisierten Datenverarbeitung. Dazu gehörte auch die nichtnumerische Datenverarbeitung, also jener Softwarebereich, der keine Großrechnerleistungen von Computern benötigte, wie die Textverarbeitung oder Tabellenkalkulationsprogramme. Auch die Anwendungen der nächsten „Killerapplikation“, des Internets, das sich bereits 1992 zum größten internationalen Datennetz in Forschung und Lehre entwickelte, wurde zunächst dazugezählt. An den Universitäten florierten vor allem mit dem Aufkommen der ersten graphischen Webbrowser wie Mosaic und Netscape spätestens ab 1994 die „Campusinformationssysteme“, die ersten Internetauftritte, die die wissenschaftliche Community zu einem Global Campus zusammenzuschließen schien. ${ }^{19}$

\footnotetext{
14 About DARPA, Defense Advanced Research Project Agency, URL: https://www.darpa.mil/aboutus/about-darpa (abgerufen 19.11.2019).

15 Susan Schreibman/Ray Siemens/John Unsworth (Hg.), A Companion to Digital Humanities, Oxford 2004, Part I: History, URL: http://www.digitalhumanities.org/companion/ (abgerufen 19.10.2020).

16 Ray Tomlinson, The first email, URL: http://openmap.bbn.com/ tomlinso/ray/firstemailframe. html (abgerufen 19.11.2019).

17 Siehe ausführlicher dazu: Peter Haber, Digital Past. Geschichtswissenschaft im digitalen Zeitalter, München 2011.

18 Pfanzelter, Datenverarbeitung, 617.

19 Ebd., 636-640.
} 
Tatsächlich ist es die nichtnumerische Datenverarbeitung, die die Adaption digitaler Methoden und Arbeitsweisen in den Geisteswissenschaften ab den frühen 1990er-Jahren erleichterte und förderte. Zu nennen sind für den Einstieg in die digitale Welt zunächst einmal Initiativen im Bereich der Lehre, die es zum Beispiel in Linz bzw. Salzburg oder etwa in Innsbruck gab. Einen Internethöhepunkt erreichte die österreichische Zeitgeschichtsforschung in den 1990er-Jahren wohl auch mit dem Zeitgeschichteinformationssystem, das von Innsbruck aus - zumindest für eine Zeit lang - zu einem zentralen Einstiegspunkt ins World Wide Web werden sollte. Last, but not least sind die österreichischen Zeitgeschichtetage zu nennen, die, seit 1993 in zweijährlichem Rhythmus an unterschiedlichen Standorten abgehalten, eine Gesamtschau der österreichischen Zeitgeschichtsforschung versuchten, wodurch digitale Herangehensweisen eine Plattform zur Vernetzung und Wahrnehmung erhielten.

\subsection{Interdisziplinäre Biographien: Manfred Thaller, CLIO und die Salzburg Summer School}

Dass die elektronische Datenverarbeitung auch in den geisteswissenschaftlichen Fächern auf dem Vormarsch war, entsprach durchaus dem internationalen Trend. Das zeigt etwa der Aufruf der Gesellschaft für wissenschaftliche Datenverarbeitung Göttingen (GWDG) und des Max-Planck-Instituts für Geschichte (MPIG) in Göttingen im August 1988, der zur Teilnahme an einer gemeinsamen Weiterbildungsveranstaltung für die „[n]ichtnumerische Datenverarbeitung in den Geisteswissenschaften“

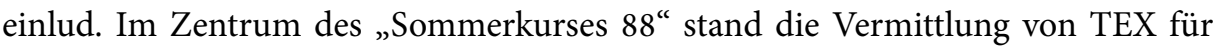
„anspruchsvolle Druckvorhaben“ in den Geisteswissenschaften, computerlinguistische Methoden, das quellenorientierte Datenbanksystem KLEIOS (CLIO) oder auch der Einsatz von optischen Platten im Arbeitsplatzrechner. ${ }^{20}$

CLIO hatte sich bis Mitte der 1990er-Jahre seit seiner Entwicklung im Jahr 1987 von einem Forschungsprojekt zu einer marktgerechten Softwareversion für Computer und eine Vielzahl von Unix-Plattformen weiterentwickelt. Die Programmierung des Datenbanksystems CLIO ist dem aus Österreich stammenden Historiker Manfred Thaller und seinen Kollegen vom Max-Planck-Institut für Geschichte in Göttingen zu verdanken. Thaller selbst gilt nicht nur im deutschsprachigen Raum

20 Gesellschaft für Wissenschaftliche Datenverarbeitung Göttingen (GWDG)/Max-Planck-Institut für Geschichte (MPIG), Nichtnumerische Datenverarbeitung in den Geisteswissenschaften, in: Historical Social Research/Historische Sozialforschung 13 (1988) 1 (45), 147-148. 
als einer der einflussreichsten Forscher zur historischen Datenverarbeitung und einer der führenden Verfechter der inzwischen anerkannten quellenorientierten Datenverarbeitung. ${ }^{21}$ Seine Biographie kann stellvertretend für jene Entwicklungen stehen, die den transdisziplinären Forschungs- und Arbeitsbereich der digitalen Geschichtswissenschaft seither geprägt haben.

Geboren wurde Manfred Thaller in Feldkirch, er studierte an der Universität Graz Geschichte und orientalische Altertumskunde und promovierte 1975 mit einer Arbeit zum europäischen Amerikabild. Am Institut für Höhere Studien in Wien spezialisierte er sich auf historische Mobilitätsstudien und wirkte an verschiedenen historischen Forschungsprojekten mit. Ab 1978 arbeitete er am Max-Planck-Institut für Geschichte in Göttingen und hatte Gastprofessuren in Jerusalem, London und Florenz inne. Von 1995 bis 2000 war er außerdem Professor für Historische Informatik und Direktor des Humanities Information Technology Research Programme an der Universität Bergen, Norwegen. 2000 wurde Thaller Professor der HistorischKulturwissenschaftlichen Informationsverarbeitung an der Universität zu Köln, wo er bis zu seiner Emeritierung 2015 lehrte und forschte. Von 1991 bis 1994 war er unter anderem auch Präsident der Association for History and Computing und von 2002 bis 2008 war er Mitglied des Library Committee der Deutschen Forschungsgemeinschaft DFG. In einem Interview mit Julianne Nyhan und Andrew Flinn (2016) erzählte Manfred Thaller über seine ersten Erfahrungen mit dem Computer in den Geisteswissenschaften und insbesondere in den Geschichtswissenschaften:

Das Interessante an der Erfindung des PCs ist, dass damit einige sehr einfach gehaltene Statistikprogramme verbunden waren, die die Möglichkeit boten, sehr einfach graphische Darstellungen von statistischen Daten zu erstellen. Die ersten drei Jahre nach der Einführung von PCs in den Geschichtsabteilungen brachten eine Flut von völlig unbearbeiteten Kuchendiagrammen hervor. Einige von ihnen zeigten absurde Dinge [...]. Nun, nachdem die Leute etwa 3 bis 5 Jahre lang mit PCs gespielt hatten, stellte sich heraus, dass die Dinge nicht ganz so einfach waren, wie sie in der Zwischenzeit erschienen waren. ${ }^{22}$

Der interdisziplinär arbeitende Historiker leistete einen wesentlichen Beitrag zur Weiterentwicklung der digitalen Geisteswissenschaften, vor allem im Bereich Soft-

21 Charles Harvey/Jon Press, Databases in Historical Research. Theory, Methods and Applications, New York 1996, 190-192.

22 Julianne Nyhan/Andrew Flinn, It's Probably the only Modestly Widely Used System with a Command Language in Latin: Manfred Thaller and Julianne Nyhan, in: Julianne Nyhan/Andrew Flinn (Hg.), Computation and the Humanities. Springer Series on Cultural Computing, o. O. 2016, 195208, 200-201 (aus dem Englischen übersetzt). 
ware, Digitalisierung des kulturellen Erbes und in der Entwicklung der Forschungsinfrastruktur. Besonders $\mathrm{CLIO} / \mathrm{k} \lambda \varepsilon \iota \omega$, das ursprünglich als Datenbankprogrammiersystem für HistorikerInnen konzipiert war und - wohl einzigartig - mit einer Kommandozeile in lateinischer Sprache arbeitete, galt jahrelang als Vorzeigeprojekt in der „historischen Fachinformatik“. Die spätere Umstellung auf die englische Sprache führte zur Integration des Systems in zahlreiche Nachfolgeprojekte, in denen es um Archivierung und Verlinkung historischer Daten ging. Thallers Ansätze und Ideen, die er in den 1970er-Jahren entwickelte, erwiesen sich dabei so manches Mal als visionär. ${ }^{23}$ In seinem Buch „Materialien zur Historischen Sozialwissenschaft“ schrieb Thaller 1982 zur Eignung von Datenverarbeitung für HistorikerInnen etwa:

[D]enn Datenverarbeitung als solche muß ein reines Instrument der Arbeitstechnik für den Historiker bleiben, solange keine geschlossene Theorie des Informationsgehalts historischer Quellen vorliegt. [...] Techniken und Methoden sind etwas grundverschiedenes: einen methodischen Anspruch kann und sollte beispielsweise die Verwendung statistischer Verfahren begründen - der Gebrauch elektronischer Arbeitsmittel aber ist genauso wenig zur Ableitung eines methodischen Anspruchs geeignet wie der Gebrauch eines speziellen Systems, seine Arbeitsunterlagen zu ordnen. ${ }^{24}$

Manfred Thaller wirkte in einer Reihe von Forschungsprojekten mit, in denen digitale Methoden angewandt und weiterentwickelt wurden. ${ }^{25}$ Nicht von ungefähr wurde ihm 2017 ein Sonderband der Zeitschrift „Historical Social Research / Historische Sozialforschung “26 gewidmet, in dem 13 seiner zahlreichen Publikationen gesammelt nachzulesen sind. Diese Abhandlungen zum schwer definierbaren Bereich History and Computing aus mehr als 30 Jahren Schaffensarbeit beschreiben die vielfältigen Herausforderungen der Digitalisierung in den Geisteswissenschaften treffend. Sie zeigen eindrucksvoll, welche Spannbreite von Themen, Entwicklungen, Erfolgen und Fehlschlägen den Gang in die digitale Welt begleiteten. Dazu gehörten praxisnahe Arbeit, Programmieren und Projektentwicklung ebenso wie die Lehre, wo Thaller zum Beispiel in den 1990er-Jahren in der Salzburg Summer School als regelmäßiger Gast vertreten war.

23 Ebd., 195.

24 Manfred Thaller, Materialien zur Historischen Sozialwissenschaft. Numerische Datenverarbeitung für Historiker (Materialien zur Historischen Sozialwissenschaft 1), Wien/Köln 1982, 1.

25 Codices Electronici Ecclesiae Coloniensis (CEEC), URL: http://www.ceec.uni-koeln.de/ (abgerufen 10.12.2019).

26 Manfred Thaller, From History to Applied Computer Science in the Humanities. Historical Social Research/Historische Sozialforschung, Supplement 29 (2017). 


\subsection{EDV-Ausbildung für GeisteswissenschaftlerInnen an der Universität Innsbruck}

Lehrprojekte für die Geisteswissenschaften gab es in den 1990er-Jahren an mehreren Standorten und häufig waren ZeithistorikerInnen an deren Gestaltung federführend bzw. beteiligt. Ein Beispiel dafür ist der Video-History-Lehrgang in Salzburg, der zunächst zwar nicht digitale Quellen und Methoden enthielt, in dem dann aber digitale Videolehrgänge umgesetzt wurden. ${ }^{27}$ Ähnlich wurde in Graz die Video-History-Forschung und -Lehre ab dem Wintersemester 1999/2000 zur Gänze auf Digital Video umgestellt. Als Beispielprojekt diente „Emigration Austria - New York“, das anhand von 23 Interviews mit 40 Stunden Videomaterial die Flucht aus Österreich in den Jahren 1938/1939 thematisierte. Ausschnitte der Interviews finden sich bis heute auf der Website des Projektes, „Continental Divide - geteilte leben“. ${ }^{28}$ Die dazugehörigen Lehrveranstaltungen behandelten die Themen Migration, Flucht, Randgruppen und Identität. ${ }^{29}$

Der Mathematiker und Germanist Michael Bürkle und der Historiker Wolfgang Meixner formulierten in Innsbruck die komplexen Forderungen geisteswissenschaftlicher Fächer an die Computerwissenschaft: Es seien besonders quantifizierende Methoden, die für die Disziplinen von Interesse seien, was konkret computerlinguistische Verfahren und quantitative Statistik bedeute (zum Beispiel für die historische Demographie wichtiger Datenbestände wie Pfarrmatriken und Volkszählungsergebnisse). Ebenso, stellten die Autoren fest, sei ein Trend zur „,Standardisierung' maschinenlesbar gemachte[r] Quellen, Sekundäranalyse von bereits einmal mit Hilfe der EDV ausgewerteter Daten sowie dem Kompilieren von ,Metaquellen aus bestehenden Datenbasen erkennbar“.30

Die Studienpläne an den österreichischen Universitäten waren nicht darauf ausgerichtet, Studierende auf das damit zusammenhängende Hintergrundwissen, die Techniken und Computerprogramme sowie den praktischen Umgang mit großen Datenbeständen bzw. deren maschinengesteuerten Verarbeitung vorzubereiten.

27 Albert Lichtblau, Audiovisuelle Geschichte? Der „Video-History“-Lehrgang an der Universität Salzburg, in: Manfred Lechner/Dietmar Seiler (Hg.), zeitgeschichte.at. 4. österreichischer Zeitgeschichtetag '99. Ausgabe auf CD-Rom, Innsbruck/Wien/Bozen 1999, 241-249.

28 Andrea Strutz/Manfred Lechner, continental divide. geteilte leben/Emigration. Austria - New York, URL: http://www-gewi.kfunigraz.ac.at/zg/cd/cd1.htm (abgerufen 16.12.2019).

29 Manfred Lechner/Andrea Strutz, Erfahrungen mit Video History Lehrgängen an der Abteilung Zeitgeschichte der Karl-Franzens-Universität Graz, in: Lechner/Seiler (Hg.), zeitgeschichte.at, 224-228.

30 Michael Bürkle/Wolfgang Meixner, Datenverarbeitung und Geisteswissenschaft - eine Mésalliance? Über einen Versuch zur Integration innerhalb der universitären Lehre, in: Zeitschrift für Hochschuldidaktik 16 (1992) 3-4, 387-396. 
Zusatzqualifikationen im Bereich der elektronischen Datenverarbeitung könnten, so der Aufruf der Autoren, die schwierige Situation der AbsolventInnen geisteswissenschaftlicher Studiengänge mildern und diese besser auf den Arbeitsmarkt vorbereiten. Professionalisierung und Erhöhung der „employability“, so die modernen Begriffe dafür, waren deswegen auch die Gründe für eine solche Zusatzausbildung. Die Folge war eine „EDV-Ausbildung für Studierende der Geisteswissenschaftlichen Fakultät" (Geiwi-EDV) ab dem Wintersemester 1990/91. Das Studienprogramm umfasste 26 Semesterwochenstunden, von denen 14 als Pflichtfächer, der Rest als individuell $\mathrm{zu}$ gestaltende Schwerpunkte $\mathrm{zu}$ verstehen waren. In vier Semestern sollte das - nicht als Ersatz eines Informatikstudiums zu verstehende - Programm im Rahmen des sogenannten Fächerbündels zu absolvieren sein. ${ }^{31}$ Ziel der GeiwiEDV-Ausbildung war es, „Problemübersetzer“ zwischen den Disziplinen hervorzubringen: Als voll ausgebildete HistorikerInnen, LiteraturwissenschaftlerInnen, SprachwissenschaftlerInnen oder PädagogInnen sollten sie nach dem Studium in der Lage sein, der Informatik die Probleme des jeweiligen Faches zu erklären und zu beschreiben bzw. auch an den Lösungen mitzuarbeiten. ${ }^{32}$

Das ambitionierte Vorhaben und die durchaus gelungene Einführung des Studienganges mit zahlreichen KursteilnehmerInnen erhielt jedoch einen scharfen Dämpfer. In Beantwortung einer schriftlichen Parlamentarischen Anfrage vom November 1991 war die Replik des BMfWF hinsichtlich einer Institutionalisierung der EDV-Ausbildung - im Sinne einer Studienrichtung EDV für Geisteswissenschaften - in Innsbruck negativ:

Die EDV stellt in den Geisteswissenschaften ein, wenngleich immer wichtigeres und daher stärker zu berücksichtigendes Hilfsmittel dar, das lediglich die methodische Ebene der Forschungsarbeit tangiert. Institutionalisierungen [...] pflegen im geisteswissenschaftlichen Bereich jedoch sinnvoller- und notwendigerweise nach gegenstandsbezogenen Kriterien zu erfolgen. Ebensowenig, wie es beispielsweise zielführend wäre, eine eigene Studienrichtung Paläographie einzurichten, kommt daher eine Studienrichtung EDV für Geisteswissenschafter in Frage. ${ }^{33}$

Für weitere zwei Jahre konnte die Ausbildung in Innsbruck noch absolviert werden, dann kam es zu einer Fusionierung mit dem eben entstandenen Studiengang

\footnotetext{
31 Ebd.

32 Ebd., 390-393.

33 Zit. n. ebd., 394.
} 
„Medien und Geisteswissenschaften“. ${ }^{34}$ Letztlich endete die Initiative im „Wahlfachstudiengang Medien in Theorie und Praxis". ${ }^{35}$ Koordiniert vom Vorstand des Instituts für Zeitgeschichte Rolf Steininger und dem Wirtschafts- und Sozialhistoriker Wolfgang Meixner war der Studiengang inter- und transdisziplinär ausgelegt und sollte den „Brückenschlag zwischen geschichts, gesellschafts, sprach, zeichen, literatur, kommunikations- und erziehungswissenschaftlichen Ansätzen der Medientheorie" gewährleisten. ${ }^{36} 2010$ entstand daraus der Masterstudiengang Medien, der eine gezielte Vertiefung im Bereich der Medienwissenschaften bot. Die „kritische Auseinandersetzung mit den Kommunikationsprozessen in den Medien" stand dabei im Vordergrund. Professionalisierung war weiterhin das Ziel der Ausbildung, wenn auch bei dem nun von der Philologisch-Kulturwissenschaftlichen Fakultät getragenen und vom Institut für Germanistik organisierten Master als potenzielle Berufsfelder „Print-Medien, Radio, Fernsehen, Film oder Online-Medien“ angegeben waren. ${ }^{37}$ Im seit 2018 gültigen Curriculum hat sich der Fokus der Ausbildung noch mehr in Richtung „medienlinguistische Auseinandersetzung mit Medienprodukten im Zusammenhang gesellschaftlicher Kommunikationsprozesse“ und in Richtung „literaturwissenschaftlich fundierte Analyse, Deutungs- und Vermittlungskompetenz mit Blick auf die Medialität der Kulturproduktion“" verschoben. Als künftige Betätigungsfelder der AbsolventInnen sind wiederum „Öffentlichkeitsarbeit, in der Kulturvermittlung, im Verlags- und Bildungswesen " zu finden..$^{8}$

Der Fokus auf eine EDV-Ausbildung in den geisteswissenschaftlichen Fächern ist somit schon seit den frühen 20ooer-Jahren nicht mehr in diesen Studienprogrammen zu finden, auch wenn digitale Arbeitsweisen und Methoden fraglos bis heute Teil der Curricula sind.

34 Ebd., 395.

35 Mitteilungsblatt der Leopold-Franzens-Universität Innsbruck Nr. 41 vom 04.06.2002, 693-704, URL: https://www.uibk.ac.at/service/c101/mitteilungsblatt/2001/41/mitteil.pdf (abgerufen 19.10.2020).

36 Wolfgang Meixner/Rolf Steininger, Wahlfachstudiengang Medien in Theorie und Praxis (Vorschlag), letzte Fassung (Manuskript erhalten von W. Meixner).

37 Mitteilungsblatt der Leopold-Franzens-Universität Innsbruck Nr. 37 vom 22.06.2010, 323-338, URL: https://www.uibk.ac.at/service/c101/mitteilungsblatt/2009-2010/37/mitteil.pdf (abgerufen 19.10.2020).

38 Mitteilungsblatt der Leopold-Franzens-Universität Innsbruck Nr. 26 vom 05.04.2019, 281-298, URL: https://www.uibk.ac.at/service/c101/mitteilungsblatt/2018-2019/26/mitteil.pdf (abgerufen 19.10.2020). 


\subsection{Zeitgeschichte-Informations-System}

Einen ganz anderen Fokus hatte das 1995 vom BMfWF finanziell gestützte Projekt ZIS: das Zeitgeschichte-Informations-System (ZIS) des Instituts für Zeitgeschichte an der Universität Innsbruck. Die Initiative ging auf eine Äußerung von Wissenschaftsminister Erhard Busek im Jahr 1992 zurück, als dieser seine Unzufriedenheit über die „heimische Zeitgeschichtsforschung und -lehre“ angesichts des wachsenden Rechtsextremismus äußerte. Daraus entstand die Idee eines Informationsmediums, das die österreichische Zeitgeschichte besser vernetzen und an internationale Trends anbinden sollte. Mit dem zeitgleich stattfindenden Durchbruch des Internets, der Verbreitung der ersten graphischen Benutzeroberflächen für das World Wide Web und den Aufrufen der Universität, das Campusinformationssystem auch von Seiten der Institute zu unterstützen, war der Schritt in Richtung Internetinformationssystem nahezu vorgegeben. ZIS sollte als Internetdienst verwirklicht werden, bei dem nicht die Erhebung und Digitalisierung von Daten im Vordergrund stand, sondern die Verlinkung bereits im Netz vorhandener und im Entstehen begriffener Informationen. ${ }^{39}$

Das Zeitgeschichte-Informations-System wurde von Anfang an als annotierte Linkliste in einer umfangreichen Datenbank organisiert. Es sollte Orientierung in dem schon damals als Datendschungel empfundenen Weiten des Internets bieten und "gute“ von „schlechter" Information unterscheiden helfen. Das ZIS konnte somit als Gateway zu historischen Themen für die akademische zeithistorische Zunft und für Unterrichtspersonal an Schulen begriffen werden. Als ausführlich beschriebene Liste von Links, die nur ,relevante "Seiten aufgenommen hatte, war es als Fachportal für Zeitgeschichte im deutsch- und englischsprachigen Raum konzipiert, das die Schwächen der damaligen Suchmaschinen (deren Ergebnislisten von Beliebigkeit geprägt waren, wie zum Beispiel bei AltaVista) auszugleichen versuchte..$^{40}$

bvDie einige hundert Internetlinks waren, wie in Abb. 1 zu sehen, nach Ländern und Themen geordnet. Zur besseren Orientierung sollte eine Zeitleiste (Abb. 2) dienen, die einen Zugang nach Zeiträumen ermöglichte.

Während sowohl Webauftritte von Universitätsinstituten, Museen und Regierungsbehörden als auch Onlinekataloge zu Bibliothekskatalogen beinahe zum Standard der jeweiligen Institution gehörten, waren, so zeigte eine Analyse der ZISDatenbank 1999, Onlineausstellungen, online verfügbare Fachliteratur und digital

39 Ingrid Böhler/Michael Kröll/Eva Pfanzelter, Surfen in der Zeitgeschichte. ZIS: Das österreichische Zeitgeschichte-Informations-System im Internet, in: Medien \& Zeit 14 (1999) 7, 43-50, 43.

40 Ebd., 44-46. 


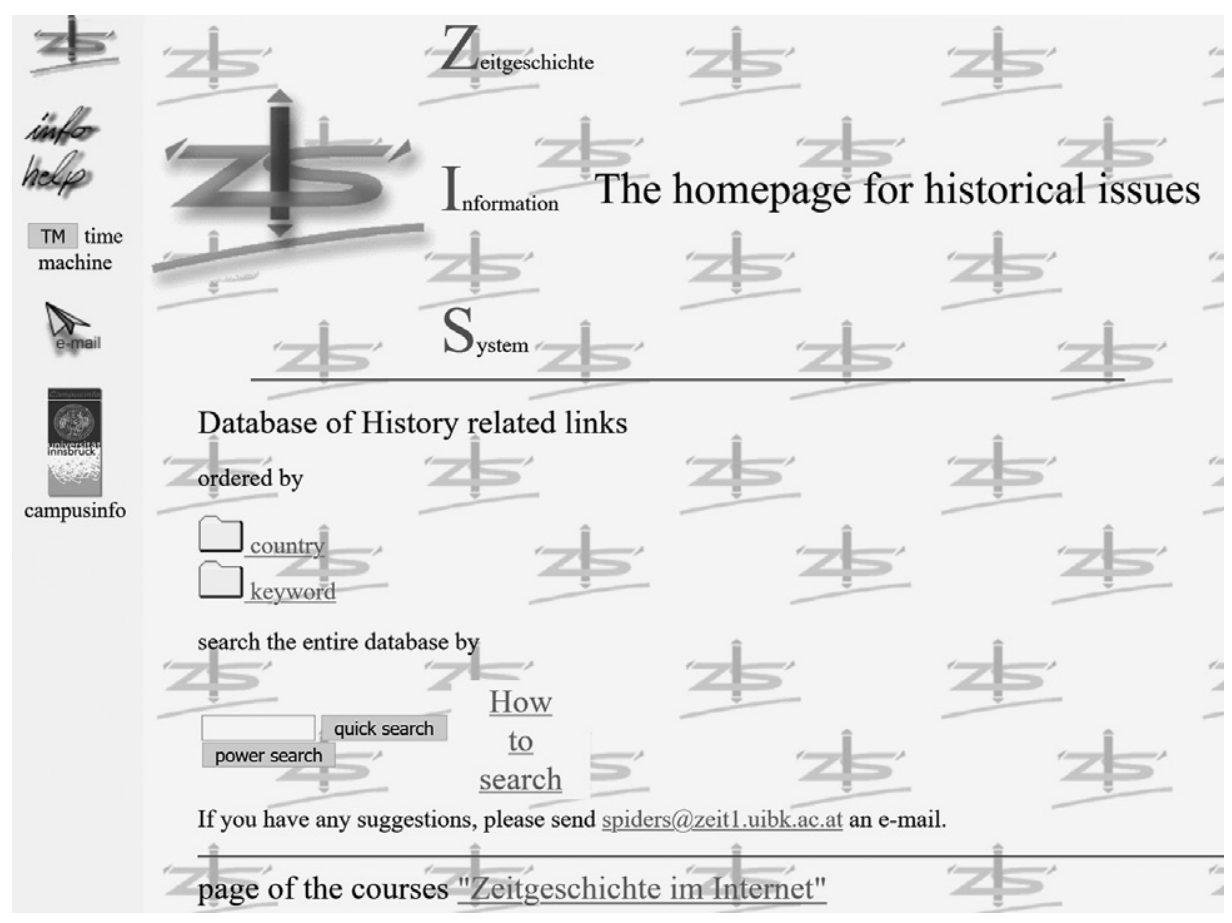

Abb. 1: Die erste in der Wayback-Machine archivierte Website von ZIS vom 27. Dezember 1996; zu finden in englischer Sprache. URLs: http://zeit1.uibk.ac.at. https://web.archive.org/web/19961227192334/ http://zeit1.uibk.ac.at/ (Screenshot der Autorinnen)

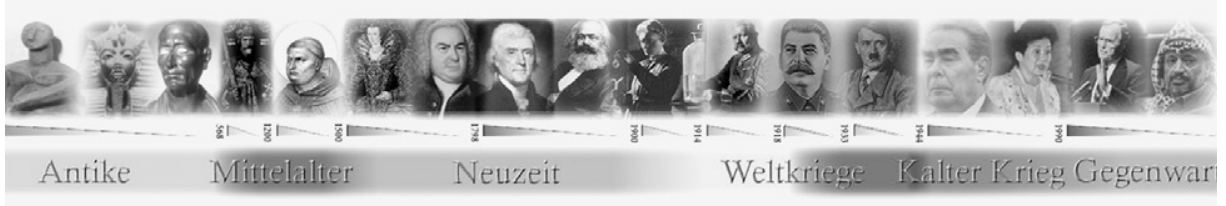

Abb. 2: Die erste Time-Machine von ZIS. Nicht irritieren sollte der lange Zeitraum von Beginn der Antike an, da viele der in der Datenbank gesammelten Links Epochen abdeckten, die weit über die unmittelbare Zeitgeschichte hinausreichten. URL: https://web.archive.org/web/19991113115239fw_/http:// zeit1.uibk.ac.at/time_machine.html (Screenshot der Autorinnen)

verfügbare Primärquellen noch die Ausnahme. Aus diesem Grund bot das ZIS über seine Gateway-Funktion hinaus drei Themenportale an, in denen einschlägige Primärdokumente, Chronologien und Fachartikel zu finden waren. Dazu gehörten der Schwerpunkt „Geschichte Österreichs im 20. Jahrhundert“ sowie die international 
Beachtung findende Onlineausstellung „Familie Turteltaub. Die Geschichte einer jüdischen österreichischen Familie“ und die „Südtirol-Dokumentation“.41

Neben dem Schweizer Fachportal hist.net, ${ }^{42}$ das von den beiden Historikern Peter Haber und Jan Hodel gegründet wurde und zwischen 1999 und 2012 online war, sowie H-Soz-u-Kult, ${ }^{43}$ der ersten Mailingliste des H-Net (Humanities-Net), war ZIS somit ein einflussreicher moderner Information Highway für die Geschichtswissenschaften im deutschsprachigen Raum, was sich an den wachsenden Zugriffszahlen, die sich durchaus mit jenen des deutschsprachigen Portals messen konnten, ablesen ließ.

Letztlich musste ZIS allerdings 2011 eingestellt werden: Einerseits veränderte die explodierende Anzahl von Websites und die zeitgleich seit 1997 online zu findende Suchmaschine Google das Suchverhalten der InternetnutzerInnen. Die auf Webcrawltechnologie und Relevanz basierende Suche hat seitdem schrittweise zu einer Ablöse von thematischen Linklisten und auf solchen aufgebauten Fachportalen geführt. Hist.net etwa wurde 2002 eingestellt, ZIS verabschiedete sich 2003 von seinem Herzstück, der Linkdatenbank. Andererseits konnten spätestens seit der Jahrtausendwende solche Fachportale ohne eine stabile finanzielle Stütze die kontinuierlich notwendigen Adaptierungen nicht tragen. Diese finanzielle Sicherheit hatte ZIS im Gegensatz zu zum Beispiel H-Soz-u-Kult nicht. Das deutsche Projekt war durch enge Kooperation mit Clio-Online, einem Fachinformationsportal für die Geschichtswissenschaften, ab 2001 DFG-gefördert. Seit 2007 lag die Trägerschaft des Dachportals Clio-Online beim Verein Clio-online - Historisches Fachinformationssystem e. V.44 Seit 2011 wird durch die Migration der Seite und technische Updates zwar die Zugänglichkeit von ZIS garantiert, ein Update der Inhalte gibt es aber nicht mehr. ${ }^{45}$

41 ZIS Zeitgeschichte Informationssystem, Institut für Zeitgeschichte der Universität Innsbruck, URL: https://www.uibk.ac.at/zeitgeschichte/zis/ (abgerufen 26.02.2019).

42 Peter Haber/Jan Hodel, hist.net. Internationale Plattform zum Thema Geschichtswissenschaften im digitalen Zeitalter, URL: http://archiv.hist.net/ (abgerufen 24.02.2019).

43 H-Soz-u-Kult. Humanities - Sozialgeschichte - Kulturgeschichte, Humboldt-Universität zu Berlin, URL: https://web.archive.org/web/19970618162637/http://www.h-net.msu.edu/ sozkult/ (abgerufen 24.02.2019).

44 Das Projekt, Clio-online - Historisches Fachinformationssystem e.V./Humboldt-Universität zu Berlin, URL: https://www.clio-online.de/projekt (abgerufen 26.02.2019); Profil, H/Soz/Kult, Kommunikation und Fachinformation für die Geschichtswissenschaften, URL: https://www.hsozkult. de/about (abgerufen 26.02.2019).

45 ZIS Zeitgeschichte Informationssystem, Institut für Zeitgeschichte der Universität Innsbruck, URL: https://www.uibk.ac.at/zeitgeschichte/zis/ (abgerufen 26.02.2019). 


\title{
2.5 Die Österreichischen Zeitgeschichtetage
}

Die seit 1993 (mit Unterbrechungen) im zweijährlichen Rhythmus stattfindenden österreichischen Zeitgeschichtetage erweisen sich seit den 1990er-Jahren auch als Austausch- und Präsentationsforum für digitale Fragestellungen. Besonders beim 3. Zeitgeschichtetag 1997, der in Wien ausgetragen wurde, ging es in einem von drei Themenkomplexen um Fragen des Umgangs „mit einer zunehmend virtueller werdenden Welt“. ${ }^{46}$ Ziel sei, so die Herausgeberschaft des Tagungsbandes, die zunehmende Digitalisierung aller Lebensbereiche zu thematisieren, um die

\begin{abstract}
Auswirkungen der digitalen Revolution auf Themen, Handwerkszeug und Methoden der Zeitgeschichte zu hinterfragen. Mythen über die Auswirkungen der Internet-Gesellschaft auf die Produktion historischer Analyse sollte ebenso entgegengewirkt werden wie der Ignoranz gegenüber der vielfachen Auswirkung tiefgreifender Änderungen einer Industrie- auf eine Informationsökonomie. Gerade die zeitgeschichtliche Forschung sollte sich intensiver mit derartigen neuen Fragestellungen beschäftigen, die über die methodischen/ technischen Auswirkungen hinausgehen. ${ }^{47}$
\end{abstract}

Unabhängig von dieser Forderung lag der Fokus zu diesem Zeitpunkt jedoch weniger bei digitalen Dingen, sondern es ging vielmehr darum, die österreichische Zeitgeschichte als eigene Disziplin zu definieren. Die Vielfältigkeit von Themen und methodischen Zugängen, die eine Gemeinsamkeit vermissen ließen, die mitunter angestrebte gesellschaftspolitische Relevanz, die „zum Verlust von Wissenschaftlichkeit" führte, oder der feststellbare Trend, den Zeitgeschmack zu treffen, wurden kritisch neben ein vermeintlich notwendiges „einheitliches Ganzes und eine international übliche Souveränität“ gestellt. Die bei der Tagung erkennbare Fragmentierung, die natürlich auch auf die Vorträge in der Schiene „Digitalisierung und virtuelle Welt" zutraf, wurde damit weniger als experimentierfreudig, sondern vielmehr als beliebig eingestuft. ${ }^{4}$

Dabei zeugen die 1997 diskutierten Themen und Methoden nicht nur von viel Enthusiasmus, sie lassen durchaus erkennen, wie sehr die internationalen Trends

46 Gertraud Diendorfer/Gerhard Jagschitz/Oliver Rathkolb, Einleitung, in: Gertraud Diendorfer (Hg.), Zeitgeschichte im Wandel. 3. Österreichische Zeitgeschichtetage 1997, Innsbruck 1998, $13-15,13$.

47 Ebd., 14.

48 Ebd., 14-15. 
auch in Österreich rezipiert wurden. ${ }^{49}$ Die zahlreichen angedachten Beispiele umfassen digitale Bild- und Audioquellen mit den damit einhergehenden komplexen Facetten der Archivierung und Manipulierbarkeit ebenso wie etwa die erst in Ansätzen erkennbare Nutzung digitaler Werkzeuge und des Internets als Mittel und Raum der Dokumentation für Literatur, Archivalien und Forschungsprojekte. ${ }^{50}$ Ein Projekt in Wien beschäftigte sich bis 1994 beispielsweise mit der „Retrospektiven Literaturerfassung und -erschließung mit EDV-Systemen“.51 Die Möglichkeiten der Archivierung von Bildern auf digitalen Systemen wurde hier in zwei Projekten untersucht. Der „Modellversuch einer Bildarchivierung mit Hilfe der EDV am Beispiel des Österr. Instituts für Zeitgeschichte" wurde durch das BMWF finanziert, ${ }^{22}$ die „Datenbank und [das] Handbuch photographischer Quellen Österreichs“ vom Bundesministerium für Unterricht und kulturelle Angelegenheiten. Geplant war eine Publikation auf dem damals modernen Medium CD-Rom, ${ }^{53}$ doch entstanden ist diese nie. Stattdessen flossen die Daten in das Infonet des Ministeriums ein, wo sie leichter recherchierbar waren. Einzelstudien aus dem Projekt wurden hingegen weiterhin auf Papier publiziert. ${ }^{54}$ Das viele tausende Fotografien umfassende „Bildarchiv der Zeitgeschichte", das seit den 1970er-Jahren vom Neuzeitprofessor Gerhard Jagschitz aufgebaut und 2009 endgültig an die Österreichische Nationalbibliothek (ÖNB) überging, ${ }^{55}$ wurde und wird erst in der Bibliothek digitalisiert. In einem ersten Anlauf wurden dabei etwa 10.000 Bilder eingescannt und in eine Datenbank

49 Beispielsweise verlinkten Institute auf den im deutschsprachigen Raum vielbeachteten „Werkzeugkasten Zeitgeschichte“: Werkzeugkasten Zeitgeschichte, Bibliothek für Zeitgeschichte in der Württembergischen Landesbibliothek Stuttgart, URL: https://web.archive.org/web/20000502160740/ http://www.wlb-stuttgart.de/ bfz/fia.htm (abgerufen 15.11.2019).

50 Erstmals wurde etwa in Wien eine „Internet-Dokumentation aller mit öffentlichen Mitteln geförderten Forschungsprojekte der Jahre 1993-1996/97“ veröffentlicht, die unter der Domain http:// www.univie.ac.at/zeitgeschichte (nicht mehr vorhanden) abgelegt war, siehe: Diendorfer/Jagschitz/ Rathkolb, Einleitung, 13-14.

51 Forschung. Abgeschlossene Projekte 1994, Institut für Zeitgeschichte, Universität Wien, URL: https://web.archive.org/web/19991007004850/http://www.univie.ac.at/zeitgeschichte/ (abgerufen 05.12.2019).

52 Ebd.

53 Datenbank und Handbuch photographischer Quellen Österreichs, Institut für Zeitgeschichte, Universität Wien, URL: https://web.archive.org/web/20010620113344/http://www.univie.ac.at/zeitgeschichte/ (abgerufen 05.12.2019).

54 Als Teilstudie siehe z. B. Sándor Békési, Das historische Foto - Archivsituation und Forschungsstand im Burgenland, in: Burgenländische Heimatblätter 65 (2003) 2, 76-90.

55 Archivbestände am Institut für Zeitgeschichte, Institut für Zeitgeschichte der Universität Wien, URL: https://zeitgeschichte.univie.ac.at/forschung/sammlungen-und-einrichtungen/archive/ (abgerufen 19.08.2020). 
eingepflegt, die heute Teil des Bildarchivs Austria ist. Weitere Bestände werden dabei derzeit nur on demand in die Onlinedatenbank übernommen. ${ }^{56}$

Um die „[w]issenschaftliche Erschließung von Texten und Bildern in den Katalogen der Landesaustellungen seit 1959" und deren Erfassung in einer Datenbank ging es an der Universität Klagenfurt, wobei hier bereits Dokumente und auch Bilder digitalisiert, bearbeitet sowie auf CD-Rom der Öffentlichkeit zur Verfügung gestellt werden sollten. Statt der CD-Rom entstand eine Webseite, die aus der Datenbank gespeist wurde: „KULT.DATA - Verborgene Schätze aus österreichischen Landesausstellungen“" wurde zwischen 2001 und 2006 erstellt und mit Daten gefüllt. ${ }^{57}$ Seit 2009 ist das Projekt als KULT.DOKU in die IT-Initiative „eFit Austria“ in den Projektschwerpunkt „eCulture“ integriert. ${ }^{8}$

In Graz gab es Mitte der 1980er-Jahre bereits entsprechende „Untersuchungen der Einsatzmöglichkeiten der EDV für Historische Faktendokumentation im Bereich der historischen Grundwissenschaften“ (1985-1987).59 Danach beschäftigte man sich in der steirischen Landeshauptstadt besonders mit den Möglichkeiten der digitalen Edition. ${ }^{60}$ In Klagenfurt begann bis Mitte der 1990er-Jahre der Aufbau einer „EDV-gestützten Mediathek und eines Mikrofilmarchivs“, das nicht nur als wichtige Grundlage für Forschung und Lehre angesehen wurde, sondern sowohl von Studierenden als auch MitarbeiterInnen und Lehrkräften aus der Region intensiv genutzt wurde. Auch war ein ähnlich aufgebautes regionales Zeitungsarchiv im Aufbau. ${ }^{61}$

Erste Gehversuche gab es in den 1990er-Jahren auch im Bereich der digitalen Musealisierung. Das Vorarlberger Landesmuseum fand Interesse an dem Konzept einer „virtuellen“ Ausstellung im Internet, und es gelang, mit der Vorarlberger Firma Telport und der Wiener Firma CMB Informationslogistik kompetente PartnerIn-

56 Für die Information bzgl. des Datenbankprojektes und des Bildarchivs der Zeitgeschichte wird Michaela Pfundner vom Bildarchiv und Grafiksammlung der "Österreichischen Nationalbibliothek“ herzlich gedankt.

57 KULT.DATA - Verborgene Schätze aus österreichischen Landesausstellungen, Institut für Geschichte, Universität Klagenfurt, URL: https://web.archive.org/web/20011015000000*/http://www. uni-klu.ac.at/kult.data/ (abgerufen 05.12.2019).

58 KULT.DOKU - Verborgene Schätze aus österreichischen Landesausstellungen, Universität Klagenfurt, URL: http://wwwg.uni-klu.ac.at/kultdoku/index.htm (abgerufen 05.12.2019).

59 Forschungsportal der Universität Graz, Institut für Geschichte, Projekte, Karl-Franzens-Universität Graz, URL: https://online.uni-graz.at/kfu_online/wbForschungsportal.cbShowPortal?pFpFosp $\mathrm{Nr}=\& \mathrm{pOrgNr}=14129 \& \mathrm{pPersonNr}=\& \mathrm{pMode}=\mathrm{E} \& \mathrm{pCallType}=\mathrm{PROJ} \#($ abgerufen 05.12.2019).

60 Dazu gehörten bspw. die Projekte „Integrierte Computergestützte Edition I“ (1992-1994) und „Integriere Computergestützte Edition II“ (1994-1996), siehe: ebd.

61 Forschungsbericht 1991-1994, Institut für Zeitgeschichte, Universität Klagenfurt, URL: https://web.archive.org/web/19970609134615/http://www.uni-klu.ac.at/groups/his/ (abgerufen 05.12.2019). 
nen für die technische Umsetzung des Projektes „Colónia Áustria - Bairro da Seda“ (Abb. 3) zu gewinnen. Thematisiert wurde in der Ausstellung die Vorarlberger Auswanderung nach Brasilien. ${ }^{62}$
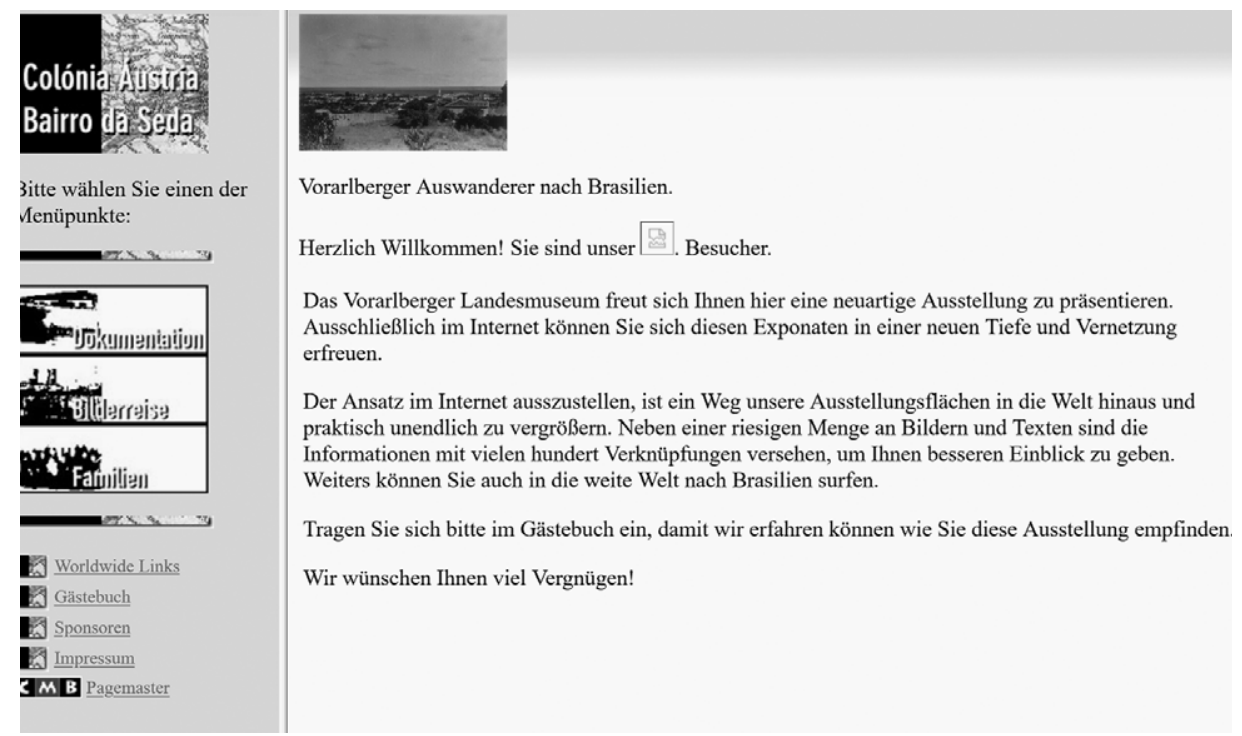

Abb. 3: Die virtuelle Ausstellung Colónia Áustria - Bairro da Seda war bis 2006 unter der Domain http://www.vol.at/vlbgbrazil erreichbar ${ }^{63}$ (Screenshot der Autorinnen) jpg

Als interaktive Multimediaausstellung und Forum zum Austausch für Angehörige der damaligen Besatzungsmächte konzipiert, war auch die Seite „Liberators and the Liberated/Occupiers and the Occupied“ (Abb. 4) von Ingrid Bauer. Diese Ausstellung dokumentierte die Besatzungszeit 1945/1955 in Salzburg. ${ }^{64}$ Auch in Innsbruck versuchte es ein junges Team von Historikern mit einer digitalen Ausstellung. Das damals noch in der Innsbrucker Rotunde beheimatete Riesenrundgemälde sollte in neuer Form durch eine Webseite (mit Quick Time Virtual Reality) und eine CD-Rom einem jüngeren Publikum nähergebracht werden (Abb. 5).

62 Werner Dreier, Eine „virtuelle Ausstellung“ im Internet: Colónia Austria Bairro de Seda - Vorarlberger Auswanderer nach Brasilien, in: Diendorfer (Hg.), Zeitgeschichte, 459-462, 459-461.

63 Werner Dreier, Colónia Áustria - Bairro da Seda, Vorarlberger Landesmuseum, URL: https://web. archive.org/web/19981202160447/http://www.vol.at/vlbgbrazil/ (abgerufen 05.12.2019).

64 Ingrid Bauer, Von Oral History zu Cyber History? Das WorldWideWeb als „bridge of communication“ eines österreichisch-amerikanischen Dialogs zur Besatzungszeit, in: Diendorfer (Hg.), Zeitgeschichte, $463-471,463$. 


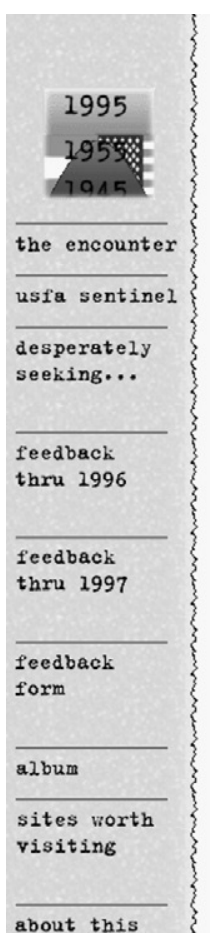

\section{"Liberators and the Liberated" "Occupiers and the Occupied"}

Abb. 4: Die Multimediaausstellung „Liberators and the Liberated/Occupiers and the Occupied“ war bis 2005 unter der Domain http://www.image-at.com/salzburg erreichbar (Screenshot der Autorinnen) ${ }^{65}$

Im Gebäude selbst sollte es ein Terminal geben, damit BesucherInnen einen direkten Vergleich bzw. Original und Reproduktion hätten, was wiederum besonders reizvoll für Kinder hätte sein können, da sich diese speziell für digitale Darstellungen begeistern ließen. Die Idee wurde auch bei einer internationalen Panoramakonferenz in Altötting 2003 vorgestellt und begeistert aufgenommen. Es sollten daraufhin europaweit historische Panoramen im Internet präsentiert werden. ${ }^{66} \mathrm{Ob}$ die Autoren dabei auf ein im Entstehen begriffenes Datenbankprojekt der International Panorama Council anspielten, lässt sich nicht eruieren.

65 „Liberators and the Liberated/Occupiers and the Occupied“, Forschungsgemeinschaft BoltzmannInstitut/Steinocher-Fonds \& IMAGE Kommunikationsdesign GmbH, URL: https://web.archive. org/web/19980110073149/http://www.image-at.com/salzburg/ (abgerufen 05.12.2019).

66 Nico Hofinger/Arno Gisinger, Promoting Visual History. Eine historisch-aktuelle Website für das Innsbruck Panorama „Die Schlacht am Bergisel 1809“, in: Lechner/Seiler (Hg.), zeitgeschichte.at, 172-177. 


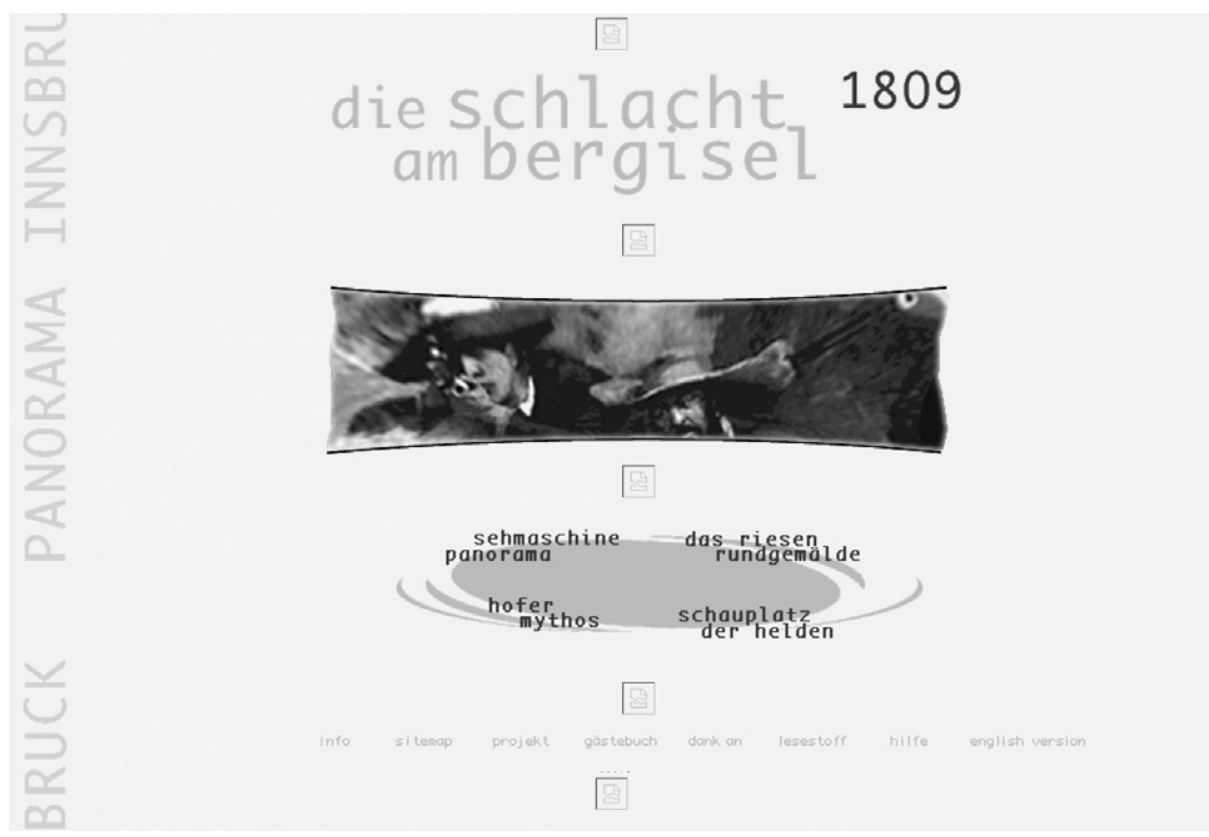

Abb. 5: Das Bergisel-Panorama wurde bis 2008 unter der Domain http://www.panorama-innsbruck.at präsentiert, ist seitdem nicht mehr aktualisiert worden, aber bis heute als Archiv im Internet erhalten geblieben (Screenshot der Autorinnen) ${ }^{67}$

Jedenfalls wird die von dieser Vereinigung angelegte Sammlung historischer Panoramen nach wie vor aufwändig gepflegt und mit Daten gespeist. Dabei ist es nicht von Bedeutung, ob es für die einzelnen Panoramen eine virtuelle Präsentation im Internet gibt. ${ }^{68}$

Überhaupt waren in den 1990er-Jahren weltweit und auch in der österreichischen Zeitgeschichte CD-Roms das Speicher- und Verteilermedium schlechthin. Dies hatte mit begrenzten Speichermöglichkeiten auf anderen Datenträgern ebenso zu tun wie mit geringen Übertragungsraten im Internet und schlichtweg den technologischen Grenzen der vorhandenen Gerätschaften. Geplant war beispielsweise die CD-Rom

67 Nico Hofinger/Arno Gisinger, panorama innsbruck: die schlacht am bergisel 1809, URL: https:// web.archive.org/web/19981201222735/http://www.panorama-innsbruck.at/d/platform.htm (abgerufen 05.12.2019).

68 Panoramas and related art forms [database], PANORAMA - International Panorama Council, URL: https://panoramacouncil.org/en/what_we_do/resources/panoramas_and_related_art_ forms_database/ (abgerufen 13.08.2020). 
„Steirische Zeitgeschichte“, die auch im Internet abrufbar war.99 Das Projekt „rom. retour" wiederum erzählte „eine Geschichte der schweizerischen Eisenbahnen“ auf CD-Rom, ${ }^{70}$ und Teile des ORF-Archivs waren gegen Ende des Jahrtausends ebenfalls auf dem tragbaren Medium erhältlich..$^{71}$ In der Umsetzung wiederum wurden zahlreiche dieser CD-Rom-Publikationen nie realisiert, da die Steigerung von Übertragungsraten, der Ausbau des Internets und der Zugang dazu sowie die sich rasant entwickelnde Hard- und Software zu veränderten Publikationsbedingungen führten: Im Laufe der 2oooer-Jahre wurde zunehmend auf die Veröffentlichung von Datenbankbeständen im Internet und deren Zugänglichkeit über das Internet gesetzt. Das erwies sich besonders bei Sammelprojekten als vorteilhaft, da damit (oft nicht vorhandene) Publikationsfinanzierungen auf Papier oder CD-Rom und Verteilungskosten wegfielen und gleichzeitig die Datenbanken kontinuierlich erweitert, ergänzt, ausgebaut und erneuert werden konnten.

War die anfängliche Begeisterung mancher KollegInnen Mitte der 1990er-Jahre noch groß, so war im Rahmen des nachfolgenden Zeitgeschichtetages 1999 deutlich ein Unbehagen angesichts des rasant wachsenden Netzes erkennbar. Die Diskurse drehten sich um das Ende der Demokratie und die Pluralität der wissenschaftlichen Welt. Auch wurde kritisch über die Rolle des Internets für die Geschichtswissenschaften nachgedacht. Allein die Steigerung von 25 Millionen vernetzten Menschen 1994 auf 200 Millionen im Jahr 1999 weise darauf hin, dass auch die Zeitgeschichte diese Entwicklung nicht ignorieren dürfe..$^{72}$

In der Retrospektive zeigt sich, dass der Zeitgeschichtetag 1999 viele Themenfelder andiskutierte, die zwanzig Jahre später immer noch eine Herausforderung für die Disziplin darstellen, für die jedoch auch zahlreiche Lösungsansätze gefunden worden sind. Manfred Thaller prognostizierte eine Konjunktur dessen, was heute als Public History bezeichnet wird, denn sowohl das Internet als auch die multimedialen Anwendungsmöglichkeiten digitaler Daten

69 Das ursprünglich unter der Webadresse http://gewi.kfunigraz.ac.at/bik-graz präsentierte Projekt ist nicht erhalten; auch in der Wayback-Machine sind die Seiten nur fehlerhaft archiviert.

70 Peter Staudacher, rom.retour. Eine Geschichte der schweizerischen Eisenbahnen auf CD-Rom, in: Diendorfer (Hg.), Zeitgeschichte, 560-566.

71 Peter Dusek/Siegfried Steinlechner, Aktuelle CD-Rom-Produktionen des ORF-Archiv - Das digitale Geschichtslabor des ORF geht seinen Weg, in: Lechner/Seiler (Hg.), zeitgeschichte.at, 64-68.

72 Johanna Gehmacher/Barbara Heller-Schuh/Siegfried Mattl/Albert Müller, Die Information der Information, in: Lechner/Seiler (Hg.), zeitgeschichte.at, 126-130; Reinhold Wagnleitner, Geschichte @ Internet. Teil I: Wir werden alle global professionals sein, oder wir werden gar nicht sein, in: Lechner/Seiler (Hg.), zeitgeschichte.at, 131-135. 
machen es möglich, historisch relevante Themen in einer Form darzustellen, die Kreise ansprechen kann, die von der Historie bisher nicht angesprochen wurden. Darin erschöpfen sie sich jedoch nicht: Sie haben vielmehr das Potential, die Bedingungen, unter denen wir historische Forschung betreiben, so zu verändern, daß einige der impliziten Grundannahmen des gegenwärtigen Geschichtsbetriebes hinfällig werden könnten. [...]

Die neuen Technologien sind ein Mittel zur Popularisierung der Geschichte. Hier können sie neue Berufszweige schaffen und neue Formen der Darstellung der Geschichte ermöglichen. Wieweit aber diese Darstellungsformen unser Verständnis der Zeitgeschichte und der Geschichte im allgemeinen verändern wird, bleibt abzuwarten. ${ }^{73}$

Der Historiker sah auch damals schon große Herausforderungen auf die Zeitgeschichte zukommen, wenn die technologischen Möglichkeiten einen permanenten Zugang auf „unverhältnismäßig größeres Quellenmaterial“ ermöglichten. Entscheidend sei dabei - hier dachte Thaller wohl noch nicht an das Internet als ein weltweit umfassendes Archiv -, wie die Geschichtswissenschaften eventuelle Archivierungssysteme mitgestalteten und wie sie mit diesen Datenbergen umzugehen wüssten. ${ }^{74}$ Big Data bestand damit noch in der Zugänglichkeit digitalisierter historischer Quellen.

Dass Archivierungsprobleme zeithistorisches Arbeiten trotz aller Potenziale sehr schnell erschweren konnten, zeigte sich am Beispiel des „ersten österreichischen Arbeitskampfs im Internet“. Die Mitte der 1990er-Jahre weitgehend mit digitalen Kommunikationsmöglichkeiten, also E-Mail und Website, organisierte Protestbewegung besonders externer Lehrender und freier WissenschaftlerInnen löste sich nach dem Scheitern der Forderungen nicht nur in der realen Welt in Luft auf, auch die digitalen Netze verschwanden nahezu vollständig: Die Websites verwaisten und wurden schließlich aus dem Internet genommen, die Kommunikation über E-Mail war und ist nicht mehr rekonstruierbar, die auf PCs verfassten Mitschriften waren nicht mehr erreichbar. Das Beispiel zeige, so Eva Blimlinger und Margit Sturm, welche archivalischen Lücken sich damit auch für die Zeitgeschichte ergäben. Zwar seien das Internet und E-Mail ursächlich dafür verantwortlich, dass sich die Protestbewegung von Universitätsangehörigen so rasch und effizient habe organisieren können, doch

während sich die Problematik der „Spurensicherung“ - der Sicherung von Quellen - von und über soziale Bewegungen nur auf einer neuen zusätzlichen Ebene, der elektronischen

73 Manfred Thaller, Virtuelle (Zeit-)Geschichte? Eine Disziplin zwischen Popularität, Postmoderne und dem Post-Post-Positivismus, in: Diendorfer (Hg.), Zeitgeschichte, 407-421, 414.

74 Ebd., 412-413. 
Kommunikation stellt, ist die Frage der Archivierung elektronischer Datenbestände aber von grundsätzlicher Bedeutung für die Geschichtswissenschaften und hier im speziellen für die Zeitgeschichtsforschung. ${ }^{75}$

2.6 Gemeinschaftsprojekte, Technologisierung, internationale Netzwerke und die Erforschung des Nationalsozialismus

Mit der Gründung der Arbeitsgemeinschaft Geschichte @ Internet durch den Neuzeithistoriker Reinhold Wagnleitner im März 1998 in Salzburg waren im Grunde die Weichen für all jene Entwicklungen gestellt, die die 2oooer-Jahre prägen und schließlich auch die österreichische Zeitgeschichte umfassend verwandeln sollten. Während eines Gastaufenthaltes an der University of New Orleans gestaltete Wagnleitner die Arbeitsgemeinschaft mit, die ein „internationales Diskussionsforum online für alle Fragen, die sich mit der Problematik von Geschichte und Internet“ auseinandersetzen, sein sollte. Neben seiner Funktion als internationales „Publikationsmedium online“, hatte HAI - Historiker@Internet die gezielte „Aus- und Weiterbildung von Historikerinnen und Historikern am Internet“ im Blick und wollte eine „kritische Auseinandersetzung mit den am Internet propagierten Inhalten Stichworte Internet-Ethik bzw. Gefährdung der Demokratie “ gewährleisten. ${ }^{76}$ Wenn HAI wegen „anhaltender Ressourcenknappheit“ letztlich 2006 eingestellt werden musste, ${ }^{77}$ so nahm dessen Gründung die Entwicklung der folgenden Jahrzehnte vorweg. In den 2oooer-Jahren ging es zunehmend um Vernetzung und Konsolidierung, was bedeutete, dass letztlich nur jene Projekte und Initiativen reüssieren konnten, denen es gelang, Synergien zu nutzen, Förderungen zu lukrieren und damit den Anschluss an internationale Trends zu schaffen. Kennzeichen der auch die Zeitgeschichte betreffenden Entwicklungen seit den 20ooer-Jahren waren eine ungeheure Technologisierung und globale Vernetzung auch historischer Diskurse sowie eine damit einhergehende, bis dahin unvorstellbare Diversifizierung von Themen, Herangehensweisen und Präsentationsfeldern.

Was die österreichische Zeitgeschichte betrifft, so erwies sich einmal mehr die Erforschung des Nationalsozialismus - was im Übrigen auch als internationales Phänomen zu sehen ist - als jener Bereich, der als paradigmatisch für den damit

75 Eva Blimlinger/Margit Sturm, Hyperhistorie - Zeitgeschichte ohne Netz? Der erste österreichische Arbeitskampf im Internet, in: Lechner/Seiler (Hg.), zeitgeschichte.at, 23-33, 31.

76 Wagnleitner, Geschichte @ Internet, 131.

77 Geschichte @ Internet, Universität Salzburg, URL: https://web.archive.org/web/20071104133544/ http://www.sbg.ac.at/hai/heimat.html (abgerufen 16.12.2019). 
einhergehenden Wandel stehen kann. Während Thomas Grotum 1997 noch umfassend über die Potenziale des Projektes „Sicherung und verbesserte Erschließung der Quellen im Archiv des Staatlichen Museums Auschwitz-Birkenau“ berichtete und ein damals wohl visionär anmutendes Modell für ein digitales, einige Millionen Seiten umfassendes Archiv der Quellen mit Auszeichnung von Orts- und Personennamen vorstellte, ${ }^{78}$ so sind vernetzte Datenbanken dieser Größenordnung aus der NS-Forschung (und Lehre) nach rund dreißig Jahren World Wide Web nicht mehr wegzudenken.

Ausgangspunkt zahlreicher Initiativen waren die Forschungsprojekte, die durch die Historikerkommission der Republik Österreich bearbeitet wurden, bzw. besonders auch jene, die seit Mitte der 1990er-Jahre durch den Nationalfonds der Republik Österreich für Opfer des Nationalsozialismus finanziert wurden. Zu nennen wären an dieser Stelle zahlreiche Aktivitäten, die mithilfe österreichischer ZeithistorikerInnen bzw. durch die Beteiligung der Zeitgeschichteinstitute und -abteilungen entstanden sind. Da sie die Entwicklungen der letzten Jahre besonders nachdrücklich wiederspiegeln, sollen stellvertretend nur einige Beispiele angesprochen werden.

Die vernetzten Datenbanken des „Findbuchs für Opfer des Nationalsozialismus“ gingen 2012 online. Entstanden aus den verstreuten Bemühungen unterschiedlicher Institutionen zur Erfassung notwendiger Datenbestände für die Arbeit des „Allgemeinen Entschädigungsfonds für Opfer des Nationalsozialismus“, waren im ersten Jahr rund 145.00o Datensätze über die Website zugänglich. Erstmals war damit eine bestandsübergreifende Suche nach Personen, Unternehmen oder Adressen in mehreren Archiven und unterschiedlichen Aktenbeständen zu Fragen des Vermögensentzuges „während der NS-Zeit sowie Restitutions- und Entschädigungsmaßnahmen nach 1945 auf dem Gebiet der Republik Österreich“ möglich. Eingearbeitete digitalisierte historische Adressbücher und Amtskalender sollten Recherchen zu Wohnadressen und Firmensitzen ermöglichen. ${ }^{79}$

Ein ähnliches Ansinnen hatte das Dokumentationsarchiv des österreichischen Widerstandes (DÖW). ${ }^{80} 1999$ konnten die Datenbanken des DÖW bereits auf zwei PCs im Zugangsbereich des Gedenkkomplexes, im Haus der Misrachi in Wien, eingesehen werden. 2001 wurde eine daraus hervorgegangene und längst nicht mehr

78 Thomas Grotum, Der Aufbau von „Digitalen Archiven“ zur Geschichte der NS-Konzentrationslager, in: Diendorfer (Hg.), Zeitgeschichte, 422-428, 422-427. Siehe auch: Albert Lichtblau, Erinnern im Zeitalter virtueller Realität, in: Diendorfer (Hg.), Zeitgeschichte, 542-548.

79 Profil: Das Findbuch, Nationalfonds der Republik Österreich, URL: https://web.archive.org/ web/20140102145242/http://www.findbuch.at/de/das-findbuch.html (abgerufen 16.12.2019).

80 Dokumentationsarchiv des österreichischen Widerstandes, URL: https://www.doew.at/ (abgerufen 09.02.2020). 
erhältliche CD-Rom dieser Daten publiziert, die nun auch im Internet auf einer Webseite zugänglich gemacht wurde. ${ }^{81}$ Jahrelange Forschungs- und Digitalisierungsaktivitäten ermöglichen es BesucherInnen heute, Informationen von mehr als 64.000 österreichischen Opfern des Holocaust zu recherchieren. Mit umfassenden Angaben zu Namen, Geburtsdaten, Wohnorten, Zielort und Datum der Deportationen ist diese Sammlung ein aus der zeithistorischen Forschung nicht mehr wegzudenkendes, laufend ergänztes Rechercheinstrument. 2015 wurde die Datenbank zudem mit den Transportlisten aus Wien abgeglichen und mit den dort gesammelten Daten von 46.0oo österreichischen Holocaustopfern verknüpft. 2011 ging außerdem das Portal „ns-quellen.at - Materialien zum Nationalsozialismus Vermögensentzug, Rückstellung und Entschädigung in Österreich" ${ }^{8_{2}}$ online, das Ergebnisse aus einem VWI-Projekt zu den Themen Vermögensentzug zwischen 1938 und 1945 und Rückstellung und Entschädigung nach 1945 präsentiert und zugänglich macht. Das Portal gibt einen Überblick über die gesetzlichen Grundlagen des NS-Vermögensentzugs und der Rückstellung und Entschädigung durch die Republik Österreich nach 1945. Darüber hinaus versteht sich „ns-quellen.at“ als Wegweiser für Archivrecherchen.

Viele der in diesen österreichischen Projekten gesammelten und gehosteten Daten sind darüber hinaus durch transnational und international äußerst erfolgreiche Kooperationen entstanden. Als Beispiel für ein international vernetztes Onlinearchiv kann das zum UNESCO-Weltdokumentenerbe gehörige und gleichzeitig umfangreichste Archiv über NS-Verfolgte in Bad Arolsen genannt werden. Das Arolsen Archives. International Center on Nazi Persecution, ehemals als International Tracing Service bekannt, stellt seit 2015 auf der Portalseite „Digital Collections Online“ Dokumente zu Inhaftierung, Zwangsarbeit und den Folgen der NS-Verbrechen online und damit interessierten Nutzergruppen zur Verfügung. Seit Sommer 2019 bietet

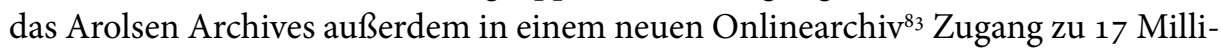
onen Dokumenten. Auch die Suche nach persönlichen Gegenständen und georeferenzierte Ansichten zum Beispiel der Todesmärsche (derzeit nur bei „Digital Collections Online“ möglich) wurde ins neue Onlinearchiv übernommen, ebenso wie umfangreiche Social-Media-Aktivitäten in das Portal eingebunden werden. Wegen der engen Zusammenarbeit mit dem United States Holocaust Memorial Museum ${ }^{84}$

81 Brigitte Bailer/Gerhard Ungar, Die namentliche Erfassung der österreichischen Holocaustopfer, in: Dokumentationsarchiv des österreichischen Widerstandes (Hg.), Opferschicksale. Widerstand und Verfolgung im Nationalsozialismus. Jahrbuch 2013, Wien 2013, 63-73.

82 NS-quellen.at, URL: http://ns-quellen.at/ (abgerufen 09.02.2020).

83 Arolsen Archives, URL: https://arolsen-archives.org/ (abgerufen 09.02.2020).

84 United States Holocaust Memorial Museum, URL: https://www.ushmm.org/ (abgerufen 09.02.2020). 
in Washington, D. C., und Yad Vashem in Israel ist somit ein weltweit wohl einzigartiges Netzwerk für die Recherche und Präsentation des Schicksals von Holocaustopfern, Überlebenden, RetterInnen und BefreierInnen entstanden.

Als internationale Drehscheibe der an diesen Institutionen anzusiedelnden Holocaust Education hat sich in Österreich die Portalseite „erinnern.at" ${ }^{\text {"85 }}$ etabliert. Dabei handelt es sich um ein Vermittlungsprojekt des Bundesministeriums für Unterricht, Kunst und Kultur für Lehrende an österreichischen Schulen, das den Transfer von Wissen fördern sowie seine Bedeutung für die Gegenwart reflektieren will. Ein wesentliches Ziel ist die Sensibilisierung für Rassismus, Antisemitismus und Hass.

\section{Fazit}

Die heute alltägliche Informationsflut führt in vielen Gesellschaften $\mathrm{zu}$ einer immer größer werdenden Unsicherheit. Beinahe dauernd steht zur Diskussion, was in den (Online)Medien nun als „wahr“ oder „unwahr“ gelten kann; der Begriff „Fake News" hat sich längst etabliert. Dieses Phänomen der Unsicherheit und die Erkenntnis, dass Informationsvielfalt und die Schnelligkeit der Verbreitung von Nachrichten keine einzelnen „Wahrheiten“ mehr zulassen - auch im wissenschaftlichen Sinne -, hatte Christiane Heibach, Professorin für Medienästhetik, bereits 1990 angedeutet:

Die Existenz elektronischer und digitaler Medien scheint diese Thesen vom Ende der Geschichte in vielerlei Hinsicht zu unterstützen: Zum einen führt sie uns durch die Tatsache der rasanten technologischen Entwicklung vor Augen, daß wir uns in einer Zeit ständiger Veränderungen befinden, die das Denken in Linearität gar nicht mehr erlaubt; zum anderen eröffnet uns die Medienvielfalt den Blick auf unendlich viele Perspektiven und Standpunkte, die eine Unterscheidung von richtig und falsch - nicht nur im moralischen, sondern auch im wissenschaftlichen Sinne - als Illusion entlarven. ${ }^{86}$

Die Erkenntnis Heibachs, dass die zunehmende technologische Entwicklung das „Denken in Linearität“ nicht mehr erlaube und dass die Linearität der Geschichtsschreibung endgültig durch eine vernetzende, fragmentarische Analyse ersetzt wer-

85 Erinnern.at, URL: http://www.erinnern.at/bundeslaender/oesterreich (abgerufen 09.02.2020).

86 Christiane Heibach, Zeitgeschichte statt Zeitgeschichten? Geschichte und Geschichtswissenschaft im digitalen Zeitalter, in: Diendorfer (Hg.), Zeitgeschichte, 392-406, 394-395. 
den müsse, ${ }^{87}$ ist heute in vielen zeithistorischen Forschungen längst Realität. Doch die Skepsis bleibt bestehen.

Während heute die Nutzung digitaler Quellen, komplexer Datenbanken oder digitaler Methoden und Arbeitsweisen auch aus geisteswissenschaftlichen Disziplinen und somit der österreichischen Zeitgeschichtsforschung nicht mehr wegzudenken ist, bedeutet dies längst nicht, dass das „digitale Zeitalter“ in Lehre und Forschung vorbehaltlos umgesetzt wird. Dies hat sowohl mit traditionellen disziplinären Ansätzen als auch mit der Komplexität der unterschiedlichen geisteswissenschaftlichen Fächer zu tun. Der in den Geschichtswissenschaften bis ins 20. Jahrhundert beklagte Mangel an Quellen ist vor allem für die Zeitgeschichte weniger zutreffend. ${ }^{88}$ Besonders in den letzten drei Jahrzehnten wuchs die Menge der verfügbaren historischen Materialien exponentiell und es ist ein rasantes Wachstum digital verfügbarer historischer Daten zu verzeichnen. So umfassen digitalisierte ebenso wie digital entstandene Archive, wie zum Beispiel digitale Zeitungssammlungen, Parlamentsprotokolle oder Verwaltungsakten, viele Millionen Seiten. ${ }^{89}$ Mit dieser Fülle stellen sich neue Herausforderungen. Auch und besonders in der Zeitgeschichte ist es eine komplexe Aufgabe geworden, Muster in diesen Informationsmassen zu erkennen. ${ }^{\circ}$ Die schiere Menge an (digital verfügbaren) historischen Quellen hat gleichzeitig neue Forschungsfragen aufgeworfen und die Heuristik des Faches nachhaltig beeinflusst. ${ }^{91}$ Die damit einhergehende - notwendige - Hybridität von klassischen und digitalen Strategien stellt gleichzeitig eine zusätzliche methodologische und erkenntnistheoretische Schwierigkeit für die Geschichtswissenschaft dar, denn neben den etablierten wissenschaftlichen Arbeitsabläufen und Standards muss nun der Umgang mit neuen Techniken, Begriffen und Konzepten konstruktiv erlernt bzw. adaptiert und kritisch reflektiert werden. ${ }^{92}$

87 Ebd., 403.

88 Alison Abbott, Informatics. Digital history, in: Nature 409 (2001) 6820, 556-557.

89 Toni Weller, Introduction, in: Toni Weller (Hg.), History in the digital age, London 2013, 1-20.

90 Peter Haber, Zeitgeschichte und Digital Humanities, Docupedia-Zeitgeschichte, URL: http://docupedia.de/zg/haber_digital_humanities_v1_2012 (abgerufen 21.10.2020).

91 Eva Pfanzelter, Die historische Quellenkritik und das Digitale, in: Archiv und Wirtschaft. Zeitschrift für das Archivwesen der Wirtschaft 48 (2015) 1, 5-19, 16-19; Peter Haber, Digital Past. Geschichtswissenschaft im digitalen Zeitalter, München 2011, 141-150; Guido Koller, Geschichte digital. Historische Welten neu vermessen, Stuttgart 2016, 33-35; das betrifft auch andere geisteswissenschaftliche Disziplinen, z. B. Johanna Drucker, Is There a „Digital“ Art History?, in: Visual Resources 29 (2013) 1-2, 5-13.

92 Andreas Fickers, Update für die Hermeneutik. Geschichtswissenschaft auf dem Weg zur digitalen Forensik?, in: Zeithistorische Forschungen/Studies in Contemporary History 17 (2020) 1, 157168. 
Dabei scheinen die Stärken der Digital History und somit auch der digitalen Zeitgeschichte in der Kombination von digitalen technischen Hilfsmitteln und traditionellen historischen Herangehensweisen zu liegen. ${ }^{93} \mathrm{Zu}$ den adaptierten (digitalen) Methoden zählen beispielsweise jene Anwendungen, die für qualitative Analysen in den Sozialwissenschaften entwickelt wurden, Datenbanken, die in der Informatik alltäglich, und korpuslinguistische Untersuchungen, die in den Sprach- und Literaturwissenschaften üblich sind. Zunehmend eignen sich HistorikerInnen damit Methoden und Werkzeuge anderer Disziplinen an, woraus allerdings auch neue Forschungsfragen und -herangehensweisen resultieren. ${ }^{94}$

Die Positionierung der Digital History innerhalb der Digital Humanities findet sich indes in drei aufeinander aufbauenden, zunehmend komplexer werdenden Bereichen wieder: der Digitalisierung, der Quantifizierung und der Qualifizierung. Subsumiert unter dem Begriff Digitalisierung, können die digitalen Prozesse der Quellenaufbereitung als erster Bereich genannt werden. Sie sind sozusagen die Grundlage der Digital History und bleiben auch wegen ihrer zentralen Bedeutung für alle folgenden Forschungsschritte im Fokus zahlreicher Debatten. In einem zweiten Bereich ist der Einsatz (digitaler) quantitativer Methoden zur Suche, Strukturierung, Kategorisierung, Organisation und Reduzierung digitaler Sammlungen zu sehen. Sowohl die Digitalisierung als auch die Quantifizierung sind schon lange interdisziplinär ausgelegt und konzentrieren sich spätestens seit der Jahrtausendwende auf den Umgang und die Bewältigung mit Big Data. ${ }^{95}$

In einem dritten Bereich haben auch ZeithistorikerInnen begonnen, sich eingehender mit der Erforschung der Möglichkeiten qualitativer Analysen digitaler Daten zu befassen, um mittels eigener Methoden und Arbeitsweisen Inhalte, (Be-)

93 Marten Düring, Verdeckte soziale Netzwerke im Nationalsozialismus. Die Entstehung und Arbeitsweise von Berliner Hilfsnetzwerken für verfolgte Juden, Berlin/Boston 2015, 42-50.

94 Daniel Alves, Introduction: digital methods and tools for historical research, in: International Journal of Humanities and Arts Computing 1 (2014) 8, 1-12.

95 Siehe beispielsweise: Rachel Sagner Buurma/Laura Heffernan, Search and Replace: Josephine Miles and the Origins of Distant Reading, in: Modernism/Modernity Print Plus 3 (2018) 1, URL: https://modernismmodernity.org/forums/posts/search-and-replace (abgerufen 21.10.2020); Robert P. Swierenga, Clio and Computers: A Survey of Computerized Research in History, in: Computers and the Humanities 5 (1970) 1, 1-21; Theodore K. Rabb, The Development of Quantification in Historical Research, in: Journal of Interdisciplinary History 13 (1983) 4, 591-601; Shawn Graham/ Ian Milligan/Scott Weingart, Exploring big historical data. The historian's macroscope, London 2016; Matthew Lee Jockers, Macroanalysis. Digital methods and literary history (Topics in the digital humanities), Urbana 2013; Franco Moretti, Distant Reading, Konstanz 2016; Ted Underwood, A Genealogy of Distant Reading, in: Digital Humanities Quarterly 11 (2017) 2, URL: http://www. digitalhumanities.org/dhq/vol/11/2/000317/000317.html (abgerufen 21.10.2020). 
Deutungen und Diskurse automatisiert oder zumindest automationsgestützt zu erschließen und somit die Erfassung bzw. das Verständnis großer Datenmengen zu erleichtern. Zu den hier zu nennenden Forschungsansätzen gehören auf Quantifizierung basierende Visualisierungen ebenso ${ }^{96}$ wie der Einsatz von Artificial Intelligence: Textaufbereitung (Text Preprocessing), Frequenzanalysen, semantische Worterfassungen (also n-Gramme und Lemmatisierung), Word Embeddings und nicht zuletzt Topic Models, Graphenvisualisierungen, Georeferenzierungen, Netzwerkanalysen, Muster- oder Trendanalysen und vieles mehr sind für HistorikerInnen, die mit großen digitalen Quellenbeständen arbeiten, zu alltäglichen Arbeitsweisen geworden - und zwar nicht nur für die Strukturierung von Korpora, sondern auch für diskursanalytische Fragestellungen. ${ }^{97}$ Die dahinter stehenden Forschungsfragen können dabei höchst unterschiedlich sein und reichen von der Verwendung von Text-Mining-Methoden zur Erkennung sprachlicher Muster im zeitlichen Wandel ${ }^{98}$ über die Entwicklung von Raumtheorien ${ }^{99}$ bis hin zu historischen Netzwerken ${ }^{100}$. Visualisierungen spielen dabei eine wichtige Rolle, sei es für die Analyse von Text, Audio, Bild oder Film als auch für überschaubare Darstellungen der Ergebnisse. Es sind diese Techniken der computergestützten Sammlung, Analyse und Darstellung, die es HistorikerInnen ermöglichen, Geschichte auf neuartige Weise zu rekonstruieren und zu interpretieren. Die österreichische Zeitgeschichtsforschung und -lehre hat in den vergangenen dreißig Jahren diese Prozesse begleitet und mitgestaltet, obwohl die institutionellen und finanziellen Rahmenbedingungen dafür nicht immer ideal waren.

Die Integration von digitalen Methoden und Arbeitsweisen in die zeithistorische Forschung und Lehre verlangt nicht weniger als eine Aktualisierung der klassischen

96 Franco Moretti, Graphs, maps, trees. Abstract models for a literary history, London 2007.

97 Kamran Kowsari/Kiana Jafari Meimandi/Mojtaba Heidarysafa/Sanjana Mendu/Laura E. Barnes/ Donald E. Brown, Text Classification Algorithms: A Survey, in: Information 10 (2020) 4, 1-68.

98 Jani Marjanen/Lidia Pivovarova/Elaine Zosa/Jussi Kurunmäki, Clustering Ideological Terms in Historical Newspaper Data with Diachronic Word Embeddings, in: Melvin Wevers/Mohammed Hasanuzzaman/Gaël Dias/Marten Düring/Adam Jatowt (Hg.), HistoInformatics 2019: International Workshop on Computational History (CEUR Workshop Proceedings 2461), Aachen 2019, 21-29.

99 Guiseppe Borruso, Geographical Analysis of Foreign Immigration and Spatial Patterns in Urban Areas: Density Estimation and Spatial Segregation, in: Osvaldo Gervasi/Beniamino Murgante/ Sanjay Misra/Chiara Garau/Ivan Blečić/David Taniar/Bernady O. Apduhan/Ana Maria A. C. Rocha/Eufemia Tarantino/Carmelo Maria Torre/Yeliz Karaca (Hg.), Computational Science and Its Applications - ICCSA (Theoretical Computer Science and Genereal Issues 12255), Schweiz 2020, 459-474.

100 Düring, Netzwerke. 
Hermeneutik. ${ }^{101}$ Während der traditionelle Dreischritt Heuristik, Quellenkritik und Interpretation unverändert bleibt, bedarf es auch einer Anpassung der Quellenkritik an die digitale Welt, um digitalen Quellen, Formaten und Diskursen gerecht zu werden. Ebenso braucht es eine inhaltliche Verifizierung automatisierter Verfahren, um Ergebnisse nachvollziehbar und glaubwürdig auch für die historische Disziplin nutzbar zu machen. Neben dem kritischen Blick auf die Digitalität gehört also auch die Reflexion über die Auswirkungen dieser Veränderung auf die Zunft und auf das Fach dazu - eine Reflexion, die auch in Österreich im kritischen Diskurs durchaus umfangreicher stattfinden könnte. ${ }^{102}$

101 Fickers, Update.

102 Pfanzelter, Quellenkritik; Drucker, „Digital“ Art. 


\title{
NS-Vermögensentzug, Restitution und Provenienzforschung
}

\author{
Birgit Kirchmayr
}

Kaum ein anderes Themenfeld in der österreichischen Zeitgeschichtsforschung weist eine so direkte Beziehung zu politischen und juristischen Diskursen auf wie jenes, das sich dem NS-bedingten Vermögensentzug zwischen 1938 und 1945 und der Rückstellungspolitik nach 1945 widmet. Dementsprechend verwoben sind Leerstellen und Konjunkturen der Forschung mit der allgemeinen gesellschaftspolitischen Entwicklung. Vor diesem Hintergrund verwundert es nicht, dass eine intensive Beschäftigung mit „Arisierungen“ und Restitutionspraxis in der zeithistorischen Forschungslandschaft erst seit den 1980er-/199oer-Jahren zu konstatieren ist, das heißt seit dem Aufbrechen des gesellschaftlichen Paradigmas der Opferthese und der einsetzenden Diskussion über die österreichische Verantwortung an nationalsozialistischen Verbrechen. Als die Fragen rund um den NS-bedingten Vermögensentzug nach Ende der NS-Herrschaft auf politisch-juristischer Ebene abgehandelt wurden (mit der Schaffung der sieben Rückstellungsgesetze zwischen 1946 und 1949), geschah dies unter Rahmenbedingungen, die von den Interessen der regierenden Parteien, dem Ziel der Schaffung eines Staatsvertrags und den Vorgaben der Alliierten bestimmt waren. ${ }^{1}$ Grundlegende Analysen zum System der Enteignungen waren ebenso wenig vorhanden wie der ernsthafte Wille zu einer vollständigen Entschädigung der Opfer, was sich am klarsten daran zeigt, dass in den Rückstellungsgesetzen ausschließlich vorhandene Vermögenswerte im Sinne einer Naturalrestitution behandelt wurden, aber generell keine Entschädigungen für nicht mehr vorhandene Besitzgüter (beispielsweise liquidierte Betriebe oder nicht mehr auffindbares Kunstgut) vorgesehen waren. Die Rückstellungsgesetze hatten zudem zahlreiche Tücken und erwiesen sich in der Praxis für ein Gros der Opfer als unzureichend und/oder nicht praktikabel. Charakteristisch für die Restitutionspolitik war weiter, dass in vielen Fällen in der Praxis dieselben Personen dafür zuständig waren, die in den Jahren zuvor die Enteignungen administriert oder sogar daraus profitiert hatten. ${ }^{2}$

1 Vgl. Brigitte Bailer-Galanda/Eva Blimlinger, Vermögensentzug - Rückstellung - Entschädigung. Österreich 1938/1945-2005, Innsbruck/Wien/Bozen 2005, 40-49.

2 Vgl. dazu als Beispiel den Fall des Juristen und Kunstsammlers Walther Kastner, der in seiner Funktion als Vorsitzender der Kontrollbank während der NS-Zeit die „Arisierung“ von österreichischen Großbetrieben abwickelte und nach 1945 im Ministerium für Vermögenssicherung und 
Alle diese Kritikpunkte sollten erst Jahrzehnte später von der zeithistorischen Forschung und der gesellschaftlichen Debatte erörtert werden. Später als in Deutschland entwickelte sich in Österreich eine auf die unmittelbare Vergangenheit bezogene Zeitgeschichtsforschung erst in den 1960er- und 1970er-Jahren. Als deren Träger fungierten die neu gegründeten Zeitgeschichteinstitute an den Universitäten (zunächst in Salzburg, Wien und Linz, später auch in Innsbruck, Graz, Klagenfurt) sowie außeruniversitäre Forschungsstellen, allen voran das 1963 in Wien etablierte Dokumentationsarchiv des österreichischen Widerstands (DÖW). Es stellt sich nun die Frage, ob und ab wann sich die österreichische Zeitgeschichte mit Aspekten der wirtschaftlichen Beraubung in der NS-Zeit und der Rückstellungs- und Wiedergutmachungspolitik befasste und wie sich dieses Forschungsfeld in den letzten Jahrzehnten entwickelt hat.

\section{Die 1960 er- bis 1980 er-Jahre: Große Leerstelle mit wenigen „Ausreißern“}

Betrachtet man die Publikationen, Aufsätze und Monographien der ersten Jahrzehnte österreichischer Zeitgeschichtsforschung, das heißt der 1960er- und 1970erJahre, muss eine von nur wenigen Ausnahmen unterbrochene Leerstelle konstatiert werden: „Arisierung“ und Restitution waren als Forschungsfelder schlichtweg nicht vorhanden. Nur wenige Publikationen widmeten sich der Thematik und erweisen sich aus heutiger Sicht als isolierte Inseln in der Forschungslandschaft, die noch länger keinen Widerhall fanden. Eine dieser Arbeiten erschien im Jahr 1966 in der DÖW-Reihe „Monographien zur Zeitgeschichte“. Sie stammt von Felix Romanik und trägt den bezeichnenden Titel „Österreichs wirtschaftliche Ausbeutung 1938-1945“.3 Ganz im Sinne der Opferthese wurde der wirtschaftliche Raubzug an österreichischen Jüdinnen und Juden, der von einer Vielzahl von ÖsterreicherIn-

Wirtschaftsplanung („Kraulandministerium“) unter anderem für die Erstellung des 5. Rückstellungsgesetzes verantwortlich war. Vgl. Birgit Kirchmayr, Provenienzforschung. Bestand Sammlung Kastner. Erster Zwischenbericht vom 13.10.2019, Oberösterreichische Landesmuseen, URL: http:// www.landesmuseum.at/de/sammlungen/provenienzforschung.html (abgerufen 03.12.2019); Brigitte Bailer-Galanda, „Schauen Sie, das Ungeordnete ist natürlich schlimmer wie das Geordnete“: Skizze zu Walther Kastner, Jurist und Staatsbediensteter für Diktatur und Demokratie, in: Michael Pammer/Herta Neiß/Michael John (Hg.), Erfahrung der Moderne. Festschrift für Roman Sandgruber, Stuttgart 2007, 289-300.

3 Felix Romanik, Österreichs wirtschaftliche Ausbeutung 1938-1945 (Monographien zur Zeitgeschichte. Schriftenreihe des Dokumentationsarchivs des österreichischen Widerstands), Wien/ Frankfurt/Zürich 1966. Der Text ist ein Auszug aus Romaniks Buch „Der Leidensweg der österreichischen Wirtschaft", das bereits 1957 erschien. 
nen mitgetragen wurde, in einem Zug mit dem „Wirtschaftskrieg des nationalsozialistischen Deutschen Reiches gegen Österreich“" ${ }^{4}$ und der Enteignung von österreichischem Staats- und kirchlichem Eigentum im Gesamten zu einer Ausbeutung „Österreichs“ umgedeutet. Zweifellos handelte es sich bei den „arisierten“ Vermögenswerten um österreichische Vermögenswerte, da es sich bei den Beraubten um ÖsterreicherInnen handelte, insofern könnte eine solche ,integrierte“ Zugangsweise auch positiv betrachtet werden. Klar weist das Buch aber in eine andere Richtung, indem der Raubzug an den jüdischen ÖsterreicherInnen externalisiert und die österreichische Beteiligung daran nicht direkt thematisiert wurde. Gleichzeitig muss die Studie aber als eine der ersten, die das System der „Arisierung“ überhaupt aufnahm und darstellte, hervorgehoben werden. Fünf Jahre später, 1971, erschien in den „Veröffentlichungen des Historischen Instituts der Universität Salzburg“ die von Erika Weinzierl betreute Dissertation von Dietmar Walch mit dem Titel „Die jüdischen Bemühungen um die materielle Wiedergutmachung durch die Republik Österreich“.5 Walch schrieb in seiner Einleitung, die „Materialbeschaffung“ für seine Dissertation sei schwierig gewesen, da das Thema mit Ausnahme eines Aufsatzes „noch keinen Niederschlag in der Sekundärliteratur" ${ }^{\text {"6 }}$ gefunden habe. Tatsächlich besteht die Literaturliste der Dissertation aus fünf (!) Titeln, darunter der von Walch in der Einleitung hervorgehobene Aufsatz. Bei diesem handelte es sich um einen 1967 in London veröffentlichten Beitrag von Gustav Jellinek zur österreichischen Wiedergutmachung. ${ }^{7}$ Drei Jahre nach Walch, 1974, publizierte schließlich Gerhard Botz, damals Universitätsassistent in Linz, in den „Wiener Geschichtsblättern“ den Beitrag „Arisierungen und nationalsozialistische Mittelstandspolitik in Wien (1938 bis 1940)“. Damit fand sich erstmals der Begriff „Arisierung“ im Titel einer österreichischen zeitgeschichtlichen Publikation. ${ }^{9}$ Ebenfalls noch in den 1970er-Jahren,

4 Romanik, Österreichs wirtschaftliche Ausbeutung, 5.

5 Dietmar Walch, Die jüdischen Bemühungen um die materielle Wiedergutmachung durch die Republik Österreich (Veröffentlichungen des Historischen Instituts der Universität Salzburg), Wien 1971.

6 Walch, Jüdische Bemühungen, Vorwort o. S.

7 Gustav Jellinek, Die Geschichte der österreichischen Wiedergutmachung, in: Josef Fraenkel (Hg.), The Jews of Austria. Essays on their Life. History and Destruction, London 1967, 395-462.

8 Gerhard Botz, „Arisierungen“ und nationalsozialistische Mittelstandspolitik in Wien (1938 bis 1940), in: Wiener Geschichtsblätter 29 (1974) 1, 122-136.

9 Auf Anfrage erklärte Botz, er sei damals eher zufällig in der Recherche zur Wiener Wohnungspolitik auf die umfangreichen „Arisierungsakten“ gestoßen. Er habe mit Kollegen vom DÖW darüber gesprochen und den Eindruck gehabt, dass es kaum Interesse für diese Thematik gebe bzw. die Befürchtung vor den Konsequenzen einer Aufarbeitung vorherrsche (Stichwort: „In diesen Wohnungen leben ja heute noch viele Menschen“). Vgl. telefonische Auskunft Gerhard Botz, 25.10.2019. 
nämlich zum vierzigjährigen Gedenkjahr an den „Anschluss“ 1978, erschien der Band „Wien 1938“, zu dem Georg Weis einen Beitrag mit dem Titel „Arisierungen in Wien“ beisteuerte. ${ }^{10}$ Das Thema der "Arisierung“ war somit - wenn auch noch vereinzelt - mit ersten Publikationen präsent.

2. Mitte der 1980er- bis Mitte der 1990er-Jahre: Gesellschaftliche Wende und die Ausweitung des Forschungsinteresses

Als 1988 das fünfzigjährige Gedenken an den „Anschluss“ stattfand, hatten sich viele Rahmenbedingungen verändert. Die „Waldheim-Debatte“ 1986 und nicht zuletzt das Gedenkjahr 1988 selbst hatten zu einer veränderten - im Sinne einer verstärkten und multiperspektivischen - Wahrnehmung und Bewertung der österreichischen NS-Vergangenheit geführt. In der Forschung zeigte sich dies durch ein vermehrtes Auftreten von Arbeiten, die sich nicht nur kritisch mit Österreichs NS-Vergangenheit selbst, sondern auch mit dem politischen und gesellschaftlichen Umgang damit nach 1945 auseinandersetzten. Besondere Aufmerksamkeit erlangte dabei das 1988 von Robert Knight veröffentlichte Buch „Ich bin dafür, die Sache in die Länge zu ziehen “. ${ }^{11}$ Knight veröffentlichte die Wortprotokolle der österreichischen Bundesregierung der Jahre 1947 bis 1952, die sich auf Fragen der sogenannten Wiedergutmachung bezogen. Die erschreckende Durchdringung zahlreicher Aussagen und Entscheidungen von antisemitischen Ressentiments und Stereotypen, nur wenige Jahre nach der Shoah, und die klare Abwehrhaltung gegen jegliche Art von ernst gemeinter und seriöser Entschädigung, die nicht nur alliierte Interessen ruhigstellen sollte, kennzeichnen die in den Wortprotokollen aufgezeichneten Verhandlungen der österreichischen Nachkriegspolitiker. Neben Knights Publikation erschienen in der zweiten Hälfte der 1980er-Jahre und zu Beginn der 1990er-Jahre zunehmend mehr Bücher, Aufsätze und Hochschulschriften, die sich mit Aspekten von „Vergangenheitsbewältigung“ auseinandersetzten. Dies zeigt auch ein Blick in die Zeitschrift „zeitgeschichte“, wo das Thema ebenfalls ab den 1980er-Jahren

10 Georg Weis, Arisierungen in Wien, in: Verein für Geschichte der Stadt Wien (Hg.), Wien 1938 (Sonderreihe der Wiener Geschichtsblätter. Forschungen und Beiträge zur Wiener Stadtgeschichte 2), Wien 1978, 183-189.

11 Robert Knight, „Ich bin dafür, die Sache in die Länge zu ziehen. “ Die Wortprotokolle der österreichischen Bundesregierung von 1945 bis 1952 über die Entschädigung der Juden, Frankfurt a. M. 1988. 
an Präsenz gewann. ${ }^{12}$ Der erste Beitrag, der sich explizit dem Thema der Rückstellungen widmete, erschien in der „zeitgeschichte“ allerdings erst 1993. Er stammte von Brigitte Bailer-Galanda und trug den Titel „,Ohne den Staat weiter damit zu belasten.' Bemerkungen zur österreichischen Rückstellungsgesetzgebung “. ${ }^{13}$ BailerGalanda war zwei Jahre zuvor, 1991, mit einer Arbeit über die österreichische Wiedergutmachungspolitik promoviert worden ${ }^{14}$ und sollte sich in ihrer Forschungsarbeit bis hin zu ihrer Tätigkeit in der Historikerkommission 1998-2003 als eine der führenden Forscherinnen auf diesem Gebiet in Österreich etablieren.

\section{Die späten 1990er- und frühen 2000er-Jahre: Die Debatte um „NS- Raubkunst" und ihre Folgen für die Forschung}

Der Impetus zu einer über Einzelarbeiten hinausgehenden Forschungsinitiative im Bereich von "Arisierungs“- und Restitutionsfragen kam allerdings nicht aus der Wissenschaft selbst, sondern war den gesellschaftspolitischen Veränderungen der 1990er-Jahre geschuldet. In Österreich hatte sich seit den 1980er-Jahren ein breiter Paradigmenwechsel vollzogen, was die Auseinandersetzung mit der NS-Zeit betrifft. 1991 bekannte sich erstmals ein österreichischer Bundeskanzler zur historischen Schuld und Verantwortung Österreichs, 1995 wurde das Nationalfondsgesetz beschlossen. Über den Nationalfonds wurde erstmals in der Geschichte der Zweiten Republik eine Pauschalsumme als Entschädigung an NS-Opfer ausbezahlt. ${ }^{15}$ Auch international betrachtet brachten die 1990er-Jahre neue Voraussetzungen. Das Wendejahr 1989 und die deutsche Wiedervereinigung machten die Entschädigungs- und

12 Beispielhaft sei verwiesen auf: Oliver Rathkolb, U.S.-Entnazifierung in Österreich zwischen kontrollierter Revolution und Elitenrestauration (1945-1949), in: zeitgeschichte 11 (1984) 9/10, 302325; Robert Knight, Britische Entnazifierungspolitik 1945-1949, in: zeitgeschichte 11 (1984) 9/10, 287-301; ders., Einige vergleichende Betrachtungen zur „Vergangenheitsbewältigung“ in Österreich und Großbritannien, in: zeitgeschichte 15 (1987) 2, 63-71; Peter Malina, Die Diagnose gilt noch ... Zur Aufarbeitung und „Bewältigung“ von Vergangenheit, in: zeitgeschichte 15 (1987) 5, 180-195 sowie weitere Beiträge, die in NS-Schwerpunktheften im Jahrgang 1987/1988 erschienen sind.

13 Brigitte Bailer-Galanda, ,Ohne den Staat weiter damit zu belasten.' Bemerkungen zur österreichischen Rückstellungsgesetzgebung, in: zeitgeschichte 20 (1993) 11/12, 367-381.

14 Als Buch erschienen 1993: Brigitte Bailer-Galanda, Wiedergutmachung kein Thema. Österreich und die Opfer des Nationalsozialismus, Wien 1993.

15 Vgl. Bailer-Galanda/Blimlinger, Vermögensentzug, 71-72; Renate Meissner (Hg.), Nationalfonds der Republik Österreich für Opfer des Nationalsozialismus. Entwicklung, Aufgaben, Perspektiven, Wien 2010. 
Wiedergutmachungspolitik in Europa in den frühen 1990er-Jahren zu einem neuerlichen Thema. In Deutschland ging es dabei - ausgehend von mehreren Sammelklagen - vor allem um das Thema der Zwangsarbeiterentschädigung. In der Schweiz brach Mitte der 1990er-Jahre eine Diskussion um die Bereicherung des Landes durch „Nazi-Raubgold“ sowie „schlafende Konten“ von NS-Opfern auf Schweizer Banken aus. 1996 wurde die Unabhängige Expertenkommission (UEK) eingerichtet, die sich den Themen wirtschaftlicher Bereicherung, aber auch der Flüchtlingspolitik, beides bis dahin große Tabuthemen in der Schweizer Öffentlichkeit und Politik, widmete. ${ }^{16}$

Bereits unter dem Eindruck dieser Entwicklungen entstand auch in Österreich eine Debatte zum Umgang der Republik mit dem Erbe der NS-Zeit. In ihrem Mittelpunkt stand nicht das Gold und nicht die Zwangsarbeit, sondern vielmehr die Kunst. Schon Ende der 196oer-Jahre hatte es eine erste Diskussion um nichtrestituierte, in der NS-Zeit entzogene Kunstgegenstände gegeben, die sich in Verwahrung der Republik Österreich befanden. Simon Wiesenthal, an den sich eine ehemals NSVerfolgte gewandt hatte, die auf der Suche nach dem Kunstbesitz ihrer Familie war, hatte von in der Kartause Mauerbach eingelagerten Kunstbeständen erfahren und sich um Rückstellung bemüht. ${ }^{17}$ Das auf diesen Anstoß hin beschlossene Bundesgesetz vom 27. Juni 1969 erteilte das Recht auf Rückforderung von in der NS-Zeit enteigneten Kunstgegenständen unter Einhaltung einer Anspruchsfrist bis 31. Dezember $1970 .^{18}$ Erstmals veröffentlichte die österreichische Regierung dazu auch eine Liste der in Mauerbach eingelagerten Kunstwerke, sie umfasste 657 Ölgemälde, 84 Aquarelle, Zeichnungen und hunderte Kunstgegenstände sowie Bücher. ${ }^{19}$ Restituiert wurde nur ein kleiner Teil davon, was angesichts der knappen Befristung und der schwierigen Auflagen zur Beweisführung nicht verwundert. ${ }^{20}$ Nach Ende der Anspruchsfrist wurde das Thema wieder ad acta gelegt. Forschungsbemühungen zur Herkunft der nichtrestituierten Objekte wurden damals nicht unternommen oder,

16 Vgl. URL: https://www.uek.ch/de/index.htm (abgerufen 03.12.2019).

17 Vgl. dazu ein Interview der Autorin mit Simon Wiesenthal: Birgit Kirchmayr, Sonderauftrag Linz. Zur Fiktion eines Museums, in: Fritz Mayrhofer/Walter Schuster (Hg.), Nationalsozialismus in Linz, Bd. 1, Linz 2001, 557-596, 591-592.

18 Bundesgesetz vom 27. Juni 1969 über die Bereinigung der Eigentumsverhältnisse des im Gewahrsam des Bundesdenkmalamtes befindlichen Kunst- und Kulturgutes (1. Kunst- und Kulturgutbereinigungsgesetz), BGBl 294/1969.

19 Amtsblatt zur Wiener Zeitung, 01.09.1969. Die in Mauerbach eingelagerten Kunstwerke waren in den 1950er-Jahren von den Alliierten nach Auflösung des so genannten Art Collecting Point in München Österreich übergeben worden.

20 Sharon Waxman, Austria: Ending the Legacy of Shame, in: ARTnews 94 (1995) 7, 122-125. Laut diesem Bericht wurden nach der Anspruchsfrist 1970-1972 von 1.200 Forderungen nur 71 Objekte retourniert. 
wie dies Sabine Loitfellner formulierte: „Die Idee, proaktiv Provenienzforschung und Erbensuche zu betreiben, hatte man gar nicht erst aufkommen lassen. ${ }^{{ }_{21}}$ Erst nach einem Artikel in der amerikanischen Kunstzeitschrift „ARTnews" mit dem Titel „A Legacy of Shame ${ }^{\text {“22 }^{2}}$ kam es zu einer politischen Wiederaufnahme des Themas, die den Beschluss eines zweiten Kunst- und Kulturgutbereinigungsgesetzes im Jahr 1985 zur Folge hatte, ${ }^{23}$ das ähnlich konzipiert und ähnlich erfolglos wie das erste war. Die Übergabe des Mauerbach-Bestandes an die Israelitische Kultusgemeinde und eine von dieser organisierte Versteigerung („Mauerbach-Auktion“) zugunsten von Holocaustopfern sollte das Problem 1995 nun lösen und einen Schlussstrich unter die Thematik der NS-Raubkunst ziehen.

Das Gegenteil war allerdings der Fall. Die „Mauerbach-Auktion“ hatte die Aufmerksamkeit bereits auf das Thema gelenkt gehabt, als nur wenig später ein neuerliches Ereignis die Diskussion erst so richtig ins Rollen brachte: Am 24. Dezember erschien in der „New York Times“ ein Artikel, in dem der österreichische Kunstsammler Rudolf Leopold ${ }^{24}$ beschuldigt wurde, Kunstwerke mit zweifelhafter Herkunft in seiner Sammlung zu haben, die sich zu diesem Zeitpunkt gerade in einer Ausstellung des Museum of Modern Art befanden. Mindestens vier Gemälde seien in der Ausstellung zu sehen, die einst jüdischen EigentümerInnen entzogen worden seien. ${ }^{25}$ Im Januar 1998 wurden schließlich die beiden Gemälde Egon Schieles „Bildnis Wally“ und „Tote Stadt III“ in New York beschlagnahmt. Das Ereignis schlug in Österreich große Wellen. Der Journalist Hubertus Czernin startete in der Tageszeitung „Der Standard“ eine mehrteilige „Raubkunst"-Serie, wissenschaftlich begleitet von den Recherchen von Gabriele Anderl. Ausgehend vom Fall Leopold wurden auch andere österreichische Museen und Sammlungen einer kritischen Betrachtung

21 Sabine Loitfellner, NS-Kunstraub und Restitution in Österreich. Institutionen - Akteure - Nutznießer, in: Verena Pawlowsky/Harald Wendelin (Hg.), Enteignete Kunst. Raub und Rückgabe - Österreich von 1938 bis heute, Wien 2006, 13-25, 23.

22 Andrew Decker, A Legacy of Shame, in: ARTnews 83 (1984) 10, 54-82.

23 2. Kunst- und Kulturgutbereinigungsgesetz, BGBl. 1986/2.

241994 war die Privatsammlung Rudolf Leopolds unter Beteiligung der Republik Österreich in eine Privatstiftung übergegangen. 2001 wurde das Leopold Museum im Wiener Museumsquartier eröffnet. Es gilt nicht als Bundesmuseum und ist daher auch nicht dem Rückgabegesetz von 1998 unterstellt. Zur gegenwärtigen Provenienzforschung im Leopoldmuseum vgl. URL: https://www.leopoldmuseum.org/de/Forschung/Provenienzforschung/Provenienzforschung-Leopold-Museum (abgerufen 03.12.2019).

25 Judith H. Dobrzynski, The zealous collector-A special report. A Singular Passion for Amassing Art, One Way or Another, The New York Times, 24.12.1997, URL: https://www.nytimes. com/1997/12/24/arts/zealous-collector-special-report-singular-passion-for-amassing-art-oneway.html (abgerufen 01.12.2020). 
unterzogen. Objekte der Kunstsammlungen von Alphonse und Louis Rothschild im Kunsthistorischen Museum sowie Gustav Klimts Bildnis „Adele Bloch-Bauer I“ im Belvedere gehörten zu den prominentesten in der Öffentlichkeit wahrgenommenen Fällen. ${ }^{26}$ Czernin gründete 1999 die Verlagsreihe „Bibliothek des Raubes“, in der die Thematik in mehreren Bänden weiterverfolgt wurde. Unter dem Titel „Was einmal war" legte Sophie Lillie in dieser Reihe 2003 eine umfassende Studie zu den in Wien „arisierten“ Kunstsammlungen vor. ${ }^{27}$

Kurz gesagt: Die Forschung zum Feld der NS-Kunstenteignungen und der Praxis der Nachkriegsrestitution war in Bewegung gekommen und auch politisch-juristisch blieb der Fall Schiele nicht ohne Folgen: Im Herbst 1998 verabschiedete die österreichische Bundesregierung ein neuerliches Kunstrückgabegesetz. ${ }^{28}$ Damit in Zusammenhang war bereits im Februar 1998 die bis heute bestehende Kommission für Provenienzforschung eingerichtet worden, deren Aufgabe es ist, die Sammlungen des Bundes nach Objekten zu untersuchen, die ihren früheren EigentümerInnen in der NS-Zeit entzogen worden waren. ${ }^{29}$ Die Etablierung dieser Kommission hatte weitgehende Auswirkungen auf die Forschungslandschaft. Zahlreiche WissenschaftlerInnen sollten in den nächsten Jahren in der Provenienzforschung ihr Tätigkeitsfeld finden - KunsthistorikerInnen, aber auch (Zeit)HistorikerInnen. Der Begriff der Provenienzforschung verweist auf eine disziplinäre Verankerung in der Kunstgeschichte, in der die Forschung nach der Herkunft (Provenienz) von Kunstwerken eine traditionelle Teildisziplin darstellt. Die nach 1998 in Österreich im Rahmen der Kommission etablierte Provenienzforschung unterscheidet sich von „klassischer“ Provenienzforschung allerdings insofern, als sie einen klaren Fokus auf der Untersuchung der Umstände hinsichtlich einer etwaigen Enteignung in den NS-Jahren hat, weswegen sie präziser auch NS-bezogene Provenienzforschung oder zeithistorische Provenienzforschung genannt werden sollte. Eine solche Benennung

26 Der Fall des Bildes „Adele Bloch-Bauer I (Goldene Adele)“, 2006 nach mehrjährigem Rechtsstreit von der Republik Österreich an die Nichte Adele Bloch Bauers, Maria Altmann, restituiert, wurde unter dem Titel „Woman in Gold“ 2015 vom US-amerikanischen Regisseur Simon Curtis verfilmt. Die Rolle Maria Altmanns mimt Helen Mirren, der österreichische Journalist Hubertus Czernin wird von Daniel Brühl dargestellt. Bereits 2001 fand das Thema der „arisierten“ Kunst Einzug in einen österreichischen „Tatort“: Nichts mehr im Griff, ORF/ARD, 28.01.2001.

Sophie Lillie, Was einmal war. Handbuch der enteigneten Kunstsammlungen Wiens, Wien 2003.

28 Kunstrückgabegesetz BGBl. I 181/1998, Novelle 2009 BGBl. I 117/2009.

29 Vgl. Anneliese Schallmeiner, 1998 - die Kommission für Provenienzforschung und der Weg zum Kunstrückgabegesetz, in: Gabriele Anderl/Christoph Bazil/Eva Blimlinger/Oliver Kühschelm/ Monika Mayer/Anita Stelzl-Gallian/Leonhard Weidinger (Hg.), ... wesentlich mehr Fälle als angenommen. 10 Jahre Kommission für Provenienzforschung (Schriftenreihe der Kommission für Provenienzforschung 1), Wien/Köln/Weimar 2009, 34-47. 
würde dem interdisziplinären Charakter Rechnung tragen und die Provenienzforschung, die sinnvollerweise ein Hybrid aus kunst- und zeithistorischen Inhalten und Methoden darstellt, auch als historisches Fachgebiet klarer sichtbar machen. Schon 2009 klagte Ingo Zechner:

Vom wissenschaftstheoretischen Diskurs ignoriert, von der Geschichtswissenschaft zu Unrecht als eine Angelegenheit der Kunstgeschichte vernachlässigt und von der interessierten Öffentlichkeit als eine Art Geheimwissenschaft mit unaussprechlichem Namen zur Kenntnis genommen $[\ldots] .^{30}$

ForscherInnen selbst haben die Provenienzforschung von Beginn an auch als Tätigkeitsfeld für (Zeit)HistorikerInnen verstanden: Das zahlenmäßige Verhältnis zwischen den Disziplinen war in den ersten Jahren relativ ausgeglichen, im Lauf der Zeit stieg die Zahl der (Zeit)HistorikerInnen in absoluten Zahlen und prozentuell an. ${ }^{31}$ Eine mögliche Begründung dafür könnte in dem Umstand gefunden werden, dass mit dem Ende der Tätigkeit der Historikerkommission im Jahr 2003 zahlreiche HistorikerInnen, die nicht institutionell verankert waren, wieder am freien „Markt“ und auf der Suche nach Jobs waren. ${ }^{32}$ Zudem übernahm mit Eva Blimlinger eine Zeithistorikerin, die Koordinatorin der Historikerkommission gewesen war, 2008 die wissenschaftliche Koordination der Provenienzforschungskommission. ${ }^{33}$ Die

30 Ingo Zechner, Von der Etablierung einer Hilfswissenschaft. Provenienzforschung in den österreichischen Bundesmuseen und Sammlungen, in: Anderl/Bazil/Blimlinger/Kühschelm/Mayer/StelzlGallian/Weidinger (Hg.), ... wesentlich mehr Fälle, 70-84, 70.

31 So waren im Jahr 2000 insgesamt 28 Personen für die Kommission tätig, 11 davon waren HistorikerInnen (39 Prozent), 9 waren KunsthistorikerInnen (32 Prozent) und 8 (29 Prozent) stammten aus anderen Disziplinen oder konnten nicht klar zugeordnet werden. Im Jahr 2010 hatte sich der Anteil an HistorikerInnen auf 16 (53 Prozent) erhöht, 10 Personen waren KunsthistorikerInnen (33 Prozent) und 13 Prozent stammten wiederum aus anderen Disziplinen oder waren nicht zuordenbar. Diese Zahlen basieren auf einer unveröffentlichten Tabelle aller Angehörigen der Provenienzforschungskommission von 1998 bis 2018 (unter Einbeziehung der in den Bundesländern tätigen „kooptierten“ Mitglieder), die von Leonhard Weidinger erstellt wurde. Ich danke Leonhard Weidinger an dieser Stelle für seine Bemühungen und die Zurverfügungstellung der Liste zur Auswertung für den vorliegenden Beitrag. Eine Auflistung aller Kommissionsmitglieder bis 2008 findet sich auch in Anderl/Bazil/Blimlinger/Kühschelm/Mayer/Stelzl-Gallian/Weidinger (Hg.), ... wesentlich mehr Fälle, 543-545.

32 Dies lässt sich anhand mehrerer Mitglieder der Kommission, die zuvor in der Historikerkommission tätig gewesen waren, nachweisen.

33 Gegenwärtig hat die Kommission für Provenienzforschung ihre Verankerung im Bundesministerium für Kunst, öffentlichen Dienst und Sport (BMKÖS). Die administrative Leitung liegt bei der promovierten Zeithistorikerin Pia Schölnberger, die wissenschaftliche Koordination seit 2020 (in Nachfolge von Eva Blimlinger) bei der Autorin des vorliegenden Beitrages. Vorsitzender des 
zeitgeschichtliche Provenienzforschung hat sich in der Zwischenzeit etabliert und in hohem Grade professionalisiert. Nicht zuletzt durch internationale Zusammenarbeit ist es gelungen, eine Spezialisierung und Ausweitung der Methoden zu entwickeln, die die Provenienzforschung zu einer hochspezialisierten historischen Teildisziplin werden ließ. Dem entspricht auch die Gründung eines Arbeitskreises deutschsprachiger ProvenienzforscherInnen, dem mittlerweile mehr als 320 WissenschaftlerInnen angehören. ${ }^{34}$ Neben der konkreten objektbezogenen Arbeit erscheinen aus dem Forschungsfeld regelmäßig wissenschaftliche Publikationen. ${ }^{35}$ Neben den jährlichen Konferenzen, die der Arbeitskreis organisiert, ist die Provenienzforschung auch auf anderen Tagungen präsent, so auch auf den österreichischen Zeitgeschichtetagen. ${ }^{36}$ Zuletzt widmete sich auf dem Zeitgeschichtetag in Wien 2018 ein Panel den neuen Digitalisierungsprojekten in der Provenienzforschung. ${ }^{37}$

\section{Die späten 1990er- und frühen 2000er-Jahre:} Die Historikerkommission der Republik Österreich

Die Etablierung der österreichischen Historikerkommission 1998 steht nicht nur zeitlich in engem Konnex zur Raubkunstdebatte. Die Ereignisse rund um die Be-

Kunstrückgabebeirats ist der Jurist und ehemalige Vorsitzende der Österreichischen Historikerkommission Clemens Jabloner. Vgl. URL: www.provenienzforschung.gv.at (abgerufen 15.09.2020).

$\mathrm{Zu}$ dessen Entstehung vgl. Leonhard Weidinger, Der Arbeitskreis Provenienzforschung e.V., in: Bulletin Kunst \& Recht 6 (2015) 1, 63-65; vgl. weiter die Webseite des Vereins unter URL: https:// arbeitskreis-provenienzforschung.org/ (abgerufen 03.12.2019).

35 Vgl. u. a. die eigene Schriftenreihe der Kommission für Provenienzforschung im Böhlau Verlag, in der bisher acht Bände erschienen sind.

36 Erstmals 2003 am Zeitgeschichtetag in Salzburg. Vgl. Programm 6. Österreichischer Zeitgeschichtetag „,kunst-kommunikation-macht“, Salzburg 28.09.-01.10.2003, Panel 6: NS-Kunstraub in Österreich. Die Akteure und ihre spezifischen ideologischen und materiellen Interessen (Chair: Birgit Kirchmayr, Beiträge: Gabriele Anderl, Gerhard Plasser, Alexandra Caruso, Tina Walzer); Panel 11: Kunst und Macht. Die Makroperspektive oder das Zusammenspiel von Märkten, Behörden und Gesetzen (Chair: Eva Blimlinger, Beiträge: Monika Wulz, Sabine Loitfellner, Sophie Lillie, Peter Melichar, Esther Tisa Francini).

37 Programm 25 Jahre Österreichischer Zeitgeschichtetag „Geschichte wird gemacht“, Wien 05.07.04.2018, Panel 33: Translokationen von Kunst- und Kulturgut unter dem NS-Regime und in der Nachkriegszeit. Projekte zur digitalen Rekonstruktion (Chair: Birgit Kirchmayr, Beiträge: Susanne Hehenberger, Lisa Frank, Meike Hopp, Leonhard Weidinger). Für den 13. Österreichischen Zeitgeschichtetag in Innsbruck 2020 war ebenfalls ein Panel zur Provenienzforschung geplant, das in der (coronabedingten) digitalen Form der Konferenz (1. Virtueller Österreichischer Zeitgeschichtetag 2020) allerdings nicht stattfand. Vgl. Panel 23 des ursprünglichen Programms, URL: https://www. uibk.ac.at/zeitgeschichte/zgt2o/so-war-s-geplant/programm.html.de (abgerufen 15.09.2020). 
schlagnahme der Schiele-Gemälde schärften den Blick für die unaufgearbeitete Thematik des NS-bedingten Vermögensentzugs, gleichzeitig ist die österreichische Situation auch im internationalen Licht zu sehen. Die Zwangsarbeiterentschädigungsdiskussion in Deutschland und die Debatte um die "schlafenden Konten“ in der Schweiz hatten dazu geführt, dass auch österreichischen Banken und Firmen Sammelklagen drohten. Von verschiedener Seite wurde daher die Einrichtung einer Kommission angedacht, die nach Schweizer Vorbild den Komplex des NS-Vermögensentzugs und der Rückstellungspraxis untersuchen sollte. Etabliert wurde die Historikerkommission der Republik Österreich mit 1. Oktober 1998, also in etwa zeitgleich mit der Verabschiedung des neuen Kunstrückgabegesetzes..$^{38}$ Ihr Mandat lautete: „Den gesamten Komplex Vermögensentzug auf dem Gebiet der Republik Österreich während der NS-Zeit sowie Rückstellungen bzw. Entschädigung (sowie wirtschaftliche oder soziale Leistungen) der Republik Österreich ab 1945 zu erforschen und darüber zu berichten. “" ${ }^{39}$ An der Spitze der Historikerkommission stand kein Historiker/keine Historikerin, sondern ein Jurist, der damalige Präsident des Verwaltungsgerichtshofes Clemens Jabloner, als weiteres Mitglied wurde Lorenz Mikoletzky, Generaldirektor des Österreichischen Staatsarchivs, bestellt. Dazu wurden Personen nominiert, die aus der zeit- und wirtschaftsgeschichtlichen Community kamen, so Brigitte Bailer-Galanda, Robert Knight, Bertrand Perz und Roman Sandgruber. Der Jurist Georg Graf, die Wirtschaftshistorikerin Alice Teichova und der Zeithistoriker Karl Stuhlpfarrer wurden schließlich als „Ständige ExpertInnen“ in die Kommission ernannt. Das abgesteckte Forschungsgebiet war überaus umfangreich, es sollten sämtliche Opfergruppen einbezogen und neben Aspekten des Vermögensentzugs auch das Thema der Zwangsarbeit untersucht werden. Lediglich der Bereich der Kunst wurde unter Verweis auf die Kommission für Provenienzforschung ausgespart. Während aber deren Berichte über den Weg des Rückgabebeirats auf Basis des Kunstrückgabegesetzes zu unmittelbaren politischen Restitutionsentscheidungen führen, wurde die Historikerkommission ausschließlich als Forschungseinrichtung etabliert. Ihre Ergebnisse hatten nicht unmittelbar politisch-juristische Konsequen-

38 Zum Hintergrund der Etablierung der Historikerkommission vgl. u. a. Clemens Jabloner/Brigitte Bailer-Galanda/Eva Blimlinger/Georg Graf/Robert Knight/Lorenz Mikoletzky/Bertrand Perz/Roman Sandgruber/Karl Stuhlpfarrer/Alice Teichova, Schlussbericht der Historikerkommission der Republik Österreich. Vermögensentzug während der NS-Zeit sowie Rückstellungen und Entschädigungen seit 1945 in Österreich. Zusammenfassungen und Einschätzungen (Veröffentlichungen der Österreichischen Historikerkommission 1), Wien/München 2003, 17-30.

39 Vgl. die archivierte Webseite der Historikerkommission, URL: https://web.archive.org/ web/20040205043152/http://www.historikerkommission.gv.at/deutsch_home.html (abgerufen 03.12.2019) sowie Bailer-Galanda/Blimlinger, Vermögensentzug, 18. 
zen, wie Eva Blimlinger schreibt: „Die Historikerkommission war weder Gericht noch Verwaltungsbehörde, sie entschied nicht über individuelle Fälle, weder über Rechtsansprüche oder die neue Durchführung von Verfahren noch über die Angemessenheit von Pauschalleistungen. " ${ }^{40}$ Etwa 160 WissenschaftlerInnen, vorwiegend Zeit- und WirtschaftshistorikerInnen sowie JuristInnen arbeiteten von 1998 bis 2003 in etwa 50 Einzelprojekten. Diese reichten von der Untersuchung der „Arisierung des Alltags“ bis zum Versuch einer ökonomischen Gesamteinschätzung. Die Ergebnisse wurden 2003 in Form eines Schlussberichts präsentiert, ebenso die Abschlussarbeiten der Einzelprojekte. ${ }^{41}$

Der NS-bedingte Vermögensentzug und der österreichische Umgang damit nach 1945 waren mit der Arbeit der Historikerkommission nach langen Jahren im Zentrum der zeitgeschichtlichen Forschung in Österreich angekommen. Nicht nur die 47 publizierten Bände der Kommission selbst zeigen das. Auch in Hochschulschriften, anderen Publikationen und auf Tagungen dominierte das Thema in den 20ooer-Jahren. Sowohl im Bereich der angewandten wie auch der Grundlagenforschung waren ZeithistorikerInnen mit einer Spezialisierung zu dieser Thematik gefragt. Neben der Kommission für Provenienzforschung und der Historikerkommission der Republik Österreich waren auch die im Laufe der 1990er- und frühen 2oooer-Jahre geschaffenen Fonds, die sich mit Opferentschädigung befassten (so der 1995 gegründete Nationalfonds, der 2001 gegründete Entschädigungsfonds und der von 2000 bis 2005 tätige Versöhnungsfonds, danach Zukunftsfonds), Arbeits- und Betätigungsfelder für HistorikerInnen. Die Fonds leisten auch nach wie vor wichtige Arbeit in der Vergabe und Förderung von NS-bezogenen Forschungsprojekten.

\section{Und jetzt? Versuch eines Ausblicks}

Zweifellos war der Aspekt des Vermögensentzugs über einen längeren Zeitraum nach Ende der NS-Herrschaft nicht nur von der Gesellschaft, sondern auch von der Forschung in Österreich wenig beachtet worden. Dies mag mehrere Gründe haben, zu denen mit einer gewissen Berechtigung eine Nachrangigkeit materiellen Verlus-

40 Bailer-Galanda/Blimlinger, Vermögensentzug, 19. Die Forschungsergebnisse bildeten aber zum Teil die Grundlage für juristische Maßnahmen, wie zum Beispiel beim Entschädigungsfondsgesetz von 2001. Vgl. ebd., 75-76.

41 Bis Ende 2004 wurden alle Ergebnisse in 49 Bänden als „Veröffentlichungen der Österreichischen Historikerkommission. Vermögensentzug während der NS-Zeit sowie Rückstellungen und Entschädigungen seit 1945 in Österreich“ im Oldenbourg Verlag veröffentlicht. Seit kurzem als Volltext auch online zugänglich, URL: https://hiko.univie.ac.at (abgerufen 15.09.2020). 
tes gegenüber physischer Verfolgung und Vernichtung gezählt werden kann. Andererseits fehlte der gesellschaftspolitische Wille zu einer Restaurierung der Vermögensverhältnisse. „Die Sache in die Länge zu ziehen“ entsprach der vorherrschenden Opferthese, ein zu genaues Hinsehen auf die Umstände und die Folgen von „Arisierung“ hätte für die nach wie vor Nutznießenden des Vermögensentzugs massive Auswirkungen gehabt. Erst langsam änderte sich der gesellschaftliche Zugang.

In dem vorliegenden Beitrag konnte aufgezeigt werden, dass die inhaltlichen Schwerpunktsetzungen und Konjunkturen der Zeitgeschichtsforschung mit dem gesellschaftlichen Wandel relativ parallel einhergingen. Waren in den 1970er-Jahren Arbeiten, die sich Fragen von „Arisierung“ und Rückstellung widmeten, noch äußerst vereinzelt und isoliert anzutreffen, begann sich dies im Laufe der 1980er-Jahre langsam zu wandeln und entwickelte sich schließlich in den späten 1990er-Jahren von einer Forschungslücke zu einem Forschungsboom, der klar in Zusammenhang mit den politischen Entscheidungen zur Etablierung von einschlägigen Forschungskommissionen zu sehen ist. Es kann konstatiert werden, dass in Bezug auf den NS-bedingten Vermögensentzug nicht die Forschung die Avantgarde darstellte, die eine gesellschaftspolitische und juristische Diskussion auslöste, sondern erst die verstärkte gesellschaftspolitische Wahrnehmung und die damit verbundenen politischen Entscheidungen eine Dynamik in die Forschungslandschaft brachten. Diese Feststellung will die Leistung, Unabhängigkeit und Kreativität der Forschung keinesfalls marginalisieren, sondern vielmehr die gesellschaftspolitische Bedeutung von Forschungsförderung klar herausstreichen. Projekte wie die Historikerkommission der Republik, in der etwa 160 ForscherInnen tätig waren, oder die Kommission für Provenienzforschung, der seit 1998 über 8o ForscherInnen angehört haben, sind für Österreich einzigartig und können mit ihrem finanziellen Rahmen natürlich ungleich mehr Forschungsleistung generieren, als dies unter „normalen“ Umständen der Fall ist.

Und jetzt? Alles erforscht, Thema abgeschlossen, Schlussstrich? Zu ihrem zehnjährigen Jubiläum im Jahr 2008 brachte die Kommission für Provenienzforschung einen Band mit dem Titel „... wesentlich mehr Fälle als angenommen“ heraus und spielte damit darauf an, dass sich entgegen anfänglicher Erwartungen, die Kunstrestitutionsfrage innerhalb kurzer Zeit abschließen zu können, die Sache anders entwickelt habe. Der Befund hat sich 2018 zum zwanzigjährigen Bestehen nicht wesentlich geändert. Noch immer wird in den Museen geforscht und noch immer tagt mehrmals jährlich der Kunstrückgabebeirat. Im Gegensatz dazu stellte die Historikerkommission ein zeitlich begrenztes Forschungsprojekt dar. Wenn diese auch viele Forschungslücken schließen konnte, abgeschlossen ist das Thema nicht, kann es nicht sein. Allerdings ist es mit Verweis auf die Arbeit der Historikerkommission 
vermutlich schwieriger geworden, Forschungsprojekte zu NS-bezogenen Themen zu betreiben, und tatsächlich stellte sich in den Jahren nach der Historikerkommission eine gewisse Neuorientierungsfrage in der österreichischen Zeitgeschichtsforschung.

Relevant ist sicherlich auch der Faktor Zeit, das berüchtigte „Ende der ZeitzeugInnen“. Denn berücksichtigt man bei der Forschung zu NS-bedingtem Vermögensentzug und Restitution neben ihrem rein wissenschaftlichen Wert auch den praxisrelevanten Bezug, so stehen wir mittlerweile vor der Situation, dass nur mehr sehr wenige unmittelbare Opfer von NS-Enteignungen leben, bald werden es gar keine mehr sein. Gerade für die Provenienz- und Restitutionsforschung, aber auch im Bereich der Entschädigung der ZwangsarbeiterInnen war es in den 20ooer-Jahren ein wesentlicher Motor, „schnell“ zu forschen, um Betroffene noch zu Lebzeiten entschädigen zu können und/oder Rückgaben durchzuführen. Restituiert wird auch an ErbInnen, dennoch verändert das Ende der ZeitzeugInnen die Dynamik. Es stellt sich daher die Frage, wie sehr es das Forschungsfeld verändern wird, wenn der anwendungsorientierte und politikrelevante Faktor zurückgeht und das Thema zu einem „historischen“ wird. 


\section{Parteien}

Margit Reiter

Historische Parteienforschung, besonders was die Zeit nach 1945 betrifft, hat in der österreichischen Zeitgeschichte keine große Tradition. Vielmehr überließen die ZeithistorikerInnen dieses Forschungsfeld weitgehend der Politikwissenschaft, die jedoch andere methodische und inhaltliche Zugänge wählt und sich stärker auf aktuelle als historische Entwicklungen fokussiert. ${ }^{1}$ Auffallend für Österreich ist zudem, dass die zeithistorische Forschung über die jeweilige Parteigeschichte nicht nur, aber vor allem von den Parteien selbst ausgeht bzw. in ihrem näheren Umfeld (Parteiarchive, Parteiakademien, Bildungsinstitute) durchgeführt wird. Viele Arbeiten zur Geschichte der SPÖ stammen aus dem Verein der Geschichte der Arbeiterbewegung und dem Bruno-Kreisky-Archiv, die Geschichte der ÖVP wird im Karl von Vogelsang-Institut und in der Dr. Wilfried-Haslauer-Bibliothek bearbeitet und zur Geschichte der KPÖ liegen Publikationen der Alfred Klahr Gesellschaft vor. Die Parteigeschichte der FPÖ und ihrer Vorläuferpartei, des Verbands der Unabhängigen (VdU), ist - wie noch aufgezeigt wird - bisher ebenfalls vorwiegend von parteinahen Historikern und ehemaligen politischen Akteuren bearbeitet worden. Da es sich hierbei in vielerlei Hinsicht um Selbstbeforschungen handelt, könnte man von einer Parteigeschichtsschreibung im engeren Sinne sprechen.

Es soll und kann hier kein vollständiger Überblick über den Forschungsstand zur wissenschaftlichen Auseinandersetzung mit den österreichischen Parteien nach 1945 gegeben, sondern lediglich einige Tendenzen benannt werden. Bemerkenswert ist, dass bisher zu keiner der zentralen Parteien der Zweiten Republik umfassende Überblicks- bzw. Gesamtdarstellungen vorliegen, sondern die vorhandenen Arbeiten entweder zeitlich oder thematisch eingeschränkt sind. Neben älteren Darstellungen zum Verhältnis der dominierenden Großparteien ÖVP und SPÖ am Beginn der Zweiten Republik ${ }^{2}$ gibt es einige zeithistorische Arbeiten zur Frühgeschichte der

1 Vgl. exemplarisch die Beiträge in: Herbert Dachs/Peter Gerlich/Herbert Gottweis (Hg.), Handbuch des politischen Systems Österreichs, Wien 1992.

2 Manfried Rauchensteiner, Die Zwei. Die Große Koalition in Österreich 1945 bis 1955, Wien 1987. 
ÖVP ${ }^{3}$ sowie der SPÖ im Kalten $\mathrm{Krieg}^{4}$ und auch die Parteigeschichte der KPÖ 5 sowie des $\mathrm{VdU}^{6}$ ist ansatzweise erforscht. (Auto)Biographische Arbeiten von und über Vertreter der „obersten Staatsspitze“ entscheidend geprägt und sind durch aktuelle biographische Ansätze ergänzt worden. ${ }^{8}$ Nachdem man sich zunächst vor allem mit den „Gründervätern“ beschäftigte, rücken in letzter Zeit auch andere wichtigen AkteurInnen der Zweiten Republik wie beispielsweise Christian Broda oder Rosa Jochmann in den Blick. ${ }^{9}$

In den folgenden Ausführungen wird eine thematische Eingrenzung auf die österreichischen Parteien nach 1945 und ihre wissenschaftliche Auseinandersetzung mit der (NS)Vergangenheit vorgenommen. Nach einem kurzen Abriss über den allgemeinen Umgang der Parteien mit der Vergangenheit werden die unterschiedlichen Versuche einer (erzwungenen oder freiwilligen) Selbstaufarbeitung der Parteigeschichte in Form von Historikerkommissionen - eine österreichische Besonderheit - dargestellt und die darin erzielten Ergebnisse problematisiert. Abschließend werden Forschungsdesiderate in der österreichischen Parteiengeschichtsschreibung aufgezeigt und einige Anregungen für neue Zugänge aus der Sicht der österreichischen Zeitgeschichtsforschung formuliert.

3 Vgl. exemplarisch die Beiträge in: Robert Kriechbaumer/Franz Schausberger (Hg.), Volkspartei. Anspruch und Realität. Zur Geschichte der ÖVP 1945-1995, Wien/Köln/Weimar 1995. Vgl. auch aktuelle Publikationsliste des Karl von Vogelsang-Instituts, URL: http://www.vogelsanginstitut.at/ at/wp-content/uploads/2019/05/publikationsverzeichnis.pdf (abgerufen 09.03.2020).

4 Fritz Weber, Der kalte Krieg in der SPÖ, Wien 2011.

5 Walter Baier, Das kurze Jahrhundert. Kommunismus in Österreich. KPÖ 1918-2008, Wien 2009.

6 Max E. Riedlsperger, The Lingering Shadow of Nazism. The Austrian Independent Party Movement since 1945, Boulder 1978; Lothar Höbelt, Von der vierten Partei zur dritten Kraft. Die Geschichte des VdU, Graz 1999.

7 Exemplarisch dafür Adolf Schärf, Österreichs Erneuerung 1945-1955. Das erste Jahrzehnt der Zweiten Republik, Wien 1955; Karl R. Stadler, Adolf Schärf. Mensch, Politiker, Staatsmann, Wien 1982.

8 Wolfgang Petritsch, Kreisky. Die Biografie, St. Pölten/Salzburg 2010; Birgit Mosser-Schuöcker, Leopold Figl. Der Glaube an Österreich, Wien 2015; Richard Saage, Der erste Präsident. Karl Renner eine politische Biographie, Wien 2016; Siegfried Nasko, Karl Renner - zu Unrecht umstritten? Eine Wahrheitssuche, Salzburg/Wien 2016.

9 Maria Wirth, Christian Broda. Eine politische Biographie, Göttingen/Wien 2010; Veronika Duma, Rosa Jochmann. Politische Akteurin und Zeitzeugin, Wien 2019. 


\section{Der Umgang der österreichischen Parteien mit der Vergangenheit}

Das Jahr 1945 stand unter dem Zeichen des demokratischen Neuanfangs. Das neue Österreich war als bewusste Antithese zur politischen Polarisierung der Ersten Republik und zum Nationalsozialismus gedacht. Die Abgrenzung vom Nationalsozialismus und das Bekenntnis zu Österreich und einer demokratischen Staatsordnung gehörten zu den Grundpfeilern der Zweiten Republik. Die ehemals verfeindeten politischen Gegner aus der Zeit vor 1938, von denen einige in NS-Konzentrationslagern gewesen waren, sollten über alle politischen Gräben hinweg („Lagerstraßenmythos") den demokratischen Wiederaufbau in Angriff nehmen. Der Blick richtete sich nach vorne und nicht zurück in die Vergangenheit.

Wie nach jedem Ende einer politischen Diktatur stellte sich 1945 auch in Österreich die Frage, wie mit den ehemaligen Machthabern und (Mit)TäterInnen zu verfahren sei. Schon in den ersten Wochen der provisorischen Regierungstätigkeit wurden mit dem NS-Verbotsgesetz und dem Kriegsverbrechergesetz die (straf) rechtlichen Grundlagen zur Entnazifizierung geschaffen. Die Entnazifizierung in Österreich war kein einheitlicher Prozess, sondern es wurden in verschiedenen zeitlichen Phasen und verschiedenen Regionen (Besatzungszonen) unterschiedliche Prioritäten gesetzt. ${ }^{10}$ Anders als in Deutschland wurde die Entnazifizierung von den Besatzungsmächten schon bald der österreichischen Regierung (und somit auf die drei Gründerparteien der Zweiten Republik) übertragen.

Wie zeithistorische Studien aufzeigen, dominierte die "Nazifrage“ den öffentlichen und politischen Diskurs der ersten Nachkriegsjahre. Unmittelbar nach der Befreiung war man sich einig, dass die führenden NS-Funktionsträger und NS-TäterInnen zur Rechenschaft gezogen und hart bestraft werden müssten. Die zentrale Streitfrage der Entnazifizierung war, wie man mit der großen Masse der vermeintlichen „Mitläufer" umgehen sollte. Trotz gewisser Nuancen im Detail versuchten sich alle Parteien als Verfechter einer baldigen Reintegration der "kleinen Nazis“ zu profilieren. Die Entscheidung über Ausnahmen von der Registrierung lag in den Händen der Parteien, wobei eine stillschweigende Übereinkunft darüber herrschte, dass jede Partei „ihre“ Leute rehabilitieren wollte. Das entscheidende Mittel dazu bot $\$ 27$ des Verbotsgesetzes, mit dem in Form von Ehrenerklärungen („Persilscheinen“) für bestimmte Personen interveniert wurde. Grundlegende Arbeiten über zeitgenös-

10 Grundlegend dazu Dieter Stiefel, Entnazifizierung in Österreich, Wien/München/Zürich 1981; Sebastian Meissl/Klaus-Dieter Mulley/Oliver Rathkolb (Hg.), Verdrängte Schuld - Verfehlte Sühne. Entnazifizierung in Österreich 1945-1955, Wien 1986; Walter Schuster/Wolfgang Weber (Hg.), Entnazifizierung im regionalen Vergleich, Linz 2004. 
sische Debatten zur „Nazifrage“ in der Öffentlichkeit, im Parlament und im Ministerrat der frühen Nachkriegsjahre belegen eindrücklich, dass diese nachsichtige Entschuldungspraxis und Integrationsbereitschaft bei allen Parteien gleichermaßen an der Tagesordnung war. ${ }^{11}$

Am offensivsten agierte in dieser Hinsicht die ÖVP, die schon im Oktober 1945 für eine bedingungslose Amnestie all jener eintrat, „die unter Zwang und Terror der NSDAP als Mitglied beigetreten waren, ohne sich jemals nationalsozialistisches Gedankengut angeeignet zu haben“" ${ }^{12}$ Während SPÖ und KPÖ für die (befristete) Entziehung des Wahlrechts von allen registrierten ehemaligen NationalsozialistInnen eintraten, wollte die ÖVP zunächst nur die "großen Nazis“ von der Wahl 1945 ausschließen. Da eine derartige Unterscheidung in so kurzer Zeit nicht möglich war, stimmte die Volkspartei einer Exklusion letztendlich zu. ${ }^{13}$ Die grundsätzlich sehr nachsichtige Haltung gegenüber ehemaligen NationalsozialistInnen brachte der ÖVP den Ruf ein, für diese eine „Reinwaschungsanstalt“ zu sein. ${ }^{14}$ Dass der Vorwurf nicht unberechtigt war, zeigen mittlerweile erschienene Teilstudien über die Integrationsaktivitäten der ÖVP in verschiedenen gesellschaftlichen Bereichen (unter anderem den Universitäten), ${ }^{15}$ die historischen Fakten wurden aber - wie noch gezeigt wird - von der ÖVP selbst erst spät und unzureichend aufgearbeitet.

Die Position der SPÖ zur „Nazifrage“ war etwas differenzierter und reichte von einer sehr unnachgiebigen bis hin zu einer gemäßigten, auf „Versöhnung“ ausgerichteten Linie. ${ }^{16}$ Ein Beispiel für eine sehr radikale Haltung, die vor allem im linken

11 Exemplarisch dazu Robert Knight, „Ich bin dafür, die Sache in die Länge zu ziehen.“ Die Wortprotokolle der österreichischen Bundesregierung von 1945 bis 1952 über die Entschädigung, Wien 2000; Siegfried Göllner, Die politischen Diskurse zur „Entnazifizierung“, „Causa Waldheim“ und „EU-Sanktionen“. Opfernarrative und Geschichtsbilder in Nationalratsdebatten, Hamburg 2009; Barbara Serloth, Von Opfern, Tätern und jenen dazwischen. Wie Antisemitismus die Zweite Republik mitbegründete, Wien 2016.

12 Zit. n. Stiefel, Entnazifizierung, 64-65.

13 Ebd., 64-65.

14 Vgl. Walter Manoschek, „Aus der Asche des Krieges wieder auferstanden“. Skizze zum Umgang der Österreichischen Volkspartei mit Nationalsozialismus und Antisemitismus nach 1945, in: Werner Bergmann/Rainer Erb/Albert Lichtblau (Hg.), Schwieriges Erbe. Der Umgang mit Nationalsozialismus und Antisemitismus in Österreich, der DDR und der Bundesrepublik Deutschland, Frankfurt a. M./New York 1995, 49-64.

15 Roman Pfefferle/Hans Pfefferle, Glimpflich entnazifiziert. Die Professorenschaft der Universität Wien von 1944 in den Nachkriegsjahren (Schriften des Archivs der Universität Wien 18), Göttingen 2014.

16 Vgl. Richard Mitten, „Die Sühne ... möglichst milde zu gestalten“. Die sozialdemokratische „Bearbeitung" des Nationalsozialismus und des Antisemitismus in Österreich, in: Bergmann/Erb/Lichtblau (Hg.), Schwieriges Erbe, 102-119. 
Parteiflügel der SPÖ anzutreffen war, stellte das „Sibirien-Plakat“ dar. Auf diesem umstrittenen Wahlplakat von 1945 wurde der Austausch von ehemaligen NationalsozialistInnen mit österreichischen Kriegsgefangenen in sowjetischen Lagern in Sibirien gefordert, wobei sich die Partei aber später von dieser radikalen Forderung distanzierte. ${ }^{17}$ Grundsätzlich verstand die SPÖ die Entnazifizierung als eine Art „Umerziehung“ zur Demokratie nach der Prämisse: „Jeder, der der nationalsozialistischen Propaganda erlegen ist, hat politisch versagt und muß umlernen. “ ${ }^{18}$ Dass dieser Anspruch in der politischen Praxis oft dem Pragmatismus geopfert wurde, ist mittlerweile gut erforscht und war auch Gegenstand der parteiinternen Aufarbeitung, die im Folgenden noch näher ausgeführt wird.

Die KPÖ als dritte Gründungspartei grenzte sich aufgrund ihrer antifaschistischen Tradition klar vom Nationalsozialismus ab, wiewohl auch ihre Haltung gegenüber ehemaligen NationalsozialistInnen nicht frei von Widersprüchen war. ${ }^{19}$ Sie setzte sich von Beginn an für eine umfassende Entnazifizierung ein, unterschied dabei aber zwischen den „großen Nazibonzen“, für die sie Vergeltung und strengste Bestrafung forderte, und den „kleinen Nazis“, als deren Fürsprecherin auch sie auftrat. Im Juli 1949 beantragte die KPÖ im Nationalrat sogar die Vernichtung der Gauakten, um damit einen „Schlußstrich unter die Vergangenheit“ zu ziehen. ${ }^{20}$ Die personelle Integration von ehemaligen NationalsozialistInnen spielte in der KPÖ aber keine nennenswerte Rolle, denn man konnte vor allem auf frühere Führungskader zurückgreifen, die aus dem Widerstand oder aus der Emigration zurückgekehrt waren. Trotz ihrer im österreichischen Vergleich kompromisslosen Haltung kam es auch zwischen der KPÖ und „Ehemaligen“ vereinzelt zu Kontakten. Der wohl weitreichendste Schritt in diese Richtung war die Initiierung und aktive Unterstützung der Nationalen Liga durch die KPÖ, die 1950 gegründet wurde. ${ }^{21}$ An ihrer Spitze stand der Ex-SS-Obersturmbannführer Adolf Slavik und in ihren Reihen waren etliche „Ehemalige“ politisch aktiv, die zwischen dem VdU und der Nationalen Liga pendelten und schließlich in der 1955/1956 gegründeten FPÖ ihre neue politische Heimat fanden. Abgesehen von diesem kurzen Zwischenspiel war die KPÖ allein

17 Stiefel, Entnazifizierung, 71.

18 SPÖ-Abgeordneter Alfred Migsch in der Nationalratssitzung am 27.07.1946, zit. n. Stiefel, Entnazifizierung, 71.

19 Margit Reiter, Zwischen Antifaschismus und Patriotismus. Die Haltung der KPÖ zum Nationalsozialismus, Antisemitismus und Holocaust, in: Bergmann/Erb/Lichtblau (Hg.), Schwieriges Erbe, $176-193$.

20 Reiter, Zwischen Antifaschismus und Patriotismus, 183.

21 Fritz Keller, Stalinistischer Populismus - Die Nationale Liga, in: Anton Pelinka (Hg.), Populismus in Österreich, Wien 1987, 110-122. 
schon aufgrund der ideologischen Differenzen und politischen Bedeutungslosigkeit wenig attraktiv für ehemalige NationalsozialistInnen. Eine (parteiinterne) Aufarbeitung von personellen NS-Kontinuitäten stand aus diesem Grund nie zur Debatte.

Am 9. Oktober 1949 fanden Wahlen zum Nationalrat statt, zu denen erstmals auch die überwiegende Mehrheit der ehemaligen NationalsozialistInnen zugelassen war, die ein enormes Wählerpotenzial darstellten. Demzufolge stand der Wahlkampf 1949 ganz im Zeichen des Buhlens um diese Stimmen, an dem sich sämtliche Parteien beteiligten, vor allem aber der Anfang 1949 eigens dafür gegründete Verband der Unabhängigen. ${ }^{22}$ Der VdU erwies sich als Sammel- und Auffangbecken für all jene NationalsozialistInnen, die sich bewusst nicht in die anderen Parteien integrieren wollten. Zu seiner politischen Hauptagenda zählte der Kampf gegen die Entnazifizierung und für eine Rehabilitierung der „entnazifizierten“ NationalsozialistInnen, die zu seiner Kernklientel zählten. Entgegen bisheriger Darstellungen war der VdU keine wirklich „liberale“ Partei, sondern ging fast vollständig in der 1955/1956 gegründeten FPÖ auf, die von zum Teil schwer belasteten NationalsozialistInnen gegründet wurde und zu einer rechten ideologischen Weltanschauungspartei wurde. ${ }^{23}$ Die personellen und ideologischen NS-Kontinuitäten waren im VdU und in der FPÖ am eindeutigsten, nichtsdestotrotz dauerte es Jahrzehnte, bis sich die freiheitliche Partei - wenn auch erzwungenermaßen und im Ergebnis unzureichend damit auseinanderzusetzen begann.

Mehr noch als die Zeit des Nationalsozialismus standen die Erfahrungen in der Ersten Republik und im austrofaschistischen Ständestaat zwischen den Nachkriegsparteien, besonders zwischen den zwei Großparteien ÖVP und SPÖ. Vor allem der Februaraufstand von 1934, das Verbot der Sozialdemokratischen Partei und die politische Verfolgung und Inhaftierung vieler SozialdemokratInnen durch das austrofaschistische Regime hatten zu einer unüberbrückbaren Kluft zwischen den ehemals verfeindeten politischen Lagern geführt. Auch ein Teil der ehemaligen NationalsozialistInnen, die nach dem NSDAP-Verbot als „Illegale“ teils gewaltsam für den „Anschluss“ gekämpft hatten und in Anhaltelagern interniert worden waren, standen der ÖVP nach 1945 unversöhnlich gegenüber. ${ }^{24}$ Als Nachfolgepartei der Christlichsozialen war vor allem der ÖVP sehr viel am „Zuschütten der Gräben“ und am Ausblenden des Austrofaschismus gelegen. Für die SPÖ hingegen blieb vor

22 Oliver Rathkolb, NS-Problem und politische Restauration. Vorgeschichte und Etablierung des VdU, in: Sebastian Meissl/Klaus-Dieter Mulley/Oliver Rathkolb (Hg.), Verdrängte Schuld - Verfehlte Sühne. Entnazifizierung in Österreich 1945-1955, Wien 1986, 73-99.

23 Margit Reiter, Die Ehemaligen. Der Nationalsozialismus und die Anfänge der FPÖ, Göttingen 2019.

24 Reiter, Die Ehemaligen, 100. 
allem der Februar 1934 ein tiefer und traumatischer Einschnitt, der trotz des gegenseitigen "Schweigeabkommens“ ${ }^{25}$ noch lange als schwelende Wunde nachwirkte und die Vergangenheitsdebatten der folgenden Jahrzehnte mitbestimmte. Die Abgrenzung vom Nationalsozialismus und die damit einhergehende Opferthese waren gewissermaßen der kleinste gemeinsame Nenner, mit deren Hilfe die beiden Großparteien die politischen Gegensätze überbrücken und die man zur Herausbildung einer österreichischen Identität einsetzen konnte. Eine umfassende zeithistorische Aufarbeitung der latent schwelenden Ressentiments und Konflikte aus der Vergangenheit zwischen ÖVP und SPÖ und deren Auswirkungen auf die Politik der Zweiten Republik steht noch aus.

\section{Parteigeschichtsschreibung als (unfreiwillige) Selbsterforschung}

\subsection{SPÖ}

Den Anfang zur Aufarbeitung der eigenen Parteigeschichte machte die SPÖ im April 2000 mit einer Erklärung des designierten SPÖ-Vorsitzenden Alfred Gusenbauer, in der er sich zu Fehlern und Versäumnissen seiner Partei im Umgang mit der NS-Vergangenheit bekannte und bei den Überlebenden entschuldigte. ${ }^{26}$ Anlass für diese selbstkritische Erklärung war der damals heftig diskutierte Fall Gross: Heinrich Gross, ein in die NS-Euthanasie tief verstrickter Arzt, war als Leiter der „Kinderfachabteilung“ am Wiener Spiegelgrund an der Ermordung von Kindern beteiligt gewesen und hatte nach 1945 mithilfe der SPÖ seine steile medizinische Karriere fortsetzen können. Gross, der 1951 dem Bund Sozialistischer Akademiker (BSA) und zwei Jahre später der SPÖ beigetreten ist, wurde einer der bekanntesten Psychiater und bestbezahlten Gerichtsgutachter der Zweiten Republik, obwohl dessen Forschungen auf den Präparaten von ermordeten Kindern basierten. ${ }^{27}$ Seine Tätigkeit im Nationalsozialismus war bereits in den 1970er-Jahren Gegenstand von

25 Anton Pelinka, Von der Funktionalität von Tabus. Zu den „Lebenslügen“ der Zweiten Republik, in: Wolfgang Kos/Georg Rigele (Hg.), Inventur 45/55. Österreich im ersten Jahrzehnt der Zweiten Republik, Wien 1996, 23-33.

26 Gusenbauer bittet um Entschuldigung, Wiener Zeitung, 07.04.2000, URL: https://www.wienerzeitung.at/nachrichten/politik/oesterreich/353141_Gusenbauer-bittet-um-Entschuldigung.html (abgerufen 29.10.2020).

27 Herwig Czech, Der Fall Heinrich Gross, in: Arbeitsgemeinschaft für Wehrdienstverweigerung/Gewaltfreiheit und Flüchtlingsbetreuung/LICRA - Österreich (Internationale Liga gegen Rassismus und Antisemitismus) (Hg.), Siegfrieds Köpfe. Rechtsextremismus, Rassismus und Antisemitismus an der Universität (Context XXI 7-8/1), Wien 2001/2002, 120. 
vereinzelter Kritik gewesen, die aber zunächst folgenlos geblieben war. Nachdem ein Gericht 1981 seine Beteiligung an den Morden am Spiegelgrund festgestellt hatte, wurde Gross aus der Partei ausgeschlossen. In den späten 1990er-Jahren wurde der Fall Gross neu aufgerollt und es kam im Jahr 2000 zu einem Prozess, der allerdings wegen angeblicher Verhandlungsunfähigkeit des Angeklagten auf unbestimmte Zeit unterbrochen und nicht mehr aufgenommen wurde, da Gross 2005 verstarb.

Die SPÖ, die die Nachkriegskarriere des schwer belasteten Mediziners massiv gefördert hatte, geriet durch diesen spektakulären Fall in erheblichen Erklärungsnotstand. Sie zog daraus die Konsequenzen und initiierte eine Aufarbeitung der eigenen Parteigeschichte, die über den Fall Gross hinausgehen und den Umgang der SPÖ mit der NS-Vergangenheit und mit ehemaligen NationalsozialistInnen allgemein durchleuchten sollte. Zu diesem Zweck gab die SPÖ drei historische Studien in Auftrag: Die Aufarbeitung der personellen NS-Kontinuitäten in der SPÖ erfolgte in einer 2005 publizierten Studie über die sogenannten „braunen Flecken“ in der SPÖ ${ }^{28}$ und mit der Untersuchung des Bundes Sozialistischer Akademiker (BSA), die ebenfalls 2005 in Buchform vorlag. ${ }^{29}$ Eine weitere Untersuchung befasste sich mit der Restitution von 1934 entzogenem sozialdemokratischen Parteivermögen und der Rückgabepraxis dieses Vermögens nach 1945, deren Endbericht ebenfalls publiziert wurde. ${ }^{30}$

Die von einem Forschungsteam am Institut für Zeitgeschichte an der Universität Wien durchgeführte Studie über personelle NS-Kontinuitäten wählte einen quantitativen und qualitativen Zugang und basierte auf einem relativ breiten Sample und umfassenden Quellenmaterial. ${ }^{31}$ Untersucht wurden sämtliche Regierungsmitglieder und ParlamentarierInnen (Nationalrat und Bundesrat), alle Mitglieder der Landesregierungen und Landtage, die Mitglieder des Bundesparteivorstandes der SPÖ, der Parteikontrolle sowie einiger zusätzlicher Parteiunterorganisationen und -komitees. Neben einer möglichst vollständigen quantitativen Erfassung aller NSDAPMitglieder in der SPÖ (wobei die begrenzte Aussagekraft einer NSDAP-Mitgliedschaft durchaus kritisch reflektiert wird) finden sich in der Studie ergänzend dazu biographische Skizzen mit exemplarischem Charakter sowie eine qualitative Analyse der Vorgangsweise und Begründungen der Nachkriegs-SPÖ bei der Neu- bzw.

28 Maria Mesner (Hg.), Entnazifizierung zwischen politischem Anspruch, Parteienkonkurrenz und Kaltem Krieg. Das Beispiel der SPÖ, Wien/München 2005.

29 Wolfgang Neugebauer/Peter Schwarz, Der Wille zum aufrechten Gang, Offenlegung der Rolle des BSA bei der gesellschaftlichen Reintegration ehemaliger Nationalsozialisten, Wien 2005.

30 Maria Mesner/Margit Reiter/Theo Venus, Enteignung und Rückgabe. Das sozialdemokratische Parteivermögen in Österreich 1934 und nach 1945, Innsbruck/Wien 2007.

31 Zum Forschungsdesign und zur Quellenbasis vgl. Mesner (Hg.), Entnazifizierung, 2-9. 
Wiederaufnahme von ehemaligen NationalsozialistInnen. Die AutorInnen der Studie ziehen abschließend eine „Zwischenbilanz“32 über die Entnazifizierungspraxis der SPÖ: Unmittelbar nach Kriegsende habe es durchaus eine Bereitschaft gegeben, alle NationalsozialistInnen zu entfernen, die nach den Novemberwahlen 1945 durch die Erkenntnis, dass die ÖVP mit der Strategie der Einbindung besser gefahren sei, jedoch rapide abgenommen habe und einem realpolitischen Pragmatismus gewichen sei. Die quantitative Auswertung der insgesamt 1.021 untersuchten Personen ergab, dass davon 10,3 Prozent Angehörige der NSDAP waren, wobei darunter auch eine erhebliche Prozentzahl (im Durchschnitt 20 Prozent, je nach Bundesländern zwischen ca. 8 und 42 Prozent) „Illegale“ und „Alte Kämpfer“ waren. ${ }^{33}$ Die (Re-) Integration der „Ehemaligen“ in der SPÖ war den AutorInnen zufolge erstens vom Zeitfaktor abhängig, das heißt, mit zeitlichem Abstand zum Kriegsende erhöhte sich die Bereitschaft der Partei zur Integration von ehemaligen NationalsozialistInnen. Zweitens gab es erhebliche regionale Unterschiede, wonach die Vorgangsweise in Wien (wo der linke Flügel der Partei stärker war) strikter war als in den westlichen und südlichen Bundesländern. Oder anders ausgedrückt: Aufgrund der eigenen politischen Schwäche in diesen Regionen nahm die Toleranz gegenüber ehemaligen NationalsozialistInnen mit der Entfernung zu Wien erheblich zu. Und drittens waren immer auch persönliche Bekanntschaften und Netzwerke (aus der Zeit vor 1938) sowie die vermeintliche „Unersetzbarkeit“ in der Parteihierarchie bei der Integration entscheidende Faktoren, die allerdings im selben Ausmaß auch in der ÖVP Gültigkeit hatten.

Die StudienautorInnen weisen zudem auf eine besondere Situation der SPÖ hin, die sich aus der politischen Polarisierung aus der Zeit vor 1938 ergab. Viele SozialdemokratInnen hatten sich nach der Niederlage im Februar 1934 aus unterschiedlichen Gründen den NationalsozialistInnen angeschlossen: sei es aus Enttäuschung über die eigene Parteiführung, aus Hass gegen das austrofaschistische Regime, unter dessen Repressionen sie zu leiden hatten, aus „Anschluss“-Befürwortung oder aus beruflichen Gründen zur Existenzsicherung. Nach 1945 ging es unter anderen um die Frage, wie man mit diesen ehemaligen Parteimitgliedern, die sich nun um eine (Wieder)Aufnahme in die Partei bemühten, umgehen sollte. In der SPÖ war der Nachweis einer Widerstandstätigkeit ein wichtiges Kriterium, oft genügten aber auch nur die Behauptung, „im Auftrag der Partei“ zur NSDAP gegangen zu sein, der Verweis auf äußeren Zwang oder die Sorge um die berufliche Existenz als Entlastungsgrund. Die Situation mochte in Einzelfällen tatsächlich oft sehr komplex und

32 Mesner (Hg.), Entnazifizierung, 337-343.

33 Ebd., 274-275. 
schwer zu entscheiden gewesen sein. Zudem kamen der geringe Kenntnisstand sowie die Schwierigkeit einer Überprüfung der Angaben durch die Betroffenen, wobei Letztere relativ großzügig gehandhabt wurde, wie die zahlreichen konkreten Beispiele in der SPÖ-Studie anschaulich zeigen.

Die große Bereitschaft der SPÖ zur Integration von „Ehemaligen“ zeigte sich vor allem am Beispiel des BSA. Im April 2002 wurde daher das Dokumentationsarchiv des Österreichischen Widerstandes vom BSA-Präsidium mit der Durchführung des Projektes über die Rolle des BSA bei der gesellschaftlichen Reintegration ehemaliger NationalsozialistInnen beauftragt. Die daraus entstandene Publikation „Der Wille zum aufrechten Gang", die 2005 erschien, behandelte nicht nur den in der Öffentlichkeit diskutierten Anlassfall Heinrich Gross, ${ }^{34}$ sondern untersuchte auch zahlreiche andere Fälle von ehemaligen, teils hochrangigen NationalsozialistInnen, die im BSA aktiv waren. Dabei handelte es sich nicht nur um eine quantitative Auswertung des Materials, sondern auch um eine umfassende biographische Dokumentation und qualitative Analyse der Erklärungszusammenhänge.

Der BSA wurde 1946 mit dem Ziel gegründet, Intellektuelle, Akademiker und Fachleute für die SPÖ zu gewinnen und diese in leitende Positionen in der öffentlichen Verwaltung und Wirtschaft einzusetzen. Während die ÖVP 1945 auf viele Führungskräfte von der Zeit vor 1938 zurückgreifen konnte, hatte die Sozialdemokratie durch die politische Exklusion im Austrofaschismus sowie die Vertreibung und Ermordung von jüdischen Führungskräften, Intellektuellen und FunktionärInnen im Nationalsozialismus einen ungeheuren wissenschaftlichen und kulturellen Verlust erlitten. Sie hatte kaum AkademikerInnen, die sie - entsprechend dem Proporzsystem - in Führungspositionen bringen konnte. Anstatt die 1934 bzw. 1938 aus Österreich Vertriebenen zurückzuholen, griff man auch auf ehemalige, zum Teil schwer belastete NationalsozialistInnen zurück, die mithilfe der SPÖ in verschiedenen Bereichen steile berufliche Karrieren machten. ${ }^{35}$

Zusammenfassend kann gesagt werden, dass das Verhältnis der SPÖ zu den „Ehemaligen“ nicht so klar und eindeutig war, wie es sich angesichts ihrer antifaschistischen Tradition vermuten ließe. Zwar grenzte sich die SPÖ nach 1945 von den „Ehemaligen“ klar ab, in der politischen Praxis gab es aber auch hier Annäherungen, die vor allem von Seiten des rechten Parteiflügels um den Parteivorsitzenden Adolf

34 Neugebauer/Schwarz, Wille zum aufrechten Gang, 29-38.

35 Eine Vielzahl von konkreten Beispielen dazu in Neugebauer/Schwarz, Wille zum aufrechten Gang. Vgl. auch Robert Hoffmann, „Bund sozialistischer Anfänger“. Zur Integration bürgerlicher Intellektueller im Salzburger BSA nach 1945, in: Hans Haas/Robert Hoffmann/Robert Kriechbaumer (Hg.), Salzburg. Städtische Lebenswelt(en) seit 1945, Wien/Köln/Weimar 2000, 247-267. 
Schärf und Innenminister Oskar Helmer forciert wurden. ${ }^{36}$ Die Partei handelte dabei oft aus parteistrategischen Überlegungen heraus, manchmal auch aus Überzeugung und immer in Konkurrenz zur ÖVP. Für viele SozialdemokratInnen war die Kluft zur ÖVP, die als Nachfolgepartei des verhassten Austrofaschismus angesehen wurde, unüberwindbar. Viele von ihnen waren in den Jahren 1933-1938 gemeinsam mit illegalen NationalsozialistInnen im Anhaltelager Wöllersdorf eingesessen und konnten sich aufgrund dieser gemeinsamen Repressions- und Gewalterfahrungen auch nach 1945 eine gewisse Kooperation mit den "Ehemaligen“ vorstellen. ${ }^{37} \mathrm{Au}$ ßerdem billigten sie ihnen ausgehend von ihrer Vorstellung der Entnazifizierung als „Umerziehung“ zur Demokratie eine Lernfähigkeit zu und legitimierten damit ihre Vorgangsweise - Bruno Kreisky war das prominenteste Beispiel für diese nachsichtige Haltung in Teilen der Nachkriegssozialdemokratie. Die vergleichsweise gründliche Aufarbeitung der Nachkriegsgeschichte der SPÖ wurde in der Öffentlichkeit breit diskutiert, was allerdings zu einer bemerkenswerten Wahrnehmungsverschiebung führte: Während die „braunen Flecken“ der SPÖ in aller Munde waren und heftig kritisiert wurden, gerieten die personellen und ideologischen NS-Kontinuitäten der anderen Parteien, die noch nicht gründlich aufgearbeitet waren, zunehmend aus dem Blick.

\section{2 ÖVP}

Etwa zeitgleich zur SPÖ unternahm auch die ÖVP erste Versuche, sich mit der eigenen Parteigeschichte in Hinblick auf die NS-Vergangenheit auseinanderzusetzen. Erste Studien des Karl von Vogelsang-Institutes zur Restitution im Zusammenhang mit Liegenschaften und Parteivermögen der ÖVP erschienen Anfang der 2oooerJahre. Darin wurde der Frage nachgegangen, ob beim Eigentumswechsel bestimmter Immobilien zwischen 1938 und 1945 eine "Arisierung" vorlag und ob bzw. inwieweit nach 1945 möglicherweise eine zweifelhafte Rückstellung zugunsten der ÖVP erfolgte..$^{8}$ Die zwischen den damaligen Großparteien vereinbarte Aufarbeitung der

36 Wilhelm Svoboda, Die Partei, die Republik und der Mann mit den vielen Gesichtern. Oskar Helmer und Österreich II. Eine Korrektur, Wien/Köln/Weimar 1993; Wilhelm Svoboda, Franz Olah. Eine Spurensicherung, Wien 1990.

37 Reiter, Die Ehemaligen, 101-107.

38 Doris Sottopietra, „Wiedergutmachung“ und Restitution im Bereich der Parteien und des ÖGB, in: Demokratie und Geschichte. Jahrbuch des Karl von Vogelsang-Institutes zur Erforschung der christlichen Demokratie in Österreich 4 (2000), 230-262; Martin David/Hannes Schönner/Doris Sottopietra/Helmut Wohnout, „Wiedergutmachung“ und Restitution im Bereich der Parteien am 
personellen NS-Kontinuitäten in den jeweils eigenen Parteien ließ von Seiten der ÖVP jedoch auf sich warten. Eine von der Restitutionsforscherin Doris Sottopietra begonnene Erfassung von ÖVP-Parteifunktionären mit einer NS-Vergangenheit wurde der ÖVP zufolge wegen des Todes der Bearbeiterin nicht veröffentlicht und blieb über Jahre in den Schubladen der Volkspartei liegen. Während sich das öffentliche Interesse auf die zwei Studien der SPÖ fokussierte, sah die ÖVP offenbar keinen Anlass, dieses unangenehme Thema von sich aus offensiv weiterzuverfolgen. Erst Jahre später beauftragte die ÖVP den Historiker Michael Wladika mit der Wiederaufnahme der Forschungen und legte mit beträchtlicher Verzögerung im April 2018 einen Endbericht vor. ${ }^{39}$ Dieser Endbericht wurde -anders als die SPÖ-Studie nicht als Buch publiziert, sondern ist auf der Webseite des Vogelsang-Institutes abrufbar, was die geringe öffentliche Wahrnehmung dieser Studie zur Folge hatte.

Nach einer allgemeinen Einführung in die komplexe Materie der NSDAP-Mitgliedschaft und der Entnazifizierung nach 1945 legt der Autor die benutzten Quellen ${ }^{40}$ und den Kreis der untersuchten Personen offen. Die ÖVP-Studie umfasst demnach auf Bundesebene die ÖVP-Regierungsmitglieder, die Parlamentarier (Nationalrat und Bundesrat) sowie auf Landesebene die Mitglieder der einzelnen Landesregierungen, Landtagspräsidenten und Klubobmänner des Landtages im Untersuchungszeitraum von 1945 bis 1980 . Nicht untersucht wurden die ÖVP-Mitglieder der einzelnen Landtage oder andere höhere Parteifunktionäre (zum Beispiel in den ÖVP-nahen Kammern). Der Kreis der Untersuchung war mit insgesamt 560 untersuchten Personen wesentlich enger gefasst als bei der SPÖ. Aus diesem Personenkreis wurden lediglich 63 Personen auf eine mögliche NSDAP-Mitgliedschaft hin überprüft und einer näheren Untersuchung unterzogen. Diese vergleichsweise geringe Zahl ergab sich zum einen aus dem eingegrenzten Sample der Studie und zum anderen aus den der Untersuchung zugrunde liegenden Auswahlkriterien, die sich auf die Registrierung nach 1945 bezogen und nicht - wie in der weitergefassten Studie der SPÖ - auf den Stand von 1938 bis 1945. Diese Vorgehensweise ist in zweierlei Hinsicht problematisch: Zum einen hatten sich viele NationalsozialistInnen

Beispiel der ÖVP, in: Demokratie und Geschichte. Jahrbuch des Karl von Vogelsang-Institutes zur Erforschung der christlichen Demokratie in Österreich 5 (2001), 188-224.

Michael Wladika, Zur Repräsentanz von Politikern und Mandataren mit NS-Vergangenheit in der österreichischen Volkspartei 1945-1980. Eine gruppenspezifische Untersuchung. Forschungsprojekt im Auftrag des Karl von Vogelsang-Institutes, Wien 2018, URL: http://www.vogelsanginstitut.at/at/wp-content/uploads/2019/05/forschungsbericht.pdf (abgerufen 09.03.2020). Darin wird auch die erhebliche Verzögerung der Veröffentlichung begründet, Wladika, Repräsentanz, 5.

NSDAP-Mitgliederkartei, „Gauakten“, Unterlagen der Deutschen Dienststelle für die Benachrichtigung der nächsten Angehörigen von Gefallenen der ehemaligen deutschen Wehrmacht (WASt), Nachlässen und Entnazifizierungsunterlagen, vgl. Wladika, Repräsentanz, 34-44. 
der 1945 vorgeschriebenen Registrierungspflicht entzogen und die darin getätigten Selbstangaben waren keineswegs immer korrekt, sodass damit keine vollständige Erfassung möglich ist. Diesem Argument hält der Studienautor entgegen, dass die Registrierung unter Wahrheitspflicht habe getätigt werden müssen und Falschangaben scharf sanktioniert worden seien.$^{41}$ Zum anderen werden mit dem Fokus auf den Stand 1945 nur die tatsächlichen NSDAP-Mitglieder, aber nicht die „Parteianwärter" erfasst, obwohl die Parteianwärterschaft gerade für die Klientel der ÖVP eine besonders große Rolle spielte: Nach dem „Anschluss“ 1938 hatten sich viele aus dem konservativen und christlichsozialen Lager (aus welchen Gründen auch immer) um eine Aufnahme in die NSDAP bemüht, waren aber aufgrund ihrer politischen Vorgeschichte (Nähe zum austrofaschistischen System, zum Landbund und Ähnliches) als „politisch nicht zuverlässig“ eingestuft und somit oft abgelehnt worden.

Die Studie kommt zu dem Ergebnis, dass von den insgesamt 63 untersuchten ÖVP-Funktionären 36 eine NSDAP-Mitgliedschaft aufgewiesen haben (davon 6 „Alte Kämpfer“ und „Illegale“) und 17 Personen als „Zweifelsfälle“ eingestuft werden müssten. Die Studie geht bei der Einstufung der „Zweifelsfälle“ allerdings überaus nachsichtig vor, wie sich am Beispiel des NSDAP-Mitgliedes und späteren Finanzministers Reinhard Kamitz exemplarisch zeigt. ${ }^{42}$ Ein überraschendes Ergebnis ist, dass sowohl die Zahl der integrierten „Alten Kämpfer“ und „Illegalen“ als auch die Anzahl der SS-Angehörigen in der ÖVP höher gewesen sei als bei der SPÖ, ${ }^{43}$ was der öffentlichen Wahrnehmung erheblich widerspricht. Beim direkten Vergleich mit den Ergebnissen der SPÖ-Studie, der leicht zugunsten der Volkspartei ausfällt (9,6 Prozent NSDAP-Mitglieder) ${ }^{44}$, werden die Unzulänglichkeiten des methodischen Zugangs der ÖVP-Studie offensichtlich. Zum einen ist eine verlässliche Vergleichbarkeit aufgrund des unterschiedlichen Samples und des großzügigen Umgangs mit den „Zweifelsfällen“ nicht gegeben, zum anderen verzerrt auch die Exklusion von Parteianwärtern das Ergebnis. Von einem „Gleichstand“ zu sprechen, wie es die ÖVP-Studie suggeriert, ${ }^{45}$ greift zu kurz.

Hier zeigt sich einmal mehr, dass sich ein rein quantitativer Zugang wissenschaftlich als wenig ergiebig erweist und vor allem kaum Erklärungsansätze bietet. Es wird dabei ausgeklammert, dass die ÖVP, als unmittelbare Nachfolgerin der Christlichsozialen Partei, nach 1945 auf die politische Elite der Zeit vor 1938 zurückgreifen

41 Wladika, Repräsentanz, 49.

42 Ebd., 56, 82-91.

43 In der ÖVP: Illegale und Alte Kämpfer 6 plus 10 „Zweifelsfälle“ (= 16,7 bis 44,4 Prozent der untersuchten Fälle); SS-Angehörige in der ÖVP: 13 Personen; vgl. Wladika, Repräsentanz, 56-58.

44 Wladika, Repräsentanz, 58-62.

45 Ebd., 61. 
konnte und es sehr wohl personelle und teilweise auch ideologische Kontinuitäten gab. Viele ehemalige politische Funktionsträger aus dem Austrofaschismus nahmen erneut Führungspositionen in der Politik, Wirtschaft, Bürokratie, Justiz und Wissenschaft ein, und es kam zu einer personellen Restauration. Dadurch war die ÖVP weniger als die SPÖ auf ehemalige NationalsozialistInnen angewiesen, was sie jedoch nicht daran hinderte, sich ebenso massiv um dieses Wählerpotenzial zu bemühen. Durch einen rein quantitativen Zugang geraten die durchaus bestehende ideologische Nähe sowie die Kooperationsversuche der ÖVP mit „Ehemaligen“ aus dem Blick. Wie Matthias Falter herausgearbeitet hat, war das Verhältnis der ÖVP zu den „Ehemaligen“ (und umgekehrt) im ersten Nachkriegsjahrzehnt überaus ambivalent und sowohl von Konkurrenz als auch von Kooperation geprägt gewesen. ${ }^{46}$ Während der Antiklerikalismus und die Repressionserfahrungen im Austrofaschismus für viele „Ehemalige“ ein unüberwindbares Hindernis für eine Zusammenarbeit mit der ÖVP waren, bildete der Antimarxismus das zentrale verbindende ideologische Element zwischen diesen Parteien. Der bekannteste Versuch einer politischen Kooperation war das Treffen von Oberweis im Mai 1949, bei dem sich die ÖVP-Spitze mit hochkarätigen ehemaligen Nationalsozialisten auf eine politische Zusammenarbeit verständigen wollte, was letztendlich jedoch an den überzogenen Forderungen der „Ehemaligen“ scheiterte. ${ }^{47}$ Doch es gab auch noch weitere konkrete Versuche zur politischen Zusammenarbeit, wie etwa die Koalitionsverhandlungen 1953 der ÖVP mit dem VdU, die letztendlich am Veto des Bundespräsidenten Theodor Körner scheiterten, oder der gemeinsame ÖVP-FPÖ-Kandidat Wolfgang Denk bei den Bundespräsidentenwahlen $1957^{48}$ sowie Kontakte einzelner ÖVP-Politiker wie etwa Alfons Gorbach und Josef Krainer sen. mit ausgewiesenen „Ehemaligen“ im Rahmen des sogenannten Ennstaler Kreises. ${ }^{49}$ Dass gerade auf Landesebene und in den verschiedenen Bünden der ÖVP zahlreiche ehemalige belastete NationalsozialistInnen aktiv waren, zeigt exemplarisch der Fall des NS-Täters Franz Murer („Schlächter von Wilna"), der nach 1945 als Bezirksbauernvertreter im Bezirk Liezen in der Steiermark fungierte..$^{50}$ Auch der antisemitische Professor Taras Borodajkewycz, der sich nach 1945 als parteipolitischer Grenzgänger zwischen dem nationalen und

46 Matthias Falter, Zwischen Kooperation und Konkurrenz. Die „Ehemaligen“ und die Österreichische Volkspartei, in: zeitgeschichte 44 (2017) 3, 160-174.

47 Falter, Zwischen Kooperation, 162-163.

48 Reiter, Die Ehemaligen, 235-239.

49 Falter, Zwischen Kooperation, 167.

50 Johannes Sachslehner, „Rosen für den Mörder“. Die zwei Leben des NS-Täters Franz Murer. Wien 2017; vgl. auch den Spielfilm von Christian Frosch, Murer - Anatomie eines Prozesses, Österreich 2017. 
katholischen Lager erwies, landete nach seinem politischen Zwischenspiel bei dem VdU bzw. der FPÖ schließlich bei der ÖVP, mit deren Hilfe er eine Professur an der Hochschule für Welthandel erhielt. ${ }^{51}$ Solche in die Volkspartei integrierten schwer belasteten NationalsozialistInnen scheinen in der ÖVP-Studie nicht auf.

\section{$2.3 \mathrm{VdU}$ und FPÖ}

Obwohl der VdU und die frühe FPÖ das Auffang- und Sammelbecken für viele ehemalige NationalsozialistInnen schlechthin waren, ließ die Aufarbeitung ihrer Geschichte am längsten auf sich warten. Die meisten Arbeiten zum VdU und zur FPÖ entstanden zunächst im Umfeld der Freiheitlichen und waren aufgrund der politischen und persönlichen Parteinähe der Autoren stark affirmativ und verharmlosend angelegt. ${ }^{52}$ Sie sind ebenso kritisch zu hinterfragen wie die retrospektiven (Selbst) Darstellungen früherer VdU-Politiker wie Herbert Kraus und Viktor Reimann, deren Geschichtsdeutung vom „liberalen“ VdU im Gegensatz zur „nationalen“ FPÖ lange Zeit unkritisch reproduziert wurde. ${ }^{53}$ In all diesen Arbeiten werden Fragen nach dem Verhältnis zum Nationalsozialismus und zu personellen und ideologischen NS-Kontinuitäten entweder gar nicht thematisiert oder bagatellisiert. ${ }^{54} \mathrm{Ab}$ den 1980er-Jahren wurde das Näheverhältnis der FPÖ zum Rechtsextremismus und zur FPÖ unter Jörg Haider und dessen problematisches Verhältnis zum National-

51 Heinz Fischer, Einer im Vordergrund. Taras Borodajkewycz. Dokumente. Berichte. Analysen, Wien 2015.

52 Kurt Piringer, Der VdU. Verband der Unabhängigen 1949-1955. Eine Dokumentation, Wien 1999; Kurt Piringer, Die Geschichte der Freiheitlichen. Beitrag der Dritten Kraft zur österreichischen Politik, Wien 1982; Höbelt, Von der vierten Partei; Lothar Höbelt (Hg.), Aufstieg und Fall des VdU. Briefe und Protokolle aus privaten Nachlässen 1948-1955 (Schriftenreihe des Forschungsinstitutes für politisch-historische Studien der Dr. Wilfried-Haslauer-Bibliothek 50), Köln/Wien/Weimar 2015; Dieter Grillmayer, National und Liberal. Die Geschichte der Dritten Kraft in Österreich, Wien 2006; Gerhard Steininger, Das Dritte Lager. Aufstieg nach dem Fall?, Wien 2007.

53 Herbert Kraus, Untragbare Objektivität. Politische Erinnerungen 1917 bis 1987, Wien/München 1988; Viktor Reimann, Die Dritte Kraft in Österreich, Wien 1980.

54 Einige Ansätze dazu bei Roland Stäuber, Der Verband der Unabhängigen (VdU) und die Freiheitliche Partei (FPÖ). Eine Untersuchung über die Problematik des Deutschnationalismus als Einigungsfaktor einer politischen Partei in Österreich seit 1945, St. Gallen 1974; Kurt Richard Luther, Zwischen unkritischer Selbstdarstellung und bedingungsloser externer Verurteilung. Nazivergangenheit, Antisemitismus und Holocaust im Schrifttum der Freiheitlichen Partei Österreichs, in: Bergmann/Erb/Lichtblau (Hg.), Schwieriges Erbe, 138-167. 
sozialismus in vielen kritischen Publikationen behandelt. ${ }^{55}$ Mit der weiteren Entwicklung in der FPÖ unter Parteiobmann Heinz Christian Strache, vor allem mit dessen neonazistischen Aktivitäten in seiner Jugend und dem zunehmenden Einfluss deutschnationaler Burschenschafter in der FPÖ befassten sich ebenfalls etliche Sachbücher. ${ }^{56}$ Bis zum Erscheinen meines Buches „Die Ehemaligen“ im September 2019 gab es somit keine wissenschaftlich fundierte und quellenbasierte Studie zur Frühgeschichte der FPÖ und zu den personellen und ideologischen NS-Kontinuitäten in dieser Partei. Diese Publikation, der bereits einige publizierte Vorstudien vorausgingen, ${ }^{57}$ fiel genau in jene Zeit, als sich auch die FPÖ - mittlerweile eine Regierungspartei - gezwungen sah, sich mit ihrer eigenen Geschichte auseinanderzusetzen.

Die FPÖ war mit der Aufarbeitung ihrer Parteigeschichte am spätesten dran, und diese erfolgte nur durch äußeren Druck. Unmittelbarer Anlass war die Anfang des Jahres 2018 bekannt gewordene „Liederbuch-Affäre“, die zeigte, dass in den schlagenden Burschenschaften Germania und Bruna Sudetia, in denen auch führende FPÖ-Funktionäre vertreten sind, Liederbücher mit antisemitischen und rassistischen Inhalten kursierten..$^{58}$ Die „Liederbuch-Affäre“ kam der FPÖ kurz nach ihrem Eintritt in die Regierung Ende 2017 äußerst ungelegen. Der damalige Parteiobmann Strache, der sich früher in Neonazikreisen bewegt hatte und nunmehr besonders seriös und staatsmännisch gab, kündigte die Aufarbeitung der Geschichte der FPÖ

55 Vgl. exemplarisch Brigitte Bailer/Wolfgang Neugebauer, Die FPÖ. Vom Liberalismus zum Rechtsextremismus, in: Dokumentationsarchiv des Österreichischen Widerstandes (Hg.), Handbuch des österreichischen Rechtsextremismus, Wien 1993, 327-428; Brigitte Bailer-Galanda, Haider wörtlich. Führer in die Dritte Republik, Wien 1995; Christa Zöchling, Haider. Licht und Schatten einer Karriere, Wien 1999.

56 Nina Horaczek/Claudia Reiterer, HC Strache. Sein Aufstieg, seine Hintermänner, seine Feinde, Wien 2009; Hans-Henning Scharsach, Stille Machtergreifung. Hofer, Strache und die Burschenschaften, Wien 2017; Hans-Henning Scharsach, Strache. Im braunen Sumpf, Wien 2012.

Margit Reiter, Inklusion und Exklusion. Zur politischen Formierung ehemaliger NationalsozialistInnen im Verband der Unabhängigen (VdU) und in der frühen FPÖ, in: zeitgeschichte 44 (2017) 3, 143-159; Margit Reiter, Die „Ehemaligen“ nach 1945 - Selbstpräsentationen, Antisemitismus und Antiamerikanismus, in: Lucile Dreidemy/Richard Hufschmied/Agnes Meisinger/Berthold Molden/Eugen Pfister/Katharina Prager/Elisabeth Röhrlich/Florian Wenninger/Maria Wirth (Hg.), Bananen, Cola, Zeitgeschichte: Oliver Rathkolb und das lange 20. Jahrhundert, Festschrift für Oliver Rathkolb, 2 Bde., Wien/Köln/Weimar 2015, 575-589; Margit Reiter, Anton Reinthaller und die Anfänge der Freiheitlichen Partei Österreichs (FPÖ). Der politische Wiederaufstieg eines Nationalsozialisten und die „Ehemaligen“ in der Zweiten Republik: in: Vierteljahreshefte für Zeitgeschichte 66 (2018) 4, 539-575.

58 Margit Reiter, Die FPÖ und die Vergangenheit, die nicht vergeht, in: Thomas Hofer/Barbara Tóth (Hg.), Wahl 2019. Strategien, Schnitzel, Skandale, Wien 2019, 247-257. 
an. Außerdem hielt er im Januar 2018 auf dem alljährlichen Ball des Wiener Korporationsrings („Akademikerball“) eine bemerkenswerte Rede, bei der er sich vor versammeltem freiheitlichen und rechtsextremen Publikum vom Antisemitismus abgrenzte. ${ }^{59}$ Während der Parteiobmann sich öffentlich um Distanzierung bemühte, beruhigte der nationale FPÖ-Ideologe Andreas Mölzer parteiintern die Gesinnungsgenossen, dass die Einsetzung der Kommission lediglich als „taktisches Manöver“ zur Beruhigung der Lage gedacht sei. Damit bediente sich die FPÖ ihrer bewährten Doppelstrategie: Sie setzt nach außen und nach innen hin unterschiedliche Signale, was zu einer klassischen Doppelzüngigkeit (double speak) führt, die sich - wie ich nachweisen konnte - durch die gesamte Geschichte der FPÖ zieht. ${ }^{60}$

Die vom ehemaligen Universitätsprofessor und FPÖ-Politiker Wilhelm Brauneder geleitete FPÖ-„Historikerkommission“ stieß wegen ihrer mangelnden Transparenz, selektiven Fragestellung und der beteiligten Personen in der Öffentlichkeit und Scientific Community von Beginn an auf einhellige Skepsis und Kritik. ${ }^{61}$ Vor allem die personelle Zusammensetzung der „Historikerkommission“, die aus FPÖParteihistorikern, Theologen, rechtsgerichteten Journalisten und freiheitlichen Parteifunktionären bestand, wurde kritisiert. Um den Schein der Objektivität zu wahren, griff man auch auf den ehemaligen sozialdemokratischen Wiener Stadtschulrat Kurt Scholz sowie auf die Historiker Stefan Karner und Michael Wladika zurück, die politisch der ÖVP zugeordnet werden. Diese von der Volkspartei initiierte Kooperation legte das Interesse des Koalitionspartners offen, die permanenten, die Regierungsarbeit störenden Diskussionen über die NS-Affinität der FPÖ aus der Welt zu schaffen.

Nach dem unfreiwilligen Abgang von Strache und dem Austritt der FPÖ aus der Regierung im Mai 2019 präsentierte sie im August 2019 einen vorläufigen „Rohbericht“, der einen Einblick in den noch nicht abgeschlossenen Endbericht liefern sollte. Das von FPÖ-Funktionären vorgestellte Papier las sich nicht wie ein wissenschaftlicher Historikerbericht, sondern wie eine Rechtfertigungs- und Verteidigungsschrift der Partei. Das vorläufige „Ergebnis“ der Kommission gipfelte in der Feststellung, dass der VdU und die FPÖ „formell keine Nachfolgepartei der NSDAP“ gewesen

59 Strache will keine Antisemiten am Akademikerball, Kurier, 26.01.2018, URL: https://kurier. at/politik/inland/strache-will-keine-antisemiten-am-akademikerball/308.372.897 (abgerufen 18.08.2020).

60 Reiter, Die Ehemaligen.

61 Vgl. Transparenz statt Diskretion! Stellungnahme am Österreichischen Zeitgeschichtetag 2018 an der Universität Wien zur sogenannten FPÖ-Historikerkommission, openPetition, URL: www. openpetition.eu/at/petition/online/transparenz-statt-diskretion-fpoe-historikerkommission (abgerufen 09.03.2020). 
seien und „auch nicht [...] politisch die Wiedererrichtung eines nationalsozialistischen Regimes“ angestrebt hätten. Damit wurde etwas dementiert, was niemand je behauptet hatte und aufgrund des NS-Verbotsgesetzes von 1945 rechtlich auch nicht möglich gewesen wäre. ${ }^{62}$ Zwar gestand man ein, dass es in der FPÖ ehemalige NationalsozialistInnen gegeben habe, doch mit dem Verweis auf die „braunen Flecken“ in ÖVP und SPÖ folgten die übliche Nivellierung und Relativierung auf dem Fuße. Angesichts der offenkundigen inhaltlichen Lücken, Verharmlosungen und Ausweichmanöver hagelte es in der Öffentlichkeit und in der Fachwelt flächendeckend Kritik. Die Ankündigung der FPÖ, sich den Bericht durch einen israelischen Forscher absegnen zu lassen - sich gewissermaßen einen „Kosher-Stempel“ zu holen -, wurde von renommierten Historikern wie Moshe Zimmermann als problematische und durchschaubare „Alibi-Aktion“ gewertet. ${ }^{63}$

Nach mehrmaligem Verschieben wurde der erweiterte Endbericht am 23. Dezember 2019, unmittelbar vor Weihnachten, in einer „Hauruck-Aktion“ (Andreas Mölzer) der Öffentlichkeit präsentiert. ${ }^{64}$ Der Bericht bot wenig Neues und reproduzierte die bereits im „Rohbericht“ formulierten Ergebnisse. Wie sich zeigte, basierte er im Wesentlichen auf der vorhandenen Sekundärliteratur aus dem Umfeld der Partei, wohingegen neue Archivquellen und neuere wissenschaftliche Arbeiten kaum in die Analyse mit einflossen. Dies betraf auch das Kapitel von Michael Wladika über ehemalige NationalsozialistInnen im VdU und in der FPÖ, das als „Herzstück“ des Berichts bezeichnet wurde, aber abgesehen von einigen biographischen Abrissen über zentrale politische Akteure die bisherige Parteigeschichtsschreibung weitgehend fortschrieb. ${ }^{65}$ Die angekündigte quantitative Erfassung und statistische Auswertung ehemaliger NationalsozialistInnen im VdU und der FPÖ fehlt darin ebenso wie eine noch ausstehende Auswertung der Entnazifizierungs- und Volksgerichtsverfahren prominenter Repräsentanten des „Dritten Lagers“.

Der an der ÖVP-Studie orientierte rein quantitative Zugang greift auch hier zu kurz und müsste um eine qualitative Analyse erweitert werden. Wie man aus der

62 Reiter, FPÖ und die Vergangenheit, 251.

63 Israelischer Forscher zu FPÖ-Bericht, Der Standard, 12.08.2019, URL: https://www.derstandard. at/story/2000107296499/israelischer-forscher-zu-fpoe-bericht-autoren-sind-nicht-die-leuchttuerme (abgerufen 18.08.2020).

64 Freiheitliches Bildungsinstitut (Hg.), Bericht der Historikerkommission. Analysen und Materialien zur Geschichte des Dritten Lagers und der FPÖ, Wien 2019, URL: https://www.fpoe.at/fileadmin/ user_upload/www.fpoe.at/dokumente/2019/PDFs/Buch-Historikerkommission-Web.pdf (abgerufen 09.03.2020) [künftig: FPÖ-Bericht].

65 Michael Wladika, Die NS-Vergangenheit der Funktionäre des „Verbandes der Unabhängigen“ (VdU) und der frühen „Freiheitlichen Partei Österreich““ (FPÖ), in: Freiheitliches Bildungsinstitut (Hg.), FPÖ-Bericht, 39-91. 
mittlerweile sehr differenzierten Täterforschung weiß, kann das (Bewertungs)Kriterium nicht allein eine NSDAP-Mitgliedschaft sein, sondern es geht um die konkreten Aktivitäten und Verantwortlichkeiten im NS-System ebenso wie um die Haltung der "Ehemaligen“ im VdU und in der FPÖ zum Nationalsozialismus nach 1945. Solche Differenzierungen sind nötig, waren doch manche der unbelehrbarsten Antisemiten im VdU und in der FPÖ (wie zum Beispiel Fritz Stüber) keine NSDAPMitglieder, wohingegen andere frühere NationalsozialistInnen und spätere Freiheitliche nicht mehr einschlägig aktiv waren und möglicherweise sogar einen gewissen Lernprozess durchgemacht hatten.

Auch sonst geht der Bericht der FPÖ im Wesentlichen kaum über die bisherige Parteigeschichtsschreibung hinaus. Lothar Höbelt reproduziert darin einmal mehr die parteiinterne Legende vom Parteigründer Anton Reinthaller als "guten Nazi“, indem er unkritisch die Entlastungsschreiben aus seinem Volksgerichts-Prozess in den 1950er-Jahren (wonach er vereinzelt politischen NS-Gegnern geholfen habe) übernimmt und dessen SS-Rang als vollkommen bedeutungslos abtut. Dabei war Reinthaller bereits 1928 der NSDAP beigetreten und muss als „Illegaler" und hoher NS-Multifunktionär als ideologisch überzeugter Nationalsozialist gelten. Seine möglichen Verantwortlichkeiten im NS-System (zum Beispiel im Bereich der „Arisierung" und Zwangsarbeit in der Landwirtschaft) werden nicht untersucht. Die Erkenntnisse meiner 2018 in den „Vierteljahresheften für Zeitgeschichte“ erschienenen Studie zu Reinthaller, ${ }^{66}$ wonach dieser auch nach 1945 den Nationalsozialismus partiell guthieß und ein antisemitisches Weltbild vertrat, wird weitgehend ignoriert. Vielmehr wird Reinthallers aktive Rolle bei der Gründung der FPÖ wiederholt beschönigend als Beitrag zur Demokratie dargestellt und Reinthaller ohne entsprechende Belege als „bester Garant gegen eine Radikalisierung der Ehemaligen" bezeichnet. ${ }^{67}$

Der Beitrag über die Burschenschaften (als eigentlicher Anlass der Aufarbeitung) beschäftigt sich vor allem mit der Geschichte vor 1938, wohingegen eine Analyse der bestehenden ideologischen Kontinuitäten (zum Beispiel des Deutschnationalismus und Antisemitismus) nach 1945 in den Burschenschaften ausbleibt. Die umfangreiche Studie von Bernhard Weidinger zu den Burschenschaften liefert dazu zahlreiches Quellenmaterial, wird aber im FPÖ-Bericht nicht rezipiert. ${ }^{68}$ Abgesehen davon finden sich im Bericht viele Beiträge zu marginalen Aspekten (Wehrpolitik,

66 Reiter, Reinthaller.

67 Freiheitliches Bildungsinstitut (Hg.), FPÖ-Bericht, 119.

68 Bernhard Weidinger, „Im nationalen Abwehrkampf der Grenzlanddeutschen“. Akademische Burschenschaften und Politik in Österreich nach 1945, Wien/Köln/Weimar 2015. 
Wahrnehmung der FPÖ in der Sowjetunion usw.), die eigentlich nicht zur Debatte standen und sich letztendlich als wortreiche Ausweichmanöver erweisen, um die „eigentlichen“ qualitativen Fragen durch Quantität zuzudecken.

Insgesamt ist vor allem aufschlussreich, was in dem FPÖ-Bericht nicht vorkommt und welche Leerstellen es in den einzelnen Beiträgen gibt. Was fehlt, ist zum Beispiel eine kritische Analyse der führenden Akteure im VdU und in der FPÖ hinsichtlich ihrer Haltung zum Nationalsozialismus nach 1945 und die vielfältigen personellen und ideologischen Verflechtungen mit rechten und rechtsextremen Akteuren und Vereinen. Die selbstformulierte Zielvorgabe, das gesamte „Dritte Lager“ zu untersuchen, wozu das „Ehemaligen“-Milieu in der Nachkriegszeit ebenso gehört wie die aktuellen Verbindungen zu rechtsgerichteten Burschenschaften und Vereinen (zum Beispiel den Identitären) wird nicht erreicht. Eine weitere Leerstelle ist die Problematisierung des Antisemitismus in der FPÖ (und in ihrem Umfeld), der ein konstitutives Element der freiheitlichen Partei war und ist, wie der eigentliche Anlass für die FPÖ-Kommission, die „Liederbuch-Affäre“, deutlich vor Augen geführt hat. Die Antisemitismusforschung wird im FPÖ-Bericht nicht rezipiert und somit auch Arbeiten über Kontinuitäten und Modifikationen (Codes, Anspielungen, double speak) von Antisemitismus in der Geschichte der FPÖ vollkommen ignoriert. ${ }^{69}$

Darüber hinaus fehlt ein quantitativer und faktenbasierter Vergleich mit den übrigen Parteien nach 1945, der die wahren Relationen wieder zurechtrücken könnte. Bei der ÖVP und der SPÖ handelt es sich um große, historisch gewachsene Parteien mit einem klaren politischen Profil und einer traditionellen Wählerstruktur, in die nach 1945 auch NationalsozialistInnen Platz fanden. In ihrem Fall kann man tatsächlich - wie umgangssprachlich üblich - von „braunen Flecken“ sprechen. Nicht so im Fall von VdU und FPÖ: Sie waren von ihrem Selbstverständnis, ihrer Programmatik und ihrer personellen Zusammensetzung her das parteipolitische Sammelbecken ehemaliger NationalsozialistInnen schlechthin - und zwar vor allem für jene besonders „Gesinnungstreuen“ unter ihnen, die sich von den vermeintlichen „Opportunisten“, die sich an die anderen Parteien anpassten, strikt abgrenzten. In dieser Hinsicht war die FPÖ keineswegs „eine Partei wie jede andere auch“, wie sie für sich beansprucht. Zwar räumt man im Abschlussbericht einmal ein, dass sich in der FPÖ „mehr als bei den anderen Parteien ehemalige Nationalsozialisten in Führungspositionen befanden“, dieser unleugbare Befund wird allerdings im Vorwort

69 Vgl. exemplarisch Anton Pelinka/Ruth Wodak (Hg.), „Dreck am Stecken“, Politik der Ausgrenzung, Wien 2002; Margit Reiter, Antisemitismus in der FPÖ und im „Ehemaligen“-Milieu nach 1945 in Österreich, in: Jahrbuch für Antisemitismusforschung 27 (2018), 117-149. 
mit der abschwächenden Formulierung „wahrscheinlich mehr" umgehend wieder relativiert. ${ }^{70}$

Alles in allem kamen sowohl ausgewiesene ExpertInnen aus dem akademischen Feld als auch die breite Öffentlichkeit zu dem Schluss, dass der FPÖ„Historikerbericht" keinen substanziellen und selbstkritischen Beitrag zur Erforschung der Geschichte der FPÖ geleistet hat und den wirklich interessanten und strittigen Fragen ausgewichen ist. ${ }^{71}$

\section{Forschungsdesiderata}

Wie eingangs ausgeführt, gibt es bis heute für keine der wichtigen österreichischen Parteien eine Gesamtdarstellung, die eine zeithistorische Perspektive einnimmt und die gesamte Zweite Republik umfasst. Dieser Sachverhalt kann als das zentrale Forschungsdesiderat der zeithistorischen Parteienforschung gelten. Was den Umgang der Parteien mit dem Nationalsozialismus betrifft, wären auf Basis der vorhandenen Literatur eine Weiterführung bisheriger quantitativer Zugänge (die aufgrund der zum Teil lückenhaften empirischen Basis ebenfalls noch ausbaufähig sind) und eine Verlagerung hin zu einer qualitativen Erforschung wünschenswert.

Im Folgenden werden einige mögliche weiterführende Forschungsansätze benannt:

Erstens: Erforschung der politischen Akteure und Akteurinnen, was ihre Rolle sowohl im Nationalsozialismus als auch nach 1945 in den jeweiligen Parteien betrifft. In Form von biographischen Studien können personelle Kontinuitäten über drei politische Systeme (Erste Republik/Austrofaschismus, Nationalsozialismus, Zweite Republik) in den Blick genommen werden. Vor allem eine (bisher oft nicht erfolgte) Miteinbeziehung der Zeit vor 1938 kann in vielerlei Hinsicht neue Perspektiven eröffnen, wie ich am Beispiel von Anton Reinthaller exemplarisch aufzeigen konnte. ${ }^{72}$ Außerdem sollten auch kollektivbiographische Zugänge forciert werden, um auf diese Weise über den Einzelfall hinausgehende Erkenntnisse zur (jeweiligen) Parteigeschichte zu ermöglichen.

$70 \quad$ Freiheitliches Bildungsinstitut (Hg.), FPÖ-Bericht, 7, 651.

71 Vgl. exemplarisch: Wissenschaftliche Stellungnahme zum FPÖ-„Historikerbericht“, URL: https:// www.doew.at/neues/wissenschaftliche-stellungnahme-zum-fpoe-historikerbericht (abgerufen 18.08.2020); Historiker zerpflückten FPÖ-Historikerbericht, ORF Online, 03.02.2020, URL: https://orf.at/stories/3153029/ (abgerufen 18.08.2020).

72 Exemplarisch dafür: Reiter, Reinthaller. 
Zweitens: Erforschung von ideologischen Kontinuitäten, Brüchen und Transformationen nach 1945 in den verschiedenen Parteien der Zweiten Republik. Exemplarische Studien zu Antisemitismus, Deutschnationalismus, AntimarxismusAntikommunismus, Antiamerikanismus, Rassismus, Demokratieverständnis in den Parteien könnten genuine ideologische Kontinuitäten herausarbeiten, gleichzeitig aber auch den Blick für ideologische Veränderungen und Verlagerungen im Laufe der Zweiten Republik schärfen.

Drittens: Forcierung von generationsspezifischen Zugängen. Ausgehend von der Tatsache, dass die im Nationalsozialismus und in der Nachkriegszeit beteiligte „Erfahrungsgeneration“ längst nicht mehr politisch aktiv ist, bestimmte Haltungen jedoch nach wie vor weiterbestehen, sollten die konkreten Auswirkungen des mittlerweile erfolgten Generationswechsels auf die Parteien näher untersucht werden. $\mathrm{Zu}$ fragen wäre beispielsweise, inwiefern sich dadurch Parteistrukturen und Inhalte im Laufe der Zweiten Republik verändert haben, ob die zeitliche und emotionale Distanz zum Nationalsozialismus zu einem Abbau früherer gegenseitiger politischer Feindschaft und Ressentiments führte oder aber die Polarisierung entlang von Parteilinien über die Generationen hinweg weiterbesteht.

Viertens: Forcierung von geschlechterspezifischen Zugängen, die den Frauen in den Parteien mehr Raum als bisher einräumt und sie als politische Akteurinnen wahrnimmt. Dabei geht es nicht nur um das Herausstellen einzelner prominenter Frauen und der damit einhergehenden Rollenzuschreibungen (zum Beispiel Rosa Jochmann als „antifaschistisches Gewissen“ der SPÖ), sondern um konkrete Interaktionen mit männlichen Akteuren, innerparteiliche Dynamiken, Strukturen und Diskurse, an denen Frauen maßgeblich beteiligt waren. Diese Fokussierung geht zwangsläufig mit einem Perspektivenwechsel weg von der offiziellen (zumeist männlich dominierten) Parteigeschichte hin zu einer Binnenanalyse der jeweiligen Parteien einher.

Fünftens: Forcierung von vergleichenden Perspektiven sowohl auf nationaler als auch internationaler Ebene. Entgegen der bisherigen starken Separierung der Forschung entlang von Parteigrenzen könnten durch einen komparatistischen Ansatz bisher erzielte Ergebnisse in einen größeren Kontext eingeordnet und miteinander in Beziehung gesetzt werden. Parteiengeschichte ist als Verflechtungs- und Interaktionsgeschichte zu verstehen, die durch den direkten Vergleich Spezifika, Ähnlichkeiten und Differenzen der österreichischen Parteien der Zweiten Republik schärfer herausarbeiten kann. Darüber hinaus wären auch transnationale vergleichende Perspektiven, etwa Vergleichsstudien zur Parteienlandschaft in Deutschland (als NS-Nachfolgestaat) oder in anderen europäischen Ländern, zielführend. Was bisher nur ansatzweise bearbeitet wurde (zum Beispiel eine Vergleichsstudie von 
ÖVP und CDU nach 1945), ${ }^{73}$ ließe sich auch auf andere Parteien übertragen. Bisher vorliegende Arbeiten zum VdU und zur FPÖ könnten beispielsweise mit bereits bestehenden Studien zur deutschen "Schwesterpartei“ FDP, in der sich ebenfalls viele ehemalige NationalsozialistInnen parteipolitisch reorganisiert haben, ${ }^{74}$ sowie mit rechtsextremen Parteien im Nachkriegsdeutschland 75 produktiv verglichen werden. Eine solche vergleichende Perspektive kann den Blick schärfen für die Unterschiede, aber auch das Spezifische der österreichischen Parteien der Zweiten Republik im Allgemeinen und in ihrem Umgang mit dem Nationalsozialismus im Besonderen.

73 Hendrik Schäfer, ÖVP, CDU/CSU und der Rechtsextremismus der Nachkriegszeit (1945-57). Ein Vergleich der Entwicklung in Österreich und der Bundesrepublik Deutschland, München 2005.

74 Vgl. exemplarisch Kristian Buchna, Nationale Sammlung an Rhein und Ruhr. Friedrich Middelhauve und die nordrhein-westfälische FDP 1945-1953 (Schriftenreihe der Vierteljahreshefte für Zeitgeschichte 1010), München 2010; Günter Trittel, „Man kann ein Ideal nicht verraten ..."Werner Naumann, NS-Ideologie und politische Praxis in der frühen Bundesrepublik, Göttingen 2013; Beate Baldow, Episode oder Gefahr? Die Naumann-Affäre, phil. Diss., Universität Berlin 2012; Jakob S. Eder, Liberale Flügelkämpfe. Hildegard Hamm-Brücher im Diskurs über den Liberalismus in der frühen Bundesrepublik, in: Vierteljahreshefte für Zeitgeschichte 64 (2016) 2, 291-325.

75 Henning Hansen, Die Sozialistische Reichspartei (SRP). Aufstieg und Scheitern einer rechtsextremen Partei, Düsseldorf 2007; Otto Büsch/Peter Fürth, Rechtsradikalismus in Nachkriegsdeutschland. Studien über die „Sozialistische Reichspartei“, Berlin/Frankfurt a. M. 1987; Oliver Sowinski, Die Deutsche Reichspartei 1950-1965. Organisation und Ideologie einer rechtsradikalen Partei, Frankfurt a. M. 1998; Daniel Schönwald, Integration durch eine Interessenpartei. Der Block der Heimatvertriebenen und Entrechteten in Bayern 1950-1981, St. Ottilien 2014. 


\section{Medizin}

Ina Friedmann und Christian Lechner

Der vorliegende Beitrag zu historischen und rezenten Entwicklungen der österreichischen Medizingeschichtsforschung fokussiert neben einem Überblick über den Weg von der traditionellen Medizingeschichte des 19. und frühen 20. Jahrhunderts bis zu aktuellen Auseinandersetzungen und Forschungsschwerpunkten einzelne Aspekte, AkteurInnen und Ereignisse, die bedeutend für Perspektivenwechsel und Aufmerksamkeitsverschiebungen in der Forschung waren. Sie stellen entweder reale "Meilensteine“ in der österreichischen Medizingeschichte dar oder sind exemplarisch zur Verdeutlichung verschiedener vergleichbarer Entwicklungen. $\mathrm{Zu}$ diskutieren sind in diesem Kontext auch Veränderungen, die in Zusammenhang mit dem Datenschutz und dessen Bedeutung für die medizinhistorische Forschung stehen - geht es hierbei doch noch stärker als in anderen geschichtswissenschaftlichen Bereichen um die Gleichzeitigkeit von Betroffenenschutz und Erforschung von (medizinischen) Verbrechen. Diese ist ohne Aktengrundlage nicht möglich, die Verweigerung von Einsichtnahmen in sensible Personendaten, die oftmals mit dem Schlagwort des „Opferschutzes“ zu rechtfertigen versucht wurde, stellt in der Praxis meist das Gegenteil dar: Schutz von TäterInnen und damit die Fortführung des von Herwig Czech so genannten „gesellschaftliche[n] Schweigepakt[s] über die Verbrechen der Medizin im Nationalsozialismus".

Kritische Auseinandersetzungen mit unterschiedlichen Aspekten der Medizin bzw. der medizinischen Wissenschaft im 20. Jahrhundert sind daher aus vielen Gründen von großer Bedeutung, die zugleich die Wichtigkeit zeithistorischer Forschungen im Allgemeinen widerspiegeln. Dass aber auch Ende der 2010er-Jahre wissenschaftliche Untersuchungen zu einzelnen AkteurInnen der österreichischen Medizin und ihren Tätigkeiten während des Nationalsozialismus Betroffenheit hervorrufen, die sich zu Opposition, Widerlegungs- und Apologetikbestrebungen entwickeln kann, bestürzt - denn es handelt sich hierbei oftmals nicht um die Betroffenheit über das Verhalten der im Forschungsinteresse Stehenden und ihre Verflechtungen mit dem NS-Regime. Vielmehr stehen emotional beeinflusste Bemü-

$1 \quad$ Herwig Czech, Das Ende des Schweigepakts? Die NS-Medizinverbrechen und die österreichische Gesellschaft seit 1945, in: Herwig Czech/Wolfgang Neugebauer/Peter Schwarz (Hg.), Der Krieg gegen die Minderwertigen. Zur Geschichte der NS-Medizin in Wien, Katalog zur Ausstellung in der Gedenkstätte Steinhof im Otto-Wagner-Spital der Stadt Wien, Wien 2018, 10-20, 12. 
hungen im Mittelpunkt, die beforschten Personen zu rehabilitieren, häufig bedingt durch ein persönliches Naheverhältnis oder fachliche Anerkennung. Die daraus resultierende, potenziell durchaus gewinnbringende Erweiterung der wissenschaftlichen Auseinandersetzung wird dann problematisch, wenn das „wissenschaftlich“ verschwindet und allein die „persönliche Auseinandersetzung“ übrigbleibt. Letztere tendiert des Öfteren zu einer vereinfachten Sicht der Dinge und verschließt sich der Komplexität tatsächlicher historischer Abläufe mit all ihren Facetten, Einflussfaktoren und wechselseitigen Abhängigkeiten. ${ }^{2}$

Auch institutionelle Vorbehalte, die Forschungen zur NS-Zeit als schädlich für das aktuelle Image der betreffenden Einrichtungen einstufen und diese als „Nestbeschmutzung" empfinden, begegnen auf medizinischer Seite nach wie vor. ${ }^{3}$ Während viele Fachverbände, Kliniken oder Institute mittlerweile aktiv die Aufarbeitung ihrer Rolle im Nationalsozialismus betreiben, ${ }^{4}$ können sich derartige Negativinterpretationen von wissenschaftlichen Arbeiten nicht nur als hemmend, sondern auch als behindernd für zeitgemäße, notwendige Forschungen erweisen. Diese Reaktionen hängen wesentlich damit zusammen, dass, wie in der primären Entnazifizierung nach der Befreiung Österreichs, so auch in der Forschung lange Zeit der

2 Als rezentes lokales Beispiel ist etwa die 2018 nach Erscheinen von Herwig Czechs biographischer Auseinandersetzung mit Hans Aspergers Tätigkeiten während der NS-Zeit sowie Edith Sheffers Studie zu den Ursprüngen des Autismuskonzepts im Nationalsozialismus entstandene und auch aktuell fortbestehende Kontroverse um Aspergers NS-Vergangenheit zu nennen. Vgl. hierzu u. a. Herwig Czech, Hans Asperger, National Socialism and „race hygiene“ in Nazi-era Vienna, in: Molecular Autism 9 (2019), 1-43; Edith Sheffer, Asperger's Children. The Origins of Autism in Nazi Vienna, New York/London 2018; Dean Falk, Non-complicit: Revisiting Hans Asperger's Career in Nazi-era Vienna, in: Journal of Autism and Developmental Disorders 49 (2019), 1-12; Werner Maleczek, Der Kinderarzt als Handlanger der NS-Mörder am „Spiegelgrund“?, Die Furche, 26./27.06.2019, 22.

3 Markus Stiehm, Wissenslücke bei Studenten: Ärzte-Verbrechen im 3. Reich, Thieme via medici, URL: https://bit.ly/2J66KtZ (abgerufen 02.07.2019).

4 Vgl. exemplarisch die Initiativen der Österreichischen Gesellschaft für Psychiatrie und Psychotherapie (ÖGPP), das Projekt „Die Innsbrucker Anatomie im Dritten Reich“ unter Leitung von Erich Brenner, die von Arnold Pollak betriebenen Auseinandersetzungen mit der Wiener Kinderklinik während des Nationalsozialismus, die von Gabriele Czarnowski durchgeführten Forschungen zu den österreichischen Universitäts-Frauenkliniken im Nationalsozialismus, das von der Österreichischen Gesellschaft für Hämatologie und Onkologie finanzierte und von Herwig Czech geleitete Projekt zur „Geschichte der Hämatologie und medizinischen Onkologie in Österreich, ca. 1890 bis 1970". Diese Beispiele wurden nicht wertend ausgewählt, sondern sollen in Auswahl auf die Vielfalt der existierenden Analysen in unterschiedlichen Disziplinen hinweisen. Vgl. auch mit Fokus auf Deutschland: Matthis Krischel/Mathias Schmidt/Dominik Groß (Hg.), Medizinische Fachgesellschaften im Nationalsozialismus. Bestandsaufnahme und Perspektiven (Medizin und Nationalsozialismus 4), Berlin 2016. 
Fokus in biographischen Analysen auf Mitgliedschaften in der NSDAP und ihren Gliederungen lag, wohingegen „inhaltliche Kollaborationen“" erst in den vergangenen drei Jahrzehnten mehr und mehr in den Blickpunkt rückten. Dabei wurden nunmehr auch Kontinuitäten berücksichtigt, die über die politischen Zäsuren 1938 und 1945 hinausreichten und eben unabhängig von Parteimitgliedschaften bestanden.

1. Die Tradition der Medizingeschichte und die österreichischen (medizinischen) Universitäten

Medizingeschichte ist ein traditionell an Universitäten bearbeitetes Forschungsfeld, das curricular in einer Randposition stand und auch heute noch steht. Bereits ab dem frühen 19. Jahrhundert war die Geschichte der Medizin als wissenschaftliche Disziplin an der Medizinischen Fakultät der Universität Wien existent. Der mährische Arzt und Medizinhistoriker Abraham Romeo Seligmann fungierte ab 1833 als Dozent für Medizingeschichte, ab 1848 als Extraordinarius und ab 1869 als Ordinarius. Sein Nachfolger, zunächst ab 1879 als Extraordinarius, ab 1888 als Ordinarius wurde der schlesische Medizinhistoriker Theodor Puschmann. ${ }^{6}$ Nach dessen Tod übernahm der Wiener Mediziner Max Neuburger die Lehrkanzel, verfügte jedoch weiterhin über keine eigenen Institutsräumlichkeiten. Erst durch konstantes Netzwerken und Drängen gelang die schließlich 1919 erfolgte Unterbringung des damit ersten und bislang in Österreich auch einzigen Institutes - offiziell gegründet bereits 1914 - am Josephinum.7 Zwar gab es beispielsweise auch an der Universität Innsbruck während der 1920er- und 1930er-Jahre Lehrveranstaltungen zur Geschichte der Medizin, die von dem Zahnmediziner Bernhard Mayrhofer abgehalten wurden, ${ }^{8}$ zu einer Institutionalisierung des Faches kam es aber nicht.

5 Mark Walker, The Nazification and Denazification of Physics, in: Walter Kertz (Hg.), Hochschule im Nationalsozialismus, Braunschweig 1994, 79-91.

6 Werner E. Gerabek/Bernhard D. Haage/Gundolf Keil/Wolfgang Wegner (Hg.), Enzyklopädie Medizingeschichte, Berlin 2005, 1204, 1318.

7 Michael Hubenstorf, Eine „Wiener Schule“ der Medizingeschichte? - Max Neuburger und die vergessene deutschsprachige Medizingeschichte, in: Michael Hubenstorf (Hg.), Medizingeschichte und Gesellschaftskritik. Festschrift für Gerhard Baader, Husum 1997, 246-289.

8 Dieser Lehrauftrag war Mayrhofer das erste Mal 1922 erteilt und auch im Sommersemester 1938 trotz Ruhestandsversetzung 1933 - aufrechterhalten worden. Bundesministerium für Unterricht, Gz. 9493-I/Ia/1938. Österreichisches Staatsarchiv (ÖStA), Allgemeines Verwaltungsarchiv (AVA), Unterricht UM allg. Akten 1137. Vgl. zu Mayrhofer auch Ina Friedmann/Dirk Rupnow, Die Uni- 
Neuburger als erster Institutsvorstand in Wien, bereits 1934 aufgrund der austrofaschistischen Sparpolitik emeritiert und schließlich aus rassistischen Gründen nach dem "Anschluss“ 1938 auch als Honorarprofessor entlassen und vertrieben, sowie die Medizinerin und Historikerin Erna Lesky, Leiterin des Instituts von 1960 bis 1979, prägten die traditionelle österreichische Medizingeschichtsforschung. ${ }^{9}$ Der Fokus lag dabei auf der Wiener Medizinischen Schule des 19. Jahrhunderts - bei Neuburger selbsterklärend -, wie auch Leskys Hauptwerk aus dem Jahr 1965 benannt ist. ${ }^{10}$ Nach der Emeritierung des Dermatologen Karl Holubar, der das Institut ab 1989 leitete, im Jahr 2001 übernahm Michael Hubenstorf bis 2020 die Leitung des weiterhin im Josephinum untergebrachten Institutes, ihm folgte im selben Jahr Herwig Czech nach. ${ }^{11}$

Anders gestaltet sich die Situation in Graz, Innsbruck, Salzburg, Klagenfurt und Linz. Einen Lehrstuhl für Geschichte der Medizin gibt es weder an den dortigen Universitäten noch an den Medizinischen Universitäten Graz und Innsbruck bzw. der Medizinischen Fakultät der Universität Linz. Medizinhistorische Forschung wird trotzdem betrieben, die damit beschäftigten WissenschaftlerInnen sind jedoch anderen Instituten zugeordnet - sowohl historischen wie medizinischen. Während allgemein vielfach die lokale Geschichte das primäre Forschungsinteresse darstellt, ${ }^{12}$ sind besonders standortübergreifende Studien hervorzuheben, die größere Ent-

versität im 20. Jahrhundert (Geschichte der Universität Innsbruck 1669-2019 Bd. I,2, hg. v. Margret Friedrich/Dirk Rupnow), Innsbruck 2019, 142-143.

9 Walter Mentzel, Max Neuburger, in: Lexikon der österreichischen Provenienzforschung, 01.07.2019, URL: https://www.lexikon-provenienzforschung.org/neuburger-max (abgerufen 30.11.2019). Von 1939 bis 1945 wurde das Institut von dem deutschen Medizinhistoriker Fritz Lejeune geleitet, vgl. zu diesem Klaus Schmierer, Medizingeschichte und Politik. Karrieren des Fritz Lejeune in der Weimarer Republik und im Nationalsozialismus (Abhandlungen zur Geschichte der Medizin und der Naturwissenschaften 96), Husum 2001. Von 1945 bis zur Berufung Leskys 1960 wurde das Institut provisorisch von dem Chirurgen Leopold Schönbauer geleitet. Zwischen 1979 und 1989 leitete Helmut Wyklicky das Institut. Gabriela Schmidt-Wyklicky, In memoriam Helmut Wyklicky, in: Wiener Medizinische Wochenschrift 158 (2008) 23-24, 745-748.

10 Erna Lesky, Die Wiener medizinische Schule im 19. Jahrhundert (Studien zur Geschichte der Universität Wien 6), Graz/Köln 1965. Für einen Überblick zu Leskys Wirken: Felicitas Seebacher, Erna Lesky, General and Diplomat. Networking as a Power Tool for History of Medicine, in: Antonio Roca-Rosell (Hg.), The Circulation of Science and Technology. Proceedings of the $4^{\text {th }}$ International Conference of the European Society for the History of Science, Barcelona, 18.-20. November 2010, Barcelona 2012, 208-216.

11 Vgl. zum Josephinum sowie zu den dort untergebrachten Sammlungen: URL: https://www.josephinum.ac.at (abgerufen 08.11.2019).

12 Damit ist sowohl die engere Institutionen- und Personengeschichte gemeint als auch die Auseinandersetzung mit lokalen Vorgängen, Ereignissen und Forschungspraktiken, die sämtlich nicht minder wichtig sind. 
wicklungen in den Blick nehmen und Gegenüberstellungen ermöglichen. Exemplarisch kann hierfür das Projekt zur Gynäkologie im Nationalsozialismus an den österreichischen Universitäten Wien, Graz und Innsbruck von Gabriele Czarnowski genannt werden, ${ }^{13}$ aber auch länderübergreifend ist Czechs aktuelles Teilprojekt zu „Hirnforschung an Instituten der Kaiser-Wilhelm-Gesellschaft im Kontext nationalsozialistischer Unrechtstaten: Hirnpräparate in Instituten der Max-Planck-Gesellschaft und die Identifizierung der Opfer" ein Beispiel für jüngere Entwicklungen in Hinblick auf größere Kontextualisierungen und Zusammenhänge. ${ }^{14}$ Gerade diese beiden Beispiele für Perspektivenerweiterung zeigen die immer wichtiger werdende Integration von lokalen bzw. spezifischen Forschungsfragen in einen größeren Kontext, die von einer isolierten Behandlung eines Forschungsthemas abrückt.

Nicht zuletzt vor dem Hintergrund der weiter voranschreitenden Forschung muss es daher als bezeichnend für den Stellenwert der Medizingeschichte an den österreichischen und speziell den medizinischen Universitäten betrachtet werden, dass auch mehr als einhundert Jahre nach Gründung des Wiener Instituts für Geschichte der Medizin an keiner anderen österreichischen (medizinischen) Universität ein derartiges Institut existiert. Zwar findet teilweise Lehre zu Medizingeschichte statt, diese ist aber derzeit nicht verpflichtend im Studienplan für angehende MedizinerInnen verankert. Wissen um „Behandlungs-“ und Forschungspraktiken während des Nationalsozialismus und das Bestehen damit zusammenhängender wissenschaftlicher Konzepte in Hinblick auf die Kategorisierung von Menschen in behauptet „wertvolle“ und „minderwertige“ wären dazu geeignet, ein breites Bewusstsein für ethische Fragestellungen zu schaffen, das durch die im Medizincurriculum üblicherweise mit unzureichend Semesterstunden ausgestatte, jedoch zumindest verpflichtende Ethiklehrveranstaltung alleine nicht abgedeckt werden kann. ${ }^{15}$

13 Zum Beispiel Gabriele Czarnowski, Österreichs „Anschluss“ an Nazi-Deutschland und die österreichische Gynäkologie, in: Christoph Anthuber/Matthias W. Beckmann/Johannes Dietl/Fritz Dross/Wolfgang Frobenius (Hg.), Herausforderungen. 100 Jahre Bayerische Gesellschaft für Geburtshilfe und Frauenheilkunde, Stuttgart/New York 2012, 138-148.

14 URL: https://www.mpg.de/11260458/max-planck-gesellschaft-schliesst-gesamtrevision-ab (abgerufen 09.11.2019).

15 Versuche, zusätzliche medizinethische Lehrveranstaltungen im Sinne von Wahlpflichtfächern im Medizinstudium einzuführen und hierüber auch die Medizingeschichte zumindest ansatzweise abzubilden, werden derzeit etwa in Innsbruck unternommen. 


\subsection{NS-Medizin und der Einfluss auf bioethische Richtlinien}

Das früheste und nach wie vor bedeutende Dokument der NS-Medizingeschichte ist die erstmals 1948 unter dem Titel „Wissenschaft ohne Menschlichkeit“ erschienene Dokumentation des Nürnberger Ärzteprozesses, die 1960 schließlich als „Medizin ohne Menschlichkeit. Dokumente des Nürnberger Ärzteprozesses“ veröffentlicht, seitdem mehrfach neu aufgelegt und zu einem Standardwerk der Medizingeschichte wurde. ${ }^{16}$ Der Herausgeber Alexander Mitscherlich war Arzt, Psychoanalytiker und Mitglied der Ärztekommission der Westdeutschen Ärztekammern, die als Prozessbeobachterin beim Ärzteprozess fungierte, Mitherausgeber war sein Mitarbeiter, der damalige Medizinstudent Fred Mielke. In der Vorbemerkung zur Erstausgabe wies Mitscherlich auf Folgendes hin: „Heute, wie zur Zeit des Prozesses, der die Vorgänge der Welt offenbar machte, müssen wir die Frage stellen, wie man diese Ungeheuerlichkeiten in unser aller wirkliche Erfahrung einordnen kann. "17 Obwohl Mitscherlich damit mehrere Ebenen ansprach, ist im Kontext des vorliegenden Beitrages besonders der Einfluss der NS-Medizin und des Ärzteprozesses auf die Standards der medizinischen Ethik von Bedeutung. Der 1947 aus dem Prozessurteil resultierende, zehn Punkte umfassende „Nürnberger Kodex“, der fortan Richtlinien für medizinische Versuche an Menschen vorgab, ${ }^{18}$ in aktualisierter Form auch heute noch richtungsweisend ist sowie mitbestimmend für die „Deklaration von Helsinki“ und weitere bioethische Grundsatzerklärungen war, muss dabei - im Gegensatz zur Einordnung in den persönlichen Erfahrungskontext - als Resultat der Erfahrungen gelten. Bereits anlässlich des fünfzigsten Jahrestages des Kodex 1997 erfolgten Auseinandersetzungen mit seiner Entstehung und Bedeutung, ${ }^{19}$ der siebzigste Jahrestag stellte schließlich den Anlass zu einem internationalen Symposium an der Medizinischen Universität Wien dar, das sich mit den Entwicklungen der Medizinethik von 1947 bis 2017 auseinandersetzte. Die daraus resultierende Publikation vereinigte

16 Alexander Mitscherlich/Fred Mielke, Medizin ohne Menschlichkeit. Dokumente des Nürnberger Ärzteprozesses. Mit einem neuen Vorwort zum Nachdruck 1977 von Alexander Mitscherlich, Frankfurt a. M. ${ }^{16} 2004$.

17 Ebd., 9 (Hervorhebung im Original).

18 Ebd., 354-355. Vgl. dazu beispielsweise auch Dominik Groß, ,Nürnberger Kodex', in: Christian Lenk/Gunnar Duttke/Heiner Fangerau (Hg.), Handbuch Ethik und Recht der Forschung am Menschen, Berlin/Heidelberg 2014, 559-563.

19 So entwickelte die Nürnberger Gruppe der IPPNW einen „Nürnberger Kodex 1997“, der die ursprünglichen Richtlinien auf aktuelle Problematiken der Medizinethik anwendete. Die Veröffentlichung des Nürnberger Kodex von 1997, URL: http://www.ippnw-nuernberg.de/aktivitaet2_2.html sowie Der Nürnberger Kodex 1997, URL: http://www.ippnw-nuernberg.de/aktivitaet2_3.html (abgerufen 30.08.2019). 
Beiträge vieler auf diesem Gebiet Forschender und rückte unterschiedliche Perspektiven in den Fokus. ${ }^{20}$ Sichtbar werden daran unter anderem die Verschiebungen in Forschungszugängen, die nun vermehrt historische Prozesse neben konkreten Ereignissen in den Blick nehmen.

\subsection{Medizingeschichte in der universitären Ausbildung}

Die eingangs angesprochene Bedeutung medizinhistorischer Forschung und Lehre erstreckt sich neben der gesamtgesellschaftlichen Relevanz auch auf den Bereich der Ausbildung heutiger Medizinstudierender. Dass derzeit ausschließlich in Wien ein Institut für Geschichte der Medizin existiert, weist diesem Forschungsbereich in Österreich ebenso einen Platz auf den hinteren Rängen zu wie das ausschließliche Angebot von medizinhistorischen Lehrveranstaltungen im Rahmen von Wahlfächern. Gleichzeitig stehen solche Institute an den meisten medizinischen Fakultäten Deutschlands bereits in langer Tradition und haben, neben zusätzlichen Wahlfächern, in der Regel einen im Pflichtcurriculum der Medizinstudierenden verankerten Anteil an der Lehre mit einem Fokus auf Medizingeschichte und Ethik. ${ }^{21}$ Auch in der Schweiz wird in der Ausbildung künftiger ÄrztInnen mehr Wert auf grundlegende geschichtliche Kenntnisse der eigenen Profession gelegt. ${ }^{22}$

Mit Blick auf Österreich existierte etwa an der Medizinischen Universität Wien im Studienjahr 2019/2020 ein Wahlfachkorb, der von mehreren Lehrenden gestaltet wurde: Neben der Hauptvorlesung von Hubenstorf über zwei Semester und einem zeitlichen Rahmen von der Antike bis ins 20. Jahrhundert hatten die Studierenden unter anderem noch die Gelegenheit, fokussierte Vorlesungen über die Medizin im Nationalsozialismus oder über bioethische Aspekte und Fragestellungen zu besuchen. $^{23}$

20 Herwig Czech/Christiane Druml/Paul Weindling (Hg.), Medical Ethics in the 70 Years after the Nuremberg Code, 1947 to the Present. International Conference at the Medical University of Vienna, $2^{\text {nd }}$ and $3^{\text {rd }}$ March 2017, in: Wiener Klinische Wochenschrift 130 (2018), Supplement 3 , 159-253.

21 Beispiele: Heidelberg, URL: https://bit.ly/34DINDG, Hamburg, URL: https://bit.ly/2q5I669, und Charité Berlin, URL: https://bit.ly/2L7lHMR (abgerufen 30.11.2019).

22 Beispiele: Bern, URL: https://bit.ly/37JZQVw, Zürich, URL: https://bit.ly/33APSmo, und Genf, URL: https://bit.ly/2sxzYw7 (abgerufen 30.11.2019).

23 Lehrveranstaltungsangebot Studienjahr 2019/20, URL: https://bit.ly/2Oyi5pf (abgerufen 30.11.2019). 
An der Medizinischen Universität Graz fand zwar eine ethische Pflichtveranstaltung Eingang in das Curriculum, in die Medizingeschichte werden die Studierenden jedoch nur mittels eines freien Wahlfaches eingeführt. ${ }^{24}$

In Innsbruck erhalten die Medizinstudierenden seit 2015 wieder eine grundlegende medizinhistorische Ausbildung über ein entsprechendes Wahlfach. Dieses initiierte der aus der Berliner bzw. deutschen Tradition der Medizingeschichte kommende Gerhard Gaedicke, der zwischen 2012 und 2017 Leiter der Innsbrucker Kinderklinik war. Auf Gaedickes Anregung hin gestaltete der in Ausbildung zum Kinderfacharzt stehende Verfasser des vorliegenden Beitrages eine Vorlesung, welche, zwei Semester dauernd, den Bogen von der antiken bis in die zeitgenössische Medizingeschichte spannte. Ab dem Wintersemester 2019/2020 wurde diese Vorlesung von den VerfasserInnen des vorliegenden Beitrags gemeinsam in ein interdisziplinäres Seminar für Studierende der Medizin und der Geschichtswissenschaften umstrukturiert. Daneben gibt es im Pflichtcurriculum der zukünftigen ÄrztInnen noch eine Vorlesung mit bioethischen Inhalten. Hierzu existiert derzeit eine Initiative, um diesem wichtigen Aspekt in der Ausbildung zukünftig mehr Anteil an der Gesamtlehre zu verschaffen.

Zusammenfassend lässt sich für Österreich sagen, dass es zumindest in Wien und Innsbruck dezidierte Lehrveranstaltungen für Medizinstudierende gibt, um sich in der Geschichte der eigenen Profession mehr Kenntnisse zu verschaffen. Eine Aufnahme dieses Forschungsbereichs in die Pflichtcurricula aller österreichischen medizinischen Universitäten bzw. Fakultäten scheint allerdings überfällig. Wie wichtig nämlich eine grundlegende historische Ausbildung für Medizinstudierende wäre, zeigt sich auch deutlich anhand der Ergebnisse der an der Berliner Charité durchgeführten „ASAMANS“-Studie („Asking Students about Medicine and National Socialism“). Hier wurde das Wissen der Studierenden über die Medizin im Nationalsozialismus überprüft. Eine Auseinandersetzung mit den ethisch-moralischen Grenzüberschreitungen der ÄrztInnen während dieser Zeit unterstützt die Bedeutung der bzw. regt an zur obligaten Reflexion des ärztlichen Handelns; Grundkenntnisse zu diesem Thema sollten also wünschenswerterweise vorhanden sein. Die Ergebnisse der Umfragestudie zeigten jedoch deutlich, wie wenig die Medizinstudierenden darüber wussten. Beispielsweise kannten nur 2,4 Prozent der Befragten die oben erwähnten Personen Mitscherlich und Mielke. Gleichzeitig gab eine deutliche Mehrheit der Medizinstudierenden an, dass sie das Thema Nationalsozialismus

24 Studienplan Graz, URL: https://bit.ly/35KP6V8 (abgerufen 30.11.2019); Lehrveranstaltungsübersicht Graz, URL: https://bit.ly/33 $\mathrm{TH}_{3} \mathrm{aX}$ (abgerufen 13.08.2020). 
als wichtig für den eigenen ärztlichen Horizont erachteten und sich entsprechend mehr Ausbildung darin wünschen würden. ${ }^{25}$

\section{Außeruniversitäre Erforschung der Geschichte der Medizin}

Neben den Universitäten fanden Auseinandersetzungen mit der NS-Medizingeschichte auch in anderem Rahmen statt. Einerseits war hier das 1963 gegründete Dokumentationsarchiv des Österreichischen Widerstands (DÖW) früh aktiv, an dem mittlerweile neben Forschungen zur NS-Zeit auch ein Rechtsextremismusschwerpunkt existiert und das den Themenbereich der Medizin in die allgemeine Dokumentation und Erforschung des Nationalsozialismus in Österreich integrierte. ${ }^{26}$ Daneben formierten sich bereits in den 1970er-Jahren Arbeitsgemeinschaften unterschiedlicher (medizinischer) Berufsgruppen, die sich mit der Vergangenheit der eigenen Disziplin auseinandersetzten. Insbesondere ist hier die Arbeitsgemeinschaft Kritische Medizin um den damals in Wien tätigen Tiroler Unfallchirurgen Werner Vogt zu nennen, die 1979 erstmals öffentlich die Vergangenheit des Psychiaters Heinrich Gross, in der NS-Zeit Arzt der „Kinderfachabteilung“ Am Spiegelgrund und als solcher an der Ermordung von PatientInnen beteiligt, thematisierte und die mangelnde Strafverfolgung in der Nachkriegszeit kritisierte. ${ }^{27}$

Zudem wurde an der Österreichischen Akademie der Wissenschaften innerhalb der Kommission für Geschichte und Philosophie der Wissenschaften die Arbeitsgruppe Geschichte der Medizin etabliert, die - abgesehen von (interdisziplinären) Forschungsprojekten - im Oktober 2019 die internationale Tagung „Medical Humanities - Interactions between Medicine and the Arts“"veranstaltete. ${ }^{28}$ Diese neue Per-

25 Peter Langkafel/Timo Drewes/Sebastian Müller, Mitscherlich und Mielke - wer sind die?, in: Deutsches Ärzteblatt 99 (2002) 13, A834-A835.

26 Vgl. etwa in den 1980er- und 1990er-Jahren erschienene Publikationen zu Verfolgung und Widerstand in den Bundesländern sowie frühe Thematisierungen der NS-Zwangssterilisationen: Wolfgang Neugebauer, „Euthanasie“ und Zwangssterilisierung, in: DÖW (Hg.), Widerstand und Verfolgung in Niederösterreich, Bd. 3, Wien 1987, 632-669; Wolfgang Neugebauer, Zwangssterilisierung und „Euthanasie“ in Österreich 1940-1945, in: zeitgeschichte 19 (1992) 1/2, 17-28; Gretl Köfler, „Euthanasie“ und Zwangssterilisierung, in: DÖW (Hg.), Widerstand und Verfolgung in Tirol 1934-1945, Bd. 1, Wien/München 1984, 483-519.

27 Siehe dazu ausführlicher Abschnitt III.

28 Arbeitsgruppe Geschichte der Medizin, URL: https://www.oeaw.ac.at/kgpw/geschichte-der-medizin/ (abgerufen 30.11.2019); Tagungsprogramm Medical Humanities - Interactions between Medicine and the Arts, URL: https://www.oeaw.ac.at/fileadmin/kommissionen/kgpw/Programm_ Medical_Humanities_A5_2019_v04_web.pdf (abgerufen 30.11.2019). 
spektive, die Medizin(geschichte) unter verschiedenen interdisziplinären Aspekten beforscht, geht mit internationalen Entwicklungen einher: Neben der Gründung des Forschungszentrums Medical Humanities an der Universität Innsbruck 2017 etablierten sich in den vergangenen Jahren vergleichbare Institutionen und Netzwerke auch in der Schweiz und in Deutschland, wo 2015 an der Berliner Charité schließlich die erste deutsche Professur für Medical Humanities eingerichtet wurde. ${ }^{29}$

Andererseits sind es aktuell besonders "Gedenk- und Lernorte", die als ehemalige Stätten der NS-Verfolgung mittlerweile eine wichtige Vermittlerrolle innehaben. In Wien existiert auf dem Gelände des Otto-Wagner-Spitals auf den ehemaligen Steinhof-Gründen als Standort des ehemaligen "Spiegelgrund-Komplexes“"30 seit 2002 die Ausstellung „Der Krieg gegen die Minderwertigen“. Anlässlich der Bestattung von Präparaten von Spiegelgrund-Opfern im Mai 2002 als Gedenkstätte Steinhof eröffnet, erfolgte 2008 eine Erweiterung und zugleich Umgestaltung zur Dauerausstellung, die 2012 durch Interviews ehemaliger Internierter des Spiegelgrunds ergänzt wurde. ${ }^{31}$

Nur ein Jahr nach der ursprünglichen Eröffnung der Gedenkstätte Steinhof wurde unter dem Namen Lern- und Gedenkort Schloss Hartheim in der ehemaligen oberösterreichischen Landes-Heil- und Pflegeanstalt, in der in der NS-Zeit ebenfalls kranke und als krank definierte Menschen ermordet wurden, ${ }^{32}$ ein vergleichbarer Gedenkort geschaffen. Bereits 1969 war in dem damals noch als Wohnhaus genutzten Schloss eine Gedenkstätte zur Erinnerung an die NS-Verbrechen auf Initiative des Instituts Hartheim und des oberösterreichischen Landeswohltätigkeitsvereins errichtet worden. Zwischen 2000 und 2003 wurde schließlich in umfassenden Renovierungs- und Sanierungsarbeiten die Umgestaltung zum Lern- und Gedenkort durchgeführt, an dem heute neben der historischen Vermittlung auch eine Doku-

29 Forschungszentrum Medical Humanities Innsbruck, URL: https://bit.ly/35M1FQo; Heinz-Peter Schmiedebach, Medical Humanities an der Charité, URL: https://bit.ly/2szfC $5 \mathrm{~L}$; exemplarisch: Medical Humanities am IMH Bonn, URL: https://bit.ly/2rCAhW2; Center for Medical Humanities an der Universität Zürich, URL: https://bit.ly/2OAVpF2 (alle abgerufen 30.11.2019).

30 Zu diesem Terminus und der Geschichte der Anstalt Am Spiegelgrund mit ihren unterschiedlichen Abteilungen, Leitern und auch Benennungen: Herwig Czech, Der Spiegelgrund-Komplex. Kinderheilkunde, Heilpädagogik, Psychiatrie und Jugendfürsorge im Nationalsozialismus, in: Österreichische Zeitschrift für Geschichtswissenschaften 25 (2014) 1-2, 194-219.

31 Hintergrund, URL: http://gedenkstaettesteinhof.at/de/content/hintergrund (abgerufen 01.09.2019).

32 Zu Schloss Hartheim als NS-Tötungseinrichtung vgl. Brigitte Kepplinger/Gerhart Marckhgott/ Hartmut Reese (Hg.), Tötungsanstalt Hartheim (Oberösterreich in der Zeit des Nationalsozialismus 3), Linz ${ }^{2} 2008$. 
mentationsstelle existiert, die Recherchen vor Ort ermöglicht. ${ }^{33}$ Beiden genannten Erinnerungsorten ist gemeinsam, dass die dort ermordeten Menschen auch namentlich dokumentiert und diese Informationen damit nicht nur der (privaten ebenso wie wissenschaftlichen) Forschung zu NS-Medizinverbrechen zugänglich gemacht werden, sondern auch zur Erinnerung und damit zur „Rückgabe“ der Identität und Individualität der Opfer beitragen. ${ }^{34}$

Dieser namentlichen Nennung der Opfer ging eine intensive gesellschaftliche Debatte voraus. Aus Angst vor anhaltender Stigmatisierung sprachen sich Angehörige von Opfern jahrzehntelang gegen eine Veröffentlichung der Namen aus. Erst in den letzten zwanzig Jahren trat hier ein Sinneswandel ein, vorangetrieben durch Angehörige, wie etwa Sigrid Falkenstein, welche das „Totschweigen der Vernichtung [als] Teil dieses Unrechts“ erachten, und HistorikerInnen, wie etwa Götz Aly. ${ }^{35}$ Ein wichtiges Resultat bestand in der Onlinestellung einer Liste von etwa 30.000 namentlich genannten Opfern der NS-,EEuthanasie“ durch das Deutsche Bundesarchiv im August 2018 mit dem Ziel, „die Opfer [...] nicht länger [zu] verschweigen“. ${ }^{6}$ Weiterhin gibt es hierzu allerdings gegenteilige Meinungen, wie etwa von der Arbeitsgemeinschaft Bund der „Euthanasie“-Geschädigten und Zwangssterilisierten. ${ }^{37}$

33 Geschichte 1945-2003, URL: http://www.schloss-hartheim.at/index.php/historischer-ort/geschichte-1945-2003; Dokumentationsstelle Hartheim, URL: http://www.schloss-hartheim.at/index.php/gedenken-ausstellung/dokumentationsstelle (beide abgerufen 01.09.2019).

34 Das „Gedenkbuch Hartheim“, das allerdings unter Berufung auf das Datenschutzgesetz 2000 nicht online verfügbar ist, beantwortet konkrete Anfragen von Angehörigen von (potenziellen) Opfern sowie WissenschaftlerInnen mittels der zugrunde liegenden Datenbank: Gedenkbuch Hartheim, URL: http://www.schloss-hartheim.at/index.php/gedenken-ausstellung/dokumentationsstelle/ gedenkbuch-hartheim (abgerufen 01.09.2019). Demgegenüber ist das „Totenbuch Spiegelgrund“, in dem die in der Anstalt Am Spiegelgrund zwischen 1940 und 1945 verstorbenen Minderjährigen verzeichnet wurden, sowohl über die Website der Gedenkstätte wie auch jener des DÖW online zugänglich: Totenbuch Spiegelgrund, URL: http://gedenkstaettesteinhof.at/de/totenbuch/totenbuchspiegelgrund sowie https://www.doew.at/personensuche (beide abgerufen 01.09.2019).

35 Robert Parzer, Sigrid Falkenstein: Ein Plädoyer für die Freigabe der Namen von Opfern der NS-„,Euthanasie“, Gedenkort-T4.eu, URL: https://www.gedenkort-t4.eu/de/blog/sigrid-falkenstein-ein-plaedoyer-fuer-die-freigabe-der-namen-von-opfern-der-ns-euthanasie (abgerufen 14.08.2020); Götz Aly, Die Belasteten - „Euthanasie“ 1936-1945. Eine Gesellschaftsgeschichte, Berlin 2013.

36 Namen von Opfern der NS-„Euthanasie“, zu denen im Bundesarchiv-Bestand R 179 Patientenakten vorliegen, Deutsches Bundesarchiv, URL: https://www.bundesarchiv.de/DE/Content/Downloads/Aus-unserer-Arbeit/liste-patientenakten-euthanasie.pdf?_blob=publicationFile (abgerufen 14.08.2020).

37 Stellungnahme der Arbeitsgemeinschaft Bund der „Euthanasie“-Geschädigten und Zwangssterilisierten zur Pressemitteilung des Bundesarchivs vom 30.08.2018 zur Online-Veröffentlichung von 
Aktuell wird an einer weiteren ehemaligen Landes-Heil- und Pflegeanstalt ein Lern- und Gedenkort ausgestaltet: am heutigen Landeskrankenhaus Hall in Tirol (Abteilungen für Psychiatrie und Psychotherapie). Durch die Entdeckung menschlicher Überreste auf dem Anstaltsgelände im Jahr 2011 kam es - nach einem bereits davor durchgeführten mehrjährigen Projekt zur Psychiatrie im historischen Raum Tirol von 1830 bis in die Gegenwart ${ }^{38}$ - zur Aufarbeitung durch eine HistorikerInnenkommission. Diese kam unter anderem zu dem Ergebnis, dass in Hall keine dezentrale „Euthanasie“ stattgefunden haben dürfte und es sich um einen nicht mehr existenten allgemeinen Anstaltsfriedhof gehandelt habe. Neben einer Publikationsreihe $^{39}$ erfolgte als weiteres Resultat der wissenschaftlichen Auseinandersetzung mit der Anstaltsgeschichte auch die Einrichtung des Historischen Archivs des Psychiatrischen Krankenhauses Hall, das aktuell neben der Archivarbeit auch Führungen anbietet und mit der Ausgestaltung zum Lern- und Gedenkort beschäftigt ist. ${ }^{40}$

Die Entwicklung am Landeskrankenhaus Hall kann zugleich als Beispiel für jene Forschung gelten, die im Folgenden als „anlassbezogen“ bezeichnet wird. Das bedeutet, dass konkrete Ereignisse - wie in diesem Fall die Entdeckung des Anstaltsfriedhofes - den Ausgangspunkt für weitere Forschungen darstellen, die bis dahin aus unterschiedlichen Gründen nicht erfolgt oder vernachlässigt worden waren.

\section{3. „Anlassbezogene" Forschung}

In welchem Sinn die Bezeichnung „anlassbezogen“ hier verwendet wird, wurde bereits dargelegt. Wichtig ist darüber hinaus, darauf hinzuweisen, dass mehrere Faktoren zu einem solchen „Forschungsanstoß“ zusammentreffen müssen: Dazu zählt wesentlich öffentliches und staatliches Interesse. Beide Aspekte bedingen einander bis zu einem gewissen Grad und können nicht isoliert voneinander betrachtet werden. Öffentliche Aufmerksamkeit für bestimmte Themenbereiche erleichterte im letzten Drittel des 20. Jahrhunderts vielfach nicht nur eine kritische wissenschaftliche

Namen der „Euthanasie“-Opfer, URL: https://www.euthanasiegeschaedigte-zwangssterilisierte.de/ neues/aktuell-2018/15-11-18-bundesarchiv-macht-namen-der-opfer-von-ns-euthanasieverbrechen-online-zugaenglich-stellungnahme-ag-bez/ (abgerufen 14.08.2020).

38 Elisabeth Dietrich-Daum/Hermann J.W. Kuprian/Siglinde Clementi/Maria Heidegger/Michaela Ralser (Hg.), Psychiatrische Landschaften. Die Psychiatrie und ihre Patientinnen und Patienten im historischen Raum Tirol seit 1830, Innsbruck 2011.

39 Veröffentlichungen der Kommission zur Untersuchung der Vorgänge um den Anstaltsfriedhof des Psychiatrischen Krankenhauses in Hall in Tirol in den Jahren 1942 bis 1945, 4 Bde., 2014-2018.

40 Gedenkort für NS-Opfer in Hall, ORF Tirol, 10.10.2019, URL: https://tirol.orf.at/stories/3016605/ (abgerufen 09.11.2019). 
Aufarbeitung, sondern ermöglichte sie erst. Ablesbar ist daran auch ein allgemeiner gesellschaftlicher bzw. politischer Wandel im Umgang mit der NS-Vergangenheit: Durch die Waldheim-Affäre in den Jahren 1986/1987 und die Abkehr von der „Opferthese" wurden nunmehr auch kritische Fragestellungen in der Medizingeschichte verstärkt massentauglich. In diesem Kontext ist eine Sendung des Diskussionsformats „Club 2“ des ORF aus dem Jahr 1989 hervorzuheben: Neben weiteren Gästen waren Michael Hubenstorf und der Kriminalbiologe Friedrich Stumpfl, der von 1939 bis 1945 das nach dem „Anschluss“ neu gegründete Innsbrucker Institut für Erbund Rassenbiologie leitete, anwesend. Diese Konfrontation war deshalb bedeutend, weil Hubenstorf mittels Archivquellen Stumpfls Narrativ der persönlichen Integrität während der NS-Zeit widerlegen konnte. Auch die Aussage des damaligen Rassenhygienikers, er habe niemals Menschen als „minderwertig“ bezeichnet, falsifizierte Hubenstorf. ${ }^{41}$ Das Beispiel Stumpfls zeigt darüber hinaus die vielfältigen Aspekte von Medizingeschichte: Von seiner Ausbildung her Psychiater, hatte er sich Anfang der 1930er-Jahre der Kriminalbiologie zugewandt und war während des Nationalsozialismus unter anderem als Gutachter für das Innsbrucker Erbgesundheitsgericht tätig gewesen. Forschungen der vergangenen zwei Jahrzehnte beschäftigten sich immer wieder mit Stumpfl, und zwar unter dem Aspekt der Eugenik und Rassenhygiene, der Universitäts- und Wissenschaftsgeschichte, aber auch in Zusammenhang mit Heim- und Fürsorgegeschichte. ${ }^{42}$ Nach wie vor ein Forschungsdesiderat ist Stumpfls

41 ORF, Club 2: „Mißbrauchte Medizin“, Fernsehsendung, 20.04.1989; vgl. auch Michael Hubenstorf, Kontinuität und Bruch in der Medizingeschichte. Medizin in Österreich 1938-1955, in: Friedrich Stadler (Hg.), Kontinuität und Bruch. 1938 - 1945 - 1955. Beiträge zur österreichischen Kulturund Wissenschaftsgeschichte (Emigration - Exil - Kontinuität. Schriften zur zeitgeschichtlichen Kultur- und Wissenschaftsforschung 3), 299-332, 330-331.

42 Thomas Mayer, Eugenische Forschung als „eine politische nationalsozialistische Tätigkeit“. Die akademische Verbindung von Eugenik, Anthropologie, Kriminalbiologie und Psychiatrie am Beispiel des Karriereverlaufs von Friedrich Stumpfl (1902-1997), in: Schriftenreihe der Deutschen Gesellschaft für Geschichte der Nervenheilkunde 15 (2009), 239-265; Horst Schreiber, „Angesichts des erheblichen Schwachsinns und der (...) psychopathischen Minderwertigkeit ist Sterilisation zu fordern", in: Monika Jarosch/Lisa Gensluckner/Horst Schreiber/Alexandra Weiss (Hg.), Gaismair-Jahrbuch 2009. Überwältigungen, Innsbruck/Wien/München/Bozen 2008, 99-106; Friedrich Stepanek, Die Vorgeschichte der Kinderbeobachtungsstation in der NSZeit und in den unmittelbaren Nachkriegsjahren, in: Elisabeth Dietrich-Daum/Michaela Ralser/ Dirk Rupnow (Hg.), Psychiatrisierte Kindheiten. Die Kinderbeobachtungsstation von Maria Nowak-Vogl, Innsbruck 2020, 87-127, 88-102; Marion Amort/Regina Bogner-Unterhofer/Monika Pilgram/Gabi Plasil/Michaela Ralser/Stefanie Stütler/Lisl Strobl, Humanwissenschaften als Säulen der „Vernichtung unwerten Lebens“. Biopolitik und Faschismus am Beispiel des Rassehygieneinstituts in Innsbruck, in: erziehung heute 1999/1, 32-40; Elisabeth Grosinger, Pseudowissenschaftliche Forschungen über Jenische während und nach der NS-Zeit, in: Horst Schreiber/Lisa Gensluckner/Monika Jarosch/Alexandra Weiss (Hg.), Gaismair-Jahrbuch 
Nachkriegstätigkeit als Gerichtsgutachter - tiefere Auseinandersetzungen mit von ihm in diesem Kontext erstellten Beurteilungen wären dazu geeignet, insbesondere Kontinuitäten oder auch Brüche in der allgemein weiterbestehenden eugenischen Beurteilung von Menschen darzustellen. Exemplarisch wird daran deutlich, dass „Medizingeschichte“ mittlerweile kein eng abgegrenztes Forschungsfeld ist, sondern Berührungspunkte, Verbindungen und Überschneidungen mit anderen Themenbereichen aufweist: mit sozialmedizinischen, juristischen, naturwissenschaftlichen und gesellschaftspolitischen Aspekten.

Als prominentestes österreichisches Beispiel ist der bereits erwähnte Fall Heinrich Gross zu sehen, der über Jahrzehnte immer wieder medial diskutiert wurde. 1975 war der Spiegelgrund-Überlebende Friedrich Zawrel mit einer Begutachtung durch den nunmehrigen Gerichtspsychiater Gross konfrontiert, was letztlich den Anstoß zu einer öffentlichen Thematisierung von Gross' NS-Verbrechen gab. Auf die bereits erwähnten Anschuldigungen durch Vogt reagierte Gross mit einer Ehrenbeleidigungsklage, die er verlor, da seine Beteiligung an der Ermordung von Kindern am Spiegelgrund bewiesen werden konnte. Trotzdem kam es erst Ende $1997 \mathrm{zu}$ einer Anklageerhebung. Dem Prozess, der Anfang 2000 begann, konnte sich der nunmehr 84-jährige Gross letztlich entziehen, da er vom Gerichtspsychiater Reinhard Haller aufgrund einer bestehenden Demenzerkrankung als verhandlungsunfähig eingestuft wurde. Ein am selben Tag von Gross gegebenes Fernsehinterview änderte daran nichts, unterstützte jedoch die internationale Kritik an Hallers Gutachten. ${ }^{43}$ Während hier Gross' Verantwortung für die Ermordung der am Spiegelgrund internierten Minderjährigen im Mittelpunkt stand, gibt es einen weiteren Aspekt, der von diesem Ausgangspunkt in den letzten Jahren zu einem zentralen Thema der NS-Medizingeschichtsforschung wurde: die Verwendung von medizinischen Präparaten, die im Nationalsozialismus aus Verfolgungskontexten entstanden, für Forschung und Lehre in der Zweiten Republik. Gross hatte wie andere Mediziner die Forschungsbedingungen der NS-Zeit wissenschaftlich für sich zu nutzen verstanden

2006. Am Rand der Utopie, Innsbruck/Wien/München/Bozen 2005, 102-112; Christian Lechner, Das Innsbrucker Institut für Erb- und Rassenbiologie, in: Österreichische HochschülerInnenschaft (Hg.), Österreichische Hochschulen im 20. Jahrhundert. Austrofaschismus, Nationalsozialismus und die Folgen, Wien 2013, 190-203; Ina Friedmann, „Man könnte direkt zweifeln, ob der Frager oder die Befragte schwachsinnig ist!“ Zwangssterilisierungen und Zwangskastrationen im Gau Tirol-Vorarlberg unter besonderer Berücksichtigung der Beteiligung der Universität Innsbruck, Innsbruck 2020, 37-42, 77-80, URL: https://www.uibk.ac.at/zeitgeschichte/ unfruchtbarmachung-und-freiwillige-entmannung/pdf-s/erbgesundheit_tirol_vorarlberg.pdf (abgerufen 17.08.2020); Friedmann/Rupnow, Universität, 298-308.

43 ORF-Interview mit „frischem“ Gross könnte Folgen haben, Kurier, 23.03.2000, URL: https://bit. ly/2QRvzhG (abgerufen 26.11.2019). 
und publizierte noch in den 1960er-Jahren auf Basis der am Spiegelgrund entstandenen Hirnpräparate, zu diesem Zeitpunkt an seiner neuen institutionellen Heimat, dem 1968 neu gegründeten Ludwig Boltzmann Institut zur Erforschung der Mißbildungen des Nervensystems. ${ }^{44}$

Diese späte Problematisierung der wissenschaftlichen Verwertung von NS-Opfern wurde Ende der 1990er-Jahre auch in Zusammenhang mit dem „PernkopfAtlas“ breit diskutiert. Eduard Pernkopf, Ordinarius für Anatomie in Wien ab 1933, Dekan der Medizinischen Fakultät 1938 bis 1943 und von 1943 bis Kriegsende Rektor der Wiener Universität sowie ab 1933 in der NSDAP und ab 1934 in der SA engagiert, hatte von 1937 bis zu seinem Tod (während der Arbeit am vierten Band) an seinem Lehrbuch „Topographische Anatomie des Menschen. Atlas der regionärstratigraphischen Präparation“ gearbeitet. Als Vorlage für die Abbildungen wurden Leichname im Nationalsozialismus hingerichteter Personen verwendet, was letztlich durch eine 1997 eingesetzte Senatskommission der Universität Wien im Detail erforscht werden sollte. Die Ergebnisse, die keinen Aufschluss über konkrete Zahlen bieten, doch die Heranziehung von NS-Opfern zweifelsfrei belegen, wurden 1998 in einem Senatsbericht publiziert. ${ }^{45}$

Der „Pernkopf-Atlas“ findet aufgrund seiner Detailtreue auch heute noch Verwendung in der Chirurgie; eine Tatsache, die aufgrund des Entstehungskontextes ein ethisches Dilemma aufwirft, dem sich MedizinerInnen, HistorikerInnen und VertreterInnen jüdischer Hinterbliebenengemeinschaften und der halachischen Rechtsauslegung gleichermaßen $\mathrm{zu}$ stellen haben. Eine rezente interdisziplinäre Auseinandersetzung diskutiert die religiösen Gesetze des Judentums über den Umgang mit dem menschlichen Leichnam gemeinsam mit den medizinischen Argumenten für eine Anwendung des Atlas im Rahmen komplexer Operationen und kommt zu folgendem, hier zusammengefassten, Ergebnis: Wenn der „PernkopfAtlas“ aus fachlichen Gründen zur Unterstützung bei Operationen herangezogen werden muss, haben die Beteiligten die Entstehungsgeschichte zu kennen und zu würdigen. Aus Sicht des jüdischen Rechtsgelehrten Joseph A. Polak und des Bioethi-

44 Wolfgang Neugebauer/Peter Schwarz, Der Wille zum aufrechten Gang. Offenlegung der Rolle des BSA bei der gesellschaftlichen Integration ehemaliger Nationalsozialisten, Wien 2005, 274. Die beruflich von Gross angelegte Separata-Sammlung befindet sich seit 2010 in der Zweigbibliothek der Geschichte der Medizin im Josephinum. Harald Albrecht/Bruno Bauer/Walter Mentzel, Josephinische Bibliothek und medizinhistorische Bestände der Universitätsbibliothek der Medizinischen Universität Wien, in: GMS Medizin - Bibliothek - Information 12 (2012) 1/2, 1-19, 12.

45 Akademischer Senat der Universität Wien (Hg.), Untersuchungen zur anatomischen Wissenschaft in Wien 1938-1945. Senatsprojekt der Universität Wien, Wien 1998. Die Erstversion des Berichts ist an der Universitätsbibliothek Wien, die zweite, korrigierte Auflage desselben Jahres ist neben Wien an den Universitätsbibliotheken Linz und Innsbruck vorhanden. 
kers Michael Grodin ist eine Verwendung des Atlas eventuell sogar obligat, wenn dadurch ein Leben gerettet werden kann (im Original: „Moreover, if it is certain that if a single life can be saved using this atlas, then doing so would not only be permissible but probably mandatory")..$^{46}$

Die Auseinandersetzung mit dem vornehmlich in Wien entstandenen „PernkopfAtlas" hat auch dazu geführt, dass rezente Empfehlungen zum Umgang mit menschlichen Überresten aus der Zeit des Holocaust als „Vienna Protocol“ bezeichnet werden. Diese Richtlinien entstanden aus den Diskussionen einer interdisziplinären Kommission von ExpertInnen auf einem entsprechenden Symposium in Yad Vashem am 14. Mai 2017.47 Die Beschäftigung mit dieser Frage war ebenfalls anlassbezogen: Im Zuge von Kanalarbeiten im Juli 2014 auf dem Gelände der Freien Universität Berlin und nahe des ehemaligen Kaiser-Wilhelm-Instituts für Anthropologie, menschliche Erblehre und Eugenik (KWI-A) in Berlin wurden Knochen von etwa 15 Personen gefunden. Trotzdem den Verantwortlichen offenbar bewusst war, dass es sich dabei um Opfer des Nationalsozialismus handeln könnte, wurden die Überreste im Dezember 2014 nach vorheriger rechtsmedizinischer Untersuchung und Fotodokumentation kremiert. Diese Knochen könnten vom KZ-Arzt Josef Mengele seinem Lehrer am KWI-A, Otmar von Verschuer, für dessen Forschung zugeschickt worden sein. Das unkritische Vorgehen der Beteiligten hatte internationale Kritik zur Folge, führte zu weiteren lokalen Ausgrabungen, der oben erwähnten Zusammenkunft in Yad Vashem und damit letztlich zu interdisziplinär getroffenen Empfehlungen für den Umgang mit zukünftigen Funden, also dem „Vienna Protocol““48

4. Die Integration sozialer, pädagogischer und naturwissenschaftlicher Ansätze in die Medizingeschichtsforschung

Eng verbunden mit der Kontroverse um Heinrich Gross waren die von (Gerichts-) PsychiaterInnen wie ihm selbst auch nach 1945 weiter vertretenen Sichtweisen auf Minderjährige aus sozial schwachen und marginalisierten Familien. Zentral dabei

46 Andrew Yee/Ema Zubovic/Jennifer Yu/Shuddhadeb Ray/Sabine Hildebrandt/William E. Seidelman/Rabbi Joseph A. Polak/Michael A. Grodin/J. Henk Coert/Douglas Brown/Ira J. Kodner/Susan E. Mackinnon, Ethical considerations in the use of Pernkopf's Atlas of Anatomy: A surgical case study, in: Surgery 165 (2018) 5, 860-867.

47 Vienna Protocol, URL: https://bit.ly/2rBvoMX (abgerufen 30.11.2019).

48 Götz Aly, Knochenfund an der FU Berlin. Unverhoffte Freuden eines Historikers, Teil 2, URL: https://bit.ly/2Rg4ipt (abgerufen 30.11.2019). Vgl. auch Vienna Protocol, URL: https://bit. ly/2rBvoMX (abgerufen 30.11.2019). 
kann, dem österreichischen Sozialhistoriker Reinhard Sieder folgend, auf das Paradigma der "schuldhaften Verwahrlosung“ hingewiesen werden.49 Diesem folgend wurde bis in die zweite Hälfte des 20. Jahrhunderts die Schuld für randständiges gesellschaftliches Dasein, soziale Marginalisierung oder Armut bei den Betroffenen selbst gesehen, ohne gesellschaftlich-strukturelle Mechanismen zu berücksichtigen. In der jüngeren Vergangenheit ist der medizinhistorische Fokus in diesem Bereich vermehrt auf die Erforschung der Rolle von Kinderpsychiatrie und Heilpädagogik im Umgang mit Minderjährigen aus Heimkontexten sowie innerhalb des Fürsorgesystems gelegt worden. Im Mittelpunkt haben dabei bisher zentrale Einrichtungen in den österreichischen Bundesländern gestanden, die als Beobachtungsräume konzipiert waren. Unter Berücksichtigung der jeweiligen Spezifika zeigen sich dennoch in einer vergleichenden Perspektive Gemeinsamkeiten, die Aufschluss über den institutionellen Umgang mit Minderjährigen in Österreich geben, die als „schwierig“ oder unangepasst eingestuft wurden oder etwa aus einem negativ bewerteten Familienumfeld kamen (beispielsweise alleinerziehende und alleinverdienende Mütter). ${ }^{\circ}$ Diese gesamtösterreichische Übereinstimmung in Wahrnehmung und Umgang mit den Betroffenen ist nicht zuletzt auf die akademische Sozialisation der in den jeweiligen Bundesländern praktizierenden Personen zurückzuführen: Nicht allein, dass diese bei den in der Zweiten Republik praktizierenden ÄrztInnen vornehmlich während des Nationalsozialismus erfolgt war, trug darüber hinaus auf dem Beispielgebiet der Heilpädagogik die langjährige Dominanz der SchülerInnen von Hans Asperger an zentralen Entscheidungs- und Begutachtungspositionen zu dieser Kon-

49 Reinhard Sieder, Wissenschaftliche Diskurse, Jugendfürsorge und Heimerziehung in Wien im 20. Jahrhundert, in: Virus. Beiträge zur Sozialgeschichte der Medizin 17 (2018), 29-56, 38.

50 Vgl. Ingrid Bauer/Robert Hoffmann/Christina Kubek, Abgestempelt und ausgeliefert. Fürsorgeerziehung und Fremdunterbringung in Salzburg nach 1945. Mit einem Ausblick auf die Wende hin zur Sozialen Kinder- und Jugendarbeit von heute, Innsbruck 2013; Magdalena Colantonio, Die Geschichte der Heilpädagogischen Station des Landes Steiermark in Wetzelsdorf - mit besonderer Berücksichtigung der historischen Entwicklung der Heilpädagogischen Arbeit, Dipl.-Arb., Universität Graz 2002; Dietrich-Daum/Ralser/Rupnow (Hg.), Kindheiten; zu Franz Wurst in Klagenfurt wurden die Ergebnisse des mehrjährigen Forschungsprojekts unter Leitung von Ulrike Loch im Jänner 2020 präsentiert, vgl. auch Alma Brkic-Elezovic/Ulrike Loch, Institutionelle Gewalt an Kindern und Jugendlichen, in: Sara Blumenthal/Karin Lauermann/Stephan Sting (Hg.), Soziale Arbeit und soziale Frage(n) (Schriftenreihe der ÖFEB-Sektion Sozialpädagogik), Opladen/Berlin/ Toronto 2018, 307-320; zur Entwicklung der Heilpädagogischen Abteilung in Wien vgl. die an der Universität Wien durchgeführte Dissertation der Verfasserin mit dem Titel „[...] ist ohne lückenlose Führung gefährlich und auch selbst gefährdet.“ Die Heilpädagogische Abteilung der Wiener Universitäts-Kinderklinik von 1911-1949. Konzepte und Kontinuitäten. Vgl. zur Wiener Heilpädagogik auch Sieder, Diskurse. 
formität und Kontinuität bei..$^{51}$ In diesem Kontext kommt auch der Auseinandersetzung mit Eugenik und „eugenischen Netzwerken“ große Bedeutung zu, die eng gefasst den Bereich der traditionellen Medizingeschichte verlässt. Gerade an diesem Beispiel wird allerdings sichtbar, wie eng verknüpft die medizinischen, biologischen, naturwissenschaftlichen und juristischen Bereiche waren.

\section{Gedenken, Erinnern und Datenschutz}

Eine weitere Entwicklung der jüngsten Vergangenheit ist die insbesondere von Paul Weindling verfolgte und vorangetriebene namentliche Erfassung sämtlicher Opfer der NS-Medizin. ${ }^{52}$ Dies steht im Gegensatz zur bisherigen Herangehensweise des Schutzes der Persönlichkeitsrechte der Betroffenen durch Anonymisierung und ist aufgrund der - international verschiedenen - Datenschutzbestimmungen durchaus schwierig durchzusetzen. Der Gedanke dieses namentlichen Gedenkens und Bekanntmachens von Opfern folgt erinnerungskulturellen Ansätzen, die unter anderem den vielfach in das Argument des Datenschutzes gekleideten Schutz von TäterInnen beenden, aber auch respektvolles Gedenken ermöglichen wollen. Dabei ist zusätzlich zwischen der namentlichen Nennung von in medizinischen Experimenten oder den euphemistisch als „Euthanasie“ bezeichneten Morden getöteten Menschen und den Überlebenden von Menschenexperimenten, Zwangssterilisierungen und anderen Medizinverbrechen zu differenzieren.

Die Entscheidung, in welcher Art und Weise den NS-Opfern, neben der Nennung in für die Öffentlichkeit einsehbaren Onlinedatenbanken, an den jeweiligen Standorten gedacht werden soll, stellt eine große Herausforderung für die Beteiligten dar. Mehrfacherwähnungen an Denkmälern von Personen, die etwa an einer NS-Hinrichtungsstätte oder in einem Konzentrationslager ermordet und deren Leichname an andernorts angesiedelten (universitären) Instituten für Forschung und Lehre herangezogen wurden, sind unvermeidlich, sollte ein Anspruch auf überregionale Kontextualisierung bestehen. Der konkrete erinnerungskulturelle Ansatz einer Gedenkplakette oder Steintafel am Ort der Erinnerung hat lange Tradition und durchaus Legitimation. Ein solches Denkmal für Opfer von NS- und anderen

51 Ingeborg Judtmann in Salzburg, Irene Plass in Graz, Erwin Schmuttermeier in Niederösterreich, Franz Wurst in Kärnten.

52 Paul Weindling, Victims and Survivors of Nazi Human Experiments. Science and Suffering in the Holocaust, London 2014; Paul Weindling/Anna von Villiez/Aleksandra Loewenau/Nichola Farron, The victims of unethical human experiments and coerced research under National Socialism, in: Endeavor 40 (2016) 1, 1-6. 
Verbrechen verbleibt jedoch letztlich im Bereich einer Geste, wenn nicht auch ein aktives Gedenken und Erinnern stattfindet. Ein Beispiel hierfür sind Gedenk- und Befreiungsfeiern von Konzentrationslagern sowie anderweitige Erinnerungsveranstaltungen anlässlich von Jahrestagen. Ein Problem bei Ersterem ist allerdings die teils vorhandene geographische Abgeschiedenheit der Lager, sodass kaum eine breite Öffentlichkeit erreicht werden kann. ${ }^{53}$ Zudem stellt sich die wichtige Frage, wer mit solchen Veranstaltungen adressiert werden soll und kann. Wie von der oben erwähnten „ASAMANS“-Studie unterstützt, sollten im medizinischen Kontext jedenfalls auch die Medizinstudierenden dezidiert eingeladen werden. Eine entsprechend aufbereitete Information der Anwesenden über die Hintergründe eines Denkmals bzw. die NS-Opfer selbst ist dabei obligat und Voraussetzung für eine Sensibilisierung der nächsten Generation für die Wichtigkeit des Erinnerns als Grundlage für die Prävention von erneuten ethisch-moralischen Grenzüberschreitungen, wie sie im Nationalsozialismus programmatisch vorgefallen sind. Nur eine Verknüpfung des Ortes des Gedenkens mit adäquaten Veranstaltungen erinnert nachhaltig an die individuellen NS-Opfer der jeweiligen Standorte und beugt dadurch der Vollendung der „Vernichtung der Opfer [...] durch das Vergessen“ vor. ${ }^{54}$

\section{Desiderate und Ausblick}

Obwohl die zeithistorische Forschung zur österreichischen Medizingeschichte in den letzten Jahrzehnten bereits viele (biographische, strukturelle, interdisziplinäre und institutionelle) Aspekte in den Blick genommen hat, von denen hier nur ein Bruchteil thematisiert werden konnte, gibt es nach wie vor Forschungslücken zu schließen. Dies betrifft nicht zuletzt Forschungsinhalte von ÄrztInnen während des Nationalsozialismus, aber vermehrt auch auf diese Zeit aufbauende berufliche Netzwerke nach 1945. ${ }^{55}$ Der außerhalb von Wien fehlenden universitären Verankerung der Medizingeschichte mittels eigener Institute wird zwar durch Initiativen

53 Die Gedenk- und Befreiungsfeier in der KZ-Gedenkstätte Mauthausen, URL: https://bit. ly/34MuFa4 (abgerufen 30.11.2019).

54 Hans-Joachim Lang, Die Namen der Nummern. Wie es gelang, die 86 Opfer eines NS-Verbrechens zu identifizieren, Hamburg 2004, 13.

55 Ein Sammelband zum Thema „Strukturen und Netzwerke - Medizin und Wissenschaft in Wien 1945 bis 2004. Kontinuitäten und Brüche einer Forschungslandschaft im Kontext internationaler Veränderungsprozesse“, herausgegeben von Wolfgang Schütz, Felicitas Seebacher, Birgit Nemec und Hans-Georg Hofer unter Mitarbeit der Arbeitsgruppe Geschichte der Medizin der Österreichischen Akademie der Wissenschaften, der sich mit ebendieser Thematik vertiefend auseinandersetzt, ist für 2020/2021 in Vorbereitung. 
von WissenschaftlerInnen(gruppen) begegnet, die Reichweite dieser Aktivitäten insbesondere hinsichtlich der notwendigen medizinhistorischen Lehre und Sensibilisierung von Medizinstudierenden ist aber begrenzt. Hinzu kommt der vielfach vernachlässigte kritische Umgang mit Sammlungsbeständen an Universitätskliniken und -instituten. Für den Standort Innsbruck etwa fehlt weiterhin für die meisten klinischen Institute eine systematische Aufarbeitung der Aktivitäten während der Zeit des Nationalsozialismus. Wie oben erwähnt, geschieht dies momentan für das Anatomische Institut sowie im Zusammenhang mit der Erbgesundheitsgerichtsbarkeit mit jenen Abteilungen, welche die Zwangssterilisierungen durchführten. Weiterhin bleibt damit aber die Geschichte des Großteils der Innsbrucker Institute und Kliniken ebenso ein Desiderat wie jene vieler weiterer österreichischer medizinischer Institutionen. 


\section{Universitäten}

Maria Wirth und Andreas Huber

Der vorliegende Beitrag beschäftigt sich mit einem Forschungsbereich, der zuletzt einen Boom erlebt hat. Er gibt zunächst einen Überblick über die Entwicklung des österreichischen Universitätssystems und die Genese der zeithistorischen Universitätsgeschichtsschreibung sowie wichtige Charakteristika des Arbeitsfeldes. Im Anschluss werden zentrale Themenfelder sowie Desiderate der Forschung beleuchtet, wobei ein besonderer Fokus auf die jüngeren Arbeiten gelegt wird. Ein Anspruch auf Vollständigkeit kann nicht erhoben werden, da sich die Materie - bedingt durch die vielen institutionsgeschichtlichen Arbeiten - durch eine große Unübersichtlichkeit und Fragmentierung auszeichnet. ${ }^{1}$

\section{Das österreichische Universitäts- und Hochschulsystem}

Die Anfänge der Universitätsentwicklung auf dem Gebiet des heutigen Österreich reichen mit den Gründungen der Universitäten in Wien (1365), Graz (1585) und Innsbruck (1669) weit in die Vergangenheit zurück. Nach der Grundsteinlegung für die Veterinärmedizinische Universität Wien (1765) etablierten sich im 19. Jahrhundert „Spezialhochschulen“, die ebenso wie die in den 1960er-Jahren (wieder) gegründeten Hochschulen in Salzburg, ${ }^{2}$ Linz und Klagenfurt seit 1975 als Universitäten bezeichnet werden (Technische Universitäten in Wien und Graz, Universität für Bodenkultur Wien, Wirtschaftsuniversität Wien, Montanistische Universität Leoben). Ein weiterer Ausbau bzw. eine Neuordnung des tertiären Bildungssystems folgten ab den 1990er-Jahren. 1994 wurde die Donauuniversität Krems als Zentrum für die universitäre Weiterbildung errichtet. Die bisherigen Kunsthochschulen in Wien, Salzburg, Graz und Linz wurden $1998^{3}$ und die Medizinischen Fakultäten

1 Der vorliegende Beitrag wurde im Sommer 2019 fertiggestellt und im Sommer 2020 leicht aktualisiert. Wir bedanken uns bei Ina Friedmann, Thomas König und Juliane Mikoletzky für die kritische Durchsicht dieses Beitrags und wertvolle Hinweise.

2 In Salzburg hatte es bereits von 1622 bis 1810 eine Universität und ab 1850 eine Theologische Fakultät gegeben.

3 Wien: Universität für angewandte Kunst, Universität für Musik und darstellende Kunst, Akademie der bildenden Künste, Salzburg: Universität Mozarteum, Graz: Universität für Musik und darstellende Kunst, Linz: Universität für künstlerische und industrielle Gestaltung. 
in Wien, Graz und Innsbruck infolge des Universitätsgesetzes 2002 (UG 2002) zu Universitäten. Die Einrichtung von Fachhochschulen als neuer (in Deutschland bereits bestehender) Ausbildungstyp mit einer starken Praxisorientierung und ohne Promotionsrecht wurde ab 1993, jene von Privatuniversitäten ab 1999 möglich. Aus den Pädagogischen Akademien, die seit 1962 der Ausbildung von PflichtschullehrerInnen gedient hatten, wurden im Zuge der Schaffung eines einheitlichen europäischen Hochschulraums (Bologna-Prozess) und einer Akademisierung der Lehrerausbildung 2005 Hochschulen. Gleichfalls ermöglichte das Hochschulgesetz 2005 auch die Anerkennung von privaten Pädagogischen Hochschulen. 2006 folgte nach längeren Debatten über die Einrichtung einer auf Grundlagenforschung spezialisierten „Eliteuniversität“, die auch $\mathrm{PhD}$-Programme anbieten sollte, die Gründung des Institute of Science and Technology (IST) Austria bei Klosterneuburg. ${ }^{4}$

Gegenwärtig (2019/2020) besteht das österreichische Universitäts- und Hochschulsystem aus 22 öffentlichen und 16 Privatuniversitäten, 21 Fachhochschulen, ${ }^{5}$ 9 staatlichen und 4 privaten Pädagogischen Hochschulen. ${ }^{6}$ Hinzu kommt das IST Austria, das hauptsächlich der Forschung dient.

\section{Abriss der österreichischen Universitätsgeschichtsschreibung}

Die Universitätsgeschichte ist kein ausschließliches Thema der Zeitgeschichte. Erste Publikationen zur Geschichte der österreichischen Universitäten erschienen bereits vor mehreren Jahrhunderten. ${ }^{7}$ Mit der Herausbildung der Zeitgeschichte ab den 1960er-Jahren wurden die Hochschulen auch zu einem Gegenstand von zeithistorischen Arbeiten, die oftmals die Trends ihrer Zeit reflektierten. So beschäf-

4 Bettina Perthold-Stoitzner, Hochschulrecht im Strukturwandel, Wien 2012.

5 Universitäten, Bundesministerium für Bildung, Wissenschaft und Forschung, URL: https://www.bmbwf.gv.at/Themen/Hochschule-und-Universit\%C $3 \%$ A 4 t/Hochschulsystem/ Universit\%C3\%A4ten.html (abgerufen 25.08.2020); Fachhochschulen, URL: https://www.bmbwf. gv.at/Themen/Hochschule-und-Universit\%C3\%A4t/Hochschulsystem/Fachhochschulen.html (abgerufen 25.08.2020); Privatuniversitäten, URL: https://www.bmbwf.gv.at/Themen/Hochschule-und-Universit\%C3\%A4t/Hochschulsystem/Privatuniversit\% $\mathrm{C}_{3} \%$ A4ten.html (abgerufen 25.08.2020).

6 Übersicht über die 14 Pädagogischen Hochschulen in den 4 Verbünden, Bundesministerium für Bildung, Wissenschaft und Forschung, URL: https://www.bmbwf.gv.at/Themen/schule/fpp/ph/ pv_verb.html (abgerufen 25.08.2020).

7 Kurt Mühlberger, Universitätsgeschichtliche Forschung in Österreich. Ausgewählte Beispiele, Wege und Methoden 16.-20. Jahrhundert, in: Ágnes Fischer-Dárdai/István Lengvári/Éva Schmelczer-Pohánka (Hg.), University and Universality, Pécs 2017, 135-161. 
tigte sich bereits Erika Weinzierl als Doyenne der österreichischen Zeitgeschichte in ihrer Salzburger Antrittsvorlesung 1969 mit dem Verhältnis von Universität und Politik in der Zwischenkriegszeit. ${ }^{8}$ Als in den frühen 1970er-Jahren erste Handbücher zur Zweiten Republik erschienen, war die Universitätspolitik wohl nicht zuletzt aufgrund der Diskussion über eine Hochschulreform, die im Universitäts-Organisationsgesetz 1975 (UOG 1975) mündete, ebenfalls präsent. ${ }^{9}$ Mit dem „Turn“ zur Arbeitergeschichte in den 1970er-Jahren sowie dem Erstarken der Frauengeschichtsforschung wurden die sozialistischen StudentInnen ebenso bearbeitet ${ }^{10}$ wie die Situation von Frauen an den Universitäten. ${ }^{11}$ In den $1980 e r-J a h r e n$, als der Umgang Österreichs mit der NS-Vergangenheit zum Gegenstand der gesellschaftlichen Auseinandersetzung wurde, entwickelte sich die Zeit des Nationalsozialismus zum wichtigen, bis heute vorherrschenden Thema der Universitätsgeschichte. ${ }^{12}$

Generell kann sowohl für Österreich, Deutschland als auch für Europa im Allgemeinen seit den 1980er-Jahren ein Aufschwung der Universitätsgeschichte (jedoch nicht beschränkt auf die Zeitgeschichte) beobachtet werden, der mit einer Vermehrung und Professionalisierung der Universitätsarchive einhergeht. ${ }^{13}$ So wurde -

8 Erika Weinzierl, Universität und Politik in Österreich (Salzburger Universitätsreden 33), Salzburg/ München 1969.

9 Bernd Schilcher, Hochschulen, in: Erika Weinzierl/Kurt Skalnik (Hg.), Österreich. Die Zweite Republik, Bd. 2, Graz 1972, 347-367.

10 Vgl. 5.3 Studierende.

11 Vgl. 5.5 Frauen.

12 Dies hat dazu geführt, dass mittlerweile für alle Universitäten bis auf die Montanuniversität Leoben mehr oder weniger ausführliche Studien vorliegen. Vgl. an jüngeren Publikationen u. a.: Paulus Ebner, Politik und Hochschule. Die Hochschule für Bodenkultur 1914-1955 (Forschungen und Beiträge zur Wiener Stadtgeschichte 37), Wien 2002; Juliane Mikoletzky, „Von jeher ein Hort starker nationaler Gesinnung“. Die Technische Hochschule in Wien und der Nationalsozialismus (Veröffentlichungen des Universitätsarchivs der Technischen Universität Wien 8), Wien 2003; Peter Goller/Georg Tidl, „Jubel ohne Ende!“ Die Universität Innsbruck im März 1938. Zur Nazifizierung der Tiroler Landesuniversität, Wien 2012; Juri Giannini/Maximilian Haas/Erwin Strouhal (Hg.), Eine Institution zwischen Repräsentation und Macht. Die Universität für Musik und darstellende Kunst Wien im Kulturleben des Nationalsozialismus (Musikkontext 7), Wien 2014; Verena Pawlowsky, Die Akademie der bildenden Künste Wien im Nationalsozialismus. Lehrende, Studierende und Verwaltungspersonal, Wien/Köln/Weimar 2015; Lisa Rettl, Die Wiener Tierärztliche Hochschule und der Nationalsozialismus. Eine Universitätsgeschichte zwischen dynamischer Antizipation und willfähriger Anpassung, Göttingen 2019; Alois Kernbauer, Der Nationalsozialismus im Mikrokosmos. Die Universität Graz 1938. Analyse - Dokumentation - Gedenkbuch (Publikationen aus dem Archiv der Universität Graz 48), Graz 2019. Eine Studie zur Universität Mozarteum Salzburg ist in Vorbereitung.

13 Neben dem Aufbau neuer Archive (vor allem an den ehemaligen „Fachhochschulen“ und Kunstakademien) wurde 2008 auf Initiative von Juliane Mikoletzky (Technische Universität Wien) auch 
nachdem an den österreichischen Universitäten bereits seit den 1960er-Jahren eigene Publikationsreihen und 1980 die Österreichische Gesellschaft für Wissenschaftsgeschichte gegründet worden waren ${ }^{14}$ - 1995 durch deutsche, österreichische und Schweizer Historiker die Gesellschaft für Universitäts- und Wissenschaftsgeschichte ins Leben gerufen, die seit 1998 das „Jahrbuch für Universitätsgeschichte“ als erste deutschsprachige Fachzeitschrift herausgibt. ${ }^{15} 1984$ erfolgte auf Initiative der europäischen Rektorenkonferenz der Startschuss zu einer großangelegten Synthese der Universitäts- und Wissenschaftsentwicklung in Europa, die in den Jahren 1993 bis 2010 in vier Bänden herausgegeben wurde. ${ }^{16}$

\section{Charakteristika}

Die Universitätsgeschichte zeichnet sich durch eine Reihe von Besonderheiten aus. Eine ist, dass sie häufig von Personen geschrieben wird, die der bearbeiteten Institution angehören und die UniversitätsarchivarInnen oftmals eine treibende und konstante Kraft darstellen. Zudem ist die Universitätsgeschichte seit jeher eng mit Jubiläen verbunden. Dies zeigt sich nicht nur darin, dass für Jubiläen Ressourcen freigemacht werden können, die bald nach diesen wieder versiegen, sondern hat auch dazu geführt, dass sich die Universitätsgeschichte in einem besonderen Spannungsfeld von kritischer Geschichtsbetrachtung und historischer Leistungsschau bewegt. ${ }^{17}$ Hinzu kommt, dass sie oftmals in Krisen- und Umbruchphasen Konjunktur hat bzw. besonders dann gefragt ist, wenn sich Universitäten in ihrer gesellschaftlichen Rolle und Funktion mit Veränderungsforderungen konfrontiert sehen. ${ }^{18}$

die Fachgruppe Archive an österreichischen Universitäten und wissenschaftlichen Einrichtungen im Rahmen des Verbands österreichischer Archivarinnen und Archivare ins Leben gerufen.

14 Eigene Publikationsreihen bestehen an: Universität Wien, Technische Universität Wien, Universität für Musik und darstellende Kunst Wien, Universität Graz, Technische Universität Graz, Universität Innsbruck, Universität Mozarteum Salzburg.

15 Ziele, Gesellschaft für Universitäts- und Wissenschaftsgeschichte, URL: https://guw-online.net/ ueber-die-guw (abgerufen 17.06.2019).

16 Walter Rüegg (Hg.), Geschichte der Universität in Europa, Bd. 1-4, München 1993-2010.

17 Mühlberger, Universitätsgeschichtliche Forschung, 135; Sylvia Paletschek, Stand und Perspektiven der neueren Universitätsgeschichte, in: Zeitschrift für Geschichte der Wissenschaften, Technik und Medizin (N.T.M.) 19 (2011) 2, 169-189, 180; Livia Prüll, „Universitätsgeschichte schreiben“ - Eine Einführung, in: Livia Prüll/Christian George/Frank Hüther, Universitätsgeschichte schreiben. Inhalte - Methoden - Fallbeispiele, Göttingen 2019, 7-24, 7-8, 19.

18 Matthias Asche/Stefan Gerber, Miszelle. Neuzeitliche Universitätsgeschichte in Deutschland. Entwicklungslinien und Forschungsfelder, in: Archiv für Kulturgeschichte 20 (2008) 1, 159-202, 160. 


\section{Rezente Universitätsjubiläen}

Betrachtet man die österreichischen Universitätsjubiläen der letzten beiden Jahrzehnte, dann fällt auf, dass keine der betroffenen Institutionen ihre Gründung ignoriert hat. Vielmehr ist die Entwicklung festzumachen, Jubiläen „groß“, über ein ganzes Jahr hinweg zu feiern. Angesichts der Umbruchphase, in der sich der tertiäre Bildungssektor seit den 1990er-Jahren durch das Entstehen neuer Konkurrenten, den Wettbewerb um Studierende, Lehrende und Gelder, die Bedeutung von „Rankings" und die Diskussion um „Exzellenz" befindet, wollte es sich keine Universität leisten, ein Jubiläum ungenutzt verstreichen zu lassen. Die Jubiläen wurden gezielt dazu verwendet, um das eigene Profil zu schärfen und sich als „Marke“ zu präsentieren. Die wissenschaftliche Auseinandersetzung mit der Universitätsgeschichte war im Rahmen dieser Großereignisse freilich oft nur ein Programmpunkt unter vielen, wobei sich die erschienenen Jubiläumspublikationen (oft begleitet durch weitere Veröffentlichungen und Internetprojekte) ${ }^{19}$ durch unterschiedliche Herangehensweisen auszeichneten. So finden sich unter den seit 2000 angefertigten Jubiläumsschriften

a) Veröffentlichungen, die dem Format einer klassischen/modernisierten „Repräsentationsschrift" entsprechen (Technische Universität Graz, Montanuniversität Leoben, Veterinärmedizinische Universität Wien, Universität für Angewandte Kunst, Akademie der Bildendenden Künste), ${ }^{20}$

b) Publikationen, die aus einer Veranstaltung hervorgegangen sind (Universität Salzburg, Universität für Bodenkultur Wien), ${ }^{21}$

19 Vgl. das Webprojekt „650 plus - Geschichte der Universität Wien“, URL: https://geschichte.univie. ac.at/ (abgerufen 25.08.2020) oder das Internetangebot zur Geschichte der Universität Innsbruck, URL: https://www.uibk.ac.at/universitaet/profil/geschichte/ (abgerufen 25.08.2020).

20 Elemente dieser Schriften sind oft: historischer Abriss, Vorstellung der Fakultäten, Disziplinen und Studienrichtungen, „facts \& figures“. Vgl. Wolfgang Wallner (Hg.), 200 Jahre Technik in Graz, Graz 2011; Montanuniversität Leoben (Hg.), Wo aus Forschung Zukunft wird. Festschrift zum Jubiläum „175 Jahre Montanuniversität Leoben“, 3 Bde., Leoben 2015; Veterinärmedizinische Universität Wien (Hg.), 250 Jahre Veterinärmedizinische Universität Wien. Verantwortung für Tier und Mensch. Festschrift, Wien 2015; Gerald Bast (Hg.), 150 Jahre Universität für Angewandte Kunst Wien. Ästhetik und Veränderung, Wien 2017; Akademie der Bildendenden Künste (Hg.), 325 Jahre, Wien 2017. Eine Besonderheit ist, dass die Jubiläumsschrift der Technischen Universität Graz als Geschenk ihrer AbsolventInnen an die Universität entstanden ist.

21 Dies waren an der Universität Salzburg eine Ringvorlesung und an der Universität für Bodenkultur eine Festveranstaltung. Vgl. Reinhold Reith (Hg.), Die Paris Lodron Universität Salzburg. Geschichte - Gegenwart - Zukunft, Salzburg 2012; Universität für Bodenkultur (Hg.), Festschrift 140 Jahre Universität für Bodenkultur Wien. Quo vadis, Universität(en)?, Wien 2012. 
c) Bücher, die mit einer übergreifenden Fragestellung verbunden sind (Universität $\operatorname{Linz}),{ }^{22}$

d) Veröffentlichungen, die eine historische Aufarbeitung mit einem Fokus auf die Zeitgeschichte mit der Repräsentation verbinden (Technische Universität Wien), ${ }^{23}$

e) Publikationen, die sich auf die jüngere Vergangenheit (1848-1955) konzentrieren und sich nur der Universitätsgeschichte widmen (Universität Wien), ${ }^{24}$ sowie

f) Arbeiten, die einen Überblick über die Gesamtgeschichte plus „Tiefenbohrungen“ zu relevanten Themen geben (Universität Innsbruck) ${ }^{25}$.

Häufig sind dabei - korrelierend mit dem Alter der Einrichtung - ebenfalls eine Entwicklung hin zu Großprojekten und ein zunehmender Verzicht auf die Titulierung als „Festschrift“ infolge eines (oftmals) kritischeren Umgangs mit der eigenen Geschichte feststellbar.

\section{Themen und Desiderate}

Die Universitätsgeschichte gilt heute als eigener Bereich der Geschichtswissenschaft, die in ihrem Kern Institutionengeschichte ist. Sie beschäftigt sich im Gegensatz zur Wissenschaftsgeschichte weniger mit epistemischen, sondern stärker mit struktur-, gesellschafts- und politikgeschichtlichen Fragestellungen. Wichtige Forschungsfelder sind die Hochschulpolitik und das Hochschulrecht sowie die Geschichte des Personals. Die Studierendengeschichte wird - wenn sie in die jüngeren Jubiläumspublikationen auch vielfach aufgenommen wurde - zum Teil als eigener Bereich, zum Teil als Gegenstand der Universitätsgeschichte bezeichnet. Hinzu kommt der Hochschulbau. Wie die Historie einzelner Disziplinen sinnvoll in die Universitäts-

22 Mit einem Fokus auf das „Neue“ in der Wissenschaft: Maria Wirth/Andreas Reichl/Marcus Gräser (Hg.), 50 Jahre Johannes Kepler Universität Linz. Eine „Hochschule neuen Stils“, Wien/Köln/Weimar 2016; Maria Wirth/Andreas Reichl/Marcus Gräser (Hg.), 50 Jahre Johannes Kepler Universität Linz. Innovationsfelder in Forschung, Lehre und universitärem Alltag, Wien/Köln/Weimar 2017.

23 Sabine Seidler (Hg.), Technik für Menschen. 200 Jahre Technische Universität Wien, 15 Bde., Wien 2015-2016. Historisch interessant sind vor allem die Bände 1/1, 1/2, 2, 11 und 14 von Juliane Mikoletzky, Paulus Ebner, Franz G. Rammerstorfer und Robert Jarczyk.

24 Friedrich Stadler (Hg.), 650 Jahre Universität Wien - Aufbruch ins neue Jahrhundert, 5 Bde., Göttingen 2015-2018. Vgl. zur Entstehung: Mitchell Ash, Die Universitätsschreibung an der Universität Wien im Jubiläumsjahr 2015 - zwischen historischer Reflexion und Eventkultur, in: Prüll/ George/Hüther, Universitätsgeschichte, 221-239.

25 Margret Friedrich/Dirk Rupnow (Hg.), Geschichte der Universität Innsbruck 1669-2019, 2 Bde. (in 3 Teilbänden), Innsbruck 2019. 
geschichte Eingang finden kann, stellt - wenn auch sie in Sammel- und Jubiläumsbänden präsent ist - eine vielfach diskutierte Herausforderung dar. Verantwortlich sind hierfür die methodische und inhaltliche Eigenständigkeit der Wissenschaftsgeschichte und das für die Disziplinengeschichte erforderliche Fachwissen. ${ }^{26}$ Aus der folgenden Darstellung wird sie deshalb ebenso ausgenommen wie die Provenienzforschung in den Bibliotheken, Archiven und Sammlungen. Diese hat sich - weitgehend losgelöst von der Universitätsgeschichte - seit den 20ooer-Jahren auch an den Universitäten etabliert und leistet seither einen wichtigen Beitrag zur Erforschung des Nationalsozialismus an den Universitäten und des Umgangs mit diesem nach 1945 .

\subsection{Hochschulpolitik/Hochschulrecht}

Die Hochschulpolitik umfasst alle gesellschaftlichen und politischen Entscheidungen, die das Hochschulsystem beeinflussen, und manifestiert sich insbesondere im Hochschulrecht. Mit der Schaffung gesetzlicher Rahmenbedingungen zielt sie zumeist auf eine Vielzahl von Einrichtungen ab, womit sie sowohl ein eigener Forschungsstrang als auch ein Teil der Institutionengeschichte sein kann.

Die zentralen Überblickswerke zur Hochschulpolitik stammen aus den 1980erJahren. Sie behandeln die staatliche Hochschulpolitik entweder als Teil einer großangelegten Bildungsgeschichte ${ }^{27}$ oder als sozialwissenschaftliche Analyse bereits vorhandener historischer Darstellungen ${ }^{28}$ und haben gemeinsam, dass sie die Entwicklung über mehrere Jahrhunderte nachzeichnen. Gleichfalls datiert auch das heute noch gültige Standardwerk über die „politische Geschichte der Universitäten“ vom ausgehenden 19. Jahrhundert bis zum Jahr $1938^{29}$ aus den späten 1980er-Jahren und somit aus einem Jahrzehnt, als die Auswirkungen der politischen Umbrüche von 1918 bis 1945 verstärkt zum Thema wurden. Untersucht wurden diese mit einer deutlichen Schwerpunktsetzung im Bereich der personellen Veränderungen bisher vor allem auf Ebene der einzelnen Universitäten. So sind trotz der Fülle an Texten,

26 Paletschek, Stand und Perspektiven, 171-176; Marian Füssel, Wie schreibt man Universitätsgeschichte?, in: Zeitschrift für Geschichte der Wissenschaften, Technik und Medizin (N.T.M) 22 (2014) 4, 287-293, 288-289.

27 Helmut Engelbrecht, Geschichte des österreichischen Bildungswesens, 4 Bde., Wien 1982-1988.

28 Susanne Preglau-Hämmerle, Die politische und soziale Funktion der österreichischen Universität. Von den Anfängen bis zur Gegenwart, Innsbruck 1986.

29 Walter Höflechner, Die Baumeister des künftigen Glücks. Fragment einer Geschichte des Hochschulwesens in Österreich vom Ausgang des 19. Jahrhunderts bis in das Jahr 1938, Graz 1988. 
die über die Geschichte der einzelnen Einrichtungen im Ersten Weltkrieg, ${ }^{30}$ in der Ersten Republik, ${ }^{31}$ im Austrofaschismus ${ }^{32}$ und vor allem im Nationalsozialismus erschienen sind, nur wenige Studien hinzugekommen, die sich mit standortübergreifenden Aspekten der Hochschulpolitik beschäftigten. Ausnahmen bilden Untersuchungen zu den Hochschullagern im Austrofaschismus, die alle männlichen Studierenden im Sinne einer körperlichen und geistigen Wehrhaftmachung besuchen mussten, ${ }^{33}$ oder erste Versuche, auf Basis jüngerer Forschungen die österreichischen Hochschulen in den politischen Umbrüchen des 20. Jahrhunderts über die Institutionsgrenzen hinweg zu beschreiben. ${ }^{34}$

Umso auffälliger wird die Lücke jedoch, je weiter man sich vom Jahr 1945 und der anschließenden Entnazifizierung entfernt. So liegen zwar vereinzelt Texte vor, die sich mit der Politikgestaltung durch Unterrichtsminister Heinrich Drimmel (1954-1964) oder der Entstehung des Hochschul-Organisationsgesetzes 1955 beschäftigen, ${ }^{35}$ das eine Vereinheitlichung und Bereinigung des bis in die Monarchie zurückreichenden Hochschulrechts brachte. ${ }^{36}$ Und auch über die Regime hinweg einflussreiche Ministerialbeamte (Otto Skrebensky), ${ }^{37}$ mächtige „Wissenschaftsfunktionäre“ (Richard Meister unter anderem als Rektor der Universität Wien und

30 Juliane Mikoletzky, „An der Seite der Heerführer steht der Ingenieur“. Hochschulen, Technik und Krieg 1914-1918 am Beispiel der Technischen Hochschule in Wien, in: Herbert Matis/Juliane Mikoletzky/Wolfgang L. Reiter (Hg.), Wirtschaft, Technik und das Militär. Österreich-Ungarn im Ersten Weltkrieg, Wien 2014, 349-368; Bernhard Reismann, In diesen schweren Tagen. Die Technische Hochschule im Ersten Weltkrieg (Archiv und Bibliothek der TU Graz 6), Graz 2018.

31 Brigitte Lichtenberger-Fenz, „... deutscher Abstammung und Muttersprache“. Österreichische Hochschulpolitik in der Ersten Republik, Wien 1990.

32 Linda Erker, Die Universität Wien im Austrofaschismus: Zur politischen Vereinnahmung einer Hochschule - im Vergleich mit der Universität Madrid im Franco-Faschismus, phil. Diss., Universität Wien 2018.

33 Tamara Ehs, Der „neue österreichische Mensch“. Erziehungsziele und studentische Lager in der Ära Schuschnigg 1934 bis 1938, in: Vierteljahreshefte für Zeitgeschichte 62 (2014) 3, 377-396.

34 Mitchell G. Ash, Die österreichischen Hochschulen in den politischen Umbrüchen der ersten Hälfte des 20. Jahrhunderts, in: Johannes Koll (Hg.), „Säuberungen“ an österreichischen Hochschulen 1934-1945. Voraussetzungen, Prozesse, Folgen, Wien/Köln/Weimar 2017, 29-73.

35 Thomas König, Die Entstehung eines Gesetzes. Österreichische Hochschulpolitik in den 1950er Jahren, in: Österreichische Zeitschrift für Geschichtswissenschaften 23 (2012) 2, 57-81.

36 Vgl. u. a.: Thomas König, A Strategy of Containment: Heinrich Drimmel's Political Activism in the Realm of Higher Education Policy in the Early Second Republic, in: Österreichische Zeitschrift für Geschichtswissenschaften 29 (2018) 1, 180-205.

37 Roman Pfefferle/Hans Pfefferle, Glimpflich entnazifiziert. Die Professorenschaft der Universität Wien von 1944 in den Nachkriegsjahren, Göttingen 2014, 45-72. 
Präsident der Österreichischen Akademie der Wissenschaften ${ }^{38}$ sowie die Hochschulgründungen der 1960er-Jahre sind zuletzt thematisiert worden. ${ }^{39}$ Die vorhandenen Studien zur Hochschulpolitik der 1960er- und 1970er-Jahre als zentraler Aufbruchsphase in der Wissenschaftspolitik nach 1945 stammen aber noch immer aus den 1990er-Jahren. Geschrieben wurden sie, kurz bevor das UOG 1975 durch das UOG 1993 abgelöst wurde, von SozialwissenschaftlerInnen mit einem zum Teil stark theorielastigen und quellenarmen Zugang, ${ }^{40}$ nachdem sich diese Gruppe bereits erstmals mit dem UOG 1975 und dessen Demokratisierungsanspruch beschäftigt hatte..$^{41}$

Auch die jüngsten Entwicklungen, das heißt der Weg vom UOG 1993 zum UG 2002, das die Universitäten als nachgeordnete Dienststellen des jeweiligen Ministeriums erst zur Teilrechtsfähigkeit und dann zur Autonomie führte, die wachsende Bedeutung von Drittmitteln, die Ausdifferenzierung des tertiären Bildungssektors und die Schaffung eines europäischen Hochschulraums, sind von Seiten der Zeitgeschichte bisher nur gestreift worden, während sich die Sozial- und Rechtswissenschaften diesem Thema bereits angenommen haben. ${ }^{42}$ So sind in den letzten Jahren nicht nur Detailstudien zur Rechtsentwicklung im späten 19. und frühen 20. Jahrhundert, ${ }^{43}$ sondern ab 2000 auch neue Überblickstudien zur Langzeitent-

38 Johannes Feichtinger, Richard Meister. Ein dienstbarer Hochschulprofessor in vier politischen Regimen, in: Mitchell G. Ash/Josef Ehmer (Hg.), Universität - Politik - Gesellschaft (650 Jahre Universität Wien 2), Göttingen 2015, 311-318.

39 Wirth/Reichl/Gräser (Hg.), Hochschule.

40 Josef Melchior, Zur sozialen Pathogenese der österreichischen Hochschulreform. Eine gesellschaftstheoretische Rekonstruktion, Baden-Baden 1993; Henrik Kreutz/Heinz Rögl, Die umfunktionierte Universitätsreform, Wien 1994.

41 Vgl. vor allem die Arbeiten von Marina Fischer-Kowalski, u. a.: Marina Fischer Kowalski, Zur Entwicklung von Universität und Gesellschaft in Österreich, in: Heinz Fischer (Hg.), Das politische System Österreichs, Wien/München/Zürich 1974, 571-624.

42 Wolfgang Mantl (Hg.), Phänomenologie des europäischen Wissenschaftssystems, Baden-Baden 2010; Jürgen Pirker, Die „Zeitenwende“ an den österreichischen Universitäten. Umbrüche, Neuerungen und Folgewirkungen des UOG 1993, in: Elmar Schübl/Harald Heppner (Hg.), Universitäten in Zeiten des Umbruchs. Fallstudien über das mittlere und östliche Europa im 2o. Jahrhundert, Münster 2011, 107-120; Peter Stachel, Die Wissenschaftspolitik der Regierungen Schüssel I und II, in: Robert Kriechbaumer/Franz Schausberger (Hg.), Die umstrittene Wende. Österreich 20002006, Wien/Köln/Weimar 2013, 331-363; Robert Rybnicek, Neue Steuerungs- und Managementmethoden an Universitäten. Über Akzeptanz und Problematik unter den Universitätsangehörigen, Wiesbaden 2014; Günther Sandner, Hochschulpolitik, in: Emmerich Tálos (Hg.), Die SchwarzBlaue Wende in Österreich. Eine Bilanz, Wien 2019, 346-365; Elisabeth Westphal, Die BolognaReform. Policy Making in Europa und Österreich, Wien/Hamburg 2020.

43 Kamila Staudigl-Ciechowicz, Das Dienst-, Habilitations- und Disziplinarrecht der Universität Wien 1848-1938. Eine rechtshistorische Untersuchung zur Stellung des wissenschaftlichen Uni- 
wicklung des Hochschulrechts hinzugekommen. ${ }^{44}$ Die gesellschaftlichen und politischen Prozesse, die zu diesen Reformen führten, sowie deren Auswirkungen auf die Universitäten und das Hochschulsystem zu untersuchen, wird in Zukunft ein Aufgabengebiet für die Zeitgeschichte sein. Nicht nur die Rolle des Bundes, bei dem bis 2002 alle wesentlichen Kompetenzen lagen, sondern auch jene der Länder, Kommunen und Wirtschaft zu untersuchen, kann hierbei ebenso wichtige Einblicke eröffnen, ${ }^{45}$ wie weiter nach zentralen AkteurInnen und den institutionellen Rahmenbedingungen (Ministerium und Ministerialbürokratie), aber auch der Finanzierung der Universitäten zu fragen.

\subsection{Personal}

Das Personal stellt die wichtigste Ressource einer Universität dar und gliedert sich grob in ProfessorInnen, das weitere wissenschaftliche sowie das Verwaltungspersonal. Forschungen zu den Hochschulangehörigen fokussieren vor allem die erste und Teile der zweiten Gruppe (ordentliche und außerordentliche ProfessorInnen), womit statushöhere Personen wesentlich besser erforscht sind als statusniedrige.

Schriften mit biographischen Porträts akademischer Funktionäre und Lehrer waren im Spätmittelalter und in der Frühen Neuzeit Ausgangspunkt der Universitätsgeschichtsschreibung. Diese Tradition setzte sich in den folgenden Jahrhunderten fort und erreichte im 20. Jahrhundert ihren vorläufigen Höhepunkt. Alleine für Deutschland liegen rund dreißig biographische Lexika zu einzelnen Hochschulen vor, die zumindest Angehörige des Professorenstandes, dies zum Teil jedoch über Jahrhunderte, behandeln. Für die österreichischen Hochschulen fehlen derartige Kompendien. Dem stehen allerdings zahlreiche disziplinenhistorische Studien gegenüber (etwa zu den Historikern der Jahre 1900 bis 1945 oder zu österreichischen PhysikerInnen). ${ }^{46}$

versitätspersonals (Schriften des Archivs der Universität Wien 22), Göttingen 2017.

44 Sascha Ferz, Ewige Universitätsreform. Das Organisationsrecht der österreichischen Universitäten von den theresianischen Reformen bis zum UOG 1993, Frankfurt a. M. 2000; Perthold-Stoitzner, Hochschulrecht.

45 Maria Wirth, Der Campus Vienna Biocenter. Entstehung, Entwicklung und Bedeutung für den Life Sciences-Standort Wien (Innovationsmuster in der österreichischen Wirtschaftsgeschichte 8), Innsbruck/Wien/Bozen 2013.

46 Karel Hruza (Hg.), Österreichische Historiker 1900-1945. Lebensläufe und Karrieren in Österreich, Deutschland und der Tschechoslowakei in wissenschaftsgeschichtlichen Porträts, 3 Bde., Wien 2008-2019; Daniela Angetter/Michael Martischnig (Hg.), Biografien österreichischer Physikerinnen. Eine Auswahl, Wien 2005. 
Abgesehen von diesen Nachschlagewerken und klassischen Einzelbiographien fokussieren personenbezogene Studien vor allem die NS- und Nachkriegszeit. Die Auseinandersetzung mit den „rassisch“ und „politisch“ motivierten Vertreibungen und deren Folgen begann 1980 mit einigen Dissertationen an der Universität Wien. ${ }^{47}$ Es folgten erste Monographien und Sammelbände zu einzelnen Hochschulen, Fakultäten und Instituten, die die NS-Zeit insbesondere am Beispiel des Personals (Forschungsschwerpunkte, Ausmaß der Vertreibungen und weitere Lebenswege, Involvierung in den Nationalsozialismus, Karriereverläufe, Habilitationen und Berufungen) aufgearbeitet haben..$^{8}$ Die Entnazifizierung wie auch die (oftmals unterbliebene) Rückkehr ehemals Vertriebener rückte ab Mitte der 199oer-Jahre stärker in den Fokus. ${ }^{49}$ Neuere Studien spannen den Bogen mitunter etwas weiter und beziehen (wie zuletzt im Falle der Veterinärmedizinischen Universität Wien) nicht nur die Nachkriegszeit, sondern auch die 1930er-Jahre, das heißt das antisemitisch geprägte Universitätsklima dieser Jahre sowie Enthebungen aus politischen Motiven, mit ein. ${ }^{50}$ Generell stellt die Zeit des Dollfuß/Schuschnigg-Regimes jedoch noch eine Forschungslücke dar.

Die seit 2015 erschienenen Publikationen zur Veterinärmedizinischen Universität, zur Akademie der bildenden Künste in Wien, zur Technischen Universität Wien und zur Universität Innsbruck berücksichtigen auch das Verwaltungspersonal, was zuvor nur sporadisch der Fall gewesen war. ${ }^{51}$ Die meisten Studien zu Personalent-

47 Andrea Vetricek, Die Lehrer der Rechts- und Staatswissenschaftlichen Fakultät der Universität Wien, die 1938 entlassen wurden, phil. Diss., Universität Wien 1980; Kurt Mühlberger, Dokumentation „Vertriebene Intelligenz 1938“. Der Verlust geistiger und menschlicher Potenz an der Universität Wien von 1938 bis 1945 , Wien 1990.

48 Vgl. etwa Steirische Gesellschaft für Kulturpolitik (Hg.), Grenzfeste deutscher Wissenschaft. Über Faschismus und Vergangenheitsbewältigung an der Universität Graz, Graz 1985; Hans Peter Weingand, Die Technische Hochschule Graz im Dritten Reich. Vorgeschichte, Geschichte und Nachgeschichte des Nationalsozialismus an einer Institution, Graz 1988; Gernot Heiß/Siegfried Mattl/ Sebastian Meissl/Edith Saurer/Karl Stuhlpfarrer (Hg.), Willfährige Wissenschaft. Die Universität Wien 1938 bis 1945 (Österreichische Texte zur Gesellschaftskritik 43), Wien 1989; Friedrich Stadler (Hg.), Kontinuität und Bruch 1938 - 1945 - 1955. Beiträge zur österreichischen Kultur- und Wissenschaftsgeschichte, Wien/München 1988; Friedrich Stadler (Hg.), Vertriebene Vernunft I-II. Emigration und Exil österreichischer Wissenschaft, 1930-1940, Wien/München 1987-1988.

Christian Fleck, Autochthone Provinzialisierung. Universität und Wissenschaftspolitik nach dem Ende der nationalsozialistischen Herrschaft in Österreich, in: Österreichische Zeitschrift für Geschichtswissenschaften 7 (1996) 1, 67-92; Peter Goller/Gerhard Oberkofler, Universität Innsbruck. Entnazifizierung und Rehabilitation von Nazikadern (1945-1950), Innsbruck 2003.

50 Rettl, Tierärztliche Hochschule.

51 Ebd.; Pawlowsky, Akademie; Juliane Mikoletzky/Paulus Ebner, Die Geschichte der Technischen Hochschule in Wien 1914-1955 (Technik für Menschen. 200 Jahre Technische Universität Wien 1), Wien 2016. 
wicklungen infolge der politischen Brüche (1933/1934, 1938, 1945) behandeln die Thematik anhand von Fallbeispielen, während kollektivbiographisch orientierte Studien die Ausnahme sind.52 Seit 2017 ist der Forschungsstand in einem Sammelband komprimiert. ${ }^{53}$ Grundsätzlich enden die meisten Arbeiten spätestens in den 1950er-Jahren. ${ }^{54}$

Die Beschäftigung mit den Karriereschritten auf dem Weg zur Professur ist in der historischen Forschung zur Personalentwicklung ein integraler Bestandteil. Eine Auseinandersetzung mit diesem Thema gewährt nicht nur Einblicke in die Zugangsregeln zur Universität. Habilitationen und Berufungen sind auch entscheidend für die Entwicklung von Fachdisziplinen in Forschung und Lehre sowie die Ausbildung und Rekrutierung des wissenschaftlichen Nachwuchses. Systematische Analysen zu Habilitationsverfahren über einen längeren Zeitraum liegen jedoch bislang nur für einzelne Fächer (unter anderem für die Geschichtswissenschaften an der Universität Wien) vor, ${ }^{55}$ was auch für das Berufungswesen gilt. ${ }^{56}$ Gleiches kann auch für die Mobilität der HochschullehrerInnen und deren Sozialstruktur (soziale und geographische Herkunft, Religion, Geschlecht) konstatiert werden. ${ }^{57}$ Während bereits in den 1950er-Jahren eine Gruppe von Göttinger Soziologen um Helmuth Plessner eine umfassende quantitative Erhebung $\mathrm{zu}$ den Lehrenden 24 deutscher Universitäten von 1864 bis 1953 erstellt hatte, aus der eine Reihe von soziographischen Analysen hervorging, ${ }^{58}$ ist ein derartiges Projekt für Österreich noch ausständig.

52 Pfefferle/Pfefferle, Glimpflich entnazifiziert; Andreas Huber, Rückkehr erwünscht. Im Nationalsozialismus aus „politischen“ Gründen vertriebene Lehrende der Universität Wien, Wien 2016.

53 Johannes Koll (Hg.), ,Säuberungen` an österreichischen Hochschulen 1934-1945. Voraussetzungen, Prozesse, Folgen, Wien 2017.

54 Eine Ausnahme bildet eine Studie von Alexander Pinwinkler zu den „Gründerprofessoren“ an der Universität Salzburg.

55 Albert Müller, Grenzziehungen in der Geschichtswissenschaft. Habilitationsverfahren 1900-1950 (am Beispiel der Universität Wien), in: Christian Fleck (Hg.), Soziologische und historische Analysen der Sozialwissenschaften (Österreichische Zeitschrift für Soziologie Sonderhefte 5), Opladen 2000, 287-307.

56 Gerhard Oberkofler, Berufungen von Naturwissenschaftlern der Universität Innsbruck an die Universität Berlin. Dokumente, in: Tiroler Heimat 48/49 (1984/85), 141-156; Juliane Mikoletzky, Die Nazifizierung des Lehrkörpers. Voraussetzungen, Berufungen auf Lehrkanzeln und ihre politischen Implikationen - das Beispiel der TH in Wien, in: Michele Barricelli/Michael Jung/Detlef Schmiechen-Ackermann (Hg.), Ideologie und Eigensinn. Die Technischen Hochschulen in der Zeit des Nationalsozialismus (Schriften zur Didaktik der Demokratie 1), Göttingen 2017, 89-103.

57 Vgl. für die österreichische Hälfte der Habsburgermonarchie bis 1918: Jan Surman, Universities in Imperial Austria 1848-1918. A Social History of a Multilingual Space, West Lafayette, Indiana 2018.

58 Christian von Ferber, Die Entwicklung des Lehrkörpers der deutschen Universitäten und Hochschulen 1864-1954, Göttingen 1956; Fritz Ringer, A Sociography of German Academics, 18631938, in: Central European History 25 (1992) 3, 251-280. 
HistorikerInnen und SozialwissenschaftlerInnen haben sich dieser Arbeit bislang erst in Ansätzen angenommen. ${ }^{59}$

\subsection{Studierende}

Die Geschichte der Studierenden bildete sich im 19. Jahrhundert als Forschungsfeld heraus und konzentrierte sich ursprünglich auf Studentenverbindungen. Diese Arbeiten nahmen ihren Ausgangspunkt meist in den Vereinen selbst und blieben damit eine Domäne der Korporierten. Der restriktive Zugang zu den Vereinsarchiven ist ein gewichtiger Grund dafür. Nichtsdestotrotz liegt für die Universität Innsbruck eine quellengesättigte Studie zum politischen Engagement deutschnationaler und katholischer Korporationen in der Zwischenkriegszeit ${ }^{60}$ und für Gesamtösterreich eine umfangreiche Monographie zur Geschichte der akademischen Burschenschaften in der Zweiten Republik vor. ${ }^{61}$ Für andere "nationale“ Verbindungen wie etwa Corps, Sängerschaften und Landsmannschaften sind derartige Publikationen noch ausständig. ${ }^{62}$ Unter den katholischen Verbindungen ist vor allem die Geschichte des Österreichischen Cartellverbandes (ÖCV) gut erforscht. ${ }^{63}$ Aber auch zu den jüdisch-nationalen Korporationen existiert eine Reihe umfassender, gut aufbereiteter Studien. ${ }^{64}$

59 Christian Fleck, „In seinem Felde alles Erreichbare zu leisten ... “ Zusammensetzung und Karrieren der Dozentenschaft der Karl-Franzens-Reichsuniversität Graz, in: Steirische Gesellschaft für Kulturpolitik (Hg.), Grenzfeste deutscher Wissenschaft, 87-111; Thomas König, Irrfahrer und Dulder, Titanen und Halbgötter. Eine empirische Analyse eines Samples von HochschullehrerInnen von 1949 bis 1964, in: zeitgeschichte 38 (2011) 1, 108-129; Andreas Huber, Die Hochschullehrerschaft der 1930er- und 1940er-Jahre. Sozialstruktur und Karrierewege vor dem Hintergrund politischer Zäsuren, in: Ash/Ehmer (Hg.), Universität - Politik - Gesellschaft, 649-696; Alexander Pinwinkler, Die „Gründergeneration“ der Universität Salzburg. Biographien, Netzwerke, Berufungspolitik, 1960-1975, Wien/Köln/Weimar 2020.

60 Michael Gehler, Studenten und Politik. Der Kampf um die Vorherrschaft an der Universität Innsbruck 1918-1938 (Innsbrucker Forschungen zur Zeitgeschichte 6), Innsbruck 1990.

61 Bernhard Weidinger, Im nationalen Abwehrkampf der Grenzlanddeutschen. Akademische Burschenschaften und Politik in Österreich nach 1945, Wien 2015.

62 Einige aufschlussreiche Abschnitte auch zu den katholischen Verbindungen finden sich jedoch in Gernot Stimmer, Eliten in Österreich, 1848-1970, 2 Bde., Wien 1997.

63 Gerhard Hartmann, Der CV in Österreich. Seine Entstehung, seine Geschichte, seine Bedeutung, Kevelaer ${ }^{4}$ 2011; Robert Rill, CV und Nationalsozialismus (Publikationen des Instituts für Kirchliche Zeitgeschichte 2/19), Wien/Salzburg 1987.

64 Vgl. insbesondere Harald Seewann, Zirkel und Zionsstern. Bilder aus der versunkenen Welt des jüdisch-nationalen Korporationsstudententums. Ein Beitrag zur Geschichte des Zionismus auf akademischem Boden, 5 Bde., Graz 1990-1996. 
Die Geschichte der Studentenverbindungen ist eng mit dem politischen Engagement der Studierenden, den Studierendenfraktionen und den Vertretungsorganen an den Hochschulen verzahnt. Deren Geschichte wurde seit Mitte der 1970er-Jahre in mehreren Publikationen aufgearbeitet. Behandelt wurden vorerst Kontroversen um den Ausschluss jüdischer StudentInnen aus der Studierendenvertretung in der Ersten Republik und die (häufig von ehemaligen Mitgliedern verfasste) Entwicklung einzelner Fraktionen bzw. Gruppen, wie der sozialistischen StudentInnen vor 1938. ${ }^{65}$ Der Ring Freiheitlicher Studenten und dessen Vorläufer blieben hingegen weitgehend unberücksichtigt. Überdies klafft für die Studentenschaft der Jahre 1938 bis 1945 eine Lücke, die in Deutschland bereits Mitte der 1990er-Jahre geschlossen wurde, weshalb auch relativ wenig über den Nationalsozialistischen Deutschen Studentenbund auf dem Gebiet der „Ostmark“ bekannt ist. ${ }^{66}$ Charakteristisch für diesen Bereich der Studierendengeschichte sind die vielen zäsuren- und universitätsübergreifenden Studien. ${ }^{67}$

Der Vertreibung der Studierenden im Nationalsozialismus nahm sich die Universitätsgeschichtsschreibung erst im 21. Jahrhundert und damit fast drei Jahrzehnte nach der Auseinandersetzung mit den Lehrenden an. 2008 erschien eine erste Bestandsaufnahme zur Universität Wien, der weitere Studien und Internetprojekte zu

65 Lichtenberger-Fenz, „... deutscher Abstammung und Muttersprach““; Marie Tidl, Die Roten Studenten. Dokumente und Erinnerungen 1938-1945 (Ludwig Boltzmann Institut für Geschichte der Arbeiterbewegung, Materialien zur Arbeiterbewegung 3), Wien 1976; Wolfgang Speiser, Die sozialistischen Studenten Wiens 1927-1938 (Ludwig Boltzmann Institut für Geschichte der Arbeiterbewegung, Materialien zur Arbeiterbewegung 40), Wien 1986; Helge Zoitl, „Student kommt von Studieren!“ Zur Geschichte der sozialdemokratischen Studentenbewegung in Wien (Ludwig Boltzmann Institut für Geschichte der Arbeiterbewegung, Materialien zur Arbeiterbewegung 62), Wien/Zürich 1992.

66 Zwei Artikel erschienen bislang zu den steirischen Hochschulen und zur Hochschule für Bodenkultur: Hans-Peter Weingand/Markus Wurzer, Innensichten und Außenblicke. Studentische NSAktivitäten in Graz und Leoben 1930-1938, in: Österreichische HochschülerInnenschaft (Hg.), Österreichische Hochschulen im 20. Jahrhundert. Austrofaschismus, Nationalsozialismus und die Folgen, Wien 2013, 54-84; Joël Adami/Fabian Frommelt, Der Nationalsozialistische Deutsche Studentenbund an der Hochschule für Bodenkultur, in: Österreichische HochschülerInnenschaft (Hg.), Hochschulen, 85-101. Auch im Standardwerk zur Universität Wien werden die Studierenden nur marginal behandelt. Vgl.: Heiß/Mattl/Meissl/Saurer/Stuhlpfarrer (Hg.), Willfährige Wissenschaft. Für Deutschland vgl. Michael Grüttner, Studenten im Dritten Reich (Sammlung Schöningh zur Geschichte und Gegenwart), Paderborn/München/Wien/Zürich 1995. In Grüttners Studie werden nur die Universitäten in den Grenzen des Deutschen Reichs 1937 behandelt.

67 Vgl. u. a. Gerhard Wagner, Von der Hochschülerschaft Österreichs zur Österreichischen Hochschülerschaft. Kontinuitäten und Brüche, Dipl. Arb., Universität Wien 2010; Andrea Griesebner, Politisches Feld Universität. Versuch einer Annäherung anhand der Mitbestimmungsmöglichkeiten der Studierenden zwischen 1918 und 1990, Dipl.-Arb., Universität Wien 1990. 
den anderen Universitäten folgten. ${ }^{68}$ In einer rezenten Publikation über die Universität Innsbruck wurden zuletzt auch Studierende aus der Ukraine aufgenommen, die nach 1945 zum Opfer des Stalinismus geworden waren. ${ }^{69}$ Studien, die sich ausschließlich mit politisch bedingten Disziplinarverfahren oder Relegierungen von 1933 bis 1938 beschäftigen, sind für die meisten Hochschulen noch ausständig, oftmals werden diese aber im Rahmen von Überblicksdarstellungen thematisiert. Gleiches gilt für die Entnazifizierung..$^{70}$ Dahingegen rückten in den letzten Jahren die Schicksale von „Mischlingen“"71 sowie die Ausgrenzung von jüdischen Studierenden vor 1938 und die damit einhergehenden Gewaltexzesse in den Fokus. ${ }^{72}$

Arbeiten zur Sozialstruktur wie auch zur sozialen Mobilität der Studierenden liegen insbesondere für die Universität Wien vor. ${ }^{73}$ Wie beim Personal wird auch bei den Studierenden die Forschungslage für die Jahre nach 1955, die durch eine Hochschulexpansion und einen enormen Anstieg der Studierendenzahlen (durch den Ausbau des Stipendienwesens und die Schaffung eines freien Zugangs) gekennzeichnet waren, schlechter. Eine Auseinandersetzung mit den Studierenden hat für diese Jahre erst punktuell stattgefunden: so etwa mit der Studentenbewegung um das Jahr $1968^{74}$ und

68 Vgl. 5.6 Erinnerungspolitiken.

69 Gisela Hormayr, Verfolgung, Entrechtung, Tod. Studierende der Universität Innsbruck als Opfer des Nationalsozialismus (Studien zu Geschichte und Politik 23), Innsbruck/Wien/Bozen 2019.

70 Andreas Huber, Entnazifizierung und Rückbruch. Studierende 1945-1950, in: Andreas Huber/Katharina Kniefacz/Alexander Krysl/Manès Weisskircher, Universität und Disziplin. Angehörige der Universität Wien und der Nationalsozialismus (Emigration - Exil - Kontinuität 11), Wien/Berlin 2011, 157-316.

71 Katharina Kniefacz/Herbert Posch, „... unter Vorbehalt des Widerrufes“. Jüdische „Mischlinge“ als Studierende an der Universität Wien, in: zeitgeschichte 43 (2016) 5, 274-290.

72 Linda Erker, Studierende der Universität Wien und ihr Antisemitismus in der Zwischenkriegszeit, in: Gertrude Enderle-Burcel/Ilse Reiter-Zatloukal (Hg.), Antisemitismus in Österreich 1933-1938, Wien/Köln/Weimar 2018, 785-806; Johannes Koll, Wider den Antisemitismus an Österreichs Hochschulen. Eine vergessene Denkschrift von 1930, in: Zeitschrift für Geschichtswissenschaft 63 (2015) 5, 451-474.

73 Stefan Lenk, Chancen sozialer Mobilität an der Universität Wien im 20. Jahrhundert. Brüche und Kontinuitäten bei der sozialen Herkunft der Studierenden, in: Ash/Ehmer (Hg.), Universität - Politik - Gesellschaft, 565-618.

74 Ewald Hiebl, „Kein ruhiges Plätzchen“. Studentenbewegung in Salzburg 1965-1975, Dipl.-Arb., Universität Salzburg 1991; Paulus Ebner/Karl Vocelka, Die zahme Revolution. '68 und was davon blieb, Wien 1998; Fritz Keller, Wien Mai '68. Eine heiße Viertelstunde, Wien 2008; Peter Goller, Innsbrucker "Studentenbewegung“ 1967-1974, in: Gaismair-Jahrbuch 2011, Innsbruck 2010, 1324; Michael John, „1968“ und die Folgen - Aufbruch, Unruhe und Veränderungen im Alltag der Universität, in: Wirth/Reichl/Gräser (Hg.), Innovationsfelder, 299-326. 
den Studierendenprotesten im Jahr 2008 („unibrennt“), die sich gegen Beschränkungen im Hochschulzugang wendeten. ${ }^{75}$

\subsection{Antisemitismus}

Das österreichische Hochschulsystem war lange durch einen ausgeprägten Antisemitismus gekennzeichnet. Das zeigte sich nicht nur darin, dass bis 1782 ausschließlich römisch-katholische Männer zum Studium zugelassen waren, sondern auch in einer systematischen Diskriminierung jüdischer Universitätsangehöriger im 19. und 20. Jahrhundert, die mit der Vertreibung und Verfolgung im Nationalsozialismus endete. Das Thema Antisemitismus ist daher in vielen Studien zur Universitätsgeschichte (Institutionengeschichte, Untersuchungen zu Personal und Studierenden) präsent. Mehrere Publikationen haben sich in den letzten Jahren zudem ausschließlich mit dem Antisemitismus an den österreichischen Hochschulen, vor allem an der Universität Wien, auseinandergesetzt. Diese beleuchten die Entwicklung des universitären Antisemitismus seit den 1870er-Jahren, etwa am Beispiel der Diskriminierung bei Habilitationen und Berufungen sowie antisemitischer Gewalt im studentischen Milieu, wobei die jüdischen HochschullehrerInnen als Kollektiv (im Gegensatz zu den Studierenden) ${ }^{76}$ noch in keiner Studie explizit im Mittelpunkt standen. ${ }^{77}$ Um eine neue Perspektive wurden diese Forschungen 2016 durch einen Vergleich mit osteuropäischen Hochschulen erweitert. ${ }^{78}$ Für die Zweite Republik stand vor allem die „Borodajkewycz-Affäre“ im Zentrum der Forschungen. Die antisemitischen Tiraden von Taras Borodajkewycz, Professor an der Hochschule für

75 Stefan Heissenberger/Viola Mark/Susanne Schramm/Peter Sniesko/Rahel Sophia Süß (Hg.), Uni brennt. Grundsätzliches - Kritisches - Atmosphärisches, Wien/Berlin 2010; Martin Haselwanter, Gesellschaft - Bildung - Protest. Studentischer Aktionismus in Zeiten der Instrumentalisierung von Bildung: Die Uni brennt!, phil. Diss., Universität Innsbruck 2014.

76 Vgl. zuletzt Beatrix Bastl, Die jüdischen Studierenden der Akademie der bildenden Künste Wien 1848-1949, Hamburg 2019.

77 Michaela Raggam-Blesch, Zwischen Antisemitismus und Antifeminismus. Jüdische Frauen an der Wiener Universität, in: Regina Fritz/Grzegorz Rossolínski-Liebe/Jana Starek (Hg.), Alma Mater Antisemitica. Akademisches Milieu, Juden und Antisemitismus an den Universitäten Europas zwischen 1918 und 1939, Wien 2016, 245-264.

78 Kaus Taschwer, Hochburg des Antisemitismus. Der Niedergang der Universität Wien im 2o. Jahrhundert, Wien 2015; Oliver Rathkolb (Hg.), Der lange Schatten des Antisemitismus. Kritische Auseinandersetzungen mit der Geschichte der Universität Wien im 19. und 20. Jahrhundert, Göttingen 2013; Fritz/Rossolínski-Liebe/Starek (Hg.), Alma Mater; Enderle-Burcel/Reiter-Zatloukal (Hg.), Antisemitismus. 
Welthandel (später Wirtschaftsuniversität Wien), riefen 1965 sowohl Pro- als auch Gegendemonstrationen hervor, im Zuge derer der Antifaschist Ernst Kirchweger von einem Rechtsextremen tödlich verletzt wurde. ${ }^{79}$

\subsection{Frauen}

Ein Studium an den österreichischen Universitäten ist für Frauen seit 1897 (an allen Fakultäten jedoch erst seit 1946) möglich. Die erste Habilitation einer Frau (Elise Richter) erfolgte 1905. Die ersten zwei Berufungen von Frauen zu ordentlichen Universitätsprofessorinnen folgten 1956 an den Universitäten Wien (Berta Karlik) und Graz (Carla Zawisch-Ossenitz). Auch in den folgenden Jahren waren Frauen in den oberen Statusgruppen jedoch nur schwach vertreten, während von der Hochschulexpansion und Öffnung der Universitäten in den 1960er- und 1970er-Jahren vor allem die Studentinnen profitierten.

Die Geschichte von Frauen an Österreichs Hochschulen wird zwar in vielen Fällen als Teil der Studien zum Personal oder zu den Studierenden abgehandelt, und auch in vielen Jubiläumsschriften der letzten Jahre sind Frauen als Thema präsent. Ihnen wurde in den letzten Jahrzehnten aber auch eine Reihe von Spezialstudien gewidmet, in denen folgende Themen „Klassiker“ sind: Zulassung zum Studium, Pionierinnen und Entwicklung des Frauenanteils unter den Studierenden und Lehrenden, Sozialstruktur, Tätigkeit in einzelnen Berufsfeldern. Anlass waren auch hierfür häufig Jubiläen von Universitätsgründungen und Studienzulassungen. So erschien etwa der erste Sammelband zu Frauen an der Universität Wien zu deren 625-JahrJubiläum, ${ }^{80}$ Publikationen zu Ärztinnen bzw. Technikerinnen wurden jeweils zum

79 Vgl. u. a. Rafael Kropiunigg, Eine österreichische Affäre. Der Fall Borodajkewycz, Wien 2015.

80 Waltraud Heindl/Marina Tichy, „Durch Erkenntnis zu Freiheit und Glück ..." Frauen an der Universität Wien (ab 1897), Wien 1990; Doris Ingrisch, „Alles war das Institut!“ Eine lebensgeschichtliche Untersuchung über die erste Generation von Professorinnen an der Universität Wien (Materialien zur Förderung von Frauen in der Wissenschaft 2), Wien 1992; Alois Kernbauer, Frauenstudium und Frauenkarrieren an der Universität Graz (Publikationen aus dem Archiv der Universität Graz 33), Graz 1996; Juliane Mikoletzky/Ute Georgeacopol-Winischhofer/Margit Pohl, „Dem Zuge der Zeit entsprechend ..." Zur Geschichte des Frauenstudiums in Österreich am Beispiel der Technischen Universität Wien, Wien 1997; Susanne Lichtmannegger, Wissenschaft, in: Horst Schreiber (Hg.), Frauen in Tirol. Pionierinnen in Politik, Wirtschaft, Literatur, Musik, Kunst und Wissenschaft (Tiroler Studien zu Geschichte und Politik 2), Innsbruck/Wien/München/Bozen 2003, 199-225. 
100-Jahr-Jubiläum des Studienzugangs in den Jahren 2000 bzw. 2019 herausgegeben. ${ }^{81}$ Studienfachbezogene Arbeiten erschienen bisher jedoch nur vereinzelt. ${ }^{82}$

Auch das Auftreten der Neuen oder Zweiten Frauenbewegung an den Universitäten ab den 1970er-Jahren stellt ein erst ansatzweise bearbeitetes Thema dar. Diese hat nicht nur zur Förderung von Frauen in der Wissenschaft, und zur Implementierung neuer Organisationsstrukturen (Arbeitskreise für Gleichbehandlungsfragen), sondern auch zur Etablierung neuer Lehrinhalte (von eigenen Sommeruniversitäten über feministische Schwerpunkte in der Lehre bis hin zu den Gender Studies) beigetragen. Dabei stellte die Geschichtswissenschaft sowohl in den USA als auch (später) in Europa eine Art „Leitwissenschaft“ dar. In der vorhandenen Literatur werden daher oftmals die genannten Bereiche gemeinsam behandelt. ${ }^{8_{3}}$

Frauenspezifische Maßnahmen an den Universitäten wurden von 1992 bis 2007 in der Buchreihe „Materialien zur Förderung von Frauen in der Wissenschaft“ des Wissenschaftsministeriums dokumentiert. Einzelne Bände behandeln auch historische Themen.

\subsection{Erinnerungspolitiken}

Im Zuge der Auseinandersetzung mit der NS-Vergangenheit ab den 1980er-Jahren und einer in der Zeitgeschichte generell zunehmenden Diskussion um Erinnerungsorte und -politiken hat auch eine verstärkte Beschäftigung mit universitären Gedenk-

81 Birgit Bolognese-Leuchtenmüller/Sonia Horn (Hg.), Töchter des Hippokrates. 100 Jahre akademische Ärztinnen in Österreich, Wien 2000; Marion Krammer/Margarethe Szeless (Hg.), 1919-2019. 100 Jahre Frauen an der Technischen Universität Wien, Wien 2019.

82 Elisabeth Fritsch, Wie die Pharmazie ein Frauenberuf wurde. Materialien zu den in Wien ausgebildeten und berufstätigen Pharmazeutinnen mit Schwerpunkt 1905 bis 1945, Berlin 2007.

83 Lisa Gensluckner, Frauenbewegte Aktivitäten im universitären Kontext, in: Lisa Gensluckner/ Christine Regensburger/Verena Schlichtmeier/Helga Treichl/Monika Windisch (Hg.), vielstimmig.mancherorts. Die Neue Frauenbewegung in Tirol seit 1970, Innsbruck/Wien/München/Bozen 2001, 217-228; Christa Hämmerle/Gabriella Hauch, „Auch die österreichische Frauenforschung sollte Wege der Beteiligung finden ..." Zur Institutionalisierung der Frauen- und Geschlechtergeschichte an der Universität Wien, in: Karl Anton Fröschl/Gerd Müller/Thomas Olechowski/ Brigitta Schmidt-Lauber (Hg.), Reflexive Innenansichten aus der Universität Wien - Disziplinengeschichten zwischen Wissenschaft, Gesellschaft und Politik (650 Jahre Universität Wien 4), Göttingen 2015, 97-109; Doris Ingrisch, Gender-Dimensionen, in: Katharina Kniefacz/Elisabeth Nemeth/Herbert Posch/Friedrich Stadler (Hg.), Universität - Forschung - Lehre. Themen und Perspektiven im langen 20. Jahrhundert (650 Jahre Universität Wien 1), Göttingen 2015, 337-361; Edeltraud Ranftl, Von der maskulinen Geburt zu feministischer Wissenschaft und Gender Studies an der JKU, in: Wirth/Reichl/Gräser (Hg.), Innovationsfelder, 327-436. 
formen stattgefunden. Dies hat sich sowohl in universitätsinternen als auch öffentlichen Kontroversen über den Umgang mit Denkmälern (wie dem „Siegfriedskopf“ an der Universität Wien), ${ }^{84}$ künstlerischen Interventionen und historischen Kontextualisierungen (wie beim „Ehrenmal“ der Universität Innsbruck), ${ }^{85}$ aber auch der Errichtung neuer Mahnmäler und Gedenktafeln für die Opfer des Nationalsozialismus (Wirtschaftsuniversität Wien), ${ }^{86}$ zur Erinnerung an die Entnazifizierung (Universität für Bodenkultur Wien) ${ }^{87}$ oder Ausstellungen zur Geschichte der Standorte (Universität Linz ${ }^{88}$ und Wien ${ }^{89}$ ) niedergeschlagen. Besondere Bedeutung kommt den (auf entsprechenden Forschungen basierenden) analogen und digitalen Gedenkbüchern, -portalen und -verzeichnissen über die vertriebenen bzw. geschädigten Universitätsangehörigen (Studierenden, Lehrenden, Personen, denen die akademischen Grade entzogen wurden) zu, die ausgehend von der Universität Wien $2008^{90}$ mittlerweile an vielen Universitäten etabliert sind und als „work in progress“ weitergeführt werden (Wirtschaftsuniversität Wien, ${ }^{91}$ Akademie der bildenden Künste Wien, ${ }^{92}$ Medizini-

84 Vgl. zur Diskussion über den „Siegfriedskopf“ und anderen erinnerungspolitischen Kontroversen an der Universität Wien: 650 plus - Geschichte der Universität Wien, Universität Wien, URL: https://geschichte.univie.ac.at/de (abgerufen 25.06.2019).

85 Das „Ehrenmal“ der Universität Innsbruck, Universität Innsbruck, URL: https://www.uibk.ac.at/ universitaet/profil/geschichte/ehrenmal-der-universitaet-innsbruck.html (abgerufen 25.08.2020).

86 Gedenkprojekt, Wirtschaftsuniversität Wien, URL: https://www.wu.ac.at/universitaet/ueber-diewu/geschichte/gedenkprojekt (abgerufen 25.06.2019).

87 Gregor Mendel auf der Wiener Türkenschanze, Wiener Zeitung, 10.11.2016, URL: https://www. wienerzeitung.at/archiv/museum/854322-Gregor-Mendel-auf-der-Wiener-Tuerkenschanze.html (abgerufen 25.06.2019).

88 Hermann Rafetseder, Zur Geschichte von Gelände und Umfeld der Johannes Kepler Universität Linz, unter besonderer Berücksichtigung der NS-Zeit im Raum Auhof - Dornach. Ein Beitrag zum 50-Jahr-Jubiläum der Johannes Kepler Universität Linz, Linz 2016.

89 Herbert Posch/Markus Stumpf/Linda Erker/Oliver Rathkolb (Hg.), Vom AKH zum Uni-Campus. Achse der Erinnerung, Wien 2015; Brigitta Schmidt-Lauber (Hg.), Universität und Stadt: Campus Altes AKH Wien, Weitra 2017.

90 Gedenkbuch für die Opfer des Nationalsozialismus an der Universität Wien 1938, Universität Wien, URL: https://gedenkbuch.univie.ac.at (abgerufen 25.06.2019).

91 Gedenkbuch für die Opfer des Nationalsozialismus an der Hochschule für Welthandel 19381945. Wirtschaftsuniversität Wien, URL: https://gedenkbuch.wu.ac.at/zum-geleit/ (abgerufen 25.06.2019).

92 Die Datenbank verzeichnet im Gegensatz zu anderen Gedenkbüchern alle an der Akademie von 1938 bis 1945 tätigen Personen. Vgl.: Die Akademie der bildenden Künste Wien im Nationalsozialismus. Lehrende, Studierende und Verwaltungspersonal, Akademie der bildenden Künste Wien, URL: http://ns-zeit.akbild.ac.at/ (abgerufen 25.06.2019). 
sche Universität Wien, ${ }^{93}$ Universität Innsbruck, ${ }^{94}$ demnächst Technische Universität Wien).

Ein wichtiger Katalysator für die Auseinandersetzung mit akademischen Ehrungen stellte die öffentliche Debatte über die Ehrendoktorate von Paul Eduard Tratz, Konrad Lorenz und Wolfgang Hefermehl an der Universität Salzburg und deren Verstrickungen mit dem NS-Staat dar. Dies führte zur Aberkennung der drei Ehrendoktorate und dazu, dass die Universität Salzburg ab 2014 ihre gesamte Tabula Honorum in Hinblick auf deren Verhältnis zum Nationalsozialismus untersuchen ließ.95 Gleichzeitig wurde ein Projekt über die Biographien der „Gründerprofessoren“ an der 1962 (wieder)errichteten Universität Salzburg in Auftrag gegeben. ${ }^{96}$ Weitere Universitäten folgten ab 2015 mit einer Überprüfung ihrer Ehrenpersonen, wobei sowohl die Universität Wien ${ }^{97}$ als auch die Universität Innsbruck ${ }^{98}$ sich dazu entschlossen haben, ihre Forschungsergebnisse online zu dokumentieren bzw. ebenfalls als „work in progress“ auszubauen. Eine Auseinandersetzung mit den für die Universitätsgeschichtsschreibung so zentralen Jubiläen (und damit eine historische Kontextualisierung vieler vorhandener Texte) steht jedoch erst am Anfang. ${ }^{99}$

\subsection{Universitätsbau/Universität und Umfeld}

Die Ausstattung mit Räumen stellt eine der wichtigsten Voraussetzungen für einen funktionierenden Universitätsbetrieb dar. Die Verteilung der vorhandenen Kapazitäten und eine Beobachtung, für welche Bereiche (Fakultäten/Institute, Forschung/

93 Vertrieben 1938 - Biographien entlassener Professoren und Dozenten der Medizinischen Fakultät der Universität Wien, Medizinische Universität Wien, URL: https://ub.meduniwien.ac.at/ blog/?p=772 (abgerufen 25.06.2019).

94 Geschichte der Universität Innsbruck, Universität Innsbruck, URL: https://www.uibk.ac.at/universitaet/profil/geschichte/ (abgerufen 25.06.2019).

95 Vgl. Alexander Pinwinkler/Johannes Koll (Hg.), Zuviel der Ehre? Interdisziplinäre Perspektiven auf akademische Ehrungen in Deutschland und Österreich, Wien/Köln/Weimar 2019.

96 Pinwinkler, „Gründergeneration“.

97 Ehrungen an der Universität Wien, Universität Wien, URL: https://geschichte.univie.ac.at/de/themen/ehrungen-der-universitat-wien (abgerufen 25.06.2019).

98 Geschichte der Universität Innsbruck, Universität Innsbruck, URL: https://www.uibk.ac.at/universitaet/profil/geschichte/ (abgerufen 25.06.2019).

99 Katharina Kniefacz/Herbert Posch, Selbstdarstellung mit Geschichte. Traditionen, Memorial- und Jubiläumskultur der Universität Wien, in: Kniefacz/Nemeth/Posch/Stadler (Hg.), Universität, 381-410; Peter Goller, Innsbrucker Universitätsjubiläen. Inszenierungen 1877-1927-1952-1969, in: Alois Kernbauer (Hg.), Wissenschafts- und Universitätsgeschichtsforschung am Archiv (Publikationen aus dem Archiv der Universität Graz 45), Graz 2016, 69-90. 
Lehre/Drittmittelprojekte) hinzugebaut wird, sagt viel über die intendierte und tatsächliche Entwicklung einer Universität aus. Die Finanzierung erlaubt hingegen Einblicke in das Verhältnis zu Politik (Bund, Land, Kommunen) und Wirtschaft, während die Art, „wie“ gebaut wird, wichtige Erkenntnisse über die Organisation des Universitätsbetriebs ermöglicht.

In der Universitätsgeschichte stellt der Hochschulbau ein fest etabliertes Thema dar, mit dem sich Zeit-, Kunst- und ArchitekturhistorikerInnen gleichermaßen beschäftigen. Dies zeigt sich auch darin, dass die universitäre Baugeschichte entweder in die genannten Jubiläumspublikationen eingegangen ist ${ }^{100}$ oder diese durch eigene Bände zur Baugeschichte ergänzt wurden. ${ }^{101}$ Das Standardwerk zum österreichischen Universitätsbau nach 1945 stammt aus dem Jahr 2005. Dieses gibt - anders als die genannten Darstellungen - einen institutionenübergreifenden Abriss über die universitäre Bauentwicklung mit einer ausführlichen Kontextualisierung (Hochschulsystem seit dem 14. Jahrhundert, Universitätspolitik, Studierendenzahlen und Hochschulfinanzierung seit 1945) $)^{102}$ und wird auch in Zukunft ein wichtiger Ausgangspunkt für die Beschäftigung mit dem Universitätsbau sein, der durch die Auseinandersetzung mit den deutschen und österreichischen Hochschulgründungen der 1960er- und 1970er-Jahre wichtige Impulse in verschiedener Hinsicht erfahren hat: der Diskussion über die Vor- und Nachteile einer Stadt- oder Campusuniversität (in Hinblick auf ein neues Zusammensein von Lehrenden und Studierenden, der vertretenen Disziplinen und dem Verhältnis zur Stadt) oder der architektonischen Unterstützung von verstärkter interdisziplinärer Zusammenarbeit. ${ }^{103}$

100 Reith, Die Paris Lodron Universität Salzburg; Wirth/Reichl/Gräser (Hg.), Hochschule.

101 Ulrike Aichhorn, Universitätsstadt Salzburg. Von der Benediktineruniversität zum Unipark Nonntal, Salzburg 2012; Julia Rüdiger/Dieter Schweizer (Hg.), Stätten des Wissens. Die Universität Wien entlang ihrer Bauten 1365-2015, Wien/Köln/Weimar 2015; Julia Rüdiger, Monumentale Universität. Funktioneller Bau und repräsentative Ausstattung des Hauptgebäudes der Universität Wien, Wien 2015; Klaus Tragbar, Die Topographie des Wissens. Eine kleine Stadtbaugeschichte der Universität Innsbruck, Innsbruck 2019. Vgl. zu einem „Baujubiläum“: Bernhard Reismann, 125 Jahre Alte Technik. 1888 bis 2013, Graz 2013; Otto Kapfinger/Matthias Boeckl, Abgelehnt - nicht ausgeführt. Die Bau- und Projektgeschichte der Hochschule für Angewandte Kunst in Wien 1873-1993. Ein ebenso unbekanntes wie lehrreiches Kapitel der Wiener Kultur- und Architekturgeschichte. 125 Jahre Hochschule für Angewandte Kunst in Wien, Wien 1993.

102 Elmar Schübl, Der Universitätsbau in der Zweiten Republik. Ein Beitrag zur Entwicklung der universitären Landschaft in Österreich, Horn/Wien 2005.

103 Vgl. u. a.: Maria Wirth (Hg.), Neue Universitäten. Österreich und Deutschland in den 1960er- und 1970er-Jahren. zeitgeschichte 47 (Sonderheft 2020); Wilfried Rudloff (Hg.), Jahrbuch für Universitätsgeschichte 22 (2019). 


\section{Resümee}

Die Universitätsgeschichte hat in den letzten Jahren zweifellos große Fortschritte gemacht, für die insbesondere die genannten Jubiläen verantwortlich sind. Dieses Spezifikum der Universitätsgeschichte hat auch zur Folge, dass in regelmäßigen Abständen eine Konjunktur an Publikationen zu verzeichnen ist, sich diese - wie es in der Disziplin generell häufig der Fall ist - aber nur mit der Geschichte einzelner Institutionen beschäftigen. Vergleichende Studien sind daher ebenso ein Desiderat wie Synthesen, die einen Überblick über die gesamtösterreichische Entwicklung geben. Gleiches gilt für eine Kontextualisierung mit europäischen und internationalen Trends, wenn einige neuere Texte und Sammelbände (wie ein Tagungsband über die Universitätsgründungen der 1960er- und 1970er-Jahre in Deutschland und Österreich) auch institutionen- und länderübergreifend ausgerichtet sind. ${ }^{104}$ Studien, die den Blick über Österreich hinaus wenden, Untersuchungen zu einem internationalen Austausch, Vernetzungen und Transfers sind ebenso gefragt wie Forschungen zu den „Außenbeziehungen“ der Universitäten - seien dies ihr regionales Umfeld, die Politik, Wirtschaft, Medien oder andere gesellschaftliche Gruppierungen.

Der Schwerpunkt der bislang erschienenen Publikationen liegt auf dem Zeitraum von 1918 bis etwa 1955. Auch für diese Jahre sind zu vielen Bereichen (etwa zu den Studierenden im Nationalsozialismus) aber noch grundlegende Forschungen ausständig. Unbearbeitet sind so auch noch immer die NS-Pläne für eine strukturelle Neuordnung der Hochschulen in der „Ostmark“. ${ }^{105}$ Eine große Lücke besteht vor allem jedoch für den Zeitraum ab 1955 inklusive jener Prozesse, die unser gegenwärtiges Universitätssystem prägen und einen zentralen Einfluss auf die zukünftige Entwicklung haben werden. Diese Leerstelle Schritt für Schritt zu schließen, wird eine wichtige Aufgabe für die Universitätsgeschichte künftiger Jahre sein.

Wünschenswert wäre schließlich auch eine verstärkte Auseinandersetzung mit der Frage, „wie“ Universitätsgeschichte geschrieben werden soll, um durch eine kritische Selbstbeobachtung und den Dialog über die Institutionengrenzen hinweg zu einer reflexiven Weiterentwicklung des Arbeitsfeldes zu gelangen. ${ }^{106}$ Ein wichtiger Ansatzpunkt hierfür kann eine Auseinandersetzung mit den Jubiläumsschriften und deren Entstehungsgeschichten sein.

\footnotetext{
104 Fritz/Rossolínski-Liebe/Starek (Hg.), Alma Mater; Koll, Säuberungen; Ash, Hochschulen; Erker, Universität Wien; Pinwinkler/Koll (Hg.), Ehre; Wirth (Hg.), Neue Universitäten.

105 Wir danken Juliane Mikoletzky für diesen Hinweis.

106 Vgl. zuletzt etwa Prüll/George/Hüther, Universitätsgeschichte.
} 


\section{Sport ${ }^{1}$}

Agnes Meisinger und Rudolf Müllner

\section{Vorbemerkungen - Gegenstandsbereich}

Was Sportgeschichte sei und was sie ausmache, sei „keine leicht zu beantwortende Frage“, schreiben Olaf Stieglitz und Jürgen Martschukat in ihrem grundlegenden „Docupedia“-Beitrag völlig zu Recht. ${ }^{2}$ Die Schwierigkeit der Begriffsklärung ist zunächst in der Komplexität und Divergenz des sportlichen Feldes begründet. Traditioneller (historischer) britischer Amateursport verstand sich als ein ausschließlich weißen, männlichen Adeligen vorbehaltener Zeitvertreib. Er war das Privileg der Angehörigen der „leisure class“. Ausgehend von der Industriellen Revolution diffundierte Sport in Großbritannien im Laufe des 19. Jahrhunderts ins Bürgertum und erreichte noch gegen Ende desselben Jahrhunderts eine gewisse Breite und Verankerung in der Arbeiterschicht. Auf dem europäischen Kontinent vollzog sich diese Entwicklung mit einer zeitlichen Verzögerung. In den urbanen Zentren der Habsburgermonarchie entfaltete vor allem der Fußball bereits in der Zwischenkriegszeit eine massenkulturelle Faszination. Doch es sollte bis in die 1960er-Jahre dauern, bis der „kometenhafte Aufstieg“ (Hajo Bernett) des Sports, zunächst in den europäischen Industrieländern, ${ }^{3}$ einsetzte.

Auf dem Höhepunkt des Fordismus hatte sich dann eine Freizeitgesellschaft etabliert, in der Sport bereits eine bedeutende alltagskulturelle Sphäre besetzte. Drei einander beeinflussende Phänomene charakterisieren den Transformationsprozess des Sports ab den 1970er-Jahren: Es war dies erstens zunächst der Bedeutungsverlust des traditionellen, vorwiegend von virilen jungen Männern im Verein betriebenen

$1 \quad$ Der Beitrag basiert auf dem Text von Agnes Meisinger/Rudolf Müllner, Zur (schwierigen) Positionierung der Sportgeschichte zwischen Sport- und Geschichtswissenschaft, in: Bertrand Perz/Ina Markova (Hg.), 50 Jahre Institut für Zeitgeschichte der Universität Wien 1966-2016, Wien 2017, 371-386. Die vorliegende Version wurde überarbeitet und aktualisiert.

2 Olaf Stieglitz/Jürgen Martschukat, Sportgeschichte, URL: https:/docupedia.de/zg/Sportgeschichte (abgerufen 12.06.2019).

3 Die kommunistischen europäischen Staaten, Lateinamerika und Asien weisen strukturell sehr unterschiedliche Entwicklungen auf. In den USA ist die Bedeutung von Sport und Körperkultur schon weitaus früher als in vielen westeuropäischen Staaten stark ausgeprägt. 
Wettkampfsports. Neben dem reinen Leistungsvergleich wurden „sport-for-all“Initiativen, informelles Sporttreiben oder neue Spielarten des Breitensports entwickelt. Dazu etablierte sich eine breite Palette kommerzieller Angebote. Zweitens expandierte die Zahl der Sporttreibenden. Bisher sportferne Gruppen, allen voran Frauen, Kinder und Ältere, wurden systematisch inkludiert. Sport entwickelte drittens eine enorme Binnendifferenzierung - nicht nur hinsichtlich seiner Organisationsformen, sondern vor allem auch, was seine Praktiken und die Sinnorientierung der Aktiven betraf. Spaß, Geselligkeit, Fitness und insbesondere auch Gesundheit und ästhetische Motive wurden jetzt hegemonial. ${ }^{4}$ Eine enorme Aufwertung des Körpers und seiner sportiven Herstellungspraxen unter dem Paradigma der Verbesserung und Optimierung bezeichnen nur einige der rezenten Ausformungen einer generell „versportlichten“ Gesellschaft. Die Verschmelzung von pop- und sportkulturellen Semantiken, wie sie sich etwa in den elektronischen Medien, aber auch im Amalgamieren von Street- und Sportswear beobachten lässt, ist ein weiterer Indikator für die sportkulturelle Durchdringung weiter Lebensbereiche. ${ }^{5}$

Eine andere Facette des Transformationsprozesses des modernen Sports lässt sich unter dem Begriff Globalisierung subsumieren. Schlagwortartig ist damit die Herausbildung eines transnationalen politischen, ökonomischen, kulturellen und organisatorischen Systems bezeichnet, das sich manifestiert in Weltsportorganisationen wie etwa dem IOC (International Olympic Committee), der FIFA (Fédération Internationale de Football Association), der FIA (Fédération Internationale de l'Automobile), in „Sportmegaevents“" wie zum Beispiel den Olympischen Spielen, der Tour de France oder Fußballweltmeisterschaften. Parallel dazu entwickelte sich der Sport zu einer beachtlichen „soft power“ der Nationalstaaten.

Sport im globalen Kontext bedeutet auch einen weltweiten Sportartikelmarkt mit Produktion vorwiegend in Billiglohnländern7, einen Süd-Nord-,,muscle-drain“ von nachgefragten und teilweise hochbezahlten SpitzenathletInnen oder die welt-

4 Werner Hägele, Sport in moderner Postmoderne. Individualisierung und Körperkultur in nationaler Moderne und globaler Postmoderne, München 2008, 58-63; Robert Schmidt, Soziologie der Praktiken. Konzeptionelle Studien und empirische Analysen, Berlin 2012, 85-88; Robert Gugutzer/Stefanie Duttweiler, Körper - Gesundheit - Sport. Selbsttechnologien in der Gesundheits- und Sportgesellschaft, in: Sozialwissenschaft und Berufspraxis 35 (2012) 1, 5-19; Simon Graf, Leistungsfähig, attraktiv, erfolgreich, jung und gesund: Der fitte Körper in postfordistischen Verhältnissen, in: Bodypolitics 1 (2013) 1, 139-157.

5 Lukas Wieselberg/Georg Spitaler, Editorial, in: Kurswechsel 1 (2004) 2, 3.

6 Richard Gruneau/John Horne (Hg.), Mega-Events and Globalization. Capital and Spectacle in a Changing World Order, London 2016.

7 Wolfgang Manzenreiter, Sport im Konsumkapitalismus: Phasen der Ökonomisierung, in: Matthias Marschik/Rudolf Müllner/Otto Penz/Georg Spitaler (Hg.), Sport Studies, Wien 2009, 112-125. 
weite Ausstrahlung und Rezeption von Sportereignissen mit einem damit einhergehenden lukrativen Handel mit Übertragungsrechten und Werbezeiten. Dies führt unter anderem zu einer Verdrängung von autochthonen bewegungskulturellen Formen, zu einer globalen Homogenisierung, Standardisierung und Durchdringung mit US-amerikanisch-europäischen Sport- und Bewegungsformaten. ${ }^{8}$

All dies rechtfertigt eine kritische, analytische zeithistorische Auseinandersetzung mit diesem komplexen sozialen Phänomen. Es geht dabei um mehr als den medial repräsentierten Hochleistungssport oder um dessen organisatorische, politische, ökonomische oder soziale Ausprägungsformen. Die hier kurz skizzierten Wirkmächte reichen weit über das eigentliche Terrain des Sports im engeren Sinne hinaus: Sie berühren unser alltägliches Körper- und Bewegungsverhalten genauso wie unser Verständnis von so basalen Werten wie Leistung, Leistungsfähigkeit, Leistungsgrenzen, Wachstum, Behinderung, Attraktivität, Geschlecht, Nation, Fairness, Gerechtigkeit, Gesundheit, Krankheit, Kooperation, Konkurrenz, Alter und vieles andere mehr. Es ist somit auch evident, dass ein traditionelles politik, ereignis, organisationsgeschichtliches oder bestenfalls noch ein biographisches Methodenrepertoire den Anforderungen einer modernen Sportgeschichtsforschung nicht mehr genügen kann.

\subsection{Turngeschichte, Sport- und Geschichtswissenschaft}

Sportgeschichte, als eine Teildisziplin der Geschichtswissenschaft, unterliegt zunächst denselben Produktionsbedingungen wie andere historiographische Fachrichtungen und arbeitet mit denselben Quellen, die schriftliche, mündliche und audiovisuelle Überlieferungen aus der Vergangenheit umfassen. Allerdings sind die schriftlichen Überlieferungen in den öffentlichen Archiven - verglichen mit herkömmlichen Untersuchungsgegenständen wie beispielsweise der Politikgeschichte - teilweise nur unter sehr viel Mehraufwand zu finden. Die Dokumentation von Unternehmungen, die in einem nicht staatlich regulierten gesellschaftlichen Bereich stattfanden, was speziell für sportliche (Freizeit)Aktivitäten und Körperkultur zutrifft, ist nicht vordringliche Aufgabe der Archive. ${ }^{9}$

8 Jesper Andreasson/Thomas Johansson, The Global Gym, Gender, Health and Pedagogies, Basingstoke 2014.

9 Vgl. Claudio Ambrosi/Wolfgang Weber, Editorial, in: Geschichte und Region/Storia e regione 13 (2004) 1, 5-19 sowie Maximilian Graf/Agnes Meisinger/Wolfgang Weber, Sport(zeit)geschichte, in: zeitgeschichte $42(2015) 4,211-214$. 
Trotz dieser schwierigen Voraussetzungen im Bereich der Quellen etablierte sich die Sportgeschichtsschreibung im deutschen Sprachraum nahezu parallel zur Historiographie als wissenschaftliche Disziplin. Dies geschah anfänglich jedoch außerhalb der Geschichtswissenschaft, in Nachbarwissenschaften wie etwa der Pädagogik. ${ }^{10} \mathrm{Im}$ Rahmen der Aufklärungspädagogik wurden bereits an der Wende vom 18. zum 19. Jahrhundert von Theoretikern wie Johann Christoph Friedrich GutsMuths, Friedrich Ludwig Jahn oder Gerhard Ulrich Anton Vieth Konzepte für eine Leibeserziehung entwickelt, die auf die Körperkultur der europäischen Antike rekurrierten. ${ }^{11}$ 1863 publizierte der Marburger Philosoph Friedrich Albert Lange sein Buch „Die Leibesübungen. Eine Darstellung des Werdens und Wesens der Turnkunst in ihrer pädagogischen und kulturhistorischen Bedeutung ". ${ }^{12}$ Darin stellte er die Sportgeschichte in einen Kontext mit der Erziehungsgeschichte und der Kulturgeschichte ein Ansatz, der seit dem Ende des 20. Jahrhunderts erneut von den Cultural Studies vertreten wird. Die Hauptfunktion dieser frühen Formen der Geschichte der Leibesübungen und Leibeserziehung lag darin, die seit der Aufklärung bestehenden Bestrebungen einer egalitären körperlichen Ausbildung ,sportpädagogisch-historisierend" zu unterstützen. Die Geschichtsforschung suchte und fand vor allem in der griechischen Agonistik das Material zur Begründung und Legitimation der bürgerlichen Leibesübungen. Folglich war es nur konsequent, dass in der 1871 eingeführten Turnlehrerausbildung (Frauen waren nicht zugelassen) an der Universität Wien die Kandidaten in der Abschlussprüfung ,allgemeine Kenntnisse der geschichtlichen Entwicklung des Turnwesens ${ }^{{ }^{\prime \prime} 13}$ nachweisen mussten.

Bis in die 196oer-Jahre diente die an den Instituten für Turnlehrerausbildung betriebene Geschichtsschreibung überwiegend der Legitimation des Bildungswertes und des pädagogischen Nutzens der schulischen Leibesübungen. Turnen und Leibesübungen wurden meist als von den „großen“ Pädagogen (wie Pestalozzi, Spieß,

10 Christiane Eisenberg bezeichnet diese ersten Sporthistoriker daher als Amateure; vgl. Christiane Eisenberg, Die Entdeckung des Sports durch die moderne Geschichtswissenschaft, in: Historical Social Research 27 (2002) 2/3, 4-21, 8.

11 Siehe etwa die Werke: Johann Christoph Friedrich GutsMuths, Gymnastik für die Jugend. Enthaltend eine praktische Anweisung zu Leibesübungen, Schnepfenthal bei Gotha 1793; Friedrich Ludwig Jahn/Ernst Wilhelm Bernhard Eiselen, Die deutsche Turnkunst zur Einrichtung der Turnplätze, Berlin 1816; oder: Gerhard Ulrich Anton Vieth, Versuch einer Enzyklopädie der Leibesübungen, 3 Bde., Berlin/Leipzig 1794-1818.

12 Friedrich Albert Lange, Die Leibesübungen. Eine Darstellung des Werdens und Wesens der Turnkunst in ihrer pädagogischen und kulturhistorischen Bedeutung, Gotha 1863.

13 Matthias Marschik/Rudolf Müllner, Probleme und Perspektiven der Geschichte des Sports in Österreich, in: Sozial- und Zeitgeschichte des Sports 12 (1998) 2, 7-36, 9. 
Jahn) geprägte Systeme dargestellt. Der Sporthistoriker Bernd Wedemeyer-Kolwe ${ }^{14}$ bezeichnet dies durchaus treffend als „ideologische Flankierung der kulturellen und nationalen Bedeutung der Turnlehrerausbildungen“. Eine Ausnahme in dieser Entwicklung stellt der bedeutende österreichische Sportwissenschaftler Karl Gaulhofer (1885-1941) dar. In seinem 1930 publizierten Text „Die Fußhaltung. Ein Beitrag zur Stilgeschichte der menschlichen Bewegung ${ }^{{ }^{15} 15}$ nahm er rezente kulturhistorische Perspektiven vorweg. Gaulhofer rückte - heute würde man sagen durchaus transdisziplinär - Aspekte in den Fokus seiner Forschung, die bis dahin im sporthistorischen Kontext einer Thematisierung für unwürdig befunden worden waren. Er fragte, ohne das semiotische oder kulturtheoretische Repertoire der heutigen Cultural Studies zur Verfügung zu haben, etwa nach der Herkunft und nach den gesellschaftlichen, ja kulturellen Entstehungsbedingungen, nach Funktionen und Bedeutungen von körperlichen Haltungen, Gesten, Gebärden oder Bewegungsstilen. Damit war er der zeitgenössischen Turnhistorikerzunft um Jahrzehnte voraus. ${ }^{16}$

\subsection{Turns, Turns, Turns}

Trotz dieser langen Tradition der Sportgeschichtsschreibung im Rahmen der akademischen Turnlehrerausbildungsinstitute war die Erforschung von Körper- und Bewegungskultur für die Geschichtswissenschaft lange Zeit ein wenig beachteter Untersuchungsgegenstand. ${ }^{17}$ Als in den 1960er-Jahren die Sportwissenschaft im deutschen Sprachraum einen enormen institutionellen und auch personellen Aufschwung verzeichnete, trat die paradoxe Situation ein, dass die geisteswissenschaftlichen Anteile (Sportgeschichte, aber auch die Pädagogik) innerhalb des Disziplinen-

14 Bernd Wedemeyer-Kolwe, „Was ist und wozu dient Sportgeschichte?" Anmerkungen zu einer Geschichte der Sporthistoriographie, in: SportZeiten. Sport in Geschichten, Kultur und Gesellschaft 2 (2002) 3, 5-24, 13.

15 Karl Gaulhofer, Die Fußhaltung. Ein Beitrag zur Stilgeschichte der menschlichen Bewegung, Kassel 1930.

16 Bei allen wissenschaftlichen Verdiensten Gaulhofers darf man jedoch sein Engagement für den Nationalsozialismus nicht ignorieren; vgl. Wolfgang Rechberger, Karl Gaulhofer. Historisch-biographische Untersuchungen zu Leben und Werk des österreichischen Schulturnreformers, Salzburg 1999.

17 Zur Geschichte der Sportgeschichtsforschung in Österreich siehe grundlegend: Marschik/Müllner, Probleme und Perspektiven, 7-36; Matthias Marschik, Die Entwicklung der Sportgeschichtsforschung in Österreich. Ein Überblick, in: SportZeiten. Sport in Geschichte, Kultur und Gesellschaft 10 (2010) 2, 47-60; Graf/Meisinger/Weber, Sport(zeit)geschichte, 211-214. 
kanons der Sportwissenschaft(en) nicht davon profitierten. ${ }^{18}$ Im Gegenteil, es setzte ein Verdrängungswettbewerb um Ressourcen ein, ${ }^{19}$ der klar zugunsten jener Subdisziplinen ausging, die „dem Sport“ ein schnell verwertbares Anwendungswissen zur Verfügung stellen konnten. Sportgeschichte wurde in Deutschland und in Österreich (und auch in vielen anderen westeuropäischen Staaten) immer mehr marginalisiert. Das geschah zum einen dadurch, dass von Sporthistorikern an Universitäten eingenommene Stellen nach deren Emeritierung an WissenschaftlerInnen der „neuen“ sportwissenschaftlichen Fachrichtungen wie beispielsweise Biomechanik oder Trainingswissenschaft vergeben wurden; ${ }^{20}$ so auch an der Universität Wien, an der nach der Pensionierung des am Sportwissenschaftlichen Institut lehrenden Historikers Hannes Strohmeyer dessen Stelle zunächst nicht mehr facheinschlägig nachbesetzt wurde. ${ }^{21}$ Dessen ungeachtet entwickelte sich seit den 1980er-Jahren außerhalb der universitären sportwissenschaftlichen Institute zweierlei: einerseits ein offensichtlich größer werdendes öffentliches Interesse und eine verstärkte Nachfrage hinsichtlich sporthistorischer Themen, Fragestellungen und Inhalte und andererseits eine - vor allem in Wien - durchaus innovative, überwiegend kulturwissenschaftlich ausgerichtete und leistungsfähige Generation von freien Forschern und zunehmend auch Forscherinnen. ${ }^{22}$ Mit der ab den 1960er-Jahren in Westdeutschland begonnenen wissenschaftlichen Aufarbeitung der NS-Geschichte eröffnete sich auch für die Sportgeschichte die Möglichkeit, im Zuge der Gesamthistoriographie über den Nationalsozialismus wahr- und ernst genommen zu werden. Die Arbeiten von Hajo Bernett über die Zeitgeschichte des Sports im NS-Staat ${ }^{23}$ stehen exemplarisch für diesen Trend. Sportgeschichte wurde über den Umweg der Politikgeschichte hoffähig und lieferte in den folgenden Jahrzehnten und bis heute eine

18 Rudolf Müllner, Sektion Sportgeschichte, in: Spectrum der Sportwissenschaften. Zeitschrift der Österreichischen Sportwissenschaftlichen Gesellschaft (Sonderheft 2015), 71-73.

19 Diese Entwicklung ist im Übrigen bis heute nicht abgeschlossen. An vielen sportwissenschaftlichen Universitätseinrichtungen geht es momentan darum, die letzten nicht systemaffirmativen Disziplinen, wie etwa die Sportsoziologie, zu streichen.

20 Christian Becker, Marginalisierung der Sportgeschichte? Eine Disziplin zwischen Entakademisierung und wachsender öffentlicher Wertschätzung, Bundeszentrale für politische Bildung - Deutschland Archiv, URL: http://www.bpb.de/geschichte/zeitgeschichte/deutschlandarchiv/135222/marginalisierung-der-sportgeschichte? $p=$ all (abgerufen 19.06.2019).

21 Zur Person und zum wissenschaftlichen CEuvre Strohmeyers siehe: Hannes Strohmeyer, Beiträge zur Geschichte des Sports in Österreich. Gesammelte Arbeiten aus vier Jahrzehnten, Wien 1999.

22 Marschik, Die Entwicklung, 52-53.

23 Siehe z. B. die beiden Monographien: Hajo Bernett, Untersuchungen zur Zeitgeschichte des Sports, Schorndorf 1973; ders., Nationalsozialistische Leibeserziehung, Schorndorf 1966. 
beachtliche Menge elaborierter Ergebnisse zu nahezu allen Aspekten des Sports im nationalsozialistischen Herrschaftsgefüge. ${ }^{24}$

In den 1970er- und 1980er-Jahren vollzog die Sportgeschichte den allgemeinen Wandel der Geschichtsforschung mit einer Hinwendung und einer Erweiterung um sozial- und strukturgeschichtliche Themen konsequent mit. Die innovativen Untersuchungen von Gertrud Pfister zum Frauensport etwa oder die von der Frankfurter Schule inspirierten Arbeiten Bero Rigauers, ${ }^{25}$ die Sport als einen Stabilisierungsfaktor in kapitalistischen Klassen- und Herrschaftsverhältnissen kritisieren, fallen in diese Phase. Auch die der Konfigurationssoziologie Nobert Elias' verpflichteten Meilensteinstudien von Eric Dunning, Allen Guttmann oder Henning Eichberg ${ }^{26}$ sind hier zu nennen. Aus diesen vollkommen neuen Perspektiven taten sich auch neue Fragen auf, etwa jene nach den gesellschaftlichen Merkmalen sportlichen Handelns: Wie prägen die Strukturen der modernen Industriegesellschaft das individuelle Handeln der Körpersubjekte und wie bringt deren Handeln wiederum neue bewegungskulturelle und sportspezifische Strukturen hervor? Hier waren es vor allem körperhistorische Untersuchungen, die das Spektrum erweiterten. Es war dies auch die Zeit - Ende der 1980er-Jahre -, als die Sportwissenschaft sich zusehends von der Sportgeschichte abwandte und die Geschichtswissenschaft die Sportgeschichte als Untersuchungsgegenstand entdeckte. Neben vermehrt kulturwissenschaftlichen Perspektiven auf Sport wurden ab den 2oooer-Jahren infolge der Globalisierung des Sports zunächst im angloamerikanischen Raum neue Themen wie etwa Ökonomisierung und Mediatisierung virulent. Sportgeschichtliche Perspektivierungen haben gegenwärtig in den Geistes, Kultur- und Sozialwissenschaften nahezu Hochkonjunktur, nachdem Sport als Gesellschafts- und Alltagsphänomen nicht mehr zu ignorieren ist. Eine Erweiterung des engen Sportbegriffes um die Dimension „Bewegungskultur“ bzw. das Einbeziehen der Ansätze aus dem Bereich der Sport Studies ${ }^{27}$ erscheinen uns in Zukunft unverzichtbar.

24 Lorenz Peiffer, Sport im Nationalsozialismus. Zum aktuellen Stand der sporthistorischen Forschung. Eine kommentierte Bibliographie, Göttingen ${ }^{2} 2009$.

25 Bero Rigauer, Sport und Arbeit. Soziologische Zusammenhänge und ideologische Implikationen, Frankfurt a. M. 1969; Gertrud Pfister, Weiblichkeitsideologie, Frauenrolle und Frauensport im „Dritten Reich“, in: Beiträge zur historischen Sozialkunde 13 (1983) 1, 19-28.

26 Eric Dunning/Kenneth Sheard, Barbarians, Gentlemen and Players. A Sociological Study of the Development of Rugby Football, Oxford 1979; Henning Eichberg, Leistung, Spannung und Geschwindigkeit. Sport und Tanz im gesellschaftlichen Wandel des 18., 19. Jahrhunderts, Stuttgart 1978; Henning Eichberg, Messen, Steigern, Produzieren. Die historisch-kulturelle Relativität des Leistens am Beispiel des Sports, in: Beiträge zur historischen Sozialkunde 13 (1983) 1, 12-18; Allen Guttmann, From Ritual to Record. The Nature of Modern Sports, New York 2004.

Marschik/Müllner/Penz/Spitaler (Hg.), Sport Studies. 


\section{Sportgeschichtsforschung in Österreich und an österreichischen Universitäten}

Sieht man sich die Entwicklung und die Tendenzen des Forschungsfeldes Sportgeschichte in Österreich an, waren es in den Anfangsjahren vor allem ereignisgeschichtliche Fragestellungen, die von SporthistorikerInnen behandelt und dokumentiert wurden. Heute stehen Fragen im Zentrum der Forschung, die gesellschaftliche, politische und ökonomische Kontexte mit einbeziehen und reflektieren. Dies spiegelt sich auch im methodischen Repertoire bzw. in den theoretischen Positionen wider. Es finden sich neben traditionell organisations- oder ereignisgeschichtlichen Darstellungen auch zahlreiche kulturwissenschaftliche und interdisziplinäre SportStudies-Positionen.

Es wird in der Folge ein kursorischer Überblick über einige, wie wir finden, beachtenswerte Aktivitäten im vergangenen Jahrzehnt gegeben. Dies kann jedoch keine vollständige und schon gar nicht repräsentative, systematische Auflistung sein.

\subsection{Forschungsstand}

Österreichs wissenschaftliche Auseinandersetzung mit der NS-Vergangenheit hinkte, nicht nur den Bereich Sport betreffend, jener (West)Deutschlands hinterher. Dies ist unter anderem auch darauf zurückzuführen, dass lange Zeit kein öffentlicher Druck existierte, sich mit besagtem Zeitraum auseinanderzusetzen..$^{28}$ Im vergangenen Jahrzehnt allerdings rückte die Periode der nationalsozialistischen Herrschaft verstärkt in den Blickpunkt sporthistorischer Forschung in Österreich. Matthias Marschik legte im Jahr 2008 ein Standardwerk über die Geschichte des Sports im nationalsozialistischen Österreich vor, ${ }^{29} \mathrm{dem}$ eine Reihe von wissenschaftlichen $\mathrm{Pu}$ blikationen folgte, die sich mit der ideologisch-politischen Ausrichtung populärer Sportvereine in der NS-Zeit auseinandersetzten. Im Jahr 2011 erschienen gleich zwei Werke, die durch die beforschten Vereine selbst initiiert und mitfinanziert wurden: In einem großangelegten länderübergreifenden Projekt zur Geschichte des Alpenvereins konnten die frühe deutschnationale, völkische und antisemitische Ausrichtung des Vereins und der Einfluss der NS-Politik auf den Alpinismus detailliert

28 Hans Joachim Teichler, Verzögertes Erinnern. Die Aufarbeitung der NS-Vergangenheit im bundesdeutschen Sport, Zeitgeschichte-online, URL: http://www.zeitgeschichte-online.de/thema/ verzoegertes-erinnern (abgerufen 20.01.2016).

29 Matthias Marschik, Sportdiktatur. Bewegungskulturen im nationalsozialistischen Österreich, Wien 2008. 
dargelegt werden. ${ }^{30}$ Eine weitere Publikation analysierte die Rolle des Sportklubs Rapid Wien, dem Deutschen Meister von 1941, im Rahmen des nationalsozialistischen Sportsystems. ${ }^{31}$ Ein Sammelband über Fußball in der „Ostmark ${ }^{\text {“32 }}$ zielte darauf ab, populäre Mythen der frühen Fußballhistoriographie zu dekonstruieren, regionale Studien zum steirischen Fußball untersuchen erstmals das Sportgeschehen ,in der Provinz" und beleuchten unter anderem die Bedeutung der Traditionsklubs Sturm Graz und des GAK im „Ostmarksport“.33

Auch der jüdische Sport fand Eingang in die Geschichtswissenschaft: 2009 erschien ein umfangreicher Sammelband über die einhundertjährige wechselvolle Geschichte des jüdischen Sportvereins Hakoah Wien, der viele Facetten des jüdischen Sports in Mitteleuropa beleuchtet und somit weit mehr als eine Vereinschronik darstellt. ${ }^{34}$ Weitere Beispiele aus dem Bereich der österreichischen Sportvereinshistoriographie stellten die Forschungen zu zwei der ältesten und populärsten Wiener Sportvereinigungen - dem im Jahr 1867 gegründeten Wiener Eislauf-Verein ${ }^{35}$ und dem First Vienna Football Club $1894^{36}$ - dar.

Andere Projekte brachten neue Ergebnisse zu der Kulturgeschichte des Radfahrens in Wien, ${ }^{37}$ der Mediatisierung des Sports in Österreich, ${ }^{38}$ der Bedeutung des Skisports in Österreich in Hinblick auf die Konstruktion nationaler Identität ${ }^{39}$. Auch der Motorsport, der sich nicht zuletzt dank flächendeckender Berichterstat-

30 Deutscher Alpenverein e.V./Oesterreichischer Alpenverein/Alpenverein Südtirol (Hg.), Berg Heil! Alpenverein und Bergsteigen 1918-1945, Wien/Köln/Weimar 2011.

31 Jakob Rosenberg/Georg Spitaler, Grün-weiß unterm Hakenkreuz. Der Sportklub Rapid im Nationalsozialismus (1938-1945), Wien 2011.

32 David Forster/Jakob Rosenberg/Georg Spitaler (Hg.), Fußball unterm Hakenkreuz in der „Ostmark“, Göttingen 2014.

33 Siehe etwa Johannes Gießauf/Walter M. Iber/Harald Knoll (Hg.), Fußball, Macht und Diktatur. Streiflichter auf den Stand der historischen Forschung, Innsbruck/Wien/Bozen 2014; Walter Iber/ Harald Knoll, Erst der Verein, dann die Partei. Der steirische Fußball und seine Traditionsklubs im Nationalsozialismus, Graz 2016.

34 Helene Betz/Pia Schölnberger/Monika Löscher (Hg.), „... mehr als ein Sportverein“. 100 Jahre Hakoah Wien 1909-2009, Innsbruck/Wien/Bozen 2009.

35 Agnes Meisinger, 150 Jahre Eiszeit. Die große Geschichte des Wiener Eislauf-Vereins, Wien/Köln/ Weimar 2017.

36 Alexander Juraske, „Blau-Gelb ist mein Herz“. Die Geschichte des First Vienna Football Club 1894, Wien 2017.

37 Bernhard Hachleitner/Matthias Marschik/Rudolf Müllner/Michael Zappe (Hg.), Motor bin ich selbst. 200 Jahre Radfahren in Wien, Wien 2013.

38 Matthias Marschik/Rudolf Müllner (Hg.), „Sind’s froh, dass Sie zu Hause geblieben sind.“ Mediatisierung des Sports in Österreich, Göttingen 2010.

39 Rudolf Müllner, Skilauf als „Volksübung“ - Die Frühphase der Entwicklung von Schulskikursen in Österreich bis 1930, in: Spectrum der Sportwissenschaften 25 (2013) 1, 44-63; ders., The Im- 
tung im öffentlichen Rundfunk zu einer durchaus beachtlichen Zuschauersportart entwickelte, wurde in einigen Monographien thematisiert. ${ }^{40}$

Nachdem die Forschung der letzten Jahrzehnte oftmals von Einzelpersonen getragen wurde, ist gegenwärtig eine Entwicklung hin zu (auch drittmittelfinanzierten) Projekten mit institutioneller Anbindung zu beobachten. Generell ist zu bemerken, dass die Untersuchung von Institutionen (Sportorganisationen, -vereinen, -verbänden) ein breites und „beliebtes“ Feld darstellt, wie auch hier schon erwähnte Studien dokumentieren. Der Fokus liegt dabei zumeist auf der NS-Zeit sowie den unmittelbaren Jahren davor und danach. Ein Projekt, das am Institut für Sportwissenschaft der Universität Wien durchgeführt wurde, setzte sich mit der Geschichte des Fußballvereins Austria Wien in der NS-Zeit auseinander. In aufwändigen Quellenstudien wurden dabei über 150 Einzelbiographien recherchiert und vor allem die Funktion des „Opfermythos“im Gesamtnarrativ des „Judenklubs“ Austria Wien dekonstruiert. ${ }^{41}$

In Salzburg konnte - erstmals für ein Bundesland - die breite Palette des Sports in der NS-Zeit in einer Region umfassend dokumentiert werden. Unter der Leitung der Landessportorganisation und in Zusammenarbeit mit der Universität Salzburg sowie dem Salzburger Landesarchiv gelang eine facettenreiche Aufarbeitung des nationalsozialistischen Sportgeschehens, darunter unter anderem die Rekonstruktion der Lebensgeschichten sowohl prominenter als auch bisher kaum bekannter Sportpersönlichkeiten. Die Studie untersucht die Mikromechanik lokaler Sportpolitik von 1938 bis 1945 und bezieht darüber hinaus auch die Übergänge von der „austrofaschistischen“ zur nationalsozialistischen Sportordnung sowie die Zeit nach 1945 mit ein. Das Projekt wurde 2018 mit einem umfassenden Sammelband abgeschlossen. ${ }^{42}$

Am Institut für Kulturwissenschaften der Universität für angewandte Kunst Wien untersuchte ein interdisziplinär verortetes Team von ForscherInnen am Beispiel jüdischer Sportfunktionäre das soziale Feld des Sports als Ort von Identitätspolitik im Wien der Zwischenkriegszeit. Ziel war es, verschüttete Traditionen des Wiener

portance of Skiing in Austria, in: The International Journal of the History of Sport 30 (2013) 6, 659-673.

40 Thomas Karny/Matthias Marschik, Autos, Helden und Mythen. Eine Kulturgeschichte des Automobils in Österreich, Wien 2015; Thomas Karny/Matthias Marschik, Motorsport in Österreich 1945 bis 1970. Faszination auf zwei und vier Rädern, Erfurt 2019.

41 Bernhard Hachleitner/Matthias Marschik/Rudolf Müllner/Johann Skocek Ein Fußballverein aus Wien. Der FK Austria im Nationalsozialismus 1938-1945, Wien/Köln/Weimar 2019.

42 Minas Dimitriou/Oskar Dohle/Walter Pfaller/Andreas Praher (Hg.), Salzburgs Sport in der NSZeit. Zwischen Staat und Diktatur (Schriftenreihe des Salzburger Landesarchivs 27), Salzburg 2018. 
Sports und populärer Kulturen Wiens in der ersten Hälfte des 20. Jahrhunderts sichtbar zu machen. ${ }^{43}$

Am Institut für Neuere Geschichte und Zeitgeschichte der Johannes Kepler Universität Linz konnte Martina Gugglberger in den vergangenen Jahren den Forschungsbereich Alpinismusgeschichte mit Schwerpunkt Frauenbergsteigen etablieren. ${ }^{44} \mathrm{Im}$ Jahr 2016 widmete sich ein Schwerpunktheft der renommierten österreichischen Fachzeitschrift „zeitgeschichte“ dem Thema „Geschlechtergeschichte(n) des Alpinismus nach $1945^{\text {"45 }}$ der in der internationalen Forschungslandschaft immer bedeutender werdenden Alpinismusforschung. Die Autorinnen untersuchten im Hinblick auf die politischen Implikationen des Alpinismus den Wandel von Geschlechterkonstruktionen und -verhältnissen im Bergsteigen. Ein Jahr zuvor, 2015, hatte das genannte Periodikum die erste Ausgabe mit einem sporthistorischen Fokus seit 1999 publiziert: ${ }^{46}$ Infolge des internationalen Trends der Beschäftigung mit gegenwartsorientierten Fragestellungen erschien ein Heft zu „Sport im Kalten Krieg",47 das drei Fallstudien mit Österreichbezug beinhaltet.

\section{2 „Work in progress“}

Ein langfristig angelegtes Projekt am Institut für Sportwissenschaft und Universitätssport der Universität Wien beschäftigt sich mit der historischen Genese der rezenten (Selbst-)Optimierungskulturen des Sports, mit den sportiven (Selbst-)Herstellungspraxen des fettfreien Körpers sowie mit der modernen Fitnessbewegung ab den frühen 1970er-Jahre in Österreich. ${ }^{4}$

43 Bernhard Hachleitner/Matthias Marschik/Georg Spitaler (Hg.), Sportfunktionäre und jüdische Differenz. Zwischen Anerkennung und Antisemitismus - Wien 1918 bis 1938, Berlin/Boston 2019.

44 Siehe u. a. Martina Gugglberger, Climbing beyond the Summits: Social and Global Aspects of Women's Expeditions in the Himalayas, in: International Journal of the History of Sport 32 (2015), 1-17; dies., Grenzen im Aufstieg. Frauenexpeditionen in den Himalaya von 1955-2014 aus geschlechterhistorischer Perspektive, Habilitationsschrift, Johannes Kepler Universität Linz 2017 (Publikation in Vorbereitung); dies./Annette R. Hofmann (Hg.), The International Journal of the History of Sport 37 (2020) 9, Special issue: Women and Mountaineering; darin Martina Gugglberger, „Joys of Exploration“: Gender-Constructions in the 1959 Cho Oyu Women's Expedition, 813-830.

45 Geschlechtergeschichte(n) des Alpinismus nach 1945. zeitgeschichte 43 (2016) 1.

46 Massen-Sport. zeitgeschichte 26 (1999) 3.

47 Sport im Kalten Krieg. zeitgeschichte 42 (2015) 4.

48 Siehe u. a. Rudolf Müllner, Discourses on the Production of the Athletic Lean Body in Central Europe around 1900, in: The International Journal of the History of Sport 31 (2014), 1896-1908, URL: http://www.tandfonline.com/doi/pdf/10.1080/09523367.2014.913238 (abgerufen 20.04.2016); 
Am Fachbereich Geschichte der Universität Salzburg befassen sich die Autoren zweier Dissertationen mit Fragestellungen der Sportgeschichte: Andreas Praher forscht zu Österreichs Skisport im Nationalsozialismus, Silvio Krameter untersucht die Entstehung von Arbeitervereinen im Fußball in England vor dem Ersten Weltkrieg.

\subsection{Desiderata der österreichischen Sportzeitgeschichte}

Vergleicht man die Situation der sporthistorischen Forschung Österreichs etwa mit der in Deutschland, Großbritannien oder Frankreich, so muss man großen Nachholbedarf feststellen. Die Fußballgeschichte bildet dabei wohl noch den am besten untersuchten Bereich der österreichischen Sportgeschichte. So ist die Zwischenkriegszeit - und hier insbesondere der urbane Fußball - relativ gut aufgearbeitet, wohingegen Studien zum Wintersport, sei es Ski- oder Eissport, die in den 1920erJahren ebenfalls einen enormen Popularitätsschub erfuhren, bis dato ausstehen. Die zeitliche Dimension in den Blick nehmend, ist eine systematische, großflächige und tiefgehende Analyse zum Sport in der Zweiten Republik von besonderem Interesse, um eine solide Basis für künftige Detailstudien zu legen. Es sind weder die institutionelle (Neu)Formierungsphase nach 1945 noch die radikale Expansion des Sports in der fordistischen Ära des Wirtschaftswachstums und dem Entstehen der sogenannten Freizeitgesellschaft sowie deren nachindustrielle Erscheinungsformen (Stichworte: Fitnessbewegung, Freestyle-Kulturen) auch nur ansatzweise dargestellt. Vordringlich wären auch wirtschaftshistorische Analysen, um die Transformation des „britischen Amateursports“ hin zum sportindustriellen Komplex besser zu verstehen. Ebenso unterbelichtet ist bisher die Formierungsphase des modernen Sports im 19. Jahrhundert sowie im Übergang zum 20. Jahrhundert, insbesondere unter

ders., (Self)Improvement in and through Sports - Cultural-Historical Perspectives, in: Zrinko Custonja/Annette R. Hofmann/Dario Skegro (Hg.), The 16th Congress of the International Society for the History of Physical Education and Sport - Abstracts Book, Split 2015, 36; ders., Die österreichische Fitnesskampagne zu Beginn der 1970er Jahre. Zur Analyse einer sportpolitischen Intervention im Spätfordismus, in: Dieter H. Jütting/Michael Krüger (Hg.), Sport für alle. Idee und Wirklichkeit, Münster 2017, 64-82; ders., „An das letzte Kind und an den letzten Senioren herankommen“. Der nationale „FIT-Lauf und FIT-Marsch“ als biopolitische Intervention, in: Matthias Marschik/Agnes Meisinger/Rudolf Müller/Johann Skocek/Georg Spitaler (Hg.), Images des Sports in Österreich. Innensichten und Außenwahrnehmungen (Zeitgeschichte im Kontext 13), Göttingen 2018, 377-389; ders., Sich in Form bringen. Historische Facetten der körperlichen (Selbst-) Verbesserung im und durch Sport seit 1900, in: Stefan Scholl (Hg.), Körperführung. Historische Perspektiven auf das Verhältnis von Biopolitik und Sport, Frankfurt a. M./New York 2018, 41-70. 
der länderübergreifenden Perspektive Mittel-Osteuropa/Habsburgermonarchie. Die verdienstvollen Arbeiten von Gilbert Norden ${ }^{49}$ stellen dafür bereits einen guten Ausgangspunkt dar. Ohne Anspruch auf Vollständigkeit können folgende weitere Desiderate schlagwortartig benannt werden: Sport in den Bundesländern (insbesondere die Entwicklung der föderalen Regulative), Studien zu Einzelsportarten, Freizeit-, Breiten- und Betriebssport. Auch Forschungen zur österreichischen Olympiageschichte stehen erst am Anfang. Im internationalen Kontext - insbesondere mit Fokus auf Sportgroßveranstaltungen mit österreichischer Beteiligung - sollten auch Entwicklungen in den Bereichen Sportpolitik und -finanzierung, Wirtschaft und Medien analysiert werden.

Im Hinblick auf die Erörterung von Fragen des soziokulturellen Einflusses des Sports ist die Erforschung des Frauensports in Österreich unerlässlich und dringlich. Hierfür kann das umfangreiche Euvre der deutschen Sportwissenschaftlerin und Sporthistorikerin Gertrud Pfister als Ausgangspunkt dienen. Von mindestens ebenso großer Bedeutung ist die gesamtheitliche Erforschung der Arbeitersportbewegung. Zentral ist auch das Verständnis der Verschränkung nationaler Sportphänomene im Kontext gesamteuropäischer und globaler Entwicklungen, insbesondere der Themenkomplexe Sport und Migration oder generell die Frage nach dem Beitrag des Sports zu nationalen Identitätskonstruktionen.

\section{Identitäten, Helden und Celebritys}

Das soziokulturelle Feld des Sports im weitesten Sinne ist stark an Themen und Phänomenen wie Zugehörigkeit, Exklusion und Inklusion, Identität und Alterität gekoppelt. Dabei geht es selbstverständlich nicht nur um nationale Identitäten, sondern um eine Vielzahl von Zugehörigkeits-, Ab- und Ausgrenzungsmechanismen. Es geht um Geschlechteridentitäten ebenso wie um ethnische, „rassische“, soziale, religiöse, körperliche, lokale oder religiöse Zugehörigkeiten, um Selbst- und Fremdzuschreibungen sowie auch um SportakteurInnen in Migrationsräumen..$^{50}$ Der fast

49 Beispielsweise Gilbert Norden, Breitensport und Spitzensport vom 19. Jahrhundert bis zur Gegenwart, in: Ernst Bruckmüller/Hannes Strohmeyer (Hg.), Turnen und Sport in der Geschichte Österreichs, Wien $1998,56-85$, v. a. 56-65. Gilbert Norden, Tennis in Österreich, in: Petra Hilscher/ Gilbert Norden/Manfred Russo/Otmar Weiß (Hg.), Entwicklungstendenzen im Sport, Wien 2007, 213-242.

50 Barbara Liegl/Georg Spitaler, Legionäre am Ball. Migration im österreichischen Fußball nach 1945, Wien 2008. 
eintausendseitige Band „Sport and the Construction of Identities“, 51 welcher 2007 vom Institut für Sportwissenschaft (Arbeitsbereich Sozial- und Zeitgeschichte des Sports) und dem Institut für klassische Archäologie der Universität Wien herausgegeben wurde, belegt die Vielfalt und die Bedeutung der Thematik.

Das politisch wirkmächtigste Diskriminierungskriterium im mediatisierten Leistungssportbetrieb ist wohl jenes der nationalen Zughörigkeit. Die Präsentation des Nationalen im Sport zeigt sich in einer Vielzahl von globalen Wettbewerben, in denen die VertreterInnen der jeweiligen Nationalstaaten gegeneinander antreten. Das wichtigste global rezipierte Megasportevent - die alle vier Jahre stattfindenden Olympischen Sommerspiele - hat seine ideellen, strukturellen und inhaltlichkonzeptionellen Wurzeln in der Hochzeit des Nationalismus und im europäischen Imperialismus um 1900, und er hat diese im Kern bis heute beibehalten. Es ist daher keine Überraschung, dass die Frage der nationalen Identitäten im Kontext des Sports zu einer der am besten untersuchten Felder der zeitgeschichtlichen Sportforschung zählt. Das beginnt etwa - auf die Österreichisch-Ungarische Doppelmonarchie bezogen - bei der schwierigen Frage, was im olympischen Kontext eigentlich als Nation gilt. Der Nationalitätenkonflikt zwischen Böhmen, Österreich und Ungarn im Vorfeld der Olympischen Spiele 1912 ist ein spannendes Beispiel dafür. ${ }^{52}$ Die fragile nationale Identität der Ersten Republik, die sich etwa in den Erfolgen des sogenannten Wunderteams der 1930er-Jahre erstmals im Terrain des Fußballsports zaghaft manifestierte, ist ein anderes Beispiel.53

Nach 1945 lässt sich eine Vielzahl von sportspezifischen Beispielen anführen, die dem Themenbereich der Konstituierung einer nationalen österreichischen Identität im und mithilfe des Sports - oder anders formuliert, der Ausdifferenzierung des spezifischen „Austrian sport space“54 - zugeordnet werden können. Grundlegend

51 Bettina Kratzmüller/Matthias Marschik/Rudolf Müllner/Hubert D. Szemethy/Elisabeth Trinkl (Hg.), Sport and the Construction of Identities. Proceedings of the XI ${ }^{\text {th }}$ International CESH-Congress Vienna, Wien 2007.

52 Michael Wenzel, Die Olympische Bewegung in Österreich. Ein historischer Beitrag aus sportlicher und struktureller Sicht im Sinne der Olympischen Idee, Dipl.-Arb., Universität Wien 2013, 12-32, URL: http://othes.univie.ac.at/27038 (abgerufen 28.06.2019).

53 Matthias Marschik (Hg.), Sternstunden der österreichischen Nationalmannschaft. Erzählungen zur nationalen Fußballkultur. Wien 2008; ders., Nationalgefühl per Unterseekabel. Willy Schmieger übertragt das „Jahrhundertspiel“, in: Marschik/Müllner (Hg.), „Sind’s froh, dass Sie zu Hause geblieben sind.“, 169-178.

54 Roman Horak/Georg Spitaler, Sport Space and National Identity. Soccer and Skiing as Formative Forces. On the Austrian Example, in: The American Behavioral Scientist 46 (2003) 11, 1506-1518; Alan Tomlinson/Andrei S. Markovits/Christopher Young, Introduction. Mapping sports space, in: The American Behavioral Scientist 46 (2003) 11, 1463-1475. 
dazu ist nach wie vor die Monographie von Matthias Marschik „Vom Idealismus zur Identität. Der Beitrag des Sports zum Nationalbewusstsein in Österreich (19451950)“.55

Einige Fallbeispiele, an denen sich die komplexe Beziehung von Sport und nationaler Identitätskonstruktion abhandeln lässt, sind etwa die erste Teilnahme österreichischer SportlerInnen an den Olympischen Spielen in St. Moritz bzw. London 1948, welche als eine Art Wiederkehr Österreichs auf dem internationalen Terrain interpretiert wurde. Weitere in diesem Kontext zu nennende Beispiele sind die beiden Olympischen Winterspiele in Innsbruck 1964 und 1976, das überstrapazierte „Wunder von Cordoba“ 1978 sowie die „Schande von Gijon“ 1982 (hier geht es immer um das komplexe und ambivalente Verhältnis Österreichs zur Bunderepublik Deutschland $)^{56}$ ebenso wie die Disqualifikation von Karl Schranz bei den Olympischen Winterspielen 1972,57 um nur einige zu nennen.

Dass dieser Themenkomplex in der zeitgeschichtlichen österreichischen Sportforschung längst nicht umfassend abgearbeitet ist, zeigt sich etwa an der 2018 an der Universität Wien approbierten Dissertation von Martin Tschiggerl „,Wir und die Anderen. Die Konstruktion nationaler Identität und Alterität in der Sportberichterstattung der drei Nachfolgegesellschaften des NS-Staates“. Diese Studie belegt unter Anwendung diskursanalytischer Methoden, wie sehr der Umgang mit der NS-Zeit die unterschiedliche Konstruktion von Identität in den drei verglichenen Ländern (Bundesrepublik Deutschland, DDR, Österreich) determiniert und wie sich diese Diskurse von nationaler Identität und Alterität in sportspezifischen massenmedialen Texten niederschlagen. Es ist daher wenig verwunderlich, dass sich auch in den untersuchten sportspezifischen massenmedialen Texten in den 1950er-Jahren der „Opfermythos“ als dominantes hegemoniales Narrativ nachweisen lässt. Im Unterschied zur Bundesrepublik Deutschland, in der „kritische Stimmen vor einem neuen Nationalismus warnten“, konnte in Österreich, so Tschiggerl, „die nationale Vereinnahmung sportlicher Leistungen zur Bereitstellung identitätskonkreter Mythen ungehinderter vonstattengehen ". ${ }^{8}$

55 Matthias Marschik, Vom Idealismus zur Identität. Der Beitrag des Sports zum Nationalbewusstsein in Österreich (1945-1950), Wien 1999.

56 Gerhard Urbanek, Österreichs Deutschland-Komplex. Paradoxien in der österreichisch-deutschen Fußballmythologie (Österreichische Kulturforschung 14), Wien 2012.

57 Rudolf Forster, Karl Schranz. Skirennläufer, in: Matthias Marschik/Georg Spitaler (Hg.), Helden und Idole. Sportstars in Österreich, Innsbruck/Wien/Bozen 2006, 259-268.

58 Martin Tschiggerl „Wir und die Anderen“. Die Konstruktion nationaler Identität und Alterität in der Sportberichterstattung der drei Nachfolgegesellschaften des NS-Staates, phil. Diss, Universität Wien 2018, 261. 
Herausragende sportliche Leistungen und daraus resultierende Mythen sind immer an Personen gebunden und somit eignet sich das soziale Feld des Sports wie kaum ein anderes zur Dauerproduktion von (meist männlichen) Sportheldenfiguren. Wie stark die emotionale Bindung, die parasoziale Identifikation mit diesen Figuren sein kann, zeigte sich im Januar 2018 etwa bei der Publikation bisher unbekannter Außenamtsakten, die den österreichischen Skiheroen Toni Sailer öffentlich mit Vergewaltigungsvorwürfen aus dem Jahr 1974 in Zakopane/Polen konfrontierten. ${ }^{59}$ Ein anderes Beispiel stellt die breitflächige Mediendarstellung und die staatstragende Partizipation der politischen Eliten anlässlich des Todes des Formel-1-Fahrers Niki Lauda im Frühsommer 2019 dar. ${ }^{60}$ Literarisch dokumentiert sich das Faszinationspotenzial an diesen Sportlergeschichten in einer Vielzahl an Publikationen, die dem Typus der (Halb)Autobiographie zugerechnet werden können. Die wissenschaftliche österreichische Sportgeschichtsschreibung hat sich in den letzten Jahren ebenfalls einschlägig mit der Sportheldenthematik beschäftigt. $\mathrm{Zu}$ nennen ist dabei an erster Stelle der Sammelband „Helden und Idole. Sportstars in Österreich“,61 der eine Art österreichische Heldengalerie, aber auch einige grundlegende theoretische konzeptionelle Texte zur Funktion von Sporthelden im Prozess der nationalen Identitätskonstruktion bietet. Die rasanten Entwicklungen im Bereich der neuen Medien führen jedoch dazu, dass dieses Thema nicht als abgeschlossen betrachtet werden kann. Es stellen sich neue Fragen über den Wandel der medialen (Re)Präsentation und Inszenierung, aber auch Fragen nach der weitreichenden Funktion von Medienprominenz (Stars, Celebritys) ${ }^{62}$ und öffentlicher Aufmerksamkeit als knappem Gut. ${ }^{63}$

Der Themenbereich Sport und österreichische Identität ist, wie zuvor kurz angesprochen, eng mit der Geschichte des Skilaufs und des Wintersports verbunden. Auf zwei, wie wir meinen, bemerkenswerte Arbeiten soll in diesem Zusammenhang hier noch hingewiesen werden: Beiden Publikationen gemeinsam ist, dass sie sich

59 Siehe dazu Fritz Neumann/Sigi Lützow/Philip Bauer/Florian Skrabal/Johann Skocek/Bernt Koschuh/Jurek Jurecki/Wojciech Cieśla/Anuška Delić, Akt Toni Sailer: Wie man einen fallenden Stern auffängt, Der Standard, 17.01.2018, URL: https://derstandard.at/2000072293048/Der-Akt-ToniSailer-Wie-man-einen-fallenden-Stern-auffaengt (abgerufen 17.06.2019).

60 Van der Bellen hält Rede bei der Trauerzeremonie, Die Presse, 25.05.2019, URL: https://diepresse. com/home/wirtschaft/economist/5634332/Van-der-Bellen-haelt-Rede-bei-LaudaTrauerzeremonie (abgerufen 28.06.2019).

61 Matthias Marschik/Georg Spitaler (Hg.), Helden und Idole. Sportstars in Österreich, Innsbruck/ Wien/Bozen 2006; Otmar Weiß/Gilbert Norden, Sporthelden, in: Emil Brix/Ernst Bruckmüller/ Hannes Stekl (Hg.), Memoria Austriae I. Menschen, Mythen, Zeiten, Wien 2004, 164-193.

62 Anthony Elliott (Hg.), Routledge Handbook of Celebrity Studies, London/New York 2018.

63 Karl-Heinrich Bette, Sporthelden. Spitzensport in postheroischen Zeiten, Bielefeld 2019, 131-168. 
durch innovative transdisziplinäre Zugangsweisen auszeichnen, die den Denkraum traditioneller sporthistorischer Perspektiven wesentlich erweitern und vertiefen. Insofern könnten diese Arbeiten gute Ausgangspunkte für zukünftige Studien zur österreichischen Wintersportkultur darstellen. Der am Institut für Sozialanthropologie und empirische Kulturwissenschaft der Universität Zürich forschende Bernhard Tschofen thematisiert zusammen mit Sabine Dettling in dem Band "Spuren. Skikultur am Arlberg" ${ }^{\prime 64}$ Aspekte wie „Raumerschließung und Terrainerkundung", „Schneewissen und Skitechnik“ oder die Faszination und den Mythos von Geschwindigkeit im Prozess der Modernisierung des Skiressorts Arlberg. Skiressorts wie der Arlberg werden in dem Sammelband "Leisure Cultures and the Making of Modern Ski Resorts“, der vom Innsbrucker Historiker Philipp Strobl und der australischen Kulturwissenschaftlerin Aneta Podkalicka herausgegeben wurde, als „highly commercialized, culturally hybrid transnational spaces" interpretiert. ${ }^{65}$ Die Entstehung einer globalen Skikultur wird mit Modellen der kulturellen Diffusion erklärt. Damit wird eine aufschlussreiche und dringend notwendige Einordnung lokaler österreichischer Entwicklung in globale Prozesse der Sportentwicklung angestoßen.

\section{Perspektiven, Trends und Popularisierung}

Die bisherigen Resultate zeigen, dass sporthistorische Perspektiven einen wichtigen und nachhaltigen Beitrag zur Zeitgeschichtsforschung zu leisten vermögen. Als Folge der wissenschaftlichen Auseinandersetzung mit Themen der Sportgeschichte ist gegenwärtig durchaus eine starke Zunahme von Tagungen und Workshops im inner- und außeruniversitären Bereich und insbesondere der musealen Verhandlung sporthistorischer Aspekte zu erkennen.

Unter dem Titel „Skispuren“ fand im Dezember 2015 eine Konferenz zur Geschichte des Wintersports in der Ski Austria Academy in St. Christoph am Arlberg statt. Dabei wurden unterschiedliche Aspekte von Skilauf und Wintersport aus österreichischer und internationaler Perspektive in den Blick genommen. Der Konferenzband zeugt von der Bandbreite skihistorischer Themen, die in den vergangenen Jahren eine wissenschaftliche Untersuchung erfuhren. ${ }^{66}$

64 Sabine Dettling/Bernhard Tschofen, Spuren. Skikultur am Arlberg, Bregenz 2014.

65 Philipp Strobl/Aneta Podkalicka (Hg.), Leisure Cultures and the Making of Modern Ski Resorts, Basingstoke 2018, 6 .

66 Rudolf Müllner/Christof Thöny (Hg.), Skispuren. Internationale Konferenz zur Geschichte des Wintersports (Dokumentationen zur Geschichte des Wintersports 1), Bludenz 2019. 
Bereits zweimal, 2014 und 2017, veranstaltete der Fachbereich Geschichte gemeinsam mit dem Interfakultären Fachbereich Sport- und Bewegungswissenschaft der Universität Salzburg die „Salzburger Fußballtagung“, bei der sich die TeilnehmerInnen in unterschiedlichsten Perspektiven und Ansätzen sowohl mit der Geschichte und Wirkung als auch mit spezifischen regionalen, politischen und gesellschaftlichen Aspekten des Fußballs befassten. ${ }^{67}$ Im Jahr 2018 widmete sich eine von Walter Iber organisierte Tagung an der Universität Graz dem Forschungsfeld Sport und Ökonomie.

Anlässlich der in Österreich und der Schweiz ausgerichteten Fußballeuropameisterschaft 2008 zeigte das Künstlerhaus Wien die Ausstellung „herz:rasen“, in der sich die Kuratoren dem Phänomen Fußball aus historischer Perspektive annäherten. ${ }^{68}$

Das MUSA, das Ersatzquartier des im Umbau befindlichen Wien Museums, erinnerte 2019/2020 mit der Ausstellung „Das rote Wien 1919-1934“ an ein international vielbeachtetes, von seinen Gegnern heftig bekämpftes soziales, kulturelles und pädagogisches Reformprojekt, das eine tiefgreifende Verbesserung der Lebensbedingungen der ArbeiterInnen und eine Demokratisierung aller Lebensbereiche anstrebte. Einen zentralen Erzählstrang nahm in der Schau der ArbeiterInnensport sowie die Freizeit- und Erholungsgestaltung in der Ersten Republik ein und führte die BesucherInnen in Spezialführungen an Orte des Roten Wiens, wie das Praterstadion, das im Zeitraum von 1929 bis 1931 anlässlich der 2. Arbeiterolympiade erbaut wurde, oder das Kongressbad. ${ }^{69}$

Obwohl die Wichtigkeit eines eigenständigen österreichischen Sportmuseums von Seiten der Politik bereits in mehreren Regierungsprogrammen festgehalten wurde - zuletzt 2017 unter dem Begriff „Haus der Geschichte des Sports“70 -, scheint die Umsetzung eines derartigen Projekts in weiter Ferne. An dieser Stelle zu erwähnen ist, dass sich das im November 2018 eröffnete Haus der Geschichte Österreich (HdGÖ) in der Neuen Burg - wenn auch nur auf sehr begrenztem Raum - mit der Sportgeschichte des Landes und ihrer identitätsstiftenden Bedeutung ausein-

67 Siegfried Göllner/Albert Lichtblau/Christian Muckenhumer/Andreas Praher/Robert Schwarzbauer (Hg.), Zwischen Provinz und Metropole. Fußball in Österreich. Beiträge zur 1. Salzburger Fußballtagung, Göttingen 2016; Siegfried Göllner/Andreas Praher/Robert Schwarzbauer/Minas Dimitriou (Hg.), Zwischenräume. Macht, Ausgrenzung und Inklusion im Fußball. Beiträge zur 2. Salzburger Fußballtagung, Göttingen 2019.

68 Johann Skocek (Red.), herz:rasen. Der Katalog zur Fußballausstellung, Künstlerhaus Wien 04.04.06.07.2008.

69 Werner Michael Schwarz/Georg Spitaler/Elke Wikidal (Hg.), Das rote Wien. Ideen, Debatten, Praxis 1919-1934 (Ausstellungskatalog), Basel 2019, 358-373.

70 Vgl. Seite 91 des Regierungsprogrammes 2017-2022, URL: https://www.wienerzeitung.at/_em_ daten/_wzo/2017/12/16/171216_1614_regierungsprogramm.pdf (abgerufen 28.10.2020). 
andersetzt. Auf der Grundlage der Ergebnisse des Arbeitskreises Sport (Matthias Marschik, Agnes Meisinger, Rudolf Müller, Johann Skocek, Georg Spitaler), der in der Konzeptionsphase des Museums ein internationales Symposium mit dem Titel „Images des Sports in Österreich. Innensichten und Außenwahrnehmungen“ veranstaltete, fanden Themen wie der ArbeiterInnensport sowie ein Rückblick auf vergangene Sportveranstaltungen auf dem Heldenplatz, dem Standort des HdGÖ, Eingang in die Eröffnungsausstellung. In den Beiträgen der 28 AutorInnen der gleichnamigen Publikation entsteht ein selektives und doch inklusives Gesamtbild des modernen österreichischen Sportgeschehens und seiner Populärkulturen von den Anfängen vor 1900 bis in die Gegenwart. ${ }^{11}$

Weitere wichtige Beiträge zur publikumswirksamen Geschichtsvermittlung leisten Privat- und Vereinsinitiativen wie etwa das Winter!Sport!Museum! Mürzzuschlag, das Rapideum in Wien-Penzing oder das Frauenmuseum Hittisau in Vorarlberg, das 2015 mit der Ausstellung „Ich, am Gipfel. Eine Frauenalpingeschichte“ eine kultur- und sozialhistorische Annäherung an die spezifischen Aspekte der Frauenalpingeschichte präsentierte. Im Jahr 2018 wurde das Thema im Rahmen des Workshops „Women and Mountaineering / Frauen im Bergsport“ erneut aufgegriffen und aus geschlechterhistorischer Perspektive verhandelt.

Im Zuge der Popularisierung geschichtlicher Narrative durch die Medien - Stichwort: Histotainment - gibt es eine doch beachtliche Medienpräsenz vergangener Sportereignisse. Nicht zuletzt bilden die Forschungsergebnisse sowie die Expertise der SporthistorikerInnen die Grundlage für TV-Produktionen, wie etwa den 2015 in Deutschland produzierten Spielfilm „Duell der Brüder. Die Geschichte von Adidas und Puma“ oder eine Folge der Dokumentationssendung „Universum History“ mit dem Titel „Olympia 36 - Der verratene Traum“ (2016), die den Olympiaboykott der jüdischen Hakoah-Schwimmerin Judith Deutsch beleuchtet. Durchaus populär und nachgefragt sind auch sporthistorisch biographische Publikationen. Zwei rezente Beispiele dafür sind die Lebensgeschichten des Fußballers und Architekten Gerhard Hanappi ${ }^{72}$ sowie von Hans Menasse ${ }^{73}$, der als Achtjähriger aufgrund der nationalsozialistischen Verfolgung von Jüdinnen und Juden mit einem Kindertransport nach England flüchten musste und als junger Mann nach seiner Rückkehr in

71 Matthias Marschik/Agnes Meisinger/Rudolf Müller/Johann Skocek/Georg Spitaler (Hg.), Images des Sports in Österreich. Innensichten und Außenwahrnehmungen (Zeitgeschichte im Kontext 13), Göttingen 2018.

72 Christoph Lechner/Katalin Hanappi/Roman Horak/Matthias Marschik (Hg.), Gerhard Hanappi. Fußballer. Architekt, Zürich 2019.

73 Alexander Juraske/Agnes Meisinger/Peter Menasse, Hans Menasse: The Austrian Boy. Ein Leben zwischen Wien, London und Hollywood, Wien/Köln/Weimar 2019. 
das österreichische Fußballnationalteam einberufen wurde. Bereits 2014 erschien mit „Mister Austria“ eine Biographie über den langjährigen Klubsekretär der Wiener Austria und Auschwitz-Überlebenden Norbert Lopper. ${ }^{74}$

Abschließend und zusammenfassend lässt sich Folgendes festhalten: Betrachtet man die sporthistoriographische Szene in Österreich inner- und außeruniversitär, so zeigt sich ein ambivalentes Bild. Auf der einen Seite findet man eine, wie zuvor dargelegt, beachtliche Publikations- und Forschungstätigkeit, die internationalen wissenschaftlichen Standards entspricht und auch wahrgenommen wird. Gleichzeit gibt es eine - Stichwort: Popularisierung - stetig steigende Nachfrage nach sporthistorischem Wissen von Seiten der Medien. Auch im Bereich der universitären Geschichtsforschung und Lehre werden die Themen Sport und Bewegungskulturen verstärkt wahrgenommen. Ein Ergebnis dieser Entwicklung ist unter anderem die Gründung des Expertennetzwerks „SPORTHISTNET“ im Februar 2013, dem aktuell ca. 110 einschlägig arbeitende HistorikerInnen, JournalistInnen und Museumsfachleute angehören..$^{75}$ Auf der anderen Seite muss beachtet werden, dass viele SporthistorikerInnen ihrer Tätigkeit unter prekären wirtschaftlichen Bedingungen nachgehen, dass die öffentliche finanzielle Förderung von Forschungsprojekten bei Weitem nicht ausreichend ist, dass die geistes- und kulturwissenschaftlichen Fachbereiche an den universitären Sportinstituten, nicht nur in Österreich, ausgehungert werden und dass die wissenschaftliche Erforschung der Geschichte der „Sportnation“ Österreich weiterhin gehörige Lücken aufweist.

74 Johann Skocek, Mister Austria. Das Leben des Klubsekretärs Norbert Lopper - Fußballer, KZHäftling, Weltbürger, Wien 2014.

75 URL: http://institut-schmelz.univie.ac.at/abt-bildung-unterricht-und-bewegungskultur/sozialund-zeitgeschichte-des-sports/netzwerksporthist/ (abgerufen 19.04.2016). Die Jahrestagung des Netzwerkes SPORTHISTNET 2015 vereinte internationale Fachleute zu einer Tagung mit dem Titel „Ski Tracks/Ski Spuren. Internationale Konferenz zur Geschichte des Wintersports“ in St. Christoph am Arlberg (10.-13.12.2015). 
(c) 2021 Böhlau Verlag | Brill Österreich GmbH https://doi.org/10.7767/9783205209980 | CC BY-NC 4.0 


\section{VERHÄLTNISSE}


(c) 2021 Böhlau Verlag | Brill Österreich GmbH https://doi.org/10.7767/9783205209980 | CC BY-NC 4.0 


\section{Zeitgeschichte und Wirtschaftsgeschichte}

Ernst Langthaler

\section{Einstieg ${ }^{1}$}

„Gibt es da überhaupt eine Beziehung?“, so lautete die Gegenfrage eines älteren Kollegen auf meine Frage nach dem Verhältnis von Zeitgeschichte und Wirtschaftsgeschichte. Diese Antwort überrascht, handelt es sich doch um einem ausgewiesenen Wirtschaftshistoriker, der immer wieder zu Themen des 20. Jahrhunderts geforscht sowie zeithistorischen Kommissionen, Beiräten und Gremien angehört hat. Ein flüchtiger Blick auf die „Wordwolke“ aus den Schlagwörtern der Beiträge des Österreichischen Zeitgeschichtetages 2020 bestätigt die Zweifel des Kollegen: Themen wie Nationalsozialismus, Erinnerungskultur, Migration, Holocaust, Transnationalität, Gedächtnis und Ausstellung stechen heraus; Wirtschaft kommt schlicht nicht vor. Bei genauerem Blick in das Tagungsprogramm lassen einige Sektionsthemen zwar wirtschaftshistorische Bezüge erahnen: Ernährung in der Wohlstandsgesellschaft, Wendezeiten gesellschaftlicher Naturverhältnisse sowie Vermögensentzug und -rückstellung. Insgesamt aber scheint Wirtschaft im wichtigsten Forum der österreichischen Zeitgeschichtsforschung kein Thema (mehr) zu sein. ${ }^{2}$

Die Beziehung der aktuellen Zeitgeschichte zur Wirtschaftsgeschichte und vice versa in Österreich tritt nicht offen zutage; sie erschließt sich erst bei genauerem Hinsehen. Das war nicht immer so. Nach dem Institutionalisierungsschub der beiden Fächer in den späten 1960er- und frühen 1970er-Jahren bestanden offensichtliche Nähebeziehungen. Zunächst trafen sie einander in Themenfeldern, die Zeit- und WirtschaftshistorikerInnen gleichermaßen beforschten, und kooperierten mitunter.

1 Ich danke Marcus Gräser, Clemens Jobst, Reinhard Sieder und meiner Linzer DissertantInnenRunde (Jonas Albrecht, Maximilian Martsch und Sofie Pfannerer-Mittas) für wertvolle Anregungen.

2 Vgl. Programm des 13. Österreichischen Zeitgeschichtetages 2020 an der Universität Innsbruck, URL: https://www.uibk.ac.at/zeitgeschichte/zgt2o/so-war-s-geplant/zgt2o_programm_enfassung. pdf (abgerufen 06.03.2021). Dieses Programm schrumpfte wegen zahlreicher Absagen von TeilnehmerInnen während der Corona-Krise zusammen. Die zunächst als Präsenzveranstaltung geplante Konferenz fand schließlich als „1. Virtueller Österreichischer Zeitgeschichtetag 2020“ statt. Damit verschwand auch die „Wordwolke“ aus den Tagungsunterlagen. 


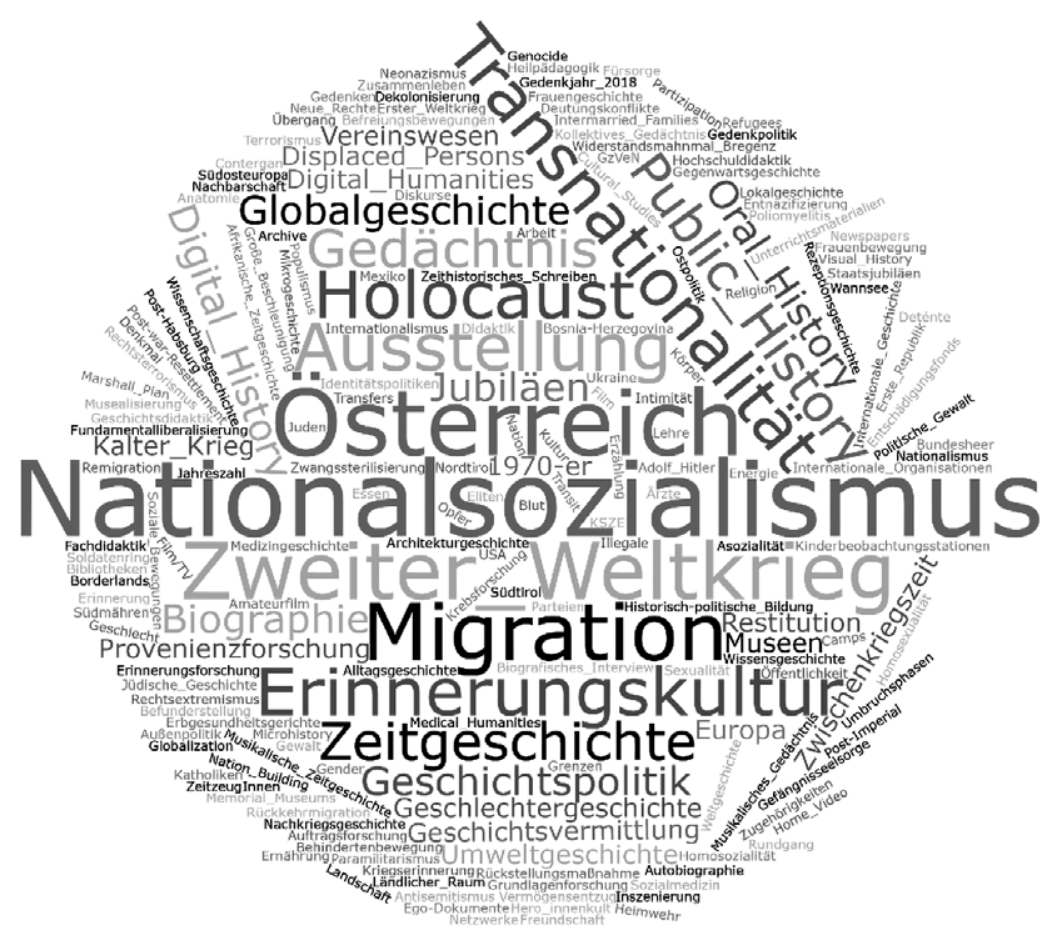

Abb. 1: „Wordwolke“ aus den Schlagwörtern der angenommenen Beiträge des 13. Österreichischen Zeitgeschichtetages 2020 (Quelle: https://www.uibk.ac.at/zeitgeschichte/zgt2o/so-war-s-geplant/zgt2o_ programm_enfassung.).

Danach beschritten sie immer häufiger getrennte Wege, begleitet von wechselseitiger Ignoranz. Zuletzt mehrten sich die Zeichen der (Wieder-)Annäherung. Alles in allem umfassen die Beziehungskonstellationen der beiden Fächer Begegnungs- und Kooperationsfelder, Parallelrouten und (Wieder-)Begegnungszonen mit fließenden Übergängen. Sie sind eingebettet in ein (geschichts)wissenschaftliches Feld kooperierender und rivalisierender AkteurInnen verschiedener Generationen, Geschlechter und Klassenlagen, das endogenen und exogenen Einflüssen unterliegt. ${ }^{3}$ Im Facebook-Jargon gesprochen: Der Beziehungsstatus ist kompliziert.

3 Zum Konzept der Wissenschaft als soziales Feld von AkteurInnen vgl. Pierre Bourdieu, Homo Academicus, Frankfurt a. M. 1992. 


\section{Begegnungs- und Kooperationsfelder}

Die Anfänge der Kooperation von Zeitgeschichte und Wirtschaftsgeschichte liegen etwa fünfzig Jahre zurück. Im Studienjahr 1967/1968 erhielt die ein Jahr zuvor eröffnete Hochschule für Sozial- und Wirtschaftswissenschaften Linz die ersten - und bis heute einzigen - Geschichtsprofessuren: eine für Sozial- und Wirtschaftsgeschichte, besetzt mit Gustav Otruba, und eine für Neuere Geschichte und Zeitgeschichte, besetzt mit Karl R. Stadler. Beide Stellen waren nicht, wie damals üblich, an einer geisteswissenschaftlichen, sondern an der Sozial- und Wirtschaftswissenschaftlichen Fakultät angesiedelt. ${ }^{4}$ Dieser Akt sowie frühere und spätere Lehrstuhlgründungen an anderen österreichischen Universitäten entsprachen dem erhöhten Stellenwert der beiden Fächer in der Aufbruchsphase rund um „1968“. Im geschichtswissenschaftlichen Feld, geprägt von historistischen und volksgeschichtlichen Traditionen, wirkten Wirtschafts- und Sozial- sowie Zeitgeschichte als Schnittstellen zu den modernen Sozialwissenschaften im englischsprachigen Raum. Die sozialwissenschaftliche Wende, die unterschiedliche Strömungen mit gemeinsamer Ablehnung traditioneller Geschichtserzählungen umfasste (Annales-Schule in Frankreich, Historische Sozialwissenschaft in Deutschland, New Economic History in den USA usw.), erschloss den historischen Fächern soziologische, ökonomische und politologische Erklärungsansätze im Spannungsfeld zwischen der Weber'schen Modernisierungstheorie und dem Marx'schen Historischem Materialismus. ${ }^{5}$ Im (wissenschafts)politischen Feld übernahmen die beiden unter der SPÖ-Alleinregierung aufgewerteten Fächer aufklärerische, wenngleich auch legitimatorische Funktionen, vor allem im schulischen Zeitgeschichte- und Sozialkundeunterricht. Damit korrespondierte die mentale Grundhaltung der - mit einer Ausnahme - rein männlichen Professorengeneration: Nach der gemeinsamen Erfahrung des Nationalsozialismus suchte sie trotz unterschiedlicher Lagerzugehörigkeit die Gräben der Bürgerkriegsstimmung zuzuschütten. ${ }^{6}$ Diese inner- und außerwissenschaftlichen Momente begünstigten thematische und personelle Annäherungen. So etwa folgten die Schwerpunkte der

4 Vgl. Helmut Konrad, Geschichtswissenschaft in Linz, in: Maria Wirth/Andreas Reichl/Marcus Gräser (Hg.), 50 Jahre Johannes Kepler Universität Linz. Innovationsfelder in Forschung, Lehre und universitärem Alltag, Wien/Köln/Weimar 2017, 117-132.

5 Vgl. Jörn Rüsen, Theorie der Geschichte, in: Richard van Dülmen (Hg.), Fischer Lexikon Geschichte, Frankfurt a. M. 1990, 32-52.

6 Vgl. Josef Ehmer/Albert Müller, Sozialgeschichte in Österreich. Traditionen, Entwicklungsstränge und Innovationspotential, in: Jürgen Kocka (Hg.), Sozialgeschichte im internationalen Überblick. Ergebnisse und Tendenzen der Forschung, Darmstadt 1989, 109-140; Reinhard Sieder, Was heißt Sozialgeschichte? Brüche und Kontinuitäten in der Aneignung des „Sozialen“, in: Österreichische Zeitschrift für Geschichtswissenschaften 1 (1990) 1, 25-48; Gerhard Botz, „Eine neue Welt, warum 
beiden Linzer Lehrstuhlinhaber einer gleichsam, sozialpartnerschaftlichen' Logik: Während der dem konservativen Lager zugerechnete Otruba sein vor- und frühindustrielles Themenspektrum zur Unternehmens- und Wirtschaftsgeschichte Österreichs im 20. Jahrhundert hin ausdehnte, ${ }^{7}$ etablierte der deklarierte Sozialdemokrat Stadler mit seinem Team die ideologisch konträre, aber fachlich komplementäre Geschichte der Arbeiterbewegung. ${ }^{8}$ Während die Professoren den Abstand wahrten, kooperierten Assistenten über Institutsgrenzen hinweg in Buchprojekten. ${ }^{9}$

Neben der Arbeiterbewegung bildete der Nationalsozialismus ein wichtiges wenn nicht das wichtigste - Begegnungs- und Kooperationsfeld von Zeit- und WirtschaftshistorikerInnen in den 1970er-Jahren. Im Diskurs der „Koalitionsgeschichtsschreibung" wäre die offene Auseinandersetzung mit der Verstrickung von ÖsterreicherInnen in das NS-Regime mit dem großkoalitionären Grundkonsens der Opferthese kollidiert. Folglich war der Nationalsozialismus am ehesten durch das Prisma von Ausbeutung, Verfolgung und Widerstand thematisierbar. ${ }^{10}$ Dieser Blickwinkel orientierte auch die historische Forschung zur österreichischen Wirtschaft in der NS-Zeit, bis dahin exklusiver Gegenstand der Wirtschafts- und Sozialwissenschaften. ${ }^{11}$ Auf zeithistorischer Seite beleuchtete Norbert Schausberger die Mobilisierung der österreichischen Arbeitskraft-, Rohstoff- und Finanzressourcen für die deutsche Rüstungswirtschaft. Er betonte die kriegswirtschaftlichen und geostrategischen Anschlussmotive des Deutschen Reiches: den Facharbeiter-, Material- und Devisenmangel sowie die Durchdringung Südosteuropas als „Ergänzungsraum“. Sein Buch „Der Griff nach Österreich“ skizziert den „Anschluss“ 1938 gemäß der Sonderwegsthese als Gipfel des deutschen Imperialismus, getrieben von großkapitalistischen und militärischen Interessen seit dem späten Kaiserreich. ${ }^{12}$ Von wirt-

nicht eine neue Geschichte?“ Teil I: Österreichische Zeitgeschichte am Ende ihres Jahrhunderts, in: ebd., 49-76.

7 Vgl. Gustav Otruba, Österreichs Wirtschaft im 20. Jahrhundert, Wien 1968.

8 Vgl. Gerhard Botz/Hans Hautmann/Helmut Konrad/Josef Weidenholzer (Hg.), Bewegung und Klasse. Studien zur österreichischen Arbeitergeschichte, Wien/München/Zürich 1978.

9 Vgl. Hans Hautmann/Rudolf Kropf, Die österreichische Arbeiterbewegung vom Vormärz bis 1945. Sozialökonomische Ursprünge ihrer Ideologie und Politik (Schriftenreihe des Ludwig Boltzmann Instituts für Geschichte der Arbeiterbewegung 4), Wien/München/Zürich 1974.

10 Vgl. Botz, Welt, 60.

11 Vgl. Wilhelm Weber (Hg.), Österreichs Wirtschaftsstruktur. Gestern - heute - morgen, 2 Bde., Berlin 1961. Die Beiträge über Wirtschaftsstruktur (Kurt Rothschild), Energie und Industrialisierung (Stephan Koren), Landwirtschaft (Peter Meihsl) und Sozialschichtung (Hertha Firnberg), die vom späten 19. bis zur Mitte des 20. Jahrhunderts reichen, behandeln auch die NS-Zeit.

12 Vgl. Norbert Schausberger, Rüstung in Österreich 1938-1945. Eine Studie über die Wechselwirkung von Wirtschaft, Politik und Kriegsführung, Wien 1970; ders., Der Griff nach Österreich. Der Anschluß, Wien 1978. 
schaftshistorischer Seite veröffentlichte Felix Butschek die erste Gesamtdarstellung der österreichischen Wirtschaft in der NS-Zeit, gefolgt von einer Geschichte der österreichischen Wirtschaft im 20. Jahrhundert. ${ }^{13}$ Als gelernter Ökonom brachte er nicht nur wirtschaftswissenschaftliche Konzepte - etwa die Spannung zwischen keynesianistischen und monetaristischen Erklärungen -, sondern auch statistische Daten und Methoden in die NS-Forschung ein. Ähnlich der marxistisch inspirierten These Schausbergers von Österreich als letztendlich ,entkolonialisierter Kolonie‘ des deutschen Imperialismus ${ }^{14}$ fällt Butscheks modernisierungstheoretisch gerahmte Bilanz der Wirtschaft in der NS-Zeit ambivalent aus: Neben den Kriegsverlusten an Menschen und Betriebsanlagen verbucht sie auf der Gewinnseite Strukturanpassungen - vor allem in der Industrie -, welche die von Ost nach West umorientierte Wirtschaftsentwicklung nach dem Krieg günstig beeinflussten. ${ }^{15}$

In den 1980er- und 1990er-Jahren übernahm eine jüngere Generation die Initiative in der zeit- und wirtschaftshistorischen Forschung, wobei neben breitangelegten Überblickskapiteln ${ }^{16}$ sowie agrar-, industrie- und handelshistorischen

13 Vgl. Felix Butschek, Die österreichische Wirtschaft 1938 bis 1945, Stuttgart 1978; ders., Die österreichische Wirtschaft im 20. Jahrhundert, Stuttgart 1985.

14 Vgl. Schausberger, Rüstung, 185.

15 Vgl. Butschek, Wirtschaft 1938 bis $1945,111-114$

16 Vgl. Hans Kernbauer/Eduard März/Fritz Weber, Die wirtschaftliche Entwicklung. Österreich 1918-1938, in: Erika Weinzierl/Kurt Skalnik (Hg.), Österreich 1918-1938. Geschichte der Ersten Republik, Bd. 1, Graz/Wien/Köln 1983, 343-380; Hans Kernbauer/Fritz Weber, Von der Inflation zur Depression. Österreichs Wirtschaft 1918-1934, in: Emmerich Tálos/Wolfgang Neugebauer (Hg.), „Austrofaschismus“. Beiträge über Politik, Ökonomie und Kultur 1934-1938 (Österreichische Texte zur Gesellschaftskritik 18), Wien 1984, 1-30; Siegfried Mattl, Die Finanzdiktatur. Wirtschaftspolitik in Österreich 1933-1938, in: ebd., 133-159; Karl Bachinger/Hildegard Hemetsberger-Koller/Herbert Matis, Grundriß der österreichischen Sozial- und Wirtschaftsgeschichte von 1848 bis zur Gegenwart, Wien 1987; Fritz Weber, Wirtschaft und Wirtschaftspolitik in der Ersten und Zweiten Republik, in: Erich Zöllner (Hg.), Österreichs Erste und Zweite Republik. Kontinuität und Wandel ihrer Strukturen und Probleme (Schriftenreihe des Instituts für Österreichkunde 47), Wien 1985, 121-152; ders., Die wirtschaftliche Entwicklung, in: Herbert Dachs/Peter Gerlich/Herbert Gottweis/Franz Horner/Helmut Kramer/Volkmar Lauber/Wolfgang C. Müller/Emmerich Tálos (Hg.), Handbuch des Politischen Systems Österreichs, Wien 1991, 20-36; ders., Die wirtschaftliche Entwicklung, in: Emmerich Tálos/Herbert Dachs/Ernst Hanisch/Anton Staudinger (Hg.), Handbuch des politischen Systems Österreichs. Erste Republik 1918-1933, Wien 1995, 23-39; ders., Wiederaufbau zwischen Ost und West, in: Reinhard Sieder/Heinz Steinert/Emmerich Tálos (Hg.), Österreich 1945-1995. Gesellschaft, Politik, Kultur (Österreichische Texte zur Gesellschaftskritik 60), Wien 1995, 68-79; Karl Aiginger, Von der Mitte aus, auf dem Weg nach vorne. Österreichs Wirtschaft in den 1980er und 1990er Jahren, in: ebd., 268-278; Franz Mathis, Die österreichische Wirtschaft. Grundlagen und Entwicklungen, in: Rolf Steininger/Michael Gehler (Hg.), Österreich im 20. Jahrhundert, Bd. 2, Wien/Köln/Weimar 1997, 415-453; Gerhard Senft, Anpassung durch Kontraktion, in: Emmerich Tálos/Wolfgang Neugebauer (Hg.), Austrofaschis- 
Handbüchern ${ }^{17}$ vertiefende Regional- und Unternehmensstudien ${ }^{18}$ sowie Länderdarstellungen ${ }^{19}$ hervortraten. Der Nationalsozialismus blieb ein wichtiges Begegnungs- und Kooperationsfeld: Einerseits erfuhr das österreichweite Bild eine Differenzierung, vor allem im wegweisenden Handbuch „NS-Herrschaft in Österreich“. ${ }^{20}$ Darin charakterisiert der Zeit- und Wirtschaftshistoriker Fritz Weber, die Argumente Schausbergers und Butscheks variierend, die NS-Ära als „abhängige Modernisierung“, die sich in Betriebskonzentration, Standortverlagerung, Eigentumsver-

mus. Politik - Ökonomie - Kultur 1933-1938, Wien 2005, 182-201; Dieter Stiefel, Die österreichische Wirtschaft seit 1950, in: Herbert Dachs/Peter Gerlich/Herbert Gottweis/Helmut Kramer/ Volkmar Lauber/Wolfgang C. Müller/Emmerich Tálos (Hg.), Politik in Österreich. Das Handbuch, Wien 2006, 64-81.

17 Vgl. Ernst Bruckmüller/Ernst Hanisch/Roman Sandgruber/Norbert Weigl, Geschichte der österreichischen Land- und Forstwirtschaft im 20. Jahrhundert, Bd. 1: Politik, Gesellschaft, Wirtschaft, Wien 2002; Ernst Bruckmüller/Ernst Hanisch/Roman Sandgruber (Hg.), Geschichte der österreichischen Land- und Forstwirtschaft im 20. Jahrhundert, Bd. 2: Regionen, Betriebe, Menschen, Wien 2003; Günther Chaloupek/Dionys Lehner/Herbert Matis/Roman Sandgruber, Österreichische Industriegeschichte, Bd. 1: Die vorhandene Chance (1700 bis 1848), Wien 2003; Johannes Jetschgo/Ferdinand Lacina/Michael Pammer/Roman Sandgruber, Österreichische Industriegeschichte, Bd. 2: Die verpasste Chance (1848 bis 1955), Wien 2004; Ferdinand Lacina/Dionys Lehner/Peter Mitterbauer/Andreas Resch/Roman Sandgruber/Gertrude Tumpel-Gugerell, Österreichische Industriegeschichte, Bd. 3: Die ergriffene Chance (1955 bis 2005), Wien 2005; Günther Chaloupek/Johannes Jetschgo/Dionys Lehner/Michael Pammer/Andreas Resch/Roman Sandgruber/Peter Schnedlitz, Österreichische Handelsgeschichte. Von den Anfängen bis zur Gegenwart, Wien/Graz/Klagenfurt 2012.

18 Vgl. Andrea Komlosy, An den Rand gedrängt: Wirtschafts- und Sozialgeschichte des Oberen Waldviertels (Österreichische Texte zur Gesellschaftskritik 34), Wien 1988; Karl Kaser/Karl Stocker, Bäuerliches Leben in der Oststeiermark seit 1848, 2 Bde., Wien/Köln/Graz 1986-1988; Christian Dirninger, Wirtschaftsbezogene Modernisierungsstrategien: Strukturpolitik - Betriebsansiedlung - Technologieförderung im Bundesland Salzburg von 1958 bis 1998, Wien/Köln/Weimar 1998; Franz Mathis, Big Business in Österreich, 2 Bde., Wien 1987-1990; Herbert Matis/Dieter Stiefel, „Mit der vereinigten Kraft des Capitals, des Credits und der Technik“. Die Geschichte des österreichischen Bauwesens am Beispiel der Allgemeinen Baugesellschaft - A. Porr Aktiengesellschaft, 2 Bde., Wien/Köln/Weimar 1994, Fritz Weber, Vor dem großen Krach. Österreichs Bankwesen der Zwischenkriegszeit am Beispiel der Credit-Anstalt für Handel und Gewerbe (Studien zur Wirtschaftsgeschichte und Wirtschaftspolitik 9), Wien/Köln/Weimar 2016 (basierend auf der Habilitationsschrift des Verfassers von 1991).

19 Vgl. vor allem die ab 1997 erscheinende Reihe „Geschichte der österreichischen Bundesländer seit 1945“, deren Bände auch wirtschaftshistorische Kapitel enthalten; Franz X. Eder/Peter Eigner/Andreas Resch/Andreas Weigl, Wien im 20. Jahrhundert. Wirtschaft, Bevölkerung, Konsum (Querschnitte 12), Innsbruck/Wien/Bozen 2003; Peter Melichar/Ernst Langthaler/Stefan Eminger (Hg.), Niederösterreich im 20. Jahrhundert, Bd. 2: Wirtschaft, Wien/Köln/Weimar 2008.

20 Vgl. Emmerich Tálos/Ernst Hanisch/Wolfgang Neugebauer (Hg.), NS-Herrschaft in Österreich 1938-1945, Wien 1988; erweiterte Neuausgabe: Emmerich Tálos/Ernst Hanisch/Wolfgang Neugebauer/Reinhard Sieder (Hg.), NS-Herrschaft in Österreich. Ein Handbuch, Wien 2000. 
schiebung, Kapazitätssteigerung und Grundstoffindustrialisierung äußere. ${ }^{21}$ Auch Themen wie Frauenarbeit, Sozialstruktur und Agrarentwicklung im Nationalsozialismus fanden erstmals fundierte Darstellungen. ${ }^{22}$ Andererseits verlagerte sich die Forschung zur NS-Wirtschaft auf quellengesättigte Regional- und Lokalstudien, entweder für ganze Bundesländer - so etwa Stefan Karner für Kärnten, ${ }^{23}$ Harald Walser für Vorarlberg, ${ }^{24}$ Horst Schreiber für Tirol ${ }^{25}$ und Josef Moser für Oberösterreich ${ }^{26}$ - oder über einzelne Standorte - so etwa Florian Freund und Bertrand Perz über Arbeitslager des Konzentrationslagers Mauthausen für Industriebetriebe. ${ }^{27}$ Diese von der „Koalitionsgeschichtsschreibung“ emanzipierte Historikergeneration konterkarierte die - mittlerweile auch staatsoffiziell verabschiedete - Opferthese, indem sie die Mittäterschaft österreichischer „Volksgenossen“ zulasten in- und ausländischer „Gemeinschaftsfremder“ akzentuierte. So etwa führen Freund und Perz den im Vergleich zum „Altreich“ durchschlagenden Industrialisierungsschub der

21 Vgl. Hans Kernbauer/Fritz Weber, Österreichs Wirtschaft 1938-1945, in: Tálos/Hanisch/Neugebauer (Hg.), NS-Herrschaft in Österreich, 49-67; Fritz Weber, Zwischen abhängiger Modernisierung und Zerstörung. Österreichs Wirtschaft 1938-1945, in: Tálos/Hanisch/Neugebauer/Sieder (Hg.), NS-Herrschaft in Österreich, 326-347; ders., Die Spuren der NS-Zeit in der österreichischen Wirtschaftsentwicklung, in: Österreichische Zeitschrift für Geschichtswissenschaften 3 (1992) 2, 135-165.

22 Vgl. Karin Berger, „Hut ab vor Frau Sedlmayer!“ Zur Militarisierung und Ausbeutung der Arbeit von Frauen im nationalsozialistischen Österreich, in: Tálos/Hanisch/Neugebauer (Hg.), NSHerrschaft in Österreich, 141-161; Klaus-Dieter Mulley, Modernität oder Traditionalität? Überlegungen zum sozialstrukturellen Wandel in Österreich 1938 bis 1945, in: ebd., 25-48; Michael Mooslechner/Robert Stadler, Landwirtschaft und Agrarpolitik, in: ebd., 69-94; Ernst Langthaler, Eigensinnige Kolonien. NS-Agrarsystem und bäuerliche Lebenswelten 1938-1945, in: Tálos/Hanisch/Neugebauer/Sieder (Hg.), NS-Herrschaft in Österreich, 348-375.

23 Vgl. Stefan Karner, Kärntens Wirtschaft 1938-1945. Unter besonderer Berücksichtigung der Rüstungsindustrie, Klagenfurt 1976. Das Nachwort stammt vom ehemaligen Reichsminister für Bewaffnung und Munition Albert Speer.

24 Vgl. Harald Walser, Bombengeschäfte. Vorarlbergs Wirtschaft in der NS-Zeit (Studien zur Geschichte und Gesellschaft Vorarlbergs 6), Bregenz 1989.

25 Vgl. Horst Schreiber, Wirtschafts- und Sozialgeschichte der Nazizeit in Tirol (Geschichte \& Ökonomie 3), Innsbruck/Wien/Bozen 1994.

26 Vgl. Josef Moser, Oberösterreichs Wirtschaft 1938 bis 1945 (Studien zur Wirtschaftsgeschichte und Wirtschaftspolitik 2), Wien/Köln/Weimar 1995.

27 Vgl. Florian Freund/Bertrand Perz, Das KZ in der Serbenhalle. Zur Kriegsindustrie in Wiener Neustadt (Industrie, Zwangsarbeit und Konzentrationslager in Österreich 1), Wien 1987; Florian Freund, Arbeitslager Zement. Das Konzentrationslager Ebensee und die Raketenrüstung (Industrie, Zwangsarbeit und Konzentrationslager in Österreich 2), Wien 1989; Bertrand Perz, Projekt Quarz. Steyr-Daimler-Puch und das Konzentrationslager Melk (Industrie, Zwangsarbeit und Konzentrationslager in Österreich 3), Wien 1991. 
„Ostmark“ auf den Masseneinsatz von ZwangsarbeiterInnen im Zweiten Weltkrieg zurück. $^{28}$

Der Komplex von Vermögensentzug durch Zwangsarbeit, Enteignung und Berufsverbote sowie die dadurch befeuerte Debatte um „Wiedergutmachung“ standen in den späten 1990er- und frühen 200oer-Jahren im Fokus von Forschungsinitiativen, die überwiegend außerhalb des Wissenschaftsfeldes entsprangen. Die von der Bundesregierung auf internationalen Druck eingesetzte Österreichische Historikerkommission (1998-2003), der auch Zeit- und WirtschaftshistorikerInnen angehörten, vergab 47 Projekte. Die mehr als 150 ForscherInnen entstammten der noch meist universitär oder anderweitig verankerten mittleren (Männer)Generation sowie der vom volatilen Markt der Antrags- und Auftragsforschung abhängigen jüngeren Generation mit hohem Frauenanteil. Sie arbeiteten zu den Themen Enteignung und Berufsverbot jüdischer und anderer Gruppen Verfolgter, Zwangsarbeit von Kriegsgefangenen, ZivilarbeiterInnen und KZ-Häftlingen sowie Rückstellung und Entschädigung nach $1945 .{ }^{29}$ Eine Reihe von (Groß)Unternehmen, allen voran die VOEST Linz, beauftragte Historikerkommissionen, um ihre Rolle im Nationalsozialismus, vor allem beim Zwangsarbeitseinsatz, aufzuklären. ${ }^{30}$ Landes- und Stadtarchive initiierten Forschungen zu diesem Themenkomplex, woraus etwa die Unternehmensstudie von Roman Sandgruber zum Zellwollewerk Lenzing entstand. ${ }^{31}$ Die Mehrzahl der Studien konzentrieren sich auf die quellenbasierte Dokumentation

28 Vgl. Florian Freund/Bertrand Perz, Industrialisierung durch Zwangsarbeit, in: Tálos/Hanisch/ Neugebauer (Hg.), NS-Herrschaft in Österreich, 95-114; dies., Zwangsarbeit von zivilen AusländerInnen, Kriegsgefangenen, KZ-Häftlingen und ungarischen Juden in Österreich, in: Tálos/Hanisch/Neugebauer/Sieder (Hg.), NS-Herrschaft in Österreich, 644-695.

29 Vgl. Clemens Jabloner/Brigitte Bailer-Galanda/Eva Blimlinger/Georg Graf/Robert Knight/Lorenz Mikoletzky/Bertrand Perz/Roman Sandgruber/Karl Stuhlpfarrer/Alice Teichova, Schlussbericht der Historikerkommission der Republik Österreich. Vermögensentzug während der NS-Zeit sowie Rückstellungen und Entschädigungen seit 1945 in Österreich. Zusammenfassungen und Einschätzungen (Veröffentlichungen der Österreichischen Historikerkommission 1), Wien/München 2003 sowie die übrigen der insgesamt 32 Bände der „Veröffentlichungen der Österreichischen Historikerkommission“, URL: https://hiko.univie.ac.at (abgerufen 06.03 2021).

30 Vgl. Oliver Rathkolb (Hg.), NS-Zwangsarbeit. Der Standort Linz der „Reichswerke Hermann Göring AG Berlin“ 1938-1945, 2 Bde., Wien/Köln/Weimar 2001; Stefan Lütgenau/Alexander Schröck, Zwangsarbeit in der österreichischen Bauindustrie. Die Teerag-Asdag AG 1938-1945, Innsbruck/ Wien/Bozen 2001; Oliver Rathkolb/Florian Freund (Hg.), NS-Zwangsarbeit in der Elektrizitätswirtschaft der „Ostmark“ 1938-1945. Ennstalwerke - Kaprun - Draukraftwerke - Ybbs-Persenbeug - Ernsthofen, Wien/Köln/Weimar 2002; Oliver Rathkolb/Maria Wirth/Michael Wladika, Die „Reichsforste“ in Österreich 1938-1945. Arisierung, Restitution, Zwangsarbeit und Entnazifizierung, Wien/Köln/Weimar 2010.

31 Vgl. Roman Sandgruber, Lenzing. Anatomie einer Industriegründung im Dritten Reich (Oberösterreich in der Zeit des Nationalsozialismus 9), Linz 2010. 
quantitativer und qualitativer Aspekte; demgegenüber tritt die theoretisch-methodologische Innovation zurück. Die internationale Forschungskonjunktur zu Unternehmen im Nationalsozialismus, die fruchtbare Kontroversen anstieß, fand hierzulande nach Ende der Österreichischen Historikerkommission wenig Resonanz. ${ }^{32}$ Insgesamt setzte das Strohfeuer der anlassbezogenen Forschungsaufträge den Höheund zugleich Endpunkt der zeit- und wirtschaftshistorischen Kooperation. Reformbewegungen in beiden Fächern strebten bereits in entgegengesetzte Richtungen.

\section{Parallelrouten und (Wieder)Begegnungszonen}

In der Zeitgeschichtsforschung äußerte in den späten 1980er- und frühen 1990erJahren eine jüngere, stärker von Frauen getragene Generation, bestärkt durch die Kritik der Neuen Sozialen Bewegungen an der bürokratisch-kapitalistischen Moderne, Unbehagen mit den etablierten Ansätzen: Der theorieabstinente politikhistorische Hauptstrang der Zeitgeschichte beschränke sich auf die Aktionen der Eliten in den ,Schlüsseljahren' (1927, 1934, 1938 usw.); der theorieaffine historisch-sozialwissenschaftliche Nebenstrang überschätze die Prägekraft sozioökonomischer Strukturen. ${ }^{33}$ Damit ignoriere die etablierte Zeitgeschichte die Perspektiven der nun in Österreich nicht nur rezipierten, sondern auch institutionalisierten internationalen Kulturwissenschaften: den Alltag der AkteurInnen und die Macht von Sprache. ${ }^{34}$ Die kulturwissenschaftliche Wende (Cultural Turn) in Abgrenzung zur Social Science History umfasste ein Bündel an reflexiv- und postmodernen Konzepten, ${ }^{35}$ von denen die Zeitgeschichte vor allem Praxis nach Pierre Bourdieu ${ }^{36}$ und Diskurs nach Michel Foucault ${ }^{37}$ aufnahm. Gemäß von Kultur als Praxis erschöpft sich menschliches Denken und Handeln nicht im Vollzug übermächtiger Strukturen und deren Reproduktion; es umfasst auch deren „eigensinnige“ Aneignung und Transfor-

32 Vgl. Norbert Frei/Tim Schanetzky (Hg.), Unternehmen im Nationalsozialismus. Zur Historisierung einer Forschungskonjunktur, Göttingen 2010.

33 Vgl. Ingrid Bauer, Kontinuitäten und Transformation. Die österreichische Zeitgeschichtsforschung im Generationenvergleich, in: zeitgeschichte 30 (2003) 6, 320-340.

34 Die Rezeption der Cultural Studies in Österreich in den 1990er-Jahren wurde durch das Internationale Forschungszentrum Kulturwissenschaften (IFK) in Wien und den ministeriellen Forschungsschwerpunkt „Kulturwissenschaften“ gefördert.

35 Vgl. Doris Bachmann-Medick, Cultural Turns. Neuorientierungen in den Kulturwissenschaften, Reinbek bei Hamburg 2006, die sieben Wenden behandelt: Interpretative, Performative, Reflexive/ Literary, Postcolonial, Translational, Spatial und Iconic Turn.

36 Vgl. Pierre Bourdieu, Sozialer Sinn. Kritik der theoretischen Vernunft, Frankfurt a. M. 1987.

37 Vgl. Michel Foucault, Archäologie des Wissens, Frankfurt a. M. 1997. 
mation durch denk- und handlungsmächtige AkteurInnen. Gemäß von Kultur als Diskurs lassen sich Sprechakte und ihre Bedeutungen nicht zum ideellen ,Überbau' einer materiellen ,Basis' reduzieren; sie folgen autonomen Logiken und erzeugen über machtvolle Diskurse (der Wissenschaft, Politik, Justiz usw.) ihre eigenen Wirklichkeiten. Praxeologische und linguistische Ansätze als wichtige, wenngleich nicht alleinige Triebkräfte des Cultural Turn erschlossen der (Zeit)Geschichte neue Themenfelder wie Alltags-, Frauen- und Geschlechter-, Medien-, Identitäts- und Erinnerungsgeschichte. ${ }^{38}$ Manche Errungenschaften der Historischen Kulturwissenschaft, die den historisch-sozialwissenschaftlichen Blick erweitern (wie die Dialektik von Struktur und Praxis), führten in der kulturalistischen Lesart eines Teils der im Wissenschaftsfeld um Disktinktion bemühten KulturhistorikerInnen zur Verengung (etwa Voluntarismus anstatt Determinismus). In diesem Zusammenhang verlagerte sich auch der Schwerpunkt der NS-Forschung von der Real- zur Gedächtnisgeschichte. ${ }^{39}$ Im Zuge des Cultural Turn verloren viele darin engagierte (Zeit) HistorikerInnen die - teils zu Recht, teils zu Unrecht - als ,strukturalistisch ${ }^{`}$ und ,materialistisch' etikettierte Wirtschaftsgeschichte aus dem Blick.

Bereits vor dem Cultural Turn der Zeitgeschichte und in Fortsetzung des Social-Scientific Turn hatten sich Teile der deutschsprachigen Wirtschaftsgeschichte, die der Historischen Schule der Nationalökonomie in Opposition zur klassischen Ökonomie entsprang, aus ihrer Einbindung in die Allgemeine Geschichte und die „Gesellschaftsgeschichte“ Bielefelder Prägung im Besonderen zu lösen begonnen. ${ }^{40}$ Eine jüngere Generation international orientierter und (informations)technologieaffiner ForscherInnen fand ihr Distinktionsmerkmal in der US-amerikanischen New Economic History, die auf Wirtschaftstheorie, Massendaten und Statistikmethoden setzte. ${ }^{41}$ Der Cliometric Turn eröffnete seinen AnhängerInnen Zugänge zu prestigeträchtigen Fachzeitschriften, deren Artikel einem dreiteiligen Schema folgen: Der erste Teil (Modell) formuliert entsprechend der Vorstellung eines nut-

38 Vgl. Reinhard Sieder, Sozialgeschichte auf dem Weg zu einer historischen Kulturwissenschaft?, in: Geschichte und Gesellschaft 20 (1994) 3, 445-468.

39 Als Pionierstudie vgl. Heidemarie Uhl, Zwischen Versöhnung und Verstörung. Eine Kontroverse um Österreichs historische Identität fünfzig Jahre nach dem „Anschluß“, Wien/Köln/Weimar 1992.

40 Die österreichische Historiographie ignorierte die "Gesellschaftsgeschichte“ in der Lesart HansUlrich Wehlers in der Regel - mit wenigen Ausnahmen wie Ernst Hanisch, Der lange Schatten des Staates. Österreichische Gesellschaftsgeschichte im 20. Jahrhundert (Österreichische Geschichte 1890-1990), Wien 1994.

41 Vgl. Richard Tilly, Wirtschaftsgeschichte als Disziplin, in: Gerold Ambrosius/Dietmar Petzina/ Werner Plumpe (Hg.), Moderne Wirtschaftsgeschichte. Eine Einführung für Historiker und Ökonomen, München 1996, 11-26. 
zenmaximierenden Individuums (Homo oeconomicus) ein Modell, von dem sich empirisch überprüfbare Hypothesen ableiten; der zweite Teil (Daten) beschreibt die zur Bemessung der Modellvariablen dienenden Massendaten; der dritte Teil (Ökonometrie) testet die Hypothesen auf Basis von Massendaten mittels statistischer Verfahren. Als Standardmethode dient die Multiple Regressionsanalyse, welche die Zusammenhänge einer abhängigen Variablen mit mehreren unabhängigen Variablen misst. ${ }^{42}$ Ein Beispiel für eine ökonometrisch orientierte Wirtschaftsgeschichte $\mathrm{zu}$ Themen des 20. Jahrhunderts ist Michael Pammers Analyse der jüdischen Vermögen in Wien 1938.43 Der Cliometric Turn wandelte die Wirtschaftsgeschichte zur Historischen Wirtschaftswissenschaft im Rahmen der neoklassischen Ökonomie, die in den 1980er- und 1990er-Jahren die Diskurshoheit über den Keynesianismus errang. Die Historische Wirtschaftswissenschaft fragt nach generalisierbaren, aus zeit- und raumspezifischen Kontexten herausgelösten statistischen Zusammenhängen zwischen quantifizierbaren Variablen. Die übrigen Wirklichkeitsbereiche, die sich meist lediglich qualitativ fassen lassen, werden ignoriert (ceteris paribus: „unter sonst gleichen Bedingungen“) oder als „anecdotal evidence“ marginalisiert. Dieses reduktionistische Vorgehen dient dem Anspruch auf Kausalerklärungen mit quasinaturwissenschaftlicher Exaktheit. Die Historische Wirtschaftswissenschaft zeigt durchaus unterschiedliche Gesichter: von den „KliometrikerInnen“, die ernsthaft an historischen Problemen interessiert sind, bis hin zu ÖkonomInnen, die historische Daten bloß als Futter für ihre Modelle nutzen. Insgesamt löste sich die Neue Wirtschaftsgeschichte nicht nur aus der traditionellen Paarung von Wirtschafts- und Sozialgeschichte; auch der Gegenstandsbereich der teils politik-, teils kulturhistorisch orientierten Zeitgeschichte geriet außer Sichtweite. ${ }^{44}$

Die wechselseitige Ignoranz von Zeit- und WirtschaftshistorikerInnen infolge des Cultural und Cliometric Turn hält zwar in vielen Bereichen an; doch von den parallel laufenden Routen zweigen Pfade ab, die auf (Wieder-)Begegnungszonen weisen. Äußere Anstöße für Alternativpfade boten zivilgesellschaftliche Gegenbewegungen zum „neoliberalen“ (Finanz-)Kapitalismus, getrieben durch die weltweite Klimakrise und die von den USA ausstrahlende „Große Rezession“ ab 2008: Einerseits vermittelten sie der kulturalistisch verengten Zeitgeschichte die Relevanz

42 Vgl. Mark Spoerer/Jochen Streb, Neue deutsche Wirtschaftsgeschichte des 20. Jahrhunderts, München $2013,1-23$.

43 Vgl. Michael Pammer, Jüdische Vermögen in Wien 1938 (Veröffentlichungen der Österreichischen Historikerkommission 8), Wien/München 2003.

44 Vgl. Hartmut Berghoff/Jakob Vogel, Wirtschaftsgeschichte als Kulturgeschichte. Ansätze zur Bergung transdisziplinärer Synergiepotenziale, in: dies. (Hg.), Wirtschaftsgeschichte als Kulturgeschichte. Dimensionen eines Perspektivenwechsels, Frankfurt a. M./New York 2004, 9-41, 9-14. 
der materiellen Welt im „Anthropozän“ oder, genauer, „Kapitalozän“, dem Zeitalter des gesellschaftlichen „Kolonisierung von Natur" entsprechend der kapitalistischen Verwertungslogik. ${ }^{45}$ Andererseits riefen sie der kliometrisch verengten Wirtschaftsgeschichte die Relevanz marktregulierender und -alternativer Institutionen für eine sozial- und umweltgerechte Globalisierung ins Bewusstsein. ${ }^{6}$ Innerhalb des fragmentierten Wissenschaftsfeldes verbreitete sich teils Resignation (unter der auf der jeweiligen Welle reitenden Avantgarde), teils Genugtuung (im sich unter der jeweiligen Welle wegduckenden Mainstream) über die reduktionistischen Tendenzen: den kulturalistischen Auslegungsfetischismus in der Zeitgeschichte, den kliometrischen Testfetischismus in der Wirtschaftsgeschichte. Die Auflösung der (durchaus problematischen) „grand narratives" sozialwissenschaftlicher Provenienz in eine Vielzahl kleinteiliger Geschichten (wie in der Zeitgeschichte) oder kleinteiliger Modelle (wie in der Wirtschaftsgeschichte) entpuppte sich nicht als Lösung, sondern als Problem - sowohl in der Scientific Community als auch in der nach historischem Sinn fragenden Öffentlichkeit. Diese Außen- und Binnenimpulse veranlassten vor allem nichtuniversitär verankerte HistorikerInnen, jenseits der kulturalistischen und kliometrischen Trampelpfade neue Erkenntniswege zu erkunden. ${ }^{47}$

In der Zeitgeschichte begannen ForscherInnen, alte Schlüsselkonzepte auf die Wirtschaft im Allgemeinen und den Markt im Besonderen zu erweitern und sich neue Konzepte anzueignen. Einerseits interessiert sich die Historische Kulturwissenschaft vermehrt für die Wirtschaft als Praxis und Diskurs: ${ }^{8}$ Denk- und handlungsmächtige AkteurInnen wirtschaften im Manövrierraum von äußeren Feld- und verinnerlichten Habitusstrukturen. ${ }^{49}$ Sie produzieren Güter und Dienstleistungen durch bezahlte oder unbezahlte Arbeit, sie konsumieren markt- oder anderweitig vermittelte Produkte durch deren Ge- und Verbrauch, und sie praktizieren als Prosumer nicht selten beides zugleich. ${ }^{50}$ Produktions-, Distributions-

Vgl. Christophe Bonneuil/Jean-Baptiste Fressoz, The Shock of the Anthropocene: The Earth, History and Us, London/New York 2017.

46 Vgl. Dani Rodrik, The Globalization Paradox: Why Global Markets, States, and Democracy Can't Coexist, Oxford 2011.

47 Vgl. Berghoff/Vogel, Wirtschaftsgeschichte, 14-24.

48 Vgl. Christoph Conrad, „How much, schatzi?“ Vom Ort des Wirtschaftens in der new cultural history, in: Berghoff/Vogel (Hg.), Wirtschaftsgeschichte als Kulturgeschichte, 43-67; Susanne Hilger/ Achim Landwehr (Hg.), Wirtschaft - Kultur - Geschichte. Positionen und Perspektiven, Stuttgart 2011; Inga Klein/Sonja Windmüller (Hg.), Kultur der Ökonomie. Zur Materialität und Performanz des Wirtschaftlichen, Bielefeld 2014.

49 Vgl. Pierre Bourdieu, Principles of an Economic Anthropology, in: Neil J. Smelser/Richard Swedberg (Hg.), The Handbook of Economic Sociology, Princeton/Oxford/New York 2005, 75-89.

50 Vgl. George Ritzer, Prosumer Capitalism, in: The Sociological Quarterly 56 (2015) 3, 413-445. 
und Konsumsphären folgen vielfältigen Logiken, die durch hegemoniale Diskurse (zum Beispiel Spielarten des "Geistes des Kapitalismus“) verabsolutiert oder durch Gegendiskurse (zum Beispiel Spielarten der Kapitalismuskritik) relativiert werden..$^{51}$ In diesem Zusammenhang entdeckt die „Gegenwartsgeschichte" die diskursive und praktische „Vermarktlichung“, die unternehmensgetriebene Zurückdrängung staatlicher und gemeinschaftlicher Marktregulierung, seit den 1970er-Jahren als Forschungsgegenstand. ${ }^{2}$ Die Kulturgeschichte des Wirtschaftens - oder auch "Wirtschaftskulturgeschichte“ "53 $^{-}$des 20 . Jahrhunderts taucht in verschiedenen zeithistorischen Forschungsarenen auf: in der Alltagsgeschichte, die saturierte und prekäre Lebensstile dechiffriert; in der Historischen Anthropologie, die der Kommerzialisierung kolonialer (Raub-)Gegenstände nachspürt; in der Geschlechtergeschichte, die als ,männlich' und ,weiblich' besetzte Domänen wie Heimwerker- und Pflegearbeit untersucht; in der Mediengeschichte, die Strategien der Produktwerbung beleuchtet; in der Konsumgeschichte, die Strategien des Branding von Waren rekonstruiert; in der Wissensgeschichte, die produktbezogene Experten- und Alltagsdiskurse analysiert. ${ }^{54}$

Andererseits sieht sich die zeithistorische Forschung mit dem Material oder Ontological Turn in den Kulturwissenschaften konfrontiert. Der Neue Materialismus kritisiert den vorherrschenden Anthropozentrismus, der die Verfügungs- und Deutungsmacht menschlicher ,Subjekte über nichtmenschliche ,Objekte in den Mittelpunkt stellt. Demgegenüber betont er die Wirkmächtigkeit (Agency) von , mehr als menschlichen ${ }^{c}$ Materialitäten entsprechend ihrer dinglichen Eigenlogiken. ${ }^{55}$ Innerhalb der postanthropozentrischen Ansätze überwindet die Akteur-Netzwerk-Theorie Bruno Latours die moderne Trennung von Kultur und Natur mit dem Konzept

51 Vgl. Luc Boltanski/Ève Chiapello, Der neue Geist des Kapitalismus, Konstanz 2003, 35-87, die den spezifischen „Geist des Kapitalismus" nach Weber generalisierend als „Ideologie (...), die das Engagement für den Kapitalismus rechtfertigt", definieren (Boltanski/Chiapello, Kapitalismus, 43).

52 Vgl. Ralf Ahrens/Marcus Böick/Marcel vom Lehn, Vermarktlichung. Zeithistorische Perspektiven auf ein umkämpftes Feld, in: Zeithistorische Forschungen/Studies in Contemporary History 12 (2015) 3, 393-402.

53 Susanne Hilger/Achim Landwehr, Wirtschaft - Kultur - Geschichte: Stationen einer Annäherung, in: dies. (Hg.), Wirtschaft, 7-26, 13.

54 Vgl. entsprechende Themenhefte von in Österreich oder unter Beteiligung von ÖsterreicherInnen herausgegebenen Fachzeitschriften: Produzieren/Konsumieren - Prosumieren/Konduzieren. Österreichische Zeitschrift für Geschichtswissenschaften 30 (2019) 1; Globale Dinge. Historische Anthropologie 25 (2017) 3; Ökonomien. L'Homme F. Z. G. 27 (2016) 1; Landwirtschaft und Ernährung im Nationalsozialismus. zeitgeschichte 45 (2018) 3.

55 Vgl. Amiria Henare/Martin Holbraad/Sari Wastell, Introduction, in: dies. (Hg.), Thinking Through Things. Theorising Artefacts Ethnographically, London/New York 2007, 1-31; Timothy J. LeCain, The Matter of History: How Things Create The Past, Cambridge 2017, 67-139. 
der hybriden „Sozionatur“; folglich erweitert sie die Akteurschaft auf nichtmenschliche ,Dinge. ${ }^{56}$ Auch wenn (Zeit-)HistorikerInnen dieser „symmetrischen Anthropologie" nicht in allen Punkten folgen, eignen sie sich - auch unter dem Blickwinkel der Umweltgeschichte - das Materielle selektiv an. So etwa sickern die Human-Animal Studies an den Rändern der Zeitgeschichte ein - mit entsprechenden Abwehrreaktionen, wie der Skandal um den Fake-Artikel über den „deutsch-deutschen Schäferhund" in einer zeithistorischen Fachzeitschrift zeigt. ${ }^{77}$ Neben Mensch-TierBeziehungen, etwa der Nutztierhaltung in der Nachkriegszeit, ${ }^{8}$ interessieren sich (Zeit-)HistorikerInnen zunehmend auch für nichtmenschliche Materialitäten wie Pflanzen, Technologien und Infrastrukturen und deren Wirkmächtigkeit - auch in Bezug auf Menschen. ${ }^{59}$ Über die neomaterialistische Wende nähert sich die (Zeit-) Geschichte einem genuin wirtschaftshistorischen Gegenstandsbereich - jenen lebenden und unbelebten ,Dingen', die als Gaben, Tribute und Waren zwischen Produktions- und Konsumsphären zirkulieren.

Wie die Zeitgeschichte zeigte auch die Wirtschaftsgeschichte Tendenzen in Richtung (Wieder-)Annäherung, wohl etwas vorschnell als „kulturalistische Wende“ der Ökonomie bezeichnet. ${ }^{60}$ Erheblichen Einfluss entfaltete die von Douglas North geprägte Neue Institutionenökonomie, die sich auf die Durchsetzung kapitalistischer Produktions- und Reproduktionsweisen im 20. Jahrhundert konzentriert. ${ }^{61}$ Gegenüber der neoklassischen Vorstellung vom „selbstregulierenden Markt“ betont

56 Vgl. Bruno Latour, Wir sind nie modern gewesen. Versuch einer symmetrischen Anthropologie, Frankfurt a. M. 1998.

57 Vgl. Enrico Heitzer/Sven Schultze (Hg.), Chimära mensura? Die Human-Animal Studies zwischen Schäferhund-Science-Hoax, kritischer Geschichtswissenschaft und akademischem Trendsurfing, Berlin 2018.

58 Vgl. Veronika Settele, Revolution im Stall. Landwirtschaftliche Tierhaltung in Deutschland 19451970 (Kritische Studien zur Geschichtswissenschaft 239), Göttingen 2020.

59 Vgl. LeCain, Matter, 67-139; Dirk van Laak, Infra-Strukturgeschichte, in: Geschichte und Gesellschaft 27 (2001), 367-393; Patrick Joyce/Chandra Mukerji, The State of Things: State History and Theory Reconfigured, in: Theory and Society 46 (2017), 1-19.

60 Vgl. Hansjörg Siegenthaler, Geschichte und Ökonomie nach der kulturalistischen Wende, in: Geschichte und Gesellschaft 25 (1999) 2, 276-301; Jakob Tanner, Die ökonomische Handlungstheorie vor der „kulturalistischen Wende“? Perspektiven und Probleme einer interdisziplinären Diskussion, in: Berghoff/Vogel (Hg.), Wirtschaftsgeschichte als Kulturgeschichte, 69-98; ders., „Kultur“ in den Wirtschaftswissenschaften und kulturwissenschaftliche Interpretationen ökonomischen Handelns, in: Friedrich Jaeger/Jörn Rüsen (Hg.), Handbuch der Kulturwissenschaften, Bd. 3: Themen und Tendenzen, Stuttgart/Weimar 2004, 195-224.

61 Vgl. Birger P. Priddat, Historische Methode und moderne Ökonomie. Über das Methodische in der Historischen Schule und das Historische in der Neuen Institutionenökonomie, in: Berghoff/Vogel (Hg.), Wirtschaftsgeschichte als Kulturgeschichte, 99-116. 
sie die institutionellen Arrangements, die Produktion, Distribution und Konsum regulieren. Institutionen umfassen formelle (Gesetze, Verträge, Abkommen usw.) und informelle (Konventionen, Gebräuche, Mentalitäten usw.) Spielregeln der Gesellschaft. Institutionelle Arrangements leiten die Wirtschaftsentwicklung entlang bestimmter Pfade, die - abgesehen von revolutionären Brüchen - auf evolutionäre Weise nur mit hohen Transaktionskosten veränderbar sind. ${ }^{62}$ Im Windschatten des Institutional Turn fanden weitere Werkzeuge Eingang in die wirtschaftshistorische Denkwerkstatt: „bounded rationality“, „path dependency“, Wirtschaftsstil, „embeddedness" und „economic culture“. ${ }^{63}$ Jenseits aller Unterschiede im Detail teilen diese Konzepte die Auffassung, dass wirtschaftliches Denken und Handeln - selbst das Geschehen auf dem scheinbar "freien Markt" - mehr oder weniger in zeit- und raumspezifische Kultur- und Sozialbeziehungen „eingebettet“ ist. ${ }^{64}$ Damit distanzieren sie sich von den zeit- und raumignoranten Generalisierungen der Kliometrie unter der wirklichkeitsfernen Annahme eines „rational“ kalkulierenden Homo oeconomicus, den Amartya Sen als „rational fool“ entlarvt. ${ }^{65}$ In diesem Zusammenhang gewinnt die interdisziplinäre Geschichte des Kapitalismus an Interesse, das hierzulande vor allem an den wirtschaftshistorischen, -soziologischen und -ethnologischen Ansatz Karl Polanyis anknüpft. ${ }^{66}$ Über die Wiederaneignung nichtquantifizierbarer Phänomene, etwa Produktqualitäten, ${ }^{67}$ nähert die neoinstitutionelle Wende die Wirtschaftsgeschichte wieder an Gegenstandsbereiche der Zeitgeschichte an.

Einen Versuch der (Wieder-)Begegnung von zeit- und wirtschaftshistorischer Forschung repräsentiert mein 2016 erschienenes Buch „Schlachtfelder“. Anhand alläglicher Interaktionsfelder zwischen NS-System und Alltagswelt im Reichsgau Niederdonau sucht es die Frage nach dem Stellenwert des Nationalsozialismus in

62 Vgl. Douglas C. North, Theorie des institutionellen Wandels, Tübingen 1988.

63 Vgl. Berghoff/Vogel, Wirtschaftsgeschichte, 18-24.

64 Vgl. Karl Polanyi, The Great Transformation. Politische und ökonomische Ursprünge von Gesellschaften und Wirtschaftssystemen, Frankfurt a. M. 1997; Mark Granovetter, Economic Action and Social Structure: The Problem of Embeddedness, in: American Journal of Sociology 91 (1985), 481-510.

65 Vgl. Tanner, Handlungstheorie; ders., „Kultur“; Amartya Sen, Rational Fools: A Critique of the Behavioral Foundations of Economic Theory, in: Philosophy and Public Affairs 6 (1977), 317-344.

66 Vgl. Ernst Langthaler/Elke Schüßler, Commodity Studies with Polanyi. Disembedding and Re-Embedding Labour and Land in Contemporary Capitalism, in: Österreichische Zeitschrift für Soziologie 44 (2019), 209-223; Erich Landsteiner/Ernst Langthaler, Editorial: Global Commodities, in: Österreichischen Zeitschrift für Geschichtswissenschaften 30 (2019) 3, 5-10; Brigitte Aulenbacher/ Markus Marterbauer/Andreas Novy/Armin Thurnher (Hg.), Karl Polanyi - Wiederentdeckung eines Jahrhundertdenkers, Wien 2019.

67 Vgl. Robert Salais/Marcel Streng/Jakob Vogel (Hg.), Qualitätspolitiken und Konventionen. Die Qualität der Produkte in historischer Perspektive, Wiesbaden 2019. 
der Agrarmodernisierung - genauer, im Übergang zum staatsgeleiteten Agrarproduktivismus auf der Makro- und zu unternehmerischen Landwirtschaftsstilen auf der Mikroebene - zu beantworten. Die regionale Mehrebenenstudie folgt einem praxeologischen Ansatz, der agrargesellschaftliche Felder des alltäglichen Ringens individueller und kollektiver AkteurInnen um Ressourcen - Boden, Arbeit, Kapital, Wissen und Güter - vermisst. Zur überregionalen Kontextualisierung dient ein institutionenökonomisch inspirierter Ansatz, der Ressourceneinsätze und -flüsse (Faktorallokation, Nutzungsintensität, Produktivität usw.) sowie formelle und informelle Regulierungsinstanzen (Staatsbürokratie, Mediendiskurs, Wirtschaftsstile usw.) verknüpft. Die Quellenbasis umfasst eine Fülle an seriellem Material auf Personen- und Betriebsebene (Betriebsstatistik, Förderaktionen, Gerichtsakten usw.) für quantifizierende Datenanalysen als Rahmen für qualitative Fallstudien auf Basis singulärer Dokumente (zum Beispiel des Briefes eines Bergbauern an den „Führer“). Die Vermessung der alltäglichen Interaktionsfelder zeigt, dass Bauernfamilien ihre Ressourcen weder nach (von Agrartechnokraten geforderten) „rationalen“ noch nach (von Agrarideologen geforderten) „völkischen“ Maßstäben einsetzten; stattdessen folgten sie habitualisierten Wirtschaftsstilen, die menschliche (familiale, finanzielle, bürokratische usw.) und nichtmenschliche (tierische, pflanzliche, technische usw.) Erfordernisse flexibel ausbalancierten. Dabei schieden sich die Wege: Einerseits veranlassten Arbeitskräfte- und Betriebsmittelmangel sowie Markt- und Preiskontrollen den Hauptstrom der diversifizierten Höfe zur Extensivierung. Andererseits nahmen ressourcenreiche Pionierbetriebe staatliche Förderpakete für den Ölfruchtanbau im Flachland und die Milchwirtschaft im Gebirge auf, die regionale Entwicklungspfade in Richtung spezialisierter (Kapital-)Intensivierung öffneten. Insgesamt argumentiert die Studie, dass das NS-Regime zwar eine umfassende Agrarmodernisierung im Sinne eines „völkischen Produktivismus“ plante; dieses Projekt entfaltete aber nur zum Teil - weniger in technischer als vielmehr in institutioneller Hinsicht nachhaltige Wirkung über 1945 hinaus. ${ }^{68}$

68 Vgl. Ernst Langthaler, Schlachtfelder. Alltägliches Wirtschaften in der nationalsozialistischen Agrargesellschaft (Sozial- und wirtschaftshistorische Studien 38), Wien/Köln/Weimar 2016; als Zusammenfassung vgl. ders., Völkischer Produktivismus. Nationalsozialismus und Agrarmodernisierung im Reichsgau Niederdonau 1938-1945, in: zeitgeschichte 45 (2018) 3, 293-318. 


\section{Rück- und Ausblick}

Die eingangs zitierte Frage, ob denn überhaupt eine Beziehung zwischen Zeitgeschichte und Wirtschaftsgeschichte bestehe, lässt sich am Schluss des vorliegenden Beitrags mit einem „Ja, aber“ beantworten. Diese komplizierte Beziehung erscheint, wie in der folgenden Graphik (Abb. 2), vereinfacht als Abfolge einer Konvergenzund einer Divergenzbewegung mit Abzweigungen über die letzten fünfzig Jahre. Im Zuge der sozialwissenschaftlichen Wende in den 1970er-Jahren näherten sich die beiden gerade erst institutionalisierten Fächer an und kooperierten in Themenfeldern wie dem Nationalsozialismus (1). Doch in den 1990er-Jahren wandten sich Teilgruppen voneinander ab und entwickelten parallel laufende Denkstile: Während die jüngere Generation der Zeitgeschichte den Cultural Turn mitvollzog (2a), orientierte sich die jüngere Generation der Wirtschaftsgeschichte am Cliometric Turn (2b). Von den bis in die Gegenwart reichenden Parallelrouten von Zeitgeschichte und Wirtschaftsgeschichte zweigten in den letzten beiden Jahrzehnten Alternativpfade ab: einerseits die (Wieder-)Aufwertung des Wirtschaftlichen und der Material Turn in der Zeitgeschichte, andererseits die (Wieder-)Aufwertung des Kulturellen und der Institutional Turn in der Wirtschaftsgeschichte. Diese Abzweigungen führen zu potenziellen und bereits ansatzweise realisierten (Wieder-)Begegnungszonen (3). Damit rücken Probleme, die im Geschichtsdiskurs ad acta gelegt schienen, erneut auf die Agenda - etwa das Verhältnis von Struktur und Praxis, das die kulturalistische Fraktion voluntaristisch und die kliometrische Fraktion deterministisch aufzulösen suchte. Die gemeinsame Herausforderung besteht darin, die Macht von Strukturen - materiellen wie ideellen - und die Macht von AkteurInnen - menschlichen wie nichtmenschlichen - als zwei Seiten derselben Medaille gegeneinander abzuwägen und dafür angemessene Erzählformen zu entwickeln. Damit rückt von den Zeitschichten Fernand Braudels zwischen der langfristigen „longue durée “ und den kurzfristigen Ereignissen die mittlere, das zugleich determinierte und kontingente Wechselspiel von Strukturen und Praktiken, ins Zentrum. ${ }^{69}$

Was hätten Zeitgeschichte und Wirtschaftsgeschichte von einer Wiederannäherung? Zunächst kann die Annäherung der beiden Fächer dazu beitragen, die jeweiligen Reduktionismen $\mathrm{zu}$ überwinden: die Blindheit der kulturalistischen Zeitgeschichte auf dem ökonomischen Auge und die Blindheit der kliometrischen Wirtschaftsgeschichte auf dem kulturellen Auge. Für ZeithistorikerInnen mag es

69 Vgl. Jan de Vries, Changing the Narrative: The New History That Was and Is to Come, in: Journal of Interdisciplinary History 48 (2018) 3, 313-334; Francesca Trivellato, Un nouveau combat pour l'historie au XXIe siècle?, in: Annales: Histoire, Sciences Sociales 70 (2015), 333-343. 


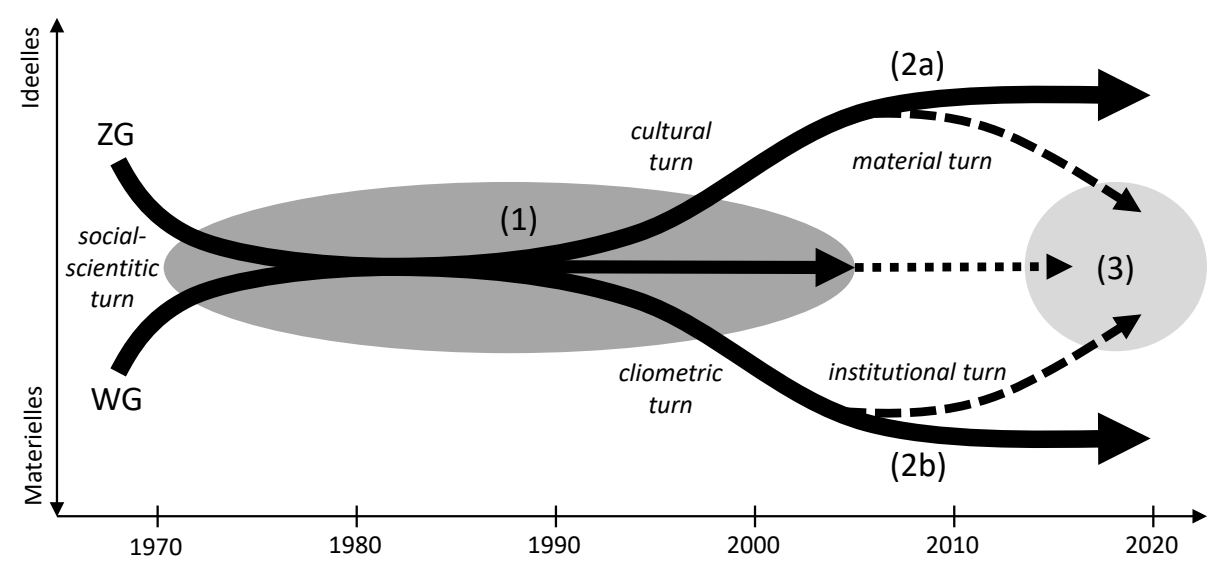

Abb. 2: Beziehungskonstellationen von Zeitgeschichte und Wirtschaftsgeschichte in Österreich seit 1970 (Quelle: eigener Entwurf)

erhellend sein, nicht nur den Weltsichten, sondern auch den Welten selbst - einschließlich ihrer materiellen Elemente - Geschichtswürdigkeit und -mächtigkeit zuzuerkennen. Damit erweitert sich die Deutungs- hin zur Realgeschichte (im umfassenden Sinne), ohne zwingend in die Falle des naiven Historismus („wie es eigentlich gewesen“) zu tappen. Gerade die boomende Geschichte der Zeit „nach dem Boom" seit den 1970er-Jahren wird Aspekte wie Vermarktlichung, Einkommensungleichheit oder Naturverbrauch kaum ignorieren können, will sie den oft mit heißer Nadel gestrickten Zeitdiagnosen der Nachbarwissenschaften überzeugende Narrative entgegensetzen..$^{\circ}$ Die Modelle der Neuen Wirtschaftsgeschichte gewännen an Wirklichkeitsnähe - und damit an Gesellschaftsrelevanz -, wenn sie das auf, rationale ' Nutzenmaximierung fixierte Menschenbild zugunsten der Vielfalt der strukturbestimmten und -bestimmenden Praxis der WirtschaftsakteurInnen überwänden. So etwa beforscht die in den USA aufblühende New History of Capitalism mit einem pluralistischen Ansatz den „Kapitalismus in Aktion“, in urbanen Zentren wie ländlichen Peripherien. Dabei greift sie alte Fragen auf und sucht nach neuen Antworten, etwa zur Rolle der Sklaverei und anderer Zwangsarbeitsverhältnisse im Kapitalismus. ${ }^{71}$

70 Vgl. Anselm Doering-Manteuffel/Lutz Raphael, Nach dem Boom. Perspektiven auf die Zeitgeschichte seit 1970, Göttingen 2008.

71 Vgl. Sven Beckert/Angus Burgin/Peter James Hudson/Louis Hyman/Naomi Lamoreaux/Scott Marler/Steven Mihm/Julia Ott/Philip Scranton/Elizabeth Tandy Shermer, Interchange: The History of Capitalism, in: The Journal of American History 101 (2014) 2, 503-536; Eric Hilt, Economic 
Neben der Überwindung der jeweiligen Reduktionismen kann die Kooperation der beiden Fächer auch gemeinsame Forschungsgegenstände erschließen. Was läge näher als eine dem State of the Art entsprechende Wirtschaftsgeschichte Österreichs im 20. Jahrhundert, eingebettet in Gesellschafts- und Umweltbeziehungen sowie inter- und transnationale Verflechtungen? Das letzte Maßstäbe setzende Gemeinschaftswerk zu diesem Thema erschien vor mehr als einem halben Jahrhundert; die letzten (Einzel-)Darstellungen datieren Jahrzehnte zurück oder bilden Kapitel epochenübergreifender Monographien..$^{72}$ Ein solches Großunternehmen könnte wohl nur arbeitsteilig, im Zusammenwirken verschiedener Personen und Fächer auf Basis eines gemeinsamen, wenngleich pluralistischen Konzepts gelingen. Dass eine Projektidee dieses Zuschnitts mit entsprechender Ambition, Expertise und Ressourcenbasis realisierbar ist, zeigt etwa die „Wirtschaftsgeschichte der Schweiz im 20. Jahrhundert" als Resultat einer konzertierten Kooperation von Allgemein-, Wirtschafts- und SozialhistorikerInnen sowie historischen ÖkonomInnen. ${ }^{73}$ Diesem Gemeinschaftswerk liegt ein erweiterter Wirtschaftsbegriff zugrunde, denn: "Wer allein die Wirtschaft ins Visier nimmt, versteht auch die Wirtschaft nicht.“ Folglich habe Wirtschaftsgeschichte „gar keine andere Wahl, als sich zu einer allgemeinen Strukturgeschichte auszuweiten" - dies jedoch, im praxeologischen Sinne, unter Bedacht auf die „,institutionellen Rahmenbedingungen, unter denen die Menschen über ökonomische Belange entscheiden“".74 Eine so verstandene Wirtschaftsgeschichte Österreichs im ,kurzen' 20. Jahrhundert zwischen der Desintegration der Österreichisch-Ungarischen Monarchie 1918 und der Integration in die Europäische Union 1995 böte Zeitgeschichte und Wirtschaftsgeschichte eine Gelegenheit, ihr synergetisches Potenzial zu heben. Sie wäre ein starkes Zeichen für die (Wieder-) Begegnung der beiden Fächer.

History, Historical Analysis, and the „New History of Capitalism“, in: The Journal of Economic History 77 (2017), 511-536; Sven Beckert/Rolf Bauer/Ernst Langthaler, Kapitalismus in Aktion, in: Österreichische Zeitschrift für Geschichtswissenschaften 30 (2019) 3, 171-181.

72 Vgl. Weber (Hg.), Wirtschaftsstruktur; Otruba, Wirtschaft; Butschek, Wirtschaft im 2o. Jahrhundert; ders., Österreichische Wirtschaftsgeschichte. Von der Antike bis zur Gegenwart, Wien/Köln/ Weimar 2012; Roman Sandgruber, Ökonomie und Politik. Österreichische Wirtschaftsgeschichte vom Mittelalter bis zur Gegenwart, Wien 1995.

73 Vgl. Patrick Halbeisen/Margrit Müller/Béatrice Veyrassat (Hg.), Wirtschaftsgeschichte der Schweiz im 20. Jahrhundert, Basel 2012.

74 Hansjörg Siegenthaler, Vorwort, in: ebd., 15-16, 16. 


\section{Zeitgeschichte und Umweltgeschichte}

Robert Groß

\section{Einführung}

Umweltgeschichte und Zeitgeschichte sind in Österreich akademische Welten, die nur selten miteinander kooperieren. Wer in Österreich umwelthistorisch arbeitet, versteht sich nicht als ZeithistorikerIn, und umgekehrt. Zeithistorische Universitätsinstitute oder andere Forschungseinrichtungen mit zeithistorischer Fokussierung beschäftigen keine UmwelthistorikerInnen. Warum ist das so? Der vorliegende Beitrag bietet Erklärungen für dieses Nichtverhältnis; vor allem in Bezug auf Themen, Methoden und theoretische Konzepte, aber auch die historischen Rahmenbedingungen der Institutionalisierung. International wurde die österreichische Umweltgeschichte bis vor kurzem als genuin interdisziplinäres Forschungsfeld rezipiert, das sich durch die Kooperation mit den Umwelt- und Naturwissenschaften und durch eine konsequente Orientierung an aktuellen Umwelt- oder Nachhaltigkeitsproblemen auszeichnet. ${ }^{1}$ Das Verständnis von Umweltgeschichte entsprach dem einer interdisziplinären Wissenschaft. In jüngster Vergangenheit wurde dieses Verständnis durch neue Perspektiven erweitert. Diese bietet Chancen, bis dato ungewohnte Perspektiven auf die Zeitgeschichte einzunehmen. Sie kann aber auch als eine erste Erklärung dafür dienen, warum der Dialog mit der Zeitgeschichte bis dato kaum praktiziert wurde.

Umwelt- und Zeitgeschichte stehen in einem „Nichtverhältnis“? Dieser erste Befund wird vom schwedischen Umwelthistoriker Sverker Sörlin durch eine Auswertung der Literaturdatenbank „Google Scholar“ gestützt. Unter jeweils rund 600.000 Treffern für die Suchbegriffe Zeitgeschichte und Umweltgeschichte befinden sich nur etwa 11.000 Titel, die beide Perspektiven kombinieren. ${ }^{2}$ Ganz ähnlich ist die Situation in Österreich. Eine Recherche in der 1973 gegründeten österreichischen

1 John McNeill, Observations on the Nature and Culture of Environmental History, in: History and Theory 42 (2003) 4, 5-43.

2 Sverker Sörlin, The Contemporaneity of Environmental History. Negotiating Scholarship, Useful History, and the New Human Condition, in: Journal of Contemporary History 46 (2011) 3, 610630. 
Zeitschrift „Zeitgeschichte“3 mit dem Suchbegriff „Umweltgeschichte“ ergab vier Treffer, alle im kurzen Zeitraum 2003-2007. Konkret handelt es sich um zwei Buchanzeigen, eine Fußnote und einen einzigen Satz mit inhaltlicher Substanz. Eine ähnliche Recherche in den deutschen „Vierteljahresheften für Zeitgeschichte“ ergibt drei, explizit umwelthistorischen Themen gewidmete Beiträge. Ein ähnliches Bild zeigen die englischsprachigen zeithistorischen Fachzeitschriften „Journal of Contemporary History" und „European Contemporary History“. Ganz anders die wichtigsten Zeitschriften der Umweltgeschichte: In der US-amerikanischen Fachzeitschrift „Environmental History" findet sich kaum ein Heft, in dem nicht (fast) alle Beiträge das 20. Jahrhundert zumindest schwerpunktmäßig behandeln. Dagegen bietet die Fachzeitschrift der europäischen Umweltgeschichte mit dem Titel „Environment and History" mehr Beiträge zu Perioden vor der Wende zum 20. Jahrhundert.

Umweltgeschichte interessiert sich für Zeitgeschichte, aber nicht umgekehrt? Das wäre doch zu kurz gegriffen. Das stumme Nebeneinander beider historischer Zugänge in Österreich ist aber zumindest bemerkenswert und erklärungsbedürftig. Im folgenden zweiten Abschnitt wird zunächst die historische Genese und Institutionalisierung von Umweltgeschichte diskutiert. Im dritten Abschnitt werden Unterschiede und Gemeinsamkeiten der Periodisierung der Umwelt- und Zeitgeschichte diskutiert. Im vierten und fünften Abschnitt werden zwei zentrale Themen der Umweltgeschichte - Energie und Mobilität - genutzt, um Unterschiede und Gemeinsamkeiten der Ansätze zu diskutieren. Dies soll LeserInnen mit einem Hintergrund in der Zeitgeschichte einen Einstieg in das konzeptuelle, methodische und inhaltliche Repertoire österreichischer Umweltgeschichte geben. Umwelthistorisch sozialisierten LeserInnen soll der vorliegende Beitrag Ähnliches in Bezug auf die Zeitgeschichte bieten.

\section{Die Etablierung der Umweltgeschichte}

Die Umweltgeschichte beginne mit „dem Ende der Natur",4 meinte Bill McKibben 2006. Diese Aussage ist irritierend, versteht man unter „Natur" doch jenen Teil der Welt, der „bleibt und sich nicht selbst vernichtet“.5 Ein Verdienst der Umweltge-

3 Benutzt wurde dazu die Volltextsuche im Portal ANNO (Austrian Newspapers Online) der Österreichischen Nationalbibliothek.

4 William McKibben, The End of Nature, New York 1990.

5 Gregor Schiemann, Natur - Kultur und ihr Anderes, in: Friedrich Jaeger/Burkhard Liebsch (Hg.), Handbuch der Kulturwissenschaften, Grundlagen und Schlüsselbegriffe, Stuttgart/Weimar 2004, $60-75,60$. 
schichte ist ein erweitertes Verständnis von „Natur“, das deren kulturelle Interpretation, politische Umkämpftheit ${ }^{6}$ sowie technische und ökonomische Aneignung mitberücksichtigt.7 Wichtig für die akademische Etablierung der Umweltgeschichte war die sozialgeschichtliche Wende der 1960er-Jahre.

Frauen, Randgruppen und Unterschichten wurden Gegenstand der Forschung. Stand, Klasse, Gender [...] Rasse und Religion waren neue oder neu gedachte [...] Analysekategorien, zu denen mit der Umweltkrise und dem Erwachen des Umweltbewusstseins die Umweltbeziehung als Kategorie hinzukam. ${ }^{8}$

Diese Erweiterung sprengte aber schnell den Rahmen einer damals erneuerten Sozialgeschichte.

Wie verlief die Institutionalisierung in der internationalen akademischen Welt? Rachel Carson publizierte 1962 „Silent Spring“ („Der stumme Frühling“), das retrospektiv als Meilenstein in der Herausbildung des Umweltbewusstseins gilt, das wiederum selbst eine wichtige Voraussetzung auch für die Umweltgeschichte war. ${ }^{9}$ Carson lenkte die öffentliche Aufmerksamkeit auf die ökologischen Konsequenzen von Dichlordiphenyltrichlorethan, kurz DDT. Breit und sorglos eingesetzt, reichert sich DDT in der Nahrungskette an und führte in den späten 1950er-Jahren zu einem merkbaren Rückgang von Singvogelpopulationen. ${ }^{10}$ Etwa zeitgleich rechnete Vance Packard in dem Besteller „The Waste Makers“ von 1959 mit den Auswüchsen der US-amerikanischen Konsumkultur ab. Carson und Packard prägten „zwei Stoßrichtungen der [modernen] Umweltbewegungen: Vergiftung und Verschmutzung “.11 Andere handlungsleitende Paradigmen waren - und sind bis heute - Konvivialität oder eine gemeinwohlorientierte Umweltethik, die Umwelthandeln nicht auf die Spezies Mensch beschränkt, ,natürliches Gleichgewicht' sowie ,Ressourcenökonomie und Entropie. ${ }^{12}$ Vor allem für das ressourcenökonomische Gleichgewichtspa-

6 Ortrun Veichtlbauer, Natur als Politikum. Beiträge zu einer österreichischen Umweltgeschichte, phil. Diss., Universität Klagenfurt 2014.

7 Finn Arne Jorgensen/Unnur Birna Karlsdóttir/Erland Marald/Bo Poulsen/Tuomas Räsänen, Entangled Environments: Historians and Nature in the Nordic Countries, in: Historisk tidsskrift 92 (2013) 1, 9-34, 10.

8 Verena Winiwarter/Martin Knoll, Umweltgeschichte. Eine Einführung, Stuttgart/Köln 2007, 30.

9 Ebd.

10 Ebd.

11 Ebd.

12 Marina Fischer-Kowalski, Wie erkennt man Umweltschädlichkeit?, in: Marina Fischer-Kowalski/ Helmut Haberl/Walter Hüttler/Harald Payer/Heinz Schandl/Verena Winiwarter/Helga Zangerl- 
radigma steht der 1972 erschienene Bericht „Limits to Growth“ des Club of Rome. ${ }^{13}$ In diesem Zeitgeist entstand die Environmental History in den USA, wo sich das Thema „in einer spezifischen Konstellation von Umweltbewusstsein, administrativer Offenheit und universitärem Wachstum auch akademisch etablieren “14 konnte. Bis in die 1980er-Jahre hatte die Umweltgeschichte auch „Eingang in die europäische Wissenschaftslandschaft" gefunden. ${ }^{15}$ Die ersten sich selbst so nennenden UmwelthistorikerInnen in Europa kamen zumeist aus der Historischen Geographie, Ökologie, biologischen Anthropologie, Technik- (Stichwort: Atomkraft), Forst- und Agrargeschichte. Ein Meilenstein der Institutionalisierung war die Gründung des Journals „Environment and History“ 1995. Im selben Jahr wurde die European Society of Environmental History (ESEH) gegründet, ${ }^{16}$ welche seit 1999 alle zwei Jahre Konferenzen abhält. ${ }^{17}$

In Österreich ist mit der Institutionalisierung der Umweltgeschichte vor allem der Name Verena Winiwarter verbunden, die das Fach international sichtbar etablierte. Nach ihrer Ausbildung in Technischer Chemie arbeitete sie als Umweltanalytikerin an der Technischen Universität Wien, wo sie sich mit Umweltbelastungen, wie der „Eutrophierung des Neusiedlersees“ und der „Luftqualität in Linz“ beschäftigte. ${ }^{18} 1986$ inskribierte sie an der Universität Wien ein Studium der Publizistik und Kommunikationswissenschaft, wechselte dann zur Geschichte und schloss dieses 1990 mit einem Magisterium ab. 1994 begann sie ein Doktoratsstudium in Geschichte, das sie 1998 mit der Arbeit „Historische und ökologische Prozesse in einer Kulturlandschaft: Umweltgeschichte als interdisziplinäre Wissenschaft" abschloss. Besonders gute Rahmenbedingungen für die österreichische Umweltgeschichte bildeten das vom Bundesministerium für Wissenschaft und Verkehr 1992 aufgelegte Forschungsprogramm „Nachhaltige Entwicklung von Landschaften und Regionen“,

Weisz, Gesellschaftlicher Stoffwechsel und Kolonisierung. Ein Versuch in sozialer Ökologie, Amsterdam 1997, 13-24, 13-21.

13 Dennis L. Meadows, Die Grenzen des Wachstums. Bericht des Club of Rome zur Lage der Menschheit, Stuttgart 1972.

14 Winiwarter/Knoll, Umweltgeschichte, 32.

15 Ebd., 33.

16 Verena Winiwarter/Marco Armiero/Petra van Dam/Andreas Dix/Per Eliasson/Poul Holm/Leos Jeleček/Robert A. Lambert/Geneviève Massard-Guilbaud/Manuel Gonzáles de Molina/Timo Myllyntaus/Jan Oosthoek u. a., Environmental History in Europe from 1994 to 2004. Enthusiasm and Consolidation, in: Environment and History 10 (2004) 4, 501-530, 502.

17 ESEH 2021, University of Bristol, 5-9 July 2021, University of Bristol, URL: http://eseh.org/event/ next-conference/ (abgerufen 17.10.2019).

18 Interview mit Verena Winiwarter, geführt von Robert Groß, 25.04.2019, Aufnahme beim Autor. 
kurz „Kulturlandschaftsforschung“ oder KLF.19 In diesen Projekten konnten ökologische mit historischen Methoden etwa über räumliche GIS-Analysen und Modellierung integriert werden, was die Wiener Schule der Umweltgeschichte prägen sollte. Aber bereits in dieser frühen Phase zeichnete sich das „Nichtverhältnis“ zu den Geschichtswissenschaften, speziell zur Zeitgeschichte ab. Die Naturwissenschaften seien damals, so erinnert sich Winiwarter, deutlich offener für interdisziplinäre Zugänge als die Geschichtswissenschaft gewesen. ${ }^{20}$ Verena Winiwarter erhielt 2007 den Ruf auf die erste Professur für Umweltgeschichte in Europa am Institut für Soziale Ökologie, damals beheimatet an der Fakultät für Interdisziplinäre Forschung und Fortbildung der Universität Klagenfurt. Dort hatte Verena Winiwarter bereits seit 1993 umwelthistorische Lehrveranstaltungen abgehalten, neben verschiedenen umwelthistorischen GastprofessorInnen wie Christian Pfister, Mart Stewart, Carole Crumley oder Rolf Peter Sieferle, die die Institutsgründerin Marina FischerKowalski an das Institut für Soziale Ökologie einlud. Mit Fischer-Kowalski teilte Verena Winiwarter Verschiedenes: ein Interesse an universalhistorischen Zugängen und den biophysischen Aspekten der Industrialisierung, ein ausgeprägtes Interesse an Kooperationen zwischen Natur- und Sozial- bzw. Geisteswissenschaften und die Gewissheit, dass jede Form der Nachhaltigkeitswissenschaft in einem kleinen Land wie Österreich der konsequenten, internationalen Vernetzung bedarf. ${ }^{21}$

Das von Verena Winiwarter, Fridolin Krausmann, Martin Schmid, Ortrun Veichtlbauer und Christoph Sonnlechner 2003 gegründete Zentrum für Umweltgeschichte (ZUG) $)^{22}$ war rund zehn Jahre lang Österreichs einzige Form der Vernetzung an einer Universität. Es organisiert bis heute eine eigene Veranstaltungsreihe, die ZUG-Minisymposien. In diesem Rahmen wurde österreichischen Forscherinnen und Forschern eine Bühne geboten und viele FachkollegInnen aus der ganzen Welt nach Wien geholt. Dies gewährleistete neben der starken Präsenz auf den Umweltgeschichtetagungen in Europa und Nordamerika die internationale Anbindung. ZeithistorikerInnen verirrten sich vor allem als junge Studierende mit Interesse an Umwelt- oder Nachhaltigkeitsfragen in das Umfeld des ZUG, wo viele die ver-

19 KLF, URL: https://bmbwf.gv.at/forschung/national/programme-schwerpunkte/kulturlandschaftsforschung/ (abgerufen 21.10.2019).

20 Interview mit Verena Winiwarter, geführt von Robert Groß, 25.04.2019, Aufnahme beim Autor.

21 Verena Winiwarter, Wikipedia. Die freie Enzyklopädie, URL: https://de.wikipedia.org/wiki/Verena_Winiwarter (abgerufen 21.10.2019).

22 Verena Winiwarter, Universität für Bodenkultur Wien, URL: https://boku.ac.at/zentrum-fuer-umweltgeschichte/mitglieder/verena-winiwarter (abgerufen 21.10.2019). 
gleichsweise guten Betreuungsverhältnisse beim Verfassen von Qualifikationsarbeiten schätzten. ${ }^{23}$

Erst in jüngerer Zeit begann sich das Feld stärker auszudifferenzieren und damit auch das Verhältnis der Umweltgeschichte zur Geschichtswissenschaft in Österreich zu verändern. 2014 erhielt Martin Knoll den Ruf auf eine Professur für Europäische Regionalgeschichte in Salzburg. Knoll hatte an der Universität Regensburg mit der Arbeit „Umwelt - Herrschaft - Gesellschaft. Die landesherrliche Jagd Kurbayerns im 18. Jahrhundert" promoviert und sich an der Technischen Universität Darmstadt mit der Schrift „Die Natur der menschlichen Welt. Siedlung, Territorium und Umwelt in der historisch-topografischen Literatur der Frühen Neuzeit" habilitiert. ${ }^{24}$ Im selben Jahr wurde Patrick Kupper auf eine Professur für Wirtschafts- und Sozialgeschichte ans Institut für Geschichtswissenschaften und Europäische Ethnologie der Universität Innsbruck berufen. Kuppers Forschungsinteressen reichen vom konflikthaften Umgang mit der Kernkraft in der Schweiz (Dissertation) über die Geschichte von Nationalparks in globalhistorischer Perspektive (Habilitation) bis hin zur Energieund Infrastrukturgeschichte. ${ }^{25}$ Zwei Jahre später erhielt Ernst Langthaler den Ruf an das Institut für Sozial- und Wirtschaftsgeschichte der Universität Linz. Langthaler hatte bis dahin zur Agrar- und Ernährungsgeschichte aus global- und regionalgeschichtlicher Perspektive geforscht und neuerdings zur Geschichte der Sojabohne im 20. Jahrhundert. ${ }^{26}$

Das Selbstverständnis der neu besetzten Professuren als Umwelthistoriker zeigt sich daran, dass diese jeweils für mehrere Monate am renommierten Rachel Carson Center for Environment and Society der LMU München, einem der führenden europäischen Umweltgeschichteinstitutionen, tätig waren. ${ }^{27} \mathrm{Zudem}$ stellen diese ihre Arbeiten regelmäßig auf internationalen umwelthistorischen Tagungen zur Diskussion, lehren die entsprechenden Methoden und Theorien an den jeweiligen Universitätsstandorten und betreuen umwelthistorische Qualifikationsarbeiten. Außerdem

23 Am ZUG betreute Qualifizierungsarbeiten, vgl. Laufende und abgeschlossene Diplom/Masterarbeiten und Dissertationen, Universität für Bodenkultur Wien, URL: https://boku.ac.at/zentrumfuer-umweltgeschichte/umweltgeschichte-studieren/laufende-und-abgeschlossene-diplom-masterarbeiten-und-dissertationen (abgerufen 20.01.2020).

24 Martin Knoll, Universität Salzburg, URL: https://www.uni-salzburg.at/index.php?id=66819 (abgerufen 11.08.2020).

25 Patrick Kupper, Universität Innsbruck, URL: https://www.uibk.ac.at/geschichte-ethnologie/mitarbeiterinnen/univ-prof/kupper-patrick/ (abgerufen 11.08.2020).

26 Ernst Langthaler, Johannes Kepler Universität, URL: https://www.jku.at/institut-fuer-sozial-undwirtschaftsgeschichte/institut/team/langthaler/ (abgerufen 11.08.2020).

27 About the Rachel Carsen Center for Environment and Society, Rachel Carson Center, URL: https:// www.carsoncenter.uni-muenchen.de/about_rcc/index.html (abgerufen 11.08.2020). 
ermöglichten die Neubesetzungen neue Vernetzungsformen neben dem in Wien angesiedelten ZUG. 2016 wurde der Environmental History Cluster Austria (EHCA) gegründet, insbesondere um den österreichischen Nachwuchs zu fördern. ${ }^{28}$

\section{Die "Große Beschleunigung": Eine Epochenschwelle nach dem Zweiten Weltkrieg?}

Im 20. Jahrhundert haben sich Prozesse der Industrialisierung, Urbanisierung und Mechanisierung tiefgreifend verändert und quantitativ beschleunigt, mit entsprechenden ökologischen Nebenwirkungen. ${ }^{29}$ Das Erkenntnisinteresse an den historischen Ursachen und Entstehungsbedingungen gegenwärtiger Umweltprobleme gilt als wichtiger gemeinsamer Nenner umwelthistorischen Arbeitens. ${ }^{30}$ Zeithistorische Epochen orientieren sich vor allem an den politischen Zäsuren der Jahre 1918, 1934, 1938, 1945, 1989 oder 2001. ${ }^{31}$ Der Fokus der Umweltgeschichtsschreibung liegt dagegen eher auf langfristigen Betrachtungen, während politische Zäsuren der Zeitgeschichte den Charakter „dröhnender Ereignisse“ “32 haben. Diese können zwar auf einen tiefergreifenden historischen Wandel hinweisen, eine umwelthistorische Epochenbildung muss sich aber am Wandel der Gesellschaft-Natur-Interaktionen orientieren, ${ }^{33}$ der sich in anderen Zeitskalen vollzieht als in denen, die für die Politik relevant sind. Im Kern sind umwelthistorische Arbeiten sehr oft damit konfrontiert, dass soziale und biologische Temporalitäten kollidieren, etwa wenn die ökologischen Folgen eines von einem despotischen politischen Regime errichteten Staudamms lange nach dem Sturz dieses Regimes wirksam werden. ${ }^{34}$

28 Environmental History Cluster Austria, EHCA, URL: https://www.ehca.at/ (abgerufen 20.01.2020).

29 John R. McNeill, Blue Planet. Die Geschichte der Umwelt im 20. Jahrhundert, Frankfurt/New York 2000, 17-18.

30 Christian Pfister, Das $1950 e r$ Syndrom. Die Epochenschwelle der Mensch-Umwelt-Beziehung zwischen Industriegesellschaft und Konsumgesellschaft, in: GAIA 3 (1994) 2, 71-90, 74.

31 Sörlin, Contemporaneity, 624-625.

32 Jean Boutier/Thomas Lüttenberg, Fernand Braudel als Historiker des Ereignisses, in: Andreas Suter/Manfred Hettling (Hg.), Struktur und Ereignis (Geschichte und Gesellschaft, Sonderheft 19), Göttingen 2001, 138-157.

33 Pfister, Das 1950er, 74.

34 Jennifer L. Derr, The Lived Nile. Environment, Disease, and Material Colonial Economy in Egypt, Stanford 2019. 
Für das 20. Jahrhundert argumentiert Christian Pfister, Professor Emeritus für Wirtschafts, Sozial- und Klimageschichte sowie Gründungspräsident der ESEH, ${ }^{35}$ für eine Epochenbildung, die sich an der gesellschaftlichen Energienutzung orientiert. ${ }^{36}$ Pfister sieht eine Epochenschwelle in den 1950er-Jahren, am Übergang von einer kohlebasierten Industriegesellschaft in eine erdölbasierte Konsumgesellschaft. ${ }^{37}$ Im Kern argumentiert Pfister mit Herman Daly, einem Pionier der Ökologischen Ökonomie, dass eine nachhaltig wirtschaftende Gesellschaft einerseits nicht mehr natürliche Ressourcen verbrauchen dürfe, als durch natürliche Prozesse nachgebildet werden; andererseits dürften die Emissionen pro Zeiteinheit die Verarbeitungskapazität von Ökosystemen nicht übersteigen. ${ }^{8}$ Geschehe dies, träten Umweltschäden auf. Immerhin konzentrierten sich diese vor 1950 noch auf das Umland von Industriegebieten und Städten und waren reversibel; etwa der Smog in London. ${ }^{39}$ An Nachhaltigkeit im geschilderten Sinne war mit der Allianz aus Erdöl und Verbrennungsmotoren nach 1950 nicht mehr zu denken. ${ }^{40}$ Warum? Erdöl ist in der Verbrennung zwar deutlich sauberer als Kohle. Die Verbrennung einer stetig wachsenden Menge von Erdöl hat aber eine exponentielle Zunahme der $\mathrm{CO}_{2}$-Emissionen zur Folge, die mittlerweile bestimmte Elemente des globalen Klimasystems an sogenannte Kipppunkte zu bringen droht, die irreversibel sind. ${ }^{41}$

Wie aber setzte sich Erdöl bei gleichzeitiger Verdrängung der Kohle durch? Im Kern von Pfisters Ausführungen steht ein Vergleich von Energiepreisen und den Lebenshaltungskosten der Bevölkerung der Schweiz: Vor 1945 entwickelten sich die Ausgaben für Energie etwa parallel zu den Lebenshaltungskosten, nach 1950 wurde Energie relativ zu anderen Gütern und Dienstleistungen immer billiger. ${ }^{42}$ Niedrige Preise regten VerbraucherInnen zum verschwenderischen Umgang mit Energie und damit auch mit allen anderen Ressourcen, die mit dieser billigen Energie bewegt wurden, an. Die Nebenwirkungen beschreibt er mit dem Begriff „1950er Syndrom“ als Platzhalter für ein ganzes Bündel an Umweltproblemen, das im Wesentlichen auf

35 Christian Pfister, Universität Bern, URL: https://www.hist.unibe.ch/ueber_uns/personen/pfister_ christian/index_ger.html (abgerufen 12.08.2020).

36 Pfister, Das 1950er, 72.

37 Ebd.

38 Ebd.

39 Peter Brimblecombe, The Big Smoke. A history of air pollution in London since medieval times, New York 1987.

40 Pfister, Das 1950er, 74.

41 Johan Rockström, A safe operating space for humanity, in: Nature 461 (2009), 472-475.

42 Pfister, Das 1950er, 83. 
eine Ursache zurückzuführen ist: stetig zunehmender Erdölverbrauch und relative Verbilligung der gesellschaftlich nutzbaren Energie nach $1950 .{ }^{43}$

Die Idee des „1950er Syndroms“ wurde vor allem von deutschen Umwelthistorikern angezweifelt. Frank Uekötter meinte: „Wenn es einen Preis gäbe für den am unglücklichsten gewählten Begriff der umwelthistorischen Forschung, dann wäre das ,1950er Syndrom' ein heißer Kandidat."44 In eine ähnliche Kerbe schlug auch Patrick Kupper. Die meisten ZeitgenossInnen dürften die „gesellschaftlichen Entwicklungen in den ,langen 1950er Jahren' [...] kaum als krankhaft erlebt haben“.45 Trotz der angeführten Kritik verneinen heute nur noch wenige UmwelthistorikerInnen die große Bedeutung der 1950er-Jahre für die Periodisierung umwelthistorischer Forschung. Im Gegenteil, die Idee einer profunden Änderung von Gesellschaft-Natur-Verhältnissen in den 1950er-Jahren erfährt seit 2000 neuen Aufwind. Die Frage lautete nun: War die Menschheit zu einer geologisch relevanten Kraft geworden und würde dies die Ausrufung eines neuen Erdzeitalters (Anthropozän) rechtfertigen? UmweltwissenschaftlerInnen begannen seit 2005 von der „Großen Beschleunigung“ zu sprechen. ${ }^{46}$ Diese sei von der Nutzung von billigem Erdöl, aber auch durch die Hegemonie der USA und internationaler Organisationen, wie des Bretton-Woods-Systems, der Weltbank und der OECD, angetrieben, deren Zweck die Beschleunigung des Wirtschaftswachstums sei. ${ }^{47}$ Eine systematische, zeithistorisch informierte Aufarbeitung der treibenden Kräfte und Akteure, Gewinner und Verlierer der „Großen Beschleunigung“ steht bis dato allerdings aus. ${ }^{48}$

Auch die späten 1960er- und frühen 1970er-Jahre haben Potenzial für die Umweltgeschichtsschreibung, das für Österreich aber kaum genutzt wurde. Naturschutz- und Protestbewegungen waren bis dahin primär vom bürgerlich-kulturkonservativen Milieu getragen und wurden dann von einer eher linken Wachstumskritik

43 Ebd., 74.

44 Frank Uekötter, Umweltbewegung zwischen dem Ende der nationalsozialistischen Herrschaft und der „ökologischen Wende“: Ein Literaturbericht, in: Historische Sozialforschung 28 (2003) 1/2, 270-289, 277.

45 Patrick Kupper, Die „1970er Diagnose“. Grundsätzliche Überlegungen zu einem Wendepunkt der Umweltgeschichte, in: Archiv für Sozialgeschichte 43 (2003), 325-348, 327.

46 Will Steffen/Wendy Broadgate/Lisa Deutsch/Owen Gaffney/Cornelia Ludwig, The trajectory of the Anthropocene. The Great Acceleration, in: The Anthropocene Review 2 (2015) 1, 81-98, 82.

47 Will Steffen/Jacques Grinevald/Paul Crutzen/John McNeill, The Anthropocene. Conceptual and historical Perspectives, in: Philosophical Transaction of the Royal Society A 369 (2011), 842-867, 850 .

48 Richard Lane, The American Anthropocene. Economic Scarcity and Growth during the Great Acceleration, in: Geoforum 99/2019, 11-21. 
überlagert. ${ }^{49}$ Letztere wurde auch vom Club of Rome angestoßen, der damals neue EDV-gestützte Methoden einsetzte, um Wachstums- und Ressourcenszenarien zu errechnen. ${ }^{50}$ Die Publikation der Ergebnisse war von zahlreichen Kontroversen begleitet. Die Einforderung von Wachstumsgrenzen schlug sich aber in der Arbeit von Nichtregierungsorganisationen, des amtlichen Natur- und Umweltschutzes sowie der Raum- und Regionalplanung nieder. ${ }^{51}$

An Österreichs Universitäten wurden ab den 1970er-Jahren erstmals Studiengänge für Ökosystemforschung eingerichtet, was die bis dahin als statisch konzipierten Naturvorstellung der Naturschutz- und Umweltbewegten dynamisierte..$^{52}$ Patrick Kupper spricht von einer wissenschaftlichen Revolution im Kuhn'schen Sinne, die eine an der Kybernetik und Systemtheorie angeleitete Konzeption der Mensch-Umwelt-Beziehungen erlaubte, aber auch die Kategorien der „Schutzwürdigkeit" in den ökologisch motivierten sozialen Bewegungen neu definierte. ${ }^{53}$ An

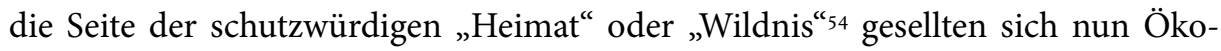
systeme, „,in denen ,biologische Gleichgewichte herrschten und sich ,(natürliche) Kreisläufe' abspielten“.55 Gesellschaftspolitisch wirksam wurden diese Natur- und Umweltbilder in einer sehr unübersichtlichen Vielzahl an Organisationen, die ihre Mitglieder aus dem Milieu der „1968er“-Bewegung rekrutierten und maßgeblich zu den verschiedenen Natur- und Umweltschutzprotesten, etwa im Bereich der Wasser- und Kernkraft, beitrugen. Anfang der 1980er-Jahre institutionalisierten sich diese zivilgesellschaftlichen Proteste im politischen Spektrum Österreichs mit der Gründung der ersten Grün-Parteien, der Alternativen Liste Österreichs (ALÖ) und der Vereinten Grünen Österreichs (VGÖ)..$^{56}$

49 Rolf Peter Sieferle, Fortschrittsfeinde? Opposition gegen Technik und Industrie von der Romantik bis zur Gegenwart, München 1984.

50 Matthias Schmelzer, Born in the corridors of the OECD. The forgotten origins of the Club of Rome, transnational networks, and the 1970 os in global history, in: Journal of Global History 12 (2017) 1, 26-48.

51 Heike Egner, Theoretische Geographie, Darmstadt 2010, 94; Robert Groß, Die Beschleunigung der Berge. Eine Umweltgeschichte des Wintertourismus in Vorarlberg/Österreich (1920-2010), Köln 2019, 259-266.

52 Ebd.

53 Kupper, 1970er, 338.

54 Martin Schmid/Ortrun Veichtlbauer, Vom Naturschutz zur Ökologiebewegung. Umweltgeschichte Österreichs in der Zweiten Republik, Wien/Innsbruck 2006, 16.

55 Kupper, $1970 e r, 338$.

56 Robert Kriechbaumer, Nur ein Zwischenspiel (?). Die Geschichte der Grünen in Österreich von den Anfängen bis 2017, Wien 2018. 
Während in der Umweltgeschichtsschreibung die 1950er-Jahre als Epochenschwelle wenig umstritten sind, werden die Umbrüche der 1970er-Jahre in der österreichischen Umweltgeschichte weniger rezipiert. Warum? Die Umweltgeschichte legte ihre Forschungsinteressen auf langfristige Prozesse. Wer sich intensiver mit Natur- und Umweltschutzkonflikten beschäftigt, wird rasch zu dem Schluss kommen, dass diese zwar imstande sind, die bereits zitierten, dröhnende[n] Ereignisse ${ }^{{ }^{57}}$ zu erzeugen, an biophysischen Austauschprozessen, konkret am weiter steigenden Material- und Energieverbrauch längerfristig in der Regel aber wenig ändern. Entkopplungseffekte zwischen Wirtschaftswachstum und Materialverbrauch in dieser Phase sind wohl eher eine Folge künstlicher Ressourcenverknappung (Stichwort: „Ölpreisschock“) als erfolgreicher Umweltproteste und der sich ab damals etablierenden Umweltpolitik. ${ }^{58}$ In den $1970 e r-J a h r e n$ habe sich zwar die gesellschaftliche Wahrnehmung radikal verändert, ein Umbruch im Sinne einer Epochenschwelle sei aber nicht gegeben, so Patrick Kupper. Dieser Begriff müsse für die großen, gesellschaftsgeschichtlichen Umbrüche reserviert bleiben. ${ }^{59}$

\section{Treiber des Wandels: Der Umbau des Energiesystems}

Energie war und ist ein zentrales Thema der Umweltgeschichte, besonders in Europa. ${ }^{60}$ Die große Bedeutung rührt daher, dass Energie und der historische Wandel von Energieträgern zentral für die Analyse des Verhältnisses von Gesellschaften zu ihrer natürlichen Umwelt sind. Dieses Verhältnis darf aber nicht deterministisch, sondern muss als eine Bedingung der Möglichkeit von Gesellschaft und ihrem Wandel gedacht werden. Die Bedeutung von Energie wird in umwelthistorischen Arbeiten besonders an der Konzeptualisierung der Industrialisierung sichtbar, das fundamental vom Verständnis der übrigen Geschichtswissenschaften abweicht. So unterscheiden etwa wirtschafts- und sozialhistorische Zugänge eine erste, zweite und oft auch weitere industrielle Revolutionen, um die Industrialisierung - als sozialen Prozess, in dem technische Innovation, Wirtschaftswachstum, neue Verkehrsmittel und -wege

57 Boutier/Lüttenberg, Braudel.

58 Marina Fischer-Kowalski/Mark Swilling/Ernst Ulrich von Weizsäcker/Yong Ren/Yuichi Moriguchi/Wendy Crane/Fridolin Krausmann/Nina Eisenmenger/Stefan Giljum/Peter Hennicke/Rene Kemp/Paty Romero Lankao u. a., Decoupling natural resource use and environmental impacts from economic growth. A report of the International Resource Panel, URL: file://C:/Users/Admin/ Downloads/decoupling_report_english.pdf (abgerufen 27.10.2020).

59 Kupper, $1970 e r, 348$.

60 McNeill, Observations, 19. 
sowie die Entfaltung des Kapitalismus und damit verbundene soziale Bewegungen zusammenwirken - historisch zu gliedern. ${ }^{61}$

Seit der Institutionalisierung der Umweltgeschichte in Österreich arbeiteten UmwelthistorikerInnen an einem durch das Energiesystem informierten Blick auf die Industrialisierung, der in aller Kürze folgendermaßen skizziert werden kann: In Großbritannien begann sich im 18. Jahrhundert die Kohlenutzung zu verbreiten und verdrängte vor allem biomassebasierte Energieträger, im Grunde alle Ernteprodukte von Landund Forstwirtschaft. ${ }^{62}$ Die Kohlenutzung setzte nicht nur technologischen Wandel in der Energiekonversion voraus, sondern führte zudem zu einem enorm wachsenden Primärenergieverbrauch auf der Basis nichtnachwachsender, fossiler Rohstoffe. Rolf Peter Sieferle bemühte in diesem Zusammenhang auch das Sprachbild des „unterirdischen Waldes". ${ }^{63}$ Eine weitere Erkenntnis des umwelthistorischen Zugangs zur Industrialisierung ist, dass die großflächige Nutzung fossiler Energieträger eine Entkopplung vom Territorium als limitierendem Faktor für Wirtschaftswachstum ermöglichte; man spricht auch vom „Ende der Fläche“.64 Die Forstwirtschaft konnte zwar durch rationales Management die Energieausbeute steigern, blieb längerfristig und prinzipiell aber immer an die Reproduktionszyklen der Agrarökosysteme gebunden. Die Nutzung des „unterirdischen Waldes“ löste diesen Flächenbezug von Energiesystemen bis in die Gegenwart auf, so die umwelthistorische Lesart der Industrialisierung.

Die fossilenergetisch betriebene Flächenemanzipation von Energiesystemen verbreitete sich seit der Mitte des 19. Jahrhunderts über Kontinentaleuropa und Nordamerika, zeigt aber durchaus regionale Charakteristika, da die Ressourcenausstattung und politökonomischen Rahmenbedingungen regional variierten. In den USA setzte etwa bereits Mitte des 19. Jahrhunderts die kommerzielle Nutzung von Erdöl ein, verstetigte sich Anfang des 20. Jahrhunderts und löste in den 1930er-Jahren die Kohle als dominierenden Energieträger ab. ${ }^{65}$ Seit den 1940er-Jahren ergänzte Erdöl

61 Jürgen Osterhammel, Die Verwandlung der Welt. Eine Geschichte des 19. Jahrhunderts, München 2009, 916.

62 Heinz Schandl/Fridolin Krausmann, The great transformation. A socio-metabolic reading of the industrialization of the United Kingdom, in: Marina Fischer-Kowalski/Helmut Haberl (Hg.), Socioecological Transitions and Global Change. Trajectories of Social Metabolism and Land Use, Cheltenham/Northhampton (MA) 2007, 61-83.

63 Rolf Peter Sieferle, Der unterirdische Wald. Energiekrise und Industrielle Revolution, München 1982.

64 Rolf Peter Sieferle/Fridolin Krausmann/Heinz Schandl/Verena Winiwarter, Das Ende der Fläche. Zum gesellschaftlichen Stoffwechsel der Industrialisierung, Köln/Weimar/Wien 2006.

65 Sylvia Gierlinger/Fridolin Krausmann, The Physical Economy of the United States of America Extraction, Trade, and Consumption of Materials from 1870 to 2005, in: Journal of Industrial Ecology 16 (2013) 3, 365-377. 
auch das europäische Energiesystem, angetrieben vor allem durch die Erschließung der enormen Erdölvorkommen im Mittleren Osten und dem geopolitischen Interventionismus der USA. ${ }^{66}$ In den 1960er-Jahren lösten Erdöl und Erdgas in Europa die Kohle als wichtigsten Energieträger ab. ${ }^{67}$ Trotzdem sich Kohle, Erdöl und Erdgas in puncto Energiedichte, regionaler Verteilung und Transportierbarkeit stark unterscheiden, sind alle drei entscheidende Triebkräfte für die prinzipielle Nichtnachhaltigkeit von Industriegesellschaften. Die konsequente Anwendung dieses Ansatzes prägt viele österreichische umwelthistorische Arbeiten und ist in Anlehnung an Uwe Lübken als „komplementäre[r] Entwurf zum ,cultural turn' [zu] lesen, der die stoffliche Grundlage kultureller Produktionen, gerade derjenigen des urbanen Lebens, oftmals in Vergessenheit geraten lässt" .68

Große Erzählungen, wie die geschilderte, haben zwar große Anziehungskraft, haben es aber auch nötig, mittels konkreter Entwicklungen konterkariert und so einer Plausibilitätsprüfung unterzogen zu werden. In den frühen Umweltgeschichten zu Österreich wurden Energieflüsse vor allem quantitativ modelliert. ${ }^{69}$ Der Vorteil eines solchen Ansatzes ist, dass verschiedene Sektoren, wie Energie, Landwirtschaft, Industrie, funktional integriert betrachtet werden können..$^{70}$ Eine solche Perspektive hat aber auch die Tendenz, die gesellschaftlichen Energiesysteme gewissermaßen zu entmaterialisieren. ${ }^{71}$ Anders gesagt: Gesellschaftliche Praktiken, politökonomische Rahmenbedingungen und konkrete materielle Infrastrukturen, die ein Energiesys-

66 David S. Painter, The Marshall Plan and Oil, in: Cold War History 9 (2009) 2, 159-175.

67 Astrid Kander/Paolo Malanima/Paul Warde, Power to the people. Energy in Europe over the last five centuries, Princeton 2013.

68 Uwe Lübken, Rezension von Rolf Peter Sieferle/Fridolin Krausmann/Heinz Schandl/Verena Winiwarter (Hg.), Das Ende der Fläche. Zum gesellschaftlichen Stoffwechsel der Industrialisierung, in: sehepunkte 7 (2007) 9, URL: http://www.sehepunkte.de/2007/09/9983.html (abgerufen 20.01.2020).

69 Fridolin Krausmann/Helmut Haberl, Der Prozess der Industrialisierung aus der Perspektive des energetischen Stoffwechsels. Sozioökonomische Energieströme in Österreich 1830-1995, in: Ökologische Ökonomie 41 (2002) 2, 177-201; Fridolin Krausmann, Eine Stadt und ihr Hinterland. Wiens Energiestoffwechsel 1800-2006, in: Simron J. Singh/Helmut Haberl/Marian Chertow/Michael Mirtl/Martin Schmid (Hg.), Sozial-ökologische Langzeitforschung. Untersuchungen zu den Wechselwirkungen zwischen Gesellschaft und Natur über räumliche und zeitliche Skalen hinweg, Dordrecht 2013, 247-268.

70 Simone Gingrich/Petra Kuskova/Fridolin Krausmann, Langfristige Veränderungen der $\mathrm{CO}_{2}$ Emissionen in Österreich und der Tschechoslowakei. Identifizierung der Treiber von Umweltbelastungen, in: Energiepolitik 39 (2011) 2, 535-543; Fridolin Krausmann/Helmut Haberl, Land-use change and socioeconomic metabolism. A macro view of Austria 1830-2000, in: Fischer-Kowalski/ Haberl (Hg.), Socioecological Transitions, 31-59.

71 Andrew Watson, Editor's Note. The Material Realities of Energy History, in: Canadian Journal of History 53 (2018) 3, 373-394; Odinn Melsted/Irene Pallua, The Historical Transition from Coal to 
tem ausmachen, wurden in der österreichischen Umweltgeschichtsschreibung kaum berücksichtigt. Dieses Defizit zu beheben, ist nicht nur ein wichtiges Forschungsdesiderat österreichischer Umweltgeschichtsschreibung, es setzt auch die Kooperation von zeit- und umwelthistorischen Methoden und Konzepten voraus, sofern damit auch ein Beitrag zu Nachhaltigkeitsdebatten geleistet werden soll.

Energie wird im Alltag erst an der Schnittstelle zwischen Distribution (zum Beispiel Tankstelle) und Service (zum Beispiel Mobilität) erlebbar, und dies vor allem dann, wenn die Treibstoffpreise steigen. ${ }^{72}$ Genau an dieser Schnittstelle lassen sich auch die eher wirtschafts- und sozialhistorischen Arbeiten zur Elektrifizierung und Elektrizitätsnutzung in Österreich einordnen. ${ }^{73}$ Was die österreichische Umweltgeschichtsschreibung aber lange ausgeblendet hat, sind die weitläufig verzweigten materiellen Infrastrukturnetzwerke, die das Rückgrat eines jeden Energiesystems bilden. Zeitgenossen nehmen diese in aller Regel nur in Konflikt- oder Störfällen, die zu Versorgungsengpässen führen, wahr. Im Normalbetrieb sind diese materiellen Infrastrukturen eher aus dem gesellschaftlichen Bewusstsein verdrängt. ${ }^{74}$ Dort fristen sie eine stille Existenz, zeigen aber Handlungsmächtigkeit, indem sie gesellschaftliche Praktiken strukturieren oder deren Wandel behindern, wie Debatten um die Dekarbonisierung des Energiesystems zeigen; und dies obwohl das globale Energiesystem das größte Infrastrukturnetzwerk bildet, dass je von Menschen errichtet wurde. ${ }^{75}$

Die österreichische Zeitgeschichtsschreibung hat indes ihre eigene Tradition im Umgang mit der Energiefrage, vor allem der Wasserkraft. Nach dem Ersten Weltkrieg hatte Österreich den Zugang zu den Kohlevorkommen Böhmens und Schlesiens verloren. Die Wasserkraft war in Österreich die wichtigste Quelle für die Energieversorgung von Industrie, Gewerbe und Transport. Ausgehend von den westlichen Bundesländern gewann die Wasserkrafterzeugung Anfang und Mitte des 20. Jahrhunderts als treibende Kraft der Industrialisierung an Bedeutung. In bester

Hydrocarbons. Previous Explanations and the Need for an Integrative Perspective, in: ebd., 395422.

72 Pfister, Das 1950er, 83.

73 Roman Sandgruber, Das elektrische Jahrhundert. Die Wirtschafts- und Sozialgeschichte der Elektrizitätsausnutzung in Österreich, in: Evelyn Gröbl-Steinbach (Hg.), Licht und Schatten. Dimensionen von Technik, Energie und Politik, Wien 1990, 33-48.

74 Dirk van Laak, Infrastrukturgeschichte, in: Geschichte und Gesellschaft 27 (2001) 3, 367-393; Martin Knoll, Nil sub sole novum oder neue Bodenhaftung? Der material turn und die Geschichtswissenschaft, in: Neue Politische Literatur 18 (2014) 2, 191-208.

75 Karen C. Seto/Steven J. Davis/Ronald B. Mitchell/Eleanor C. Stokes/Gregory Unruh/Diana ÜrgeVorsatz, Carbon Lock-In. Types, Causes, and Policy Implications, in: Annual Review of Environment and Resources 41 (2016) 2, 425-452. 
zeithistorischer Tradition finden sich hier bedeutende Beiträge, die sich an den politischen Zäsuren Österreichs im 20. Jahrhundert orientieren, wie etwa die Arbeiten zur NS-Zwangsarbeit in der „Ostmark" ${ }^{\text {"76 }}$ oder jene zum Speicherkraftwerk Kaprun. ${ }^{77}$ Wer sich aber aus diesen Arbeiten umwelthistorischen Erkenntnisgewinn erhofft, der wird eher enttäuscht sein, denn obwohl hydroelektrische Bauten immer mit gewässer- und landschaftsökologischen Konsequenzen verbunden sind, werden diese nicht thematisiert.

Die Umweltgeschichte hat in den 1990er-Jahren begonnen, Umweltfragen rund um die österreichischen Wasserkraftwerke unter den Topoi „weißes Gold“ oder „weiße Kohle“ zu bearbeiten. ${ }^{78}$ Seither ist eine Reihe an Arbeiten zu den österreichischen Alpen und ihrer hydroelektrischen Erschließung ${ }^{79}$ erschienen; auch teilweise überlappend zur Umweltgeschichte österreichischer Flüsse - hier vor allem $\mathrm{zu}$ kleinen Laufkraftwerken im ländlichen Raum, ${ }^{80}$ der Entwicklung von Grenzflüssen, ${ }^{81}$ aber auch der Erschließung der Donau. ${ }^{82}$ Das Erkenntnisinteresse der umwelthistorischen Arbeiten verlagerte sich dabei spürbar von der Technikgeschichte hin zu stärker interdisziplinären Fragestellungen, bei denen etwa wissenshistorische mit ökologischen oder hydrologischen Aspekten integriert betrachtet wurden. ${ }^{83}$

Im Gegensatz zur deutschen Umweltgeschichtsschreibung hat sich die österreichische kaum für die sozialen Proteste der 1970er- und 1980er-Jahre als einen kon-

76 Oliver Rathkolb/Florian Freund (Hg.), NS-Zwangsarbeit in der Elektrizitätswirtschaft der „Ostmark“ 1938-1945. Ennstalwerke - Kaprun - Donaukraftwerke - Ypps-Persenbeug - Ernsthofen, Wien/Köln/Weimar 2014.

77 Georg Rigele, Das Tauernkraftwerk Glockner-Kaprun. Neue Forschungsergebnisse und offene Fragen, in: Blätter für Technikgeschichte 59 (1997), 55-94.

78 Peter Staudacher, Das weiße Gold der Alpen. Vom physikalischen Phänomen zum Mythos, in: Rudolf Ardelt (Hg.), Katalog zur Ausstellung. Aus Dorfenger Welt ins Weltweite Dorf, Steyr 1995, $33-48$.

79 Marc Landry, Katalysator für den Übergang. Der Anschluss, Kaprun, und ein doppelter Energieübergang, 1938-1955, in: RCC Perspectives 2014/5, 43-52.

80 Angelika Schoder, Eine Geschichte des Kieselstein- und Schlammsedimenttransports, der Wasserkraft und der technischen Expertise an der österreichischen Donau und ihren Nebenflüssen, in: Transylvanian Review of Systematical and Ecological Research 18 (2016) 2, 1-18.

81 Ute Hasenöhrl, „Weiße Kohle“ oder „Ausbeutung der Natur“? Konflikte um die Nutzung der Wasserkräfte im (Vor)Alpenraum am Beispiel bayerisch-österreichischer Grenzflüsse, in: Bohemia 54 (2014) 1, 119-141.

82 Ortrun Veichtlbauer, Donau-Strom. Über die Herrschaft der Ingenieure, in: Christian Reder/Erich Klein (Hg.), Graue Donau - Schwarzes Meer, Wien 2008, 170-195.

83 Angelika Schoder/Martin Schmid, Where Technology and Environmentalism Meet. The Remaking of the Austrian Danube for Hydropower, in: Hrvoje Petrić/Ivana Žebec Šilj (Hg.), Environmentalism in Central and Southeastern Europe. Historical Perspectives, London 2017, 3-20. 
stituierenden Faktor österreichischer Umweltbewegungen und politischer Parteien interessiert. Die beiden größten Projekte, die nach heftigen Protesten einer breiten zivilgesellschaftlichen Bewegung aufgegeben wurden, waren das Atomkraftwerk Zwentendorf, ${ }^{84}$ das 1978 in einer Volksabstimmung abgelehnt wurde, und das 1984 abgewehrte Wasserkraftwerk Hainburg ${ }^{85}$. Solche Umweltkonflikte waren sowohl demokratisch relevant, was zum Beispiel zur Gründung der österreichischen Grünen führte, als auch für den Naturschutz: Nicht nur in Hainburg, ${ }^{86}$ sondern auch im Alpenraum trug der Kampf gegen Wasserkraftwerke zur späteren Gründung eines Nationalparks bei. Die politische Relevanz von Umweltbewegungen, die gegen große Energieinfrastrukturen kämpfen, stellt aber nach wie vor ein Desiderat umwelthistorischer Forschung dar, das ohne zeithistorische Expertise kaum zu bewerkstelligen ist. $^{87}$

\section{Transformative Technologie: Transport und Mobilität}

Transport und Mobilität sind „mit einem bestimmten Aufwand an Energie und Ressourcen verbunden. [...] Effizienz und Rentabilität von Transporten unterliegen den Grenzen des energetischen Regimes innerhalb dessen sich eine Gesellschaft bewegt." ${ }^{\circ 8}$ Konkret bedeutet dies, dass deren Funktionsweise sich mit der Nutzung fossiler Energieträger von Limitierungen der Biomasse lösen konnte. Österreich hat europaweit eines der dichtesten Straßennetze. ${ }^{89}$ Dementsprechend groß ist der Flächenverbrauch durch Verkehrsinfrastruktur von 2.060 Quadratkilometer; zum Vergleich dazu: Das Bundesland Vorarlberg umfasst 2.601,12 Quadratkilometer.90

84 Peter Weish, Zwentendorf aus der Sicht eines Zeitzeugen, in: Karl Brunner/Petra Schneider (Hg.), Umwelt Stadt. Geschichte des Natur- und Lebensraumes Wien, Wien 2005, 384-385.

85 Gernot Neuwirth, Hainburg aus der Sicht eines Zeitzeugen, in: Karl Brunner/Petra Schneider (Hg.), Umwelt Stadt. Geschichte des Natur- und Lebensraumes Wien, Wien 2005, 390-391.

86 Verena Winiwarter/Sophia Rut, Österreich ergrünt. Die Besetzung der Hainburger Au, in: Heinz Fischer/Andreas Huber/Stephan Neuhäuser (Hg.), 100 Jahre Republik. Meilensteine und Wendepunkte 1918-2018, Wien 2018, 203-216.

87 Martin Schmid/Ortrun Veichtlbauer, Vom Naturschutz zur Ökologiebewegung. Umweltgeschichte Österreichs in der Zweiten Republik, Innsbruck 2006.

88 Ebd.

89 Lukas Pawek, In Österreich um 30 Prozent mehr Autobahnen als in Deutschland, Ökonews.at, URL: https://www.oekonews.at/?mdoc_id=1072267 (abgerufen 09.05.2019).

90 Verkehr in Österreich verbraucht bereits 5 -fache Fläche Wiens, Umweltbundesamt VCÖ, URL: https://www.vcoe.at/news/details/vcoe-verkehr-in-oesterreich-verbraucht-bereits-5-fache-flaechewiens (abgerufen 09.05.2019). 
Neben dem enormen Flächenverbrauch sind die Errichtung und der Erhalt der Verkehrsinfrastruktur von einer ganzen Reihe sozialökologischer Nebenwirkungen begleitet, wie Bodenversiegelung, verminderte Wasseraufnahmekapazität, Ökosystemzerschneidung und Biodiversitätsrückgang..$^{11}$ Außerdem werden beim Bau und Erhalt viele $\mathrm{CO}_{2}$-Emissionen freigesetzt. ${ }^{92}$ Der Blick auf die Verkehrsströme zeigt ein Bild der totalen Automobilisierung. 2016 waren in Österreich rund 6,9 Millionen Kraftfahrzeuge zugelassen, mehrheitlich Personenkraftwagen. Der Verkehrssektor zählt zu einem der am stärksten von Erdöl abhängigen Lebensbereiche überhaupt. ${ }^{93}$ Entsprechend verheerend ist auch sein Beitrag zu der nationalen $\mathrm{CO}_{2}$-Bilanz. ${ }^{94}$ Problematisch ist zudem, dass der Verkehrs- und Transportsektor deutlich rascher wächst als beispielsweise das Volkseinkommen. Angesichts der geschilderten Zahlen müsste man eigentlich davon ausgehen, dass es sich dabei um ein für die Umweltgeschichte sehr attraktives Themenfeld handeln müsste. Genau das Gegenteil ist der Fall.95 Transport und Mobilität wurden auch in den Nachbarländern eher von der Technik, Wirtschafts- und Sozialgeschichte oder den Teildisziplinen der Geographie berücksichtigt als von der Umweltgeschichte..$^{96}$ Einzig der Historiker Sándor Békési bemühte sich um ein umwelthistorisch informiertes Verständnis aus Stadtentwicklung und Mobilität in der Stadt Wien. ${ }^{97}$ Die folgenden Überlegungen haben daher eher kursorischen Charakter.

91 Horst Leitner/Roland Grillmayer/Daniel Leissing/Gebhard Banko/Klara Brandl/Maria StejskalTiefenbach/Klaus Peter Zulka (Hg.), Lebensraumvernetzung Österreich. Grundlagen - Aktionsfelder - Zusammenarbeit, Wien 2016, 9, URL: http://www.lebensraumvernetzung.at/publikationen/ LRV_Endbericht_Teil\%201_web.pdf (abgerufen 20.01.2020).

92 Fridolin Krausmann/Dominik Wiedenhofer/Christian Lauk/Willi Haas/Hiroki Tanikawa/Tomer Fishman/Alessio Miatto/Heinz Schandl/Helmut Haberl, Global socioeconomic material stocks rise 23 -fold over the 2oth century and require half of annual resource use, in: PNAS 114 (2017) 8, $1880-1185$.

93 KFZ-Bestand 2018, Statistik Austria, URL: https://www.statistik.at/web_de/statistiken/energie_ umwelt_innovation_mobilitaet/verkehr/strasse/kraftfahrzeuge_-_bestand/index.html (abgerufen 09.05.2019).

94 Treibhausgase, Umweltbundesamt, URL: http://www.umweltbundesamt.at/umweltsituation/luft/ treibhausgase/ (abgerufen 09.05.2019).

95 Dietmar Klenke, Das automobile Zeitalter. Die umwelthistorische Problematik des Individualverkehrs im deutsch-amerikanischen Vergleich, zit. n. Winiwarter/Knoll, Umweltgeschichte, 209.

96 Ebd.

97 Sándor Békési, Verkehr in Wien. Personenverkehr, Mobilität und städtische Umwelt 1850-2000, in: Karl Brunner/Petra Schneider (Hg.), Umwelt Stadt. Geschichte des Natur- und Lebensraumes Wien, Wien 2005, 92-103; Sándor Békési, Stürmisch und unaufhaltsam? Motorisierung und Politik im Wien der $50 e r$ Jahre, in: Christian Rapp (Hg.), Spurwechsel, Wien 2006, 76-83. 
Die Berg- und Panoramastraßen des österreichischen Alpenraums standen vor zwanzig Jahren schon im Fokus der Arbeiten von Georg Rigele. ${ }^{8}$ Deren Funktion lag primär in der Verfügbarmachung alpiner, als Natur imaginierter Landschaften für touristische und automotorisierte Praktiken, die von der ökonomischen Rationalität des Alltags befreit waren und der nationalistisch konnotierten, ästhetischen Überhöhung von Landschaft dienten. Der Zusammenhang aus „Naturerfahrung und Verkehrslandschaften" ${ }^{\text {"99 }}$ spielte auch im höherrangigen Straßennetz eine Rolle. ${ }^{100}$ Nach dem Zweiten Weltkrieg war es in der Verkehrsplanung aber zu einer wahrnehmbaren „Interessensverschiebung weg von der Landschaftsästhetik hin “"101 zur rationalen Planung des Verkehrsflusses und damit verbunden dem Management einer steigenden Zahl von VerkehrsteilnehmerInnen gekommen. ${ }^{102}$ Ein Beitrag von Martin Knoll zu kritischen Übergängen in Mobilitätsnetzwerken fokussiert die Knotenpunkte verschiedener Mobilitätsformen in Wintersportregionen. Diese müssen laut Knoll infrastrukturell auf die Synchronisation verschiedener Mobilitätsformen ausgerichtet werden. ${ }^{103}$ Knoll unterstreicht hier den sozionaturalen Charakter von Mobilitätsinfrastruktur. Dies kann auch als Anregung für großräumiger angelegte zeit- und umwelthistorische Analysen von Knotenpunkten in Waren- und Gütertransportnetzwerken dienen. ${ }^{104}$

Ein weiterer, für die österreichische Umwelt- und Zeitgeschichte relevanter Beitrag wird von TechnikhistorikerInnen unter dem Schlagwort „hidden integration“ behandelt und befasst sich mit der Rolle transnationaler Infrastrukturnetzwerke für die europäische Integration. ${ }^{105}$ Frank Schipper zeigt, wie im Zuge des „MarshallPlans" auf die Formation europäischer Verkehrsnetzwerke eingewirkt wurde, um Wirtschaftswachstum und die europäische Integration zu befördern. Ein entsprechendes Straßenangebot sollte die Absätze in der Automobilindustrie (und wohl

98 Georg Rigele, Sommeralpen - Winteralpen. Veränderungen im Alpinen durch Bergstraßen, Seilbahnen und Schilifte in Österreich, in: Ernst Bruckmüller/Verena Winiwarter (Hg.), Umweltgeschichte. Zum historischen Verhältnis von Gesellschaft und Natur, Wien 2000, 121-150, 126.

99 Winiwarter/Knoll, Umweltgeschichte, 239.

100 Bernd Kreuzer, Der Bau der Autobahnen und Schnellstraßen, in: Asfinag (Hg.), Das Autobahnnetz in Österreich. 30 Jahre Asfinag, Absam 2012, 11-120.

101 Winiwarter/Knoll, Umweltgeschichte, 239.

102 Ebd.

103 Martin Knoll, Touristische Mobilitäten und ihre Schnittstellen, in: Ferrum 88 (2016), 54-93, 55.

104 Robert Groß/Martin Knoll, Critical Hubs of the Great Acceleration. The Social Ecology of Alpine Tourism in Vorarlberg, Austria after World War II, in: Marc Landry/Patrick Kupper (Hg.), Austrian Environmental History (Contemporary Austrian Studies 27), Innsbruck 2018, 103-133.

105 Thomas J. Misa/Johan Schot, Inventing Europe. Technology and the Hidden Integration of Europe, in: History and Technology 21 (2005) 1, 1-19. 
auch der Treibstoffindustrie) steigern. ${ }^{106}$ Über den Weg des „Marshall-Plans“ nahmen die US-Experten dann auch Einfluss auf nationale Verkehrspolitiken, forcierten gezielt den Ausbau von Fernstraßen und verhalfen damit der Straßenmobilität zu einem Vorsprung gegenüber der Schiene. ${ }^{107}$ Die Beantwortung der Frage, ob über den „Marshall-Plan“ in die längerfristigen Entwicklungen der Verkehrsnetzwerke Einfluss genommen wurde, steht indes für Österreich noch aus.

Galten Straßen bis in die Nachkriegszeit noch als „Lebensadern“, wurden diese in den 1970er-Jahren zu Transportwegen für Blechlawinen umgedeutet. ${ }^{108}$ In Zeiten des wachsenden Skeptizismus gegenüber der Automobilisierung begannen sich dann auch neue Protestbewegungen zu formieren. Exemplarisch soll hier das Projekt „Issues With Europe. A Network analysis of the German-speaking Alpine Conservation Movement (1975-2005)“ dargestellt werden, das derzeit an der LMU München sowie den Universitäten Innsbruck und Basel durchgeführt wird. Im Projekt werden die Auseinandersetzungen um die europäische Alpentransitpolitik in Österreich und der Schweiz untersucht, wobei Fragen der Spannungsfelder und Schnittmengen politischer und zivilgesellschaftlicher Akteure in der Alpenschutzbewegung zwischen 1975 und 2005 bearbeitet werden. Dabei untersucht die Arbeitsgruppe, „wie die Konflikte zwischen Transportpolitik und Alpenschutz auf europäischer Ebene gehandhabt wurden, wobei besonders die Europäische Union und der Europarat im Fokus stehen“." ${ }^{109}$ Man darf gespannt sein, welche Einsichten zur ökologisch motivierten Protestkultur bei transnationalen Verkehrsinfrastrukturgroßprojekten dieses Projekt zutage befördern wird.

\section{Fazit}

Was wollen politische Entscheidungsträger von der Wissenschaft? Diese Frage wurde 2013 rund 1.00o Entscheidungsträgern der US-Regierung gestellt. Das überraschende Ergebnis: Historische Expertise, kombiniert mit Regionalstudien und Politikanalysen, ist besonders gefragt. ${ }^{110}$ Angesichts dessen müsste man meinen, dass

106 Frank Schipper, Changing the face of Europe. European road mobility during the Marshall Plan years, in: The Journal of Transport History 28 (2007) 2, 211-228, 212.

107 Ebd.

108 Winiwarter/Knoll, Umweltgeschichte, 239.

109 Projektbeschreibung siehe Projekt „Issues with Europe“, Universität Innsbruck, URL: https://www. uibk.ac.at/projects/issues-with-europe/ (abgerufen 09.05.2019).

110 Erik Voeten, What do policymakers want from academics?, The Washington Post, URL: https:// www.washingtonpost.com/news/monkey-cage/wp/2013/09/25/what-do-policymakers-wantfrom-academics/ (abgerufen 21.01.2020). 
die Umweltgeschichte mit ihrem räumlich-regionalen Fokus und Zeitgeschichte logische Verbündete an Universitäten sein müssten. Der hier dargelegte Befund zeigt aber, dass genau das Gegenteil zutrifft. Dies ist vermutlich einer spezifischen Institutionalisierung der Umweltgeschichte abseits der Geschichtsinstitute geschuldet. Weitere Hürden liegen auch in den oben diskutierten verschiedenartig gelagerten Erkenntnisinteressen und zeitlichen Zuschnitten von Studien.

Der Blick über den Tellerrand der jeweiligen Disziplinen auf die drängenden Probleme und Krisenerscheinungen unserer Gegenwart legt aber Kooperationsmöglichkeiten und -bedarfe für die Zeit- und Umweltgeschichte nahe. Letztere legen ihren Fokus auf die grundlegenden Bedingungen menschlicher Existenz. ${ }^{111}$ Deren Analyse kann nicht ohne von NaturwissenschaftlerInnen bereitgestelltes Wissen auskommen, sofern sie durch die Oberfläche gegenwärtiger Krisenerscheinungen dringen will. Hier bieten sich UmwelthistorikerInnen der Zeitgeschichte als Verbündete an, da sie es gewohnt sind, naturwissenschaftliche Zugänge kritisch zu lesen, zu hinterfragen und zu historisieren. Solche Kooperationen setzen aber auch voraus, dass das in der Zeitgeschichte nach wie vor vertretene Durkheim'sche Paradigma Soziales sei nur durch Soziales erklärbar - zumindest reflexiv zur Diskussion gestellt wird, nicht nur um adäquater auf die Krisenphänomene unserer Zeit reagieren zu können, sondern auch, damit der wissenschaftliche Nachwuchs ermächtigt wird, sich später eigenständig, reflektiert und historisch fundiert mit Fragen sozialökologischer Nachhaltigkeit auseinanderzusetzen.

111 Sörlin, Contemporaneity, 630. 


\section{Zeitgeschichte und Politikwissenschaft}

Anton Pelinka

\section{Persönliche Vorbemerkung}

1972 wurde mir von der Rechts- und Staatswissenschaftlichen Fakultät der Universität Salzburg die Lehrbefugnis für das Fach Politikwissenschaft erteilt. Der damals (vor dem UOG 1975) nur aus ProfessorInnen bestehenden Kommission, die meine eingereichte Habilitationsschrift überprüfen und beurteilen sollte, gehörten zwei VertreterInnen der akademischen Disziplin Geschichte (Erika Weinzierl, Gerald Stourzh), zwei Vertreter der Politikwissenschaft (Norbert Leser, Franz Martin Schmölz) und ein Vertreter der Rechtswissenschaften (Theo Mayer-Maly) an. Der Grund für diese Zusammensetzung der Kommission war, dass die Habilitationsschrift ${ }^{1}$ interdisziplinär angelegt war. Eben auch deshalb habe ich mich - als Politikwissenschaftler - immer wieder als Grenzgänger zwischen Politikwissenschaft und Zeitgeschichte verstanden.

Als Grenzgänger zwischen Politikwissenschaft und Zeitgeschichte versuchte ich mich auch bei meinen Forschungen über Subhas Chandra Bose, der - neben Mahatma Gandhi und Pandit Nehru - zu den führenden Personen des Indian National Congress (INC) zählte, der allindischen Unabhängigkeitsbewegung. In den Archiven der Hoover Institution an der Stanford University (wo die Dokumente der internen Willensbildung des INC zu finden sind), in den US National Archives (wo die Position der USA - in Abgrenzung zur britischen Politik - gegenüber dem Konzept der indischen Unabhängigkeit unmittelbar vor und während des Krieges zu erforschen ist) und im Österreichischen Staatsarchiv (bezüglich der Unterlagen über Boses Aufenthalt in Österreich, in den 1930er-Jahren) erhielt ich Einblick in Boses politisches Leben: in den Hintergrund seiner Opposition gegen Gandhis Doktrin der Gewaltfreiheit, über seine Jahre in Österreich und seinen Aufenthalt in Berlin 1941 bis 1943 und seine Aktivitäten in Südostasien, wo er 1943 - in Absprache und im Bündnis mit Japan - eine indische Exilregierung etabliert und die Indian Natio-

1 Anton Pelinka, Stand oder Klasse? Die Christliche Arbeiterbewegung Österreichs, 1933 bis 1938, Wien 1972. 
nal Army (INA) aufgestellt hatte, die auf Japans Seite in der Schlussphase des Krieges im Nordosten Britisch-Indiens und in Burma kämpfte.

Das war der zeitgeschichtliche Teil der Forschung. Die vor allem politikwissenschaftlichen Schlussfolgerungen bezogen sich darauf, wie Bose (in diesem Punkt ganz auf der Linie Gandhis und Nehrus) demonstrativ die religiöse und ethnischlinguistische Fragmentierung der indischen Gesellschaft zu überbrücken versuchte durch demonstrative Machtteilung vor allem zwischen den Religionsgemeinschaften, zwischen Hindus, Muslimen und Sikhs. Boses Leben, das in den Wirren der japanischen Kapitulation endete, wurde - in Parallele zu Gandhi und Nehru, die außenpolitisch in den Jahren des Krieges eine ganz andere Position bezogen hatten - zu einem Spiegelbild der sich entwickelnden politischen Kultur Indiens, das seiner Unabhängigkeit entgegenging und zur größten (liberalen) Demokratie der Welt wurde. Am Beispiel von Boses Einfluss können die politischen Strukturen Indiens verdeutlicht werden, wie sie sich 1947 konstituierten und seither - in jahrzehntelang anhaltender Stabilität - weiterentwickelt haben: Indien als eine Demokratie, in der sich das kompetitive Element einer Westminster-Demokratie mit der Kultur des „power sharing“ und einem die sprachliche Vielfalt reflektierenden Föderalismus verbindet. ${ }^{2}$

\section{Forschungs- und Lehrobjekt - nicht wirklich trennbar}

Zeitgeschichte und Politikwissenschaft sind zwar im Alltag des akademischen Forschungs- und Lehrbetriebes voneinander getrennt. Institute oder Abteilungen tragen den Namen Zeitgeschichte oder Politikwissenschaft, die beiden Fächer gehören meistens unterschiedlichen Fakultäten an. Aber zeitgeschichtliche und politikwissenschaftliche Forschung überlappen einander, sie sind nicht prinzipiell abgrenzbar.

Ein Beispiel dafür ist das Forschungsfeld „Austromarxismus“. Norbert Leser habilitierte sich 1969 mit einer Analyse des Austromarxismus ${ }^{3}$ an der Universität Graz und wurde 1971 an die Universität Salzburg als Professor für Politikwissenschaft berufen. Ernst Hanisch, der als Professor für Geschichte an der Universität Salzburg sich vor allem mit Themenstellungen der Zeitgeschichte befasste, stützte sich in der

2 Anton Pelinka, Democracy Indian Style. Subhas Chandra Bose and the Creation of India's Political Culture, New Brunswick 2003.

3 Norbert Leser, Zwischen Reformismus und Bolschewismus. Der Austromarxismus als Theorie und Praxis, Wien 1968. 
Biographie Otto Bauers ${ }^{4}$ auch und wesentlich auf die - politikwissenschaftliche Arbeit Lesers.

Ein anderes, ebenfalls auf Österreich bezogenes Beispiel ist die 1955 durch ein Verfassungsgesetz verankerte „immerwährende Neutralität“ Österreichs. Die Vorgeschichte und die geopolitischen Hintergründe dieser Weichenstellung ist durch (zeit)geschichtliche Forschung ausführlich dargestellt. ${ }^{5}$ Die politikwissenschaftliche Forschung zur österreichischen Außenpolitik kann und muss sich auf diese Erkenntnisse der Zeitgeschichte stützen. ${ }^{6}$

Ähnliche Zusammenhänge zwischen zeitgeschichtlicher und politikwissenschaftlicher Forschung gibt es selbstverständlich überall - auch und gerade im Bereich der Internationalen Politik. Die von Richard Nixon betriebene und von Henry Kissinger umgesetzte Einbindung der Volksrepublik China in eine neu konzipierte geopolitische Ordnung, die anstelle der Bipolarität des „Kalten Krieges“ ein multipolares, „trianguläres“ Arrangement setzen sollte, ist zeitgeschichtlich erforscht.7 Aber ebenso hat die Politikwissenschaft, nicht zuletzt durch Kissinger selbst, durch dessen spezifisch doppelbödiger Rolle als Politikwissenschaftler und Politiker, die Ergebnisse dieser zeitgeschichtlich erforschten politischen Weichenstellung systematisch komprimiert und daraus Wahrscheinlichkeiten für die weltpolitische Zukunft extrapoliert. Kissinger war, als Akteur, Quelle der Zeitgeschichte; und er war nach dem Ende seiner Rolle als politischer Akteur politikwissenschaftlicher Analytiker. ${ }^{8}$

Als in überraschend kurzer Zeit die von Moskau aus kontrollierte „Zweite Welt“ zusammenbrach - von der Öffnung des „Eisernen Vorhangs“ 1989 bis zum Ende der UdSSR 1991 -, da wurde die Abfolge der Ereignisse dokumentiert und analysiert von Vertretern der Zeitgeschichte, etwa von Charles S. Maier. ${ }^{9}$ Die Abfolge der Ereignisse wurde aber auch in Verbindung mit den Mustern internationaler Politik gebracht, die das Verständnis der Geopolitik davor geprägt hatten - etwa zur mit dem Namen George F. Kennan verbundenen Politik des „Containment“, der Ein-

\footnotetext{
4 Ernst Hanisch, Der große Illusionist: Otto Bauer, 1881-1938, Wien 2011.

5 Gerald Stourzh, Um Einheit und Freiheit. Staatsvertrag, Neutralität und das Ende der Ost-WestBesetzung Österreichs 1945-1955, Wien 1998.

6 Zum Beispiel Paul Luif, On the Road to Brussels. The Political Dimension of Austria's, Finland's and Sweden's Accession to the European Union, Wien 1995; Heinz Gärtner, Modelle europäischer Sicherheit. Wie entscheidet Österreich?, Wien 1997.

7 Jussi Hanhimäki, The Flawed Architect. Henry Kissinger and American Foreign Policy, Oxford 2004, 185-200.

8 Henry Kissinger, Diplomacy, New York 1994, 703-732.

9 Charles S. Maier, Dissolution. The Crisis of Communism and the End of East Germany, Princeton 1997.
} 
dämmung, die auf ein „Gleichgewicht des Schreckens“ baute. ${ }^{10}$ Und die sowjetische Politik, deren Abfolge nach der Öffnung der Archive der KPdSU der zeitgeschichtlichen Forschung zugänglich war, ${ }^{11}$ wurde politikwissenschaftlich mit den durch diese Abfolge falsifizierten Erwartungen einer „Konvergenz" der Systeme und der damit verbundenen Vermutung einer allmählichen Liberalisierung der UdSSR konfrontiert. ${ }^{12}$

Diese Beispiele können durch eine Unzahl anderer ergänzt werden, die vor allem eines belegen: Politikwissenschaft baut - auch und wesentlich - auf den Forschungsergebnissen der Zeitgeschichte auf. Und Zeitgeschichte erfährt - auch und wesentlich - eine Ergänzung durch die Politikwissenschaft. Und diese Verbindung ist vorgegeben: Was heute Politik ist, ist morgen schon Geschichte (zum Beispiel die Analyse des Wahlverhaltens 2019 ist 2019 Politikwissenschaft, aber 2020 schon Material für die zeitgeschichtliche Forschung) - und was Geschichte war, beeinflusst die Politik und deren Analyse heute (zum Beispiel die Renaissance der nationalen Opfernarrative in Mittel- und Osteuropa).

\section{Wesentliche Unterschiede der methodischen Wurzeln}

Zeitgeschichte ist Geschichte, zeitgeschichtliche Forschung steht generell in der Tradition der historischen Forschung. Dazu zählen die Suche nach schriftlichen Quellen und deren Darstellung und Analyse - etwa in Form der Archivforschung. Durch den deutlich geringeren Abstand zwischen dem Zeitpunkt von Ereignissen und dem Zeitpunkt der Erhebung ist aber der Zeitgeschichte ein zusätzlicher methodischer Zugang ermöglicht, der einer Erforschung weiter zurückliegender historischer Perioden verwehrt ist: Oral History generell, die systematische Befragung historischer AkteurInnen speziell.

Das zeigt sich etwa an der Auslotung der Rolle, die Albert Speer als Teil der funktionalen Elite des NS-Systems zukam, auch an der Dekonstruktion der Rolle, die Albert Speer ab 1945 für sich selbst konstruierte. ${ }^{13}$ An diesem Beispiel wird deutlich, wie sehr zeitgeschichtliche Forschung die allgemeine, wissenschaftlich gestützte Erkenntnis eines politischen Systems vertiefen kann und damit auch die politikwissenschaftliche Forschung und Lehre unmittelbar beeinflusst und bereichert.

10 George F. Kennan, The Nuclear Delusion, New York 1982.

11 Ian Kershaw, The Global Age. Europe 1950-2017, 313-397.

12 Zdenek Mlynar, Can Gorbachev Change the Soviet Union?, Boulder 1990.

13 Gitta Sereny, Albert Speer. His Battle with Truth, London 1995. 
Das gilt freilich nicht nur für die Zeitgeschichte: Auch Forschungen, die sich auf andere historische Perioden beziehen, sind ein „impact factor“ für die Entwicklung politikwissenschaftlicher Erkenntnis: Etwa beeinflussten und beeinflussen die Erkenntnisse, die James McPherson mehr als ein Jahrhundert nach dem Ende des USamerikanischen Bürgerkriegs publizierte, ${ }^{14}$ die als politikwissenschaftlich firmierte Sicht der Entwicklung des Nation-Building-Prozesses und die Dynamik des Föderalismus in den USA - etwa auch mit Bezug auf die Analogien des (unvollendeten) Aufbaus eines europäischen Bundesstaates und des (durch das Resultat des Bürgerkrieges) vollendeten Aufbaus der USA als Föderation. ${ }^{15}$

Dass der Einfluss zeitgeschichtlicher (und nicht nur allgemein historischer) Forschung auf die Politikwissenschaft von einer spezifischen Bedeutung ist, kann etwa durch die Publikation und Analyse der Ministerratsprotokolle der österreichischen Bundesregierung von 1945 bis 1952 deutlich gemacht werden. ${ }^{16}$ Diese auf Archivforschung beruhende Veröffentlichung hatte nicht nur erheblichen Einfluss - etwa im Zusammenhang mit der zeitgleichen Debatte über die „Waldheim-Affäre“ - auf den Umgang der österreichischen Politik mit der Verflechtung zwischen der österreichischen Gesellschaft und dem NS-System, sie hatte auch Einfluss auf die politikwissenschaftliche Wahrnehmung der Koalitionsregierungen in der unmittelbaren Nachkriegszeit und vor allem auf deren Neigung, innenpolitische Befriedung durch offiziell geförderten Gedächtnisverlust zu ermöglichen. ${ }^{17}$

Die Entwicklung der Politikwissenschaft hat verschiedene methodische Ursprünge. Einer dieser Ursprünge liegt in der Politischen Philosophie. Thomas Hobbes, John Locke, Baruch Spinoza, Charles Montesquieu und andere entwickelten - im Umfeld der europäischen Aufklärung und im Vorfeld „bürgerlicher“ Revolutionen - Konzepte, die (ohne selbst den heute für die Politikwissenschaft geltenden Ansprüchen einer sich auf Empirie stützenden politikwissenschaftlichen Theoriebildung zu genügen) wesentlich Einfluss auf die reale Gestaltung politischer Ordnung nahmen und damit, in einer Weiterführung, auch die Politikwissenschaft prägten. Den Brückenschlag von einer im Vorfeld der Politikwissenschaft angesiedelten Politischen Philosophie und der Politikwissenschaft vollendeten dann die theoretischen und praktischen Begleiter „bürgerlicher“ Revolutionen - wohl am besten ersichtlich im Diskurs, der die Gestaltung der USA und deren Verfassung begleitete: die „Fe-

\footnotetext{
14 James M. McPherson, Battle Cry for Freedom. The Civil War Era, Oxford 1988.

15 Symposium: The EU Constitution: RIP?, in: PS: Political Science and Politics 39 (2006) 2, 237-272.

16 Robert Knight (Hg.), „Ich bin dafür, die Sache in die Länge zu ziehen“. Die Wortprotokolle der österreichischen Bundesregierung von 1945 bis 1952 über die Entschädigung der Juden, Frankfurt a. M. 1988.

17 Anton Pelinka, Austria. Out of the Shadow of the Past, Boulder 1998, 173-203.
} 
deralist Papers" und deren Autoren, die sowohl als praktische Politiker wie auch als politische Theoretiker Hand an die Gestaltung einer neuen politischen Ordnung legten. ${ }^{18}$

Ein weiterer Ursprung (und seither fester Bestandteil) der Politikwissenschaft findet sich in der empirischen Sozialforschung. Am Beispiel Paul Lazarsfelds wird deutlich, dass hier verschiedene methodische Einflüsse zusammenkommen: Einflüsse der Psychologie (in Form der teilnehmenden Beobachtung), die für die bahnbrechenden Analyse über die Arbeitslosen von Marienthal grundlegend waren. ${ }^{19}$ Die „Marienthal-Studie“ galt und gilt aus nachvollziehbaren Gründen weder als eine der Politikwissenschaft noch der Zeitgeschichte direkt zuzuschreibende Arbeit. Aber sie spiegelt Zeitgeschichte - sie beschreibt, systematisch, die Folgen der krisenhaften sozialen und wirtschaftlichen Entwicklung im Österreich der Ersten Republik. Und sie macht die Handlungsunfähigkeit eines politischen Systems deutlich. Auch die späteren Arbeiten Lazarsfeld wurden zum Zeitpunkt ihres Entstehens nicht unmittelbar als „Politikwissenschaft" etikettiert: etwa die gerade für die empirische Wahlforschung und deren Entwicklung so wichtige Analyse des Wahlverhaltens in der US-amerikanischen Präsidentschaftswahl 1940. ${ }^{20}$ Dass diese Arbeit, die für den Standard der Politikwissenschaft generell und für deren Methodologie speziell zentral werden sollte, den Ruf des Sociology Department der Columbia Universität begründete - obwohl das Forschungsthema politisches Verhalten vor dem Hintergrund einer zeitgeschichtlichen Weichenstellung war (der erst- und letztmaligen Wahl eines US-Präsidenten für eine dritte Amtszeit) -, diese potenzielle Mehrfachetikettierung (Soziologie, Zeitgeschichte, Politikwissenschaft) demonstriert die Durchlässigkeit zwischen verschiedenen akademischen Disziplinen und die Problematik des Versuches rigider Grenzziehungen.

Eine besondere Bedeutung kommt der Erinnerung von Personen zu - sei es Form der Oral History, sei es in Form der Memoirenliteratur. Winston Churchills mit dem Literaturnobelpreis ausgezeichnetes vielbändiges Werk „The Second World War" ist eine wichtige Quelle für die Geschichte der Welt in der ersten Hälfte des 20. Jahrhunderts; eine Quelle, die freilich vor dem Hintergrund der immer zu vermutenden subjektiven (und damit parteilichen) Wahrnehmung des Akteurs zu bewerten ist.

18 Morris, Richard B., Witnesses at the Creation. Hamilton, Madison, Jay, and the Constitution, New York 1985; Joseph J. Ellis, The Quartet. Orchestrating the Second American Revolution, 17831789, New York 2015.

19 Marie Jahoda/Paul Lazarsfeld/Hans Zeisel, Die Arbeitslosen von Marienthal: Ein soziographischer Versuch über die Wirkungen langdauernder Arbeitslosigkeit, Leipzig 1933.

20 Paul F. Lazarsfeld/Bernard Berelson/Hazel Gaudet, The People's Choice - How the Voter makes up his Mind in a Presidential Campaign, New York 1944. 
Die Bände der Churchill-Memoiren sind aber auch eine Quelle für die Politikwissenschaft - etwa mit Bezug auf Struktur und Funktion des britischen Parlamentarismus und die dort entwickelte Durchlässigkeit zwischen den Regierungs- und Oppositionsbänken; etwa auf das erst allmähliche (und im Fall Churchills verspätete) Durchsickern der Erkenntnis, dass der im 19. Jahrhundert an seinen Höhepunkt gelangte Kolonialismus und Imperialismus nach dem Ende des Zweiten Weltkrieges unvermeidlich seinem Ende zugehen musste; auch darüber, welche Anzeichen des „Kalten Krieges“ schon bei den Konferenzen von Teheran, Jalta und Potsdam zu erkennen waren. Und damit sind die Memoiren auch Informationen über den Hintergrund der Ordnung der Welt nach 1945.

Für die Möglichkeiten und Grenzen autobiographischer Literatur als potentielle Quellen wissenschaftlicher Forschung liefern die Erinnerungen des österreichischen Sozialdemokraten Julius Deutsch ein aufschlussreiches Beispiel: Deutsch, einer der Prominentesten im Führungsteam der Sozialdemokratischen Partei Deutschösterreichs zwischen 1918 und 1934, berichtet von seinem politischen Weg aus den ländlichen Verhältnissen im österreichisch-ungarischen Grenzgebiet; von seiner Zeit als Offizier der K.u.k.-Armee und von seiner Rolle beim Aufbau der sozialdemokratischen Miliz (des Republikanischen Schutzbundes); ebenso über seine Flucht 1934 vor der Repression des autoritären „Ständestaates“, über seine Aktivitäten für die Spanische Republik, über seine Zeit im US-amerikanischen Exil. Aber in seinen Erinnerungen findet sich kein Wort einer Beobachtung und Bewertung seiner Herkunft aus dem Judentum. Damit aber versperrte er sich jeder Analyse des vor, während und nach dem Ersten Weltkrieges in Politik und Alltag so massiv präsenten Antisemitismus. ${ }^{21}$ Diese auffallende Auslassung ist eine Herausforderung für Zeitgeschichte und Politikwissenschaft und - durch das demonstrative Negieren der auch Deutsch persönlich betreffenden Erfahrungen mit der aggressiven Feindschaft gegenüber Jüdinnen und Juden - geradezu eine Fundgrube für den wissenschaftlichen Diskurs über den sozialen, wirtschaftlichen und politischen Hintergrund des Judenhasses in Vergangenheit und Gegenwart.

Politikwissenschaft kommt ohne die Erkenntnisse der zeitgeschichtlichen Forschung nicht aus. Und Zeitgeschichte nutzt ebenso politikwissenschaftliche Erkenntnisse. Arend Lijphart entwickelte sein Konzept der „Consociational Democracy“ auf der Grundlage der empirisch erhobenen Erfahrungen in europäischen Ländern (etwa der „cross cutting cleavages“ der Schweiz und der niederländischen „Verzuilung“, Folge der historisch erklärbaren Fragmentierung entlang der Bruchlinie des konfessionellen Gegensatzes), aber auch in nichteuropäischen Ländern (wie

21 Julis Deutsch, Ein weiter Weg. Lebenserinnerungen, Wien 1960. 
Kolumbien und Libanon). ${ }^{22}$ Später führte Lijphart diesen historisch gewonnenen Ansatz zu einer Typologie demokratischer politischer Systeme weiter. ${ }^{23}$ Ohne zeitgeschichtliche Forschung ist eine politikwissenschaftliche Systemtypologie nicht vorstellbar. Und politikwissenschaftliche Systemtypologie hilft dem Verstehen zeithistorischer Abläufe - etwa in der britischen „Westminster-Demokratie“, etwa bezüglich der Realität der eidgenössischen Konkordanzdemokratie und des Prozesses der Säkularisierung in den Niederlanden.

Die Nutzung der Forschungsergebnisse der einen durch die andere Disziplin ist in beide Richtungen selbstverständlich - etwa auch im Feld internationaler Politik. Der nach dem Ende der UdSSR möglich gewordene Zugang zu den Archiven der KPdSU und zu den Protokollen der Sitzungen des Politbüros (bzw. des Präsidiums) der sowjetischen Monopolpartei ermöglichte Einsichten in den Ablauf des „Kalten Krieges" wie auch in die Defizite der wechselseitigen Wahrnehmung politischer Entwicklungen. So beschreiben Aleksandr Fursenko und Timothy Naftali den Hintergrund der Zuspitzung des Konfliktes zwischen den USA und der Sowjetunion im Jahr 1962, dem Jahr der Kuba-Krise, und machen deutlich, wie sehr eine ideologische Voreingenommenheit ein Faktor strategischer Fehlkalkulation auf sowjetischer Seite war: Der innerste Kreis der sowjetischen Führung war fest davon überzeugt, das letztlich nicht die in der US-Verfassung verankerten Strukturen die Politik der USA bestimmten, sondern „plutocrats, militarists, and alarmists“. Es wäre daher sekundär, ob Dwight D. Eisenhower oder John F. Kennedy als Präsident im Weißen Haus säße - denn „both represent the same class with different shades“. ${ }^{24}$ Mangels Erfahrung bestimmten Stereotype die Weltpolitik des Jahres 1962 - eine erst Jahrzehnte später ermöglichte Einsicht.

\section{Analoge Entwicklungsgeschichte}

Zeitgeschichte (Contemporary History) hat ihre spezifische Identität infolge eines Ablöse- und Emanzipationsprozesses von der Neueren Geschichte (Modern History) gewonnen. Die Grenzziehung zwischen diesen beiden Teildisziplinen macht durch ihren oft als willkürlich empfundenen Charakter (zum Beispiel gilt als österreichische Zeitgeschichte die Periode ab 1918) diesen Zusammenhang deutlich.

22 Arend Lijphart, Democracy in Plural Societies, A Comparative Exploration, New Haven 1977.

23 Ders., Patterns of Democracy. Government Forms and Performance in Thirty-Six Countries, New Haven 1999.

24 Aleksandr Fursenko/Timothy Naftali, Khrushchev’s Cold War, New York 2006, 413. 
1918 ist speziell aus österreichischer wie auch allgemein europäischer Sicht ein Einschnitt, um eine spezifisch neue Periode der Geschichte zu markieren: das Ende der alten Reiche in Europa und der Beginn einer Neuordnung, die unter der zunächst und dann wiederum weitgehend unbestrittenen Norm der Demokratie stand und steht. Aus der Erfahrung etwa Lateinamerikas ist hingegen das Jahr 1918 von einer anderen, viel weniger Ende und Anfang einer Epoche bestimmenden Bedeutung.

Politikwissenschaft wiederum hat ihre spezifische Identität durch Emanzipation von bzw. in Abgrenzung zu Soziologie und Rechtswissenschaft gefunden. Politikwissenschaft steht nach wie vor in einem Graubereich zur Politischen Soziologie, und dass gerade an US-Universitäten politikwissenschaftliche Departments oft „Government" heißen, was am besten mit Staatswissenschaft zu übersetzen ist, unterstreicht nach wie vor eine zweite Entwicklungslinie - die Loslösung von Staats- und Verfassungsrecht, aber auch vom Völkerrecht. Dabei ging es in dieser Entwicklungsgeschichte in Österreich nach 1945 nicht zuletzt darum, die unter der NS-Herrschaft verschütteten Ansätze einer zwar so nicht benannten, aber substanziell vorhandenen Politikwissenschaft wiederzubeleben - wie das Beispiel von Paul Lazarsfeld zeigt, der nach seinem Studium der Mathematik an der Universität Wien und als einer der Autoren der bahnbrechenden Studie über die Arbeitslosen von Marienthal eine herausragende Karriere an der Columbia University machte und zu einem der global anerkannten Größen der empirischen Wahlforschung wurde. ${ }^{25}$

Beiden Disziplinen - der Zeitgeschichte wie auch der Politikwissenschaft - ist gemeinsam, dass sie oft als Störenfriede empfunden wurden und wohl auch immer noch werden: als Eindringlinge in ein bereits abgegrenztes Feld wissenschaftlicher Zuständigkeit. Von dort erklärt sich der gelegentliche Widerstand gegen Institutsgründungen (vor allem Zeitgeschichte) und gegen die Etablierung von Studienrichtungen (vor allem Politikwissenschaft). Beiden Disziplinen ist gemeinsam, dass sie ihre Identität als Differenzidentität entwickelt haben: Sie waren und sind vielleicht auch noch immer gezwungen, die Sinnhaftigkeit der Grenzziehung etwa zur Geschichte der Neuzeit (im Fall der Zeitgeschichte) oder zur Staatslehre und zum Öffentlichen Recht unter Beweis zu stellen. ${ }^{26}$

Speziell in Österreich begründet die Verspätung beider Fächer eine weitere Gemeinsamkeit: Zeitgeschichte sonderte sich vergleichsweise spät von der Neueren Geschichte ab, und die Etablierung der Politikwissenschaft in Österreich glückte erst

25 Jacques Lautman/Bernard-Pierre Lécuyer (Hg.), Paul Lazarsfeld (1901-1976). La sociologie de Vienne à New York, Paris 1998.

26 Waldemar Hummer, Politikwissenschaft in Österreich unter besonderer Berücksichtigung der Europapolitik. Institutionelle und materielle Rahmenbedingungen, Innsbruck 2015. 
in den 1970er-Jahren. Diese Verspätung war die Folge eines universitären Strukturkonservatismus, und die verzögerte Etablierung beider Fächer war Teil einer gegen den universitären Status quo gerichteten Protest- und Reformbewegung. Bis zu den Innovationen der 1970er-Jahre (in Österreich als „Ära Firnberg" bekannt) waren die Fakultäten und die Studienrichtungen wie auch die Curricula weitgehend identisch mit denen, wie sie schon vor 1914 bestanden hatten. Dazu kam, als Konsequenz der politischen Eingriffe in die Universitäten 1934 und vor allem 1938, dass Universitäten zu einer Zurückhaltung gegenüber institutionellen Neuerungen tendierten, die daran erinnert hätten, wie sehr strukturelle Kontinuität auch nach 1945 auch die personellen „Säuberungsaktionen“ 1938 einschloss.

In der Politikwissenschaft war dies besonders deutlich: Die österreichische Politikwissenschaft (ähnlich der deutschen) wurde nach 1945 wesentlich von den in der Ära des Nationalsozialismus ins Exil getriebenen wissenschaftlichen Denkansätzen definiert. In (West)Deutschland fand die Wiederkehr der „,vertriebenen Vernunft“ unter kreativer, direkter Mitwirkung der Alliierten statt - wie die Beispiele von Ernst Fraenkel, Ossip Flechtheim und Wolfgang Abendroth zeigen. ${ }^{27}$ In Österreich war der Einfluss der Westalliierten nicht direkt gegeben, da die Universitäten schon ab 1945 in der Kompetenz der bereits am 27. April dieses Jahres konstituierten österreichischen Regierung standen - zunächst der Provisorischen Staatsregierung, dann der im Gefolge der Nationalratswahl vom November bestellten Bundesregierung. Der westalliierte, vor allem der US-amerikanische Einfluss bei der Gründung und Entwicklung der österreichischen Politikwissenschaft war vielmehr ein indirekter, der erst in den 1960er-Jahren spürbar wurde: durch das von der Ford Foundation finanzierte, in Wien etablierte Institut für Höhere Studien und Wissenschaftliche Forschung, das neben einer Förderung der schon vor 1938 in Österreich entwickelten Wirtschaftswissenschaften und der vor 1938 in einem Anfangsstadium befindlichen Soziologie auch die in Österreich als eigenständige wissenschaftliche Disziplin unbekannte Politikwissenschaft in Form eines post-graduate Studiums einführte. Dabei spielte das österreichische Exil, das die Ford Foundation von der Sinnhaftigkeit einer solchen Innovation zu überzeugen vermochte, eine wesentliche Rolle. ${ }^{28}$

Während die Politikwissenschaft ihre Eigenständigkeit als Disziplin in wissenschaftlicher Forschung und Lehre erst mit indirekter internationaler Unterstützung zu beweisen hatte, musste die Zeitgeschichte nicht ihre wissenschaftliche (speziell

27 Rainer Eisfeld, Ausgebürgert und doch angebräunt. Deutsche Politikwissenschaft 1920-1945, Baden-Baden 2013.

28 Bernd Marin, Politische Organisation sozialwissenschaftlicher Forschung. Fallstudie zum Institut für Höhere Studien - Wien, Wien 1978. 
universitäre) Legitimation mit einer der Methoden der ja bereits etablierten Geschichtswissenschaft belegen, sondern es ging um den Nachweis der Funktionalität ihrer Lösung von dem Fach Geschichte generell - sei es in Form von Instituten neben den bestehenden Historischen Instituten, sei es in Form autonomer Untergliederungen (Abteilungen) innerhalb dieser Institute. Ein Beispiel für den Facettenreichtum in jeder ebenso notwendigen wie durchlässigen Abgrenzung der Zeitgeschichte ist die gesamte Struktur der Festschrift für Oliver Rathkolb. ${ }^{29}$ Aber für beide Fächer - für Zeitgeschichte und Politikwissenschaft - stand die Etablierung unter dem Zeichen des Anspruches auf Innovation, vor dem Hintergrund einer als Versteinerung empfundenen Struktur des österreichischen Wissenschaftsbetriebes in den 1930er, 1940er- und 1950er-Jahren.

Der Entwicklung beider Fächer stand - im universitären System nicht nur, aber vor allem auch in Österreich - die durch die Erfahrungen mit der NS-Wissenschaftspolitik nach 1945 im Wissenschaftsbetrieb dominierende Abneigung gegen das „Politische“ entgegen. Dass sich eine Disziplin a priori als „politisch“ definierte, provozierte per se eine Abwehrhaltung, die Politikwissenschaft als politische Parteilichkeit und Ideologisierung missverstand. Der Ludergeruch des Politischen haftete aber nach 1945 auch der Zeitgeschichte an, denn sie musste zur Beschäftigung mit dem zwingen, dem viele, allzu viele im traditionellen Betrieb der Universitäten gerne auszuweichen versucht waren: mit dem Nationalsozialismus und damit auch mit der Verflechtung zwischen universitärer Forschung und Lehre auf der einen, dem NS-Herrschaftssystem und dessen Vorgeschichte auf der anderen Seite. ${ }^{30}$ Zeitgeschichte musste, nach ihrem Selbstverständnis, diese Tabuisierung in Frage stellen.

\section{Analoge Wirkungsproblematik}

Unvermeidlich rühren Zeitgeschichte und Politikwissenschaft an gesellschaftliche, an politische Tabus. Zeitgeschichte und Politikwissenschaft sind - selbstverständlich - Erfahrungswissenschaften, die sich im weitesten Sinn als empirisch verstehen und in ihrem Selbstverständnis Hannah Arendts Diktum verpflichtet sind: „Was ist

29 Lucile Dreidemy/Richard Hufschmied/Agnes Meisinger/Berthold Molden/Eugen Pfister/Katharina Prager/Elisabeth Röhrlich/Florian Wenninger/Maria Wirth (Hg.), Bananen, Cola, Zeitgeschichte. Oliver Rathkolb und das lange 20. Jahrhundert, 2 Bde., Wien 2015.

30 Klaus Taschwer, Hochburg des Antisemitismus. Der Niedergang der Universität Wien im 20. Jahrhundert, Wien 2015. 
der Gegenstand unseres Denkens? Erfahrung! Nichts anderes!“" ${ }^{31}$ Beiden Disziplinen geht es nicht um Sollen, sondern um Sein - eben um Erfahrung, deren Kenntnis und Vermittlung freilich auf unterschiedliche Weise gewonnen werden kann: durch das Studium historischen Quellenmaterials, durch die Beobachtung eines sich entwickelnden, öffentlichen Meinungsbildes, durch qualitative Erhebungen in Form von Gesprächen mit politischen Akteuren, durch vieles andere mehr. Zeitgeschichte und Politikwissenschaft haben ständig mit Meinungen zu tun - sie müssen sich aber selbst von eigenen Meinungen freihalten, um interpersonell vermittelt gesellschaftliche Wirklichkeit darstellen zu können; um einen „,onviction bias“ zu vermeiden.

Ob diese Wirklichkeit dann der Zeitgeschichte zugeordnet wird - etwa durch das von Quellenstudien ermöglichte Ausleuchten des Vorfeldes politischer Interessen, die zur „Moskauer Deklaration“ am 1. November 1943 führten - oder etwa der Politikwissenschaft - etwa in Form der Beobachtung und Analyse der Verschiebungen des Wahlverhaltens bestimmter elektoraler Schlüsselgruppen unmittelbar vor der US-Präsidentschaftswahl 2016: Das ändert nichts daran, dass dieses Erfahrungswissen sich mit massiven Interessen und den diese ausdrückenden Meinungen beschäftigen muss: etwa damit, ob in Moskau im Herbst 1943 die „polnische Frage“ zur Seite geschoben werden musste, weil die Alliierten sich über diese Frage nicht einigen konnten und deshalb Österreich plötzlich die Rolle eines „ersten Opfers“ der NS-Expansionspolitik zugewiesen bekam, um zu verhindern, dass die Moskauer Außenministerkonferenz als Fehlschlag eingeordnet werden musste; oder, bezogen auf das andere Beispiel, ob die Abstiegsängste einer „weißen“ Unterschicht, die das Wahlergebnis im November 2016 beeinflussten, Ausdruck eines gerade im Zusammenhang mit der Präsidentschaft Barack Obamas politisch steuerbaren Rassismus waren und deshalb den Wahlerfolg Donalds Trumps ermöglichten: Zeitgeschichte und Politikwissenschaft können das Gestrüpp politischer Interessen und Meinungen nicht ignorieren. Zeitgeschichte und Politikwissenschaft sollen, können und müssen sich aber selbst, in ihren Forschungen, von diesem Gestrüpp freihalten. Sie sind sich dabei freilich immer bewusst, dass dieses Gestrüpp den Diskurs ihrer Forschungsergebnisse bestimmen wird.

Die Kollision zwischen wissenschaftlicher Forschung und politischer Empfindlichkeit kann etwa an der Sensibilität der Etikettierung des österreichischen politischen Systems zwischen 1934 und 1938 erkannt werden: „Austrofaschismus“ oder „Autoritärer Unrechtsstaat“";2 ebenso auch beim Diskurs über „Rechtsextremis-

31 Hannah Arendt, zit. n. Melvyn A. Hill (Hg.), Hannah Arendt. The Recovery of the Public World, New York 1979, 308.

32 Emmerich Tálos, Das austrofaschistische Herrschaftssystem. Österreich 1933-1938, Wien 2013. 
mus“ und/oder „Rechtspopulismus“33. Zeitgeschichte und Politikwissenschaft haben gemeinsam, mit der Unvermeidlichkeit von Auseinandersetzungen mit politischen Meinungen leben zu müssen. Das betrifft andere wissenschaftliche Fächer nicht - eine durch Quellenforschung begründete Neuinterpretation der englischen Rosenkriege oder neue Studien zur Kontroverse zwischen Sigmund Freund und C. G. Jung müssen nicht mit einer so vehementen politischen, höchst kontroversen Reaktion rechnen wie zum Beispiel die Darstellung der spezifisch deutschen Geschichte als Bestimmungsfaktor des Holocaust in der Arbeit Daniel Goldhagens. ${ }^{34}$

Goldhagen hatte als Politikwissenschaftler in seiner Dissertation in den Augen mancher HistorikerInnen sich offenbar einer Grenzüberschreitung „schuldig“ gemacht. In den Ergebnissen seiner Forschung hatte er vor allem durch (notgedrungen) historische Befunde die These zu falsifizieren versucht, die deutsche Öffentlichkeit insgesamt habe bis 1945 vom Holocaust nur am Rande und nur in Teilen Kenntnis gehabt: Zwar sei die Vertreibung der Jüdinnen und Juden allgemein bekannt gewesen, nicht aber deren konsequente Ausmordung. Goldhagen wurde nach der Veröffentlichung seiner Dissertation vorgehalten, er habe die bereits vorhandenen Erkenntnisse der Zeitgeschichte zu wenig berücksichtigt - etwa die Arbeiten von Christopher Browning. ${ }^{35}$ An der Debatte über den „Goldhagen-Effekt“ beteiligten sich in kontroverser Form VertreterInnen sowohl der Zeitgeschichte als auch der Politikwissenschaft. ${ }^{36}$

Der Diskurs über Goldhagen war keine Konfrontation zwischen Zeitgeschichte und Politikwissenschaft, sondern eine intellektuelle Auseinandersetzung, ausgelöst durch die Publikation und Interpretation wissenschaftlicher Forschung. Dies war eine Konfrontation, an der sich VertreterInnen beider Disziplinen beteiligten. Auffallend war dabei auch, dass eine andere, analoge Grenzüberschreitung zwar breite Anerkennung in der Wissenschaft erfahren hatte, ohne eine analoge Diskussion zur provozieren: Peter Pulzers Arbeit über den Aufstieg des politisch instrumentalisierten Antisemitismus in Deutschland und Österreich um 1900 wurde zentraler Bestandteil der historischen Wahrnehmung insbesondere der Rolle Karl Luegers unabhängig davon, dass Pulzer in Oxford Politikwissenschaft unterrichtete. ${ }^{37}$ Auch

33 Ruth Wodak/Anton Pelinka (Hg.), The Haider Phenomenon in Austria, New Brunswick 2002.

34 Daniel Jonah Goldhagen, Hitler's Willing Executioners, New York 1996.

35 Christopher R. Browning, The Path to Genocide, Cambridge 1992; Christopher R. Browning, Ordinary Men. Reserve Battalion 101 and the Final Solution in Poland, New York 1993.

36 Norman G. Finkelstein/Ruth Bettina Birn (Hg.), A Nation on Trial. The Goldhagen Thesis and Historical Truth, New York 1998; Geoff Eley (Hg.), The „Goldhagen Effect“. History, Memory, Nazism - Facing the German Past, Ann Arbor 2000.

37 Peter Pulzer, The Rise of Political Anti-Semitism in Germany \& Austria, London 1988. 
die akademisch etablierte Zeitgeschichte, die sich etwa in der Person John Boyers ebenso und zeitgleich mit dem „politischen Antisemitismus" in Österreich und dem Aufstieg Karl Luegers beschäftigte, hatte keine Probleme mit der unterschiedlichen Etikettierung Pulzers als „Politikwissenschaftler“ und Boyers als „Historiker“.38

Gerade die Goldhagen-Debatte machte klar, dass Zeitgeschichte und Politikwissenschaft - mehr als andere Fächer - für politische Aufregung sorgen und mitten in politischen Konflikten stehen können. Eben deshalb richtet sich gegen beide Fächer immer wieder der Vorwurf, wissenschaftlich nicht „objektiv“ zu sein und den Standard politischer Neutralität zu verletzen, der oft von jedem Zweig der Wissenschaft erwartet wird. Zeitgeschichte und Politikwissenschaft haben es deshalb immer schwer, sich einer politischen, durchaus auch parteipolitischen Vereinnahmung zu entziehen.

Unvermeidlich sind Zeitgeschichte und Politikwissenschaft Objekte, ja Opfer von Instrumentalisierungsversuchen: Politisch motivierte „Historikerkommissionen“ und der politische Umgang mit deren Ergebnissen sind ebenso ein Beispiel für die Politisierung des wissenschaftlichen Diskurses wie die Frage nach der Kompatibilität des politischen Umgangs mit Migration auf der einen, dem Geist und den Buchstaben der von den Vereinten Nationen, dem Europarat und der Europäischen Union vertretenen Normen universeller Menschenrechte auf der anderen Seite. Deshalb trifft der Vorwurf mangelnder „Objektivität“ immer wieder Zeitgeschichte und Politikwissenschaft: Politikwissenschaftliche Analysen werden von außen, etwa durch Medien, als ÖVP- oder SPÖ-nah etikettiert. HistorikerInnen werden als „links“ oder "rechts" abgetan, um so einen Wall der Immunisierung gegen wissenschaftlich gewonnene Erkenntnisse aufzubauen, um sich mit diesen erst gar nicht auseinandersetzen zu müssen.

Zeitgeschichte und Politikwissenschaft können freilich aus diesem ihnen anhaftenden "Geruch“ des Politischen einen Vorteil ziehen: Die „objektiven“ Naturwissenschaften können sich leichter (auch nach der Entdeckung und dem Einsatz von Giftgas im Ersten Weltkrieg, auch nach Los Alamos und Hiroshima) der Illusion absoluter Politikferne hingeben. Zeitgeschichte und Politikwissenschaft können das nicht. Und beide sind eben deshalb auch geeignet, das Illusionäre des Glaubens an die Möglichkeit genereller Politikferne von Wissenschaft aufzuzeigen.

38 John W. Boyer, Culture and Political Crisis in Vienna. Christian Socialism in Power, 1897-1918, Chicago 1995; John W. Boyer, Karl Lueger (1844-1910). Christlichsoziale Politik als Beruf. Eine Biografie, Wien 2010. 


\section{Analoge Bedürfnisse, analoge Funktionen}

Die Freiheit des Forschens und Lehrens brauchen Zeitgeschichte und Politikwissenschaft mehr als alle anderen Wissenschaftsdisziplinen. Sie brauchen, um ihren eigenen Ansprüchen gerecht zu werden, Zugang zu den Quellen des Regierens, sie brauchen die Offenheit des politischen Diskurses für die Analyse von „public opinion“. Gegen beide Fächer richtet sich das nachvollziehbare, das verständliche Misstrauen derer, die kein Interesse haben, dass Zusammenhänge der Macht ausgeleuchtet werden - nicht die Zusammenhänge von gestern, nicht die von heute. Zeitgeschichte und Politikwissenschaft brauchen für die Ausschöpfung ihrer Potenziale vor allem eines: die Freiheit, das zu erforschen, was den Vertreterinnen und Vertretern dieser Fächer wichtig ist; und die Freiheit, das zu lehren, was das Resultat ihrer Forschung ist.

Diese Freiheit kann aber - so die Erfahrung - nur die liberale Demokratie gewährleisten. Nuklearphysik war auch in der UdSSR voll entwickelt - Zeitgeschichte und Politikwissenschaft nicht. Die Erforschung des literarischen Wirkens von Goethe und Schiller war auch unter den Rahmenbedingungen des NS-Systems möglich - Zeitgeschichte und Politikwissenschaft waren, wenn man die Ansprüche dieser beiden Fächer ernst nehmen wollte, in diesem System ausgesperrt und verboten.

Zeitgeschichte und Politikwissenschaft sind Demokratiewissenschaften, sie brauchen die Demokratie, um sich zu entwickeln. Und sie stärken auch die Demokratie, weil sie - wie bei Andersens Märchen - in der Lage sind, dem Kaiser entgegenzutreten und ihn „nackt“"zu nennen. Die im August 1968 durch die militärische Intervention der Warschauer Pakt-Staaten unterbrochene Demokratisierungswelle erlaubte in der ČSSR die Aufdeckung des repressiven, des totalitären Charakters auch des spätstalinistischen Herrschaftsapparates durch die Veröffentlichung der Hintergründe des Schauprozesses gegen Rudolf Slánský und die anderen, willkürlich als Opfer ausgewählten Kommunisten. ${ }^{39}$ Der Sozialismus à la Stalin und Gottwald trug nicht die Kleider, die er zu tragen vorgab.

Politikwissenschaft und Zeitgeschichte beanspruchen oft die Etikette „kritisch“. Das ist ebenso verständlich wie banal - erklärbar aus dem historischen Zusammenhang eines traditionellen Wissenschaftsbetriebes, der sich explizit oder implizit den als „neu“ verstandenen Fächern widersetzte. „Kritisch“ ist aber, als inhaltliche Etikettierung, ganz einfach banal, weil dies eine Selbstverständlichkeit ausdrückt.

39 Anne Applebaum, Iron Curtain. The Crushing of Eastern Europe 1944-1956, New York 2012, 281288; Eugen Löbl/Dusan Pokorny, Die Revolution rehabilitiert ihre Kinder. Hinter den Kulissen des Slánsky-Prozesses, Wien 1970. 
In der deutschen Politikwissenschaft insbesondere galt die Eigendefinition als „kritisch“ auch als Beleg für den Anspruch, den Status quo der lange als „CDU-Staat“ betrachteten Bundesrepublik Deutschland zu hinterfragen..$^{40}$ In Österreich sahen sich die VertreterInnen einer zweiten oder dritten Generation der zeitgeschichtlichen Forschung der Aufgabe verpflichtet, dem (etwa mit der Präsidentschaft Kurt Waldheims verbundenen) „Opferanspruch“ Österreichs entgegenzutreten. ${ }^{41}$ Die zeitgeschichtlichen Fragestellungen und die durch Forschungsergebnisse gestützten Antworten fanden eine Entsprechung durch die Ergebnisse der empirischen Sozialforschung, in der quantitative Daten in einen funktionalen Erklärungszusammenhang gestellt wurden..$^{42}$

Parteilichkeit ist der Zeitgeschichte und der Politikwissenschaft notwendig vorgegeben - aber nicht im Sine einer traditionellen Parteinahme („links“ oder „rechts“), sondern einer Parteinahme für Aufklärung: im Sinne der historischen Aufklärung, im Sinne der Kerntugend dieser Aufklärung. Und diese Kerntugend ist die Skepsis gegenüber allen Herrschaftsansprüchen, gleichgültig, ob und wie diese etikettiert sind - als „konservativ“ oder „progressiv“, als ,links“ oder „rechts“. Zeitgeschichte und Politikwissenschaft, mehr als andere Forschungsbereiche politisch beargwöhnt, sind nicht „bürgerlich“ oder "sozialistisch“ - sie sind entweder gut oder schlecht. In diesem Sinn ist zeitgeschichtliche, ist politikwissenschaftliche Forschung immer „kritisch“, weil sie immer unbequem ist - wenn sie ihre Aufgabe erfüllt: unbequem den Herrschenden, unbeschadet von deren ideologischer Etikettierung.

\section{Konklusion: Die Ambivalenz akademischer Abgrenzung}

Zeitgeschichte und Politikwissenschaft existieren unabhängig voneinander als eigenständige Fächer innerhalb der internationalen Forschungslandschaft und innerhalb der internationalen Standards folgenden universitären Curricula. Sie sind, institutionell, voneinander getrennt. Diese Trennung ist unvermeidlich, ja notwendig: Institutionalisierte Forschung braucht etikettierte Ordnungssysteme. Institutionalisierte wissenschaftsgestützte Lehre braucht etikettierte Lehrprogramme. Es würde den Fortschritt und die Etablierung von Zeitgeschichte und Politikwissenschaft in

40 Kurt P. Tudyka, Kritische Politikwissenschaft, Stuttgart 1973.

41 Heidemarie Uhl, Zwischen Versöhnung und Verstörung. Eine Kontroverse um Österreichs Identität fünfzig Jahre nach dem „Anschluß“, Wien 1992.

42 Zum Beispiel Max Haller, Identität und Nationalstolz der Österreicher. Gesellschaftliche Ursachen und Funktionen. Herausbildung und Transformation seit 1945. Internationaler Vergleich, Wien 1996. 
der universitären Landschaft (gerade auch in Österreich) gefährden, würde auf die mit wechselseitiger Abgrenzung verbundene jeweilige Eigenständigkeit verzichtet werden.

Doch diese Abgrenzung ist ambivalent - und, wenn sie zur wechselseitigen Ausschließung führt, geradezu unsinnig. Gerade die Forschung, gerade eine innovative Forschung ist grenzüberschreitend. Ein Beispiel dafür ist Hannah Arendt: Als in Deutschland promovierte Philosophin, aber auch - gerade in ihrem US-amerikanischen Exil - Politische Theoretikerin im Sinne der Politikwissenschaft war sie auch Historikerin im Feld der Zeitgeschichte. Ihre Arbeit zum Totalitarismus eröffnete ein neues interdisziplinäres wissenschaftliches Diskursfeld und prägte die politische (politikwissenschaftliche) Theorie, aber auch die politikwissenschaftliche Subdisziplin „Comparative Politics“ über Jahrzehnte wesentlich - durch die Provokation von Widerspruch, durch die Anregung zu weiterer Forschung; durch die immer wieder diskutierte Frage, ob der Vergleich der beiden Repressionssysteme „Nationalsozialismus“ und „Kommunismus“ zumindest indirekt deren Gleichsetzung bedeute, oder ob nicht gerade dieser Vergleich der einzig mögliche Weg sei, neben Gemeinsamkeiten auch Unterschiede herauszuarbeiten. ${ }^{43}$

Hannah Arendt lieferte aber auch durch ihre zunächst in Artikelfolge, dann als Buch veröffentlichte Studie „Eichmann in Jerusalem“ einen Beitrag zur Zeitgeschichte, der - abermals als intellektuelle, als wissenschaftliche Provokation - nachhaltig Wirkung zeigte: Die Deutung des Wirkens und Lebens eines Hauptakteurs des Holocaust als „Banalität des Bösen“ wurde zunächst zwar verständlich, aber Arendts Denkansatz missverstehend als Banalisierung des Holocaust interpretiert; und ihre Kritik an der zwar nicht intendierten, aber funktional faktischen Kollaboration der „Judenräte“ galt vielen als ein Versuch eines „Blaming the Victims“.44

Hannah Arendt erinnert daran, was intellektuelle Redlichkeit im Wissenschaftsbetrieb zu bedeuten hat: der Wirklichkeit auf der Spur zu bleiben, jenseits des Schielens auf Akzeptanz innerhalb eines akademisch abgegrenzten Bereichs, einer bestimmten Disziplin; immer der Spur der historischen ebenso wie der aktuellen Wirklichkeit zu folgen; und diese Wirklichkeit nicht von einem dogmatisch fixierten Axiom zu deduzieren, sondern jeweils aufs Neue in Frage zu stellen. Es ist diese Suche nach der Wirklichkeit, die Wissenschaft auszeichnet; und es ist eine wissenschaftsethische Aufgabe, dieser Suche verpflichtet zu bleiben, mag dies politisch

43 Hannah Arendt, Elemente und Ursprünge totaler Herrschaft, München 1986.

44 Hannah Arendt, Eichmann in Jerusalem. Ein Bericht von der Banalität des Bösen, München 1986; Kurt Sontheimer, Hannah Arendt. Der Weg einer großen Denkerin, München 2006, 201-212. 
auch noch so unbequem sein: Das ist der Kern dessen, was Zeitgeschichte und Politikwissenschaft auszeichnet.

War Hannah Arendt Philosophin? Zweifellos. War sie auch Vertreterin zeitgeschichtlicher Forschung? Natürlich, das war sie auch. War sie aber nicht auch Repräsentantin der akademischen Disziplin Politikwissenschaft? Ja, selbstverständlich. Hannah Arendt macht deutlich, dass gerade originelle Forschung inter, besser transdisziplinär sein kann, ja sein muss. 


\title{
Zeitgeschichte und Kulturwissenschaften
}

\author{
Regina Thumser-Wöhs
}

Durch den Einfluss der Kulturwissenschaften auf die Zeitgeschichte wurde, ${ }^{1}$ ähnlich wie in der Soziologie, eine zunehmende Marginalisierung des Fachs befürchtet. ${ }^{2}$ Die Unschärfen der Begrifflichkeiten Neue/Neuere Kulturgeschichte - (Historische) Kulturwissenschaft(en) - Cultural Studies usw. beförderten ein gewisses Misstrauen und die Sorge um ein Weiterbestehen der Zeitgeschichte. Zugleich war die Zeitgeschichte - speziell in Österreich - nach dem Abschluss der Historikerkommissionen um das Jahr 2003 auf neue Zugänge angewiesen. ${ }^{3}$ Ich gehe im vorliegenden Beitrag davon aus, dass die zunehmend populär gewordene Anwendung kulturwissenschaftlicher Ansätze und Methoden hinsichtlich zeithistorischer Themen das Fortbestehen der Zeitgeschichte auf unbestimmte Zeit gewährleistet. Um dem von Doris Bachmann-Medick bezeichneten „Schleudertrauma“ der Turns einen weite-

1 Ich danke allen Kolleginnen und Kollegen für ihre Kommentare zu meinem Beitrag „Flucht nach vorne. Vom Verhältnis der Zeitgeschichte zu den Kulturwissenschaften“ im Rahmen des Mittwochskolloquiums an der Johannes Kepler Universität am 6. November 2019, insbesondere Karin Harrasser und Jasmin Mersmann. Mein besonderer Dank gilt Ellinor Forster für die intensive Auseinandersetzung mit meinem Text und ihre Kommentare. Nicht alle Anregungen konnten in den vorliegenden Beitrag einfließen.

2 Vgl. URL: http://www.bpb.de/apuz/28893/soziologie (abgerufen 16.09.2020); Josef Ehmer, Sozialwissenschaftler/innen oder Zeithistoriker/innen: Wer schreibt die Geschichte des 20. Jahrhunderts?, in: Heinrich Berger/Melanie Dejnega/Regina Fritz/Alexander Prenninger (Hg.), Politische Gewalt und Machtausübung im 20. Jahrhundert. Zeitgeschichte, Zeitgeschehen und Kontroversen. Festschrift für Gerhard Botz, Wien 2011, 59-71; Günter Dux, Historisch-genetische Theorie der Kultur. Instabile Welten - Zur Prozessualen Logik im kulturellen Wandel (Gesammelte Schriften 2), Wiesbaden 2017, 115-128.

3 Vgl. Johanna Gehmacher, Am Rand der Geschichte. Zeitgeschichte und ihre Marginalisierungen Anmerkungen aus österreichischer Perspektive, in: zeitgeschichte 32 (2005) 5, 301-322, 303. Ich verweise insbesondere auf die Österreichische Historikerkommission (1998-2003), die von der Österreichischen Postsparkasse eingesetzte Kommission zur Untersuchung „schlafender“ Konten und Sparbücher (1998), Forschungen zur Zwangsarbeit, etwa in der voestalpine (1998), das Einsetzen des Kunstrückgabebeirats (1999) und die damit verbundene Provenienzforschung, aber auch auf Kommissionen der Nachbarländer, wie die „Unabhängige Expertenkommission Schweiz Zweiter Weltkrieg“, kurz Bergier-Kommission genannt (1996-2002). Vgl. URL: https://www.voestalpine.com/group/de/konzern/historie/ns-zwangsarbeit/ (aufgerufen 16.09.2020); Eva Blimlinger, Das Gedenkjahr 1998 und seine Folgen, APA-Science, 24.10.2018, URL: https://science.apa. at/dossier/Das_Gedenkjahr_1998_und_seine_Folgen/SCI_20181024_SCI80495393444941398 (abgerufen 16.09.2020). 
ren hinzuzufügen, könnte man einen Contemporary History Turn hin zur Neuesten Zeitgeschichte andenken. ${ }^{4}$ Problematisch indes wird so ein Turn, wenn kulturwissenschaftliche Begrifflichkeiten - mit zeithistorischem Inhalt - marketingmäßig verwendet oder esoterisch verbrämt werden. Als Beispiel sei die „Bewusstseinsregion Mauthausen - Gusen - St. Georgen“ genannt. ${ }^{5}$ Der Wortfindungsprozess verlief analog zu jenem der „Genuss Region Österreich“ als Dachmarke für österreichisches Tourismus- und Agrarmarketing.

\section{Datierungen, Definitionen und Konjunkturen}

Eine der ersten Definitionen von Zeitgeschichte nahm Hans Rothfels 1953 vor. Er legte die Zeitgeschichte als „Epoche der Mitlebenden und ihre wissenschaftliche Behandlung“ fest. ${ }^{6}$ Das an der Friedrich-Schiller-Universität Jena angesiedelte Jena Center versteht Zeitgeschichte heute als „Geschichte des 20. Jahrhunderts“ und schenkt dabei der Geschichte des Nationalsozialismus und seiner Folgewirkungen in Deutschland und Europa - bis in die Gegenwart hinein - besondere Aufmerksamkeit, schränkt die Zeitgeschichte also mehr oder weniger auf das „Zeitalter der Extreme“ ein.7 Die „Zeitgeschichtliche Bibliothek“, in der vorliegender Band erschienen ist, definiert, so die Prämisse der Herausgeber, „ZZeitgeschichte als Geschichte

4 Doris Bachmann-Medick, Cultural Turns, Version 2.o, Docupedia-Zeitgeschichte, URL: http:// docupedia.de/zg/Bachmann-Medick_cultural_turns_v2_de_2019 (abgerufen 16.09.2020). Die im Folgenden als Docupedia-Beiträge zitierten Aufsätze erschienen ursprünglich in: Frank Bösch/ Jürgen Danyel (Hg.), Zeitgeschichte. Konzepte und Methoden, Göttingen 2012 sowie Alexander Nützenadel/Wolfgang Schieder (Hg.), Zeitgeschichte als Problem. Nationale Traditionen und Perspektiven in Europa, Göttingen 2004. Als Internet-Publikationen wurden sie teilweise überarbeitet und aktualisiert vgl. URL: http://docupedia.de/zg/Docupedia:\%C3\%9Cber_Docupedia (abgerufen 16.09.2020); vgl. auch: Frank Bajohr, Der Cultural Turn und die Gesellschaftsgeschichte des Nationalsozialismus, in: Vierteljahrshefte für Zeitgeschichte 65 (2017) 2, 223-232; Neil Gregor, Die Geschichte des Nationalsozialismus und der Cultural-Historical Turn, in: ebd., 233-246; Johann Chapoutot, Die Geschichtsschreibung zum Nationalsozialismus und der Cultural Turn, in: ebd., 247-258; Hans-Peter Schwarz, Die neueste Zeitgeschichte, in: Vierteljahrshefte für Zeitgeschichte 51 (2003) 1, 5-28.

5 Vgl. URL: http://www.bewusstseinsregion.at/ (abgerufen 16.09.2020).

6 Hans Rothfels, Zeitgeschichte als Aufgabe; in: Vierteljahrshefte für Zeitgeschichte 1 (1953) 1, 1-8, 4; vgl. auch: Gabriele Metzler, Zeitgeschichte: Begriff - Disziplin - Problem, Version 1.o, Docupedia-Zeitgeschichte, URL: http://docupedia.de/zg/metzler_zeitgeschichte_v1_de_2014 (abgerufen 16.09.2020); Erika Weinzierl, Die Anfänge der österreichischen Zeitgeschichte, in: zeitgeschichte 30 (2003) 6, 306-309, 306.

7 Vgl. URL: https://www.jenacenter.uni-jena.de/das-jena-center/ (abgerufen 16.09.2020); Martin Sabrow, Der Zeitraum der Zeitgeschichte, 1-16, 1, URL: https://zzf-potsdam.de/sites/ 
des 20. und 21. Jahrhunderts [...], wobei - dem Verständnis von ,Zeitgeschichte als ,Vorgeschichte der Gegenwart' folgend - problemorientiert auch frühere Jahrzehnte relevant sein können“. Das Institut für Zeitgeschichte der Universität Wien wiederum plädierte noch im Herbst 2019 - in Anlehnung an Günter Grass und/ oder Umberto Eco - für eine „Erweiterung der Untersuchungszeiträume [...] im historiografischen Krebsgang“ und nahm „das 19. Jahrhundert mit seinen prägenden sozioökonomischen Entwicklungen stärker in den Blick“" ${ }^{8}$ Ein Mission Statement bzw. Aussagen zur Ausrichtung der Zeitgeschichtsforschung sucht man auf der neuen Institutswebseite inzwischen leider vergeblich. ${ }^{9}$

Die „späte“ Einführung der Zeitgeschichte in Österreich - ab 1960 - wurde andernorts bereits ausführlich diskutiert. ${ }^{10} 1973$ legte Erika Weinzierl (1925-2014), die Grande Dame der österreichischen Zeitgeschichte, anlässlich der Gründung der gleichnamigen Zeitschrift den Untersuchungszeitraum der Zeitgeschichte auf die „NS-Zeit und die Epoche nach 1945“ fest, wobei dieser nicht nur politische, sondern auch wirtschaftliche, soziale und kulturelle Aspekte umfassen sollte. ${ }^{11}$ Im Editorial der Zeitschrift zum dreißigjährigen Jubiläum im Jahr 2003 hieß es jedoch, dass die Veröffentlichung von kulturgeschichtlichen Beiträgen nur selten gelungen sei. Ein Grund dafür könnte sein, dass diese zwischenzeitlich Eingang in die 1990 gegründete „Österreichische Zeitschrift für Geschichtswissenschaften“ (OeZG) gefunden hatten. ${ }^{12}$ -

default/files/mitarbeiter/PDFs/sabrow/vortrag_martin_sabrow_der_zeitraum_der_zeitgeschichte_01_10_2014_paris.pdf (abgerufen 16.09.2020).

8 URL: https://www.univie.ac.at/zeitgeschichte/institut/schwerpunkte/osterreichische-zeitgeschichteals-republikgeschichte-im-internationalen-vergleich-bis-zur-gegenwart/ (abgerufen 12.08.2019). Vgl. auch: URL: https://www.uibk.ac.at/zeitgeschichte/institutsprofil/ (abgerufen 11.09.2019); Günter Grass, Im Krebsgang. Eine Novelle, München 2004; Umberto Eco, Im Krebsgang voran. Heiße Kriege und medialer Populismus, München 2011.

9 Vgl. URL: https://zeitgeschichte.univie.ac.at/ueber-uns/geschichte-des-instituts/ (abgerufen 16.09. 2020).

10 Vgl. Helmut Konrad, Von Linz aus. Die Formierung der österreichischen Zeitgeschichte, in: Berger/Dejnega/Fritz/Prenninger (Hg.), Politische Gewalt, 47-57; Ernst Hanisch, Österreich - Die Dominanz des Staates. Zeitgeschichte im Drehkreuz von Politik und Wissenschaft, Version 1.o, Docupedia-Zeitgeschichte, URL: http://docupedia.de/zg/hanisch_oesterreich_zeitgeschichte_v1_ de_2011 (abgerufen 16.09.2020); Gehmacher, Am Rand, 303-304.

11 Vgl. Erika Weinzierl, Zeitgeschichte - Programm einer Zeitschrift, in: zeitgeschichte 1 (1973) 1, 3.

12 Vgl. URL: https://journals.univie.ac.at/index.php/oezg (abgerufen 16.09.2020); Erika Weinzierl/ Rudolf Ardelt, Editorial, in: zeitgeschichte 30 (2003) 6, 303-304; Reinhard Sieder, Kulturwissenschaften. Fragen und Theorie. Erste Annäherung, in: Christina Lutter/Margit Szöllösi-Janse/Heidemarie Uhl (Hg.), Kulturgeschichte. Fragestellungen, Konzepte, Annäherungen, Innsbruck/Wien/ München/Bozen 2004, 13-36. 
Die scheidende Herausgeberin Erika Weinzierl definierte die Zeitgeschichte neu als Geschichte des 20. Jahrhunderts mit seinen „Wurzelzonen“.13

Im Jahr 2000 erreichte die Zeitgeschichte in Österreich im Rahmen der NS-Auftragsforschung der Historikerkommission(en) einen Peak und eine Beschäftigungsquote, die sie vermutlich nie wieder erlangen wird. ${ }^{14}$ Ernst Hanisch machte diesen Markstein der Zeitgeschichtsforschung, der durch das Zugänglichmachen der NSBestände nicht zuletzt die „Bastion Archiv“ sprengte, nicht an einer Jahreszahl, sondern an ,der ${ }^{6} 1968$ er-Generation fest. ${ }^{15}$ Vermutlich bedingten die beiden Faktoren einander; viele der ProjektleiterInnen der Österreichischen Historikerkommission waren der „68er“-Generation zuzuordnen, während die ProjektnehmerInnen ein bis gar zwei Generationen jünger waren.

Ich bezweifle, dass um das Jahr 2000 jemand an die Notwendigkeit einer Neuorientierung/definition der Zeitgeschichte dachte. Zuvor hatten die Exil- und damit die Opferforschung sowie die Oral und Video (heute Visual) History einen international gesehen späten Höhepunkt erreicht, gerade war durch die Öffnung der Archive ein breiter Zugang zu NS-Akten (Opfer/TäterInnen) ermöglicht worden. ${ }^{16}$ Zwischen 1998 und 2002/2003 verfassten 160 ForscherInnen im Rahmen der von der österreichischen Regierung eingesetzten Historikerkommission 53 Berichte; diese wurden in 32 Bänden bei Oldenbourg verlegt. ${ }^{17}$ Nach Abschluss dieser Auftragsarbeiten waren viele ProjektnehmerInnen "ge-brandet“, mussten sich umorientieren, NS-Themen wurden nicht oder kaum mehr gefördert. ${ }^{18}$ Die Zeitgeschichte stürzte in eine „Identitätskrise“, ${ }^{19}$ die Auftragsforschung - etwa die projektbezogenen, ,jobsichernden“ Jubiläumsjahre, darunter der Boom der Universitätsgeschichte(n) - war noch

13 Weinzierl, Die Anfänge, 306-309, 306.

14 Vgl. Blimlinger, Das Gedenkjahr 1998; Eva Blimlinger, „... Das geht sich nie aus, das könnt ihr nicht verlangen, Wahnsinn!“ Konzeption und Organisation von Auftragsforschungsprojekten am Beispiel der Historikerkommission, in: zeitgeschichte 30 (2003) 5, 281-292; vgl. auch: Hans Georg Golz, Editorial, in: Aus Politik und Zeitgeschichte 2003/B40-41, 2, URL: http://www.bpb.de/shop/ zeitschriften/apuz/27373/deutsche-geschichte (abgerufen 16.09.2020).

15 Vgl. Hanisch, Österreich; Ehmer, Sozialwissenschaftler/innen oder Zeithistoriker/innen, 60-61.

16 Vgl. Blimlinger, Das geht sich nie aus.

17 Vgl. Historikerkommission: NS-Entschädigung oft nur halbherzig, ORF Science, 01.01.2010, URL: https://sciencev1.orf.at/news/68286.html (abgerufen 16.09.2020); Clemens Jabloner/Brigitte Bailer-Galanda/Eva Blimlinger/Georg Graf/Robert Knight/Lorenz Mikoletzky/Bertrand Perz/Roman Sandgruber/Karl Stuhlpfarrer/Alice Teichova, Schlussbericht der Historikerkommission der Republik Österreich. Vermögensentzug während der NS-Zeit sowie Rückstellungen und Entschädigungen seit 1945 in Österreich. Zusammenfassungen und Einschätzungen (Veröffentlichungen der Österreichischen Historikerkommission 1), Wien/München 2003.

18 Vgl. Konrad, Von Linz aus, 57.

19 Vgl. Gehmacher, Am Rand, 303. 
fern. Ab 2003 wurde, besonders auf den Zeitgeschichtetagen, denn auch verstärkt eine Neuausrichtung der österreichischen Zeitgeschichte gefordert und diskutiert. ${ }^{20}$ Diese war an die diskursiven Prozesse über die Zeitgeschichtsforschung in Deutschland angelehnt. ${ }^{21}$ Bisweilen fand denn auch ein $\mathrm{Zu}$-Tode-Reden, ein $\mathrm{Zu}$-Grabe-Tragen der Österreichischen Zeitgeschichte statt, ${ }^{22}$ was insbesondere all jenen als eine Bankrotterklärung erschien, die als ,JunghistorikerInnen' im Rahmen der Historikerkommissionen vermeintlich in der Wissenschaftswelt Fuß gefasst hatten. 2003 und dieses Jahr scheint eine markante Wende für die Zeitgeschichte eingeleitet $\mathrm{zu}$ haben - forderte Ernst Hanisch bei der abschließenden Diskussion auf dem Salzburger Zeitgeschichtetag eine „Neuschreibung“ der Zeitgeschichte im Sinne einer Revidierung der NS-Zeit durch die jüngere Generation. ${ }^{23}$ Meinte Hanisch schon damals weniger die ,jüngere Generation“" als vielmehr einen neuen - kulturwissenschaftlichen - Zugang zur Zeitgeschichte? Zieht man Hanischs 2004, also ein Jahr später, erschienenen Beitrag zur „Dominanz des Staates“ heran, so dachte er jedoch mehr an ein In-Bezug-Setzen von Zeitgeschichtsforschung und (Wissenschafts)Politik. ${ }^{24}$ Jüngst hat der eindeutig als Zeithistoriker ausgewiesene Hanisch allerdings mit einem kulturwissenschaftlich orientierten Buchtitel aufhorchen lassen: „Landschaft

20 Vgl. auch: Ehmer, Sozialwissenschaftler/innen oder Zeithistoriker/innen, 63-64.

21 Vgl. Stefan Jordan, Theorien und Methoden der Geschichtswissenschaft, Paderborn ${ }^{3} 2016,143-$ 149 .

22 Die im Laufe der Jahre vakant gewordenen Professuren für Zeitgeschichte wurden mit dem Zusatz europäisch, international, global, nie aber mit österreichischem oder kulturwissenschaftlichem Schwerpunkt ausgeschrieben. Eine markante Zäsur erfuhr die Österreichische Zeitgeschichte zudem durch verzögerte Besetzungen der Professuren mit deutschen KollegInnen; teilweise wurde lange verhandelt und die KollegInnen kamen dann doch nicht oder sie nutzten die österreichische Professur als Sprungbrett und waren schnell wieder weg - oder sie betrieben keine österreichische Zeitgeschichte mehr. Vgl. Hanisch, Österreich; weiter u. a. das Verfahren um die Nachfolge von Helmut Konrad in Graz, vgl. Uni Graz: Panne bei Nachfolge an Zeitgeschichte-Professur, Der Standard, 19.04.2017, URL: https://www.derstandard.at/story/2000056177549/uni-graz-pannebei-nachfolge-an-zeitgeschichte-professur (abgerufen 16.09.2020); Tanja Malle, Mehr Deutsche, weniger österreichische Zeitgeschichte?, ORF Science, 10.02.2017, URL: https://science.orf.at/ stories/2825061/ (abgerufen 16.09.2020); Otmar Lahodynsky, Verdrängungsbeschwerden, Profil, 29.03.2013, URL: https://www.profil.at/home/universitaeten-verdraengungs-beschwerden-355720 (abgerufen 16.09.2020).

23 Vgl. 6. Österreichischer Zeitgeschichtetag, Salzburg 01.10.2003: Podiumsdiskussion mit Albert Lichtblau (Chair), Ernst Hanisch, Ilse König, Bertrand Perz, Regina Thumser, Heidemarie Uhl: Welche österreichische/n Zeitgeschichte/n? Kommentare und Diskussion zum Evaluierungsbericht der European Science Foundation.

24 Vgl. Hanisch, Österreich; vgl. auch: Ehmer, Sozialwissenschaftler/innen oder Zeithistoriker/innen. 
und Identität. Versuch einer österreichischen Erfahrungsgeschichte“. ${ }^{25}$ Neben der Erfahrungs- nimmt darin aber ebenso die Zeitgeschichte einen breiten Raum ein.

Während manche, auch in Deutschland, um das Jahr 2000 von einer Hochkonjunktur der „Zeitgeschichte“ sprachen, sah Martin Sabrow den Verlust ihrer „Strahlkraft“ zu einem Zeitpunkt, als die Zeitgeschichte „von der außeruniversitären Randdisziplin und politisch gestützten Volkspädagogik nach 1989 zur stärksten Lokomotive des Faches und seiner Wirkung in die Öffentlichkeit" wurde. Der Begriff Zeitgeschichte sei eine „Einheit, die mehr und mehr überdehnt“ worden sei, so Sabrow in einem Beitrag zum „Zeitraum der Zeitgeschichte“. ${ }^{26}$ Diese Überdehnung kam durch das Ausweiten des Zeitraums, aber auch durch die Öffnung hin zu interdisziplinären Ansätzen und zu den Kulturwissenschaften zustande. Mit den ab den 1970er-Jahren entwickelten neuen, richtungsweisenden Methoden, darunter die Mentalitätengeschichte, die Makro/Mikrohistorie oder die Alltagsgeschichte, taten sich Wegbereiter für die, so Joachim Landwehr, „,Wiedergeburt' der Kulturgeschichte“ auf. ${ }^{27}$ Die tatsächliche Geburtsstunde der Neueren Kulturgeschichte fiel in das bereits genannte Jahr 1989. Zugleich war die Neueste Zeitgeschichte vor allem in Deutschland - durch die „Wende“ gefordert. Wenn man will, so ist das Jahr 1989 der Kreuzungspunkt der beiden Zugänge. ${ }^{28}$ - Obwohl Österreich als „Insel der Seligen“ im Zentrum des Umbruchs lag, schlug sich das Jahr 1989 kaum in der österreichischen Zeitgeschichtsforschung nieder. Auch die - und ich nenne es salopp - „Befruchtung“ der Zeitgeschichte durch Theorien und Methoden der Kulturwissenschaften sollte erst später einsetzen. ${ }^{29} 2005$ explizierte schließlich die Wiener Zeithistorikerin Johanna Gehmacher die Forderung von Schweizer KollegInnen nach einer „innovativen“ Zeitgeschichte, nach einer „Zeitgeschichte zwischen Kriegsfolgenbewältigung, Globalisierung und cultural turn“.30 „Vor diesem Hintergrund“, so Gehmacher,

sei ein Konfliktfeld angesprochen, von dem vorab zu sagen ist, dass es sich keinesfalls auf die Zeitgeschichte beschränkt - gemeint ist jene Debatte, die unter wechselnden Begriffen,

25 Vgl. Ernst Hanisch, Landschaft und Identität. Versuch einer österreichischen Erfahrungsgeschichte, Wien/Köln/Weimar 2019.

26 Sabrow, Zeitraum.

27 Vgl. ebd.; Achim Landwehr, Kulturgeschichte, Version 1.o, Docupedia-Zeitgeschichte, URL: http:// docupedia.de/zg/landwehr_kulturgeschichte_v1_de_2013 (abgerufen 16.09.2020); vgl. auch: Metzler, Zeitgeschichte; Peter Burke, What is Cultural History?, Cambridge 2004.

28 Vgl. Sabrow, Zeitraum; Landwehr, Kulturgeschichte.

29 Vgl. auch: Ehmer, Sozialwissenschaftler/innen oder Zeithistoriker/innen, 66.

30 Gehmacher, Am Rand, 301. 
wie „Diskursanalyse“, dekonstruktivistische Methode, schließlich auch - meist abgrenzend - „Postmoderne“ der grundlegenden Frage nachgeht, was in der Geschichtswissenschaft über vergangene Wirklichkeiten ausgesagt werden kann. ${ }^{31}$

\section{Alles eine Frage der „Perspektive“? Gemeinsames und Trennendes}

Eine Definition des Verhältnisses der Zeitgeschichte zu den Kulturwissenschaften scheint schwierig, eine Standortbestimmung ohne den Verweis auf die „Kulturgeschichte“ kaum zu bewerkstelligen. Zudem werden die Begriffe „Kulturgeschichte“, „Kulturwissenschaft“ und „Kulturwissenschaften“ (!) oftmals identisch, ${ }^{32}$ aber somit irreführend verwendet. ${ }^{33}$ Sie entsprechen einander nicht. Achim Landwehr bringt in seinem Beitrag zur „Kulturgeschichte“ auf den Punkt, woran sich diese „Verwechslung“, diese falsch übergestülpte Definition, festmachen lässt - nämlich daran,

die „Kultur“ der Kulturwissenschaften und Kulturgeschichte gewissermaßen ex negativo zu definieren, insofern sie dasjenige repräsentieren soll, das übrig bleibt, nachdem man Politik, Gesellschaft, Wirtschaft, Recht, Technik und alle weiteren „harten“ Fakten des Lebens subtrahiert hat. ${ }^{34}$

Die „jüngere Kulturgeschichte“ definiere sich, ${ }^{35}$ so Landwehr weiter, allerdings nicht über einen „Gegenstandsbereich“, sondern durch ihre Perspektivierung auf „Sinnmuster und Bedeutungskontexte“. Zugrunde liegt die „kulturwissenschaftliche Einsicht [...], dass kein Mensch und keine soziale Gruppe umhinkommen, in Auseinandersetzung mit ihrer Umwelt dieser Umwelt bestimmte Bedeutungen zuzuschreiben". ${ }^{36}$

31 Ebd., 307.

32 Einen ausgezeichneten Überblick zu den Begrifflichkeiten bietet Hartmut Böhme, Was ist Kulturwissenschaft? Eine Einführung, URL: https://www.kuwi.europa-uni.de/de/lehrstuhl/sw/sw2/ lehre/08-09/Einfuehrung_in_die_Kulturwissenschaften/tutorium/Literatur1/boehme.pdf (abgerufen 16.09.2020).

33 Vgl. Johannes Hürter/Thomas Raithel/Jürgen Zarusky, Cultural Turn und NS-Geschichte, in: Vierteljahrshefte für Zeitgeschichte 65 (2017) 2, 219-221; vgl. insbesondere die redaktionelle Vorbemerkung der Herausgeber zu Stefan Hördlers Beitrag. Stefan Hördler, Sichtbarmachen. Möglichkeiten und Grenzen einer Analyse von NS-Täter-Fotografien, in: ebd., 259-271, 259.

34 Landwehr, Kulturgeschichte (Hervorhebung im Original).

35 Vgl. Lynn Hunt (Hg.), The New Cultural History, Berkeley/Los Angeles/London 1989.

36 Landwehr, Kulturgeschichte. 
Eine der wichtigsten Grundlagen der Kulturgeschichte ist ihre theoretische Reflexion(sfähigkeit), die als Basis den Poststrukturalismus, die Ethnologie, die Historische Anthropologie und etwa die Geschichtstheorie heranzieht. ${ }^{37}$ In Bereichen der empirischen Forschung rück(t)en Repräsentation, Medien, Körper und Bild in den Fokus; sie waren in "politik, sozial- und wirtschaftshistorischen Ansätzen“ etwa bis zum Erscheinen von Lynn Hunts Band zur jüngeren Kulturgeschichte im Jahr 1989 kaum berücksichtigt worden..$^{38}$ In Aleida Assmanns „Einführung in die Kulturwissenschaft" finden sich diese Themen durch die Kategorien Zeichen, Zeit, Raum, Gedächtnis und Identität erweitert. ${ }^{39}$

Im Grunde gibt es für die Kulturwissenschaften keine eindeutige Definition. Peter Burke benennt in seinem Beitrag „Einheit und Vielfalt der Kulturgeschichte“ die Cultural Studies als Kulturstudien, nicht als Kulturwissenschaften. Inzwischen besteht für die jeweiligen Studiengänge Kulturwissenschaften eine Flut von Bezeichnungen, etwa der geläufige Ausdruck der Cultural Studies (Birmingham School), die (Applied) Cultural Sciences (Schweden), weiter Cultures and Humanities, Humanities and Cultural Studies und vice versa Cultural Studies and Humanities. Einigkeit herrscht einerseits darüber, dass die Bedeutung weit über die „,Opernhaus'-Konzeption von Kultur" hinausgehe, ${ }^{40}$ andererseits dass der Begriff Kultur an sich schwer zu definieren sei. Im Grunde läuft es auf eine Definition des amerikanischen Historikers und Soziologen William H. Sewell hinaus, der das Wirrnis um die Kulturgeschichte/die Kulturwissenschaften schon 1999 als "cacophony of contemporary discourse about culture" bezeichnete. ${ }^{41}$ Erschwert wird der Begriff Kultur zudem durch die Pluralisierung in „Kulturen“ sowie durch das Prozesshafte im Verständnis der Bezeichnung. ${ }^{22}$ Silvia Tschopp etwa verweist auf die Spannungsfelder Identi-

37 Vgl. ebd.; Renato Rosaldo, Whose Cultural Studies?, in: American Anthropologist, New Series 96 (1994) 3, 524-529.

38 Vgl. Landwehr, Kulturgeschichte; Hunt, The New Cultural History.

39 Vgl. Aleida Assmann, Einführung in die Kulturwissenschaft. Grundbegriffe, Themen, Fragestellungen, Berlin 42017; Ljiljana Radonić/Heidemarie Uhl (Hg.), Gedächtnis im 21. Jahrhundert. Zur Neuverhandlung eines kulturwissenschaftlichen Leitbegriffs, Bielefeld 2016.

40 Roy Wagner, The Invention of Culture, Chicago/London ${ }^{2} 1981$, 21, zit. n. Peter Burke, Einheit und Vielfalt der Kulturgeschichte, in: Silvia Serena Tschopp (Hg.), Kulturgeschichte. Basistexte, Stuttgart 2008, 147-173, 148; vgl. auch: Ansgar Nünning, Vielfalt der Kulturbegriffe, URL: https://www.bpb. de/gesellschaft/bildung/kulturelle-bildung/59917/kulturbegriffe? $\mathrm{p}=$ all (abgerufen 16.09.2020).

41 William H. Sewell, The Concept(s) of Culture, in: Victoria E. Bonnell/Lynn Hunt (Hg.), Beyond the Cultural Turn. New Directions in the Study of Society and Culture, Berkeley/Los Angeles/London 1999, 35-61, 35, zit. n. Silvia Serena Tschopp, Einleitung, in: Tschopp (Hg.), Kulturgeschichte, 9-11, 9 .

42 Vgl. ebd., 9-10; Michael Maurer, Kulturgeschichte. Eine Einführung, Köln/Weimar/Wien 2008. 
tät - Alterität, Akkulturation - Kulturtransfer, Körper, Gender, politische, gesellschaftliche, ökonomische, ästhetische Handlungsräume sowie Eliten- versus Populärkultur. ${ }^{43}$ Befremdlich wiederum ist es, wenn ausgewiesene Kulturhistoriker wie Peter Gay die Frauen- und Geschlechtergeschichte in seinem 2008 erschienenen Band „Die Moderne" so gar nicht miteinbeziehen. ${ }^{44}$

Für Österreich konstatierte Ernst Hanisch ab etwa 1991 einen Boom der Neuen Kulturgeschichte und machte sie unter anderem für die Bereiche Geschlechtergeschichte, Semiotik, Mediengeschichte, Cultural Studies und Erinnerungsgeschichte fest. ${ }^{45}$ Hinsichtlich der Zeitgeschichte beklagte Hanisch - mit Verweis auf Josef Ehmer - ein Sichauflösen in und Verschmelzen mit den Kunstwissenschaften. ${ }^{46}$ Auch bei Hanisch verschwammen wiederum die Grenzen der Bezeichnungen. Er sah eine Konkurrenz der Sozial- und Kulturwissenschaften mit den Geschichtswissenschaften um das Forschungsfeld Zeitgeschichte. ${ }^{47}$ Allerdings definierte er die Gesellschaftsgeschichte als „anderen Typus der österreichischen Zeitgeschichte“; dieser sei im Versuch einer Synthese eine neue Aufgabe erwachsen. Gesellschaftsgeschichte wurde in der österreichischen Zeitgeschichte dreifach diskutiert: nach dem „Bielefelder Modell““48 nach Pierre Bourdieu und „Von den Rändern, den Minoritäten und marginalisierten Teilen der Gesellschaft" her. ${ }^{49}$

\section{Von Linz/Von Österreich aus: Standortbestimmung und Ausblicke}

Einer Verortung von Zeitgeschichte und Kulturwissenschaften müssen zunächst Definitionen zugrunde gelegt werden: Was ist Zeitgeschichte, was ist Kulturgeschichte und wie stehen diese in Beziehung zu den Kulturwissenschaften? Letztere verhinderten durch theoretische Ansätze und Analysekriterien zunehmend eine positivistische Geschichtsschreibung in der Zeitgeschichte. Hanisch hielt im Gegenzug fest, dass gerade das Beharren auf dem „Typus der positivistischen Ereignis- und

43 Vgl. Tschopp, Einleitung, 11; vgl. auch: Landwehr, Kulturgeschichte.

44 Vgl. Peter Gay, Die Moderne. Eine Geschichte des Aufbruchs, Frankfurt a. M. ${ }^{2} 2009$.

45 Vgl. ebd.

46 Vgl. ebd.

47 Vgl. Hanisch, Österreich.

48 Vgl. Hans-Ulrich Wehler, Aus der Geschichte lernen?, München 1988, 115-129.

49 Hanisch, Österreich; vgl. auch: Ehmer, Sozialwissenschaftler/innen oder Zeithistoriker/innen, 68-69. 
Tatsachengeschichte“ es ermöglicht habe, das Profil der Zeitgeschichte - weit über die 1970er-Jahre hinaus - aufrechtzuerhalten. ${ }^{50}$

Essenziell erscheinen darüber hinaus Fragen, wie sie etwa Achim Landwehr stellt, „ob die Kulturgeschichte [sic] nicht eine grundsätzliche Bedrohung für die Geschichtswissenschaft darstelle“; „ob sie nicht der Beliebigkeit“, „den ,kleinen“ und ,weichen' Themen Tür und Tor öffne“ und damit die Auseinandersetzung mit ,harten Themen' (politischen, wirtschaftlichen, sozialen) sowie den "großen historischen Prozessen“ hintanstelle. ${ }^{51}$ Die Begrifflichkeiten Kulturgeschichte/Kulturwissenschaft sind hier erneut vermengt. Gabriele Metzler, die die Zeitgeschichte noch 2014 in einer Krise sah, forderte wiederum, diese müsse sich neu ausrichten, „ihre Gegenstände neu definieren, ihre Perspektiven neu justieren“ und „die Frage nach ihrer Eigenschaft als historische (Teil)Disziplin neu beantworten“.52 Metzler ortete zudem einen „aus der Dominanz des Historismus geborenen Minderwertigkeitskomplex“ der ZeithistorikerInnen. Für Österreich lässt sich eine solche Tendenz nicht wahrnehmen, im Gegenteil. Hier sehen sich die ZeithistorikerInnen eher als „Elite“, nah am Puls der Zeit, präsent in der Medienlandschaft, in den Museen, tätig in vielerlei Kommissionen. Letztlich hängen zeithistorische Auftragsprojekte, wie bereits am Beispiel der Österreichischen Historikerkommission gezeigt, besonders vom politischen Willen ab. Aktuelle Opfer dieses Willens, der sich eher als Unwillen manifestiert, sind das „erste zeitgeschichtliche Museum der Republik“, das Haus der Geschichte Österreich, ${ }^{53}$ und die 2009 beschlossene und nach mittlerweile mehr als zehn Jahren noch immer nicht umgesetzte Neugestaltung der Österreich-Ausstellung „Entfernung. Österreich in Auschwitz“ im Staatlichen Museum AuschwitzBirkenau. ${ }^{54}$

Heute, rund zwanzig Jahre nach dem von mir festgemachten „Wendejahr“ 2003, arbeiten viele ZeithistorikerInnen mit einem kulturwissenschaftlichen Zugang. Ein frischer, kulturwissenschaftlicher Blick auf die damals gewonnenen Ergebnisse zeithistorischer Forschung wäre wünschenswert, vielleicht kann diesen aber

50 Hanisch, Österreich; vgl. auch: Nina Schneider, Transitional Justice: Historische Aufarbeitung und Geschichtsschreibung, in: Anja Mihr/Gert Pickel/Susanne Pickel (Hg.), Handbuch Transitional Justice, Wiesbaden 2016, 1-17.

51 Landwehr, Kulturgeschichte.

52 Metzler, Zeitgeschichte.

53 URL: https://www.hdgoe.at/museum (abgerufen 16.09.2020); vgl. Marcus Gräser, Große Ambition auf kleinem Raum. Das Haus der Geschichte Österreich, in: neues museum 2019/1, 62-69; Haus der Geschichte: Experten für Neubau am Heldenplatz, Der Standard, 09.12.2019, URL: https:// www.derstandard.at/story/2000112034921/hdgoe-expertengremium-spricht-sich-fuer-neubauam-heldenplatz-aus (abgerufen 16.09.2020).

54 Vgl. URL: https://www.nationalfonds.org/auschwitz.html (abgerufen 16.09.2020). 
erst die nächste Generation leisten: eine Neubewertung von Zwangsarbeit, von „Arisierung“ und Rückstellungen, eine Beleuchtung der Arbeit der Historikerkommission/en (etwa Oral-History-Interviews mit Kommissionsmitgliedern und ProjektnehmerInnen); 55 weiter wäre eine Reihe von Lücken zu schließen. So war der Abschluss der Verhandlungen über die Entschädigung von NS-Opfern mit den USA erfolgt, noch bevor konkrete Ergebnisse der historischen Aufarbeitung vorlagen. ${ }^{56}$ Der Zugang zu den Akten ist besser denn je, und die Kulturwissenschaften bieten neue, ergänzende Sichtweisen in vielen zeithistorischen Forschungsbereichen.

„Den Kulturwissenschaften“ wurde in Österreich ab den frühen 1970er-Jahren Rechnung getragen: 1971 wurden die „Innsbrucker Beiträge zur Kulturwissenschaft“ ins Leben gerufen, die vor allem einen sprachwissenschaftlichen Zugang haben. 1993 erfolgte die Gründung des IFK, des Internationalen Forschungszentrums für Kulturwissenschaften, ${ }^{57}$ das 2015 schließlich an die Kunstuniversität Linz angedockt wurde, um das Überleben der Institution zu sichern. ${ }^{58} 1997$ förderte das Bundesministerium für Bildung, Wissenschaft und Kultur einen für fünf Jahre gut dotierten Forschungsschwerpunkt mit dem Titel „Cultural Studies/Kulturwissenschaften“. Der Output mündete 2003 in einem von Lutz Musner und Christina Lutter herausgegebenen Band „Kulturstudien in Österreich“, an dem auch eine Reihe von ZeithistorikerInnen mitwirkte. ${ }^{59}$ In den Kulturwissenschaften früh federführend waren aber auch die ZeithistorikerInnen Siegfried Mattl (1954-2015) und Heidemarie Uhl. ${ }^{60}$ Eine Standortbestimmung ist wichtig, ist gut; interessant ist sie in meinen Augen insbesondere für den universitären Zeitgeschichtestandort Linz. Wenngleich Linz als Kaderschmiede für ProfessorInnen und Rektoren gelten kann - Helmut Konrad bezeichnete das Linzer Zeitgeschichteinstitut als Brutstätte für den „Marsch durch

55 Vgl. Blimlinger, Das geht sich nie aus; Clemens Jabloner, Die Historikerkommission der Republik Österreich, in: Forum Politische Bildung (Hg.), Gedächtnis und Gegenwart. HistorikerInnenkommissionen, Politik und Gesellschaft (Informationen zur Politischen Bildung 20), Innsbruck/Wien/ München/Bozen 2003/2004, 15-21.

56 Vgl. Stuart Eizenstat, Imperfect Justice. Looted Assets, Slave Labor, and the Unfinished Business of World War II, New York 2003.

57 Vgl. Manfred Wagner, Europäische Kulturgeschichte: gelebt, gedacht, vermittelt, Wien/Köln/Weimar 2009, 13-28, 13-14.

58 Vgl. URL: http://www.ifk.ac.at/index.php/mission-geschichte.html (abgerufen 14.09.2020).

59 Vgl. Lutz Musner/Christina Lutter (Hg.), Kulturstudien in Österreich, Wien 2003.

60 Vgl. Johanna Gehmacher/Albert Müller/Bertrand Perz, In memoriam Siegfried Mattl (19542015). Nachruf des Instituts für Zeitgeschichte, 28.04.2015, URL: https://medienportal.univie. ac.at/uniview/uni-intern/detailansicht/artikel/in-memoriam-siegfried-mattl-1954-2015/ (abgerufen 14.09.2020); URL: https://www.oeaw.ac.at/ikt/team/heidemarie-uhl/ (abgerufen 14.09.2020). 
die Institutionen“ - ${ }^{61}$, so war mit 2010 ursprünglich das Ende des Instituts laut Entwicklungsplan der Johannes Kepler Universität festgeschrieben. Nicht nur dessen „Rettung“, sondern auch die Etablierung eines Kulturwissenschaftsstudiums an der JKU erwiesen sich als schwierige Unterfangen; ${ }^{62}$ die ersten Versuche, das Linzer Institut für Neuere Geschichte und Zeitgeschichte wieder attraktiv zu machen, reichen bis in das Jahr 2005 zurück. Erste Entwürfe wurden schubladiert, 2008 entstand indes ein Bachelor „Kulturwissenschaften“ gemeinsam mit der Fernuniversität Hagen; dieser ist nun am Auslaufen. 2007 und 2009 rief Peter Becker - im Rahmen des Kulturhauptstadtjahres - in Linz die „Kulturgeschichte[!] tage“ ins Leben und organisierte sie mit dem Institut für Neuere Geschichte und Zeitgeschichte der Johannes Kepler Universität Linz. Einmal gab es ihn noch, den Kulturgeschichtetag, in Innsbruck 2012, der Versuch einer Wiederbelebung im Jahr 2018 scheiterte. Am Standort Linz gelang allerdings ein universitätsübergreifendes Bachelorstudium „Kulturwissenschaften neu“, das mit dem Wintersemester 2019/2020 gemeinsam mit der Kunstuniversität Linz und der Katholischen Privatuniversität Linz implementiert wurde und nun erfolgreich in das zweite Studienjahr geht. ${ }^{63}$

Das Herstellen eines Bezugs zur Zeitgeschichte ergibt ausschließlich Sinn im Rahmen der „Neueren Kulturgeschichte"64 und den in diesem Zusammenhang besonders „intensiv diskutierten Entwicklungen innerhalb der damit einhergehenden Veränderungen der Forschungsperspektive", 65 dem Cultural Turn, der für die Geschichtswissenschaft neue historische Fragestellungen und methodische Ansätze und damit vor allem neue Erkenntnisse brachte. ${ }^{66}$ Aber selbst diese Öffnung hin zu einer methodischen Vielfalt und Reflexion scheint nach wie vor nicht unumstritten: Johannes Hürter, Thomas Raithel und Jürgen Zarusky meinen in ihrer Einleitung zum Schwerpunktheft der „Vierteljahreshefte für Zeitgeschichte“ aus dem Jahr 2017, „,der Kulturalismus“ habe als „pluralistischer methodischer Ansatz“ die Zeitgeschichtsforschung erreicht. Diese öffne sich allerdings „aufgrund ihres stetigen Quellenzuflusses neuen Ansätzen eher langsam“.67 „Kulturgeschichtlich ,inspiriert", zumindest aber ,informiert' zu sein“, sei „zum Mainstream geworden“ und scheine

\footnotetext{
61 Konrad, Von Linz aus, 55-56.

62 Als zweiter „Rettungsanker“ erwies sich das ebenfalls großteils vom Institut bespielte Masterstudium der „Politischen Bildung“.

63 URL: https://www.ufg.at/Bachelorstudium.14672.o.html (abgerufen 14.09.2020).

64 Vgl. Maurer, Kulturgeschichte; Tschopp (Hg.), Kulturgeschichte; Lutter/Szöllősi-Janse/Uhl (Hg.), Kulturgeschichte; Wagner, Kulturgeschichte.

65 Tschopp, Einleitung, 9.

66 Vgl. ebd., 9-11; Ehmer, Sozialwissenschaftler/innen oder Zeithistoriker/innen, 61-62.

67 Hürter/Raithel/Zarusky, Cultural Turn und NS-Geschichte, 219-221.
} 
„die Grenze zu markieren, ob eine wissenschaftliche Studie state of the art sei oder nicht" ${ }^{68}$ Die Historikerin und Kulturwissenschaftlerin Karin Harrasser leitet den von ihr 2017 herausgegebenen Band „Auf Tuchfühlung. Eine Wissensgeschichte des Tastsinns“ mit den Worten ein, es sei ein „oberflächliches“, ein an der Oberfläche bleibendes, nicht tiefer eindringendes Buch. Obwohl sie dabei metaphorisch die Haut anspricht, nimmt sie zugleich der Kritik den Wind aus den Segeln ${ }^{69}$ und lässt kurz die Frage aufblitzen, ob nicht genau das den Unterschied zwischen KulturwissenschaftlerInnen und ZeithistorikerInnen ausmache: Evidenz und Aktenlage versus Metapher und diskursives Geplänkel?

(Zeit)HistorikerInnen können sich keine „oberflächlichen“ Publikationen leisten, sie wälzen Berge von Aktenbeständen. ${ }^{70}$ Dies beinhaltet einen Vorwurf, der sich bisweilen gegen KulturwissenschaftlerInnen zu richten scheint. So postulieren denn auch die Herausgeber des Bandes "Cultural Turn und NS-Geschichte“, dass hinsichtlich der Erforschung der NS-Diktatur ,auch künftig der wissenschaftliche Erkenntnisgewinn entscheidend $[\ldots$ sei ...] und nicht die Frage, ob die angewandte Methode ,richtig', ,modern' und ,innovativ “" sei. ${ }^{71}$ Das Zeitgeschichteinstitut der Universität Wien forderte neben Transnationalität und Interdisziplinarität „Klarheit in der Methodenauswahl“ und die kritische Aufnahme (!) von „trendige[n] ,Turns' vom Cultural über den Visual bis zum Memory Turn“. Weiter sollten „kulturgeschichtliche Fragestellungen und Methoden mit dem Politischen, Sozialen und Ökonomischen in Beziehung" gesetzt werden..$^{72}$ „Dass etwa Bild, Blick, Performativität oder Raum in den letzten Jahren zu zentralen Analysekategorien werden konnten“, gehe, so Doris Bachmann-Medick,

auf Veränderungen der gesellschaftlichen und medialen Wahrnehmungslage zurück: auf gesellschaftliche Bilderflut und Blickregime, auf die Übermacht der (Selbst-)Inszenierung in Medien und Politik, auf Raumumbrüche, globale Ortlosigkeit und die Ungleichheiten geopolitischer Raumbeziehungen. ${ }^{73}$

68 Ebd. (Hervorhebung im Original).

69 Karin Harrasser, Einleitung, in: Karin Harrasser (Hg.), Auf Tuchfühlung. Eine Wissensgeschichte des Tastsinns, Frankfurt a. M. 2017, 7-13, 7. Mit dem Wort „oberflächlich“ macht Harrasser die Publikation - vermutlich ungewollt - auch „klein“, bezeichnet sie als nicht ernst zu nehmend.

70 Vgl. auch: Ehmer, Sozialwissenschaftler/innen oder Zeithistoriker/innen, 65.

71 Hürter/Raithel/Zarusky, Cultural Turn und NS-Geschichte, 219-221, 221.

72 URL: https://www.univie.ac.at/zeitgeschichte/institut/schwerpunkte/osterreichische-zeitgeschichteals-republikgeschichte-im-internationalen-vergleich-bis-zur-gegenwart/ (abgerufen 12.08.2019). Vgl. URL: https://www.univie.ac.at/zeitgeschichte/institut/schwerpunkte/visuelle-zeit-und-kulturgeschichte-film-und-andere-medien/ (abgerufen 03.08.2019).

73 Bachmann-Medick, Cultural Turns. 
Auch Ernst Hanisch stellt in seinem Beitrag „Österreich - Die Dominanz des Staates“ die Frage nach dem „Pluralismus einer offenen Wissenschaft“ oder einer „postmoderne[n] Beliebigkeit“, aber auch danach, wo sich „angesichts dieser Herausforderungen die Zeitgeschichte eines kleinen Landes, mit knappen intellektuellen Ressourcen, dann platzieren“ könne. Bescheidenheit sei angesagt. Postmoderne Spielereien würden das Dilemma nicht lösen, vielmehr müsse die Nationalgeschichte „ein Schwerpunkt bleiben“: „in möglichst vielen Dimensionen, auf möglichst vielen Ebenen und bis nahe an die Gegenwart heranreichen“. Er sieht eine positive Herausforderung in einem das Erbe der Habsburger kritisch beleuchtenden transnationalen Zugang zur Zeitgeschichte. ${ }^{74}$ „Schließlich“, so argumentiert Doris Bachmann-Medick dagegen,

könnte die Traditions- und Disziplinensicherheit einer geisteswissenschaftlichen Integrations- und Orientierungswissenschaft, die immer noch gern in Nationalbezüge eingebunden wird, endgültig abgelöst werden: durch die Grenzüberschreitungen einer kulturwissenschaftlichen Vernetzungs- und Übersetzungswissenschaft, die sich immer stärker global ausrichtet. ${ }^{75}$

Es braucht die Phasen des Aktenbergewälzens, vermutlich legitimieren große, neu entdeckte Bestände auch heute noch positivistische Darstellungen, aber dann, in der Folge, müssen innovative Fragen an den "Stoff“, an die Quellen, gestellt werden. ${ }^{76}$ Ja, es gibt sie, die ausgewiesene kulturwissenschaftliche Zeitgeschichtsforschung. Sie manifestiert sich beispielsweise in der von Elisabeth Timm und Karin Harrasser herausgegebenen „Zeitschrift für Kulturwissenschaften“,77 in Arbeiten mit Fokus auf die Visual History, in den Sound Studies, in Publikationen wie der „Zeitgeschichte des Selbst um und nach 1968“, nicht zuletzt in dem mittlerweile ,ausgefransten ' Bereich der Erinnerungsforschung: ${ }^{78}$ Die Zeitgeschichte kann und muss durch kulturwissenschaftliche Neuerungen neue Perspektivierungen treffen. Ich plädiere zudem

74 Vgl. Hanisch, Österreich.

75 Bachmann-Medick, Cultural Turns.

76 Vgl. Stefan Haas, Theoriemodelle der Zeitgeschichte, Version 2.o, Docupedia-Zeitgeschichte, URL: http://docupedia.de/zg/haas_theoriemodelle_v2_de_2012 (abgerufen 14.09.2020).

77 Zuletzt: Zuzanna Dziuban/Kirsten Mahlke/Gudrun Rath (Hg.), Forensik. Zeitschrift für Kulturwissenschaften 13 (2019) 1.

78 Gerhard Paul, Visual History, Version 3.0, Docupedia-Zeitgeschichte, URL: https://docupedia.de/ zg/Visual_History_Version_3.o_Gerhard_Paul (abgerufen 16.09.2020); Pascal Eitler/Jens Elberfeld, Von der Gesellschaftsgeschichte zur Zeitgeschichte des Selbst - und zurück, in: Pascal Eitler/ Jens Elberfeld (Hg.), Zeitgeschichte des Selbst. Therapeutisierung - Politisierung - Emotionalisierung, Bielefeld 2015, 7-30. 
für eine neue, innovative Bezeichnung des Fachs, etwa „Zeithistorische Kulturwissenschaften“ oder „(Neueste) Kulturwissenschaftliche Zeitgeschichte“.79

79 Vgl. Jörg Rogge, Historische Kulturwissenschaften. Eine Zusammenfassung der Beiträge und konzeptionelle Überlegungen, in: Jan Kusber/Mechthild Dreyer/Jörg Rogge/Andreas Hütig (Hg.), Historische Kulturwissenschaften. Positionen, Praktiken und Perspektiven, Bielefeld 2010, 351-379; Schwarz, Die neueste Zeitgeschichte. 


\section{Zeitgeschichte und Rechtsgeschichte ${ }^{1}$}

Kamila Staudigl-Ciechowicz

\section{Einleitung}

\subsection{Zur Frage der Abgrenzung des Untersuchungsgegenstandes}

Rechtsgeschichte ist eine interdisziplinäre Wissenschaft, die rechts- und geschichtswissenschaftliche Methoden in sich vereint. Rechtswissenschaftliche Methoden werden immer dann angewendet, wenn juristische Texte wie zum Beispiel Gesetze oder Gerichtsurteile, inhaltlich analysiert werden müssen, was einen großen Teil der rechtshistorischen Arbeit ausmacht. Rechtlich relevante Ereignisse, wie etwa die Tatsache, dass ein Gesetzgebungsakt oder die Fällung eines Urteils überhaupt stattgefunden haben, sind dagegen in Zeit und Ort lokalisierbare Vorgänge und daher mit den allgemeinen Methoden der Geschichtswissenschaften zu ermitteln. Etwas vereinfachend kann gesagt werden, dass der Anteil geschichtswissenschaftlicher Methoden zunimmt, je weiter man sich in die Vergangenheit zurückbewegt und beispielsweise Urkunden nur mehr mithilfe profunder Kenntnisse in Diplomatik gelesen werden können. Je weiter sich der Rechtshistoriker der Gegenwart nähert, desto stärker ähnelt sein Quellenmaterial demjenigen des im geltenden Recht arbeitenden Juristen und kann er seine juristischen Vorkenntnisse besser zum Einsatz bringen. Dennoch ist auch die ,juristische Zeitgeschichte " deutlich von der dogmatischen Erschließung des geltenden Rechts verschieden. Denn während der am geltenden Recht arbeitende Jurist und insbesondere der Richter bestrebt ist, eine Rechtsfrage eindeutig zu lösen, also dem Rechtsstoff einen eindeutigen und insofern „objektiven" Sinn zu entnehmen, ist der rechtshistorisch arbeitende Wissenschaftler primär daran interessiert, wie die Rechtsfrage von Zeitgenossen - und sei es auch von Zeitgenossen der jüngsten Vergangenheit - angesehen und gelöst wurde. ${ }^{2}$

$1 \quad$ Für wertvolle Hilfe möchte ich Thomas Olechowski danken. Aufgrund der ursprünglichen Abgabefrist spiegelt der Beitrag - bis auf wenige Ausnahmen - den Literaturstand vom Frühjahr 2019 wider.

2 Thomas Olechowski, Rechtsgeschichte. Einführung in die historischen Grundlagen des Rechts, Wien ${ }^{5} 2019,20-21$. 
Eine in diesem Sinne verstandene Rechtsgeschichte wird sowohl von JuristInnen als auch von HistorikerInnen betrieben. Explizit der „Rechtsgeschichte“ gewidmete Professuren und Institute finden sich in Österreich allerdings nur an Juristischen Fakultäten. Die an Juristischen Fakultäten betriebene rechtsgeschichtliche Forschung hat sich lange Zeit auf Altertum und Mittelalter konzentriert und sich erst spät, etwa seit 1980, auch den jüngeren Perioden der Rechtsgeschichte zugewendet. Parallel dazu ist auch bei (Zeit)HistorikerInnen in jüngster Zeit ein vermehrtes Interesse an rechtshistorischen Problemen zu beobachten. Dies ist nicht zuletzt eine Folge der zunehmenden Verrechtlichung der Gesellschaft im 20. und 21. Jahrhundert, woraus sich die Notwendigkeit ergibt, das rechtliche Umfeld des erforschten Themas - auch bei nichtjuristischen Untersuchungen - zu berücksichtigen.

Daraus ergibt sich folglich die Frage, wie für die vorliegende Darstellung das Thema abzugrenzen ist. Ziel ist es, eine Standortbestimmung für die österreichische Rechtsgeschichte in ihrem Verhältnis zur Zeitgeschichte zu liefern. Um die Überschneidungen mit den anderen im Band dargestellten Bereichen so knapp wie möglich zu gestalten, wird sich der vorliegende Beitrag primär mit Forschungen und Untersuchungen von Rechtshistorikerinnen und Rechtshistorikern beschäftigen, die an den österreichischen Forschungsanstalten durchgeführt wurden. Dabei werden thematische Schwerpunkte gesetzt unter Berücksichtigung der Vielfalt an Forschungsthemen der letzten Jahrzehnte. Angesichts des zeitlichen und thematischen Umfangs strebt die Autorin zwar eine möglichst umfassende Darstellung an, ohne jedoch den Anspruch zu erheben, eine vollständige Forschungsdokumentation der letzten Jahrzehnte zu erstellen.

\subsection{Institutionelle Gegebenheiten}

Institutionell ist die österreichische Rechtsgeschichte an einzelnen Universitäten Österreichs und an der Österreichischen Akademie der Wissenschaften beheimatet. In den letzten Jahrzehnten wurden sowohl der Stellenwert der Rechtsgeschichte im juristischen Studium als auch die Zahl rechtshistorischer ProfessorInnen und AssistentInnen - trotz stetig steigender Zahl der Studierenden - immer weiter reduziert; in Salzburg existiert derzeit kein einziger der Rechtsgeschichte gewidmeter Lehrstuhl. Während das Fach „Rechtsgeschichte Österreichs“ 1978 noch zwölf Semesterstunden umfasste, wird es heute nur noch im Ausmaß von drei bis fünf Semesterstunden gelehrt. ${ }^{3}$

3 Nicht berücksichtigt wird in dieser Darstellung das Römische Recht, das ein eigenes Fach bildet. 
In diesem verkleinerten Rahmen hat der Stellenwert der juristischen Zeitgeschichte innerhalb des Faches Rechtsgeschichte stetig zugenommen; ein Blick auf Lehrmaterialien, Lehrveranstaltungsübersichten und Stoffabgrenzungen zeigt, dass sich das Fach Rechtsgeschichte zu etwa einem Drittel mit Themen des 20. und 21. Jahrhunderts beschäftigt.

Als innerösterreichische Vernetzungsstelle der rechtshistorischen Forschung in Österreich fungiert die Kommission für Rechtsgeschichte Österreichs (KRGÖ) der Österreichischen Akademie der Wissenschaften (ÖAW). Es handelt sich dabei um eine aus 15 ehrenamtlichen Mitgliedern, die in verschiedenen Bereichen der Rechtsgeschichte tätig sind, bestehende Kommission unter der Leitung von Thomas Olechowski. Als Zeitschrift der KRGÖ erscheint zweimal jährlich die Zeitschrift „Beiträge zur Rechtsgeschichte Österreichs",4 darüber hinaus publiziert die KRGÖ Quellen zur österreichischen Rechtsgeschichte in der Reihe „Fontes iuris“.

Größere Forschungsvorhaben sind mit den regulären finanziellen Mitteln der Forschungseinrichtungen kaum durchführbar, somit große Teile der Forschung in den Drittmittelbereich ausgelagert. Eine wichtige Finanzierungsmöglichkeit größerer Projekte - insbesondere der letzten zwanzig Jahre - bieten die Programme des österreichischen Fonds zur Förderung der wissenschaftlichen Forschung (FWF), der Jubiläumsfonds der OeNB und die Hochschuljubiläumsstiftung der Stadt Wien.

\section{Forschungsfelder und Forschungsthemen}

\subsection{Biographisch-rechtshistorische Forschungen}

Ein wiederkehrender Topos in der österreichischen Rechtsgeschichte sind Untersuchungen zu bedeutenden Persönlichkeiten in Politik, Rechtswissenschaft und Rechts(durch)setzung, womit nicht nur „Biographien“ im engeren Sinne, ${ }^{6}$ sondern auch mehr personenbezogene Arbeiten zu Entwicklungen im Recht gemeint sind. Während frühere Studien zwar einen wichtigen Beitrag zur biographischen Erforschung des Juristenstandes leisteten, allerdings oft die Tendenz hatten, die „schwierigen Jahre" von Austrofaschismus und Nationalsozialismus auszublenden oder nur

\footnotetext{
4 URL: http://www.rechtsgeschichte.at/index.php?article_id=7\&clang=1 (abgerufen 03.11.2020).

5 URL: http://www.rechtsgeschichte.at/index.php?article_id=9\&clang=1 (abgerufen 03.11.2020).

6 Auf den mehrfach gewandelten Stellenwert der „Biographie“ im Rahmen der historischen Forschung kann hier nur allgemein hingewiesen werden.
} 
beiläufig zu erwähnen, ${ }^{7}$ stellen sich die rezenten Arbeiten verstärkt auch der Herausforderung, diese zum Teil noch heiklen Topoi anzusprechen. ${ }^{8}$

Einen besonderen Stellenwert in der rechtshistorischen und rechtstheoretischen Forschung Österreichs der letzten Jahrzehnte hatte Hans Kelsen. ${ }^{9}$ Als „Architekt“ der österreichischen Bundesverfassung, ${ }^{10}$ bedeutender Richter am Verfassungsgerichtshof ${ }^{11}$ und Volksbildner ${ }^{12}$ prägte er die österreichische Rechtsordnung, ${ }^{13}$ war aber als

7 So bspw. Wolf-Dietrich Grussmann, Adolf Julius Merkl. Leben und Werk (Schriftenreihe des Hans Kelsen-Instituts 13), Wien 1989; in diesem Stil sind auch meist die Kurzbiographien gehalten, in: Wilhelm Brauneder (Hg.), Juristen in Österreich. 1200-1980, Wien 1987.

8 Intensiv mit diesen Aspekten beschäftigt sich anhand zahlreicher Kurzbiographien der Sammelband: Franz-Stefan Meissel/Thomas Olechowski/Ilse Reiter-Zatloukal/Stefan Schima (Hg.), Vertriebenes Recht - Vertreibendes Recht. Zur Geschichte der Wiener Rechts- und Staatswissenschaftlichen Fakultät zwischen 1938 und 1945 (Juridicum Spotlight 2), Wien 2012; Irmgard Schartner, Die Staatsrechtler der juridischen Fakultät der Universität Wien im, Ansturm ' des Nationalsozialismus. Umbrüche mit Kontinuitäten, Frankfurt a. M. 2011; Jürgen Busch/Kamila Staudigl-Ciechowicz, „Ein Kampf ums Recht“? Bruchlinien in Recht, Kultur und Tradition in der Kontroverse zwischen Kelsen und Hold-Ferneck an der Wiener Juristenfakultät, in: Szabolcs Hornyá/Botond Juhász/Krisztina Korsósné Delacasse/Zsuzsanna Peres (Hg.), Turning Points and Breaklines (Jahrbuch Junge Rechtsgeschichte 4), München 2009, 110-138.

9 Grundlegend nunmehr: Thomas Olechowski, Hans Kelsen. Biographie eines Rechtswissenschaftlers, Tübingen 2020.

10 Thomas Olechowski, Der Beitrag Hans Kelsens zur österreichischen Bundesverfassung, in: Robert Walter/Werner Ogris/Thomas Olechowski (Hg.), Hans Kelsen: Leben - Werk - Wirksamkeit (Schriftenreihe des Hans Kelsen-Instituts 32), Wien 2009, 211-230; Thomas Olechowski, Über Wert und Unwert von Verfassungspräambeln, in: Tamara Ehs (Hg.), Hans Kelsen und die Europäische Union. Erörterungen moderner (Nicht-)Staatlichkeit, Baden-Baden 2008, 75-93.

11 Robert Walter, Hans Kelsen als Verfassungsrichter (Schriftenreihe des Hans Kelsen-Instituts 27), Wien 2005; Ewald Wiederin, Hans Kelsen als praktischer Verfassungsrechtler, in: Nikita Aliprantis/ Thomas Olechowski (Hg.), Hans Kelsen: Die Aktualität eines großen Rechtswissenschafters und Soziologen des 20. Jahrhunderts (Schriftenreihe des Hans Kelsen-Instituts 36), Wien 2014, 109118.

12 Tamara Ehs, Hans Kelsen und politische Bildung im modernen Staat (Schriftenreihe des Hans Kelsen-Instituts 29), Wien 2007.

13 Thomas Olechowski, Kelsens Gutachten zur Wiederherstellung des österreichischen Staates von 1944, in: Clemens Jabloner/Thomas Olechowski/Klaus Zeleny (Hg.), Das internationale Wirken Hans Kelsens (Schriftenreihe des Hans Kelsen-Instituts 37), 121-140. 
Völkerrechtsexperte ${ }^{14}$ und vor allem als Begründer der „Reinen Rechtslehre“ ${ }^{15}$ von weltweiter Bedeutung. ${ }^{16}$ Maßgebliche Publikationen zu Kelsen erschienen in der Schriftenreihe des 1971 gegründeten Hans Kelsen-Instituts, ${ }^{17}$ welche 2020 bereits 41 Bände verzeichnet. ${ }^{18}$ Mehrere Projekte, finanziert durch den FWF unter der Leitung von Thomas Olechowski, beschäftigten sich mit dem Leben und Wirken Kelsens in Europa $^{19}$ und in Übersee ${ }^{20}$. Anhand von Kelsens akademischen und persönlichen Werdegang wird nicht nur seine individuelle Geschichte anschaulich dargestellt, vielmehr verdeutlicht die Darstellung auch das feindliche antisemitische Klima an der Universität Wien und zeigt die Verknüpfung Kelsens mit der jungen Republik auf.

Ebenfalls mit einer Persönlichkeit der Ersten Republik beschäftigt sich die preisgekrönte Biographie zum Anwalt Gustav Harpner, verfasst von Ilse Reiter-Zatlou-

14 Robert Walter/Clemens Jabloner/Klaus Zeleny (Hg.), Hans Kelsen und das Völkerrecht (Schriftenreihe des Hans Kelsen-Instituts 26), Wien 2004; Jürgen Busch/Judith v. Schmädel/Kamila StaudiglCiechowicz, „Peace Through Law“: Kelsen's (and His School's) Struggle for Universal Peace; in: Péter Cserne/Miklós Könczöl (Hg.), Legal and Political Theory in the Post-National Age (Central and Eastern European Forum for Legal, Political, and Social Theory Yearbook 1), Frankfurt a. M. 2011, 161-180; Tamara Ehs, Welt ohne Gericht. Die stets vertagte Völkerrechtsrevolution, in: Blätter für deutsche und internationale Politik 59 (2014) 4, 65-72.

15 Hier seien nur beispielhaft genannt: Robert Walter/Clemens Jabloner/Klaus Zeleny (Hg.), Der Kreis um Hans Kelsen. Die Anfangsjahre der Reinen Rechtslehre (Schriftenreihe des Hans KelsenInstituts 30), Wien 2008; Robert Walter (Hg.), Schwerpunkte der Reinen Rechtslehre (Schriftenreihe des Hans Kelsen-Instituts 18), Wien 1992.

16 Miriam Gassner, Der Kreis um Hans Kelsen in Lateinamerika. Wie die Reine Rechtslehre Lateinamerika eroberte, in: Beiträge zur Rechtsgeschichte Österreichs 4 (2014) 1, 64-83; Thomas Olechowski, Hans Kelsen in Berkeley. „Des Wandermüden letzte Ruhestätte“, in: Beiträge zur Rechtsgeschichte Österreichs 6 (2016) 1, 58-73; Thomas Olechowski/Stefan Wedrac, Hans Kelsen und Washington, in: Lucile Dreidemy/Richard Hufschmied/Agnes Meisinger/Berthold Molden/Eugen Pfister/Katharina Prager/Elisabeth Röhrlich/Florian Wenninger/Maria Wirth (Hg.), Bananen, Cola, Zeitgeschichte. Oliver Rathkolb und das lange 20. Jahrhundert, Wien/Köln/Weimar 2015, 280-295.

17 URL: https://www.univie.ac.at/staatsrecht-kelsen/index.php (abgerufen 03.11.2020).

18 URL: https://www.univie.ac.at/staatsrecht-kelsen/schriftenreihe.php (abgerufen 03.11.2020).

19 Das erste Projekt beschäftigte sich 2006 bis 2010 mit biographischen Untersuchungen zu Hans Kelsen 1881-1940: FWF-Projekt P 19287: „Biographische Untersuchungen zu Hans Kelsen in den Jahren 1881-1940", Projektleitung: Thomas Olechowski (2006-2010).

20 Das zweite Projekt hatte Kelsens Leben in Amerika 1940-1973 und die weltweite Verbreitung seiner Rechtslehre zum Gegenstand: FWF-Projekt P 23747: „Kelsens Leben in Amerika (1940-73) und die Verbreitung seiner Rechtslehre auf der Welt", Projektleitung: Thomas Olechowski (20112015). 
kal. ${ }^{21}$ Auch diese Studie geht weit über rein Biographisches hinaus und zeichnet ein Bild der untergehenden Monarchie und der frühen Jahre der Republik. Kleinere Untersuchungen zu den Lehrenden der Rechts- und Staatswissenschaftlichen Fakultät zeigen den Einfluss ihrer wissenschaftlichen Tätigkeit auf ihr persönliches Leben, insbesondere vor dem Hintergrund politischer Umbrüche. ${ }^{22}$

Weniger Untersuchungen gibt es zu den Juristen der Zweiten Republik. Dieses Gebiet ist bislang primär von Historikerinnen und Historikern bearbeitet worden. Erwähnenswert ist in diesem Zusammenhang die umfassende Biographie zu Christian Broda von Maria Wirth. ${ }^{23}$ Eine kollektiv-biographische Untersuchung zu den Lehrenden der Universität Wien - so auch den Juristen - mit besonderem Fokus auf die Entnazifizierung erstellten Roman Pfefferle und Hans Pfefferle. ${ }^{24}$

\subsection{Untersuchungen zum Juristenstand}

Mit den biographischen Forschungen durchaus verbunden sind die Untersuchungen zum Juristenstand, ein Themengebiet, das aus unterschiedlichen Blickwinkeln behandelt wurde. Beleuchtet wurde die Geschichte der verschiedenen juristischen Berufszweige sowohl als Geschichte einer Institution, aber auch aus biographischen und prosopographischen Gesichtspunkten. Dabei spielte die Zusammenarbeit mit den Vertreterinnen und Vertretern der entsprechenden Berufsgruppe durchaus eine große Rolle. Mithilfe interdisziplinärer Projekte wird so eine Standesgeschichte geschrieben, die auch aktuelle Entwicklungen berücksichtigt und im Rahmen von Tagungen der interessierten Fachwelt nähergebracht wird. In den letzten Jahren

21 Ilse Reiter-Zatloukal, Gustav Harpner (1864-1924). Vom Anarchistenverteidiger zum Anwalt der Republik, Wien/Köln/Weimar 2008.

22 Johannes Kalwoda, Ernst Schönbauer (1885-1966). Biographie zwischen Nationalsozialismus und Wiener Fakultätstradition, in: Beiträge zur Rechtsgeschichte Österreichs 2 (2012) 2, 282-316; Thomas Olechowski/Kamila Staudigl-Ciechowicz, Die Staatsrechtslehre an der Universität Wien 1933-1938, in: Ilse Reiter-Zatloukal/Christiane Rothländer/Pia Schölnberger (Hg.), Österreich 1933-1938. Interdisziplinäre Annäherungen an das Dollfuß-/Schuschnigg-Regime, Wien/Köln/ Weimar 2012, 227-241.

23 Maria Wirth, Christian Broda. Eine politische Biographie (Zeitgeschichte im Kontext 5), Göttingen 2011.

24 Roman Pfefferle/Hans Pfefferle, Glimpflich entnazifiziert. Die Professorenschaft der Universität Wien von 1944 in den Nachkriegsjahren. Mit zahlreichen Professorenportraits (Schriften des Archivs der Universität Wien 18), Göttingen 2014. 
konzentrierten sich entsprechende Untersuchungen auf die Richter ${ }^{25}$ sowie deren Interessensvertretung ${ }^{26}$ und die Staatsanwälte ${ }^{27}$. Methodisch besonders hervorzuheben ist in diesem Zusammenhang die von Gerald Kohl betreute Dissertation von Georg Grünstäudl, der für seine rechtsvergleichende Untersuchung der Richterschaft nach 1945 auch mit Interviews und Befragungen aktuelle Daten erhob. ${ }^{28}$ Ausgiebig mit dem österreichischen Notariatsrecht und dessen Einfluss auf die Nachfolgestaaten nach dem Zerfall der Monarchie beschäftigte sich Christian Neschwara. ${ }^{29}$ Ebenfalls in den letzten Jahren erforscht wurden die Rechtsanwälte als Berufsgruppe, ${ }^{30}$ wobei ein besonderer Fokus auf dem Schicksal jüdischer Rechtsanwältinnen und Rechtsanwälte lag. ${ }^{31}$

Gut untersucht - wenn auch nicht für das gesamte 20. Jahrhundert - ist die Fakultäts- bzw. Wissenschaftsgeschichte der Juridischen Fakultäten an den österreichischen Universitäten und deren Lehrende. Ab den späten 1960er-Jahren erschienen die ersten Publikationen, die sich mit einzelnen Lehrfächern des rechts- und staatswissenschaftlichen Studiums und deren Vertretern im 20. Jahrhundert beschäftigten - zunächst zur Universität Graz. ${ }^{32}$ Erst spät begann die Aufarbeitung

25 Gerald Kohl/Ilse Reiter-Zatloukal (Hg.), RichterInnen in Geschichte, Gegenwart und Zukunft. Auswahl, Ausbildung, Fortbildung und Berufslaufbahn, Wien 2014; Gerald Kohl, Richter in der Habsburgermonarchie, in: Kohl/Reiter-Zatloukal (Hg.), RichterInnen in Geschichte, 63-82; Gerald Kohl/Georg Grünstäudl, Akademikerkinder, Gerechtigkeitsfanatiker, Arbeitstiere? Soziale Herkunft, Ausbildung und berufliches Selbstverständnis der Richter/innen vom letzten Viertel des 20. Jahrhunderts bis heute, in: Kohl/Reiter-Zatloukal (Hg.), RichterInnen in Geschichte, 253-274.

26 Barbara Helige/Thomas Olechowski (Hg.), 100 Jahre Richtervereinigung. Beiträge zur Juristischen Zeitgeschichte, Wien 2007.

27 Gerald Kohl/Ilse Reiter-Zatloukal (Hg.), „... das Interesse des Staates zu wahren“. Staatsanwaltschaften und andere Einrichtungen zur Vertretung öffentlicher Interessen. Geschichte, Gegenwart, Perspektiven, Wien 2018.

28 Georg Grünstäudl, Richterauswahl und Richterausbildung im Systemvergleich. Österreich, Deutschland und die Schweiz seit 1945 (Schriftenreihe zur Justizforschung 16), Bern 2018.

29 Christian Neschwara, Österreichs Notariatsrecht in Mittel- und Osteuropa. Zur Geltung und Ausstrahlung des österreichischen Notariatsrechts (Schriftenreihe des österreichischen Notariats 13), Wien 2000.

30 Christian Neschwara, Die Entwicklung der Advokatur in Cisleithanien/Österreich vom Ende des 18. Jahrhunderts bis zum Ende der Monarchie 1918 im Spiegel der Gesetzgebung, in: Zeitschrift der Savigny-Stiftung für Rechtsgeschichte. Germanistische Abteilung 115 (1998) 1, 441-473.

31 Ilse Reiter-Zatloukal/Barbara Sauer, Advokaten 1938. Das Schicksal der in den Jahren 1938 bis 1945 verfolgten österreichischen Rechtsanwältinnen und Rechtsanwälte, Wien 2010.

32 Robert Walter, Die Lehre des öffentlichen Rechts an der Karl-Franzens-Universität zu Graz von 1827-1938, in: Juristische Blätter 88 (1966), 546-553; Gunter Wesener, Römisches Recht und Naturrecht (Geschichte der Rechtswissenschaftlichen Fakultät der Universität Graz 9/1), Graz 1978; Hermann Ibler, Nationalökonomie (Geschichte der Rechtswissenschaftlichen Fakultät der Univer- 
der nationalsozialistischen Phase der Fakultätsgeschichten, ${ }^{33}$ maßgeblich beteiligt an diesen Projekten war Ilse Reiter-Zatloukal, die das Thema Nationalsozialismus und die verschiedenen Facetten seiner Schreckensherrschaft nach wie vor untersucht und im Rahmen von Speziallehrveranstaltungen den Studierenden näherbringt. Einen neuen Anstoß für die Beschäftigung mit den Lehrenden 1938 brachte das Gedenkjahr 2008. Anlässlich des siebzigsten Gedenkjahres an den „Anschluss“ 1938 veranstaltete die Wiener Juridische Fakultät die Ausstellung „Erinnerungen im Exil - Exiled Memories“34 sowie eine Vortragsreihe, die sich mit den Inhalten des Studiums der Rechtswissenschaften im Nationalsozialismus beschäftigte, aber auch problematisierte, welche Lehrenden vertrieben worden bzw. welche Lehrenden an den Vertreibungen beteiligt gewesen waren und davon profitiert hatten. ${ }^{35}$ Mit den Wiener Staatsrechtlern in der Zeit des Nationalsozialismus beschäftigten sich Bernd-Christian Funk ${ }^{36}$ und darauf aufbauend Irmgard Schartner, die umfangreiche Archivquellen hierzu sichtete. ${ }^{37}$ Daneben wurden einzelne Beiträge zu den Lebensund Leidenswegen jüdischer Hochschullehrer im Nationalsozialismus publiziert, ${ }^{38}$

sität Graz 9/2), Graz 1985; Karlheinz Probst, Strafrecht - Strafprozeßrecht - Kriminologie (Geschichte der Rechtswissenschaftlichen Fakultät der Universität Graz 9/3), Graz 1987; Robert Walter, Die Lehre des Verfassungs- und Verwaltungsrechts an der Universität Wien von 1810-1938, in: Juristische Blätter 110 (1988), 609-624; Susanne Lichtmannegger, Die Rechts- und Staatswissenschaftliche Fakultät der Universität Innsbruck 1945-1955. Zur Geschichte der Rechtswissenschaft in Österreich im 20. Jahrhundert (Rechts- und Sozialwissenschaftliche Reiche 23), Frankfurt a. M. 1999; Gunter Wesener, Österreichisches Privatrecht an der Universität Graz (Geschichte der Rechtswissenschaftlichen Fakultät der Universität Graz 9/4), Graz 2002.

33 Oliver Rathkolb, Die Rechts- und Staatswissenschaftliche Fakultät der Universität Wien zwischen Antisemitismus, Deutschnationalismus und Nationalsozialismus 1938, davor und danach, in: Gernot Heiss/Siegfried Mattl/Sebastian Meissl/Edith Saurer/Karl Stuhlpfarrer (Hg.), Willfährige Wissenschaft. Die Universität Wien 1938-1945 (Österreichische Texte zur Gesellschaftskritik 43), Wien 1989, 197-232. Mit zahlreichen Beiträgen zu den verschiedenen Rechtsgebieten: Ulrike Davy/Helmut Fuchs/Herbert Hofmeister/Judith Marte/llse Reiter (Hg.), Nationalsozialismus und Recht. Rechtsetzung und Rechtswissenschaft in Österreich unter der Herrschaft des Nationalsozialismus, Wien 1990.

34 Wiener Rechtswissenschaft widmet sich Auswirkungen des Anschlusses - Ausstellung „Erinnerung im Exil - Exiled Memories" bis 12. Dez im Juridicum, Der Standard, URL: https://www. derstandard.at/story/1227287071792/wiener-rechtswissenschaft-widmet-sich-auswirkungen-desanschlusses (abgerufen 03.11.2020).

35 Die Ergebnisse dieser Untersuchungen wurden 2012 publiziert: Meissel/Olechowski/Reiter-Zatloukal/Schima (Hg.), Vertriebenes Recht - Vertreibendes Recht.

36 Bernd-Christian Funk, „Österreichische“ Staats(rechts)lehre in der nationalsozialistischen Ära, in: Davy/Fuchs/Hofmeister/Marte/Reiter (Hg.), Nationalsozialismus und Recht, 388-411.

37 Schartner, Staatsrechtler.

38 Franz-Stefan Meissel, Römisches Recht und Erinnerungskultur - zum Gedenken an Stephan Brassloff (1875-1943) (Vienna Law Inauguration Lectures. Antrittsvorlesungen an der Rechtswis- 
parallel dazu beschäftigten sich mehrere Mitglieder des Wiener Instituts für Rechtsgeschichte auch mit der Rolle der Lehrenden im Austrofaschismus. ${ }^{39}$ Verhältnismäßig spät erschienen Studien, welche die Juridischen Fakultäten in ihrer Gesamtheit für eine Zeitperiode untersuchten: 1999 lieferte Susanne Lichtmannegger eine Studie zur Innsbrucker Rechtsfakultät $1945-1955,{ }^{40}$ einen Überblick zu den Wiener Lehrenden im gleichen Zeitraum gab 2005 Margarete Grandner. ${ }^{41}$ Die Wiener Fakultät in der Zwischenkriegszeit erfuhr einzelne Überblicksdarstellungen, ${ }^{42}$ eine umfassende Studie wurde erst im Rahmen des FWF-Projekts „Die Wiener Rechtsund Staatswissenschaftliche Fakultät 1918-1938“43 erstellt und 2014 veröffentlicht. ${ }^{44}$ Sie behandelt nicht nur die unterschiedlichen "Schulen“ an der Wiener Fakultät, beispielsweise die Kreise um Kelsen, Mises und deren akademische „Feinde“, sondern gibt auch Einblicke in den akademischen Antisemitismus und beleuchtet das Frauenstudium sowie die Entwicklung der einzelnen Fächer und ihrer Vertreter.

senschaftlichen Fakultät der Universität Wien 1), Wien 2008; Klaus Taschwer, Kämpfer gegen den Antisemitismus und Opfer der Shoah. Leben und Sterben von Josef Hupka (1875-1944), Ordinarius für Handels- und Wechselrecht an der Universität Wien, in: Johannes Koll (Hg.), Säuberungen' an österreichischen Hochschulen 1934-1945. Voraussetzungen, Prozesse, Folgen, Wien/Köln/ Weimar 2017, 459-489; Ilse Reiter-Zatloukal, Georg Lelewer - eine biografische Skizze, in: Peter Bild/Irene Messinger (Hg.), A Cherry Dress. Kommentierte Memoiren der exilierten Bühnen- und Lebenskünstlerin Anita Bild (Manuscripta theatralia. Schriftenreihe zu raren Dokumenten und Archivalien im Fokus kulturhistorischer Grundlagenforschung 2), Göttingen 2018, 161-176.

39 Vgl. dazu näher unten Unterkapitel 2.6.

40 Lichtmannegger, Fakultät; Den Zeitraum 1669-1945 behandeln kursorisch: Gerhard Oberkofler/ Peter Goller, Geschichte der Universität Innsbruck 1669-1945 (Rechts- und Sozialwissenschaftliche Reihe 14), Frankfurt a. M. ${ }^{2} 1996$.

41 Margarete Grandner, Das Studium an der Rechts- und Staatswissenschaftlichen Fakultät der Universität Wien 1945-1955, in: Margarete Grandner/Gernot Heiss/Oliver Rathkolb (Hg.), Zukunft mit Altlasten: die Universität Wien 1945 bis 1955, Innsbruck 2005, 290-312.

42 Werner Ogris, 1884-1984. Einhundert Jahre Rechtswissenschaft im Haus am Ring (1986), in: Werner Ogris, Elemente Europäischer Rechtskultur, hg. v. Thomas Olechowski, Wien/Köln/Weimar 2003, 401-428; Ilse Reiter, JuristInnenausbildung an der Wiener Universität. Ein historischer Überblick, URL: https://homepage.univie.ac.at/ilse.reiter-zatloukal/aaalle\%2oPubl\%2oin\%2opdf/ Reiter-RewiStudiumWien.pdf (abgerufen 03.11.2020).

43 FWF-Projekt P 21280: „Die Wiener Rechts- und Staatswiss. Fakultät 1918-1933“, Projektleitung: Thomas Olechowski (2009-2013). Vgl. URL: http://www.univie.ac.at/restawi/ (abgerufen 03.11.2020).

44 Thomas Olechowski/Tamara Ehs/Kamila Staudigl-Ciechowicz, Die Wiener Rechts- und Staatswissenschaftliche Fakultät 1918-1938 (Schriften des Archivs der Universität Wien 20), Göttingen 2014; aus dem Projekt ging auch das Zeitschriften-Themenheft hervor: Kamila Staudigl-Ciechowicz/Tamara Ehs/Thomas Olechowski (Hg.), Zwischen Wien und Czernowitz. Rechts- und Staatswissenschaftliche Karrierewege um 1918. Beiträge zur Rechtsgeschichte Österreich 4 (2014) 2. 
Trotz vielfältiger Untersuchungen gibt es auch im Bereich der Geschichte des Juristenstandes immer noch wenig erforschte Gebiete. Wie auch in den anderen Bereichen ist bei den Untersuchungen zum Juristenstand festzustellen, dass die Periode nach 1945 bislang nur bruchstückhaft erforscht wurde. ${ }^{45}$ Ein spannendes, wenn auch schwieriges Unterfangen würde eine entsprechende Studie zu den Verwaltungsjuristen darstellen. Grundlegend als Ausgangspunkt für diese Untersuchung ist die Studie von Gabriele Kuscko-Stadlmayer ${ }^{46}$ zu nennen, so wie das zur Zeit laufende FWF-Projekt von Therese Garstenauer zum Thema „Österreichische Staatsbedienstete und deren standesgemäße Lebensführung (1918-1940)“47.

\subsection{Untersuchungen zu Rechtsetzung und Parlamentarismus}

Ein wichtiges Forschungsgebiet der Rechtsgeschichte ist die Entwicklung der Rechtsetzung und des Parlamentarismus. Der Begriff Rechtsetzung umfasst verschiedene Formen der Rechtserzeugung. Primär ist damit freilich die ordentliche Gesetzgebung, die sich seit dem Konstitutionalismus (großteils) im Parlament abspielte, gemeint, doch fallen unter diesen Begriff im weiteren Sinne auch die Rechtsgestaltung im Einzelfall durch Gerichte und Verwaltungsbehörden sowie die außerordentliche Gesetzgebung durch Organe der Exekutive - wie Bundespräsident oder Regierung. Dieses klassische Forschungsgebiet der Rechtsgeschichte hat auch in den letzten Jahren nicht an Aktualität verloren. In den letzten Jahrzehnten hatte das Thema Wahlrecht alleine wegen der zu feiernden Jubiläen Konjunktur: 2007 wurde an die Einführung des allgemeinen Männerwahlrechts hundert Jahre zuvor erinnert, ${ }^{48}$ 2018/2019 stand unter dem Motto von einhundert Jahren Frauenwahlrecht. ${ }^{49}$ Nicht zuletzt vor dem Hintergrund aktueller Tendenzen in den gegenwärtigen politischen Systemen mehrerer Staaten und anknüpfend an das Kriegswirtschaftliche Ermächtigungsgesetz aus dem Jahr 1917 veranstaltete die Kommission für Rechtsgeschichte Österreichs 2017 eine internationale Tagung, die sich mit Normsetzung im Notstand, insbesondere

45 So bspw. Thomas Olechowski, Die richterliche Standesvertretungen seit 1945, in: Helige/Olechowski (Hg.), Richtervereinigung, 147-189; Lichtmannegger, Fakultät.

46 Gabriele Kuscko-Stadlmayer, Das Disziplinarrecht der Beamten, Wien ${ }^{4} 2010$.

47 Therese Garstenauer, Projektblog: Österreichische Staatsbedienstete und standesgemäße Lebensführung, URL: https://homepage.univie.ac.at/therese.garstenauer/ (abgerufen 03.11.2020).

48 Thomas Simon (Hg.), Hundert Jahre allgemeines und gleiches Wahlrecht in Österreich. Modernes Wahlrecht unter den Bedingungen eines Vielvölkerstaates (Rechtshistorische Reihe 400), Frankfurt a. M. 2010.

49 Anita Ziegerhofer, Ohne Frauenbewegung kein Frauenwahlrecht. „Müht Euch um den Stimmzettel, er ist der Schlüssel zu allen bürgerlichen Rechten!“, Graz/Wien 2018. 
den außerordentlichen Gesetzgebungsbefugnissen exekutiver Organe beschäftigte..$^{50}$ Neben solchen thematisch fokussierten Konferenzen ist in diesem Zusammenhang die Internationale Kommission für die Geschichte des Ständewesens und der Parlamente (ICHRPI) zu nennen, die in jährlich stattfindenden Tagungen die Möglichkeit des breiten wissenschaftlichen Austauschs und der Vernetzung bietet. ${ }^{51}$

\subsection{Rechtliche Aspekte der Universitätsgeschichte}

Studien zu Universitätsrecht sowie Studienrecht stellen ein Forschungsgebiet dar, das in den letzten Jahrzehnten immer wieder von RechtshistorikerInnen bearbeitet worden ist. ${ }^{52}$ Bis in die 1970er-Jahre basierte das österreichische Studien- und Universitätssystem auf dem durch Unterrichtsminister Leo Thun von Hohenstein Mitte des 19. Jahrhunderts eingeführten System. Während sich eine von Hans Lentze 1962 publizierte Monographie ${ }^{53}$ auf das 19. Jahrhundert konzentrierte, präsentierte Sascha

50 Das Zeitschriften-Themenheft erschien 2018: Christian Neschwara/Ilse Reiter-Zatloukal/Kamila Staudigl-Ciechowicz/Anita Ziegerhofer (Hg.), Normsetzung im Notstand. Außerordentliche Gesetzgebungsbefugnisse im 19. und 20. Jahrhundert. Beiträge zur Rechtsgeschichte Österreich 8 (2018) 2. Zum Kriegswirtschaftlichen Ermächtigungsgesetz sind insbes. die beiden Untersuchungen von Gernot Hasiba zu erwähnen: Gernot D. Hasiba, Das Kriegswirtschaftliche Ermächtigungsgesetz (KWEG) von 1917. Seine Entstehung und seine Anwendung vor 1933, in: Rechtswissenschaftliche Fakultät der Universität Salzburg (Hg.), Aus Österreichs Rechtsleben in Geschichte und Gegenwart. Festschrift für Ernst C. Hellbling zum 80. Geburtstag, Berlin 1981, 543-565; ders., Das Notverordnungsrecht in Österreich (1848-1917). Notwendigkeit und Mißbrauch eines „Staatserhaltenden Instrumentes“" (Studien zur Geschichte der österreichisch-ungarischen Monarchie 22), Wien 1985.

51 URL: http://www.ichrpi.com/ (abgerufen 03.11.2020).

52 So u. a. Ilse Reiter, Die Universität im Dritten Reich. Hochschulrecht im Dienste ideologischer Gleichschaltung, in: Davy/Fuchs/Hofmeister/Marte/Reiter (Hg.), Nationalsozialismus und Recht, 347-387; Thomas Simon, Die Thun-Hohensteinsche Universitätsreform und die Neuordnung der juristischen Studien- und Prüfungsordnung in Österreich, in: Zoran Pokrovac (Hg.), Juristenausbildung in Osteuropa bis zum Ersten Weltkrieg, Frankfurt a. M. 2007, 1-36; Thomas Olechowski, Rechtsphilosophie gegen Rechtsgeschichte? Ein Juristenstreit aus der Zwischenkriegszeit an der Wiener Rechtsfakultät, in: Gerald Kohl/Christian Neschwara/Thomas Simon (Hg.), Festschrift für Wilhelm Brauneder zum 65. Geburtstag. Rechtsgeschichte mit internationaler Perspektive, Wien 2008, 425-442; Thomas Olechowski, Zweihundert Jahre österreichisches Rechtsstudium. Rückblicke und Ausblicke, in: Clemens Jabloner/Gabriele Kucsko-Stadlmayer/Gerhard Muzak/Bettina Perthold-Stoitzner/Karl Stöger (Hg.), Vom praktischen Wert der Methode. Festschrift für Heinz Mayer zum 65. Geburtstag, Wien 2011, 455-479; Kamila Staudigl-Ciechowicz, „... dass die Facultätsstudien Staatsdiener, nicht Gelehrte heranzubilden haben ..." - Zur Einführung der juristischen Staatsprüfung 1850, in: Beiträge zur Rechtsgeschichte Österreichs 1 (2011) 2, 339-355.

53 Hans Lentze, Die Universitätsreform des Ministers Graf Leo Thun-Hohenstein, Graz/Wien/Köln 1962. 
Ferz 2000 eine Studie, ${ }^{54}$ die sich mit den Universitätsreformen bis zum Universitätsorganisationsgesetz 1993 auseinandersetzte. Einen zusätzlichen Aufschwung erfuhr das Thema Universität durch das 650. Gründungsjubiläum der Wiener Universität 2015. Gleich mehrere Beiträge rund um das Jubiläumsjahr 2015 beschäftigten sich mit der Rechtsgeschichte der Wiener Universität sowie mit der Ausgestaltung der juridischen Studien. 55 Für den Zeitraum 1848 bis 1938 folgte 2017 eine vertiefende Studie zum universitären Dienst, Habilitations- und Disziplinarrecht, die zum ersten Mal die Fülle der Disziplinarfälle gegen Lehrende berücksichtigte. ${ }^{66}$ Thematisch verwandt, obwohl nicht direkt mit den Universitäten verbunden, sei hier auch auf Arbeiten zum Vereinswesen der Juristen und Staatswissenschaftler verwiesen. ${ }^{57}$

\subsection{Der Erste Weltkrieg, Zerfall Österreich-Ungarns und österreichisches Minderheitenrecht}

Das Centennium des Ersten Weltkrieges gab Anlass auch zu einigen rechtshistorischen Arbeiten, unter anderem zur rechtlichen Dimension der Kriegserklärung

54 Sascha Ferz, Ewige Universitätsreform. Das Organisationsrecht der österreichischen Universitäten von den theresianischen Reformen bis zum UOG 1993 (Rechts- und Sozialwissenschaftliche Reihe 27), Frankfurt a. M./Berlin/Bern/Bruxelles/New York/Oxford/Wien 2000.

55 Thomas Olechowski, Jurisprudenz oder Rechtswissenschaft? Zur Entwicklung des wissenschaftlichen Leitbilds der juristischen Fakultät der Universität Wien seit 1852, in: Karl A. Fröschl/Gerd B. Müller/Thomas Olechowski/Brigitta Schmidt-Lauber (Hg.), Reflexive Innensichten aus der Universität. Disziplinengeschichte zwischen Wissenschaft, Gesellschaft und Politik (650 Jahre Universität Wien. Aufbruch ins neue Jahrhundert 4), Göttingen 2015, 401-416; Ilse Reiter-Zatloukal, Restauration - Fortschritt - Wende. Politik und Hochschulrecht 1945-2015, in: Mitchell G. Ash/ Josef Ehmer (Hg.), Universität - Politik - Gesellschaft (650 Jahre Universität Wien. Aufbruch ins neue Jahrhundert 2), Göttingen 2015, 461-494; Kamila Staudigl-Ciechowicz, Zwischen Aufbegehren und Unterwerfung. Politik und Hochschulrecht 1848-1945, in: Ash/Ehmer (Hg.), Universität, 429-460; Kamila Staudigl-Ciechowicz, Die Wiener Rechts- und Staatswissenschaftliche Fakultät 1933-1945, in: Fröschl/Müller/Olechowski/Schmidt-Lauber (Hg.), Reflexive Innensichten, 597606.

56 Kamila Staudigl-Ciechowicz, Das Dienst-, Habilitations- und Disziplinarrecht der Universität Wien 1848-1938. Eine rechthistorische Untersuchung zur Stellung des wissenschaftlichen Universitätspersonals (Schriften des Archivs der Universität Wien 22), Göttingen 2017.

57 Wilhelm Brauneder, Leseverein und Rechtskultur. Der juridisch-politische Leseverein zu Wien 1840-1990, Wien 1992; Tamara Ehs, Das extramurale Exil, in: Evelyn Adunka/Georg Traska/Gerhard Lamprecht (Hg.), Jüdisches Vereinswesen in Österreich im 19. und 20. Jahrhundert (Schriftenreihe des Centrums für Jüdische Studien der Universität Graz 18), Innsbruck 2011, 15-29. 
Österreich-Ungarns. ${ }^{58}$ Vor allem aber die Friedensschlüsse, die diesen Krieg beendeten, sind breit untersucht worden. Als Kooperationsprojekt mehrerer österreichischer RechtshistorikerInnen unter der Leitung von Anita Ziegerhofer startete 2017 ein vom FWF gefördertes Projekt „Die rechtliche Bedeutung des Vertrags von St. Germain", das es sich zum Ziel macht, eine Kommentierung des gesamten Vertrags mit juristischen Methoden vorzulegen. ${ }^{59}$ Mit einzelnen Teilen des Vertrags von St. Germain haben sich bereits in den letzten Jahrzehnten RechtshistorikerInnen und JuristInnen beschäftigt - hier sei nur auf die Minderheitenbestimmungen hingewiesen, die nach wie vor in Kraft sind. ${ }^{60}$

\subsection{Erste Republik und Austrofaschismus}

Aus rechtshistorischer Sicht bietet diese Periode freilich eine Vielzahl an spannenden, thematisch unterschiedlich ausgerichteten Anknüpfungspunkten: Große Veränderungen in der verfassungsrechtlichen Ordnung Österreichs, ${ }^{61}$ die Neufor-

58 Christoph Schmetterer, Die Kriegserklärung vom 28. Juli 1914 aus rechtshistorischer Sicht, in: Journal on European History of Law 4 (2013) 2, 69-75; ders., Hans Kelsens Vorschläge zur Reform der österreichisch-ungarischen Wehrverfassung, in: Beiträge zur Rechtsgeschichte Österreichs 6 (2016) 1, 129-155.

59 Siehe dazu künftig: Herbert Kalb/Thomas Olechowski/Anita Ziegerhofer (Hg.), Der Vertrag von St. Germain, Wien 2021 (in Vorbereitung). Aus dem genannten FWF-Projekt sind bereits zwei Zeitschriftenthemenhefte hervorgegangen: Michael Gehler/Thomas Olechowski/Stefan Wedrac/ Anita Ziegerhofer (Hg.), Der Vertrag von Saint Germain im Kontext der europäischen Nachkriegsordnung. Beiträge zur Rechtsgeschichte Österreichs 9 (2019) 2; Anita Ziegerhofer (Hg.), Eine Friedensordnung für Europa? Der Vertrag von St. Germain im Kontext der Pariser Vororte-Verträge. zeitgeschichte 46 (2019) 3.

60 Ilse Reiter, Ausgewiesen, abgeschoben. Eine Geschichte des Ausweisungsrechts in Österreich vom ausgehenden 18. bis ins 20. Jahrhundert (Studien aus Recht, Geschichte und Gesellschaft 2), Frankfurt a. M./Berlin/Bern/Bruxelles/New York/Oxford/Wien 2000; Ilse Reiter, Die autochthonen Volksgruppen Österreichs. Ein Überblick über die Rechtslage von 1848 bis in die Gegenwart, URL: https://forhistiur.de/2001-04-reiter/?l=de (abgerufen 03.11.2020); Stefan Hammer, Das Recht der autochthonen Minderheiten in Österreich, in: Christoph Pan/Beate Sibylle Pfeil (Hg.), Zur Entstehung des modernen Minderheitenschutzes in Europa. Handbuch der europäischen Volksgruppen, Bd. 3, Wien/New York 2006, 300-329.

61 Klaus Berchtold, Verfassungsgeschichte der Republik Österreich, Bd. 1: 1918-1933: Fünfzehn Jahre Verfassungskampf, Wien 1998; Gerald Kohl, Das bundesstaatliche Prinzip in der österreichischen Verfassungsrechtswissenschaft der Ersten Republik, in: Martin P. Schennach (Hg.), Rechtshistorische Aspekte des österreichischen Föderalismus. Beiträge zur Tagung an der Universität Innsbruck am 28. und 29. November 2013, Wien 2015, 117-145; Ewald Wiederin, Die Rechtsstaatskonzeption der Verfassung 1934. Zugleich Mutmaßungen über die Gründe einer Begriffsrenaissance, in: 
mierung als mitteleuropäischer Kleinstaat, ${ }^{62}$ aber auch die Auseinandersetzung mit den sozialen Herausforderungen ${ }^{63}$ und privatrechtlichen Problemen ${ }^{64}$ zeigen nur einige wenige Themenschwerpunkte. Eine umfassende Darstellung erfuhren einzelne Organe des demokratischen ${ }^{65}$ wie auch des autoritären Staates. ${ }^{66} \mathrm{Im}$ Fo-

Parlamentsdirektion (Hg.), Staats- und Verfassungskrise 1933, Wien/Köln/Weimar 2014, 75-97; Helmut Wohnout, Die Verfassung 1934 im Widerstreit der unterschiedlichen Kräfte im Regierungslager, in: Ilse Reiter-Zatloukal/Christiane Rothländer/Pia Schölnberger (Hg.), Österreich 1933-1938. Interdisziplinäre Annäherungen an das Dollfuß-/Schuschnigg-Regime, Wien/Köln/ Weimar 2012, 17-30.

62 Wilhelm Brauneder, Deutsch-Österreich 1918. Die Republik entsteht, Wien 2000; Christoph Schmetterer, Die Entstehung der Ersten Republik Österreich 1918-1920 aus rechtshistorischer Sicht, in: Christoph Gusy/Robert Chr. van Ooyen/Hendrik Wassermann (Hg.), 100 Jahre Weimarer und Wiener Republik - Avantgarde der Pluralismustheorie (Recht und Politik. Beihefte 3), Berlin 2018, 95-114; Christian Neschwara/J. Michael Rainer, 100 Jahre Republik Österreich. Die Provisorische Nationalversammlung und ihre Rolle bei der Entstehung der Republik Deutschösterreich, Graz 2018.

63 Michael Stampfer, Die Anfänge des Mieterschutzes in Österreich, Wien 1995; Mathias Krempl, Die Genese des Arbeitslosenversicherungsgesetzes aus dem Jahr 1920 - Eine „Vogel-Strauß-Politik“?, in: Das Recht der Arbeit 2017/2, 33-68.

64 So u. a. Oskar Lehner, Familie - Recht - Politik. Die Entwicklung des österreichischen Familienrechts im 19. und 20. Jahrhundert, Wien/New York 1987; Ulrike Harmat, Ehe auf Widerruf? Der Konflikt um das Eherecht in Österreich 1918-1938 (Studien zur Europäischen Rechtsgeschichte 121), Frankfurt a. M. 1999; Gerald Kohl, Stockwerkseigentum, Berlin 2007; Christian Neschwara, Überleitung ungarischen Rechts im österreichischen Burgenland nach 1921, in: Jan Neckář/Michal Radvan/David Sehnálek/Jiří. Valdhans (Hg.), Dny práva - 2008 - Days of Law (Acta Universitatis Brunensis Iuridica 337), Brünn 2009, 469-495; Herbert Kalb, Das Eherecht in der Republik Österreich 1918-1978, in: Beiträge zur Rechtsgeschichte Österreichs 2 (2012) 1, 27-43; Martin Schennach, The Effects of World War I on Austrian Private Law, in: Comparative Legal History 2 (2014) 2, 215-241; Christian Neschwara, Konfessionell gebundene Ehehindernisse im österreichischen Allgemeinen Bürgerlichen Gesetzbuch. Strategien zur Umgehung des österreichischen Eherechts, in: Beiträge zur Rechtsgeschichte Österreichs 8 (2018) 1, 173-199; Kamila Staudigl-Ciechowicz, Österreich: Das österreichische Zivilrecht und die österreichische Zivilrechtswissenschaft in der Zwischenkriegszeit, in: Martin Löhnig/Stefan Wagner (Hg.), „Nichtgeborene Kinder des Liberalismus“? Zivilgesetzgebung im Mitteleuropa der Zwischenkriegszeit, Tübingen 2018, 39-69.

65 Lothar Höbelt, Die Bundespräsidentenwahl in der 1. und 2. Republik, Wien 1986; Christian Neschwara, Verfassungsgerichtsbarkeit und Parlament in Österreichs erster Republik, in: Jean Garrigues/Eric Anceau/Frédéric Attal/Noëlline Castagnez, Noëlle Dauphin, Sabine Jansen/Olivier Tort (Hg.), Actes du 57e congrès de la CIHAE: Assemblées et parlements dans le monde, du Moyen-Age à nos jours, Paris 2010, 1235-1248; ders., Verfassungsgerichtsbarkeit im Spannungsfeld von Regierung und Parlament: Österreichs Verfassungsgerichtshof 1918-1934, in: Zeitschrift der SavignyStiftung für Rechtsgeschichte. Germanistische Abteilung 130 (2013) 1, 435-453.

66 Helmut Wohnout, Regierungsdiktatur oder Ständeparlament? Gesetzgebung im autoritären Österreich, Wien 1993; Christoph Schmetterer, Die Gesetzgebung im Österreichischen Ständestaat 1934-1938, in: Franz Adlgasser/Jana Malínská/Helmut Rumpler/Lubos Velek (Hg.), Hohes Haus! 
kus der Forschung standen auch die Verfassungsgerichtsbarkeit ${ }^{67}$ sowie Aspekte des Föderalismus, ${ }^{68}$ ein Thema, das auch 2013 unter der Leitung von Martin Schennach in Innsbruck vertieft wurde. ${ }^{69}$

Gerade das Thema Austrofaschismus hat in den letzten Jahren einen merkbaren Aufschwung erfahren ${ }^{70}$ - von rechtshistorischer Seite sind insbesondere Ilse ReiterZatloukal und ihre Mitarbeiterinnen Christiane Rothländer und Pia Schölnberger zu nennen, die zwei große Tagungen organisierten ${ }^{71}$ und eine Reihe von Spezialun-

150 Jahre moderner Parlamentarismus in Österreich, Böhmen, der Tschechoslowakei und der Republik Tschechien im mitteleuropäischen Kontext (Studien zur Geschichte der österreichischungarischen Monarchie 35), Wien 2015, 281-304.

67 Christian Neschwara, Hans Kelsen und das Problem der Dispensehen, in: Robert Walter/Werner Ogris/Thomas Olechowski (Hg.), Hans Kelsen: Leben - Werk - Wirksamkeit (Schriftenreihe des Hans Kelsen-Instituts 32), Wien 2009, 249-267; Gerald Kohl/István Szabó, Staatsgerichtsbarkeit in Mitteleuropa. Beiträge zur Tagung „Staatsgerichtsbarkeit in Vergangenheit und Gegenwart", Budapest 2015 (A Pázmány Péter Katolikus Egyetem Jog- és Államtudományi Karának Könyvei Tanulmányok 38), Budapest 2017.

68 Martin Polaschek/Thomas Olechowski, Verfassungsentwürfe, Föderalismus und „Anschlussfrage“, in: Robert Kriechbaumer/Michaela Maier/Maria Mesner/Helmut Wohnout (Hg.), Die Junge Republik. Österreich 1918/19, Wien/Köln/Weimar 2018, 77-86.

69 Der entsprechende Tagungsband erschien 2015: Martin P. Schennach (Hg.), Rechtshistorische Aspekte des österreichischen Föderalismus. Beiträge zur Tagung an der Universität Innsbruck am 28. und 29. November 2013, Wien 2015.

70 Peter Huemer, Verfassungsbruch 1933/34, in: Erich Fröschl/Helge Zoitl (Hg.), Der 4. März 1933. Vom Verfassungsbruch zur Diktatur, Wien 1984, 105-122; Heimo Halbrainer/Martin Polaschek, „Im Namen des Bundesstaates Österreich“. Die politischen Verfolgungen im Austrofaschismus in der Steiermark, in: Werner Anzenberger/Heimo Halbrainer (Hg.), Unrecht im Sinne des Rechtsstaates. Die Steiermark im Austrofaschismus, Graz 2014, 239-253; Richard Lein, Selbstausschaltung oder geplanter Putsch? Das Ende des Parlamentarismus im März 1933, in: Franz Adlgasser/ Jana Malínská/Helmut Rumpler/Luboš Velek (Hg.), Hohes Haus! 150 Jahre moderner Parlamentarismus in Österreich, Böhmen, der Tschechoslowakei und der Republik Tschechien im mitteleuropäischen Kontext (Studien zur Geschichte der österreichisch-ungarischen Monarchie 35), Wien 2015, 259-280; Martin Polaschek, Statt „ständisch-autoritär“ ständig autoritär. Die Steiermark zwischen 1933 und 1938, in: Alfred Ableitinger (Hg.), Bundesland und Reichsgau. Demokratie, "Ständestaat" und NS-Herrschaft in der Steiermark 1918 bis 1945 (Geschichte der Steiermark 9/I), Wien/Köln/Weimar 2015, 239-287; ders., Verteidigung einer Demokratie. 12. Februar 1934, Graz 2004; ders./Heimo Halbrainer (Hg.), Aufstand, Putsch und Diktatur. Das Jahr 1934 in der Steiermark, Graz 2007. Erwähnt sei hier auch: Pia Schölnberger, Das Anhaltelager Wöllersdorf 1933-1938. Strukturen - Brüche - Erinnerungen, Wien 2015.

71 Vgl. die aus diesen Tagungen hervorgegangenen Tagungsbände: Ilse Reiter-Zatloukal/Christiane Rothländer/Pia Schölnberger (Hg.), Österreich 1933-1938. Interdisziplinäre Annäherungen an das Dollfuß-/Schuschnigg-Regime, Wien/Köln/Weimar 2012; Gertrude Enderle-Burcel/Ilse ReiterZatloukal (Hg.), Antisemitismus in Österreich 1933-1938, Wien/Köln/Weimar 2018. 
tersuchungen vorlegten, namentlich zu politisch motiviertem Vermögensentzug ${ }^{72}$ und zu politischen Ausbürgerungen im Austrofaschismus ${ }^{73}$.

\subsection{Das Unrecht im Recht - Österreich und der Nationalsozialismus}

Erst in den 1980er-Jahren begannen sich RechtshistorikerInnen mit der Entstehung und dem Einfluss des nationalsozialistischen Rechts auf die österreichische Rechtsordnung, aber auch mit den rechtlichen Aspekten der nationalsozialistischen Herrschaft auseinanderzusetzen. Einen wichtigen Beitrag leistete eine 1988 von mehreren (damals) jüngeren Mitgliedern der Wiener Rechtswissenschaftlichen Fakultät organisierte Tagung, deren Ergebnisse in dem Sammelband „Nationalsozialismus und Recht" publiziert wurden. ${ }^{74}$ Eine wichtige Rolle in der Aufarbeitung des nationalsozialistischen Vermögensentzugs spielte sodann die Österreichische Historikerkommission, die notabene nicht von einem Historiker, sondern von einem Juristen, dem damaligen Präsidenten des Verwaltungsgerichtshofs Clemens Jabloner, geleitet wurde und die umfangreiche Forschungsaufträge sowohl an HistorikerInnen als auch an JuristInnen vergab. Hervorzuheben ist hier insbesondere eine rechtshistorische Studie von Franz-Stefan Meissel, Thomas Olechowski und Christoph Gnant zur praktischen Vollziehung des sogenannten Rückstellungsrechts, das heißt zur Rückgabe von in der NS-Zeit entzogenem Vermögen. ${ }^{75} \mathrm{Im}$ besonderen Fokus der Forschung stand in den letzten Jahren die Frage der nationalsozialistischen Privatrechtswissenschaft. Unter der Leitung von Franz-Stefan Meissel wurde von 2013 bis 2017 im Rahmen des FWF-Projekts „Privatrecht in unsicheren Zeiten“ die Zivilrechtsjudikatur des Landesgerichts für Zivilrechtssachen Wien im Zeitraum von 1938 bis 1945 untersucht. ${ }^{76}$

72 FWF-Projekt P 19783: „Politisch motivierter Vermögensentzug in Wien 1933-1938“, Projektleitung: Ilse Reiter-Zatloukal (2008-2013), URL: https://vermoegensentzug.univie.ac.at/ (abgerufen 03.11.2020).

73 Projekt „Politische Ausbürgerungen im Austrofaschismus“, Projektleitung: Ilse Reiter (2005-2006). Vgl. Ilse Reiter, Ausbürgerung. Politisch motivierter Staatsbürgerschaftsverlust im Austrofaschismus, Teil I, in: juridikum. Zeitschrift im Rechtsstaat 2006/4, 173-176.

74 Davy/Fuchs/Hofmeister/Marte/Reiter (Hg.), Nationalsozialismus und Recht.

75 Franz-Stefan Meissel/Thomas Olechowski/Christoph Gnant, Untersuchungen zur Praxis der Verfahren vor den Rückstellungskommissionen, Wien 2004.

76 Aus diesem Projekt gingen mehrere Publikationen und ein Tagungsband hervor, so v. a.: FranzStefan Meissel, Die Umgestaltung der Zivilrechtsjustiz nach der NS-Machtergreifung in Österreich, in: Richterzeitung 2014/6, 136-140; Benjamin Bukor, Zivilrecht und Ideologie. Die Entwicklung des österreichischen Abstammungsrechts in der NS-Zeit unter Berücksichtigung der Judikatur des 
Traurige Aktualität erfuhr das Thema Nationalsozialismus und Antisemitismus an der Wiener Juridischen Fakultät 2017 durch den „AG-Leaks-Skandal“",77 bei dem Vertreter der Aktionsgemeinschaft Jus, einer Fraktion der Österreichischen Hochschülerschaft, der gesetzlichen Vertretung aller Studierenden, welche zu diesem Zeitpunkt die Studienvertretung der Rechtswissenschaften stellte, in geheimen Chats Witze über den Holocaust rissen und Behinderte verspotteten. Die Juridische Fakultät reagierte nach Bekanntwerden dieser Chats mit einem verstärkten Fokus auf das Thema Nationalsozialismus in der Lehre, um so die Studierenden mehr dafür zu sensibilisieren, und führte auch zu einigen Publikationen von Wiener RechtshistorikerInnen..$^{78}$

\subsection{Völkerrechtsgeschichte, Globalrechtsgeschichte, Europäische Union}

In den letzten Jahren hat sich die Völkerrechtsgeschichte zu einem weiteren Schwerpunkt an der Universität Wien herausgebildet. ${ }^{79} \mathrm{Zu}$ verzeichnen sind auf diesem Gebiet insbesondere einige Arbeiten aus dem Team um Miloš Vec: Mit Fragen

LGZ bzw. LG Wien und des Reichsgerichts, iur. Diss., Universität Wien 2015; Stefan Wedrac, Die Richter des Obersten Gerichtshofs vom Anschluss 1938 bis zur Eingliederung ins Reichsgericht 1939, in: Richterzeitung 2014/6, 152-158; Franz-Stefan Meissel/Stefan Wedrac (Hg.), Privatrecht in unsicheren Zeiten. Zivilgerichtsbarkeit im Nationalsozialismus. Beiträge zur Rechtsgeschichte Österreich 7 (2017) 2.

77 Vgl. dazu Nina Horaczek, Das ist ein Super-GAU, Falter, 09.05.2017, 16.

78 Ines Schwaighofer-Glück/Sebastian M. Spitra, Kritik formulieren. Aktuelle Überlegungen zur rechtshistorischen Didaktik, in: juridikum. Zeitschrift im Rechtsstaat 2017/3, 317-326; Paul Hahnenkamp, Freispruch per Weisung. Kein Verbotsgesetz für Anwältinnen?, in: juridikum. Zeitschrift im Rechtsstaat 2017/2, 186-195; Paul Hahnenkamp, Das Gleiche ist nicht Dasselbe. Welser Anwalt wegen Verbreitung von NS-Gedankengut bestraft, in: juridikum. Zeitschrift im Rechtsstaat 2018/3, 285-288; Kamila Staudigl-Ciechowicz, Die „Säuberung“ der Universitäten 1938 am Beispiel der Wiener Rechtswissenschaftlichen Fakultät, in: Journal on European History of Law 9 (2018) 2, $40-49$.

79 Miloš Vec, Challenging the Laws of War by Technology, Blazing Nationalism and Militarism: Debating Chemical Warfare before and after Ypres, 1899-1925, in: Bretislav Friedrich/Dieter Hoffmann/Jürgen Renn/Florian Schmaltz/Martin Wolf (Hg.), One Hundred Years of Chemical Warfare: Research, Deployment, Consequences, Heidelberg 2017, 105-134; Miloš Vec, Sources in the 19th Century European Tradition. The Myth of Positivism, in: Samantha Besson/Jean d'Aspremont (Hg.), Oxford Handbook on the Sources of International Law, Oxford 2017, 121-145; Luigi Nuzzo/ Miloš Vec (Hg.), Constructing International Law - The Birth of a Discipline (Studien zur europäischen Rechtsgeschichte 273), Frankfurt a. M. 2012; Thomas Hippler/Miloš Vec (Hg.), Paradoxes of Peace in 19th Century Europe, Oxford 2015. 
rund um Recht und Kultur im Völkerrecht beschäftigte sich Sebastian Spitra, ${ }^{80}$ zur Neutralität in der Völkerrechtslehre forschte Julia Schreiner. ${ }^{81}$ Der rezente Trend in der Rechtsgeschichte geht dahin, die nationalen Fragestellungen globalhistorisch zu untersuchen. Diese neue Richtung lässt sich insbesondere durch internationale und interdisziplinäre Projekte und Workshops verfolgen, als das führende Institut ist in diesem Bereich, das in Frankfurt am Main beheimatete Max-Planck-Institut für Rechtsgeschichte und Rechtstheorie, $\mathrm{zu}$ nennen. $\mathrm{Zu}$ den rezenten Topoi dieser Untersuchungen gehört das Gebiet „Recht und Diversität“ - ein Thema, welches in Workshops von europäischen und lateinamerikanischen ForscherInnen auf Gemeinsamkeiten, Unterschiede und mögliche Entwicklungslinien in Geschichte und Gegenwart untersucht wird..$^{82}$

Ein bereits seit mehreren Jahren etabliertes Thema in der Rechtsgeschichte ist die Geschichte der Europäischen Integrationsgeschichte - ein Bereich, den vor allem die Historikerin und Rechtshistorikerin Anita Ziegerhofer untersuchte. ${ }^{83}$

\subsection{Privatrechtsgeschichte}

Gerade in der Privatrechtsgeschichte fehlen noch in vielen Bereichen zeithistorischrechtshistorische Forschungen. Bereits erwähnt wurden die Untersuchungen zum Familien- und Eherecht in der Ersten Republik und die Forschungen zum Privatrecht im Nationalsozialismus. Mit dem Eherecht der letzten zweihundert Jahre beschäftigte sich eine 2011 organisierte Tagung der Kommission für Rechtsgeschichte Österreichs der ÖAW. ${ }^{84}$ In den letzten Jahren gab es in diesem Bereich mehrere

80 Sebastian Spitra, Die Verwaltung von Kultur im Völkerrecht. Eine postkoloniale Geschichte, iur. Diss., Universität Wien 2018.

81 Julia Schreiner, Neutralität „nach Schweizer Muster“? Österreichische Völkerrechtslehre zur immerwährenden Neutralität, 1955 bis 1989, iur. Diss., Universität Wien 2017.

82 Tagung: Recht und Diversität - Europäische und lateinamerikanische Erfahrungen in rechtshistorischer Perspektive II, Max-Planck-Institut für europäische Rechtsgeschichte, URL: https://www. rg.mpg.de/1711948/event-19-06-24-tagung-recht-und-diversitaet-ii.html (abgerufen 03.11.2020). Von österreichischer Seite sind Thomas Simon und Kamila Staudigl-Ciechowicz in dieses Projekt involviert.

83 Vgl. vor allem Anita Prettenthaler-Ziegerhofer, Europäische Integrationsgeschichte, Innsbruck 32012; Anita Prettenthaler-Ziegerhofer, Botschafter Europas. Richard Nikolaus Coudenhove-Kalergi und die Paneuropa-Bewegung in den zwanziger und dreißiger Jahren, Wien 2004.

84 Gerald Kohl/Thomas Olechowski/Kamila Staudigl-Ciechowicz/Doris Täubel-Weinreich (Hg.), Eherecht 1811 bis 2011 . Historische Entwicklungen und aktuelle Herausforderungen. Beiträge zur Rechtsgeschichte Österreich 2 (2012) 1. 
rechtsvergleichende Projekte seitens deutscher Rechtshistoriker, die die österreichische Privatrechtsentwicklung der Zwischenkriegszeit im weiteren Sinne mit umfassten. ${ }^{85} \mathrm{Zu}$ erwähnen ist in diesem Zusammenhang auch das von Thomas Simon in Gemeinschaft mit dem Max-Planck-Institut für Rechtsgeschichte und Rechtstheorie geleitete Projekt „Die Rechtsordnungen Südosteuropas im 19. und 20. Jahrhundert: Rechtstransfer und rechtliche Modernisierungsprozesse in Südosteuropa im 19. und 20. Jahrhundert ${ }^{\text {" }}{ }^{86}$ welches sich auch mit privatrechtlichen Fragen beschäftigte.

\section{Tendenzen und Perspektiven}

Die österreichische rechtshistorische Forschung hat in den letzten Jahrzehnten eine Vielfalt an Themen behandelt, darunter verschiedene Aspekte aus der österreichischen, aber auch europäischen und internationalen Zeitgeschichte. Während die Rechtsgeschichte sich bis in die 1980er-Jahre kaum mit zeithistorischen Fragen auseinandersetzte, erfolgte mit dem Wechsel der Generationen an Rechtshistorikerinnen und Rechtshistorikern in den 1980er- und 1990er-Jahren eine Neuorientierung der Rechtsgeschichte. Zwar verloren die „alten“ Themen nicht völlig an Bedeutung, doch blickte die rechtshistorische Forschung nunmehr nicht ausschließlich in die weit zurückliegende Vergangenheit, sondern wandte sich auch Themen des 20. Jahrhunderts zu. In den letzten Jahrzehnten richtete sich der Blick in der rechtshistorischen Zeitgeschichtsforschung insbesondere auf die Periode des Nationalsozialismus und des Austrofaschismus. Diese Themen wurden sowohl aus dem öffentlich-rechtlichen als auch aus dem privatrechtlichen Blickwinkel in interdisziplinären Studien untersucht. Bislang noch weniger Beachtung hat die Zeit nach 1945 in der österreichischen rechtshistorischen Forschung gefunden. In vielen Bereichen gibt es zu dieser Periode noch Forschungslücken, wie schon die dargestellten Schwerpunktthemen erahnen lassen.

Ein Blick auf die europäische Forschungslandschaft lässt einen weiteren Trend erkennen, der zwar nicht per se neu ist, aber aufgrund der schwierigen Finanzierung wirtschaftlich nicht verwertbarer Wissenschaft an Bedeutung zunimmt: die Jubiläums- bzw. Gedenkjahrforschung als Antriebsmotor für Forschungsprojekte. Dies

85 Löhnig/Wagner (Hg.), Zivilgesetzgebung. Darin enthalten zu Österreich: Staudigl-Ciechowicz, Das österreichische Zivilrecht; Martin Löhnig/Stephan Wagner (Hg.), Das ADHGB von 1861 als gemeinsames Obligationenrecht in Mitteleuropa, Tübingen 2018; Stefan Wedrac, Republik Österreich (1918-1938), in: Löhnig/Wagner (Hg.), ADHGB, 147-167.

86 Thomas Simon (Hg.), Konflikt und Koexistenz. Die Rechtsordnungen Südosteuropas im 19. und 20. Jahrhundert, Bd. 2: Serbien, Bosnien-Herzegowina, Albanien, Frankfurt a. M. 2017. 
betrifft im Prinzip natürlich auch ältere Themen der Rechtsgeschichte, ${ }^{87}$ hat aber in der Praxis vor allem in der juristischen Zeitgeschichte immer mehr an Bedeutung zugenommen. ${ }^{8}$ Unbestreitbar ist, dass diverse Jubiläen eine erhöhte Aufmerksamkeit auch außerhalb des engen Kreises der FachkollegInnen versprechen und mitunter sogar die Einwerbung von Drittmitteln erleichtern. Problematisch wird dies dann, wenn aus ebendiesen Gründen Forschungsgebiete, die nicht mit einem derartigen „Bonus“ aufwarten können, vernachlässigt werden (müssen).

Wie eingangs betont, hat die Rechtsgeschichte in den letzten Jahrzehnten innerhalb des juristischen Studiums stark an Bedeutung verloren, was sich auch in der stetig sinkenden Zahl an rechtshistorischen ProfessorInnen und AssistentInnen niedergeschlagen hat. Dieser Abwärtstrend hat sich in den letzten Jahren etwas abgeflacht bzw. lassen jüngste Berufungstendenzen in Wien und Graz sogar wieder auf einen (leichten) Aufschwung hoffen. Dies ist sicherlich nicht zuletzt der stärkeren Berücksichtigung der juristischen Zeitgeschichte innerhalb der Rechtsgeschichte zuzuschreiben, die auch JuristInnen anderer Disziplinen die große Relevanz rechtshistorischer Forschung ebenfalls für das heute geltende Recht gezeigt hat.

87 Hingewiesen sei etwa auf die vielen rechtshistorischen Tagungen und Publikationen rund um den 200. „Geburtstag“ des Allgemeinen bürgerlichen Gesetzbuches 2011/2012.

88 Vgl. etwa die in den Anmerkungen 48, 49 und 50 angeführten Forschungen zum Wahlrecht, zum Ersten Weltkrieg und zu den Pariser Friedensverträgen. Besonders bemerkenswert ist es, dass der 650. Jahrestag der Gründung der Universität Wien (12. März 1365) nicht zum Anlass für eine Untersuchung der gesamten Universitätsgeschichte, sondern für Forschungen zur Geschichte der Universität Wien seit 1848 genommen wurde. 


\section{Zeitgeschichte und Literaturwissenschaft}

Norbert Christian Wolf

\section{Literaturwissenschaft und Gegenwartsliteratur}

Die Beschäftigung mit der Zeitgeschichte fristet in der germanistischen Literaturwissenschaft von jeher ein Schattendasein, was sich etwa darin niederschlägt, dass man in dem 1997-2003 publizierten, fachmaßgeblichen „Reallexikon der deutschen Literaturwissenschaft " zwar einen ausführlichen Artikel zur Gegenreformation, ${ }^{1}$ aber keinen zur Gegenwartsliteratur findet. Entsprechendes gilt bereits für das erstmals 1926 erschienene (und dann nach dem Zweiten Weltkrieg neu bearbeitete) Vorgängerwerk „Reallexikon der deutschen Literaturgeschichte“.2 Auch das 2007 veröffentlichte, vom Anspruch her umfassende „Handbuch Literaturwissenschaft" kommt ohne einen eigenen Artikel zur Gegenwartsliteratur aus, ${ }^{3}$ wofür man keinerlei Begründungsaufwand betreiben zu müssen glaubte. Die Literatur unserer Gegenwart gilt weniger als Herausforderung denn als Problem, spätestens seit den 1990er Jahren wird ihr hartnäckig eine Krise nachgesagt. ${ }^{4}$ Ihre geringe Reputation spiegelt sich auch im deutschsprachigen Wissenschaftsbetrieb: Mit zeitgeschichtlichen Themen und Untersuchungen im engeren Sinn konnte und kann man sich in der (bundes)deutschen Germanistik nur in Ausnahmefällen akademisch für eine Professur oder Vergleichbares qualifizieren, Lehrstühle mit der (Teil)Denomination „Gegenwartsliteratur" wurden dort überhaupt erst in jüngster Zeit eingerichtet; als würdige literarische Forschungsgegenstände galten und gelten weithin immer noch

1 Harald Fricke/Jan-Dirk Müller/Klaus Weimar u. a. (Hg.), Reallexikon der deutschen Literaturwissenschaft. Neubearbeitung des Reallexikons der deutschen Literaturgeschichte, 3 Bde., Berlin/New York 1997-2003; Klaus Weimar/Harald Fricke/Klaus Grubmüller/Jan-Dirk Müller (Hg.), Reallexikon der deutschen Literaturwissenschaft. Neubearbeitung des Reallexikons der deutschen Literaturgeschichte, Bd. 1: A-G, Berlin/New York 1997, 673-678.

2 Werner Kohlschmidt/Wolfgang Mohr, in Zusammenarbeit mit Klaus Kanzog (Hg.), Reallexikon der deutschen Literaturgeschichte. Begründet von Paul Merker und Wolfgang Stammler, 5 Bde., Berlin 1958-1988.

3 Thomas Anz (Hg.), Handbuch Literaturwissenschaft. Gegenstände - Konzepte - Institutionen, 3 Bde., Stuttgart 2007.

4 Christian Döring (Hg.), Deutschsprachige Gegenwartsliteratur. Wider ihre Verächter, Frankfurt a. M. 1995; darin insbesondere der Beitrag von Friedhelm Rathjen, Crisis? What Crisis?, 9-17. 
jene historischen Werke, Autoren und Epochen, die bereits kanonisiert sind und die sich mit gehöriger zeitlicher Distanz in den Blick nehmen und analysieren lassen.

Ein wenig anders stellt sich die Situation in Österreich dar, wo ab ca. 1970 hierzulande einflussreiche Neugermanisten wie Alfred Doppler (Innsbruck), Walter Weiss (Salzburg) und Wendelin Schmidt-Dengler (Wien) die wissenschaftliche Auseinandersetzung mit der zeitgenössischen Literatur zu einem ihrer Hauptforschungsgebiete erhoben und eine beeindruckende Zahl an akademischen Qualifikationsschriften betreut haben. ${ }^{5}$ Dies hat auf die anderen österreichischen Germanistikinstitute ausgestrahlt und hängt zum einen mit der besonderen Qualität österreichischer Literatur im letzten Drittel des 20. Jahrhunderts zusammen, die mittlerweile durch die Nobelpreise für Elfriede Jelinek (2004) und Peter Handke (2019) auch international konsekriert wurde, zum anderen mit dem auffallenden Mangel kanonischer österreichischer Literatur vor 1800 . So konnte sich hier die seit den 1970er Jahren stark auf die heimische Literaturproduktion und -rezeption fokussierte neugermanistische Literaturwissenschaft in Forschung und Lehre auf das 19. und vor allem auf das 20. Jahrhundert konzentrieren.

Die im Vergleich zu länger zurückliegenden Epochen anders geartete Quellenlage der Gegenwartsliteratur und ihrer Kontexte ${ }^{6}$ führte freilich auch in Österreich nur in Ausnahmefällen dazu, eine spezifische wissenschaftliche, theoretisch begründete Methodik ihrer Erforschung zu entwickeln.7 Häufig bewegen sich jene KollegInnen, die in diesem Bereich einen genuinen Arbeitsschwerpunkt ausgebildet und wichtige Publikationen vorgelegt haben, im Übergangsbereich zur Literaturvermittlung und Literaturkritik. Letzteres ist unter anderem mit den sehr beschränkten Möglichkeiten zu erklären, an den heimischen Wissenschaftsinstitutionen als hauptberufliche

5 Dazu grundlegend Walter Weiss/Josef Donnenberg/Adolf Haslinger/Karlheinz Rossbacher, Gegenwartsliteratur. Zugänge zu ihrem Verständnis, Stuttgart/Berlin/Köln/Mainz 1973.

6 Grundsätzliche Überlegungen - darunter auch von den österreichischen Germanistinnen Claudia Dürr und Doris Moser - finden sich in Maik Bierwirth/Anja Johannsen/Mirna Zeman (Hg.), Doing Contemporary Literature. Praktiken, Wertungen, Automatismen (Schriftenreihe des Graduiertenkollegs „Automatismen“), München 2012; darin speziell zum Begriff Gegenwartsliteratur: Norbert Otto Eke, Beobachtungen beobachten. Beiläufiges aus germanistischer Sicht zum Umgang mit einer Literatur der Gegenwart, 23-40; darüber hinaus manche Beiträge in Jürgen Brokoff/Ursula Geitner/Kerstin Stüssel (Hg.), Engagement. Konzepte von Gegenwart und Gegenwartsliteratur (Literatur- und Mediengeschichte der Moderne 1), Göttingen 2016, etwa Ursula Geitner, Stand der Dinge: Engagement-Semantik und Gegenwartsliteratur-Forschung, 19-58, oder Silke Horstkotte, Zeitgemäße Betrachtungen: Die Aktualität der Gegenwartsliteratur und die Aktualisierungsstrategien der Gegenwartsliteraturwissenschaft, 371-387.

7 Zur Problematik vgl. etwa Paul Brodowsky/Thomas Klupp (Hg.), Wie über Gegenwart sprechen? Überlegungen zu den Methoden einer Gegenwartsliteraturwissenschaft, Frankfurt a. M./Berlin/ Bern/Bruxelles/New York/Oxford/Wien 2010. 
LiteraturwissenschaftlerIn ohne Nebenbeschäftigungen im Feuilleton oder Rundfunk ein Auskommen zu finden, sowie mit der nach 1945 schwachen institutionellen Entwicklung einer eigenen Literatursparte in den Printmedien, die aufgrund ihrer nunmehr vergleichsweise kleinen Reichweite kaum die finanzielle Basis für eigene Literaturredaktionen hatten. Im Zusammenspiel führten diese Faktoren einerseits zu einer auffallenden Prominenz der Literaturwissenschaft in der nationalen Medienöffentlichkeit, wobei VertreterInnen der universitären Germanistik - im Unterschied zu Deutschland - häufig in Personalunion als KritikerInnen auftraten und auftreten, andererseits aber zu einer eher geringen Sichtbarkeit germanistischer Literaturwissenschaft aus Österreich im internationalen Fachdiskurs, der sich gerade im deutschsprachigen Raum von feuilletonistischen Formaten abgrenzt.

In diesem Zusammenhang sollte freilich nicht unterschlagen werden, dass die (literatur)historischen Begriffe "Zeitgeschichte“ und "Gegenwartsliteratur" im Deutschen keineswegs kongruieren, weil Ersterer insbesondere in Österreich auf die gesamte Zeitspanne zumindest vom Ersten Weltkrieg bis zur unmittelbaren Gegenwart angewendet wird, während Zweiterer sich der üblichen Verwendungsweise zufolge auf die literarische Produktion des halben Jahrhunderts seit 1968 beschränkt. Dass die Gegenwart in der Literatur gerade einmal die Hälfte der von der Zeitgeschichtsforschung abgedeckten Geschichte ausmacht, mag kurios anmuten; dieses etwas widersprüchliche Begriffsverständnis hat sich aber mittlerweile allgemein durchgesetzt und kann durch den Gebrauch des seltener verwendeten Terminus "Gegenwartsgeschichte“ partiell aufgehoben werden.

Maßgebliche wissenschaftliche Paradigmen zur Erforschung der modernen Literatur im engeren Sinne und der Gegenwartsliteratur im Besonderen, deren Anspruch über kluge Analysen von Einzelfällen hinausgeht und die international Schule gemacht hätten, wurden in Österreich kaum federführend entwickelt; generell war hier sogar lange eine gewisse Theorieabstinenz zu bemerken, die in den vergangenen Jahrzehnten durch das meist verspätete und umso geflissentlichere Nachvollziehen methodischer Innovationen und Moden aus den angelsächsischen und französischsprachigen Ländern kaum wettgemacht werden konnte, zumal jene in der Regel erst über den deutschen Umweg nach Österreich importiert wurden. Gleichwohl führte die Notwendigkeit, die Spezifik österreichischer Literatur aus den hier wirksamen und von Deutschland abweichenden institutionellen, medialen und kulturellen Produktions, Distributions- und Rezeptionsbedingungen zu erklären, ${ }^{8}$

8 Dazu u. a. Sigurd Paul Scheichl, Weder Kahlschlag noch Stunde Null. Besonderheiten des Voraussetzungssystems der Literatur in Österreich zwischen 1945 und 1966, in: Albrecht Schöne (Hg.), Kontroversen, alte und neue. Akten des VII. Internationalen Germanisten-Kongresses Göttingen 
zu einer besonderen Sensibilität der hiesigen Literaturwissenschaft für zeithistorische Kontexte und Problematiken. ${ }^{9}$

\section{Die literarische Entwicklung im Kontext der allgemeinen Geschichte}

Dass die Literatur und das literarische Leben Österreichs eng mit der Gesellschaftsund Politikgeschichte des Landes verknüpft waren und sind, lässt sich schon in der Konstitutionsphase der Ersten Republik beobachten, als (zumeist männliche) Literaten an vorderster Front an den Wiener revolutionären Ereignissen beteiligt waren und (vergeblich) eine auch soziale Revolution anstrebten. Zum zweiten Mal seit 1848 standen in Wien prominente Schriftsteller wie Egon Erwin Kisch, Franz Werfel und Franz Blei selbst im Zentrum des historischen Geschehens, indem sie sich bei der Gründung der Wiener Roten Garde engagierten oder deren Ziele aktionistisch und publizistisch propagierten, während andere schreibende Zeitgenossen wie Robert Musil, Arthur Schnitzler und Karl Kraus die revolutionären Aktionen distanziert bis sarkastisch kommentierten. ${ }^{10}$ Das Scheitern einer radikalen Gesellschaftsveränderung hat schließlich dazu beigetragen, dass diese Episode langfristig aus dem kulturellen Gedächtnis des Landes getilgt wurde. Generell ist im Blick auf die in sozialem Aufbruch befindliche und nunmehr häufig von Frauen verfasste Literatur der Zwischenkriegszeit erinnerungspolitisch eine weitgehende und lang anhaltende Amnesie zu verzeichnen. ${ }^{11}$ Auch auf der anderen Seite des politischen Spektrums war es mit Hugo von Hofmannsthal ein Dichter, dessen persönliches Engagement und intensive publizistische Tätigkeit die Gründung der Salzburger Festspiele ermöglichte. Diese wurden dann als programmatisches Gegengewicht zum ,roten Wien' ein regelrechtes Identifikationsvehikel der Ersten und Zweiten Repub-

1985, Bd. 10, Tübingen 1986, 37-51; Norbert Christian Wolf, Umkreisungsversuche. Zur Identität österreichischer Literatur, in: Heinz Ludwig Arnold (Hg.), O Österreich! (Göttinger Sudelblätter), Göttingen 1995, 96-107.

9 Eine Fundgrube und ein Beleg für die Fruchtbarkeit dieser Fragestellung ist die Anthologie: Walter Weiss/Ernst Hanisch (Hg.), Vermittlungen. Texte und Kontexte österreichischer Literatur und Geschichte im 20. Jahrhundert, Salzburg/Wien 1990.

10 Norbert Christian Wolf, Revolution in Wien. Die literarische Intelligenz im politischen Umbruch 1918/19, Wien/Köln/Weimar 2018.

11 Wendelin Schmidt-Dengler, Ohne Nostalgie. Zur österreichischen Literatur der Zwischenkriegszeit, Wien/Köln/Weimar 2002; Evelyne Polt-Heinzl, Österreichische Literatur zwischen den Kriegen. Plädoyer für eine Kanonrevision, Wien 2018; Primus Heinz Kucher, Verdrängte Moderne vergessene Avantgarde. Diskurskonstellationen zwischen Literatur, Theater, Kunst und Musik in Österreich 1918-1938, Göttingen 2016. 
lik Österreich im Sinne einer invention of tradition (Eric Hobsbawm), die nach dem Untergang des Habsburgerreichs und der verlustreichen Redimensionierung des Staates notwendig geworden war. Eine Voraussetzung dafür war der Umstand, dass die so offene wie stets umkämpfte Vorstellung von Festspielen, die seit Rousseau immer auch einen identitätspolitischen Auftrag zu erfüllen hatten, ideologisch ganz unterschiedlich konkretisiert werden konnte. Hofmannsthal und seine Mitstreiter Max Reinhardt und Richard Strauss bedienten sich nach Bedarf heterogener Elemente der historisch variierenden Konzeptionen, um für ihre Gegenwart und ihre künstlerischen Bedürfnisse eine passende zu (er)finden. ${ }^{12}$ Die dann tatsächlich in Salzburg realisierte Form und ihre durchaus widersprüchlichen Begründungen sowie Weiterentwicklungen sind vor diesem Hintergrund zu sehen, der sich bis heute als changierende konzeptionelle und kulturpolitische Herausforderung erweist. Gerade aufgrund der anhaltenden Auseinandersetzungen um die Bestimmung und konkrete Ausgestaltung der Salzburger Festspiele, also aufgrund ihrer zahlreichen Um- und Neudefinitionen, konnten diese zu einem zentralen ,Erinnerungsort' der österreichischen und europäischen Kulturgeschichte werden, wobei auch in späteren Jahren SchriftstellerInnen an den Debatten maßgeblich beteiligt waren.

Die Literatur der Ersten Republik erwies sich freilich nicht nur als Medium unterschiedlicher und zum Teil konkurrierender kulturpolitischer Bestrebungen, sondern auch als mehr oder weniger kritischer Reflexionsort österreichischer Geschichte. Diese Funktion erfüllten etwa jene Romane und Dramen, die sich auf elegische oder ironische Weise einer erzählerischen und zum Teil auch essayistischen Bewältigung der unmittelbaren Vergangenheit widmeten; genannt seien pars pro toto - aus unterschiedlichen ideologischen Perspektiven - Franz Theodor Csokors „3. November 1918“ (1936), Joseph Roths „Radetzkymarsch“ (1932) und „Die Kapuzinergruft“ (1938) oder Robert Musils „Der Mann ohne Eigenschaften“ (1930/1932/postum) Musil vertrat in seinem Roman mit Blick auf den Ersten Weltkrieg, den Untergang der Donaumonarchie und die Konflikte der Ersten Republik sogar ausdrücklich den Anspruch, „Beiträge zur geistigen Bewältigung der Zeit“ zu geben, ${ }^{13}$ ohne dass er in der Lage gewesen wäre, Schlimmeres zu verhindern. Der "Anschluss" an das sogenannte „Dritte Reich“ wurde ebenfalls aktiv von heimischen SchriftstellerInnen herbeigeschrieben und dann literarisch geadelt, wie etwa das „Bekenntnisbuch österreichischer Dichter“ belegt, das der Bund deutscher Schriftsteller Österreichs

12 Norbert Christian Wolf, Eine Triumphpforte österreichischer Kunst. Hugo von Hofmannsthals Gründung der Salzburger Festspiele, Salzburg/Wien 2014.

13 Robert Musil, Gesammelte Werke in neun Bänden, hg. v. Adolf Frisé, Bd. 7, Reinbek bei Hamburg 1978, 942; dazu und zum Kontext Norbert Christian Wolf, Kakanien als Gesellschaftskonstruktion.

Robert Musils Sozioanalyse des 20. Jahrhunderts, Wien/Köln/Weimar 2011. 
1938 im Wiener Krystall-Verlag herausgab. Darin begrüßten über siebzig AutorInnen begeistert den „Anschluss“ an das nationalsozialistische Deutschland und huldigten lyrisch dessen „Führer“ Adolf Hitler, der ja aus Österreich stammte. ${ }^{14}$ Parallel dazu sahen sich zahlreiche ihrer KollegInnen nicht nur ihrer materiellen Existenzgrundlage beraubt, sondern wurden aus der öffentlichen Sphäre systematisch ausgeschlossen und - beginnend unmittelbar nach dem „Anschluss“ - auch verfolgt und vertrieben oder ermordet. ${ }^{15}$

Nach 1945 litt das Literatursystem Österreichs lange und in besonderem Ausmaß unter den politischen und personellen Folgen der historischen Schlüsseljahre 1934, 1938 und 1945, deren fatale Konsequenz eben in der weitgehenden Vertreibung oder Ermordung maßgeblicher kultureller Trägerschichten bestand. Die florierende und in ihren Spitzenleistungen auf Weltniveau befindliche literarische und intellektuelle Kultur der Vor- und Zwischenkriegszeit sah sich dadurch auf das Mittelmaß eines Staates von bescheidener Größe zurückgestutzt, der zudem durch die aktive Beteiligung zahlreicher ÖsterreicherInnen an den NS-Verbrechen erheblich kompromittiert war. Befördert wurde die Ablehnung künstlerischer Innovationen überdies durch das teilweise repressive, jedenfalls nicht experimentierfreudige kulturelle Klima des Kalten Krieges, dessen Auswirkungen auf die Kultur der offiziell neutralen Republik Österreich erst im vergangenen Jahrzehnt intensiver erforscht worden ist. ${ }^{16}$ Wie in der Wissenschaft betrieben dieser Staat und seine politische Klasse, die keinerlei eigene Verantwortung für die Verbrechen des Nationalsozialismus sah, auch im Bereich der Literatur bis in die 1970er Jahre wenig Aufwand, die vertriebenen AkteurInnen des Literaturbetriebs zurückzuholen. Das führte unter anderem dazu, dass die hier kulturpolitisch maßgeblichen Personen und Werte bis in die späten 1960er Jahre den scharf antimodernen ästhetischen, ethischen und ideologischen Vorstellungen der Zeit des christlichsozialen Ständestaats oder sogar des Nationalsozialismus verpflichtet blieben. ${ }^{17}$ Veranschaulichen lässt sich dieser

14 Klaus Amann, Der Anschluss österreichischer Schriftsteller an das Dritte Reich. Institutionelle und bewusstseinsgeschichtliche Aspekte, Frankfurt a. M. 1988.

15 Kurt Mühlberger, Vertriebene Intelligenz 1938. Der Verlust geistiger und menschlicher Potenz an der Universität Wien 1938-1945, Wien 1993; Christian Fleck, Etablierung in der Fremde. Vertriebene Wissenschaftler in den USA nach 1933, Frankfurt a. M. 2015; Herbert Lackner, Die Flucht der Dichter und Denker. Wie Europas Künstler und Wissenschaftler den Nazis entkamen, Wien 2017. Michael Hansel/Michael Rohrwasser (Hg.), Kalter Krieg in Österreich. Literatur - Kunst - Kultur (Profile 17), Wien 2010; Stefan Maurer/Doris Neumann-Rieser/Günther Stocker (Hg.), Diskurse des Kalten Krieges. Eine andere österreichische Nachkriegsliteratur (Literaturgeschichte in Studien und Quellen 29), Wien/Köln/Weimar 2017.

17 Evelyne Polt-Heinzl, Die grauen Jahre. Österreichische Literatur nach 1945 - Mythen, Legenden, Lügen, Wien 2018. 
Sachverhalt etwa an den Trägern des Großen Österreichischen Staatspreises für Literatur der 1950er Jahre, deren Namen heute - mit der Ausnahme Heimito von Doderers und Carl Zuckmayers - kaum noch jemandem ein Begriff sind.${ }^{18}$ Andere - wie die Mitglieder der avantgardistischen Wiener Gruppe ${ }^{19}$ - wurden in ihrer künstlerischen Entfaltung im Inland durch fehlende Auftritts- und Publikationsmöglichkeiten und generell durch ausbleibende Wertschätzung, geschweige denn Förderung, massiv behindert; einige von ihnen - wie Oswald Wiener oder auch Ingeborg Bachmann - verließen schließlich frustriert das Land.

Erst gegen Ende der 1960er Jahre veränderten sich die mit Literatur verbundenen Vorstellungen auch außerhalb einer literarischen Elite - in dieser Hinsicht machte sich in der österreichischen Literaturgeschichte die Bedeutung der sonst hier schwächer ausgeprägten Epochenzäsur 1968 bemerkbar: Ein neuer Typ des kritischen Schriftstellers bzw. der kritischen Schriftstellerin setzte sich in der öffentlichen Wahrnehmung durch. Von Intellektuellen und ihrer Aufgabe wurde nunmehr gleichsam erwartet, mit der Autorität des akkumulierten symbolischen Kapitals autonomer Kunst in das politische Feld zu intervenieren, um dort gegen ein veraltetes Kulturverständnis, reaktionäre und antidemokratische Tendenzen, andere ideologische Verkrustungen und soziale Missstände aufzutreten. Zu nennen sind hier Namen wie Thomas Bernhard, Peter Handke und Elfriede Jelinek, die freilich ganz unterschiedliche ästhetische Verfahren und kritische Praxisformen pflegten. Als Kuriosum der österreichischen Situation in den 1970er Jahren, die in mancher Hinsicht an die josephinische Aufklärung von oben erinnert, sei freilich erwähnt, dass die schriftstellerische Verehrung des sozialdemokratischen Bundeskanzlers Bruno Kreisky und seiner Reformpolitik bisweilen hagiographische Züge annahm, ${ }^{20}$ die

18 Sigurd Paul Scheichl, Vergessene. Träger des Großen Österreichischen Staatspreises in den fünfziger Jahren, in: Wendelin Schmidt-Dengler (Hg.), Literatur in Österreich von 1950 bis 1965. WalterBuchebner-Tagung 1984, Mürzzuschlag [1985], 75-91; Wendelin Schmidt-Dengler, Die ansehnliche Spitze des Eisberges. Der Große Österreichische Staatspreis und die Literaturgeschichte, in: John Sailer (Hg.), KUNST KUNST KUNST - Der Große Österreichische Staatspreis. Katalog zur gleichnamigen Ausstellung im Museum des 20. Jahrhunderts von 1. März bis 6. April 2003, Wien/ Salzburg 2003, 207-213.

19 Gerhard Rühm (Hg.), Die Wiener Gruppe. Achleitner, Artmann, Bayer, Rühm, Wiener, Reinbek bei Hamburg 1985; Gerhard Fuchs, Avantgardismus in den fünfziger Jahren. Die Wiener Gruppe, in: Hubert Lengauer (Hg.), „Abgelegte Zeit“? Österreichische Literatur der fünfziger Jahre, Wien 1992; Thomas Eder/Juliane Vogel (Hg.), verschiedene sätze treten auf. Die Wiener Gruppe in Aktion (Profile 15), Wien 2008; Klaus Kastberger, Wien 50/60. Eine Art einzige österreichische Avantgarde, in: Klaus Kastberger/Thomas Eder (Hg.), Schluß mit dem Abendland! Der lange Atem der österreichischen Avantgarde (Profile 5), Wien 2000, 5-26.

20 Vgl. etwa die Geburtstagspublikation Gerhard Roth/Peter Turrini, Bruno Kreisky. Fotografiert von Konrad R. Müller. Texte von Gerhard Roth und Peter Turrini, Berlin/Wien 1981, sowie die harsche 
unfreiwillig komisch anmuteten und kaum dem eigenen Anspruch kritischer Öffentlichkeit genügten.

Ein weiteres Schlüsseldatum österreichischer Literaturgeschichte der Gegenwart ist das Jahr 1986, in dem Kurt Waldheim trotz oder gerade wegen heftiger internationaler Proteste zum Bundespräsidenten gewählt wurde. Die damals noch ungeklärten Verstrickungen des ehemaligen Wehrmachtsoffiziers Waldheim in die NSPolitik der Jahre 1938-1945, insbesondere aber sein unsensibler Umgang damit und seine augenscheinliche Verdrängungsstrategie, die ihn schließlich in den USA auf die Watchlist und nach der gewonnenen Wahl in weitgehende internationale Isolation brachten, führten im Inland dazu, dass sich die Intellektuellen verstärkt kritisch mit der jüngeren Vergangenheit und ihrer Bewältigung auseinandersetzten. Literaturgeschichtlich schlug sich das etwa 1988 in der skandalumwobenen Uraufführung von Thomas Bernhards historischem Abrechnungsdrama „Heldenplatz“ nieder, das der umstrittene Theaterdirektor Claus Peymann zum hundertjährigen Jubiläum des Burgtheaters in Auftrag gegeben hatte. Schon vorher hatte Elfriede Jelinek in ihrem 1985 in Bonn - also bezeichnenderweise im Ausland - uraufgeführten Stück „Burgtheater" mit den Mitteln einer radikal überzeichnenden Posse die Verantwortung Österreichs und prominenter heimischer Kulturschaffender an den Verbrechen des Nationalsozialismus zur Sprache gebracht. Dieses als Schlüsselwerk zur beliebten Schauspielerfamilie um Paula Wessely und Attila Hörbiger skandalisierte Drama wurde bis heute jedoch - auch aufgrund von Protesten verschiedener BurgtheaterschauspielerInnen - nicht in Wien gespielt und überhaupt nur ein einziges Mal in Österreich aufgeführt; es begründete gleichwohl Jelineks ambivalenten Ruf als „Nestbeschmutzerin“. ${ }^{21}$ Zugleich trat 1986 eine neue Generation von SchriftstellerInnen auf den Plan, die die „schlampige“ Aufarbeitung der jüngeren österreichischen Vergangenheit zum Gegenstand nicht nur literarischer Auseinandersetzung, sondern auch publizistischer Texte und öffentlicher Aktionen machten. So trugen die Waldheim-Affäre und ihr publizistisches Nachspiel zur Etablierung von Autoren jüdischer Herkunft wie Robert Schindel, Robert Menasse und später Doron Rabinovici bei, ${ }^{22}$ aber auch Josef Haslinger konnte sich mit seinem Essayband „Politik der

Reaktion von Thomas Bernhard, Der pensionierte Salonsozialist, profil, 26.01.1981, 51-52. Dazu Harald Gschwandtner, Strategen im Literaturkampf. Thomas Bernhard, Peter Handke und die Kritik (Literaturgeschichte in Studien und Quellen 31), Wien/Köln/Weimar 2020, 343-362.

21 Pia Janke (Hg.), Die Nestbeschmutzerin. Jelinek \& Österreich, Salzburg/Wien 2002.

22 Matthias Beilein, 86 und die Folgen. Robert Schindel, Robert Menasse und Doron Rabinovici im literarischen Feld Österreichs (Philologische Studien und Quellen 213), Berlin 2008. 
Gefühle“ im literarischen Feld Österreichs durchsetzen und später als Romancier international reüssieren. ${ }^{23}$

Ein drittes Schlüsseldatum der literarischen Zeitgeschichte Österreichs nach dem lange umstrittenen, aber 1995 mit einem eindeutigen Referendum erfolgten EUBeitritt ist das Jahr 2000, als die erste Regierungskoalition der ÖVP mit der rechtspopulistischen und den Nationalsozialismus verharmlosenden FPÖ unter Jörg Haider im In- und Ausland die Gemüter erhitzte. Insbesondere die durch die anderen 14 EU-Staaten beschlossenen „EU-Sanktionen gegen Österreich“, wie manche VertreterInnen der Bundesregierung Schüssel I einen Beschluss der 14 Partnerregierungen apostrophierten, der darin bestand, bilaterale Kontakte zu österreichischen RegierungsvertreterInnen und DiplomatInnen auf das notwendige Mindestmaß zu reduzieren, führte zu heftigen Debatten um die Vergangenheit, Gegenwart und Zukunft des Landes. SchriftstellerInnen waren daran an vorderster Front beteiligt. Die von ihnen in diesem Zusammenhang verfassten Texte spielten wiederum eine wichtige Rolle im nationalen Selbstverständigungsdiskurs. ${ }^{24}$

Wie diese drei Zäsuren belegen, hatte die politische Zeitgeschichte Österreichs entscheidende Auswirkungen auf eine durchaus eigenständige, von Deutschland deutlich abgehobene Entwicklung der österreichischen Gegenwartsliteratur, die in gesellschaftlicher Hinsicht zudem lange von der von Robert Menasse diagnostizierten „sozialpartnerschaftlichen Ästhetik“ geprägt war. ${ }^{25}$ Inwieweit sich die mit dem EU-Beitritt vollzogene Öffnung des Landes auch in einer weiteren Internationalisierung seiner schon seit den 1960er-Jahren wieder erstaunlich hochkarätigen Literatur niederschlägt, wäre sicherlich eine eigene Untersuchung wert. Diese hätte zu berücksichtigen, dass die international sichtbare Literatur Österreichs meist in deutschen Verlagen publiziert und damit auch in einen diskursiven Zusammenhang gestellt wurde, der sich vom Entstehungskontext signifikant unterscheidet. Ohne dass dies im gegenwärtigen Rahmen angemessen diskutiert werden könnte, seien abschließend kursorisch wichtige Forschungsfelder, Fragestellungen und Desiderate einer zeitgeschichtlich ausgerichteten Literaturwissenschaft umrissen.

23 Josef Haslinger, Politik der Gefühle. Ein Essay über Österreich, Darmstadt 1987.

24 Isolde Charim/Doron Rabinovici (Hg.), Österreich. Berichte aus Quarantanien, Frankfurt a. M. 2000 .

25 Robert Menasse, Die sozialpartnerschaftliche Ästhetik. Essays zum österreichischen Geist, Wien 1990. 


\section{Forschungsfelder und Desiderate}

\subsection{Großstadt versus Provinz}

Während die Schriftstellergenerationen der Moderne zu großen Teilen im Umfeld der urbanen Metropole Wien sozialisiert wurden oder zumindest dort ihren Lebensmittelpunkt hatten, selbst wenn sie in anderen Teilen der vielsprachigen und multiethischen Habsburgermonarchie geboren waren, stammten wichtige AutorInnen der Nachkriegszeit und noch der unmittelbaren Gegenwart aus der österreichischen Provinz und blieben auch häufig bewusst in den Landeshauptstädten (Graz, Salzburg, Innsbruck, Klagenfurt und anderen). Nicht von ungefähr stellte Graz, etwa mit dem „Forum Stadtpark“ und der Zeitschrift „manuskripte“, in den späten 196oer und den frühen 1970er Jahren als Zentrum der jungen Literaturszene sogar Wien in den Schatten. Erst seit den späteren 1970er Jahren konnte die Hauptstadt durch die Gründung von Institutionen wie die Alte Schmiede (1975) oder das Literaturhaus Wien (1991) ihre führende literaturpolitische Rolle als Entstehungs- und Wirkungsort von Literatur zurückerlangen. $\mathrm{Zu}$ maßgeblichen AkteurInnen und Gruppierungen literarischer Innovation wie Autorenvereinigungen oder Ähnlichem liegen mittlerweile wichtige Studien vor. ${ }^{26}$ Wünschenswert wären aber auch systematische Untersuchungen der Bedeutung von Herkunfts-, Schaffens- und Wirkungsmilieus für soziale Praktiken, symbolische Formen und kulturelle Aneignungen der Gegenwartsliteratur.

\subsection{Literatur von Frauen}

Mit den weit über die Grenzen des Landes hinaus wahrgenommenen Werken Ilse Aichingers, Ingeborg Bachmanns und Friederike Mayröckers zeichnete sich in Österreich schon vergleichsweise früh die gewachsene und weiter wachsende Bedeutung von Autorinnen im Literatur- und Kulturbetrieb der Gegenwart ab - eine Tendenz, die von der Entwicklung nach 1968 bestätigt wurde und der eine zeitgemäße literaturwissenschaftliche Aufarbeitung Rechnung tragen muss. Auch hier liegt mittler-

26 Vgl. etwa Wendelin Schmidt-Dengler, Eine Avantgarde aus Graz (Klagenfurter Universitätsreden 10), Klagenfurt 1979; Roland Innerhofer, Die Grazer Autorenversammlung (1973-1983). Zur Organisation einer „Avantgarde“, Wien/Köln/Graz 1985; Stefan Maurer, Wolfgang Kraus und der österreichische Literaturbetrieb nach 1945 (Literaturgeschichte in Studien und Quellen 30), Wien/ Köln/Weimar 2020. 
weile eine Vielzahl von Einzelstudien vor, ${ }^{27}$ aber keine vergleichende systematische Untersuchung der Auswirkungen weiblicher Autorschaft auf Habitusformen, Thematiken, Stile, Verfahren und Schreibweisen österreichischer Gegenwartsliteratur. Welche Konsequenzen hatte es für diese sowie für ihre öffentliche Wahrnehmung, dass die aktive Teilnahme von Frauen am literarischen Leben immer sichtbarer und selbstverständlicher wurde, welche Veränderungen zeichnen sich im Lauf der Jahre $\mathrm{ab}$ ?

\subsection{Jüdische Literatur nach der Shoah}

Die besondere Rolle Österreichs als offizielles Opfer (nach der Moskauer Deklaration) und zugleich inoffizielles Täterland nationalsozialistischer Gewaltverbrechen begünstigte es, dass hier neben vielen NS-belasteten SchriftstellerInnen relativ bald nach 1945 auch AutorInnen mit jüdischen Wurzeln wie Friedrich Torberg, Hilde Spiel oder Ilse Aichinger und ab 1955 auch Elfriede Gerstl literarisch aktiv wurden. Im Lauf der Jahre kamen weitere hinzu, etwa seit den 1970er Jahren Robert Schindel, seit den 1980er Jahren Robert Menasse, Isolde Charim, Doron Rabinovici, Eva Menasse und andere. Wenngleich viele unter ihnen nicht praktizierende Juden im engeren Sinn waren und sind, ist es bemerkenswert, dass sich in Wien nach der Shoah wieder eine quantitativ eher kleine, aber qualitativ bemerkenswerte und international wahrgenommene literarische Kultur in deutscher Sprache herausbilden konnte, die sich intensiv mit der komplexen Thematik jüdischen Lebens und Schreibens nach der Shoah auseinandersetzte. Auch hier liegen manche Einzelstudien vor, ${ }^{28}$ eine systematische Gesamtschau steht aber noch aus.

\subsection{Medien und Institutionen der Gegenwartsliteratur}

Mit dem medialen Wandel im Zeitalter der modernen Massenkommunikation haben sich im 20. und 21. Jahrhundert die Orte der Publikation, Performation, Kritik und Rezeption erzählender, dramatischer und lyrischer Texte fundamental und fort-

27 Vgl. etwa verschiedene Beiträge in Christa Gürtler/Brigitte Mazohl-Wallnig/Katrina Bachinger (Hg.), Frauenbilder, Frauenrollen, Frauenforschung. Ringvorlesung an der Geisteswissenschaftlichen Fakultät Universität Salzburg, Wien/Salzburg 1987; Daniela Strigl (Hg.), Frauen verstehen keinen Spaß (Profile 9), Wien 2002.

28 Vgl. etwa Helga Embacher, Neubeginn ohne Illusionen. Juden in Österreich nach 1945, Wien 1995; Andrea Reiter, Jüdische Literatur in Österreich nach Waldheim, Wien 2018. 
laufend verändert. Um diese Entwicklung und ihre Auswirkungen auf die Qualität und Quantität der Literatur selbst zu erfassen, sind medienhistorische Forschungen angebracht, die sich einer systematischen Untersuchung der Rolle von Zeitschriften, Almanachen und Jahrbüchern sowie immer stärker auch von Radio, Fernsehen und Internet bei der Etablierung und Positionierung von AutorInnen im literarischen Feld widmen. Sie können sich mittlerweile auf Datenbanken wie „Literaturzeitschriften in Österreich 1945-1990“ der ÖNB stützen. ${ }^{29}$ Ebenfalls wünschenswert wäre eine (in Österreich bisher nur in Einzelstudien ansatzweise vorliegende) historisch-systematische Aufarbeitung der Funktion offizieller Kultur- und Identitätspolitik, wie sie etwa durch (halb)staatliche Stipendien, Preise, Verlagsförderungen, durch die Lehrpläne an den öffentlichen Schulen und Hochschulen etc. in den verschiedenen Phasen der Zeitgeschichte für den Strukturwandel des hiesigen literarischen Feldes wirksam gewesen ist. In diesem Zusammenhang wäre auch das intrikate Verhältnis zwischen AutorInnen und staatlichen bzw. staatlich subventionierten Institutionen zu analysieren, deren vergleichsweise großzügige Stipendienvergabe bei allen positiven Aspekten der heimischen Literaturförderung wiederum zu neuen Formen schriftstellerischer Abhängigkeit geführt hat.

\subsection{Literatur als Kommentar der Zeitgeschichte}

Durch den gewandelten Literaturbegriff stellten sich SchriftstellerInnen stärker als vordem die Aufgabe, politische und allgemein gesellschaftliche Ereignisse und Entwicklungen kritisch zu kommentieren, was sich nicht nur in den Sujets traditioneller Genres der Dramatik und Erzählliteratur niederschlug (zu nennen wären etwa Erich Hackls dokumentarische Erzählungen ${ }^{30}$ oder Robert Schindels epische Darstellung der WaldheimZeit ${ }^{31}$ ), sondern auch in innovativen Formen wie den Kurzdramoletten Antonio Fians, die zunächst in Tages- und Wochenzeitungen wie „Der Standard“ oder „Falter“ veröffentlicht wurden, den literarischen Essays von Karl-Markus Gauß, die ebenfalls häufig zuerst in der Presse erschienen, den satirischen bis sarkastischen Statements Elfriede Jelineks, die in unterschiedlichster Ausführlichkeit auf ihrer persönlichen Webseite zu finden sind, ${ }^{32}$ oder den aufrüttelnden Reden Josef Winklers oder Michael Köhlmeiers. ${ }^{33}$

\footnotetext{
URL: https://www.onb.ac.at/oe-literaturzeitschriften/ (abgerufen 15.04.2020).

Vgl. etwa Erich Hackl, Abschied von Sidonie. Erzählung, Zürich 1989.

Robert Schindel, Der Kalte. Roman, Berlin 2013.

URL: http://www.elfriedejelinek.com/ (abgerufen 15.04.2020).

Michael Köhlmeier, Erwarten Sie nicht, dass ich mich dumm stelle. Reden gegen das Vergessen, München 2018.
} 
Dessen Ansprache „Erwarten Sie nicht, dass ich mich dumm stelle“, die auf dem österreichischen Gedenktag gegen Gewalt und Rassismus am 4. Mai 2018 in der Wiener Hofburg gehalten wurde, zählt in Österreich bereits jetzt zu den einschneidenden Daten neuester Literatur- und Gesellschaftsgeschichte. In ihrem jüngsten Roman „Flammenwand“ hat Marlene Streeruwitz den vorderhand unpolitischen Plot durch Anmerkungen am Ende des Buch ergänzt, die das geschichtsgetränkte private Geschehen in den zeitgeschichtlichen Rahmen der sich überstürzenden Ereignisse innerhalb der erneuten ÖVP-FPÖ-Koalition unter Sebastian Kurz stellen und somit beides kritisch perspektivieren. ${ }^{34}$ Es sind solche kritischen literarischen Strategien, die umgekehrt dazu führten, dass der Rechtspopulist Jörg Haider es im Rahmen der Wiener Gemeinderatswahlen 1995 für stimmenmaximierend hielt, mit Aversionen gegen Elfriede Jelinek und andere KünstlerInnen Wahlkampf zu machen. Nicht nur politische Ereignisse im engeren Sinn, sondern auch technische Errungenschaften wie der Bau der Staumauern von Kaprun oder gesellschaftliche Erscheinungen wie der moderne Massentourismus und der immer extremere Massensport wurden kritisch verarbeitet. ${ }^{35}$ Phänomene wie diese wären aus kulturwissenschaftlichem Gesichtspunkt systematisch mit Blick auf die Funktionalisierung in unterschiedlichen Diskurstypen und Textsorten zu untersuchen.

\subsection{Spezifische literarische Traditionen}

Die besonderen geschichtlichen Voraussetzungen konfessioneller, dynastischer, staatlicher, sozialer und kultureller Art haben in Österreich zur Entwicklung spezifischer symbolischer Formen wie der katholischen Litanei, einem charakteristischen bürokratischen Diskurs oder dem Wiener Volkstheater geführt. Spuren der dabei etablierten Vertextungsverfahren im Sinne eines „liturgischen Katalysator[s]“, ${ }^{36}$ einer „Ämterpoesie“ ${ }^{37}$ oder einer besonderen Freude am Grotesken und Fäkalen ${ }^{38}$ finden sich auch in zahlreichen Werken der Gegenwartsliteratur. So lassen sich etwa in Arbeiten der Wiener Gruppe, in Texten von Elfriede Jelinek, Peter Turrini, Werner Schwab

34 Marlene Streeruwitz, Flammenwand. Roman, Frankfurt a. M. 2019.

35 Christoph Ransmayr, Der Weg nach Surabaya. Reportagen und kleine Prosa, Frankfurt a. M. 1997; Elfriede Jelinek, Ein Sportstück, Reinbek bei Hamburg 2004.

36 Vgl. dazu Wendelin Schmidt-Dengler, Das Gebet in die Sprache nehmen. Zum Säkularisationssyndrom in der österreichischen Literatur der siebziger Jahre, in: Christiane Pankow (Hg.), Österreich. Beiträge über Sprache und Literatur, Umea 1992, 45-62, 59.

37 Vgl. Juliane Vogel, Portable Poetics oder „Kennst Du das Wörtchen Ordnung nicht?“ Neue Anmerkungen zu einem Thema der österreichischen Literatur, in: manuskripte 33 (1993) 119, 105-112, 110.

38 Vgl. dazu etwa Silke Uertz-Jacquemain, Rotweißrotes Fleischtheater. Über die Komik in Werner Schwabs Dramen (Literatur und Leben 90), Wien/Köln/Weimar 2019. 
und anderen ganz unterschiedliche Formen einer kreativen Fortschreibung oder aber Subversion von Verfahren des Wiener Volkstheaters rekonstruieren, die zeigen, wie künstlerisch produktiv die Auseinandersetzung mit regionalen und sogar lokalen literarischen Reihenbildungen in der österreichischen Nachkriegs- und Gegenwartsliteratur war. Dass diese Traditionen stark ausgeprägt sind und sich signifikant von jenen in anderen deutschsprachigen Gebieten unterscheiden, wodurch sie eine wichtige identitäts- und mentalitätsprägende Funktion für das nationale Selbstverständnis erhalten, bestätigt die Notwendigkeit einer vertieften literaturwissenschaftlichen Auseinandersetzung mit den künstlerischen Hervorbringungen, kulturellen Praktiken und sozialen wie medialen Aneignungsweisen von Gegenwartsliteratur.

\section{Fazit}

Das Verhältnis von Literatur(wissenschaft) und Zeitgeschichte ist in Österreich relativ eng im Sinne einer starken Prägung jener durch diese: Es sind insbesondere zeitgeschichtliche Voraussetzungen, Faktoren und Entwicklungen nicht nur politischer, sondern auch allgemein gesellschaftlicher Art, die es geboten erscheinen lassen, die Geschichte der hiesigen modernen Literatur und Gegenwartsliteratur und ihre kontextsensible Erforschung unter fokussierter Berücksichtigung der hier wirksamen spezifischen Rahmenbedingungen und herrschenden Diskurse zu konzeptualisieren. Die seit langem schwelende Frage nach dem genuin ,Österreichischen' der hier entstandenen Literatur kann somit ohne Rückgriff auf essenzialistische Kategorien beantwortet werden. ${ }^{39}$ Dies scheint insofern besonders im Inland nötig zu sein, als die österreichische Gegenwartsliteratur auch im deutsch- und fremdsprachigen Ausland intensiv rezipiert wird, dort aber häufig kaum Kenntnisse der österreichischen Zeitgeschichte erwartet werden können.

39 Vgl. zuletzt den instruktiven Abriss einer langen Diskussion von Konstanze Fliedl, Da capo. Das Österreichische in der österreichischen Literatur, in: Desiree Hebenstreit/Arno Herberth/Kira Kaufmann/Rebecca Schönsee/Laura Tezarek/Christian Zolles (Hg.), Austrian Studies: Literaturen und Kulturen. Eine Einführung. Anlässlich der Emeritierung von Roland Innerhofer am 30. September 2020, Wien 2020, 17-29. 


\title{
Zeitgeschichte und Jüdische Geschichte
}

\author{
Nikolaus Hagen
}

\section{Einleitung ${ }^{1}$}

Die Etablierung und Institutionalisierung des Arbeitsfelds ${ }^{2}$ jüdische Geschichte ${ }^{3}$ bzw. der umfassenderen Jüdischen Studien ist im österreichischen Wissenschaftskontext eine noch jüngere Entwicklung wie die Herausbildung der Zeitgeschichte als Fach. In vielerlei Hinsicht handelt es sich dennoch um eine parallele und gemeinsame Geschichte, stark geprägt durch die erinnerungspolitischen Debatten der 1980er-Jahre, die im Wesentlichen den problematischen Umgang Österreichs mit der NS-Vergangenheit zum Inhalt hatten. ${ }^{4}$ Dieser Entstehungskontext ist nach wie vor prägend und bedeutend und beschränkt sich keineswegs auf zeithistorische Forschungen in diesem zeitlich und thematisch weiten Arbeitsfeld. Eine "Standortbestimmung“ ist indessen keine leichte Aufgabe, $\mathrm{zu}$ fragmentarisch und jung - trotz einer teilweise erfolgreichen Institutionalisierung in den letzten Jahrzehnten - scheint dieses Feld, selbst wenn man sich auf ,jüdische Zeitgeschichte“5 beschränken möchte. Eine ge-

1 Ich danke Lisa Silverman (Wien/Milwaukee) und Thomas Albrich (Innsbruck) für ihre Anmerkungen.

2 An Universitäten im deutschsprachigen Raum sind vereinzelt so bezeichnete (Kern-/Studien-)Fächer „Jüdische Geschichte“ bzw. „Jüdische Kulturgeschichte“ als Teilbereiche der Geschichtswissenschaften, der Kulturwissenschaften oder der Jüdischen Studien eingerichtet worden. Wahlweise kann ,jüdische Geschichte“ auch als ein Forschungsfeld, eine (Teil-)Disziplin oder als bestimmte Such- und Frageanordnung bzw. als Untersuchungsgebiet aufgefasst werden. Ich verwende in der Folge den neutralen Begriff Arbeitsfeld, der Erforschung, Lehre und auch Vermittlung jüdischer Geschichte umfasst.

3 Die Frage, ob es einen Unterschied zwischen einer „jüdischen Geschichte (als Innensicht) und „Geschichte der Juden“ (als Außensicht) gibt, erscheint mir hier nicht entscheidend, und ich verwende in der Folge ersteren Begriff im umfassenden Sinne.

4 Vgl. Heidemarie Uhl, Zeitgeschichteforschung und „österreichisches Gedächtnis“, in: zeitgeschichte 30 (2003) 6, 341-356.

5 Ein allgemeiner Konsens über die inhaltliche und epochale Abgrenzung der Zeitgeschichte existiert freilich nicht, in der österreichischen Praxis wird allerdings häufig zumindest die Zeit ab dem Ersten Weltkrieg als Gegenstand der Zeitgeschichte begriffen. Im Arbeitsfeld ,jüdische Geschichte" werden oft abweichende zeitliche Einteilungen vorgeschlagen, beginnend bspw. mit der endgültigen bürgerlichen Gleichstellung 1867, die für das Gebiet des heutigen Österreichs auch ei- 
meinsame „Fachgeschichte" lässt sich für Österreich deshalb kaum schreiben und ist bisher auch nur in Ansätzen versucht worden. ${ }^{6}$ Vor diesem Hintergrund werden in dem vorliegenden Beitrag die institutionelle Entwicklung sowie aktuell wichtige Fragestellungen und Herausforderungen in Forschung, Lehre und Vermittlung jüdischer Geschichte, ohne Anspruch auf eine umfassende Darstellung, skizziert.

\section{Jüdische Geschichte als Teilgebiet Jüdischer Studien}

Die internationale Tendenz geht dahin, jüdische Geschichte als Teilgebiet und Kern der weitgefassten „Jüdischen Studien“ anzusehen, wobei die beiden Begriffe im Wesentlichen synonym verwendet werden. Damit sind in der Regel Forschungen zu jüdischer Geschichte, aber auch zu jüdisch-nichtjüdischen Interaktionen gemeint, die nicht nur als reines Beiprodukt oder als Unterkapitel einer „allgemeinen“ oder Mehrheitsgeschichtsschreibung betrieben werden oder Jüdinnen und Juden, wie das selbst in Studien zu Nationalsozialismus und Holocaust vorkommt, als selbständige AkteurInnen ausklammern und marginalisieren. Der Begriff Jüdische Studien, der als Lehnübersetzung (Jewish Studies) aus dem anglophonen Wissenschaftskontext übernommen wurde, bezeichnet heute ein sehr breites, hauptsächlich aber nicht ausschließlich kulturwissenschaftlich orientiertes Spektrum an diversen Forschungsund Lehransätzen. Er ist freilich bedeutend jünger als die in der Folge beschriebene Entwicklung und war bis in die frühen 20ooer-Jahre durchaus noch Gegenstand von kontrovers geführten Begriffsdebatten, in denen vor allem die Abgrenzung zur Judaistik und zu anderen akademischen Disziplinen - auch dem klassischen Fächerka-

nen starken Zuwachs der jüdischen Bevölkerung bedeutete, bis zur Zäsur Nationalsozialismus und Holocaust. Als Resultat einer häufig praktizierten ,jüdischen Landesgeschichtsschreibung“ sind auch zeitlich weit zurückreichende, epochenüberschreitende Längsschnittstudien keine Seltenheit.

$6 \mathrm{Zu}$ den Ausnahmen gehört ein Sammelband von 2003, der einige sehr wichtige Aufsätze enthält, freilich aber auch am Anfang der jüngsten Entwicklungsphase stand: Klaus Hödl (Hg.), Jüdische Studien. Reflexionen zu Theorie und Praxis eines wissenschaftlichen Feldes (Schriftenreihe des Centrums für Jüdische Studien 4), Innsbruck 2003. Die Entwicklung in Graz beleuchtet ein jüngerer Artikel: Gerald Lamprecht, Jewish Studies at the University of Graz and in Austria, in: Jewish Culture and History 17 (2016) 3, 183-188. Als Bericht über die regionalhistorische Erforschung jüdischer Geschichte in Westösterreich: Thomas Albrich, 700 Jahre erforschen: Zur Forschungsgeschichte über die jüdische Minderheit in Tirol, Südtirol und Vorarlberg seit Mitte der 1980er-Jahre, in: Ursula Schattner-Rieser/Josef M. Oesch (Hg.), 700 Jahre jüdische Präsenz in Tirol, Innsbruck 2018, 439-460. 
non der Geschichtswissenschaften - verhandelt wurde. ${ }^{7}$ Inzwischen scheint er sich allerdings auch im deutschsprachigen Wissenschaftsbetrieb etabliert zu haben und spiegelt zudem die Tatsache wider, dass die wesentlichen Institutionen in Österreich und im gesamten deutschsprachigen Raum inter- und transdisziplinär ausgerichtet sind. ${ }^{8}$

Jüngst haben sich Christina von Braun und Micha Brumlik in ihrem „Handbuch Jüdische Studien“, das sich neben angehenden Religionswissenschaftlern explizit auch an Geschichtsstudierende richtet, an einer eigenen Begriffsdefinition für den deutschen Sprachraum versucht:

Die „Jüdischen Studien“ - ein Begriff, der in Analogie zu den Jewish Studies des anglophonen Raums entstand - umfassen die Gesamtheit aller Lehrfächer und Forschungsprojekte, die für die Erforschung der jüdischen Geschichte, Philosophie und Religion von Bedeutung sind. Sie beinhalten mithin auch Fragen des Antijudaismus, der Nichtjuden betrifft, aber die jüdische Geschichte immer wieder tiefgehend geprägt hat. $\mathrm{Zu}$ den Jüdischen Studien gehören auch Gebiete wie Memorialkultur, Recht, Ökonomie und Geschlechterrollen, die allesamt in den jüdischen Traditionen spezifische Ausprägungen erfuhren. ${ }^{9}$

In Deutschland und Österreich lasse sich „,jüdisch“ kaum ohne den Begriff der ,Shoah' denken“, weshalb stets auch die (Vor)Geschichte und Nachwirkung des Nationalsozialismus, insbesondere eben auch das nichtjüdische Umfeld, mitzudenken und mitzubehandeln seien. ${ }^{10}$ Noch offener ist die Definition, trotz Einschränkung auf Kulturgeschichte, in der Einleitung zum an der Universität Salzburg herausgegebenen Onlinehandbuch „Jüdische Kulturgeschichte“. Es handle sich um

ein im höchsten Maße interdisziplinäres und nicht genau abgrenzbares Forschungsgebiet; sowohl das Judentum als religiöse und geistesgeschichtliche Größe als auch Jüdinnen und Juden mit den verschiedensten Identitätskonzepten sind in allen Bereichen und Epochen

7 Steven Beller, Knowing your Elephant: why Jewish Studies is not the same as Judaistik, and why that is a good thing, in: Hödl (Hg.), Jüdische Studien, 13-23.

8 Vgl. Anna Menny/Miriam Rürup/Björn Siegel, Jüdische Geschichte im deutschsprachigen Raum, in: Laura Busse/Wilfried Enderle/Rüdiger Hohls/Thomas Meyer/Jens Prellwitz/Annette Schuhmann (Hg.), Clio Guide. Ein Handbuch zu digitalen Ressourcen für die Geschichtswissenschaften, Berlin 2018, URL: https://guides.clio-online.de/guides/themen/juedische-geschichte-im-deutschsprachigen-raum/2018 (abgerufen 10.11.2019).

9 Christina von Braun/Micha Brumlik, Einleitung, in: Christina von Braun/Micha Brumlik (Hg.), Handbuch Jüdische Studien, Wien/Köln/Weimar 2018, 7-13, 7.

10 Ebd. 
der Kulturgeschichte präsent. Oftmals gilt es, sich diese Präsenz und Bedeutung des Jüdischen überhaupt erst bewusstzumachen. ${ }^{11}$

Die großen, internationalen Fachverbände European Association for Jewish Studies (EAJS) und Association for Jewish Studies (AJS) definieren Jüdische Studien bzw. Jewish Studies voneinander abweichend als „Disziplin“" ${ }^{12}$ bzw. als „Untersuchungsgebiet“ („field of inquiry“),13 betonen unisono die breite disziplinäre und thematische Ausrichtung und die zentrale Bedeutung der Historizität. Als wesentliche Bestandteile der Jüdischen Studien gelten für beide Vereinigungen die Holocaust- und die Israel-Studien. Die disziplinäre, thematische und zeitliche Bandbreite Jüdischer Studien wird auch im einleitenden Aufsatz von Martin Goodman zum „Oxford Handbook of Jewish Studies“ aus dem Jahr 2002 betont:

The topics included under the rubric of Jewish studies are exceptionally disparate, ranging not only over a long period of time and all the countries in which Jews have lived, but also over a plethora of different aspects of Jewish culture - literature, history, theology, law, sociology, the fine arts, and more. ${ }^{14}$

Auch an den österreichischen Forschungsinstituten, (jüdischen) Museen und Universitätseinrichtungen kann man diese thematische und disziplinäre Breite Jüdischer Studien feststellen. Lässt man Philologie, Literatur- und Religionswissenschaften aber außer Acht, so verbleibt eine doch recht kleine Anzahl von Historikerinnen und Historikern mit dezidiertem Schwerpunkt in neuerer und neuester jüdischer Sozial- und Kulturgeschichte. Einigermaßen verbindliche Zahlen existieren indessen mangels eines repräsentativen Fachverbandes oder statistischer Erhebungen schlichtweg nicht. ${ }^{15}$ Die breite Definition, die - wie in den oben genannten Bei-

11 Handbuch Jüdische Kulturgeschichte, Zentrum für Jüdische Kulturgeschichte (Hg.), URL: http:// hbjk.sbg.ac.at/ (abgerufen 05.02.2020).

12 Jewish Studies in Europe, URL: https://www.eurojewishstudies.org/history-and-aims/ (abgerufen 01.02.2020).

13 What is Jewish Studies?, URL: https://www.associationforjewishstudies.org/what-is-jewish-studies (abgerufen 01.02.2020).

14 Martin Goodman, The Nature of Jewish Studies, in: Martin Goodman/Jeremy Cohen/David Sorkin (Hg.), The Oxford Handbook of Jewish Studies, Oxford 2002, 1-13, 1.

15 Zwar erhebt die Statistik Austria Zahlen über Forschungszweige und -einrichtungen, in der Österreichischen Systematik der Wissenschaftszweige (ÖFOS 2012) sind allerdings weder ,Jüdische Studien" noch "Jüdische Geschichte" als Arbeitsgebiete enthalten. Diese Systematik birgt überhaupt erhebliche Probleme: „Judaistik“ wird als Untergebiet der Sprach- und Literaturwissenschaften, „Jüdische Religion“ als Untergebiet der Religionswissenschaften ausgewiesen. Im Forschungsstät- 
spielen - selbst Aspekte der (mehrheitsgesellschaftlichen?) „Erinnerungskultur“ an den Holocaust umfassen kann, führt dazu, dass Jüdische Studien kaum von anderen (kultur)historischen Arbeitsfeldern abgrenzt werden können, was als Stärke, aber auch als Schwäche gedeutet werden kann. Die in den 1990er-Jahren durchaus noch heftig diskutierte Frage, was die Jüdischen Studien eine und wie sie sich zu anderen Disziplinen verhielten, scheint indessen angesichts des Aufbrechens traditioneller disziplinärer Grenzen und einer inzwischen de facto Normalität transdisziplinärer Arbeitsverbünde und Forschungsprogramme in den Geistes, Kultur- und Sozialwissenschaften bereits weitgehend überholt. ${ }^{16}$

In jüngerer Zeit sind vereinzelt auch Vergleiche von „jüdisch“ bzw. „jewish“ mit "Geschlecht" bzw. „Gender" gestellt worden. Letztere haben sich mittlerweile als Analysekategorien quer durch die Geistes, Sozial- und Kulturwissenschaften fest etabliert und bedürfen nicht mehr zwangsläufig eigener Fächer (wie Frauen- oder Geschlechtergeschichte), die einen Mangel an entsprechenden Forschungen in den „etablierten“ Disziplinen kompensierten. Auch vor diesem Hintergrund bleibt kritisch zu hinterfragen, ob jüdische Geschichte in Österreich primär im institutionellen und konzeptionellen Rahmen Jüdischer Studien bzw. unter diesem „Label“ erforscht und gelehrt wird und ob dies überhaupt dem Selbstverständnis vieler Forschenden und Lehrenden in diesem Feld entspricht, was aber hier offenbleiben muss. Ebenso ließe sich trefflich darüber streiten, ob sich die Holocaustforschung, die wiederum eng mit der Nationalsozialismus- und Faschismusforschung verbunden ist, wirklich unter dem Begriff Jüdische Studien subsummieren lässt oder ob es sich um sich überschneidende Teilgebiete oder gar Querschnittsmaterien verwandter Forschungsbereiche handelt. Dasselbe gilt auch für die Antisemitismusforschung, die im deutschsprachigen Raum in den unterschiedlichsten Disziplinen (Zeitgeschichte bzw. Geschichtswissenschaften, Soziologie, Psychologie, Pädagogik, Politikwissenschaften, Religionswissenschaften usw.) institutionell verankert ist. Dieses möglicherweise unklare Verhältnis ist freilich auch in der spezifischen Situation der Holocaustforschung in der deutschen und österreichischen Nachkriegsgeschichte begründet. Die beinahe vollständige Vernichtung der jüdischen Gemeinden führte

tenkatalog erfolgen völlig unsystematische Zuweisungen von Teilgebieten der Geschichtswissenschaften zu einzelnen Instituten. Das Centrum für Jüdische Studien in Graz ist bspw. allgemein den „Geschichtswissenschaften“ zugeordnet, das Jüdische Museum der Stadt Wien nur der „Zeitgeschichte“, jenes in Hohenems wiederum nur „Geschichtlicher Landeskunde“ und „Regionalgeschichte“. Österreichischer Forschungsstättenkatalog, Statistik Austria, URL: https://fsk.statistik.at/ startseite/ (abgerufen 01.02.2020).

16 Diese Feststellung Klaus Hödls von 2003 gilt heute umso mehr. Klaus Hödl, Einleitung, in: ders. (Hg.), Jüdische Studien, 13-23. 
zwangsläufig dazu, dass die Erforschung des Holocaust hier lange Zeit überwiegend auf Basis und über die Dokumente der NS-Täter geschah. Im anglophonen Raum wurde dagegen die Perspektive Überlebender schon viel früher in die dortigen Forschungen einbezogen, die Mehrzahl der entsprechenden frühen Forschungsarbeiten ging in der Regel auch von Forscherinnen und Forschern aus, die selbst als Jüdinnen und Juden der nationalsozialistischen Vernichtungspolitik entkommen waren. ${ }^{17}$ Damit fielen Holocaustforschung und jüdische Geschichte im anglophonen Wissenschaftsbetrieb beinahe „natürlich“ zusammen, während das Verhältnis in Deutschland und Österreich länger distanziert blieb. Spätestens seit den 1990erJahren ist auch hier die Situation eine ganz andere - davon zeugen beispielsweise zahlreiche Zeitzeugenprojekte ${ }^{18}$ und die längst etablierte Zusammenarbeit mit den großen Videoarchiven in den Vereinigten Staaten. ${ }^{19}$ Dennoch mag dieser historiographische Hintergrund für die spezifische Ausprägung der Holocaustforschung in Deutschland und Österreich, oftmals dezidiert abgegrenzt von jüdischer Geschichte und Jüdischen Studien und an separaten Institutionen beheimatet, prägend gewesen sein und bis heute nachwirken. Eine klare Trennung zwischen den beiden Feldern lässt sich aber kaum argumentativ aufrechterhalten.

Ähnlich wie die Zeitgeschichte, aber möglicherweise noch viel stärker als diese, stehen die Jüdischen Studien, gerade im deutschsprachigen Raum, vor einem kontinuierlichen und sich in jüngster Zeit wieder intensivierenden Prozess der Selbstvergewisserung und Selbstverortung. Prägend für das Feld sind durchaus komplexe Fragen nach dem Gegenstand und Adressaten von Forschung und Lehre, insbesondere wenn es um Fragen des Antisemitismus geht, nach dem Verhältnis zu Religion und Judentum, zu den jüdischen Gemeinden, zum Staat Israel, letztlich auch nach der Legitimität, Berechtigung und Aktualität des Forschungsfelds an sich. Diese Fragen sind gerade in den in den postnazistischen Staaten, wo entsprechenden Studien, anders als im anglophonen Sprachraum und in Israel, überwiegend von nichtjüdischen Forscherinnen und Forschern (für ein überwiegend nichtjüdisches Publikum) betrieben werden, bedeutend und bergen Potenzial zur Kontroverse, werden

17 Elisabeth Gallas, Frühe Holocaustforschung in Amerika. Dokumentation, Zeugenschaft und Begriffsbildung, in: Raphael Gross (Hg.), Jahrbuch des Simon-Dubnow-Instituts XV 2016, Bd. 15, Göttingen/Bristol 2017, 535-569.

18 Bspw. das vom Verein Gedenkdienst in Zusammenarbeit mit dem Leo Baeck Institute Jerusalem, dem Wiener Wiesenthal Institut für Holocaust-Studien (VWI) und weiteren Partnern betriebene digitale Austrian Heritage Archive, URL: http://austrianheritagearchive.at/ (abgerufen 01.02.2020).

19 Dafür stehen bspw. die Kooperation zwischen VWI und dem Fortunoff Video Archive for Holocaust Testimonies der Yale University und verschiedene Lernmaterialen von „erinnern.at“, dem Institut für Holocaust-Education des Bildungsministeriums, die unter anderem mit Videointerviews des USC Shoah Foundation Visual History Archives realisiert wurden. 
aber kaum offen diskutiert und reflektiert. Stattdessen entzünden sie sich oft an vermeintlichen Sach- oder Personalfragen. Nicht zuletzt lässt sich auch ein generationeller Umbruch beobachten, der das Feld jüdische Geschichte heute ähnlich trifft wie jenes der Zeitgeschichte.

\section{Institutionalisierung der Forschungslandschaft}

Das Arbeitsfeld jüdische Geschichte war und ist stark von Einzelpersonen und regionalen Initiativen geprägt, die stets neue Themen erschlossen haben bzw. erschließen und damit Impulse für die gesamte Forschungslandschaft leisten. Eine besondere Dynamik haben diese Forschungen, wie eingangs erwähnt, insbesondere ab den 1980er-Jahren erhalten. Federführend waren dabei damals junge Nachwuchshistorikerinnen und -historiker innerhalb und außerhalb der Universitäten, weiter Gedenkinitiativen und Museumsprojekte ${ }^{20}$ sowie Initiativen aus dem Bereich der historisch-politischen Bildungsarbeit bzw. der Geschichtsdidaktik. Im Sinne einer kritischen Regionalgeschichte von unten waren viele dieser Initiativen stark lokal verankert und zuvorderst an der Erforschung der jüdischen Aspekte ihrer unmittelbaren Umgebung interessiert. Die jüdische Geschichte des 20. Jahrhunderts bringt es mit sich, dass eine derartige Regionalgeschichte fast immer transnationale Aspekte und Migrationserfahrungen beinhaltet. Aus der Erforschung regionaler und lokaler jüdischer Geschichte entwickelten sich so rasch Netzwerke und Verbindungen über einzelne Regionen, Länder und schließlich weit über Europa hinaus. ${ }^{21}$

In einzelnen Fällen kamen die Impulse so auch über Umwege nach Österreich. Ein Beispiel dafür ist die Erforschung der jüdischen Displaced Persons (DPs) in Österreich, der Holocaustüberlebenden, die maßgeblich mit dem Namen Thomas Albrich am Institut für Zeitgeschichte in Innsbruck verbunden ist. Walter Laqueur regte 1979 den damaligen Praktikanten an der Wiener Library zu diesen Forschungen an. In den darauffolgenden zwei Jahrzehnten etablierte sich ein österreichweites DP-Forschungsnetzwerk, sodass heute zu beinahe allen Regionen Österreichs ent-

20 Vgl. Gerald Lamprecht, Die österreichischen jüdischen Museen im zeitgeschichtlichen Kontext, in: Dirk Rupnow/Heidemarie Uhl (Hg.), Zeitgeschichte ausstellen in Österreich. Museen - Gedenkstätten - Ausstellungen, Wien/Köln/Weimar 2011, 213-235.

21 Bspw. das Forschungsnetzwerk Alemannia Judaica, Arbeitsgemeinschaft für die Erforschung der Geschichte der Juden im süddeutschen und angrenzenden Raum, das seit 2001 im Internet präsent ist, vgl. URL: http://www.alemannia-judaica.de/ (abgerufen 01.02.2020). 
sprechende Arbeiten vorliegen. ${ }^{22}$ Diese Forschungen sind ein Paradebeispiel für die Verbindung von regionalen, nationalen und inter- bzw. transnationalen Ansätzen und Aspekten. Ein weiteres Beispiel dafür sind biographische und lebensgeschichtliche Forschungsprojekte, die besonders ab den frühen 1990er-Jahren verstärkte Aufmerksamkeit erhielten. Zum einen waren das genealogisch-lebensgeschichtliche Forschungen, wie sie etwa in Innsbruck zunehmend betrieben wurden, zum anderen Oral-History-Interviews mit Holocaustüberlebenden, wie sie in Österreich vor allem Albert Lichtblau an der Universität Salzburg nachhaltig als Methode geprägt und popularisiert hat. ${ }^{23} \mathrm{Im}$ Rahmen verschiedener Projekte sind in den letzten 25 Jahren zahlreiche neue Interviews mit österreichischen Überlebenden geführt worden, unter anderem für das Visual History Archive oder das Austrian Heritage Archive. Zudem wurden bereits existierende Interviews aus den großen Sammlungen mit Bezug zu Österreich ausgewertet und insbesondere auch für den Unterricht und eine breitere Öffentlichkeit nutzbar und zugänglich gemacht. Für den „Cultural Turn“ im Feld jüdischer Geschichte, also das zunehmende Interesse an kulturwissenschaftlichen Fragestellungen und Methoden, die insbesondere in den letzten beiden Jahrzehnten stark an Konjunktur gewonnen haben, stehen vor allem die Arbeiten Klaus Hödls in Graz. Jüdische Geschichte wird in diesen Arbeiten nicht als ein Addendum oder gar Gegenstück zu einer „allgemeinen Geschichte“ betrachtet, sondern als konstituierender Bestandteil einer größeren Gesamtkultur, deren inneres Gefüge und multiple Beziehungsgeflechte zum eigentlichen Untersuchungsobjekt werden. In jüngster Zeit lässt sich ein verstärktes Interesse an der jüdischen Geschichte der Zwischenkriegszeit sowie an jüdisch-nichtjüdischen Verhältnissen nach 1945 feststellen. Die genannten Forscher waren freilich nicht allein und die genannten Forschungsansätze nicht die Einzigen, die verfolgt wurden. Die Pionierleistungen, die Einzelne in diesem Feld erbracht haben, werden aber deutlich, wenn man sich die erst junge Geschichte der Institutionalisierung des Arbeitsfelds vergegenwärtigt.

22 Philipp Strobl/Nikolaus Hagen, New Perspectives on Displaced Persons (DPs) in Austria, in: zeitgeschichte 47 (2020) 2, 172-175.

23 Johannes Hofinger, I think this is the beginning of a beautiful friendship. Albert Lichtblau, Oral History und die Österreichische Mediathek, in: Regina Thumser-Wöhs/Martina Gugglberger/ Birgit Kirchmayr/Grazia Prontera/Thomas Spielbüchler (Hg.), Außerordentliches. Festschrift für Albert Lichtblau, Wien/Köln/Weimar 2019, 95-103; Sammlung Lichtblau. Interviews mit Opfern des Nationalsozialismus in Österreich, Österreichische Mediathek (Hg.), URL: https://www.mediathek.at/oesterreich-am-wort/sammlungen/sammlung/col/27/cd/show/sc/Collection/gc/27/ (abgerufen 01.02.2020). 
Sieht man vom Wiener Institut für Judaistik ab, das in seinen frühesten Ausformungen bereits seit 1945 (als Institut und Ordinariat allerdings erst seit 1966) existiert und damit, wenn auch unter anderen Vorzeichen, zeitlich an die nationalsozialistische "Judenforschung ${ }^{{ }^{24}}$ anschloss, so entstanden die ersten formellen Forschungsschwerpunkte und -einrichtungen für jüdische Geschichte in Österreich überwiegend erst ab Mitte bzw. Ende der 1980er-Jahre. Zum einen geschah das an damals neu etablierten oder bereits existierenden Zeitgeschichte- bzw. Sozialgeschichteinstituten, zum anderen an neuen Einrichtungen. Auch wenn es im deutschsprachigen Raum durchaus Versuche gab und gibt, zumindest symbolisch an die Tradition der "Wissenschaft des Judentums“ und verwandter Strömungen anzuknüpfen - etwa durch Namensgebung (man denke nur das mittlerweile umbenannte David-Herzog-Centrum in Graz oder an das Abraham Geiger Kolleg und das Selma Stern Zentrum in Berlin) -, so war der Gründungskontext diese Institute, gerade auch in Österreich, ein durchaus anderer und von einem völligen Bruch mit etwaigen Tendenzen vor 1938 gekennzeichnet. ${ }^{25}$ Es ist geradezu typisch für das Arbeitsfeld, dass die ersten dezidierten Einrichtungen für jüdische Geschichte größtenteils außerhalb der Universitäten und häufig als Resultat zivilgesellschaftlichen Engagements, vorangetrieben von lokalen oder regionalen Erinnerungsinitiativen, aber auch einzelnen Forscherinnen und Forschern, entstanden.

Als zeitlicher Ausreißer hatte bereits 1972 das von Bund und Ländern getragene Österreichische Jüdische Museum in Eisenstadt, das im deutschsprachigen Raum damit eine Pionierrolle innehatte, eröffnet. Dieses Vorhaben, „ein wissenschaftliches Institut zur Geschichte der österreichischen Juden sowie eine Stätte der Besinnung und Begegnung, der Verständigung und Toleranz zwischen den Menschen ${ }^{{ }^{26} 6} \mathrm{zu}$ schaffen, wie es bereits 1970 angekündigt worden war, wurde unter anderem auch vom Dokumentationsarchiv des Österreichischen Widerstands gefördert. Es ist allerdings bis heute chronisch unterfinanziert und kann deshalb seinen im Namen formuliertem Anspruch, ein gesamtösterreichisches Museum zu jüdischer Kultur und Geschichte zu sein, nicht erfüllen. Mehr als eine Dekade später, im „Bedenk-

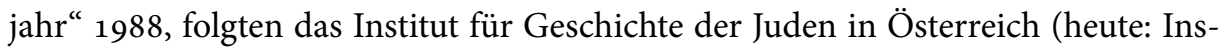
titut für jüdische Geschichte Österreichs) - ein Verein, getragen durch Bund und Länder, der seit 2011 mit dem in die Universität Wien eingegliederten Institut für

24 Dirk Rupnow, Judenforschung im Dritten Reich. Wissenschaft zwischen Politik, Propaganda und Ideologie, Baden-Baden 2011.

25 Siehe auch: Markus J. Wenninger, Jüdische Studien in der österreichischen „Provinz“. Möglichkeiten und Grenzen, in: Hödl (Hg.), Jüdische Studien, 25-36.

26 Österreichisches jüdisches Museum, in: Der Neue Mahnruf 23 (1970) 12, 8. 
Österreichische Geschichtsforschung assoziiert ist $\mathrm{t}^{27}$ - und, damals noch als Provisorium, das städtische Jüdische Museum in Wien. Heute betreibt Letzteres neben seinen Sammlungen und Ausstellungsräumen die größte außeruniversitäre Fachbibliothek zum Judentum und zur jüdischen Geschichte des Landes. ${ }^{28}$ Im selben Jahr wie in Wien wurde auch in Frankfurt am Main das erste Jüdische Museum Nachkriegsdeutschlands eröffnet und ein Jahr darauf, 1989, die Association of European Jewish Museums gegründet. ${ }^{29}$ Diese ist Ausdruck und Resultat der europaweiten Gründungswelle der damaligen Zeit. In Österreich folgte schließlich 1991 die Eröffnung des Jüdischen Museums Hohenems, getragen durch einen bereits 1986 gegründeten Verein, der wiederum auf noch früheren Bestrebungen, die bis in die $1970 e r-J a h r e$ zurückreichen, basierte. ${ }^{30}$ Es blieb bis dato das dritte und auf absehbare Zeit wahrscheinlich auch das letzte neu gegründete Museum dieser Art in Österreich. Hohenems schloss schon früh eine Kooperation mit dem Institut für Zeitgeschichte in Innsbruck, die sich in gemeinsamen Buchreihen, Veranstaltungen und Forschungsprojekten niederschlug. ${ }^{31}$ Diese langjährige Zusammenarbeit zwischen Museum und universitärem Institut, die nach wie vor andauert, war und ist zweifelsohne vorbildlich.

Unweit von Hohenems, in Bregenz, wurde im Jahr 2000 das Projektbüro des Lehrerinnen- und Lehrerbildungsnetzwerkes „erinnern.at“ eingerichtet, das inzwischen auch als Institut für Holocaust Education des Bildungsministeriums firmiert und zahlreiche bedeutende geschichtsdidaktische Projekte durchführt sowie nationale und internationale Kooperationen, darunter mit der Gedenkstätte Yad Vashem in Jerusalem, unterhält. ${ }^{32}$ Das Netzwerk ist größtenteils dezentral und von unten durch engagierte Geschichtsdidaktikerinnen und -didaktiker organisiert und damit

27 Institut für jüdische Geschichte Österreichs, URL: http://www.injoest.ac.at/de/institut (abgerufen 01.02.2020).

28 Jüdisches Museum Wien, URL: http://www.jmw.at/de/ueber-uns (abgerufen 01.02.2020).

29 Association of European Jewish Museums (AEJM), URL: https://www.aejm.org/about-us/ (abgerufen 01.02.2020).

30 Ein Zentrum für Geschichte und Gegenwart, Jüdisches Museum Hohenems, URL: https://www. jm-hohenems.at/ueber-uns/entstehung-und-leitbild (abgerufen 01.02.2020).

31 In der gemeinsamen Buchreihe im Böhlau Verlag erschienen zwischen 1994 und 1999 insgesamt vier Bände: Schriften des Instituts für Zeitgeschichte der Universität Innsbruck und des Jüdischen Museums Hohenems, URL: https://www.uibk.ac.at/zeitgeschichte/publikationen/buchreihen. html.de\#hohenems (abgerufen 01.02.2020). Das gemeinsame Projekt „Biografische Datenbank zur jüdischen Bevölkerung Tirols und Vorarlbergs" besteht mittlerweile seit fast drei Jahrzehnten und ist nach wie vor „work in progress“. Der aktuelle Stand kann über das Internetportal „Hohenems Genealogie" abgerufen werden, URL: http://www.hohenemsgenealogie.at/ (abgerufen 01.02.2020).

32 erinnern.at - Das Holocaust-Education Institut des BMBWF, URL: https://www.erinnern.at/ueberuns/ueber-uns (abgerufen 01.08.2020). 
ein erfolgreiches Beispiel für eine fruchtbringende Kooperation zwischen Schulen, außerschulischen Bildungs- und Forschungseinrichtungen sowie den Universitäten und Pädagogischen Hochschulen. Zudem bündelt es auf regionaler Ebene zahlreiche Forschungsaktivitäten zu jüdischer (Regional-)Geschichte und ist insbesondere in Zeitzeuginnen- und Zeitzeugenprojekten aktiv.

Mit dem an der Universität Graz angesiedelten Centrum für Jüdische Studien bzw. seinen Vorläufereinrichtungen wurde um die Jahrtausendwende erstmals eine interdisziplinär ausgerichtete universitäre Einrichtung für Jüdische Studien etabliert. Auch dieses Forschungs- und Studienzentrum war das Resultat eines langen zivilgesellschaftlichen und inneruniversitären Engagements einzelner Forscherinnen und Forscher, das bis in die 1980er-Jahre zurückreicht. ${ }^{33}$ Besonderheit des Grazer Centrums war und ist eine jährlich ausgeschriebene Gastprofessur für Jüdische Studien, die von Beginn an für eine starke internationale Vernetzung und Wahrnehmung sorgte. Einige Jahre nach Graz, im Jahr 2004, wurde auch an der Universität Salzburg ein Zentrum für Jüdische Kulturgeschichte etabliert, das ebenso interdisziplinär ausgerichtet ist. ${ }^{34}$ Sowohl in Graz als auch in Salzburg handelt es sich nicht um klassische Universitätsinstitute, sondern um fakultäts- und institutsübergreifende Forschungsverbünde. Beide Zentren geben eigene Fachzeitschriften heraus, welche deren interdisziplinäre Ausrichtung widerspiegeln. ${ }^{35}$ An beiden Universitäten wurden mittlerweile kulturhistorisch ausgerichtete Masterstudiengänge eingerichtet: in Graz ein Joint-Degree-Programm „Jüdische Studien. Geschichte jüdischer Kulturen“ gemeinsam mit der Hochschule für Jüdische Studien Heidelberg, in Salzburg der Studiengang ,Jüdische Kulturgeschichte“. Die Studierendenzahlen auf Masterniveau sind in Graz und Salzburg bzw. Wien (Judaistik) allerdings sehr gering. ${ }^{36}$ Wie viele Studierende einen geschichtswissenschaftlich orientierten Schwerpunkt innerhalb dieser interdisziplinären Studiengänge setzen oder entsprechende Abschlussarbeiten verfassen, lässt sich aus den veröffentlichten Statistiken nicht ablesen. Das klassische Geschichtsstudium dürfte vermutlich auch in Graz und Salzburg der do-

33 Lamprecht, Jewish Studies, 184-185.

34 Gerhard Bodendorfer, Ein Forschungsinstitut für „Jüdische Kulturgeschichte“ in Salzburg?!, in: Hödl (Hg.), Jüdische Studien, 51-72.

35 Zentrum für Jüdische Kulturgeschichte Salzburg (Hg.), Chilufim. Zeitschrift für Jüdische Kulturgeschichte; Centrum für Jüdische Studien Graz (Hg.), transversal. Zeitschrift für Jüdische Studien (erschien zuletzt 2016).

36 Im Studienjahr 2019/2020 in Graz vier, in Salzburg zwölf MA-Studierende, in Wien (Judaistik) insgesamt 117 BA- und MA-Studierende. Studierendenstatistiken der Universitäten Salzburg und Wien; schriftliche Auskunft Studieninfoservice Universität Graz, 11.02.2020. 
minierende universitäre Ausbildungsweg für an jüdischer Geschichte interessierte Studierende bleiben.

Im Jahr 2008 schlossen sich die Zentren in Graz und Salzburg und die Institute in St. Pölten und Wien zur Arbeitsgemeinschaft für Jüdische Studien in Österreich zusammen, die allerdings nicht öffentlich in Erscheinung tritt und jenseits der internen Vernetzung der jeweiligen Institutsangehörigen bislang keine von außen erkennbare Funktion hat. ${ }^{37}$ Seit 2009 ist zudem das Jüdische Museum Hohenems Schauplatz der Europäischen Sommeruniversität für Jüdische Studien, die als gemeinsames Projekt deutscher, österreichischer und schweizerischer Institute und Lehrstühle unter organisatorischen Leitung des Lehrstuhls für Jüdische Geschichte und Kultur der Ludwig-Maximilians-Universität München jährlich veranstaltet wird. ${ }^{38}$ Ebenfalls 2009 wurde nach langen Vorarbeiten das international ausgerichtete Wiener Wiesenthal Institut für Holocaust-Studien (VWI) eingerichtet, das unter anderem den Nachlass Simon Wiesenthals und die holocaustbezogenen Bestände des Archivs der Israelitischen Kultusgemeinde Wien (IKG) beherbergt. Neben eigenen Forschungsprojekten, die häufig in Kooperation mit Partnerinstitutionen durchgeführt werden, sorgt vor allem ein jährliches Fellowship-Programm für eine internationale Vernetzung des Instituts. Zudem gibt das VWI eine zweimal jährlich erscheinende Open-Access-Zeitschrift heraus. ${ }^{39}$

Seit 2019 gibt es am Institut für Zeitgeschichte der Universität Innsbruck eine Laufbahnstelle für Israel-Studien, die mit dem Forschungsnetzwerk Austria-Israel Academic Network Innsbruck ${ }^{40}$ verbunden ist. Damit wurden erstmals Israel-Studien an einer österreichischen Universität in einem Historischen Institut verankert und finden in der Lehre auch Eingang in die entsprechenden geschichtswissenschaftlichen Studiengänge. Auch diese Stelle hat eine längere Vorgeschichte. Schon in den 1990er-Jahren war der Versuch unternommen worden, einen entsprechenden Forschungsschwerpunkt zu österreichisch-israelischen Beziehungen in Inns-

37 Als einziger öffentlicher Auftritt existierte eine Facebook-Seite: AG Jüdische Studien in Österreich, URL: https://www.facebook.com/AG-J\%C3\%BCdische-Studien-in-\%C3\%96sterre ich-238975696121273/ (abgerufen 07.02.2020).

38 Europäische Sommeruniversität für Jüdische Studien in Hohenems, URL: https://www.jgk.geschichte.uni-muenchen.de/sommeruniversitaet/index.html (abgerufen 07.02.2020).

39 Shoah: Intervention. Methods. Documentation. (S:I.M.O.N.), URL: https://simon.vwi.ac.at/ (abgerufen 01.02.2020).

40 Das Austria-Israel Academic Network Innsbruck (AIANI) ist Teil der Internationalisierungsbestrebungen der Universität Innsbruck und soll Kooperationen mit israelischen Partnerinstitutionen ermöglichen und vertiefen. 
bruck aufzubauen. ${ }^{41}$ In Wien existiert parallel ein auf Vereinsbasis organisiertes Center for Israel Studies, das zur Zeit primär über öffentliche Vorträge in Erscheinung tritt, aber als langfristiges Ziel die Einrichtung eines Bachelorstudiengangs für Israel-Studien an der Universität Wien anstrebt. ${ }^{42}$ Allerjüngste Entwicklung ist die 2019 angelaufene Übersiedelung der Central European University (CEU) von Budapest nach Wien. An der CEU ist seit 1996 ein Jewish-Studies-Programm eingerichtet, das zur Zeit in Form einer Vertiefungsspezialisierung unter anderem in den Masterstudien Geschichte und Nationalism Studies belegt werden kann. ${ }^{43}$ Wie sich dieses Programm in das österreichische Umfeld einfügen wird und ob in Zukunft möglicherweise auch eine Vertiefung auf Bachelorebene angeboten wird, ist derzeit noch nicht absehbar. Zweifelsohne aber wird dieses international ausgerichtete Programm das Arbeitsfeld jüdische Geschichte in Österreich beleben.

Neben den erwähnten spezialisierten Instituten, Museen und Lehrstühlen findet die Forschung - in Summe wohl sogar quantitativ überwiegend - an (Zeit-) Historischen Instituten aller österreichischen Universitäten, an außeruniversitären Instituten und Archiven sowie an (kultur-)historischen Museen statt. Zu erwähnen sind die Institute für Zeitgeschichte in Wien und Innsbruck, die Abteilung für Zeitgeschichte in Klagenfurt und das Institut für Neuere und Zeitgeschichte in Linz. Die Kernfächer Zeitgeschichte in Graz und Salzburg der jeweiligen Geschichtsinstitute sind maßgeblich in die dort jeweils eingerichteten Forschungszentren eingebunden. Auch an den Instituten für Wirtschafts- und Sozialgeschichte in Wien und Linz wird zu jüdischer Geschichte geforscht. Eine Reihe von einschlägig interessierten Forscherinnen und Forschern ist am Institut für Kulturwissenschaften und Theatergeschichte der Österreichischen Akademie der Wissenschaften tätig, ${ }^{44}$ andere am Ludwig Boltzmann Institute for Digital History in Wien, ${ }^{45}$ auch an der Universität für angewandte Kunst gibt es entsprechende Schwerpunktsetzungen. ${ }^{46}$

41 Daraus ging u. a. die von Rolf Steininger und Moshe Zimmermann herausgegebene Schriftenreihe „Österreich-Israel-Studien“ hervor.

42 Über uns, Center for Israel Studies, URL: http://center-for-israel-studies.at/de/ueber-uns/ (abgerufen 01.02.2020).

43 Jewish Studies Program, Central European University, URL: https://jewishstudies.ceu.edu/ (abgerufen 01.02.2020).

44 Hier speziell am Forschungsschwerpunkt „Orte des Gedächtnisses - Erinnerungsräume“, URL: https://www.oeaw.ac.at/ikt/forschung/gedaechtnis/ (abgerufen 01.02.2020).

45 Aktuell etwa im EU-finanzierten Großprojekt „Visual History of the Holocaust: Rethinking Curation in the Digital Age“, URL: https://geschichte.lbg.ac.at/tags/visual-history-holocaust (abgerufen 01.02.2020).

46 U. a. am Institut für Design, URL: https://www.designhistorytheory.at/faculty/shapira/ (abgerufen 01.2.2020). 
Traditionell ist auch das bereits erwähnte Dokumentationsarchiv des Österreichischen Widerstands, das in einigen Fällen als Träger bzw. Gründungsmitglied bereits erwähnter Institute fungiert, ein wichtiger Akteur in diesem Feld, insbesondere in der Holocaust- und Antisemitismusforschung. Auch an den Politikwissenschaftlichen und Soziologischen Instituten wird immer wieder zu Aspekten jüdischer Zeitgeschichte, speziell auch zum Antisemitismus geforscht. Nachhaltig prägend für das Forschungsfeld war zweifelsohne auch die auf Urgenz des damaligen Präsidenten der IKG Wien Ariel Muzicant eingerichtete Österreichische Historikerkommission, die zwischen 1998 und 2003 tätig war. ${ }^{47}$ Einerseits wurde hier mit dem Komplex „Arisierung“ ein besonders bedeutendes Kapitel der NS-Geschichte aufgearbeitet, andererseits gingen aus den Arbeiten zahlreiche Folgeprojekte und Impulse zu Provenienzforschung, Restitution und anderen Aspekten jüdischer Geschichte und des Holocaust hervor. Provenienzforschung ist mittlerweile an den größeren österreichischen Museen fest verankert, teilweise gingen die Ergebnisse bereits in Ausstellungen ein, wie etwa die 2008/2009 am Museum für angewandte Kunst Wien gezeigte Schau „Recollecting. Raub und Restitution“.48 Viele Mitarbeiterinnen und Mitarbeiter der Historikerkommission waren und sind in der Folge an zahlreichen universitären und außeruniversitären Institutionen in der Holocaustforschung und Projekten zur jüdischen Geschichte tätig geworden. Auch die mittlerweile umbenannte Anlaufstelle für Jüdische NS-Verfolgte der IKG Wien war personell und thematisch eng mit der Kommission verbunden. ${ }^{49}$ Aus dem Kontext Entschädigung und Restitution stammen auch der Nationalfonds für Opfer des Nationalsozialismus und der Zukunftsfonds der Republik Österreich, die beide enorm wichtige Fördergeber für Projekte zu jüdischer Geschichte sind. ${ }^{\circ 0}$

47 Clemens Jabloner/Brigitte Bailer-Galanda/Eva Blimlinger/Georg Graf/Robert Knight/Lorenz Mikoletzky/Bertrand Perz/Roman Sandgruber/Karl Stuhlpfarrer/Alice Teichova, Schlussbericht der Historikerkommission der Republik Österreich. Vermögensentzug während der NS-Zeit sowie Rückstellungen und Entschädigungen seit 1945 in Österreich. Zusammenfassungen und Einschätzungen (Veröffentlichungen der Österreichischen Historikerkommission 1), Wien/München 2003. $\mathrm{Zu}$ den Hintergründen: Eva Blimlinger, „... Das geht sich nie aus, das könnt ihr nicht verlangen, Wahnsinn!“ Konzeption und Organisation von Auftragsforschungsprojekten am Beispiel der Historikerkommission, in: zeitgeschichte 30 (2003) 5, 281-292.

48 Katalog zur Ausstellung: Alexandra Reininghaus (Hg.), Recollecting. Raub und Restitution, Wien 2009.

49 Heute „Abteilung für Restitutionsangelegenheiten“ der IKG, URL: http://www.restitution.or.at/ (abgerufen 01.02.2020).

50 Projektförderung des Nationalfonds, URL: https://www.nationalfonds.org/projektfoerderung (abgerufen 01.02.2020); Projekte 2006-2019, Zukunftsfonds der Republik Österreich, URL: http:// www.zukunftsfonds-austria.at/projects.php (abgerufen 01.02.2020). 
Die hier grob skizzierte Breite und „Streuung“ der Forschungslandschaft macht eine Stärke des Feldes aus. Aspekte jüdischer Geschichte bzw. entsprechendes Fachwissen sind somit an zahlreichen Institutionen und in verschiedensten Studiengängen in Forschung und Lehre verankert. Diese Streuung ist aber gleichermaßen auch Symptom einer großen Schwäche, weil die Forschung in der Regel von wenigen Einzelpersonen und deren spezifischen Forschungsinteressen abhängig ist. Die in Österreich vorherrschende Logik der projektbasierten Forschungsfinanzierung und der damit zusammenhängende Mangel an entsprechenden dauerhaften Arbeitsstellen sorgen dafür, dass langfristige Schwerpunktsetzungen und die Etablierung großer Langzeitprojekte zukünftig vermutlich noch schwieriger zu realisieren sind, als das in der Vergangenheit bereits der Fall war.

\section{Aktuelle Herausforderungen}

Zweifelsohne ist es in den letzten Jahrzehnten an einigen Institutionen und in verschiedenen Teilen Österreichs gelungen, Forschungsschwerpunkte zu jüdischer Geschichte langfristig zu etablieren; dies, wie erwähnt, oft nur dank des langjährigen Engagements von einzelnen Forscherinnen und Forschern und oft genug mit erstaunlich geringen finanziellen Mitteln. Das Arbeitsfeld jüdische Geschichte hatte Anteil an zahlreichen methodischen, theoretischen und thematischen Innovationen im Bereich der Zeitgeschichtsforschung: von transnationaler Geschichtsschreibung über lebensgeschichtliche Forschungsansätze und Migrationsgeschichte bis hin zu Fragen nach Identitäten und gesellschaftlichen Interaktionen. Die internationale Vernetzung in diesem Arbeitsfeld ist groß und reicht weit über den deutschsprachigen Raum hinaus. Einige der gegenwärtigen Herausforderungen sind deswegen auch keineswegs auf Österreich beschränkt, zeigen sich aber auch hier.

Gerade die jüdischen Museen sind heute unterschiedlichen und oft stark divergierenden Forderungen von Seiten ihrer Trägereinrichtungen, der Mehrheitsgesellschaft und der jüdischen Gemeinden ausgesetzt. Das spiegelt zum einen aktuelle und größere erinnerungspolitische Diskussionen, die zahlreiche kulturhistorische und zeitgeschichtliche Museen betreffen, hat aber im Fall der jüdischen Museen noch eine besondere Ausprägung. ${ }^{51}$ Jüdische Museen (aber auch akademische For-

51 Rüdiger Schaper, Jüdische Museen weltweit zeigen, wie politisch Erinnerung ist, Der Tagesspiegel, 01.07.2019, URL: https://www.tagesspiegel.de/politik/zehn-beispiele-von-new-york-bis-budapest-juedische-museen-weltweit-zeigen-wie-politisch-erinnerung-ist/24508818.html (abgerufen 01.02.2020). 
schungseinrichtungen), selbst wenn sie überwiegend historisch ausgerichtet sind, sehen sich zunehmend dazu gezwungen, Stellung zu tagespolitischen Themen zu beziehen: zum gegenwärtigen Antisemitismus, zum „Nahostkonflikt“, zu Israel, ja sogar zu diversen Aspekten der aktuellen Migrationspolitik. Forderungen, die von verschiedener Seite an die Institution Museum herangetragen werden, schließen sich dabei inhaltlich oft gegenseitig aus bzw. verlangen Spagatübungen. Jüdische Museen sollen - so eine offene oder implizite Forderung der öffentlichen Träger etwa zu allgemeiner Toleranz und „Begegnungen“ beitragen, aber andererseits auch explizit „jüdische“ Positionen repräsentieren. Gerade letzteres ist zudem eine häufige Erwartungshaltung des Publikums, aber auch von jüdischen Gemeinden und Organisation. Wer die jeweiligen Positionen legitim repräsentiert, darüber herrscht allerdings keine Einigkeit. Häufig als Erinnerungsorte an im Holocaust zerstörte Gemeinden errichtet und damit ursprünglich oft als Stätten der historisch-politischen Bildungsarbeit konzipiert, ${ }^{52}$ haben einige Museen in den letzten Jahren völlig neue Profile als transkulturelle und transnationale Diskurs- und Lernorte entwickelt. ${ }^{53}$ Darin spiegelt sich eine kontinuierliche Transformation des Selbstverständnisses dieser Institutionen, weg vom ursprünglich oft rein erinnerungspolitisch aufgeladenen Gründungskontext. Derartige Veränderungen und Neupositionierung sorgen mitunter für scharfe interne und externe Konflikte und lassen auch das akademische Umfeld nicht unberührt. Diese Fragen und Problemstellungen sind kein österreichisches Spezifikum, sondern wenigstens ein europäisches und wohl auch ein US-amerikanisches Phänomen, weshalb der entsprechende Diskurs heute längst international geführt wird. ${ }^{54}$ Die daraus entstehenden Auseinandersetzungen, die völlig unabhängig von wissenschaftlichen oder methodischen Streitfragen stattfinden, sind, wie angedeutet, dazu geeignet, starke Bruchlinien in einer ohnedies schon kleinen und zerklüfteten Forschungslandschaft zu erzeugen. Man denke dabei an die jüngsten Kontroversen um die Führung des Jüdischen Museums Berlin, ${ }^{55}$ die

52 Lamprecht, Die österreichischen jüdischen Museen, 213-214.

53 Siehe dazu das Gespräch zwischen Katrin Piper und Joachim Baur, Dialog: Jüdische Museen/Museen der Migration, 01.04.2016, Jüdisches Museum Hohenems, URL: https://www.youtube.com/ playlist?list=PLL1gcifXNN6P9FUC-WWeo_TN33GaWg6oHV (abgerufen o1.02.2020).

54 Vgl. Edward Rothstein, The Problem with Jewish Museums, Mosaic, Februar 2016, URL: https:// mosaicmagazine.com/essay/history-ideas/2016/o2/the-problem-with-jewish-museums/ (abgerufen 01.02.2020).

55 Aus der Vielzahl der zu diesem Thema verfassten Artikel herausgegriffen: Hanno Loewy, Ein jüdisches Museum - was ist das überhaupt?, FAZ.net, 26.06.2019, URL: https://www.faz.net/aktuell/ feuilleton/debatten/ein-juedisches-museum-was-ist-das-ueberhaupt-16253726.html (abgerufen 01.02.2020). 
auch Anfang 2020 noch immer nicht abgeebbt ist, ${ }^{56}$ oder um den richtigen Umgang mit der Israel-Boykott-Bewegung BDS. ${ }^{77}$ Diese Konflikte sind nicht nur auf die ganz großen und symbolträchtigen Häuser, wie in Berlin oder New York City, beschränkt. Die vom Jüdischen Museum Hohenems konzipierte Ausstellung „Sag Schibbolet!“ eine künstlerisch-historische Ausstellung zum historischen und gegenwärtigen Umgang mit Grenzen, inspiriert von der historischen Flucht von österreichischen Jüdinnen und Juden während der NS-Zeit - wurde bei ihrer zweiten Station am Jüdischen Museum München im Sommer 2019 durch eine kleine Gruppe von Journalisten dem Vorwurf ausgesetzt, antiisraelische bzw. gar antisemitische Propaganda zu beinhalten. ${ }^{58}$ Dieser Vorwurf war gänzlich unberechtigt, aber symptomatisch für die aufgeheizte Stimmung. Auch das sich in Österreich gerade erst etablierende Feld der „Israel-Studien“ dürfte vor ähnlichen Debatten und Kontroversen in Zukunft nicht gefeit sein.

Die zeitweilige und wiederkehrende mediale Präsenz derartiger Debatten, auch in österreichischen Feuilletons, ${ }^{59}$ sollte freilich nicht über den Stellenwert der jüdischen Geschichte und Jüdischer Studien innerhalb der Geistes-, Kultur- und Sozialwissenschaften bzw. der Universitäts- und Museumslandschaft hinwegtäuschen. Die insbesondere in den Vereinigten Staaten und in Großbritannien breitdiskutierte Krise der Geisteswissenschaften ${ }^{60}$ dürfte auch vor Kontinentaleuropa nicht haltmachen. Eine neuerliche „Gründungswelle“ von musealen und akademischen Einrichtungen wie Ende der 1980er-Jahre und in den 20ooer-Jahren, so klein diese auch letztlich war, scheint auf absehbare Zeit nicht mehr vorstellbar. Insofern wird es

56 Jannis Hagmann, Opfer gegen Opfer, FAZ.de, 18.01.2020, URL: https://taz.de/Juedisches-Museum-Berlin/!5657573/ (abgerufen 01.02.2020).

57 In Form von zwei sich inhaltlich entgegenstehenden offenen Briefen an die deutsche Bundesregierung von 2019 zeigt sich die Bruchlinie: Appell an Bundesregierung: BDS ist Form des heutigen Antisemitismus, 14.07.2019, Mena-Watch, URL: https://www.mena-watch.com/appell-an-bundesregierung-bds-ist-form-des-heutigen-antisemitismus/; A Call to German Parties not to Equate BDS with Anti-Semitism, Mai 2019, Haaretz, URL: https://www.haaretz.com/embeds/pdf_upload/2019/20190516-185634.pdf (abgerufen 01.02.2020).

58 Einer der Artikel, in denen der Vorwurf erhoben wurde: Cnaan Lipshitz/Benjamin Weinthal, Jewish museum in Munich is accused of libel against Israel, 14.07.2019, URL: https://www.jpost. com/Diaspora/Jewish-museum-in-Munich-is-accused-of-libel-against-Israel-595546 (abgerufen 01.02.2020). Siehe auch: Schaper, Jüdische Museen weltweit.

59 Man denke an die jüngsten Debatten um Achille Mbembe. Siehe dazu bspw. Dani Kranz/Natan Sznaider, Missverständnis als Fortschritt, Der Standard, 26.07.2020, URL: https://www.derstandard. at/story/2000118969987/missverstaendnis-als-fortschritt (abgerufen 01.08.2020).

60 Benjamin Schmidt, The Humanities Are in Crisis, The Atlantic, 23.08.2018, URL: https://www. theatlantic.com/ideas/archive/2018/08/the-humanities-face-a-crisisof-confidence/567565/ (abgerufen 01.02.2020). 
tendenziell wichtig sein, bereits existierende Strukturen nachhaltig zu stärken und auszubauen.

Das Forschungsinteresse an jüdischer Geschichte bleibt jedenfalls nach wie vor groß. Das ursprüngliche Programm des Zeitgeschichtetags 2020 in Innsbruck zeigt, dass quer durch die österreichischen Institutionen zu unterschiedlichsten Aspekten jüdischer Geschichte geforscht wird. ${ }^{61}$ Der Schwerpunkt der Erforschung jüdischer Zeitgeschichte liegt dabei nach wie vor auf der Geschichte des Holocaust, wobei aber zunehmend Fragen von Erinnerungskultur und Gedächtnispolitik im Mittelpunkt stehen. Daneben scheint es, wenn man das Programm als Indikator heranzieht, aktuell ein gewisses Comeback der Forschungen zu jüdischen Displaced Persons zu geben. In Graz hat sich indessen am dortigen Centrum ein zeitlicher Forschungsschwerpunkt um 1900 und zu jüdisch-nichtjüdischen Interaktionen gebildet. Die Frage nach den jüdischen Aspekten bei der Herausbildung einer „österreichischen Identität" vor und nach dem Zweiten Weltkrieg ist eine Thematik, zu der auch international geforscht wird. ${ }^{62}$ Auch Fragen von transnationalen Wissens- und Kulturtransfers, vor dem Hintergrund jüdischer Flucht vor Nationalsozialismus und dem Holocaust, haben jüngst neue Aufmerksamkeit erhalten. ${ }^{63}$ Von „Austrian-Jewish Studies“, wie sie die Literaturwissenschaftlerin Leslie Morris 2010 analog und in Abgrenzung zu den "German-Jewish Studies“ vorgeschlagen hat, ${ }^{64}$ kann man indessen, so scheint mir, noch nicht sprechen. Das Potenzial dazu gäbe es allerdings, wie gerade die lebensgeschichtlichen Forschungen beweisen, in denen stets Brücken von der Lokal- und Regionalgeschichte in den gesamten Raum der ehemaligen österreichisch-ungarischen Monarchie und weit darüber hinaus geschlagen wurden.

Wenn die Zeitgeschichte stetig mit der Zeit und den lebenden Generationen wandert, dann werden zukünftig auch die jüngeren Aspekte jüdischer Geschichte stärker in den Mittelpunkt des Interesses rücken müssen. Große Teile der jüdischen Nachkriegsgeschichte sind nicht aufgearbeitet oder existieren nur als Epilog einer Untergangsgeschichte in skizzenhafter Form. Wie das Beispiel des Altpräsidenten der IKG

61 13. Österreichischer Zeitgeschichtetag 2020, Institut für Zeitgeschichte, Universität Innsbruck, URL: https://www.uibk.ac.at/zeitgeschichte/zgt2o/dateien/zgt2o_programm_enfassung.pdf (abgerufen 01.02.2020).

62 Siehe bspw. Deborah Holmes/Florian Krobb/Lisa Silverman (Hg.), Jews, Jewish Difference and Austrian Culture. Literary and Historical Perspectives (Austrian Studies 24), Cambridge 2016.

63 Siehe dazu bspw. die Tagung „Imaging Emigration-Translating Exile“, 01.-03.04.2019, Universität für Musik und darstellende Kunst Wien, URL: https://static.uni-graz.at/fileadmin/juedischestudien/tagungsprogramme/Imaging_Emigration_v5b_Print_programm.pdf (abgerufen 01.02.2020).

64 Leslie Morris, Austrian-Jewish Studies?, in: Günter Bischof/Fritz Plasser (Hg.), The Schüssel Era in Austria (Contemporary Austrian Studies 18), New Orleans/Innsbruck 2010, 348-350. 
Innsbruck Ernst Beschinsky zeigt, dessen falsche Identität erst jüngst, Jahrzehnte nach seinem Tod aufgedeckt wurde ${ }^{65}$ gibt es hier noch genügend Forschungsarbeit und Potenzial für Überraschungen. Das beginnt bei Biographien wichtiger Gemeindefunktionäre und anderer Symbolfiguren und zahlreichen Aspekten der Reetablierung jüdischen Lebens, darunter etwa der Geschichte jüdischer Vereine, Unternehmen und Initiativen, die es heute wieder zahlreich gibt. Dazu gehört auch die Integration ehemaliger Displaced Persons, ebenso wie die jüdische Einwanderung aus verschiedenen Teilen der Erde nach 1945, ohne welche die jüdischen Gemeinden in Österreich nicht mehr vorstellbar wären. Insofern sollten auch in jüngeren Jahren etablierte Forschungsansätze einer neuen Migrationsgeschichte auf die jüdische Geschichte angewendet werden, da hier zahlreiche Parallelen existieren. $\mathrm{Zu}$ den Forschungslücken gehören auch verschiedene Aspekte des Verhältnisses zwischen Österreich und seinen im Ausland lebenden jüdischen Emigrantinnen und Emigranten sowie der zweiten und dritten Generation. Die Beziehungen zwischen Israel und Österreich sind auch jenseits der Diplomatiegeschichte ein Feld, das noch viel unausgeschöpftes Potenzial bietet, gerade im Bereich kultureller Transfers und kultureller Übersetzungen. Genauso muss auch die Persistenz und Transformation des Antisemitismus nach 1945 bis in die Gegenwart, unter den Bedingungen einer längst zur Realität gewordenen Migrationsgesellschaft, immer wieder erneut in den Blick genommen werden.

Jüdische Aspekte lassen sich in allen Bereichen der österreichischen und europäischen Gesellschafts- und Kulturgeschichte und in allen gesellschaftlichen Sphären nach 1945 finden. Es gilt, wie eingangs aus dem „Handbuch Jüdische Kulturgeschichte“ zitiert, sich diese „Präsenz und Bedeutung des Jüdischen überhaupt erst bewusstzumachen".

65 Vgl. Niko Hofinger, Maneks Listen, Innsbruck 2018. 


\title{
Zeitgeschichte und Queer Studies
}

\author{
Elisa Heinrich und Johann Kirchknopf
}

Wenn wir das Verhältnis der österreichischen zeitgeschichtlichen Forschung zur Homosexualitätengeschichte bzw. zu den Queer Studies - eine Bestimmung dieser Ausdifferenzierung wird noch erfolgen - anhand der Thematisierung von lesbischschwul-bisexuell-trans ${ }^{*}$-inter ${ }^{*}$-queerer $\left(\mathrm{LSBT}^{*} \mathrm{I}^{\star} \mathrm{Q}\right.$ ) Geschichte in der Fachzeitschrift „zeitgeschichte" bestimmen würden, so fiele das Ergebnis ernüchternd aus. Von den bis Ende 2018 erschienenen 418 Heften $^{1}$ griff nur eines ein LSBT ${ }^{\star} \mathrm{I}^{\star} \mathrm{Q}$ Thema explizit auf: „Homosexuellenverfolgung in Österreich. Geschichte und Nachgeschichte “. ${ }^{2}$ Ein 1987 von Siegfried Mattl herausgegebenes Heft widmete sich der Sexualitätengeschichte insgesamt. ${ }^{3}$ Das geringe Interesse erstaunt umso mehr, als prominente VertreterInnen der österreichischen Zeitgeschichte der letzten Jahrzehnte, etwa Helmut Konrad, ${ }^{4}$ der „1968er“-Bewegung, die der Sexualität einen zentralen Stellenwert gerade in der politischen Debatte einräumte, einen großen Einfluss auf ihre politische Sozialisation zurechnen. Ende der 1960er-Jahre sahen insbesondere linke Intellektuelle, wovon einige ProponentInnen wesentlich an der Etablierung einer kritischen zeitgeschichtlichen Forschung mitwirkten, zum Beispiel Christian Broda, die Frage der sexuellen Freiheit als eine grundlegende Frage der Freiheit einer Gesellschaft an. Sigrid Nitsch konstatiert in ihrer 2004 erschienenen Diplomarbeit über die Geschichte des Verbands Sozialistischer StudentInnen (VSStÖ), dass dieser durch die Beschäftigung mit der Kritischen Theorie und den Thesen Herbert Marcuses begonnen habe, sich auch dem Thema der „Triebunterdrückung als repressives Element der modernen Gesellschaft" zu widmen. ${ }^{5}$ Ende

1 Die Zeitschrift „zeitgeschichte“ erschien erstmals im Oktober 1973. Der Jahrgangszyklus verlief zunächst von Oktober bis September. Die Jahrgänge 1 bis einschließlich 25 umfassten jeweils zwölf Hefte, wobei es manche Doppelhefte gab - im Jahrgang 18 (1990-1991) wurde der Zyklus des Zeitschriftenjahrgangs an das Kalenderjahr angeglichen. Die Jahrgänge 26 bis einschließlich 44 (2017) umfassten jeweils sechs Hefte. Seit 2018 erscheint die „zeitgeschichte“ viermal pro Jahr.

2 Vgl. zeitgeschichte 43 (2016) 2, URL: http://anno.onb.ac.at/cgi-content/anno-plus?aid=ztg\&datum $=2016$ \&page $=66 \&$ size $=45$ (abgerufen 20.07.2019).

3 „Macht - Körper - Sexualität“. zeitgeschichte 14 (1987) 11/12.

4 Helmut Konrad, Die 68er Generation der österreichischen ZeithistorikerInnen - eine Perspektive auf generationsspezifische Sozialisationsmerkmale und Karriereverläufe, in: zeitgeschichte 30 (2003) 6, 315-319.

5 Sigrid Nitsch, Die Entwicklung des allgemeinpolitischen Vertretungsanspruches innerhalb des Verbandes Sozialistischer StudentInnen Österreichs (VSStÖ) in Wien im Zeitraum von 1965 bis 1973, Dipl.-Arb., Universität Wien 2004, 113. 
der 1960er-Jahre wurde diese grundlegende Frage in Österreich konkret an der geplanten Reform des Strafrechts, insbesondere an den Fragen der Entkriminalisierung gleichgeschlechtlicher sexueller Handlungen und des Schwangerschaftsabbruchs diskutiert. Der VSStÖ veranstaltete etwa im Oktober 1967 an der Universität Wien eine Tagung zum Thema "Sexualität ist nicht pervers. Normierte Sittlichkeit im österreichischen Strafrecht", 6 weil die ÖVP, die nach den Nationalratswahlen 1966 allein regierte, entgegen den Empfehlungen der Strafrechtskommission eine Beibehaltung der Strafbarkeit gleichgeschlechtlicher sexueller Handlungen und des Schwangerschaftsabbruchs anstrebte. ${ }^{7}$ Dabei ging es dem VSStÖ nicht nur um die „Modernisierung" überholter und wissenschaftlich angefochtener Rechtsnormen, wie dessen damaliger Obmann Silvio Lehmann im Tagungsband konstatierte, sondern auch darum, Anstoß zu Studienreform und permanenter Wissenschafts- und Studienkritik zu geben. Lehmann sah in der „Bestrafung der Lust am Geschlecht“ überhaupt ein Instrument des Machterhalts konservativer Kreise:

Noch immer ist das Strafrecht der Ort, wo aufklärende Vernunft und irrationale Ideologeme zur Verschleierung überholter Herrschaftspositionen am härtesten aufeinanderstoßen. [...] Innerhalb des Strafrechts ist es die Bestrafung der Lust am Geschlecht, an der die Polarität gesellschaftlicher Positionen am deutlichsten wird, entgegen allem Gerede von der Interessen-Harmonie pluralistischer Gesellschaft, in der Kategorien wie „links“ und "rechts" überholt seien, Konflikte nur noch zwischen verschiedenen Gruppenegoismen stattfänden: in einer solchermaßen um ihre bestimmende Totalität gebrachten Gesellschaft ließe es sich für die Interessenten an einer repressiven Gesellschaft gemütlich argumentieren. ${ }^{8}$

6 „Sexualität ist nicht pervers. Normierte Sittlichkeit im österreichischen Strafrecht - Positionen moderner Wissenschaft" Eine Informationsreihe des Verbandes Sozialistischer Studenten, 16.20.10.1967, Universität Wien (ein Programmheft der Veranstaltung befindet sich im Bestand von QWIEN - Zentrum für queere Geschichte, Signatur 38).

7 Die Regierungsvorlage eines neuen Strafgesetzes, die die ÖVP-Alleinregierung unter Bundeskanzler Klaus im Februar 1968 dem Nationalrat vorlegte, sah für „Unzucht mit einer Person des gleichen Geschlechtes" eine Freiheitsstrafe bis zu drei Jahren vor $(\$ 228)$ und gestattete einen Schwangerschaftsabbruch nur dann, wenn dadurch ,von der Schwangeren eine gegenwärtige, nicht anders abwendbare Lebensgefahr oder Gefahr dauernden schweren Schadens an ihrer Gesundheit abgewendet wird“ ( $\$ 92)$ : 706 der Beilagen zu den stenographischen Protokollen des Nationalrats XI. GP., URL: https://www.parlament.gv.at/PAKT/VHG/XI/I/I_00706/index.shtml (abgerufen 11.07.2019).

8 Silvio Lehmann, Anstelle einer Einleitung: Aufforderung zum Widerstand. Zu den Motiven einer Veranstaltung des Verbandes Sozialistischer Studenten Österreichs, in: VSStÖ (Hg.), Sexualität ist nicht pervers. Vorträge und Diskussionen im Rahmen einer Informationsreihe, veranstaltet vom 
Die Liste der Vortragenden und Diskutanten - Frauen waren keine darunter bei der fünf Tage dauernden Konferenz war überaus prominent besetzt: Leopold Ungar (Prälat und Chef der Wiener Caritas), Wilhelm Dantine (Professor für systematische Theologie, Universität Wien), Theodor Adorno (Professor für Philosophie und Soziologie, Goethe-Universität, Frankfurt am Main), Friedrich Nowakowski (Ordinarius für Strafrecht, Universität Innsbruck), Fritz Bauer (Generalstaatsanwalt in Frankfurt am Main), Franz Pallin (Generalprokurator beim Österreichischen Obersten Gerichtshof) und Christian Broda (Justizminister 1960-1966 und 1970-1983), um nur die prominentesten zu nennen. Im Zentrum der abschließenden Forumsdiskussion am 20. Oktober 1967, die im dichtgedrängten Hörsaal 1 des Neuen Institutsgebäudes stattfand, stand die anstehende Reform des österreichischen Strafrechts. Dabei wurden so grundlegende Fragen wie etwa das Verhältnis zwischen Kirche und Staat anhand der zentralen Regelungsmaterien Schwangerschaftsabbruch, „Gotteslästerung“ und gleichgeschlechtliche Sexualität diskutiert, wie Barbara Coudenhove-Kalergi in der „Arbeiter-Zeitung“ berichtete ${ }^{9}$ - die zentralen Wortmeldungen sind ebenfalls im Tagungsband abgedruckt. ${ }^{10}$

Zur Umsetzung der Strafrechtsreform kam es schließlich 1971 bzw. 1975 während der SPÖ-Alleinregierung unter Bruno Kreisky, ${ }^{11}$ die die sozialdemokratischen Forderungen nach Aufhebung des Totalverbots gleichgeschlechtlicher Sexualhandlungen und nach Ermöglichung des Schwangerschaftsabbruchs weitgehend durchsetzte. ${ }^{12}$ Die zeitgeschichtliche Forschung hat mittlerweile sowohl die Entkri-

Verband Sozialistischer Studenten Österreichs an der Universität Wien, Wien/Frankfurt/Zürich $1969,11$.

9 Barbara Coudenhove-Kalergi, „Sünde geht den Staat nichts an“. Beim Strafrecht sind Theologen fortschrittlicher als konservative Politiker, Arbeiter-Zeitung, 22.10.1967, 3.

10 VSStÖ (Hg.), Sexualität ist nicht pervers, 145-155.

11 Das Kabinett Kreisky I zog die Aufhebung des Totalverbots gleichgeschlechtlicher Sexualhandlungen vor und reformierte 1971 noch das alte Strafgesetz von 1852 (Strafrechtsänderungsgesetz 1971, BGBl. 273/1971), bevor schließlich mit 1. Januar 1975 ein gänzlich neues Strafgesetzbuch in Kraft trat, wodurch auch die sogenannte Fristenlösung, also die Straflosigkeit des grundsätzlich verbotenen Schwangerschaftsabbruchs unter bestimmten Voraussetzungen innerhalb der ersten drei Monate einer Schwangerschaft, eingeführt wurde ( $\$ 97$ Strafgesetzbuch 1974, BGBl. 60/1974). Ein Zugeständnis an konservative Kreise war die Einführung vier neuer Straftatbestände im Zuge der Aufhebung des Totalverbots gleichgeschlechtlicher Sexualhandlungen (Werbungs- und Versammlungsverbot, Verbot gleichgeschlechtlicher Prostitution für Männer und ein höheres Schutzalter für gleichgeschlechtliche Sexualkontakte zwischen Männern; siehe Strafrechtsänderungsgesetz 1971, BGBl. 273/1971). Siehe dazu auch Peter Schieder, Der Kampf um LGBT-Rechte in Österreich und Europa. Persönliche Erinnerungen aus 40 Jahren, in: Martin Gössl, Von der Unzucht zum Menschenrecht. Eine Quellensammlung zu lesbisch-schwulen Themen in den Debatten 
minalisierung gleichgeschlechtlicher Sexualhandlungen ${ }^{13}$ als auch die Einführung der Fristenlösung weitgehend durchleuchtet. ${ }^{14}$ Die Frage aber, welche Bedeutung diverse Sexualitätskonzepte und die nicht nur, aber vor allem rund um die „1968er“Bewegung öffentlich geführten Debatten darüber für eine politische Geschichte der Zweiten Republik haben, ist bisher nicht im Fokus gestanden. ${ }^{15}$

Ziel des vorliegenden Beitrags ist es, das Verhältnis zwischen Zeitgeschichte und Queer Studies auszuloten; er widmet sich gleichermaßen einer (für diesen Forschungsbereich in der österreichischen Zeitgeschichtsforschung wenige Jahrzehnte umfassenden) Bilanz und möglichen Perspektiven für die Zukunft dieses Feldes. Dabei schließt dieses Verhältnis zwischen zeitgeschichtlicher Forschung und queeren Themenstellungen unterschiedliche Aspekte inhaltlicher sowie theoretisch-methodischer Verknüpfung oder Vernetzung ein.

\section{Homosexualitätengeschichte und/oder Queer Studies}

Bevor Mitte der 1990er-Jahre auch in Österreich eine Rezeption der - maßgeblich von heute längst kanonisierten AutorInnen wie Teresa de Lauretis, ${ }^{16}$ Judith Butler ${ }^{17}$

des österreichischen Nationalrats von 1945 bis 2002 (Edition Regenbogen - Studienreihe Homosexualität 4), Graz 2011, 9-16.

13 Zum Beispiel Gössl, Von der Unzucht zum Menschenrecht; Roman Birke/Barbara Kraml, Gleichzeitigkeit von Inklusion und Exklusion: Homosexualitäten zwischen Verfolgung und Normalisierung in Österreich 1971, in: zeitgeschichte 43 (2016) 2, 85-100.

14 Zum Beispiel Maria Mesner, Geburten/Kontrolle. Reproduktionspolitik im 20. Jahrhundert, Wien/ Köln/Weimar 2010; dies., Frauensache? Die Auseinandersetzung um den Schwangerschaftsabbruch in Österreich, Wien 1994.

15 So ist etwa kein einziger der 111 Beiträge des Sammelbands zum 7. Österreichischen Zeitgeschichtetag, der sich mit der ,'68er“-Bewegung beschäftigte, dem Thema Sexualität gewidmet: Ingrid Böhler (Hg.), 1968 - Vorgeschichten - Folgen. Bestandsaufnahme der österreichischen Zeitgeschichte, Innsbruck 2010.

16 Die Literaturwissenschaftlerin Teresa de Lauretis prägte das begriffliche Konzept der Queer Theory im Rahmen einer Ausgabe des Journals „differences“: Teresa de Lauretis, Queer Theory: Lesbian and Gay Sexualities, in: differences 6 (1991), iii-xviii.

17 Die erste Übersetzung von ihrem 1990 erschienenen Buch „Gender Trouble. Feminism and the Subversion of Identity“ erschien 1991 unter dem Titel „Das Unbehagen der Geschlechter“. 
und Eve Kosofsky Sedgwick ${ }^{18}$ geprägten - Queer Theory einsetzte, ${ }^{19}$ war es vor allem die Homosexualitätengeschichte, die als deviant geltende Formen von Sexualität beforschte. Die seit den späten 1970er-Jahren immer häufiger werdende Pluralsetzung des Forschungsgegenstandes soll zum Ausdruck bringen, dass es die Geschichtsforschung nicht mit einem einzigen, über die Zeiten konstanten Phänomen zu tun hat. Darauf deutet schon allein die Vielzahl der Begriffe hin, die im Lauf der Jahrhunderte für gleichgeschlechtliche Begehrensformen, Praktiken und Identitätskonzepte verwendet wurden, wie Sodomie, worunter auch andere Formen illegitimer Sexualität gefasst wurden, Päderastie, Tribadie oder der Ende des 19. Jahrhunderts erfundene Begriff der Homosexualität. ${ }^{20}$ Im Kern der theoretischen Debatte stand in der Homosexualitätengeschichte die Auseinandersetzung zwischen essenzialistischen und konstruktivistischen Positionen: EssenzialistInnen betonten die Kontinuität gleichgeschlechtlichen Begehrens über die Zeiten und Kulturen hinweg, während KonstruktivistInnen die sich verändernden kulturellen Umgangsweisen in den Vordergrund rückten. Die Mitte der 1990er-Jahre einsetzende Rezeption der Queer Theory veränderte die Sichtweise auf den Gegenstand. Die im angelsächsischen Raum seit Ende der 1980er-Jahre bedeutsam werdende kritische Erforschung von Geschlechterverhältnissen und Sexualitäten bildet weniger ein eigenes Forschungsfeld als vielmehr eine die Disziplinen durchkreuzende Perspektive. ${ }^{21}$ Die Queer Studies richten ihren Fokus unter anderem auf Fragen nach der Herstellung und essenzialisierenden Absicherung normativer Modelle von Weiblichkeit und Männlichkeit sowie von Homo- und Heterosexualität. ${ }^{22}$ Sie positionieren sich kritisch gegenüber allen Formen hegemonialer Identitätskonzepte und verstehen sich als explizit politische

18 Eve Kosofsky Sedgwick, Between Men: English Literature and Male Homosocial Desire, New York 1985. Sedgwick entwickelte ein als Queer Reading bekannt gewordenes Lektüremodell, das nach Subtexten und Gegengeschichten in literarischen Texten fragt, die der heteronormativen Logik der Zeichen zuwiderlaufen.

19 Siehe Christine M. Klapeer, queer.contexts. Entstehung und Rezeption von Queer Theory in den USA und Österreich, Innsbruck/Wien/Bozen 2007.

20 Franz X. Eder, Homo- und andere gleichgeschlechtliche Sexualitäten in Geschichte und Gegenwart, in: Florian Mildenberger (Hg.), Was ist Homosexualität? Forschungsgeschichte, gesellschaftliche Entwicklungen und Perspektiven, Hamburg 2014, 17-39.

21 Ähnlich dem Begriff „schwul“ im deutschsprachigen Raum wurde „queer“ im englischen Sprachraum zunächst als Schimpfwort benutzt, dann aber - vor allem im Zuge der Aids-Krise Ende der 1980er-Jahre - positiv gewendet und als Selbstbezeichnung angeeignet. Das ursprünglich aus dem Deutschen entlehnte Wort „,verquer" wurde im Zuge dieser Transformation dann auch herangezogen, um der Erforschung der Homosexualitäten einen Namen zu geben. Siehe dazu: Andreas Kraß (Hg.), Queer Denken. Queer Studies, Frankfurt a. M. 2003.

22 Mittlerweile liegen Einführungen für Studierende in deutscher Sprache vor, siehe etwa: Nina Degele, Gender/Queer Studies. Eine Einführung, Paderborn 2008. 
Forschung, die gesellschaftliche Prozesse nicht nur untersuchen, sondern auch gegen sie intervenieren will. Den Ansatzpunkt dieser interventionistischen Kritik bildet vor allem das Herrschaftsmoment, das Geschlechter- und Sexualitätsmodellen als stabilen Identitätskonzepten innewohnt und nach dem Modus von Ein- und Ausschlüssen funktioniert. In den Fokus der Kritik geraten aber nicht nur konservative Modelle einer heterosexuellen Paarbeziehung, wie etwa das der bürgerlich-rechtlichen oder katholischen Ehe. Teils umstrittene Konzepte wie Homonormativität - von Lisa Duggan Anfang der 20ooer-Jahre geprägt ${ }^{23}$ - oder das von der Queer-Theoretikerin Jasbar Puar entwickelte Konzept des Homonationalismus ${ }^{24}$ richten ihre Aufmerksamkeit und Kritik auf die Beteiligung an hegemonialen Lebensentwürfen und nationalistischen Politiken sowie den damit verbundenen Verwerfungen und Ausschlüssen innerhalb von $\mathrm{LSBT}^{\star} \mathrm{I}^{\star} \mathrm{Q}-$ Bewegungen. ${ }^{25}$

Judith Butlers Konzept der Performativität von Geschlecht bildet für die Queer Studies ebenso einen zentralen Eckpfeiler wie der Rekurs auf Michel Foucaults Thesen zur Historizität und kulturellen Konstruktion von Sexualität. ${ }^{26}$ Gerade diese Aspekte bilden weitere Anknüpfungspunkte der Zeitgeschichtsforschung an die Queer Studies. Zum einen liefern sie Impulse, über die Erforschung von Homo- und Heterosexualität hinauszugehen und stattdessen eine Bandbreite von als fluid gefassten Gender- und sexuellen Identitäten zu untersuchen. Zum anderen fordern die Queer Studies historisches Arbeiten besonders in theoretisch-methodologischer Weise heraus. ${ }^{27}$ Die kanadische Historikerin Jennifer Evans hat 2016 unter dem Titel „Why Queer German History?"“ die Herausforderungen betont, die ein solches Queering auf grundlegende Eckpfeiler historischer Forschung hat - nicht nur in Bezug auf die beforschten Subjekte, sondern auch auf die Prozesse der Produktion von Bedeutung und Erfahrung sowie auf Vorstellungen von Raum und Zeit: „A queered history

23 Duggan versteht unter Homonormativität ,a politics that does not contest dominant heteronormative assumptions and institutions but upholds and sustains them". Lisa Duggan, The New Homonormativity. The Sexual Politics of Neoliberalism, in: Russ Castronovo/Dana D. Nelson (Hg.), Materializing Democracy. Toward a Revitalized Cultural Politics, Durham/London 2002, 175-194, 179 .

24 Jasbir Puar, Terrorist Assemblages. Homonationalism in Queer Times, Durham 2007.

25 Laura Eigenmann, Zur Kritik der Homonationalismus-Kritik, in: Imke Leicht/Nadja Meisterhans/ Christine Löw/Katharina Volk (Hg.), Feministische Kritiken und Menschenrechte. Reflexionen auf ein produktives Spannungsverhältnis (Politik und Geschlecht 27), Opladen/Berlin/Toronto 2016, 75-94.

26 Bekanntermaßen dargelegt in Michel Foucault, Der Wille zum Wissen (Sexualität und Wahrheit 1), Frankfurt a. M. 1983.

27 Siehe dazu auch George Haggerty/Molly McGarry (Hg.), A Companion to Lesbian, Gay, Bisexual, Transgender, and Queer Studies, Maiden 2007. 
questions claims to a singular, linear march of time and universal experience and points out the unconscious ways in which progressive narrative arcs often seep into our analyses. ${ }^{28}$ Historisches Arbeiten um queere Perspektiven zu erweitern, bedeutet darüber hinaus, die Aufmerksamkeit auf Prozesse der Konstruktion von Identitäten und Zugehörigkeiten zu lenken, statt historische Subjekte mit vorgefertigten Schablonen zu untersuchen.

Im Vergleich zu anderen Disziplinen wie der Politikwissenschaft und Soziologie blieb der Impact der Queer Studies in der österreichischen Geschichtswissenschaft dennoch gering. ${ }^{29}$ Die Historikerin und Soziologin Hanna Hacker hat für Österreich als eine der Ersten - und bis heute eine der wenigen - queere Perspektiven in die geschichtswissenschaftliche Forschung eingebracht und insbesondere mit Fragestellungen der Postcolonial und Critical Whiteness Studies verknüpft ${ }^{30}-$ im Übrigen in der österreichischen Zeitgeschichtsforschung ebenfalls wenig bearbeitete Querschnittsmaterien. In den letzten Jahren finden sich zunehmend Beispiele einer Anbindung der Zeitgeschichte an Forschungsfragen aus dem Bereich der Queer Studies. ${ }^{31}$ Die Anzahl der historischen Abschlussarbeiten mit queeren Bezügen ist im Gegensatz etwa zu den Sozialwissenschaften immer noch deutlich geringer, wie wir am Beispiel der Universität Wien in den letzten zehn Jahren in der Tabelle demonstrieren (in Summe ca. $1: 4$ ) - mit Blick auf „Homosexualität“ fällt der Unterschied geringer aus (in Summe ca. $1: 2$ ).

28 Jennifer Evans, Introduction. Why Queer German History?, in: German History 34 (2016) 3, 371$384,371$.

29 Eder, Homo- und andere gleichgeschlechtliche Sexualitäten, 17-39.

30 Siehe ihre überarbeitete Habilitationsschrift: Hanna Hacker, Gewalt ist: keine Frau. Der Akteurin oder eine Geschichte der Transgressionen, Königstein/Taunus 1998. Außerdem dies., Erinnerungen an die Möglichkeit einer Historiografie lesbischer Frauen und die queere Notwendigkeit ihres Verlusts, in: L'Homme F. Z. G. 28 (2017) 1; dies., „Queer entwickeln“. Im Gespräch: Claudia Ulbrich mit Hanna Hacker, in: L'Homme F. Z. G. 23 (2012) 2, 101-105; dies., La Chine, mon amour? Feministische und queere Transfers durch den Maoismus: Tel Quel, 1974, in: Österreichische Zeitschrift für Geschichtswissenschaften 22 (2011) 1, 161-184.

31 Zum Beispiel Christopher Treiblmayr, Bewegte Männer. Männlichkeit und männliche Homosexualität im deutschen Kino der 1990er Jahre (L’Homme Schriften 19), Köln 2015. 


\begin{tabular}{|l|l|l|l|l|l|l|l|l|l|l|l|l|}
\hline & $\begin{array}{l}\text { Fakul- } \\
\text { tät }\end{array}$ & 2008 & 2009 & 2010 & 2011 & 2012 & 2013 & 2014 & 2015 & 2016 & 2017 & 2018 \\
\hline Queer & $\begin{array}{l}\text { Hist.- } \\
\text { Kult. }\end{array}$ & 6 & 10 & 6 & 8 & 14 & 15 & 6 & 8 & 6 & 14 & 6 \\
\cline { 2 - 11 } & Sowi & 19 & 46 & 20 & 41 & 70 & 23 & 30 & 49 & 42 & 22 & 23 \\
\hline $\begin{array}{l}\text { Homo- } \\
\text { sexua- } \\
\text { lität }\end{array}$ & $\begin{array}{l}\text { Kult. } \\
\text { Kult. }\end{array}$ & 34 & 25 & 25 & 19 & 28 & 50 & 14 & 29 & 16 & 24 & 14 \\
\cline { 2 - 11 } & Sowi & 46 & 98 & 50 & 68 & 103 & 40 & 33 & 53 & 36 & 21 & 16 \\
\hline
\end{tabular}

Tabelle: Ergebnis der Volltextsuche beim Onlinehochschulschriftenservice der Universität Wien nach Diplom, Magister, Masterarbeiten, Dissertationen, Habilitationsschriften und Masterthesen (ULG) an der Historisch-Kulturwissenschaftlichen Fakultät (Hist.-Kult.) und der Fakultät für Sozialwissenschaften (SoWi) von 2008 bis 2018, die im gesamten Text entweder den Begriff „queer“ oder „Homosexualität" enthalten - manche Arbeiten enthalten beide Begriffe, weshalb Schnittmengen innerhalb der jeweiligen Fakultät vorhanden sind, URL: http://othes.univie.ac.at/cgi/search/advanced (abgerufen 02.03.2021).

Wie eine von uns herausgegebene Nummer der „Österreichischen Zeitschrift für Geschichtswissenschaften“ (ÖZG) zum Thema Homosexualitäten revisited zeigt, ${ }^{32}$ sollte die Homosexualitätengeschichte nicht im Sinne einer Fortschrittsentwicklung als von einer queeren Geschichte abgelöst gesehen werden, weist doch die zeithistorische Forschung über Homosexualitäten weiterhin große Lücken auf. Die Kategorie der Homosexualität bildet dabei nach wie vor „eine nützliche Kategorie von historischer Analyse“..33

Im nun folgenden Forschungsüberblick richten wir den Fokus auf Österreich unter Berücksichtigung der internationalen Entwicklungen.

32 Elisa Heinrich/Johann Karl Kirchknopf (Hg.), Homosexualitäten revisited. Österreichische Zeitschrift für Geschichtswissenschaften 29 (2018) 2. Mit Beiträgen von Hanna Hacker, Rüdiger Lautmann, Ina Friedmann, Manuela Bauer/Andreas Brunner/Hannes Sulzenbacher/Christopher Treiblmayr, Maria Bühner, Teresa Tammer und Masha Neufeld/Katharina Wiedlack.

33 Joan W. Scott, Gender. A Useful Category of Historical Analysis, in: The American Historical Review 91 (1986) 5, 1053-1075. 


\section{Standortbestimmung}

Den Stand der Forschung in Österreich zu einem bestimmten Gegenstand zu ermitteln, der sich an keiner Universität oder akademischen Forschungseinrichtung dieses Landes in irgendeiner Form institutionalisiert findet, ist eine schwierige Aufgabe. Weder die Homosexualitätengeschichte noch die Queer Studies, ja nicht einmal die Sexualitätengeschichte finden sich im Gegensatz zu anderen Ländern bis dato auch nur in der Denomination einer Professur - so gilt etwa Franz X. Eder, der gerade auch die Erforschung der $\operatorname{LSBT}^{*} \mathrm{I}^{*} \mathrm{Q}-$ Geschichte vorangetrieben hat, international vor allem als Experte der Sexualitätengeschichte, was sich aber nicht in der Denomination seiner Professur widerspiegelt. Obgleich in den letzten zehn Jahren die Zahl der akademischen Abschlussarbeiten zu LSBT ${ }^{*} I^{*} \mathrm{Q}$-Themen durchweg hoch war, wird ein Großteil dieser Forschung bis heute außerhalb der Universitäten betrieben. Für die Anfangsphase dieser Forschung gilt für Österreich derselbe Befund, den der US-amerikanische Historiker Clayton Whysnant über Westdeutschland stellte:

The study of Germany's gay history has come a long way since its meager beginnings in the 1970s. Drawing vitality from the gay and lesbian liberation movement that sprung to life in West Germany at the beginning of the 1970s, the study of gay history was driven forward by a relatively small cadre of devoted historians. Some of them were academically trained, but most were admirably self-taught. ${ }^{34}$

Und so müssen wir uns bei der Ermittlung des Forschungsstands der queeren österreichischen Zeitgeschichte derselben Frage stellen wie Stefanie Mayer, die den feministischen Aktivismus in Wien ab den 1970er-Jahren untersucht hat, der ebenfalls in erster Linie aus der politischen Bewegung heraus beforscht wurde: „Wo endet ,akademisch und wo beginnt die Literatur aus der Bewegung?"“35 Homosexualität galt „lange Zeit als Unthema für seriöse Historiografie“, wie Eder konstatiert, weil ihr politische Motivation vorgeworfen wurde:

34 Clayton John Whisnant, Introduction. Gay German History: Future Directions?, in: Journal of the History of Sexuality 17 (2008) 1, 1-10, 1.

35 Stefanie Mayer, Politik der Differenzen: Ethnisierung, Rassismen und Antirassismus im weißen feministischen Aktivismus in Wien (Politik und Geschlecht 31), Opladen/Berlin/Toronto 2018, 17 (Hervorhebung im Original). 
Mit der Geschichte des gleichgeschlechtlichen Begehrens würden primär emanzipatorische Ambitionen sowie politische Zielsetzungen verfolgt - beides Motive, die wissenschaftlichen Ansprüchen entgegenstünden und eine ausgewogene Sicht verhinderten. ${ }^{36}$

Dem Vorwurf unwissenschaftlicher Parteilichkeit sah sich zunächst auch die feministische Forschung ausgesetzt, bis diese schließlich in den 1980er-Jahren einen Paradigmenwechsel herbeiführte und aufzeigte, dass keine Forschung über Geschlechterverhältnisse im wertneutralen Raum stattfinde, „sondern in einem bestimmten gesellschaftlichen Rahmen, der von Unterdrückungs, Macht- und Ohnmachtverhältnissen bestimmt ist“.37 Fortan wurden Subjektpositionen nicht mehr als Behinderung einer objektiven Forschung, sondern als eine epistemologische Bereicherung verstanden, insofern diese kritisch reflektiert werden. Damit eröffnete sich auch der Homosexualitätengeschichte der Zugang zum akademischen „Elfenbeinturm“ und ließ emanzipatorische Politiken und Aktivismen in die Theoriebildung einfließen. In den letzten Jahrzehnten zeichnen sich gerade die Homosexualitätengeschichte und die Queer Studies durch einen überaus produktiven, wenn auch teilweise friktionsreichen Austausch zwischen aktivistischen Praktiken und Politiken einerseits und wissenschaftlicher Forschung andererseits aus, wie wir noch zeigen werden.

Der Vorwurf unwissenschaftlicher Parteilichkeit, der erst in den 1980er-Jahren überwunden werden konnte, war aber nur der Widerstand auf Ebene der theoretischen Debatte. Sexualität ganz allgemein und insbesondere nichthegemoniale Formen wurden auf breiter Front tabuisiert, vor allem wenn es darum ging, gleichgeschlechtliche Sexualität gerade nicht in Narrativen von Devianz und Pathologie darzustellen. Roland Grassberger etwa, der von 1948 bis 1975 Ordinarius für Strafrecht, Strafprozessrecht und Kriminologie, im Studienjahr 1962/1963 Rektor der Universität Wien war und bis 1955 auch der Strafrechtskommission angehörte, ${ }^{38}$ war

36 Franz X. Eder, Homosexualitäten. Diskurse und Lebenswelten 1870-1970, Weitra 2011, 15.

37 Claudia Opitz, Um-Ordnungen der Geschlechter. Einführung in die Geschlechtergeschichte, Tübingen 2005, 27. Dass dieser Paradigmenwechsel seit einiger Zeit in Teilen der Gesellschaft und auch der Wissenschaft wieder in Frage steht, zeigen die massiven Anfeindungen gegenüber den Gender und Queer Studies aus unterschiedlichen politischen Richtungen. Selbst von aktivistischer Seite innerhalb der $\mathrm{LSBT}^{\star} \mathrm{I}^{\star} \mathrm{Q}$-Community werden geradezu feindselige Positionen gegenüber zentralen VertreterInnen und Studierenden des Fachs eingenommen, wie die Diskussion um einen mittlerweile in der vierten Auflage erschienenen Sammelband zeigt: Patsy l'Amour laLove (Hg.), Beissreflexe. Kritik an queerem Aktivismus, autoritären Sehnsüchten, Sprechverboten, Berlin ${ }^{4} 2017$.

38 Regierungsvorlage eines neuen Strafgesetzes von 1968, 706 der Beilagen zu den stenographischen Protokollen des Nationalrats XI. GP., 53. 
ein vehementer Gegner einer Entkriminalisierung gleichgeschlechtlicher Sexualakte und äußerte sich 1961 in einer Festschrift besonders kritisch zum Reformvorhaben:

In der von der Strafrechtskommission empfohlenen Lösung liegt ein sehr entscheidender Bruch mit der bisherigen Rechtsauffassung. Wenn auch unser gegenwärtiges Strafgesetz seinem 14. Hauptstück die bescheidene Überschrift gibt „Von der Notzucht, Schändung und anderen schweren Unzuchtsfällen“, so hat es doch darin ganz allgemein die Sittlichkeit geschützt. Hierdurch hat es den Fortbestand jener Normen garantiert, die von der Sitte als einer aus den Erfahrungen tausendjährigen Zusammenlebens schöpfende Ordnungsmacht entwickelt wurden. ${ }^{39}$

Die Tabuisierung des Themas wurde im Zuge der Strafrechtsreform 1971 durch Einführung des Verbots der „Werbung für Unzucht mit Personen des gleichen Geschlechtes oder mit Tieren" $(\$ 517)^{40}$ sogar noch verstärkt. Der Tatbestand wurde 1974 in das neue Strafgesetzbuch übernommen $(\$ 220)^{41}$ und bis 1996 beibehalten. ${ }^{42}$ Obwohl es zwischen 1975 und 1996 nur zu vier Verurteilungen wegen $\$ 220$ StGB und $\$ 221$ StGB (Verbindungsverbot) kam, ,schwebte das Werbe- und Vereinsverbot stets wie ein Damoklesschwert vor allem über der österreichischen Lesben- und Schwulenbewegung“, wie der Historiker Hans-Peter Weingand betont. ${ }^{43}$ Und dennoch erschien schon ein Jahr nach der Kleinen Strafrechtsreform mit „Die Männer mit dem rosa Winkel“ die erste autobiographische Erzählung eines Mannes, der wegen "gleichgeschlechtlicher Unzucht“ mehrere Jahre in nationalsozialistischen Konzentrationslagern eingesperrt gewesen war. ${ }^{44}$ Die Geschichte dieser biographischen Erzählung, angefangen vom Niederschreiben in der politisch bewegten Szene und dem anonymen Veröffentlichen über die allmählich einsetzende wissenschaftliche Aufarbeitung bis hin zur Würdigung im öffentlichen Raum ${ }^{45}$ kann als paradigmatisch gelten für das Verhältnis der österreichischen Zeitgeschichte zur Homo-

39 Roland Grassberger, Zur Strafwürdigkeit der Sittlichkeitsdelikte, in: Paul Bockelmann/Wilhelm Gallas (Hg.), Festschrift für Eberhard Schmidt. Zum 70. Geburtstag, Göttingen 1961, 333-342, 334 .

$40 \quad \$ 517$ Strafgesetz von 1852, in der Fassung BGBl. 273/1971.

$41 \$ 220$ Strafgesetzbuch, BGBl. 60/1974.

42 Strafrechtsänderungsgesetz 1996, BGBl. 762/1996.

43 Hans-Peter Weingand, Homosexualität und Kriminalstatistik in Österreich, in: Invertito - Jahrbuch für die Geschichte der Homosexualitäten 13 (2011), 40-87, 79.

44 Heinz Heger, Die Männer mit dem rosa Winkel. Der Bericht eines Homosexuellen über seine KZHaft von 1939-1945, Hamburg 1972.

452010 wurde der südliche Teil des Zimmermannplatzes im 9. Wiener Bezirk in „Heinz-Heger-Park“ umbenannt. 
sexualitätengeschichte. Aus wissenschaftsgeschichtlicher Perspektive können zwei markante Wendepunkte in der österreichischen Forschungslandschaft ausgemacht werden: Zum einen begann sich die akademische Forschung in den 1980er-Jahren mit der Geschichte der Homosexualitäten zu beschäftigen, zum anderen setzte Anfang der 20ooer-Jahre eine Beforschung dieser Geschichte im öffentlichen Interesse und Auftrag ein. Den Wendepunkt in den 1980er-Jahren markieren vor allem die 1985 am Institut für Soziologie der Universität Wien vorgelegte Dissertation von Hanna Hacker, die sich mit weiblicher Homosexualität in Österreich zwischen 1870 und 1938 beschäftigt, ${ }^{46}$ sowie das Ende der 1980er-Jahre vom Soziologen Christian Fleck geleitete und vom Fonds zur Förderung der wissenschaftlichen Forschung finanzierte Forschungsprojekt „Soziale Kontrolle einer Minderheit. Homosexuellenverfolgung in wechselnden politischen Systemen Österreichs“, zu dem aber erst zehn Jahre später eine erste Publikation in der ÖZG erschien ${ }^{47}$ - das von Franz X. Eder herausgegebene Heft war das erste einer österreichischen historischen Fachzeitschrift zum Thema Homosexualitäten. Den Wendepunkt Anfang der 20ooerJahre stellt schließlich die Historikerkommission der Republik Österreich dar, die im Auftrag der Bundesregierung zwischen 1998 und 2003 den Vermögensentzug während der NS-Zeit untersuchte und bis Ende 2004 ihre Ergebnisse in 49 Bänden veröffentlichte. ${ }^{48}$ Band 25 dieser Publikation war der Verfolgung und dem Vermögensentzug Homosexueller gewidmet ${ }^{49}$ - eine gesetzliche Anerkennung dieser Opfergruppe erfolgte in Österreich erst 2005..$^{50}$ Ein nächster Wendepunkt wäre die institutionelle Verankerung dieser Forschungstradition an einer österreichischen Universität - diese steht noch aus.

46 Hanna Hacker, Die Ordnung der Frauen und Freundinnen. Zur Rekonstruktion homosozialer Handlungsmuster und ihrer institutionellen Kontrolle (Österreich, 1870-1938), phil. Diss., Universität Wien 1985; gekürzt veröffentlicht: dies., Frauen und Freundinnen. Studien zur „weiblichen Homosexualität" am Beispiel Österreich 1870-1938, Weinheim 1987. Siehe auch dies., Frauen* und Freund_innen. Lesarten „weiblicher Homosexualität“. Österreich, 1870-1938, Wien 2015.

47 Albert Müller/Christian Fleck, „Unzucht wider die Natur“. Gerichtliche Verfolgung der „Unzucht mit Personen gleichen Geschlechts" in Österreich von den 1930er bis zu den 1950er Jahren, in: Österreichische Zeitschrift für Geschichtswissenschaften 9 (1998) 3, 400-422, 401; eine weitere Publikation aus diesem Projekt: Philipp Korom/Christian Fleck, Wer wurde als homosexuell verfolgt?, in: Kölner Zeitschrift für Soziologie und Sozialpsychologie 64 (2012) 4, 755-782.

48 Siehe URL: http://www.boehlau-verlag.com/histkom/ (abgerufen 22.07.2019).

49 Niko Wahl, Verfolgung und Vermögensentzug Homosexueller auf dem Gebiet der Republik Österreich während der NS-Zeit. Bemühungen um Restitution, Entschädigung und Pensionen in der Zweiten Republik (Veröffentlichungen der Österreichischen Historikerkommission 25), Wien 2004.

50 Anerkennungsgesetz 2005, BGBl. I 86/2005. 
Die Fragestellungen, die die Homosexualitätengeschichte und die Queer Studies in den letzten Jahrzehnten mit Blick auf Österreich behandelt haben, können in drei große Themenbereiche gegliedert werden: Verfolgung und Opfergedenken, Identität(en) sowie Bewegungsgeschichte. Der Themenkomplex der Verfolgung ist dabei am meisten beforscht, was wohl einerseits dem politischen Interesse der Community auf Anerkennung staatlicher Repression als heute gesellschaftlich geächtete Verfolgung und andererseits der Quellenlage geschuldet ist - zu keinem anderen Aspekt der $\operatorname{LSBT}^{\star} \mathrm{I}^{\star} \mathrm{Q}$-Geschichte gibt es so viele Quellen. So bildeten auch Gerichtsakten der Strafverfolgung die Grundlage für jenes bereits erwähnte Forschungsprojekt Ende der 1980er-Jahre - mehr als 2.00o Akten aus den Landesgerichtssprengeln Wien, Graz, Innsbruck und Linz von ca. 1930 bis 1950 sind untersucht worden. ${ }^{51}$ Hinzu kommt, dass die Verfolgungsintensität in Österreich im internationalen Vergleich im 20. Jahrhundert enorm hoch war, wie von Hans-Peter Weingand akribisch aufgearbeitete Kriminalstatistiken zeigen. ${ }^{52}$ Die Erforschung der zeitgeschichtlich besonders relevanten Periode des Nationalsozialismus durch die Homosexualitätengeschichte setzte in Deutschland bereits Mitte der $1970 e r-J a h r e ~ e i n,{ }^{53}$ stellte in Österreich aber noch Mitte der 1980er-Jahre ein Desiderat dar, wie die Politikwissenschaftlerin Gudrun Hauer damals monierte. ${ }^{54}$ In ihrer Kritik unterstrich sie, dass es vor allem kein Wissen über die Situation von Frauen gebe, die in Österreich doch zumindest dem Gesetz nach ebenso wegen gleichgeschlechtlicher Sexualhandlungen verfolgt worden waren. Die deutsche Historikerin Claudia Schoppmann veröffentlichte schließlich 1999 die erste Studie über die Lebensverhältnisse lesbischer Frauen in Wien während des Nationalsozialismus - wofür sie zum Großteil Gerichtsakten der Strafverfolgung in Wien als Quellen heranzog. ${ }^{55}$ Mit dem bereits erwähnten Band 25 der Veröffentlichungen der Österreichischen Historikerkommission erreichte die Erforschung der Verfolgung während der NS-Zeit einen ersten Höhepunkt.

Untrennbar verbunden mit dem Thema der Verfolgung ist das Thema der Erinnerung und des Gedenkens, insbesondere an die Opfer der nationalsozialistischen

51 Müller/Fleck, Unzucht, 401-402.

52 Weingand, Homosexualität, 40.

53 Rüdiger Lautmann/Winfried Grikschat/Egbert Schmidt, Der rosa Winkel in den nationalsozialistischen Konzentrationslagern, in: Rüdiger Lautmann (Hg.), Seminar. Gesellschaft und Homosexualität, Frankfurt a. M. 1977, 325-365.

54 Gudrun Hauer, Homosexuelle im Faschismus. Erschienen in: Lambda-Nachrichten 1/1984, in: Gudrun Hauer/Dieter Schmutzer (Hg.), Das Lambda-Lesebuch. Journalismus andersrum. Die besten Beiträge aus 17 Jahrgängen der „Lambda-Nachrichten“, Wien 1996, 107-124.

55 Claudia Schoppmann, Verbotene Verhältnisse. Frauenliebe 1938-1945, Berlin 1999. 
Homosexuellenverfolgung. Gerade die Frage des Gedenkens hat in Österreich wie in Deutschland Debatten nicht nur in politischen Öffentlichkeiten, sondern auch in wissenschaftlichen Kontexten ausgelöst. ${ }^{56} \mathrm{Im}$ Zentrum steht dabei die Frage, ob und, wenn ja, wie sich die Verfolgung des Nationalsozialismus von der davor und danach unterscheidet. Mit der seit Mitte der 200oer-Jahre in Wien diskutierten Errichtung eines Denkmals für Opfer der nationalsozialistischen Homosexuellenverfolgung verbinden sich Fragen nach historischen und aktuellen Identitäten und Zugehörigkeiten, nach Selbst- und Fremdbildern und den Möglichkeiten der Nutzung eines solchen Gedenkortes, die über die Erinnerung an die NS-Verfolgung hinausreicht. Die Queer Studies versprechen gerade auch bei der Erforschung des Umgangs mit homosexuellen Männern und Frauen in nationalsozialistischen Konzentrationslagern neue Erkenntnisse zutage zu bringen. Wie die Leiterin der Mahn- und Gedenkstätte Ravensbrück - in der NS-Zeit das größte KZ für Frauen - Insa Eschebach resümiert, seien „für die Gruppe der inhaftierten weiblichen und männlichen Homosexuellen [...] kaum Selbstzeugnisse überliefert" und die Erinnerungsberichte anderer Überlebender bildeten ,eine der wenigen, wenngleich auch ausgesprochen problematischen Quellen zum Thema der homosexuellen Häftlinge" aufgrund der darin dominanten homophoben Narrative. ${ }^{57}$ Die Historikerin Anna Hájková schlägt in diesem Zusammenhang vor, den Holocaust queer zu erzählen, und versteht darunter den Versuch, den heteronormativen Narrativen in den Erinnerungsberichten Gegennarrative entgegenzusetzen, Subjekte in ihrer Ambivalenz sichtbar zu machen und damit eine „vielschichtigere und inklusivere Geschichte zu schreiben“.58

Opfergedenken ist auf vielfältige Weise mit Fragen der Identität einer Gruppe verknüpft. Identitäten bilden aber noch in zahlreichen anderen Kontexten den Fokus historischer Forschung, wie etwa in der erwähnten Monographie von Hanna Hacker ${ }^{59}$ oder in den Sammelbänden „Das lila Wien um 1900“ (1986) ${ }^{60}$ oder „Der

56 Elisa Heinrich, Marginalisierte Erinnerung. Auseinandersetzungen um homosexuelle NS-Opfer im Nachkriegsösterreich, in: zeitgeschichte 43 (2016) 2, 101-115; Insa Eschebach (Hg.), Homophobie und Devianz. Weibliche und männliche Homosexualität im Nationalsozialismus (Forschungsbeiträge und Materialien der Stiftung Brandenburgische Gedenkstätten 6), Berlin 2012.

57 Insa Eschebach, Einleitung, in: dies. (Hg.), Homophobie und Devianz, 11-20, 15-16.

58 Anna Hájková, Den Holocaust queer erzählen, in: Initiative Queer Nations/Janin Afken/Jan Feddersen/Benno Gammerl/Rainer Nicolaysen/Benedikt Wolf (Hg.), Jahrbuch Sexualitäten 2018, Göttingen 2018, 86-110, 110.

59 Hacker, Frauen*.

60 Neda Bei (Hg.), Das lila Wien um 1900. Zur Ästhetik der Homosexualitäten, Wien 1986. Der Sammelband geht auf ein Symposium der Österreichischen Gesellschaft für Homosexuellenforschung und Lesbierinnenforschung (ÖGHL) zurück. 
andere Blick. Lesbischwules Leben in Österreich“ (2001). ${ }^{61}$ Unter den Topos Identität fallen auch biographische Forschungen wie das Porträt jener Frau, die als die einzige Lesbe, die von Sigmund Freud behandelt worden war, Bekanntheit erlangte. ${ }^{62}$ Die nach wie vor dünn gesäte Forschung zu Trans ${ }^{\star}$ gender-Personen in der österreichischen Geschichte - auch hier ist die deutsche Forschung vor allem durch die Arbeiten von Rainer Herrn weit voraus ${ }^{63}$ - wurde erst vor kurzem durch einen Aufsatz der Rechtshistorikerin Ilse Reiter-Zatloukal über zwei Fälle eines rein administrativen Geschlechtswechsels von Frau zu Mann während der NS-Zeit bereichert. ${ }^{64}$ Die Quellen, zwei Personenstandsakten, waren ein Zufallsfund. Einen Beitrag zur jüngeren Geschichte trans*identer Personen in Österreich hat kürzlich Persson Perry Baumgartinger mit seiner Studie zum Transsexuellenerlass zwischen 1980 und 2010 vorgelegt. ${ }^{65} \mathrm{Zu}$ einer weiter angelegten, systematischen Aufarbeitung der Geschichte von Trans ${ }^{\star}$ gender-Personen in Österreich fehlt es derzeit noch an finanziellen Mitteln.

Bewegungsgeschichte wurde am längsten vor allem aus der Bewegung heraus geschrieben. Als Publikationsmedium war die im Jahr 1979 gegründete Zeitschrift der Homosexuelleninitiative Wien „Lambda-Nachrichten“ besonders wichtig. Ein 1996 herausgegebener Sammelband der besten Beiträge der ersten 17 Jahre spiegelt die Qualität und Bedeutung dieses Mediums für die zeitgeschichtliche Forschung wider. ${ }^{66}$ Seit den späten $1990 e r-J a h r e n$ interessieren sich auch wissenschaftliche Fachzeitschriften für Themen der $\operatorname{LSBT}^{\star} \mathrm{I}^{\star} \mathrm{Q}$-Bewegungsgeschichte; seit 2006 sind einige Monographien zur Bewegungsgeschichte erschienen. ${ }^{67}$

61 Wolfgang Förster/Tobias G. Natter/Ines Rieder (Hg.), Der andere Blick. Lesbischwules Leben in Österreich, Wien 2001.

62 Ines Rieder/Diana Voigt, Heimliches Begehren. Eine verbotene Liebe in Wien, Reinbek bei Hamburg 2003.

63 Rainer Herrn, Schnittmuster des Geschlechts. Transvestitismus und Transsexualität in der frühen Sexualwissenschaft (Beiträge zur Sexualforschung 85), Gießen 2005.

64 Ilse Reiter-Zatloukal, Geschlechtswechsel unter der NS-Herrschaft. „Transvestitismus“, Namensänderung und Personenstandskorrektur in der „Ostmark“ am Beispiel der Fälle Mathilde/Mathias Robert S. und Emma/Emil Rudolf K., in: Beiträge zur Rechtsgeschichte Österreichs 4 (2014) 1, 172-209.

65 Persson Perry Baumgartinger, Die staatliche Regulierung von Trans. Der Transsexuellen-Erlass in Österreich (1980-2010). Eine Dispositivgeschichte, Bielefeld 2019.

66 Hauer/Schmutzer (Hg.), Lambda-Lesebuch.

67 Ulrike Repnik, Die Geschichte der Lesben- und Schwulenbewegung in Österreich, Wien 2006; Käthe Kratz/Lisbeth N. Trallori (Hg.), Liebe, Macht und Abenteuer. Zur Geschichte der Neuen Frauenbewegung in Wien, Wien 2013; Frauenkollektiv RitClique (Hg.), Zündende Funken. Wiener Feministinnen der 7oer Jahre, Wien 2018. 
Obgleich die Homosexualitätengeschichte und die Queer Studies mittlerweile eine eigene Forschungsgeschichte aufweisen, können sie nicht losgelöst von der Sexualitätsgeschichte betrachtet werden. Jüngste Debatten im Forschungsfeld, die sich noch nicht in Publikationen niedergeschlagen haben, tendieren überhaupt in Richtung einer breiteren Betrachtung historischer Formen von gleichgeschlechtlicher Sexualität im Kontext anderer bzw. aller Formen von Sexualität. Es sei daher auf einige zentrale Monographien zur Geschichte der Sexualitäten im deutschsprachigen Raum verwiesen, die als Standardwerke der Forschung gelten: 2002 erschien in erster Auflage „Kultur der Begierde“ von Franz X. Eder, das diverse Aspekte von Sexualität von der Frühen Neuzeit bis ins 20. Jahrhundert beleuchtet. ${ }^{68} 2005$ kam „Die Politisierung der Lust“ von Dagmar Herzog heraus, die darin die Sexualitätsgeschichte in Deutschland im 20. Jahrhundert in den Fokus nimmt. ${ }^{69}$ Während die 2011 veröffentlichte Habilitationsschrift „Wie der Sex nach Deutschland kam“ von Sybille Steinbacher die Zeit der frühen Bundesrepublik untersucht, ${ }^{70}$ widmet sich Josie McLellan in ihrer im selben Jahr erschienenen Studie sexualitätsgeschichtlichen Aspekten der DDR. ${ }^{11}$

Neben der wachsenden Literatur hat in den letzten Jahren auch die Zahl an Konferenzen $^{72}$ und die Finanzierung von zumindest teilweise an Universitäten angebundenen Forschungsprojekten zugenommen. ${ }^{73}$ Starke Sichtbarkeit hat die Forschung

68 Franz X. Eder, Kultur der Begierde. Eine Geschichte der Sexualität, München ${ }^{2} 2009$.

69 Dagmar Herzog, Die Politisierung der Lust. Sexualität in der deutschen Geschichte des 2o. Jahrhunderts, München 2005. Im Original: dies., Sex after Fascism. Memory and Morality in Twentieth-Century Germany, Princeton 2005.

70 Sybille Steinbacher, Wie der Sex nach Deutschland kam. Der Kampf um Sittlichkeit und Anstand in der frühen Bundesrepublik, München 2011.

71 Josie McLellan, Love in the Time of Communism. Intimacy and Sexuality in the GDR, Cambridge 2011.

7245 Jahre „Kleine Strafrechtsreform“. Kontinuitäten und Brüche im Umgang mit Homosexualität(en) in Österreich im 20. Jahrhundert, 23./24.06.2016 an der Universität Wien; Verfolgung, Diskriminierung, Emanzipation. Homosexualität in Europa seit dem Zweiten Weltkrieg, 26.-28.05.2017, Akademie für politische Bildung Tutzing; Queering Memory. Archives, Libraries, Museums and special collections: an international LGBTIQ+ Conference, 27.-29.06.2019 Berlin.

73 Während es in Deutschland schon eine namhafte Dotierung durch die Einrichtung der Bundesstiftung Magnus Hirschfeld gegeben hat, steht in Österreich eine vergleichbare finanzielle Unterstützung noch aus. Diese findet zumeist regional und projektbezogen statt: ,Namentliche Erfassung der homosexuellen und transgender Opfer des Nationalsozialismus in Wien, durchgeführt von QWIEN, gefördert durch den Nationalfonds der Republik Österreich für Opfer des Nationalsozialismus, die Gemeinde Wien und den Zukunftsfonds der Republik Österreich; Die Strafverfolgung homosexueller Handlungen durch die NS-Militärgerichtsbarkeit in Wien 1938-1945, durchgeführt von QWIEN, gefördert durch den Nationalfonds und den Zukunftsfonds. Siehe Manuela Bauer, Werkstattbericht Forschungsprojekte QWIEN, in: zeitgeschichte 43 (2016) 2, 116-117. 
zur $\operatorname{LSBT}^{\star} \mathrm{I}^{\star} \mathrm{Q}$-Geschichte Österreichs in den letzten beiden Jahrzehnten gewonnen durch außeruniversitär initiierte Projekte wie die Ausstellungen „Geheimsache Leben“ (2005/2006 in Wien),74 in deren Folge das QWIEN - Zentrum für schwul/ lesbische Kultur und Geschichte (heute: Zentrum für queere Geschichte) gegründet wurde, die Ausstellung „1[i]eben uferlos und andersrum“ (2010 in Graz)75 und die 2016 im Wien Museum gezeigte Ausstellung „Sex in Wien“76 - die bis dahin erfolgreichste Sonderausstellung dieses Museums. Neben außeruniversitären Forschungsprojekten kommt insbesondere Sammlungen und Archiven im Bereich der $\mathrm{LSBT}^{\star} \mathrm{I}^{\star} \mathrm{Q}-\mathrm{Geschichte}$, deren Beforschung häufig mit einer schwierigen archivalischen Überlieferungslage konfrontiert ist, eine hohe Bedeutung zu. Institutionen wie QWIEN oder auch „Stichwort - Archiv der Frauen- und Lesbenbewegung“ sammeln und archivieren nicht nur gezielt Bestände, die ihren Weg kaum in andere Archive finden würden. Durch die Sammlung von Selbstzeugnissen, grauer Literatur und Material aus politischen Bewegungen erweitern sie auch die Forschung zu Verfolgung, Kontrolle und Repression um Perspektiven auf die Lebensumstände und Handlungsräume von AkteurInnen.

\section{Forschungsperspektiven}

Welche Perspektiven und Desiderate ergeben sich nun für die österreichische Zeitgeschichtsforschung, wenn sie nicht nur die bestehenden Lücken in der Homosexualitätengeschichte füllen, sondern auch die zuvor genannten Herausforderungen annehmen und sich mit den Queer Studies in ein Verhältnis setzen will? Die Erforschung der Verfolgung homosexueller Männer und Frauen während des Nationalsozialismus und das Gedenken daran sind nach wie vor wichtige Themen. So wurde erst im Juni 2019 bekanntgegeben, dass ein neuer Standort für ein permanentes „Denkmal für die Männer und Frauen, die Opfer der Homosexuellenverfolgung in der NS-Zeit wurden“, im Wiener Resselpark gefunden wurde. ${ }^{77}$ Im Juli 2020 wurde

74 Andreas Brunner/Ines Rieder/Nadja Schefzig/Hannes Sulzenbacher/Niko Wahl, Geheimsache. Leben. Schwule und Lesben im Wien des 20. Jahrhunderts (Katalog zur gleichnamigen Ausstellung), Wien 2005.

75 Maria Froihofer/Elke Murlasits/Eva Taxacher (Hg.), 1[i]eben und Begehren zwischen Geschlecht und Identität, Wien 2010.

76 Andreas Brunner/Frauke Kreutler/Michaela Lindinger/Gerhard Milchram/Martina Nußbaumer/ Hannes Sulzenbacher (Hg.), Sex in Wien. Lust, Kontrolle, Ungehorsam (Ausstellungskatalog), Wien 2016.

77 Die Stadt Wien sowie der Nationalfonds unterstützten das Projekt, zu dem acht nationale und internationale KünstlerInnen eingeladen wurden. Siehe Wien: Standort für Denkmal für Opfer der 
mit dem Entwurf des britischen Künstlers Marc Quinn das Siegerprojekt für das neu ausgeschriebene Denkmal präsentiert. ${ }^{78}$ Gerade der Prozess der Umsetzung dieses Denkmals muss von der Zeitgeschichtsforschung weiterhin aufmerksam beobachtet und kommentiert werden. ${ }^{79}$

Die 1950er- und 1960er-Jahre bilden ein weiteres großes Desiderat: So existieren bis dato keine umfangreicheren Arbeiten, die Debatten zu Sexualität unter Berücksichtigung der unterschiedlichen Positionen der Parteien und der Zivilgesellschaft dieser Phase zum Thema machen, wie sie etwa anhand der zu Beginn des vorliegenden Beitrags thematisierten Tagung sichtbar werden. Eine Studie, wie sie Steinbacher oder Herzog für die Bundesrepublik Deutschland vorgelegt haben, ${ }^{80}$ fehlt für Österreich. Zu den Lebensumständen lesbischer Frauen und schwuler Männer in den ersten Nachkriegsjahrzehnten existieren ebenso keine Untersuchungen.

Aus Perspektive einer queeren Zeitgeschichtsforschung weitgehend unbeleuchtet sind ebenfalls die 1980er- und 1990er-Jahre - die in dieser Phase in feministischen Kontexten geführten Debatten über lesbische bzw. queere Sexualität, über Pornographie, Prostitution und $\mathrm{BDSM}^{81}$ sind für Österreich bisher nur in einer

Homosexuellen-Verfolgung in der NS-Zeit fixiert. Entscheidung nach breitem Beteiligungsprozess für Resselpark, OTS-Presseaussendung, 10.06.2019, URL: https://www.ots.at/presseaussendung/ OTS_20190610_OTSo012/wien-standort-fuer-denkmal-fuer-opfer-der-homosexuellen-verfolgung-in-der-ns-zeit-fixiert (abgerufen 17.07.2019).

78 Stadt Wien präsentiert Entwurf für das Denkmal für die Männer und Frauen, die Opfer der Homosexuellen-Verfolgung in der NS-Zeit wurden, URL: https://www.wien.gv.at/presse/2020/07/o1/ stadt-wien-praesentiert-entwurf-fuer-das-denkmal-fuer-die-maenner-und-frauen-die-opfer-derhomosexuellen-verfolgung-in-der-ns-zeit-wurden (abgerufen 21.09.2020).

79 Bereits seit 2014 wird der Prozess von HistorikerInnen und ExpertInnen intensiver begleitet als im Rahmen der Denkmal-Initiative 2005. So wurde 2014 die Tagung „Gedenken neu gedacht" von der Wiener Antidiskriminierungsstelle für gleichgeschlechtliche und transgender Lebensweisen (WASt) u. a. in Kooperation mit QWIEN veranstaltet. Anschließend fanden zwei Open-SpaceAbende statt, zu der HistorikerInnen wie Interessierte der LGBT ${ }^{\star} \mathrm{I}^{\star} \mathrm{Q}-\mathrm{Communitys}$ zur gemeinsamen Reflexion über einen geeigneten Ort sowie die Ausschreibungsmaterialien eingeladen waren. Eine explizite Folge ist etwa, dass der für das Denkmal 2005 vorgesehene Titel „Mahnmal für homosexuelle und transgender Opfer des Nationalsozialismus" geändert wurde; Trans*genderAktivistInnen hatten sich bei den Veranstaltungen gegen eine Inklusion von „transgender“ in den Mahnmaltitel und die Ausschreibung ausgesprochen. Siehe Panel: Was will die Wiener Community?, in: QWIEN/WASt (Hg.), ZU SPÄT? Dimensionen des Gedenkens an homosexuelle und transgender Opfer des Nationalsozialismus, Wien 2015, 150-172.

80 Steinbacher, Sex; Herzog, Politisierung.

81 BDSM ist ein Akronym, das sich aus den Anfangsbuchstaben der Begriffe „Bondage“, „Discipline“, „Dominance“, „Submission“, „Sadism“ und „Masochism“ zusammensetzt. 
Masterarbeit thematisiert worden. ${ }^{82}$ Auch die Auswirkungen der Aids-Krise in Österreich, die gesamtgesellschaftliche Debatten auslöste, die österreichische Gesetzgebung beeinflusste ${ }^{8_{3}}$ und massive Folgen für schwule und lesbische Subkulturen hatte, waren bisher kein Gegenstand von Forschungsprojekten oder umfassenden Publikationen, ${ }^{84}$ wie das mittlerweile für andere europäische Länder und insbesondere die USA der Fall ist.

Seit 2015 ist außerdem die Frage nach der Verfolgung von Homosexualität in unterschiedlichen Ländern und den Implikationen für Asylverfahren in EU-Mitgliedstaaten wie Österreich Teil eines gesellschaftlichen Diskurses geworden. ${ }^{85}$ Eine in aktuelle Debatten eingreifende Zeitgeschichte wird sich in den kommenden Jahren auch diesem Thema im Kontext von Grenzregimen, Migrationspolitiken und globalen Ungleichheitsverhältnissen zuwenden müssen. ${ }^{86}$

Nicht zuletzt sollte die seit 2019 bestehende Möglichkeit eines dritten Geschlechtseintrags in Österreich ${ }^{87}$ Anlass für eine queer ausgerichtete Zeitgeschichte sein, sich vermehrt mit den Transgender bzw. den Intersex Studies zu vernetzen. ${ }^{88}$ Auch der seit einigen Jahren in queertheoretischen Zusammenhängen von VertreterInnen der Crip Theory und Disability Studies ${ }^{89}$ angestoßenen Auseinandersetzungen um die Zusammenhänge zwischen Disability und Queerness bieten Anknüpfungs-

82 Lisa Weinberg, Pleasure and Danger - Feminist Sex Wars auf Deutsch. Diskussionen über Lesbisch_queere Sexualität und Butch/Femme in Wien und Westberlin in den 8oer und frühen goer Jahren, MA-Arbeit, Universität Wien 2018.

83 Siehe die Abschaffung des 1971 eingeführten Tatbestands der ,gewerbsmäßigen gleichgeschlechtlichen Unzucht“, der mit 1. Juli 1989 als Zugeständnis an Aids-Präventionsmaßnahmen wieder aufgehoben wurde. Änderung des Strafgesetzbuches und des Aids-Gesetzes, BGBl. 243/1989.

84 Zumindest finden sich aus diesem Themenfeld einige Diplom- und Masterarbeiten.

852013 entschied der Europäische Gerichtshof, dass Verfolgung aufgrund der sexuellen Orientierung als Asylgrund anerkannt werden müsse: EUGH 07.11.2013, C-199/12 bis C-201/12.

86 Siehe dazu beispielhaft aus dem deutschen Kontext Elisabeth Tuider/llka Quirling, Cruzando Fronteras - zur Heteronormativität von Grenz- und Migrationsregimen am Beispiel von Asylund aufenthaltrechtlichen Verfahren, in: Bundesstiftung Magnus Hirschfeld (Hg.), Forschung im Queerformat: aktuelle Beiträge der LSBTI*-, Queer- und Geschlechterforschung, Bielefeld 2014, 251-272.

87 Verfassungsgerichtshof (VfGH) 15.06.2018, G 77/2018-9.

88 Elisabeth Greif (Hg.), No Lessons from the Intersexed? (Linzer Schriften zu Gender und Recht 62), Linz 2019; Persson Perry Baumgartinger, Trans Studies. Historische, begriffliche und aktivistische Aspekte, Wien 2017.

89 Die Disability Studies arbeiten mit einem konstruktivistischen Konzept von „Behinderung“ und sehen „[d]ie gesellschaftliche Benachteiligung, die mit einer Beeinträchtigung verbunden ist, [...] demnach nicht vom Individuum abhängig, sondern [als] Resultat gesellschaftlicher Prozesse“. Vgl. URL: https://dista.uniability.org/glossar/disability-studies-2/ (abgerufen 20.07.2019). Diese Perspektive macht „Behinderung“ auch einer Historisierung zugänglich. 
punkte für zeithistorische Zugriffe ${ }^{\circ \circ}$ - auch hier spielt etwa die Wiener Community eine Vorreiterrolle gegenüber der zeitgeschichtlichen Forschung. ${ }^{91}$

\section{Fazit}

Der vorliegende Sammelband nimmt die Umbruchsituation, in der sich die österreichische Zeitgeschichtsforschung derzeit befindet, zum Ausgangspunkt, Bilanz zu ziehen und Perspektiven zu eröffnen. Am Ende des vorliegenden Beitrags wollen wir deshalb fragen, inwiefern dies auch eine Zeitgeschichtsforschung, die sich zu den Queer Studies in ein Verhältnis setzt, betrifft. Wie kann die zentrale Rolle, die Fragen von Geschlecht und Sexualität in historischen wie gegenwärtigen Gesellschaften spiel(t)en, stärker in das Blickfeld einer kritischen Zeitgeschichtsforschung rücken?

LGBT $^{*} I^{\star} \mathrm{Q}$-Lebensweisen sind in den letzten Jahren so präsent wie nie zuvor in Österreich: Die Öffnung der zivilen Ehe für gleichgeschlechtliche Paare, ${ }^{92}$ die erwähnte Möglichkeit eines dritten Geschlechtseintrags, Wien als Ort der „Europride

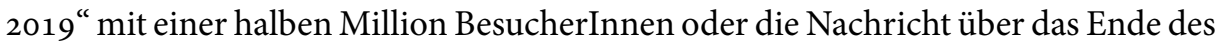
Life Ball waren in den letzten Monaten Gegenstand vielfältiger gesellschaftlicher und vor allem medialer Debatten - ganz abgesehen von der seit Jahren international geführten Debatte um sexuelle Selbstbestimmung (zum Beispiel „MeToo“-Debatte). ${ }^{93}$ Auch wichtige historische Ereignisse jähr(t)en sich gerade, wie die Aufhebung des Totalverbots 1971, die Stonewall Riots in New York 1969 oder das Jahr 1968 als Synonym für das Erproben alternativer Lebensstile und Beziehungsformen.

Zugleich stehen Themen, die als weitgehend selbstverständlich galten, wieder zur Disposition. So wurde etwa mit den Stimmen der ehemaligen Regierungsparteien FPÖ und ÖVP beschlossen, dass sexualpädagogische Angebote an Schulen, die bisher von externen Fachkräften und Vereinen durchgeführt werden konnten und hier

90 Zum Beispiel für Deutschland Dagmar Herzog, Unlearning Eugenics. Sexuality, Reproduction, and Disability in Post-Nazi Europe, Wisconsin 2018.

91 Fachkonferenz der WASt am 13.11.2017: „Intersektionalität: LGBTIQ und Behinderungen“, URL: https://www.wien.gv.at/menschen/queer/veranstaltungen/fachkonferenz-2017.html (abgerufen 19.07.2019).

92 VfGH 04.12.2017, G258/2017.

93 Elisabeth Holzleithner, Sexuelle Selbstbestimmung als Individualrecht und als Rechtsgut. Überlegungen zu Regulierungen des Intimen als Einschränkung sexueller Autonomie, in: Ulrike Lembke (Hg.), Regulierungen des Intimen. Sexualität und Recht im modernen Staat, Wiesbaden 2017, $31-50$. 
zum Beispiel Akzente in Richtung LGBT $^{\star} I^{\star}$ Q-Lebensweisen oder HIV-Prävention setzen konnten, nicht mehr zulässig sind. ${ }^{94}$

In anderen Ländern haben die Universitäten auf die vielfältigen gesellschaftlichen Auseinandersetzungen um Geschlechtsidentitäten und Sexualitäten reagiert. Der erst vor kurzem am Goldsmith College in London eröffnete Masterstudiengang Queer History oder die 2019 erfolgte Ausschreibung eines Chair in History of Gender and Sexuality am Europäischen Hochschulinstitut Florenz (EUI) zeugen davon. Und die internationale Vernetzung wird zunehmend dichter, wie etwa das Sexuality Network der European Social Science and History Conference zeigt oder der jüngst gegründete Arbeitskreis Sexualitäten in der Geschichte. ${ }^{95}$

Österreichische Universitäten sollten sich ebenfalls in diese Richtung engagieren. Eine Professur mit sexualitätsgeschichtlicher Widmung, die selbstverständlich queertheoretische Perspektiven einbezieht, wäre ein erster wichtiger Schritt. Aber auch für eine interdisziplinäre und Universitäten übergreifende Forschungsplattform sehen wir die Zeit gekommen: Die bereits vorhandene Expertise aus den Bereichen (Zeit)Geschichte, Soziologie, Rechtswissenschaft oder Bildungswissenschaft könnte optimal gebündelt und weitere ForscherInnen gewonnen werden. Kooperationen mit außeruniversitären Einrichtungen und der Zivilgesellschaft wären im Rahmen einer solchen Plattform nicht nur möglich; sie sind durch die Geschichte des Forschungsbereichs und seiner ProponentInnen vielfach bereits etabliert. Gerade im Bereich der Ausbildung von LehrerInnen ${ }^{96}$ könnte sich eine solche Forschungsplattform als wichtiges Bindeglied zwischen universitärer Forschung und schulischer Bildung erweisen.

Die Universität Wien hat im Rahmen von „Europride 2019“ mit dem Slogan „Proud to be part of it“ vor Regenbogenfarben geworben. Die Frage wird sein, ob diesen symbolpolitischen Gesten auch Konsequenzen auf Ebene der Strukturen folgen. Eine queere Zeitgeschichtsforschung könnte wichtige Anstöße dazu geben.

94 Parlamentskorrespondenz Nr. 785 vom 03.07.2019, Sexualerziehung an Schulen: Externe Vereine sollen nicht mehr einbezogen werden, URL: https://www.parlament.gv.at/PAKT/PR/JAHR_2019/ PKo785/\#XXVI_A_00911 (abgerufen 20.07.2019).

95 Gründungsworkshop des Arbeitskreises Sexualitäten in der Geschichte, 17./18.05.2019, Freie Universität Berlin.

96 Etwa im Rahmen einer Kooperation mit „Ausgesprochen! Verein für LGBTIQ* Lehrer*innen und Lehramtsstudierende". 


\section{Zeitgeschichte und Politische Bildung}

Thomas Hellmuth

Beschäftigen wir uns mit der Verbindung von Zeitgeschichte und Politischer Bildung, sind vorweg einige Anmerkungen zur „Objektivität“ der Geschichte im Allgemeinen notwendig: In der Geschichtswissenschaft wird häufig - unter Bezugnahme auf Aleida Assmann - zwischen "Geschichte-als-Wissenschaft" und „Geschichteals-Gedächtnis" unterschieden. ${ }^{1}$ Erstere garantiere ein kritisch-distanziertes Herangehen an einen historischen Gegenstand, wozu Verfahren und Regeln dienen sollen, die intersubjektiv überprüfbar seien. „Geschichte-als-Gedächtnis“ entziehe sich dagegen einer rationalen Überprüfbarkeit und konstruiere Geschichtsbilder und Mythen, die der Identitätsbildung dienten. Bei genauerer Betrachtung erweist sich aber diese Unterscheidung als unklar und letztlich unhaltbar. ${ }^{2}$ Auch "Geschichteals-Wissenschaft" stellt sich bei genauerer Betrachtung als eine Konstruktion dar, die ihren Ursprung in der Gesellschaft hat, in der sie entstanden ist. " "Geschichte" ist also gegenwärtig, nicht nur in dem Sinne, dass wir die Gegenwart aus der Vergangenheit heraus erklären und damit vielleicht sogar in die Zukunft blicken wollen, sondern auch in Form der Instrumentalisierung von „Geschichte“ als relevanter Faktor bei der Identitätsbildung und als Geschichtspolitik.

1 Aleida Assmann, Erinnerung als Erregung. Wendepunkte der deutschen Erinnerungsgeschichte, in: Wolf Lepenies (Hg.), Wissenschaftskolleg Jahrbuch 1998/99, Berlin 2000, 200-220, 202.

2 Max Weber, Die „Objektivität“ sozialwissenschaftlicher und sozialpolitischer Erkenntnis (1904), in: ders., Gesammelte Aufsätze zur Wissenschaftslehre, Tübingen 71988, 146-214; Hayden White, Metahistory. Die historische Einbildungskraft im 19. Jahrhundert in Europa, Frankfurt a. M. 1994, 39.

3 In Österreich, Deutschland und der Schweiz wird in diesem Zusammenhang auch der Begriff „ReKonstruktion“ verwendet, der sich im Kompetenzstrukturmodell der ForscherInnengruppe „Förderung und Entwicklung von reflektiertem Geschichtsbewusstsein“ (FUER) findet. Der Begriff ist m. E. aber aus zwei Gründen nur begrenzt tauglich: 1) Auch wenn dies wohl nicht intendiert ist, erinnert er doch - trotz Bindestrich - an den Versuch der „Rekonstruktion“ von Vergangenheit und somit an den Historismus. 2) Hinter dem Begriff steckt ein sehr technisches Verständnis von "Geschichte“: Es geht v. a. um den Aufbau und die Struktur historischer Erzählungen und weniger um deren gesellschaftliche Kontextualisierung. Die Ausführungen in dem vorliegenden Beitrag orientieren sich daher u. a. an dem Dekonstruktivismus (Jacques Derrida) und der Diskursanalyse (Michel Foucault). 


\section{Zeitgeschichte - sowohl Objekt als auch zentraler Teil Politischer Bildung}

Der Zeitgeschichte kommt in diesem Zusammenhang eine besondere Bedeutung zu: Als historische Teildisziplin konnte sie sich - zunächst in der Bundesrepublik Deutschland - erst nach dem Zweiten Weltkrieg etablieren. Die Frage nach den Ursachen der damals jüngsten Vergangenheit, des Nationalsozialismus, stellte einen „politisch-moralischen Bestandteil des staatlichen Selbstverständnisses der jungen Bundesrepublik" dar und bedurfte daher auch eines ,institutionell gesonderten Zweig[es] der Geschichtsforschung “. ${ }^{4}$ Österreich folgte, wohl wegen seines lange nicht in Frage gestellten „Opfer“-Status, erst seit Ende der 1960er-Jahre nach.

Zunächst rief die neue historische Disziplin aber in der Historikerzunft Skepsis hervor. Sie wurde mit dem Begriff der "Re-Education“ in Verbindung gebracht. Wegen ihrer fehlenden Distanz zum Forschungsthema herrschte Zweifel an ihrer „Objektivität“. Dieser Einwand ist heutzutage nicht mehr haltbar, zumal - wie bereits dargestellt - Geschichte im Allgemeinen ohnehin als Konstruktion zu betrachten ist. Dennoch nimmt die Zeitgeschichte eine besondere Stellung in der Geschichtswissenschaft ein, zumal sie sich, auch wenn ihr Forschungsinteresse bis zum beginnenden 20. Jahrhundert zurückreicht, zum Teil noch immer für die „Epoche der Mitle-

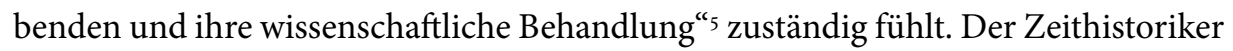
und die Zeithistorikerin beschäftigen sich somit auch mit einer Vergangenheit, die die Zeitgenossen noch erlebt haben. Diese wird von mehreren Generationen und unterschiedlichen Gruppen ,aus ihrer jeweiligen Perspektive unterschiedlich, vielfach auch in einer politisch bedeutsamen Weise kontrovers " gedeutet. ${ }^{6}$ Zunächst war dies bei der Auseinandersetzung mit dem Nationalsozialismus deutlich geworden, bei der unterschiedliche Deutungsperspektiven nicht selten in unterschiedliche politische Urteile mündeten. Heute zeigt sich diese Besonderheit der Zeitgeschichte, wenn die Aufarbeitung des Nationalsozialismus, damit in Verbindung etwa auch die österreichische „Opfer"-These analysiert und bewertet werden. Auch Themen wie die „1968er"-Bewegung oder, um ein weiteres österreichisches Beispiel zu nennen, die Ära Kreisky unterliegen unterschiedlichen Deutungen. Somit wirkt Zeitgeschichte - nicht zuletzt auch im Zusammenhang mit der "Erinnerungs" und "Geschichtspolitik“ - elementarer als etwa die mittelalterliche Vergangenheit auf das

4 Axel Schildt, Zeitgeschichte, in: Hans-Jürgen Goertz (Hg.), Geschichte. Ein Grundkurs (rowohlts enzyklopädie 55576), Reinbek bei Hamburg 1998, 318-330, 319.

5 Hans Rothfels, Zeitgeschichte als Aufgabe, in: Vierteljahreshefte für Zeitgeschichte 1 (1953) 1, 1-8, 2.

6 Bernhard Sutor, Historisches Lernen als Dimension politischer Bildung, in: Wolfgang Sander (Hg.), Handbuch politische Bildung (Politik und Bildung 32), Schwalbach/Ts. ${ }^{32005}, 347-378,358-359$. 
Denken, Verhalten und Handeln der „Mitlebenden“ und somit auf unsere Gegenwart und Zukunft ein. Direkte Betroffenheit, verwandtschaftliche und freundschaftliche Eingebundenheit sowie politische Sozialisation machen die jüngere Vergangenheit für die eigene Lebenswelt ohne Zweifel bedeutsamer als etwa Karl der Große.

Eine moderne Zeitgeschichte hat folglich nicht nur die jüngere und jüngste Vergangenheit $\mathrm{zu}$ erforschen, sondern auch die Aufgabe, in sich geschlossene und daher gleichsam wie unumstößliche „Monolithe" erscheinende Geschichtsbilder aufzulösen, diese einer Reflexion zuzuführen und dem Einzelnen im Sinne „wissenschaftliche[r] Aufklärung “ ${ }^{\text {}}$ deutlich zu machen, dass das eigene Denken, Verhalten und Handel nicht völlig autonom ist, sondern von Sozialisation und Erziehung, von einem "kollektiven Gedächtnis" ${ }^{\text {" }}$ abhängt. So verstanden überschneidet sich Zeitgeschichte mit den Zielen der Politischen Bildung bzw. lässt sich mit dieser verbinden, indem drei Aspekte berücksichtigt werden:

1. Zeitgeschichte muss „Objekt" der Politischen Bildung sein, indem ihre besondere Stellung in der Geschichtswissenschaft, ihre - zum Teil durch die unmittelbare Eingebundenheit des Historikers bzw. der Historikerin in den zeitgeschichtlichen Untersuchungsgegenstand oder zumindest durch die Nähe zu diesem - noch immer die Gegenwart prägende Bedeutung analysiert wird. Dazu gehört auch die Bereitschaft des Historikers bzw. der Historikerin selbst, diese mangelnde Distanz zum zeitgeschichtlichen Untersuchungsgegenstand immer auch zu reflektieren.

2. In diesem Zusammenhang bedeutet Politische Bildung die Dekonstruktion zeitgeschichtlicher Darstellung, somit den Versuch, diese - im Sinne eines diskursanalytischen Ansatzes - im gesellschaftlichen Kontext ihrer Entstehungszeit zu betrachten. Die Vermittlung von Zeitgeschichte ist also immer mit Multiperspektivität und dem sogenannten politikdidaktischen „Überwältigungsverbot“, der im „Beutelsbacher Konsens“ von $1976^{9}$ formuliert wurde, verbunden: Die

7 Christoph Kleßmann, Zeitgeschichte als wissenschaftliche Aufklärung, in: Martin Sabrow/Ralph Jessen/Klaus Große Kracht (Hg.), Zeitgeschichte als Streitgeschichte. Große Kontroversen nach 1945, München 2003, 240-262, 250-262.

8 Jan Assmann, Kollektives Gedächtnis und kulturelle Identität, in: Jan Assmann/Tonio Hölscher (Hg.), Kultur und Gedächtnis, Frankfurt a. M. 1988, 9-19.

9 Auf einer Tagung der Landeszentrale für politische Bildung in Beutelsbach (Baden-Württemberg) im Jahr 1976, an der PolitikdidaktikerInnen unterschiedlicher parteipolitischer Coleur teilnahmen, wurden im „Beutelsbacher Konsen “ folgende Prinzipien für die politische Bildung festgelegt: 1) Überwältigungsverbot; 2) Kontroversität: alle in Wissenschaft und Gesellschaft kontrovers diskutierten Themen müssen auch im Unterricht so dargestellt werden; 3) SchülerInnenorientierung: SchülerInnen sollen befähigt werden, die politische Situation sowie die eigene Position zu analysieren, politisch zu partizipieren und die politische Lage im Sinne ihrer Interessen zu beeinflussen. 
Lehrperson darf den Schülern und Schülerinnen nicht ihre Meinung aufzwingen, sondern diese sollen in die Lage versetzt werden, sich mithilfe des Unterrichts eine eigene Meinung zu bilden.

3. Daher müssen Zeitgeschichte und Politische Bildung die Möglichkeiten bieten, eigene historisch-politische Narrationen zu kreieren und diese - so wie der Zeithistoriker bzw. die Zeithistorikerin selbst - auch immer wieder zu hinterfragen. Damit kann zur Identitätsbildung beigetragen werden, die als subjektiver Konstruktionsprozess zu verstehen ist, „, in dem Individuen eine Passung von innerer und äußerer Welt“, das heißt eine „stimmige Passung“ oder „innere Kohärenz" und somit auch "Sinn“ suchen. ${ }^{10}$ Keineswegs geht damit die Bedeutung von historischem „Wissen“, verstanden als Wissen über Fakten, Ereignisse und Personen, für das bessere Verständnis der Gegenwart und die Gestaltung der Zukunft verloren. Allerdings darf dieses Wissen nicht in eine zeithistorische „Meistererzählung“ verpackt und als solche gleichsam in die Köpfe der Lernenden „verpflanzt“ werden. Vielmehr sollen diese damit selbst Erklärungen für die Vergangenheit und Gegenwart suchen und ihre eigenen Schlüsse für die $\mathrm{Zu}$ kunft ziehen, zugleich aber diese Erklärungen und Schlüsse auch immer wieder in Frage stellen.

\section{Historisch-politische Sinnbildung}

Wird ein breiter Politikbegriff verwendet, ist Zeitgeschichte durch die beschriebene enge Verknüpfung mit der Gegenwart immer als historisch-politisch zu verstehen. Als solche bildet sie nicht nur das „Rückgrat politischer Bildung“, ${ }_{11}$ sondern einen wichtigen Bestandteil historisch-politischer Sinnbildung und muss somit in einem kulturwissenschaftlichen Kontext betrachtet werden. ${ }^{12}$

Siegfried Schiele/Herbert Schneider (Hg.), Reicht der Beutelsbacher Konsens? (Didaktische Reihe 16), Schwalbach/Ts. 1996.

10 Heiner Keupp/Thomas Ahbe/Wolfgang Gmür/Renate Höfer/Beate Mitzscherlich/Wolfgang Kraus/ Florian Straus, Identitätskonstruktionen. Das Patchwork der Identitäten in der Spätmoderne, Reinbek bei Hamburg 1999, 7.

11 Peter Steinbach, Geschichte: Vom Rückgrat politischer Bildung, in: Politische Bildung 31 (1988), 112-126.

12 Thomas Hellmuth, Wer erschlägt hier wen? Historisch-politische Bildung, in: Public History Weekly 1 (2013) 5, URL: dx.doi.org/10.1515/phw-2013-278 (abgerufen 30.03.2020); ders., Historisch-politische Sinnbildung. Geschichte - Geschichtsdidaktik - politische Bildung (Wochenschau Wissenschaft), Schwalbach/Ts. 2014. 
In diesem Zusammenhang hat in der Geschichtsdidaktik der Bewusstseinsbegriff als „psychischer Verarbeitungsmodus historischen Wissens ${ }^{\text {"13 }}$ Einzug gehalten und sich weitgehend durchgesetzt. In der Politikdidaktik findet sich der Bewusstseinsbegriff als „Bürgerbewusstsein“ dagegen nur bei Dirk Lange. Dieses „Bürgerbewusstseins" bilde "die vorgefundene politisch-gesellschaftliche Wirklichkeit [...] nicht einfach ab, sondern konstruiert Modelle [...], welche die gesellschaftlichen Strukturen und Prozesse subjektiv verständlich und erklärbar machen".14 Die Politische Bildung müsse auf dieses Bürgerbewusstsein insofern einwirken, als sie „auf Seite der Lernenden ein Höchstmaß an Autonomie und Mündigkeit zu entwickeln" habe und somit auch eine kritisch-analytische Perspektive und die „Reflexion der subjektiven Konzepte“ erlaube. ${ }^{15}$ Das Verständnis von „Bürgerbewusstseins“, das die „Reflexion“ subjektiver Konzepte und die Subjektivität bei der Analyse gesellschaftlicher Verhältnisse betont, weicht allerdings von jenem des „Geschichtsbewusstseins" partiell ab. Basierend auf fachwissenschaftlichen Überlegungen und Operationen oktroyiert nämlich Letzteres den Lernenden normative Vorgaben. Deutlich wird dieses Problem, das hier nur angedeutet werden kann, etwa bei empirischen Untersuchungen zum „historischen Denken“, wenn etwa in Aufgabenformaten danach gefragt wird, „wie man mit Vergangenheit entweder nicht umgehen darf, umgehen kann oder umgehen muss“. ${ }^{16}$ Es wird also ein „Richtig“ und ein „Falsch“ unterstellt, womit hier sind etwa auch Fragen der Inklusion mitzudenken - subjektiven Verarbeitungsmodi nur geringer Raum zugestanden und Lernende, die von der Norm abweichen, grundsätzlich als defizitär betrachtet werden. ${ }^{17}$

13 Hans-Jürgen Pandel, Geschichtsbewusstsein, in: Ulrich Mayer/Hans-Jürgen Pandel/Gerhard Schneider/Bernd Schönemann (Hg.), Wörterbuch Geschichtsdidaktik, Schwalbach/Ts. 2006, 69-70. Siehe dazu grundlegend: Jörn Rüsen, Geschichtsbewusstsein. Psychologische Grundlagen, Entwicklungskonzepte, empirische Befunde, Wien/Köln/Weimar 2001.

14 Dirk Lange, Kernkonzepte des Bürgerbewusstseins. Grundzüge einer Lerntheorie der politischen Bildung, in: Georg Weißeno (Hg.), Politikkompetenz. Was Unterricht zu leisten hat (Schriftenreihe der Bundeszentrale für politische Bildung 645), Bonn 2008, 245-258, 247-248.

15 Dirk Lange, Konzepte als Grundlage der politischen Bildung. Lerntheoretische und fachdidaktische Überlegungen, in: Autorengruppe Fachdidaktik (Hg.), Konzepte der politischen Bildung. Eine Streitschrift, Schwalbach/Ts. 2011, 95-109.

16 Ulrich Trautwein/Christiane Bertram/Bodo von Borries/Nicola Brauch/Matthias Hirsch/Kathrin Klausmeier/Andreas Körber/Christoph Kühberger/Johannes Meyer-Hamme/Martin Merkt/ Herbert Neureiter/Stephan Schwan, Kompetenzen historischen Denkens erfassen. Konzeption, Operationalisierung und Befunde des Projekts „Historical Thinking - Competencies in History“ (HiTCH), Münster/New York 2017, 66.

17 Bärbel Völkel konstatiert sogar eine Verbindung zwischen Geschichtsbewusstsein und Geschichtskultur im Allgemeinen, verortet den Begriff im Historismus und befürchtet, dass mit seiner Verwendung nationale bzw. kollektive Identität angestrebt und Ethnozentrismus generiert würden. 
Unbestritten bleibt freilich, dass die zahllosen Eindrücke, die auf das Individuum von außen einwirken, sowie die damit verbundenen Erfahrungen besser verarbeitet bzw. „rund(er)“ gemacht werden können, wenn sie - unter anderem mithilfe von Narrationen ${ }^{18}$ - in miteinander verknüpften Vorstellungen von Vergangenheit, Gegenwart und Zukunft eingebettet werden. Zum einen beschäftigen sich die Geschichtsdidaktik und die Politische Bildung also damit, die Konstruktion von notwendigen Sinnzusammenhängen zu ermöglichen, zumal der Einzelne sich nur dadurch in der Welt, die im Grunde fragmentiert und nicht als Ganzes zu erfassen ist, zurechtfinden kann. Zum anderen sollte diese Konstruktion, dieser Versuch, die Welt kohärent zu machen, aber immer auch reflektiert, weiterentwickelt und gegebenenfalls auch revidiert werden. Dadurch wird es auch möglich, die Positionen der anderen nachzuvollziehen, zu akzeptieren und auf diese adäquat - gleichsam im Sinne der Habermas'schen Theorie des kommunikativen Handelns ${ }^{19}$ - zu reagieren. Nur auf diese Weise kann am „offenen Diskurs“ partizipiert werden, der als Austausch unterschiedlicher Meinungen und Konsenssuche, aber auch als Überschreitung von Normen und Regeln, die nicht mehr zeitgemäß sind und die individuelle Freiheit einengen, definiert werden kann. ${ }^{20}$ In den folgenden fachdidaktischen Überlegungen soll daher nicht auf den Bewusstseinsbegriff zurückgegriffen, sondern - wie dem Konzept des „Bürgerbewusstseins“ implizit - der Begriff des „selbstreflexiven Ich“ verwendet werden.

Damit ist letztlich die Brücke von der (Zeit)Geschichte zur Politischen Bildung vollends hergestellt: Das „selbstreflexive Ich“ strebt einen Ausgleich zwischen den individuellen Bedürfnissen und dem kollektiv geltenden Regeln- und Normensystem an. Misslingt dieser Ausgleich, entwickelt der Einzelne entweder einen „egozentrischen Widerstand“ oder strebt eine weitgehende Anpassung an gesellschaftliche Vorgaben an, die als „subordinierende Anpassung“ bezeichnet werden kann. Um das Spannungsverhältnis zwischen Individuum und gesamtgesellschaftlicher Struktur aufzulösen, also ein „selbstreflexives Ich“ zu ermöglichen, sind vier individuelle Ziele anzustreben: Emanzipation, Autonomie, Kritikfähigkeit und Partizipation.

Bärbel Völkel, Subjektorientierte Geschichtsdidaktik. Überlegungen zu einem uneinheitlichen Begriff, in: Heinrich Ammerer/Thomas Hellmuth/Christoph Kühberger (Hg.), Subjektorientierte Geschichtsdidaktik, Schwalbach/Ts. 2015, 73-91.

18 Zur historischen Erzählung siehe u. a: Michele Barricelli, Schüler erzählen Geschichte. Narrative Kompetenz im Geschichtsunterricht (Forum Historisches Lernen), Schwalbach/Ts. 2005; dies., Narrativität, in: Mayer/Pandel/Schneider/Schönemann (Hg.), Wörterbuch Geschichtsdidaktik, 135-136.

19 Jürgen Habermas, Theorie des kommunikativen Handelns, 2 Bde., Frankfurt a. M. 1988.

20 Zum „offenen Diskurs" siehe: Hellmuth, Historisch-politische Sinnbildung, 28-29; Thomas Hellmuth, Frankreich im 19. Jahrhundert. Eine Kulturgeschichte, Wien/Köln/Weimar 2020, 22-26. 
selbstreflexives Ich

individuelle Bedürfnisse

Normen und Regeln

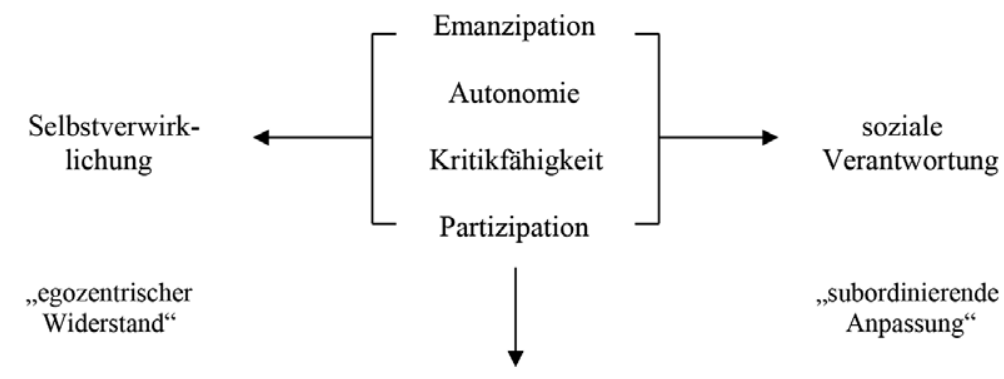

$$
\begin{aligned}
& \text { Selbstverwirklichung } \\
& \text { im Sinne sozialer } \\
& \text { Verantwortung } \\
& \text { Mitgestalten } \\
& \text { nach bestimmten } \\
& \text { Regeln } \\
& \text {,demokratischer } \\
& \text { Widerstand“ } \\
& \text { im Sinne des } \\
& \text { "offenen Diskurses“ bzw. } \\
& \text { der Multiperspektivität }
\end{aligned}
$$

Abb. 1: Das „selbstreflexive Ich“ (Quelle: Thomas Hellmuth, Das „selbstreflexive Ich“. Politische Bildung und kognitive Struktur, in: Ders. (Hg.), Das „selbstreflexive Ich“. Beiträge zur Theorie und Praxis politischer Bildung, Innsbruck/Wien/Bozen 2009, S. 17.)

Mit Emanzipation ist der Versuch gemeint, sich von den „Fesseln“ der Sozialisation $\mathrm{zu}$ befreien, indem diese kritisch reflektiert und bewusst gemacht werden. Wenn sich auch der Einzelne den gesellschaftlichen Einflüssen nicht völlig entziehen kann, ist auf diese Weise individuelle Autonomie zumindest zum Teil möglich. Kritikfähigkeit meint wiederum die Fähigkeit, auf rationaler Basis über die Sinnhaftigkeit der eigenen Bedürfnisse und Interessen, aber auch jener der anderen in Bezug auf die Gemeinschaft zu urteilen, das heißt darüber zu urteilen, ob sie die Freiheit des anderen nicht einschränken und somit auch nicht das gesamtgesellschaftliche Wohl gefährden. Nur auf der Basis der individuellen Emanzipation und Autonomie sowie der Kritikfähigkeit ist schließlich die Partizipation an gesellschaftlichen Entscheidungsprozessen möglich und damit auch der Erhalt und die Fortentwicklung einer 
demokratischen politischen Kultur. ${ }^{21}$ Letztlich sind alle diese Ziele unter anderem infolge historisch-politischen Lernens zu erreichen, durch das Hinterfragen von Geschichtsbildern und ihrer Funktionen, das heißt durch die kritische Analyse von Geschichtskultur und Geschichtspolitik sowie durch die Entwicklung individueller, an die eigene Lebenswelt gebundener Vorstellungen von Vergangenheit, Gegenwart und Zukunft.

\section{Eine Didaktik historisch-politischer Sinnbildung}

Es gibt zahlreiche Versuche, Geschichte bzw. Geschichtsdidaktik und Politische Bildung miteinander zu verbinden, ${ }^{22}$ wobei sich die meisten auf ein Nebeneinander beider Didaktiken bzw. wissenschaftlichen Disziplinen ${ }^{23}$ oder auf die Bestimmung von Überschneidungsbereichen konzentrieren. Im ersteren Fall hat der Geschichtsunterricht eine vorbereitende oder eine ergänzende Funktion für die Politikdidaktik. Im zweiten Fall scheinen die beiden Disziplinen eher gleichberechtigt nebeneinander positioniert: Karl-Ernst Jeismann hat etwa das Verhältnis der beiden Disziplinen als zwei einander überschneidende Kreise beschrieben, zumal beide „gleichermaßen auf den Erwerb von Kompetenzen“ abzielten, „sich in Gegenwart und Zukunft unserer Welt zuverlässig zu orientieren und verantwortlich zu verhalten“. ${ }^{24}$ Weiterhin werden damit, nicht zuletzt wohl auch infolge eines traditionellen Professionsdenkens, die beiden Disziplinen voneinander abgegrenzt. Denn wenn die Überschneidungsbereiche das „Feld ihrer Zusammenarbeit“ bilden, muss es auch einen „,von diesem Überschneidungsbereich abzugrenzenden geschichts- beziehungsweise

21 Thomas Hellmuth, Das „selbstreflexive Ich“. Politische Bildung und kognitive Struktur, in: ders. (Hg.), Das „selbstreflexive Ich“. Beiträge zur Theorie und Praxis politischer Bildung, Innsbruck/ Wien/Bozen 2009, 16-18.

22 Hellmuth, Historisch-politische Sinnbildung, 187-195.

23 Politische Bildung hat sich mit der "didaktischen Wende" in den 1960er-Jahren von ihren Mutterdisziplinen, der Politik- und der Rechtswissenschaft, emanzipiert und versteht sich seitdem als eigene politische Disziplin. Bei der Geschichtsdidaktik scheiden sich die Geister: Zum einen wird sie als eine Dimension der Geschichtswissenschaft betrachtet, zum anderen aber auch als eigene wissenschaftliche Disziplin, zumal Beziehungen zur Pädagogik, Psychologie und den Sozialwissenschaften bestehen. Siehe dazu u. a.: Wolfgang Sander, Politik in der Schule. Kleine Geschichte der politischen Bildung in Deutschland, Marburg 2004, 136; Thomas Hellmuth/Cornelia Klepp, Politische Bildung. Geschichte - Modelle - Praxisbeispiele (UTB 3222), Wien/Köln/Weimar 2010, 60-61; Joachim Rohlfes, Geschichtsunterricht und Geschichtsdidaktik, Göttingen ${ }^{32005}$, 17, 23; Hellmuth, Historisch-politische Sinnbildung, 308.

24 Karl-Ernst Jeismann, Thesen zum Verhältnis von Politik im Geschichtsunterricht, in: Geschichte in Wissenschaft und Unterricht 43 (1993) 9, 557-569, 560. 
politikspezifischen Bereich“ ${ }^{25}$ geben. Deutlich wird diese gegenseitige Abgrenzung auch am Beispiel der gängigen Kompetenzorientierung, bei der - wenn überhaupt lediglich Überschneidungsbereiche formuliert werden. Überlegungen zur Entwicklung eines eigenen historisch-politischen Kompetenzmodells sind bislang - mit wenigen Ausnahmen ${ }^{26}$ - nicht festzustellen. Dies ist insbesondere mit dem noch immer stark ausgeprägten Professionsdenken und der damit verbundenen gegenseitigen Abgrenzung der Geschichts- und Politikdidaktik verbunden.

Historische und politische Kompetenzmodelle erweisen sich aber auch aufgrund ihrer Trennung von „Wissen“ und „Kompetenzen“ als partiell problematisch. Damit besteht die Gefahr, dass der Unterricht an der Oberfläche verharrt, nicht zuletzt weil im Gefolge der Kompetenzvermittlung die traditionelle Vermittlung von „Wissen“, die sich oft im Auswendiglernen und Abprüfen von Fakten sowie der Vermittlung von „Meistererzählungen“ erschöpfte, ohne Zweifel und nicht ganz zu Unrecht in ein schiefes Licht geraten ist. Unterricht in (Zeit)Geschichte und Politischer Bildung kann eben nicht nur, wie bereits oben deutlich gemacht, die Vermittlung und das Auswendiglernen von Inhalten sein. Allerdings bedeutet Lernen in der Lernpsychologie die Aufnahme von Informationen, deren Verarbeitung und Speicherung im Gedächtnis sowie deren Anwendung und Nutzung. Dieses komplexe Ergebnis von Lernprozessen wird in seiner Gesamtheit als „Wissen“ bezeichnet. ${ }^{27}$ Ein solch breiter Wissensbegriff unterscheidet sich folglich von jenem, der in den Kompetenzmodellen verwendet wird. Im Folgenden soll daher ein didaktisches Modell historisch-politischer Sinnbildung ${ }^{28}$ präsentiert werden, das sich auf einen lernpsychologischen Wissensbegriff bezieht und eine künstliche Trennung von „Wissen“ und „Kompetenzen" vermeidet (Abb. 2).

Bei diesem Modell wird zwischen drei Formen von „Wissen“ unterschieden: zwischen metakognitivem Wissen, strategischem Wissen und domänenspezifischem

25 Peter Massing, Zeitgeschichte als Rückgrat der Politischen Bildung?, in: Michele Barricelli/Julia Hornig (Hg.), Aufklärung, Bildung, „Histotainment“? Zeitgeschichte in Unterricht und Gesellschaft heute, Frankfurt a. M./Berlin/Bern/Bruxelles/New York/Oxford/Wien 2008, 67-84, 70.

26 Thomas Hellmuth, Politische Bildung als historisch-politische Sinnstiftung: Überlegungen zu einem historisch-politischen Kompetenzmodell, in: Österreichische Zeitschrift für Politikwissenschaft 38 (2009) 4, 493.

27 Roland Arbinger, Psychologie des Problemlösens. Eine anwendungsorientierte Einführung, Darmstadt $1997,17-45$.

28 Dabei handelt es sich um die Weiterentwicklung und partielle Vereinfachung eines bereits bestehenden Modells historisch-politischer Sinnbildung: Hellmuth, Historisch-politische Sinnbildung, 196-209; ders., Eine „liaison dangereuse“? Der Unterricht in Geschichte und Politischer Bildung als historisch-politische Sinnstiftung, in: ders. (Hg.), Politische Bildung im Fächerverbund, Schwalbach/Ts. 2017, 34-42. 
Wissen. ${ }^{29}$ Metakognitives Wissen beschreibt das Wissen über den eigenen Wissenserwerb, somit also die Fähigkeit zur Selbstreflexion. Unter strategischem Wissen werden „allgemeine Prozeduren“30 verstanden, die nicht nur domänenspezifisch von Bedeutung sind. Dazu zählen etwa allgemeine Problemlösungsstrategien, Lernstrategien oder Textzugänge und semantische Regeln der Textproduktion. Domänenspezifisches Wissen, also Wissen zur Geschichte, Politik und zum Recht, unterteilt sich schließlich in deklaratives und prozedurales Wissen. Ersteres meint isoliertes Wissen über Fakten, Ereignisse oder Namen (episodisches Wissen) sowie deren Verknüpfung zu größeren Zusammenhängen (semantisches Wissen). Um dieses semantische Wissen zu ermöglichen, bedarf es neben dem allgemeinen strategischen Wissen auch prozeduralen Wissens, etwa bestimmter Kategorien und Begriffe, Denkoperationen und Methoden.

Ein (zeit)geschichtliches Beispiel soll diese Wissensformen und die ihnen impliziten Zusammenhänge verdeutlichen: Ein Zeitungsartikel über Eugenik aus dem beginnenden 20. Jahrhundert mag in der Gegenwart möglicherweise Verwunderung wecken, weil darin bereits rassistische Argumente formuliert werden, die sich in der nationalsozialistischen Ideologie finden. Ebenso lassen sich vielleicht die kulturfundamentalistischen Positionen der Neuen Rechten, die etwa die Bewegung der Identitären vertritt, nicht so recht in den traditionellen Rassismus, der auf einem biologistischen Fundament beruht, einordnen. Damit ist ein „klassischer“ Fall von episodischem Wissen umschrieben: Es ist bekannt, dass Rassismus ein zentraler Bestandteil der nationalsozialistischen Ideologie war, wie sich Rassismus definiert und dass daher im genannten Zeitungsartikel rassistische Ressentiments zu finden sind. Ebenso wird der Kulturfundamentalismus der Identitären als Ab- und Ausgrenzungsinstrumentarium identifiziert und intuitiv dem Rassismus zugeordnet. Eine Zusammenführung der einzelnen Wissensfragmente zu semantischem Wissen gelingt aber letztlich nicht, weil weiteres Kontextwissen fehlt. Zu diesem Kontextwissen gehört ein im Rationalismus der Aufklärung verankerter Widerspruch: Mithilfe von Beobachtungen und Messungen wurden Unterschiede zwischen Menschen und Tieren, aber auch zwischen Menschen - aus heutiger Perspektive - pseudowissenschaftlich argumentiert und in hierarchisierenden Kategorien verankert. Ferner setzte die Aufklärung vermeintlich biologisch begründbare Unterschiede von Menschen mit ästhetischen Merkmalen in Verbindung, indem sie auf die Antike zurück-

29 Arbinger, Psychologie des Problemlösens, 17-45. Auf die Geschichtsdidaktik bezogen finden sich diese Wissensformen bei: Hilke Günther-Arndt, Historisches Lernen und Wissenserwerb, in: dies. (Hg.), Geschichtsdidaktik. Praxishandbuch für die Sekundarstufe I und II, Berlin 2003, 39; Hellmuth, Historisch-politische Sinnbildung, 168-171, 200-209.

30 Arbinger, Psychologie des Problemlösens, 26. 
griff, die gleichsam als Geburtsort der bürgerlichen Gesellschaft gefeiert wurde. ${ }^{31}$ Die Aufklärung verglich dabei - wie der Soziologe Zygmunt Bauman betont - die neu zu erschaffende Gesellschaft mit einem idealen Garten. ${ }^{32}$ „Man bildet Pflanzen durch Pflege, Menschen durch Erziehung", schreibt etwa Rousseau, ${ }^{33}$ womit er implizit auch auf die Tilgung von schädlichen Einflüssen, von „Unkraut“, hinweist. Die Eugenik und schließlich auch die Nationalsozialisten, deren Weltbild aus unterschiedlichen ideologischen Versatzstücken gleichsam zusammengewürfelt war, ${ }^{34}$ sollten darauf in besonders radikaler Weise zurückgreifen. Nachdem schließlich die Genforschung die biologische Begründung von Rassismus widerlegt hatte und die "Rassenlehre" nicht zuletzt aufgrund des Holocaust desavouiert worden war, griff die Neue Rechte auf kulturfundamentalistische Positionen der Ab- und Ausgrenzung zurück. Dieser Kulturfundamentalismus, den Pierre-André Taguieff als „differenziellen Rassismus" bezeichnet, ${ }^{35}$ betrachtet zwar alle Kulturen - zumindest in der offiziellen Diktion - als gleichwertig, allerdings als nicht miteinander kompatibel. Ihre Vermischung führe daher unweigerlich zu sozialen und kulturellen Konflikten, weshalb MigrantInnen gar nicht erst ins Land gelassen werden sollten. Ein solcher Kulturbegriff ist freilich ein statischer, und die eigene Kultur wird als eine in der "Heimat" gewachsene verortet, womit wiederum ein biologisches Moment Eingang in den Kulturbegriff findet. Dabei wird auf Maurice Barrès, der in den 189oer-Jahren die „Erde und die Ahnen“, „la terre et les morts“, beschwor, ${ }^{36}$ Bezug genommen. Erfahrung und Traditionen würden laut Barrès über das Nervensystem vererbt. Somit gingen Biologie und Kultur in Form generationsübergreifender Erfahrung gleichsam Hand in Hand. Um ein solches semantisches Wissen zu erlangen, bedarf es freilich strategischen und prozeduralen Wissens, etwa allgemeiner Denkstrategien, die episodisches Wissen in größere Kontexte einzuordnen erlauben, oder der Fähigkeit, Konzepte, Kategorien oder Schemata nicht nur abzurufen, sondern mit diesen auch umzugehen und diese weiterzuentwickeln. Neben dem prozeduralen und strategischen Wissen hat im Übrigen auch vorhandenes semantisches Wissen gleichsam methodische Funktion, weil es durch die vorhandenen Strukturen, die bereits eine

31 George L. Mosse, Die Geschichte des Rassismus in Europa, Frankfurt a. M. 1990, 29.

32 Zygmunt Bauman, Moderne und Ambivalenz. Das Ende der Eindeutigkeit, Hamburg 1992, 35-36.

33 Jean-Jacques Rousseau, Émile ou de l'éducation (Collection Folio/Essais), Paris 1999 [Erstausgabe 1762], 9.

34 Helmut Auerbach, Nationalsozialismus vor Hitler, in: Wolfgang Benz/Hans Buchheim/Hans Mommsen (Hg.), Der Nationalsozialismus. Studien zur Ideologie und Herrschaft, Frankfurt a. M. 1993, 13-28; Martin Broszat, Der Nationalsozialismus. Weltanschauung, Programm und Wirklichkeit, Stuttgart 1960, 21.

35 Pierre-André Taguieff, La force du préjugé. Essai sur le racisme et ses doubles, Paris 1987.

36 Maurice Barrès, Scène et doctrines du nationalisme, Paris [um 1895], 88. 
Vernetzung von episodischem Wissen gewährleisten, die Möglichkeiten vorgibt, wie weitere Einzelinformationen kognitiv verarbeitet werden können. Es zeigt sich, dass eine klare Trennung sowohl von „Wissen“ und „Kompetenzen“ als auch von einzelnen Kompetenzdomänen, wie dies die Kompetenzmodelle versuchen, kaum möglich ist.

Semantisches Wissen erlaubt es den Lernenden, unterschiedliche historische und politische Phänomene in einem Zusammenhang zu bringen und auch mit der Gegenwart in Verbindung zu setzen. Historisch-politische Sinnbildung muss aber semantisches Wissen auch mit den Lebenswelten der Lernenden verknüpfen. Nur durch den Gegenwarts- und Lebensweltbezug lässt sich schließlich - ein zentraler Aspekt für die Politische Bildung - die Basis für zukünftige Handlungsoptionen schaffen. Das hier vorgestellte Modell historisch-politischer Sinnbildung (Abb. 2) unterscheidet daher zwischen Objekt- und Subjektebene und berücksichtigt somit explizit die Lebenswelt von Lernenden. Die Objektebene bezieht sich demnach auf die "Sachlogik“ und umfasst fachspezifische Inhalte und Themen sowie Fakten und Begriffe, ferner die in Lehr- und Lernprozessen anzuwendenden Methoden und Medien. Die „Subjektebene“ beruht dagegen auf der „Lernlogik“, setzt folglich neben die Rationalität auch Emotionen und verbindet kognitive Prozesse mit Aktivität. Mit anderen Worten: Für die Lernenden ist die Vergangenheit und (politische) Gegenwart auf der Objektebene inhaltlich - freilich nicht vollständig, wie ja in der Einleitung betont wurde - über Quellen und bereits vorhandene Darstellungen zugänglich. Allerdings graben die Lernenden aus der „Schutthalde“ der Vergangenheit und der Gegenwart nur jene „Steine“ aus, die für sie brauchbar bzw. sinnstiftend sind. Sie fügen diese - geleitet von den Bedürfnissen und emotionalen Beweggründen, die auf der Subjektebene angesiedelt sind, und im Kontext des bereits verfügbaren semantischen Wissens - aneinander und schaffen ein ständig erweiterbares „Wissensgebäude“. Es liegt nahe, dass dem Lernenden eher zeitlich nahestehende und möglicherweise selbst miterlebte Ereignisse der Vergangenheit, also Zeitgeschichte, auf der Subjektebene tangieren können: Weniger die Bemühungen von Friedrich Barbarossa, dem Kaisertum neuen Glanz zu verleihen und die kaiserliche Autorität in Italien durchzusetzen, wird die Emotionen und Interessen der SchülerInnen wecken als vielmehr die Erzählungen der Großmutter über die Sozialreformen in der Ära Kreisky.

Als Bindeglied zwischen der Objekt- und Subjektebene dienen die oben vorgestellten Wissensformen, die durch handlungs- und prozessorientierte Unterrichtsmethoden gefördert werden sollen. Der traditionelle Unterricht im Sinne einer „Nürnberger-Trichter-Didaktik“, die Lernende als passiv und gewissermaßen als 
Objektebene

Subjektebene

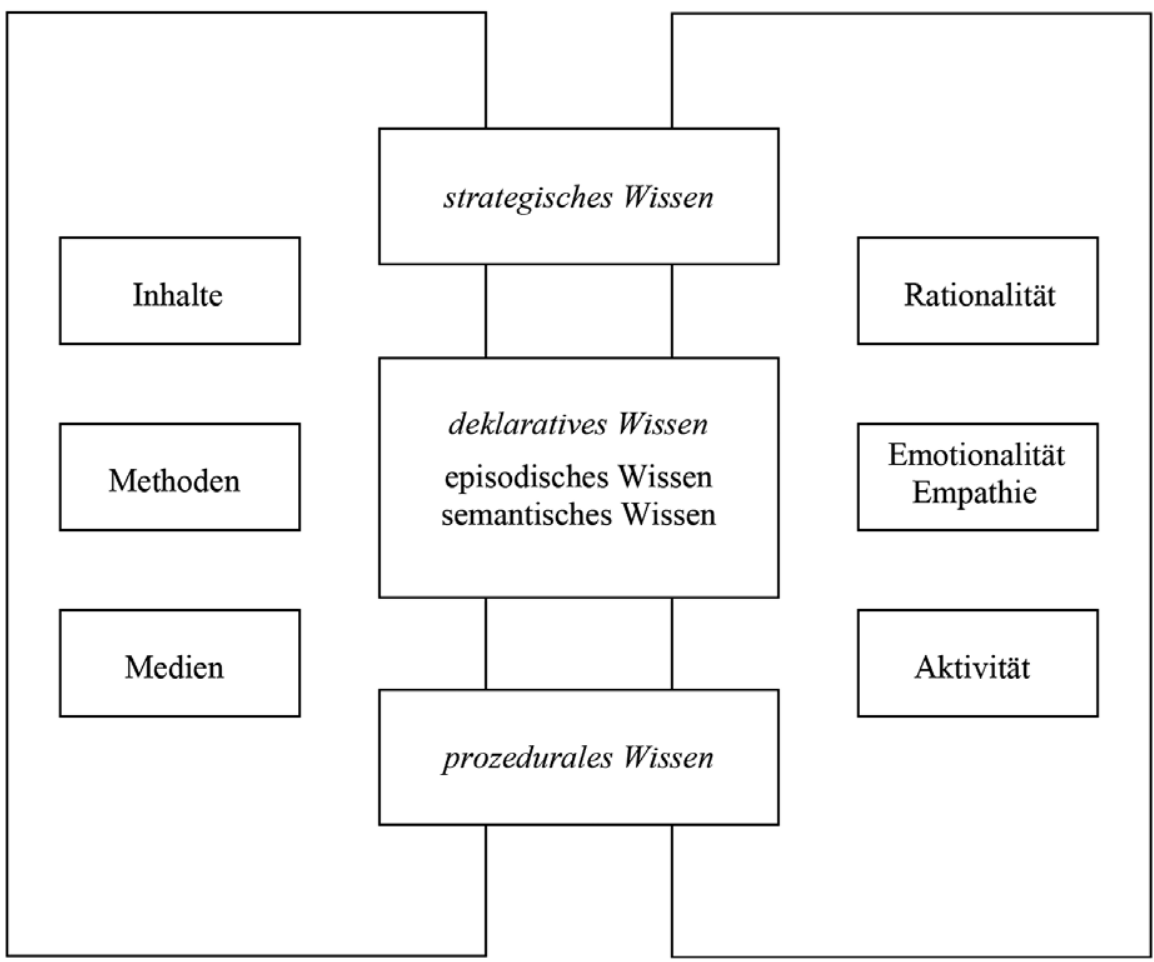

Sachlogik

Lernlogik

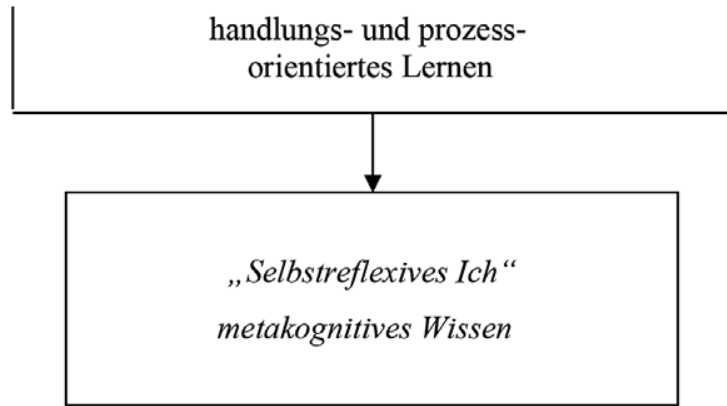

Abb. 2: Ein Modell historisch-politischer Sinnbildung (Quelle: Thomas Hellmuth, Historisch-politische Sinnbildung. Geschichte-Geschichtsdidaktik-politische Bildung, Schwalbach/Ts. 2014, S. 202). 
„Schülermaterial“ 37 betrachtet, das nach den Vorstellungen der Lehrenden geformt werden könne, wird somit von einem „interpretativen Paradigma einer wechselseitigen Verständigungsbemühung “38 abgelöst. Einfach ausgedrückt bedeutet dies, dass die SchülerInnen - immer auch im Sinne eines „Beziehungslernens“ ${ }^{39}$ und somit in Kommunikation mit den anderen - individuelle, an ihren Lebenswelten orientierte Lernwege und Lösungen suchen und finden. Ziel historisch-politischer Sinnbildung ist es folglich nicht, „kleine“ (Zeit)HistorikerInnen auszubilden, sondern den Lernenden zu helfen, sich in ihren Lebenswelten besser zurechtzufinden und zu diesem Zweck ein „selbstreflexives Ich“ zu entwickeln.

Um das oben erwähnte Beispiel des Rassismus wieder aufzugreifen: Selbstverständlich bedeutet historisch-politisches Lernen, Rassismus definieren zu können und etwa über dessen Auswirkung in der Zeit des Nationalsozialismus Bescheid zu wissen. Es soll aber auch in die Lage versetzen, Rassismus in der eigenen Lebenswelt und die damit verbundenen Gefahren für eine demokratische Gesellschaft zu erkennen, eigene Voraus- und Vorurteile zu hinterfragen und zu verwerfen, sowohl die persönlichen als auch die gemeinschaftlichen Vorteile einer pluralistisch verfassten Gesellschaft zu erkennen und für diese einzutreten. Manchmal wird zwar in diesem Zusammenhang die Kritik geäußert, dass hier letztlich ja nur eine Form „demokratischer Indoktrination“ angestrebt und somit dem „Beutelsbacher Konsens“ widersprochen werde. Tatsächlich steht aber eine Politische Bildung, die Demokratiebildung inkludiert, jeglicher Form von Indoktrination diametral gegenüber, zumal sie Vielfalt und Multiperspektivität anstrebt und fördert. Demokratie braucht den Konflikt, den Austausch unterschiedlicher Argumente und Meinungen (freilich unter der Voraussetzung, dass diese den „offenen Diskurs“ unter dem Vorwand demokratischer Meinungsfreiheit nicht selbst in Frage stellen). Zeitgeschichte ist somit nicht nur als eine Basis oder ein „Rückgrat“ der Politischen Bildung zu verstehen. Beide ergänzen einander und sind im kulturwissenschaftlichen Kontext als historisch-politische Sinnbildung zu betrachten.

37 Der Begriff des „Schülermaterials“ war vor allem im 19. Jahrhundert im Zusammenhang mit didaktischen Überlegungen üblich, wurde aber auch noch im 20. Jahrhundert verwendet. Siehe dazu: Thomas Hellmuth, Zwischen Freiheit und Herrschaft. Bildung und Schule in der bürgerlichen Gesellschaft, in: Elisabeth Loinig/Oliver Kühschelm/Willibald Rosner/Stefan Eminger (Hg.), Niederösterreich im 19. Jahrhundert, Bd. 2, St. Pölten, S. 781 (in Vorbereitung, erscheint im Frühjahr 2021).

38 Ortfried Schäffter, Lebensweltorientierung, in: Klaus-Peter Hufer (Hg.), Lexikon der politischen Bildung, Bd. 2, Schwalbach/Ts. 22003, 156-158, 158.

39 Bärbel Völkel, Inklusive Geschichtsdidaktik. Vom inneren Zeitbewusstsein zur dialogischen Geschichte, Schwalbach/Ts. 2017, 152. 


\section{Zeitgeschichte und Geschichtsunterricht}

Christoph Kühberger

\section{Annäherung}

Um den Stellenwert bestimmen zu können, den Zeitgeschichte als Epoche und Diskurs im österreichischen Geschichtsunterricht einnimmt, wird zunächst eine knappe Positionierung der Geschichtsdidaktik als Fachdisziplin vorgenommen. Anschließend wird auf die Konzeption von Zeitgeschichte als epochales Konzept eingegangen. Eine strukturelle Analyse der österreichischen Lehrpläne der Sekundarstufe I von 1955 bis 2016, die Frage nach der selektiven Wahrnehmung von Zeitgeschichte sowie Einblicke zum Umgang mit dem Bereich Nationalsozialismus und Holocaust führen vertiefend in Entwicklungsstränge des österreichischen Geschichtsunterrichtes ein, abschließend wird ein Ausblick auf die Herausforderungen in einer post-postmodernen Gesellschaft gegeben.

\section{Geschichtsdidaktik als Leitdisziplin}

Die wissenschaftliche Auseinandersetzung mit dem Geschichtsunterricht, seinen Zielen, Medien und Realitäten wird im Kanon der deutschsprachigen Wissenschaftsdisziplinen weitgehend der Geschichtsdidaktik als Teil der Geschichtswissenschaften überlassen. Dabei handelt es sich um eine relativ junge Teildisziplin, die sich vor allem im Nachlauf zu „1968“ in Österreich als Teilbereich der Geschichtswissenschaft langsam etablierte und sich durch die Beforschung des „Geschichtsbewusstseins in der Gesellschaft“ (Karl-Ernst Jeismann) stabilisierte. ${ }^{1}$ Um den wissenschaftlichen Anspruch der geschichtsdidaktischen Auseinandersetzung im 21. Jahrhundert in Österreich verstehen zu können, muss man die enge Verwobenheit der drei „Dimensionen der Geschichtswissenschaft“ (Geschichtsforschung,

1 Vgl. Christoph Kühberger, Kann man fachspezifisches Denken nachweisen? Etablierungsphasen der empirischen Forschung und aktuelle Tendenzen in der Geschichtsdidaktik, in: Bettina Bussmann/Markus Tiedemann (Hg.), Lebenswelt und Wissenschaft (Jahrbuch für Didaktik der Philosophie und Ethik 19), Dresden 2018, 29-40, 30. 
Theorie der Geschichtswissenschaft und Didaktik der Geschichte) nachvollzogen haben. ${ }^{2}$ Anerkennung genießt die Disziplin im tertiären Bereich aber vor allem durch ihre theoretische Begründung, die pragmatische Umsetzung und empirische Beforschung von historischem Lernen in der Schule. Daher definiert Nicola Brauch:

Geschichtsdidaktik erforscht das Geschichtsbewusstsein der Gesellschaft und korreliert den Befund mit den Ergebnissen geschichtswissenschaftlicher Forschung mit dem Erkenntnisziel, relevantes Orientierungswissen des Faches für die Gesellschaft zu identifizieren und in lernpsychologisch angemessener Weise den Rezipienten historischer Erzählungen im Alltag aufzubereiten und so den Mitgliedern der Gesellschaft die Ausprägungen eines reflektierten Geschichtsbewusstseins zu ermöglichen. ${ }^{3}$

Eine derartige Positionierung der Geschichtsdidaktik hat aber auch unmittelbare Auswirkungen auf den Geschichtsunterricht und die dort anvisierten Ziele. Galt Geschichtsunterricht lange Zeit als Ort der Weitergabe von stabil geglaubten Wissensinhalten über die Vergangenheit, an dem die Lehrperson kunstfertig als zentral erachtete Episoden in gute Erzählungen zu verpacken hatte und so historiographische Minima - meist über die eigene Nation - an die nächste Generation weitergeben sollte, ${ }^{4}$ kann man heute im deutschsprachigen Raum und insbesondere auch in Österreich den Erwerb von kritischem historischen Denken als normative Zielvorstellung erkennen. ${ }^{5}$

2 Vgl. Ernst Weymars, Dimensionen der Geschichtswissenschaft. Geschichtsforschung - Geschichtstheorie - Geschichtsdidaktik, in: GWU 33 (1982) 1-3, 1-11, 65-78, 129-153.

3 Nicola Brauch, Geschichtsdidaktik, Berlin 2015, 311.

4 Vgl. den Beitrag des österreichischen Geschichts- und Deutschdidaktikers Linke: Karl Linke, Der erzählende Geschichtsunterricht, Braunschweig/Hamburg 1914, 192.

5 Vgl. Andreas Körber/Waldtraud Schreiber/Andreas Schöner (Hg.), Kompetenzen historischen Denkens. Ein Struktur-Modell als Beitrag zur Kompetenzorientierung in der Geschichtsdidaktik, Neuried 2007; Michael Sauer, „Historisches Denken“ fördern. Kompetenzentwicklung im Geschichtsunterricht, in: Friedrich Jahresheft XXV (2007), 42-45; Bodo von Borries, Historisch Denken Lernen. Opladen 2008; Christoph Kühberger, Kompetenzorientiertes historisches und politisches Lernen. Methodische und didaktische Annäherungen an Geschichte, Sozialkunde und politische Bildung, Innsbruck/Wien 2009; Kadriye Ercikan/Peter Seixas (Hg.), New directions in assessing historical thinking, New York 2015; Ulrich Trautwein/Christiane Bertram/Bodo von Borries/Nicola Brauch/Matthias Hirsch/Kathrin Klausmeier/Andreas Körber/Christoph Kühberger/Johannes Meyer-Hamme/Martin Merkt/Herbert Neureiter/Stephan Schwan u. a., Kompetenzen historischen Denkens erfassen. Konzeption, Operationalisierung und Befunde des Projektes „Historical Thinking in History“ (HiTCH), Münster/New York 2017, 20-25. 


\section{Zeitgeschichte als epochales Konzept im Geschichtsunterricht}

Was man unter Zeitgeschichte im Geschichtsunterricht versteht, wird oft vorausgesetzt und nicht explizit in normativen Vorgaben der Bildungsbehörden thematisiert. Die Geschichtsdidaktik diskutiert diesen Zeitabschnitt im Kontext der geschichtswissenschaftlichen Auseinandersetzungen. Man darf dabei durchaus die von Martin Sabrow getätigte Beobachtung aus 2012 noch teilen, dass sich eine „Neujustierung der Zeitgeschichte in einem undefinierten Zustand " ${ }^{\text {" }}$ befinde und andere Varianten (wie zum Beispiel "Geschichte des 20. Jahrhunderts“ oder "Contemporary History") besser geeignet scheinen, um das historiographische Phänomen zu definieren. Die im deutschsprachigen Raum traditionell herangezogene Definition von Hans Rothfels, wonach Zeitgeschichte als Epoche im Jahr 1917 beginne, wird teilweise auch heute noch verwendet. Sie ignoriert aber die bereits damals artikulierte Intention nach einer notwendigen Verschiebung dieser Grenze im Sinne der „Epoche der Mitlebenden "7. Während in Deutschland eine Verschiebung der epochalen Einteilung aufgrund der staatsgeschichtlichen Ereignisse um 1989/1990 stattfand bzw. stattfindet, muss man für Österreich auch heute noch den provokanten Einwurf von Ernst Hanisch aus dem Jahr 2001 zitieren, wonach „die Geschichte der Zweiten Republik nur eine Geschichte der unaufgearbeiteten österreichischen NS-Vergangenheit" sei, wodurch eine fragmentierte österreichische Zeitgeschichte mit einem Hauptfokus auf die Zeit zwischen 1938 und 1945 zutage trete. ${ }^{8}$ Wenngleich sich in der Forschungs- und Publikationspraxis ein durchaus differenzierteres Bild zeigt ${ }^{9}$ und auch verschiedene geschichtswissenschaftliche Publikationen versuchen, die Zeitgeschichte nicht in der Diktatur einzufrieren,${ }^{10}$ kristallisieren sich keine anderen

6 Martin Sabrow, Die Zeit der Zeitgeschichte, Göttingen 2012, 7.

7 Vgl. Hans Rothfels, Zeitgeschichte als Aufgabe, in: Vierteljahreshefte für Zeitgeschichte 1 (1953), $1-8$.

8 Werner Suppanz, Österreichischer Zeitgeschichtetag 2001, 04.-06.10.2001 in Klagenfurt, Demokratie - Zivilgesellschaft - Menschenrechte. Ein Kommentar, in: eForum zeitGeschichte 2001/3-4, URL: http://www.eforum-zeitgeschichte.at/3_01a1.html (abgerufen 12.08.2019).

9 Jiří Pešek/Nina Lohmann/Oliver Rathkolb/Jan Horský/Thomas Walter/Jan Serých, Zeitgeschichte in Bewegung. Die österreichische Erforschung des 20. Jahrhunderts, Prag 2013, 20-22.

10 Vgl. Ernst Hanisch, Der lange Schatten des Staates. Österreichische Gesellschaftsgeschichte im 20. Jahrhundert (Österreichische Geschichte 1890-1990), Wien 1994; Reinhard Sieder/Heinz Steinert/Emmerich Talòs (Hg.), Österreich 1945-1995. Gesellschaft, Politik, Kultur, Wien 1995; Rolf Steininger/Michael Gehler (Hg.), Österreich im 20. Jahrhundert, Bd. 1-2, Wien 1997; Oliver Rathkolb, Die paradoxe Republik. Österreich 1945-2005, Wien 2005; vgl. auch die Beiträge von Oliver Rathkolb zur Ersten und Zweiten Republik in der Gesamtdarstellung: Thomas Winkelbauer, (Hg.), Geschichte Österreichs, Stuttgart 2015. 
zentralen Themen für Österreich heraus, die auch verstärkt von der Öffentlichkeit rezipiert werden. Selbst der Versuch, das Jahr 1989 als Zäsur für Österreich zu beschreiben, wie dies Michael Gehler argumentiert, ${ }^{11}$ findet bisher wenig bis keinen Widerhall im Geschichtsunterricht. ${ }^{12}$

Dem geschichtsdidaktischen Diskurs selbst ist der Stellenwert der Zeitgeschichte für das historische Lernen durchaus bewusst. Es kann darauf verwiesen werden, dass erste zeitliche Vorstellungen von Kindern im Wahrnehmungshorizont des Mit(er) lebens und des unmittelbaren (zeitgeschichtlichen) Umfelds angesiedelt sind. ${ }^{13}$ Die Wiener Geschichtsdidaktikerin Sabine Hofmann-Reiter erkennt auf der Grundlage ihrer Erkenntnisse zum Zeitverständnis von Kindern am Übergang von der Primarstufe zur Sekundarstufe in einer „regressiven Chronologie“ durchaus ein zukunftsträchtiges Potenzial für den Geschichtsunterricht. ${ }^{14}$ Gerade Unterrichtskonzepte für den Sachunterricht in der Primarstufe offenbaren, dass ein Zugang zum historischen Lernen über die nahe Vergangenheit als geeignet angesehen werden kann, um Vergangenheit bzw. Geschichte verstehbar zu machen. ${ }^{15}$ Es gehört für die Sekundarstufe I nach wie vor zu den einzulösenden Forderungen, wie sie Reinhard Krammer bis ins 19. Jahrhundert zurückverfolgt hat, nämlich darüber nachzudenken, ob nicht

11 Vgl. Michael Gehler, Zeitgeschichte, in: Helmut Reinalter/Peter J. Brenner (Hg.), Lexikon der Geisteswissenschaften. Sachbegriffe - Disziplinen - Personen, Wien 2011, 1128; Michael Gehler, Paving Austria’s Way to Brussels. Chancellor Franz Vranitzky (1986-1997). A Banker, Social Democrat, and Pragmatic Leader, in: Journal of European Integration History 2 (2012) 18, 170-171; Michael Gehler, Die Europäische Union - ein postmodernes Imperium?, in: Michael Gehler/Robert Rollinger (Hg.), Imperien und Großreiche in der Weltgeschichte. Epochenübergreifende und globalgeschichtliche Vergleiche, Bd. 2, Wiesbaden 2014, 1255-1307.

12 Christoph Kühberger, 1989 im österreichischen Geschichtsunterricht. Über Zeitpunkte und Ikonen, in: Andrea Brait/Michael Gehler (Hg.), Grenzöffnung 1989. Innen- und Außenperspektiven und die Folgen für Österreich, Wien 2012, 469-481.

13 Vgl. Rita Rohrbach, Historisches Lernen im Sachunterricht der Grundschule. Ein erprobtes Curriculum, in: Klaus Bergmann/Rita Rohrbach (Hg.), Kinder entdecken Geschichte. Theorie und Praxis historischen Lernens in der Grundschule und im frühen Geschichtsunterricht, Schwalbach/Ts. 2005, 51-70, 61-63. - Neuere empirische Forschungen deuten jedoch darauf hin, dass Kinder auch ganz andere Themenbereiche wahrnehmen und verarbeiten. - Vgl. Stefanie Zabold, Ausprägungen historischen Denkens vor dem ersten Geschichtsunterricht, in: Monika Fenn, Frühes historisches Lernen, Frankfurt a. M. 2018, 53-74.

14 Sabine Hoffmann-Reiter, Zeitverständnis am Übergang von der Grundschule zur Sekundarstufe. Empirische Erkenntnisse der Geschichtsdidaktik, Innsbruck/Wien 2015, 35.

15 Vgl. Dietmar von Reeken, Historisches Lernen im Sachunterricht. Eine Einführung mit Tipps für den Unterricht, Baltmannsweiler ${ }^{2} 2004,10$. 
auch ein Geschichtsunterricht, der in der Gegenwart beginnt und zurückschreitet, einen besonderen Beitrag für den Erwerb historischen Denkens leisten könnte. ${ }^{16}$

In der Regel wird jedoch im geschichtsdidaktischen Diskurs auf theoretische Momente verwiesen, die einerseits aus der Zeitgeschichte als geschichtswissenschaftlicher Disziplin erwachsen, andererseits aus den Besonderheiten eines (zeit)historischen Lernens. Die besonderen Potenziale können entlang einer Systematik von Hartmut Voit in sieben Bereichen konzentriert werden: ${ }^{17}$

- Orientierung: Zeitgeschichtliche Betrachtungen tragen dazu bei, gegenwärtige Herausforderungen und ihre Genese zu reflektieren, um damit ein kritischeres Verständnis des Erlebten in der unmittelbaren Vergangenheit und Gegenwart aufzubauen und um damit auch historisch-politische Orientierung zu finden.

- Wissenschaftliche Aufarbeitung: Das kritische Erforschen der unmittelbaren Vergangenheit erschwert es unterschiedlichsten Instanzen (aber auch Menschen), die jüngste Vergangenheit beliebig auszulegen oder gar Mythen aufzubauen, ${ }^{18}$ die nicht belegbare Überhöhungen, Verzerrungen, Verharmlosungen oder Verdrängungen etablieren. Versuche der Instrumentalisierung der jüngsten Vergangenheit oder ihrer Beugung können so thematisiert oder aufgedeckt werden.

- „Kommunikatives Gedächtnis“ und „kulturelles Gedächtnis“: Zeitgeschichte als geschichtswissenschaftliche Auseinandersetzung vernetzt individuelle Erfahrungen und Erinnerungen von einzelnen Mitlebenden aus der unmittelbaren Vergangenheit mit den breiteren Kontexten dieser Zeit, wodurch zufällige Phänomene oder partikulare Erlebnisse einer wissenschaftlichen Erforschung und Deutung zwar eingeschrieben werden können, aber eben auf eine ausbalancierte und verantwortungsvolle Weise Eingang in Geschichtsdarstellungen finden sollten.

- Verbindung von Forschenden und beforschten Objekten: Die Auseinandersetzung mit Zeitgeschichte befördert in besonderem Maße Reflexivität in Forschungs- und Lernprozessen, da sie aufgrund der Nähe bzw. des Zusammenfalls

16 Vgl. Reinhard Krammer, Intention und Prozess im Geschichtsunterricht. Der Einfluss externer Faktoren auf die Praxis an den deutschsprachigen Mittelschulen Österreichs 1849-1914, Innsbruck/Wien 2008, 147-155.

17 Hartmut Voit, „Zeitgeschichte als Aufgabe“. Überlegungen in geschichtsdidaktischer Absicht, in: Zeitschrift für Geschichtsdidaktik 1 (2002), 7-17, 13-14. - Weniger systematische Hinweise bei August Walzl, Schüler und Zeitgeschichte. Die Erfahrungen des Geschichtlichen im Unterricht, Wien 1979.

18 Vgl. Roland Bernhard/Susanne Grindel/Felix Hinz/Christoph Kühberger (Hg.), Mythen in deutschsprachigen Geschichtsschulbüchern. Von Marathon bis zum Élysée-Vertrag, Göttingen 2017. 
des erkennenden Subjektes und des zu erforschenden Objektes eine besondere epistemische Notwendigkeit darstellt.

- Nähe der Geschehnisse: Die Zeitleiste der Zeitgeschichte kommt Lernenden in der Pflichtschule entgegen, da es sich dabei um einen kürzeren und überschaubaren zeitlichen Abschnitt handelt, der unmittelbar mit der Gegenwart der SchülerInnen verknüpft ist. Die dadurch oftmals angeregte emotionale und soziale Nähe zur zeitlichen Dimension kann als lernförderliches Betroffensein (nicht aber als Ergriffensein) bzw. idealerweise als unmittelbarer Lebensweltbezug interpretiert werden, was sich günstig auf fachspezifische historisch(-politische) Lernprozesse auswirkt. Distanzlose Primärerfahrungen der älteren Generation sollten im Rahmen des zeithistorischen Lernens zu kritisch reflektierten und (selbst-)reflexiven Sekundärerfahrungen der jüngeren Generation werden.

- Unabgeschlossenheit der Einsichten: Zeitgeschichte kann als Epoche aufgrund ihrer in die Zukunft reichenden Auswirkungen als Ort von gesellschaftlichen Diskursen bzw. Kontroversen verstanden werden, wobei die Dynamik der strukturell verankerten Unabgeschlossenheit der betrachteten zeitlichen Phase als Motivationsfaktor für historische Lernprozesse genutzt werden kann, um sich als Lernender aktiv in Interpretationen einzubringen.

- Nutzung besonderer Quellengattungen: Zeithistorische Quellen sind aufgrund von Archivsperren vielfach nicht zugänglich, weshalb unabhängig von staatlichen oder administrativen Überlieferungen auf eine Vielzahl von ganz unterschiedlichen Quellengattungen zugegriffen wird. Zugänge der Oral History sind dabei besonders hervorzuheben. Auf diese Weise können jedoch gleichzeitig günstige Settings für historisches Lernen geschaffen werden.

Und trotz dieser guten Argumente beharrt die Geschichtsdidaktik darauf, keine Epochendidaktik zu betreiben, ${ }^{19}$ wenngleich eine „,epochenspezifische Differenzierung “ ${ }^{20}$ durchaus angestrebt wird. In diesem Sinne fragt die Geschichtsdidaktik eben nach den Charakteristika, die man anhand von zeithistorischen Beispielen zur Anbahnung eines reflektierten und (selbst-)reflexiven Geschichtsbewusstseins erwerben soll. Es geht dabei im Sinne der Förderung eines historischen Denkens nicht darum, bestimmte inhaltliche Bereiche oder vorgefertigte Interpretationen $\mathrm{zu}$ setzen, sondern die Transferierbarkeit von fachspezifischen Konzepten und Prozeduren - die in besonderem Maße im Rahmen der Zeitgeschichte auftreten - auf andere, auch

19 Vgl. auch Christian Heuer, Geschichtsdidaktik, Zeitgeschichte und Geschichtskultur, in: Geschichte, Politik und ihre Didaktik. Zeitschrift für historisch-politische Bildung 33 (2005) 3/4, 170-175, 172; Markus Furrer/Kurt Messmer, Zur Einleitung, in: Markus Furrer/Kurt Messmer (Hg.), Handbuch Zeitgeschichte im Unterricht, Schwalbach/Ts. 2013, 7-17, 7.

20 Voit, Zeitgeschichte, 7. 
unbekannte Fallbeispiele zu ermöglichen, um damit eine Zukunftsoffenheit im kritischen Umgang mit diesem wandernden Zeitabschnitt abzusichern. ${ }^{21}$ Es geht also darum, historisches Denken vor den Bedingungen der zeitgeschichtlichen Spezifik - hinsichtlich der Konzepte und Prozeduren - zu profilieren.

Fachliche Konzepte, die im Kontext der Zeitgeschichte durch besondere Ausprägungen und/oder Problemkonstellationen in Erscheinung treten, besitzen aufgrund der erinnerungskulturellen Formationen innerhalb von Gesellschaften eine besondere Bedeutung, die auch einem kurzfristigen Wandel bzw. einer ideologischen Instrumentalisierung unterworfen sein können. Die sachlichen, politischen, emotionalen, identitätsstiftenden Dimensionen von Begriffen und eben die in ihnen ruhenden Konzepte gilt es daher im Rahmen des Geschichtsunterrichtes zu reflektieren. ${ }^{22}$ Man benötigt diese Termini und ihre Aufladungen jedoch, um gesellschaftlich anschlussfähig zu bleiben und mit belastbaren Konzepten jüngere historische Entwicklungen, die in die Gegenwart ausgreifen, beschreiben und reflektieren zu können. Dazu zählen Begriffe wie Zeitgenossenschaft, Gegenwart, erste/zweite/ dritte Generation, Nachkommen, Vorfahren, TäterInnen, Tätervolk, Opfer und viele mehr. Zudem reichen diese fachspezifischen Konzepte auch in den epistemischen Apparat der Zeitgeschichte, nämlich dort, wo sie auf spezifische Formen der Erkenntnisgewinnung oder der Perspektivität verweisen (Zeitzeugenschaft, Augenzeugenschaft, Primärerfahrung etc.) oder treten als reflexive Konzepte auf, die den zeitgeschichtlichen Diskurs und seine Kontroversen auf einer Metaebene beschreiben möchten (Erinnerungskultur, Gedächtnis, Verantwortung etc.), nicht in jedem Fall, ohne dabei politisch aufgeladen zu sein (Opfermythos, Kollektivschuld, Heldengräber etc.). ${ }^{23}$

21 Vgl. Kühberger, Kompetenzorientiertes, 87; Ulrike Greiner/Irmtraud Kaiser/Christoph Kühberger/Günter Maresch/Verena Oesterhelt/Hubert Weiglhofer, Reflexive Grundbildung bis zum Ende der Schulpflicht. Konzepte und Prozeduren im Fach (Salzburger Beiträge zur Lehrer/innen/bildung. Der Dialog der Fachdidaktiken mit Fach- und Bildungswissenschaften 5), Münster 2019.

22 Christoph Kühberger, Konzeptionelles Wissen als besondere Grundlage für das historische Lernen, in: Christoph Kühberger (Hg.), Historisches Wissen. Geschichtsdidaktische Erkundungen über Art, Umfang und Tiefe für das historische Lernen, Schwalbach/Ts. 2012, 33-74; Thomas Hellmuth/Christoph Kühberger, Historisches und politisches Lernen mit Konzepten, in: Historische Sozialkunde 46 (2016) 1, 3-8; Christoph Kühberger, Historisches Wissen. Verschiedene Formen seiner Strukturiertheit und der Wert von Basiskonzepten, in: Wolfgang Hasberg/Holger Thünemann (Hg.), Geschichtsdidaktik in der Diskussion. Grundlagen und Perspektiven, Frankfurt a. M. 2016, 91-107.

23 Andreas Körber, Kompetenz(en) zeitgeschichtlichen Denkens, in: Michele Barricelli/Julia Hornig (Hg.), Aufklärung, Bildung, „Histotainment“? Zeitgeschichte in Unterricht und Gesellschaft heute, Frankfurt a. M. 2008, 43-66, 55. 
Neben derartigen fachlichen Konzepten gilt es jedoch auch fachliche Prozeduren in den Blick zu nehmen. Dies spielt etwa bei der Entwicklung von Fragen an die Vergangenheit eine Rolle, indem etwa gegenwärtige oder erwartete „Orientierungsprobleme mit Bezug zu Ereignissen und Strukturen der jüngeren Vergangenheit in spezifisch anschlussfähige und bearbeitbare Fragen“ übersetzt werden. Hinsichtlich der anzuwendenden zeithistorischen Methoden kann festgehalten werden, dass es jene Momente in Lernprozessen anzubahnen gilt, die es dem zeithistorisch denkenden Subjekt ermöglichen,

nach den verschiedenen Bedeutungen zu fragen, welche die jeweilige Geschichte für unterschiedliche Positionen und Perspektiven in aktuellen Auseinandersetzungen hat, was bedeutet, nach der Pluralität gegenwärtiger Verarbeitungs- und Verwendungsweisen der Geschichte(n) und nach ihren Orientierungsgehalten fragen zu können. Stärker noch als etwa bei der Analyse von Quellen und Darstellungen zu weiter zurückliegenden Zeiten geht es darum, auch die eigene soziale und kulturelle Perspektive als unmittelbar oder über den Generationenzusammenhang mittelbar Beteiligte(r) und als historisch Denkende(r) zu erweitern und das Prinzip der Anerkennung zu Grund zu legen. ${ }^{24}$

Selbstreflexion in Bezug auf den eigenen Standpunkt und die eigene Sozialisation sind dabei ebenso gefragt wie das für die Zeitgeschichte stärker notwendige Herausarbeiten von Deutungs- und Interpretationsmustern in Abhängigkeit von sozialen, kulturellen und politischen Perspektiven der AutorInnen. In diesen Momenten verbergen sich letztlich auch schon politische Dimensionen einer Nutzung oder Kritik fremder oder der Schaffung eigener Orientierungsangebote, die unter Rückgriff auf historische Interpretationen (lies: Geschichte) getätigt werden. ${ }^{25}$

\section{Lehrpläne als normative Leitplanken}

Die bundesweit geltenden Lehrpläne sind in Österreich als Kodifikationsformen für die Erteilung von öffentlichem Unterricht zu verstehen. Sie sind dazu bestimmt, „Bildungsangebote der Schule in den einzelnen Fächern schulform- und stufenspezifischen Normen zu unterwerfen“. ${ }^{26}$ In ihnen spiegeln sich pädagogische und

24 Körber, Kompetenz(en), 56-57 (Hervorhebungen im Original).

25 Vgl. Körber, Kompetenz(en), 57.

26 Klaus Fröhlich, Richtlinien, Lehrpläne, in: Klaus Bergmann/Klaus Fröhlich/Annette Kuhn/Jörn Rüsen/Gerhard Schneider (Hg.), Handbuch der Geschichtsdidaktik, Seelze-Velber 1997, 510-520, 510. 
(fach-)didaktische Intentionen, aber auch politische Ausrichtungen wider, die innerhalb einer Gesellschaft als so zentral erachtet werden, dass sie an die nächste Generation weitergegeben werden sollen. Nach 1945 war eine Neuordnung der Lehrpläne in Österreich aufgrund der massiven ideologischen Indienstnahme des Geschichtsunterrichts durch das NS-Regime notwendig geworden. Man griff dazu auf die Lehrpläne aus dem Jahr 1928 zurück, die am 18. Oktober 1946 als „Provisorische Lehrpläne“ für die Hauptschulen und am 12. Oktober 1955 für die Mittelschulen erlassen wurden. Bereits in diesen Übergangsdokumenten wird das Bestreben deutlich, die Themen des Geschichtsunterrichts bis in die Gegenwart heraufzuführen. Der Geschichtsunterricht in der 8. und 12. Schulstufe sollte auch die unmittelbare Vergangenheit der NS-Diktatur miteinbeziehen. So sollten die Themenbereiche „Faschismus und Nationalsozialismus als Störer des Weltfriedens“ und „Der Zweite Weltkrieg“ (8. Schulstufe) und „Faschismus und Nationalsozialismus als kulturfeindliche und den Weltfrieden untergrabende Bewegung“ und „Autarkie und Aufrüstung in den faschistischen Staaten“ (12. Schulstufe) behandelt werden. ${ }^{27}$

Erst ab 1963 kam es aber durch die Einführung der "Sozialkunde“ in den Hauptschulen im Schlepptau des sozialwissenschaftlichen Paradigmenwechsels in der Geschichtswissenschaft zu einem erkennbar geänderten Umgang mit Vergangenheit und Geschichte im schulischen Kontext. Gleichzeitig wurde mit dem Lehrplan für das neu benannte Unterrichtsfach "Geschichte und Sozialkunde“ aus dem Jahr 1963 die jüngste Zeitgeschichte breiter in den Kanon des österreichischen Geschichtsunterrichtes aufgenommen. ${ }^{28}$ Damit wurde fixiert, dass die zeitliche Spanne des Geschichtsunterrichts an Hauptschulen von den Frühen Hochkulturen („Geschichte des Orients“) bis zur „Neutralitätserklärung“ (1955) reichen sollte. Der Unterricht in der gymnasialen Unterstufe sollte entlang des Lehrplans aus dem Jahr 1967 von der Urgeschichte sogar bis hin zu ge-

27 Leopold Rettinger, Teil 1, in: Hermann Schnell/Leopold Rettinger/Ilan Knapp/Maria Hofstätter/ Peter Vitouch (Hg.), Zeitgeschichtlicher Unterricht und Vergangenheitsbewältigung in Schulen. Die Effizienz der Erziehung gegen Faschismus und Antisemitismus, Wien 1989, 1-29, 1-2; Verordnungsblatt für den Dienstbereich des Bundesministeriums für Unterricht, Jg. 1955, 15.10.1955, Stück 10a, 87. Erlass: Neuverordnung der Provisorischen Lehrpläne für die Mittelschulen.

28 Vgl. Karl Sretenovic, Innenansichten, in: Oskar Achs/Karl Sretenovic (Hg.), Hermann Schnell. Erinnerung und Lebenswerk, Wien 1999, 58-68, 64. - Zwar gab es bereits in den provisorischen Lehrplänen aus der Nachkriegszeit eindeutige Hinweise auf zeitgeschichtliche Themen, aber erst 1963 wurde ein entsprechender Lehrplan verordnet. - Vgl. I. Sondernummer zum Verordnungsblatt für den Dienstbereich des Bundesministeriums für Unterricht, Jg. 1963, 01.07.1963, Stück 7a, 48. Verordnung: Lehrpläne der Volks-, Haupt- und Sonderschulen. 
genwärtigen Phänomenen der Gesellschaft und Politik reichen. ${ }^{29}$ August Walzl lässt die dazugehörigen wissenschaftlichen Diskussionen um „Zeitgeschichte im Geschichtsunterricht“ für Österreich rückblickend im Jahr 1960 beginnen. ${ }^{30}$ $\mathrm{Ob}$ alle diese Interventionen, von denen natürlich auch andere Schulformen im Nachlauf betroffen waren (zum Beispiel Handelsakademien oder Handelsschulen), unmittelbar fruchteten, ist anzuzweifeln. So erhoffte man sich zwar, über die Einführung von Zeitgeschichte als „sekundäres Erfahrungsfeld“ den Nachweis zu erbringen, dass „die sehr begrenzte persönliche soziopolitische Erfahrung des jungen Menschen“ ersetzt oder ergänzt werden könne und dass „die ökonomischen, gesellschaftlichen und politischen Phänomene und Probleme der Gegenwart in ihrer geschichtlichen Sättigung und in ihrer ganzen Komplexität und Vielschichtigkeit" durch GeschichtslehrerInnen vermittelt werden könnten. ${ }^{31}$ Die geschichtsdidaktische Debatte deutet an manchen Stellen aber auch auf massive Schwierigkeiten hin, indem engagierte Berichte aus den Klassenzimmern beschreiben, welch „verwirrende Erfahrung“" es sei,

daß Schülern jedes politische und historische Koordinatensystem fehlt. Die [...] Entpolitisierung der Jugend kommt in der Handelsschule voll zum Tragen. Die politische Beziehungslosigkeit der Schüler hat natürlich eine unhistorische bzw. geschichtslose Betrachtungsweise zur Folge: Zeitgeschichte wird so zur Urgeschichte. ${ }^{32}$

29 Vgl. Bundesgesetzblatt, Jg. 1967, 24.08.1967, 70. Stück, 295. Verordnung: Neuerliche Abänderung der Verordnung, mit der Lehrpläne für die allgemeinbildenden höheren Schulen erlassen werden, hinsichtlich der Gymnasien, Realgymnasien und Wirtschaftskundlichen Realgymnasien für Mädchen sowie des Bundesgymnasiums für Slowenen; Bekanntmachung der Lehrpläne für den Religionsunterricht an diesen Schulen.

30 Walzl führt diesbezüglich die Tagung „Österreichische Zeitgeschichte und Geschichtsunterricht“ an. Vgl. Walzl, Schüler, 7. - Die Tagungsergebnisse wurden veröffentlicht: Anton Kolbabek (Hg.), Österreichische Zeitgeschichte im Geschichtsunterricht. Bericht über die Expertentagung von 14.XII.-16.XII.1960 in Reichenau, Wien 1961. - Die Debatten zur Zeitgeschichte im Geschichtsunterricht finden jedoch in einem nicht geklärten Verhältnis zur Politischen Bildung statt. Vgl. Rudolf E. Wordian, Didaktisch-methodische Skizze des zeitgeschichtlichen Unterrichtes in Österreich, in: zeitgeschichte 1 (1973/1974) 3, 64-68; Hans R. Katschthaler, Der Gelegenheitsunterricht als Hilfe für die zeitgeschichtlich-sozialkundliche Bildungsarbeit auf der Oberstufe der Allgemeinbildenden Höheren Schule, in: zeitgeschichte 1 (1973/1974) 5, 120-125; Engelbert Deusch, Zeitgeschehen im Geschichtsunterricht, in: zeitgeschichte 4 (1976/1977) 3, 92-93.

31 August Walzl, Zeitgeschichte an kommerziellen Schulen oder Wie ein Lehrplan entsteht, in: zeitgeschichte 7 (1979/80) 8, 298-307, 303-304.

32 Gerfried Brandstetter/Reinhard Krammer, Die lichten Höhen der Didaktik, die Niederungen des Schulalltags. Erfahrungen im Zeitgeschichteunterricht an Handelsschulen, in: zeitgeschichte 8 $(1980 / 1981) 8,323-331,325$. 
Zugespitzt formulieren Gerfried Brandstetter und Reinhard Krammer weiter:

Zu groß ist die Diskrepanz zwischen papierenem Anspruch und schulischer Wirklichkeit. Diese Schulwirklichkeit (auch SCHÜLERWIRKLICHKEIT) ist leicht vergessen im Elfenbeinturm einer wissenschaftlichen Pädagogik. ${ }^{33}$

Einen Versuch, der ab den späten 1970er-Jahren eingeleitet wurde, um Zeitgeschichte für den schulischen Unterricht attraktiver auszugestalten, stellten etwa die "Medienkoffer" 1 bis 3 zur „Österreichischen Zeitgeschichte“ für den Zeitabschnitt von 1918 bis $1980^{34}$ und die damit in Verbindung stehende, vom Bundesunterrichtsministerium und dem ORF initiierte Aktion „Schüler \& Zeitgeschichte“ dar, in deren Rahmen über Projektunterricht Zugänge zum zeithistorischen Lernen ermöglicht werden sollten. ${ }^{35}$

Betrachtet man die Anteile der Zeitgeschichte ${ }^{36}$ an den thematischen Einheiten („Lehrstoff“ bzw. „thematische Konkretisierungen“) am Lehrplan für „Geschichte und Sozialkunde/Politische Bildung" aus dem Jahr 2016 für die Sekundarstufe I, ${ }^{37}$ kann festgestellt werden, dass diesem Zeitabschnitt 37 Prozent der inhaltlich ausgewiesenen Dimensionen zugerechnet werden können. Im Vergleich zu den Lehrplänen aus dem Jahr 2000 und 2008 kann man erkennen, dass der Bereich sich in den inhaltlichen Vorgaben ausdehnte, was vor allem damit in Zusammenhang zu bringen ist, dass in der 2. und 3. Klasse der Sekundarstufe I (6. und 7. Schulstufe) Hinweise gegeben werden, wie über Vergleiche oder Längsschnitte Beispiele aus der Zeitgeschichte zu integrieren sind. Der Lehrplan 2016 offeriert zudem, wie das die Spalte "Zeitgeschichtliche Themen (möglich)“ ausweist, Möglichkeiten, um wahlweise zeitgeschichtliche Inhalte in unterschiedlichen Kontexten zu integrieren. Es ist zudem in dieser quantitativen Aufstellung interessant zu beobachten, dass die Einführung der Politischen Bildung ab dem Jahr 2008 nicht zulasten von zeitgeschicht-

33 Brandstetter/Krammer, Höhen, 330 (Hervorhebung im Original).

34 In diesen „Koffern“ wurden allen österreichischen Mittelschulen zeithistorische Darstellungen und Quellen für SchülerInnen und LehrerInnen zur Verfügung gestellt, vgl. Peter Dusek, Österreichische Zeitgeschichte 1918 -1938. Didaktik (Medienkoffer 3), Wien o. J. Eine digitale Variante des Projektes findet sich auch im Internet, URL: https://digitaler-medienkoffer.eu/ (abgerufen 13.08.2020).

35 Einige Lernprodukte von SchülerInnen haben sich in einer Publikation verfangen: Peter Dusek/ Peter Malina/Michael Mitterauer, Schüler \& Zeitgeschichte. 1945-1955/85, Wien 1987.

36 Hier wird trotz aller darin lagernden Problematik von einer Definition von Zeitgeschichte ausgegangen, die von 1917 bis heute reicht.

37 Der Lehrplan in "Geschichte und Sozialkunde/Politische Bildung" ist für die untersuchten Jahrgänge für die Hauptschule bzw. (Neue) Mittelschule und das Gymnasium wortidentisch verordnet. 


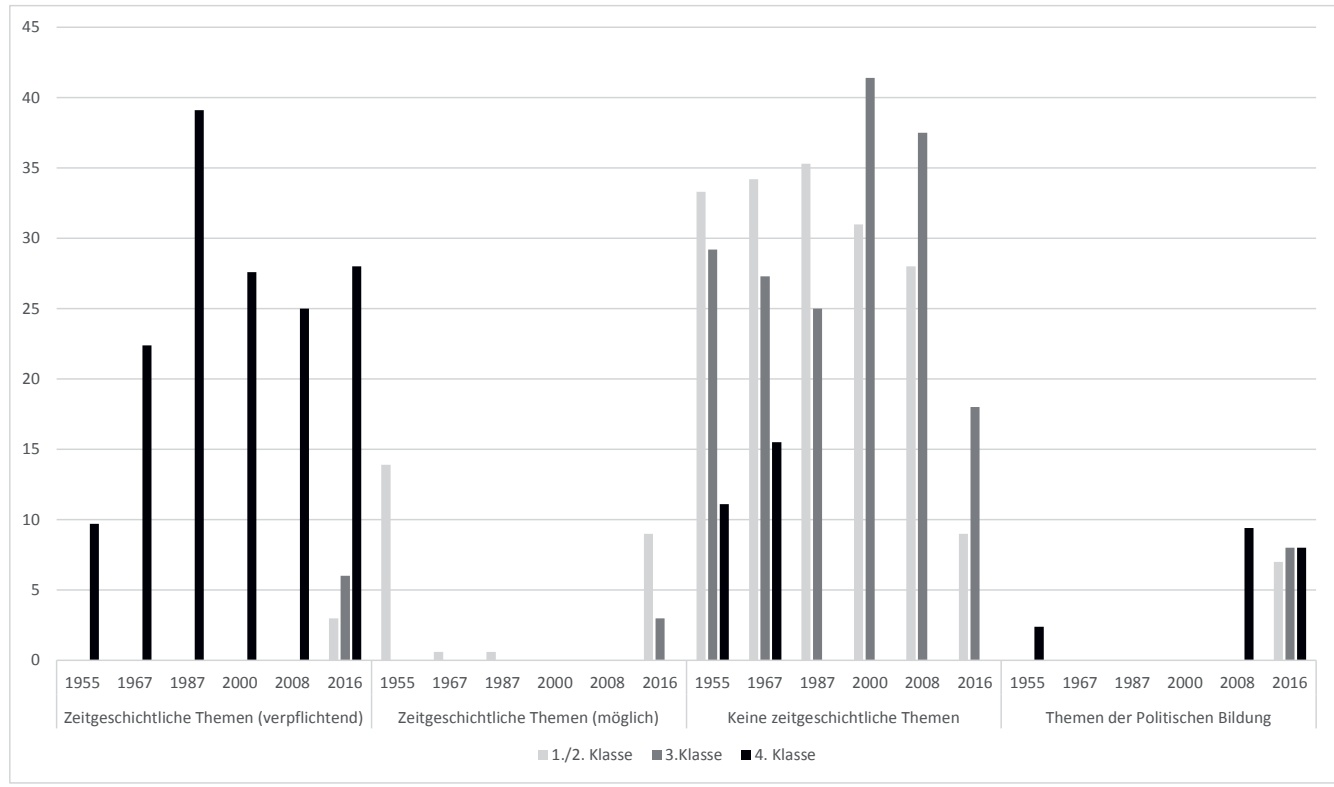

Abb. 1: Vergleich der inhaltlichen Vorgaben in den Lehrplänen für den Geschichtsunterricht in Prozent (Quelle: eigene Berechnung)

lichen Themen umgesetzt wurde. Nur in der lern- und lehrzielorientierten Reform für das Fach „Geschichte und Sozialkunde" aus Jahr 1987 wird mit 39,1 Prozent ein noch höherer Anteil an verpflichtenden zeitgeschichtlichen Themen erreicht (Abb. 1).

Aus dem Diagramm in Abb. 1 kann man zudem ablesen, dass sich zeitgeschichtliche Themen vor allem zwischen 1955 und 1987 ausdehnten, indem sie sukzessive die Unterrichtszeit der gesamten 8. Schulstufe für sich beanspruchen - eine Entwicklung, die erst durch die Einführung von explizit positionierter Politischer Bildung ab 2008 gebremst wurde.

\section{Welche Zeitgeschichte?}

Der Geschichtsunterricht ist, trotz des großen Anteils an Zeitgeschichte, den der Lehrplan für die Sekundarstufe I diesem zeitlichen Abschnitt heute einräumt, mit einem Auswahlproblem konfrontiert. Zeitgeschichte definiert vorrangig den zeitlichen Rahmen, nicht aber die räumliche Verortung oder den konzeptionellen $\mathrm{Zu}$ griff auf die Vergangenheit. Aufgrund der engen Verwobenheit der unmittelbaren 


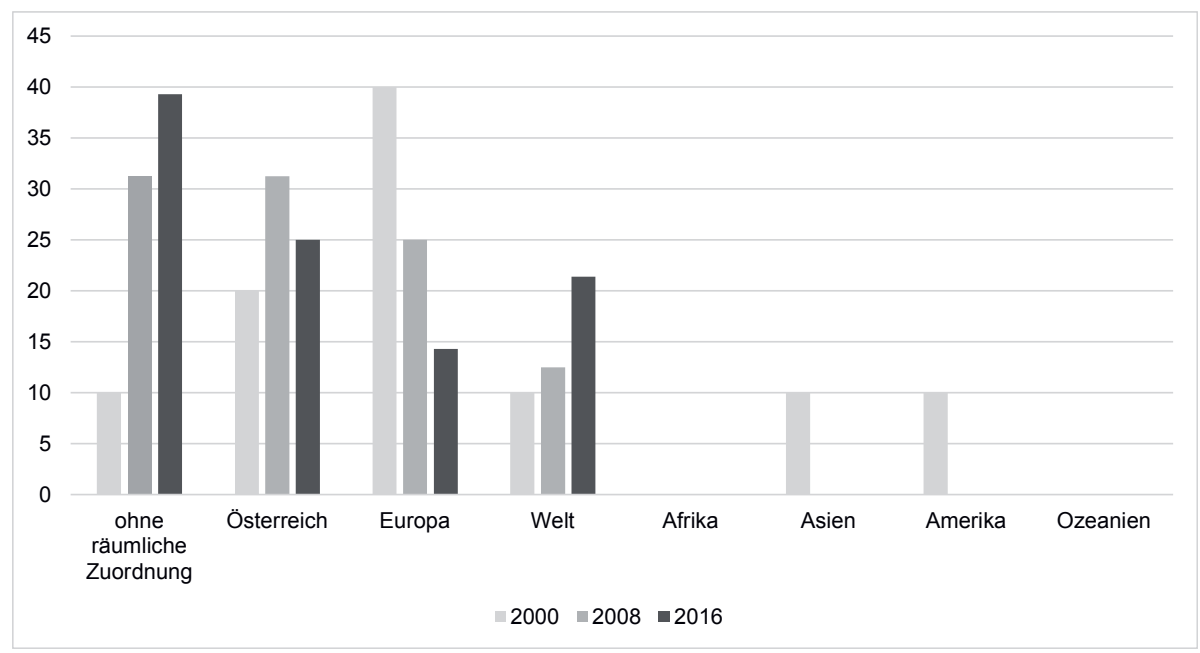

Abb. 2: Räumliche Verortung zeitgeschichtlicher Themen (in Prozent) in den österreichischen Lehrplänen im frühen 21. Jahrhundert ${ }^{38}$

Vorgeschichte der Gegenwart mit politischen Entscheidungen im Heute spielt der nationale Rahmen eine wichtige Rolle. Gleichzeitig bleibt man sich in der Auseinandersetzung mit den Räumen der Zeitgeschichte aber auch bewusst, dass dies zu einem ungewollten Ethnozentrismus führen kann, weshalb Vorgaben für den Geschichtsunterricht in Österreich dazu tendieren, auch lokale, regionale, europäische, transkulturelle und globale Dimensionen anzusprechen oder zumindest eine Offenheit in den Formulierungen anzustreben, die dies ermöglichen würde. Betrachtet man die Räume, in denen Geschichte im Lehrplan für die 8. Schulstufe in den Lehrplänen der Sekundarstufe I im 21. Jahrhundert verortet wurde (Abb. 2), wird deutlich, dass der Anteil der explizit europäischen Themen zugunsten thematischer Anforderungen ohne räumliche Verortung bzw. global- und weltgeschichtlicher Themen zurückging. Der Anteil der zeitgeschichtlichen Themen, die in Raum „Österreich" angesiedelt sind, liegt zwischen 20 und 31 Prozent. Es ist auffällig, dass bestimmte Kontinente, insbesondere Afrika und Ozeanien (mit Australien), keinerlei Aufmerksamkeit erfahren und es den Lehrpersonen überlassen wird, diese Regionen über die Themen „ohne räumliche Zuordnung“ einzubinden.

38 Verglichen werden hier inhaltliche Themen, wie sie im „Lehrstoff“ bzw. in den „thematischen Konkretisierungen" in der 8. Schulstufe in der gymnasialen Unterstufe und Hauptschule/Neue Mittelschule festgelegt wurden. Für das Jahr 2016 wurden die Module der Politischen Bildung nicht berücksichtigt. - Vgl. für die Daten zu 2000 und 2008: Christoph Kühberger, Globalgeschichte als Vernetzungsgeschichte. Geschichtsunterricht im Mehr-Ebenen-System, Hildesheim/New York 
Eine derartige Aufstellung regt - über die Kategorie „Raum“ hinaus - dazu an, danach zu fragen, welche Zeitgeschichte keinen oder wenig Platz hat. Es stellt sicherlich eine Herausforderung dar, Diskussionen und Forschungsergebnisse, die sich im Rahmen einer sich über Jahrzehnte hinweg demokratisch öffnenden geschichtswissenschaftlichen bzw. geschichtsdidaktischen Auseinandersetzung im deutschsprachigen Raum zwar zeigen, aber nur zögerlich oder gar nicht den Weg in den Schulunterricht finden, zu integrieren. Mit Gayatri Chakravorty Spivak lässt sich im Modus einer postkolonialen Kritik danach fragen, wer überhaupt im österreichischen Geschichtsunterricht „sprechen“ darf ${ }^{39}$ und welches Wissen damit an die nächste Generation weitergegeben wird. Dazu ist etwa der Stellenwert von unterschiedlichen Diversitätskategorien und ihre intersektionale Verwobenheit zu ermitteln, ${ }^{40}$ wie dies in der Forschungsarbeit von Elfriede Windischbauer zur Kategorie Geschlecht und deren Berücksichtigung in österreichischen Geschichtsschulbüchern der 8. Schulstufe in Ansätzen deutlich wird. Windischbauer arbeitet dabei für den Bereich der Zeitgeschichte heraus, dass nach wie vor eine auf geschichtsprägende Männer zentrierte historische Darstellung dominiere, obwohl der Anteil an in den Büchern genannten Frauen zwischen 1963 und 2006 von 3,9 auf 11,5 Prozent ansteige. ${ }^{41}$ In Summe muss man jedoch festhalten, dass die Kategorie Geschlecht eine weit bessere Absicherung besitzt ${ }^{42}$ als andere Kategorien, wie etwa Diskurse

2012, 37, 42. - Die Verortung von Geschichte, die auf mehreren Kontinenten angesiedelt ist, wurde hier als „Welt“ codiert. Dazu zählt etwa die Politik der USA oder Sowjetunion im Kalten Krieg.

39 Gayatri Chakravorty Spivak, Can the Subaltern Speak? Postkolonialität und subalterne Artikulation, Wien 2007.

40 Vgl. Christoph Kühberger, Intersektionalität - ein Weg für den geschlechtersensiblen Geschichtsunterricht?, in: Nadja Bennewitz/Hannes Burkhardt (Hg.), Gender in Geschichtsdidaktik und Geschichtsunterricht. Neue Beiträge zu Theorie und Praxis, Münster 2016, 55-86; Sebastian Barsch/ Bettina Degner/Christoph Kühberger/Martin Lücke (Hg.), Handbuch Diversität im Geschichtsunterricht. Zugänge einer inklusiven Geschichtsdidaktik, Frankfurt a. M. 2019.

41 Elfriede Windischbauer, Geschlecht als historische Kategorie in österreichischen Schulbüchern 1963 bis 2005, phil. Diss., Universität Salzburg 2006, 288, 422.

42 Vgl. Reinhard Krammer, Gender-Kompetenz durch historisch-politischen Unterricht, in: Informationen zur Politischen Bildung 26/2006, 58-66; Martin Lücke, Walk on the wild side. Genderkompetenz, Zeitgeschichte und Historisches Lernen, in: Michele Barricelli/Julia Hornig (Hg.), Aufklärung, Bildung, „Histotainment“? Zeitgeschichte in Unterricht und Gesellschaft heute, Frankfurt a. M. 2008, 223-236. 
und Ergebnisse der Queer History ${ }^{43}$ oder der Disability History, ${ }^{44}$ die nach wie vor einer stärkeren Tabuisierung unterworfen sind. ${ }^{45}$ Forschungsarbeiten, welche die Kategorie „race“ berücksichtigen, können zwar für die österreichische Zeitgeschichte nachgewiesen werden, ${ }^{46}$ aber ihre Relevanz ist im Kontext der geschichtsdidaktischen Auseinandersetzungen und im Geschichtsunterricht in Österreich erst marginal berücksichtigt. ${ }^{47}$

\section{Nationalsozialismus und Holocaust}

Besondere geschichtsdidaktische Aufmerksamkeit und durchaus eine wahrnehmbare Dominanz gegenüber anderen Abschnitten der Zeitgeschichte erfährt in Österreich der Themenbereich Nationalsozialismus und Holocaust. Fragen des Umgangs und der Vermittlung stehen dabei ebenso im Fokus wie Erinnerungskultur und Geschichtspolitik. Zu keinem anderen zeithistorischen Abschnitt können derartig viele geschichts-

43 Vgl. Franz X. Eder, Homosexualitäten. Diskurse und Lebenswelten 1870-1970, Wien/Weitra 2011; Andreas Brunner/Frauke Kreutler/Michaela Lindinger/Gerhard Milchram/Martina Nußbaumer/ Hannes Sulzenbacher (Hg.), Sex in Wien. Lust. Kontrolle. Ungehorsam, Wien 2016; Homosexualitäten revisited. Österreichische Zeitschrift für Geschichtswissenschaften 29 (2018) 2.

44 Vgl. Petra Flieger/Sascha Plangger (Hg.), Aus der Nähe. Zum wissenschaftlichen und behindertenpolitischen Wirken von Volker Schönwiese, Neu Ulm 2013; Petra Flieger/Volker Schönwiese (Hg.), Das Bildnis eines behinderten Mannes. Bildkultur der Behinderung vom 16. bis ins 21. Jahrhundert, Wissenschaftlicher Sammelband, Neu Ulm 2006; Oskar Dohle/Ulrike Feistmantl/Elisabeth Telsnig, „... Trotl bin ich nicht“. Kreatives Schaffen in der Landesheilanstalt Salzburg 1849-1969, Salzburg 2018.

45 Christoph Kühberger, Inklusives historisches Wissen, in: Sebastian Barsch/Bettina Degner/Christoph Kühberger (Hg.), Handbuch Diversität im Geschichtsunterricht. Zugänge zu einer inklusiven Geschichtsdidaktik, Frankfurt a. M. 2019.

46 Vgl. Ingrid Bauer, Welcome Ami Go Home. Die amerikanische Besatzung in Salzburg 19451955, Salzburg 1998; Walter Sauer (Hg.), Von Soliman zu Omofuma. Afrikanische Diaspora in Österreich - 17. bis 20. Jahrhundert, Innsbruck 2007; Niko Wahl/Philipp Rohrbach/Tal Adler, SchwarzÖsterreich. Die Kinder afroamerikanischer Besatzungssoldaten. Wien 2016; Philipp Rohrbach/Niko Wahl, Bandbreiten der Erinnerung. Lebensgeschichten im Forschungs- und Ausstellungsprojekt. Lost in Administration/SchwarzÖsterreich, in: Regina Thumser-Wöhs/Martina Gugglberger/Birgit Kirchmayr/Grazia Prontera/Thomas Spielbüchler (Hg.), Außergewöhnlich. Festschrift für Albert Lichtblau, Wien 2019, 211-225.

47 Christoph Kühberger, „Race“ - a neccessary category?, in: Public History Weekly 2 (2014) 32, URL: dx.doi.org/10.1515/phw-2014-2520 (abgerufen 20.10.2020). - Vgl. auch: Lale Yildirim/Martin Lücke, Race als Kategorie historischen Denkens, in: Sebastian Barsch/Bettina Degner/Christoph Kühberger/Martin Lücke (Hg.), Handbuch Diversität im Geschichtsunterricht. Zugänge einer inklusiven Geschichtsdidaktik, Frankfurt a. M. 2020, 146-158. 
didaktische Forschungsergebnisse, ${ }^{48}$ theoretische Annäherungen ${ }^{49}$ oder pragmatische Impulse $^{50}$ für Österreich ausgemacht werden. Dies verwundert angesichts des dik-

48 Vgl. Eduard Fuchs, Das Geschichtsbewußtsein österreichischer Jugendlicher unter besonderer Berücksichtigung österreichischer Zeitgeschichte von 1918 bis 1945, Bd. 2, phil. Diss., Universität Wien 1986; Herbert Bastel/Brigitte Halbmayr (Hg.), Mauthausen im Unterricht. Ein Gedenkstättenbuch und seine vielfältigen Herausforderungen, Wien 2004; Christiane Hintermann, Dissonante Geschichtsbilder? Empirische Untersuchung zu Geschichtsbewusstsein und Identitätskonstruktionen von Jugendlichen mit Migrationshintergrund, Wien 2007; Philipp Mittnik, Trivialisierung und/oder Überforderung? Die Darstellung des Themengebietes Nationalsozialismus und Holocaust in österreichischen Schulbüchern der Primarstufe, in: Christian Fridrich/Reingard Klingler/Renate Potzmann (Hg.), Forschungsperspektiven 7, Wien 2016, 57-72; Philipp Mittnik, Holocaust Studies in Austrian Elementary and Scondary Schools, in: Global Education Review 2 (2016) 3, 14-31; Christoph Kühberger, Teaching the Holocaust and National Socialism in Austria. Politics of Memory, History Classes and Empirical Insights, in: Holocaust Studies. A Journal of Culture and History 23 (2017) 3, 396-424; Christian Matzka/Helene Miklas, Erinnerungskultur in Mauthausen. Ergebnisse eines empirischen Projektes zur Wahrnehmung von Gedenkstättenpädagogik durch Schüler/innen, in: Alois Ecker/Bettina Paireder/Judith Breitfuß/Isabella Schild/Thomas Hellmuth (Hg.), Historisches Lernen im Museum/Historical Leraning in the Museum, Frankfurt a. M. 2018, 94-106; Bernadette Edmaier, Welche Bedeutung hat der Holocaust für Jugendliche mit Migrationsgeschichte?, in: Helga Embacher/Manfred Oberlechner/Robert Obermair/Adelheid Schreilechner (Hg.), Eine Spurensuche. KZAußenlager in Salzburg und Oberösterreich als Lernorte, Frankfurt a. M. 2019, 157-175.

49 Reinhard Krammer, Um vom Unsagbaren zu reden ... Didaktische Anmerkungen zur Behandlung der Geschichte der Juden im österreichischen Geschichtsunterricht, in: Internationale Schulbuchforschung 21 (1999), 109-126; Reinhard Krammer, Nationale Amnesie und die Strategie des Geschichtsunterrichtes. Ein österreichischer Sachverhalt, in: Christian Giordano/Jean-Luc Patry/ Francois Rüegg (Hg.), Trugschlüsse und Umdeutungen. Multidisziplinäre Betrachtungen unbehaglicher Praktiken, Münster/Wien 2009, 55-66; Yariv Lapid/Christian Angerer/Maria Ecker, „Was hat das mit mir zu tun?"“ Das Vermittlungskonzept der Gedenktätte Mauthausen, in: Bogusław Dybas/Tomasz Kranz/Irmgard Nöbauer/Heidemarie Uhl (Hg.), Gedenkstätten für die Opfer des Nationalsozialismus in Polen und Österreich. Bestandsaufnahme und Entwicklungsperspektiven, Frankfurt a. M. 2013, 327-336; Christoph Kühberger, Ethik und Erinnerung. Über den Umgang mit jüdischer Vergangenheit, in: Petra Ernst/Gerald Lamprecht (Hg.), Konzeptionen des Jüdischen. Kollektive Entwürfe im Wandel, Innsbruck/Wien 2009, 458-473; Helga Embacher/Manfred Oberlechner/Robert Obermair/Adelheid Schreilechner (Hg.), Eine Spurensuche. KZ-Außenlager in Salzburg und Oberösterreich als Lernorte, Frankfurt a. M. 2019.

50 Vgl. Sigrid Langer/Elfriede Windischbauer, Das Thema Holocaust in der Volksschule, in: Christoph Kühberger/Elfriede Windischbauer (Hg.), Politische Bildung in der Volksschule. Annäherungen aus Theorie und Praxis, Innsbruck/Wien 2010, 173-188; Erinnerungskulturen. Geschichtsmythen und Erinnerungspolitik unter der Lupe. Historische Sozialkunde 46 (2016) 3; Wilfried Beimrohr/ Richard Schober (Hg.), Zeitgeschichtliche Streiflichter. Tirol in der Ersten Republik, unter dem Nationalsozialismus und in der Nachkriegszeit, Ein Unterrichtsbehelf für Lehrerinnen und Lehrer, Innsbruck 2010; Andrea Brait, Museale Präsentationen im Umgang mit dem Holocaust. Österreich und Deutschland im Vergleich, in: Ursula von Keitz/Thomas Weber (Hg.), Mediale Transformationen des Holocaust, Berlin 2013, 415-449. - Vgl. auch das Unterrichtsmaterial von „erinnern.at“, URL: http:// www.erinnern.at/bundeslaender/oesterreich/lernmaterial-unterricht (abgerufen 18.09.2019). 
tatorischen Systems und des industrialisierten Massenmords unter der Beteiligung vieler ÖsterreicherInnen wenig. Die sich nicht abkühlende Geschichte, die auch in der Gegenwart - aufgrund ihrer schwer bewältigbaren Ereignisse und Verstrickungen selbst bei neu vorgetragenen Details dazu in der Lage ist, starke Emotionen hervorzurufen und die österreichische Tagespolitik zu irritieren, besitzt nach wie vor eine hohe gesellschaftliche Relevanz. Diese ist dazu imstande, Diskussionen zu anderen Abschnitten der Zeitgeschichte zu überflügeln, wenn nicht sogar - bezogen auf den Geschichtsunterricht - zu verdrängen bzw. zu marginalisieren. Betrachtet man den Umgang mit dem Nationalsozialismus und Holocaust in Österreich aus geschichtsdidaktischer Perspektive, so kann man vier Phasen identifizieren, die durchaus mit der allgemeinen gesellschaftlichen Entwicklung verbunden sind und Modi der Vergangenheitsbewältigung bzw. der Geschichtskultur widerspiegeln. Es handelt sich dabei um idealtypische Verdichtungen, wobei neuere Phasen die älteren nicht paradigmatisch ablösten, sondern sich mit unterschiedlicher Intensität als persistent erwiesen.

\begin{tabular}{|l|l|l|l|}
\hline Phasen & Name der Phase & $\begin{array}{l}\text { Zeitliche } \\
\text { Einordnung }\end{array}$ & Didaktische Kennzeichen \\
\hline 1. Phase & $\begin{array}{l}\text { Nichtthematisie- } \\
\text { rung }\end{array}$ & ab 1945 & $\begin{array}{l}\text { Vermeidungsstrategie } \\
\text { Schweigen/kollektive Amnesie } \\
\text { Tabuisieren } \\
\text { Externalisierung } \\
\text { Keine systematische Bearbeitung }\end{array}$ \\
\hline 2. Phase & $\begin{array}{l}\text { Positionierung der } \\
\text { Opferthese }\end{array}$ & ab 1945 & $\begin{array}{l}\text { Inhaltsorientierung } \\
\text { Informationsweitergabe } \\
\text { Belehrung } \\
\text { Emotionalisierung, tw. Überwältigung } \\
\text { Identitätsstiftung }\end{array}$ \\
\hline 3. Phase & $\begin{array}{l}\text { Positionierung der } \\
\text { Täter/innen-Opfer- } \\
\text { These }\end{array}$ & $\begin{array}{l}\text { ab Wald- } \\
\text { heim-Affäre } \\
\text { (1986) }\end{array}$ & $\begin{array}{l}\text { Inhaltsorientierung/, Stoff“ } \\
\text { Aufarbeitung von verdrängten Themen } \\
\text { Zusammenhänge klären }\end{array}$ \\
\hline 4. Phase & $\begin{array}{l}\text { Pluralisierung der } \\
\text { Gedenk- und Erin- } \\
\text { nerungskultur }\end{array}$ & $\begin{array}{l}\text { ab dem } \\
\text { 21. Jahrhun- } \\
\text { dert }\end{array}$ & $\begin{array}{l}\text { Kompetenzorientierung/,Historisches Denken“ } \\
\text { Exemplarisches Lernen } \\
\text { Pluralisierung der Einsichten und Perspektiven } \\
\text { Analyse der Geschichtskultur/Erinnerungskultur } \\
\text { Identitätsfindung }\end{array}$ \\
\hline
\end{tabular}

Tabelle: Sich überlappende Phasen des Umgangs mit dem Nationalsozialismus und Holocaust in Österreich - eine geschichtsdidaktische Perspektive ${ }^{51}$

51 Christoph Kühberger/Herbert Neureiter, Zum Umgang mit Nationalsozialismus, Holocaust und Erinnerungskultur. Eine quantitative Untersuchung bei Lernenden und Lehrenden an Salzburger Schulen aus geschichtsdidaktischer Perspektive, Schwalbach/Ts. 2017, 21. 
Diese Schichtungen und Verschleppungen von Diskursen im österreichischen Geschichtsunterricht sind leider bisher nicht ausreichend zeitgeschichtlich untersucht worden. Während es Schulbuchanalysen zulassen, ältere Traditionen in unterschiedlichen Jahrzehnten von 1945 bis in die Gegenwart zu erforschen und vorgenommene Tradierung zu beschreiben, ${ }^{52}$ fehlen bisher empirisch dokumentierte Berichte von ehemaligen SchülerInnen aus unterschiedlichen Jahrzehnten, die noch bis in die 1980er-Jahre hinein davon berichten, dass der Nationalsozialismus (un-) bewusst aus dem Unterricht in Österreich ausgeklammert worden sei. ${ }^{53}$

Nachdem die Kriegsgeneration unter den LehrerInnen einer Auseinandersetzung mit dieser - ihrer! - Geschichte häufig aus dem Weg gegangen war, werden heute an den Unterricht über die nationalsozialistische Gewaltherrschaft hohe und vielfältige Erwartungen verknüpft. Nicht nur historisches Wissen soll vermittelt werden, sondern es soll auch erzieherisch auf Werthaltungen eingewirkt werden. Am Beispiel der radikalen Negierung

52 Vgl. Heinz P. Wassermann, Verfälschte Geschichte im Unterricht. Nationalsozialismus und Österreich nach 1945, Innsbruck/Wien 2004; Ina Markova, Balancing Victimhood and Complicity in Austrian History Textbooks. Visual and Verbal Stratgies of Depicting the Past in post-Waldheim Austria, in: Journal of Educational Media, Memory and Society 3 (2011), 58-73; Ina Markova, Wie Vergangenheit neu erzählt wird. Der Umgang mit der NS-Zeit in österreichischen Schulbüchern, Marburg 2013; Wolfgang Bilewicz, Der Holocaust in Schulbüchern und Lehrplänen, Marburg 2016; Philipp Mittnik, Holocaust-Darstellungen in Schulbüchern. Deutsche, österreichische und englische Geschichtsschulbüchern im Vergleich, Schwalbach/Ts. 2017; Christoph Kühberger, The problem of personalising history. Myths around Hitler in Austrian history textbooks - exploring the issue via qualitative and quantitative methods, in: Roland Bernhard/Susanne Grindel/ Felix Hinz/Christoph Kühberger (Hg.), Myths in German-language Textbooks. Their Influence on Historical Accounts from the Battle of Marathon to the Élysée Treaty (Eckert. Dossiers 4), Braunschweig 2019, 211-238; Nikolaus Eigler/Christoph Kühberger, Zur kompetenzorientierten Einbindung von Bildern in Geschichtsschulbüchern. Eine geschichtsdidaktisch kategoriale Erschließung am Beispiel des Themenbereiches Nationalsozialismus und Holocaust, in: Christoph Bramann/ Christoph Kühberger/Roland Bernhard (Hg.), Historisches Denken lernen mit Schulbüchern, Frankfurt a. M. 2018, 160-180.

53 Dies ist durchaus auf die gesellschaftliche, schulische und in Teilen familiäre Haltung des Schweigens über die nationalsozialistische Vergangenheit zurückzuführen. - Vgl. Margit Reiter, Das Familiengedächtnis oder Die Tücken der Erinnerung, in: Meike Sophia Baader/Tatjana Freytag (Hg.), Erinnerungskulturen. Eine pädagogische und bildungspolitische Herausforderung, Köln 2015, 39-57, 40; Heribert Bastel/Christian Matzka/Helene Miklas, Holocaust Education in Austria. A (Hi)story of Complexity and Prospects for the future, in: Zehavit Gross/E. Doyle Stevick (Hg.), As the Witnesses Fall Silent. $21^{\text {st }}$ century Holocaust Education in Curriculum, Policy and Practice, Heidelberg/New York 2015, 407-425, 412. 
von Menschenrechten und Humanität durch das NS-Regime soll die Wertschätzung von Demokratie und Pluralität gelernt werden. ${ }^{54}$

Die Überschneidungen mit einem ethisch-moralischen oder politischen Lernen sind dabei unvermeidbar, sollten jedoch im Unterricht sichtbar gemacht werden, um so auch den Lernenden die verschiedenen Zugriffsarten auf den Themenbereich Nationalsozialismus und Holocaust zu verdeutlichen.

Es scheint aus geschichtsdidaktischer Perspektive jedoch ein wenig redlicher Zugang zu sein, den Holocaust ohne historische Quellen, verschiedene triftige Interpretationen oder zeitliche Kontexte zu unterrichten, da damit seine historische Einbettung in ein bestimmtes kulturelles, ökonomisches und politisches Setting ignoriert werden würde. Vielmehr sollte die historische Orientierungskompetenz, ${ }^{55}$ welche aus der kritischen Arbeit an der Vergangenheit (Quellen) und mit Geschichte (Darstellungen) Orientierungsangebote für Gegenwart und Zukunft ableitet, verstärkt berücksichtigt werden. Da eine solche Orientierung verschiedenartig ausfallen kann, zumal ja die Vergangenheit keine Bewertungen und Sinnbildungsmuster für die Gegenwart und Zukunft vorgibt, zeigt sich gerade dort der Überlappungsbereich hin zur Politischen Bildung..$^{56}$

Zusammenfassend kann jedoch festgehalten werden, dass es in den letzten Jahren zu einer erkennbaren Entflechtung des sozialisationsbedingten Umgangs mit dem Bereich Nationalsozialismus und Holocaust in den Familien der Lernenden gekommen ist. Es sind nämlich nicht mehr das Elternhaus und die Peers, welche entscheidenden Einfluss auf das Wissen über diese Zeit nehmen (wovon Lehrpersonen noch ausgehen), sondern der Geschichtsunterricht. ${ }^{57}$

54 Werner Dreier, Education on National Socialism and the Holocaust in Austria, in: erinnern.at (Hg.), Holocaust Education in Austria, Bregenz 2010, 12-16, 12.

55 Vgl. Waltraud Schreiber, Kompetenzbereich Historische Orientierungskompetenz, in: Andreas Körber/Waltraud Schreiber/Alexander Schöner (Hg.), Kompetenzen historischen Denkens. Ein Strukturmodell als Beitrag zur Kompetenzorientierung in der Geschichtsdidaktik, Neuried 2007, 236-264.

56 Kühberger/Neureiter, Umgang, 119-120. - Vgl. dazu auch: Klaus Hornung, Politik und Zeitgeschichte in der Schule. Didaktische Grundlagen, Villingen 1966, 9-11; Peter Massing, Zeitgeschichte als Rückgrat der politischen Bildung?, in: Michele Barricelli/Julia Hornig (Hg.), Aufklärung, Bildung, „Histotainment“? Zeitgeschichte in Unterricht und Gesellschaft heute, Frankfurt a. M. 2008, $67-81,75-77$.

57 Kühberger/Neureiter, Umgang, 47-48. 
Es steht diesbezüglich zu vermuten, dass die Geschichtslehrerinnen und Geschichtslehrer aufgrund einer von den früher unterrichteten Generationen verschleppten Vorstellung oder Praxiserfahrung, wonach die Familie einen verstärkten Einfluss auf das Geschichtsbild der Schülerinnen und Schüler habe, den Grad der Historisierung ihrer aktuellen Schülerinnen und Schüler mit Geburtsjahrgängen um 2002 verkennen. Aktuell handelt es sich beim Themenbereich Nationalsozialismus und Holocaust um Wissensbestände, welche bereits viel stärker kulturell vermittelt werden (u. a. über die Schule, Museen, TV, Internet) als über die in Familien oder auch peers weitergegebenen unmittelbaren Erinnerungen an die NS-Zeit. ${ }^{8}$

Aufgrund der notwendigen Beschäftigung mit dem Nationalsozialismus und Holocaust bleiben andere Gebiete der Zeitgeschichte im Geschichtsunterricht jedoch relativ farblos oder werden nur sehr punktuell betrachtet. Hervorzuheben sind jedoch jene Bereiche, zu denen in Österreich publiziert wurde („1968“ und die Folgen, ${ }^{59}$ 1989, Europäische Union, ${ }^{60}$ Zeitgeschichte im Museum $\left.{ }^{61}\right)$.

58 Kühberger/Neureiter, Umgang, 107 (Hervorhebung im Original).

59 Christoph Kühberger/Elfriede Windischbauer, Kleidung und Mode in unterschiedlichen Lebenswelten seit 1950. Annäherungen für den Geschichtsunterricht, in: Historische Sozialkunde 37 (2007) 4, 41-44; Christoph Kühberger/Elfriede Windischbauer, „Uni-Ferkelei“. Die 68er-Bewegung in Österreich, in: Geschichte Lernen 133/2009, 38-43; Christoph Kühberger, „Das Schwein von Salzburg“. Provokation als Mittel der unkonventionellen Partizipation. Oder: Wenn SchülerInnen über ein Schwein schreiben - Rekonstruktion im Geschichtsunterricht, in: Historische Sozialkunde 40 (2010) 3, 39-46.

60 Christoph Kühberger/Dirk Mellies (Hg.), Inventing the EU. Zur De-Konstruktion von „fertigen Geschichten“ über die EU in deutschen, polnischen und österreichischen Schulgeschichtsbüchern, Schwalbach/Ts. 2009; Christoph Kühberger, Die Geschichte der Europäischen Union in Schulgeschichtsbüchern. Reflexionen zur normativen Triftigkeit anhand von deutschen, polnischen und österreichischen Beispielen, in: Christoph Kühberger/Clemens Sedmak (Hg.), Europäische Geschichtskultur - Europäische Geschichtspolitik. Vom Erfinden, Entdecken, Erarbeiten der Bedeutung von Erinnerung für das Verständnis und Selbstverständnis Europas, Innsbruck/Wien 2009, 143-159; Johannes Fischer/Christoph Kühberger, Die EU in Schulgeschichtsbüchern. Drei Länder im Vergleich, in: Linda Erker/Alexander Salzmann/Lucile Dreidemy/Klaudija Sabo (Hg.), Update! Perspektiven der Zeitgeschichte. Zeitgeschichtstage 2010, Innsbruck/Wien 2012, 194-200.

61 Andrea Brait, Der Erste Weltkrieg in österreichischen und deutschen Historischen Museen, in: Reinelde Motz-Linhart (Red.), Tagungsbericht des 25. Österreichischen Historikertages. St. Pölten 16.-19.09.2008, St. Pölten 2010, 421-428; Andrea Brait, Der Museumsboom als Ausdruck der Visualisierung von Geschichte. Herausforderungen und Chancen für die Geschichtsdidaktik, in: Zeitschrift für Geschichtsdidaktik 12 (2013), 95-111; Christoph Kühberger, Zur geschichtskulturellen Verarbeitung des Ersten Weltkrieges im Jahr 2014 in Österreich, in: Monika Fenn/Christiane Kuller (Hg.), Auf dem Weg zur transkulturellen Erinnerungskultur? Konvergenzen, Inferenzen und Differenzen der Erinnerung an den Ersten Weltkrieg im Jubiläumsjahr 2014, Schwalbach/Ts. 2016, 118-144; Andrea Brait, 1917. Narrationen eines Wendepunkts in österreichischen Geschichtslehr- 


\section{Subjekte des zeithistorischen Lernens in post-postmodernen Gesellschaften}

Fokussiert man die lernenden Subjekte des Geschichtsunterrichts, so zeigt sich durchaus ein erhöhtes Interesse an Zeitgeschichte gegenüber allen anderen historischen Epochen. ${ }^{62}$ Dies steht vermutlich mit der „Primärerfahrung“ in Verbindung. Zwar besitzen SchülerInnen diese selbst nur in zeitlich sehr eingeschränktem Maße, doch leben sie in einer zwangsläufig erfahrungsgesättigten Lebenswelt, in der Zeitgeschichte eben tatsächlich eine „Epoche der Mitlebenden“ darstellt. Die Zugänglichkeit zu Informationen in Form von Lebensgeschichten, Erfahrungen, Gegenständen, zeitgenössischen Publikationen etc. ist in der Regel weit augenfälliger und nachvollziehbarer, als dies bei anderen historischen Epochen auch überhaupt nur möglich ist, für die nämlich verstärkt formale Vermittlungsinstanzen (Archive, Museen, Bildungseinrichtungen etc.) eine Rolle spielen. ${ }^{63}$ Im Alltag werden SchülerInnen davon auch eingeholt, dass die Vorgeschichte der Gegenwart in gegenwärtige gesellschaftliche und politische Fragen eingeschrieben ist und dort mit Bezug auf eine zu gestaltende Zukunft verhandelt wird. Markus Furrer betont daher zu Recht, dass die „Grenzen zwischen politischer Auseinandersetzung, ideologischem Ringen und historischer Aufarbeitung" im Zusammenhang mit zeitgeschichtlichen Fragen fließend seien und „die Aufdeckung vergangener Zusammenhänge häufig zur Entdeckung unangenehmer Wahrheiten “ führen könne. ${ }^{64}$ Die Relevanz der zeitgeschichtlichen Auseinandersetzung ist daher unmittelbarer und in der Orientierungsfunktion offenkundiger, wenngleich wissenschaftliche Einsichten in der Öffentlichkeit mit journalistischen Recherchen, Aussagen von ZeitzeugInnen, politisch-ideologischen Interpretationen, wirtschaftlich ausgestalteten Produkten der Unterhaltungsindustrie etc. konkurrieren. Es stellt daher eine Aufgabe des Geschichtsunterrichts im Zusammenhang mit zeitgeschichtlichen Fragestellungen dar, die verschiedenen Formen des Umgangs mit Zeitgeschichte, wie sie uns in der analogen und digitalen

werken und in Ausstellungen, in: Revue d'Allemagne et des Pays de langue allemande 49 (2017) 2, 447-462; Andrea Brait, Zur Vermittlung des Kriegsendes 1945 in nationalen Militärmuseen. Militärmuseen im 21. Jahrhundert und die Darstellung des Zweiten Weltkrieges, in: Robert Kriechbaumer/Wolfgang Mueller/Erwin A. Schmidl (Hg.), Militär und Politik im 19.-20. Jahrhundert. Österreichische und europäische Aspekte, Wien/Köln/Weimar 2017, 465-484.

62 Vgl. die Befragung von 15-Jährigen in Europa: Bodo von Borries, Jugend und Geschichte. Ein europäischer Kulturvergleich aus deutscher Sicht, Opladen 1999, 41.

63 Vgl. Martin Lücke/Michael Sturm, Stiefschwestern. Zum Verhältnis von Zeitgeschichte und Geschichtsdidaktik, in: Michele Barricelli/Julia Hornig (Hg.), Aufklärung, Bildung, „Histotainment“? Zeitgeschichte in Unterricht und Gesellschaft heute, Frankfurt a. M. 2008, 27-41, 33-34.

64 Markus Furrer, Grundfragen und Themen der Zeitgeschichte, in: Markus Furrer/Kurt Messmer (Hg.), Handbuch Zeitgeschichte im Geschichtsunterricht, Schwalbach/Ts. 2013, 21-60, 23. 
Geschichtskultur entgegentreten, analysier- und verstehbar zu machen. Denn - und dies betont Christian Heuer diesbezüglich -

in diesen Objektivationen (Belletristik, Film, Gedenktage, Museum, Denkmäler, Spiel, Comic etc.) des alltäglichen Geschichtsbewusstseins werden die unterschiedlichen Erinnerungen ästhetisch, moralisch und politisch inszeniert und stellen Sinnstiftungsangebote für den „Mitlebenden“ zur Verfügung. Nimmt man diese Erkenntnis ernst, dann muss dies die Abkehr von den kompakten und normativen Formen der Wissensvermittlung bedeuten. Vielmehr müsste es im Geschichtsunterricht um „Geschichten“ und deren unterschiedliche Erinnerungsdiskurse gehen. Dies bedeutet aber zugleich die Abkehr von der unsinnigen Vorstellung, man habe die Schülerinnen und Schüler allein durch ihre erlerntes Schulbuchwissen auf eben diesen außerschulischen Diskurs genügend vorbereitet. ${ }^{65}$

Damit ein derart neu konzipierter Zeitgeschichteunterricht nicht zu einer Entfremdung von seinen Lerngegenständen führt, sollten geschichtskulturelle Erfahrungen der SchülerInnen sowie die ihnen begegnenden geschichtskulturellen Produkte und deren Interpretationen miteinbezogen werden. Der Unterricht hat damit den Umgang mit Vergangenheit und Geschichte in Lernprozessen - viel stärker, als dies traditionell der Fall war - vom lernenden Subjekt her auszugestalten. Individuelle Wahrnehmungen, gemachte Erfahrungen, abrufbare Gefühlslagen, artikulierbare Interessen, bereits vollzogene Denkakte und subjektive Vorstellungen der Lernenden bilden dabei günstige Anschlussstellen, um persönliche Bedeutsamkeiten, die als lebensweltlich verortete, biographische und damit identitätskonkrete Momente aufzufassen sind, motivational zu nutzen, um fachliches Lernen zu ermöglichen. ${ }^{66}$ Ein derartiger Zugang reagiert aber nicht nur auf pädagogische Konzeptionen und psychologische Erkenntnisse zum Lernen, sondern ist auch als Produkt von postmodernen Gesellschaften zu lesen. Diese „sind radikal individualisiert, ökonomisiert, globalisiert, eben divers. Zeitgeschichte in der Wanderungsgesellschaft ist daher die Geschichte von diversity. "Nach Michele Barricelli konstituiere Zeitgeschichte im 21. Jahrhundert „zunehmend, glatte‘, deterritorialisierte Räume mobiler Individuen, Dienstleister, Konsumenten anstelle der , gekerbten' Räume von sesshaften, (einstmals) landwirtschaftlich geprägten Gemeinschaften“. Damit verliere aber „das Sprechen über Vergangenheit (,historisches Erzählen') [...] an Verbindlichkeit, wird

65 Heuer, Geschichtsdidaktik, 173.

66 Christoph Kühberger, Subjektorientierte Geschichtsdidaktik. Eine Annäherung zwischen Theorie, Empirie und Pragmatik, in: Heinrich Ammerer/Thomas Hellmuth/Christoph Kühberger (Hg.), Subjektorientierte Geschichtsdidaktik, Schwalbach/Ts. 2015, 13-47, 40-41. 
zunehmend abgeleitet, fragmentarisch, metaphorisch“. Aus diesem Grund fordert Barricelli eine Neuausrichtung:

Ziel von Geschichtsunterricht in Zeiten von Migration und Mobilität, mithin Orts- und Heimatlosigkeit muss es sein, eine Weltgesellschaft zu schaffen, die gemeinsam geteilte Erinnerungsbestände an die Stelle von trennenden Partikularinteressen setzt. ${ }^{67}$

Zeitgeschichtliches Lernen könne darin über ein „grenzenlose[s], nicht hierarchisch regulierte[s] Erkenntnisinteresse“ als „Autonomiestütze aller Individuen“ dienen. ${ }^{68}$

\section{Ausblick}

Zeitgeschichte wird in der Konzeption des österreichischen Geschichtsunterrichts schon lange nicht mehr national verengt verstanden. ${ }^{69}$ Transkulturelle und globale Fragestellungen sind für diesen Zeitabschnitt ebenso $\mathrm{zu}$ behandeln wie etwa thematische Aspekte der Neuen Kulturgeschichte, Umweltgeschichte oder Migrationsgeschichte. Es besteht jedoch für den Geschichtsunterricht in Österreich die Herausforderung, die darin lagernden Aspekte einer sich selbst gegenüber kritisch eingestellten wissenschaftlichen Zeitgeschichte, die sich gegenüber einer Geschichte der Haupt- und Staatsaktionen dezentriert und damit öffnet sowie neue Formen der zeithistorischen Darstellung zulässt, für das historische Lernen aufzugreifen. ${ }^{70}$ Es muss daher ein anhaltendes Kennzeichen einer zeitgeschichtlichen Beschäftigung im Unterricht bleiben, Multiperspektivität auf der Ebene der historischen Quellen („Multiperspektivität“), der Darstellungen von Vergangenheit („Kontroversität“) sowie der persönlichen bzw. aktuellen Gegenwartsinterpretationen („Pluralität“) als Unterrichtsprinzip zu nutzen. ${ }^{71}$ Nur so kann es gelingen, dass einseitige geschichtspolitische Indienstnahmen der Zeitgeschichte, etwa über ein Schüren von Betroffenheit oder die Überwältigung durch glaubhaft wirkende, aber zwingend pers-

67 Michele Barricelli, Collected Memories statt kollektives Gedächtnis. Zeitgeschichte als Migrationsgeschichte, in: Markus Furrer/Kurt Messmer (Hg.), Handbuch Zeitgeschichte im Geschichtsunterricht, Schwalbach/Ts. 2013, 89-118, 94-95.

68 Barricelli, Collected, 97.

69 Eine sehr frühe Stimme gegen eurozentrische Standpunkte im zeitgeschichtlich ausgerichteten Geschichtsunterricht findet man bei: Wanda Kampmann, Zur Didaktik der Zeitgeschichte, Stuttgart 1968,87 .

70 Lücke/Sturm, Stiefschwestern, 37-39.

71 Vgl. Klaus Bergmann, Multiperspektivität. Geschichte selber denken, Schwalbach/Ts. 2000. 
pektivische Berichte von ZeitzeugInnen, einer kritischen Analyse und Bewertung zugeführt werden..$^{72}$

Durch die damit einhergehende Erosion von fixierten Themenbereichen einer klassischen Zeitgeschichte oder eines als stabil erträumten Kanons von Jahreszahlen oder Interpretationen für das 20. und beginnende 21. Jahrhundert braucht es sicherlich eine anhaltende Diskussion zu zentralen Angelpunkten der Entwicklungen. ${ }^{73}$ Dies sollte jedoch nicht als Diskussion um ein undifferenziertes Abprüfen von isolierten Datensätzen oder vorgefertigten Interpretationen für den Geschichtsunterricht missverstanden werden, sondern als Verständigungsprozess innerhalb der Gesellschaft über die Auswirkungen von Begebenheiten und deren Bedeutung für unsere Gegenwart oder eine erwartete Zukunft gelesen werden. Darin lagern letztlich Orientierungsangebote und diese unterstreichen nochmals die Orientierungsfunktion einer Beschäftigung mit Zeitgeschichte. Aus diesem Grund wird es notwendig sein, eine enorme Offenheit für die lebensweltorientierten Fragen der Lernenden selbst und für die Fragwürdigkeiten, welche die Gegenwart stets neu produziert, im Geschichtsunterricht zu wahren.

Zeitgeschichte ist jene Epoche, die beobachtbar im eigenen Leben nachwächst. Es gilt daher, bei den SchülerInnen im Geschichtsunterricht ein flexibles fachspezifisches Denken mit epistemischer Tiefenstruktur anzubahnen, um diese - zwar an konkreten (zeit-)historischen Fallbeispielen erlernten - Fähigkeiten und Fertigkeiten zukünftig auch in noch nicht antizipierbaren Konstellationen des Historischen und des Politischen zur Anwendung bringen zu können.

72 Vgl. Heuer, Geschichtsdidaktik, 173. - auch: Reinhard Krammer, Zeitgeschichte in der Schule. Ein didaktischer Problemaufriss, in: Informationen zur Politische Bildung 20/2003, 105-114, 105.

73 Vgl. etwa zu 1989: Christoph Kühberger, 1989 im österreichischen Geschichtsunterricht. Über Zeitpunkte und Ikonen, in: Grenzöffnung 1989. Innen- und Außenperspektiven und die Folgen für Österreich, Wien 2012, 469-481; Andrea Brait (Hg.), Österreich und die Ostöffnung 1989 (Historisch-politische Bildung. Themendossiers zur Didaktik von Geschichte, Sozialkunde und Politischer Bildung 8), Wien 2015; Andrea Brait, 1989. Ein Epochenjahr auch für Österreich, in: SWS-Rundschau 54 (2014) 3, 305-330. 


\section{Zeitgeschichte und Internationale Geschichte}

Elisabeth Röhrlich

\section{Einleitung}

In seiner großen Studie zur Geschichte der Zweiten Republik hat Oliver Rathkolb vom österreichischen Solipsismus gesprochen: vom Hang zur Selbstbezogenheit. ${ }^{1}$ Lässt sich Rathkolbs Vorwurf auch auf die österreichische Zeitgeschichte übertragen? Oder ist die Disziplin offen für internationale Themen, Fragestellungen und Kooperationen? Diesen Fragen möchte ich in diesem kurzen Überblicksbeitrag nachgehen. Zu Beginn erläuterte ich kurz, warum die Disziplin Zeitgeschichte nicht nur in Österreich - traditionell vor allem auf die Geschichte des jeweils eigenen Landes geschaut hat. In einem zweiten Schritt skizziere ich kurz die Unterschiede zwischen den beiden historischen Teildisziplinen Internationale Geschichte und Globalgeschichte und erkläre, warum diese Unterschiede - bei allen Gemeinsamkeiten - für die Zeitgeschichte relevant sind. Im Anschluss übertrage ich meine Überlegungen auf den österreichischen Forschungskontext und fasse institutionelle Entwicklungen und aktuelle Forschungstrends in groben Zügen zusammen. Ich erhebe dabei keineswegs einen Anspruch auf Vollständigkeit. So streife ich die in diesem Zusammenhang so zentrale Rolle der Forschung zum Kalten Krieg nur am Rande, da sie ein eigenes größeres Forschungsfeld darstellt. Abschließend ziehe ich ein kurzes Fazit, in dem ich stichwortartig auf zukünftige Entwicklungsmöglichkeiten eingehe.

\section{Zeitgeschichte als Problemgeschichte der Gegenwart}

Das Fach Zeitgeschichte, welches sich mit der „Vorgeschichte der Gegenwart“ beschäftigt, hat eine viel offensichtlichere Relevanz für gesellschaftliche und politische Fragen der Gegenwart als andere historische Disziplinen. ${ }^{2}$ Für den deutschsprachi-

1 Oliver Rathkolb, Die paradoxe Republik: Österreich 1945 bis 2015, München 2015, 26.

2 Anselm Doering-Manteuffel/Lutz Raphael/Thomas Schlemmer (Hg.), Vorgeschichte der Gegenwart. Dimensionen des Strukturbruchs nach dem Boom, Göttingen 2016. 
gen Raum gilt das in ganz besonderem Maße. In der Bundesrepublik liegen die Anfänge der institutionalisierten Zeitgeschichte in der unmittelbaren Nachkriegszeit. 1949 wurde in München das Institut für Zeitgeschichte gegründet (anfangs noch unter anderem Namen), um den Nationalsozialismus und die Vorgeschichte der Weimarer Republik wissenschaftlich zu erschließen. ${ }^{3}$ In Österreich formierte sich das Fach Zeitgeschichte etwa zehn Jahre später. Ein erster wichtiger Fokus lag auf der Geschichte des österreichischen Widerstands gegen den Nationalsozialismus. Die Auseinandersetzung mit der österreichischen Geschichte war in weiten Teilen das Projekt einer „Koalitionsgeschichtsschreibung“, welche die Erfolgsgeschichte der Zweiten Republik untermauern wollte. ${ }^{4}$ Erst in späterer Folge gerieten das DollfußSchuschnigg-Regime und der österreichische Anteil am Nationalsozialismus in die zeithistorische Perspektive. Aus den geschichtspolitischen Motivationen, welche die Anfänge der wissenschaftlichen Zeitgeschichte in Österreich und Westdeutschland begleiteten, folgte, dass sich in beiden Ländern das Fach Zeitgeschichte zunächst vor allem auf die jüngste Geschichte des jeweiligen Landes konzentrierte. Ernst Hanisch hat in diesem Zusammenhang von einer „nationalstaatlichen Verengung der Zeitgeschichte" gesprochen. ${ }^{5}$

Noch immer widmet sich die österreichische Zeitgeschichtsforschung zu großen Teilen der Geschichte des Nationalsozialismus und der österreichischen Geschichte. Die Innsbrucker OrganisatorInnen des Österreichischen Zeitgeschichtetags 2020 zeigen dies anschaulich in einer grafischen Wortwolke, die sie aus den Schlagwörtern zu den für den Zeitgeschichtetag angenommenen Beiträgen erstellt haben. Die beiden Begriffe Nationalsozialismus und Österreich befinden sich in großer Schrift in der Mitte der Wortwolke. ${ }^{6}$ Josef Ehmer, der die Programme der Zeitgeschichtetage des ersten Jahrzehnts des 21. Jahrhunderts vor einigen Jahren ausgewertet hat, ist zu einem ähnlichen Ergebnis gekommen: Österreichische Geschichte und NS-Geschichte waren in dem von ihm untersuchten Zeitraum die prägendsten Themen.7 Andere Bereiche der Neuesten Geschichte, so Ehmers Befund weiter, würden dagegen von ZeithistorikerInnen vernachlässigt. Stattdessen überließen sie

3 Hans Günter Hockerts, Zeitgeschichte in Deutschland. Begriff, Methoden, Themenfelder, in: Historisches Jahrbuch 113 (1993), 98-127, 101.

4 Ernst Hanisch, Österreichische Zeitgeschichte im Drehkreuz von Politik und Wissenschaft, in: Alexander Nützenadel/Wolfgang Schieder (Hg.), Zeitgeschichte als Problem. Nationale Traditionen und Perspektiven der Forschung in Europa, Göttingen 2004, 54-77.

5 Hanisch, Österreichische Zeitgeschichte, 75.

6 Programm des Österreichischen Zeitgeschichtetags 2020, Universität Innsbruck, URL: https:// www.uibk.ac.at/zeitgeschichte/zgt2o/programm.html.de (abgerufen 15.02.2020).

7 Josef Ehmer, Sozialwissenschaftler/innen oder Zeithistoriker/innen: Wer schreibt die Geschichte des 20. Jahrhunderts, in: Heinrich Berger/Melanie Dejnega/Regina Fritz/Alexander Prenninger 
diese den SozialwissenschaftlerInnen. Laut Ehmer habe das dazu geführt, „dass die Zeitgeschichte zu vielen aktuellen gesellschaftlichen Entwicklungen nichts zu sagen hat". 8

Während sich die oben beschriebene nationalstaatliche Schwerpunktsetzung der Zeitgeschichte aus der Entstehungsgeschichte des Fachs ergibt, verlagerten sich die Interessensgebiete in den letzten Jahren teilweise, trotz klarer Kontinuität bei den stärksten Forschungszweigen. Diese Entwicklung lässt sich sowohl innerhalb Österreichs als auch in anderen Ländern beobachten. Anstöße zu dieser Neuperspektivierung kamen aus unterschiedlichen Richtungen. Zum einen ist die Zeitgeschichte, je näher sie mit ihren Untersuchungen an die Gegenwart rückte, zu einer „Problemgeschichte der Gegenwart" geworden, um es in Anlehnung an eine viel zitierte Überlegung Hans Günter Hockerts zu formulieren. ${ }^{9}$ Hier ist etwa das vermehrte Forschungsinteresse an der Geschichte der 1970er-Jahre zu nennen. Gesellschaftlicher Wandel, Ölpreiskrise, die Anfänge der Umweltbewegung - all das sind Themen, welche die Genese aktueller Problemstellungen freilegen können. Zur Erfahrung der 1970er-Jahre gehörte auch die sich immer komplexer gestaltende - und im Alltag immer erfahrbarer werdende - wirtschaftliche und gesellschaftliche Globalisierung. Ein 2010 von Niall Ferguson, Charles S. Maier, Erez Manela und Daniel J. Sargent herausgegebener Sammelband zur Geschichte der 1970er-Jahre hieß daher treffend: "The Shock of the Global“. ${ }^{10}$

Die österreichische Zeitgeschichtsforschung hat sich zuletzt stärker gegenüber Fragen der internationalen und globalen Geschichte geöffnet. In den letzten zehn Jahren haben sich in Österreich forschende und lehrende ZeithistorikerInnen etwa zunehmend mit der außereuropäischen Geschichte und den Nord-Süd-Beziehungen beschäftigt. Auch die klassische Diplomatiegeschichte erfährt - methodisch erneuert und auf Basis multiarchivalischer Recherchen - einen neuen Aufschwung. Häufig, aber nicht immer, haben diese Forschungen gleichzeitig weiterhin einen Bezug zur österreichischen Geschichte und fragen beispielsweise nach den Beziehungen Chinas und Österreichs im Kalten Krieg. ${ }^{11}$ Für den Forschungsstandort Ös-

(Hg.), Politische Gewalt und Machtausübung im 2o. Jahrhundert. Zeitgeschichte, Zeitgeschehen und Kontroversen. Festschrift für Gerhard Botz, Wien 2011, 59-72, 63.

8 Ehmer, Sozialwissenschaftler/innen oder Zeithistoriker/innen, 64.

9 Hockerts, Zeitgeschichte in Deutschland, 124; Anselm Doering-Manteuffel/Lutz Raphael (Hg.), Nach dem Boom. Perspektiven auf die Zeitgeschichte seit 1970, Göttingen ²010, 25.

10 Niall Ferguson/Charles S. Maier/Erez Manela/Daniel J. Sargent (Hg.), The Shock of the Global. The 1970 in Perspective, Cambridge (MA) 2010.

11 Maximilian Graf/Wolfgang Mueller, Austria and China, 1949-1989: A Slow Rapprochement, in: Valeria Zanier/Marco Wyss/Janick Schaufbühl (Hg.), Europe and China in the Cold War, Leiden 2019, 19-41. 
terreich hat die zeithistorische Auseinandersetzung mit internationalen und globalen Themen und Fragestellungen eine besondere Relevanz, die nicht völlig neu ist. So haben sich insbesondere im Bereich der Kalte-Krieg-Forschung österreichische ZeithistorikerInnen früh - und auch außerhalb Österreichs gut sichtbar - in der Internationalen Geschichte positioniert. Das Interesse an diesem Thema hat sich nicht zuletzt aus der spezifischen Lage Österreichs an der Grenze zwischen den beiden Blöcken des Kalten Krieges und der Neutralität des Landes ergeben. Als Sitz internationaler Organisationen und Austragungsort wichtiger diplomatischer Kongresse ist die Geschichte der internationalen Beziehungen aber auch außerhalb des KalteKrieg-Kontexts für Österreich und die hiesige Forschungslandschaft nach wie vor relevant. ${ }^{12}$ So ist in den letzten Jahren auch Österreichs Rolle in den internationalen Beziehungen nach 1989/1991 verstärkt zum Gegenstand der Forschung geworden. ${ }^{13}$ Jüngere Ereignisse, wie das im Sommer 2015 in Wien abgeschlossene sogenannte Atomabkommen mit dem Iran und die Rolle der ebenfalls in Wien ansässigen International Atomic Energy Agency (IAEA) bei der Verifikation dieses Abkommens sind nur zwei Beispiele hierfür. Sich mit der Frage des Verhältnisses von Zeitgeschichte und Internationaler Geschichte in Österreich eingehender zu beschäftigen, scheint daher auf der Hand zu liegen.

\section{Globalgeschichte und Internationale Geschichte}

Zunächst ist eine begriffliche Differenzierung zwischen Globalgeschichte und Internationaler Geschichte nötig. Das ist der wissenschaftlichen Genauigkeit geschuldet, birgt aber auch eine gewisse Brisanz. Denn, soviel sei vorweggenommen, im Vergleich zur Globalgeschichte ist die Internationale Geschichte, zumindest unter diesem Label und in institutionalisierter Form, in der österreichischen Wissenschaftslandschaft deutlich weniger sichtbar. Das bildet sich auch in der Klassifikationsdatenbank der Statistik Austria (ÖFOS) für die Wissenschaften ab. Wer als WissenschaftlerIn ihre/seine Arbeiten mit Schlagwörtern versehen will, hat die Begriffe

12 Eric Frey, Konferenzplatz Wien: Vienna as an International Conference Site, in: Günter Bischof/ Fritz Plasser/Anton Pelinka/Alexander Smith (Hg.), Global Austria. Austria's Place in Europe and the World (Contemporary Austrian Studies 20), Innsbruck/New Orleans 2011, 147-160.

13 Günter Bischof/Ferdinand Karlhofer (Hg.), Austria’s International Position after the End of the Cold War (Contemporary Austrian Studies 22), Innsbruck/New Orleans 2013. 
Zeitgeschichte und Globalgeschichte zur Auswahl, jedoch nicht Internationale Geschichte. ${ }^{14}$

Wie verhalten sich Internationale Geschichte und Globalgeschichte zueinander? Der Boom der Disziplin Globalgeschichte, die Zunahme transnationaler Perspektiven in der historischen Forschung und die verstärkte Analyse von Verflechtungsund Transferprozessen haben dazu geführt, dass in den vergangenen rund 15 Jahren zahlreiche Standortbestimmungen erschienen sind, die sich mit der Frage beschäftigen, was denn überhaupt Globalgeschichte sei. Dabei geht es neben methodischen Aspekten um die Frage, wie sich die Globalgeschichte zu Nachbardisziplinen wie den Area Studies verhält. Es wird außerdem kontrovers diskutiert, ob es sich bei Globalgeschichte um eine Forschungsperspektive handelt, die aller historischen Forschung gemein sein sollte, oder um ein eigenes Fach, das sich genuin globalhistorischen Forschungsgegenständen widmet. ${ }^{15}$ Ein großer Teil dieser Arbeiten geht auch auf das Verhältnis zur Internationalen Geschichte ein. Letztere konzentriert sich traditionell besonders auf staatliche Akteure sowie die Beziehungen zwischen unterschiedlichen Regierungen und die Geschichte des Staatensystems. Die klassische Internationale Geschichte ist daher vor allem Diplomatiegeschichte.

Viele der oben angesprochenen globalhistorischen Standortbestimmungen sprechen sich dennoch dagegen aus, zwischen der Globalgeschichte und der Internationalen Geschichte eine klare Trennlinie zu ziehen. Wie etwa der an der Harvard University lehrende Akira Iriye in seiner Arbeit über die Geschichte internationaler Organisationen anschaulich gezeigt hat, werden internationale Beziehungen nicht nur von DiplomatInnen gemacht, sondern von einer Vielzahl transnationaler AkteurInnen, darunter zivilgesellschaftliche Organisationen, WissenschaftlerInnen und andere ExpertInnen sowie Unternehmen. ${ }^{16}$ Kulturhistorische Fragenstellungen und Ansätze der Frauen- und Geschlechterforschung dienen nicht nur einer Modernisierung der Disziplin Internationale Geschichte, sondern sind dringend nötig, will man außenpolitische Entscheidungsprozesse und internationale Beziehungen

14 Klassifikationsdatenbank, Wissenschaftszweige, Statistik Austria, URL: http://www.statistik.at/ KDBWeb/kdb_Einstieg.do?NAV=DE (abgerufen 20.02.2020).

15 Als einige Beispiele von vielen seien genannt: Sebastian Conrad/Andreas Eckert/Ulrike Freitag (Hg.), Globalgeschichte. Theorien, Ansätze, Themen, Frankfurt a. M./New York 2007; Andrea Komlosy, Globalgeschichte. Methoden und Theorien, Wien/Köln/Weimar 2011; Roland Wenzlhuemer, Globalgeschichte schreiben. Eine Einführung in 6 Episoden, Konstanz/München 2017; Benedikt Stuchtey, Zeitgeschichte und vergleichende Imperiengeschichte. Voraussetzungen und Wendepunkte ihrer Beziehung, in: Vierteljahrshefte für Zeitgeschichte 65 (2017), 301-338.

16 Akira Iriye, Global Community. The Role of International Organizations in the Making of the Contemporary World, Berkeley/Los Angeles 2002. 
in ihrer Vielschichtigkeit verstehen. ${ }^{17}$ Diplomatie, einst klassisches Themengebiet der Internationalen Geschichte, ist damit auch zum Gegenstand der Globalgeschichte geworden. ${ }^{18}$ In diesem Sinne argumentieren auch Barbara Haider-Wilson, William Godsey und Wolfgang Mueller in einem vom Institut für Neuzeit der Österreichischen Akademie der Wissenschaften herausgegebenen großen Band zur Standortbestimmung der Internationalen Geschichte. Bereits das breitgefächerte Inhaltsverzeichnis zeigt die Vielfalt der Themen und Ansätze, die hier unter Internationale Geschichte zusammengefasst werden. In ihrer Einleitung zum Band spricht sich Haider-Wilson deutlich gegen eine Trennung von Internationaler Geschichte und Globalgeschichte aus, die sie für nicht zweckdienlich hält. Sie fasst hinsichtlich transnationaler und internationaler Perspektiven pointiert zusammen: „Ergänzung und nicht Gegenkonzept lautet hier die Losung. “19

Bei anderen stößt dieses Verwischen der Grenzen zwischen Internationaler Geschichte und Globalgeschichte hingegen auf Widerstand. Joseph Maiolo, Professor für Internationale Geschichte am King's College London, hat kürzlich argumentiert, dass die Grenzen zwischen den beiden Disziplinen wichtig und wieder stärker zu betonen seien. Maiolo erinnert in diesem Zusammenhang an die institutionellen Anfänge der Geschichte der internationalen Beziehungen, deren entscheidende Wurzeln er - trotz der diplomatiegeschichtlichen Vorläufer im 19. Jahrhundert vor allem in den Jahren nach dem Ende des Ersten Weltkriegs sieht. Geprägt von der Erfahrung des Krieges und inspiriert von der Gründung des Völkerbundes unterstützten liberale Denker und Stiftungen die politikwissenschaftliche und historische Auseinandersetzung mit den großen Fragen von Krieg und Frieden. Als Fach setzt sich die Internationale Geschichte seit diesen institutionellen Anfängen eng mit der Theorie der Internationalen Beziehungen auseinander und hat daher eine Nähe zur Politikwissenschaft. Was in Maiolos Sicht die Internationale Geschichte aber vor allem auszeichne, sei ihr Potenzial, zu einem besseren Verständnis aktueller internationaler Konflikte beitragen zu können: „what defines international history is its focus on the origins, structures, processes, and outcomes of international politics,

17 Glenda Sluga/Carolyn James (Hg.), Women, Diplomacy, and International Politics Since 1500, London/New York 2016.

18 Madeleine Herren, Diplomatie im Fokus der Globalgeschichte, in: Neue Politische Literatur 61 (2016) 3, 413-438.

19 Barbara Haider-Wilson, Humpty Dumpty, die Geschichtswissenschaft und der Pluralismus: Einlassung auf die historische Subdisziplin „Internationale Geschichte“, in: Barbara Haider-Wilson/ William D. Godsey/Wolfgang Mueller (Hg.), Internationale Geschichte in Theorie und Praxis/International History in Theory and Practice (Internationale Geschichte 4), 9-61. 
above all the causes of war and the conditions of peace“. ${ }^{20}$ Angesichts solcher Kritik hat der italienische Historiker Leopoldo Nuti sogar von einer Kluft zwischen GlobalhistorikerInnen und DiplomatiehistorikerInnen gesprochen. Beide Seiten hätten unterschiedliche Vorstellungen von der Wichtigkeit staatlicher AkteurInnen (deren Bedeutung die GlobalhistorikerInnen unterschätzen würden, so Nuti). So wirft er der Globalgeschichte beispielsweise vor, dass sie Fragen der Sicherheits- und Rüstungspolitik vernachlässige. ${ }^{21}$

Die hier kurz angerissenen Positionen mag man als akademischen Schulenstreit abtun, in dem es in erster Linie um die Verteidigung der eigenen Forschungsinteressen und -schwerpunkte geht, aber es steckt doch mehr dahinter. Tatsächlich warnen auch eingeschworene GlobalhistorikerInnen wie Jürgen Osterhammel davor, diese Themen in der geschichtswissenschaftlichen Forschung zu vernachlässigen: „the burning issues of war, peace, and the military [...] do not feature prominently enough in current global history“.22 Osterhammels große Globalgeschichte des 19. Jahrhunderts, „Die Verwandlung der Welt“, enthält hingegen auch Kapitel zur Diplomatie oder den internationalen Organisationen. ${ }^{23}$ Einige LeserInnen, so Osterhammel, hätten sich über diese Themen in einer globalhistorischen Studie gewundert, gelte Internationale Geschichte doch als veraltete Disziplin: „a redundant relic of an out-of-date type of historiography“. ${ }^{24}$ Auch Günter Bischof macht zu Beginn eines Themenheftes der „Contemporary Austrian Studies“ eine ähnliche Beobachtung: „In the historical profession today diplomatic history and foreign relations are not considered sexy and fashionable topics. Many colleagues think it is a hidebound field." ${ }_{25}$ Doch wie sieht es aktuell in Österreich mit der Bearbeitung dieser Themen aus? Ist Internationale Geschichte tatsächlich so altmodisch? Und wie verhält es sich mit der Trennung von Internationaler Geschichte und Globalgeschichte in der Forschungspraxis?

20 Joseph Anthony Maiolo, Systems and Boundaries in International History, in: The International History Review 40 (2018), 576-591, 577.

21 Leopoldo Nuti, The Making of the Nuclear Order and the Historiography of the 1970s, in: The International History Review 40 (2018), 965-974, 971.

22 Jürgen Osterhammel, Arnold Toynbee and the Problems of Today, in: Bulletin of the GHI 60/2017, $69-87,86$.

23 Jürgen Osterhammel, Die Verwandlung der Welt. Eine Geschichte des 19. Jahrhunderts, München 2009.

24 Osterhammel, Arnold Toynbee, 86.

25 Günter Bischof, Preface, in: Bischof/Karlhofer (Hg.), Austria’s International Position, ix. 


\section{Zeitgeschichte und Internationale Geschichte in Österreich}

Die von Ehmer konstatierte, weiter oben bereits angesprochene Arbeitsteilung zwischen SozialwissenschaftlerInnen und ZeithistorikerInnen bei der wissenschaftlichen Auseinandersetzung mit der gegenwartsnahen Zeitgeschichte zeigt sich bereits in der Vielzahl der Institutionen, an denen Zeitgeschichte in ihren internationalen und globalen Kontexten erforscht wird. Wer sich für österreichische Forschung zu diesen Themen interessiert, wird diese nicht an einem Ort gebündelt finden. Forschung zur internationalen Zeitgeschichte beschränkt sich auch keineswegs nur auf die Zeithistorischen Institute der österreichischen Universitäten. Um es am Wiener Beispiel, das ich am besten kenne, zu zeigen: Spannende zeithistorische Forschung, die sich mit internationalen und globalhistorischen Themen und Fragen beschäftigt, wird nicht nur am Institut für Zeitgeschichte der Universität Wien betrieben, sondern beispielsweise auch am Institut für Wirtschafts- und Sozialgeschichte, am Institut für Osteuropäische Geschichte und am Institut für Geschichte. Auch außerhalb der Historischen Institute wird zeithistorisch geforscht: von den KollegInnen der Area Studies, der Internationalen Entwicklung oder auch der Europäischen Ethnologie kommen wichtige Impulse.

Dagegen gibt es österreichweit an den universitären Zeithistorischen Instituten keine einzige Professur, die den Widmungsbereich Internationale Geschichte oder Geschichte der internationalen Beziehungen hat. Am nächsten kommt dem noch die Professur Oliver Rathkolbs in Wien, die sich der österreichischen Republikgeschichte im internationalen Kontext widmet. ${ }^{26}$ Unter Rolf Steininger setzte die Innsbrucker Zeitgeschichte von 1984 bis 2010 auf ein klares diplomatiegeschichtliches Profil. Steiningers Schriften umfassen Forschungsarbeiten, Einführungswerke und Synthesen zu Themen wie der Südtirolfrage, der Kubakrise, dem Kalten Krieg, dem Mittleren Osten und den amerikanisch-europäischen Beziehungen. ${ }^{27}$ Als die Universität Graz Anfang 2019 die dortige Professur für Zeitgeschichte neu ausschrieb, konzipierte sie die Stelle als globale Zeitgeschichte und suchte nach BewerberInnen, die das Fach "in seiner ganzen Breite aus einer globalen Perspektive“ vertreten. ${ }^{28}$ Die

26 Maximilian Graf/Elisabeth Röhrlich, Von der Diplomatiegeschichte zur International History. Das Institut für Zeitgeschichte und die internationalen Beziehungen, in: Bertrand Perz/Ina Markova (Hg.), 50 Jahre Institut für Zeitgeschichte der Universität Wien 1966-2016, Wien 2017, 334-354.

27 Für einen Überblick über Rolf Steiningers umfangreiches Schaffen siehe dessen Webseite, URL: https://www.rolfsteininger.at/publikationen.html (abgerufen 27.02.2020).

28 Stellenanzeige „Professur für Zeitgeschichte“ der Universität Graz, in: Mitteilungsblatt der KarlFranzens-Universität Graz Nr. 18 vom 13.02.2019, 244-245, URL: https://mitteilungsblatt.unigraz.at/de/2018-19/18/pdf/ (abgerufen 30.11.2020). 
Stelle ist in der Zwischenzeit mit der Globalhistorikerin und Lateinamerikaexpertin Christiane Berth besetzt worden.

Interessanterweise forschen österreichische ZeithistorikerInnen, die sich mit der Geschichte der internationalen Beziehungen und der Diplomatiegeschichte beschäftigen, oft außerhalb der österreichischen Universitäten. Hier sind vor allem Michael Gehler an der Stiftung Universität Hildesheim und Günter Bischof an der University of New Orleans zu nennen, aber auch Vertreter einer jüngeren Generation, wie Roman Birke an der Friedrich-Schiller-Universität Jena und Maximilian Graf an der Karls-Universität in Prag. Auch außeruniversitäre Institute schenken der Internationalen Geschichte teils größere Aufmerksamkeit als die universitären Institute, beispielsweise die Diplomatische Akademie in Wien oder das Ludwig Boltzmann Institut für Kriegsfolgenforschung in Graz.

Ist diese Trennung ein Zufall oder gibt es dafür Gründe? Die Diplomatiegeschichte und die Internationale Geschichte haben, wie auch aus den weiter oben zitierten Anmerkungen von Bischof und Osterhammel hervorgeht, häufig den Ruf, methodisch altbacken und konservativ zu sein. Die Gründe für dieses Image sind fachhistorisch begründet, doch gelten sie für die meisten der aktuellen Forschungen aus diesem Bereich nicht mehr. Doch das alte Image wirkt nach und ist weniger attraktiv für die Einwerbung von Forschungsgeldern, bei denen methodische und theoretische Innovation verlangt werden. Außerdem scheint es unter HistorikerInnen (mit wichtigen Ausnahmen) mitunter eine gewisse Scheu zu geben, sich bei Themen zu positionieren, die eine tagespolitische Relevanz haben, sowie davor, dezidiert policy-relevante Forschung zu betreiben. Solche Ansätze finden sich eher in den Sozialwissenschaften (wenn auch unter Beteiligung von HistorikerInnen), wie etwa dem Momentum-Kongress oder dem Österreichischen Institut für Internationale Politik (ÖIIP).

Dennoch haben in den letzten Jahren internationale Fragestellungen auch an den österreichischen Zeitgeschichte-Instituten wieder vermehrt Aufmerksamkeit erfahren. An der Schnittstelle innenpolitischer und außenpolitischer Fragen ergeben sich hier besonders spannende Arbeiten der Zeitgeschichte, die helfen, das Fach neu zu positionieren und die Einseitigkeit der traditionellen Diplomatiegeschichte bzw. der Internationalen Geschichte zu überwinden. Ein wichtiges Forschungsfeld ist hier die Migrationsgeschichte, die spätestens seit der großen „Gastarbajteri“-Ausstellung im Wien Museum 2004 neues Interesse von ZeithistorikerInnen erfahren hat. Auch das Innsbrucker Institut für Zeitgeschichte unter Dirk Rupnow hat sich in diesem 
Bereich stark mit Forschungsprojekten positioniert. ${ }^{29}$ Das Thema Migration wird nicht nur in seinen gesellschaftlichen und sozialen Dimensionen erforscht, sondern auch in internationalen politischen Kontexten: So forscht etwa Sarah Knoll am Wiener Institut für Zeitgeschichte zur Rolle von NGOs und dem UNHCR beim Umgang mit Kommunismusflüchtlingen in Österreich 1956-1989/1990. Doch nicht nur beim Thema Migration rückt die Rolle internationaler Organisationen (einschließlich der Rolle von NGOs) aktuell vermehrt ins Forschungsinteresse. So haben Oliver Rathkolb und Petra Mayrhofer ein neues Forschungsprojekt zu internationalen „Expert Clearing Houses“ in Wien konzipiert, in dem sie unter anderem die Geschichte des IIASA, des International Institute for Applied Systems Analysis, untersuchen. Im Kalten Krieg war das Institut ein wichtiger Begegnungsplatz von ExpertInnen aus Ost und West. Es ist daher ein besonders geeigneter Untersuchungsgegenstand, um internationale und transnationale Entwicklungen zusammenhängend zu analysieren..$^{30}$ Meine eigenen Forschungen konzentrieren sich seit knapp zehn Jahren auf die Geschichte der größten und ältesten internationalen Organisation in Österreich, der IAEA. Als internationale Organisation ist die IAEA ein Schauplatz internationaler zwischenstaatlicher Diplomatie, aber zugleich ein wichtiges Forum, in dem sich ExpertInnen unterschiedlicher Länder austauschen und zivilgesellschaftliche Organisationen Einfluss auf die Organisation und ihre Agenda erlangen. ${ }^{31}$ Auch die Forschungen Eva-Maria Muschiks am Wiener Institut für Internationale Entwicklung stärken das Wiener Profil in der Erforschung der Geschichte internationaler Organisationen. ${ }^{32}$ Das ist für Wien als UN-Sitz ein besonders attraktives und relevantes Forschungsfeld. Einige dieser Arbeiten stehen dabei auch in einem Zusammenhang mit Fragestellungen, wie sie an der Historisch-Kulturwissenschaftlichen Fakultät

29 Ausstellungskatalog: Hakan Gürses/Cornelia Kogoj/Silvia Matti (Hg.), Gastarbajteri. 40 Jahre Arbeitsmigration, Wien 2004; FWF-Projekt P-24468-G18: „Deprovincializing Austrian Contemporary History (MIGRANATION)“, Projektleitung: Dirk Rupnow (2012-2017). FWF-Projekt P-32959: „Ideentransfers durch ,Expert Clearing Houses` in Wien“, Projektleitung: Oliver Rathkolb (2020-2022).

31 IAEA History Research Project, Projektleitung: Elisabeth Röhrlich (laufend), URL: https://iaeahistory.univie.ac.at (abgerufen 27.02.2020).

32 Roman Birke, Geburtenkontrolle als Menschenrecht. Die Diskussion um globale Überbevölkerung seit den 1940er Jahren (Schriftenreihe Menschenrechte im 20. Jahrhundert 5), Göttingen 2020; Eva-Maria Muschik, Managing the World: The United Nations, Decolonization and the Strange Triumph of State Sovereignty in the 1950s and 1960s, in: Journal of Global History 12 (2018), 122-144. 
der Universität Wien epochen- und raumübergreifend unter dem Titel „Geschichte der Demokratie und der Menschenrechte " erforscht werden. ${ }^{33}$

Auffallend ist ferner die wachsende Zahl von Forschungsarbeiten, welche die Untersuchung der Nachkriegsgeschichte und des Kalten Krieges aus der lange dominierenden Fokussierung auf die Ost-West-Dichotomie lösen und mehr in NordSüd- und Süd-Süd-Perspektiven verankern möchten. In diesem Zusammenhang sind etwa Kerstin von Lingens Arbeiten zur internationalen Gerichtsbarkeit und den Kriegsverbrechertribunalen in Asien anzuführen. ${ }^{34}$ Eine Fülle von Einzelstudien trägt zum Wachstum einer solchen methodisch und perspektivisch erneuerten Internationalen Geschichte bei. Zu nennen sind etwa Berthold Unfrieds Arbeiten zur Rolle von Entwicklungshilfeexperten im Kalten Krieg, ${ }^{35}$ die Forschung Lucile Dreidemys zu westdeutschen und amerikanischen Stiftungen in der Entwicklungshilfepolitik während des Kalten Krieges und die Arbeiten Eric Burtons zu den Ost-Süd-Beziehungen im Kalten Krieg, mit einer Schwerpunktsetzung in der afrikanischen Geschichte. Diese Tendenz zur Erneuerung der Kalte-Krieg-Forschung in einem globalen Kontext - inspiriert durch die bahnbrechenden Arbeiten Odd Arne Westads ${ }^{36}$ - zeigt sich auch in den aktuell von Lucile Dreidemy und Katharina Kreuder-Sonnen initiierten Bemühungen, in Wien ein über die Institutsgrenzen hinausgehendes Kooperationsprojekt zu New Cold War Studies zu etablieren. Explizit geht es dabei darum, Nord-Süd- und Süd-Süd-Beziehungen verstärkte Aufmerksamkeit zu schenken.

Während das Bewusstsein für die Relevanz außereuropäischer Perspektiven zunimmt, scheint die zeithistorische Forschung zur Geschichte der europäischen Integration, wenn freilich auch mit wichtigen Ausnahmen - insbesondere den Arbeiten Michael Gehlers - in den letzten Jahren zurückgegangen zu sein, zumindest was

33 Siehe die Webseite der Forschungsgruppe Demokratie und Menschenrechte an der HistorischKulturwissenschaftlichen Fakultät der Universität Wien, URL: https://menschenrechte-demokratie.univie.ac.at (abgerufen 27.02.2020).

34 Kerstin von Lingen (Hg.), War Crimes Trials in the Wake of Decolonization and Cold War in Asia, 1945-1956: Justice in Time of Turmoil, Basingstoke 2016; dies. (Hg.), War Crimes Trials in Asia: Debating Collaboration and complicity in the aftermath of War, Basingstoke 2017; dies. (Hg.), Transcultural Justice: The Tokyo Tribunal and the Allied Struggle for Justice, 1946-1948, Leiden 2018.

35 FWF-Projekt P-25949: „Entwicklungsexpert/inn/en in der Zeit der ,West-Ost ' Systemkonkurrenz“, Projektleitung: Berthold Unfried (2013-2017).

36 Odd Arne Westad, The Global Cold War. Third World Interventions and the Making of our Times, Cambridge 2005; Odd Arne Westad, The Cold War: A World History, London 2017. 
die Geschichte Westeuropas betrifft. ${ }^{37}$ Dies ist angesichts aktueller Ereignisse wie dem Brexit und dem sich stark wandelnden transatlantischen Verhältnis bedauerlich, wäre die zeithistorische Perspektivierung doch höchst relevant. Ein aus einer Ringvorlesung des Masters Global Studies an der Universität Graz hervorgegangener Sammelband hat sich jüngst den Perspektiven auf die österreichische, europäische und internationale Geschichte gewidmet. ${ }^{38}$ In Wien haben Claudia Kraft und Philipp Ther zuletzt durch die Einrichtung neuer Forschungsplattformen und Forschungszentren die Forschung zu Transformationsprozessen in der osteuropäischen Geschichte gestärkt.

Je mehr sich in Österreich forschende und lehrende ZeithistorikerInnen aber mit Themen wie den oben angesprochenen beschäftigen und sich von der Fokussierung auf Österreich lösen, umso mehr müssen sie sich fragen, in welcher Sprache die Ergebnisse dieser Forschung publiziert werden und in welcher Sprache diese Art von Geschichte gelehrt werden sollte. Beides findet in erster Linie noch auf Deutsch statt. Das hat wichtige Gründe, von der Zugänglichkeit von Forschungsergebnissen für eine breite Öffentlichkeit in Österreich bis hin zur so wichtigen Ausbildung der Geschichtsstudierenden im Lehramt. Vor allem auf Masterebene wird Österreich aber auch für Studierende aus dem Ausland immer attraktiver, was sich beispielsweise im Erfolg des englischsprachigen Erasmus-Mundus-Programms „Global Studies: A European Perspective“ an der Universität Wien zeigt. Wissenschaftliche Publikationen zur internationalen Geschichte richten sich nicht mehr primär an österreichische (oder andere deutschsprachige) HistorikerInnen, sondern an ein internationales Fachpublikum.

Um die Besetzung zeithistorischer Professuren in Österreich gab es zuletzt immer wieder auch öffentlich geführte Diskussionen, die sich an der Frage entzündeten, ob zu viele deutsche WissenschaftlerInnen berufen würden. Die Debatte konzentrierte sich Anfang 2017 auf die letztlich gescheiterte Besetzung der Grazer ZeitgeschichteProfessur (die Stelle wurde 2019 neu ausgeschrieben, siehe oben). ${ }^{39}$ Ein Argument

37 Zum umfangreichen Werk Michael Gehlers siehe dessen Webseite, URL: http://www.gehler.at/index.php?id=4000 (abgerufen 28.02.2020).

38 Walter M. Iber/Peter Teibenbacher (Hg.), Österreich, Europa und die Welt. Internationale Beziehungen im 20. und 21. Jahrhundert (Wissenschaft kompakt: Wirtschaft, Gesellschaft, Politik. Schriften des Instituts für Wirtschafts-, Sozial- und Unternehmensgeschichte an der Karl-Franzens-Universität Graz 1), Münster 2019.

39 Tanja Malle, Mehr Deutsche, weniger österreichische Zeitgeschichte?, ORF online, URL: https:// science.orf.at/v2/stories/2825061/ (abgerufen 15.02.2020); Barbara Mader, Neue deutsche Welle? Die Germanisierung der österreichischen Universitäten, Kurier online, URL: https://kurier.at/ politik/ausland/die-germanisierung-der-oesterreichischen-universitaeten/400748118 (abgerufen 20.02.2020). 
in der Debatte lautete, dass es wichtig sei, das Zeitgeschichte-ProfessorInnen in Österreich auch österreichische Zeitgeschichte unterrichten und diese aus ihrer eigenen Forschungspraxis gut kennen. Dies sei vor allem für die Lehrerausbildung wichtig. Es gibt berechtige Gründe für und gegen diese Position, aber es ist zumindest auffällig, dass nicht mit einer gleichen Selbstverständlichkeit danach verlangt wird, dass Zeitgeschichte-ProfessorInnen in Österreich europäische Geschichte und internationale Geschichte lehren. Es scheint, als habe in der österreichischen Zeitgeschichtsforschung die österreichische Geschichte noch immer Priorität vor der internationalen Geschichte.

\section{Ausblick}

Wie österreichspezifisch sollte Zeitgeschichte in Österreich sein? In ihren institutionellen Anfängen interessierte sich die österreichische Zeitgeschichte vor allem für österreichische Themen und Fragestellungen. Diese nationale Fokussierung "Verengung", wie Hanisch es nennt - ergab sich aus der Entstehungsgeschichte des Faches und dem damit zusammenhängenden geschichtspolitischen Anspruch. Sie wurde lange kaum hinterfragt. Gleichwohl erklärte Erika Weinzierl bereits 1973 in der ersten Ausgabe der Zeitschrift „zeitgeschichte“, dass es die Aufgabe des neuen Fachorgans sei, auch ,immer wieder über die Grenzen Österreichs und Europas hinauszublicken “..$^{40}$ Dies war eine wichtige und zukunftsweisende Aufgabenstellung, deren Formulierung jedoch gleichzeitig zu erkennen gab, dass das Hauptinteresse nach wie vor der spezifisch österreichischen Zeitgeschichte galt.

In den letzten Jahren hat sich Weinzierls Anspruch jedoch mehr und mehr erfüllt. Angeregt nicht zuletzt durch den Aufschwung der Globalgeschichte befindet sich auch das Fach Zeitgeschichte aktuell in einer Umbruchphase, in welcher die Bearbeitung nichtösterreichischer Themen immer selbstverständlicher wird. Das ändert nichts daran, dass die geschichtswissenschaftliche Auseinandersetzung mit dem Holocaust auch in Zukunft eine wichtige Aufgabe der österreichischen Zeitgeschichte bleiben muss. Das hängt mit der gesellschaftlichen Bedeutung zeithistorischer Forschung zusammen, die sich beispielsweise in der Ausbildung zukünftiger LehrerInnen manifestiert. Die Zeitgeschichtsforschung in Österreich kann und muss hier eine Balance finden zwischen der wissenschaftlichen Auseinandersetzung mit österreichspezifischen Themen und internationalen Entwicklungen und Fragestellungen.

40 Erika Weinzierl, Zeitgeschichte - Programm einer Zeitschrift, in: zeitgeschichte 1 (1973) 1, 3. 
Um es in Anlehnung an Barbara Haider-Wilson zu formulieren: Auch hier sollte Ergänzung und nicht Gegenkonzept die Losung sein.

Das Einnehmen internationaler Perspektiven hat aber nicht nur Konsequenzen für die behandelten Themen, sondern wirkt sich auch auf andere Aspekte historischer Arbeit aus, etwa auf die Auswahl der Zeitschriften und Verlage, in denen Forschungsergebnisse veröffentlicht werden; auf die Entscheidung, ob diese auf Deutsch oder Englisch publiziert werden; auf die Frage, mit welchen KooperationspartnerInnen Projekte durchgeführt und in welchen Ländern Archivrecherchen unternommen werden. Während nach wie vor ein großer Teil der österreichischen Zeitgeschichtsforschung mit internationalen oder globalgeschichtlichen Perspektiven zugleich einen thematischen Bezug zu Österreich aufweist (was angesichts der Nähe zu österreichischen Archiven und zeithistorischen Sammlungen auch durchaus sinnvoll ist), werden sich die behandelten Themenfelder in den nächsten Jahren vermutlich noch vielfältiger gestalten und ein Österreichbezug nicht immer selbstverständlich sein - auch deshalb, weil es immer üblicher wird, dass ZeithistorikerInnen aus anderen Ländern in Österreich forschen und lehren.

Etwas Weiteres kommt hinzu: Angesichts der von Ehmer angesprochenen Arbeitsteilung zwischen SozialwissenschaftlerInnen und ZeithistorikerInnen liegt es nahe, vermehrt interdisziplinäre Herangehensweisen zu wählen. Doch während in wissenschaftsstrategischen Planungen oft die Förderung von Interdisziplinarität in den Vordergrund gerückt wird, werden interdisziplinär konzipierte Projekte in der Praxis mitunter bestraft: Eingereichte Drittmittelprojekte haben es teilweise so scheint es zumindest - schwerer, in Begutachtungsprozessen positiv evaluiert zu werden. Für jüngere WissenschaftlerInnen, die sich früh auf interdisziplinäre Forschungen einlassen, kann die Karriereplanung noch unvorhersehbarer werden als ohnehin schon.

Neben der Forschung sollte eine methodisch und theoretisch erweiterte Geschichte der internationalen Beziehungen auch in der akademischen Lehre größere Aufmerksamkeit erhalten. Denn erstaunlicherweise finden sich in den Vorlesungsverzeichnissen trotz der jüngeren Studienprogramme im Bereich der Global Studies verhältnismäßig wenig Lehrveranstaltungen zur Geschichte der Außenpolitik, der Geschichte militärischer Konflikte im 20. und 21. Jahrhundert sowie der Geschichte internationaler Organisationen oder internationaler Sicherheitspolitik. Ein verstärktes Lehrangebot in diesen Feldern wäre nicht nur aufgrund des Anspruchs auf thematische Breite wichtig, sondern auch, um methodische und theoretische Herausforderungen kritisch zu reflektieren, beispielsweise folgende: Wie sollten HistorikerInnen mit WikiLeaks umgehen? Wie können international angelegte Forschungsprojekte organisatorisch bewältigt werden (Stichwort: Archivrecherchen 
in unterschiedlichen Ländern)? Wie verhält sich die Zeitgeschichte zu den Politikwissenschaften? Und: Ist es die Aufgabe von ZeithistorikerInnen, „policy advice“ zu geben (und in welchen Formen kann dies geschehen?). Eine Vielzahl aktueller Forschungsprojekte, von denen ich hier nur einige wenige nennen konnte, zeigen eine zunehmende Pluralisierung des Fachs Zeitgeschichte in Österreich, die auch zu einer verstärkten Auseinandersetzung mit Themen und Fragen der Internationalen Geschichte geführt hat. Für den Forschungsstandort Österreich wäre die Weiterentwicklung dieser Initiativen ein großer Gewinn. 


\title{
Zeitgeschichte und Museen
}

\author{
Monika Sommer ${ }^{1}$
}

Im Jahr 2011 legten Dirk Rupnow und Heidemarie Uhl den Band „Zeitgeschichte ausstellen in Österreich. Museen - Gedenkstätten - Ausstellungen“ mit insgesamt 16 Beiträgen vor, die gemeinsam die „Bedingungen und Möglichkeiten“ der Musealisierung der österreichischen Zeitgeschichte reflektierten. ${ }^{2}$ Die Publikation erschien just zu einem Zeitpunkt, als die Diskussion um die etwaige Errichtung eines „Hauses der Geschichte“ gerade wieder von der politischen Agenda rutschte, obgleich 2009 mit der Durchführung einer umfassenden Machbarkeitsstudie Bewegung in die Sache gekommen war, die schon in den Jahrzehnten davor immer wieder heiße und lauwarme Phasen durchlebt hatte. Der vorliegende Beitrag versucht einen Überblick über die Dynamik der Idee eines Hauses der Geschichte seit dem Erscheinen der Publikation „Zeitgeschichte ausstellen in Österreich“ zu bieten. ${ }^{3}$ Zwar öffnete mittlerweile das erste zeitgeschichtliche Museum des Bundes zur einhundertsten Wiederkehr der Ausrufung der demokratischen Republik 1918 am 10. November 2018 in der Neuen Burg am Heldenplatz mit der Überblicksausstellung „Aufbruch ins Ungewisse - Österreich seit 1918“ und der Ausstellung „Nur die Geigen sind geblieben. Arnold und Alma Rosé“ im Kontext des Gedenk- und Erinnerungsjahres 2018 seine Pforten, ${ }^{4}$ doch die weitere Entwicklung blieb und bleibt ein Spielball der politisch Verantwortlichen. Dies lässt sich ebenso mit Gewissheit feststellen wie die Tatsache, dass die wechselvolle Entwicklung des Hauses der Geschichte Österreich flankiert wurde von einem Erstarken der Bedeutung der Kultur- bzw. Zeitgeschichte in den österreichischen Landesmuseen, die diesbezüglich im Jahr 2011 vielerorts

1 Monika Sommer ist seit Februar 2017 Gründungsdirektorin des Hauses der Geschichte Österreich. Der vorliegende Beitrag konzentriert sich daher auf die Entwicklung des neuen zeitgeschichtlichen Museums des Bundes. Ein Museum aufzubauen ist Teamarbeit, daher wird sowohl die Ich-Form als auch die Wir-Form verwendet.

2 Dirk Rupnow/Heidemarie Uhl (Hg.), Zeitgeschichte ausstellen in Österreich. Museen - Gedenkstätten-Ausstellungen, Wien/Köln/Weimar 2011.

3 Zur Vorgeschichte vgl. u. a. Richard Hufschmied, „Ohne Rücksicht auf Parteizugehörigkeit und sonstige Bestrittenheit oder Unbestrittenheit“. Die (un)endliche Geschichte von Karl Renners Museum der Ersten und Zweiten Republik (1946-1998), in: Rupnow/Uhl (Hg.), Zeitgeschichte ausstellen, 45-86; Dirk Rupnow, Nation ohne Museum? Diskussion, Konzepte und Projekte, in: ebd., 417-464.

4 Dirk Rupnow, Das Gedenk- und Erinnerungsjahr 2018 - eine Rückschau, in: zeitgeschichte 46 (2019) 4, 463-478. 
noch zwischen Experiment und Leerstelle schwankten ${ }^{5}$ - wobei im selben Jahr in Innsbruck das Tirol Panorama mit der Dauerausstellung „Schauplatz Tirol“ eröffnete und das Schlossmuseum Linz (das ein Teil des oberösterreichischen Landesmuseums ist) seine Kulturgeschichteabteilung um den „Verschütteten Raum“ erweiterte, um einen Erinnerungsort im Museum für Jüdinnen und Juden sowie Roma und Sinti zu schaffen. Damit wurde in Oberösterreich auf einen museologischen Diskurs der Repräsentation von gesellschaftlichen Minderheiten reagiert. Doch damit nicht genug: 2013 konnte nach dreijährigem Um- bzw. Neubau das Vorarlberg Museum eröffnen, das für seine gelungene Konzeption und innovative Tätigkeit 2016 den österreichischen Museumspreis erhielt. In Sachen Stärkung der Musealisierung der Kulturgeschichte zog die Steiermark 2017 mit der Erweiterung des Universalmuseums Joanneum um ein Museum für Geschichte im Palais Herberstein in unmittelbarer Nachbarschaft zum städtischen Graz Museum nach. Einschneidenden Veränderungen in der Kulturpolitik des Landes verdankte sich die Erweiterung des niederösterreichischen Landesmuseums - das sich später in Museum Niederösterreich umbenannte - um ein Haus der Geschichte in St. Pölten 2017, das neben dem Naturkundemuseum einziehen konnte, da die Landesgalerie für die Präsentation des österreichischen Kunstschaffens einen Neubau in Krems erhielt, der im Mai 2019 der Öffentlichkeit übergeben wurde. Weitere Bundesländer beschlossen große Investitionsprojekte für die regionale Geschichte: Das einhundertjährige Jubiläum des Burgenlands ist Anlass für die für 2021 geplante Eröffnung eines Hauses der Geschichte auf der Burg Schlaining. Der Spatenstich für die Renovierung des Kärntner Landesmuseums erfolgte im Mai 2020 mit dem Ziel, im Jahr 2022 das rundum sanierte Rudolfinum-Gebäude aus dem 19. Jahrhundert inhaltlich überarbeitet der Öffentlichkeit wieder zu übergeben. Die Bundeshauptstadt entschied sich nach jahrelangen Debatten um den richtigen Standort für das Beibehalten des Wien Museums am Karlsplatz, dessen Erweiterungsbau des denkmalgeschützten OswaldHaerdtl-Gebäudes bereits in vollem Gange ist - der Publikumsbetrieb soll an diesem Standort im Dezember 2023 wiederaufgenommen werden. Es lässt sich also ein deutlicher Aufwind für die Musealisierung der Zeitgeschichte im Bereich der österreichischen Landesmuseen konstatieren. Dieser findet seinen Niederschlag neben Neu- und Umbauten auch in Ausstellungsprojekten wie „Asche, Schutt, Trümmer das Salzburg Museum in der NS-Zeit“ und „Das große Welttheater - Salzburg und seine Festspiele“ im Salzburg Museum oder „Zwischen den Kriegen. Oberösterreich

5 Monika Sommer, Zwischen Experiment und Leerstelle. Zur Musealisierung der österreichischen Zeitgeschichte in den österreichischen Landesmuseen, in: Rupnow/Uhl (Hg.), Zeitgeschichte ausstellen, 313-336. 
1918-1938“ und „Befreit und besetzt. Oberösterreich 1945-1955“ im Oberösterreichischen Landesmuseum - um nur einige Beispiele zu nennen. Zu berücksichtigen ist, dass die in den 1960er-Jahren in Deutschland und Österreich einsetzende und in den 1980er-Jahren intensivierte Praxis der dislozierten Landesausstellungen in zahlreichen Bundesländern zur Popularisierung kulturgeschichtlicher Inhalte wesentlich betragen hat, wobei zeitgeschichtliche Themen im engeren Sinn allerdings selten gewählt wurden. ${ }^{6}$ Ob sich dies mit den Erfahrungen mit der Wanderausstellung „Vernichtungskrieg. Verbrechen der Wehrmacht 1941-1944“ erklären lässt, muss an dieser Stelle dahingestellt bleiben.

\section{Eine lange Geschichte komplexer Rahmenbedingungen}

Ein kurzer Rückblick auf die Museumsgeschichte des 19. Jahrhunderts hilft, die Entwicklungen im 20. Jahrhundert zu verstehen: Anders als in anderen Monarchien kam es während der Regentschaft der Habsburger zwar zur Gründung zahlreicher Museen, doch keines galt - nicht zuletzt aufgrund der pluralistischen Verfasstheit der habsburgischen Länder - als „österreichisches Nationalmuseum“, wenngleich das Museum für Kunst und Industrie (heute MAK) die Aufgabe hatte, den „österreichischen Geschmack“ zu pflegen,7 und das Museum der K.-u.-k.-Armee den Ruhm der sich aus allen Erb- und Kronländern rekrutierenden Armee propagieren sollte. Seine Nachfolgeeinrichtung - das Heeresgeschichtliche Museum Wien - verstand sich stets als „heimliches Nationalmuseum“, so sein Direktor Franz Kaindl, ${ }^{8}$ der dem Haus in den Jahren 1983 bis 1992 vorstand. Nicht zuletzt inspiriert von den jüngsten Museumsentwicklungen in Deutschland, wo die CDU-Regierung unter Bundeskanzler Helmut Kohl die Gründung eines Hauses der Geschichte der Bundesrepublik Deutschland in Bonn forcierte und 1994 in einem Neubau eröffnete, hatte die Idee einer ähnlichen Gründung in Österreich im Nachklang der turbulenten Waldheim-Affäre 1986/1988 Mitte der 1990er- und Anfang der 20ooer-Jahre unter ÖVPBundeskanzler Wolfgang Schüssel Konjunktur. So lag es nahe, dass der Direktor des

6 Daniela Sommer, Niederösterreichische Landesausstellungen: eine Kulturtradition mit Zukunft?, Innsbruck/Wien 1999; Caroline Oellerer, Landesausstellungen: eine Institution im mitteleuropäischen Kontext, Wien 2001.

7 Peter Noever (Hg.), Kunst und Industrie: Die Anfänge des Museums für Angewandte Kunst in Wien, Ostfildern 2000.

8 Vgl. Franz Kaindl, Das Heeresgeschichtliche Museum, ein historisches Nationalmuseum von internationaler Dimension, in: Marie-Louise von Plessen (Hg.), Die Nation und ihre Museen, Frankfurt a. Main/New York 1992, 271-280. 
Heeresgeschichtlichen Museums Manfried Rauchensteiner - er führte das Haus in der Zeit von 1992 bis 2005 - die Idee zur Gründung eines Hauses der Geschichte mit seinem Haus zu verknüpfen versuchte, indem er zahlreiche zeitgeschichtliche Objekte für das Museum erwarb und 1998 mit der Einrichtung eines Ausstellungssaales zum Thema „Republik und Diktatur. Österreich 1918-1945“9 das Museum an die jüngere Geschichte heranführte. Damit wurde dieser Zeitabschnitt der österreichischen Geschichte erstmals in einer Dauerausstellung musealisiert. Der Idee, das Heeresgeschichtliche Museum in ein Haus der Geschichte zu transformieren, stand seit der Mitte der 1990er-Jahre das Konzept eines „Hauses der Toleranz“ gegenüber, das im an der Ringstraße gelegenen Palais Epstein hätte untergebracht werden sollen, da der Wiener Stadtschulrat bis zum Jahr 2000 aus dem Gebäude ausziehen wollte. Promotor dieser Idee war der Holocaustüberlebende, Publizist und Leiter des Wiener Jewish Welcome Service Leon Zelman. SPÖ-Wissenschaftsminister Caspar Einem unterstützte die Idee, doch dem Vorhaben widerfuhr mehrfach Gegenwind: Der damalige Leiter des Stadtschulrates Kurt Scholz plädierte stattdessen für ein „Museum der Republik“, da dies eine Leerstelle in der österreichischen Museumslandschaft sei. Andreas Khol, ÖVP-Klubobmann, machte sich für ein „Haus der Zeitgeschichte“ stark, wofür der Grazer Historiker Stefan Karner im Auftrag von ÖVP-Vizekanzler Wolfgang Schüssel ein Konzeptpapier präsentierte. Schließlich fiel im Jahr 2002 unter SPÖ-Nationalratspräsident Heinz Fischer die Entscheidung, das Palais Epstein künftig für eine Nutzung durch das Parlament zu verwenden. Keines der von beiden konkurrierenden Großparteien entwickelten Museumskonzepte gelangte daher schließlich zur Umsetzung. Zwei große Ausstellungen des Jahres 2005 verstanden sich allerdings als Vorläuferinitiativen für ein künftig zu errichtendes Haus der Geschichte: Die Schau „Das neue Österreich“ - auf Eigeninitiative vorangetrieben vom ehemaligen SPÖ-Politiker und Unternehmer Hannes Androsch, dem Journalisten und ehemaligen Generalsekretär der Industriellenvereinigung Herbert Krejci und dem Journalisten und Kulturmanager Peter Weiser - war im Belvedere zu sehen, die Ausstellung „Österreich ist frei“ auf der niederösterreichischen Schallaburg, kuratiert vom Historiker Stefan Karner. Er verantwortete drei Jahre später gemeinsam mit dem Generaldirektor des Österreichischen Staatsarchivs Lorenz Mikoletzky schließlich auch die Ausstellung „Republik.Ausstellung 1918/2008“

9 Aktuell steht insbesondere dieser Saal in der Kritik, da er seit seiner Einrichtung nicht mehr aktualisiert worden war. Neben einer HistorikerInnen-Kommission unter dem Vorsitz von Wolfgang Muchitsch prüfte auch der Rechnungshof das Gebaren des Museums und stellte einigen Handlungsbedarf fest. Vgl. Gravierende Mängel und Missstände im HGM, Rechnungshof, 23.10.2020, URL: https://www.rechnungshof.gv.at/rh/home/news/Gravierende_Maengel_und_Missstaende_ im_Heeresgeschichtlic.html\# (abgerufen 01.12.2020). 
in der Säulenhalle des Parlaments. Nicht zuletzt, weil auf Bundesebene über so viele Jahrzehnte hinweg kein Konsens für die Gründung einer zeitgeschichtlichen $\mathrm{Mu}$ seumseinrichtung erzielt werden konnte, wurde schließlich im April 2014 im niederösterreichischen Landtag - wo die ÖVP mit Landeshauptmann Erwin Pröll die absolute Mehrheit inne hatte - der Entschluss gefasst, ein Haus der Geschichte in St. Pölten zu etablieren, ${ }^{10}$ womit der politisch motivierte Wettkampf um die zeitgeschichtlichen Museen und deren Konzepte in eine neue Phase trat. ${ }^{11}$

\section{Der Heldenplatz und der Altan der Neuen Burg - Ein „work in progress“}

Die jüngste Initiative zur Gründung eines Hauses der Geschichte auf Bundesebene geht zurück auf eine Idee von SPÖ-Kulturminister Josef Ostermayer, der mit seinen Plänen im November 2014 die Öffentlichkeit und die Museums-Community überraschte, wobei er vermutlich im Kontext des „langen Schattens der 8er Jahre“ ${ }^{12}$ und in Hinblick auf das nahende „Supergedenkjahr“"13 2018 agierte. Gemeinsam mit dem Historiker Oliver Rathkolb und einem 31-köpfigen internationalen Fachbeirat wollte er - Sohn der geschichtsträchtigen burgenländischen Gemeinde Schattendorf - ein Haus der Geschichte in der Neuen Burg am Heldenplatz ins Leben rufen: Auf einer Fläche von ca. 3.00o Quadratmetern, mit einem Errichtungsbudget von etwa 30 Millionen Euro, ausgestattet mit einem laufenden Budget von ca. 3,5 bis 4 Millionen Euro sollte dieses Haus in der Größe und Ausstattung mit international vergleichbaren zeitgeschichtlichen Museen mithalten können. Für sein Konzept konnte Ostermayer auf zahlreiche Vorstudien aus früheren Jahren zurückgreifen, die Vorgängerregierungen beauftragt hatten. ${ }^{14}$ Die Pläne von Josef Ostermayer hätten eine Neuverteilung der Ausstellungsflächen für die Museen der Neuen Burg mit sich gebracht: Das Haus der Geschichte Österreich sollte im ersten Stock der Neuen Burg einziehen, wo sich der Zugang zum Altan der Neuen Burg befindet. Von dort

10 Siehe dazu ausführlicher und detaillierter: Dirk Rupnow, Nation ohne Museum? Diskussionen, Konzepte und Projekte, in: Rupnow/Uhl (Hg.), Zeitgeschichte ausstellen, 417-463.

11 Stephan Neuhäuser, 2020. Coming to Terms with the Past: The Case of the ,House of Austrian History' (Haus der Geschichte Österreich) in the Wake of the Rise of Populist Nationalism in Austria, in: Modern Languages Open 2020/1, 24, URL: https://www.modernlanguagesopen.org/articles/10.3828/mlo.voio.326/ (abgerufen 31.12.2020).

12 Oliver Rathkolb, Der lange Schatten der 8er Jahre. Kritische Geschichtsbetrachtung und Demokratiebewusstsein, in: Aus Politik und Zeitgeschichte 68 (2018) 34-35, 41-46.

13 Heidemarie Uhl, Editorial, in: zeitgeschichte 46 (2019) 4, 453-462.

14 Herunterzuladen unter URL: http://haus-der-geschichte.at/Vorarbeiten/Haas_2009_1.pdf (abgerufen 01.12.2020). 
hatte Adolf Hitler am 15. März 1938 unter frenetischem Jubel von ca. 200.00o Menschen den „Anschluss" seiner Heimat an das nationalsozialistische Deutsche Reich bekanntgegeben - gleichzeitig hatten die gewalttätigen Übergriffe gegen die Jüdinnen und Juden begonnen. Nach 1945 waren es vor allem die Bilder der unüberschaubaren Menschenmenge auf dem Heldenplatz, die als Beweis für die Begeisterung vieler Österreicherinnen und Österreicher für die Ideologie und das Regime des Nationalsozialismus betrachtet wurden. Mit der sogenannten Waldheim-Affäre des Jahres 1986, mit dem Gedenkjahr 1988 und spätestens mit der Rede von SPÖBundeskanzler Franz Vranitzky 1991, in der er die Mitverantwortung von Österreicherinnen und Österreichern an den Verbrechen des Nationalsozialismus erstmals öffentlich eingestand, setzte sich ein kritischer Umgang mit dieser Geschichte breitenwirksam durch - Heldenplatz und „Hitlerbalkon“ wurden zu zentralen Topoi der österreichischen Gedenk- und Erinnerungspolitik. Künstler wie Carl Merz und Helmut Qualtinger, deren Skandalstück „Herr Karl“ 1961 im österreichischen Fernsehen ausgestrahlt wurde, und Thomas Bernhard, dessen „Heldenplatz“ 1988 im Burgtheater zur Aufführung gebracht wurde, verstanden es, mit dem Topos zu operieren und den Finger in die Wunde der österreichischen Nachkriegsgesellschaft zu legen, die sich bis 1986/1988 gut mit der Opferthese arrangiert hatte. Bis heute ist der Altan der Neuen Burg wohl das Symbol für die Ambivalenz der österreichischen Zeitgeschichte, stehen doch die Bilder der „Anschluss“-Rede im krassen Gegensatz zur jahrzehntelang gepflegten These von Österreich als erstem Opfer des Nationalsozialismus. ${ }^{15}$ Die zeitgeschichtliche Bedeutung des ersten Stocks der Neuen Burg verstärkt zusätzlich die Tatsache, dass sich hier in der NS-Zeit das Depot für „arisierte "Kunstwerke befand. ${ }^{16}$ Nicht zuletzt aufgrund dieser beiden Tatsachen ist die Neue Burg, obgleich sie in ihrem architektonischen Erscheinungsbild auf imperiale Planungen aus dem 19. Jahrhundert zurückgeht, in ihrer Nutzungsgeschichte ein zentraler Ort der österreichischen Zeitgeschichte. Am 17. Juni 1992 wurde hier wieder Geschichte geschrieben - dieses Mal war es allerdings ein Meilenstein der zivilgesellschaftlichen Initiativen der Republikgeschichte: Anlässlich der einjährigen Absetzung von Jörg Haider als Kärntner Landeshauptmann nach seinem Ausspruch über die „ordentliche Beschäftigungspolitik im Dritten Reich“ organisierten Enga-

15 Vgl. zur Geschichte: Alisia Douer, Wien - Heldenplatz, Wien 1998; Peter Stachel, Mythos Heldenplatz, Wien/Graz/Klagenfurt 2018; Heidemarie Uhl, Wien, Heldenplatz, 15. März 1938, in: Monika Sommer (Hg.), Susan Philipsz. The Voices, Wien 2018, 18-35.

16 Maria Welzig (Hg.), Die Wiener Hofburg seit 1918. Von der Residenz zum Museumsquartier (Veröffentlichungen zur Bau- und Funktionsgeschichte der Wiener Hofburg 5), Wien 2018; Anna Stuhlpfarrer, Hofburg und Heldenplatz als Bühne der politischen Machtdemonstration, in: ebd., 134-189, 137-138. 
gierte ein „Konzert für Österreich“ - symbolhaft auf dem Heldenplatz. Während die Bühne für die künstlerischen Beiträge - unter anderem von Maria Bill, André Heller, Konstantin Wecker und Werner Schneyder - vor der Neuen Burg aufgebaut war, hielt der rumänisch-amerikanische Holocaustüberlebende und Friedensnobelpreisträger Elie Wiesel - als Erster und Einziger seit 1938 - eine Rede auf dem Altan der Neuen Burg. Diese konnte allerdings im kollektiven Gedächtnis die Erinnerung an den 15. März 1938 nicht überschreiben. Wiesels Überzeugung, dass der Balkon nichts sei, entscheidend sei vielmehr, was unten auf dem Platz geschehe, bewahrheitete sich schon wenige Monate später: Am 23. Januar 1993 fand als Zeichen gegen Jörg Haiders Politik der Fremdenfeindlichkeit und des Rassismus das „Lichtermeer“ bewusst wieder auf dem Heldenplatz statt, um just dort ein Signal des anderen Österreich zu setzen. Mehr als 300.000 Menschen waren dem Aufruf der NGO SOS Mitmensch gefolgt. Der Altan wurde 1993 allerdings nicht mehr betreten - vielleicht weil das organisatorische Team von Seiten österreichischer Holocaustopfer Kritik für die Einladung des Amerikaners Elie Wiesel geerntet hatte, der zu Österreich keinen näheren Bezug hatte. ${ }^{17}$ Gerade für österreichische Überlebende des Holocaust ist der Altan der Neuen Burg ein besonders wichtiges Symbol: Für den im Jahr 1978 produzierten Film „Erinnerungen an Österreich“, in dem Exilösterreicherinnen und -österreicher interviewt wurden, drehte der ORF-Journalist Rudolf Stoiber auf dem Altan. ${ }^{18}$ Für ein weiteres Filmprojekt war der Altan namengebend: In „Der Mann auf dem Balkon“ führte Rudolf Gelbard, der 1942 in das Lager Theresienstadt deportiert worden war, in der Schlussszene als Zeichen der Überwindung des Nationalsozialismus auf den Altan der Neuen Burg. Ein weiterer Holocaustüberlebender aus Wien, der Medizinnobelpreisträger Eric Kandel, wünschte sich 2019 ein Familienfoto auf dem Balkon der Neuen Burg, das an seinem neunzigsten Geburtstag auch tatsächlich aufgenommen werden konnte. Mit der Standortwahl für das Haus der Geschichte Österreich war die naheliegende Erwartung verbunden, auf das kontaminierte Erbe zu reagieren, womit der Ort für das Haus der Geschichte höchst symbolhaft ausgesucht worden war und von keinem anderen Standort in seiner Zeichenhaftigkeit zu übertreffen ist. Diese politische Geste wollten nicht alle anerkennen, so kritisierte etwa die Historikerin Eva Blimlinger die „Konzentration von Herrschaftswissen im Zentrum der Stadt" und die Kunsthistorikerin und Museumsexpertin Claudia Haas übersah offenbar die zeitgeschichtliche Bedeutung der

17 Freundliche Auskunft von Friedrun und Peter Huemer.

18 Veranstaltung „Rudolf Stoiber, Erinnerungen an Österreich“, Literaturhaus, URL: http://www.literaturhaus.at/index.php?id=205\&tx_ttnews\% 5 Btt_news\%5 D=2065\&cHash=8ed79dod 3 of $6266 \mathrm{~d}_{2} 9$ 841f1625a72931 (abgerufen 01.12.2020). 
Neuen Burg, als sie Anfang 2015 konstatierte, die Habsburgerarchitektur sei weder inhaltlich noch funktional geeignet für ein Haus der Geschichte ${ }^{19}$ - noch im selben Jahr erstellte sie eine Studie zum Haus der Geschichte in der Neuen Burg. ${ }^{20}$ Andere, wie etwa der Künstler Richard Kriesche, machten sich stark für diesen Standort und erkannten die Chance für ein „Haus der Zeitgenossenschaft“. ${ }^{21}$ Die Frage, ob die Neue Burg der richtige Ort für das Museum sei, war auch eines der vielen Themen, die im Rahmen einer Enquete an der Österreichischen Akademie der Wissenschaften heftig diskutiert und teilweise polemisiert wurden. Initiiert vom Historiker Thomas Winkelbauer, kamen fast nur Historikerinnen und Historiker aus Österreich zu Wort. ${ }^{22}$ Fest steht, dass Fachleute unersetzbare Partnerinnen und Partner für $\mathrm{Mu}$ seen sind, da die Museen inhaltliche Expertisen an die breite Öffentlichkeit für die breite Öffentlichkeit übersetzen. Fest steht allerdings auch, dass es für diese Translationsarbeit neben Historikerinnen und Historikern zahlreiche weitere Professionen braucht - erst das komplexe Zusammenspiel vieler bringt die besondere Qualität des Mediums Museum als Geschichtsvermittlung im dreidimensionalen Raum zum Schwingen. So ist es schade, dass weder internationale Stimmen zu Erfahrungen mit Häusern der Geschichte noch eine Umfrage unter potenziellen künftigen BesucherInnen noch internationale Positionen von Historikerinnen und Historikern zu diesem Austausch eingeholt wurden. ${ }^{23}$

Wenn das Haus der Geschichte als Folge der Polemiken jetzt nicht gelingt, gibt es erneut nichts, und dann bliebe Hitlers Balkon, auch wenn er ursprünglich nur als Dach für eine Kutscheneinfahrt errichtet worden sein mag [...], weiter so „unbespielt“ wie bis

19 Weltmuseum: Breite Front gegen „Redimensionierung“, Kurier, 15.01.2015, URL: https://kurier.at/ kultur/weltmuseum-breite-front-gegen-redimensionierung/108.297.400 (abgerufen 01.12.2020).

20 Claudia Haas, Raum und Funktionsprogramm und Grobschätzung der Betriebskosten für ein Haus der Geschichte Österreichs in Wien 2014/15, erstellt für den internationalen wissenschaftlichen Beirat des Hauses der Geschichte Österreich im Auftrag des Vereins zur wissenschaftlichen Aufarbeitung der Zeitgeschichte, o. O. Mai 2015.

21 Ein Haus der Geschichte und der Zukunft, Der Standard, 11.01.2016, URL: https://www.derstandard.at/story/2000028856562/ein-haus-der-geschichte-und-der-zukunft (abgerufen 01.12.2020).

22 Thomas Winkelbauer (Hg.), Haus? Geschichte? Österreich? Ergebnisse einer Enquete über das neue historische Museum in Wien, Wien 2016.

23 Vgl. Andrea Brait, Tagungsbericht: Braucht Österreich ein neues historisches Museum („Haus der Geschichte") und, wenn ja, was für eines? Eine Enquête, H-Soz-Kult, 03.11.2015, URL: www. hsozkult.de/conferencereport/id/tagungsberichte-6237 (abgerufen 01.12.2020). 
anhin, während er in Wahrheit der Erinnerungs-Ort der österreichischen Zeitgeschichte schlechthin sein müsste, ${ }^{24}$

resümierte etwa der Schweizer Historiker Carlo Moos im Jahr 2016 in seiner Rezension des Konferenzbandes.

„Unbespielt“ ist der Altan der Neuen Burg auch noch 2020, im Jahr des 75. Jubiläums der Zweiten Republik, und trotz der Tatsache, dass das Haus der Geschichte Österreich 2018 dort einzog. Denn das Betreten des Altans der Neuen Burg ist nach den Vorgaben der Österreichischen Burghauptmannschaft nicht möglich, da die „Verkehrssicherheit“ nicht gegeben sei. Nichtsdestotrotz arbeitet das Haus der Geschichte Österreich mit der etwa 200 Quadratmeter großen Fläche des Gebäudevorbaus. Allein deren Größe zeigt, dass die Bezeichnung Balkon nicht sachgemäß ist, die Begriffe Altan oder Söller sind kunsthistorisch korrekt, allerdings in der Öffentlichkeit kaum bekannt. So sind allein die Bezeichnung ebenso wie die Nutzung des historischen Gebäudeteils eine inhaltliche Herausforderung, vor allem vor dem Hintergrund des behördlichen Betretungsverbots. Die erste Form, diese anzunehmen, war die Beauftragung einer neu zu entwickelnden künstlerischen Arbeit von internationalem Rang, die im März 2018 im Auftrag des Hauses der Geschichte Österreich durch eine Förderung des Bundeskanzleramts realisiert werden konnte. Das Team der KuratorInnen Kaspar König, Stella Rollig, Monika Sommer und Thomas D. Trummer lud die schottische Künstlerin und Turner-Preisträgerin Susan Philipsz ein, ein Kunstwerk für diesen Ort zu entwickeln. Diese entwarf die Arbeit „The Voices“ - eine Soundinstallation, die auf dem Heldenplatz zwischen der Neuen Burg und den Pavillons des Parlaments zweimal am Tag für jeweils $10 \mathrm{Mi}$ nuten zu hören war und an jene Stimmen erinnerte, die mit dem „Anschluss“ 1938 zum Schweigen gebracht worden waren, gleichzeitig aber auch an die Gegenwart appellierte, Verantwortung zu übernehmen, gegen Antisemitismus, Rassismus und Fremdenfeindlichkeit aufzustehen. Den bekannten Bildern von der „Anschluss“Rede sollte mit dieser Arbeit etwas Zerbrechliches, Fragiles entgegengesetzt werden. Heidemarie Uhl sprach von einem „Gegenklang“, der uns daran erinnere, dass die Sicherung der Demokratie „von unten“ kommen müsse. ${ }^{25}$ Die Arbeit war vom 12. März 2018 bis 8 . Mai 2019 zu hören. ${ }^{26}$

24 Carlo Moos, Rezension zu Thomas Winkelbauer (Hg.), Haus? Geschichte? Österreich? Ergebnisse einer Enquete über das neue historische Museum in Wien, H-Soz-Kult, 25.10.2016, URL: www. hsozkult.de/publicationreview/id/reb-24708 (abgerufen 01.12.2020).

25 Uhl, Heldenplatz, 35.

26 Sommer (Hg.), The Voices. 
Die Auseinandersetzung mit dem Altan, der in den Medien oft auch als „Hitler-Balkon" bezeichnet wird, ist freilich eine laufende Verpflichtung des Hauses der Geschichte Österreich. Diese betrifft nicht alleine den Außenbereich, auch eine innenliegende, etwa 250 Quadratmeter große Fläche, von der aus der Austritt auf den genannten Altan erfolgt, wurde dem Haus der Geschichte überantwortet. Diese Fläche ist Teil der Prunkstiege der Neuen Burg, die sich in drei Plateaus gliedert, die bis zum Einzug des Hauses der Geschichte Österreich die Namen „Jagdplateau I, II und III" trugen. Das Jagdplateau I wird aktuell von der Hof-, Jagd- und Rüstkammer für Ausstellungszwecke genutzt, das Jagdplateau III diente früher als Raum für die Vermittlungsaktivitäten des Völkerkundemuseums und wird nun als Erweiterungsbereich für das Ephesos Museum verwendet. Das mittlere Plateau ist die Verbindungsfläche zwischen dem Altan und der Sammlung alter Musikinstrumente, auf der ein singuläres Objekt aus der SAM präsentiert worden war. Bevor das Haus der Geschichte Österreich in die Neue Burg einzog, hatte der KHM-Museumsverband das Jagdplateau II in der wärmeren Jahreszeit an Firmen oder Privatpersonen für Events und Galadiners vermietet. Wer dafür bezahlte, konnte offenbar selbst den Altan nutzen - in der Silvesternacht 1999/2000 wurde dort ein großes privates Fest gefeiert. ${ }^{27}$

Obgleich diese Fläche aus konservatorischen und architektonischen Gründen ein sehr schwieriger Ausstellungsort ist, haben wir - nicht zuletzt aufgrund in Ermangelung anderer Wechselausstellungsflächen - entschieden, diesen Bereich für temporäre Ausstellungen mit dem inhaltlichen Schwerpunkt Holocaust sowie zu Themen wie Ausgrenzung und Rassismus nutzen zu wollen. Die Fläche haben wir von "Jagdplateau II" unbenannt in "Alma Rosé Plateau“, womit die Erinnerung an die Opfer der Shoah dem Gebäude eingeschrieben und die beiden Nachbarschaften Altan der Neuen Burg und Sammlung alter Musikinstrumente - inhaltlich verbunden werden sollte: Alma Rosé war eine talentierte Geigerin aus Wien, die vertrieben wurde und in Auschwitz-Birkenau ums Leben kam, nachdem sie zuvor dort das Frauenorchester des Konzentrationslagers geleitet hatte. Ihr Vater Arnold Rosé war der Konzertmeister der Wiener Philharmoniker gewesen, hatte in die Familie Gustav Mahlers eingeheiratet und war mit seinem Rosé-Quartett ein Superstar des Wiener Musik- und Gesellschaftslebens gewesen, doch wenige Stunden nach der Rede Hitlers am 15. März 1938 war er von den Wiener Philharmonikern zwangsbeurlaubt worden. Das Schicksal von Vater und Tochter und die Geschichten ihrer beiden Geigen, die heute noch gespielt werden, zeigten wir in der ersten Ausstellung „Nur die Geigen sind geblieben. Arnold und Alma Rosé“ an dieser vulnerablen Fläche der

27 Freundliche Auskunft von Johannes Rau. 
Neuen Burg. ${ }^{28}$ Von Beginn an als Wanderausstellung konzipiert, konnte die Schau mittlerweile bereits an das Haus der Musik in Innsbruck, an der Royal Academy of Music in London und an der Western University in London Ontario gezeigt werden. In Kooperation mit der Wiener-Festwochen-Programmschiene „Into the City“ zeigten wir als Folgeprojekt die Installation „Stricken“ der Künstlerin Magda Korsinsky. Sie hatte Frauen mit schwarzer Hautfarbe über die NS-Vergangenheit ihrer Großmütter interviewt; inspiriert wurde sie dabei von dem Buch „Amon. Mein Großvater hätte mich erschossen“ von Jennifer Teege, ${ }^{29}$ der Enkelin des aus Wien stammenden NS-Schergen Amon Göth, der seit dem Erscheinen des Spielfilms „Schindlers Liste“ 1993 vielen ein Begriff ist. Diese Interviews, groß projiziert auf Tücher aus dem Besitz der Großmütter, brachten eine in Österreich bislang kaum berücksichtige Dimension des Holocaust an diesen Ort und ins Herz der Republik. Durch die Unterstützung des Bundeskanzleramts konnte eine internationale Wanderausstellung über den Vernichtungsort Maly Trostinec ${ }^{30}$ nahe Minsk nach Österreich gebracht und um einen österreichspezifischen Teil ergänzt werden. Diese Ausstellung hatte zum Ziel, das Wissen um diesen in der österreichischen Gesellschaft kaum bekannten Ort der Gewalt gegen Jüdinnen und Juden aus Österreich zu erhöhen. Die türkis-blaue Bundesregierung hatte eine Denkmalsetzung zur Erinnerung an die fast 10.000 österreichischen Jüdinnen und Juden, die dort ermordet worden waren, veranlasst. Das vom Architekten Daniel Sanwald entworfene Denkmal wurde im März 2019 in Belarus enthüllt und war als Modell in der Ausstellung im Haus der Geschichte Österreich zu sehen. Aktuell ist die von Birgit Johler kuratierte Ausstellung „Nicht mehr verschüttet. Jüdisch-österreichische Geschichte in der Wiener Malzgasse“ zu sehen, die erstmals einen einzigartigen archäologischen Fund präsentiert, auf den der Schulverein Machsike Hadass bei Bauarbeiten im Bereich der ehemaligen Synagoge aufmerksam wurde: Zwischen Tonnen von Schutt war man auf kistenweise kulturhistorische Artefakte gestoßen, die von der ambivalenten jüdisch-österreichischen Geschichte des Ortes Malzgasse 16 Zeugnis ablegten. Selbst lange gesuchte Objekte aus dem ehemaligen Jüdischen Museum Wien - dem ersten

28 Michaela Raggam-Blesch/Monika Sommer/Heidemarie Uhl, Nur die Geigen sind geblieben. Alma \& Arnold Rosé, Wien 2019.

29 Jennifer Teege/Nikola Sellmair, Amon. Mein Großvater hätte mich erschossen, Reinbek bei Hamburg 2013.

30 Monika Sommer/Heidemarie Uhl, Malyj Trostenez - ein österreichischer Gedenkort. Der Österreich-Teil der Wanderausstellung, Vernichtungsort Malyj Trostenez. Geschichte und Erinnerung im Haus der Geschichte Österreich (14. Juni bis 27. Oktober 2019), in: Pia Schölnberger (Hg.), Das Massiv der Namen. Ein Denkmal für die österreichischen Opfer in Maly Trostinec, Wien 2020, 136-144. 
weltweit - tauchten wieder auf. Ab Januar 2021 werden wir die vom Haus der Wannseekonferenz konzipierte Schau „Verfolgen und aufklären. Die erste Generation der Holocaustforschung “ zeigen, die auf Initiative des Vienna Wiesenthal Institute for Holocaust Studies nach Wien kommt. Denn dieser Ort ist uns Verpflichtung. Ständig dort ausgestellt wird die Nutzungsgeschichte des Altans der Neuen Burg in Bildern, darüber hinaus wollen wir von unseren BesucherInnen erfahren, ob sie für die Öffnung dieses Bauteils stimmen oder aufgrund seiner Geschichte dagegen sind wobei aktuell die überwiegende Mehrheit für das Zugänglichmachen votierte. Auf Initiative des Webkurators Stefan Benedik und der Teamleiterin der Vermittlung Eva Meran startete das Haus der Geschichte Österreich im Internet einen Ideenwettbewerb, der die Öffentlichkeit einlädt, Nutzungen für den Altan vorzuschlagen und zu bewerten. ${ }^{31}$ Die Beteiligung ist höchst erfreulich! Aus Sicht des Hauses der Geschichte wäre es schon einmal ein erster wichtiger Schritt, wenn der Altan zumindest im Rahmen von Führungen und Workshops genutzt werden könnte. Denn das Betretungsverbot wirkt heute wie eine Verlängerung des Schweigens der österreichischen Nachkriegsgesellschaft über die Mitverantwortung an den Verbrechen des Nationalsozialismus. ${ }^{32}$

\section{Neuordnungen in der Neuen Burg}

Doch kommen wir zur Neuen Burg selbst, die als Gebäude schon ein Erlebnis und ein begehbares Objekt ist, das Monarchie- und Republikgeschichte verbindet. Mit den Plänen von Kulturminister Ostermayer einher wäre jedenfalls eine Neuordnung einzelner musealer Sammlungen der Neuen Burg gegangen, die alle zum KHM-Museumsverband ressortieren. Kaum betroffen gewesen wäre das Ephesos Museum, das seit 1978 - eingerichtet unter SPÖ-Bundesministerin Hertha Firnberg - in der Prunkstiege die Ende des 19. Jahrhunderts nach Wien gebrachten Relikte präsentiert. Im ersten Stock der Neuen Burg wären allerdings Veränderungen vorgenommen worden: Seit dem Frühjahr 1947 befindet sich dort die Sammlung alter Musikinstrumente, die in der Zeit des Nationalsozialismus zum Großteil im

31 „Der Balkon“. Eine Baustelle, Haus der Geschichte Österreich, URL: https://heldenplatz.hdgoe.at (abgerufen 01.12.2020).

32 Zu den - leider nicht - realisierten Vorhaben des Jahres 2020 vgl. Stefan Benedik/Eva Meran/Monika Sommer/Heidemarie Uhl, Die Neue Burg am Heldenplatz - von der Gedenk- zur Denkstätte, in: neues museum 2020/3, 26-33. 
Palais Pallavicini gezeigt worden war. ${ }^{33}$ Für die Einrichtung eines Hauses der Geschichte in der Neuen Burg hätte die Sammlung in das Mezzanin übersiedeln und dort in attraktiver, museologisch innovativer Form neu präsentiert werden sollen. Diese Räume sind bislang als Depots und Restaurierungswerkstätten genutzt worden. Doch der KHM-Museumsverband hatte bereits andere Pläne für diese Fläche und wenig Freude mit den neuen Ideen des Kulturministers: Im Zuge der Generalsanierung des Völkerkundemuseums - das 2013 unter Direktor Steven Engelsman in Weltmuseum umbenannt wurde - war die Einrichtung eines „Korridors des Staunens“ geplant worden. Freunde und Freundinnen des Weltmuseums sowie die Geschäftsführung des KHM-Museumsverbandes zeigten sich enttäuscht von der Reduktion der geplanten neuen Ausstellungsflächen für das lange Jahre geschlossen gewesene Haus. Eva Blimlinger, zu diesem Zeitpunkt Rektorin der Akademie der bildenden Künste, machte sich zu einer Wortführerin der Kritik gegen das Vorhaben Ostermayers. ${ }^{34}$ Parallel dazu formierte sich eine Gruppe von AktivistInnen um die Sammlung alter Musikinstrumente, flankiert von PolitikerInnen wie beispielsweise der ÖVP-Bezirksvorsteherin des ersten Wiener Gemeindebezirkes Ursula Stenzel. Sie traten gegen die „Zerstörung der bedeutendsten Musikinstrumentensammlung der Welt" ein und mobilisierten zu einem Sturm der Entrüstung gegen die geplante Übersiedlung und publikumswirksame Neuaufstellung der SAM, ${ }^{35}$ deren Sammlungsgeschichte in der NS-Zeit erst jüngst erforscht worden ist. ${ }^{36}$ Eine internationale Petition gegen die Übersiedlung der SAM wurde im Frühjahr 2015 gestartet, wobei viele offenbar befürchteten (oder unterstellten), die Sammlung würde zur Gänze magaziniert werden. ${ }^{37}$ Die Diskussion erreichte einen vorläufigen Höhepunkt in einer von ICOM-Österreich initiierten Veranstaltung am 22. Juni 2015 in der

33 Die Geschichte der Sammlung, Kunsthistorisches Museums Wien, URL: https://www.khm.at/besuchen/sammlungen/sammlung-alter-musikinstrumente/die-geschichte-der-sammlung (abgerufen 01.12.2020).

34 Vgl. dazu u. a. Ostermayer: „Habe nicht vor, Museumsdirektor zu werden“, Der Standard, 30.01.2015, URL: https://www.derstandard.at/story/2000011092438/ostermayer-ich-habe-nichtvor-museumsdirektor-zu-werden (abgerufen 01.12.2020); Bildende-Rektorin gegen Haus der Geschichte, orf.at, 04.01.2016, URL: https://sciencev2.orf.at/stories/1765978/index.html (abgerufen $01.12 .2020)$.

35 Stenzel: „Wir dürfen uns nicht selbst abschaffen“, Die Presse, 24.09.2015, URL: https://www.diepresse.com/4828437/stenzel-wir-durfen-uns-nicht-selbst-abschaffen (abgerufen 13.07.2020).

36 Stephan Turmalin, Die Sammlung alter Musikinstrumente des Kunsthistorischen Museums in Wien während der Zeit des Nationalsozialismus, Wien 2018.

37 Haus der Geschichte: Musiksammlung zittert um Existenz, Die Presse, 05.03.2015, URL: https:// www.diepresse.com/4677514/haus-der-geschichte-musiksammlung-zittert-um-existenz (abgerufen 13.07.2020). 
Säulenhalle des Völkerkundemuseums, die der Kulturjournalist Thomas Trenkler moderierte. Das hohe Maß an Aggressivität, das während dieser Veranstaltung dem Projekt Haus der Geschichte Österreich entgegenschlug, legte einmal mehr Zeugnis ab von der emotionalen Kraft, die die Identifikation mit kulturhistorischen Objekten bzw. musealen Sammlungen auszulösen vermag. ${ }^{38}$

Mit den Überlegungen zur Neuverteilung der museal genutzten Flächen innerhalb der Neuen Burg einher gingen auch Pläne zur Neugestaltung des Heldenplatzes, unter dem ein Tiefspeicher für die Österreichische Nationalbibliothek geschaffen werden sollte, und für eine Nutzbarmachung des Äußeren Burgtors. ${ }^{39}$ Unabhängig davon schritten die Planungen für das Haus der Geschichte voran: Im September 2015 präsentierten Kulturminister Josef Ostermayer und ÖVP-Wissenschaftsminister Harald Mahrer die vom 31-köpfigen internationalen Beirat unter der Leitung von Oliver Rathkolb erarbeitete Umsetzungsstrategie für das Haus der Geschichte Österreich. ${ }^{40}$ Kurz zuvor hatte Mahrer die Idee der Errichtung eines „Hauses der Zukunft“ präsentiert, das auf dem Heldenplatz neben dem Heldentor in Holzbauweise errichtet werden sollte. ${ }^{41}$ Mahrer stellte somit dem von der SPÖ vorangetriebenen Museumsprojekt in der Neuen Burg ein ÖVP-Vorhaben neben dem Äußeren Burgtor gegenüber oder zur Seite. Symbolisch verortete er somit seine Partei in der Zukunft und den Koalitionspartner in der Geschichte. ${ }^{42}$ Mit seinem Vorschlag entfachte Mahrer die Diskussion um das Haus der Geschichte neu, da einige AkteurInnen lieber einen Neubau für das Zeitgeschichtemuseum gesehen hätten oder dieses zur Gänze verhindern wollten. Mahrers Überlegung war es, „eine Signatur unserer Zeit auf der Ringstraße" entstehen zu lassen. ${ }^{43}$ Für die Beantwortung der Frage, wofür dieses Haus genutzt werden könnte, wurde der Sozialwissenschaftler

38 „Haus der Geschichte Österreichs“ - Rückblick zu Vortrag \& Podiumsdiskussion vom 22.06.2015, ICOM Österreich, 23.06.2015, URL: http://icom-oesterreich.at/news/haus-der-geschichte-oesterreichs-rueckblick-zu-vortrag-podiumsdiskussion-vom-2262015 (abgerufen 13.07.2020).

39 Wie der Heldenplatz umgebaut wird, Die Presse, 02.08.2015, URL: https://www.diepresse. com/4791588/wie-der-heldenplatz-umgebaut-wird (abgerufen 13.07.2020); vgl. Heidemarie Uhl/ Richard Hufschmid/Dieter Binder (Hg.), Gedächtnisort der Republik. Das Österreichische Heldendenkmal im Äußeren Burgtor der Wiener Hofburg, Wien 2021 (im Druck).

40 Kulturminister Ostermayer: Haus der Geschichte in der Neuen Burg, APA, 09.09.2015, URL: https://www.ots.at/presseaussendung/OTS_20150909_OTSo129/kulturminister-ostermayer-hausder-geschichte-in-der-neuen-burg (abgerufen 13.07.2020).

41 Haus der Geschichte: ÖVP will lieber ein „Haus der Zukunft“, Die Presse, 05.08.2015, URL: https:// www.diepresse.com/4793874/haus-der-geschichte-ovp-will-lieber-ein-haus-der-zukunft (abgerufen 13.07.2020).

42 Tatsächlich sollte dieses Szenario mit den Neuwahlen 2018 eintreten.

43 Haus der Geschichte: Der Plan steht, Die Presse, 09.09.2015, URL: https://www.diepresse. com/4817426/haus-der-geschichte-der-plan-steht (abgerufen 13.07.2020). 
und Netzwerkforscher Harald Katzmaier engagiert, dem ein „neuer Begegnungsund Aushandlungsraum für die Entwicklung von Zukunftsvisionen“ vorschwebte, den er gemeinsam mit VertreterInnen der Zivilgesellschaft entwickeln wollte. ${ }^{44}$ Trotz aller politischen Kalküle und Vorbehalte kam der Gesetzesvorschlag für die Novellierung des Bundesmuseumsgesetzes Ende des Jahres 2015 in die Begutachtung und wurde im April 2016 beschlossen, womit die rechtliche Grundsteinlegung für das Haus der Geschichte Österreich geschaffen wurde: Das neue zeitgeschichtliche Museum wurde unter Wahrung seiner wissenschaftlichen Unabhängigkeit der Österreichischen Nationalbibliothek zugeordnet. ${ }^{45}$ Damit war zwar ein Durchbruch gelungen, allerdings auch eine schwierige Ausgangslage für das Haus der Geschichte Österreich zementiert, das künftig räumlich untrennbar verbunden und umgeben sein sollte mit Sammlungen, die vom KHM-Museumsverband verwaltet werden. Nichtsdestotrotz stellt dieser Beschluss nach Jahrzehnten der Diskussionen um die Etablierung eines zeitgeschichtlichen Museums auf Bundesebene einen Meilenstein der österreichischen Museumsgeschichte und einen Aufbruch in ein neues, modernes Verständnis der Institution Geschichtsmuseum dar, wenn es heißt, das Haus der Geschichte Österreich solle ein „Diskussionsforum“ sein:

Zusätzlich zu den Aufgaben gemäß Abs. 1 bis 3 führt die Österreichische Nationalbibliothek das Haus der Geschichte Österreich als fachlich eigenständiges Museum. Dieses soll die Zeitgeschichte Österreichs ab der zweiten Hälfte des 19. Jahrhunderts mit thematischen Rückblicken in die Zeit der Aufklärung und davor und einem besonderen Schwerpunkt auf die Zeit von 1918 bis in die Gegenwart in ihrem europäischen und internationalen Kontext vermitteln. Das Haus der Geschichte Österreich soll auch ein aktives und offenes Diskussionsforum für zeithistorische Fragestellungen und Themen der Gegenwartsgeschichte sein und ist zu einer objektiven wissenschaftlichen Darstellung geschichtlicher Entwicklungen und Ereignisse verpflichtet. ${ }^{46}$

Doch die Freude derjenigen, die sich für das Haus der Geschichte in der geplanten Variante eingesetzt hatten, währte nicht lange. Wenige Tage nach der Verabschiedung des Bundesmuseengesetzes erfolgte im Mai 2016 eine Regierungsumbildung

44 Harald Katzmair, Das Haus der Zukunft, in: FAS research Nr. 381 2/2016, URL: https://www.fas. at/fileadmin/user_upload/wp-news/FAS 381-HausderZukunft-NEWS-0220161.pdf (abgerufen 13.07.2020).

45 Bundesrecht konsolidiert: Gesamte Rechtsvorschrift für Bundesmuseen-Gesetz 2002, URL: https:// www.ris.bka.gv.at/GeltendeFassung.wxe?Abfrage=Bundesnormen\&Gesetzesnummer=20001728 (abgerufen 13.07.2020).

46 Ebd. 
mit weitreichenden Konsequenzen für die Planungen zur Errichtung eines Hauses der Geschichte: SPÖ-Bundeskanzler Werner Faymann und sein Kanzleramtsminister Josef Ostermayer schieden aus ihren Funktionen aus und legten alle politischen Ämter nieder. Ihnen folgten zwei Quereinsteiger: Christian Kern trat von seiner Aufgabe als ÖBB-Vorstandsvorsitzender zurück und übernahm das Amt des SPÖ-Bundeskanzlers, Thomas Drozda verließ die Geschäftsführung der Vereinigten Bühnen Wiens und zog als SPÖ-Kanzleramtsminister am Ballhausplatz ein. Am 20. Oktober 2016 gab er in seiner Funktion als Kulturminister in einer Pressekonferenz neue Eckdaten und einen sportlichen Zeitplan für das Haus der Geschichte bekannt ${ }^{47}$ - das Haus solle als Ausstellung pünktlich zum Republikjubiläum öffnen. Verlautbart wurde damit eine Entscheidung, die wohl am besten als österreichische Lösung zu bezeichnen ist, denn das Museum wurde mit dieser Erklärung als Provisorium an den Start geschickt. Die AktivistInnen rund um die Sammlung alter Musikinstrumente hatten Anlass zur Freude: Die SAM sollte unverändert in ihren bisherigen Räumlichkeiten im ersten Stock bleiben und das Haus der Geschichte auf einer Fläche von lediglich 1.00o Quadratmetern im Mezzanin einziehen. Obschon im Bundesmuseumsgesetz verankert, blieb mit dieser Entscheidung offen, ob das Haus der Geschichte eine dauerhafte Einrichtung oder wieder nur eine temporäre Ausstellung sein sollte. Für die Sanierung der Räume wurden nunmehr 6 Millionen Euro zur Verfügung gestellt und deren Verwaltung in die Verantwortung des KHMMuseumsverbandes gelegt. Mit der Redimensionierung der bisherigen Pläne für das Haus der Geschichte Österreich einher ging eine stille Vergrößerung des Ephesos Museums um 360 Quadratmeter auf dem Jagdplateau III der Prunkstiege der Neuen Burg. Als Aufbau- bzw. Betriebsbudget wurden für das zeitgeschichtliche Museum nur noch 1,2 Millionen Euro für 2017, 2 Millionen für 2018 und 1 Million Euro für 2019 zugesichert. Für die Nutzbarmachung des Altans der Neuen Burg standen keine Mittel zur Verfügung. Allerdings teilte man - wie oben schon erwähnt - dem Haus der Geschichte Österreich die unmittelbar vor dem Altan der Neuen Burg gelegene Fläche - das Jagdplateau II - zur Nutzung zu, womit die institutionellen Grenzen mitten durch die Prunkstiege geführt wurden.

Die über 2019 hinausreichende finanzielle Zukunft blieb ebenso offen wie die langfristige räumliche Verortung des jüngsten Museums des Bundes. Die Museumsräume im Mezzanin der Neuen Burg - auch Gartentrakt genannt - wurden „temporär" vom KHM-Museumverband an die Österreichische Nationalbibliothek für

47 „Haus der Geschichte“ kommt 2018 in reduzierter Form, Ziel ist Neubau, Der Standard, 20.10.2016, URL: https://www.derstandard.at/story/2000046239454/ziel-ist-neubau-haus-der-geschichtekommt-2018-in-reduzierter (abgerufen 13.07.2020). 
die Nutzung durch das Haus der Geschichte Österreich im Sommer 2018 untervermietet. Im Auftrag des Hauses der Geschichte Österreich entstand als künstlerische Begleitung des Bauprojekts die Arbeit „Dazwischen Geschichten“ des Künstlerduos Ruth Anderwald und Leonhard Grond. ${ }^{48}$ Baulich realisiert wurden dabei allerdings nicht die ursprünglichen, bereits sehr detailliert ausgearbeiteten Pläne für den „Korridor des Staunens“. Denn mittlerweile hatte der KHM-Museumsverband seine Strategie geändert und ein neues Vorhaben entwickelt: Die Gartentraktsanierung wurde so ausgeführt, dass in Zukunft - also nach dem ins Auge gefassten Auszug des Hauses der Geschichte Österreich - das Ephesos Museum nochmals um 1.00o Quadratmeter vergrößert werden kann, mit der Absicht, das Heroon von Trysa auszustellen. Dabei handelt es sich um ein antikes Steinfries aus der südwestlichen Türkei, das Ende des 19. Jahrhunderts nach Wien gebracht wurde. ${ }^{49}$ Argumente, warum dieses - unbestritten bedeutsame - Artefakt der Antike just in der Neuen Burg aufgestellt werden soll, sind der Autorin nicht bekannt. „Um die monumentalen Steinreliefs aus Trysa, die einst die Umfassungsmauer des Heroon bildeten, erstmals öffentlich zeigen zu können, ging ein großer Teil der rund sechs Millionen Euro teuren Umbauarbeiten in Verbesserungen der Statik der Säle“, berichtete der „Der Standard“ diesbezüglich am 19. Oktober 2018. Interessant ist zudem, dass jene Gruppe, die einst gegen Ostermayers Pläne der „Verkleinerung“ des Weltmuseums polemisiert hatte, gegen die Kursänderung der KHM-Geschäftsführung in Bezug auf den einst vorgesehenen „Korridor des Staunens“ nicht protestierte. Wie dem auch sei: Der aktuelle Status ist jedenfalls aus der Sicht der BesucherInnen unbefriedigend. Denn die räumliche Situation bedingt den gemeinsamen Eintritt und das gemeinsame Ticket für den Besuch des Hauses der Geschichte Österreich und des Ephesos Museums. Die Ideen, einen Brückenschlag zwischen beiden Einrichtungen des Bundes zu finden und diesen gleichzeitig zu nutzen für eine Aktualisierung des vor über vierzig Jahren eingerichteten Ephesos Museums, sind bislang nicht verfolgt worden. Spannend wäre beispielsweise die Darstellung der österreichischen Wissenschaftstradition an der archäologischen Grabungsstätte in der Südwesttürkei, die durchaus zeitgeschichtliche Aspekte enthält, wie etwa das im Jahr 2016 von der Türkei erteilte Grabungsverbot. Bis zu einer weiteren kulturpolitischen Entscheidung bleibt die räumliche Verteilung in der Neuen Burg jedenfalls in dem Status, wie er 2016 unter Bundesminister Drozda entschieden wurde.

48 Monika Sommer (Hg.), Dazwischen Geschichte - eine künstlerische Baubegehung, Wien 2018.

49 Alice Landskron, Das Heroon von Trysa (Schriften des Kunsthistorischen Museums 13/1), Wien 2015. 


\section{Eine einmalige Chance}

Trotz der komplexen politischen, strukturellen und räumlichen Lage verstanden wir die Situation als eine einmalige Chance. Die Eröffnung des Hauses der Geschichte Österreich nach der knappen Aufbauzeit von 17 Monaten und innerhalb des gegebenen Budgetrahmens war tatsächlich ein historischer Moment, ein Meilenstein für die österreichische Museumslandschaft. Wir als Team des Hauses der Geschichte Österreich ${ }^{50}$ - erweitert um die KonsulentInnen Dieter A. Binder (Universität Graz), Dirk Rupnow (Universität Innsbruck) und Heidemarie Uhl (Österreichische Akademie der Wissenschaften) - konnten uns die Frage stellen, wie man ein Museum bzw. eine Ausstellung zur Geschichte eines Landes im 21. Jahrhundert vor dem Hintergrund der gegenwärtigen internationalen Standards einer kulturwissenschaftlich orientierten Ausstellungspraxis neu konzipiert.

Denn parallel zur Gründungswelle von Geschichtsmuseen in den 1980er-Jahren haben all die wissenschaftlichen „Turns“ der Cultural Studies ihre deutlichen Spuren in der Institution Museum hinterlassen - vor allem aber der Reflexive Turn, der dazu geführt hat, dass sich Museen nicht mehr als neutral und außerhalb der Zeit stehend sehen, sondern als Teil eines kulturellen Systems der Produktion von Sichtbarkeit, Wissen und Identität. Die „new museology“ (Peter Vergo) war geboren. Auf postkoloniale und feministische Kritik folgten heftigen Debatten zu Fragen des Ausstellens und der Teilhabe von bislang nicht repräsentierten gesellschaftlichen Gruppen an der Museumsarbeit. Zudem erschütterte die grundsätzliche Kritik am Zusammenhang zwischen nationaler Geschichte und Identitätsstiftung Kunst- und Geschichtsmuseen in ihren Grundfesten, gingen doch viele Museumsgründungen aus dem Nationalismus des 19. Jahrhunderts hervor. Jan und Aleida Assmann haben das in ihrer Theorie des kulturellen Gedächtnisses klar definiert: Das nationale „Wir“ bedeutet immer auch den Ausschluss der anderen, der Nichtzugehörigen. Viele Gruppierungen haben die Leerstelle in ihrer musealen Repräsentation zu recht reklamiert, und auch ethische und juristische Themen haben die Museumsarbeit radikal verändert: Raub und Restitution wurden, ebenso wie das Reflektieren von Geschlechtervorstellungen und eurozentrischer Geschichtsschreibung bzw. einer Geschichtsschreibung aus der Perspektive der weißen Mehrheitsgesellschaft, zu

50 Zum inhaltlichen Kernteam zählten 2017/2018: Stefan Benedik (Webkurator), Jennifer CarvillSchellenbacher (kuratorische Assistenz), Sophie Gerber (kuratorische Assistenz), Georg Hoffmann (Kurator), Birgit Johler (Kuratorin), Monika Sommer (Direktorin). Als Ergänzung zur Ausstellung - nicht als Ausstellungskatalog - erschien folgende Publikation: Monika Sommer/Nicole-Melanie Goll/Stefan Benedik/Georg Hoffmann/Birgit Johler/Eva Meran/Heidemarie Uhl (Hg.), Was ist Österreich? Menschen und Geschichten in 101 Objekten, Wien 2019. 
zentralen Themen des Sammelns und Ausstellens. Hinterfragt wurde die Deutungsmacht der Museen: Wer spricht aus welcher Position zur Öffentlichkeit?51

Vor dem Hintergrund der aktuellen geschichtstheoretischen und museologischen Debatten kann Geschichte somit nicht mehr traditionell, das heißt als geschlossenes chronologisches Narrativ dargestellt werden, vielmehr: Geschichtsmuseen werden heute in die Pflicht genommen, nationale Stereotypen und traditionelle Geschichtsmythen kritisch zu hinterfragen, aufzubrechen und zu dekonstruieren. Die Vorstellung von dem, was ein Museum ist, hat sich mit den gesellschaftlichen Transformationen der späten 196oer-Jahre enorm verändert, als die Forderung nach der Steigerung der gesellschaftlichen Relevanz der Museen laut wurde, wenn etwa der Bibliothekar Wieland Schmidt in der berühmt gewordenen Publikation „Das Museum der Zukunft“ meinte,

es führt wohl auch für das Museum kein Weg daran vorbei, seinem Publikum das rein rezeptive, passive Genießen der zur Schau gestellten Ware abzugewöhnen. Es muß vielmehr seine Besucher provozieren und aktivieren, will es einen Sinn in der Gesellschaft haben, die sich nur dadurch emanzipieren kann, daß sie sich selbst und damit ihre Herkunft in Frage stellt. Das problemlose Präsentieren vergangener Werte kann auch dem Museum - einst wirklich als Schatzkammer vorbildlicher Leistungen, als Schatzhaus der Geschichte - kein festes Fundament mehr sein. ${ }^{52}$

Das Museum des 21. Jahrhunderts kann sich nicht mehr als Ort der alleinigen Deutungsmacht über die Geschichte verstehen, es ist vielmehr zu einer „contact zone“, zu einem Reflexionsraum und zu einem Raum geworden, in dem Geschichte ausverhandelt wird. ${ }^{53}$ Vor diesem Hintergrund kann kein Museum unpolitisch sein. Auch das Haus der Geschichte Österreich versteht sich als positioniert im Sinne des Selbstverständnisses eines modernen, überparteilichen Geschichtsmuseums, das Raum für Diskussionen eröffnet.

51 Die Bandbreite an museologischen Fragestellungen zeigt sich beispielsweise in der Publikationsreihe „schnittpunkt. Ausstellungstheorie \& praxis“.

52 Wieland Schmidt, Der Auftrag lautet Gegenwart. Gedanken zu einem erweiterten Museum, in: Gerhard Bott (Hg.), Die Zukunft des Museums, Köln 1970, 248-255, 249, zit. n. Martina GriesserStermscheg/Christine Haupt-Stummer/Renate Höllwart/Beatrice Jaschke/Monika Sommer/Nora Sternfeld/Luisa Ziaja, Das Museum der Zukunft, in: schnittpunkt/Joachim Baur (Hg.), Das Museum der Zukunft. 43 neue Beiträge zur Diskussion über die Zukunft des Museums, Bielefeld 2020, 17-31, 23.

53 Ljiljana Radonić/Heidemarie Uhl (Hg.), Das umkämpfte Museum. Zeitgeschichte ausstellen zwischen Dekonstruktion und Sinnstiftung, Bielefeld 2020. 
Das Haus der Geschichte Österreich als Diskussionsforum will ein Ort der Reflexion und Auseinandersetzung mit Österreichs Vergangenheit, Gegenwart und Zukunft sein. Es interessiert sich für die Meinung seiner BesucherInnen und tritt mit diesen auf Augenhöhe in einen Austausch und Dialog. Dieses Selbstverständnis hat zur Konsequenz, dass der Stellenwert der Vermittlung von der Gründung der Institution an von großer Bedeutung war. Grundlage für den Aufbau der Vermittlungsaktivitäten war ein Papier von ExpertInnen des Büros trafo K. ${ }^{54}$ gemeinsam mit Beatrice Jaschke, die seit mehr als einem Jahrzehnt das Feld der Vermittlung in Museen und Ausstellungen aufgebaut und begleitet haben. Ihrer Studie für das Haus der Geschichte Österreich haben sie den Leitsatz von Hannah Arendt „Denken ohne Geländer"vorangestellt. Auf diesem Grundlagenpapier konnte die Leiterin der Vermittlung, Eva Meran, aufbauen, viele Grundsätze in die Konzeption der Eröffnungsausstellung aufnehmen und umsetzen, denn sie war frühzeitig ins Team gekommen und in die Entwicklung der Schau eingebunden worden. Zum Selbstverständnis des Hauses gehört es daher auch, das Team der Vermittlung als integralen Bestandteil der Institution zu verstehen und konsequenterweise auch durch Anstellungsverhältnisse mit dem Haus zu verknüpfen.

Gerade das Team der Vermittlung ist gemeinsam mit den kuratorisch Verantwortlichen gefordert, in den repräsentativen Räumlichkeiten der Neuen Burg das Haus der Geschichte Österreich als ein Museum des 21. Jahrhunderts zu strukturieren. Dies bedeutet für uns, dass das Haus der Geschichte Österreich Vielstimmigkeit und Multiperspektivität an die Stelle einer linearen Narration setzt. Dem Prinzip der „Hospitality“ verpflichtet, ist es vor allem ein Dienstleister an der Gesellschaft, indem es Einladungen zur Auseinandersetzung mit der Vergangenheit anbietet. Das Museum teilt die Deutungsmacht über die Vergangenheit, indem es - zum Beispiel mithilfe der Webplattform - auch jene, die nicht im Museum arbeiten, partizipativ teilhaben lässt am Archivieren und Ausstellen von historischen Themen und Ereignissen und dadurch Bezüge zu den Lebensrealitäten des Publikums hergestellt werden können.

Auf einer Ausstellungsfläche von 750 Quadratmetern im Mezzanin der Neuen Burg bietet die Eröffnungsausstellung „Aufbruch ins Ungewisse - Österreich seit $1918^{\prime \prime}$ in sieben eigenständigen Themenschwerpunkten einen Überblick über wesentliche Aspekte der österreichischen Zeitgeschichte bis in die Gegenwart. Am Beginn lädt die Ausstellung zu einer Auseinandersetzung mit der Zeitenwende Kriegsende und Aufbruch in die Erste Republik ein. Zentral ist es für uns, in diesem ersten Themenschwerpunkt die demokratiepolitische Zäsur des 12. November

54 Das Kollektiv wird gebildet von Renate Höllwart, Elke Smodics und Nora Sternfeld. 
1918 ins Bewusstsein zu rufen. Standen bislang in der Geschichtsbetrachtung oftmals der Aspekt des Zerfalls des Habsburgerreiches und die Kleinheit des neuen Staates Deutschösterreich im Vordergrund der Erzählung, wollen wir in der Ausstellung vor allem demokratiepolitische Aspekte der ersten Jahre der Ersten Republik wie die Selbstermächtigung des Parlaments zur Gründung eines neuen Staates, die Erlangung des allgemeinen, gleichen und geheimen Wahlrechtes für Männer und Frauen und die österreichische Bundesverfassung in den Fokus rücken sowie aufzeigen, welche unmittelbare Auswirkung dieser gesamteuropäische Umbruch auf individuelle Biographien hatte. Da die wirtschaftliche Situation eines Landes das Leben der Menschen grundlegend prägt, ist der Wirtschaftsgeschichte Österreichs ein zweiter Themenschwerpunkt gewidmet. Eine besondere Herausforderung stellte der Themenblock „Diktatur, NS-Terror und Erinnerung“ dar - nicht nur wegen der räumlichen Beschränkung von ca. 8o Quadratmetern. Allein die Benennung der Jahre 1933/1934 bis 1938 sorgte für Diskussionen im Wissenschaftlichen Beirat: Austrofaschismus, Ständestaat, Dollfuß-Schuschnigg-Regime oder Kanzlerdiktatur? Wir entschieden uns schließlich, einen neuen Begriff einzuführen: DollfußSchuschnigg-Diktatur. Die Diskussion über die Benennung der politischen Ära haben wir in einer eigenen Station offengelegt und die Konnotationen der jeweiligen Begriffe ausgeführt, um auch an der eignen Neuerfindung Kritik zu üben. Denn ein idealer Begriff für die Jahre 1933/1934 bis 1938 ist noch nicht gefunden. Im Bereich des NS-Regimes stellten wir Orte des Terrors ins Zentrum der Erzählung, wobei uns wichtig war, die Österreicherinnen und Österreicher nicht allein als Opfer und WiderstandskämpferInnen, sondern auch als TäterInnen zu zeigen. Für Debatten unter den MuseumsbesucherInnen sorgt immer wieder die „Erinnerungsplattform“, die vom sogenannten Waldheim-Pferd nach einem Entwurf von Alfred Hrdlicka, einer Leihgabe des Vereins Republikanischer Club, überragt wird. Das Großobjekt - positioniert über anderen Artefakten, die den Prozess des Wandels der österreichischen Position im Umgang mit der Vergangenheit seit 1945 thematisieren - bringt aus kuratorischer Sicht zum Ausdruck, dass es sich bei der kritischen Auseinandersetzung mit Waldheims Kriegsvergangenheit 1986 um die größte, wichtigste und nachhaltigste geschichtspolitische Debatte der Zweiten Republik handelt, die schließlich 1991 zum ersten Bekenntnis des offiziellen Österreich zur Mitverantwortung an den Verbrechen des Nationalsozialismus führte. Im Themenbereich „Was ist Österreich?" haben wir identitätspolitische Topoi zur Diskussion gestellt, während wir im anschließenden Bereich anhand ausgewählter Orte die Frage nach Österreichs wechselvollem Umgang mit seinen Grenzen stellen. Ausgehend von Österreichs Verfassung, in der die Gleichheit aller StaatsbürgerInnen festgeschrieben ist, fragen wir im Abschnitt „Gleiche Rechte?!“, welche Gruppierungen um die Anerkennung 
ihrer Rechte im Laufe des letzten Jahrhunderts kämpfen mussten. Bislang marginalisierte gesellschaftliche Gruppen bekamen so erstmals Präsenz in einer Jubiläumsausstellung des Bundes. Flankiert werden diese Themenschwerpunkte von einer chronologisch organisierten Installation, die wie ein Handlauf durch die Jahrzehnte dieses Jahrhunderts führt und dabei mediengeschichtlich nach der Macht der Bilder fragt. Wichtig ist es uns, Aspekte des „undesired heritage“ (Sharon MacDonald) sichtbar zu machen, so etwa das rassistisch motivierte mörderische Bombenattentat auf vier Roma in Oberwart 1995. Zum Selbstverständnis des Hauses gehört es, Geschichte begreifbar zu machen: Zahlreiche Hands-on-Stationen sind Teil des kuratorischen Konzepts und Teil der Vermittlungsaktivitäten, denn jede/ $\mathrm{r}$ hat ihre/seine Geschichte. Diese in die Ausstellung einzubringen, ermöglicht auch die Webplattform, auf der Bilder zu spezifischen Themen hochgeladen werden können - Bilder, die dann wiederum in der Ausstellung zu sehen sind. ${ }^{5}$

Dass die zur Verfügung stehenden 750-Quadratmeter-Ausstellungsfläche prall mit Inhalten gefüllt sind, mag zu Recht kritisiert werden, ${ }^{56}$ wobei kaum eine Ausstellungsbesprechung Vorschläge für eine Reduktion macht, dafür aber oft Feststellungen getroffen werden, welche Themen breiter hätten ausgeführt werden sollen. Die Schau soll vor allem auch Lust auf mehr Geschichte machen: Denn dass ein Haus der Geschichte Österreich mehr Ressourcen als 700 Quadratmeter Fläche und etwas mehr als 1 Million Euro Basisabgeltung braucht, um internationalen Standards von zeitgeschichtlichen Museen gerecht zu werden, ist evident. Ob und wann es dazu kommt, bleibt abzuwarten, denn das Museum ist in der jüngsten Vergangenheit im Hinblick auf die Klärung seiner Rahmenbedingungen in den Sog einer turbulenten Politik geraten.

$55 \mathrm{Zu}$ den Grundsätzen des Hauses vgl. auch Stefan Benedik/Eva Meran/Monika Sommer, Haus der Geschichte Österreich - das zeitgenössische Museum als Diskussionsforum und Prozess, in: Rainer Wenrich/Josef Kirmeier/Henrike Bäuerlein (Hg.), Zeitgeschichte im Museum. Das 20. und 21. Jahrhundert ausstellen und vermitteln (Kommunikation. Interaktion. Partizipation. Kunst- und Kulturvermittlung im Museum am Beginn des 21. Jahrhunderts 4), München 2021 (im Druck).

56 Vgl. z. B. Marcus Gräser, Große Ambition auf kleinem Raum. Das Haus der Geschichte Österreich, in: neues museum 2019/1, 62-69, 66; Andrea Brait, Rezension zu Haus der Geschichte Niederösterreich, H-Soz-Kult, 01.06.2019, URL: www.hsozkult.de/exhibitionreview/id/rezausstellungen-346 (abgerufen 15.11.2020). 


\section{Im Sog der Politik}

Die Novellierung des Bundesmuseumsgesetzes brachte neben der Etablierung des Museums eine weitere Novität. Denn kein anderes Museum in Österreich verfügt so wie das Haus der Geschichte Österreich über zwei gesetzlich verankerte Gremien, die der/dem Direktor/in beratend zur Seite stehen: Zur Einbindung der Zivilgesellschaft wurde ein Publikumsforum einberufen, zusammengesetzt aus VertreterInnen von $34 \mathrm{im}$ Gesetz genannten Vereinen und Institutionen - das sind mehr Mitglieder, als der Publikumsbeirat des ORF aufweist. Darüber hinaus wurde ein sechsköpfiger Wissenschaftlicher Beirat installiert, der politisch zu besetzen ist. Ende Januar 2017 ernannte mich die Generaldirektorin der Österreichischen Nationalbibliothek, Johanna Rachinger, zur Gründungsdirektorin des Hauses der Geschichte Österreich. ${ }^{57}$ Sie folgte damit der Reihung des Wissenschaftlichen Beirats, der, wie im Bundesmuseumsgesetz vorgesehen, nach einem Hearing von sechs eingeladenen BewerberInnen einen Dreiervorschlag erstellt hatte. Seine Arbeit hatte der Wissenschaftliche Beirat für die erste Periode im Oktober 2016 aufgenommen, die Zusammensetzung dieses Gremiums ist gesetzlich geregelt: Der Historiker und ehemalige langjährige Leiter des Wiener Vereins für die Geschichte der Arbeiterbewegung Wolfgang Maderthaner gehörte ihm in seiner Funktion als Generaldirektor des Österreichischen Staatsarchivs bis zu seiner Pensionierung im Mai 2019 an, der habilitierte Historiker und Salzburger Landeshauptmann a. D. Franz Schausberger wurde von der Landeshauptleutekonferenz als Vertreter der Bundesländer entsandt. Der Bundeskanzler ernannte die Konstanzer Kulturwissenschaftlerin Aleida Assmann und den Historiker Oliver Rathkolb, der den Vorsitz des Gremiums übernahm. ÖVP-Wissenschaftsminister Reinhold Mitterlehner nominierte den Leiter des Dokumentationsarchivs des österreichischen Widerstands Gerhard Baumgartner und Eva Blimlinger, zu diesem Zeitpunkt Rektorin der Akademie der bildenden Künste Wien, deren Bestellung Erstaunen hervorrief, da sie sich schon 2015 mehrfach als Gegnerin des Projekts positioniert hatte. ${ }^{8}$ Über die Aufgaben des Gremiums herrschten Auffassungsunterschiede, die erst durch ein Rechtsgutachten des Verfassungsdienstes des Bundeskanzleramts beseitigt werden konnten, das klarstellte, dass das Gremium eine beratende und keine exekutive Funktion hat. Im Juni 2018, ein Monat nachdem bekannt

57 Monika Sommer-Sieghart: Vielseitige Vermittlerin der Landesgeschichte, Der Standard, 26.01.2017, URL: https:/www.derstandard.at/story/2000051582617/monika-sommer-sieghartvielseitige-vermittlerin-der-landesgeschichte (abgerufen 13.07.2020).

58 Ostermayer: „Habe nicht vor, Museumsdirektor zu werden“, Der Standard, 30.01.2015, URL: https://www.derstandard.at/story/200001 1092438/ostermayer-ich-habe-nicht-vor-museumsdirektor-zu-werden (abgerufen 13.07.2020). 
geworden war, dass Eva Blimlinger in ihrer Funktion als Rektorin vom Universitätssenat der Akademie der bildenden Künste nicht verlängert werden würde, und vier Monate vor der Eröffnung des Museums legten Baumgartner und Blimlinger ihre Beiratsfunktion schließlich zurück. ${ }^{59}$ Im August 2018 nominierte der zuständige ÖVP-Bundesminister Heinz Faßmann zwei neue Mitglieder: Hans-Walter Hütter, Präsident der Stiftung Haus der Geschichte der Bundesrepublik Deutschland, der vier historische Museen in drei deutschen Städten verantwortet, und Danièle Wagener, die jahrzehntelang die beiden Museen der Stadt Luxemburg geleitet hatte. Mit dieser Neubesetzung erfuhr der Beirat eine Internationalisierung und Stärkung der Museumsexpertise. Faßmanns Entscheidung war die erste das Haus der Geschichte Österreich betreffende seit der Angelobung der türkis-blauen Bundesregierung mit ÖVP-Bundeskanzler Sebastian Kurz und FPÖ-Vizekanzler Heinz-Christian Strache im Dezember 2017 gewesen, die sich eine „Evaluierung der derzeit bestehenden Pläne“ zum Projekt Haus der Geschichte (zum Beispiel Ort, Konzept, Finanzierung) und Einbettung des Projekts in eine gesamthafte „Museenstrategie ${ }^{\text {“60 }}$ vorgenommen hatte, allerdings offenbar den Start des Publikumsbetriebs der Ausstellung abwarten wollte.

Denn zwei Wochen vor der Eröffnung des Museums präsentierten der für EU, Kunst, Kultur und Medien verantwortliche ÖVP-Kanzleramtsminister Gernot Blümel und ÖVP-Nationalratspräsident Wolfgang Sobotka die Vision für ein „Haus der Republik" unter dem Dach des Parlaments, wobei die wissenschaftliche Unabhängigkeit gewahrt bleiben sollte. ${ }^{61}$ Zwei Monate nach der Eröffnung des Museums wurden schließlich Anfang Januar 2019 die Mitglieder der Evaluierungskommission bekanntgegeben: Barbara Glück (Leiterin der Gedenkstätte Mauthausen), Hannah Lessing (Generalsekretärin des Nationalfonds der Republik Österreich für die Opfer des Nationalsozialismus), Hans-Peter Wipplinger (Direktor der Stiftung Le-

59 Haus der Geschichte: Blimlinger und Baumgartner verließen Beirat, Der Standard, 07.07.2018, URL: https://www.derstandard.at/story/2000083019172/haus-der-geschichte-blimlinger-undbaumgartner-verliessen-beirat; Blimlinger: „Es müsste eine großartige Ausstellung werden, um den Fortbestand des Haus der Geschichte zu sichern.", igkultur, 09.11.2018, URL: https://www.igkultur.at/artikel/eva-blimlinger-haus-der-geschichte; Haus der Geschichte: Blimlinger und Baumgartner verließen Beirat, Die Presse, 09.07.2018, URL: https://www.diepresse.com/5461116/hausder-geschichte-blimlinger-und-baumgartner-verliessen-beirat (alle abgerufen 13.07.2020).

60 Neue Volkspartei/Freiheitliche Partei Österreichs, „Zusammen. Für unser Österreich“. Regierungsprogramm 2017-2022, 96, URL: https:/www.wienerzeitung.at/_em_daten/_ wzo/2017/12/16/171216_1614_regierungsprogramm.pdf (abgerufen 12.12.2020).

61 Haus der Geschichte wird an Parlament angebunden, Parlamentskorrespondenz 1156 vom 24.10.2018, Republik Österreich Parlament, URL: https:/www.parlament.gv.at/PAKT/PR/ JAHR_2018/PK1156/index.shtml (abgerufen 13.07.2020). 
opold Museum) und die beiden internationalen ExpertInnen Hans-Walter Hütter (Präsident der Stiftung Haus der Geschichte der Bundesrepublik Deutschland) und Constanze Itzel (Direktorin des Hauses der europäischen Geschichte) kamen dem Auftrag der Bundesregierung nach, die Situation des Hauses der Geschichte Österreich zu evaluieren, um dieses langfristig auf eine solide Basis zu stellen. Durch die am 17. Mai 2019 ins Rollen geratene „Ibiza-Affäre“ verzögerte sich die Arbeit dieser Gruppe, da die amtierende Bundesregierung durch ein erstmals in der Geschichte der Ersten und Zweiten Republik erfolgreiches Misstrauensvotum des Parlaments abgewählt und von Bundespräsident Alexander Van der Bellen eine Beamtenregierung unter der ersten Bundeskanzlerin Österreichs Brigitte Bierlein eingesetzt wurde. Der parteilose Außen- und Kulturminister Alexander Schallenberg hatte im Juni 2019 auf Vorschlag von Sektionschef Jürgen Meindl einer Verlängerung der Eröffnungsausstellung zugestimmt, da diese mit 17. Mai 2020 ohne ein finanziertes Nachfolgeprojekt ausgelaufen wäre und eine weitere Entscheidung über die Zukunft des Museums der nächsten gewählten Bundesregierung überlassen werden sollte. Für das Team des Hauses der Geschichte Österreich bedeutete dies, sich weiterhin in Geduld zu üben und mit Neugierde die weiteren Entwicklungen abzuwarten. Eine Partei - die Grünen - widmete ihren Plänen zum Haus der Geschichte Österreich einen Absatz im Wahlprogramm: „Das Haus der Geschichte in der Hofburg soll in seiner derzeitigen Form nicht weitergeführt werden ${ }^{\text {“ }}{ }^{62}$ hieß es da. Die Präsentation des Evaluierungsberichts Anfang Dezember 2019 fiel in die Zeit der Regierungsverhandlungen zwischen der ÖVP und den Grünen. ${ }^{63}$ Die Evaluierungskommission sprach sich einhellig für die institutionelle Selbständigkeit und die wissenschaftliche Unabhängigkeit des Hauses der Geschichte aus und favorisierte einen Neubau auf dem Heldenplatz. Die NEOS drängten darauf, „dass die Empfehlungen der Expert_ innen ins nächste Regierungsprogramm übernommen werden", so Kultursprecher Sepp Schellhorn. ${ }^{64}$ Dazu sollte es allerdings nicht kommen. Das Haus der Geschichte Österreich wurde im Programm der ersten türkis-grünen Bundesregierung nicht expliziert erwähnt. ${ }^{65}$ Eva Blimlinger, die mittlerweile in die Politik eingestiegen war

62 Die Grünen, Das Grüne Wahlprogramm. Nationalratswahl 2019, Wien 2019, 65, URL: https:// www.gruene.at/partei/programm/wahlprogramme (abgerufen 12.12.2020).

63 Evaluierungsbericht Haus der Geschichte liegt vor, APA, 09.12.2019, URL: https://www.ots.at/ presseaussendung/OTS_20191209_OTSooo8/evaluierungsbericht-haus-der-geschichte-liegt-vor (abgerufen 13.07.2020).

64 NEOS: Evaluierungsbericht zu Haus der Geschichte zeigt Handlungsbedarf klar auf, APA, 09.12.2019, URL: https://www.ots.at/presseaussendung/OTS_20191209_OTSoo76/neos-evaluierungsbericht-zu-haus-der-geschichte-zeigt-handlungsbedarf-klar-auf (abgerufen 13.07.2020).

65 Bundeskanzleramt Österreich (Hg.), Aus Verantwortung für Österreich. Regierungsprogramm 2020-2024, Wien 2020, URL: https://www.bundeskanzleramt.gv.at/bundeskanzleramt/die-bundesregierung/regierungsdokumente.html (abgerufen 12.12.2020). 
und für die Grünen den Kulturteil des Regierungsprogramms mitverhandelt hatte, erklärte Anfang Januar 2020 in einem Interview: „Das Haus der Geschichte Österreich (hdgö) sei absichtlich nicht aufgenommen worden, da der Evaluierungsbericht zum Zeitpunkt der Verhandlungen noch nicht vorgelegen sei“"66- dem steht freilich gegenüber, dass der Abschluss der Regierungsverhandlungen erst nach Weihnachten erfolgte. ${ }^{67}$

Mit der Angelobung der türkis-grünen Bundesregierung Anfang Januar 2020 kamen die Kunst- und Kulturagenden in die Verantwortung des Grünen-Vizekanzlers Werner Kogler, der dafür ein Staatssekretariat einrichtete, das er überraschenderweise nicht mit Eva Blimlinger, dafür aber mit der ehemaligen Europa-Abgeordneten Ulrike Lunacek besetzte, die allerdings das Regierungsprogramm im Bereich Kunstund Kultur nicht mitverhandelt hatte. Ulrike Lunacek nahm sich vor, innerhalb des Jahres 2020 über die Zukunft des Hauses der Geschichte Österreich entscheiden zu wollen, wozu es in dieser Form nicht mehr kam, da sie aufgrund des heftigen Protestes der Kunst- und Kulturszene bezüglich des Managements der Corona-Krise Mitte Mai 2020 ihren Rücktritt erklärte. Ihr folgte Andrea Mayer (vormals Ecker), die als ehemalige Sektionschefin für Kunst und Kultur mit dem Vorhaben der Gründung eines Hauses der Geschichte Österreich bereits in den Jahren 2014 und 2015 befasst gewesen war. Anlässlich des zweiten Geburtstag des Museums, der in den zweiten Corona-bedingten Lockdown des Jahres 2020 und somit in die Schließzeit des Museums fiel, überraschte sie mit einem erfreulichen Bekenntnis: „Ich gratuliere dem Haus der Geschichte Österreich zum zweijährigen Bestehen und möchte dem gesamten Team meinen großen Dank für ihre engagierte und hochprofessionelle Arbeit übermitteln." Und weiter:

Es ist mir daher ein großes Anliegen, dass wir das Haus auf solide strukturelle Beine stellen. Um dies zu gewährleisten, bin ich aktuell mit allen Beteiligten im engen Austausch. Ich erwarte mir, dass wir in naher Zukunft zu einem Ergebnis kommen, das die Weiterführung des Hauses ermöglicht und den Mitarbeiterinnen und Mitarbeitern eine Perspektive gibt. Ich bin zuversichtlich, dass wir eine gute und langfristige Lösung finden. ${ }^{68}$

66 Eva Blimlinger: „Fotomuseum wird es nicht geben“, Kurier, 03.01.2020, URL: https://kurier.at/kultur/eva-blimlinger-fotomuseum-wird-es-nicht-geben/400716909 (abgerufen 13.07.2020).

67 Kurz und Kogler bestätigen: Türkis-Grün kurz vor Abschluss, Kurier, 27.12.2019, URL: https://kurier.at/politik/inland/kurz-und-kogler-bestaetigen-tuerkis-gruen-kurz-vor-abschluss/400713399 (abgerufen 13.07.2020).

68 Haus der Geschichte Österreich: Staatssekretärin Mayer gratuliert zum zweijährigen Bestehen, APA, 10.11.2020, URL: https://www.ots.at/presseaussendung/OTS_20201110_OTSo055/haus- 
Mit dieser Aussage sprach erstmals seit der Eröffnung im November 2018 eine kulturpolitische Verantwortungsträgerin in Österreich dem Haus der Geschichte Österreich öffentlich schriftlich Respekt und Anerkennung für die Aufbauleistung des Teams und den inhaltlichen Zugang aus. Der Innsbrucker Zeithistoriker Dirk Rupnow mahnt Eile ein:

Die Musealisierung der österreichischen Zeitgeschichte, so wird man konstatieren können, steckt nach dem übervollen Erinnerungs- und Gedenkjahr 2018 in einer Krise wie selten zuvor. Das Hinterherhecheln hinter den jeweils gerade allen kurzfristig bewusst werdenden Jubiläen ist ermüdend und sicher keine gute und vor allem keine nachhaltige Strategie. ${ }^{69}$

Die politische Konsensfindung und die Ausarbeitung einer machbaren Lösung für den nächsten Schritt der Entwicklung des Hauses der Geschichte Österreich sind nun drängende kulturpolitische Aufgaben. Auf europäischer Ebene ist jedenfalls die konsequente Positionierung des Hauses der Geschichte Österreich als diskursives Forum zur Auseinandersetzung mit Demokratie, Multiperspektivität der Vergangenheit und Interaktion bereits positiv aufgefallen. So erhielt die Autorin eine Vortragseinladung vom Europäischen Rat, wo aktuell an der Entwicklung neuer Empfehlungen für den Geschichtsunterricht gearbeitet wird, in dem auch Geschichtsmuseen eine größere Rolle einnehmen sollen:

In this context we would like to invite you to present the innovative work done by your museum in Vienna that engages with issues of democracy and human rights with exceptional courage, honesty and intellectual clarity. We believe that your museum takes a very radical approach, by not offering a single narrative, but presenting multiple perspectives. It also recovers previously hidden and difficult narratives and incorporates them into a public reflection on democracy and identity. This would be an excellent example to show to members of our committee in terms of the above mentioned themes that Rapporteur would like to promote in his report. ${ }^{70}$

der-geschichte-oesterreich-staatssekretaerin-mayer-gratuliert-zum-zweijaehrigen-bestehen (abgerufen 13.07.2020).

69 Dirk Rupnow, Österreichische Zeitgeschichte und ihre langwierige Musealisierung. Ein Befund zum Haus der Geschichte Österreich, in: Museum Aktuell 269/2020, 9-14.

70 E-Mail von Dana Karanjac, Council of Europe, Commitee on Culture, Science, Education and Media, 13.11.2020. 
Es obliegt nun der türkis-grünen Bundesregierung - trotz der Corona-Krise -, zukunftsweisende Weichen für die museale Präsentation der österreichischen Zeitgeschichte zu stellen, denn die derzeitige räumliche und finanzielle Situation des Hauses der Geschichte ist unbefriedigend. Doch immerhin wurde seit dem Erscheinen des Bandes „Zeitgeschichte ausstellen“ 2011 in Sachen Haus der Geschichte Österreich ein entscheidender Anfang gemacht und nun gilt es, die Chance, die sich mit der - im internationalen Vergleich - späten Gründung auftut, zu nutzen: Österreich kann unter Beweis stellen, dass es sich 75 Jahre nach Ende der NS-Terrorherrschaft auf der Basis einer gefestigten Demokratie seiner historischen Verantwortung selbstkritisch auf Länder- und auf Bundesebene aktiv und offensiv stellt. Darin läge auch ein konstruktiver Beitrag zu einer europäischen Erinnerungskultur. 


\title{
Zeitgeschichte und Archive
}

\author{
Stefan Eminger
}

In seinem programmatischen Aufsatz über „Regionale Zeitgeschichte“ verlieh der Innsbrucker Zeithistoriker Michael Gehler 1992 dem verbreiteten Ärger über die „zeitgeschichtsferne “ Praxis der Archive deutlichen Ausdruck. ${ }^{1}$ Was er über die Zustände im Tiroler Landesarchiv schrieb, galt damals auch für die meisten anderen Landesarchive:

Das Tiroler Landesarchiv begriff sich bis in die jüngste Zeit nicht als zeitgeschichtliche Servicestelle, sondern erschwerte und verschloß den Zugang zu den einschlägigen Quellen. „Zeitgeschichtsfeindliche“ Mentalität ging Hand in Hand mit teilweise sinnentleerten Archivsperren und Forschungsbehinderungen. So fehlte es an kompetenter Fachbetreuung, an weiterführenden Repertorien und Suchbehelfen für zeitgeschichtlich relevante Bestände. All dies blockierte jahrzehntelang die Aufarbeitung der jüngeren und jüngsten Landesgeschichte. $^{2}$

Einen der Hauptgründe dafür, dass sich Landesarchivare „kaum zeitgeschichtlich exponieren“, verortete Gehler in deren Ausbildung am 1854 gegründeten Institut für österreichische Geschichtsforschung (IÖG). Dieses sehe sich „nach wie vor als eine Historikerelitenschmiede in Österreich" mit mediävistisch-hilfswissenschaftlichem Schwerpunkt, das über ein Ausbildungsmonopol im Archivwesen verfüge. Der dreijährige „Institutskurs“ am IÖG fördere bei den AbsolventInnen die Herausbildung der „Mentalität eines gewissen exklusiven Korpsgeistes“ und beschäftige sich „nicht mit Zeitgeschichte und daher auch kaum mit modernen Fragestellungen, wie Theorien und Methoden der Geschichtswissenschaft".3

Die zitierte Stellungnahme verweist auf mehrere Spannungsfelder im Verhältnis von Archiven und Zeitgeschichte. Diese Spannungen waren zwischen der Waldheim-Debatte 1986 und den frühen 1990er-Jahren am deutlichsten sichtbar und

$1 \quad$ Für kritische Bemerkungen zum Text danke ich Hanns Jürgen Küsters, Gerhart Marckhgott und Lorenz Mikoletzky. Für allfällige Unzulänglichkeiten trägt freilich der Verfasser die alleinige Verantwortung.

2 Michael Gehler, „Regionale“ Zeitgeschichte als „Geschichte überschaubarer Räume“. Von Grenzen, Möglichkeiten, Aufgaben und Fragen einer Forschungsrichtung, in: Geschichte und Region/Storia e regione 1 (1992) 2, 85-120, 94.

3 Ebd., 95. 
verliefen, überspitzt formuliert, entlang folgender Bruchlinien: elitäre „Institutler“ gegen egalitäre Zeithistoriker, Mediävisten gegen NS-Forscher, positivistische „Landeshistoriker" gegen theorieaffine Regionalgeschichtler, (landes-)politiknahe Konservative gegen herrschaftskritische Progressive.

Der vorliegende Beitrag spürt dem spannungsreichen Verhältnis von Archiven und Zeitgeschichte nach. Im Fokus befinden sich dabei die Landesarchive und das 1945 neu geschaffene Österreichische Staatsarchiv (ÖStA). ${ }^{4}$ Folgende Fragen stehen im Mittelpunkt: Welche Ursachen hatten die erwähnten Spannungen? Wo und warum waren sie besonders ausgeprägt? Und umgekehrt: Wo lagen die Anfänge einer Zeitgeschichtsforschung durch Archivare und Archivarinnen? Was waren die bestimmenden Themen? Welche Positionen nahmen diese „Zeithistoriker-Archivare“ im Feld der Zeitgeschichte ein? Wie sieht das Verhältnis zwischen Archiven und Zeitgeschichte heute aus?

Diese Fragen sollen durch eine Analyse von Kommunikationsnetzwerken beantwortet werden, worunter neben persönlichen Beziehungen vor allem Fachzeitschriften verstanden werden. ${ }^{5}$ Gegenstand der Untersuchung bilden auf Seiten der Archive die Zeitschrift „Scrinium“, das Medium des 1967 gegründeten Verbandes Österreichischer Archivarinnen und Archivare (VÖA), und die „Mitteilungen des Österreichischen Staatsarchivs" (MÖSTA). Auf Seiten der ZeithistorikerInnen werden die 1973 von Erika Weinzierl geschaffene Zeitschrift „zeitgeschichte“ und die seit 1993 stattfindenden Zeitgeschichtetage für die Analyse herangezogen. Der Begriff Zeitgeschichte wird pragmatisch als Epochenbegriff (seit 1918) verwendet. ${ }^{6}$

\section{Das Österreichische Staatsarchiv - Archivare als frühe Zeithistoriker}

Betrachten wir dieses gespannte Verhältnis, so mag es überraschen, dass die Anfänge der österreichischen Zeitgeschichtsforschung nach 1945 stark von Archivaren mitgeprägt wurden. Das galt weniger für die spätere Grande Dame der österreichischen Zeitgeschichte, Erika Weinzierl (1925-2014), die als Absolventin des Institutskurses zunächst als Kirchenhistorikerin und bis 1964 im Haus-, Hof- und Staats-

4 Die Stadtarchive, die mitunter, wie etwa das Stadtarchiv Linz, schon früh und qualitätsvoll Zeitgeschichte betrieben haben, müssen hier aus Platzgründen unberücksichtigt bleiben.

5 Lutz Raphael, Der Beruf des Historikers seit 1945, in: Christoph Cornelißen (Hg.), Geschichtswissenschaften. Eine Einführung, Frankfurt a. M. ${ }^{2} 2000,39-52,46$.

6 Zum Facettenreichtum des Begriffs: Thomas Sandkühler, Zeitgeschichte in Deutschland am Ende des 20. Jahrhunderts, in: Cornelißen (Hg.), Geschichtswissenschaften, 114-129, 115, 119. 
archiv tätig war, ${ }^{7}$ als für ihren politisch gut vernetzten Kollegen im IÖG-Kurs und Archiv, den späteren Generaldirektor des ÖStA, Rudolf Neck (1921-1999). ${ }^{8}$ Auch die ersten Monographien der Zeitgeschichtsschreibung über Österreich nach 1945 stammten von prominenten Archivaren: Walter Goldinger (1910-1990) und Hanns Leo Mikoletzky (1907-1978).

Goldinger wie Mikoletzky waren ausgebildete Mediävisten und hatten naturgemäß den Kurs des IÖG absolviert. Sie waren damit Schüler des 1940 verstorbenen, nationalsozialistisch orientierten Direktors des IÖG Hans Hirsch. ${ }^{9}$ Am Beginn der Zweiten Republik habilitierten sie sich an der Universität Wien. Beide erlangten in den frühen 1960er-Jahren das Amt eines außerordentlichen Professors und beendeten ihre beruflichen Karrieren als Generaldirektoren des ÖStA an der Spitze der österreichischen Archivlandschaft. ${ }^{10}$

Mikoletzky und Goldinger waren geprägt vom Kurs am IÖG. Mikoletzky sah die Absolvierung des Kurses generell als Voraussetzung für den Zugang zu Archivquellen. Er nahm gegen eine Aufweichung der geltenden Benützungsgrenze Stellung - sie lag im ÖStA seit 1956 bei 1918 -, weil er die Zeit für eine ausgewogene Interpretation dieser Quellen noch nicht gekommen sah. ${ }^{11}$ Für Goldinger, der von seinem Freund Adam Wandruszka als „Bahnbrecher und Pionier der österreichischen Zeitgeschichte“ gefeiert wurde, ${ }^{12}$ waren Kurs und IÖG zeitlebens von größter Bedeutung. „Wir sind und bleiben ,Institutler“, schloss er etwa seinen Beitrag in

7 Erika Weinzierl war 16 Jahre lang (1948-1964) am Haus-, Hof- und Staatsarchiv beschäftigt; Fritz Fellner/Doris A. Corradini, Österreichische Geschichtswissenschaft im 20. Jahrhundert. Ein biographisch-bibliographisches Lexikon (Veröffentlichungen der Kommission für Neuere Geschichte Österreichs 99), Wien/Köln/Weimar 2006, 444.

8 Isabella Ackerl, Ehemaliger Generaldirektor des Staatsarchives verstorben. Neck hat Zeitgeschichte salonfähig gemacht, Wiener Zeitung, 30.07.1999, URL: https://www.wienerzeitung.at/nachrichten/politik/oesterreich/365311_Neck-hat-Zeitgeschichte-salonfaehig-gemacht.html (abgerufen 15.01.2020).

9 Zu Hirsch: Andreas Zajic, Hans Hirsch (1878-1940). Historiker und Wissenschaftsorganisator zwischen Urkunden- und Volkstumsforschung, in: Karel Hruza (Hg.), Österreichische Historiker 1900-1945. Lebensläufe und Karrieren in Österreich, Deutschland und der Tschechoslowakei in wissenschaftsgeschichtlichen Porträts, Wien/Köln/Weimar 2008, 307-418.

10 Fellner/Corradini, Geschichtswissenschaft, 144, 282-283.

11 Hanns Leo Mikoletzky, Österreichische Zeitgeschichte. Vom Ende der Monarchie bis zum Abschluss des Staatsvertrages 1955, Wien/München 1962, 11-13; vgl. auch Hans Safrian, Anfänge der österreichischen Zeitgeschichtsschreibung: mit oder ohne Quellen?, in: Bertrand Perz/Ina Markova (Hg.), 50 Jahre Institut für Zeitgeschichte der Universität Wien 1966-2016, Wien 2017, 202-223, 213-215.

12 Adam Wandruszka, Walter Goldinger, in: Österreichische Akademie der Wissenschaften. Almanach $141(1990 / 91), 371-377,372$. 
der Festschrift zum Hundertjahrjubiläum des IÖG $1954 \cdot{ }^{13}$ Goldinger war 1935 in das Archiv des Inneren und der Justiz (ab 1945 Allgemeines Verwaltungsarchiv) eingetreten und 1941 zur Deutschen Wehrmacht eingezogen geworden. Nach der Befreiung Österreichs vom Nationalsozialismus kehrte er in den Archivdienst zurück. Als er in das neu geschaffene ÖStA eintrat, fand er einen völlig veränderten Personalstand vor. Viele seiner Archivarkollegen hatten der NSDAP angehört und wurden nicht mehr weiterbeschäftigt. ${ }^{14}$ Goldinger selbst war der Partei nicht beigetreten; ihm wurde aber vorgeworfen, sich vor 1938 illegal für die NSDAP betätigt $\mathrm{zu}$ haben. Er konnte diese Behauptungen zwar weitgehend entkräften, ${ }^{15}$ dennoch scheint seine Biographie "nicht ganz frei von klärungsbedürftigen Episoden“. ${ }^{16}$

Für Mikoletzky hatte die NS-Zeit hingegen einen scharfen Bruch bedeutet; sein Verhältnis zu Goldinger war denkbar schlecht. Wegen seiner oppositionellen politischen Gesinnung und der jüdischen Herkunft seiner Mutter, die 1944 nach Theresienstadt deportiert worden war, ${ }^{17}$ hatte Mikoletzky 1938 seine Anstellung in der Bibliothek der Technischen Hochschule in Wien verloren. Nach einer Denunziation war er in einen Rüstungsbetrieb dienstverpflichtet worden und hatte dort fast bis Kriegsende Schwerarbeit leisten müssen. ${ }^{18}$

Mikoletzky trat 1946 in das Haus-, Hof- und Staatsarchiv ein, 1950 wurde er Leiter des Finanz- und Hofkammerarchivs. 1962 veröffentlichte er seine „Österreichische Zeitgeschichte“. Wegen der Archivsperre stützte er sich vor allem auf Zeitungsberichte und seine Erfahrungen als Zeitgenosse, die er in Tagebüchern niedergelegt hatte. Sein Buch erschien bis 1969 in drei Auflagen, die dritte unter dem Titel „Österreich im 20. Jahrhundert. Zeitgeschichte“.19

Der vielseitig interessierte Mikoletzky befasste sich nur vorübergehend mit der jüngsten Geschichte. In seiner „Zeitgeschichte“ brachte er aber Themen zur Sprache,

13 Walter Goldinger, Die österreichischen Archive und die Geschichtswissenschaft, in: Mitteilungen des Österreichischen Staatsarchivs 7 (1954), 165-189, 189.

14 Rudolf Jeřábek, Zu den Anfängen des Österreichischen Staatsarchivs 1945-1948, in: Mitteilungen des Österreichischen Staatsarchivs 54 (2010), 319-386, 345.

15 Ebd., 367.

16 Michael Hochedlinger, Österreichische Archivgeschichte. Vom Spätmittelalter bis zum Ende des Papierzeitalters, Wien/Köln/Weimar 2013, 248.

17 Institut Theresienstädter Initiative/Dokumentationsarchiv des österreichischen Widerstandes (Hg.), Theresienstädter Gedenkbuch.Österreichische Jüdinnen und Juden in Theresienstadt 19421945, Prag 2005, 493.

18 Leopold Auer, Mikoletzky, Hanns Leo, in: Neue Deutsche Biographie 17 (1994), 494-495 [Onlineversion], URL: https://www.deutsche-biographie.de/pnd12847114X.html\#ndbcontent (abgerufen 17.12.2019).

19 Hanns Leo Mikoletzky, Österreich im 20. Jahrhundert. Zeitgeschichte, Wien ${ }^{3} 1969$. 
die im damaligen Österreich unüblich waren. Wohl auch aufgrund seiner persönlichen Erfahrungen widmete er der NS-Herrschaft in Österreich breiteren Raum. ${ }^{20}$ Nach Hans Safrian war Mikoletzky der erste österreichische Fachhistoriker, der sich im Rahmen einer Republiksgeschichte eingehender mit der Ausgrenzung, Beraubung, Deportation und Vernichtung der jüdischen Bevölkerung in Österreich beschäftigte. ${ }^{21}$ Die „Ächtung“ von Mikoletzkys „Zeitgeschichte“ in den Lehrveranstaltungen des ehemaligen Nationalsozialisten und nunmehrigen Gründervaters der österreichischen Zeitgeschichte, Ludwig Jedlicka, könnte darin eine Ursache haben. ${ }^{22}$

Mikoletzkys Nachfolger als Generaldirektor des ÖStA, Walter Goldinger, avancierte nicht nur zum bedeutendsten Archivwissenschaftler Österreichs in der Zweiten Republik, ${ }^{23}$ sondern er firmierte 1954 auch als einer der Hauptautoren des Sammelbandes „Geschichte der Republik Österreich“. ${ }^{24}$ Diese Publikation, herausgebracht von dem aus dem britischen Exil zurückgekehrten Heinrich Benedikt, entwickelte sich rasch zum Standardwerk. Adam Wandruszka, wie Jedlicka ehemaliger Nationalsozialist, ${ }^{25}$ präsentierte dort seine einflussreiche Theorie der politischen „Lager“; ${ }^{26}$ Goldinger steuerte mit der Ereignisgeschichte 1918 bis 1945 fast die Hälfte des Bandes bei. ${ }^{27}$ Diesen Beitrag brachte Goldinger 1962 weitgehend unverändert unter dem Titel „Geschichte der Republik Österreich“ als Monographie heraus. ${ }^{28}$

Walter Goldinger war an der Institutionalisierung der österreichischen Zeitgeschichte direkt beteiligt. Als einziger Archivar nahm er 1960 an der „Reichenauer

20 Mikoletzky, Zeitgeschichte, 379-403, 421-445.

21 Safrian, Anfänge, 216.

22 Der Sohn Hanns Leo Mikoletzkys schreibt etwa von einem „Hausverbot“ des Buches in den Seminaren von Jedlicka; Lorenz Mikoletzky, Das Österreichische Staatsarchiv und die Zeitgeschichte, in: Dokumentationsarchiv des österreichischen Widerstandes (Hg.), Forschungen zum Nationalsozialismus und dessen Nachwirkungen in Österreich. Festschrift für Brigitte Bailer, Wien 2012, 291-296, 292.

23 Michael Hochedlinger, Miteinander - Gegeneinander - Nebeneinander? Archive und Geschichtswissenschaft im Schatten von „Erinnerungskultur“, Kulturgeschichte und Digitalisierungspopulismus. Eine Empörung, in: Scrinium 67 (2013), 27-63, 49.

24 Heinrich Benedikt (Hg.), Geschichte der Republik Österreich, Wien 1954.

25 Fritz Fellner, Adam Wandruszka $†$ 6. August 1914 - 10. Juli 1997, in: Mitteilungen des Instituts für Österreichische Geschichtsforschung 106 (1998), 443-450, 447.

26 Adam Wandruszka, Österreichs politische Struktur. Die Entwicklung der Parteien und politischen Bewegungen, in: Benedikt (Hg.), Geschichte, 289-486.

27 Walter Goldinger, Der geschichtliche Ablauf der Ereignisse in Österreich von 1918 bis 1945, in: Benedikt (Hg.), Geschichte, 15-288.

28 Walter Goldinger, Geschichte der Republik Österreich, Wien 1962. 
Tagung" teil, die gemeinhin als Geburtsstunde der österreichischen Zeitgeschichtsforschung firmiert. ${ }^{29}$ Von Goldinger stammte auch der dort diskutierte Entwurf eines Leitfadens für Lehrer „Österreich 1918-1945“, der mit einigen Änderungen und bis 1955 ausgedehnt den Schulen als Lehrbehelf zuging. ${ }^{30}$

Goldingers „Geschichte der Republik Österreich“ war für damalige Verhältnisse enorm kenntnisreich und informativ. ${ }^{31}$ In einer bearbeiteten und auf die Zwischenkriegszeit beschränkten Form hat sie daher Dieter A. Binder 1992 neu herausgegeben. ${ }^{32}$ Der Schluss liegt nahe, dass Goldinger bei den Recherchen seinen privilegierten Zugang zu Archivquellen in unrechtmäßiger Weise nutzte und Quellen verarbeitete, die damals noch gar nicht zugänglich waren. ${ }^{33}$ Typisch für die frühe österreichische Zeitgeschichtsforschung war hingegen die knappe Darstellung der NS-Herrschaft in Österreich auf nur wenigen Seiten. Die Ausgrenzung, Vertreibung und Vernichtung der jüdischen Bevölkerung handelte Goldinger auf siebeneinhalb Zeilen ab. ${ }^{34}$

Der gläubige Katholik Walter Goldinger war in der frühen ZeitgeschichteCommunity vor allem als Autor eine fixe Größe. Nicht zuletzt wegen seiner stupenden Quellenkenntnis wirkte er an den ersten großen Überblicksdarstellungen zur Zeitgeschichte Österreichs mit, die von Erika Weinzierl und Kurt Skalnik herausgebracht wurden. In der 1972 erschienenen Darstellung der Zweiten Republik zeichnete Goldinger für das Kapitel über den „Anschluss“ 1938 verantwortlich; in der Geschichte der Ersten Republik, die 1983 herauskam, verfasste er den Beitrag über die Verwaltungsgeschichte. ${ }^{35}$ Neben Rudolf Neck war er zudem der einzige Archivar unter den fast fünfzig Mitgliedern der von Bundeskanzler Bruno Kreisky (SPÖ) und Nationalratspräsident Alfred Maleta (ÖVP) eingesetzten „Wissenschaft-

29 Anton Kolbabek (Hg.), Österreichische Zeitgeschichte im Geschichtsunterricht. Bericht über die Expertentagung von 14.XII. bis 16.XII.1960 in Reichenau, Wien 1961, 232.

30 Andreas Cornaro, Bibliographie Walter Goldinger, in: Mitteilungen des Österreichischen Staatsarchivs 28 (1975), 3-7, 4; Kolbabek (Hg.), Zeitgeschichte, 180-181.

31 Goldinger, Geschichte.

32 Walter Goldinger/Dieter A. Binder, Geschichte der Republik Österreich 1918-1938, Wien/München 1992.

33 Safrian, Anfänge, 208; die allgemeine Sperrfrist für Archivalien im Österreichischen Staatsarchiv lag bis 1956 bei 1904 und wurde dann auf 1918 verkürzt, vgl. Gebhard Rath, 20 Jahre Österreichisches Staatsarchiv 1945-1965, in: Mitteilungen des Österreichischen Staatsarchivs 17/18 (1964/1965), 562-610, 563.

34 Safrian, Anfänge, 211-212.

35 Walter Goldinger, Gleichschaltung, in: Erika Weinzierl/Kurt Skalnik (Hg.), Österreich. Die Zweite Republik, Bd. 1, Graz/Wien/Köln 1972, 91-108; Walter Goldinger, Verwaltung und Bürokratie, in: Erika Weinzierl/Kurt Skalnik (Hg.), Österreich 1918-1938. Geschichte der Ersten Republik, Bd. 1, Graz/Wien/Köln 1983, 195-208. 
lichen Kommission des Theodor Körner-Stiftungsfonds und des Leopold KunschakPreises zur Erforschung der österreichischen Geschichte der Jahre 1927 bis $1938^{\text {“. }{ }^{36}}$

Der bis heute profilierteste "Zeithistoriker-Archivar" in Österreich war Rudolf Neck. Im Roten Wien sozialisiert, begann er 1939 an der Universität Wien Geschichte, Germanistik und Romanistik zu studieren. Im Februar 1941 wurde er zur Deutschen Wehrmacht eingezogen und kehrte im März 1946 aus der britischen Kriegsgefangenschaft zurück. ${ }^{37}$ Der überzeugte Sozialdemokrat nahm sein Geschichtsstudium wieder auf und schloss es 1948 mit einer Dissertation über Österreichs Türkenpolitik unter Melchior Khlesl ab. Parallel dazu absolvierte er den Institutskurs, der ihm laut Wandruszka aber nicht wie vielen anderen „Institutlern“ „akademische und geistige Heimat" wurde. ${ }^{38}$ Neck stieg 1976 zum Direktor des Allgemeinen Verwaltungsarchivs auf und war von 1979 bis 1986 Generaldirektor des ÖStA. ${ }^{39}$

Rudolf Neck beschäftigte sich schon sehr früh mit österreichischer Zeitgeschichte. Bereits 1953 und 1955 veröffentlichte er in den von Erika Weinzierl redigierten „Mitteilungen des Österreichischen Staatsarchivs" (MÖSTA) informative Berichte über „Zeitgeschichtliche Literatur über Österreich“.40 Eine nennenswerte Wirkung auf die sich erst formierende Disziplin ging davon aber nicht aus. In der zweiten Hälfte der 1950er-Jahre begann Neck seine bemerkenswerte Laufbahn als Wissenschaftsmanager und wandte sich dabei der historischen Forschung über die Arbeiterbewegung zu. Über Vermittlung Wandruszkas, der abgelehnt hatte, übertrug der damalige Staatssekretär für Auswärtige Angelegenheiten, Bruno Kreisky, Neck 1957 die Leitung der neu geschaffenen Arbeitsgemeinschaft für Geschichte der Arbeiterbewegung. ${ }^{41}$ Darüber hinaus gründete Neck gemeinsam mit dem aus der britischen Emigration zurückgekehrten Herbert Steiner (1923-2001), der 1963 das DÖW ge-

36 Rudolf Neck, Die Wissenschaftlichen Kommission des Theodor-Körner-Stiftungsfonds und des Leopold-Kunschak-Preises zur Erforschung der österreichischen Geschichte der Jahre 1927 bis 1938, in: Ludwig Jedlicka/Rudolf Neck (Hg.), Vom Justizpalast zum Heldenplatz. Studien und Dokumentationen 1927 bis 1938, Wien 1975, 15-16, 16.

37 Adam Wandruszka, Rudolf Neck - Archivar und Historiker, in: Isabella Ackerl/Walter Hummelberger/Hans Mommsen (Hg.), Politik und Gesellschaft im alten und neuen Österreich. Festschrift für Rudolf Neck zum 6o. Geburtstag, Bd. 1, Wien 1981, 13-18, 13.

38 Ebd., 14.

39 Anna Hedwig Benna, Rudolf Neck zum 6o. Geburtstag, in: Mitteilungen des Österreichischen Staatsarchivs 39 (1986), 1-3, 2.

40 Rudolf Neck, Zeitgeschichtliche Literatur über Österreich. Teil I., in: Mitteilungen des Österreichischen Staatsarchivs 6 (1953), 422-444; ders., Zeitgeschichtliche Literatur über Österreich, Teil II. in: Mitteilungen des Österreichischen Staatsarchivs 8 (1955), 368-389.

41 Wandruszka, Neck, 16. 
schaffen hatte, 1964 die heute noch bestehende Internationale Tagung der Historiker der Arbeiterbewegung (ITH). Gemeinsam leiteten die beiden die jährlichen Konferenzen der ITH in Linz und bauten dabei ein internationales, über die Systemgrenze des „Eisernen Vorhangs" hinausreichendes Kommunikationsnetzwerk auf.42

1971 ging Bundeskanzler Kreisky an die Umsetzung seines langgehegten Vorhabens, eine Kommission zur Erforschung der Geschichte Österreichs zwischen 1927 und $1938 \mathrm{zu}$ gründen. Er beauftragte damit Rudolf Neck, der ihm eine Art „historischer Berater" geworden war, und den umtriebigen Vorstand des Instituts für Zeitgeschichte der Universität Wien, Ludwig Jedlicka. Neck wurde Geschäftsführer der Wissenschaftlichen Kommission des Theodor-Körner-Stiftungsfonds und des Leopold Kunschak-Preises zur Erforschung der österreichischen Geschichte der Jahre 1927 bis 1938, organisierte die alljährlichen Tagungen und gab mit Jedlicka (nach dessen Tod mit Wandruszka) die Referate der Kommissionssitzungen heraus. ${ }^{43}$

Necks Kontakte zu Bundeskanzler Kreisky ermöglichten Anfang der 1980erJahre bedeutende archivische Weichenstellungen. So setzte Neck den Neubau eines österreichischen Zentralarchives in Wien-Erdberg durch (eröffnet 1988) und erreichte auch die Schaffung eines zeithistorischen Teilarchivs unter dem Dach des ÖStA - das Archiv der Republik (AdR). Gegründet 1983, übernahm das AdR von den übrigen Teilarchiven die Unterlagen seit der Republiksgründung 1918.44

Als Autor war Rudolf Neck enorm produktiv. Sein bevorzugtes Arbeitsfeld waren Politik- und Parteiengeschichte. In den Sammelbänden Erika Weinzierls und Kurt Skalniks über die Erste und Zweite Republik verfasste er die Beiträge über die Innenpolitik und die Sozialdemokratie, ${ }^{45}$ in den Veröffentlichungen der Wissenschaftlichen Kommission trat er unter anderem als Historiker der Februarkämpfe 1934 hervor. ${ }^{46}$ Wie für die meisten anderen Zeithistoriker der 1970er-Jahre waren auch für ihn die Geschichte der NS-Zeit, von Antisemitismus und Judenfeindlichkeit noch kein vordringliches Thema.

Als Wissenschaftsmanager stützte sich Neck auf gute Kontakte zu einflussreichen Persönlichkeiten aller politischen Richtungen. Er arbeitete mit dem KP-Mitglied

42 Herbert Steiner, Internationale Tagung der Historiker der Arbeiterbewegung, in: Ackerl/Hummelberger/Mommsen (Hg.), Politik, 353-355.

43 Neck, Kommission, 15.

44 Hochedlinger, Archivgeschichte, 253-255.

45 Rudolf Neck, Innenpolitik, in: Weinzierl/Skalnik (Hg.), Österreich, Bd. 1, 267-293; Rudolf Neck, Sozialdemokratie, in: Weinzierl/Skalnik (Hg.), Österreich 1918-1938, Bd. 1, 225-248.

46 Rudolf Neck, Thesen zum Februar. Ursprünge, Verlauf und Folgen, in: Das Jahr 1934: 12. Februar. Protokoll des Symposiums in Wien am 5. Februar 1974 (Wissenschaftliche Kommission des Theodor-Körner-Stiftungsfonds und des Leopold-Kunschak-Preises zur Erforschung der österreichischen Geschichte der Jahre 1927 bis 1938. Veröffentlichungen 2), Wien 1975, 15-24. 
Herbert Steiner ebenso gut zusammen wie mit Adam Wandruszka und Ludwig Jedlicka, ${ }^{47}$ die sich vor 1938 in der illegalen NS-Bewegung engagiert hatten und in der Zweiten Republik im Umfeld der ÖVP standen. ${ }^{4}$ Die Neck zum sechzigsten Geburtstag gewidmete zweibändige Festschrift gab der renommierte deutsche Zeithistoriker Hans Mommsen (1930-2015) mit heraus; die Liste der Autoren und Autorinnen liest sich wie ein Who's who der zeithistorischen Szene in Österreich. Sie versammelte einen Gutteil der damals jüngeren Generation von ZeithistorikerInnen, die das Forschungsfeld in den kommenden Jahrzehnten prägen sollten. ${ }^{49}$ Necks Verhältnis zu seiner Kurskollegin Erika Weinzierl war hingegen nicht ungetrübt. Die Ausgrenzung Weinzierls aus der Wissenschaftlichen Kommission durch Jedlicka hatte Neck offenbar mitgetragen, obwohl sich Wissenschaftsministerin Hertha Firnberg für eine Nominierung Weinzierls einsetzte. ${ }^{50}$

\section{Die Landesarchive - Unverständnis und Distanz}

War die Beschäftigung mit Zeitgeschichte seit den späten 1960er-Jahren für Archivare im ÖStA fast schon ein Karrieresprungbrett, so herrschten in den Landesarchiven andere Verhältnisse. Hier war nach wie vor die Publikationstätigkeit auf mediävistischem Gebiet statusbildend. Im Geleitwort der ersten Ausgabe der Zeitschrift des VÖA 1969 ärgerte sich Karl Lechner, erster Präsident des neu geschaffenen Interessenverbandes und ehemaliger Direktor des Niederösterreichischen (NÖ) Landesarchivs, ${ }^{51}$ über das seiner Ansicht nach weit überzogene öffentliche Interesse an der Zeitgeschichte. Er beklagte sich darüber, dass „bei vielen Zeitgenossen, und nicht nur bei primitiven und naiven, die ,Zeitgeschichte $[$ [...] als das heute allein Wichtige gesehen" werde..$^{2}$

47 So brachte Neck mit Wandruszka etwa die Festschrift für Ludwig Jedlicka heraus: Rudolf Neck/ Adam Wandruszka (Hg.), Beiträge zur Zeitgeschichte. Festschrift für Ludwig Jedlicka zum 6o. Geburtstag, St. Pölten 1976.

48 Fellner, Wandruszka, 444-445; Oliver Rathkolb, Ludwig Jedlicka: Vier Leben und ein typischer Österreicher. Biographische Skizze zu einem der Mitbegründer der Zeitgeschichtsforschung, in: zeitgeschichte 32 (2005) 6, 351-370, 352-357.

49 Ackerl/Hummelberger/Mommsen (Hg.), Politik, 2 Bde.

50 Ein Hinweis darauf findet sich in Rathkolb, Jedlicka, 367, 370 (Fn. 82).

51 Zu Lechner: Stefan Eminger/Ralph Andraschek-Holzer, Karl Lechner (1897-1975). Landeshistoriker zwischen Katholizismus und Nationalsozialismus, in: Karel Hruza (Hg.), Österreichische Historiker. Lebensläufe und Karrieren 1900-1945, Bd. 2, Wien/Köln/Weimar 2012, 523-590.

52 Karl Lechner, Zum Geleit, in: Scrinium 1 (1969), 4. 
Die Landesarchive waren auf die Herausforderungen der zeitgeschichtlichen Forschung in keiner Weise vorbereitet. Die Ausbildung im Institutskurs berücksichtigte zeithistorische Quellen kaum; die Übernahme zeitgeschichtlicher Unterlagen lief in vielen Landesarchiven erst in den 1980er-Jahren an. Die meisten "InstitutlerInnen“ betrachteten das massenhaft anfallende Archivgut der jüngsten Zeit abschätzig als Registraturgut; die Erschließungsarbeiten delegierten sie vielfach an nichtakademische Bedienstete des mittleren Dienstes. ${ }^{53}$

Bis 1979, damals wurde eine gleitende Fünfzig-Jahres-Schutzfrist eingeführt, gab es in den Landesarchiven nicht einmal einheitliche Sperrfristen für Archivalien. ${ }^{54}$ In manchen Bundesländern galten starre Fristen, wodurch die Benützungsgrenze bis zu achtzig Jahre betragen konnte. Der Fortschritt durch die Vereinheitlichung wurde jedoch durch die Erlassung des Datenschutzgesetzes 1978 (in Kraft seit 1980) mit erheblich verlängerten Schutzfristen für personenbezogene Unterlagen relativiert. ${ }^{55}$

Ein früher Impuls für die Landesarchive, sich mit Zeitgeschichte auseinanderzusetzen, war die Publikationsreihe „Widerstand und Verfolgung 1934 bis $1945^{\text {“ des }}$ DÖW. Obwohl vor allem aus der NS-Zeit erst wenige Unterlagen von den Landesarchiven übernommen worden waren, erwies sich die Beteiligung von Archivaren an diesem Projekt als unerlässlich. Bereits in den 1970er-Jahren erschienen die Bände für Wien und das Burgenland, in den 1980er-Jahren folgten Oberösterreich, Tirol und Niederösterreich, 1991 erschien Salzburg. ${ }^{56}$ In den übrigen Bundesländern kam das Projekt nicht zustande, weil die Landesregierungen nicht kooperierten. In Vorarlberg etwa wurde die Einsichtnahme in die Bestände des Landesarchivs nicht gewährt. ${ }^{57}$ Das DÖW unterstützte daher die Publikation der privaten Johann-August-Malin-Gesellschaft, die sich des Themas annahm. Das Buch, verfasst vor allem

53 Gerhart Marckhgott, Archivare und Zeitgeschichte, in: Scrinium 42 (1990), 73-80, 74, 78-80; Wilfried Beimrohr, Die zeitgeschichtliche Forschung und das Tiroler Landesarchiv. Ein kurzer Erfahrungsbericht, in: Scrinium 65 (2011), 7-11, 8.

54 Fridolin Dörrer, Archivar und Datenschutz, in: Scrinium 41 (1989), 3-18, 7.

55 Ebd., 7; Ernst Hanisch, Archiv und Zeitgeschichte - ein notwendiges und spannungsreiches Verhältnis, in: Scrinium 57 (2003), 24-34, 29.

56 URL: https://www.doew.at/erforschen/publikationen/gesamtverzeichnis/widerstand-und-verfolgung-widerstandsforschung/widerstand-und-verfolgung-in-den-oesterreichischen-bundeslaendern-1934-1945 (abgerufen 15.01.2020).

57 Wolfgang Neugebauer, Geleitwort, in: Johann-August-Malin-Gesellschaft (Hg.), Von Herren und Menschen. Verfolgung und Widerstand in Vorarlberg 1933-1945 (Beiträge zu Geschichte und Gesellschaft Vorarlbergs 5), Bregenz 1985, 10-11, 11. 
von Gymnasiallehrern, die den „regionalen ,Faschismus aufarbeiten“ wollten, ${ }^{58} \mathrm{er}$ schien 1985 - freilich ohne Verwendung von Archivalien des Landesarchivs. ${ }^{59}$ Das Klima zwischen den „Malin-Historikern“ und dem Vorarlberger Landesarchiv sollte noch bis weit in die 1990er-Jahre von gegenseitigem Misstrauen geprägt bleiben. ${ }^{60}$ Bezeichnend für das lange Zeit schlechte Verhältnis zwischen der zeithistorischen Einrichtung DÖW und manchen Landesarchiven ist auch die Tatsache, dass der Band über die Steiermark erst 2019, ${ }^{61}$ jener über Kärnten bis heute nicht erschienen ist.

Demgegenüber zählten das Wiener Stadt- und Landesarchiv und das Oberösterreichische (OÖ) Landesarchiv zu den zeitgeschichtlichen Pionieren unter den Landesarchiven. Das Wiener Archiv orientierte sich in Fragen der Schutzfrist traditionell an der liberaleren Praxis des ÖStA und öffnete seine Publikationsreihen der jüngsten Geschichte schon Mitte der 1970er-Jahre. Gerhard Botz etwa konnte dort bereits 1974 eine der ersten Analysen über „Arisierungen“ vorlegen, ${ }^{62}$ und auch seine Arbeit über die nationalsozialistische „Ostmark“-Politik in der Frühphase der NS-Herrschaft fand dort ein Forum. ${ }^{63}$

Im OÖ Landesarchiv wurde nur drei Jahre nach der Betrauung des aus der Emigration zurückgeholten Karl R. Stadler mit einer de facto zeitgeschichtlichen Professur an der späteren Universität Linz 1971 die Abteilung „Zeitgeschichte und Dokumentation“ geschaffen. ${ }^{64}$ Sie war zugeschnitten auf den langjährigen Chefredakteur des „Linzer Volksblattes“, Harry Slapnicka, der nun in den Archivdienst wechselte. Der gelernte Jurist wirkte dort weniger als Archivar, sondern fast ausschließlich als

58 Werner Bundschuh, Anmerkungen zur Gründungsgeschichte der Johann-August-Malingesellschaft, in: Rheticus. Vierteljahresschrift der Rheticus-Gesellschaft 26 (2004) 4, 67-72, URL: https:// www.malingesellschaft.at/archiv/veranstaltungen/2004-werner-bundschuh-anmerkungen-zurgrundungsgeschichte-der-johann-august-malingesellschaft (abgerufen 15.01.2020).

59 Johann-August-Malin-Gesellschaft (Hg.), Herren.

60 Wolfgang Weber, Zeitgeschichte, Bestandserfassung und das Vorarlberger Landesarchiv, in: Karl Heinz Burmeister/Alois Niederstätter (Hg.), Archiv und Geschichte. 100 Jahre Vorarlberger Landesarchiv (Forschungen zur Geschichte Vorarlbergs 3 N.F.), Konstanz 1998, 171-181, 172-173.

61 Dokumentationsarchiv des österreichischen Widerstandes (Hg.), Widerstand und Verfolgung in der Steiermark. ArbeiterInnenbewegung und PartisanInnen 1938-1945, Graz 2019.

62 Gerhard Botz, „Arisierungen“ und nationalsozialistische Mittelstandspolitik in Wien (1938 bis 1940), in: Wiener Geschichtsblätter 29 (1974) 1, 122-136.

63 Gerhard Botz, Von der Bundeshauptstadt zum Reichsgau. Die nationalsozialistische „Ostmark“Politik und die Wiener Stadtverfassung und -verwaltung in den Jahren 1938 bis 1940, in: Wiener Geschichtsblätter 30 (1975), Sonderheft 2, 166-185.

64 Gerhard Botz, „Eine neue Welt, warum nicht eine neue Geschichte?“ Österreichische Zeitgeschichte am Ende ihres Jahrhunderts, Teil I, in: Österreichische Zeitschrift für Geschichtswissenschaften 1 (1990) 1, 49-76, 58. 
Autor zeithistorischer Publikationen, die er in journalistischem Stil und weitgehend ohne methodisches Handwerkszeug der universitären Forschung verfasste. ${ }^{65}$ Seine zahlreichen Veröffentlichungen folgten zwar einem engen ereignis- und politikzentrierten Schema und basierten überwiegend auf Zeitungsberichten; dennoch wurden sie zu Standardwerken der oberösterreichischen Landeszeitgeschichte. ${ }^{66}$ Slapnicka setzte sich zudem ungewöhnlich früh mit dem Antisemitismus der Zwischenkriegszeit auseinander ${ }^{67}$ und brachte bereits 1978 (!) eine Monographie über die NS-Zeit in Oberösterreich heraus. ${ }^{68}$ Er unterhielt Kontakte zu Karl R. Stadler und stand mit dem kommunistischen Widerstandskämpfer Peter Kammerstätter in enger Verbindung. ${ }^{69}$ Die von Slapnicka 1974 begründete Reihe „Beiträge zur Zeitgeschichte Oberösterreichs“, herausgebracht im Verlag des OÖ Landesarchivs, war im Kreise der damaligen Landesarchive einzigartig. ${ }^{70}$ Als Slapnicka 1983 in den Ruhestand trat, folgte ihm mit Gerhart Mackhgott ein am IÖG ausgebildeter Archivar, der sich intensiv um die Aufarbeitung der zeitgeschichtlichen Bestände im OÖ Landesarchiv bemühte und zum wichtigsten Fürsprecher der Zeitgeschichte in der Archivlandschaft werden sollte.

Die Integration der Zeitgeschichte in den Alltag der Landesarchive schritt indessen weiter voran. Impulse kamen von innen und außen. Die Debatte um die NSVergangenheit des Präsidentschaftskandidaten Kurt Waldheim, die direkt in das Bedenkjahr 1988 mündete, verlieh der Zeitgeschichte einmal mehr viel mediale Aufmerksamkeit. Sie zeigte aber gleichzeitig, wie wenig die Ergebnisse der zeithistorischen Forschung in Österreich in das Bewusstsein der Bevölkerung eingegangen und wie groß die Defizite der Erforschung der NS-Zeit in Österreich immer noch waren. ${ }^{71}$ Im ÖStA kam es daraufhin zu einer Liberalisierung des Zugangs zu Archivalien, die Kanzler Franz Vranitzky bei der feierlichen Eröffnung des neuen

65 Cornelia Sulzbacher/Gerhart Marckhgott, Zeitgeschichte im OÖ Landesarchiv, in: Scrinium 65 (2011), 127-138, 127 .

66 Ebd., 127.

67 Harry Slapnicka, Zum Antisemitismus-Problem in Oberösterreich, in: zeitgeschichte 1 (1973/74) $11 / 12,264-267$.

68 Harry Slapnicka, Oberösterreich als es „Oberdonau“ hieß 1938-1945, Linz 1978.

69 Harry Slapnicka, Ein Stück meiner Erinnerungen: Die Anfänge der Zeitgeschichts-Forschung in Oberösterreich, in: Mitteilungen des Oberösterreichischen Landesarchivs 21 (2008), 693-700, 696.

70 Die eigenständige Reihe kam von 1974 bis 1995 auf 13 Bände, von denen die Mehrzahl von Slapnicka verfasst wurde.

71 Ernst Hanisch, Die Dominanz des Staates. Österreichische Zeitgeschichte im Drehkreuz von Politik und Wissenschaft, in: Alexander Nützenadel/Wolfgang Schieder (Hg.), Zeitgeschichte als Problem. Nationale Traditionen und Perspektiven der Forschung in Europa (Geschichte und Gesellschaft, Sonderheft 20), Göttingen 2004, 54-77, 69 . 
Zentralarchivbaus in der Nottendorfergasse bekanntgab. ${ }^{72}$ Dem Wiener Zeithistoriker Oliver Rathkolb verweigerte man dennoch die Einsicht in die Protokolle des österreichischen Ministerrates der Jahre 1945 bis 1951. Rathkolb erhob Beschwerde beim Verfassungsgerichtshof. Dieser gab ihm teilweise Recht, hob die Benutzungsrichtlinien für das ÖStA auf und forderte indirekt die Erlassung eines Archivgesetzes ein. ${ }^{73}$

Ein aufsehenerregender Appell für mehr Akzeptanz der Zeitgeschichte in den Landesarchiven kam damals auch aus der Zunft der ArchivarInnen selbst. Auf dem Archivtag in Radstadt 1989 redete der Oberösterreicher Gerhart Marckhgott seinen KollegInnen in einem vieldiskutierten Vortrag „Archivare und Zeitgeschichte“ ins Gewissen. ${ }^{74}$ Er konstatierte „ein krasses Mißverhältnis zwischen der Zusammensetzung des Archivmaterials und der Zahl, Ausbildung und Tätigkeit der Archivare“. Bei seinen Archivarskolleginnen und -kollegen verortete er „mangelndes Interesse und Verständnis für die heute längst dominierenden Massenbestände des 20. Jahrhunderts“. Im wichtigsten Forum der österreichischen Archivszene mahnte er einen Wandel in den „Wertvorstellungen der Archivare“ ein, denn sonst werde man noch länger „mit dem Großteil der heutigen Archivbestände, mit dem Datenschutz und mit einer wachsenden Zahl von Forschern auf Kriegsfuß stehen“.

\section{Historikerkommission als Zäsur - Entspannung}

Die entscheidende Zäsur im Verhältnis von Zeitgeschichtsforschung und Archiven war aber die Installierung der Historikerkommission 1998.75 Ausgestattet mit dem Auftrag der Bundesregierung, den „Vermögensentzug auf dem Gebiet der Republik Österreich während der NS-Zeit sowie Rückstellungen bzw. Entschädigungen (sowie wirtschaftliche und soziale Leistungen) der Republik Österreich ab $1945^{\text {“ }}$

72 Die allgemeine Archivgrenze wurde von 40 auf 30 Jahre, für wissenschaftliche Arbeiten bewilligungspflichtig auf 20 Jahre herabgesetzt; Kurt Peball, Das Österreichische Staatsarchiv erhielt ein neues Haus, in: Mitteilungen des Österreichischen Staatsarchivs 41 (1990) 11-13, 12.

73 Waltraut Kotschy/Oliver Rathkolb, Archivsperre und Datenschutz, in: Historicum (Sommer 1993), 20-24, 20; Ernst Hanisch, Archiv und Zeitgeschichte - ein notwendiges und spannungsreiches Verhältnis, in: Scrinium 57 (2003), 24-34, 30-31.

74 Hier und im Folgenden: Marckhgott, Archivare, 78-79.

75 Auf die Kritik an der Historikerkommission („,̈rrgste Auftragsforschung“) seitens mancher (Zeit-) Historiker sei hier nur hingewiesen, vgl. etwa: Forscherstreit um Historikerkommission, Der Standard, 10.01.2001, URL: https://www.derstandard.at/story/438718/forscher-streit-um-historikerkommission (abgerufen 15.01.2020). 
zu untersuchen und „die ehemaligen NS-Zwangsarbeiter“ rasch zu entschädigen, ${ }^{76}$ vergab die Historikerkommission insgesamt 47 Projekte, in die rund 160 WissenschaftlerInnen eingebunden waren. ${ }^{77}$ Die Archive waren in diesem größten zeitgeschichtlichen Forschungsvorhaben der Zweiten Republik von Anbeginn prominent vertreten. So fungierte der Generaldirektor des ÖStA als Stellvertretender Vorsitzender der Historikerkommission; der Direktor des NÖ Landesarchivs firmierte als Vertreter der Bundesländer und der Landeshauptleutekonferenz im Österreichischen Versöhnungsfonds, der für die Koordination der „Entschädigungs“-Anträge ehemaliger NS-ZwangsarbeiterInnen zuständig war. ${ }^{78}$

Die Arbeiten der Historikerkommission waren 2003 abgeschlossen, die Folgen für die zeitgeschichtliche Forschung vielfältig. So war es in vielen Archiven zur Auffindung „vergessener“ wie zur Übernahme längst fälliger zeithistorischer Aktenbestände und zur Erschließung einer Vielzahl zeitgeschichtlicher Archivalien gekommen. ${ }^{79}$ Im Bereich der Firmen- und Wirtschaftsarchive lenkte die Historikerkommission die Aufmerksamkeit erstmals auch auf die ehemals verstaatlichte Industrie und auf die seit den 1980er-Jahren aus der öffentlichen Verwaltung ausgegliederten Körperschaften. Das zwischen 1933 und 1967 angefallene Schriftgut von 74 derartigen Institutionen wurde mit Verordnung vom 6. März 2001 unter Denkmalschutz gestellt. ${ }^{80}$

Die Arbeit der Historikerkommission stimulierte überdies eine lange Reihe von zeitgeschichtlichen Forschungsprojekten, die unter der Leitung oder Mitwirkung der Landesarchive stattfanden. Beispiele dafür waren die dreibändige Publikation „Niederösterreich im 20. Jahrhundert“, 2008 vom NÖ Landesarchiv herausgebracht, ${ }^{81}$ oder die Großprojekte des zeitgeschichtsaffinen OÖ Landesarchivs: So wurden zwischen 2004 und 2014 die Ergebnisse des oberösterreichischen „NS-Projektes“ in 13 (!) Bänden vorgelegt, das seit 2010 laufende Vorhaben der Erforschung der Zwischenkriegszeit in Oberösterreich umfasst bislang 48 Einzelprojekte und 6 Mono-

76 So Bundeskanzler Wolfgang Schüssel am 09.02.2000; zit. n. Stefan Eminger, Entschädigung von Zwangsarbeit in Österreich, in: Historische Sozialkunde. Geschichte - Fachdidaktik - Politische Bildung 33 (2003) 1, 24-29, 24.

77 Lorenz Mikoletzky, Die Historikerkommission, in: Scrinium 65 (2011), 87-91, 89.

78 Hermann Rumschöttel, Archive als Häuser der Zeitgeschichte, in: Scrinium 57 (2003), 5-23, 8.

79 Eva Blimlinger, Forscherparadies Archiv? Oder der Biss in den Apfel, in: Scrinium 64 (2010), 16$24,20-21$.

80 Mikoletzky, Historikerkommission, 90.

81 Stefan Eminger/Ernst Langthaler/Oliver Kühschelm/Peter Melichar, Niederösterreich im 20. Jahrhundert, 3 Bde.: Politik, Wirtschaft, Kultur, Wien/Köln/Weimar 2008. 
graphien. ${ }^{82}$ Einer Zusammenarbeit des Vorarlberger Landesarchivs mit dem Linzer Stadtarchiv entstammten gehaltvolle Sammelbände über die Entnazifizierung in Österreich und über Elitenwandel und -kontinuitäten in der österreichischen Spitzenbürokratie zwischen 1918 und 1938; beide Publikationen wurden überwiegend von ArchivmitarbeiterInnen verfasst. ${ }^{83}$ Angeregt von Diskussionen auf dem Deutschen Archivtag 2005 in Stuttgart, untersuchten auch die österreichischen Archive ihre NS-Geschichte und veröffentlichten die Ergebnisse in einem umfangreichen Band der MÖSTA. ${ }^{84}$

Die Tätigkeit der Historikerkommission erwies sich ferner als entscheidender Impuls für die lange geforderte Erlassung des Bundesarchivgesetzes, dem die Archivgesetze der Bundesländer folgten. Diese Gesetze definierten erstmals Archivalien und Schriftgut. Sie normierten eine Anbietungs- und Informationspflicht der abgebenden Stellen und regelten den Zugang zum Archivgut und den Schutz der Geheimhaltungsinteressen der vom Archivgut Betroffenen.85 Die Benutzungsgrenze wurde nun (fast) einhellig auf den internationalen Standard von dreißig Jahren gelegt; lediglich Kärnten, das Bundesland mit dem ersten Archivgesetz, verordnete sich eine vierzigjährige Sperrfrist. ${ }^{86}$ Gegenwärtig ist nur noch das Burgenland ohne Archivgesetz.

Die Arbeit der Historikerkommission rückte die Zeitgeschichte auch im VÖA ins Zentrum des Interesses. 2001 beschäftigte sich erstmals ein Jahresheft des „Scrinium“ zur Gänze mit einem zeitgeschichtlichen Thema: mit der NS-Zwangsarbeit. ${ }^{87}$ Der Österreichische Archivtag in Salzburg 2002 stand ebenfalls ganz im Zeichen der Zeitgeschichte. Mit Ernst Hanisch hielt ein prominenter Zeithistoriker einen Vortrag zum Verhältnis von Archiven und Zeitgeschichte. ${ }^{88}$ Auf dem Archivtag in

82 Die Publikationen der „Oberdonau“-Reihe finden sich unter URL: https://www.landesarchiv-ooe. at/bibliothek_verlag/verlagsprogramm/produktdetail/?tt_products\%5BbackPID\%5D=65\&tt_ products\%5Bproduct\%5D=182 (abgerufen 15.01.2020); die Projekte und Monographien über die Zwischenkriegszeit unter URL: https://www.landesarchiv-ooe.at/projekte/erste-republik/projekte/ (abgerufen 15.01.2020).

83 Walter Schuster/Wolfgang Weber (Hg.), Entnazifizierung im regionalen Vergleich. Historisches Jahrbuch der Stadt Linz 2002, Linz 2004; Wolfgang Weber/Walter Schuster (Hg.), Biographien und Zäsuren. Österreich und seine Länder 1918-1933-1938. Historisches Jahrbuch der Stadt Linz 2010/2011, Linz 2011.

84 Österreichs Archive unter dem Hakenkreuz. Mitteilungen des Österreichischen Staatsarchivs 54 (2010).

85 Mikoletzky, Historikerkommission, 90.

86 Fritz Koller, Archivgesetzgebung in Österreich - Ein Überblick, in: Archivalische Zeitschrift 90 (2008), 35-49, 40-41, 44 .

87 Scrinium 55 (2001).

88 Publiziert in Scrinium 57 (2003), 24-34. 
Linz 2009 berichtete Eva Blimlinger, die ehemalige Forschungskoordinatorin der Historikerkommission, von ihren Erfahrungen an der Schnittstelle zwischen ZeithistorikerInnen und ArchivarInnen. ${ }^{89} 2011$ zogen die Landesarchive in einem eigenen Themenheft des „Scrinium“ Bilanz über ihre Tätigkeit auf dem Gebiet der jüngsten Geschichte. $9^{\circ}$

Die gestiegene Akzeptanz der Zeitgeschichte zeigte sich auch in den Entscheidungen der Archivträger in den Bundesländern. Seit den 200oer-Jahren gelangten in einer Reihe von Landesarchiven erstmals zeitgeschichtlich informierte Archivare und Archivarinnen an die Spitzen ihrer Häuser. ${ }^{91}$

\section{Koexistenz statt Kooperation}

Gegenseitige Akzeptanz bedeutet aber noch nicht Zusammenarbeit. Es fällt auf, dass die beiden Communitys miteinander kaum ins Gespräch kommen. Unverändert sind MediävistInnen und FrühneuzeitspezialistInnen für die Ausbildung der künftigen Archivare und Archivarinnen zuständig;,92 gelernte ZeithistorikerInnen zählen weiterhin nicht zum Lehrpersonal. Von wenigen Ausnahmen abgesehen, ${ }^{93}$ nehmen ArchivmitarbeiterInnen kaum am zeithistorischen Diskurs teil. In der Zeitschrift "zeitgeschichte" haben seit deren Gründung 1973 lediglich zwei Archivmitarbeiter publiziert, nur einer davon hatte den IÖG-Kurs absolviert.94 Bei den seit 1993

89 Scrinium 64 (2010), 16-24.

90 Scrinium 65 (2011).

91 So etwa in Kärnten mit Wilhelm Wadl 2001, in Tirol mit Richard Schober 2003 und danach mit Wilfried Beimrohr, in Salzburg mit Oskar Dohle 2010, in Oberösterreich mit Gerhart Marckhgott 2003 und Cornelia Sulzbacher 2015, in Wien mit Brigitte Rigele 2010.

92 URL: https://ufind.univie.ac.at/de/vvz_sub.html?path=236140 (abgerufen 15.01.2020).

93 So etwa Stefan Spevak, Schule und Antisemitismus in den Akten des Wiener Stadtschulrates 1933-1938, in: Gertrude Enderle-Burcel/Ilse Reiter-Zatloukal (Hg.), Antisemitismus in Österreich 1933-1938, Wien/Köln/Weimar 2018, 587-618; Stefan Eminger, „Christen, kauft bei Christen!“ Antisemitismus im Gewerbe 1933-1938, in: ebd., 537-554; Stefan Eminger, Politik und Wirtschaft. Die österreichischen Handelskammern 1930-1938, in: Florian Wenninger/Lucile Dreidemy (Hg.), Das Dollfuß/Schuschnigg-Regime 1933-1938. Vermessung eines Forschungsfeldes, Wien/ Köln/Weimar 2013, 295-308; Wolfgang Weber, „Die sich vom Westen nach Osten erstreckende Wurst ...“. Aspekte der NS-Herrschaft in Vorarlberg, Tirol und Salzburg 1938 bis 1945, in: Emmerich Tálos/Ernst Hanisch/Wolfgang Neugebauer/Reinhard Sieder (Hg.), NS-Herrschaft in Österreich. Ein Handbuch, Wien 2000, 260-291.

94 Untersucht wurden nur die Aufsätze in der Zeitschrift. Beide Autoren stammen aus dem OÖ Landesarchiv: Harry Slapnicka, 1973/1974, 1975/1976 und 1976/1977 sowie Gerhart Marckhgott, 1994 . 
stattfindenden, insgesamt zwölf Zeitgeschichtetagen waren lediglich drei Mitarbeiter von Landesarchiven als Referenten tätig; ${ }^{95}$ nur zweimal gab es ein archivwissenschaftliches Panel (1997 und 2018). ${ }^{96}$

Vice versa zeigt sich ein ähnliches Bild: Im „Scrinium“ publizierten ZeithistorikerInnen nur im ersten Jahrzehnt nach dessen Erscheinen. ${ }^{97}$ Danach blieben Ernst Hanisch (2003) und Eva Blimlinger (2010 und 2013) die einzigen Vertreter der Zeithistorie, die dort einen Beitrag verfassten..$^{98}$ In der Lehre an Zeithistorischen Instituten oder Abteilungen wird Archivkunde zwar berücksichtigt, ArchivarInnen als Lehrende gibt es nur selten. ${ }^{99}$ Habilitierte Zeithistoriker fand man nur im Vorarlberger Landesarchiv (Wolfgang Weber bis 2011) und seit 2012 im ÖStA (Wolfgang Maderthaner und dessen Nachfolger Helmut Wohnout).

Dieser fehlende Dialog ist nicht etwa eine Spätfolge der spannungsreichen Vergangenheit im Verhältnis von Archiven und Zeitgeschichte. Er ist eingebettet in einen breiteren, internationalen Entwicklungsstrang des Auseinanderdriftens von Archiv- und Geschichtswissenschaften seit den 1970er-Jahren, der auch das her-

95 Gerald Gänser †/Martin F. Polaschek, Grazer Volksgerichtsprozesse: Überblick über die Archivsituation, Zugangsfragen, Fallbeispiele, in: Österreichischer Zeitgeschichtetag 1995. Österreich 50 Jahre Zweite Republik, Innsbruck/Wien 1996, 332-336; Stefan Eminger, Marktort ohne Juden: Lokalhistorie zwischen „Wiedergutmachungs“-Diskursen, Gemeindepolitik und örtlicher Erinnerungskultur, in: Ingrid Böhler/Eva Pfanzelter/Thomas Spielbüchler/Rolf Steininger (Hg.), 7. Österreichischer Zeitgeschichtetag. 1968 - Vorgeschichten - Folgen. Bestandsaufnahme der österreichischen Zeitgeschichte, Innsbruck/Wien/Bozen 2010, 739-746; ders., Kernland Niederösterreich. Zur Karriere eines Mythos, im Rahmen von Präsentation und Diskussion, Haus der Geschichte Niederösterreich, in: Stefan Benedik/Lisbeth Matzer/Markus Wurzer (Hg.), Constructive Unrest. Austrian Conference on Contemporary History 2016, Graz 2016, 130; Heinrich Berg, Digitalisierung und virtuelle Welt: Aufgaben der Archivare, in: Gertraud Diendorfer/Gerhard Jagschitz/Oliver Rathkolb (Hg.), Zeitgeschichte im Wandel. 3. Österreichische Zeitgeschichtetage 1997, Innsbruck/Wien 1998, 536-541.

96 Panel 20: Archivierung im digitalen Zeitalter, in: Gertraud Diendorfer/Gerhard Jagschitz/Oliver Rathkolb (Hg.), Zeitgeschichte im Wandel. 3. Österreichische Zeitgeschichtetage 1997, Innsbruck/ Wien 1998, 588; Panel 1: Vom Umgang mit digitalen Daten in (online) Archiven, der WaybackMachine und sozialen Medien, in: 25 Jahre Österreichischer Zeitgeschichtetag. Geschichte wird gemacht [Wien 2018], 12.

97 Es waren dies Herbert Steiner (1974 und 1980), Walter Hummelberger (1975-1977), Reinhold Wagnleitner (1975 und 1977) und Maren Seliger (1978).

98 Hanisch, Archiv, 24-34; Blimlinger, Forscherparadies, 16-24; dies., „Digital - analog“ - Digitalisat und der Akt in Lehre und Forschung, in: Scrinium 67 (2013), 22-26.

99 Eine der wenigen Ausnahmen war Rudolf Jeřábek vom ÖStA/Archiv der Republik, der um die Jahrtausendwende am Institut für Zeitgeschichte der Universität Wien „Umgang mit zeitgeschichtlichen Quellen"lehrte. 
kömmliche Berufsbild der ArchivarInnen als „Archivar-Historiker“ veränderte. ${ }^{100}$ In Österreich wurde dieser Trend in den 1990er-Jahren spürbar. Die Etablierung der Zeitgeschichte spielte dabei eine Rolle, denn die Übernahme der Massenakten erforderte die Wiederauferstehung des "Archivar-Registrators" des 19. Jahrhunderts, der zeitaufwändige Bewertungs- und Erschließungsarbeiten durchführte. Darüber hinaus verlangte die verstärkte Serviceorientierung der Verwaltung, spürbar forciert nach Österreichs EU-Beitritt 1995 und flankiert vom erhöhten öffentlichen Legitimationsdruck, (mehr) Öffentlichkeitsarbeit und die Erweiterung des Berufsbildes auf den „Archivar-Kulturmanager“. Die Einführung der elektronischen Akte in den Verwaltungen und die bevorstehenden Übernahmen digitaler Daten riefen gebieterisch nach dem „Archivar-Techniker", der über fundierte IT-Kenntnisse verfügte. ${ }^{101}$ Gefragt ist also immer weniger der „Archivar-Historiker", sondern ein „Tausendsassa" (Astrid Eckert), der die wissenschaftliche Forschung überwiegend als Privatangelegenheit in seiner Freizeit betreibt.

Umgekehrt wurde die Kluft zwischen Geschichts- und Archivwissenschaft auch durch Entwicklungen in der Geschichtsforschung verbreitert. Mit der Herausforderung des historistisch-positivistischen Paradigmas durch sozial- und kulturwissenschaftliche Zugänge verloren Archive als Quellenspeicher an Bedeutung. Veränderte Fragestellungen und Methoden richteten den Blick auf neue Quellensorten abseits der Archive. ${ }^{102}$ Die erstaunlich lang andauernde Fixierung der Zeitgeschichte auf textförmige Quellen ist allmählich im Schwinden, unter anderem gewinnen Spezialarchive für audiovisuelle Medien an Bedeutung. ${ }^{103}$

Dennoch wird das öffentliche Behördenarchiv auch für die Zeitgeschichte weiterhin unverzichtbar bleiben. ${ }^{104}$ Gerade der positivistische Strang der NS-Forschung und Politikgeschichte ist darauf angewiesen. ${ }^{105}$ Das singuläre Organisations- und Kontextwissen der Archivarinnen und Archivare wird seinen Wert nicht verlieren. ${ }^{106}$

100 Astrid Eckert, Archivar, in: Anne Kwaschik/Mario Wimmer (Hg.), Von der Arbeit des Historikers. Ein Wörterbuch zu Theorie und Praxis der Geschichtswissenschaft, Bielefeld 2010, 21-25, 23.

101 Gerhart Marckhgott, Vom Diener zum Dienstleister. Gedanken zu einem neuen Selbstbewusstsein der Archive, in: Thomas Aigner/Stefanie Hohenbruck/Thomas Just/Joachim Kemper (Hg.), Archive im Web - Erfahrungen, Herausforderungen, Visionen, St. Pölten 2012, 12-20, 14-15.

102 Eckert, Archivar, 23.

103 Kiran Klaus Patel, Zeitgeschichte im digitalen Zeitalter. Neue und alte Herausforderungen, in: Vierteljahrshefte für Zeitgeschichte 59 (2011) 3, 331-351, 340.

104 Ebd., 341.

105 Siehe dazu Hanisch, Dominanz, 72.

106 Marckhgott, Diener, 17. 


\section{Zusammenfassung und Ausblick}

Das Verhältnis von Archiven und Zeitgeschichte in Österreich war bis in die späten 1990er-Jahre reich an Spannungen. Einer der Hauptgründe dafür waren fehlende archivgesetzliche Grundlagen, die den Zugang zu rezentem Archivgut regelten. Darüber hinaus trennten sozialkulturelle Prägungen ArchivarInnen, die allesamt am IÖG ausgebildet wurden, von ZeithistorikerInnen, die sich ihren Platz in der Scientific Community erst erkämpfen mussten. In den traditionsreichen Landesarchiven, wo sich prärepublikanische Vorstellungen eines archivischen Arkanbereichs länger hielten als im ÖStA, waren diese Differenzen besonders spürbar. Generell war (und ist) vielen „Institutlern“ der politisch-emanzipatorische Zugang der ZeitgeschichtlerInnen suspekt.

Im Archivbereich kamen die ersten Signale einer Öffnung hin zur Zeitgeschichte aus dem neu geschaffenen ÖStA. Pensionierungen und eine strenger als in den Landesarchiven durchgeführte Entnazifizierung erforderten hier einen Neubeginn. Archivare des ÖStA verfassten die ersten Gesamtdarstellungen der österreichischen Zeitgeschichte nach 1945. Die Arbeit der großkoalitionär inspirierten Historischen Kommission verschaffte dem ÖStA Einfluss auf die Wissenschaftsorganisation der zeithistorischen Forschung der 1970er-Jahre.

In den Landesarchiven waren die (standes-)politischen Kontinuitätslinien ausgeprägter als im ÖStA. Lediglich Wien und Oberösterreich erwiesen sich gegenüber den spezifischen Bedürfnissen der zeitgeschichtlichen Forschung als aufgeschlossener. Die Tätigkeit der Historikerkommission und die Verrechtlichung der Beziehungen zwischen NutzerInnen und Archiven schufen einen deutlichen Wandel. Im neuen Jahrtausend, vier Jahrzehnte nach der Institutionalisierung der Zeitgeschichte in Österreich, erfolgte die Normalisierung der Beziehungen zwischen Archiven und Zeitgeschichte. Die traditionelle Verschränkung von Archivarsberuf mit Mediävistik und Frühneuzeitforschung ist aber weiterhin dominant.

Seit der Ablöse des wissenschaftsorganisatorisch bedeutsamen Netzwerkes Jedlicka-Wandruszka-Neck Ende der 1970er-Jahre blieb der Einfluss der „ArchivarZeithistorikerInnen" auf die universitäre Zeitgeschichtsforschung beschränkt. Der Hauptteil ihres Beitrags liegt in methodisch zumeist traditionell gearbeiteten Untersuchungen zur Landeszeitgeschichte. Ihre Stärken liegen in der Grundlagenforschung, im Quellenreichtum und in der Quellennähe der Arbeiten.

Der längerfristige Trend der Entkoppelung von (Zeit-)Geschichtsforschung und Archivwissenschaft schadet beiden Seiten. Die Marginalisierung der wissenschaftlichen Forschung von Archivaren und Archivarinnen schmälert die Qualität der 
Benutzerberatung. ${ }^{107}$ Gerade in der gegenwärtigen Phase der digitalen Wende tut ein intensiverer Dialog not. Die historisch erstmalige Übernahme großer Mengen an genuin digitalen Akten steht unmittelbar bevor. An der seit Jahren laufenden Diskussion der ArchivarInnen über die Folgen der technologischen Innovationen beteiligen sich weder ZeithistorikerInnen noch VertreterInnen anderer historischer Disziplinen. ${ }^{108}$ Obwohl in naher Zukunft viele (Zeit-)HistorikerInnen mit genuin digitalen Quellen arbeiten werden, fehlt in Österreich - von wenigen Ausnahmen abgesehen ${ }^{109}$ - eine quellenkritische Diskussion darüber. ${ }^{110}$ Auch die Frage der Erhaltung digitaler Dokumente und der Sicherstellung von deren Authentizität erfordert den Dialog zwischen Archiven und Zeitgeschichte. ${ }^{111}$ Mehr Zusammenarbeit ist nicht nur hier wünschenswert und im Sinne einer verantwortungsbewussten Überlieferungsbildung unabdingbar.

107 Gespräch mit Hanns Jürgen Küsters zum Verhältnis von Archiven und historischer Forschung, in: Archivar 64 (November 2011) 4, 391-396, 392.

108 Patel, Zeitgeschichte, 339.

109 Eva Pfanzelter, Von der Quellenkritik zum kritischen Umgang mit digitalen Ressourcen, in: Martin Gasteiner/Peter Haber (Hg.), Digitale Arbeitstechniken für die Geistes- und Kulturwissenschaften, Wien/Köln/Weimar 2010, 39-49.

110 Der deutsche Historikertag 2018 widmete sich der Digitalen Geschichte, URL: https://www. hsozkult.de/debate/id/diskussionen-4643 (abgerufen 15.01.2020).

111 Christian Keitel, Über den Zusammenhang zwischen Quellenkritik und Informationserhalt. Ergebnisse der Anfrage „Forschen mit ,digitalen Quellen“', URL: https://www.hsozkult.de/debate/id/ diskussionen-1173 (abgerufen 15.01.2020). 


\section{Autorinnen und Autoren}

Stefan Benedik ist Leiter des Teams Public History am Haus der Geschichte Österreich in Wien und Lehrbeauftragter an der Universität Graz. Nach dem Studium der Geschichte und Kulturanthropologie in Graz und Prag war er in universitärer Forschung am Institut für Geschichte, Fachbereich Zeitgeschichte, der Universität Graz und an der Munk School of Global Affairs und der University of Toronto tätig. Er war Stipendiat der ÖAW (DOC-Team) und der Steiermärkischen Sparkasse (Jungforscherpreis). 2016 leitete er das Organisationsteam des Österreichischen Zeitgeschichtetags, 2010 war er Koordinator des Doktoratsprogramms „Interdisziplinäre Geschlechterstudien“ an der Universität Graz, seit Juni 2015 arbeitet er an der „Österreichischen Zeitschrift für Geschichtswissenschaften“ mit.

Publikationen mit einem Schwerpunkt auf Geschlechter, Migrations- und Rassismusgeschichte, aktuell u. a.: Non-committal memory: The ambivalent inclusion of Romani suffering under National Socialism in hegemonic cultural memory, in: Memory Studies 13 (2020) 6; (Hg., mit Monika Sommer/Nicole-Melanie Goll/Georg Hoffmann/Birgit Johler/Eva Meran/Heidemarie Uhl) Was ist Österreich? - Menschen und Geschichten in 101 Objekten, Wien 2019; (Hg., mit Heidrun Zettelbauer/ Nina Kontschieder/Käthe Sonnleitner) „Verkörperungen - Embodiment“, Göttingen 2017.

Günter Bischof hat in Innsbruck, Wien und New Orleans Geschichte und Englisch/ Amerikanistik studiert und wurde an der Harvard University in amerikanischer Geschichte promoviert. Er ist der Marshall Plan Chair of History und der Direktor des Center Austria: The Austrian Marshall Plan Center for European Studies an der Universität von New Orleans, wo er seit mehr als 30 Jahren unterrichtet. Er war Gastprofessor an den Universitäten München, Innsbruck, Salzburg, Wien und den Wirtschaftsuniversitäten in Wien und Prag sowie der Hebräischen Universität in Jerusalem. Seine Hauptforschungsbereiche liegen in der internationalen Zeitgeschichte, vor allem der USA und Mitteleuropas im Kalten Krieg. Er ist Mitherausgeber der „Contemporary Austrian Studies“ (29 Bände) und Autor/Herausgeber von weiteren 25 Büchern. Seine jüngsten Veröffentlichungen sind eine Sammlung seiner ausgewählten Aufsätze: Relationships/Beziehungsgeschichten: Austria and the United States in the Twentieth Century, Innsbruck/Wien/Bozen 2014 sowie (gem. mit Hans Petschar) Der Marshallplan, Wien 2017; mit Hannes Richter hat er für die österreichische Botschaft in Washington eine Wanderausstellung zum Thema „Towards the American Century: Austrians in the United States“ zusammengestellt, 
die auch in Buchform mit demselben Titel erschienen ist. Im Herbst 2020 ist die Geschichte des Zukunftsfonds erschienen, die er mit Barbara Stelzl-Marx und Katharina Bergmann-Pfleger geschrieben hat: „Auftrag Zukunft: 3000 Zeichen für Gedenken, Toleranz und Demokratie. 15 Jahre Zukunftsfonds der Republik Österreich“. Im Jahr 2019 hat ihn das Land Vorarlberg zum „Wissenschaftler des Jahres“ gewählt.

Eric Burton ist Assistenzprofessor für Globalgeschichte am Institut für Zeitgeschichte der Universität Innsbruck mit einem Forschungsschwerpunkt auf den verflochtenen Geschichten von Dekolonisierung, Entwicklung, Sozialismen und Bildungsmigration im 20. Jahrhundert. Im Anschluss an Studien der Internationalen Entwicklung und Kultur- und Sozialanthropologie an den Universitäten Wien und Dar es Salaam wurde er 2018 in Geschichte promoviert. Seine Dissertation, die mit dem Walter Markov-Preis 2019/2020 des European Network in Universal and Global History (ENIUGH) ausgezeichnet wurde, erscheint demnächst als „In Diensten des Afrikanischen Sozialismus. Die globale Entwicklungsarbeit der beiden deutschen Staaten in Tansania, 1961-1990", Berlin/Boston 2021. 2019 war er Gastdozent an der University of Ghana in Legon; zuvor Mitarbeiter im Projekt „Socialism Goes Global" an der University of Exeter, Gastforscher am Leibniz Science Campus „Eastern Europe, Global Area“ an der Universität Leipzig und Lehrbeauftragter sowie wissenschaftlicher Projektmitarbeiter an der Universität Wien im Projekt „Entsandte Expert/inn/en von Entwicklungshilfe und Sozialistischer Hilfe in Zeiten der Systemkonkurrenz". Seine Aufsätze erschienen u. a. in: Journal of Global History, Zeithistorische Forschungen, Jahrbuch für historische Kommunismusforschung und Cold War History. Herausgegebene Schwerpunktausgaben: „Socialisms in Development“ (Journal für Entwicklungspolitik, 2017) und „Journeys of Education and Struggle. African Mobility in Times of Decolonization and the Cold War" (Stichproben. Wiener Zeitschrift für kritische Afrikastudien, 2018).

Stefan Eminger ist Leiter des Referates Zeitgeschichte im Niederösterreichischen Landesarchiv in St. Pölten. Nach dem Studium der Geschichte, Deutschen Philologie und zwei Semestern Rechtswissenschaften war er wissenschaftlicher Mitarbeiter mehrerer Forschungsprojekte zur österreichischen Geschichte der Zwischenkriegszeit sowie Lehrbeauftragter am Institut für Zeitgeschichte der Universität Wien. Er ist Mitglied der Wissenschaftlichen Beiräte des Hauses der Geschichte Niederösterreich und des Karl von Vogelsang-Institutes sowie Vorstandsmitglied des Institutes für Geschichte des ländlichen Raumes sowie Kurator zahlreicher zeithistorischer Ausstellungen. Unter seinen wichtigsten Publikationen sind: (Hg., mit Ernst Langthaler/Oliver Kühschelm/Peter Melichar) Niederösterreich im 20. Jahrhundert, 
3 Bde., Wien/Köln/Weimar 2008; (gem. mit Ernst Langthaler) Niederösterreich. Vom Ersten Weltkrieg bis zur Gegenwart, Innsbruck/Wien 2013; (Hg.) St. Pölten zwischen den Kriegen. Politik, Wirtschaft, Kultur 1918-1938, St. Pölten 2015; (gem. mit Ernst Langthaler/Klaus-Dieter Mulley) Nationalsozialismus in Niederösterreich. Opfer. Täter. Gegner, Innsbruck (im Druck).

Ina Friedmann ist Zeithistorikerin am Wissenschaftsbüro Innsbruck, derzeit als Mitarbeiterin in einem Forschungsprojekt zu konfessionellen Kinderheimen in Tirol nach 1945. Sie studierte Latein und Geschichte an der Universität Wien. Von 2014 bis 2020 war sie Mitarbeiterin in Forschungsprojekten zur Medizingeschichte (Kinderpsychiatrie, Erbgesundheitsgerichte) und Universitätsgeschichte am Institut für Zeitgeschichte der Universität Innsbruck. 2013 erhielt sie den Fred SinowatzWissenschaftspreis des Landes Burgenland, 2014 den Irma Rosenberg-Förderpreis für die Erforschung der Geschichte des Nationalsozialismus. Publikationen u. a.: (Hg., mit Christian Lechner/Thomas Beddies/Markus Breu) Hans Asperger und die Heilpädagogik. Monatsschrift Kinderheilkunde 168 (2020), Sonderheft 3; (gem. mit Dirk Rupnow) Die Universität im 20. Jahrhundert (Geschichte der Universität Innsbruck 1669-2019. Bd. I/2), Innsbruck 2019; „Vom Standpunkt der Erbpflege und der Bevölkerungspolitik ist in diesem Fall eine Sterilisierung dringend geboten“. Kooperationsformen der Universität Innsbruck mit den Erbgesundheitsgerichten in Tirol und Vorarlberg zwischen 1940 und 1945, in: Margret Friedrich/Dirk Rupnow (Hg.), Geschichte der Universität Innsbruck 1669-2019, Bd. II: Aspekte der Universitätsgeschichte, Innsbruck 2019; „Homosexueller Charakter“ und der „Schutz der übrigen Buben“. Homosexualität und Heilpädagogik in Wien und Tirol im 20. Jahrhundert, in: Elisa Heinrich/Johann Karl Kirchknopf (Hg.), Homosexualitäten revisited. Österreichische Zeitschrift für Geschichtswissenschaften 29 (2018) 2.

Maximilian Graf ist Research Fellow im ERC-Projekt „Unlikely refuge? Refugees and citizens in East-Central Europe in the 2oth Century“ am Masaryk Institute und Archiv der Tschechischen Akademie der Wissenschaften. Nach dem Studium der Geschichte an der Universität Wien war er als Postdoc ebendort und an der Österreichischen Akademie der Wissenschaften (ÖAW) tätig. Von 2017 bis 2019 arbeitete er am Europäischen Hochschulinstitut in Florenz. Er war Gastwissenschaftler an der Stanford University, dem Centre Marc Bloch Berlin und am Österreichischen Historischen Institut in Rom. Seine Arbeiten wurden mit dem Preis für die beste Publikation aus dem Bereich der philosophisch-historischen Klasse der ÖAW (2017), dem Dr. Alois Mock-Wissenschaftspreis (2015) und dem Karl von Vogelsang-Staatspreis für Geschichte der Gesellschaftswissenschaften (Förderpreis 2014) ausgezeichnet. 
Zu seinen wichtigsten Publikationen zählen: Österreich und die DDR 1949-1990. Politik und Wirtschaft im Schatten der deutschen Teilung (International History 3), Wien 2016; (gem. mit Sarah Knoll/Ina Markova/Karlo Ruzicic-Kessler) Franz Marek - Ein europäischer Marxist. Die Biografie, Wien 2019; (Hg., mit Michael Gehler) Österreich und die deutsche Frage 1987-90. Vom Honecker-Besuch zur Einheit, Göttingen 2018; (Hg., mit Sarah Knoll) Franz Marek. Beruf und Berufung Kommunist. Lebenserinnerungen und Schlüsseltexte, Wien 2017; (Hg., mit Michael Gehler) Europa und die deutsche Einheit. Beobachtungen, Entscheidungen und Folgen, Göttingen 2017; (Hg., mit Barbara Haider-Wilson) Orient und Okzident. Begegnungen und Wahrnehmungen aus fünf Jahrhunderten, Wien 2016; (Hg., mit Agnes Meisinger) Österreich im Kalten Krieg. Neue Forschungen im internationalen Kontext, Göttingen 2016.

Marcus Gräser ist seit Oktober 2011 Universitätsprofessor für Neuere Geschichte und Zeitgeschichte und Institutsvorstand an der Johannes Kepler Universität Linz. Er hat Mittlere und Neuere Geschichte, Soziologie und Politikwissenschaft an der Universität Frankfurt am Main studiert und ist dort 1993 promoviert worden. Die Wanderjahre nach der Promotion führten zu Aufenthalten an der University of Chicago und an Forschungseinrichtungen in Berlin und Wien. Die Basis seiner wissenschaftlichen Aktivitäten lag lange Jahre am Zentrum für Nordamerikaforschung und dem Historischen Seminar der Universität Frankfurt am Main, wo er sich 2005 habilitierte und in den darauffolgenden Jahren als Privatdozent lehrte. In den Jahren 2009/2010 vertrat er die Professur für nordamerikanische Geschichte an der Universität Heidelberg, im Jahr darauf wirkte er als Stellvertretender Direktor des Deutschen Historischen Instituts in Washington, D. C. 2008 erhielt er den DavidThelen-Award der Organization of American Historians (für den besten Aufsatz im Feld der amerikanischen Geschichte, der 2007/2008 in einer nichtenglischsprachigen Zeitschrift veröffentlicht wurde), 2007 wurde ihm der Forschungspreis der Josef-Popper-Nährpflicht-Stiftung (für das beste Manuskript im Feld der Wohlfahrtsstaatsforschung) zuerkannt. Wichtige Veröffentlichungen: Wohlfahrtsgesellschaft und Wohlfahrtsstaat. Bürgerliche Sozialreform und Welfare State Building in den USA und in Deutschland 1880-1940 (Bürgertum Neue Folge 6), Göttingen 2009; World History in a Nation-State: The Transnational Disposition in Historical Writing in the United States, in: Journal of American History 95 (2009) 4; (gem. mit Susanna Delfino/Hans Krabbendam/Vincent Michelot) Europeans Writing American History: The Comparative Trope, in: The American Historical Review 119 (2014) 3; „Gallert-Demokratien“? Migration, Parteibildung und kommunale Politik in Wien und Chicago 1890-1938, in: Elisabeth Röhrlich (Hg.), Migration und Innovation 
um 1900. Perspektiven auf das Wien der Jahrhundertwende, Wien 2016; „The Great Middle Class“ in the Nineteenth-Century United States, in: Christof Dejung/David Motadel/Jürgen Osterhammel (Hg.), The Global Bourgeoisie: The Rise of the Middle Classes in the Age of Empire, Princeton 2019.

Robert Groß hat 2017 ein Doktorat in Umweltgeschichte am Institut für Soziale Ökologie der Universität Klagenfurt abgeschlossen. Seit 2018 ist er am Institut für Geschichtswissenschaften und Europäische Ethnologie der Universität Innsbruck als Universitätsassistent sowie am Institut für Soziale Ökologie der Universität für Bodenkultur als Forschungsassistent tätig. Im Rahmen dieser Tätigkeiten arbeitet Groß an seiner Habilitation zur transnationalen Umweltgeschichte des MarshallPlans in Westeuropa. Nach Abschluss seiner Dissertation trat Groß ein Fellowship des Botstiber Institute for Austrian-American Studies an den National Archives in Washington, D. C. an. Danach war er als Stipendiat am Forschungsinstitut für Wissenschafts- und Technikgeschichte am Deutschen Museum tätig. Im Jahr 2019 absolvierte er außerdem ein Fellowship am Rachel Carson Center for Environment and Society der LMU München. Groß ist seit 2014 Mitglied des Zentrums für Umweltgeschichte, Gründungsmitglied des Environmental History Cluster Austria sowie Mitglied der European Society for Environmental History. Zu seinen wichtigsten Publikationen zählen: Die Beschleunigung der Berge. Eine Umweltgeschichte des Wintertourismus in Vorarlberg/Österreich (1920-2010) (Umwelthistorische Forschungen 7), Wien/Köln/Weimar 2018; Wie das 1950er Syndrom in die Täler kam. Umwelthistorische Überlegungen zur Konstruktion von Wintersportlandschaften anhand des Beispiels Damüls in Vorarlberg, Regensburg 2012; (Hg., mit Martin Knoll/Katharina Scharf) Transformative Recovery? The European Recovery Program (ERP)/Marshall Plan in European Tourism, Innsbruck 2020. Außerdem hat Groß mehrere Beiträge in internationalen Fachzeitschriften, z. B. Water History, Zeitschrift für Tourismuswissenschaft oder Economic and Ecohistory publiziert.

Martina Gugglberger ist assoziierte Universitätsprofessorin am Institut für Neuere Geschichte und Zeitgeschichte der Johannes Kepler Universität Linz; Studium der Romanistik und Geschichte an der Universität Salzburg; Forschungsaufenthalte u. a. in Frankreich, Südafrika, Großbritannien, Nepal und Deutschland; Auszeichnungen u. a.: 2019 Käthe Leichter-Preis, 2016 Routledge Best Paper Award, 2014 JKU goes gender-Habilitationsstipendium; Mitglied des Wissenschaftlichen Beirats „Denkmal Frauen im Widerstand gegen das NS-Regime in Oberösterreich“ des Landes Oberösterreich; Publikationen (Auswahl): Grenzen im Aufstieg. Frauenexpeditionen in den Himalaya (Geschichte und Geschlechter), Frankfurt a. M./New York (erscheint 
2021); Reguliertes Abenteuer. Missionarinnen in Südafrika nach 1945 (L'HommeSchriften 22), Köln/Wien 2014; (Hg., mit Christine Egger) Missionsräume. Missionary spaces. Österreichische Zeitschrift für Geschichtswissenschaften 24 (2013) 2; (Hg.) Geschlechtergeschichte(n) des Alpinismus nach 1945. zeitgeschichte 43 (2016) 1; Climbing Beyond the Summits. Social and Global Aspects of Women's Expeditions in the Himalayas, in: The International Journal of the History of Sport 32 (2015) 4; Wanda Rutkiewicz - Crossing Boundaries in Women's Mountaineering, in: Sport in Society (2016); „Joys of exploration“. Gender-constructions in the 1959 Cho Oyu Women's Expedition, in: International Journal of the History of Sport 37 (2020) 9; Abenteuer Mission. Lebensgeschichten von Missionarinnen als Beitrag zur expatriate-Forschung, in: Österreichische Zeitschrift für Geschichtswissenschaften 24 (2013) 2; „Versuche, anständig zu bleiben“. Widerstand und Verfolgung im Reichsgau Oberdonau, in: Gabriella Hauch (Hg.), Frauen im Reichsgau Oberdonau. Geschlechtsspezifische Bruchlinien im Nationalsozialismus (Oberösterreich in der Zeit des Nationalsozialismus 5), Linz 2006; Den Feind lieben. Geschorene Frauen in Frankreich 1944-1945, in: Ingrid Bauer/Christa Hämmerle/Gabriella Hauch (Hg.), Liebe und Widerstand. Ambivalenzen historischer Geschlechterbeziehungen (L'Homme-Schriften 10), Wien/Köln/Weimar 2005.

Nikolaus Hagen studierte Geschichte an der Universität Innsbruck (Dr. phil. 2018) und war Projektmitarbeiter und Lektor am dortigen Institut für Zeitgeschichte. Kuratorische und wissenschaftliche Tätigkeit in Forschungs- und Ausstellungsprojekten $u$. a. am vorarlberg museum in Bregenz, am Jüdischen Museum München und am Jüdischen Museum Hohenems. 2019/2020 Research Fellow am Wiener Wiesenthal Institut für Holocaust Studien und am Fortunoff Video Archive for Holocaust Testimonies der Yale University. Zuvor EHRI-Fellow an den Arolsen Archives. Wichtige Publikationen: (Hg., mit Tobias Neuburger) Antisemitismus in der Migrationsgesellschaft, Innsbruck 2020; (Hg., mit Ingrid Böhler/Philipp Strobl) Displaced-Persons-Forschung in Österreich und Deutschland. zeitgeschichte 47 (2020) 2; (Hg., mit Peter Melichar) Der Fall Riccabona. Eine Familiengeschichte zwischen Akzeptanz und Bedrohung, Wien/Köln/Weimar 2017.

Elisa Heinrich hat Geschichte und Gender Studies studiert. Zwischen 2013 und 2017 war sie wissenschaftliche Mitarbeiterin in verschiedenen zeithistorischen Projekten an den Universitäten Wien und Innsbruck. 2017 bis 2020 war sie Universitätsassistentin und uni:docs-Stipendiatin am Institut für Zeitgeschichte der Universität Wien mit Forschungsaufenthalten am Cornelia Goethe Centrum, Frankfurt am Main sowie an der Basel Graduate School of History. Ihre im Sommer 
2020 eingereichte Dissertation mit dem Titel „Intim und respektabel. Aushandlungen von Homosexualität und Freundinnenschaft in der deutschen Frauenbewegung 1870 bis 1914 “ wurde u. a. durch ein Stipendium der Literar Mechana gefördert und mit dem Johanna-Dohnal-Stipendium 2020 ausgezeichnet. Wichtige Publikationen: (mit Johanna Gehmacher/Corinna Oesch) Käthe Schirmacher. Agitation und autobiografische Praxis zwischen radikaler Frauenbewegung und völkischer Politik, Wien/Köln/Weimar 2018; (Hg., mit Johann Kirchknopf) Homosexualitäten Revisited. Österreichische Zeitschrift für Geschichtswissenschaften 29 (2018) 2; Marginalisierte Erinnerung. Auseinandersetzungen um homosexuelle NS-Opfer im Nachkriegsösterreich, in: zeitgeschichte 43 (2016) 2; Option - Geschlecht - Erinnerung. Genderspezifische Handlungsräume in der Erinnerung von ZeitzeugInnen an die Südtiroler Option 1939, in: Geschichte und Region/Storia e regione 22 (2013) 2.

Thomas Hellmuth ist Universitätsprofessor am Institut für Geschichte und am Zentrum für Lehrer*innenbildung der Universität Wien. Nach dem Studium der Geschichte und Sozialkunde sowie Deutschen Philologie an der Universität Salzburg war er Mitarbeiter im FWF-Projekt „Sozialstruktur einer Bergbaustadt: Hallein im 19. Jahrhundert", von 1997 bis 2009 als AHS-Lehrer und von 2000 bis 2011 - z. T. parallel mit der Lehrtätigkeit an der AHS - als Universitätsassistent und Senior Scientist am Institut für Neuere Geschichte und Zeitgeschichte der Johannes Kepler Universität tätig. Von 2011 bis 2016 erhielt er an der Paris-Lodron-Universität Salzburg eine Tenure-Track-Stelle (Assistenzprofessur) und 2014 - nach der Habilitation - eine assoziierte Universitätsprofessur. 2016 folgte er dem Ruf auf die Universitätsprofessur für die Didaktik der Geschichte an der Universität Wien. 2009 initiierte er das Masterstudium „Politische Bildung“ an der Johannes Kepler Universität Linz, 2010 bis 2015 war er Vorsitzender der Interessengemeinschaft Politische Bildung. Er ist Vorstandsmitglied der Gesellschaft für Geschichtsdidaktik Österreich, seit 2018 Mitglied des Wissenschaftlichen Beirates von „erinnern.at“, Mitherausgeber der „Wiener Beiträge zur Politischen Bildung“ und des Blog „Journal Public History Weekly“. Publikationen (Auswahl): Frankreich im 19. Jahrhundert. Eine Kulturgeschichte, Wien/Köln/Weimar 2020; Historisch-politische Sinnbildung. Geschichte - Geschichtsdidaktik - politische Bildung, Schwalbach/Ts. 2014; (gem. mit Cornelia Klepp) Politische Bildung. Geschichte - Modelle - Praxisbeispiele, Wien/ Köln/Weimar 2010; (Hg., mit Ewald Hiebl) Kulturgeschichte des Salzes 1800-2000, Wien/München 2001; (Hg.) Politische Bildung im Fächerverbund, Schwalbach/Ts. 2017; (Hg., mit Christian Dirninger/Anton Thuswaldner) Salzkammergut schauen. Ein Blick ins Ungewisse, Wien/Köln/Weimar 2015; (Hg., mit Heinrich Ammerer/ Christoph Kühberger) Subjektorientierte Geschichtsdidaktik, Schwalbach/Ts. 2015. 
Georg Hoffmann ist Historiker und Ausstellungskurator. Nach dem Studium der Geschichte an der Karl-Franzens-Universität Graz sowie als ÖAD-Stipendiat an der Andrássy-Universität Budapest war er von 2008 bis 2017 als wissenschaftlicher Mitarbeiter und Lehrbeauftragter am Fachbereich Zeitgeschichte des Instituts für Geschichte der Karl-Franzens-Universität Graz tätig, 2013 zudem Botstiber-Fellow an der University of New Orleans. Von 2017 bis 2019 war er Ausstellungskurator am Haus der Geschichte Österreich in Wien und danach Mitarbeiter am Österreichischen Staatsarchiv. Seit 2021 als Historiker an der Landesverteidigungsakademie tätig. Zudem ist er Mitglied der Rechnitz-Kommission des Bundesdenkmalamtes und des Historiker-Expertenstabes des Streitkräftekommandos. Seine Arbeitsschwerpunkte liegen im Bereich der NS-Täterforschung sowie der Sozialund Kulturgeschichte von Gewalt und Krieg. Publikationen zuletzt u. a.: „Fliegerlynchjustiz“. Gewalt gegen abgeschossene alliierte Flugzeugbesatzungen 1943-1945, Paderborn 2016 (2018 mit dem Karl-von-Vogelsang-Staatsförderpreis ausgezeichnet); (Hg., mit Harald Heppner/Nicole-Melanie Goll) Globaler Krieg. Visionen und ihre Umsetzung, Berlin 2018; (gem. mit René Bienert) Die Täter von Minsk und Maly Trostinec. Betrachtungen zu Täterschaft und Nachkriegsjustiz im „österreichischen Kontext", in: Bundeskanzleramt (Hg.), Massiv der Namen, Wien 2019; (gem. mit Nicole-Melanie Goll) SS-Kaserne Wetzelsdorf. Täterschaft und Gewalt zu Kriegsende am Beispiel des Grazer Raumes 1945 (im Druck).

Andreas Huber arbeitet als Historiker und Soziologe am Institut für Höhere Studien in Wien. Zuvor war er u. a. wissenschaftlicher Mitarbeiter bzw. Universitätsassistent am Institut für Zeitgeschichte und Mitarbeiter im Forum „Zeitgeschichte der Universität Wien“. Seine Forschungen fokussieren die Wissenschafts- und Universitätsgeschichte insbesondere der Universität Wien wie auch Vereine und Netzwerke im 20. Jahrhundert. 2018 bekam er für sein Dissertationsprojekt den Theodor-KörnerPreis verliehen, 2020 wurde seine Monographie zum Deutschen Klub (mit Linda Erker und Klaus Taschwer) als „Wissenschaftsbuch des Jahres 2021“ (Shortlist) nominiert. Zu seinen wichtigsten Publikationen zählen: Rückkehr erwünscht. Im Nationalsozialismus aus „politischen“ Gründen vertriebene Lehrende der Universität Wien, Wien/Münster 2016; (Hg., mit Heinz Fischer/Stephan Neuhäuser) 100 Jahre Republik. Meilensteine und Wendepunkte in Österreich 1918-2018, Wien 2018; (gem. mit Linda Erker/Klaus Taschwer) Der Deutsche Klub. Austro-Nazis in der Hofburg, Wien 2020. 
Johann Kirchknopf ist wissenschaftlicher Mitarbeiter der Kulturbetriebe Burgenland $\mathrm{GmbH}$ und assistiert dort dem Kurator der Ausstellung zum einhundertjährigen Landesjubiläum, Oliver Rathkolb. Seine Diplomarbeit hat er über die Verfolgung weiblicher Homosexualität in Wien während der NS-Zeit verfasst und anschließend für QWIEN - Zentrum für queere Geschichte als wissenschaftlicher Mitarbeiter im Rahmen des Forschungsprojekts „,Namentliche Erfassung der homosexuellen und transgender Opfer des Nationalsozialismus in Wien“ gearbeitet. Aus diesem Forschungsprojekt ging sein laufendes Dissertationsprojekt über die Strafverfolgung weiblicher und männlicher Homosexualität in Österreich im 20. Jahrhundert hervor, für welches er von 2014 bis 2017 ein uni:docs-Stipendium der Universität Wien erhielt. Zu seinen wichtigsten Publikationen zählen: Die strafrechtliche Verfolgung homosexueller Handlungen in Österreich im 20. Jahrhundert, in: zeitgeschichte 43 (2016) 2, und die Herausgeberschaft des Themenhefts „Homosexualitäten revisited“ der Österreichischen Zeitschrift für Geschichtswissenschaften 29 (2018) 2 gemeinsam mit Elisa Heinrich.

Birgit Kirchmayr ist assoziierte Universitätsprofessorin am Institut für Neuere Geschichte und Zeitgeschichte der Johannes Kepler Universität Linz und Wissenschaftliche Koordinatorin der österreichischen Kommission für Provenienzforschung. Nach dem Studium der Geschichte und Slawistik an der Universität Salzburg wissenschaftliche Mitarbeiterin am Ludwig Boltzmann Institut für Gesellschafts- und Kulturgeschichte, Linz (2000-2004); 2005-2017 Universitätsassistentin bzw. Assistenzprofessorin am Institut für Neuere Geschichte und Zeitgeschichte; 2017 Venia Legendi für Neuere Geschichte und Zeitgeschichte; 2018/2019 Gastprofessorin am Institut für Zeitgeschichte der Universität Wien; seit 2020 Mitglied des Kunstrückgabebeirats der Republik Österreich. Neben der wissenschaftlichen Tätigkeit zahlreiche Projekte im Bereich der Public History, so u. a. Ausstellungskuratierungen (z. B. 2008/09 „Kulturhauptstadt des Führers. Kunst und Nationalsozialismus in Linz und Oberösterreich“; 2017 „Aphrodite - Eine Bestandsaufnahme“, Linzer Stadtmuseum Nordico) sowie Beratung und Mitwirkung an zeitgeschichtlichen Dokumentarfilmen. Publikationen u. a.: Zeitwesen. Autobiographik österreichischer Künstlerinnen und Künstler im Spannungsfeld von Politik und Gesellschaft 1900-1945, Wien 2020; (Hg., mit Regina Thumser-Wöhs/Martina Gugglberger/Grazia Prontera/Thomas Spielbüchler) Außerordentliches. Eine Festschrift für Albert Lichtblau, Wien/ Köln/Weimar 2019; George Wozasek. Eine Spurensuche, Linz 2012; (gem. mit Friedrich Buchmayr/Michael John) Geraubte Kunst in Oberdonau, Linz 2007; (Hg., mit Albert Lichtblau) Marko Feingold. Wer einmal gestorben ist, dem tut nichts mehr weh, Salzburg 2001. 
Helmut Konrad war von 1984 bis 2016 ordentlicher Professor für Allgemeine Zeitgeschichte an der Universität Graz, währenddessen Rektor der Universität Graz 1993-1997 sowie für drei Perioden Dekan der Geisteswissenschaftlichen Fakultät. Nach dem Studium an der Universität Wien (sub auspiciis praesidentis 1972) Universitätsassistent an Linz, Habilitation 1981. Anschließend Vertretungsprofessur an der Universität Innsbruck. Gastprofessor an der Cornell University, New York, an der University of Waterloo, Kanada, und an der Yale University, Connecticut. Leitung des Ludwig Boltzmann Instituts für Gesellschafts- und Kulturgeschichte. 1995-1998 Vizepräsident der Österreichischen Rektorenkonferenz. Präsident des österreichischen Akkreditierungsrates 2000-2005. Kurator von Ausstellungen, darunter der steirische Landesausstellung 2000 und der Kärntner Landesaustellung 2020. Victor Adler-Staatspreis 1983, Preis der Stadt Wien für Geistes- und Kulturwissenschaften 2002.Veröffentlichungen zur Kulturgeschichte, zur Arbeiter- und Sozialgeschichte, zuletzt: Erkundungen zur Zeitgeschichte, Wien 2016 und (gem. mit Gabriella Hauch) Hundert Jahre Rotes Wien. Die Zukunft einer Geschichte, Wien 2019.

Claudia Kraft ist seit 2018 Universitätsprofessorin am Institut für Zeitgeschichte der Universität Wien. Nach dem Studium der Osteuropäischen Geschichte, Politikwissenschaft und Slawistik wurde sie im Jahr 2000 mit einer Arbeit zur polnischen Rechtsgeschichte der Zwischenkriegszeit an der Universität Marburg/Lahn promoviert. Nach Stationen als wissenschaftliche Mitarbeiterin am Deutschen Historischen Institut Warschau und der Ruhr-Universität Bochum lehrte sie Geschichte Ostmitteleuropas an der Universität Erfurt (2005-2011) und Europäische Zeitgeschichte an der Universität Siegen (2011-2018). Sie ist u. a. Mitherausgeberin der Zeitschrift „L'Homme - Europäische Zeitschrift für feministische Geschichtswissenschaft", der „Zeitschrift für Ostmitteleuropaforschung" und der „Österreichischen Zeitschrift für Geschichtswissenschaften“. Unter ihren wichtigsten Publikationen sind: (gem. mit Ulf Brunnbauer) Statehood in Socialism, in: Włodzimierz Borodziej/Sabina Ferhadbegović/Joachim v. Puttkamer (Hg.), The Routledge History Handbook of Central and Eastern Europe in the Twentieth Century, Bd. 2: Statehood, London/ New York 2020; (gem. mit Béatrice v. Hirschhausen/Hannes Grandits/Dietmar Müller/Thomas Serrier) Phantomgrenzen: Räume und Akteure in der Zeit neu denken, Göttingen 2015; (Hg., mit Alf Lüdtke/Jürgen Martschukat) Kolonialgeschichten. Regionale Perspektiven auf ein globales Phänomen, Frankfurt a. M./New York 2010; (Hg.) Geschlechterverhältnisse in Ostmitteleuropa nach dem Zweiten Weltkrieg: Soziale Praxis und Konstruktion von Geschlechterbildern, München 2008; Europa im Blick der polnischen Juristen. Rechtsordnung und juristische Profession im 
Spannungsfeld zwischen Nation und Europa 1918-1939 (Studien zu Europäischen Rechtsgeschichte 156 des Max-Planck-Instituts für Europäische Rechtsgeschichte), Frankfurt a. M. 2002.

Christoph Kühberger ist Universitätsprofessor für Geschichts- und Politikdidaktik am Fachbereich Geschichte der Universität Salzburg und Obmann der Gesellschaft für Geschichtsdidaktik Österreich (www.gdoe.at). Er promovierte mit einem Vergleich der faschistischen und nationalsozialistischen Festkultur an der Universität Salzburg und arbeitete danach als Forschungsassistent am Institut für Philosophie der Universität Salzburg zur Ethik und Erkenntnistheorie der historischen Armutsforschung. Später war er Leiter der Geschichtsdidaktik am Historischen Institut der Universität Greifswald. 2008 wurde er Professor für Vergleichende Neuere und Neueste europäische Kulturgeschichte am Institut für Geschichte der Universität Hildesheim. Dort habilitierte er sich und erhielt die Venia Legendi für Neuere und Neueste Geschichte und ihre Didaktik. Nach seiner Tätigkeit als Vizerektor und Hochschulprofessor an der Pädagogischen Hochschule Salzburg wechselte er 2017 an die Universität Salzburg. Unter seinen wichtigsten Publikationen sind: (Hg., mit Sebastian Barsch/Bettina Degner/Martin Lücke) Handbuch Diversität im Geschichtsunterricht. Inklusive Geschichtsdidaktik, Frankfurt a. M. 2020; (Hg.) Historisches Wissen. Geschichtsdidaktische Erkundungen zu Art, Tiefe und Umfang für das historische Lernen, Schwalbach/Ts. 2012; (Hg., mit Andreas Pudlat) Vergangenheitsbewirtschaftung. Public History zwischen Wirtschaft und Wissenschaft, Innsbruck 2012; (gem. mit Clemens Sedmak) Ethik der Geschichtswissenschaft. Zur Einführung, Wien 2008; Metaphern der Macht. Ein kultureller Vergleich der politischen Feste im faschistischen Italien und im nationalsozialistischen Deutschland, Münster 2006.

Ernst Langthaler ist seit 2016 Universitätsprofessor für Sozial- und Wirtschaftsgeschichte und Vorstand des gleichnamigen Instituts an der Johannes Kepler Universität Linz sowie Vorstand des Instituts für Geschichte des ländlichen Raumes in St. Pölten. Nach dem Diplom- und Doktoratsstudium der Geschichte habilitierte er sich 2010 im Fach Wirtschafts- und Sozialgeschichte an der Universität Wien. Nach Antrags- und Auftragsprojekten (u. a. für die Österreichische Historikerkommission) war er von 2002 bis 2016 Mitarbeiter bzw. Leiter des Instituts für Geschichte des ländlichen Raumes in St. Pölten. Er war Gastprofessor an den Universitäten Innsbruck, Wien und Santiago de Compostela und Research Fellow am Rachel Carson Center for Environment and Society in München. Er ist Redaktionsmitglied der Zeitschrift „zeitgeschichte“ sowie Mitherausgeber der „Österreichischen Zeitschrift 
für Geschichtswissenschaften“, des „Jahrbuchs für Geschichte des ländlichen Raumes", des Journals „Commodity Frontiers" und der Buchreihen „Sozial- und wirtschaftshistorische Studien“ und „Quellen und Forschungen zur Agrargeschichte“. Er ist Secretary der European Rural History Organisation, Mitglied der Kommission für Interdisziplinäre Ökologische Studien der Österreichischen Akademie der Wissenschaften und Beiratsmitglied des Forschungsinstituts für politisch-historische Studien der Dr.-Wilfried-Haslauer-Bibliothek. Wichtigste Buchpublikationen: (gem. mit Ulrich Ermann/Marianne Penker/Markus Schermer) Agro-Food Studies. Eine Einführung, Wien/Köln/Weimar 2018; Schlachtfelder. Alltägliches Wirtschaften in der nationalsozialistischen Agrargesellschaft 1938-1945, Wien/Köln/Weimar 2016; (Hg., mit Reinhard Sieder) Globalgeschichte 1800-2010, Wien/Köln/Weimar 2010.

Christian Lechner ist seit 2015 Assistenzarzt am Department für Kinder- und Jugendheilkunde der Medizinischen Universität Innsbruck. Nach dem Studium der Humanmedizin in Innsbruck und der Geschichtswissenschaften in Innsbruck, New Orleans und Heidelberg Beginn der derzeit noch anhaltenden Weiterbildung zum Kinderfacharzt. Hierbei liegt der klinische und wissenschaftliche Schwerpunkt auf dem Gebiet der pädiatrischen Neurologie und Neuroimmunologie. 2018 verbrachte er in diesem Kontext ein halbes Jahr am Brigham and Women's Hospital der Harvard Medical School in Boston. Der geschichtswissenschaftliche Fokus liegt auf der Geschichte der Pädiatrie und Anatomie. Die laufende Dissertation arbeitet die Geschichte des Innsbrucker Anatomischen Institutes auf. Seit 2018 ist er Obmann des medizinhistorischen Vereins Freundeskreis Pesthaus und kuratierte in diesem Kontext bereits zahlreiche kleinere und größere Ausstellungen medizin- und gesundheitshistorischen Inhalts für den Raum Innsbruck. 2018 hat er zudem die Leitung des Referates Geschichte der Pädiatrie der Österreichischen Gesellschaft für Kinderund Jugendheilkunde übernommen. Die wichtigste rezente geschichtswissenschaftliche Publikation ist „Hans Asperger und die Heilpädagogik“, hg. als Sonderheft der Monatsschrift Kinderheilkunde, 2020, mit Thomas Beddies, Markus Breu und Ina Friedmann. Zudem diverse Publikationen zum medizinischen Forschungsschwerpunkt.

Kerstin von Lingen ist Historikerin an der Universität Wien und dort seit 1. März 2019 Inhaberin der Professur für Zeitgeschichte (Vergleichende Diktatur, Gewaltund Genozidforschung). Zuvor war sie am Exzellenzcluster „Asia and Europe in a Global Context" sowie am Historischen Seminar der Universität Heidelberg tätig. Sie ist Heisenberg-Stipendiatin (2018) und Preisträgerin des Ernst-Otto Czempiel-Preises 2020. Am Exzellenzcluster leitete sie eine Nachwuchsgruppe zum Thema Kriegs- 
verbrecherprozesse in Asien. Gastprofessuren führten Sie an die ULB Brüssel (2016) und nach Wien (2017) sowie im Rahmen eines Fellowship ans Lauterpacht Centre for International Law, Cambridge (2018). Ihre Forschungsschwerpunkte gelten der Genozid- und Gewaltgeschichte, insbesondere dem Holocaust, Dekolonisierungsprozessen (mit Schwerpunkt Asien), zeithistorischer Rechtsgeschichte, Studien zu Memory, Identity and Apology sowie der globalen Migrations- und Zwangsarbeiterforschung. Unter ihren Publikationen sind drei Monographien (darunter ihre Dissertation „Kesselrings letzte Schlacht. Kriegsverbrecherpolitik, Vergangenheitspolitik, Wiederbewaffnung: der Fall Kesselring“, Paderborn 2004 sowie ihre Habilitation zu „Crimes against Humanity“, Paderborn 2018) sowie die Tagungsbände „Kriegserfahrung und nationale Identität in Europa" (Paderborn 2009) und (gem. mit Klaus Gestwa) „Zwangsarbeit als Kriegsressource in Europa und Asien“, Paderborn 2014, und die Ergebnisse ihrer Asienforschung in den Bänden „War Crimes Trials in the Wake of Decolonization and Cold War in Asia, 1945-1956: Justice in Time of Turmoil“ (Basingstoke 2016), „Debating Collaboration and Complicity in War Crimes Trials in Asia, 1945-1956“ (Basingstoke 2017) sowie „Transcultural Justice at the Tokyo Tribunal: the Allied Struggle for Justice 1946-1948“ (Boston 2018).

Lisbeth Matzer ist Historikerin mit einem Fokus auf europäische Geschichte und Bildungsgeschichten des späten 19. bis zum 21. Jahrhundert. In Forschung und Lehre beschäftigt sie sich besonders mit Kulturgeschichte(n), der Geschichte von Grenzräumen (Borderlands Studies), der Geschichte von Jugend und generellen Fragen bezüglich der Transformation und Tradierung von kollektiven Gedächtnissen, Narrativen und Ideologien im Kontext von Autoritarismus, Faschismus und/ oder Demokratisierung. Lisbeth Matzer studierte in Graz Geschichte (MA 2016) und Erziehungswissenschaften (Schwerpunkt Erwachsenenbildung; MA 2015) und arbeitete ebendort bereits ab 2014 als wissenschaftliche Mitarbeiterin und Lehrbeauftragte. Von 2017 bis 2020 war sie MSCA-Fellow im „EUmanities“-Programm der a.r.t.e.s. Graduate School der Universität zu Köln (Horizon 2020: Marie SkłodowskaCurie grant), wo sie im Sommer 2020 „summa cum laude“ promoviert wurde. Ende 2020 wechselte sie an den Lehrstuhl für Europäische Geschichte der Ludwig-Maximilians-Universität München. Jüngste Publikationen: Aufwachsen als Teil der „Volksgemeinschaft“ - Jugendliche Handlungsspielräume im Nationalsozialismus zwischen Hitler-Jugend, Schule und Freizeitvergnügen, in: zeitgeschichte 47 (2020) 3; Be(com)ing „German”. Borderland Ideologies and Hitler Youth in NS-occupied Slovenia (1941-1945), in: Journal of Borderlands Studies (2020). 
Agnes Meisinger ist Historikerin mit dem Forschungsschwerpunkt Sportgeschichte, Mitarbeiterin am Institut für Zeitgeschichte der Universität Wien und am Jüdischen Museum Wien sowie Redaktionsassistentin der Zeitschrift „zeitgeschichte“. Studium der Geschichte und Politikwissenschaft an der Universität Wien. Veröffentlichungen zu Themen der österreichischen Sportgeschichte, zuletzt: 150 Jahre Eiszeit. Die große Geschichte des Wiener Eislauf-Vereins, Wien/Köln/Weimar 2017; (Hg., mit Matthias Marschik/Rudolf Müllner/Johann Skocek/Georg Spitaler) Images des Sports in Österreich. Innensichten und Außenwahrnehmungen (Zeitgeschichte im Kontext 13), Göttingen 2018; (gem. mit Alexander Juraske/Peter Menasse) The Austrian Boy. Ein Leben zwischen Wien, London und Hollywood, Wien/Köln/Weimar 2019.

Rudolf Müllner ist außerordentlicher Universitätsprofessor am Institut für Sportwissenschaft der Universität Wien und Leiter der Abteilung Sportpädagogik, Fachdidaktik Bewegung und Sport, Sozial- und Zeitgeschichte des Sports. Studium der Leibeserziehung, Geschichte, Sozialkunde und Politische Bildung; Habilitation im Fach Sportwissenschaft (Schwerpunkt Historische Bewegungskultur- und Sportforschung), Aus- und Weiterbildung in Neoreichianischer Körperpsychotherapie: Bioenergetische Analyse (DÖK), Gruppendynamik (ÖAGG, Österreichischer Arbeitskreis für Gruppentherapie und Gruppendynamik), Team- und Organisationsberater (TAO, Team für angewandte Psychologie und Organisationsberatung). Auszeichnungen u. a.: Ludwig Jedlicka Preis 1991, ISHPES-Award der International Society for the History of Physical Education and Sport 2015. Veröffentlichungen zu Transformationsprozessen von Bewegungskulturen, Körpergeschichte und Machtdispositiven, Sportgeschichte, (Selbst)Verbesserungskulturen des Körpers: (gem. mit Bernhard Hachleitner/Matthias Marschik/Johann Skocek) Ein Fußballverein aus Wien. Der FK Austria Wien im Nationalsozialismus 1938-1945, Wien 2018; (Hg., mit Matthias Marschik/Agnes Meisinger/Johann Skocek/Georg Spitaler) Images des Sports in Österreich. Innensichten und Außenwahrnehmungen, Wien 2018; Sich in Form bringen. Historische Facetten der körperlichen (Selbst-)Verbesserung im und durch Sport seit 1900, in: Stefan Scholl (Hg.), Körperführung. Historische Perspektiven auf das Verhältnis von Biopolitik und Sport, Frankfurt/New York 2018; Perspektiven der historischen Sport- und Bewegungskulturforschung, Wien 2011.

Eva Pfanzelter ist assoziierte Professorin am Institut für Zeitgeschichte und dessen Stellvertretende Institutsleiterin sowie Stellvertretende Leiterin des Forschungszentrum Digital Humanities der Universität Innsbruck. Nach dem Studium der Ge- 
schichte und der Fächerkombination Englisch, Philosophie und EDV für Geisteswissenschaften in Innsbruck sowie an der Eastern Illinois University, Charleston, IL war sie Mitarbeiterin an verschiedenen Forschungsprojekten (z. B. Beziehungen Österreich-Israel nach 1945, die Südtirolfrage zwischen 1950 und 1980, Zeitgeschichte-Informations-System - ZIS etc.), die mit zahlreichen Forschungs- und Archivaufenthalten in Italien, Österreich, Deutschland, England und den USA einhergingen. $\mathrm{Zu}$ ihren derzeitigen Forschungsprojekten gehört das „Horizon2020“Projekt „NewsEye. A Digital Investigator for Historical Newspapers“ (2018-2021), in dem sie für die Leitung des DH-Teams verantwortlich ist. Außerdem koordiniert sie seit Oktober 2020 das Projekt „ReMIGRA: Return Migration as an Interdisciplinary Research Area Using the Example of the South Tyrolean ,Return Option“". $\mathrm{Zu}$ den wichtigsten Publikationen gehören: (Hg., mit Dirk Rupnow) einheimischzweiheimisch-mehrheimisch. Geschichte(n) der neuen Migration in Südtirol, Bozen 2017; (Hg., mit Walter Obwexer) 70 Jahre Pariser Vertrag: Handbuch, Wien 2017; Option und Gedächtnis. Erinnerungsorte an die Südtiroler Umsiedlung 1939, Bozen 2014; (Hg., Sonderheft) Option und Erinnerung. Geschichte und Region/ storia e regione 22 (2013) 2; Südtirol unterm Sternenbanner. Die amerikanische Besatzung Mai-Juni 1945. Mit Bilddokumentation und DVD, Bozen 2005.

Sarah Oberbichler ist wissenschaftliche Mitarbeiterin am Institut für Zeitgeschichte der Universität Innsbruck und forscht zu den Themen (Re)Migration, Medien und digitale Geisteswissenschaften. Sie hat Geschichte und Germanistik an der Universität Innsbruck, der University of Gothenburg und der University of Minnesota studiert. 2019 wurde sie an der Universität Innsbruck mit einer Arbeit über die Wahrnehmung von Migration in Südtiroler Tageszeitungen promoviert. Ihre Dissertation, für die sie 2019 mit dem Marianne-Barcal-Preis der Stadt Innsbruck ausgezeichnet wurde, erscheint unter dem Titel „Autochthone Minderheiten und Migrant*innen. Mediale Argumentationsstrategien von 1990 bis 2015 am Beispiel Südtirols“ im Band 29 der Reihe „Innsbrucker Forschungen zur Zeitgeschichte“. Sie arbeitet in internationalen und interdisziplinären Projekten zur Digitalisierung, Analyse und Visualisierung von digitalen Archiven.

Anton Pelinka war 1975 bis 2006 ordentlicher Professor für Politikwissenschaft an der Universität Innsbruck und 2006 bis 2018 Professor of Nationalism Studies and Political Science an der Central European University, Budapest. Seit 2018 Mitglied des Universitätsrates der Universität Innsbruck. Nach dem Studium der Rechtswissenschaften an der Universität Wien (Dr. iur. 1964) und der Politikwissenschaft am Institut für Höhere Studien Wien folgte 1972 die Habilitation für das Fach Politik- 
wissenschaft an der Universität Salzburg. Gastprofessuren an der Nehru University, New Delhi, der University of New Orleans, der Harvard University (Schumpeter Fellow), der Stanford University (Austrian Chair), der University of Michigan (Ann Arbor), der Université Libre de Bruxelles und der Hebrew University (European Forum). Veröffentlichungen zu Themen des österreichischen politischen Systems, der europäischen Integration und der Demokratietheorie. Zuletzt: Die gescheiterte Republik. Kultur und Politik in Österreich, 1918 bis 1938, Wien 2017; Der politische Aufstieg der Frauen. Am Beispiel Eleanor Roosevelt, Indira Gandhi und Margaret Thatcher, Wien 2020.

Bertrand Perz ist Universitätsprofessor am Institut für Zeitgeschichte der Universität Wien. 1998-2003 Mitglied der Historikerkommission der Republik Österreich, 2009-2013 wissenschaftlicher Leiter der Neugestaltung der KZ-Gedenkstätte Mauthausen, 2011-2014 Vorsitzender der Kommission zur Untersuchung der Vorgänge um den Anstaltsfriedhof des Psychiatrischen Krankenhauses in Hall in Tirol 19421945, derzeit: Vorsitzender des Wissenschaftlichen Beirates der KZ-Gedenkstätte Mauthausen, Präsident der Österreichischen Gesellschaft für Zeitgeschichte, Vorstandsmitglied des Wiener Wiesenthal Instituts für Holocauststudien, Mitglied des International Advisory Board der KZ-Gedenkstätte Bergen-Belsen und des Wissenschaftlichen Kuratoriums der Stiftung Gedenkstätten Buchenwald und MittelbauDora, Mitglied des Wissenschaftlichen Beirates zur Unternehmens- und Familiengeschichte von Bahlsen. Publikationen u. a.: (Hg., mit Gabriele Hackl/Alexandra Wachter) Wasserstraßen. Die Verwaltung von Donau und March 1918-1955, Wien 2020; (Hg., mit Verena Pawlowsky/Ina Markova) Inbesitznahmen. Das Parlamentsgebäude in Wien 1933-1956, Salzburg/Wien 2018; Das Projekt „Quarz“ Der Bau einer unterirdischen Fabrik durch Häftlinge des KZ Melk für die Steyr-Daimler-Puch AG 1944-1945, Innsbruck 22014; (Hg., mit Günter Morsch) Neue Studien zu nationalsozialistischen Massentötungen durch Giftgas. Historische Bedeutung, technische Entwicklung, revisionistische Leugnung, Berlin 2011; Die KZ-Gedenkstätte Mauthausen. 1945 bis zur Gegenwart, Innsbruck 2006; (Hg., mit Florian Freund/ Mark Spoerer) Zwangsarbeiter und Zwangsarbeiterinnen auf dem Gebiet der Republik Österreich 1939-1945, Wien/München 2004.

Christian Rabl ist Mitbegründer und wissenschaftlicher Leiter des Zeithistorischen Zentrums Melk, seine Forschungsschwerpunkte sind KZ-Forschung, Nachkriegsjustiz, Politische Bildung und Public History. Nach dem Studium der Politikwissenschaft an der Universität Wien war er Projektassistent in dem am Wiener Institut für Zeitgeschichte angesiedelten FWF-Forschungsprojekt „Lager-SS Mauthausen“ (Lei- 
tung Bertrand Perz). Er widmete seine Dissertation dem Thema „Der KZ-Komplex Mauthausen vor Gericht“, die im Herbst 2018 mit dem Mauthausen-Memorial-Forschungspreis ausgezeichnet wurde. In Melk ist er für die inhaltliche und organisatorische Betreuung der KZ-Gedenkstätte Melk zuständig und laufend an regionalen, nationalen und internationalen Forschungs- und Vermittlungsprojekten beteiligt. Seit 2016 wirkt er an dem niederösterreichweiten Dokumentations, Vermittlungsund Vernetzungsprojekt „Zwischenräume“ des Museums Erlauf Erinnert mit und war im Herbst 2019 Mitorganisator der internationalen Tagung „Unsichtbare Lager in Niederösterreich: Beforschen, dokumentieren, zugänglich machen“ in St. Pölten. Er ist Mitbegründer und Obmann der Gedenkinitiative KZ-Außenlager St. Aegyd am Neuwalde (NÖ). Unter seinen wichtigsten Publikationen sind: Das KZ-Außenlager St. Aegyd am Neuwalde (Mauthausen-Studien 6), Wien 2008; Am Strang. Die österreichischen Angeklagten in den Dachauer Mauthausen-Prozessen, Wien 2018; Mauthausen vor Gericht. Nachkriegsprozesse im internationalen Vergleich (Mauthausen-Studien 13), Wien 2019.

Ljiljana Radonić leitet das vom Europäischen Forschungsrat (ERC) finanzierte Projekt „Globalised Memorial Museums. Exhibiting Atrocities in the Era of Claims for Moral Universals“ am Institut für Kulturwissenschaften und Theatergeschichte (IKT) der Österreichischen Akademie der Wissenschaften. Ihre zuvor am IKT verfasste Habilitation über den Zweiten Weltkrieg in postsozialistischen Gedenkmuseen (2013-2017, gefördert durch ein APART-Stipendium, 2018/2019 durch das Elise-Richter-Programm des FWF) reichte sie im Juni 2019 am Institut für Politikwissenschaft der Universität Wien ein, wo sie seit 2004 über Antisemitismustheorie sowie (Ostmittel)Europäische Erinnerungskonflikte seit 1989 lehrt. 2015 war sie Gastprofessorin für Kritische Gesellschaftstheorie an der Universität Gießen, 2017 am Centrum für Jüdische Studien der Universität Graz. Ihre Dissertation schrieb sie über den „Krieg um die Erinnerung. Kroatische Vergangenheitspolitik zwischen Revisionismus und europäischen Standards“, Frankfurt a.M. 2010. Zuletzt erschienen: (Hg., mit Heidemarie Uhl) Das umkämpfte Museum. Zeitgeschichte ausstellen zwischen Dekonstruktion und Sinnstiftung, Bielefeld 2020; (Hg.) The Holocaust/ Genocide Template in Eastern Europe, London/New York 2020; Die friedfertige Antisemitin reloaded. Weibliche Opfermythen und geschlechtsspezifische antisemitische „Schiefheilung“, Graz 2018.

Margit Reiter ist Universitätsprofessorin für Europäische Zeitgeschichte an der Universität Salzburg. Nach dem Studium der Geschichte und Germanistik in Wien als Zeithistorikerin in Forschung und Lehre tätig; neben Fellowships am IFK Wien, 
Charlotte Bühler-Habilitationsstipendium und Botstiber Fellowship for AustrianAmerican Studies auch Mitglied mehrerer Historikerkommissionen sowie Leiterin mehrerer FWF-Projekte; nach ihrer Habilitation 2006 als Privatdozentin und Senior Research Fellow dem Institut für Zeitgeschichte an der Universität Wien zugeordnet und als Gastprofessorin an den Universitäten Salzburg und Wien tätig. 2006-2007 Gastforscherin am Berliner Kolleg für Vergleichende Geschichte Europas (FU Berlin) und am Zentrum für Antisemitismusforschung an der TU Berlin sowie 2016 Senior Fellow am Zentrum für Holocaust-Studien des Instituts für Zeitgeschichte München. Für ihre Forschungen erhielt sie mehrere Auszeichnungen, u. a. den ErnstFraenkel-Prize der Wiener Library in London (2005), den Theodor-Körner-Preis (2006) und den Bruno-Kreisky-Anerkennungspreis für das Politische Buch (2006). Ihr aktuelles Buch, „Die Ehemaligen. Der Nationalsozialismus und die FPÖ“ (2019) stand auf der Shortlist für das „Wissenschaftliche Buch des Jahres 2020". Publikationen u. a.: (gem. mit Helga Embacher) Gratwanderungen. Die Beziehungen zwischen Österreich und Israel im Schatten der Vergangenheit, Wien 1998; Unter Antisemitismus-Verdacht. Die österreichische Linke und Israel nach der Shoah, Innsbruck/ Wien/München/Bozen 2001; Die Generation danach. Der Nationalsozialismus im Familiengedächtnis, Innsbruck/Wien/Bozen 2006; (Hg., mit Helga Embacher) Europa und der 11. September 2001, Wien/Köln/Weimar 2011; Die Ehemaligen. Der Nationalsozialismus und die Anfänge der FPÖ, Göttingen 2019.

Elisabeth Röhrlich ist Assistenzprofessorin (Tenure-Track) am Institut für Geschichte der Universität Wien und Cosprecherin des Forschungsschwerpunkts Globalgeschichte der Historisch-Kulturwissenschaftlichen Fakultät. Nach dem Studium an der Universität Tübingen und der Universität Wien wurde sie mit einer Arbeit über Bruno Kreiskys Außenpolitik promoviert. Im Anschluss arbeitete sie am Demokratiezentrum Wien und am Institut für Zeitgeschichte der Universität Wien, zuletzt als vom Österreichischen Wissenschaftsfonds (FWF) geförderte EliseRichter-Stelleninhaberin. Sie war u. a. Gastwissenschaftlerin am Deutschen Historischen Institut und am Woodrow Wilson International Center for Scholars (beide in Washington) und der Monash University South Africa (in Johannesburg). Ihre Forschung wurde mit dem Bruno Kreisky-Anerkennungspreis für das Politische Buch (2009) und dem Förderungspreis der Stadt Wien (2017) ausgezeichnet. Ihre aktuellen Arbeiten zur Geschichte der International Atomic Energy Agency erschienen u. a. in „Cold War History“, dem „Journal of Cold War Studies" und „Diplomacy and Statecraft". Ihre Monographie zum Thema erscheint 2021 bei der Johns Hopkins University Press. 
Dirk Rupnow ist Universitätsprofessor am Institut für Zeitgeschichte der Universität Innsbruck und derzeit Dekan der Philosophisch-Historischen Fakultät. Nach dem Studium der Geschichte, Germanistik, Philosophie und Kunstgeschichte an der FU Berlin und der Universität Wien war er Mitarbeiter der Historikerkommission der Republik Österreich (1999/2000). Seine Forschungen führten ihn an das Simon Dubnow-Institut für jüdische Geschichte und Kultur in Leipzig, die Duke University, das Dartmouth College sowie das Center for Advanced Holocaust Studies des US Holocaust Memorial Museums, in Wien an das Internationale Forschungszentrum Kulturwissenschaften, das Institut für die Wissenschaften vom Menschen und das Institut für Zeitgeschichte der Universität Wien. 2017 war er Distinguished Visiting Austrian Chair Professor an der Stanford University. Er ist Mitglied des Wissenschaftlichen Beirats des Wiener Wiesenthal Instituts für Holocaust-Studien VWI. Der Eröffnungsausstellung des Hauses der Geschichte Österreich in Wien (2018) stand er als Konsulent zur Seite. Für seine Arbeiten erhielt er eine Reihe von internationalen Preisen und Auszeichnungen, u. a. 2009 den Fraenkel Prize in Contemporary History der Wiener Library (London). Unter seinen wichtigsten Publikationen sind: (Hg., mit Günter Bischof) Migration in Austria, Innsbruck 2017; (Hg., mit Amos Morris-Reich) Ideas of ,Race' in the History of the Humanities, London 2017; (Hg., mit Iris Roebling-Grau) „Holocaust“-Fiktion. Kunst jenseits der Authentizität, Paderborn 2015; (Hg., mit Heidemarie Uhl) Zeitgeschichte ausstellen in Österreich. Museen - Gedenkstätten - Ausstellungen, Wien/Köln/Weimar 2011; Judenforschung im Dritten Reich. Wissenschaft zwischen Politik, Propaganda und Ideologie, Baden-Baden 2011; Vernichten und Erinnern. Spuren nationalsozialistischer Gedächtnispolitik, Göttingen 2005.

Monika Sommer ist seit 2017 Gründungsdirektorin des Hauses der Geschichte Österreich. Sie studierte Geschichte und gewählte Fächer an den Universitäten Graz und Wien. 1999-2003 war sie wissenschaftliche Mitarbeiterin der Kommission für Kulturwissenschaften und Theatergeschichte der Österreichischen Akademie der Wissenschaften, 2002/2003 Junior Fellow am Internationalen Forschungszentrum Kulturwissenschaften, bevor sie 2003-2008 als Assistentin des damaligen Direktors Wolfgang Kos federführend an der Neupositionierung des Wien Museums beteiligt war, an dem sie 2009-2013 als Kuratorin wirkte. 2009 verantwortete sie im Rahmen der „Europäischen Kulturhauptstadt“ Linz gemeinsam mit Heidemarie Uhl und Dagmar Höss das Projekt „IN SITU. Zeitgeschichte findet Stadt“. 2014-2016 war sie Leiterin des Kulturprogramms des Europäischen Forum Alpbach. Sie war (u. a. mit Beatrice Jaschke) als Kuratorin und Beraterin mehrerer österreichischer Museen tätig. Zudem ist sie seit 2006 Coleiterin des /ecm-Lehrgangs für Ausstellungstheo- 
rie und praxis an der Universität für angewandte Kunst Wien und erhielt 2010 den Theodor Körner-Preis der Stadt Wien für KuratorInnen-Tägigkeit. Monika Sommer ist Vorstandsmitglied von schnittpunkt. ausstellungstheorie \& praxis, Finanzreferentin des Österreichischen Museumsbundes, Mitglied der Militärhistorischen Denkmalkommission des Bundesministeriums für Landesverteidigung und Mitglied des Wissenschaftlichen Beirates des Hauses der Geschichte Nordrhein-Westfalen. Kuratorin zahlreicher Ausstellungen, z. B. (gem. mit Michaela Raggam-Blesch/Heidemarie Uhl) „Nur die Geigen sind geblieben. Arnold und Alma Rosé“. Veröffentlichungen zu museologischen und kulturgeschichtlichen Themen, zuletzt u. a.: (gem. mit Stefan Benedik) Ein neues Zeitgeschichte-Museum: Bedingungen und Chancen einer transmedialen Vermittlung von NS-Geschichte, in: Markus Stumpf/Hans Petschar/Oliver Rathkolb (Hg.), Nationalsozialismus digital, Wien 2021.

Kamila Staudigl-Ciechowicz ist Postdoc-Universitätsassistentin am Institut für Rechts- und Verfassungsgeschichte der Universität Wien. Sie studierte Rechtswissenschaften, Kirchenrecht und Geschichte an der Universität Wien (Mag. iur. 2008, LL.M. Kirchenrecht 2014, Dr. iur. 2017). Anschließend war sie als wissenschaftliche Mitarbeiterin an der Kommission für Rechtsgeschichte Österreichs der Österreichischen Akademie der Wissenschaften und als Projektmitarbeiterin am FWF-Projekt „Die Wiener Rechts- und Staatswissenschaftliche Fakultät 1918-1938“ unter der Leitung von Thomas Olechowski tätig. Im Rahmen ihrer Forschungen hat sie in in- und ausländischen Archiven recherchiert und an zahlreichen europäischen Universitäten vorgetragen. 2019/2020 war sie als wissenschaftliche Beraterin für das Jüdische Museum der Stadt Wien (Ausstellung: „Hans Kelsen und die Eleganz der österreichischen Bundesverfassung“) tätig. 2020 wurde ihr das Marie Jahoda-Stipendium der Universität Wien für exzellente Nachwuchskräfte zuerkannt. Zu ihren wichtigsten Publikationen zählen: (gem. mit Thomas Olechowski/Tamara Ehs) Die Wiener Rechts- und Staatswissenschaftliche Fakultät 1918-1938, Göttingen 2014, sowie Das Dienst-, Habilitations- und Disziplinarrecht der Universität Wien 1848-1938. Eine rechthistorische Untersuchung zur Stellung des wissenschaftlichen Universitätspersonals, Göttingen 2017, eine umfangreiche Studie, die mit Preisen ausgezeichnet wurde. $\mathrm{Zu}$ ihren weiteren Forschungsschwerpunkten gehören u. a. der universitäre Antisemitismus, die Entwicklung des österreichischen Privatrechts, der Einfluss der österreichischen Gesetzgebung auf die Nachfolgestaaten der österreichisch-ungarischen Monarchie und die Ausgestaltung der außerordentlichen Gesetzgebung. 
Barbara Stelzl-Marx ist Universitätsprofessorin für europäische Zeitgeschichte an der Karl-Franzens-Universität Graz und Leiterin des Ludwig Boltzmann Instituts für Kriegsfolgenforschung, Graz - Wien - Raabs, sowie Vizepräsidentin der Österreichischen UNESCO-Kommission. Nach dem Studium der Geschichte, Anglistik und Slawistik in Graz, Oxford, Volgograd und an der Standford University forschte sie ein Jahr in Rahmen eines Erwin Schrödinger-Stipendiums des FWF in Moskau. Die ÖAW verlieh ihr ein Doktoranden- und ein APART-Stipendium. Stelzl-Marx ist Schriftführerin der Österreichisch-Russischen Historikerkommission und Mitglied des Wissenschaftlichen Beirates des Hauses der Geschichte im Museum Niederösterreich. Für ihre Arbeiten erhielt die Grazerin eine Reihe von Preisen, u. a. den Jubiläumspreis des Böhlau Verlages und den Josef-Krainer-Würdigungspreis im Bereich Zeitgeschichte. 2020 wurde sie als „Wissenschafterin des Jahres“ ausgezeichnet. Zu ihren Forschungsschwerpunkten zählen Kriegsfolgen des Zweiten Weltkrieges, Kalter Krieg, Kinder des Krieges, Migration, Stalins Propaganda für sowjetische DPs, Erinnern und Gedenken. 2018 kuratierte sie die Ausstellung „Lager Liebenau. Ein Ort verdichteter Geschichte“ im GrazMuseum. Aktuell leitet sie u. a. Forschungsprojekte zum „Lebensborn“ (ÖNB und Land Niederösterreich) und zu tschechoslowakischen Nachrichtendiensten in Österreich (FWF). Sie ist Autorin bzw. Herausgeberin zahlreicher Publikationen, darunter u. a.: Stalins Soldaten in Österreich. Die Innensicht der sowjetischen Besatzung 1945-1955, Wien/München 2012; (Hg., mit Silke Satjukow) Besatzungssoldaten. Die Nachkommen alliierter Soldaten in Österreich und Deutschland 1945-1955, Wien/München 2015; (Hg., mit Stefan Karner) The Red Army in Austria. Soviet Occupation, 1945-1955 (The Harvard Cold War studies book series), Lanham (MD) 2020.

Regina Thumser-Wöhs ist assoziierte Universitätsprofessorin am Institut für Neuere Geschichte und Zeitgeschichte der Johannes Kepler Universität Linz. Studium der Instrumental- und Gesangspädagogik, Musikerziehung, Geschichte und Sozialkunde am Mozarteum Salzburg und an der Universität Salzburg; Lehrtätigkeit an den Universitäten Salzburg, Linz, Wien. 1998 bis 2000 wissenschaftliche Mitarbeiterin des Vereins Orpheus Trust, 2000 bis 2002 Projektnehmerin der Historikerkommission der Republik Österreich. Sie ist u. a. Mitglied im Wissenschaftlichen Beirat des Anton Bruckner Instituts Linz (ABIL) sowie Mitherausgeberin der „Österreichischen Zeitschrift für Geschichtswissenschaften“, seit 2013 im Team der Geschäftsführenden HerausgeberInnen der OeZG. Forschungsschwerpunkte u. a. in den Bereichen Kulturpolitik/en im 19. und 20. Jahrhundert, (Musik)Theater, Kabarett, Exilforschung, Nationalsozialismus, Medizingeschichte, Suchtforschung, Frauen- und Geschlechtergeschichte, Biographieforschung und Sound Studies. Zu 
ihren wichtigsten Publikationen zählen: „... zauberlacht Unlust in blaue Heiterkeit“. Sucht und Kunst im 19. und frühen 20. Jahrhundert, Innsbruck/Wien/Bozen 2017; (gem. mit Christian Klösch) „From Vienna“ - Exilkabarett in New York 1938 bis 1950, Wien 2002; (Hg., mit Maria Heidegger/Lisa Pfahl/Gabriele Werner-Felmayer) „Gutachterei“. Beiträge der Medical Humanities zu Ambivalenzen der Begutachtung. Österreichische Zeitschrift für Geschichtswissenschaften 31 (2020) 3; (Hg., mit Gabriella Hauch/Luboš Velek) Frauen Politik Transformation. Österreichische Zeitschrift für Geschichtswissenschaften 26 (2015) 2; (Hg., mit Klaus Petermayr) Klänge der Macht. Nationalsozialistische Musikpolitik in Oberösterreich, Linz 2010; weiter die Dokumentarfilme „King Without A Crown. Sängerportrait René Pape“, Salzburg/Wien 2003; (gem. mit Albert Lichtblau) „Wiener Mafia - Österreicher an New Yorks Opernhäusern“, Salzburg 2001.

Heidemarie Uhl ist Historikerin (Senior Research Associate) am Institut für Kulturwissenschaften und Theatergeschichte der Österreichischen Akademie der Wissenschaften sowie Lehrbeauftragte an den Universitäten Wien und Graz (bis 2018). Gastprofessuren in Jerusalem, Strasbourg, Budapest und Stanford. Sie ist u. a. Mitglied der Austrian Delegation to the International Holocaust Remembrance Alliance, Stellvertretende Vorsitzende der Militärhistorischen Denkmalkommission am Verteidigungsministerium, Vorsitzende des Beirats zur Errichtung von Gedenk- und Erinnerungszeichen (Freiplastiken und Gedenktafeln) der Stadt Wien, Stellvertretende Vorsitzende des Internationalen Wissenschaftlichen Beirats für das Haus der Geschichte Österreich, Mitglied des Kuratoriums der Österreichischen Nationalbibliothek sowie der Fachkommission der Stiftung Brandenburgische Gedenkstätten. Zuletzt erschienen u. a.: (Hg., mit Ljiljana Radonić) Das umkämpfte Museum. Zeitgeschichte ausstellen zwischen Dekonstruktion und Sinnstiftung, Bielefeld 2020; (Hg., mit Dieter J. Hecht/Michaela Raggam-Blesch) Letzte Orte. Die Wiener Sammellager und die Deportationen 1941/42, Wien 2019; (Hg., mit Monika Sommer/Klaus Zeyringer) 100xÖsterreich. Neue Essay aus Literatur und Wissenschaft, Wien 2018; (Hg., mit Johannes Feichtinger) Habsburg neu denken. Vielfalt und Ambivalenz in Zentraleuropa. 30 kulturwissenschaftliche Stichworte, Wien/ Köln/Weimar 2016.

Florian Wenninger ist Leiter des Instituts für Historische Sozialforschung, Senior Research Fellow und Lehrbeauftragter am Institut für Zeitgeschichte der Universität Wien und Redaktionsmitglied der Zeitschrift „zeitgeschichte“. Er leitet das Forschungsprojekt „Politische Repressionsmaßnahmen 1933-1938“. Nach dem Zivilersatzdienst an der Gedenkstätte Yad Vashem, Jerusalem Studium der Politikwis- 
senschaft und Geschichte an der Universität Wien. 2008-2012 Praedoc, 2015-2019 Postdoc-Assistent am Institut für Zeitgeschichte der Universität Wien, 2015 und 2016 Research Fellowships an der Carnegie Mellon University Pittsburgh und an der University of California, Berkeley. Arbeitsschwerpunkte bilden neben der österreichischen Zeitgeschichte die Diktatur- und Transformationsforschung, Polizei- und Militärgeschichte sowie die Geschichte der Arbeiterbewegung. Zum Thema seines Beitrages in diesem Buch gab Wenninger u. a. 2013 gemeinsam mit Lucile Dreidemy einen umfangreichen Sammelband heraus: Das Dollfuß/Schuschnigg-Regime 1933-1938. Vermessung eines Forschungsfeldes, Wien/Köln/Weimar 2013. Siehe auch das unter seiner Mitarbeit publizierte Werk von Emmerich Tálos, Das austrofaschistische Österreich 1933-1938, Wien 2017 und „The Duty to Express Value Judgments“. Charles Adams Gulick, Interwar Austria and the Question of Political Neutrality as a Scholarly Virtue, in: Günter Bischof/David M. Wineroither (Hg.), Democracy in Austria (Contemporary Austrian Studies 28), Innsbruck/New Orleans 2019. Zuletzt erschien „Ein Brückenkopf des Deutschtums in Südost?“ Die Schwarze Reichswehr in Österreich 1919-1922, in: Adrian Hänni/Daniel Rickenbacher/Thomas Schmutz (Hg.), Über Grenzen hinweg. Transnationale politische Gewalt im 20. Jahrhundert, Frankfurt a. M. 2020.

Christina Wieder ist Doktorandin am Schwerpunkt Visuelle Zeit- und Kulturgeschichte am Institut für Zeitgeschichte der Universität Wien. Sie studierte Geschichte und Romanistik an der Universität Wien und der Universidad de Buenos Aires. Seit 2016 ist sie wissenschaftliche Mitarbeiterin und Lektorin am Schwerpunkt Visuelle Zeit- und Kulturgeschichte am Institut für Zeitgeschichte der Universität Wien. Gemeinsam mit Klaudija Sabo leitete sie das Forschungs- und Dokumentarfilmprojekt „Die Zweite Reihe des Filmexils“ (2015-2018). Überdies kuratierte sie zusammen mit Frank Stern und in Kooperation mit dem Filmarchiv Austria die Filmretrospektive „FILM NOIR RELOADED“ (2015-2019). Mit ihrem Dissertationsprojekt „Visuelle Selbstermächtigungsstrategien im Exil. Jüdische Künstlerinnen von Mitteleuropa nach Argentinien" war sie Junior Fellow am Internationalen Forschungszentrum Kulturwissenschaften (IFK Wien) sowie als Gastwissenschaftlerin am Institut für Kulturwissenschaft der Humboldt-Universität zu Berlin, am Instituto de Artes del Espectáculo der Universidad de Buenos Aires und an der Cinémathèque française tätig. Publikationen (Auswahl): Montages of Exile. Photographic techniques and spatial dimensions in the artwork of Grete Stern, in: Jewish Culture and History 21 (2019) 1; Ästhetische Grenzüberschreitungen und widerständige Körper in Fernando Solanas „Tangos. El Exilio de Gardel“ (1985), in: Aylin Basaran/Julia B. Köhne/ Klaudija Sabo/Christina Wieder (Hg.), Sexualität und Widerstand. Internationale 
Filmkulturen, Wien 2018; (gem. mit Klaudija Sabo) Visual History in Bewegung. Bildliche Quellen in der historischen Forschung, in: Bertrand Perz/Ina Markova (Hg.), 50 Jahre Institut für Zeitgeschichte der Universität Wien 1966-2016, Wien 2017.

Renée Winter ist Senior Postdoc am Institut für Zeitgeschichte der Universität Wien. Forschungsschwerpunkte: Mediengeschichte und theorie, Nachgeschichte des Nationalsozialismus, Wissenskulturen und Audio/Visualität, Geschlechtergeschichte und Migration/Postkolonialismus nach/in Österreich. Sie studierte Geschichte und eine Fächerkombination aus Frauen- und Geschlechterforschung, Internationaler Entwicklung und Russisch in Wien, wo sie 2012 promoviert wurde. Studienjahr 2001/2002 an der Université Paris VII - Denis Diderot, 2011 Junior Visiting Fellow am Institute of Germanic and Romance Studies/School of Advanced Study der University of London. Für die 2014 publizierte Dissertation wurde sie mit dem Theodor Körner-Preis, dem Irma Rosenberg-Preis und dem Michael Mitterauer-Preis ausgezeichnet. Lehraufträge am Institut für Zeitgeschichte, Europäische Ethnologie und Theater, Film- und Medienwissenschaften der Universität Wien, Kunstuniversität Linz und Paris-Lodron-Universität Salzburg. 2014-2016 wissenschaftliche Mitarbeiterin im WWTF-Projekt „The changing role of audio-visual archives as memory storages in the public space. Using the example of private video sources" an der Österreichischen Mediathek. Seit 2018 leitet sie das Projekt „Video as Technology of the Self" (Elise Richter-Programm des FWF). Publikationen (Auswahl): Geschichtspolitiken und Fernsehen. Repräsentationen des Nationalsozialismus im frühen österreichischen TV (1955-1970), Bielefeld 2014; (Hg., mit Christina Waraschitz/ Gabriele Fröschl) Aufnahme läuft. Private Videobestände - Öffentliche Archive?, Wien 2016.

Maria Wirth ist seit 2019 (bis 2021) Projektleiterin am Institut für Zeitgeschichte der Universität Wien (Studie: Hertha Firnberg. Eine wissenschaftspolitische Biographie). Nach dem Abschluss des Diplomstudiums (Geschichte, Politikwissenschaft und Soziologie) an der Universität Wien war sie wissenschaftliche Mitarbeiterin im Kreisky-Archiv (1998-2005) und Provenienzforscherin für die Wienbibliothek (1999/2000). 2002-2004 Projektmitarbeiterin am Institut für Zeitgeschichte der Universität Wien im Rahmen einer Studie über die „braunen Flecken“ in der SPÖ. 2000-2011 wissenschaftliche Mitarbeiterin und Webredakteurin im Demokratiezentrum Wien. 2007-2011 Coleitung eines Projekts über die Buchbestände in den österreichischen Justizanstalten im Auftrag des Bundesministeriums für Justiz/Vollzugsdirektion. 2010 Promotion an der Universität Wien mit einer Biographie über 
Christian Broda (ausgezeichnet mit dem Bruno Kreisky-Anerkennungspreis für das politische Buch 2011). Ab 2011 Projektmitarbeiterin beim Verein zur wissenschaftlichen Aufarbeitung der Zeitgeschichte am Institut für Zeitgeschichte der Universität Wien sowie am Institut für Zeitgeschichte der Universität Wien. 2015-2017 Universitätsassistentin an der Johannes Kepler Universität Linz. Seit 2017 Lehrtätigkeiten an den Universitäten Linz und Wien. Publikationen u. a. über das Vienna Biocenter, das Europäische Forum Alpbach, die Johannes Kepler Universität Linz. Forschungsschwerpunkte: Österreichische Zeitgeschichte, Umgang mit der NS-Vergangenheit, Demokratie, Rechts- und Wissenschafts/Universitätsgeschichte, Biographieforschung.

Norbert Christian Wolf ist Professor für Neuere deutsche Literatur an der Universität Wien seit 2020. Nach dem Studium der Germanistik, Geschichte sowie der AVL in Wien, Paris (Sorbonne Nouvelle, ENS Fontenay-St. Cloud) und Berlin (FU) (Promotion 1999) war er wissenschaftlicher Mitarbeiter an der FU Berlin 1998-2004, APART-Stipendiat der Österreichischen Akademie der Wissenschaften in Wien 2004, Juniorprofessor für Neuere deutsche Literatur und Literaturtheorie an der FU Berlin 2005-2009 (Habilitation 2009) und ordentlicher Professor für Neuere deutsche Literatur an der Universität Salzburg 2009-2020 sowie Fachreferent für Literatur- und Sprachwissenschaften des österreichischen Wissenschaftsfonds (FWF) 2014-2020. Er ist Mitglied mehrerer wissenschaftlicher Vereine und Präsident der Internationalen Robert-Musil-Gesellschaft (IRMG). Zu seinen Publikationen zählen u. a.: Kakanien als Gesellschaftskonstruktion. Robert Musils Sozioanalyse des 20. Jahrhunderts, Wien/Köln/Weimar 2011; Eine Triumphpforte österreichischer Kunst. Hugo von Hofmannsthals Gründung der Salzburger Festspiele, Salzburg/ Wien 2014; (Hg., mit Uta Degner/Hans Weichselbaum) Autorschaft und Poetik in Texten und Kontexten Georg Trakls, Salzburg/Wien 2016; (Hg., mit Birgit Nübel) Robert-Musil-Handbuch, Berlin/Boston 2016; (Hg., mit Clemens Peck) Poetiken des Posturalen. Inszenierungen von Autorschaft in der Literatur der Zwischenkriegszeit, Paderborn 2017; (Hg., mit Werner Michler/Klemens Renoldner) Von der Produktivkraft des Eigensinns. Die Literaturen des Karl-Markus Gauß, Salzburg/ Wien 2017; Revolution in Wien. Die literarische Intelligenz im politischen Umbruch 1918/19, Wien/Köln/Weimar 2018. Forschungsschwerpunkte: deutschsprachige Literatur des 18.-21. Jahrhunderts (bes. Aufklärung, Klassik, klassische Moderne, Gegenwartsliteratur), literarische Ästhetik, Literatursoziologie, Intermedialität, österreichische Literatur. 
Markus Wurzer ist Postdoctoral Researcher am Max-Planck-Institut für ethnologische Forschung in Halle an der Saale. Er studierte Geschichte und Germanistik an der Karl-Franzens-Universität Graz sowie an der Università di Bologna und war wissenschaftlicher Mitarbeiter und Lehrbeauftragter am Institut für Geschichte der Karl-Franzens-Universität in Graz sowie Universitätsassistent am Institut für Neuere Geschichte und Zeitgeschichte an der Johannes Kepler Universität Linz. Seine Forschungen führten ihn an das Österreichische Historische Institut in Rom, an das Internationale Forschungszentrum Kulturwissenschaften in Wien, an das European University Institute in Florenz, an die Harvard University sowie an die Europäische Akademie (EURAC) in Bozen/Bolzano. Er ist Cokoordinator von www.postcolonialitaly.com und Mitglied des Steering Committee von „Evidence and Imagination Special Editions“. Für seine Arbeiten erhielt Wurzer zahlreiche Preise, darunter 2016 den Förderpreis der Dr. Alois Mock Europa-Stiftung für seine Diplomarbeit sowie 2019 den Förderpreis des Theodor Körner-Fonds für seine Dissertation. Unter seinen wichtigsten Publikationen sind: Der essentialisierende Blick zurück. Kolonialkrieg und Zugehörigkeit(en) im Fotoalbum, in: Jahrbuch für Antisemitismusforschung 29 (2020); (Hg., mit Birgit Kirchmayr) Krieg und Fotografie. Neue Aspekte einer alten Beziehung in transnationaler und postkolonialer Perspektive, in: zeitgeschichte 45 (2018) 2; „Nachts hörten wir Hyänen und Schakale heulen“. Das Tagebuch eines Südtirolers aus dem Italienisch-Abessinischen Krieg 1935-1936 (EEB 6), Innsbruck 2016.

Anita Ziegerhofer ist außerordentliche Universitätsprofessorin und Leiterin des Fachbereiches Rechtsgeschichte und Europäische Rechtsentwicklung am Institut für Rechtswissenschaftliche Grundlagen der Universität Graz. Nach dem Studium der Geschichte war sie u. a. Mitarbeiterin am FWF-Projekt „Ständische Gesandtschaften“. Forschungsaufenthalte in Moskau, Genf und Bonn. Lehrbeauftragte an der Johannes-Gutenberg-Universität in Mainz sowie Lehre an der Universität Istanbul und der Universität Batumi/Georgien. Leiterin des FWF-Forschungsprojektes „Die rechtliche Bedeutung des Vertrages von St. Germain“. Für ihre Forschungsarbeiten erhielt sie den Kardinal Innitzer-Preis, Leopold Kunschak-Preis und Käthe LeichterPreis; Ehrenzeichen für Wissenschaft, Forschung und Kunst des Landes Steiermark. Ziegerhofer ist Mitglied der Kommission für Österreichische Rechtsgeschichte an der Akademie der Wissenschaften und Mitglied der Historischen Landeskommission für die Steiermark. Zu den wichtigsten Publikationen zählen: Botschafter Europas. Richard Nikolaus Coudenhove-Kalergi und die Paneuropa-Bewegung in den zwanziger und dreißiger Jahren, Wien 2004; Verfassungsgeschichte Europas. Vom 18. Jahrhundert bis zum Zweiten Weltkrieg, Darmstadt 2013; Europäische Integ- 
rationsrechtsgeschichte, Innsbruck ${ }^{32012}$; (gem. mit Karin Schmidlechner/Michaela Sohn-Kronthaler/Ute Sonnleitner/Elisabeth Holzer) Geschichte der Frauen in der Steiermark. Von der Mitte des 19. Jahrhunderts bis zur Gegenwart, Graz 2017; (gem. mit Alois Kernbauer) Frauen in den Rechts- und Staatswissenschaften der Universität Graz. Der Weg zur Zulassung und die ersten Doktorinnen von 1919 bis 1945, GraZ 2019; Vom Rand ins Zentrum EUropas. Die Geschichte der Steiermark ab 1918. Analog und digital erzählt, Graz 2020. 